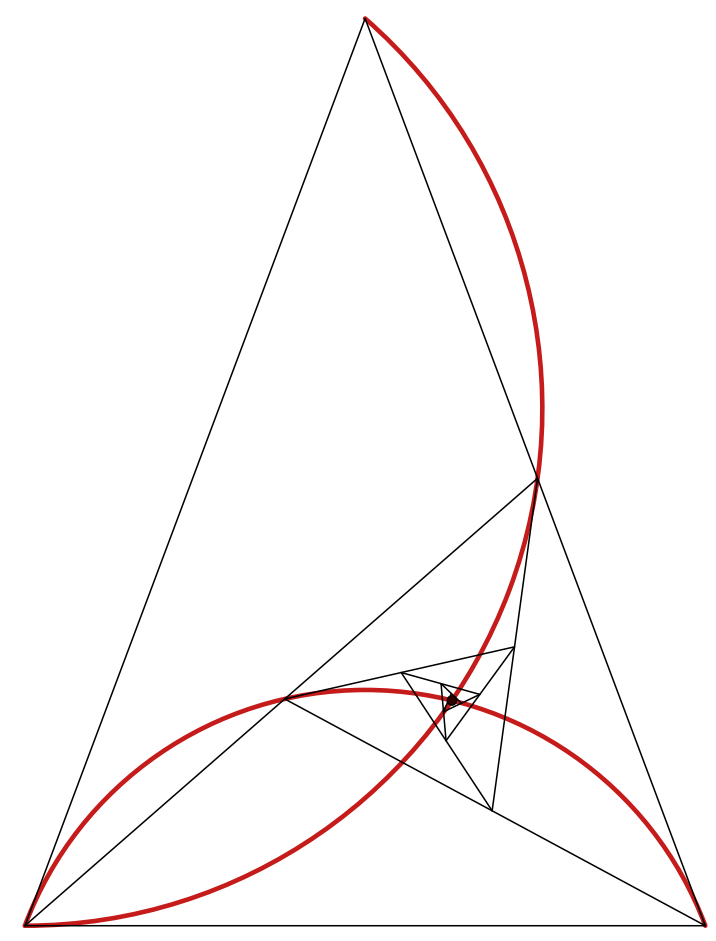

\title{
Patterns of Information Law
}

Intellectual Property Done Right

\author{
James Grimmelmann
}




\section{Table of Contents}

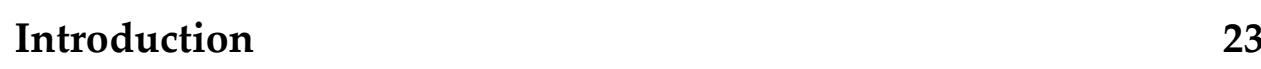

1 Undeveloped Ideas 35

Desny v. Wilder. . . . . . . . . . . . 35

Michael J. Burstein, Exchanging Information

Without Intellectual Property. . . . . . . . . . 37

Apfel v. Prudential-Bache Securities, Inc. . . . . . 38

Bizarro World Problem . . . . . . . . . . . 41

Debt Collection Problem . . . . . . . . . . . 41

2 Trade Secret $\quad 43$

A Subject Matter ................... 43

Restatement (Third) of Unfair Competition \$ 3943

Religious Technology Center v. Netcom On-Line Communications Services, Inc. . . . . . . . . . . 44

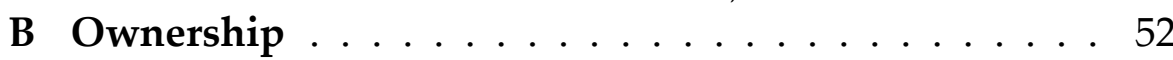

UTSA $₫ 1(4) \ldots \ldots \ldots . \ldots 52$

1 Actual Secrecy ................ . . 52

United States v. Lange . . . . . . . . . . . 52

Learning Curve Toys, Inc. v. PlayWood Toys, Inc. 55

Exploits Problem .................. 66

2 Priority ....................... 67

3 Collaborations ................ 67

Restatement (Third) of Unfair Competition \&

$42 \mathrm{cmt.} \mathrm{e} \ldots \ldots \ldots 67$

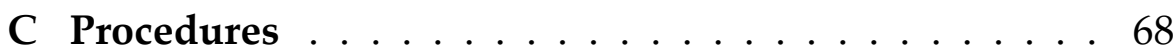

United States v. Lange . . . . . . . . . . . . 69

Rockwell Graphic Systems, Inc. v. DEV Industries, Inc. . . . . . . . . . . . . . 69

D Infringement: Similarity ............. 72

Big Vision Private, Ltd. v. E.I. Dupont De

Nemours \& Co. . . . . . . . . . . 72

E Infringement: Prohibited Conduct . . . . . . . . . 72

1 Proving Infringement . . . . . . . . . . . . . . . . . . . . . . .

Grynberg $v . B P, P L C$. . . . . . . . . . . . . . . . . . . . . . . . . . .

2 Direct Infringement . . . . . . . . . . . . . 74 


\begin{tabular}{|c|c|c|}
\hline & Restatement (Third) of Unfair Competitition \$ & \\
\hline & $43 \ldots \ldots \ldots \ldots \ldots$ & 74 \\
\hline & UTSA $₫ 1(1) \ldots \ldots \ldots \ldots$ & 74 \\
\hline & E.I. du Pont de Nemours \& Co. v. Christopher. & 75 \\
\hline & 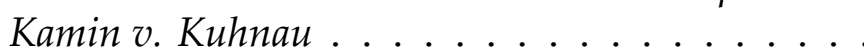 & 78 \\
\hline $3 \quad \operatorname{Sec} 0$ & ondary Infringement & 81 \\
\hline & UTSA $\S 1(2) \ldots$. & 82 \\
\hline F Defense & s.......... & 82 \\
\hline & Questions . . . . . . . . . . . . . . . . & 83 \\
\hline & Flaming Moe's Problem . . . . . . . . . . & 83 \\
\hline & Locksmiths Problem . . . & 84 \\
\hline G Privacy & $\ldots \ldots \ldots \ldots \ldots$ & 85 \\
\hline & Restatement (Second) of Torts $\S 652 B$. . . . . & 85 \\
\hline & Neil M. Richards \& Daniel J. Solove, Privacy's & \\
\hline & Other Path: Recovering the Law of Confiden- & \\
\hline & 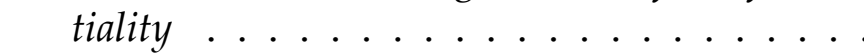 & 86 \\
\hline & Florida v. Riley .... & 88 \\
\hline & Kyllo v. United States & 89 \\
\hline H Governn & nent Secrets ...... & 91 \\
\hline & Freedom of Information Act . . . . . . . & 91 \\
\hline & U.S. Dept. of Justice v. Tax Analysts. . . . . & 92 \\
\hline & Chrysler Corp. v. Brown . . . . . . . . . . . & 93 \\
\hline & Coastal States Gas Corp. v. Department of Energy & 95 \\
\hline & Congressional Research Service, The Protec- & \\
\hline & tion of Classified Information: The Legal & \\
\hline & 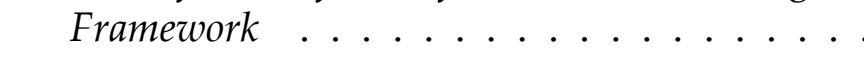 & 100 \\
\hline & Phillippi v. Central Intelligence Agency . . . & 103 \\
\hline
\end{tabular}

3 Patent 107

United States Constitution, art. I, § 8, cl. 8 . . 107

A Subject Matter . . . . . . . . . . . . . . . . . . . . . . 108

Patent Act $\S 101 \ldots \ldots \ldots$. . . . . . . . . 108

1 Utility . . . . . . . . . . . . . . . . . 108

uicy Whip, Inc. v. Orange Bang, Inc. . . . . . . 108

MPEP $\$ \S 2701,2701.01$. . . . . . . . . . . . . 112

2 Statutory Subject Matter . . . . . . . . . . . . . . 116

Tun-Jen Chiang, The Rules and Standards of Patentable Subject Matter . . . . . . . . . . . 116

Mayo Collaborative v. Prometheus Labs . . . . . . 117

Tax Planning Patent Problem . . . . . . . . 120

B Procedures . . . . . . . . . . . . . . . . . . 121

1 Claims . . . . . . . . . . . . . . . . . 125

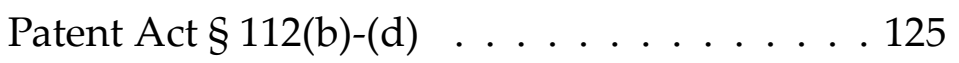

a Indefiniteness . . . . . . . . . . . . . . . . 125

Nautlius, Inc. v. Biosig Instruments Inc. . . . . . 125 
Freeny v. Apple Inc. . . . . . . . . . . . . . 125

Datamize, LLC v. Plumtree Software, Inc. . . . . . 128

b Claim Drafting . . . . . . . . . . . . . 130

Catalina Marketing Intern. v. Coolsavings.com . . 130

MPEP $\$ \S 2111,2173 \ldots \ldots$. . . . . . . . . . 130

2 Disclosure . . . . . . . . . . . . . . . . . 131

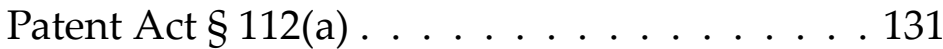

a Enablement ................. . . 131

O'Reilly v. Morse. . . . . . . . . . . . . . . . 131

Wyeth E Cordis Corp. v. Abbott Labs. . . . . . . . 132

Plastic Dye Problem . . . . . . . . . . . . . . . 136

b Written Description . . . . . . . . . . . 136

Ariad Pharmaceuticals, Inc. v. Eli Lilly and Co . . 136

c Best Mode . . . . . . . . . . . . . 137

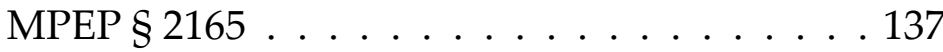

Salt Shaker Problem . . . . . . . . . . . . . . 138

3 Patent Prosecution . . . . . . . . . . . . . . . . . . 139

Cuozzo Speed Technologies, LLC v. Lee . . . . . . 139

Patent Act $\$ 122$. . . . . . . . . . . . . . . . . . 139

37 C.F.R. pt 1. . . . . . . . . . . . . . . 140

Therasense, Inc. v. Becton, Dickinson and Co. . . . 140

a Priority Dates ... . . . . . . . . . . . . . 141

USPTO, General Information Concerning Patents . . . . . . . . . . . . . 141

b Multiple Applications . . . . . . . . . . . . 141

Patent Act $\$ 121$. . . . . . . . . . . . . . . . 141

MPEP $\$ \$ 201.07$. . . . . . . . . . . . . . . . 142

c Judicial Review . . . . . . . . . . . . . . . 142

d Post-Grant Proceedings . . . . . . . . . . . . 143

Patent Act $\S 121$. . . . . . . . . . . . . . . . 143

Cuozzo Speed Technologies, LLC v. Lee . . . . . . 143

4 Term ...................... . . . 145

Patent Act $\S 135(a)(2)$

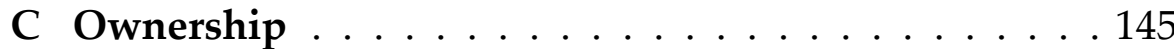

1 Collaborations . . . . . . . . . . . . . . 145

MPEP $\$ 2137.01 \ldots \ldots \ldots \ldots$

Patent Act $\$ 135$. . . . . . . . . . . . . . . . 147

2 Priority: Novelty and Statutory Bars . . . . . . . 147

a Categories of Prior Art . . . . . . . . . . . 148

1 "patented" . . . . . . . . . . . . . . . . . . . 149

2 "described in a printed publication" . . . . . . 149

In re Klopfenstein . . . . . . . . . . . . . . . . 149

3 "in public use" . . . . . . . . . . . . . . . 154

Mark A. Lemley, Does "Public Use" Mean the Same Thing It Did Last Year? . . . . . . . . . 154 
Egbert v. Lippmann . . . . . . . . . . . . 156

Lough v. Brunswick Corp. . . . . . . . . . . . 159

4 "on sale" . . . . . . . . . . . . . . . . . . 161

MPEP $\$ \S 2152.02(\mathrm{~d}), 2133.03(\mathrm{~b}) \&(\mathrm{c}) \ldots$

5 "otherwise available to the public" . . . . . . . 162

b Anticipation . . . . . . . . . . . . . 163

MPEP \& 2131 . . . . . . . . . . . . . . . 163

Titanium Metals Corp. of America v. Banner . . . 164

c Priority . . . . . . . . . . . . . . . . . . . . . 169

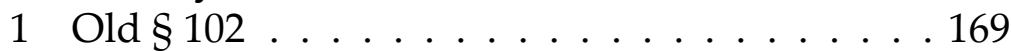

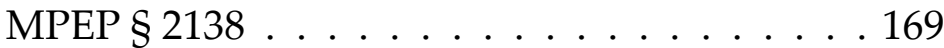

Morway v. Bondi . . . . . . . . . . . . . . . . 171

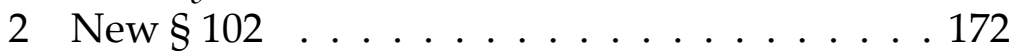

Patent Act $\$ 102 \ldots \ldots$. . . . . . . . . . . 172

Questions . . . . . . . . . . . . . . . . . . . . 173

Pleistocene Park Problem . . . . . . . . . . . . . 173

3 Nonobviousness . . . . . . . . . . . . . . . . . . . 174

Patent Act $\$ 103 \ldots \ldots \ldots$

KSR Intern. Co. v. Teleflex Inc. . . . . . . . . . . 175

In re Clay . . . . . . . . . . . . . . . . . 185

KSR Problem . . . . . . . . . . . . . . . 187

D Infringement: Similarity . . . . . . . . . . . . . . 188

leanne C. Fromer, Claiming Intellectual Property 188

N.D. Cal. Model Patent Jury Instructions . . . 189

1 Claim Construction . . . . . . . . . . . . . . 190

Phillips v. AWH Corp. . . . . . . . . . . . . . 190

Thorner v. Sony Computer Entertainment Amer-

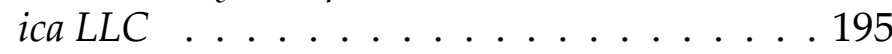

2 Literal Infringement . . . . . . . . . . . . . . . . . 201

Angelo Mongiello's Children, LLC v. Pizza Hut, Inc. . . . . . . . . . . . . . . . . 201

3 Doctrine of Equivalents . . . . . . . . . . . . . 203

Freedman Seating Co. v. American Seating Co. . . 203

Festo Corp. v. Shoketsu Kinzoku Kogyo Kabushiki

Co. ................... 211

Iohnson \& Johnston Associates v. R.E. Service Co. 212

4 A Hybrid: Means-Plus-Function Claims . . . . . . 213

Kemco Sales, Inc. v. Control Papers Co., Inc. . . . 213

Super Soaker Problem . . . . . . . . . . . . 215

E Infringement: Prohibited Conduct . . . . . . . . . . . 216

Herman v. Youngstown Car Mfg. Co. . . . . . . . 216

1 Direct Infringement . . . . . . . . . . . . . . . . 216

Patent Act $\$ 271(\mathrm{a}) \ldots \ldots \ldots . . . . . . . .216$

Akamai Technologies, Inc. v. Limelight Networks,

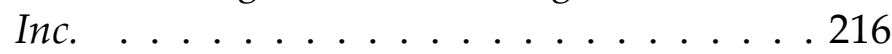


2 Indirect Infringement . . . . . . . . . . . . . 217

Patent Act $\$ 271(\mathrm{~b})-(\mathrm{c}) \ldots \ldots \ldots . . . . . . . .217$

Limelight Networks, Inc. v. Akamai Technologies, Inc. . . . . . . . . . . . . . . . . 217

Global-Tech Appliances, Inc. v. SEB S.A. … . . . 218

Commil USA, LLC v. Cisco Systems Inc. . . . . . 219

Lucent Technologies, Inc. v. Gateway, Inc. . . . . . 219

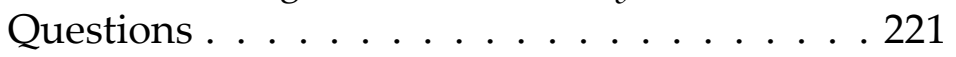

F Defenses . . . . . . . . . . . . . . . . . . . . 221

1 Invalidity . . . . . . . . . . . . . . . 221

Microsoft Corp. v. i4i Ltd. Partnership . . . . . . 221

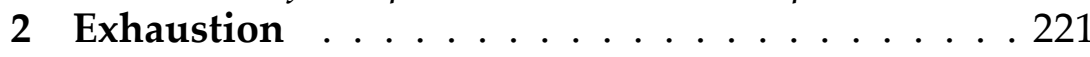

Aktiebolag v. E.J. Co. . . . . . . . . . . . . . 221

Quanta Computer, Inc. v. LG Electronics, Inc. . . 226

Lexmark Intern., Inc. v. Impression Products, Inc. 232

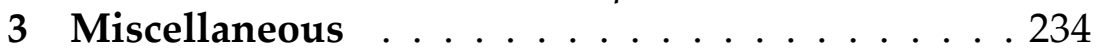

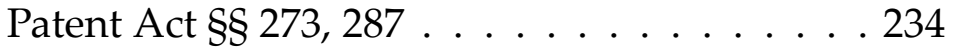

Madey v. Duke University. . . . . . . . . . . . 234

4 Copyright 237

A Subject Matter . . . . . . . . . . . . . . . . . . 237

Copyright Act $\$ 102(a) \ldots \ldots . . . . . . .237$

Feist Publications, Inc. v. Rural Telephone Service

Co. .................. . 238

1 Creativity: How Much Is a Modicum? . . . . . . . 238

37 C.F.R. $\$ 202.1(\mathrm{a}) \ldots \ldots . \ldots . . . . . .238$

Feist Publications, Inc. v. Rural Telephone Service

Co. . . . . . . . . . . . . 239

Arrows Problem . . . . . . . . . . . . . 242

Baseball Card Price Report Problem . . . . . . 243

2 Aesthetic Nondiscrimination . . . . . . . . . . . . 243

Bleistein v. Donaldson Lithographing Co. . . . . . 243

Copyright Compendium $\$ 310$. . . . . . . . . 245

Mitchell Bros. Film Group v. Cinema Adult Theater 246

Belcher v. Tarbox . . . . . . . . . . . . . . 246

3 Idea and Expression . . . . . . . . . . . . . . 247

Copyright Act $\S 102(b)$

Blehm v. Jacobs . . . . . . . . . . . . . . . . 247

Walker v. Time Life Films, Inc. . . . . . . . . . . 254

Hula Problem . . . . . . . . . . . . . . . . 254

Baker v. Selden ... . . . . . . . . . . . . 254

Bikram's Yoga College of India v. Evolation Yoga .257

Concrete Machinery Co. v. Classic Lawn Ornaments ................. . . 261

Cooking for Kids Problem . . . . . . . . . . . 261 
B Ownership ... . . . . . . . . . . . . . . . . 261

Sheldon v. Metro-Goldwyn Pictures Corp. . . . . . 261

1 Authorship . . . . . . . . . . . . . 262

Burrow-Giles Lithographic Co. v. Sarony . . . . . 262

Monkey Selfie Problem . . . . . . . . . . . . . . 263

Copyright Act $\$ 105 \ldots \ldots$. . . . . . . . . . 264

2 Collaborations . . . . . . . . . . . . . . . 264

Copyright Act $\$ \$ 201,202 \ldots \ldots$. . . . . . . 264

Thomson v. Larson . . . . . . . . . . . . . . 265

Greene v. Ablon. . . . . . . . . . . . . . . . 270

Community for Creative Non-Violence v. Reid . . 271

Garcia v. Google, Inc. . . . . . . . . . . . . . . 275

3 Derivative Works . . . . . . . . . . . . . . . 277

Copyright Act $\$ 103 \ldots \ldots \ldots$. . . . . . . 277

DC Comics v. Towle . . . . . . . . . . . . . . 277

Pickett v. Prince . . . . . . . . . . . . . . . 278

Keeling v. Hars . . . . . . . . . . . . . . . . 280

C Procedures ......... . . . . . . . . . . . . 281

1 Formalities Then . . . . . . . . . . . . . . . 281

Christopher Sprigman, Reform(aliz)ing Copyright 281

Estate of Martin Luther King v. CBS, Inc. . . . . . 282

Estate of Martin Luther King v. CBS, Inc. . . . . . 284

Wildman v. New York Times Co. . . . . . . . . . . 284

2 Formalities Now . . . . . . . . . . . . . . 285

a Fixation . . . . . . . . . . . . . . . . 285

Copyright Compendium $\$ 305$. . . . . . . . . 285

Stern Electronics, Inc. v. Kaufman . . . . . . . . . 287

Questions. . . . . . . . . . . . . . . . . . . 288

Photoshoot Problem . . . . . . . . . . . . . 289

b Registration . . . . . . . . . . . . . . . . 290

Copyright Compendium $\S 202$. . . . . . . . 290

c Deposit . . . . . . . . . . . . . . . . 291

Copyright Compendium $\S \S 1502,1511$. . . . . 291

d Notice. . . . . . . . . . . . . . . . . . 292

Copyright Compendium $\S \S 2202,2204$. . . . . 292

3 Term .................... . . . 293

Copyright Act $\$ \$ 302,305 \quad \ldots \ldots . . . \ldots 293$

Eldred v. Ashcroft . . . . . . . . . . . . . . . . 294

Klinger v. Conan Doyle Estate . . . . . . . . . . 296

D Infringement: Similarity . . . . . . . . . . . . . . . . 298

Sheldon v. Metro-Goldwyn Pictures Corp. . . . . . 298

Nichols v. Universal Pictures Corporation . . . . . 298

Arnstein v. Porten . . . . . . . . . . . . . . . 301

Children's Book Problem . . . . . . . . . . . . 302

Gottlieb Development LLC v. Paramount Pictures . 302 
Boisson v. Banian, Ltd. . . . . . . . . . . . . 304

New Yorker Problem . . . . . . . . . . . . . . 308

E Infringement: Prohibited Conduct . . . . . . . . . . . 309

1 Proof of Copying . . . . . . . . . . . . . . . . . 309

Three Boys Music Corp. v. Bolton . . . . . . . . . 309

Bee Gees Problem . . . . . . . . . . . . . . 315

2 Direct Infringement . . . . . . . . . . . . . 316

Copyright Act $\$ 106$. . . . . . . . . . . . . . . . . . . . . . . . . . . .

Capitol Records, LLC v. ReDigi Inc. . . . . . . . . 317

CoStar Group, Inc. v. LoopNet, Inc. . . . . . . . . 319

American Broadcasting v. Aereo, Inc. . . . . . . 320

Copyright Act $\$ 110$. . . . . . . . . . . . . . . . . . . . . . . . . . . . . . . .

3 Secondary Liability . . . . . . . . . . . . . . . . . 325

Fonovisa, Inc. v. Cherry Auction, Inc. . . . . . . . 325

Sony Corp. of America v. Universal City Studios,

Inc. . . . . . . . . . . . . . . 329

Metro-Goldwyn-Mayer Studios Inc. v. Grokster, Ltd. . . . . . . . . . . . 330

Exclusive Rights Problem . . . . . . . . . . . . . 330

4 Paracopyright ..................... 331

Copyright Act $\$ 1201$. . . . . . . . . . . . 331

MDY Industries, LLC. v. Blizzard Entertainment,

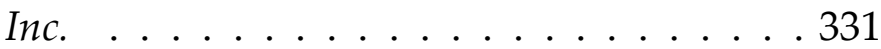

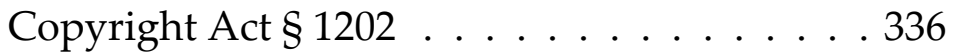

Murphy v. Millennium Radio Group LLC . . . . . 337

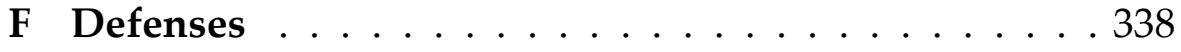

1 First Sale . . . . . . . . . . . . . . . . . . . 338

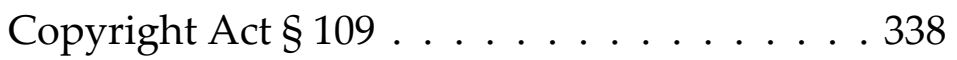

UMG Recordings, Inc. v. Augusto . . . . . . . . . 339

Capitol Records, LLC v. ReDigi Inc. . . . . . . . . 342

2 Fair Use . . . . . . . . . . . . . . . . . . 343

Copyright Act $\$ 107$. . . . . . . . . . . . . . . . . . . . . . . . . . . . . . . . . .

Fair Use Checklist . . . . . . . . . . . . . . . . 343

Harper E Row, Publishers, Inc. v. Nation Enterprises ......................... 344

Campbell v. Acuff-Rose Music, Inc. . . . . . . . . 351

City of Inglewood v. Teixeira . . . . . . . . . . . . 353

Fox Broadcasting Co., Inc. v. Dish Network LLC . 359

Capitol Records, LLC v. ReDigi Inc. . . . . . . . . 362

Chicago HOPE Problem . . . . . . . . . . . . 363

3 Section $512 \ldots \ldots \ldots 363$

Copyright Act $\$ 512$. . . . . . . . . . . . 363

UMG Recordings, Inc. v. Shelter Capital Partners 365

4 Statutory Licenses . . . . . . . . . . . . . . . . . . . 370

WPIX, Inc. v. ivi, Inc. . . . . . . . . . 370 
Fox Television Stations, Inc. v. AereoKiller . . . . 372

5 Miscellaneous . . . . . . . . . . . . . 374

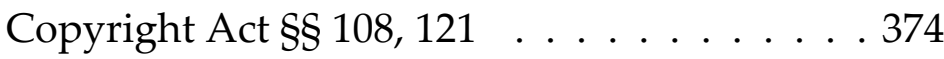

5 Music 375

Steve Albini, The Problem with Musid . . . . . . 375

A Musical Works and Sound Recordings .... . . . . 376

Robert Brauneis, Musical Work Copyright for the Era of Digital Sound Technology . . . . . . 376

White-Smith Music Publishing Co. v. Apollo Co. .377

Copyright Office, FEDERAL COPYRIGHT PROTECTION FOR PRE-1972 SOUNd RECORdINGS . . . . 378

Copyright Act $\$ \S 101,102 \ldots . . . . . .379$

Lydia Pallas Loren, Untangling the Web of Music Copyrights . . . . . . . . . . . . 379

Newton v. Diamond . . . . . . . . . . . . 380

B Reproductions . . . . . . . . . . . . . . . . . . . . . 382

1 Musical Works . . . . . . . . . . . . . . . . . . . 382

Copyright Act $\$ 115(\mathrm{a}) \ldots \ldots \ldots$

37 C.F.R. pt. $385 \ldots \ldots$. . . . . . . . . . 383

Lydia Pallas Loren, Untangling the Web of Music Copyrights . . . . . . . . . . . . 383

Leadsinger, Inc. v. BMG Music Pub. . . . . . . . 384

2 Sound Recordings . . . . . . . . . . . . . . . . . . 385

Copyright Act $\$ 114(\mathrm{~b}) \ldots \ldots \ldots$

Bridgeport Music, Inc. v. Dimension Films . . . . 385

VMG Salsoul, LLC v. Ciccone . . . . . . . . . . 387

C Performances.............. . . . . . 389

United States v. American Society of Composers, Authors, and Publishers . . . . . . . . . . . . . 389

1 Musical Works . . . . . . . . . . . . . . . . . . . 390

a Broadcasting and Receiving . . . . . . . . . . . 390

Buck v. Jewell-LaSalle Realty Co. . . . . . . . . . . 390

Copyright Act \$110(5) . . . . . . . . . . . . . 391

b The Performing Rights Organizations . . . . . 392

Broadcast Music, Inc. v. Columbia Broadcasting

System, Inc. . . . . . . . . . . . . . . . 392

ASCAP 2010 Radio Station License Agreement . . 394

Range Road Music, Inc. v. East Coast Foods, Inc. . 395

Robert Stigwood Grp., Ltd. v. Sperber . . . . . . . 396

c Miscellaneous . . . . . . . . . . . . . . . 398

Copyright Act $\$ 116 \ldots \ldots$

History of the Jukebox License Office . . . . . . . . 398

Copyright Act $\$ 110 \ldots \ldots$. . . . . . . . . . . 398

2 Sound Recordings . . . . . . . . . . . . . . . . . . . . 399 
Copyright Act $\$ 114$. . . . . . . . . . . . . . 399

Copyright Office, Copyright AND the Musid MarketPlaCE ............... 399

D State-Law Protection for Pre-1972 Sound Recordings . 402

Copyright Act $\$ \$$ 301(c) . . . . . . . . . . . . 402

RCA Mfg. Co. v. Whiteman ... . . . . . . . 403

Copyright Office, Federal CopYright ProtecTION FOR PRE-1972 SOUND RECORDINGS $\ldots .404$

Flo \& Eddie, Inc. v. Sirius XM Radio, Inc. . . . . 406

Flo \& Eddie, Inc. v. Sirius XM Radio, Inc. . . . 408

UMG Recordings, Inc. v. Escape Media Group, Inc.409

Capitol Records, LLC v. Vimeo, LLC . . . . . . . . 410

E Bootlegging ..................... . . 411

Metropolitan Opera Assoc. v. Wagner-Nichols Recorder Corp. . . . . . . . . . . . 4412

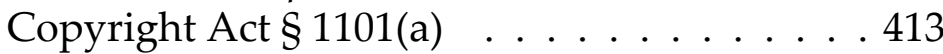

United States v. Martignon . . . . . . . . . . . 413

Questions......... . . . . . . . . . 415

6 Trademark 417

The Trade-Mark Cases . . . . . . . . . . . . . 417

A Subject Matter . . . . . . . . . . . . . . . . . . . 418

Lanham Act $\$ 45$ ("trademark") . . . . . . . . . 418

Drug Stamps Problem . . . . . . . . . . . . . 418

1 Word Marks . . . . . . . . . . . . . . . . . . 419

Zatarains, Inc. v. Oak Grove Smokehouse, Inc. . . 419 Innovation Ventures, LLC v. N.V.E., Inc. . . . . . 425

TMEP $\$ 1202 \ldots \ldots \ldots \ldots \ldots$. . . . . . . . . . . . . . . . .

Elliot v. Google Inc. . . . . . . . . . . . . . . . . . . . . . . . . . . . .

TMEP $\S 1209.03 \ldots \ldots \ldots . \ldots . \ldots . \ldots 432$

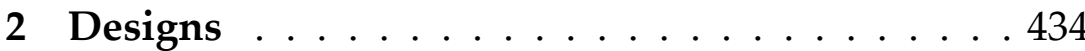

Star Industries, Inc. v. Bacardi \& Co. Ltd. . . . . . 434

Melting Bad Problem . . . . . . . . . . . . . 435

B Ownership .................... . . . 436

1 Priority at Common Law . . . . . . . . . . . . . . 436

Galt House Inc. v. Home Supply Company . . . . 436

United Drug Co. v. Theodore Rectanus Co. . . . . 438

Planetary Motion, Inc. v. Techsplosion, Inc. . . . . 441

Dudley v. HealthSource Chiropractic, Inc. . . . . . . 444

CreAgri, Inc. v. USANA Health Sciences, Inc. . . 445

Bilgewater Bill's Problem . . . . . . . . . . . 448

2 Federal Registration . . . . . . . . . . . . . . . . 448

a Registration . . . . . . . . . . . . . . 448

Lanham Act $s \S 1(a), 7 \ldots \ldots . . . . . . .448$

Burger King of Florida, Inc. v. Hoots . . . . . . 449 
Bilgewater Bill's Problem, Redux . . . . . . . . 450

b Intent-to-Use Applications . . . . . . . . . . . 451

Lanham Act $\$ 1(b) \ldots \ldots . . . . . . . . .451$

Kelly Services, Inc. v. Creative Harbor, LLC [I] . . 451

Kelly Services, Inc. v. Creative Harbor, LLC [II] . 455

Bilgewater Bill's Problem, Re-Redux . . . . . . . 456

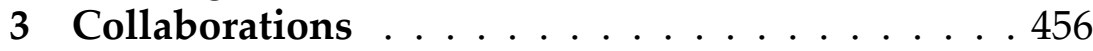

Boogie Kings v. Guillory . . . . . . . . . . . . 456

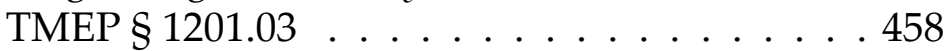

Duff Problem . . . . . . . . . . . . . 459

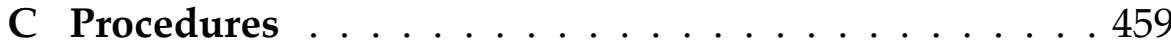

1 Registration . . . . . . . . . . . . . . . . . . . 459

Lanham Act $\$ 2(a)$

Lanham Act $\$ 2$. . . . . . . . . . . . . . . . 460

In re Tam . . . . . . . . . . . . . . . 460

In re Boulevard Entertainment, Inc. . . . . . . . . 461

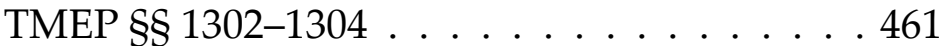

TMEP $\$ \$ 904,1401,1402 \ldots$. . . . . . . . . . . . 462

TMEP $\$ 906 \ldots \ldots$. . . . . . . . . . . . 463

2 Opposition .................. . . . . . . . .

Lanham Act $\$ \S 2(\mathrm{~d}), 12,13 \ldots \ldots$. . . . . . . . 463

BEB Hardware, Inc. v. Hargis Industries, Inc. . . 464

BEB Hardware, Inc. v. Hargis Industries, Inc. . . 466

3 Maintenance ................. . . 466

Lanham Act $\$ \$ 8,9 \ldots \ldots$

4 Cancellation and Incontestability . . . . . . . . . 467

Lanham Act $\$ \S 14,15 \ldots$. . . . . . . . . . . 467

Park 'N Fly, Inc. v. Dollar Park \& Fly, Inc. . . . . 468

5 Abandonment ... . . . . . . . . . . . . . . . 469

Lanham Act $\$ 45$ ("abandoned") . . . . . . . . 469

Procter \& Gamble Co. v. Johnson E Johnson Inc. . 469

Trademark Throwback Problem . . . . . . . . 473

D Infringement: Confusion . . . . . . . . . . . . . . 473

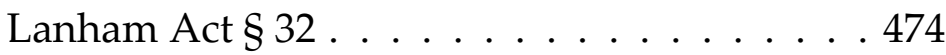

Virgin Enterprises Ltd. v. Nawab . . . . . . . . . 474

Sally Beauty Co., Inc. v. Beautyco, Inc. . . . . . . 484

Cheat Sheet Problem . . . . . . . . . . . . . 485

Boats Problem . . . . . . . . . . . . . . . . 485

E Infringement: Prohibited Conduct . . . . . . . . . . . . 486

1 Threshold Conditions . . . . . . . . . . . . . . . . . 486

Rescuecom Corp. v. Google Inc. . . . . . . . . . . 486

Radiance Foundation, Inc. v. NAACP . . . . . . . 492

2 Theories of Confusion . . . . . . . . . . 496

a Reverse Confusion . . . . . . . . . . . . 496 
Restatement (Third) of Unfair Competition § $20 \mathrm{cmt} . \mathrm{f} \ldots \ldots \ldots . \ldots 496$

b Initial Interest Confusion . . . . . . . . . . 497

Grotrian, Helfferich, Schult, Th. Steinweg Nachf v. Steinway \& Sons . . . . . . . . . . . 497

Brookfield Communications v. West Coast Entertainment. . . . . . . . . . . . 497

Hearts on Fire Company, LLC v. Blue Nile, Inc. . . 498

c Post-Sale Confusion ............. 500

General Motors Corp. v. Keystone Automotive Industries, Inc. . . . . . . . . . . . . . . 500

3 Section 43(a) . . . . . . . . . . . . . . . 503

Lanham Act $\$ 43(\mathrm{a})(1)(\mathrm{A})$. . . . . . . . . . . 503

a Unfair Competition . . . . . . . . . . . . 504

Margreth Barrett, Finding Trademark Use . . . . 504

William R. Warner \& Co. v. Eli Lilly \& Co. . . . . 505

Blinded Veterans Association v. Blinded American Veterans Foundation . . . . . . . . . . 506

b False Endorsement . . . . . . . . . . . . . . . 509

Yale Electric Corp. v. Robertson . . . . . . . . . . 509

Conan Properties, Inc. v. Conans Pizza, Inc. . . . 510 International Order of Job's Daughters v. Lindeburg \& Co. ............. . . 512

c Failure to Attribute . . . . . . . . . . . . . 514

Dastar Corp. v. Twentieth Century Fox Film Corp 514

4 Dilution ..................... 519

Frank I. Schechter, The Rational Basis of Trademark Protection . . . . . . . . . . . . . . 519

Jeremy N. Sheff, The (Boundedly) Rational Basis

of Trademark Liability . . . . . . . . . . . 520

Ty Inc. v. Perryman . . . . . . . . . . . . . . 521

Lanham Act \$ 43(c) . . . . . . . . . . . . . 521

Nike, Inc. v. Nikepal Intern., Inc. . . . . . . . . 523

Dilution Lightning Round . . . . . . . . . . . . 530

5 Problems . . . . . . . . . . . . . . . . 5 532

Ambush Marketing Problem . . . . . . . . . . . 532

Iack Daniel's Problem . . . . . . . . . . . . . . 533

Paper Handbag Problem . . . . . . . . . . . . 533

6 Secondary Liability . . . . . . . . . . . . . 533

Inwood Laboratories, Inc. v. Ives Laboratories, Inc. 533

Philip Morris USA Inc. v. Lee . . . . . . . . . . . 534

F Defenses . . . . . . . . . . . . . . . . . . 5 537

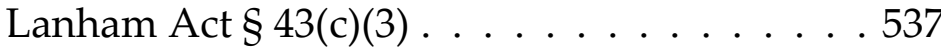

1 Descriptive Fair Use . . . . . . . . . . . . . . . 537

Zatarains, Inc. v. Oak Grove Smokehouse, Inc. . . 537 
2 Nominative Fair Use . . . . . . . . . . . . . . . . 539

New Kids on the Block v. New America Pub., Inc. .539

Smith v. Chanel, Inc. . . . . . . . . . . . . . 544

3 Exhaustion . . . . . . . . . . . . . . . . 548

Champion Spark Plug Co. v. Sanders . . . . . . 548

Hart v. Amazon.com, Inc. . . . . . . . . . . 550

4 Expressive Use . . . . . . . . . . . . . . . 550

Louis Vuitton Malletier v. Haute Diggity Dog . . 550

Louis Vuitton Mallatier v. Warner Bros. . . . . . . 560

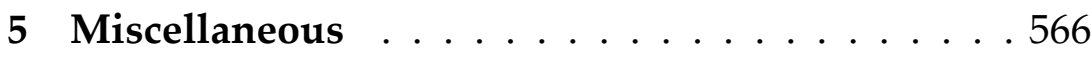

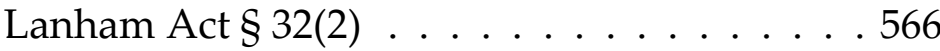

Trademark Defenses Lightning Round . . . . . 567

G Other Identifier Registries . . . . . . . . . . . . . . . . 573

1 Phone Numbers . . . . . . . . . . . . . . . . . 573 Holiday Inns, Inc. v. 800 Reservation, Inc. … . 573

2 Radio Callsigns . . . . . . . . . . . . . . . . 575 In re WSM, Inc. . . . . . . . . . . . . . . . 575

3 Business Names . . . . . . . . . . . . . . . . 577

Model Business Corporation Act . . . . . . . . 577

Harvard Business Services v. Coyle . . . . . . . . 579

Cooper v. Goodman . . . . . . . . . . . . . . . 580

Friedman v. Rogers . . . . . . . . . . . . . . 580

4 Ticker Symbols . . . . . . . . . . . . . . . . . . . . . 582

Eric Levenson, Investors Buy Up Worthless

Stock After Confusing It for an Actual Success-

ful Company .............. . . 582

FINRA Uniform Practice Advisory \# 39 -13 . . . . 583

Central Parking Corp. v. Park One Inc. . . . . . . . 583

Exxon Corp. v. Xoil Energy Resources, Inc. . . . . 584

MDT Corp. v. New York Stock Exchange, Inc. . . 586

Comments of James Angel on General Portability

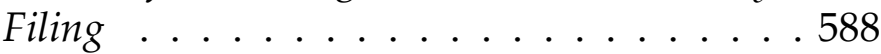

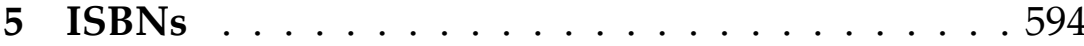

ISBN.org, FAQs: General Questions . . . . . . . 594

6 License Plates . . . . . . . . . . . . . . . . . . . . . 596

Wooley v. Maynard . . . . . . . . . . . . . 596

Mitchell v. Maryland Motor Vehicle Administration 597

Nevada Administrative Code $\S 482.320$. . . . 602

7 Domain Names . . . . . . . . . . . . . . . . . 603

Anticybersquatting Consumer Protection Act . 603

Uniform Domain-Name Dispute Resolution

Policy ....................605

8 Online Accounts . . . . . . . . . . . . . . . . . . . . 608

Twitter Rules . . . . . . . . . . . . . . . . 608

9 Stage Names . . . . . . . . . . . . . . . . . 610 
Professional Name Policy . . . . . . . . . . . 610

David Fagundes, Talk Derby to Me: Intellec-

tual Property Norms Governing Roller Derby

Pseudonyms............... . 6 610

7 Advertising 619

A False Advertising . . . . . . . . . . . . . . . . . 620

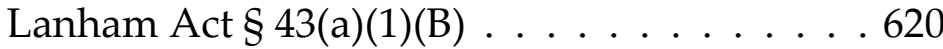

1 "Ownership": Competitor Standing . . . . . . . 620

American Washboard Co. v. Saginaw Mfg. Co. . . 621

Ely-Norris Safe Co. v. Mosler Safe Co. . . . . . . 621

Mosler Safe Co. v. Ely-Norris Safe Co. . . . . . . 622

Lexmark International, Inc. v. Static Control

Components, Inc. . . . . . . . . . . 622

2 "Infringement": Prohibited Conduct . . . . . . . 626

Greater Houston Transportation Company 0.

Uber Technologies, Inc. . . . . . . . . . . . . . 626

Procter \& Gamble Co. v. Haugen . . . . . . . . 628

3 "Infringement": Falsity and Materiality . . . . . . 629

Pizza Hut, Inc. v. Papa John's Intern., Inc. . . . 629

McNeil-PPC, Inc. v. Pfizer Inc. . . . . . . . . . 642

Satellite TV Problem . . . . . . . . . . . . . 645

4 Secondary Liability . . . . . . . . . . . . . . . . . 646

Duty Free Americas, Inc. v. Estee Lauder Companies, Inc. . . . . . . . . . . . . . . 646

B Alternatives to Competitor Suits . . . . . . . . . . . . 649

1 Commercial Disparagement and Related Torts . . 649

HipSaver, Inc. v. Kiel. . . . . . . . . . . . . . 649

Aviation Charter, Inc. v. Aviation Research . . . . 650

2 Consumer Suits . . . . . . . . . . . . . . 653

Perrine v. Sega of America, Inc. . . . . . . . . . 653

3 FTC Enforcement ................ 656

Federal Trade Commission v. Winsted Hosiery

Company ................6656

Kraft, Inc. v. FTC . . . . . . . . . . . . . . 658

Letter from Federal Trade Commission to Mi-

crosoft Corp. and Starcom MediaVest Group . . 659

C Other Sources of Advertising Law . . . . . . . . . . . . 662

1 Trademark . . . . . . . . . . . . . . . . . 662

Lanham Act $\$ \S 2(\mathrm{e})(1),(\mathrm{f})$

In re Budge Mfg. Co. . . . . . . . . . . . . . . 662

2 Certifications . . . . . . . . . . . . . . . . . . 664

Lanham Act § 45 ("certification mark"). . . . . 664

TMEP $\$ 1306 \ldots \ldots \ldots$. . . . . . . . . 665

Fair Trade USA Farm Workers Standard . . . . . 666 
Understanding the FCC Regulations for LowPower, Non-Licensed Transmitter . . . . . . 667

Inspection E Grading of Meat and Poultry: What Are the Differences? . . . . . . . . . . . . . . 668

3 Geographic Indications . . . . . . . . . . . . . . 669

Justin Hughes, Champagne, Feta, and BourbonThe Spirited Debate About Geographical Indi-

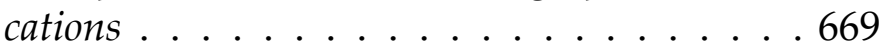

TRIPS arts. 22-24 . . . . . . . . . . . . . . . . . . . . . . . . . . . . . . . . .

Lanham Act $\S 2$. . . . . . . . . . . . . 672

Guantanamera Cigar Co. v. Corporacion Habanos 673

Labeling and Advertising of Distilled Spirits,

27 C.F.R Part 5 . . . . . . . . . . . . 677

Textile Products Identification Act . . . . . . 678

Melting Bad Problem, Redux . . . . . . . . . . 679

4 Regulation ................... 679

POM Wonderful LLC v. The Coca-Cola Company 680

Rebecca Tushnet, It Depends on What the Meaning of "False" is: Falsity and Misleadingness in Commercial Speech Doctrine. . . . . . . . 682

Commack Self-Service Kosher Meats, Inc. v. Weiss 684 Levy v. Kosher Overseers Ass'n of America, Inc. . 687

5 Mandatory Disclosures . . . . . . . . . . . 688

American Meat Institute v. Dept. of Agriculture . 688

National Ass'n of Mfrs. v. Securities and Exchange Commission [I] . . . . . . . . . 690

National Ass'n of Mfrs. v. Securities and Exchange Commission [II] . . . . . . . . . . . . . . . . . 691

6 Self-Regulation. . . . . . . . . . . . . . 692 Mead Johnson Nutritionals (Enfamil LIPIL) . . . . 692 CARU Press Release . . . . . . . . . . . . 695

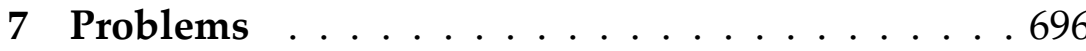
Scavenger Hunt Problem . . . . . . . . . . . 696 problems/fortunetelling . . . . . . . . . 696

8 Personality Rights 697

A Right of Publicity . . . . . . . . . . . . . . . . . 697

1 Ownership . . . . . . . . . . . . . 6 697

a Privacy Theories . . . . . . . . . . . . 698

Roberson v. Rochester Folding Box Co. . . . . . 698

New York Civil Rights Law $\$ 51$. . . . . . . . . 700

Pavesich v. New England Life Ins. Co. . . . . . . . 701

O’Brien v. Pabst Sales Co. . . . . . . . . . . . . . 704

b Property Theories............... . . 705

Haelan Laboratories v. Topps Chewing Gum . . . 705 


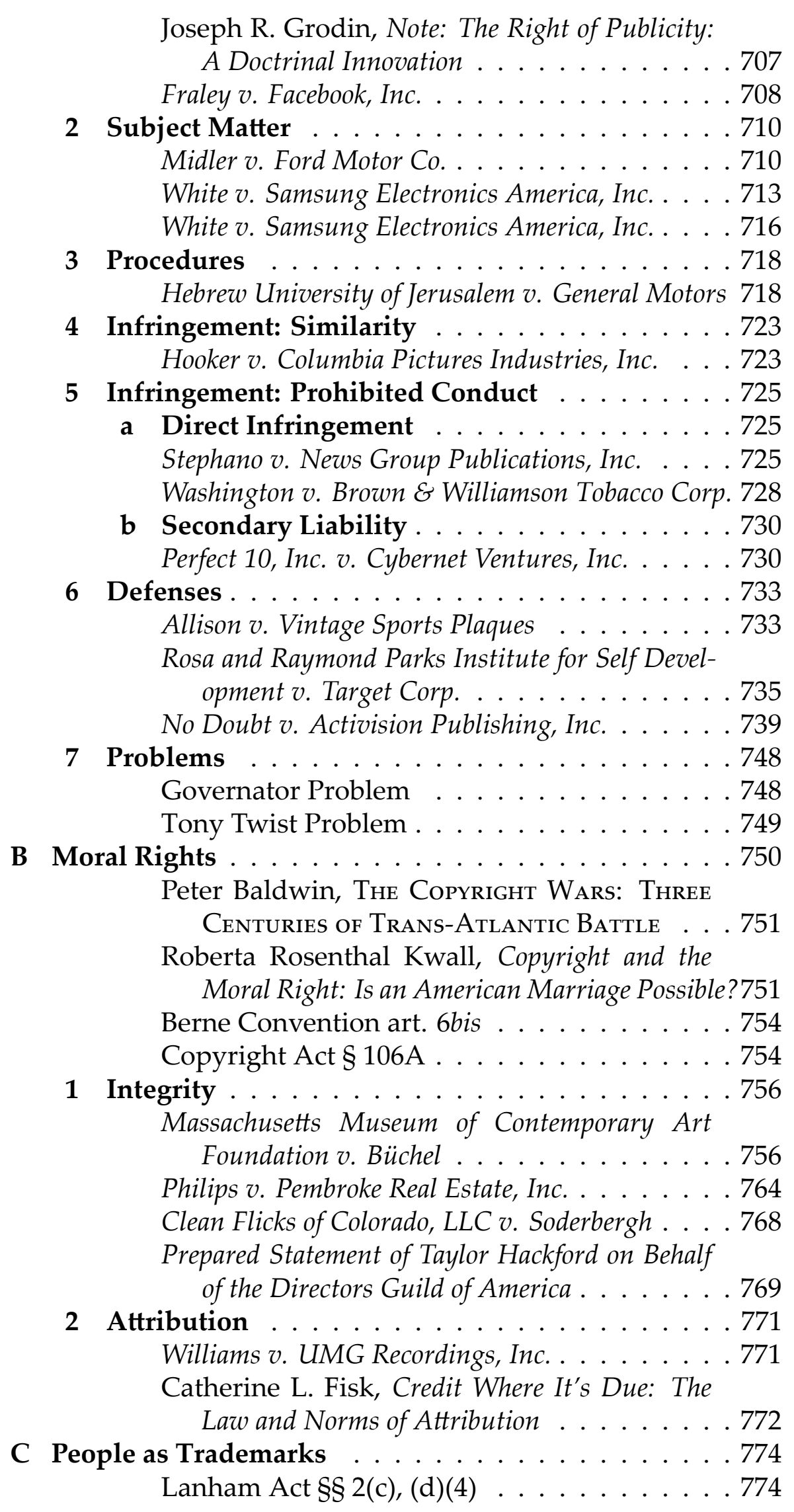


Peaceable Planet, Inc. v. Ty, Inc. . . . . . . . . . 774

David B. Findlay, Inc. v. Findlay . . . . . . . . 775

Hebrew University of Jerusalem v. General Mo-

tors LLC . . . . . . . . . . . . . . . 779

Brown v. Electronic Arts, Inc. … . . . . . . . 780

Melting Bad Problem, Re-Redux . . . . . . . 782

D Personal Names . . . . . . . . . . . . . . . . . . . . . . 782

Laura A. Heymann, Naming, Identity, and

Trademark Law ... . . . . . . . . . 782

Carlton F.W. Larson, Naming Baby: The Consti-

tutional Dimensions of Parental Naming Rights 783

In re Mokiligon . . . . . . . . . . . . . . . . 785

Petition of Variable . . . . . . . . . . . . . 786

In re Ravitch . . . . . . . . . . . . . . . . 787

In re Serpentfoot . . . . . . . . . . . . . 788

Weingand v. Lorre . . . . . . . . . . . . . 789

Application of Clark . . . . . . . . . . . . . . . 790

In re Name Change of Handley . . . . . . . . . . 791

In re Porter . . . . . . . . . . . . . . . . 792

E Defamation and False Light . . . . . . . . . . . . . . 792

Milkovich v. Lorain Journal Co. . . . . . . . . . . 792

Restatement (Second) of Torts $\$ 652 \mathrm{E}$. . . . . . 797

Tyne ex rel. Tyne v. Time Warner Entertainment Co., L.P. . . . . . . . . . . . . . 798

Restatement (Second) of Torts \$ $564 \mathrm{cmt}$. d . . 801

Iessica Litman, Information Privacy/Information

Property . . . . . . . . . . . 802

9 Design 803

A Patent . . . . . . . . . . . . . . . . . . . 8803

B Copyright . . . . . . . . . . . . . . . . . . . . 8 803

1 Useful Articles . . . . . . . . . . . . . . . . . 804

Mazer v. Stein . . . . . . . . . . . . . . . . 804

Copyright Act $\$ 101$ ("useful article") . . . . . . 805

H.R. Rep No. 94-1476 . . . . . . . . . . . . 806

Brandir Intern., Inc. v. Cascade Pacific Lumber Co. 807

Eames Chair Problem . . . . . . . . . . . . . . . 813

Copyright Act $\$ 113$. . . . . . . . . . . . . . 813

Report of the Register of Copyrights on the

General Revision of the Copyright Law (1961) . . . . . . . . . . . . 814

Model Car Problem . . . . . . . . . . . . . 815

2 Architecture ................. . . . . . . . 
Kevin Emerson Collins, Economically Defeasible Rights to Facilitate Information Disclosure: The Hidden Wisdom of Pre-AWCPA Copyright 816

Copyright Act $\$ 120 \ldots$. . . . . . . . . 817

37 C.F.R. \& 202.11 . . . . . . . . . . . 817

Intervest Construction., Inc. v. Canterbury Estate Homes ................ . . 817

Zalewski v. Cicero Builder Dev., Inc. . . . . . . . . 818

Embassy Problem . . . . . . . . . . . . . . . . . 821

3 Moral Rights . . . . . . . . . . . . . . . . . . 821

Cheffins v. Stewart . . . . . . . . . . . 8821

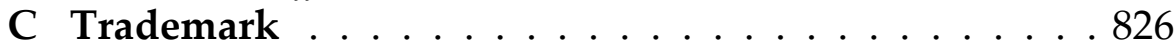

Wal-Mart Stores, Inc. v. Samara Brothers, Inc. . . 827

Lanham Act $\$ \S 2(\mathrm{e})(5), 43(\mathrm{a})(3) \ldots . . . . .830$

TrafFix Devices, Inc. v. Marketing Displays, Inc. .830

In re Florists' Transworld Delivery, Inc. . . . . . . 835

Maker's Mark Distillery, Inc. v. Diageo North

America, Inc. . . . . . . . . . . . . . 837

Eames Chair Problem, Revisited . . . . . . . . . 838

Pez Dispenser Problem . . . . . . . . . . . . 838

D Design Patent . . . . . . . . . . . . . . . . 838

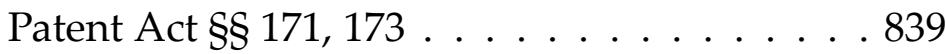

1 Subject Matter . . . . . . . . . . . . . . . . . . . 844

a Articles of Manufacture . . . . . . . . . . . . 844

In re Hruby . . . . . . . . . . . . . . . . . . . . . . . . . . . . . . . . . . . . . . . . . .

In re AlSabah . . . . . . . . . . . . . . . 847

b Ornamentality . . . . . . . . . . . . . . . . . . . . . . . . . . . . . . . .

In re Webb. . . . . . . . . . . . . . . . . . . . . . . . . . . . . . . . . . . . . . . . . .

Rosco, Inc. v. Mirror Lite Co. . . . . . . . . . . 851

In re Koehring . . . . . . . . . . . . . . . . . 852

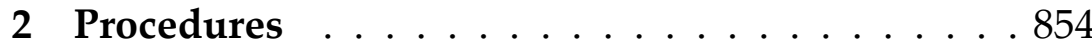

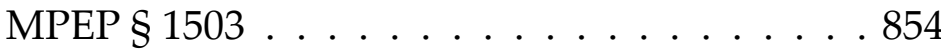

Patent Act $\S 173 \ldots$. . . . . . . . . . . . . . . 856

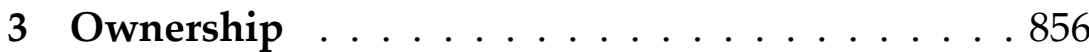

a Novelty . . . . . . . . . . . . . . . 857

International Seaway Trading Corp. v. Walgreens Corp................. . . 857

b Obviousness................... 859

MRC Innovations, Inc. v. Hunter Mfg., LLP, . . . 859

4 Infringement: Similarity . . . . . . . . . . 863

Egyptian Goddess, Inc. v. Swisa, Inc. . . . . . . 863

Wing Shing Products (BVI) Co. v. Sunbeam Prod-

ucts, Inc. . . . . . . . . . . . . . . . . 868

OddzOn Products, Inc. v. Iust Toys, Inc. . . . . . 873

L.A. Gear, Inc. v. Thom McAn Shoe Co. . . . . . . 874 
5 Infringement: Prohibited Conduct . . . . . . . . 874 Patent Act $\$ 289$. . . . . . . . . . . . . . . 874

Milo \& Gabby, LLC v. Amazon.com . . . . . . . . 875

6 Defenses. . . . . . . . . . . . . . . 877

Iazz Photo Corp. v. International Trade Com'n . . 877

Ralph D. Clifford \& Richard J. Peltz-Steele, The

Constitutionality of Design Patents $\ldots . .8877$

Eames Chair Problem, Re-revisited . . . . . . . 879

E Sui Generis Regimes . . . . . . . . . . . . . . . . . . . 880

1 Semiconductor Masks . . . . . . . . . . . . . 880

Pamela Samuelson, Creating a New Kind of In-

tellectual Property: Applying the Lessons of

the Chip Law to Computer Programs. . . . . . 880

Kal Raustiala \& Christopher Sprigman, The

Piracy Paradox, Innovation and Intellectual Property in Fashion Design . . . . . . . . . . . 882

Altera Corp. v. Clear Logic, Inc. . . . . . . . . . 882

2 Vessel Hulls . . . . . . . . . . . . . . . . . . 885

Bonito Boats, Inc. v. Thunder Craft Boats, Inc. . . 885

Copyright Act ch. 13 . . . . . . . . . . . 887

Maverick Boat Co., Inc. v. American Marine

Holdings, Inc. . . . . . . . . . . . . . . . . . 8890

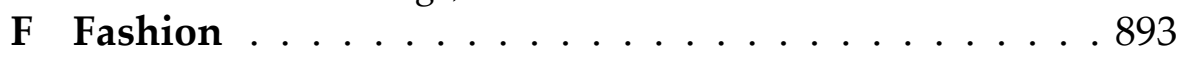

1 Copyright . . . . . . . . . . . . . . . . . 893

Iack Adelman, Inc. v. Sonners E Gordon, Inc. . . . 893

Cheney Bros. v. Doris Silk Corporation . . . . . . 894

Fashion Originators' Guild of America v. Federal

Trade Commission ............ 895

Peter Pan Fabrics, Inc. v. Brenda Fabrics, Inc. . . . 898

Varsity Brands, Inc. v. Star Athletica, LLC . . . . 899

2 Trademark ................... . 904

Christian Louboutin v. Yves Saint Laurent America 904

Christian Louboutin v. Yves Saint Laurent Americal 911

3 Design Patent. . . . . . . . . . . . . . . . . 914

Kal Raustiala \& Christopher Sprigman, The

Piracy Paradox, Innovation and Intellectual Property in Fashion Design . . . . . . . . . . 914

4 Sui Generis Protection? . . . . . . . . . . . . . . . . 915

ames Surowiecki, The Piracy Paradox . . . . . . 915

C. Scott Hemphill \& Jeannie Suk, The Law, Culture, and Economics of Fashion . . . . . . . 916

Innovative Design Protection Act of $2012 \ldots 918$

10 Software 925

A Trade Secret . . . . . . . . . . . . . . . . 925 
Barr-Mullin, Inc. v. Browning. . . . . . . . . . 926

Silvaco Data Systems v. Intel Corp. . . . . . . . . 926

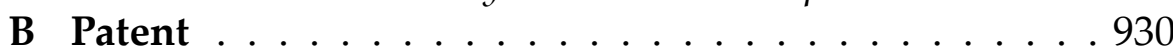

1 Subject Matter . . . . . . . . . . . . . . . . 9930

a Then .................... . . . . . . . . . . . . .

In re Bernhart . . . . . . . . . . . . . . . . . . . . . . . . . . . . . . . . . . . . . . .

In re Alappat .................. 931

State Street Bank \& Trust Co. v. Signature Finan-

cial Group . . . . . . . . . . . . . . . . . . . . . . . 934

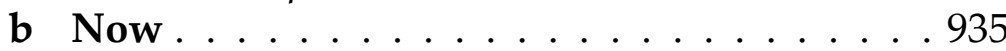

Alice Corp. v. CLS Bank Int' . . . . . . . . . 9935

McRO, Inc. v. Bandai Namco Games America Inc. 941

Synopsys, Inc. v. Mentor Graphics Corp. . . . . . 946

2 Procedures ..................... 951

Williamson v. Citrix Online, LLC . . . . . . . . 951

Mark A. Lemley, Software Patents and the Re-

turn of Functional Claiming . . . . . . . . 953

3 Obviousness ................ . . 954

Apple Inc. v. Samsung Electronics Co., Ltd. . . . . 954

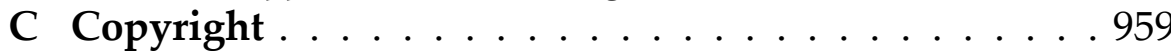

1 Subject Matter . . . . . . . . . . . . . . . . 959

Apple Computer, Inc. v. Franklin Computer Corp. 959

Adobe Systems Inc. v. Southern Software Inc. . . . 961

Whelan Associates, Inc. v. Jaslow Dental Labora-

tory, Inc. . . . . . . . . . . . 963

Computer Associates Intern., Inc. v. Altai, Inc. . . 964

Oracle America, Inc. v. Google Inc. . . . . . . . . 969

Oracle America, Inc. v. Google Inc. . . . . . . . . 975

Tetris Problem . . . . . . . . . . . . . . 982

2 Defenses..................... . . . 982

Copyright Act $\$ 117$. . . . . . . . . . . . . . . 982

Sega Enterprises Ltd. v. Accolade, Inc. . . . . . . . 983

Universal City Studios, Inc. v. Corley . . . . . . . 985

D Trademark .................. 987

Apple Inc. v. Samsung Electronics Co., Ltd. . . . . 987

E Design Patent . . . . . . . . . . . . . . . . 988

Michael Risch, Functionality and Graphical User Interface Design Patents . . . . . . . . . . . 989

Smartphone Problem . . . . . . . . . . . 991

11 Biotechnology 993

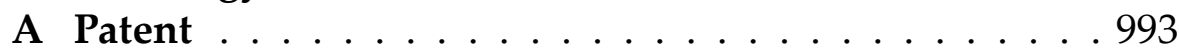

1 Subject Matter .................. 993

Association for Molecular Pathology v. Myriad

Genetics, Inc. . . . . . . . . . . . . 9993 


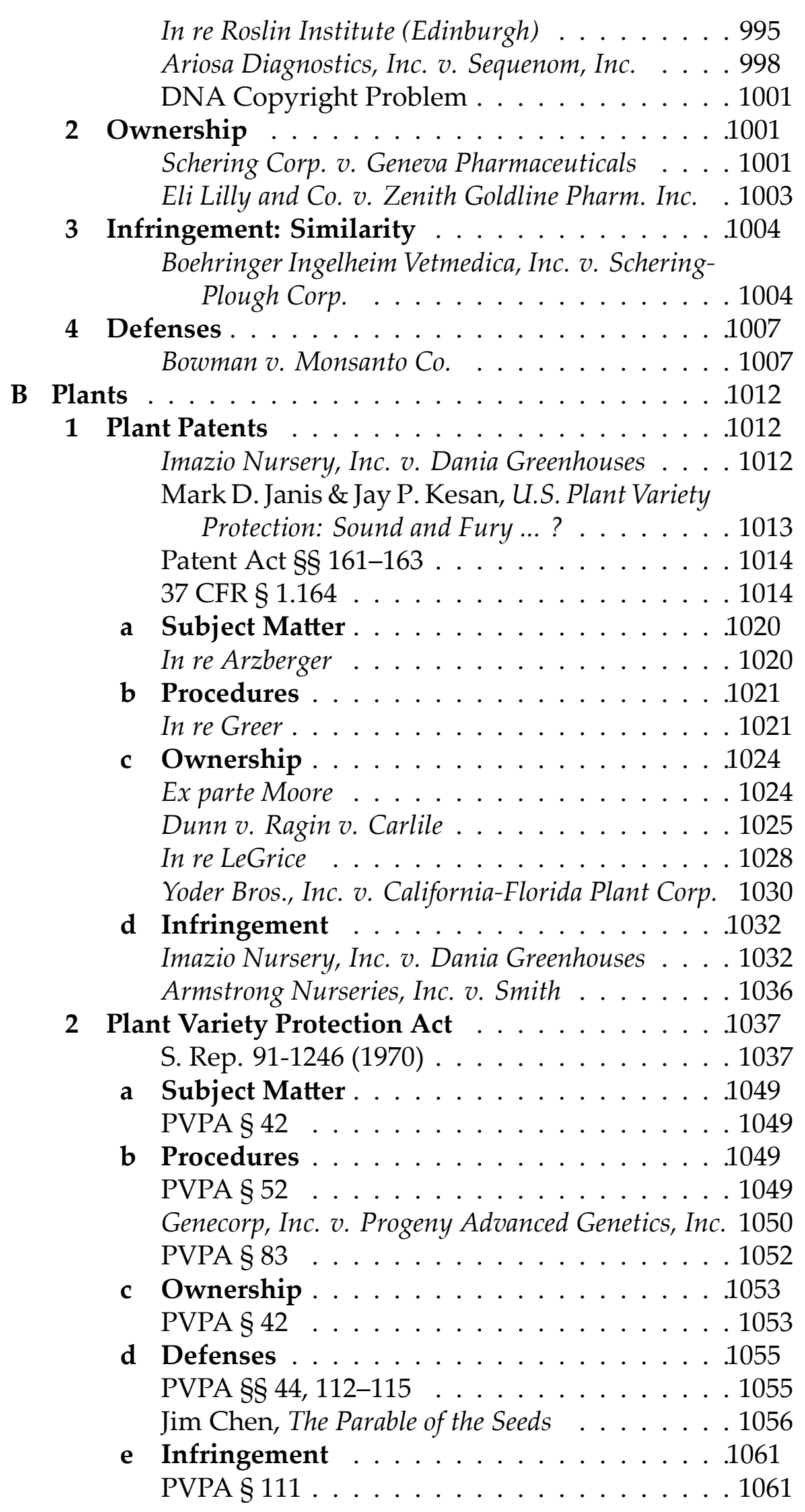


Delta and Pine Land Co. v. Sinkers Corp. . . . . . 1063

3 The Punchline . . . . . . . . . . . . . . . 1073

IEM Ag Supply, Inc. v. Pioneer Hi-Bred International, Inc. . . . . . . . . . . . . 1073

C Drug Approval . . . . . . . . . . . . . . . . . . . . 1075

1 Patent Issues . . . . . . . . . . . . . . . . . . 1075

Kara B. Swanson, Food and Drug Law as Intellectual Property Law . . . . . . . . . . . . . 1075

Merck KGaA v. Integra Lifesciences I, Ltd. . . . 1079

Eli Lilly \& Co. v. Medtronic, Inc. . . . . . . . . . 1079

2 Hatch-Waxman . . . . . . . . . . . . . . . . 1081

United States v. Generix Drug Corp. . . . . . . . 1082

FTC v. Actavis, Inc. . . . . . . . . . . . . . 1083

Actavis Elizabeth LLC v. U.S. Food and Drug Admin. . . . . . . . . . . . . . 1083

Erika Lietzan, The Myths of Data Exclusivity . . 1085

Caraco Pharmaceutical Labs v. Novo Nordisk . . . 1087

FTC v. Actavis, Inc. . . . . . . . . . . . . . . 1090

3 Orphan Drugs . . . . . . . . . . . . . . . . . . . . 1094

Genentech, Inc. v. Bowen . . . . . . . . . . . . 1094

Sigma-Tau Pharmaceuticals, Inc. v. Schwetz . . 1096

D Drug Marketing . . . . . . . . . . . . . . . . . . . . . 1098

1 Names . . . . . . . . . . . . . . . . . . . . . . 1098

Note on Drug Naming . . . . . . . . . . . . 1098

S. Rep. 87-448 (1961) . . . . . . . . . . . . . . 1103

21 C.F.R. \$ 201.10 . . . . . . . . . . . . 1104

Kos Pharmaceuticals, Inc. v. Andrx Corp. . . . . 1105

666 Problem . . . . . . . . . . . . . . 1108

2 Design . . . . . . . . . . . . . . . . . . . . . 1108

Shire US Inc. v. Barr Laboratories, Inc. . . . . . . 1108

Jeremy A. Greene \& Aaron S. Kesselheim,

Why Do the Same Drugs Look Different? Pills,

Trade Dress, and Public Health . . . . . . . . . 1111

3 Labeling and Advertising.

Consumer-Directed Broadcast Advertisements:

Guidance for Industry . . . . . . . . . . . . . 1114

Letter from Robert Dean, Division Director,

OPDP, FDA, to Eric Gervais . . . . . . . . . . 1115

United States v. Caronia . . . . . . . . . . . . 1117

Wyeth v. Levine. . . . . . . . . . . . . . . 1120

PLIVA, Inc. v. Mensing . . . . . . . . . . . . 1121

SmithKline Beecham v. Watson Pharmaceuticals . 1122

Bizarro World Redux Problem . . . . . . . . . . 1125 


\section{Introduction}

\section{Why This Book?}

This book takes its subtitle from Sheldon Axler's Linear Algebra Done Right and its inspiration from a line by the great mathematician Emil Artin: "It is my experience that proofs involving matrices can be shortened by $50 \%$ if one throws the matrices out." Matrices are numerical representations of mathematical operations; proofs involving them tend to look something like:

$$
c\left[\begin{array}{ccccc}
a_{1,1} & \cdots & a_{1, i} & \cdots & a_{1, n} \\
\vdots & & \vdots & & \vdots \\
a_{j, 1} & \cdots & a_{j, i} & \cdots & a_{j, n} \\
\vdots & & \vdots & & \vdots \\
a_{m, 1} & \cdots & a_{m, i} & \cdots & a_{m, n}
\end{array}\right]=\left[\begin{array}{ccccc}
c a_{1,1} & \cdots & c a_{1, i} & \cdots & c a_{1, n} \\
\vdots & & \vdots & & \vdots \\
c a_{j, 1} & \cdots & c a_{j, i} & \cdots & c a_{j, n} \\
\vdots & & \vdots & & \vdots \\
c a_{m, 1} & \cdots & c a_{m, i} & \cdots & c a_{m, n}
\end{array}\right]
$$

Axler's book throws most of the matrices out, and as a result, is one of the clearest college mathematics textbooks ever written. There are matrices and proofs using them, but they are secondary to the algebraic explanations and proofs, which tend to look more like:

$$
c T(v)=T(c v)
$$

This book is my attempt to take intellectual property law and throw the matrices out. The matrices aren't literal matrices, of course, or IP would be much less fun and interesting to study, to teach, and to practice. Instead, the matrices consist of built-up expectations about how the subject is structured, and how it should be taught. But many of these traditions have nothing but tradtion to support them. Cast them aside, and what emerges is simpler, richer, and more elegant.

\section{Coverage}

The first tradition to is the assumption that "intellectual property" primarily means patent, copyright, and trademark. These three fields 
It probably does not help that the Big Three are all federal regimes, leading students to neglect the importance of state law. dominate most IP courses and most casebooks. Trade secret law usually makes a walk-on appearance, as does the right of publicity, but that is typically it. Design patents, false advertising, and idea protection may be mentioned as afterthoughts. I don't mean to denigrate patent, copyright, and trademark. They are important, and an IP course that omitted one of them would be seriously deficient. But they are not so much more important than other fields of IP that they should push those other fields out of the picture.

For one thing, these other fields are important in regular "IP" practice: just ask any observer of the smartphone design-patent wars, any employment lawyer negotiating an NDA, or any business lawyer reviewing ad copy for substantiation. A professor who lets students leave the IP survey unaware these bodies of law even exist commits academic malpractice.

If that weren't enough, these other fields help illuminate the traditional ones. Trademark law's treatment of descriptive and misdescriptive marks looks very different after a trip through falseadvertising law: the difference between an arbitrary mark and a misdescriptive one is whether consumers are in on the joke. Recognizing that the reverse engineering privilege in trade secret law is a form of exhaustion helps clarify exhaustion in patent law.

Thus, this book casts an extremely broad net when including IP regimes. In my view, intellectual property consists of any private right to prevent other people from using information. This encompasses contracts for the use of information, trade secrets, copyrights, trademarks, unfair competition, parts of false advertising law, geographic indications, rights of publicity, moral rights, design patents, and a miscellany of federal and state regimes like boat-hull protections and common-law misappropriation. They are all given serious attention.

Having cast a wide net to gather in IP regimes, the book then casts its net widely again within each system. My working motto when debating what to include was no unpleasant surprises. It is fine to gesture at something big and messy whose details are not filled in in the slightest - like the compulsory copyright license for satellite broadcasting, whose rules fill dozens of pages in sections 119 and 122 of title 17. But it is not fine to pass by something that comes up regularly, is important when it does, and whose existence is not easily predictable -like the exemption in section 110 for many in-person noncommercial public performances. Thus, the book is unusually detailed in covering theories of liability and major defenses: examples include the DMCA's prohibition on removing copyright management information, the unfair-competition cause of action for deliberate passing off even in the absence of trademark rights, and the limitation of patent remedies against medical practitioners. 
And finally, the book casts its net widely a third time to sweep in bodies of law that are not traditionally regarded as "intellectual property" at all, but have something to teach about how intellectual property law works. Sometimes, this is because they provide useful points of comparison: FOIA and classification effectively create a body of secrecy law for the government, and seeing how they work clarifies what is distinctive about trade secret law. Sometimes, it is because they provide the backdrop against which "intellectual property" law plays out: pharmaceutical patent law is unintelligible without a grounding in the drug-approval process. And sometimes, it is because they really are intellectual property law: Actors Equity gives out stage names on a first-come first-served basis, and while the resulting rights are narrow and privately created, they are absolute within the relevant domain. Thus, the book includes such unusual topics as FOIA, privacy torts, drug approval and labeling, state business name registries, country-of-origin labeling statutes, the law of personal name changes, and the BBB's advertising self-regulatory programs.

Given this wide range of subjects, the book does not cover each of them in equal depth. Instead, I have tried to do two things. On the one hand, I try to give a good conceptual sense for how each body of IP law thinks about the world. Students should know that copyright is built around originality and similarity; that trademark is built around distinctiveness, priority, and confusion; that advertising is built around truth; and so on. The cases and materials are selected and arranged to build this intuition, even at the expense of detail. The point is to leave readers in a position where they can make plausible interpolations in the parts of the subjects they have not seen. A good first guess and good research skills will take you surprisingly far.

On the other hand, the book is relentlessly comparative. I don't mean that it's internationally comparative, although some sections do sketch the major distinctions between the U.S. approach and other countries' (e.g. on geographic indications and moral rights). Instead, it draws every possible comparison within American IP law. It does this at a macro level, emphasizing the similarities and the differences between the basic principles undergirding each body of IP law. For example, patent and copyright think similarly about incentives, while trademark and false advertising think similarly about consumers. And it does this at a micro level, setting up similar doctrines across IP fields to compare and contrast. For example, trade secret law shares with copyright law the requirement that the defendant must have copied from the plaintiff to infringe, which plays out in their similarly permissive attitude in allowing multiple independent parties to lay claim to the same information simultaneously. They stand in sharp contrast to patent and trademark, where subsequent 
The only exceptions are those fields, like geographic indications, discussed too briefly to bother with the full structure.

None of these divisions are as fully implemented as I would like in the current version. independent creation can only mitigate the consequences of infringement, rather than negating it entirely.

\section{A Taxonomy of IP}

To make the internal logic of each IP field clearer, and to facilitate comparisons between them, I have imposed a rigorous structure on them. The two basic issues for any form of IP are protection and infringement; as far as possible, I try to keep them distinct. I insist on the division even for areas, like rights of publicity, where it is not conventionally made. But whether the defendants are trading on the plaintiff's identity is a different question than which aspects of that identity are protectable at all, and separating them clarifies what is at stake in each.

I further divide protection into subject matter, ownership, and procedures, or, roughly "what?", "who?" and "how?" In copyright, for example, subject matter includes Feist's famous "modicum of creativity" and the idea/expression dichotomy; ownership includes joint works, works made for hire, and derivative works; and procedures include term, registration, deposit, notice, and fixation. Yes, fixation. It isn't a question of what information is copyrightable so much as what one must do to obtain a copyright in that information (answer: not much). This arrangement is a bit unconventional, but I think it's clearer. I tend to break up subject matter doctrines into thresholds, which ask whether something is [creative, secret, distinctive, etc.] enough for an IP field to care about, and boundary conditions like functionality, which declare something the wrong kind of thing for an IP field. Ownership rules subdivide into rules to allocate ownership with collaborations, rules to assign priority among competitors, and rules for derivative creation that builds on others' information. Procedures are too diverse to taxonomize systematically, although registration and notice are common that I have tried to flag them wherever they appear, and their absence wherever they don't.

I subdivide infringement into similarity, prohibited conduct, and defenses. The distinction between the first two is all-important. Similarity is a test of the relationship between the plaintiff's information and the defendant's; prohibited conduct deals with what the defendant did with that information. Similarity is the domain of claim construction and the every-element rule, of substantial similarity, and of the likelihood of confusion. Prohibited conduct is the domain of "makes, uses, offers to sell, or sells" and of the exclusive rights. It further breaks down into threshold conditions like Lanham Act $\S 43(\mathrm{a})(1)(\mathrm{B})$ 's "in commercial advertising or promotion," into intent requirements (or their absence), (sometimes) into proof of copying from the plaintiff, into the specific enumerated or unenumerated the- 
ories of direct infringement, and into various secondary liability doctrines. Here is where I have found the comparative method most useful; it has forced me to find and present cases on topics like secondary liability for right of publicity violations and on proving copying in trade secret misappropriation. They exist, and they display interesting and revealing variations from their more familiar cousins.

Some IP defenses are idiosyncratic, like the compulsory mechanical license in copyright or the vestigial experimental use defense in patent. But others display systematic consistency across almost all of IP. The exhaustion defenses, which define the interface between intellectual property rights in information and personal property rights in tangible things, are essentially universal - and especially revealing, because while every IP field embraces the exhaustion principle, each IP field puts characteristically different limits on it. Another cluster of common defenses protect expressive uses. Sometimes these limits are internal to the doctrinal logic of an IP field; sometimes they appear as separate defenses; sometimes they are explicitly stated as First Amendment requirements. Again, both the similarities and the differences are instructive.

\section{Organization}

There are three natural ways to organize material on intellectual property. One could - like most casebooks - present it by field: trade secret, patent, copyright, trademark, etc., in each case starting with protectability and moving through infringement. One could present it by subject matter: literature, music, characters, industrial design, software, etc., in each case discussing all of the relevant IP fields. Or one could present it by doctrine: subject matter, ownership, procedure, similarity, etc., in each case moving through relevant IP fields. I have used all three.

Large parts of the book are organized by IP field: there are chapters (or major sections) devoted to trade secret, patent, copyright, trademark, false advertising, right of publicity, and design patents. Each of them takes a single IP field and marches through the sexpartite taxonomy of topics. The order varies a bit (the complexity and centrality of patent prosecution means it makes sense to address patent procedures before patent ownership), sometimes the divisions aren't worth insisting on (in trademark, similarity tests are just one factor in multiple likelihood of confusion tests), and some areas omit one or more entirely (there are no meaningful procedural prerequisites to protection against false advertising). But these sections all more or less stick to this structure. These six topics - subject matter, ownership, procedures, similarity, prohibited conduct, and defenses - suffice to give a reasonably clear account of how an IP field looks at 
I would have liked to include a chapter on federal preemption that also covers the miscellaneous fragments of state IP law that survive preemption and are not already covered elsewhere. I did not complete that chapter in time for my fall 2016 course.

This "rest" of the book remains hypothetical for now. the world.

Mixed in with these in-depth treatments are quicker hits on related fields of IP and IP-adjacent law. The general rule is that they are presented in connection with the major IP fields they shed light on. Thus intrusion on seclusion, FOIA, and classification show up in the trade secret chapter; phone numbers, radio callsigns, and business name registries in the trademark chapter; FTC and consumer false advertising suits in the advertising chapter; and so on.

Conversely, I have also distributed out subject-matter-specific parts of traditional IP fields to chapters dedicated to IP fields that more squarely address those subject matters. This first happens in the advertising chapter; I deliberately hold over the material on certification marks and deceptive marks from the trademark chapter so that I can juxtapose it with the false advertising materials. Materiality in the context of Lanham Act $\S 2$ (a) makes more sense once readers have seen it at work in $\S 43(\mathrm{a})(1)(B)$ cases. I pull similar stunts by putting moral rights in the "personality rights" chapter rather than the copyright chapter; geographically descriptive and misdescriptive marks in the geographic indications chapter; useful articles, architectural works, and functional marks in the design chapter alongside design patents.

The extreme examples of this approach are the chapters devoted to software and to biotechnology, both of which are immensely important and can only properly be understood by considering how different IP fields interact. Software requires consideration of trade secret, copyright, and patent; biotechnology law involves patent and trademark, but also discussion of the FDA drug approval process and regulation of drug marketing and labeling. (Again, my broad understanding of what is relevant to IP means that I have no compunction against treating these regulatory regimes as establishing de facto IP regimes.)

The rest of the book consists of chapters devoted to cross-cutting topics where there is more insight to be gained from setting out general principles and then seeing how different IP fields play out variations on the theme: litigation, remedies, transactions, and international IP. One could include these issues within each substantive chapter, but for the most part, I find it clearer just to save these issues for dedicated chapters.

\section{What This Book Is Not}

This is, as I said, a book about the structure of IP law. Traditional casebooks try to do many other things, and I want to be clear on the sacrifies I have made.

This is not a book on learning to think like a lawyer. I have made 
no concessions to making cases "teachable" in a standard Socratic sense. I have cut out procedural postures. I have cut out reasoning from precedent. I have cut out dissents, even brilliant and wellargued ones. I have cut judges' names, and sometimes cut parties' names. In extreme cases, I have cut out all the facts, or all of the reasoning supporting a holding.

Part of this is a sense that traditional case reading and analysis valuable skills that they are - are overvalued in most law schools. Part of it also is the freedom that comes from teaching IP to LLM students, for whom "thinking like a lawyer" is not something to be learned but one of the prerequisites for admission. And part of it is the critical distance that I have gained on the enterprise of legal education since moving to an institution where most of my colleagues are not law professors. Things that once seemed natural to me are strange now.

This is also not a book on IP policy. My discussions of the policy rationales for IP fields are exceedingly brief. I have cut substantial chunks of the policy discussions from the cases I excerpt. In some cases, the policy arguments are essential to understanding the holdings and the concepts they rely on. But if this book is at all useful for teeing up discussions of IP policy, it is entirely by accident.

\section{Cases and Materials}

The overriding principle for my selection of cases and other materials was clarity. Accordingly, I have tried hard to find cases that are either broadly representative of the doctrinal point they stand for or that state it succinctly. In my years of teaching the IP survey I came to loathe the memorable but unusual cases, because students invariably remembered them for the wrong points. I have tried to avoid including cases that go off on tangents that haven't been picked up on; they give an incorrect impression of where the action is.

Where there is a genuine doctrinal split in contemporary caselaw, I have tried to make this clear in the materials I have chosen: either by pairing cases on either side of an issue, by picking a case with a strong and well-taken dissent, or by picking a case that respectfully presents the other side of the debate before disagreeing with it. Where there is not a major split in the caselaw, I have tried hard to present the false impression of one.

I have also tried to strike a balance between teachability and authority. My sense is that most casebooks tend too much towards respectful but excessive quotation from Supreme Court opinions. But for various institutional reasons - including the Supreme Court's rarified docket, its emphasis on following its own precedents to the exclusion of "inferior" courts' wisdom, its frequent unwillingness to resolve the actual case before it, and some Justices' regrettable writerly 
habits - Supreme Court opinions are often terrible teaching cases. I have responded by excerpting these cases with extreme brevity, or by presenting them in reflection - as other courts apply the Supreme Court's holdings to crisper fact patterns.

\section{Editing}

My editorial technique is borrowed from Sweeney Todd: extensive and shocking cuts. These are pedagogical materials, not a legal brief. I have not put words in anyone else's mouth, but I have been unconcerned with the usual editorial apparatus of ellipses and brackets. I drop words from sentences, sentences from paragraphs, paragraphs from opinions - all with no indication that anything is gone. I also reorder paragraphs and sometimes sentences as needed to improve the readability of a passage. My goal is to make it easy for the reader. If it matters to you what the original said, consult the original.

Similarly, I have been ruthless in pruning citations. Editorial conventions that make sense in briefs and opinions are not appropriate for teaching materials. Generally, I have kept citations only when the case being cited is important in its own right or when the citation is impossible to remove without great awkwardness. I have had no qualms about attributing to courts things they quoted other courts as saying.

I also discarded the tradition that a case should be presented as a case. There are cases with wonderful discursive passages - like Judge Posner's musings on the protectability of names as trademarks in Peaceable Planet - embedded in larger messes. My edit of peaceableplanet keeps this discussion of name marks and discards everything else, including the facts and holding. There are also cases that are important for their holdings, like Grokster and $A W H$, but which take their damn time getting there. I kept the holdings and cut everything else.

Sometimes, the best way to make a point isn't with a case at all. The federal government has published outstanding guides to patent, copyright, and trademark law: the MPEP, Compendium, and TMEP, respectively. I have freely drawn from them, along with Restatement sections, regulations, and law-review articles whenever I thought that they covered the ground better than the cases I had to work with. For rarely-litigated matters like the deposit requirement, these secondary materials are far and away the best option. I have written notes and introductory materials where necessary, but I tried to keep them focused on bringing out structural issues, rather than saying again what others have already said better. 


\section{Formatting}

Another crucial early decision was to format the text with a twoand-three-quarter-inch outer margin, placing notes and illustrations in the margin alongside the text they pertain to. The design is not original; I had seen it used very effectively in Donald Knuth et al's Concrete Mathematics, Robert Bringhurst's The Elements of Typographic Style, and Edward Tufte's books on information design. From my point of view, it solved three problems simultaneously:

First, the narrower text column is typographically attractive. With such a larger outer margin, the resulting column is five inches wide, which makes for lines that have a comfortable font size and a comfortable length. Extended reading is easier and the page looks nice.

Second, margins are for marginalia. A note in the margin is less intrusive than a box cut out of the text and easier to glance back and forth to than a footnote. The result is that I have been free to annotate the text liberally and a little Talmudically. I have extensively decorated the margin with illustrations from the cases being excerpted. I have also included quotations and case summaries that might have gone in the notes after a case in a traditional casebook, or been presented as squib cases. Having the margin available lets me include them precisely where they are relevant. Sometimes I include see also citations to interesting articles. And occasionally I pop in with a leading question or just a straight-up joke.

And third, the margin enables me to remove citations and other unnecessary apparatus from the body of cases themselves. For the most part, cases are presented with only the name of the case in the main text: the citation is evacuated to the margin. This is another way of clarifying of the cases themselves; citations are a remarkable hindrance to readability. By putting citations alongside the text (as in some law reviews' online supplements), I believe I have resolved the Garner-Posner debate over whether citations belong in text or in footnotes. The best answer is neither: they belong in the margin.

\section{Document Production}

I used the XeLaTeX document preparation system to prepare the manuscript of this book. XeLaTeX is a computer typsetting system derived from Leslie Lamport's LATEXand built on Donald Knuth's TEX. I type out the text of the book in a set of individual text files, marked up with tags like

Itextit $\{$ this is in italics\}

. XeLaTeX then assembles the hundreds of individual files into a single PDF output.
There is a reason that law reviews print on pages that are narrower than 8.5 inches. 
This approach has several advantages compared with a more traditional word processor. First, where Word or Pages.app might have choked or slowed down on a document this size, XeLaTeX has no trouble at all. True, I needed to take a minute to recompile the PDF each time I make changes. But the editing itself is fast and responsive.

Second, this method gave me fine-grained control over every aspect of how the book appears. My choice of a wide margin, for example, with sidenotes that float with the main text, would have been extremely difficult to implement in a word processor. With XeLaTeX, it was a matter of specifying the width of the margins and then writing a few commands to place materials in them in particular ways. I have been able to customize the fonts, the colors, the formatting of trademarks and the captioning of images. I have also been able to hyperlink the short forms of cases back to the full citation introducing them - all while automatically pulling them into the indices at the back of the book.

Some of my more specific formatting choices are also worth commenting on. At the moment, the book is set primarily in Palatino, which I chose because it is an attractive typeface that is widely available and happens to be Cornell's principal typeface. (Similarly, the accent color is Cornell red.) The header typeface, used for the running heads, the marginal notes and captions, and case names, is Myriad, which is also widely available.

I think the choice to use splashes of color is a no-brainer. It doesn't print out on black-and-white printers, but given that so many people read so much on screens already, it livens up the experience for the majority. I also think the use of a contrasting sans-serif font is easily defensible; it makes entirely clear what is part of the excerpted material and what is editoral apparatus.

\section{Permissions}

Excerpts from cases and statutes are in the public domain as edicts of government. Congressional reports, excerpts from the MPEP, Copyright Compendium and TMEP, and other federal materials are in the public domain as government works. All other excerpted materials are used under the fair use provisions of 17 U.S.C. § 107. If you disagree with my interpretation of fair use as applied to any particular materials, please get in touch with me to discuss.

All of my own contributions to these materials - including any original writing, edits to existing materials, and the selection and arrangement of those materials - are hereby made available for free reuse under the terms of the Creative Commons Attribution 4.0 International license. Credit is not important to me, but I do care that you preserve the license notice if you redistribute these materials. 


\section{In Closing}

Although I respectfully disagree with the organizational choices and emphases of all existing casebooks, I have learned a great deal from them. Many cases in these materials came to my attention as good teaching prospects because I found them in other books and admired how the authors used them. I am grateful to everyone else who has blazed a trail through the overgrowth that is IP law; I hope they will not begrudge me blazing one more.

These materials were assembled for my Fall 2016 Intellectual Property survey course at Cornell Tech. I may revise and update them the next time I teach the course. I am sure that many errors remain (indeed, I have marked many on my printouts of the chapters) - but I have not had the to go back and fix even the ones I know of, let alone to look for the rest. I welcome any comments, suggestions, and corrections and will try to incorporate them if I am able to make revisions. If you would like to customize these materials for your own use or others', please get in touch so we can discuss the mechanics.

I hope that you enjoy working with these materials as much as I have enjoyed assembling them.

November 11, 2016

James Grimmelmann

Cornell Tech and Cornell Law School

james.grimmelmann@cornell.edu 


\section{1}

\section{Undeveloped Ideas}

To understand intellectual property law, it is necessary to understand the problems it tries to solve. And thus we start with one of the negative spaces of intellectual property: the submission of undeveloped ideas. These ideas - for reasons we will study in detail later - fail to qualify for protection under the various bodies of intellectual property law. And yet they still have value, which means there are rewards to be reaped by anyone who can create them and get them into the right hands.

\section{Desny v. Wilder}

In November, 1949, plaintiff telephoned Wilder's office. Wilder's secretary, who was also employed by Paramount, answered, and plaintiff stated that he wished to see Wilder. At the secretary's insistence that plaintiff explain his purpose, plaintiff "told her about this fantastic unusual story. ... I described to her the story in a few words. ... I told her that it was the life story of Floyd Collins who was trapped and made sensational news for two weeks ... and I told her the plot.... I described to her the entrapment and the death, in ten minutes, probably. She seemed very much interested and she liked it." Plaintiff sought to send Wilder a copy of the story but when the secretary learned of its length of some 65 pages she stated that Wilder would not read it, that he wanted stories in synopsis form, that the story would first be sent to the script department, and "in case they think it is fantastic and wonderful, they will abbreviate it and condense it in about three or four pages, and the producers and directors get to see it." Plaintiff protested that he preferred to do the abbreviating of the story himself, and the secretary suggested that he do so. Two days later plaintiff, after preparing a three or four page outline of the story, telephoned Wilder's office a second time and told the secretary the synopsis was ready. The secretary requested plaintiff to read the synopsis to her over the telephone so that she could take it down in shorthand, and plaintiff did so. During the conversation the secretary
See Elizabeth L. Rosenblatt, $A$ Theory of IP's Negative Space, 34 Colum. J. L. \& Arts 317 (2011).

46 Cal. 2d 715 (1956)

Billy Wilder was the famous director of films such as Double Indemnity (1949) and Some Like It Hot (1959)

In 1925, Floyd Collins was exploring a cave in Kentucky when a rock fell on his leg, pinning him where he was. He was trapped about 50 feet underground and his friends were for several days able to reach him from the cave's entrance, but neither Collins nor his would-be rescuers could get at the rock. The story of the trapped caver became a media sensation. Unfortunately, by the time a rescue shaft dug from the surface reached him after two weeks of work, Collins had already died. 
Ace in The Hole (1951), directed and cowritten by Wilder

The court also stated that disclosure might constitute a benefit sufficient to support a future promise to pay. Cf. Restatement (Second) of Contracts § 86 ("A promise made in recognition of a benefit previously received by the promisor from the promisee is binding to the extent necessary to prevent injustice."). told plaintiff that the story seemed interesting and that she liked it. "She said that she would talk it over with Billy Wilder and she would let me know." Plaintiff on his part told the secretary that defendants could use the story only if they paid him "the reasonable value of it ... I made it clear to her that I wrote the story and that I wanted to sell it. ... I naturally mentioned again that this story was my story which has taken me so much effort and research and time, and therefore if anybody used it they will have to pay for it ... She said that if Billy Wilder of Paramount uses the story, "naturally we will pay you for it."' Plaintiff's only subsequent contact with the secretary was a telephone call to her in July, 1950, to protest the alleged use of his composition and idea in a photoplay. The photoplay, as hereinafter shown in some detail, closely parallels both plaintiff's synopsis and the historical material concerning the life and death of Floyd Collins.

We conclude that conveyance of an idea can constitute valuable consideration and can be bargained for before it is disclosed to the proposed purchaser, but once it is conveyed, i.e., disclosed to him and he has grasped it, it is henceforth his own and he may work with it and use it as he sees fit. In the field of entertainment the producer may properly and validly agree that he will pay for the service of conveying to him ideas which are valuable and which he can put to profitable use. But, assuming legality of consideration, the idea purveyor cannot prevail in an action to recover compensation for an abstract idea unless (a) before or after disclosure he has obtained an express promise to pay, or (b) the circumstances preceding and attending disclosure, together with the conduct of the offeree acting with knowledge of the circumstances, show a promise of the type usually referred to as "implied" or "implied-in-fact."

Such inferred or implied promise, if it is to be found at all, must be based on circumstances which were known to the producer at and preceding the time of disclosure of the idea to him and he must voluntarily accept the disclosure, knowing the conditions on which it is tendered. The idea man who blurts out his idea without having first made his bargain has no one but himself to blame for the loss of his bargaining power. The law will not imply a promise to pay for an idea from the mere facts that the idea has been conveyed, is valuable, and has been used for profit; this is true even though the conveyance has been made with the hope or expectation that some obligation will ensue. So, if the plaintiff here is claiming only for the conveyance of the idea of making a dramatic production out of the life of Floyd Collins he must fail unless in conformity with the above stated rules he can establish a contract to pay.

From plaintiff's testimony, as epitomized above, it does not appear that a contract to pay for conveyance of the abstract photoplay idea had been made, or that the basis for inferring such a contract 
from subsequent related acts of the defendants had been established, at the time plaintiff disclosed his basic idea to the secretary. Defendants, consequently, were at that time and from then on free to use the abstract idea if they saw fit to engage in the necessary research and develop it to the point of a usable script.

Carter, Justice:

I concur only in the result reached in the majority opinion.

When we consider the difference in economic and social backgrounds of those offering such merchandise for sale and those purchasing the same, we are met with the inescapable conclusion that it is the seller who stands in the inferior bargaining position. It should be borne in mind that producers are not easy to contact; that those with authority to purchase for radio and television are surrounded by a coterie of secretaries and assistants; that magazine editors and publishers are not readily available to the average person. It should also be borne in mind that writers have no way of advertising their wares - that, as is most graphically illustrated by the present opinion, no producer, publisher, or purchaser for radio or television, is going to buy a pig in a poke. And, when the writer, in an earnest endeavor to sell what he has written, conveys his idea or his different interpretation of an old idea, to such prospective purchaser, he has lost the result of his labor, definitely and irrevocably. And, in addition, there is no way in which he can protect himself. If he says to whomever he is permitted to see, or, as in this case, talk with over the telephone, "I won't tell you what my idea is until you promise to pay me for it," it takes no Sherlock Holmes to figure out what the answer will be! This case is a beautiful example of the practical difficulties besetting a writer with something to sell.

It seems to me that in the ordinary situation, when the so-called "idea man" has an opportunity to see, or talk with, the prospective purchaser, or someone in his employ, it is at that time, without anything being said, known to both parties that the one is there to sell, and the other to buy. This is surely true of a department store when merchandise is displayed on the counter - it is understood by anyone entering the store that the merchandise so displayed is for sale - it is completely unnecessary for the storekeeper, or anyone in his employ, to state to anyone entering the store that all articles there are for sale. I am at a loss to see why any different rules should apply when it is ideas for sale rather than normal run of merchandise.

Michael J. Burstein

Exchanging Information Without Intellectual Property

91 Tex. L. Rev. 227 (2012)

An inventor seeking funds or development expertise may be reluctant to disclose information about her invention for fear that the re- 
See Kenneth J. Arrow, Economic Welfare and the Allocation of Resources for Invention, in The Rate and Direction of Inventive Activity (1962). It is now usually called "Arrow's Information Paradox" in his honor.

81 N.Y.2d 470 (1993) cipients of the information can take it for themselves. On the other side of the transaction, the funders or developers will be unwilling to commit money or resources to the project unless or until they can assess its value. Arrow observed this dynamic and deemed it a "fundamental paradox": the value of information "for the purchaser is not known until he has the information, but then he has in effect acquired it without cost." More recently, Cooter and his collaborators have described this phenomenon as a "double trust dilemma": "To develop an innovation, the innovator must trust the investor not to steal his idea, and the investor must trust the innovator not to steal his capital."

Apfel v. Prudential-Bache Securities, Inc.

Defendant, an investment bank, seeks to avoid an agreement to purchase plaintiffs' idea for issuing and selling municipal bonds. Its principal contention is that plaintiffs had no property right in the idea because it was not novel and, therefore, consideration for the contract was lacking. For reasons which follow, we conclude that a showing of novelty is not required to validate the contract. The decisive question is whether the idea had value, not whether it was novel.

\section{I}

In 1982, plaintiffs, an investment banker and a lawyer, approached defendant's predecessor with a proposal for issuing municipal securities through a system that eliminated paper certificates and allowed bonds to be sold, traded, and held exclusively by means of computerized "book entries". Initially, the parties signed a confidentiality agreement that allowed defendant to review the techniques as detailed in a 99-page summary. Nearly a month of negotiations followed before the parties entered into a sale agreement under which plaintiffs conveyed their rights to the techniques and certain trade names and defendant agreed to pay a stipulated rate based on its use of the techniques for a term from October 1982 to January 1988. Under the provisions of the contract, defendant's obligation to pay was to remain even if the techniques became public knowledge or standard practice in the industry and applications for patents and trademarks were denied. Plaintiffs asserted that they had not previously disclosed the techniques to anyone and they agreed to maintain them in confidence until they became public.

From 1982 until 1985, defendant implemented the contract, although the parties dispute whether amounts due were fully paid. Defendant actively encouraged bond issuers to use the computerized "book entry" system and, for at least the first year, was the sole underwriter in the industry employing such a system. However, in 1985, following a change in personnel, defendant refused to make any fur- 
ther payments. It maintained that the ideas conveyed by plaintiffs had been in the public domain at the time of the sale agreement and that what plaintiffs sold had never been theirs to sell. Defendant's attempts to patent the techniques proved unsuccessful. By 1985, investment banks were increasingly using computerized systems, and by 1990 such systems were handling $60 \%$ of the dollar volume of all new issues of municipal securities.

Plaintiffs commenced this litigation seeking \$45 million in compensatory and punitive damages.

\section{II}

Under the traditional principles of contract law, the parties to a contract are free to make their bargain, even if the consideration exchanged is grossly unequal or of dubious value. Absent fraud or unconscionability, the adequacy of consideration is not a proper subject for judicial scrutiny. It is enough that something of "real value in the eye of the law" was exchanged. The fact that the sellers may not have had a property right in what they sold does not, by itself, render the contract void for lack of consideration.

Manifestly, defendant received something of value here; its own conduct establishes that. After signing the confidentiality agreement, defendant thoroughly reviewed plaintiffs' system before buying it. Having done so, it was in the best position to know whether the idea had value. It decided to enter into the sale agreement and aggressively market the system to potential bond issuers. For at least a year, it was the only underwriter to use plaintiffs" "book entry" system for municipal bonds, and it handled millions of such bond transactions during that time. Having obtained full disclosure of the system, used it in advance of competitors, and received the associated benefits of precluding its disclosure to others, defendant can hardly claim now the idea had no value to its municipal securities business. Indeed, defendant acknowledges it made payments to plaintiffs under the sale agreement for more than two years, conduct that would belie any claim it might make that the idea was lacking in value or that it had actually been obtained from some other source before plaintiffs' disclosure.

III

Defendant's position rests on Downey v. General Foods Corp., Soule v. Bon Ami Co. and similar decisions. It contends those cases establish

Downey: 331 N.Y.2d 56 (1971) Soule: 201 App. Div. 794 (1922) an exception to traditional principles of contract law and require that the idea must be novel before it can constitute valid consideration for a contract.

In Downey, plaintiff submitted an idea for an advertising campaign. A short time later, defendant General Foods mounted a cam- 
paign that was similar to the one plaintiff had suggested and plaintiff sought damages in a complaint alleging several theories for recovery. We ordered the dismissal of the complaint on two separate grounds: first, the lack of novelty and, second, defendant's prior possession of the idea - i.e., its lack of novelty as to defendant. To the extent plaintiff's causes of action were grounded on assertions of a property right, we found that they were untenable "if the elements of novelty and originality [were] absent, since the property right in an idea is based upon these two elements." Second, we concluded that the defendant possessed plaintiff's ideas prior to plaintiff's disclosure. Thus, the ideas could have no value to defendant and could not supply consideration for any agreement between the parties.

In Soule, plaintiff made an express contract with Bon Ami to disclose a way to increase profits. The idea consisted largely of a proposal to raise prices. The Appellate Division, in a frequently cited opinion, denied plaintiff any recovery, finding that the bargain lacked consideration because the idea was not novel. This Court affirmed but it did so on a different basis: it held that plaintiff had failed to show that profits resulted from the disclosure.

These decisions do not support defendant's contention that novelty is required in all cases involving disclosure of ideas. Indeed, we have explicitly held that it is not. Downey, Soule and cases in that line of decisions involve a distinct factual pattern: the buyer and seller contract for disclosure of the idea with payment based on use, but no separate postdisclosure contract for use of the idea has been made. Thus, they present the issue of whether the idea the buyer was using was, in fact, the seller's.

Such transactions pose two problems for the courts. On the one hand, how can sellers prove that the buyer obtained the idea from them, and nowhere else, and that the buyer's use of it thus constitutes misappropriation of property? Unlike tangible property, an idea lacks title and boundaries and cannot be rendered exclusive by the acts of the one who first thinks it. On the other hand, there is no equity in enforcing a seemingly valid contract when, in fact, it turns out upon disclosure that the buyer already possessed the idea. In such instances, the disclosure, though freely bargained for, is manifestly without value. A showing of novelty, at least novelty as to the buyer, addresses these two concerns. Novelty can then serve to establish both the attributes of ownership necessary for a property-based claim and the value of the consideration - the disclosure - necessary for contract-based claims.

There are no such concerns in a transaction such as the one before us. Defendant does not claim that it was aware of the idea before plaintiffs disclosed it but, rather, concedes that the idea came from them. When a seller's claim arises from a contract to use an idea en- 
tered into after the disclosure of the idea, the question is not whether the buyer misappropriated property from the seller, but whether the idea had value to the buyer and thus constitutes valid consideration. In such a case, the buyer knows what he or she is buying and has agreed that the idea has value, and the Court will not ordinarily go behind that determination. The lack of novelty, in and of itself, does not demonstrate a lack of value. To the contrary, the buyer may reap benefits from such a contract in a number of ways - for instance, by not having to expend resources pursuing the idea through other channels or by having a profitmaking idea implemented sooner rather than later. The law of contracts would have to be substantially rewritten were we to allow buyers of fully disclosed ideas to disregard their obligation to pay simply because an idea could have been obtained from some other source or in some other way.

\section{Bizarro World Problem}

Apfel and Desny give us a glimpse of a world without intellectual property laws. Suppose that you lived in such a world. A client comes to you with one of the following. How would you advise her to proceed?

- A 75,000-word novel about a boy who discovers that he is a wizard

- A new drug for treating heart disease, which will cost $\$ 100$ million to test in humans

- An easier-to-hold design for a pipe wrench

- A process for producing pure aluminum from aluminum ore that reduces the cost by $85 \%$

- A catchy song about taking revenge on a cheating boyfriend, recorded in the client's kitchen with lots of background noise

- A recut version of a popular action movie, which takes five minutes off the running time and makes it more suspenseful

- A sketch for an elegant off-the-shoulder dress

- A joke about traffic in Los Angeles

- The perfect name for a laundromat

\section{Debt Collection Problem}

Debt collection is a shady, high-pressure business. Collection agencies buy unpaid debts in bulk from lenders and from each other, usually for a fraction of the face value of the debts. The buyer typically receives a spreadsheet listing the debtors, their addresses, the amounts they owe, and perhaps some information about previous failed attempts at collection, along with an assignment of the seller's right to collect the debt. Then the buyer goes to work, calling the debtor, send-
Note that the defendant in Apfe tried and failed to obtain a patent on the computerized-book-entry idea, and that the plaintiff's suit proceeded under general principles of contract law. Ideas, such as "a movie about the death of Floyd Collins," are not copyrightable. 
Jake Halpern, Paper Boys, N.Y. Times, Aug. 15, 2014. ing letters, negotiating payment schedules or write-downs of the debt in exchange for partial payment, and threatening legal action and perhaps following through, Unsurprisingly, debt collectors are known to use sharp tactics, including issuing unfounded legal threats, making repeated calls, trying to collect on debts that have been discharged in bankruptcy or where the statute of limitations has expired, and sometimes even intimating the possibility of violence. The federal Fair Debt Collection Practices Act and numerous state laws try to prevent these abusive tactics. Here is another:

Around the same time that Theresa was getting phone calls from a mysterious law firm, Siegel received an email from the owner of an agency that he had hired to do his collecting. The collectors at this agency were getting the same message from many debtors: We just paid off these accounts - to someone else. Siegel was both flummoxed and concerned. Was this the work of a renegade collector at one of his agencies who was collecting on his own and pocketing the cash? Or had the paper simply been stolen from his offices?

The notion that a portfolio of debt could be stolen may seem improbable, but plenty of debt brokers are all too willing to sell "bad paper." Such brokers sometimes "double sell" or "triple sell" the same file to multiple unsuspecting buyers. Other times, a broker may sell paper that he does not own and obtained by nefarious means. I spoke at length with one debt broker from Buffalo, who told me that he had hired a hacker from China to break into a former client's email account and obtain his password. Once he had the client's password, the broker had access to his paper. He then simply took a portfolio and, subsequently, sold it to another buyer - who didn't know and didn't ask where it came from.

Is this an "intellectual property" problem? Does it have anything in common with the problems discussed in Desny and Apfel? 


\section{Trade Secret}

Trade secret law protects against the theft of valuable business secrets. Doctrinally, trade secret law has deep common-law roots as a branch of "unfair competition" law. Over time it has become more statutory and more federal. The Uniform Trade Secrets Act has been adopted in some form by 47 states. The federal Economic Espionage Act criminalized an important subset of trade secret misappropriation, and the 2016 Defend Trade Secrets Act added a federal civil cause of action and an important seizure remedy.

Why protect trade secrets? At least four stories rub elbows in the cases and commentary.

- Contracting: protecting trade secrets helps resolve Arrow's Information Paradox by making it possible to contract securely for disclosing them.

- Innovation: keeping secrets safe gives companies incentives to invest in creating valuable information in the first place.

- Arms Race: unless trade secrets received legal protection, companies would inefficiently overinvest in self-help to protect them, and other companies would inefficiently overinvest in stealing them.

- Competition: trade secret law deters unethical business practices and encourages companies to compete with each other fairly.

\section{A Subject Matter}

\section{Restatement (Third) of Unfair Competition}

A trade secret is any information that can be used in the operation of a business or other enterprise and that is sufficiently valuable and secret to afford an actual or potential economic advantage over others.
The leading trade secret treatises are Roger M. Milgrim \& Eric Bensen, Milgrim on Trade Secrets (Matthew Bender, on Lexis), Louis Altman \& Malla Pollack, Callmann on Unfair Competition, Trademarks, and Monopolies (Thomson West, on Westlaw), and Melvin F. Jager, Trade Secrets Law (Thomson West, on Westlaw). The older Restatement (First) of Torts and the newer Restatement (Third) of Unfair Competition are regularly cited.

§ 39

Definition of Trade Secret 
cmt. e Subject matter. - A trade secret can consist of a formula, pattern, compilation of data, computer program, device, method, technique, process, or other form or embodiment of economically valuable information. A trade secret can relate to technical matters such as the composition or design of a product, a method of manufacture, or the know-how necessary to perform a particular operation or service. A trade secret can also relate to other aspects of business operations such as pricing and marketing techniques or the identity and requirements of customers.

The prior Restatement of this topic limited the subject matter of trade secret law to information capable of "continuous use in the operation of a business," thus excluding information relating to single events such as secret bids and impending business announcements or information whose secrecy is quickly destroyed by commercial exploitation. Both the case law and the prior Restatement, however, offered protection against the "improper" acquisition of such short-term information under rules virtually identical to those applicable to trade secrets. The definition of "trade secret" adopted in the Uniform Trade Secrets Act does not include any requirement relating to the duration of the information's economic value. The definition adopted in this Section similarly contains no requirement that the information afford a continuous or long-term advantage.

Restatement (Third) of Unfair Competition $\S 39 \mathrm{cmt}$. e

923 F. Supp. 1231 (N.D. Cal. 1995)
Not every secret is a trade secret. When one fifth-grader asks another to cross her heart and hope to die before revealing a bit of gossip about a mutual friend, this is not the kind of secret the courts will take an interest in. The economic value requirement performs this screening function.

In theory, economic value could be a threshold test: the courts could ask whether particular information is valuable enough for trade secret law to protect. But in practice, the threshold of value is so low it rarely matters. "It is sufficient if the secret provides an advantage that is more than trivial." Instead, economic value expresses a general exclusion from trade secret subject matter. Personal - rather than professional - secrets are the wrong sort of thing for trade secret law.

\section{Religious Technology Center v. Netcom On-Line Communications Services, Inc.}

Plaintiffs, two Scientology-affiliated organizations claiming copyright and trade secret protection for the writings of the Church's 
founder, L. Ron Hubbard, brought this suit against defendant Dennis Erlich, a former Scientology minister turned vocal critic of the Church, who allegedly put plaintiffs' protected works onto the Internet.

\section{BACKGROUND}

Defendant Dennis Erlich was a member of the Church of Scientology from approximately 1968 until 1982. During his years with the Church, Erlich received training to enable him to provide ministerial counseling services, known as "auditing." While with the Church, Erlich had access to various Scientology writings, including those of the Church's founder, L. Ron Hubbard, which the Church alleges include published literary works as well as unpublished confidential materials (the "Advanced Technology works"). According to plaintiffs, Erlich had agreed to maintain the confidentiality of the Advanced Technology works.

Since leaving the Church, Erlich has been a vocal critic of Scientology and he now considers it part of his calling to foster critical debate about Scientology through humorous and critical writings. Erlich has expressed his views about the Church by contributing to the Internet "Usenet news-group" called "alt.religion.scientology" ("the newsgroup"), which is an on-line forum for the discussion of issues related to Scientology.

Plaintiff Religious Technology Center ("RTC"), a nonprofit religious corporation, "was formed by Scientologists, with the approval of Hubbard, to act as the protector of the religion of Scientology and to own, protect, and control the utilization of the Advanced Technology in the United States."

RTC allege[s] that Erlich misappropriated its trade secrets in the works, the confidentiality of which it alleges has been the subject of elaborate security measures. RTC further claims that those works are extremely valuable to the Church. Erlich admits to having posted excerpts from some of the works, but argues that the quotations were used to provide context for debate and as a basis for his criticism. Erlich further argues that he has neither claimed authorship of any of the works nor personally profited from his critique, satire, and commentary. Erlich contends that all of the documents he posted had been previously posted anonymously over the Internet, except for one, which he claims he received anonymously through the mail.

\section{Likelihood of Success on Trade Secret Claim}

In the third cause of action, plaintiff RTC alleges that Erlich misappropriated its trade secrets. California has adopted a version of the Uniform Trade Secret Act. 
Wollersheim: 796 F.2d 1076 (9th Cir. 1986)

Vien: 827 F. Supp. 629 (S.D. Cal. 1993)

Clark: 453 F.2d 1006 (9th Cir.1972)
To establish its trade secret claim, RTC must show, inter alia, that the Advanced Technology works (1) have independent economic value to competitors and (2) have been kept confidential.

\section{Nature of Works}

As a preliminary matter, Erlich argues that the Advanced Technology works cannot be trade secrets because of their nature as religious scriptures. In Religious Technology Center v. Wollersheim, the Ninth Circuit rejected the Church's application for a preliminary injunction on the basis of a trade secret claim against a splinter Scientology group that had acquired stolen copies of the Advanced Technology. The Church argued not that the works gave them a competitive market advantage but that disclosure of the works would cause its adherents "religious harm from premature unsupervised exposure to the materials." Although the Ninth Circuit rejected plaintiffs' trade secret argument based on the spiritual value of the harm, it later noted that it had left open the question of whether the Advanced Technology works could qualify as trade secrets, assuming plaintiffs could prove that the secrets confer on them an actual economic advantage over competitors. Nonetheless, the court noted that such an allegation would "raise grave doubts about the Church's claim as a religion and a not-for-profit corporation."

The Church contends that the Advanced Technology works consist of "processes and the theory behind those processes that are to be used precisely as set forth by L. Ron Hubbard to assist the parishioner in achieving a greater spiritual awareness and freedom." Erlich responds that the works are essentially religious texts. Erlich argues that the Church cannot have trade secrets because trade secret law is necessarily related to commerce. The Church contends that, like other organizations, it must pay bills, and that licensing fees from these documents allow it to continue operating.

The Church's status as a religion does not itself preclude it from holding a trade secret. Restatement $\$ 39 \mathrm{cmt}$. d ("[N]onprofit entities such as ... religious organizations can also claim trade secret protection for economically valuable information such as lists of prospective members or donors."); UTSA § 3426.1(c) (defining "person" to include a "corporation ... or any other legal or commercial entity"). With the exception of Bridge Publications, Inc. v. Vien [(another Scientology case)], there is little authority to support a finding that religious materials can constitute trade secrets. However, there is "no category of information [that] is excluded from protection as a trade secret because of its inherent qualities." Clark v. Bunker (upholding as a trade secret a "detailed plan for the creation, promotion, financing, and sale of contracts for 'prepaid' or 'pre-need' funeral services").

Nor is there any authority to support Erlich's argument that the 
Church's religious texts cannot be trade secrets because, unlike most trade secrets, these secrets are not used in the production or sales of a commodity but are the commodities themselves. The Church's Advanced Technology "course" materials, which are an integral part of the Church's spiritual counseling techniques, do not appear fundamentally different from the course manuals upheld as trade secrets in SmokEnders, Inc. v. Smoke No More, Inc.:

The SmokEnders ("SE") program requires attendees to follow a rigid structured regimen comprised of specific assignments and detailed concepts as recited in the manual.

The SE program is a step-by-step regimented program which requires that each person attending a SE program perform each act of the program at a particular time. Each act required by a SE seminar attendee must be performed by attendees at the same time in the program, with each a minimum departure from the program.

The SE trade secret resides in the composite program as it is arranged for step-by-step delivery to the attendees.

SmokEnders is arguably distinguishable because only the "moderators" and not the attendees were given access to the course materials in that case. However, the adherents of the Church, unlike the attendees and like the moderators in SmokEnders, are under a duty of confidentiality as to the materials. This case is analogous to SmokEnders because in both cases the "commodity" that is produced from the trade secrets is the result achieved by the person using the course materials and their techniques (whether it be stopping smoking or reaching a "higher spiritual existence").

Thus, there is at least some precedent for granting trade secret status to works that are techniques for improving oneself (though not specifically spiritually). Conversely, there is no authority for excluding religious materials from trade secret protection because of their nature. Indeed, there is no authority for excluding any type of information because of its nature. While the trade secret laws did not necessarily develop to allow a religion to protect a monopoly in its religious practices, the laws have nonetheless expanded such that the Church's techniques, which clearly are "used in the operation of the enterprise," are deserving of protection if secret and valuable.

Although trade secret status may apply to works that are techniques for spiritually improving oneself, the secret aspect of those techniques must be defined with particularity. See Restatement (requiring plaintiff to define the information claimed as a trade secret with sufficient definiteness). It appears that plaintiffs are claiming that the entire works themselves, which they describe as "processes
SmokEnders: 184 U.S.P.Q. 309 (S.D. Fla. 1974)

Restatement (Third) of Unfair Competition $\S 39$

$\S 39 \mathrm{cmt}$. d 
and the theory behind those processes," constitute the trade secrets. This definition is problematic because it is impossible to determine when the "secret" has been lost after portions of the works have been disclosed. Although plaintiffs' definition has at least some support in SmokEnders, where the court upheld as a trade secret a "composite stop-smoking program" found in an instructional manual, this court is not satisfied that plaintiffs have identified their trade secrets with sufficient definiteness to support injunctive relief.

\section{Independent Economic Value}

A trade secret requires proof of independent economic value, actual or potential, from not being generally known to the public or to other persons who can obtain economic value from its disclosure or use. A trade secret must have sufficient value in the owner's operation of its enterprise such that it provides an actual or potential advantage over others who do not possess the information.

RTC's president, Warren McShane, attests that

The Advanced Technology is a source of substantial revenue for RTC in the form of licensing fees paid by Churches that are licensed to use the Advanced Technology. These Churches themselves receive a significant amount of their income from donations by parishioners for services based upon the Advanced Technology. These Churches pay RTC a percentage of the donations paid by parishioners for the services based upon the Advanced Technology. These donations and fees provide the majority of operating expenses of these various Church organizations.

The Church's need for revenues to support its services is no less because of its status as a religion. RTC points out that it receives six percent of what the individual churches receive in licensing fees. This evidence is sufficient to establish the value of the Advanced Technology works to the Church.

Erlich also argues that, to constitute a trade secret, information must give its owner a competitive advantage, which implies that the Church must have competitors. Although Erlich is clearly not a "competitor" of the Church, there is no requirement that a trade secret have any value to the defendant; the value can be to others who do not possess it. This evidence can be shown by direct evidence of the impact of the information on the business or by circumstantial evidence of the resources invested in producing the information, the precautions taken to protect its secrecy, and the willingness of others to pay for its access. The several past instances of breakaway Scientology-like groups exploiting RTC's Advanced Technology works for their profit 
constitute reasonable circumstantial evidence that these works give the Church a competitive advantage. In fact, McShane's declaration constitutes direct evidence that the works have a significant impact on the donations received by the Church, providing a majority of its operating expenses. The status of the Advanced Technology works as trade secrets should not depend on Erlich's use of them. Accordingly, this court finds support for the court's conclusion in Vien that the Church has shown independent economic value.

\section{Secrecy}

Information is protectable as a trade secret where the owner has taken efforts that are reasonable under the circumstances to maintain its secrecy. "Reasonable efforts" can include advising employees of the existence of a trade secret, limiting access to the information on a "need to know basis," The court finds that RTC has put forward sufficient evidence that it took steps that were reasonable under the circumstances to protect its purported trade secrets. RTC's president describes elaborate means taken to ensure the confidentiality of the Advanced Technology works, including use of locked cabinets, safes, logging and identification of the materials, availability of the materials at only a handful of sites worldwide, electronic sensors attached to documents, locked briefcases for transporting works, alarms, photo identifications, security personnel, and confidentiality agreements for all of those given access to the materials. McShane testifies that all copies of the Advanced Technology works that are outside of the Church were gained through improper means, such as by theft. Thirty-five other declarants confirm that the measures mentioned by McShane have been used, though not in exactly the same manner, in other Churches and at other times. There is further evidence that Erlich himself signed confidentiality agreements with respect to the Advanced Technology materials and, specifically, the upper-level "NOTS" course materials. The court is unpersuaded by Erlich's claims that the Church's measures have not covered all locations where the Advanced Technology works are found and do not cover crucial time periods. Efforts at maintaining secrecy need not be extreme, just reasonable under the circumstances. The Church has made more than an adequate showing on this issue.25

\footnotetext{
${ }^{25}$ The notion that the Church's trade secrets are disclosed to thousands of parishioners makes this a rather unusual trade secrets case. However, because parishioners are required to maintain the secrecy of the materials, the court sees no reason why the mere fact that many people have seen the information should negate the information's trade secret status. While it is logically more likely that a secret will leak out when more people are entrusted with it, absent evidence of leakage the court finds that giving out the secrets to a large number of people, though no more than necessary, is not itself an unreasonable security step.
} 
Restatement $\S 39 \mathrm{cmt}$. f.

Fishman: No. 91-6426 (C.D. Cal. 1994)
Erlich raises a number of objections to the Church's claims of confidentiality. Erlich argues that the Church's trade secrets have been made available to the public through various means. The unprotected disclosure of a trade secret will cause the information to forfeit its trade secret status, since "information that is generally known or readily ascertainable through proper means by others is not protectable as a trade secret." Once trade secrets have been exposed to the public, they cannot later be recalled.

Erlich argues that many of the Advanced Technology documents have been available in open court records in another case, Church of Scientology Int'l $v$. Fishman, destroying the necessary element of secrecy. However, the Fishman court recently issued an order sealing the file pending a decision on whether the documents are trade secrets. Even if those records were temporarily open to the public, the court will not assume that their contents have been generally disclosed, especially when this question is still pending before the district court in Fishman. Such a disclosure, without evidence that the secrets have become generally known, does not necessarily cause RTC to forfeit its trade secrets. The contrary result would mean that if documents were ever filed without a sealing order, even for a short time, the court would not be able to decide that they should be sealed because the documents would have lost their potential trade secret status by virtue of the temporary unsealing. The only fair result would be to allow trade secret status for works that are otherwise protectable as trade secrets unless they were somehow made generally available to the public during the period they were unsealed, such as by publication.

Erlich further asserts that the Advanced Technology has been largely disclosed in the popular press. These articles may reveal information referring to or hinting at the trade secrets, but may not disclose the secrets themselves, see However, as previously noted, the court is not certain how to properly define the "secrets." To the extent that someone uses or discloses any information taken from any of these articles, there is clearly no trade secret claim. However, much of Erlich's postings copied all or almost all of sections of the Advanced Technology works, which is far more than has ever been disclosed in the popular press. In fact, several of the works posted by Erlich are not mentioned in any of the clippings in the Berger declaration. Arguably, the Church's alleged secrets are such that their value depends on the availability of the complete courses and not mere fragments, thus disclosures that describe parts of the works or disclose isolated portions do not necessarily suffice to ruin the value of the entire works as secrets. However, without a clearer definition of what constitute the "secrets," the court is unable to determine whether some have been made generally known to the public. 
Finally, Erlich newly emphasizes in his Reply that the works he posted were not secrets because he received them through proper means: eight of the documents were allegedly previously posted anonymously to a public portion of the Internet and one of the documents allegedly came to Erlich anonymously through the U.S. mail. Erlich claims that because the alleged trade secrets were received from "public sources," they should lose their trade secret protection. Although the Internet is a new technology, it requires no great leap to conclude that because more than 25 million people could have accessed the newsgroup postings from which Erlich alleges he received the works, these works would lose their status as secrets. While the Internet has not reached the status where a temporary posting on a newsgroup is akin to publication in a major newspaper or on a television network, those with an interest in using the Church's trade secrets to compete with the Church are likely to look to the newsgroup. Thus, posting works to the Internet makes them "generally known" to the relevant people - the potential "competitors" of the Church.

The court is troubled by the notion that any Internet user, including those using "anonymous remailers" to protect their identity, can destroy valuable intellectual property rights by posting them over the Internet, especially given the fact that there is little opportunity to screen postings before they are made. Nonetheless, one of the Internet's virtues, that it gives even the poorest individuals the power to publish to millions of readers, can also be a detriment to the value of intellectual property rights. The anonymous (or judgment proof) defendant can permanently destroy valuable trade secrets, leaving no one to hold liable for the misappropriation. Although a work posted to an Internet newsgroup remains accessible to the public for only a limited amount of time, once that trade secret has been released into the public domain there is no retrieving it. While the court is persuaded by the Church's evidence that those who made the original postings likely gained the information through improper means, as no one outside the Church or without a duty of confidence would have had access to those works, this does not negate the finding that, once posted, the works lost their secrecy. Although Erlich cannot rely on his own improper postings to support the argument that the Church's documents are no longer secrets, evidence that another individual has put the alleged trade secrets into the public domain prevents RTC from further enforcing its trade secret rights in those materials. Because there is no evidence that Erlich is a privy of any of the alleged original misappropriators, he is not equitably estopped from raising their previous public disclosures as a defense to his disclosure. The court is thus convinced that those postings made by Erlich were of materials that were possibly already generally available to the public. Therefore, RTC has not shown a likelihood of success on 
an essential element of its trade secret claim.

\section{B Ownership}

\section{Uniform Trade Secrets Act}

$\S 1$

Definitions

Most of this chapter is devoted to helping you understand this sentence.
(4) “Trade secret" means information, including a formula, pattern, compilation, program, device, method, technique, or process, that:

(i) derives independent economic value, actual or potential, from not being generally known to, and not being readily ascertainable by proper means by, other persons who can obtain economic value from its disclosure or use, and

(ii) is the subject of efforts that are reasonable under the circumstances to maintain its secrecy.

It is clear, uncontroversial, and unsurprising that the essential requirement for owning a trade secret is actual secrecy: the information must not be widely known. The concept is not complicated, but it is subtle. "Secrecy" is something of a term of art; whether something is considered secret as a factual matter depends heavily on what kinds of observation and disclosure trade secret law will protect against.

But because this book is, well, this book, we will also direct our attention to two other important facts about the way the actual-secrecy element operates. It resolves priority questions by allowing multiple independent parties each to have a trade secret in the same information. And it resolves questions of allocating ownership within collaborations by looking to contract, agency, and employment law.

\section{Actual Secrecy}

\section{United States v. Lange}

Matthew Lange has been convicted of violating 18 U.S.C. § 1832, part of the Economic Espionage Act of 1996. This statute makes it a felony to sell, disseminate, or otherwise deal in trade secrets, or attempt to do so, without the owner's consent. Lange stole computer data from Replacement Aircraft Parts Co. (RAPCO), his former employer, and attempted to sell the data to one of RAPCO's competitors. He allows that his acts violated $\S 1832$, if the data contained "trade secrets," but denies that the data met the statutory definition [that the] "information derives independent economic value, actual or potential, from 
not being generally known to, and not being readily ascertainable through proper means by, the public."

18 U.S.C. $§ 1839$

RAPCO is in the business of making aircraft parts for the aftermarket. It buys original equipment parts, then disassembles them to identify (and measure) each component. This initial step of reverse engineering, usually performed by a drafter such as Lange, produces a set of measurements and drawings. Because this case involves an effort to sell the intellectual property used to make a brake assembly, we use brakes as an illustration.

Knowing exactly what a brake assembly looks like does not enable RAPCO to make a copy. It must figure out how to make a substitute with the same (or better) technical specifications. Aftermarket manufacturers must experiment with different alloys and compositions until they achieve a process and product that fulfils requirements set by the Federal Aviation Administration for each brake assembly. Completed assemblies must be exhaustively tested to demonstrate, to the FAA's satisfaction, that all requirements have been met; only then does the FAA certify the part for sale. For brakes this entails 100 destructive tests on prototypes, bringing a spinning 60-ton wheel to a halt at a specified deceleration measured by a dynamometer. Further testing of finished assemblies is required. It takes RAPCO a year or two to design, and obtain approval for, a complex part; the dynamometer testing alone can cost $\$ 75,000$. But the process of experimenting and testing can be avoided if the manufacturer demonstrates that its parts are identical (in composition and manufacturing processes) to parts that have already been certified. What Lange, a disgruntled former employee, offered for sale was all the information required to obtain certification of several components as identical to parts for which RAPCO held certification. Lange included with the package - which he offered via the Internet to anyone willing to pay his price of $\$ 100,000$ - a pirated copy of AutoCAD, the computerassisted drawing software that RAPCO uses to maintain its drawings and specifications data. One person to whom Lange tried to peddle the data informed RAPCO, which turned to the FBI. Lange was arrested following taped negotiations that supply all the evidence necessary for conviction - if the data satisfy the statutory definition of trade secrets.

According to Lange, all data obtained by reverse engineering some other product are "readily ascertainable ... by the public" because everyone can do what RAPCO did: buy an original part, disassemble and measure it, and make a copy. The prosecutor responds to this contention by observing that "the public" is unable to reverse engineer an aircraft brake assembly.

The prosecutor's assumption is that the statutory reference in $\S 1839(3)$ to "the public" means the general public - the man in the 
street. Ordinary people don't have AutoCAD and 60-ton flywheels ready to hand. But is the general public the right benchmark?

A problem with using the general public as the reference group for identifying a trade secret is that many things unknown to the public at large are well known to engineers, scientists, and others whose intellectual property the Economic Espionage Act was enacted to protect. This makes the general public a poor benchmark for separating commercially valuable secrets from obscure (but generally known) information. Suppose that Lange had offered to sell Avogadro's number for $\$ 1$. Avogadro's number, $6.02 \times 10^{23}$, is the number of molecules per mole of gas. It is an important constant, known to chemists since 1909 but not to the general public (or even to all recent graduates of a chemistry class). We can't believe that Avogadro's number could be called a trade secret. Other principles are known without being comprehended. Most people know that $E=m c^{2}$, but a pop quiz of the general public would reveal that they do not understand what this means or how it can be used productively.

One might respond that the context of the word "public" addresses this concern. The full text of $\S 1839(3)(B)$ is: "the information derives independent economic value, actual or potential, from not being generally known to, and not being readily ascertainable through proper means by, the public". Avogadro's number and other obscure knowledge is not "generally known to" the man in the street but might be deemed "readily ascertainable to" this hypothetical person. It appears in any number of scientific handbooks. Similarly one can visit a library and read Einstein's own discussion of his famous equation. Members of the general public can ascertain even abstruse information, such as Schrodinger's quantum field equation, by consulting people in the know - as high school dropouts can take advantage of obscure legal rules by hiring lawyers.

Section 1839(3)(B) as a whole refers to the source of economic value - that the information is not known to or easily discoverable by persons who could use it productively. And for purposes of this case those people would be engineers and manufacturers of aircraft parts, who have ample means to reverse engineer their competitors' products. It is by keeping secrets from its rivals that RAPCO captures the returns of its design and testing work. Thus it is unnecessary here to decide whether "general" belongs in front of "public" - for even if it does, the economically valuable information is not "readily ascertainable" to the general public, the educated public, the economically relevant public, or any sensible proxy for these groups.

Lange wants us to proceed as if all he tried to sell were measurements that anyone could have taken with calipers after disassembling an original-equipment part. Such measurements could not be called trade secrets if, as Lange asserts, the assemblies in question were easy 
to take apart and measure. But no one would have paid $\$ 100,000$ for metes and bounds, while Lange told his customers that the data on offer were worth more than that asking price. Which they were. What Lange had, and tried to sell, were the completed specifications and engineering diagrams that reflected all the work completed after the measurements had been taken: the metallurgical data, details of the sintering, the results of the tests, the plans needed to produce the finished goods, everything required to get FAA certification of a part supposedly identical to one that had been approved. Those details "derived independent economic value, actual or potential, from not being generally known to, and not being readily ascertainable through proper means by, the public." Every firm other than the original equipment manufacturer and RAPCO had to pay dearly to devise, test, and win approval of similar parts; the details unknown to the rivals, and not discoverable with tape measures, had considerable "independent economic value ... from not being generally known". A sensible trier of fact could determine that Lange tried to sell trade secrets. It was his customer's cooperation with the FBI, and not public access to the data, that prevented closing of the sale.

Learning Curve Toys, Inc. v. PlayWood Toys, Inc.

PlayWood Toys, Inc. ("PlayWood") obtained a jury verdict against Learning Curve Toys, Inc. and its representatives, Roy Wilson, Harry Abraham and John Lee (collectively, "Learning Curve"), for misappropriation of a trade secret in a realistic looking and sounding toy railroad track under the Illinois Trade Secrets Act

342 F. 3d 714 (7th Cir. 2003)

\section{BACKGROUND}

In 1992, Robert Clausi and his brother-in-law, Scott Moore, began creating prototypes of wooden toys under the name PlayWood Toys, Inc., a Canadian corporation. Clausi was the sole toy designer and Moore was the sole officer and director of PlayWood. Neither Clausi nor Moore had prior experience in the toy industry, but Clausi had "always been a bit of a doodler and designer," and the two men desired to "create high-quality hardwood maple toys for the independent toy market." As a newly formed corporation, PlayWood did not own a facility in which it could produce toys. Instead, it worked in conjunction with Mario Borsato, who owned a wood-working facility. Subject to a written confidentiality agreement with PlayWood, Borsato manufactured prototypes for PlayWood based on Clausi's design specifications.

PlayWood's first attempt to market publicly its toys was at the Toronto Toy Fair on January 31, 1992. PlayWood received favorable reviews from many of the toy retailers in attendance; PlayWood also learned that the best way to get recognition for its toys was to attend 
the New York Toy Fair ("Toy Fair") the following month. Based on this information, Clausi and Moore secured a position at the Toy Fair in order to display PlayWood's prototypes. It was during this Toy Fair that Clausi and Moore first encountered Learning Curve representatives Roy Wilson, Harry Abraham and John Lee.

On the morning of February 12, 1993, the first day of the Toy Fair, Roy Wilson stopped at PlayWood's booth and engaged Clausi and Moore in conversation. Wilson identified himself as Learning Curve's toy designer and explained that his company had a license from the Britt Allcroft Company to develop Thomas the Tank Engine \& Friends ${ }^{\mathrm{TM}}$ (hereinafter "Thomas") trains and accessories. Wilson commented that he was impressed with the look and quality of PlayWood's prototypes and raised the possibility of working together under a custom manufacturing contract to produce Learning Curve's line of Thomas products. Clausi and Moore responded that such an arrangement would be of great interest to PlayWood. Later that same day, Harry Abraham, Learning Curve's vice president, and John Lee, Learning Curve's president, also stopped by PlayWood's booth. They too commented on the quality of PlayWood's prototypes and indicated that PlayWood might be a good candidate for a manufacturing contract with Learning Curve.

Clausi and Moore continued to have discussions with Learning Curve's representatives over the remaining days of the Toy Fair, which ended on February 14. During these discussions, Lee indicated that he would like two of his people, Abraham and Wilson, to visit PlayWood in Toronto the day after the Toy Fair ended in order to determine whether the two parties could work out a manufacturing arrangement for some or all of Learning Curve's wooden toys.

On February 18, 1993, Abraham and Wilson visited PlayWood in Toronto as planned. The meeting began with a tour of Borsato's woodworking facility, where the prototypes on display at the Toy Fair had been made. After the tour, the parties went to the conference room at Borsato's facility. At this point, according to Clausi and Moore, the parties agreed to make their ensuing discussion confidential. Clausi testified:

After we sat down in the board room, Harry [Abraham of Learning Curve] immediately said: "Look, we're going to disclose confidential information to you guys, and we're going to disclose some designs that Roy [Wilson of Learning Curve] has that are pretty confidential. If Brio were to get their hands on them, then we wouldn't like that. And we're going to do it under the basis of a confidential understanding."

And I said: "I also have some things, some ideas on 
how to produce the track and produce the trains now that I've had a chance to look at them for the last couple of days, and I think they're confidential as well. So if we're both okay with that, we should continue." So we did.

Moore testified to the existence of a similar conversation:

It was at this point that Harry Abraham told us that they were going to disclose some confidential documents, drawings, pricing, margins, and asked us if we would keep that information confidential. ...

I believe it was Robert [Clausi] who said that, you know, absolutely, we would keep it confidential. In fact, we had some ideas that we felt would be confidential we would be disclosing to them, and would they keep it, you know, confidential? Would they reciprocate? And Harry [Abraham] said: "Absolutely." And then we proceeded to go along with the meeting.

Immediately after the parties agreed to keep their discussion confidential, Wilson, at Abraham's direction, showed Clausi and Moore drawings of various Thomas characters and provided information on the projected volume of each of the products. Clausi testified that he considered the documents disclosed by Learning Curve during the meeting confidential because they included information on products not yet released to the public, as well as Learning Curve's projected volumes, costs and profit margins for various products.

The parties' discussion eventually moved away from train production and focused on track design. Wilson showed Clausi and Moore drawings of Learning Curve's track and provided samples of their current product. At this point, Abraham confided to Clausi and Moore that track had posed "a bit of a problem for Learning Curve." Abraham explained that sales were terrific for Learning Curve's Thomas trains, but that sales were abysmal for its track. Abraham attributed the lack of sales to the fact that Learning Curve's track was virtually identical to that of its competitor, Brio, which had the lion's share of the track market. Because there was "no differentiation" between the two brands of track, Learning Curve's track was not even displayed in many of the toy stores that carried Learning Curve's products. Learning Curve had worked unsuccessfully for several months attempting to differentiate its track from that of Brio.

After detailing the problems with Learning Curve's existing track, Abraham inquired of Clausi whether "there was a way to differentiate" its track from Brio's track. Clausi immediately responded that he "had had a chance to look at the track and get a feel for it [over] the last few days" and that his "thoughts were that if the track were more real- 
istic and more functional, that kids would enjoy playing with it more and it would give the retailer a reason to carry the product, especially if it looked different than the Brio track." Clausi further explained that, if the track "made noise and [] looked like real train tracks, that the stores wouldn't have any problem, and the Thomas the Tank line, product line would have [] its own different track" and could "effectively compete with Brio." Abraham and Wilson indicated that they were "intrigued" by Clausi's idea and asked him what he meant by "making noise."

Clausi decided to show Abraham and Wilson exactly what he meant. Clausi took a piece of Learning Curve's existing track from the table, drew some lines across the track (about every threequarters of an inch), and stated: "We can go ahead and machine grooves right across the upper section, which would look like railway tracks, and down below machine little indentations as well so that it would look more like or sound more like real track. You would roll along and bumpity-bumpity as you go along." Clausi then called Borsato into the conference room and asked him to cut grooves into the wood "about a quarter of an inch deep from the top surface." Borsato left the room, complied with Clausi's request, and returned with the cut track three or four minutes later. Clausi ran a train back and forth over the cut piece of track. The track looked more realistic than before, but it did not make noise because the grooves were not deep enough. Accordingly, Clausi instructed Borsato to cut the grooves "just a little bit deeper so that they go through the rails." Borsato complied with Clausi's request once again and returned a few minutes later with the cut piece of track. Clausi proceeded to run a train back and forth over the track. This time the track made a "clickety-clack" sound, but the train did not run smoothly over the track because the grooves were cut "a little bit too deep." Based on the sound produced by the track, Clausi told Abraham and Moore that if PlayWood procured a contract with Learning Curve to produce the track, they could call it "Clickety-Clack Track."

Both Abraham and Wilson indicated that Clausi's concept of cutting grooves into the track to produce a clacking sound was a novel concept. Thereafter, Wilson and Clausi began to discuss how they could improve the idea to make the train run more smoothly on the track, but Abraham interrupted them and stated: "No, focus. You guys have to get the contract for the basic product first, and then we can talk about new products, because it takes [our licensor] a long time to approve new products and new designs."

The meeting ended shortly thereafter without further discussion about Clausi's concept for the noise-producing track. Before he left, Wilson asked Clausi if he could take the piece of track that Borsato had cut with him while the parties continued their discussions. 
Clausi gave Wilson the piece of track without hesitation. The piece of track was the only item that Abraham and Wilson took from the meeting. Clausi and Moore did not ask Wilson for a receipt for the cut track, nor did they seek a written confidentiality agreement to protect PlayWood's alleged trade secret. After the meeting, Clausi amended PlayWood's confidentiality agreement with Borsato to ensure that materials discussed during the meeting would remain confidential. Clausi also stamped many of the documents that he received from Learning Curve during the meeting as confidential because they included information on products not yet released to the public. PlayWood never disclosed the contents of Learning Curve's documents to anyone.

During March of 1993, PlayWood and Learning Curve met on three separate occasions to discuss further the possibility of PlayWood manufacturing Learning Curve's Thomas products. At one of the meetings, and at Learning Curve's request, PlayWood submitted a manufacturing proposal for the Thomas products. Learning Curve rejected PlayWood's proposal. Learning Curve told Clausi that its licensor wanted the Thomas products to be made in the United States.

Thereafter, PlayWood had no contact with Learning Curve until late October of 1993, when Abraham contacted Clausi to discuss another possible manufacturing contract because Learning Curve's secondary supplier was not providing enough product. Again, PlayWood submitted a manufacturing proposal at Learning Curve's request, but it too was rejected. Learning Curve later stated that its new business partner had decided to manufacture the product in China.

Clausi and Moore continued to work on PlayWood's toy concepts. After the 1994 New York Toy Fair, which was not particularly successful for PlayWood, Clausi and Moore began to focus their efforts on refining PlayWood's concept for the noise-producing track. During this time, Clausi and Moore made no attempt to license or sell the concept to other toy companies because they believed that PlayWood still had "an opportunity to get in the door" with Learning Curve if they could perfect the concept and also because they believed that they were bound by a confidentiality agreement.

In December of 1994, while shopping for additional track with which to experiment, Moore discovered that Learning Curve was selling noise-producing track under the name "Clickety-Clack Track." Like the piece of track that Clausi had Borsato cut during PlayWood's February 18, 1993, meeting with Learning Curve, Clickety-Clack Track $^{\mathrm{TM}}$ has parallel grooves cut into the wood, which cause a "clacking" sound as train wheels roll over the grooves. Learning Curve was promoting the new track as

the first significant innovation in track design since the in- 
U.S. Pat. No. $5,454,513$

On the facts as found by the jury, Wilson was not the inventor and the patent should not have issued.

The relevant portions of the ITSA track the UTSA. ception of wooden train systems.... It is quite simply the newest and most exciting development to come along recently in the wooden train industry, and it's sure to cause a sensation in the marketplace.... [I]t brings that sound and feel of the real thing to a child's world of make-believe without bells, whistles, electronic sound chips or moving parts.

PlayWood promptly wrote a cease and desist letter to Learning Curve. The letter accused Learning Curve of stealing PlayWood's concept for the noise-producing track that it disclosed to Learning Curve "in confidence in the context of a manufacturing proposal." Learning Curve responded by seeking a declaratory judgment that it owned the concept.

Previously, on March 16, 1994, Learning Curve had applied for a patent on the noise-producing track. The patent, which was obtained on October 3, 1995, claims the addition of parallel impressions or grooves in the rails, which cause a "clacking" sound to be emitted as train wheels roll over them. The patent identifies Roy Wilson of Learning Curve as the inventor.

Clickety-Clack Track ${ }^{\mathrm{TM}}$ provided an enormous boost to Learning Curve's sales. Learning Curve had $\$ 20$ million in track sales by the first quarter of 2000, and $\$ 40$ million for combined track and accessory sales.

\section{Discussion}

The parties agree that their dispute is governed by the Illinois Trade Secrets Act ("Act"). To prevail on a claim for misappropriation of a trade secret under the Act, the plaintiff must demonstrate that the information at issue was a trade secret, that it was misappropriated and that it was used in the defendant's business. The issue currently before us is whether there was legally sufficient evidence for the jury to find that PlayWood had a trade secret in its concept for the noiseproducing toy railroad track that it revealed to Learning Curve on February 18, 1993.

Although the Act explicitly defines a trade secret in terms of [actual secrecy and reasonable efforts], Illinois courts frequently refer to six common law factors (which are derived from $\S 757$ of the Restatement (First) of Torts) in determining whether a trade secret exists: (1) the extent to which the information is known outside of the plaintiff's business; (2) the extent to which the information is known by employees and others involved in the plaintiff's business; (3) the extent of measures taken by the plaintiff to guard the secrecy of the information; (4) the value of the information to the plaintiff's business and to its competitors; (5) the amount of time, effort and money expended by the plaintiff in developing the information; and (6) the 
ease or difficulty with which the information could be properly acquired or duplicated by others.

Contrary to Learning Curve's contention, we do not construe the foregoing factors as a six-part test, in which the absence of evidence on any single factor necessarily precludes a finding of trade secret protection. Instead, we interpret the common law factors as instructive guidelines for ascertaining whether a trade secret exists under the Act.

1. Extent to which PlayWood's concept for noise-producing toy railroad track was known outside of PlayWood's business

PlayWood presented substantial evidence from which the jury could have determined that PlayWood's concept for noise-producing toy railroad track was not generally known outside of Playwood's business. It was undisputed at trial that no similar track was on the market until Learning Curve launched Clickety-Clack Track ${ }^{\mathrm{TM}}$ in late 1994, more than a year after PlayWood first conceived of the concept. Of course, as Learning Curve correctly points out, merely being the first or only one to use particular information does not in and of itself transform otherwise general knowledge into a trade secret. If it did, the first person to use the information, no matter how ordinary or well known, would be able to appropriate it to his own use under the guise of a trade secret. However, in this case, there was additional evidence from which the jury could have determined that PlayWood's concept was not generally known within the industry.

First, there was substantial testimony that Learning Curve had attempted to differentiate its track from that of its competitors for several months, but that it had been unable to do so successfully.

Furthermore, PlayWood's expert witness, Michael Kennedy, testified that PlayWood's concept, as embodied in Clickety-Clack Track $^{\mathrm{TM}}$, was unique and permitted "its seller to differentiate itself from a host of competitors who [were] making a generic product." Kennedy explained that the look, sound and feel of the track made it distinct from other toy railroad track: "[W]hen a child runs a train across this track, he can feel it hitting those little impressions. And when you're talking about young children[,] having the idea that they can see something that they couldn't see before, feel something that they couldn't feel before, hear something that they couldn't hear before, that is what differentiates this toy from its other competitors."

Finally, PlayWood presented evidence that Learning Curve sought and obtained a patent on the noise-producing track. It goes without saying that the requirements for patent and trade secret protection are not synonymous. Unlike a patentable invention, a trade secret need not be novel or unobvious. The idea need not be complicated; it may be intrinsically simple and nevertheless qualify as a 
secret, unless it is common knowledge and, therefore, within the public domain. However, it is commonly understood that if an invention has sufficient novelty to be entitled to patent protection, it may be said a fortiori to be entitled to protection as a trade secret.

2. Extent to which PlayWood's concept was known to employees and others involved in PlayWood's business

We agree with PlayWood that the evidence was sufficient to establish that its concept for noise-producing track was known only by key individuals in its business.

At the outset, we note briefly that PlayWood was a small business, consisting only of Clausi and Moore. Illinois courts have recognized on several occasions that the expectations for ensuring secrecy are different for small companies than for large companies. Apart from Clausi (PlayWood's sole toy designer and the person who conceived of the concept for noise-producing track) and Moore (PlayWood's sole officer and director), the only person who knew about the concept was Borsato, the person who physically produced PlayWood's prototype at Clausi's direction. The concept was disclosed to Borsato in order for PlayWood to develop fully its trade secret. Moreover, Borsato's actions were governed by a written confidentiality agreement with PlayWood. Indeed, as an extra precaution, Clausi even amended PlayWood's confidentiality agreement with Borsato immediately after the February 18, 1993, meeting to ensure that materials discussed during the meeting would remain confidential.

\section{Measures taken by PlayWood to guard the secrecy of its concept}

There also was sufficient evidence for the jury to determine that PlayWood took reasonable precautions to guard the secrecy of its concept. The Act requires the trade secret owner to take actions that are "reasonable under the circumstances to maintain [the] secrecy or confidentiality" of its trade secret; it does not require perfection. Whether the measures taken by a trade secret owner are sufficient to satisfy the Act's reasonableness standard ordinarily is a question of fact for the jury. Indeed, we previously have recognized that only in an extreme case can what is a "reasonable" precaution be determined, because the answer depends on a balancing of costs and benefits that will vary from case to case.

Here, the jury was instructed that it must find "by a preponderance of the evidence that PlayWood's trade secrets were given to Learning Curve as a result of a confidential relationship between the parties." By returning a verdict in favor of PlayWood, the jury necessarily found that Learning Curve was bound to PlayWood by a pledge of confidentiality. The jury's determination is amply supported by the evidence. Both Clausi and Moore testified that they 
entered into an oral confidentiality agreement with Abraham and Wilson before beginning their discussion on February 18, 1993. In particular, Clausi testified that he told Abraham and Wilson: "I also have some things, some ideas on how to produce the track and produce the trains now that I've had a chance to look at them for the last couple of days, and I think they're confidential as well. So if we're both okay with that, we should continue." In addition to this testimony, the jury heard that Learning Curve had disclosed substantial information to PlayWood during the February 18th meeting, including projected volumes, costs and profit margins for various products, as well as drawings for toys not yet released to the public. The jury could have inferred that Learning Curve would not have disclosed such information in the absence of a confidentiality agreement. Finally, the jury also heard (from several of Learning Curve's former business associates) that Learning Curve routinely entered into oral confidentiality agreements like the one with PlayWood.

PlayWood might have done more to protect its secret. As Learning Curve points out, PlayWood gave its only prototype of the noiseproducing track to Wilson without first obtaining a receipt or written confidentiality agreement from Learning Curve-a decision that proved unwise in hindsight. Nevertheless, we believe that the jury was entitled to conclude that PlayWood's reliance on the oral confidentiality agreement was reasonable under the circumstances of this case. First, it is well established that the formation of a confidential relationship imposes upon the disclosee the duty to maintain the information received in the utmost secrecy and that the unprivileged use or disclosure of another's trade secret becomes the basis for an action in tort. Second, both Clausi and Moore testified that they believed PlayWood had a realistic chance to "get in the door" with Learning Curve and to produce the concept as part of Learning Curve's line of Thomas products. Clausi and Moore did not anticipate that Learning Curve would violate the oral confidentiality agreement and utilize PlayWood's concept without permission; rather, they believed in good faith that they "were going to do business one day again with Learning Curve with respect to the design concept." Finally, we believe that, as part of the reasonableness inquiry, the jury could have considered the size and sophistication of the parties, as well as the relevant industry. Both PlayWood and Learning Curve were small toy companies, and PlayWood was the smaller and less experienced of the two.

\section{Value of the concept to PlayWood and to its competitors}

There was substantial evidence from which the jury could have determined that PlayWood's concept had value both to PlayWood and to its competitors. It was undisputed at trial that Learning Curve's 
sales skyrocketed after it began to sell Clickety-Clack Track ${ }^{\mathrm{TM}}$. In addition, PlayWood's expert witness, Michael Kennedy, testified that PlayWood's concept for noise-producing track had tremendous value. Kennedy testified that the "cross-cuts and changes in the [track's] surface" imparted value to its seller by causing the track to "look different, feel different and sound different than generic track." Kennedy further testified that, in his opinion, the track would have commanded a premium royalty under a negotiated license agreement because the "invention allows its seller to differentiate itself from a host of competitors who are making a generic product with whom it is competing in a way that is proprietary and exclusive, and it gives [the seller] a significant edge over [its] competition."

Despite this evidence, the district court concluded that PlayWood's concept had no economic value. The court's conclusion was based, in part, on the fact that PlayWood's prototype did not work perfectly; as noted by the court, the first set of cuts were too shallow to produce sound and the second set of cuts were too deep to permit the train to roll smoothly across the track. In the district court's view, even if the concept of cutting grooves into the wooden track in order to produce noise originated with Clausi, the concept lacked value until it was refined, developed and manufactured by Learning Curve.

We cannot accept the district court's conclusion because it is belied by the evidence. At trial, Kennedy was asked whether, in his opinion, the fact that PlayWood's prototype did not work perfectly affected the value of PlayWood's concept, and he testified that it did not. Kennedy testified that he would assign the same value to PlayWood's concept as it was conceived on February 18, 1993, as he would the finished product that became known as Clickety-Clack Track ${ }^{\mathrm{TM}}$ because, at that time, he would have known "that most of the design [had] already been done and that [he] just need[ed] to go a little bit further to make it really lovely." Kennedy further testified that it was standard practice in the industry for a license to be negotiated based on a prototype (much like the one PlayWood disclosed to Learning Curve) rather than a finished product and that the license generally would cover the prototypical design, as well as any enhancements or improvements of that design. Based on this testimony, we cannot accept the district court's conclusion that PlayWood's concept possessed no economic value.

It is irrelevant under Illinois law that PlayWood did not actually use the concept in its business. The proper criterion is not 'actual use' but whether the trade secret is "of value" to the company. Kennedy's testimony was more than sufficient to permit the jury to conclude that the concept was "of value" to PlayWood. It is equally irrelevant that PlayWood did not seek to patent its concept. So long as the concept 
remains a secret, i.e., outside of the public domain, there is no need for patent protection. Professor Milgrim makes this point well: "Since every inventor has the right to keep his invention secret, one who has made a patentable invention has the option to maintain it in secrecy, relying upon protection accorded to a trade secret rather than upon the rights which accrue by a patent grant." It was up to PlayWood, not the district court, to determine when and how the concept should have been disclosed to the public.

5. Amount of time, effort and money expended by PlayWood in developing its concept

PlayWood expended very little time and money developing its concept; by Clausi's own account, the cost to PlayWood was less than one dollar and the time spent was less than one-half hour. The district court determined that "such an insignificant investment is insufficient as a matter of Illinois law to establish the status of a 'trade secret."' We believe that the district court gave too much weight to the time, effort and expense of developing the track.

A significant expenditure of time and/or money in the production of information may provide evidence of value. However, we do not understand Illinois law to require such an expenditure in all cases.

As pointed out by the district court, several Illinois cases have emphasized the importance of developmental costs. However, notably, none of those cases concerned the sort of innovative and creative concept that we have in this case. Indeed, several of the cases in Illinois that emphasize developmental costs concern compilations of data, such as customer lists. In that context, it makes sense to require the expenditure of significant time and money because there is nothing original or creative about the alleged trade secret. Given enough time and money, we presume that the plaintiff's competitors could compile a similar list.

Here, by contrast, we are dealing with a new toy design that has been promoted as "the first significant innovation in track design since the inception of wooden train systems." Toy designers, like many artistic individuals, have intuitive flashes of creativity. Often, that intuitive flash is, in reality, the product of earlier thought and practice in an artistic craft. We fail to see how the value of PlayWood's concept would differ in any respect had Clausi spent several months and several thousand dollars creating the noise-producing track.

6. Ease or difficulty with which PlayWood's concept could have been properly acquired or duplicated by others

Finally, we also believe that there was sufficient evidence for the jury to determine that PlayWood's concept could not have been easily acquired or duplicated through proper means. PlayWood's expert wit- 
ness, Michael Kennedy, testified: "This is a fairly simple product if you look at it. But the truth is that because it delivers feeling and sound as well as appearance, it isn't so simple as it first appears. It's a little more elegant, actually, than you might think." In addition to Kennedy's testimony, the jury heard that Learning Curve had spent months attempting to differentiate its track from Brio's before Clausi disclosed PlayWood's concept of noise-producing track. From this evidence, the jury could have inferred that, if PlayWood's concept really was obvious, Learning Curve would have thought of it earlier.

Despite this evidence, the district court concluded that PlayWood's concept was not a trade secret because it could have been easily duplicated, stating that "[h]ad PlayWood succeeded in producing and marketing [the] notched track, the appearance of the track product itself would have fully revealed the concept PlayWood now claims as a secret." Of course, the district court was correct in one sense; PlayWood's own expert recognized that, in the absence of patent or copyright protection, the track could have been reverse engineered just by looking at it. However, the district court failed to appreciate the fact that PlayWood's concept was not publicly available. As Professor Milgrim states: "A potent distinction exists between a trade secret which will be disclosed if and when the product in which it is embodied is placed on sale, and a 'trade secret' embodied in a product which has been placed on sale, which product admits of discovery of the 'secret' upon inspection, analysis, or reverse engineering. Until disclosed by sale the trade secret should be entitled to protection." see also Callmann ("The fact that a secret is easy to duplicate after it becomes known does not militate against its being a trade secret prior to that time."). Reverse engineering can defeat a trade secret claim, but only if the product could have been properly acquired by others, as is the case when the product is publicly sold. Here, PlayWood disclosed its concept to Learning Curve (and Learning Curve alone) in the context of a confidential relationship; Learning Curve had no legal authority to reverse engineer the prototype that it received in confidence. Accordingly, we must conclude that the jury was entitled to determine that PlayWood's concept could not easily have been acquired or duplicated through proper means.

\section{Exploits Problem}

Exploit brokers are in the business of helping people defeat computer security. Governments want to thumb through the hard drives of terrorists, criminals, and dissidents. Identity thieves want passwords and bank account numbers. Extortionists want to delete data and hold it for ransom. Corporate spies want access to competitors' computers. All of them are willing to pay handsomely for the technical tools that enable them to do so. These tools are typically built around 
"exploits": short pieces of software that take advantage of bugs in commonly-used software like Windows, Adobe Flash, and iOS. As soon as as software companies learn about these bugs, they race to issue updates to fix them; once that happens, any exploits based on those bugs stop working. Thus, secrecy is essential to the exploit business in two ways: many of the uses are illegal, and exploits become worthless soon after they become public knowledge.

Can exploit brokers - who buy exploits from the computer security experts who discover them and then resell those exploits to various clients - rely on trade secret law? Should they be able to? Do the materials in this chapter and the previous one shed any light on how you would expect the exploit business to work, and how it ought to be regulated?

\section{Priority}

Because there is no requirement that a trade secret be unique - more than one person can have the same information and each has a valid and independent trade secret provided the other requirements are met - trade secret does not generally raise difficult issues about which of several competing claimants developed the information first.

\section{Collaborations}

\section{Restatement (Third) of Unfair Competition}

cmt. e. Allocation of ownership between employers and employees. - The law of agency has established rules governing the ownership of valuable information created by employees during the course of an employment relationship. See Restatement, Second, Agency $\S 397$. In the absence of a contrary agreement, the law ordinarily assigns ownership of an invention or idea to the person who conceives it. However, valuable information that is the product of an employee's assigned duties is owned by the employer, even when the information results from the application of the employee's personal knowledge or skill.

An employee is ordinarily entitled to claim ownership of patents and trade secrets developed outside the scope of the employee's assigned duties, even if the invention or idea relates to the employer's business and was developed using the employer's time, personnel, facilities, or equipment. In the latter circumstances, however, the employer is entitled to a "shop right" - an irrevocable, nonexclusive, royalty-free license to use the innovation. Similarly, employees retain ownership of infor-

$\S 42$

Breach of Confidence by Employees 
mation comprising their general skill, knowledge, training, and experience.

Although the rules governing ownership of valuable information created during an employment relationship are most frequently applied to inventions, the rules are also applicable to information such as customer lists, marketing ideas, and other valuable business information. If an employee collects or develops such information as part of the assigned duties of the employment, the information is owned by the employer. Thus, if the information qualifies for protection as a trade secret, unauthorized use or disclosure will subject the employee to liability.

cmt. g. Contractual protection. - Absent an applicable statutory prohibition, agreements relating to the ownership of inventions and discoveries made by employees during the term of the employment are generally enforceable according to their terms. Employment agreements sometimes include provisions granting the employer ownership of all inventions and discoveries conceived by the employee during the term of the employment. In some situations, however, it may be difficult to prove when a particular invention was conceived. The employee may have an incentive to delay disclosure of the invention until after the employment is terminated in order to avoid the contractual or common law claims of the employer. It may also be difficult to establish whether a post-employment invention was improperly derived from the trade secrets of the former employer. Some employment agreements respond to this uncertainty through provisions granting the former employer ownership of inventions and discoveries relating to the subject matter of the former employment that are developed by the employee even after the termination of the employment. Such agreements can restrict the former employee's ability to exploit the skills and training desired by other employers and may thus restrain competition and limit employee mobility. The courts have therefore subjected such "holdover" agreements to scrutiny analogous to that applied to covenants not to compete. Thus, the agreement may be unenforceable if it extends beyond a reasonable period of time or to inventions or discoveries resulting solely from the general skill and experience of the former employee.

The Restatements treated reasonable efforts as part of the secrecy analysis. Under the UTSA, EEA, and DTSA, it is a separate element.

\section{Procedures}

The most important - and arguably the only - procedural prerequisite to having a valid trade secret is making reasonable efforts to preserve its secrecy. There is no requirement that the owner of a trade 
secret register it as one with a government agency, or take other formal steps to identify the secret in advance. Remember that everyone agrees a trade secret must actually be secret to be protected; what does a reasonable efforts requirement add? Why?

\section{United States v. Lange}

One ingredient of a trade secret is that "the owner thereof has taken reasonable measures to keep such information secret". Lange contends that the proof fell short, but a sensible trier of fact could have concluded that RAPCO took "reasonable measures to keep the information secret". RAPCO stores all of its drawings and manufacturing data in its CAD room, which is protected by a special lock, an alarm system, and a motion detector. The number of copies of sensitive information is kept to a minimum; surplus copies are shredded. Some information in the plans is coded, and few people know the keys to these codes. Drawings and other manufacturing information contain warnings of RAPCO's intellectual property rights; every employee receives a notice that the information with which he works is confidential. None of RAPCO's subcontractors receives full copies of the schematics; by dividing the work among vendors, RAPCO ensures that none can replicate the product. This makes it irrelevant that RAPCO does not require vendors to sign confidentiality agreements; it relies on deeds (the splitting of tasks) rather than promises to maintain confidentiality. Although, as Lange says, engineers and drafters knew where to get the key to the CAD room door, keeping these employees out can't be an ingredient of "reasonable measures to keep the information secret"; then no one could do any work. So too with plans sent to subcontractors, which is why dissemination to suppliers does not undermine a claim of trade secret.

Rockwell Graphic Systems, Inc. v. DEV Industries, Inc. The requirement of reasonable efforts has both evidentiary and remedial significance, and this regardless of which of the two different conceptions of trade secret protection prevails. (Both conceptions have footholds in Illinois law, as we shall see.) The first and more common merely gives a remedy to a firm deprived of a competitively valuable secret as the result of an independent legal wrong, which might be conversion or other trespass or the breach of an employment contract or of a confidentiality agreement. Under this approach, because the secret must be taken by improper means for the taking to give rise to liability, the only significance of trade secrecy is that it allows the victim of wrongful appropriation to obtain damages based on the competitive value of the information taken. The second conception of trade secrecy is that "trade secret" picks out a class of socially valuable information that the law should protect even against nontrespas-
312 F.3d 263 (7th Cir. 2002)

925 F.2d 174 (7th Cir. 1991)

Rockwell, which manufactures printing presses, sued DEV, a competing manufacturer, for making replacement parts for Rockwell presses. A key component of Rockwell's claims ws that DEV had in its possession about 100 "piece part drawings": detailed manufacturing diagrams for parts to Rockwell presses. Rockwell alleged that the piece part drawings had been stolen by former Rockwell employees including Fleck and Peloso, both of whom were subequently employed by DEV. Along the way, DEV argued that Rockwell failed to make reasonable efforts to keep the diagrams secret, which led Judge Posner to discuss the purpose of the reasonable efforts requirement. 
sory or other lawful conduct.

It should be apparent that the two different conceptions of trade secret protection are better described as different emphases. The first emphasizes the desirability of deterring efforts that have as their sole purpose and effect the redistribution of wealth from one firm to another. The second emphasizes the desirability of encouraging inventive activity by protecting its fruits from efforts at appropriation that are, indeed, sterile wealth-redistributive - not productive - activities. The approaches differ, if at all, only in that the second does not limit the class of improper means to those that fit a preexisting pigeonhole in the law of tort or contract or fiduciary duty - and it is by no means clear that the first approach assumes a closed class of wrongful acts, either.

Under the first approach, at least if narrowly interpreted so that it does not merge with the second, the plaintiff must prove that the defendant obtained the plaintiff's trade secret by a wrongful act, illustrated here by the alleged acts of Fleck and Peloso in removing piece part drawings from Rockwell's premises without authorization, in violation of their employment contracts and confidentiality agreements, and using them in competition with Rockwell. Rockwell is unable to prove directly that the 100 piece part drawings it got from DEV in discovery were stolen by Fleck and Peloso or obtained by other improper means. But if it can show that the probability that DEV could have obtained them otherwise - that is, without engaging in wrongdoing - is slight, then it will have taken a giant step toward proving what it must prove in order to recover under the first theory of trade secret protection. The greater the precautions that Rockwell took to maintain the secrecy of the piece part drawings, the lower the probability that DEV obtained them properly and the higher the probability that it obtained them through a wrongful act; the owner had taken pains to prevent them from being obtained otherwise.

Under the second theory of trade secret protection, the owner's precautions still have evidentiary significance, but now primarily as evidence that the secret has real value. For the precise means by which the defendant acquired it is less important under the second theory, though not completely unimportant; remember that even the second theory allows the unmasking of a trade secret by some means, such as reverse engineering. If Rockwell expended only paltry resources on preventing its piece part drawings from falling into the hands of competitors such as DEV, why should the law, whose machinery is far from costless, bother to provide Rockwell with a remedy? The information contained in the drawings cannot have been worth much if Rockwell did not think it worthwhile to make serious efforts to keep the information secret.

The remedial significance of such efforts lies in the fact that if the 
plaintiff has allowed his trade secret to fall into the public domain, he would enjoy a windfall if permitted to recover damages merely because the defendant took the secret from him, rather than from the public domain as it could have done with impunity. It would be like punishing a person for stealing property that he believes is owned by another but that actually is abandoned property. If it were true, as apparently it is not, that Rockwell had given the piece part drawings at issue to customers, and it had done so without requiring the customers to hold them in confidence, DEV could have obtained the drawings from the customers without committing any wrong. The harm to Rockwell would have been the same as if DEV had stolen the drawings from it, but it would have had no remedy, having parted with its rights to the trade secret. This is true whether the trade secret is regarded as property protected only against wrongdoers or as property protected against the world. In the first case, a defendant is perfectly entitled to obtain the property by lawful conduct if he can, and he can if the property is in the hands of persons who themselves committed no wrong to get it. In the second case the defendant is perfectly entitled to obtain the property if the plaintiff has abandoned it by giving it away without restrictions.

It is easy to understand therefore why the law of trade secrets requires a plaintiff to show that he took reasonable precautions to keep the secret a secret. If analogies are needed, one that springs to mind is the duty of the holder of a trademark to take reasonable efforts to police infringements of his mark, failing which the mark is likely to be deemed abandoned, or to become generic or descriptive (and in either event be unprotectable). The trademark owner who fails to police his mark both shows that he doesn't really value it very much and creates a situation in which an infringer may have been unaware that he was using a proprietary mark because the mark had drifted into the public domain, much as DEV contends Rockwell's piece part drawings have done.

But only in an extreme case can what is a "reasonable" precaution be determined on a motion for summary judgment, because the answer depends on a balancing of costs and benefits that will vary from case to case and so require estimation and measurement by persons knowledgeable in the particular field of endeavor involved. On the one hand, the more the owner of the trade secret spends on preventing the secret from leaking out, the more he demonstrates that the secret has real value deserving of legal protection, that he really was hurt as a result of the misappropriation of it, and that there really was misappropriation. On the other hand, the more he spends, the higher his costs. The costs can be indirect as well as direct. The more Rockwell restricts access to its drawings, either by its engineers or by the vendors, the harder it will be for either group to do the work expected 
of it. Suppose Rockwell forbids any copying of its drawings. Then a team of engineers would have to share a single drawing, perhaps by passing it around or by working in the same room, huddled over the drawing. And how would a vendor be able to make a piece part - would Rockwell have to bring all that work in house? Such reconfigurations of patterns of work and production are far from costless; and therefore perfect security is not optimum security.

\section{Infringement: Similarity}

The essence of trade secret misappropriation is to obtain or use secret information acquired through "improper means." Note that this essence includes an implicit requirement that the information the defendant obtained or used is the same information the plaintiff claims as a trade secret.

Big Vision Private, Ltd. v. E.I. Dupont De Nemours \& Co.

Big Vision's second argument is that DuPont's recyclable banner product lines misappropriate Big Vision's trade secret. Quite simply, Big Vision cannot demonstrate that its recyclable banners are substantially similar to DuPont's. The parties do not dispute that DuPont's recyclable banner products are not made by either lamination or coextrusion. None of DuPont's recyclable banner products use the three-layer structures tested at the Trials, the range of $\mathrm{CaCO}_{3}$ tested at the Trials, or "minimal" amounts of Entira (to the extent it has been defined), since DuPont's products either use $100 \%$ or $0 \%$ Entira. Furthermore, DuPont's recyclable banner products are not printable with solvent ink. Thus, to the extent Big Vision's trade secret is discernible, DuPont's products implicate almost none of its elements. 60

\section{E Infringement: Prohibited Conduct}

Before you dive into the new cases, look back at the cases from the first half of the chapter. You read them as cases on the existence of trade secrets. They are also cases on misappropriation. What did the defendants in each case do? Was it misappropriation? This duality is typical of intellectual property cases. Both protectability and misappropriation are required to find a defendant liable, which means that both protectability and misappropriation are potentially in play

\footnotetext{
${ }^{60}$ Plaintiff argues that because DuPont's banners do not exhibit the four-item "wish list" that Big Vision's trade secret is supposed to cause, DuPont must have ineptly misappropriated its trade secret. While clever, this argument is not a fair reading of the record, which makes clear that DuPont's recyclable banners are simply not substantially similar to Big Vision's alleged trade secret.
} 
in every case. A trade secret defendant can win by showing that the plaintiff lacked a valid protectable trade secret in the first place, or by showing that the defendant did not misappropriate that trade secret.

\section{Proving Infringement}

\section{Grynberg v. BP, PLC}

In the enormous record before the court, there is no direct evidence that ARCO used Grynberg's information in evaluating Tengiz or the Caspian pipeline. How ARCO came to make those investments is no mystery however: engineers and executives alike have testified in detail as to the evaluation and decision-making process. With respect to both investments, publically available resources were used initially, and then supplemented at length in data rooms set up by the organizations managing the investment - for Tengiz the Chevron data room and for the Caspian Pipeline the Oman data room. Further, although plaintiff's experts state generally that the publically available sources were inferior to Grynberg's information, plaintiff concedes that his information - obtained in 1989-90 - was "outdated" by 1996. Moreover, plaintiff admits that when Chevron invested in Tengiz it had been given access by the Kazakhs to all the information to which Grynberg was privy, information that would have been available in the comprehensive and up to date data rooms prepared for ARCO when it reviewed the Tengiz investment years later.

Plaintiff argues that ARCO's alleged use can be proven circumstantially, in much the same way that "use of a trade secret can be proven by showing access to the trade secret plus the subsequent similarity of the trade secret and a Defendant's product." Indeed, the law of trade secrets acknowledges the basic logic that when two products look alike, there is probably more than a coincidental connection between them. See Electro-Miniatures Corp. v. Wendon Co. (misappropriation provable by circumstantial evidence where company that had struggled to produce printed circuit slip rings suddenly "issued a catalog depicting an entire line of printed circuit slip ring assemblies, resembling those built by the plaintiff"). Nor is there any inherent reason to limit this approach to cases involving products (electrical or otherwise). Logically, in any case where what is done or produced by the alleged thief bears some unique markers of the allegedly stolen secrets, it may be inferred that the thief used the secrets. Thus in Rochester Midland Corp. v. Enerco Corp., use of pricing, product, and customer information could be inferred where eighteen accounts associated with a poached employee switched to the defendant company shortly after the confidential information was brought over. However, the inference is only as strong as logic demands -
For more on the relationship between protection and infringement, see Mark A. Lemley \& Mark P. McKenna, Scope, 57 Wm \& Mary L. Rev. 2197 (2016).

No. 06 Civ. 6494 (RJH), 2011 U.S. Dist. LEXIS 34286 (S.D.N.Y. Mar. 30, 2011)

Electro-Miniatures: 771 F.2d 23, 26 (2d Cir. 1985)

Rochester Midland: No. 1:08-cv98, 2009 U.S. Dist. LEXIS 46103, 2009 WL 1561817, *19 (W.D. Mich. June 1, 2009) 
where an alleged thief's products lack a suspicious similarity to the secrets, the inference would not lie.

Grynberg could make a circumstantial case for use under this theory, then, only to the extent that ARCO's actions bore the unique marks of his information, or showed a suspicious similarity to it. ARCO did eventually make investments in Tengiz and the Caspian pipeline, which were among the investments that Grynberg had endorsed and relayed information about. However ARCO also declined to pursue other investments Grynberg had advocated, such as the Karachaganak oil field also in the area of mutual interest. Moreover nothing about ARCO's investments bears the markers of the Grynberg information in such a way as to justify inferring the use of that information. It is not as if ARCO built wells at particular locations previously suggested by Grynberg, worked primarily through contacts developed by Grynberg, or tied its investments to Grynberg's numbers in a suspiciously similar way. Rather, an oil company chose to invest in one of the largest oil fields in the world, in a manner different from that envisioned by Grynberg at the time he developed his proposed consortium. That it did so is unsurprising and does not evince the kind of suspicious similarity present in Electro-Miniatures and Rochester Midland. Accordingly an inference of use based on similarity is not appropriate here.

\section{Direct Infringement}

$\S 43$

Improper Acquisition of Trade Secrets

\section{Restatement (Third) of Unfair Competition}

"Improper" means of acquiring another's trade secret ... include theft, fraud, unauthorized interception of communications, inducement of or knowing participation in breach of confidence, and other means either wrongful in themselves or wrongful under the circumstances of the case. Independent discovery and analysis of publicly available products or information are not improper means of acquisition.

\section{Uniform Trade Secrets Act}

"Improper means" includes theft, bribery, misrepresentation, breach or inducement of a breach of a duty to maintain secrecy, or espionage through electronic or other means;

These lists of "improper means" can be roughly divided into two types of wrongful conduct. On the one hand there is espionage, which 
often involves theft, trespass, or computer hacking. On the other hand there is breach of confidence, which often involves violating a promise to keep someone else's secrets. It is tempting to to conclude that "improper means" consist of torts (espionage) and breach of contract (breach of confidence), but this equation is a little too pat.

\section{E.I. du Pont de Nemours \& Co. v. Christopher}

This is a case of industrial espionage in which an airplane is the cloak and a camera the dagger. The defendants-appellants, Rolfe and Gary Christopher, are photographers in Beaumont, Texas. The Christophers were hired by an unknown third party to take aerial photographs of new construction at the Beaumont plant of E. I. DuPont de Nemours \& Company, Inc. Sixteen photographs of the DuPont facility were taken from the air on March 19, 1969, and these photographs were later developed and delivered to the third party.

DuPont subsequently filed suit against the Christophers, alleging that the Christophers had wrongfully obtained photographs revealing DuPont's trade secrets which they then sold to the undisclosed third party. DuPont contended that it had developed a highly secret but unpatented process for producing methanol, a process which gave DuPont a competitive advantage over other producers. This process, DuPont alleged, was a trade secret developed after much expensive and time-consuming research, and a secret which the company had taken special precautions to safeguard. The area photographed by the Christophers was the plant designed to produce methanol by this secret process, and because the plant was still under construction parts of the process were exposed to view from directly above the construction area. Photographs of that area, DuPont alleged, would enable a skilled person to deduce the secret process for making methanol. DuPont thus contended that the Christophers had wrongfully appropriated DuPont trade secrets by taking the photographs and delivering them to the undisclosed third party.

The Christophers argued both at trial and before this court that they committed no "actionable wrong" in photographing the DuPont facility and passing these photographs on to their client because they conducted all of their activities in public airspace, violated no government aviation standard, did not breach any confidential relation, and did not engage in any fraudulent or illegal conduct. In short, the Christophers argue that for an appropriation of trade secrets to be wrongful there must be a trespass, other illegal conduct, or breach of a confidential relationship. We disagree.

It is true, as the Christophers assert, that the previous trade secret cases have contained one or more of these elements. However, we do not think that the Texas courts would limit the trade secret protection exclusively to these elements.
431 F.2d 1012 (5th Cir. 1970)

Edmund Kitch, in The Law and Economics of Rights in Valuable Information, 9 J. Legal Stud. 683 (1980), speculates that "The appearance of the airplane at such an opportune moment [may have] suggested to DuPont that some kind of inside leak had tipped off the photographers (or their client) to the opportunity." 
Fowler: 316 S.W.2d 111 (Tex. Civ. App. 1958)
Although the previous cases have dealt with a breach of a confidential relationship, a trespass, or other illegal conduct, the rule is much broader than the cases heretofore encountered. Not limiting itself to specific wrongs, Texas adopted subsection (a) of the Restatement which recognizes a cause of action for the discovery of a trade secret by any "improper" means.

The question remaining, therefore, is whether aerial photography of plant construction is an improper means of obtaining another's trade secret. We conclude that it is and that the Texas courts would so hold. The Supreme Court of that state has declared that "the undoubted tendency of the law has been to recognize and enforce higher standards of commercial morality in the business world." Hyde Corporation $v$. Huffines. That court has quoted with approval articles indicating that the proper means of gaining possession of a competitor's secret process is through inspection and analysis of the product in order to create a duplicate. Later another Texas court explained:

The means by which the discovery is made may be obvious, and the experimentation leading from known factors to presently unknown results may be simple and lying in the public domain. But these facts do not destroy the value of the discovery and will not advantage a competitor who by unfair means obtains the knowledge without paying the price expended by the discoverer."

Brown v. Fowler. We think, therefore, that the Texas rule is clear. One may use his competitor's secret process if he discovers the process by reverse engineering applied to the finished product; one may use a competitor's process if he discovers it by his own independent research; but one may not avoid these labors by taking the process from the discoverer without his permission at a time when he is taking reasonable precautions to maintain its secrecy. To obtain knowledge of a process without spending the time and money to discover it independently is improper unless the holder voluntarily discloses it or fails to take reasonable precautions to ensure its secrecy.

In the instant case the Christophers deliberately flew over the DuPont plant to get pictures of a process which DuPont had attempted to keep secret. The Christophers delivered their pictures to a third party who was certainly aware of the means by which they had been acquired and who may be planning to use the information contained therein to manufacture methanol by the DuPont process. The third party has a right to use this process only if he obtains this knowledge through his own research efforts, but thus far all information indicates that the third party has gained this knowledge solely by taking it from DuPont at a time when DuPont was making reasonable efforts to preserve its secrecy. In such a situation DuPont has a valid 
cause of action to prohibit the Christophers from improperly discovering its trade secret and to prohibit the undisclosed third party from using the improperly obtained information.

In taking this position we realize that industrial espionage of the sort here perpetrated has become a popular sport in some segments of our industrial community. However, our devotion to free wheeling industrial competition must not force us into accepting the law of the jungle as the standard of morality expected in our commercial relations. Our tolerance of the espionage game must cease when the protections required to prevent another's spying cost so much that the spirit of inventiveness is dampened. Commercial privacy must be protected from espionage which could not have been reasonably anticipated or prevented. We do not mean to imply, however, that everything not in plain view is within the protected vale, nor that all information obtained through every extra optical extension is forbidden. Indeed, for our industrial competition to remain healthy there must be breathing room for observing a competing industrialist. A competitor can and must shop his competition for pricing and examine his products for quality, components, and methods of manufacture. Perhaps ordinary fences and roofs must be built to shut out incursive eyes, but we need not require the discoverer of a trade secret to guard against the unanticipated, the undetectable, or the unpreventable methods of espionage now available.

In the instant case DuPont was in the midst of constructing a plant. Although after construction the finished plant would have protected much of the process from view, during the period of construction the trade secret was exposed to view from the air. To require DuPont to put a roof over the unfinished plant to guard its secret would impose an enormous expense to prevent nothing more than a school boy's trick. We introduce here no new or radical ethic since our ethos has never given moral sanction to piracy. The marketplace must not deviate far from our mores. We should not require a person or corporation to take unreasonable precautions to prevent another from doing that which he ought not do in the first place. Reasonable precautions against predatory eyes we may require, but an impenetrable fortress is an unreasonable requirement, and we are not disposed to burden industrial inventors with such a duty in order to protect the fruits of their efforts. "Improper" will always be a word of many nuances, determined by time, place, and circumstances. We therefore need not proclaim a catalogue of commercial improprieties. Clearly, however, one of its commandments does say "thou shall not appropriate a trade secret through deviousness under circumstances in which countervailing defenses are not reasonably available."

Having concluded that aerial photography, from whatever altitude, is an improper method of discovering the trade secrets exposed
Would Christopher have been decided the same way if it were 2015 and the defendants used publicly available satellite photos from Google Earth to observe the the construction of the plant? What if they flew a small ten-pound remote-control drone over the plant? What if they flew the drone over their neighbor's fenced backyard and photographed him sunbathing nude? 
during construction of the DuPont plant, we need not worry about whether the flight pattern chosen by the Christophers violated any federal aviation regulations. Regardless of whether the flight was legal or illegal in that sense, the espionage was an improper means of discovering DuPont's trade secret.

\section{Kamin v. Kuhnau}

For approximately 25 years plaintiff had been employed by a knitting mill as a mechanic. In 1953 he entered into the garbage collection business. From the time plaintiff entered into the garbage collection business he began thinking of methods of facilitating the loading of garbage trucks and of compressing or packing the materials after they were loaded. By 1955 he had done some experimental work on his own truck, devising a hoist mechanism operated by hydraulic cylinders to lift a bucket from the ground to the top of the truck box. By this time he had also arrived at the conclusion that the packing of the loaded materials could best be effected through the use of a hydraulically operated plow which would move against the loaded materials and compress them against the interior of the truck. At the time plaintiff conceived this solution there were on the market garbage truck bodies containing various "packer" mechanisms, including hydraulically operated plows. However, plaintiff and defendant apparently were not aware of the use of hydraulic cylinders for this purpose and thought that plaintiff's idea was novel in this respect.

In January, 1955, plaintiff made arrangements with defendant Kuhnau, president and manager of Oregon Rental Equipment Company, to use the company's machine shop and one or more of its employees to assist plaintiff in carrying on further experimental work in developing plaintiff's ideas. This experimental work was carried on for approximately one year. According to plaintiff's evidence, all of the experimental work was done under his supervision and Kuhnau had no voice or control as to the manner in which the developmental work was to be carried on. It is Kuhnau's contention that he and the employees of Oregon Rental Equipment Company contributed suggestions and ideas which were used in the development and improvement of the truck body and compressor mechanism.

In the course of working on the project several persons who were engaged in the garbage collection business came to the defendant's machine shop, observed the progress being made by plaintiff and made suggestions as to the practical application of plaintiff's idea. Sometime in the summer of 1956 the truck and compressor mechanism which plaintiff was seeking to develop was crystallized substantially in the form in which it now exists.

When plaintiff had completed his experimental work he began to receive orders for truck bodies embodying his improvements. The 
first two units sold were manufactured by Oregon Rental Equipment Company. After the sale of these two units (in the spring of 1956) Kuhnau terminated his connections with Oregon Rental Equipment Company. He rented a machine shop at another location and began business under the name of R.K. Truck Sales. Between May and October, 1956, he manufactured ten units for plaintiff. For each unit Kuhnau received an amount agreed upon by the parties. Plaintiff fixed the selling price of the unit and his profit consisted of the difference between the selling price and the amount he paid Kuhnau.

On or about October 1, 1956, Kuhnau informed plaintiff that he was going to manufacture truck bodies in competition with plaintiff. Kuhnau testified that the relationship was terminated as a result of a disagreement over the amount he was to receive for manufacturing the unit for plaintiff. Plaintiff contends that Kuhnau terminated the relationship for the purpose of entering into competition with plaintiff. The units manufactured by Kuhnau were similar to those which he had previously manufactured for plaintiff. However, there were some differences in the design of the two units. The principal difference was that Kuhnau mounted the hydraulic cylinder operating the plow or blade under the truck bed whereas the cylinder in plaintiff's truck was above the bed. There was testimony supporting plaintiff's assertion that it was his idea to place the cylinder under the bed of the truck but that suggestion was not adopted because Kuhnau did not think it was feasible.

Whether the information disclosed was intended to be appropriable by the disclosee will depend upon the relationship of the parties and the circumstances under which the disclosure was made. It is not necessary to show that the defendant expressly agreed not to use the plaintiff's information; the agreement may be implied. And the implication may be made not simply as a product of the quest for the intention of the parties but as a legal conclusion recognizing the need for ethical practices in the commercial world. In the case at bar the relationship between plaintiff and Kuhnau was such that an obligation not to appropriate the plaintiff's improvements could be implied. Kuhnau was paid to assist plaintiff in the development of the latter's idea. It must have been apparent to Kuhnau that plaintiff was attempting to produce a unit which could be marketed. Certainly it would not have been contemplated that as soon as the packer unit was perfected Kuhnau would have the benefit of plaintiff's ideas and the perfection of the unit through painstaking and expensive experimentation. It is to be remembered that the plaintiff's experimentation was being carried on, not on the assumption that he was duplicating an existing machine, but upon the assumption that he was creating a new product. It has been recognized in the cases that a manufacturer who has been employed to develop an inventor's ideas is not entitled 
to appropriate those ideas to his own use.

Hyde is closely in point. In that case the defendant manufacturer, having gained knowledge of a garbage compressor through a licensing agreement with the plaintiff inventor, repudiated the agreement and proceeded to manufacture and sell on its own account a compressor of similar design. Defendant was enjoined. The court held that the parties were in a confidential relationship and that the information relating to the compressor acquired by the defendant incident to that relationship could not be appropriated by him. In that case, as in the present case, plaintiff obtained a patent during the course of the trial. The defendant argued that since plaintiff's process was revealed by the patent the process could not be regarded as a trade secret. The court held that the public disclosure of plaintiff's process did not remove defendant's duty not to exploit the economic advantage gained through the information initially disclosed to him by plaintiff. We see no essential difference between the facts in the Hyde case and the case at bar.

The principles applied in the foregoing cases have been recognized by this court. In McKinzie v. Cline, the plaintiff employed the defendants to manufacture a gun swivel which one of the plaintiffs had invented. The defendants discontinued manufacturing the swivel for the plaintiffs and proceeded to manufacture and sell it for their own account. It was held that defendants violated a confidential relationship which existed between the parties and that therefore plaintiffs were entitled to an injunction and damages. In that case, as in the present one, plaintiffs had placed their product on the market and had discussed its manufacture with various machinists. The court noted that there was no "evidence in the record that anyone other than defendant Cline and the plaintiffs had any knowledge of the inside workings of the gadget." The court went further and held that even though others might have become acquainted with the manufacturing process this would not entitle the defendants to violate the confidence reposed in them by the plaintiffs. With respect to this point, defendants in the present case argue that the McKinzie case is distinguishable from the case at bar in that the mechanism of the gun swivel was complex, whereas the mechanism of the garbage truck was not. The evidence does not support this contention. The description of the packer mechanism, particularly the manner in which the blade was attached (the proper adjustment of which was one of the principal improvements claimed by plaintiff), would indicate that it was of such complexity that more than a general inspection of the unit would be required to reveal the secret of plaintiff's improvements. The McKinzie case followed the line of authority previously discussed which de-emphasizes the elements of secrecy and novelty and stresses the breach of the confidential relation between the parties. The court 
adopted the higher standard of commercial ethics to which we have already alluded:

If our system of private enterprise on which our nation has thrived, prospered and grown great is to survive, fair dealing, honesty and good faith between contracting parties must be zealously maintained; therefore, if one who has learned of another's invention through contractual relationship, such as in the present case, takes unconscionable and inequitable advantage of the other to his own enrichment and at the expense of the latter, a court of equity will extend its broad equitable powers to protect the party injured.

We reaffirm this declaration of business ethics and hold that defendant Kuhnau violated his duty to plaintiff by appropriating the information derived through their business relationship.

Defendants contend that there was no proof that their product contained the improvements alleged to have been developed by plaintiff. There is evidence that the plaintiff's and defendants' trucks were similar in structure and design. The trial judge, who inspected the trucks, concluded that defendants' trucks used the improvements developed by plaintiff. Where a person develops a product similar to that developed by his discloser, the proof of similarity may be sufficient to impose upon the disclosee the burden of proving that there was no misappropriation. Hoeltke v. C.M. Kemp Mfg. Co. stated: "The similarity of defendant's device to that of complainant is strong proof that one was copied from the other; for it is hardly probable that different persons should independently of each other invent devices so nearly similar at so nearly the same time." In the same case the court said that "one who admittedly receives a disclosure from an inventor, proceeds thereafter to manufacture articles of similar character, and, when called to account, makes answer that he was using his own ideas and not the ideas imparted to him" must sustain his position by proof that is "clear, satisfactory, and beyond a reasonable doubt." We are of the opinion that there was sufficient evidence to support the conclusion that defendants appropriated plaintiff's improvements.

\section{Secondary Infringement}

If a vice-president at MatrixCorp receives an email from someone calling himself Cypher offering to provide details of a computer graphics technology similar to one used by its competitor NeoCorp, can he take the deal? A moment's thought should suggest that the answer depends on how Cypher obtained the information and on what MatrixCorp knows about it. What about MatrixCorp's customers? Do 
they need to worry that their widgets were produced using a misappropriated trade secret?

\section{Uniform Trade Secrets Act}

$\S 1$

Definitions

For more, see Grynberg.
(2) “Misappropriation" means:

(i) acquisition of a trade secret of another by a person who knows or has reason to know that the trade secret was acquired by improper means; or

(ii) disclosure or use of a trade secret of another without express or implied consent by a person who

(A) used improper means to acquire knowledge of the trade secret; or

(B) at the time of disclosure or use, knew or had reason to know that his knowledge of the trade secret was

(I) derived from or through a person who had utilized improper means to acquire it;

(II) acquired under circumstances giving rise to a duty to maintain its secrecy or limit its use; or

(III) derived from or through a person who owed a duty to the person seeking relief to maintain its secrecy or limit its use; or

(C) before a material change of his [or her] position, knew or had reason to know that it was a trade secret and that knowledge of it had been acquired by accident or mistake.

\section{F Defenses}

The two most significant "defenses" to trade secret infringement are independent discovery and reverse engineering. I put "defenses" in quotation marks to emphasize that neither adds anything to the doctrines you have already seen. The defendant who establishes that she independently came up with the same information has actually defeated a crucial element of the plaintiff's case-in-chief: that the defendant stole the information from the plaintiff.

Similarly, the usual definitions of "improper means" simply exclude reverse engineering: the plaintiff who proves only that the defendant reverse engineered her product has again failed to show an act of misappropriation. Reverse engineering is conventionally defined as "starting with the known product and working backward to divine the process which aided in its development or manufacture." Kewanee Oil Co. v. Bicron Corp. Courts sometimes add that the 
"known product" must have been obtained lawfully: it is no defense to argue that you reverse engineered the widget-making-machine you stole from your competitor's factory.

Why allow reverse engineering? For one thing, it reflects a policy of recognizing personal property owners' rights over their things. If you buy it, you can break it down. Reverse engineering also promotes the same values as trade secret law itself. In the words of the Supreme Court, it is "an essential part of innovation" that "often leads to significant advances in technology." Bonito Boats, Inc. v. Thunder Craft Boats, Inc.

\section{Questions}

1. In 2007, the New England Patriots football team videotaped the hand signals used by coaches for the New York Jets to send instructions to players on the field. Anyone in the stadium with a clear line of sight is able to see the signals. The National Football League's rules allow for such videotaping, but only from specific areas not including the areas the Patriots taped from (which had better views). Did the Patriots misappropriate a trade secret?

2. In 2011, the Houston Astros baseball team hired Jeff Luhnow as their new general manager. Previously, Luhnow had been an executive with the St. Louis Cardinals. While with the Cardinals, Luhnow and others build an extensive database with detailed statistical information about players and reports on prospective hires. When Luhnow moved to the Astros, several Cardinals employees went with him. Other Cardinals employees suspected that Luhnow might have helped design a similar database for the Astros. They guessed that he and the other exCardinal employees might have used the same passwords for the new Astros system, a guess that turned out to be correct. The Cardinals employees logged into the Astros system using these passwords and examined some of the information in it. Identify all of the trade secret issues these facts raise.

\section{Flaming Moe's Problem}

Moe Szyslak is the owner of Moe's Tavern, where the specialty drink is a "Flaming Moe." Moe mixes the drinks in a back room, then sets them on fire in front of customers.

1. Representatives from Tipsy McStagger's Good-Time Drinking and Eating Emporium meet with Moe to discuss licensing the recipe. As part of the negotiations, Moe tells them how it's made. Tipsy McStagger's breaks off talks and start selling its own version. What result?

Based on Mason v. Jack Daniel Distillery, 518 So.2d 130 (Ala. Ct. Civ. App. 1987) 
Based on Chicago Lock Co. v. Fanberg, 676 F.2d 400 (9th Cir. 1982)
2. A Tipsy's employee orders a Flaming Moe, pours it into a thermos, and uses a gas chromatograph to analyze its chemical composition. By so doing, he learns that the secret ingredient is cough syrup. What result?

3. A Tipsy's employee goes to Moe's Tavern and bribes a bartender to tell her the formula. What result?

4. Same facts as before, except that anyone who tastes the drink can recognize that it's cough syrup. The Tipsy's employee still bribes the bartender to tell them. What result?

5. Woud Moe be better off trying to patent the formula for the Flaming Moe? Would society be better off if he did?

\section{Locksmiths Problem}

You represent the Chicago Lock Company, whose "Ace" series of locks is used in vending machines, burglar alarms, and other highsecurity settings. Ace locks use an unusual cylindrical key that requires specialized equipment to cut. Each lock has a serial number printed on it; the company uses a secret formula to translate the configuration of tumblers inside the lock into a serial number. The company's policy is that it will sell replacement keys only to the registered owner of a lock with a given serial number. All Ace locks and keys are stamped "Do Not Duplicate."

For years, locksmiths have known how to analyze Ace locks. After a few minutes poking at the lock with their tools, they can write down the configuration of pins and tumblers inside the lock. They can then go back to their toolkits and grind a replacement key, which will open the lock. If the locksmiths keep the configuration information on file, they can grind replacement keys in the future without needing to go back to the lock and analyze it again. Individual locksmiths have, for years, kept such files for their local customers.

Recently, Morris and Victor Fanberg, two locksmiths, published a book entitled "AA Advanced Locksmith's Tubular Lock Codes." They asked locksmiths around the country to send them lists of Ace lock serial numbers and the corresponding tumbler configurations. Based on that information, they were able to program a computer to reconstruct Chicago's secret formula. The book contains a table that shows how to turn an Ace serial number into a key configuration, which any locksmith with the proper equipment could then use to cut a key opening the lock with that serial number.

Because the serial numbers on Ace locks are frequently printed on the outside, Chicago is concerned that the publication of this book will undermine the security of Ace locks. It has asked you whether it can and should sue the Fanbergs for damages and to halt publication of the book. What is your advice? Is there anything further it would 
be helpful for you to know? Are there changes that Chicago Lock can and should make to its procedures in the future?

\section{G Privacy}

\section{Restatement (Second) of Torts}

One who intentionally intrudes, physically or otherwise, upon the solitude or seclusion of another or his private affairs or concerns, is subject to liability to the other for invasion of his privacy, if the intrusion would be highly offensive to a reasonable person.

cmt. b The invasion may be by physical intrusion into a place in which the plaintiff has secluded himself, as when the defendant forces his way into the plaintiff's room in a hotel or insists over the plaintiff's objection in entering his home. It may also be by the use of the defendant's senses, with or without mechanical aids, to oversee or overhear the plaintiff's private affairs, as by looking into his upstairs windows with binoculars or tapping his telephone wires. It may be by some other form of investigation or examination into his private concerns, as by opening his private and personal mail, searching his safe or his wallet, examining his private bank account, or compelling him by a forged court order to permit an inspection of his personal documents.

cmt. c The defendant is subject to liability under the rule stated in this Section only when he has intruded into a private place, or has otherwise invaded a private seclusion that the plaintiff has thrown about his person or affairs. Thus there is no liability for the examination of a public record concerning the plaintiff, or of documents that the plaintiff is required to keep and make available for public inspection. Nor is there liability for observing him or even taking his photograph while he is walking on the public highway, since he is not then in seclusion, and his appearance is public and open to the public eye. Even in a public place, however, there may be some matters about the plaintiff, such as his underwear or lack of it, that are not exhibited to the public gaze; and there may still be invasion of privacy when there is intrusion upon these matters.

One who gives publicity to a matter concerning the private life of another is subject to liability to the other for invasion of his privacy, if the matter publicized is of a kind that (a) would be highly offensive to $\S 652 \mathrm{D}$

Publicity Given to Private Life a reasonable person, and (b) is not of legitimate concern to the public.

$\S 652 B$

Intrusion upon Seclusion 
cmt. b Private life. - The rule stated in this Section applies only to publicity given to matters concerning the private, as distinguished from the public, life of the individual. There is no liability when the defendant merely gives further publicity to information about the plaintiff that is already public. Thus there is no liability for giving publicity to facts about the plaintiff's life that are matters of public record, such as the date of his birth, the fact of his marriage, his military record, the fact that he is admitted to the practice of medicine or is licensed to drive a taxicab, or the pleadings that he has filed in a lawsuit. On the other hand, if the record is one not open to public inspection, as in the case of income tax returns, it is not public, and there is an invasion of privacy when it is made so.

Similarly, there is no liability for giving further publicity to what the plaintiff himself leaves open to the public eye. Thus he normally cannot complain when his photograph is taken while he is walking down the public street and is published in the defendant's newspaper. Nor is his privacy invaded when the defendant gives publicity to a business or activity in which the plaintiff is engaged in dealing with the public. On the other hand, when a photograph is taken without the plaintiff's consent in a private place, or one already made is stolen from his home, the plaintiff's appearance that is made public when the picture appears in a newspaper is still a private matter, and his privacy is invaded.

Every individual has some phases of his life and his activities and some facts about himself that he does not expose to the public eye, but keeps entirely to himself or at most reveals only to his family or to close friends. Sexual relations, for example, are normally entirely private matters, as are family quarrels, many unpleasant or disgraceful or humiliating illnesses, most intimate personal letters, most details of a man's life in his home, and some of his past history that he would rather forget. When these intimate details of his life are spread before the public gaze in a manner highly offensive to the ordinary reasonable man, there is an actionable invasion of his privacy, unless the matter is one of legitimate public interest.

Neil M. Richards \& Daniel J. Solove

\section{Privacy's Other Path: Recovering the Law of Confidentiality}

According to the oft-told legend, the right to privacy was born when Samuel Warren and Louis Brandeis penned The Right to Privacy in 1890. Spanning just twenty-eight pages in the Harvard Law Review, the article identified privacy as an implicit concept running through- 
out Anglo-American common law. Warren and Brandeis also based much of their argument for a right to privacy upon Prince Albert $v$. Strange, an English case from 1848.

The dispute arose when Queen Victoria and her husband Albert, the Prince Consort, sued in equity to prevent the exhibition by William Strange of etchings that the royal couple had made of their family. They intended the etchings to be shared only with their family and close friends. On appeal, the Lord Chancellor agreed that Strange had no right to print and sell the etchings or the catalog. The Chancellor concluded that Prince Albert had a common law literary property right in the unpublished work - essentially, a common law copyright in unpublished works. Prince Albert suggested that intellectual property law could afford a remedy of restricting publication in unpublished works. Warren and Brandeis took this facet of the opinion and used it to turn Prince Albert from an opinion protecting intellectual property rights to a case protecting individual feelings and emotions from the pain of unwanted publicity.

The story of privacy in Britain serves as an interesting contrast to the American experience. English law, like American law, also developed a law of "private" information. As in America, this English strand of the common law also traces its origins back to Prince Albert. Warren and Brandeis minimized the second basis for the judgment - breach of confidence. Because Victoria and Albert had circulated copies of the etchings only to a few friends, and had only sent copies outside such a circle to the printer for purpose of making these copies, the Lord Chancellor concluded that Strange's possession "must have originated in a breach of trust, confidence, or contract," most likely by a clerk to the royal printer. Disclosure represented a breach of confidence because a clerk to trusted professionals like printers and merchants owed the same implied contractual duty as his master "that he will not make public that which he learns in the execution of his duty as clerk." Thus, the printer's assistant had a duty to the Queen and the Prince to maintain the confidentiality of their etchings. The breach of this duty could be enforced against subsequent holders of the etchings and the plates used to make copies of them.

The English law of confidence is quite different from the American law of privacy. Consider the case of Barrymore v. News Group Newspapers, Ltd.. Actor Michael Barrymore had a homosexual affair with Paul Wincott, who worked for a company Barrymore jointly owned with his wife. Wincott provided details of the affair to a newspaper, including letters written by Barrymore. The court held that there was a breach of confidence: "When people enter into a personal relationship of this nature, they do not do so for the purpose of it subsequently being published in The Sun, or any other newspaper. The information about the relationship is for the relationship and not for

Prince Albert: (1848) 41 Eng. Rep. 1171 (Ch.)

Put this thought aside for now; common law literary property will return in the Copyright and Music chapters.

Barrymore: [1997] F.S.R. 600 (Ch.) (U.K.) 
a wider purpose."

The results in these cases would very likely be different under American privacy law. Courts might dismiss the cases, either concluding that the information was not private since others knew about it or finding that the information was "of legitimate concern to the public." Beyond the privacy torts, the American breach of confidentiality tort would have difficulty because only a few courts have held that it can make third parties liable for knowingly using information obtained via a breach. Moreover, the American tort currently has been applied only to a limited set of relationships; courts have not yet extended the tort to friends or lovers. In contrast, English law is much more open-ended in the relationships it protects.

488 U.S. 445 (1989)

\section{Florida v. Riley}

This case originated with an anonymous tip to the Pasco County Sheriff's office that marijuana was being grown on respondent's property. When an investigating officer discovered that he could not see the contents of [respondent's] greenhouse from the road, he circled twice over respondent's property in a helicopter at the height of 400 feet. With his naked eye, he was able to see through the openings in the roof and one or more of the open sides of the greenhouse and to identify what he thought was marijuana growing in the structure. A warrant was obtained based on these observations, and the ensuing search revealed marijuana growing in the greenhouse. Respondent was charged with possession of marijuana under Florida law. The trial court granted his motion to suppress [for violating the Fourth Amendment's prohibition on "unreasonable searches and seizures."] California $v$. Ciraolo controls this case. There, acting on a tip, the police inspected the backyard of a particular house while flying in a fixed-wing aircraft at 1,000 feet. With the naked eye the officers saw what they concluded was marijuana growing in the yard. A search warrant was obtained on the strength of this airborne inspection, and marijuana plants were found.

We recognized that the yard was within the curtilage of the house, that a fence shielded the yard from observation from the street, and that the occupant had a subjective expectation of privacy. We held, however, that such an expectation was not reasonable and not one that society is prepared to honor. Our reasoning was that the home and its curtilage are not necessarily protected from inspection that involves no physical invasion. What a person knowingly exposes to the public, even in his own home or office, is not a subject of Fourth Amendment protection. As a general proposition, the police may see what may be seen from a public vantage point where they have a right to be, Thus the police, like the public, would have been free to inspect the backyard garden from the street if their view had been 
unobstructed. They were likewise free to inspect the yard from the vantage point of an aircraft flying in the navigable airspace as this plane was.

We arrive at the same conclusion in the present case.

Kyllo v. United States

This case presents the question whether the use of a thermal-imaging device aimed at a private home from a public street to detect relative amounts of heat within the home constitutes a "search" within the meaning of the Fourth Amendment.

In 1991 Agent William Elliott of the United States Department of the Interior came to suspect that marijuana was being grown in the home belonging to petitioner Danny Kyllo. Indoor marijuana growth typically requires high-intensity lamps. In order to determine whether an amount of heat was emanating from petitioner's home consistent with the use of such lamps, at 3:20 a.m. on January 16, 1992, Agent Elliott and Dan Haas used an Agema Thermovision 210 thermal imager to scan the triplex. Thermal imagers detect infrared radiation, which virtually all objects emit but which is not visible to the naked eye. The imager converts radiation into images based on relative warmth-black is cool, white is hot, shades of gray connote relative differences; in that respect, it operates somewhat like a video camera showing heat images. The scan of Kyllo's home took only a few minutes and was performed from the passenger seat of Agent Elliott's vehicle across the street from the front of the house and also from the street in back of the house. The scan showed that the roof over the garage and a side wall of petitioner's home were relatively hot compared to the rest of the home and substantially warmer than neighboring homes in the triplex. Agent Elliott concluded that petitioner was using halide lights to grow marijuana in his house, which indeed he was. Based on tips from informants, utility bills, and the thermal imaging, a Federal Magistrate Judge issued a warrant authorizing a search of petitioner's home, and the agents found an indoor growing operation involving more than 100 plants.

One might think that examining the portion of a house that is in plain public view, while it is a "search" despite the absence of trespass, is not an "unreasonable" one under the Fourth Amendment. But in fact we have held that visual observation is no "search" at all. In assessing when a search is not a search, we have applied somewhat in reverse the principle first enunciated in Katz v. United States. Katz involved eavesdropping by means of an electronic listening device placed on the outside of a telephone booth - a location not within the catalog ("persons, houses, papers, and effects") that the Fourth Amendment protects against unreasonable searches. We held that the Fourth Amendment nonetheless protected Katz from the warrant- 
less eavesdropping because he "justifiably relied" upon the privacy of the telephone booth. As Justice Harlan's oft-quoted concurrence described it, a Fourth Amendment search occurs when the government violates a subjective expectation of privacy that society recognizes as reasonable. We have applied the test on two different occasions in holding that aerial surveillance of private homes and surrounding areas does not constitute a search. Ciraolo; Florida v. Riley.

We think that obtaining by sense-enhancing technology any information regarding the interior of the home that could not otherwise have been obtained without physical intrusion into a constitutionally protected area, constitutes a search - at least where (as here) the technology in question is not in general public use. This assures preservation of that degree of privacy against government that existed when the Fourth Amendment was adopted. On the basis of this criterion, the information obtained by the thermal imager in this case was the product of a search.

The Government also contends that the thermal imaging was constitutional because it did not "detect private activities occurring in private areas," It points out that in Dow Chemical Co. v. United States we observed that the enhanced aerial photography did not reveal any "intimate details." Dow Chemical, however, involved enhanced aerial photography of an industrial complex, which does not share the Fourth Amendment sanctity of the home. The Fourth Amendment's protection of the home has never been tied to measurement of the quality or quantity of information obtained. In Silverman $v$. United States, for example, we made clear that any physical invasion of the structure of the home, "by even a fraction of an inch," was too much, and there is certainly no exception to the warrant requirement for the officer who barely cracks open the front door and sees nothing but the nonintimate rug on the vestibule floor. In the home, our cases show, all details are intimate details, because the entire area is held safe from prying government eyes.

Justice Stevens, dissenting:

There is, in my judgment, a distinction of constitutional magnitude between "through-the-wall surveillance" that gives the observer or listener direct access to information in a private area, on the one hand, and the thought processes used to draw inferences from information in the public domain, on the other hand. The Court has crafted a rule that purports to deal with direct observations of the inside of the home, but the case before us merely involves indirect deductions from "off-the-wall" surveillance, that is, observations of the exterior of the home. 


\section{H Government Secrets}

\section{Freedom of Information Act}

(a) Each agency shall make available to the public information as follows:

(3) (A) ... each agency, upon any request for records which (i) reasonably describes such records and (ii) is made in accordance with published rules stating the time, place, fees (if any), and procedures to be followed, shall make the records promptly available to any person.

(b) This section does not apply to matters that are -

(1) (A) specifically authorized under criteria established by an Executive order to be kept secret in the interest of national defense or foreign policy and (B) are in fact properly classified pursuant to such Executive order;

(2) related solely to the internal personnel rules and practices of an agency;

(3) specifically exempted from disclosure by statute ...

(4) trade secrets and commercial or financial information obtained from a person and privileged or confidential;

(5) inter-agency or intra-agency memorandums or letters which would not be available by law to a party other than an agency in litigation with the agency;

(6) personnel and medical files and similar files the disclosure of which would constitute a clearly unwarranted invasion of personal privacy;

(7) records or information compiled for law enforcement purposes, but only to the extent that the production of such law enforcement records or information (A) could reasonably be expected to interfere with enforcement proceedings, (B) would deprive a person of a right to a fair trial or an impartial adjudication, (C) could reasonably be expected to constitute an unwarranted invasion of personal privacy, (D) could reasonably be expected to disclose the identity of a confidential source ... (E) would disclose techniques and procedures for law enforcement investigations or prosecutions ... if such disclosure could reasonably be expected to risk circumvention of the law, or (F) could reasonably be expected to endanger the life or physical safety of any individual;
5 U.S.C. § 552

Public information; agency rules, opinions, orders, records, and proceedings 
492 U.S. 136 (1989)

Kissinger: 445 U.S. 136 (1980) Forsham: 445 US 169 (1980)
(8) contained in or related to examination, operating, or condition reports prepared by, on behalf of, or for the use of an agency responsible for the regulation or supervision of financial institutions; or

(9) geological and geophysical information and data, including maps, concerning wells.

\section{U.S. Dept. of Justice v. Tax Analysts}

The question presented is whether the Freedom of Information Act requires the United States Department of Justice (Department) to make available copies of district court decisions that it receives in the course of litigating tax cases on behalf of the Federal Government. We hold that it does.

We consider first whether the district court decisions at issue are "agency records," a term elaborated upon both in Kissinger $v$. Reporters Comm. for Freedom of Press and in Forsham v. Harris. Kissinger involved three separate FOIA requests for written summaries of telephone conversations in which Henry Kissinger had participated when he served as Assistant to the President for National Security Affairs from 1969 to 1975, and as Secretary of State from 1973 to 1977. At the time of this request, these summaries were stored in Kissinger's office at the State Department in his personal files. We first concluded that the summaries were not "agency records" at the time they were made because the FOIA does not include the Office of the President in its definition of "agency." We further held that these documents did not acquire the status of "agency records" when they were removed from the White House and transported to Kissinger's office at the State Department, a FOIA-covered agency.

Forsham, in turn, involved a request for raw data that formed the basis of a study conducted by a private medical research organization. Although the study had been funded through federal agency grants, the data never passed into the hands of the agencies that provided the funding, but instead was produced and possessed at all times by the private organization. We recognized that records of a nonagency certainly could become records of an agency as well, but the fact that the study was financially supported by a FOIA-covered agency did not transform the source material into "agency records." Nor did the agencies' right of access to the materials under federal regulations change this result. As we explained, "the FOIA applies to records which have been in fact obtained, and not to records which merely could have been obtained."

Two requirements emerge from Kissinger and Forsham, each of which must be satisfied for requested materials to qualify as "agency records." First, an agency must either create or obtain the requested 
materials. In performing their official duties, agencies routinely avail themselves of studies, trade journal reports, and other materials produced outside the agencies both by private and governmental organizations. To restrict the term "agency records" to materials generated internally would frustrate Congress' desire to put within public reach the information available to an agency in its decision-making processes.

Second, the agency must be in control of the requested materials at the time the FOIA request is made. By control we mean that the materials have come into the agency's possession in the legitimate conduct of its official duties. This requirement accords with Kissinger's teaching that the term "agency records" is not so broad as to include personal materials in an employee's possession, even though the materials may be physically located at the agency.

Applying these requirements here, we conclude that the requested district court decisions constitute "agency records." First, it is undisputed that the Department has obtained these documents from the district courts. Second, the Department clearly controls the district court decisions that Tax Analysts seeks.

\section{Chrysler Corp. v. Brown}

The expanding range of federal regulatory activity and growth in the Government sector of the economy have increased federal agencies' demands for information about the activities of private individuals and corporations. These developments have paralleled a related concern about secrecy in Government and abuse of power. The Freedom of Information Act (hereinafter FOIA) was a response to this concern, but it has also had a largely unforeseen tendency to exacerbate the uneasiness of those who comply with governmental demands for information. For under the FOIA third parties have been able to obtain Government files containing information submitted by corporations and individuals who thought that the information would be held in confidence.

This case belongs to a class that has been popularly denominated "reverse-FOIA" suits. Chrysle seeks to enjoin agency disclosure on the grounds that it is inconsistent with the FOIA and 18 U.S.C. § 1905, a criminal statute with origins in the 19th century that proscribes disclosure of certain classes of business and personal information. We agree with the Court of Appeals for the Third Circuit that the FOIA is purely a disclosure statute and affords Chrysler no private right of action to enjoin agency disclosure. But we cannot agree with that court's conclusion that this disclosure is "authorized by law" within the meaning of $\S 1905$.

As a party to numerous Government contracts, Chrysler is required to comply with Executive Orders 11246 and 11375, which 
charge the Secretary of Labor with ensuring that corporations that benefit from Government contracts provide equal employment opportunity regardless of race or sex. The United States Department of Labor's Office of Federal Contract Compliance Programs (OFCCP) has promulgated regulations which require Government contractors to furnish reports and other information about their affirmativeaction programs and the general composition of their work forces. OFCCP regulations require that Chrysler make available to this agency written affirmative-action programs (AAP's) and annually submit Employer Information Reports, known as EEO-1 Reports.

Regulations promulgated by the Secretary of Labor provide for public disclosure of information from records of the OFCCP and its compliance agencies. It is the voluntary disclosure contemplated by this regulation, over and above that mandated by the FOIA, which is the gravamen of Chrysler's complaint in this case.

This controversy began on May 14, 1975, when the [government] informed Chrysler that third parties had made an FOIA request for disclosure of the 1974 AAP for Chrysler's Newark, Del., assembly plant.

Although we have not had to face squarely the question whether the FOIA textitex proprio vigore forbids governmental agencies from disclosing certain classes of information to the public, we have consistently recognized that the basic objective of the Act is disclosure.

Chrysler contends that the nine exemptions in general, and Exemption 4 in particular, reflect a sensitivity to the privacy interests of private individuals and nongovernmental entities. That contention may be conceded without inexorably requiring the conclusion that the exemptions impose affirmative duties on an agency to withhold information sought. In fact, that conclusion is not supported by the language, logic, or history of the Act.

Enlarged access to governmental information undoubtedly cuts against the privacy concerns of nongovernmental entities, and as a matter of policy some balancing and accommodation may well be desirable. We simply hold here that Congress did not design the FOIA exemptions to be mandatory bars to disclosure.

Chrysler contends, however, that even if its suit for injunctive relief cannot be based on the FOIA, such an action can be premised on the Trade Secrets Act. The Act provides:

Whoever, being an officer or employee of the United States or of any department or agency thereof, publishes, divulges, discloses, or makes known in any manner or to any extent not authorized by law any information coming to him in the course of his employment or official duties or by reason of any examination or investigation made by, 
or return, report or record made to or filed with, such department or agency or officer or employee thereof which information concerns or relates to the trade secrets, processes, operations, style of work, or apparatus, or to the identity, confidential statistical data, amount or source of any income, profits, losses, or expenditures of any person, firm, partnership, corporation, or association; or permits any income return or copy thereof or any book containing any abstract or particulars thereof to be seen or examined by any person except as provided by law; shall be fined not more than $\$ 1,000$, or imprisoned not more than one year, or both; and shall be removed from office or employment.

The Court of Appeals held that the Trade Secrets Act was not applicable to the agency disclosure at issue here because such disclosure was "authorized by law" within the meaning of the Act. The court found the source of that authorization to be the OFCCP regulations that DLA relied on in deciding to disclose information on the Hamtramck and Newark plants. [The Court disagreed.]

We reject, however, Chrysler's contention that the Trade Secrets Act affords a private right of action to enjoin disclosure in violation of the statute. Most importantly, a private right of action is not necessary to make effective the congressional purpose, for we find that review of DLA's decision to disclose Chrysler's employment data is available under the Administrative Procedures Act.

Section 10(a) of the APA provides that "a person suffering legal wrong because of agency action, or adversely affected or aggrieved by agency action, is entitled to judicial review thereof." We conclude that DLA's decision to disclose the Chrysler reports is reviewable agency action and Chrysler is a person "adversely affected or aggrieved" within the meaning of $\S 10(a)$.

\section{Coastal States Gas Corp. v. Department of Energy}

This case raises issues concerning the scope of Exemptions 5 and 7 to the general disclosure requirements of the Freedom of Information Act. In 1975 and 1976, plaintiff Coastal States Gas Corporation (Coastal States) filed Freedom of Information requests with the defendant, seeking copies of agency interpretations of its regulations which had not been made public. The issue in this appeal is focused on memoranda from regional counsel to auditors working in DOE's field offices, issued in response to requests for interpretations of regulations within the context of particular facts encountered while conducting an audit of a firm. The plaintiff contends that these memoranda constituted a body of "secret law" which the agency was using

5 U.S.C. § 702. 
in its dealings with the public and which must be disclosed, while DOE responds that the documents were properly withheld under Exemption 5, as documents which would not be subject to disclosure during discovery, and in a few cases, under Exemption 7 as documents within an investigatory file.

After the 1973 oil embargo, a compliance program was established to assure the observance of petroleum pricing and allocation regulations. Ten regional offices were established within which regional counsel were located. Each regional office also employed auditors and other investigative personnel, whose job was auditing individual firms to assure compliance with the regulations. These audits were not "investigations;" at that point, no charge had been made nor was a violation necessarily suspected.

While the regional counsel has many responsibilities, the particular task relevant to this case is that of providing interpretations of the pertinent regulations to the auditors at this early stage of compliance review. If the auditors should encounter a problem of regulatory interpretation, a request for advice would be sent to the regional counsel, couched in a specific factual context, either real or hypothetical. The response would be a legal memorandum, interpreting any applicable regulations in light of those facts, and often pointing out additional factors which might make a difference in the application of the regulation.

The agency points out that these were not "formal" interpretations of the regulations, emphasizing that there is a published procedure for issuing such interpretations. Also, the agency insists that the interpretations were not "binding" on the audit staff; it contends that the agency staff "is free to reject the memorandum." The district court found, however, that in fact the advice was regularly and consistently followed by the non-legal staff, a conclusion which we find to be fully supported by the evidence. There is evidence in the record that agency staff failed to follow a regional counsel opinion only if it could be distinguished on the facts, or if the matter were referred to a higher authority within the agency. Furthermore, in some of the offices the documents were indexed by subject matter and used as precedent in later cases; they were circulated among the area offices and supplied to new personnel; they were at times "amended" or "rescinded," which would hardly be necessary if the documents contained merely informal suggestions to staff which could be disregarded; and on at least one occasion a regional counsel memorandum involving the audit of a different firm was cited to a member of the public as binding precedent.

The language of Exemption 5 is cast in terms of discovery law; the agencies need turn over no documents "which would not be available by law to a private party in litigation with the agency." This discovery 
standard can only serve as a rough guide to the courts, since decisions as to discovery are usually based on a balancing of the relative need of the parties, and standards vary according to the kind of litigation involved. It is clear, however, that Congress intended that agencies should not lose the protection traditionally afforded through the evidentiary privileges simply because of the passage of the FOIA. The courts have recognized that Exemption 5 protects, as a general rule, materials which would be protected under the attorney-client privilege, the attorney work-product privilege, or the executive "deliberative process" privilege.

We have difficulty in perceiving any purpose which would be served by applying the attorney-client privilege in this case. While it is clear that an agency can be a "client" and agency lawyers can function as "attorneys" within the relationship contemplated by the privilege, this does not seem to be such a case. It is hard to imagine the "confidential information" which an auditor might have communicated to the regional counsel. The factual situations the auditor communicates to the attorneys are encountered in the course of auditing third parties, the companies. They do not contain private information concerning the agency. Rather than "counseling," intended to assist the agency in protecting its interests, the memoranda here seem to be neutral, objective analyses of agency regulations. They resemble, in fact, question and answer guidelines which might be found in an agency manual. In sharp contrast are the documents and memoranda in issue in Mead Data Cent., Inc. v. US Dept. of Air Force, in which disclosure was sought of material generated in the course of negotiating a contract between the Air Force and a private company. In such a case, the Government is dealing with its attorneys as would any private party seeking advice to protect personal interests, and needs the same assurance of confidentiality so it will not be deterred from full and frank communications with its counselors. This case bears little resemblance to that situation.

Assuming, however, that the purposes of the attorney-client privilege might be served by extending its protection to the situation here, we agree with the district court that DOE has failed to demonstrate a fundamental prerequisite to assertion of the privilege: confidentiality both at the time of the communication and maintained since. The agency has admitted that it does not know who has had access to the documents, and there is undisputed testimony that at least in some regions, copies of the memoranda were circulated to all area offices, filed and indexed for future use, relied on as precedent and used as training materials for new personnel.

Another traditional area of privilege which has been recognized under Exemption 5 is attorney work-product. This doctrine stands in contrast to the attorney-client privilege; rather than protecting confi- 
dential communications from the client, it provides a working attorney with a "zone of privacy" within which to think, plan, weigh facts and evidence, candidly evaluate a client's case, and prepare legal theories. There is one significant limitation of the doctrine, however, which defeats the agency's claim of privilege here; it has uniformly been held to be limited to documents prepared in contemplation of litigation. o the extent the Government provided some indication in its index that a specific claim had taken shape in the course of an audit, so that the attorney's work could fairly, if generously, be characterized as "in contemplation of litigation," the district court permitted these documents to be withheld. Beyond that, the DOE has failed to carry its burden of establishing that litigation was fairly foreseeable at the time the memoranda were prepared, and thus is not entitled to invoke the exception.

A privilege unique to the government is one which is variously described as predecisional or deliberative process privilege. The privilege has a number of purposes: it serves to assure that subordinates within an agency will feel free to provide the decisionmaker with their uninhibited opinions and recommendations without fear of later being subject to public ridicule or criticism; to protect against premature disclosure of proposed policies before they have been finally formulated or adopted; and to protect against confusing the issues and misleading the public by dissemination of documents suggesting reasons and rationales for a course of action which were not in fact the ultimate reasons for the agency's action.

In deciding whether a document should be protected by the privilege we look to whether the document is "predecisional" -whether it was generated before the adoption of an agency policy - and whether the document is "deliberative" - whether it reflects the give-and-take of the consultative process. The exemption thus covers recommendations, draft documents, proposals, suggestions, and other subjective documents which reflect the personal opinions of the writer rather than the policy of the agency. Documents which are protected by the privilege are those which would inaccurately reflect or prematurely disclose the views of the agency, suggesting as agency position that which is as yet only a personal position. To test whether disclosure of a document is likely to adversely affect the purposes of the privilege, courts ask themselves whether the document is so candid or personal in nature that public disclosure is likely in the future to stifle honest and frank communication within the agency. Human experience teaches that those who expect public dissemination of their remarks may well temper candor with a concern for appearances and for their own interests to the detriment of the decisionmaking process. We also ask whether the document is recommendatory in nature or is a draft of what will become a final document, and whether the docu- 
ment is deliberative in nature, weighing the pros and cons of agency adoption of one viewpoint or another. Finally, even if the document is predecisional at the time it is prepared, it can lose that status if it is adopted, formally or informally, as the agency position on an issue or is used by the agency in its dealings with the public.

It is readily apparent that the memoranda in issue bear little resemblance to the types of documents intended to be protected under the deliberative process privilege. The documents were not suggestions or recommendations as to what agency policy should be. Unlike the documents in EPA v. Mink and Murphy v. Dep't of the ArmyMurphymurphy613 F.2d 1151 (1979), the memoranda are not advice to a superior, nor are they suggested dispositions of a case, as in Renegotiation Bd. v. Grumman Aircraft Engineering Corp.. They are not one step of an established adjudicatory process, which would result in a formal opinion, as were the documents held exempt in NLRB $v$. Sears, Roebuck $\mathcal{E}$ Co. There is nothing subjective or personal about the memoranda; they are simply straightforward explanations of agency regulations in specific factual situations. They are more akin to a "resource" opinion about the applicability of existing policy to a certain state of facts, like examples in a manual, to be contrasted to a factual or strategic advice giving opinion. Nor do they reflect agency giveand-take - of the deliberative process - by which the decision itself is made. Characterizing these documents as "predecisional" simply because they play into an ongoing audit process would be a serious warping of the meaning of the word. No "decision" is being made or "policy" being considered; rather the documents discuss established policies and decisions - the agency regulations - in the light of a specific, and often hypothetical, fact pattern.

Exemption 7 affords protection to investigatory files to prevent harm to the government's case in court. In 1974, the scope of the privilege was sharply narrowed when Congress, dissatisfied with the broad scope given to Exemption 7 by the courts, amended the exemption to make it clear that the Government must establish not only that the document was prepared in the course of an "investigation," but that disclosure of the document would "interfere with enforcement proceedings." The Government asserts this privilege as to fifty-three documents.

We need not decide whether any of these memoranda are of a sort which would be protected if the Government had demonstrated - or even conclusorily asserted - that there are presently active investigations underway or contemplated in each of these fifty-three cases. . There is no reason to protect yellowing documents contained in longclosed files. DOE made no effort whatsoever in the district court to demonstrate that any of these cases are still under investigation or being actively pursued. The district court was correct in concluding 
(2013)

Exec. Order No. 13526, 3 C.F.R. 298 (2009). that DOE had failed generally to meet its burden of establishing the prerequisites to invocation of Exemption 7.

\section{Congressional Research Service}

The Protection of Classified Information: The Legal Framework

Congress has directed the President to establish procedures governing the access to classified material so that no person can gain such access without having undergone a background check. With the authority to determine classification standards vested in the President, these standards tend to change whenever a new administration takes control of the White House.

The present standards for classifying and declassifying information were last amended on December 29, 2009. Under these standards, the President, Vice President, agency heads, and any other officials designated by the President may classify information upon a determination that the unauthorized disclosure of such information could reasonably be expected to damage national security. Such information must be owned by, produced by, or under the control of the federal government, and must concern one of the following:

- military plans, weapons systems, or operations;

- foreign government information;

- intelligence activities, intelligence sources/methods, cryptology;

- foreign relations or foreign activities of the United States, including confidential sources;

- scientific, technological, or economic matters relating to national security;

- federal programs for safeguarding nuclear materials or facilities;

- vulnerabilities or capabilities of national security systems; or

- weapons of mass destruction.

Information may be classified at one of three levels based on the amount of danger that its unauthorized disclosure could reasonably be expected to cause to national security. Information is classified as "Top Secret" if its unauthorized disclosure could reasonably be expected to cause "exceptionally grave damage" to national security. The standard for "Secret" information is "serious damage" to national security, while for "confidential" information the standard is "damage" to national security. Significantly, for each level, the original classifying officer must identify or describe the specific danger potentially presented by the information's disclosure. In case of significant doubt as to the need to classify information or the level of classification appropriate, the information is to remain unclassified 
or be classified at the lowest level of protection considered appropriate.

The officer who originally classifies the information establishes a date for declassification based upon the expected duration of the information's sensitivity. If the office cannot set an earlier declassification date, then the information must be marked for declassification in 10 years' time or 25 years, depending on the sensitivity of the information. The deadline for declassification can be extended if the threat to national security still exists.

Classified information is required to be declassified "as soon as it no longer meets the standards for classification." The original classifying agency has the authority to declassify information when the public interest in disclosure outweighs the need to protect that information. On December 31, 2006, and every year thereafter, all information that has been classified for 25 years or longer and has been determined to have "permanent historical value" under Title 44 of the U.S. Code will be automatically declassified, although agency heads can exempt from this requirement classified information that continues to be sensitive in a variety of specific areas.

Access to classified information is generally limited to those who demonstrate their eligibility to the relevant agency head, sign a nondisclosure agreement, and have a need to know the information. The need-to-know requirement can be waived, however, for former Presidents and Vice Presidents, historical researchers, and former policy-making officials who were appointed by the President or Vice President. The information being accessed may not be removed from the controlling agency's premises without permission. Each agency is required to establish systems for controlling the distribution of classified information.

Under E.O. 13526, each respective agency is responsible for maintaining control over classified information it originates and is responsible for establishing uniform procedures to protect classified information and automated information systems in which classified information is stored or transmitted. Agencies that receive information classified elsewhere are not permitted to transfer the information further without approval from the classifying agency. Persons authorized to disseminate classified information outside the executive branch are required to ensure it receives protection equivalent to those required internally.

Generally, federal law prescribes a prison sentence of no more than a year and/or a $\$ 1,000$ fine for officers and employees of the federal government who knowingly remove classified material without the authority to do so and with the intention of keeping that material at an unauthorized location. Stiffer penalties - fines of up to $\$ 10,000$ and imprisonment for up to 10 years - attach when a federal em- 
ployee transmits classified information to anyone that the employee has reason to believe is an agent of a foreign government. A fine and a 10-year prison term also await anyone, government employee or not, who publishes, makes available to an unauthorized person, or otherwise uses to the United States' detriment classified information regarding the codes, cryptography, and communications intelligence utilized by the United States or a foreign government. Finally, the disclosure of classified information that discloses any information identifying a covert agent, when done intentionally by a person with authorized access to such identifying information, is punishable by imprisonment for up to 15 years. A similar disclosure by one who learns the identity of a covert agent as a result of having authorized access to classified information is punishable by not more than 10 years' imprisonment. Under the same provision, a person who undertakes a "pattern of activities intended to identify and expose covert agents" with reason to believe such activities would impair U.S. foreign intelligence activities, and who then discloses the identities uncovered as a result is subject to three years' imprisonment, whether or not violator has access to classified information.

In addition to the criminal penalties outlined above, the executive branch employs numerous means of deterring unauthorized disclosures by government personnel using administrative measures based on terms of employment contracts. The agency may impose disciplinary action or revoke a person's security clearance. The revocation of a security clearance is usually not reviewable by the Merit System Protection Board and may mean the loss of government employment. Government employees may be subject to monetary penalties for disclosing classified information. Violators of the Espionage Act and the Atomic Energy Act provisions may be subject to loss of their retirement pay.

Agencies also rely on contractual agreements with employees, who typically must sign non-disclosure agreements prior to obtaining access to classified information, sometimes agreeing to submit all materials that the employee desires to publish to a review by the agency. The Supreme Court enforced such a contract against a former employee of the Central Intelligence Agency (CIA), upholding the government's imposition of a constructive trust on the profits of a book the employee sought to publish without first submitting it to Snepp v. United States, 444 U.S. 507 (1980)

\section{CIA for review.}

Under some circumstances, the government can also use injunctions to prevent disclosures of information. The courts have generally upheld injunctions against former employees' publishing information they learned through access to classified information. The Supreme Court also upheld the State Department's revocation of passports for overseas travel by persons planning to expose U.S. 
covert intelligence agents, despite the fact that the purpose was to disrupt U.S. intelligence activities rather than to assist a foreign government.

As noted above, E.O. 13526 sets the official procedures for the declassification of information. Once information is declassified, it may be released to persons without a security clearance. Leaks, by contrast, might be defined as the release of classified information to persons without a security clearance, typically journalists. Recent highprofile leaks of information regarding sensitive covert operations in news stories that seemed to some to portray the Obama Administration in a favorable light raised questions regarding the practice of "instant declassification," or whether disclosure of classified information to journalists may ever be said to be an "authorized disclosure" by a senior official.

The processes for declassification set forth in E.O. 13526 seem to presuppose that agencies and classifying officials will not have any need or desire to disclose classified information in their possession other than to comply with the regulations. Yet it has long been noted that there seems to be an informal process for "instant declassification" of information whose release to the public serves an immediate need.

As a practical matter, there is little to stop agency heads and other high-ranking officials from releasing classified information to persons without a security clearance when it is seen as suiting government needs. The Attorney General has prosecutorial discretion to choose which leaks to prosecute. If in fact a case can be made that a senior official has made or authorized the disclosure of classified information, successful prosecution under current laws may be impossible because the scienter requirement (i.e., guilty state of mind) is not likely to be met.

Executive branch policy appears to treat an official disclosure as a declassifying event, while non- attributed disclosures have no effect on the classification status of the information. For example, the Department of Defense instructs agency officials, in the event that classified information appears in the media, to neither confirm nor deny the accuracy of the information.

\section{Phillippi v. Central Intelligence Agency}

This is an action under the Freedom of Information Act, in which plaintiff-appellant seeks to compel the Central Intelligence Agency to disclose certain records alleged to be in its possession concerning its relationship with the Hughes Glomar Explorer.

In March 1975 several news organizations published stories purporting to describe a secret operation conducted by the United States. The central figure in these stories was the Hughes Glomar Explorer., a 
large vessel publicly listed as a research ship owned and operated by the Summa Corporation. According to the stories, the ship's actual owner and operator was the Government of the United States.

Following publication of these stories, other stories described the alleged efforts of the CIA to convince the news media not to make public what they had learned about the Glomar Explorer. The latter stories interested appellant, a journalist, and she filed a FOIA request for all Agency records relating to the reported contacts with the media. That request was denied on two grounds. First, the Agency claimed that "any records that might exist which reveal any CIA connection with or interest in the activities of the Glomar Explorer; and, indeed, any data that might reveal the existence of any such records" would be classified and therefore exempt from disclosure. Second, the Agency stated that

the fact of the existence or non-existence of the records you request would relate to information pertaining to intelligence sources and methods which the Director of Central Intelligence has the responsibility to protect from unauthorized disclosure in accordance with the National Security Act of 1947.

We are dealing with a case in which the Agency has refused to confirm or deny the existence of materials requested under the FOIA. In effect, the situation is as if appellant had requested and been refused permission to see a document which says either "Yes, we have records related to contacts with the media concerning the Glomar Explorer" or "No, we do not have any such records." On appeal appellant does not assert that the Government may never claim that national security considerations require it to refuse to disclose whether or not requested documents exist. Rather, her principal argument, and the only question we decide, is that the Agency should have been required to support its position on the basis of the public record.

It is clear that the FOIA contemplates that the courts will resolve fundamental issues in contested cases on the basis of in camera examinations of the relevant documents. Appellant maintains that this authority does not extend to in camera examination of affidavits, the procedure used below. In the peculiar context of this case we must reject this contention. When the Agency's position is that it can neither confirm nor deny the existence of the requested records, there are no relevant documents for the court to examine other than the affidavits which explain the Agency's refusal. Therefore, to fulfill its congressionally imposed obligation to make a de novo determination of the propriety of a refusal to provide information in response to a FOIA request the District Court may have to examine classified affidavits in camera and without participation by plaintiff's counsel. 
Before adopting such a procedure, however, the District Court should attempt to create as complete a public record as is possible. Adapting these procedures to the present case would require the Agency to provide a public affidavit explaining in as much detail as is possible the basis for its claim that it can be required neither to confirm nor to deny the existence of the requested records.[7] The Agency's arguments should then be subject to testing by appellant, who should be allowed to seek appropriate discovery when necessary to clarify the Agency's position or to identify the procedures by which that position was established. Only after the issues have been identified by this process should the District Court, if necessary, consider arguments or information which the Agency is unable to make public. 


\section{Patent}

\section{United States Constitution}

The Congress shall have Power ... To promote the Progress of Science and useful Arts, by securing for limited Times to Authors and Inventors the exclusive Right to their respective Writings and Discoveries.

Patent law provides exclusive rights over new and useful inventions. Although it structure has shifted over time, the modern synthesis of patent law (appropriately enough) is an intricately interlocking doctrinal machine. The mainspring of this system is the claim: a precise statement of the technologies over which the inventor asserts rights. The point of of patent prosecution is to generate appropriately clear claim language that covers (or "reads on") what the inventor actually invented; patent infringement is directed to comparing claims with the defendant's product or process. As we will see, patent law uses a handful of basic concepts - e.g., "prior art reference," "the person of ordinary skill in the art," and "equivalent" - but it uses them again and again. The key to understanding patent law is to pay attention to these recurring concepts.

Why patent law? Three stories are usually advanced, two of which should already be familiar. It is said that patent law serves an innovation function by giving incentives that enable investors to recoup their investment and a contracting function by enabling them to commercialize their inventions without fear of being ripped off by business partners or imitated by competitors. But patent law also is designed to serve a disclosure function: it requires inventors to make public significant information about how their inventions work, and multiple doctrines subtly push actors toward greater disclosure. art. I, § 8, cl. 8

Looking at these cases is much like looking at a wonderful machine. But, of course, when looking at a beautiful piece of machinery that functions like a clock or like clockwork, the next question might be whether this wonderful precision instrument bears any relation to reality.

-Dan L. Burk, Biotechnology in the Federal Circuit: A Clockwork Lemon", 46 Ariz. L. Rev. 441 (2004)

The name of the game is the claim. -Giles S. Rich

No economist, on the basis of present knowledge, could possibly state with certainty that the patent system, as it now operates, confers a net benefit or a net loss upon society. If we did not have a patent system, it would be irresponsible, on the basis of our present knowledge of its economic consequences, to recommend instituting one. But since we have had a patent system for a long time, it would be irresponsible, on the basis of our current knowledge, to recommend abolishing it.

—Fritz Machlup

The leading patent treatises are Donald S. Chisum, Chisum on Patents (Matthew Bender, on Lexis), R. Carl Moy, Moy's Walker on Patents (Thomson Reuters, on Westlaw), and Robert C. Faber, Faber on Mechanics of Patent Claim Drafting (PLI, on Bloomberg Law). 


\section{A Subject Matter}

\section{Patent Act}

35 U.S.C. § 101

Inventions patentable

185 F.3d 1364 (Fed. Cir. 1999)
Whoever invents or discovers any new and useful process, machine, manufacture, or composition of matter, or any new and useful improvement thereof, may obtain a patent therefor, subject to the conditions and requirements of this title.

As interpreted by the courts, this section imposes two conditions on patentability: utility and statutory subject matter. It is conventional to begin with statutory subject matter. We begin with utility.

\section{Utility}

Utility was at one time a subject matter exclusion from patentability. No longer. But it still does some important work as a threshold condition, which can significantly affect the timing of patentability.

Juicy Whip, Inc. v. Orange Bang, Inc.

\section{I}

Juicy Whip, Inc., is the assignee of United States Patent No. 5,575,405, which is entitled "Post-Mix Beverage Dispenser With an Associated Simulated Display of Beverage." A "post-mix" beverage dispenser stores beverage syrup concentrate and water in separate locations until the beverage is ready to be dispensed. The syrup and water are mixed together immediately before the beverage is dispensed, which is usually after the consumer requests the beverage. In contrast, in a "pre-mix" beverage dispenser, the syrup concentrate and water are pre-mixed and the beverage is stored in a display reservoir bowl until it is ready to be dispensed. The display bowl is said to stimulate impulse buying by providing the consumer with a visual beverage display. A pre-mix display bowl, however, has a limited capacity and is subject to contamination by bacteria. It therefore must be refilled and cleaned frequently.

The invention claimed in the ' 405 patent is a post-mix beverage dispenser that is designed to look like a pre-mix beverage dispenser. The claims require the post-mix dispenser to have a transparent bowl that is filled with a fluid that simulates the appearance of the dispensed beverage and is resistant to bacterial growth. The claims also require that the dispenser create the visual impression that the bowl is the principal source of the dispensed beverage, although in fact the 
beverage is mixed immediately before it is dispensed, as in conventional post-mix dispensers.

The District Court concluded that the invention lacked utility because its purpose was to increase sales by deception, i.e., through imitation of another product. The court explained that the purpose of the invention "is to create an illusion, whereby customers believe that the fluid contained in the bowl is the actual beverage that they are receiving, when of course it is not." Although the court acknowledged Juicy Whip's argument that the invention provides an accurate representation of the dispensed beverage for the consumer's benefit while eliminating the need for retailers to clean their display bowls, the court concluded that those claimed reasons for the patent's utility "are not independent of its deceptive purpose, and are thus insufficient to raise a disputed factual issue to present to a jury."

\section{II}

The threshold of utility is not high: An invention is "useful" under section 101 if it is capable of providing some identifiable benefit.

To be sure, since Justice Story's opinion in Lowell v. Lewis, it has been stated that inventions that are "injurious to the well-being, good policy, or sound morals of society" are unpatentable. As examples of such inventions, Justice Story listed "a new invention to poison people, or to promote debauchery, or to facilitate private assassination." Courts have continued to recite Justice Story's formulation, but the principle that inventions are invalid if they are principally designed to serve immoral or illegal purposes has not been applied broadly in recent years. For example, years ago courts invalidated patents on gambling devices on the ground that they were immoral, but that is no longer the law.

In holding the patent in this case invalid for lack of utility, the district court relied on two Second Circuit cases dating from the early years of this century, Rickard v. Du Bon, and Scott \& Williams v. Aristo Hosiery Co.. In the Rickard case, the court held invalid a patent on a process for treating tobacco plants to make their leaves appear spotted. At the time of the invention, according to the court, cigar smokers considered cigars with spotted wrappers to be of superior quality, and the invention was designed to make unspotted tobacco leaves appear to be of the spotted - and thus more desirable - type. The court noted that the invention did not promote the burning quality of the leaf or improve its quality in any way; "the only effect, if not the only object, of such treatment, is to spot the tobacco, and counterfeit the leaf spotted by natural causes."

The Aristo Hosiery case concerned a patent claiming a seamless stocking with a structure on the back of the stocking that imitated a seamed stocking. The imitation was commercially useful because at
Lowell: 15 F. Cas. 1018 (C.C.D. Mass. 1817)

Rickard: 103 F. 868 (2d Cir. 1900)

Aristo Hosiery: 7 F.2d 1003 (2d Cir. 1925) 


\section{U.S. Patent $\quad$ Nov. 19, $1996 \quad$ Sheet 1 of $3 \quad 5,575,405$}

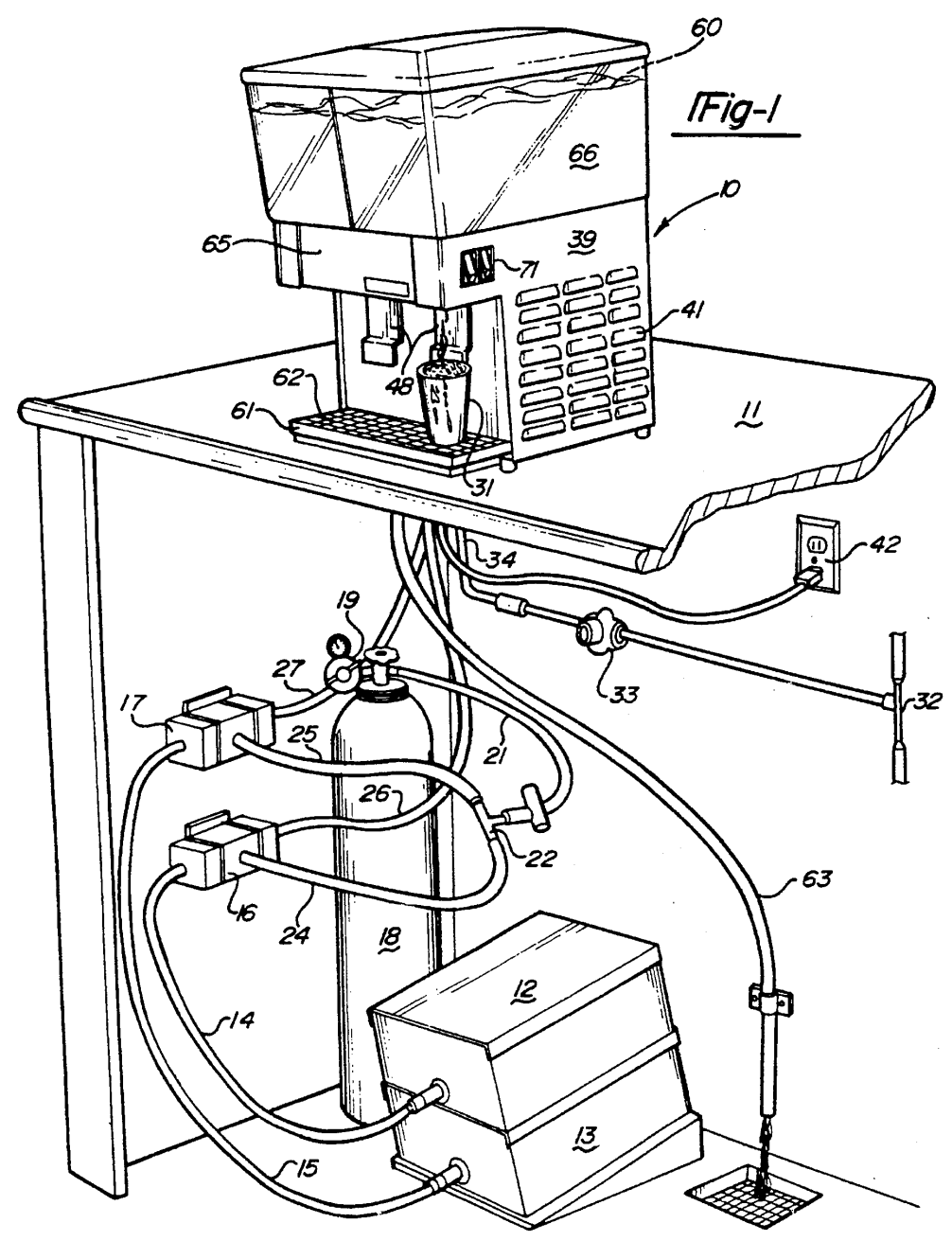

U.S. Patent No. 5,575,405, Post-Mix Beverage Dispenser With an Associated Simulated Display of Beverage. 
the time of the invention many consumers regarded seams in stockings as an indication of higher quality. The court noted that the imitation seam did not "change or improve the structure or the utility of the article," and that the record in the case justified the conclusion that true seamed stockings were superior to the seamless stockings that were the subject of the patent. "At best," the court stated, "the seamless stocking has imitation marks for the purposes of deception, and the idea prevails that with such imitation the article is more salable." That was not enough, the court concluded, to render the invention patentable.

We decline to follow Rickard and Aristo Hosiery, as we do not regard them as representing the correct view of the doctrine of utility under the Patent Act of 1952. The fact that one product can be altered to make it look like another is in itself a specific benefit sufficient to satisfy the statutory requirement of utility.

It is not at all unusual for a product to be designed to appear to viewers to be something it is not. For example, cubic zirconium is designed to simulate a diamond, imitation gold leaf is designed to imitate real gold leaf, synthetic fabrics are designed to simulate expensive natural fabrics, and imitation leather is designed to look like real leather. In each case, the invention of the product or process that makes such imitation possible has "utility" within the meaning of the patent statute, and indeed there are numerous patents directed toward making one product imitate another. See, e.g., U.S. Pat. No. $5,762,968$ (method for producing imitation grill marks on food without using heat); U.S. Pat. No. 5,899,038 (laminated flooring imitating wood); U.S. Pat. No. 5,571,545 (imitation hamburger). Much of the value of such products resides in the fact that they appear to be something they are not. Thus, in this case the claimed post-mix dispenser meets the statutory requirement of utility by embodying the features of a post-mix dispenser while imitating the visual appearance of a pre-mix dispenser.

The fact that customers may believe they are receiving fluid directly from the display tank does not deprive the invention of utility. Orange Bang has not argued that it is unlawful to display a representation of the beverage in the manner that fluid is displayed in the reservoir of the invention, even though the fluid is not what the customer will actually receive. Moreover, even if the use of a reservoir containing fluid that is not dispensed is considered deceptive, that is not by itself sufficient to render the invention unpatentable. The requirement of "utility" in patent law is not a directive to the Patent and Trademark Office or the courts to serve as arbiters of deceptive trade practices. Other agencies, such as the Federal Trade Commission and the Food and Drug Administration, are assigned the task of protecting consumers from fraud and deception in the sale of food prod- 
Watson: 517 F.2d 465 (C.C.P.A. 1975)

Webber: 103 U.S. (13 Otto) 344 (1880)

"The patent for a dynamite powder does not prevent the State from prescribing the conditions of its manufacture, storage, and sale, so as to protect the community from the danger of explosion. A patent for the manufacture and sale of a deadly poison does not lessen the right of the State to control its handling and use."

--Webber

$\S 2107$

Guidelines for Examination of Applications for Compliance with the Utility Requirement

$\S 2107.01$

General Principles Governing Utility Rejections ucts. Cf. In re Watson (stating that it is not the province of the Patent Office to determine, under section 101, whether drugs are safe). As the Supreme Court put the point more generally, "Congress never intended that the patent laws should displace the police powers of the States, meaning by that term those powers by which the health, good order, peace and general welfare of the community are promoted." Webber v. Virginia.

Of course, Congress is free to declare particular types of inventions unpatentable for a variety of reasons, including deceptiveness. Cf. 42 U.S.C. $§ 2181$ (a) (exempting from patent protection inventions useful solely in connection with special nuclear material or atomic weapons). Until such time as Congress does so, however, we find no basis in section 101 to hold that inventions can be ruled unpatentable for lack of utility simply because they have the capacity to fool some members of the public. The district court therefore erred in holding that the invention of the ' 405 patent lacks utility because it deceives the public through imitation in a manner that is designed to increase product sales.

\section{Manual of Patent Examination Procedure (Rev. Nov. 2013)}

A claimed invention must have a specific and substantial utility. This requirement excludes "throw-away," "insubstantial," or "nonspe-

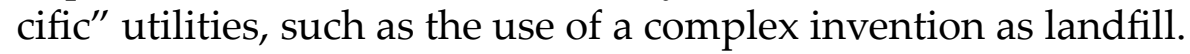

Credibility is assessed from the perspective of one of ordinary skill in the art in view of the disclosure and any other evidence of record (e.g., test data, affidavits or declarations from experts in the art, patents or printed publications) that is probative of the applicant's assertions. An applicant need only provide one credible assertion of specific and substantial utility for each claimed invention to satisfy the utility requirement.

\section{Specific and Substantial Requirements}

Courts have recognized that the term "useful" used with reference to the utility requirement can be a difficult term to define. Where an applicant has set forth a specific and substantial utility, courts have been reluctant to uphold a rejection under 35 U.S.C. $\$ 101$ solely on the basis that the applicant's opinion as to the nature of the specific and substantial utility was inaccurate.

Practical considerations require the Office to rely on the inventor's understanding of his or her invention in determining whether and in what regard an invention is believed to be "useful." Because of this, Office personnel should focus on and be receptive to assertions made by the applicant that an invention is "useful" for a particular reason. 


\section{A. Specific Utility}

A "specific utility" is specific to the subject matter claimed and can "provide a well-defined and particular benefit to the public." In re Fisher. This contrasts with a general utility that would be applicable to the broad class of the invention. Office personnel should distinguish between situations where an applicant has disclosed a specific use for or application of the invention and situations where the applicant merely indicates that the invention may prove useful without identifying with specificity why it is considered useful. For example, indicating that a compound may be useful in treating unspecified disorders, or that the compound has "useful biological" properties, would not be sufficient to define a specific utility for the compound. Similarly, a claim to a polynucleotide whose use is disclosed simply as a "gene probe" or "chromosome marker" would not be considered to be specific in the absence of a disclosure of a specific DNA target. See Fisher ("Any EST [expressed sequence tag] transcribed from any gene in the maize genome has the potential to perform any one of the alleged uses. Nothing about applicant's seven alleged uses set the five claimed ESTs apart from the more than 32,000 ESTs disclosed in the application or indeed from any EST derived from any organism. Accordingly, we conclude that applicant has only disclosed general uses for its claimed ESTs, not specific ones that satisfy § 101."). A general statement of diagnostic utility, such as diagnosing an unspecified disease, would ordinarily be insufficient absent a disclosure of what condition can be diagnosed. Contrast the situation where an applicant discloses a specific biological activity and reasonably correlates that activity to a disease condition. Assertions falling within the latter category are sufficient to identify a specific utility for the invention. Assertions that fall in the former category are insufficient to define a specific utility for the invention, especially if the assertion takes the form of a general statement that makes it clear that a "useful" invention may arise from what has been disclosed by the applicant.

\section{B. Substantial Utility}

"[A]n application must show that an invention is useful to the public as disclosed in its current form, not that it may prove useful at some future date after further research. Simply put, to satisfy the 'substantial' utility requirement, an asserted use must show that the claimed invention has a significant and presently available benefit to the public." Fisher. The claims at issue in fisher were directed to expressed sequence tags (ESTs), which are short nucleotide sequences that can be used to discover what genes and downstream proteins are expressed in a cell. The court held that "the claimed ESTs can be used only to gain further information about the underlying genes and the
Fisher: 421 F.3d 1365 (Fed. Cir. 2005) 
proteins encoded for by those genes. The claimed ESTs themselves are not an end of [applicant's] research effort, but only tools to be used along the way in the search for a practical utility. Applicant does not identify the function for the underlying protein-encoding genes. Absent such identification, we hold that the claimed ESTs have not been researched and understood to the point of providing an immediate, well-defined, real world benefit to the public meriting the grant of a patent." Thus a "substantial utility" defines a "real world" use. Utilities that require or constitute carrying out further research to identify or reasonably confirm a "real world" context of use are not substantial utilities. For example, both a therapeutic method of treating a known or newly discovered disease and an assay method for identifying compounds that themselves have a "substantial utility" define a "real world" context of use. An assay that measures the presence of a material which has a stated correlation to a predisposition to the onset of a particular disease condition would also define a "real world" context of use in identifying potential candidates for preventive measures or further monitoring. On the other hand, the following are examples of situations that require or constitute carrying out further research to identify or reasonably confirm a "real world" context of use and, therefore, do not define "substantial utilities":

(A) Basic research such as studying the properties of the claimed product itself or the mechanisms in which the material is involved;

(B) A method of treating an unspecified disease or condition;

(C) A method of assaying for or identifying a material that itself has no specific and/or substantial utility;

(D) A method of making a material that itself has no specific, substantial, and credible utility; and

(E) A claim to an intermediate product for use in making a final product that has no specific, substantial and credible utility.

Office personnel must be careful not to interpret the phrase "immediate benefit to the public" or similar formulations in other cases to mean that products or services based on the claimed invention must be "currently available" to the public in order to satisfy the utility requirement. Rather, any reasonable use that an applicant has identified for the invention that can be viewed as providing a public benefit should be accepted as sufficient, at least with regard to defining a "substantial" utility.

\section{Research Tools}

Some confusion can result when one attempts to label certain types of inventions as not being capable of having a specific and substantial 
utility based on the setting in which the invention is to be used. One example is inventions to be used in a research or laboratory setting. Many research tools such as gas chromatographs, screening assays, and nucleotide sequencing techniques have a clear, specific and unquestionable utility (e.g., they are useful in analyzing compounds). An assessment that focuses on whether an invention is useful only in a research setting thus does not address whether the invention is in fact "useful" in a patent sense. Instead, Office personnel must distinguish between inventions that have a specifically identified substantial utility and inventions whose asserted utility requires further research to identify or reasonably confirm. Labels such as "research tool," "intermediate" or "for research purposes" are not helpful in determining if an applicant has identified a specific and substantial utility for the invention.

\section{Wholly Inoperative Inventions; "InCRedible" Utility}

An invention that is "inoperative" (i.e., it does not operate to produce the results claimed by the patent applicant) is not a "useful" invention in the meaning of the patent law. However, as the Federal Circuit has stated, "[t]o violate 35 U.S.C. $\$ 101$ the claimed device must be totally incapable of achieving a useful result." Brooktree Corp.v.Advanced Micro Devices, Inc.. See also E.I. du Pont De Nemours and Co. v. Berkley and Co. ("A small degree of utility is sufficient. The claimed invention must only be capable of performing some beneficial function. An invention does not lack utility merely because the particular embodiment disclosed in the patent lacks perfection or performs crudely. A commercially successful product is not required. Nor is it essential that the invention accomplish all its intended functions or operate under all conditions, partial success being sufficient to demonstrate patentable utility. In short, the defense of non-utility cannot be sustained without proof of total incapacity.") If an invention is only partially successful in achieving a useful result, a rejection of the claimed invention as a whole based on a lack of utility is not appropriate.

Situations where an invention is found to be "inoperative" and therefore lacking in utility are rare, and rejections maintained solely on this ground by a Federal court even rarer. In many of these cases, the utility asserted by the applicant was thought to be incredible in the light of the knowledge of the art, or factually misleading when initially considered by the Office. Other cases suggest that on initial evaluation, the Office considered the asserted utility to be inconsistent with known scientific principles or speculative at best as to whether attributes of the invention necessary to impart the asserted utility were actually present in the invention. However cast, the underlying finding by the court in these cases was that, based on the factual record of the case, it was clear that the invention could not and
Brooktree: 977 F.2d 1555,(Fed. Cir. 1992)

Berkley: 620 F.2d 1247 (8th Cir. 1980) 
Consider U.S. Pat No. 6,960,975 B1 for a "Space Vehicle Propelled by the Pressure of Inflationary Vacuum State." Does it matter if the USPTO occasionally issues a patent on a device that violates the known laws of physics?

2010 Wisc. L. Rev. 1353

Nuclear weapons: 42 U.S.C. § 2181 (a).

Human organisms: America Invents Act $\S 33(a)$. did not work as the inventor claimed it did. Indeed, the use of many labels to describe a single problem (e.g., a false assertion regarding utility) has led to some of the confusion that exists today with regard to a rejection based on the "utility" requirement. Examples of such cases include: an invention asserted to change the taste of food using a magnetic field, a perpetual motion machine, a flying machine operating on "flapping or flutter function," a "cold fusion" process for producing energy, a method for increasing the energy output of fossil fuels upon combustion through exposure to a magnetic field, uncharacterized compositions for curing a wide array of cancers, and a method of controlling the aging process. These examples are fact specific and should not be applied as a per se rule. Thus, in view of the rare nature of such cases, Office personnel should not label an asserted utility "incredible," "speculative" or otherwise unless it is clear that a rejection based on "lack of utility" is proper.

\section{Statutory Subject Matter}

\section{Tun-Jen Chiang}

The Rules and Standards of Patentable Subject Matter

A close examination of all of the patentable subject-matter categories reveals a clear distinction. Virtually all of the restrictions, save two, have been in the nature of categorical rules. The two exceptions are the closely-related (indeed, for all practical purposes, identical) prohibitions on patenting "laws of nature" and "abstract ideas." The laws of nature and abstract ideas prohibitions account for almost the entirety of patentable subject-matter case law, and the consequent uncertainty in the area. Section 101 thus contains a dichotomy: clear exclusionary rules that have almost never caused administrative difficulty or litigation; and a vague scope limiting standard that has caused tremendous difficulty and much litigation.

At present, there are two clear subject-matter exclusions from patentability: nuclear weapons and human organisms. Federal statutes direct that "No patent shall hereafter be granted for any invention or discovery which is useful solely in the utilization of special nuclear material or atomic energy in an atomic weapon" and that "Notwithstanding any other provision of law, no patent may issue on a claim directed to or encompassing a human organism." What policies do these exclusions express?

As for laws of nature and abstract ideas, the Supreme Court profoundly shifted course in a series of four major decisions between 2010 and 2014. Three of them are excerpted in this book: Mayo here, 
Myriad in the biotechnology chapter, and CLS Bank in the software chapter. (The fourth, Bilski, is discussed in CLS Bank.)

\section{Mayo Collaborative v. Prometheus Labs}

Section 101 of the Patent Act defines patentable subject matter. The Court has long held that this provision contains an important implicit exception. Laws of nature, natural phenomena, and abstract ideas are not patentable.

The patents before us concern the use of thiopurine drugs in the treatment of autoimmune diseases, such as Crohn's disease and ulcerative colitis. When a patient ingests a thiopurine compound, his body metabolizes the drug, causing metabolites to form in his bloodstream. Because the way in which people metabolize thiopurine compounds varies, the same dose of a thiopurine drug affects different people differently, and it has been difficult for doctors to determine whether for a particular patient a given dose is too high, risking harmful side effects, or too low, and so likely ineffective.

At the time the discoveries embodied in the patents were made, scientists already understood that the levels in a patient's blood of certain metabolites, including, in particular, 6-thioguanine and its nucleotides (6-TG) and 6-methyl-mercaptopurine (6-MMP), were correlated with the likelihood that a particular dosage of a thiopurine drug could cause harm or prove ineffective. But those in the field did not know the precise correlations between metabolite levels and likely harm or ineffectiveness. The patent claims at issue here set forth processes embodying researchers' findings that identified these correlations with some precision.

More specifically, the patents - U.S. Patent No. 6,355,623 (623 patent) and U.S. Patent No. 6,680,302 (302 patent) - embody findings that concentrations in a patient's blood of 6-TG or of 6-MMP metabolite beyond a certain level (400 and 7000 picomoles per $8 \times 10^{8}$ red blood cells, respectively) indicate that the dosage is likely too high for the patient, while concentrations in the blood of 6-TG metabolite lower than a certain level (about 230 picomoles per $8 \times 10^{8}$ red blood cells) indicate that the dosage is likely too low to be effective.

The patent claims seek to embody this research in a set of processes. Like the Federal Circuit we take as typical claim 1 of the 623 Patent, which describes one of the claimed processes as follows:

A method of optimizing therapeutic efficacy for treatment of an immune-mediated gastrointestinal disorder, comprising: 
(a) administering a drug providing 6-thioguanine to a subject having said immune-mediated gastrointestinal disorder; and

(b) determining the level of 6-thioguanine in said subject having said immune-mediated gastrointestinal disorder,

wherein the level of 6-thioguanine less than about 230 pmol per $8 \times 10^{8}$ red blood cells indicates a need to increase the amount of said drug subsequently administered to said subject and

wherein the level of 6-thioguanine greater than about 400 pmol per $8 \times 10^{8}$ red blood cells indicates a need to decrease the amount of said drug subsequently administered to said subject."

$B$

Respondent, Prometheus Laboratories, Inc. (Prometheus), is the sole and exclusive licensee of the 623 and 302 patents. It sells diagnostic tests that embody the processes the patents describe. For some time petitioners, Mayo Clinic Rochester and Mayo Collaborative Services (collectively Mayo), bought and used those tests. But in 2004 Mayo announced that it intended to begin using and selling its own testa test using somewhat higher metabolite levels to determine toxicity (450 pmol per $8 \times 10^{8}$ for 6 -TG and 5700 pmol per $8 \times 10^{8}$ for 6 -MMP). Prometheus then brought this action claiming patent infringement.

The District Court found that Mayo's test infringed claim 7 of the 623 patent. In interpreting the claim, the court accepted Prometheus' view that the toxicity-risk level numbers in Mayo's test and the claim were too similar to render the tests significantly different. The number Mayo used (450) was too close to the number the claim used (400) to matter given appropriate margins of error. The District Court also accepted Prometheus' view that a doctor using Mayo's test could violate the patent even if he did not actually alter his treatment decision in the light of the test. In doing so, the court construed the claim's language, "indicates a need to decrease" (or "to increase"), as not limited to instances in which the doctor actually decreases (or increases) the dosage level where the test results suggest that such an adjustment is advisable.

\section{II}

Prometheus' patents set forth laws of nature - namely, relationships between concentrations of certain metabolites in the blood and the likelihood that a dosage of a thiopurine drug will prove ineffective 
or cause harm. Claim 1, for example, states that if the levels of 6-TG in the blood (of a patient who has taken a dose of a thiopurine drug) exceed about 400 pmol per $8 \times 10^{8}$ red blood cells, then the administered dose is likely to produce toxic side effects. While it takes a human action (the administration of a thiopurine drug) to trigger a manifestation of this relation in a particular person, the relation itself exists in principle apart from any human action. The relation is a consequence of the ways in which thiopurine compounds are metabolized by the body - entirely natural processes. And so a patent that simply describes that relation sets forth a natural law.

The question before us is whether the claims do significantly more than simply describe these natural relations. To put the matter more precisely, do the patent claims add enough to their statements of the correlations to allow the processes they describe to qualify as patenteligible processes that apply natural laws? We believe that the answer to this question is no.

\section{$A$}

If a law of nature is not patentable, then neither is a process reciting a law of nature, unless that process has additional features that provide practical assurance that the process is more than a drafting effort designed to monopolize the law of nature itself. A patent, for example, could not simply recite a law of nature and then add the instruction "apply the law." Einstein, we assume, could not have patented his famous law by claiming a process consisting of simply telling linear accelerator operators to refer to the law to determine how much energy an amount of mass has produced (or vice versa). Nor could Archimedes have secured a patent for his famous principle of flotation by claiming a process consisting of simply telling boat builders to refer to that principle in order to determine whether an object will float.

What else is there in the claims before us? The process that each claim recites tells doctors interested in the subject about the correlations that the researchers discovered. In doing so, it recites an "administering" step, a "determining" step, and a "wherein" step. These additional steps are not themselves natural laws but neither are they sufficient to transform the nature of the claim.

First, the "administering" step simply refers to the relevant audience, namely doctors who treat patients with certain diseases with thiopurine drugs. That audience is a pre-existing audience; doctors used thiopurine drugs to treat patients suffering from autoimmune disorders long before anyone asserted these claims. In any event, the prohibition against patenting abstract ideas cannot be circumvented by attempting to limit the use of the formula to a particular technological environment. 
A patent lawyer walks into a barber shop. The barber takes a look at the lawyer for a bit, and then says, "Ok, that'll be \$20." The lawyer responds, "But you didn't cut my hair!" The barber replies, "That's 'insignificant post-solution activity."'

Michael S. Kwun, Alice Tells a Joke, 19 Green Bag 2d 329 (2016). Unfair?

Is there anything here that the inventors could have patented with better drafting, or were their claims unsalvageable?
Second, the "wherein" clauses simply tell a doctor about the relevant natural laws, at most adding a suggestion that he should take those laws into account when treating his patient. That is to say, these clauses tell the relevant audience about the laws while trusting them to use those laws appropriately where they are relevant to their decisionmaking (rather like Einstein telling linear accelerator operators about his basic law and then trusting them to use it where relevant).

Third, the "determining" step tells the doctor to determine the level of the relevant metabolites in the blood, through whatever process the doctor or the laboratory wishes to use. As the patents state, methods for determining metabolite levels were well known in the art. Indeed, scientists routinely measured metabolites as part of their investigations into the relationships between metabolite levels and efficacy and toxicity of thiopurine compounds. Thus, this step tells doctors to engage in well-understood, routine, conventional activity previously engaged in by scientists who work in the field. Purely conventional or obvious pre-solution activity is normally not sufficient to transform an unpatentable law of nature into a patent-eligible application of such a law. The prohibition against patenting abstract ideas cannot be circumvented by adding insignificant post-solution activity.

Fourth, to consider the three steps as an ordered combination adds nothing to the laws of nature that is not already present when the steps are considered separately. Anyone who wants to make use of these laws must first administer a thiopurine drug and measure the resulting metabolite concentrations, and so the combination amounts to nothing significantly more than an instruction to doctors to apply the applicable laws when treating their patients.

The upshot is that the three steps simply tell doctors to gather data from which they may draw an inference in light of the correlations. To put the matter more succinctly, the claims inform a relevant audience about certain laws of nature; any additional steps consist of well-understood, routine, conventional activity already engaged in by the scientific community; and those steps, when viewed as a whole, add nothing significant beyond the sum of their parts taken separately. For these reasons we believe that the steps are not sufficient to transform unpatentable natural correlations into patentable applications of those regularities.

\section{Tax Planning Patent Problem}

You are staff counsel to Representative Helvering (R-IA), who has read a number of newspaper articles on the growing phenomenon of "tax planning patents." These patents describe transactions designed to help a company reduce the taxes it owes. For example, one such patent describes dividing a real estate portfolio into a number 
of shares held as tenancies in common subject to a master lease, in which each holder receives guaranteed annual income and is subject to repurchase at fair market value at a specified date, such that the investments qualify for tax-deferred treatment under ... you get the picture.

The Representative has asked you to help her think through the policy and legal issues these patents raise. She wants to know whether they are valid under current law and whether they're contributing to tax evasion. If they're problematic, she would like your suggestions on possible legislative fixes (either to the Patent Act or to the Internal Revenue Code).

\section{B Procedures}

A patent (an example follows) has two jobs. It must describe the scope of the owner's rights in the invention. This is the job of the claims. It must also disclose the invention in enough detail that others could (if not for the patent) make use of it. This is the job of the specification. The process of patent prosecution is designed not just to check that the invention is substantively eligible to be patented (discussed in the next section), but also to ensure that the claims and specification adequately carry out their jobs.
For purposes of evaluating an invention under section 102 [novelty] or 103 [nonobviousness], any strategy for reducing, avoiding, or deferring tax liability, whether known or unknown at the time of the invention or application for patent, shall be deemed insufficient to differentiate a claimed invention from the prior art.

America Invents Act $\S 14(a)$. What do you think of this solution? 
[54] METHOD AND APPARATUS FOR TEMPORARILY IMMOBILIZING AN EARTHWORM

[76] Inventor: Loren Lukehart, 4391 Greer, Boise, Id. 83703

[21] Appl. No.: 161,144

[22] Filed: Feb. 26, 1988

[51] Int. $\mathrm{Cl}^{4}$ A01K 97/02

[52] U.S. Cl. 43/4; 43/4.5;

[58] Field of Search $43 / 55$ $43 / 4,4.5,54.1,55$, $43 / 56,57.1$ References Cited

\section{U.S. PATENT DOCUMENTS}

$1,929,833 \quad 10 / 1933$ Vanvuren 2,257,879 10/1941 Graham $43 / 54.1$ $2,507,319 \quad 5 / 1950$

$2,527,214$ 10/1950 Graves

$3,193,966 \quad 7 / 1965$ Lawson et al.

Duerst

$$
\text { 3,566,836 3/1971 Elfert . }
$$

$43 / 55$

Primary Examiner-M. Jordan Attorney, Agent, or Firm-Frank J. Dykas

\section{[57]}

\section{ABSTRACT}

Method and apparatus for immobilization of an earthworm 13 to facilitate the baiting of a fishing hook. To immobilize the earthworm, the earthworm is partially coated with sharp grained sand $\mathbf{1 1}$ having a grain size of less than $1 / 20$ th of an inch. The apparatus 10 for carrying out the method consists of rectangular container 12 and a reservoir of sharp grained sand 11 and cover 14. Placing earthworm 13 in the apparatus 10 and allowing earthworm 13 to at least partially coat itself with sharp grained sand 11, results in the temporary immobilization of earthworm 13. Earthworm 13 is then impaled on the fishing hook by the fisherman. As soon a the baited hook is immersed in water, the sand is rinsed from earthworm 13 and it resumes wiggling.

3 Claims, 1 Drawing Sheet

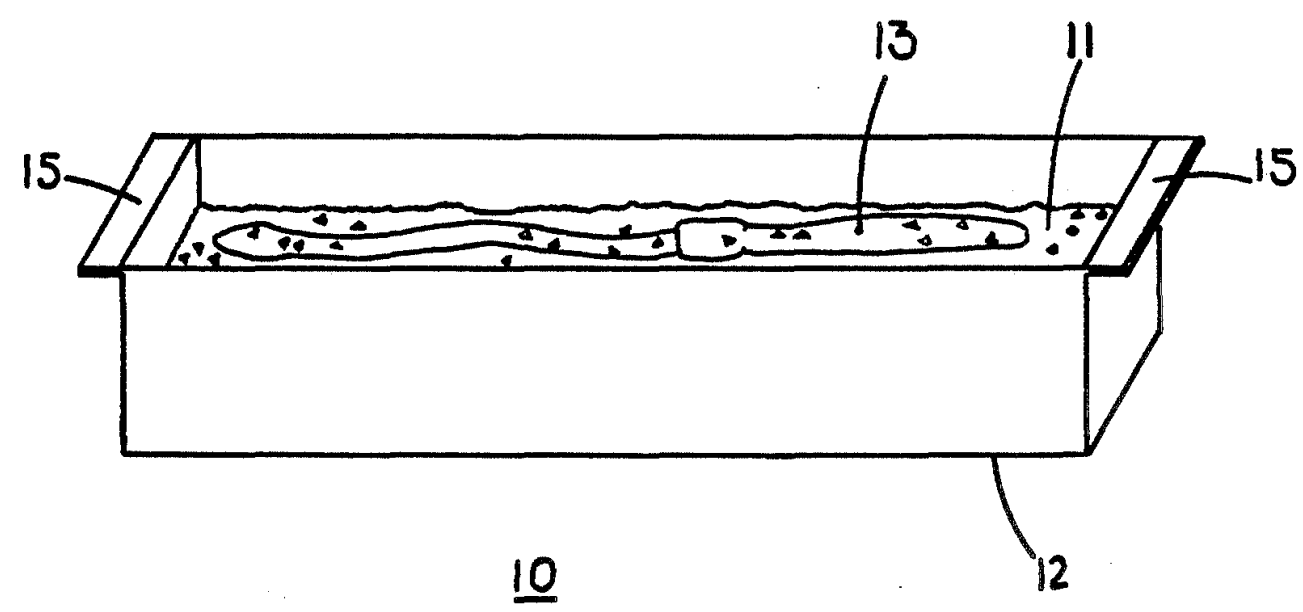




\section{FIG.1}
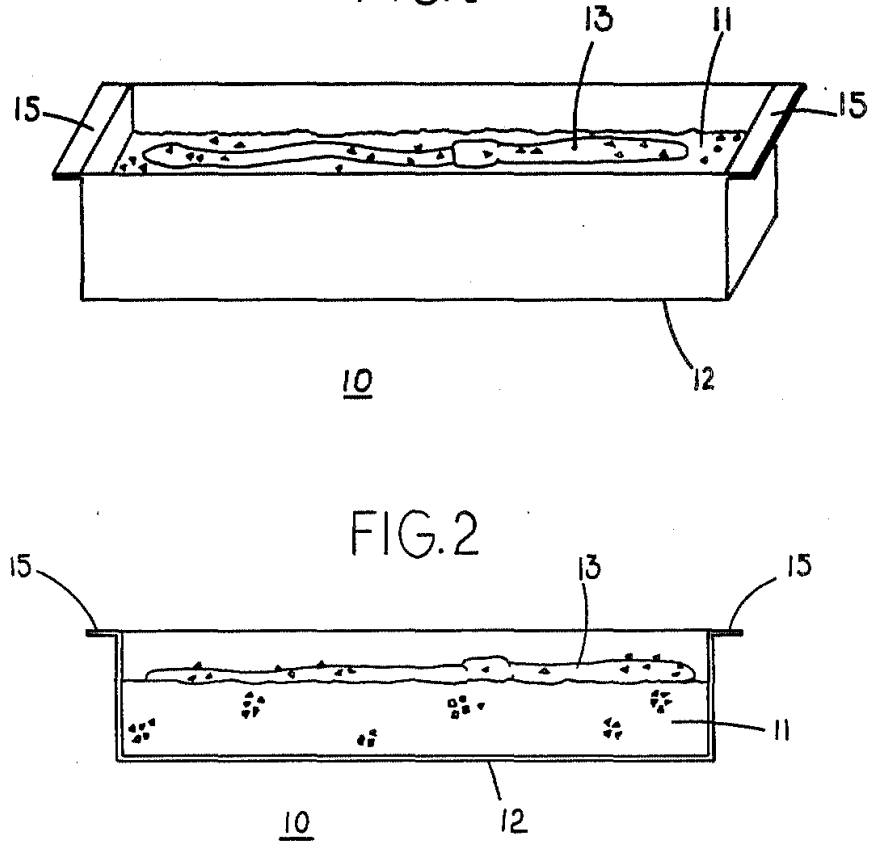

$F \mid G .3$

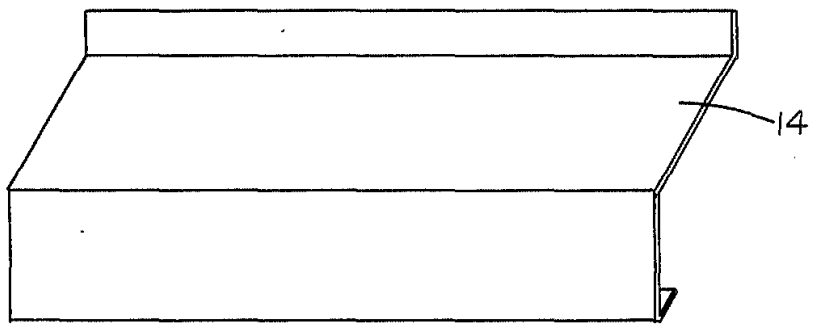


1

\section{METHOD AND APPARATUS FOR TEMPORARILY IMMOBILIZING AN EARTHWORM}

\section{BACKGROUND OF THE INVENTION}

1. Technical Field.

This invention relates to the immobilization of live bait for use in fishing. In particular, the invention relates to a method and apparatus for the dewiggling of earthworms.

2. Background Art.

The use of live bait in fishing has long been known to be one of the most effective means for catching fish. The problem with live bait is that any creature has a natural tendency to resist the baiting process. A further complication in the specific case of earthworms is that they are naturally slimy. The ability of the earthworm to curl its body in almost any direction, connected with the fact that it is coated with slimy film, makes it extremely difficult for the fisherman to impale the earthworm witl the fishing hook.

GRAHAM, U.S. Pat. No. 2,257,879, discloses a bait box having a compartment that is filled with a dry sand. The worm is dropped into the dry sand which adheres to the worm's body which makes it easier for the fisherman to hold onto the worm. The problem with the method is that the worm is still able to wiggle and curl its body, making it difficult for the fisherman to impale the worm on the fishing hook.

Accordingly, it is the object of this invention to provide a means for immobilizing an earthworm and thereby facilitating the impalement of the earthworm on a fishing hook by the fisherman.

\section{DISCLOSURE OF INVENTION}

These objects are accomplished by coating the earthworm with small sharp grained sand. Small sharp grained sand, as opposed to regular dry sand, has a dramatic affect on the worm's ability to curl its body.

A small rectangular container of sufficient length to harbor an earthworm is partially filled with sharp grained sand having a grain size equal or less than $1 / 20$ th of an inch. The rectangular container is also fitted with a removable cover which prevents sand spillage during transport. To dewiggle a worm, the fisherman has to simply set the worm in the rectangular container on top of the sharp grained sand. During the worm's natural locomotion process, the sand becomes partially imbedded in the earthworm and causes an immediate reaction wherein the earthworm completely relaxes. The earthworm is then effectively dewiggled and ready to be impaled onto the fishing hook.

Once the sand coated earthworm is immersed in water, the sand rinses free and the earthworm resume its 55 normal wiggly character.

\section{BRIEF DESCRIPTION OF THE DRAWINGS}

FIG. 1 is a top perspective view of the container and sand reservior with a worm.

FIG. 2 is a sectional side view of the container and sand reservoir with a worm.

FIG. 3 is a perspective view of the container cover.

BEST MODE FOR CARRYING OUT INVENTION 65

Referring to FIGS. 1, 2 and 3, an apparatus for the immobilization of earthworms is generally designated as
2

10 and is illustrated in its preferred embodiment. The first and only step in the immobilization of an earthworm by the preferred method is to coat the earthworm with small sharp grained sand $\mathbf{1 1}$ having a grain size

5 equal to or less than $1 / 20$ th of an inch by momentarily depositing earthworm 13 on sand 11.

The preferred apparatus for the immobilization of an earthworm has a reservoir of sharp grained sand $\mathbf{1 1}$ having a grain size equal to or less than $1 / 20$ th of an 0 inch, and a rectangular container 12 for housing the sand reservoir.

Sand reservoir container $\mathbf{1 2}$ is sized for transverse insertion into a standard bait box, not shown. Retainer lips 15 are attached to and extend perpendicularly out 15 from the top edges of the ends of container 12. Retainer lips $\mathbf{1 5}$ are sized for cooperative engagement with the top edges of the sides of the bait box, so that when container 12 is transversely inserted into a bait box it is held suspended above the bottom of the bait box which contains a mixture of live worms and humus material.

Cover $\mathbf{1 4}$ is contoured to provide for a seal for sand reservoir container $\mathbf{1 2}$ and is held in place by the lid of the standard bait box.

To immobilize earthworm 13, one merely deposits earthworm 13 on top of sand 11. During the earthworm's natural locomotion process individual grains of sand 11 become partially imbedded in earthworm 13 and causes an immediate immobilizing reaction in earth30 worm 13. As a result earthworm 13 will rapidly straighten out and become immobilized. Since earthworm 13 is covered with grains of sand 11, it is not only immobilized, but also easy to pick up and handle.

Once earthworm 13 has been impaled upon the fisher35 man's hook, not shown, and immersed in water, said 11 washes off earthworm 13 and earthworm 13 will resume wiggling.

While there is shown and described the present preferred embodiment of the invention, it is to be distinctly

40 understood that this invention is not limited thereto but may be variously embodied to practice within the scope of the following claims.

Accordingly, what I claim is:

1. An apparatus for temporarily immobilizing an 45 earthworm which comprises:

a container for housing the a reservoir of sand;

a reservoir of sharp sand having a grain size of $1 / 20$ th of an inch or less.

2. The apparatus of claim 1 wherein said container 50 further comprises:

a rectangular shaped container for holding a reservoir of sand, said rectangular container having a length slightly less than the width of a standard bait box;

retainer lips attached to and extending perpendicularly from the ends of said rectangular container for cooperative engagement with the top edges of the sides of a standard bait box for transversely suspending and supporting the rectangular container within the bait box;

a cover for cooperative engagement with the rectangular shaped container for containing the sand.

3. A method for immobilizing an earthworm which comprises partially coating said earthworm with a sharp grained sand having a grain size equal to or less than $1 / 20$ th of an inch.

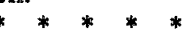




\section{Claims}

\section{Patent Act}

(b) Conclusion. - The specification shall conclude with one or more claims particularly pointing out and distinctly claiming the subject matter which the inventor or a joint inventor regards as the invention.

(c) Form. - A claim may be written in independent or, if the nature of the case admits, in dependent or multiple dependent form.

(d) Reference in Dependent Forms. - A claim in dependent form shall contain a reference to a claim previously set forth and then specify a further limitation of the subject matter claimed. A claim in dependent form shall be construed to incorporate by reference all the limitations of the claim to which it refers.

a Indefiniteness

Nautlius, Inc. v. Biosig Instruments Inc.

The Patent Act requires that a patent specification "conclude with one or more claims particularly pointing out and distinctly claiming the subject matter which the applicant regards as [the] invention." According to the Federal Circuit, a patent claim passes the threshold so long as the claim is "amenable to construction," and the claim, as construed, is not "insolubly ambiguous." We conclude that the Federal Circuit's formulation, which tolerates some ambiguous claims but not others, does not satisfy the statute's definiteness requirement. In place of the "insolubly ambiguous" standard, we hold that a patent is invalid for indefiniteness if its claims, read in light of the specification delineating the patent, and the prosecution history, fail to inform, with reasonable certainty, those skilled in the art about the scope of the invention.

\section{Freeny v. Apple Inc.}

[Patent No. 7,110,744 ("the '744 patent"), described a single device that can communicate wirelessly with a variety of providers, such as hotel systems, vehicle parking systems, and toll systems, using multiple frequencies. It claimed:

A communication unit connected to a public communication system, the communication unit capable of detecting a plurality of wireless devices and servicing each of the plurality of wireless devices by providing access to
35 U.S.C. § 112

Specification

134 S. Ct. 2120 (2014)

No.2:13-CV-00361-WCB， 2014 WL 4294505 (E.D. Tex. Aug. 28, 2014)

For "public communication system," think "Internet" 
the public communication system when the wireless devices are within a predetermined proximity distance from the communication unit, the communication unit comprising [various elements, including a] transceiver simultaneously communicating with at least two wireless devices with different types of low power communication signals.]

The final term in dispute for purposes of claim construction is the term "low power communication signals." The plaintiffs argue that the term "low power communication signals" should be construed to mean "signals having a power for transmission up to a maximum of several hundred feet." The defendant argues that the term is indefinite because the words "low power" are wholly lacking in specificity.

While it is true that the patent does not define the term "low power" with precision, precision is not required as long as the claim language is as specific as is reasonably possible under the circumstances, and as long as a person of skill in the art would understand the scope of the claims with reasonable certainty. The Federal Circuit has frequently addressed claim language that was imprecise and has frequently upheld claims containing similar language, based on the commonsense observation that sometimes precision is impossible to achieve, consistent with an accurate description of the full scope of the invention. As the court has explained: "Definiteness problems often arise when words of degree are used in a claim. That some claim language may not be precise, however, does not automatically

Seattle Box: 731 F.2d 818 (Fed. Cir. 1984) render a claim invalid." Seattle Box Co. v. Indus. Crating \& Packing, Inc. (upholding claim using term "substantially equal to"). When a word of degree is used, "the district court must determine whether the patent's specification provides some standard for measuring that degree. The trial court must decide, that is, whether one of ordinary skill in the art would understand what is claimed when the claim is read in light of the specification."

Indefiniteness is a legal determination; if the court concludes that a person of ordinary skill in the art, with the aid of the specification, would understand what is claimed, the claim is not indefinite. For example, the term "substantially" has frequently been held not indefinite if a person of ordinary skill can discern from the claims and specification what the bounds of the claim are with reasonable certainty. [Cases cited found the terms "about 0.06," "substantially planar," "to increase substantially," "not interfering substantially," "relatively small," "substantially equal to," "closely approximate," and "about 5:1 to about 7:1" not indefinite.] On numerous occasions, district courts, including this court, have held similarly imprecise claim language not indefinite. [Cases cited found the phrases "substan- 
tially collimated," "roughly the same," "low frequency forces," "low hydroxyl ion content," and "low DC electrical voltage" not indefinite.]

In pressing its indefiniteness argument, the defendant relies heavily on the Supreme Court's recent decision in Nautilus, which addressed the issue of indefiniteness and modified the test applied in some prior Federal Circuit cases. The Nautilus Court held "a patent's claims, viewed in light of the specification and prosecution history, [must] inform those skilled in the art about the scope of the invention with reasonable certainty." Contrary to the defendant's suggestion, that standard does not render all of the prior Federal Circuit and district court cases inapplicable, nor does it require that the claim language in this case be held indefinite. The Supreme Court recognized that "some modicum of uncertainty" is "the price of ensuring the appropriate incentives for innovation," and that because patents are directed to persons of skill in the art, all that is required is that the patent apprise such persons of the scope of the invention. Indeed, the Court cited with approval Eibel Process Co. v. Minn. E Ontario Paper Co., where the Court upheld claim language requiring a wire to be placed at a "high" or "substantial" elevation. That language, the Eibel Court held, would be sufficiently clear in context for persons of skill in the art to understand and therefore was not invalid for indefiniteness.

In light of the applicable caselaw, including the Nautilus case, the Court concludes that the term "low power communication signals" is not indefinite. The specification on several occasions refers to low power signals as those that do not communicate farther than a few hundred feet. See, e.g., '744 patent, col. 32, 11. 29-31 ("low power wireless link ... does not typically communicate farther than about 300 feet"); id., col. 35, 11. 50-51 (detection range of "say several hundred feet"); id., col. 36, 11. 31-38 (wireless connection ranges "will vary from several hundred feet to only several feet"); id., col. 39, 11. 13-15 (transmissions possible "within several hundred feet" of a communication unit); id., col. 7, 11. 4-8 (transceiver capable of communicating "up to at least a predetermined proximity distance such as a hundred feet"); id., col. 13, 1l. 49-52 (different signal strengths designed for detection at 500 feet and 20 feet); id., col. 16, 11. 4951 (authorization distance set at 500 feet and 20 feet). Moreover, the plaintiffs' expert filed a declaration pointing to the references in the patent to infrared signals, $900 \mathrm{MHz}$ signals, $1.8 \mathrm{GHz}$ signals, and 2.4 $\mathrm{GHz}$ signals as examples of different types of low power communication signals. He explained that a common characteristic of such signals is the limited distance over which they can be transmitted, as discussed in the specification. One of ordinary skill in the art, he explained, would understand from reading the' 744 specification that the claim term "different types of low power communication signals" 
means "different types of communication signals having a power for transmission up to a maximum of several hundred feet." The defendant has not submitted a contrary expert declaration on the issue of indefiniteness.

Accordingly, the Court concludes that the term "low power communication signals," viewed in light of the specification, would be understood by persons of skill in the art with reasonable certainty. The asserted claims in the' 744 patent are therefore not indefinite. Furthermore, in light of the discussion of low power communications in the specification, the Court agrees with the plaintiffs that the term should be interpreted to mean "communication signals having a power for transmission of up to a maximum of several hundred feet."

\section{Datamize, LLC v. Plumtree Software, Inc.}

[U.S. Patent No. 6,014,137], entitled "Electronic Kiosk Authoring System," discloses a software program that allows a person to author user interfaces for electronic kiosks. "The authoring system enables the user interface for each individual kiosk to be customized quickly and easily within wide limits of variation, yet subject to constraints adhering the resulting interface to good standards of aesthetics and user friendliness." '137 patent, Abstract. [It claimed, in relevant part (emphasis added):

In an electronic kiosk system ... a method for defining custom interface screens ... said method comprising the steps of: ... providing a plurality of pre-defined interface screen element types, each element type defining a form of element available for presentation on said custom interface screens, wherein each said element type permits limited variation in its on-screen characteristics in conformity with a desired uniform and aesthetically pleasing look and feel for said interface screens on all kiosks of said kiosk system .... .

Datamize, the patentee, argued that the term "aesthetically pleasing" should be contrued to refer to the intent of a person practicing the invention. That person must intend to create an aesthetically pleasing interface screen; whether she succeeds is irrelevant.]

Datamize's proposed construction of "aesthetically pleasing" in the context of claim 1 is not reasonable for several reasons. First and foremost, the plain meaning of the claim language requires that the look and feel of interface screens actually be "aesthetically pleasing." That the uniform and "aesthetically pleasing" look and feel must also be "desired" does not alter that fact.

Here Datamize has offered no objective definition identifying a standard for determining when an interface screen is "aesthetically 
pleasing." In the absence of a workable objective standard, "aesthetically pleasing" does not just include a subjective element, it is completely dependent on a person's subjective opinion. To the extent Datamize argues that such a construction of "aesthetically pleasing" does not render the phrase indefinite, we disagree. The scope of claim language cannot depend solely on the unrestrained, subjective opinion of a particular individual purportedly practicing the invention. Some objective standard must be provided in order to allow the public to determine the scope of the claimed invention. Even if the relevant perspective is that of the system creator, the identity of who makes aesthetic choices fails to provide any direction regarding the relevant question of how to determine whether that person succeeded in creating an "aesthetically pleasing" look and feel for interface screens. A purely subjective construction of "aesthetically pleasing" would not notify the public of the patentee's right to exclude since the meaning of the claim language would depend on the unpredictable vagaries of any one person's opinion of the aesthetics of interface screens. While beauty is in the eye of the beholder, a claim term, to be definite, requires an objective anchor. Thus, even if we adopted a completely subjective construction of "aesthetically pleasing," this would still render the ' 137 patent invalid.

And while the description of an embodiment provides examples of aesthetic features of screen displays that can be controlled by the authoring system, it does not explain what selection of these features would be "aesthetically pleasing." Major aesthetic choices apparently may include some aspect of button styles and sizes, window borders, color combinations, and type fonts. The written description, however, provides no guidance to a person making aesthetic choices such that their choices will result in an "aesthetically pleasing" look and feel of an interface screen. For example, the specification does not explain what factors a person should consider when selecting a feature to include in the authoring system. Left unanswered are questions like: which color combinations would be "aesthetically pleasing" and which would not? And more generally, how does one determine whether a color combination is "aesthetically pleasing"? Again, one skilled in the art reading the specification is left with the unhelpful direction to consult the subjective opinions of aesthetic design specialists, database specialists, and academic studies.

Simply put, the definition of "aesthetically pleasing" cannot depend on an undefined standard. We therefore affirm the district court's grant of summary judgment of invalidity of all claims of the '137 patent. 


\section{b Claim Drafting}

289 F.3d 801 (Fed. Cir. 2002)

MPEP § 2111.03

Transitional Phrases

Gillette: 405 F.3d 1367 (Fed. Cir. 2005)

MPEP 2173.05(e)

Lack of Antecedent Basis

\section{Catalina Marketing Intern. v. Coolsavings.com}

In general, a preamble limits the invention if it recites essential structure or steps, or if it is necessary to give life, meaning, and vitality to the claim. Conversely, a preamble is not limiting where a patentee defines a structurally complete invention in the claim body and uses the preamble only to state a purpose or intended use for the invention.

Perhaps a hypothetical best illustrates these principles: Inventor A invents a shoe polish for shining shoes (which, for the sake of example, is novel, useful, and nonobvious). Inventor A receives a patent having composition claims for shoe polish. Indeed, the preamble of these hypothetical claims recites "a composition for polishing shoes." Clearly, Inventor B could not later secure a patent with composition claims on the same composition because it would not be novel. Upon discovering, however, that the polish composition grows hair when rubbed on bare human skin, Inventor B can likely obtain method claims directed to the new use of the composition to grow hair.

\section{Manual of Patent Examination Procedure (Rev. Aug. 2012)}

The transitional phrases "comprising", "consisting essentially of" and "consisting of" define the scope of a claim with respect to what unrecited additional components or steps, if any, are excluded from the scope of the claim. The determination of what is or is not excluded by a transitional phrase must be made on a case-by-case basis in light of the facts of each case.

The transitional term "comprising", which is synonymous with "including," "containing," or "characterized by," is inclusive or open-ended and does not exclude additional, unrecited elements or method steps. In Gillette Co. v. Energizer Holdings Inc., the court held that a claim to "a safety razor blade unit comprising a guard, a cap, and a group of first, second, and third blades" encompasses razors with more than three blades because the transitional phrase "comprising" in the preamble and the phrase "group of" are presumptively open-ended. The transitional phrase "consisting of" excludes any element, step, or ingredient not specified in the claim. The transitional phrase "consisting essentially of" limits the scope of a claim to the specified materials or steps and those that do not materially affect the basic and novel characteristic(s) of the claimed invention.

A claim is indefinite when it contains words or phrases whose meaning is unclear. The lack of clarity could arise where a claim refers to "said lever" or "the lever," where the claim contains no earlier recita- 
tion or limitation of a lever and where it would be unclear as to what element the limitation was making reference. Similarly, if two different levers are recited earlier in the claim, the recitation of "said lever" in the same or subsequent claim would be unclear where it is uncertain which of the two levers was intended.

Alternative expressions are permitted if they present no uncertainty or ambiguity with respect to the question of scope or clarity of the claims. A "Markush" claim recites a list of alternatively useable species. A Markush claim is commonly formatted as: "selected from the group consisting of A, B, and C;" however, the phrase "Markush claim" means any claim that recites a list of alternatively useable species regardless of format. Inventions in metallurgy, refractories, ceramics, pharmacy, pharmacology and biology are most frequently claimed under the Markush formula but purely mechanical features or process steps may also be claimed by using the Markush style of claiming. It is improper to use the term "comprising" instead of "consisting of."

\section{Disclosure}

\section{Patent Act}

The specification shall contain a written description of the invention, and of the manner and process of making and using it, in such full, clear, concise, and exact terms as to enable any person skilled in the art to which it pertains, or with which it is most nearly connected, to make and use the same, and shall set forth the best mode contemplated by the inventor or joint inventor of carrying out the invention.

This language has been interpreted by the courts to create three distinct disclosure requirements: enablement, written description, and best mode. Of the three, enablement is the most practically significant.

\section{a Enablement}

\section{O'Reilly v. Morse}

[Morse sued O'Reilly for infringing his patent on the telegraph. The Supreme Court found that Morse was the inventor of the technology and found that O'Reilly's "Columbian Telegraph" infringed. But it narrowed Morse's patent by striking its now-famous eighth claim:]
MPEP 2173.05(h)

Alternative Limitations

35 U.S.C. § 112(a)

Specification

The phrase "person skilled in the art" and the related phrase "person having ordinary skill in the art" from Section 103 are frequently abbreviated to "PHOSITA." The PHOSITA is the hypothetical reasonable person of patent law.

56 U.S. 62 (1853) 
Eighth. I do not propose to limit myself to the specific machinery or parts of machinery described in the foregoing specification and claims; the essence of my invention being the use of the motive power of the electric or galvanic current, which I call electro-magnetism, however developed for marking or printing intelligible characters, signs, or letters, at any distances, being a new application of that power of which I claim to be the first inventor or discoverer.

It is impossible to misunderstand the extent of this claim. He claims the exclusive right to every improvement where the motive power is the electric or galvanic current, and the result is the marking or printing intelligible characters, signs, or letters at a distance.

If this claim can be maintained, it matters not by what process or machinery the result is accomplished. For aught that we now know some future inventor, in the onward march of science, may discover a mode of writing or printing at a distance by means of the electric or galvanic current, without using any part of the process or combination set forth in the plaintiff's specification. His invention may be less complicated-less liable to get out of orderl- ess expensive in construction, and in its operation. But yet if it is covered by this patent the inventor could not use it, nor the public have the benefit of it without the permission of this patentee.

Nor is this all, while he shuts the door against inventions of other persons, the patentee would be able to avail himself of new discoveries in the properties and powers of electro-magnetism which scientific men might bring to light. For he says he does not confine his claim to the machinery or parts of machinery, which he specifies; but claims for himself a monopoly in its use, however developed, for the purpose of printing at a distance. New discoveries in physical science may enable him to combine it with new agents and new elements, and by that means attain the object in a manner superior to the present process and altogether different from it. And if he can secure the exclusive use by his present patent he may vary it with every new discovery and development of the science, and need place no description of the new manner, process, or machinery, upon the records of the patent office. And when his patent expires, the public must apply to him to learn what it is. In fine he claims an exclusive right to use a manner and process which he has not described and indeed had not invented, and therefore could not describe when he obtained his patent. The court is of opinion that the claim is too broad, and not warranted by law. 
Wyeth and Cordis Corporation (Wyeth) appeal from the U.S. District Court for the District of New Jersey's grant of summary judgment that claims 1 and 2 of U.S. Patent No. 5,516,781 ('781 patent) and claim 1 of U.S. Patent No. 5,563,146 ('146 patent) are invalid for nonenablement. Because we hold that there is no genuine issue of material fact that the specification does not enable one of ordinary skill to practice the asserted claims without undue experimentation, we affirm.

\section{BACKGROUND}

The patents-in-suit relate to the use of rapamycin for the treatment and prevention of restenosis, which is the renarrowing of an artery. To open a blocked artery, a physician guides a balloon catheter to the site of accumulated plaque, and then inflates the balloon to crush the plaque. As the balloon inflates, however, it may cause injury to the arterial wall. That vascular injury causes smooth muscle cells to proliferate, which thickens the arterial wall, and, in turn, leads to restenosis.

The claims recite a method of treating or preventing "restenosis in a mammal ... which comprises administering an antirestenosis effective amount of rapamycin to said mammal." In general, "rapamycin" may refer to a class of compounds. While the patents-in-suit use the term "rapamycin," the parties agree that the shared specification discloses only one rapamycin species called sirolimus. Sirolimus is naturally produced by a bacterium called Streptomyces hygroscopicus. [Sirolimus's chemical structure has two relevant features: a "macrocyclic triene ring" and a specific "substituent group."]

The parties do not dispute that the effective filing date of both patents is January 9, 1992. At that time, it was known that sirolimus acts in part by binding two proteins at sites within the macrocyclic ring. It was also known that there were four additional compounds with the same macrocyclic ring as sirolimus, but different substituent groups.

The parties also do not dispute that the specification discloses the immunosuppressive and antirestenotic properties of sirolimus. The specification discloses in vitro test data indicating that sirolimus inhibits rat smooth muscle cell proliferation. It also discloses in vivo test data indicating that intraperitoneal injection of sirolimus in rats reduced the thickening of the arterial wall following vascular injury.

In two separate actions, Wyeth sued the defendants for infringement of the patents-in-suit. The defendants market stent products that elute everolimus and zotarolimus, two drugs that have the same macrocyclic ring as sirolimus but different [substituent groups]. After briefing and a hearing, the district court adopted Wyeth's proposed construction of "rapamycin" as "a compound containing a macrocyclic triene ring structure produced by Streptomyces hygroscop- 
icus, having immuno-suppressive and anti-restenotic effects." Based in part on that construction, the court granted defendants' joint motions for summary judgment of invalidity for nonenablement and lack of written description.

\section{Discussion}

I.

A patent's specification must describe the invention and "the manner and process of making and using it, in such full, clear, concise, and exact terms as to enable any person skilled in the art to which it pertains ... to make and use the same." 35 U.S.C. § 112(a). Claims are not enabled when, at the effective filing date of the patent, one of ordinary skill in the art could not practice their full scope without undue experimentation.

II.

The central issue on appeal is whether practicing the full scope of the claims requires excessive - and thus undue - experimentation. The district court held that it does. It found that the claims cover any structural analog of sirolimus that exhibits immunosuppressive and antirestenotic effects. The court also found that, while the specification describes assays to ascertain whether a potential rapamycin compound exhibits the recited functional effects, the only species disclosed is sirolimus. In further support of its holding of nonenablement, the court relied on the unpredictability of the chemical arts, the complexity of the invention, and the limited knowledge of treatment of restenosis using sirolimus at the time of the invention.

Wyeth argues that the district court ignored evidence that practicing the full scope of the claims would have required only routine experimentation. First, a skilled artisan could ascertain whether a candidate rapamycin compound has the same macrocyclic ring as sirolimus. Second, a skilled artisan could routinely determine whether a candidate has immunosuppressive and antirestenotic effects using the assays disclosed in the specification.

Regarding the amount of experimentation, Wyeth acknowledges that one of its experts testified that there could be millions of compounds made by varying the substituent groups outside of sirolimus's macrocyclic ring. Wyeth counters that the same expert testified that the number of compounds that would exhibit the recited functional effects would be significantly smaller. [Wyeth's expert argued that a PHOSITA would have known that only compounds permeable across cell membranes, typically having molecular weights below 1,200 Daltons would need to be considered. For purposes of summary judgment, the court accepted this claim as true, and also the claim that the assays would effectively confirm whether a candidate 
compound had the desired immunosuppressive and antirestinotic effects.]

We agree with Appellees and the district court that there is no genuine dispute that practicing the full scope of the claims, measured at the time of filing, would require excessive experimentation. The scope of the claims at issue is broad. Under the district court's unchallenged construction of "rapamycin," the invention is a new method of use of a known compound (sirolimus) and any other compounds that meet the construction's structural and functional requirements. We also agree that there is no genuine dispute that the specification's guidance is limited to disclosures of the immunosuppressive and antirestenotic properties of sirolimus and assays to screen for those properties.

Yet, even accepting Wyeth's assertions, we find no genuine dispute that practicing the full scope of the claims would require more than routine experimentation for two reasons.

First, there is no dispute that, even if potential rapamycin compounds must have a molecular weight below 1,200 Daltons, there are still at least tens of thousands of candidates. The specification is silent about how to structurally modify sirolimus, let alone in a way that would preserve the recited utility. Second, there is no genuine dispute that it would be necessary to first synthesize and then screen each candidate compound using the assays disclosed in the specification to determine whether it has immunosuppressive and antirestenotic effects. There is no evidence in the record that any particular substitutions outside of the macrocyclic ring are preferable. Indeed, a Wyeth scientist confirmed the unpredictability of the art and the ensuing need to assay each candidate by testifying that, "until you test [compounds], you really can't tell whether they work or not [i.e., have antirestenotic effects]." In sum, there is no genuine dispute that practicing the full scope of the claims would require synthesizing and screening each of at least tens of thousands of compounds.

The remaining question is whether having to synthesize and screen each of at least tens of thousands of candidate compounds constitutes undue experimentation. We hold that it does. Undue experimentation is a matter of degree. Even a considerable amount of experimentation is permissible, as long as it is merely routine or the specification provides a reasonable amount of guidance regarding the direction of experimentation. Yet, routine experimentation is not without bounds.

Our cases have described limits on permissible experimentation in the context of enablement. For example, in ALZA Corp. v. Andrx Pharmaceuticals, $L L C$, we affirmed a judgment of nonenablement where the specification provided "only a starting point, a direction for further research." We concluded that one of ordinary skill "would 
have been required to engage in an iterative, trial-and-error process to practice the claimed invention even with the help of the specification." Finally, in In re Vaeck, we affirmed the PTO's nonenablement rejection of claims reciting heterologous gene expression in as many as 150 genera of cyanobacteria. The specification disclosed only nine genera, despite cyanobacteria being a "diverse and relatively poorly understood group of microorganisms," with unpredictable heterologous gene expression. Here, the specification similarly discloses only a starting point for further iterative research in an unpredictable and poorly understood field. Synthesizing candidate compounds derived from sirolimus could, itself, require a complicated and lengthy series of experiments in synthetic organic chemistry. Even putting the challenges of synthesis aside, one of ordinary skill would need to assay each of at least tens of thousands of candidates. Wyeth's expert conceded that it would take technicians weeks to complete each of these assays. The specification offers no guidance or predictions about particular substitutions that might preserve the immunosuppressive and antirestenotic effects observed in sirolimus. The resulting need to engage in a systematic screening process for each of the many rapamycin candidate compounds is excessive experimentation. We thus hold that there is no genuine dispute that practicing the full scope of the claims, measured at the filing date, required undue experimentation.

\section{Plastic Dye Problem}

You are drafting claims for a patent application for an industrial dye that turns certain plastics an attractive shade of blue. Your client has tested it, with success, on PETE, HDPE, PEEK, and PVDC (all semicrystalline plastics). You could draft a broad claim that refers to "plastic" or you could draft a narrow claim that refers to "a plastic selected from the group of PETE, HDPE, PEEK, and PVDC." What are the advantages and disadvantages of each approach?

\section{b Written Description}

598 F.3d 1336 (Fed Cir. 2010) (en banc)

\section{Ariad Pharmaceuticals, Inc. v. Eli Lilly and Co}

Since its inception, this court has consistently held that $\S 112$, first paragraph, contains a written description requirement separate from enablement, and we have articulated a fairly uniform standard, which we now affirm. Specifically, the description must clearly allow persons of ordinary skill in the art to recognize that the inventor invented what is claimed. In other words, the test for sufficiency is whether the disclosure of the application relied upon reasonably conveys to those skilled in the art that the inventor had possession of the claimed subject matter as of the filing date. 
The term "possession," however, has never been very enlightening. It implies that as long as one can produce records documenting a written description of a claimed invention, one can show possession. But the hallmark of written description is disclosure. Thus, "possession as shown in the disclosure" is a more complete formulation. Yet whatever the specific articulation, the test requires an objective inquiry into the four corners of the specification from the perspective of a person of ordinary skill in the art. Based on that inquiry, the specification must describe an invention understandable to that skilled artisan and show that the inventor actually invented the invention claimed.

We have made clear that the written description requirement does not demand either examples or an actual reduction to practice; a constructive reduction to practice that in a definite way identifies the claimed invention can satisfy the written description requirement. Conversely, we have repeatedly stated that actual "possession" or reduction to practice outside of the specification is not enough. Rather, as stated above, it is the specification itself that must demonstrate possession. And while the description requirement does not demand any particular form of disclosure, or that the specification recite the claimed invention in haec verba, a description that merely renders the invention obvious does not satisfy the requirement.

\section{c Best Mode}

\section{Manual of Patent Examination Procedure (Rev. Nov. 2013)}

The best mode requirement is a safeguard against the desire on the part of some people to obtain patent protection without making a full disclosure as required by the statute. The requirement does not permit inventors to disclose only what they know to be their secondbest embodiment, while retaining the best for themselves.

Determining compliance with the best mode requirement requires a two-prong inquiry. First, it must be determined whether, at the time the application was filed, the inventor possessed a best mode for practicing the invention. This is a subjective inquiry which focuses on the inventor's state of mind at the time of filing. Second, if the inventor did possess a best mode, it must be determined whether the written description disclosed the best mode such that a person skilled in the art could practice it. This is an objective inquiry, focusing on the scope of the claimed invention and the level of skill in the art. All applicants are required to disclose for the claimed subject matter the best mode contemplated by the inventor even if the inventor was not the discoverer of that mode.

$\S 2165$

The Best Mode Requirement 
Failure to disclose the best mode need not rise to the level of active concealment or inequitable conduct in order to support a rejection. Where an inventor knows of a specific material or method that will make possible the successful reproduction of the claimed invention, but does not disclose it, the best mode requirement has not been satisfied.

Section 15 of the Leahy-Smith America Invents Act (AIA) did not eliminate the requirement for a disclosure of the best mode, but effective September 16, 2011, it amended 35 U.S.C. 282 (the provision that sets forth defenses in a patent validity or infringement proceeding) to provide that the failure to disclose the best mode shall not be a basis on which any claim of a patent may be canceled or held invalid or otherwise unenforceable. As this change is applicable only in patent validity or infringement proceedings, it does not alter current patent examining practices as set forth above for evaluation of an application for compliance with the best mode requirement of 35 U.S.C. 112.

\section{Salt Shaker Problem}

Assume that you represent the inventor of the first screw-top salt shaker. (In this alternate universe, prior art salt shakers were filled through a hole in the bottom.) Draft a claim for this new invention. Suggestions:

- What are the constituent parts of the screw-top shaker? Your claim will need to describe them and explain how they are related.

- Which features of the screw-top shaker are essential to its use? Which can safely be omitted?

- Once the new screw-top shaker is publicly available, competing shaker-makers will try to invent around the patent. How can you make their job harder?

- Inventors in other industries may be inspired by the screw-top design. Can you make sure that your claim is not restricted to the one use your client has in mind? 


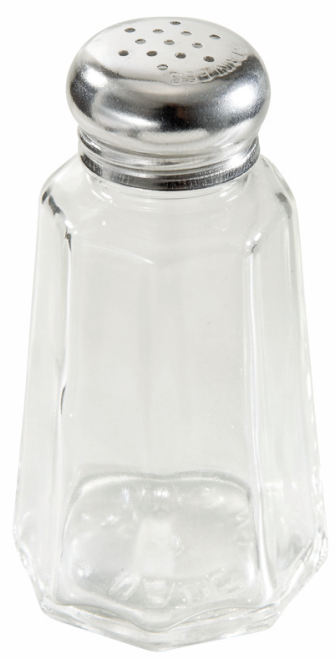

\section{Patent Prosecution}

Cuozzo Speed Technologies, LLC v. Lee

An inventor obtains a patent by applying to the Patent Office. A patent examiner with expertise in the relevant field reviews an applicant's patent claims, considers the prior art, and determines whether each claim meets the applicable patent law requirements.

If the examiner rejects a claim, the applicant can resubmit a narrowed (or otherwise modified) claim, which the examiner will consider anew, measuring the new claim against the same patent law requirements. If the examiner rejects the new claim, the inventor typically has yet another chance to respond with yet another amended claim. Ultimately, the Patent Office makes a final decision allowing or rejecting the application. The applicant may seek judicial review of any final rejection.

\section{Patent Act}

(a) Confidentiality. - Except as provided in subsection (b), applications for patents shall be kept in confidence by the Patent and Trademark Office.

(b) Publication. -

(1)(A) Subject to paragraph (2), each application for a patent shall be published, in accordance with procedures determined by the Director, promptly after the expiration of a period of 18 months from the earliest filing date for which a benefit is sought under this title. At the request of the applicant, an application may be published earlier than the end of such 18-month period. 
37 C.F.R. § 1.56(a) (2015)

Duty to disclose information material to patentability.
(2)(B)(i) If an applicant makes a request upon filing, certifying that the invention disclosed in the application has not and will not be the subject of an application filed in another country, or under a multilateral international agreement, that requires publication of applications 18 months after filing, the application shall not be published as provided in paragraph (1)

\section{Code of Federal Regulations}

A patent by its very nature is affected with a public interest. The public interest is best served, and the most effective patent examination occurs when, at the time an application is being examined, the Office is aware of and evaluates the teachings of all information material to patentability. Each individual associated with the filing and prosecution of a patent application has a duty of candor and good faith in dealing with the Office, which includes a duty to disclose to the Office all information known to that individual to be material to patentability as defined in this section. The duty to disclose information exists with respect to each pending claim until the claim is cancelled or withdrawn from consideration, or the application becomes abandoned.

Therasense, Inc. v. Becton, Dickinson and Co.

649 F.3d 1276 (Fed. Cir. 2011) (en banc) that, if proved, bars enforcement of a patent. This judge-made doctrine evolved from a trio of Supreme Court cases that applied the doctrine of unclean hands to dismiss patent cases involving egregious misconduct before the PTO.

As the inequitable conduct doctrine evolved from these unclean hands cases, it came to embrace a broader scope of misconduct, including not only egregious affirmative acts of misconduct intended to deceive both the PTO and the courts but also the mere nondisclosure of information to the PTO. Inequitable conduct also diverged from the doctrine of unclean hands by adopting a different and more potent remedy - unenforceability of the entire patent rather than mere dismissal of the instant suit.

To prevail on a claim of inequitable conduct, the accused infringer must prove that the patentee acted with the specific intent to deceive the PTO. A finding that the misrepresentation or omission amounts to gross negligence or negligence under a "should have known" standard does not satisfy this intent requirement. In a case involving nondisclosure of information, clear and convincing evidence must show that the applicant made a deliberate decision to withhold a known material reference. In other words, the accused infringer must 
prove by clear and convincing evidence that the applicant knew of the reference, knew that it was material, and made a deliberate decision to withhold it.

Because direct evidence of deceptive intent is rare, a district court may infer intent from indirect and circumstantial evidence. However, to meet the clear and convincing evidence standard, the specific intent to deceive must be the single most reasonable inference able to be drawn from the evidence. Indeed, the evidence must be sufficient to require a finding of deceitful intent in the light of all the circumstances.

This court holds that, as a general matter, the materiality required to establish inequitable conduct is but-for materiality. When an applicant fails to disclose prior art to the PTO, that prior art is but-for material if the PTO would not have allowed a claim had it been aware of the undisclosed prior art.

a Priority Dates

\section{USPTO, General Information Concerning Patents}

A provisional application for patent (provisional application) is a U.S. national application filed in the USPTO under 35 U.S.C. $\S 111(\mathrm{~b})$. A provisional application is not required to have a formal patent claim or an oath or declaration. Provisional applications also should not include any information disclosure (prior art) statement since provisional applications are not examined. A provisional application provides the means to establish an early effective filing date in a later filed nonprovisional patent application filed under 35 U.S.C. § 111(a). It also allows the term "Patent Pending" to be applied in connection with the description of the invention.

A provisional application for patent has a pendency lasting 12 months from the date the provisional application is filed. The 12month pendency period cannot be extended. Therefore, an applicant who files a provisional application must file a corresponding nonprovisional application for patent (nonprovisional application) during the 12-month pendency period of the provisional application in order to benefit from the earlier filing of the provisional application.

b Multiple Applications

\section{Patent Act}

If two or more independent and distinct inventions are claimed in one application, the Director may require the application to be restricted

35 U.S.C. § 121

Divisional Applications 
MPEP § 201.07

Continuation Application

MPEP § 201.08

Continuation-in-Part Application to one of the inventions. If the other invention is made the subject of a divisional application it shall be entitled to the benefit of the filing date of the original application. The validity of a patent shall not be questioned for failure of the Director to require the application to be restricted to one invention.

Manual of Patent Examination Procedure (Rev. July. 2015)

A continuation application is an application for the invention(s) disclosed in a prior-filed copending nonprovisional application. The disclosure presented in the continuation must not include any subject matter which would constitute new matter if submitted as an amendment to the parent application. The inventorship in the continuation application must include at least one inventor named in the priorfiled application. At any time before the patenting, abandonment, or termination of proceedings on an earlier application, an applicant may have recourse to filing a continuation application in order to introduce into the application a new set of claims and to establish a right to further examination by the Office.

A continuation-in-part is an application filed during the lifetime of an earlier nonprovisional application, repeating some substantial portion or all of the earlier nonprovisional application and adding matter not disclosed in the said earlier nonprovisional application.

What's the difference? Divisionals and continuations repeat the specification of their parent applications; they are entitled to share its priority date. Divisionals are required when the examiner concludes that an inventor is trying to claim two distinct inventions in the same patent; they split the claims across two distinct applications. Continuations allow an applicant to appeal the rejection of claims, or to add new claims, without holding up the examination and issuance of the claims the examiner allows. A continuation-in-part (CIP) adds new subject matter to the specification, so it is not automatically entitled to the same priority date. Instead, priority dates are assessed on a claim-by-claim basis.

\section{c Judicial Review}

Applicants can appeal rejections to the Patent Trial and Appeal Board (PTAB). 35 U.S.C. § 134(a). If the PTAB also rejects the application, the applicant can seek judicial review either before the Federal Circuit, $i d$. $\S 141$, or the Eastern District of Virginia, id. $\S 145$. 
d Post-Grant Proceedings

\section{Patent Act}

(a) In general. - Whenever any patent is, through error, deemed wholly or partly inoperative or invalid, by reason of a defective specification or drawing, or by reason of the patentee claiming more or less than he had a right to claim in the patent, the Director shall, on the surrender of such patent and the payment of the fee required by law, reissue the patent for the invention disclosed in the original patent, and in accordance with a new and amended application, for the unexpired part of the term of the original patent. No new matter shall be introduced into the application for reissue.

(d) Reissue patent enlarging scope of claims. - No reissued patent shall be granted enlarging the scope of the claims of the original patent unless applied for within two years from the grant of the original patent.

\section{Cuozzo Speed Technologies, LLC v. Lee}

For several decades, the Patent Office has also possessed the authority to reexamine - and perhaps cancel - a patent claim that it had previously allowed. In 1980, for example, Congress enacted a statute providing for "ex parte reexamination.". That statute (which remains in effect) gives "any person at any time" the right to "file a request for reexamination" on the basis of certain prior art "bearing on the patentability" of an already-issued patent. If the Patent Office concludes that the cited prior art raises "a substantial new question of patentability," the agency can reexamine the patent. And that reexamination can lead the Patent Office to cancel the patent (or some of its claims). Alternatively, the Director of the Patent Office can, on her "own initiative," trigger such a proceeding. And, as with examination, the patent holder can seek judicial review of an adverse final decision.

In 1999 and 2002, Congress enacted statutes that established another, similar procedure, known as "inter partes reexamination." Those statutes granted third parties greater opportunities to participate in the Patent Office's reexamination proceedings as well as in any appeal of a Patent Office decision.

In 2011, Congress enacted the statute before us. That statute modifies "inter partes reexamination," which it now calls "inter partes review" (IPR). Like inter partes reexamination, any third party can ask the agency to initiate inter partes review of a patent claim. But the new statute has changed the standard that governs the Patent Office's

35 U.S.C. § 251

Reissue of defective patents

136 S. Ct. 2131 (2016)

See 35 U.S.C. S 302 et seq.

See 35 U.S.C. § 311 et seq. 
37 CFR S 42.100(b). Why would the PTO use a different standard of construction than the courts? Why would it matter?

See 35 U.S.C. § 321 et seq.

See AIA § 18 institution of the agency's process. Instead of requiring that a request for reexamination raise a "substantial new question of patentability," it now requires that a petition show "a reasonable likelihood that" the challenger "would prevail."

The new statute provides a challenger with broader participation rights. It creates within the Patent Office a Patent Trial and Appeal Board (Board) composed of administrative patent judges, who are patent lawyers and former patent examiners, among others. That Board conducts the proceedings, reaches a conclusion, and sets forth its reasons.

The statute sets forth time limits for completing this review. It grants the Patent Office the authority to issue rules. Like its predecessors, the statute authorizes judicial review of a "final written decision" canceling a patent claim. And, the statute says that the agency's initial decision "whether to institute an inter partes review" is "final and nonappealable." Like the Court of Appeals, we believe that Cuozzo's contention that the Patent Office unlawfully initiated its agency review is not appealable.

Cuozzo further argues that the Patent Office lacked the legal authority to issue its regulation requiring the agency, when conducting an inter partes review, to give a patent claim "its broadest reasonable construction in light of the specification of the patent in which it appears." Instead, Cuozzo contends that the Patent Office should, like the courts, give claims their ordinary meaning as understood by a person of skill in the art.

The statute, however, contains a provision that grants the Patent Office authority to issue "regulations ... establishing and governing inter partes review under this chapter." The Court of Appeals held that this statute gives the Patent Office the legal authority to issue its broadest reasonable construction regulation. We agree.

Even more confusingly, the AIA also introduced "post-grant review" (PGR). PGR is only available within nine months after a patent issues - except for a "transitional" program that allows for PGR of any "covered business method patent" at any time, but sunsets in 2020. IPR becomes available after the nine-month PGR window closes. The major differences are that IPR only allows for challenges under $\S 102$ (novelty) and $\S 103$ (nonobviousness) and that the threshold for the PTO to hear an IPR is higher. Paradoxically, because of the wider range of challenges available in PGR, the potential estoppel against parties who bring one is much broader. 


\section{Term}

\section{Patent Act}

Subject to the payment of fees under this title, such grant shall be for a term beginning on the date on which the patent issues and ending 20 years from the date on which the application for the patent was filed in the United States or, if the application contains a specific reference to an earlier filed application or applications under section 120,121, 365(c), or 386(c), from the date on which the earliest such application was filed.

Section 135 also contains an extensive and intricate set of provisions for adjusting the patent term "if the issue of an original patent is delayed due to the failure of the Patent and Trademark Office" to act expeditiously, as specified by the statute, in its examination of the application.

\section{Ownership}

\section{Collaborations}

\section{Manual of Patent Examination Procedure (Rev. Nov. 2013)}

The inventor, or each individual who is a joint inventor of a claimed invention, in an application for patent (other than a provisional application) must execute an oath or declaration directed to the application, except as provided for in 37 CFR 1.64.

The definition for inventorship can be simply stated: The threshold question in determining inventorship is who conceived the invention. Unless a person contributes to the conception of the invention, he is not an inventor. Insofar as defining an inventor is concerned, reduction to practice, per se, is irrelevant. One must contribute to the conception to be an inventor. With regard to the inventorship of chemical compounds, an inventor must have a conception of the specific compounds being claimed. General knowledge regarding the anticipated biological properties of groups of complex chemical compounds is insufficient to confer inventorship status with respect to specifically claimed compounds. One who suggests an idea of a result to be accomplished, rather than the means of accomplishing it, is not an coinventor. See MPEP $\S 2138.04-\S 2138.05$ for a discussion
$\S 135$

Contents and term of patent

Prior to June 8, 1995, patent terms were set at 17 years from the date of the patent grant. Given that applicants can partially control the pace at which applications move, can you think of ways this rule was vulnerable to gamesmanship?

$\S 2137$

Inventorship 
Mattor: 530 F.2d 1391 (CCPA 1976)

Tucker: ,

Carrier: 81 F.2d 250 (CCPA 1936) of what evidence is required to establish conception or reduction to practice.

In arriving at conception the inventor may consider and adopt ideas and materials derived from many sources such as a suggestion from an employee, or hired consultant so long as he maintains intellectual domination of the work of making the invention down to the successful testing, selecting or rejecting as he goes even if such suggestion or material proves to be the key that unlocks his problem. (Adoption of the ideas and materials from another can become a derivation.)

Difficulties arise in separating members of a team effort, where each member of the team has contributed something, into those members that actually contributed to the conception of the invention, such as the physical structure or operative steps, from those members that merely acted under the direction and supervision of the conceivers. It is not essential for the inventor to be personally involved in carrying out process steps where implementation of those steps does not require the exercise of inventive skill. There is no requirement that the inventor be the one to reduce the invention to practice so long as the reduction to practice was done on his behalf. See also Mattor $v$. Coolegem (one following oral instructions is viewed as merely a technician); Tucker v. Naito 188 USPQ 260 (Bd. Pat. Inter. 1975) (inventors need not "personally construct and test their invention"); Davis v. Carrier (noninventor's work was merely that of a skilled mechanic carrying out the details of a plan devised by another).

The inventive entity for a particular application is based on some contribution to at least one of the claims made by each of the named inventors. "Inventors may apply for a patent jointly even though (1) they did not physically work together or at the same time, (2) each did not make the same type or amount of contribution, or (3) each did not make a contribution to the subject matter of every claim of the patent." The statute neither states nor implies that two inventors can be "joint inventors" if they have had no contact whatsoever and are completely unaware of each other's work. What is required is some quantum of collaboration or connection. In other words, for persons to be joint inventors, there must be some element of joint behavior, such as collaboration or working under common direction, one inventor seeing a relevant report and building upon it or hearing another's suggestion at a meeting. It is not necessary that the inventive concept come to both joint inventors at the same time.

Each joint inventor must generally contribute to the conception of the invention. A coinventor need not make a contribution to every claim of a patent. A contribution to one claim is enough. "The contributor of any disclosed means of a means-plus-function claim element is a joint inventor as to that claim, unless one asserting sole 
inventorship can show that the contribution of that means was simply a reduction to practice of the sole inventor's broader concept." Ethicon Inc. v. United States Surgical Corp. (The electronics technician who contributed to one of the two alternative structures in the specification to define "the means for detaining" in a claim limitation was held to be a joint inventor.).

\section{Patent Act}

(a) Institution of Proceeding. -

(1) In general. - An applicant for patent may file a petition with respect to an invention to institute a derivation proceeding in the Office. The petition shall set forth with particularity the basis for finding that an individual named in an earlier application as the inventor or a joint inventor derived such invention from an individual named in the petitioner's application as the inventor or a joint inventor and, without authorization, the earlier application claiming such invention was filed.

(b) Determination by Patent Trial and Appeal Board. - In a derivation proceeding instituted under subsection (a), the Patent Trial and Appeal Board shall determine whether an inventor named in the earlier application derived the claimed invention from an inventor named in the petitioner's application and, without authorization, the earlier application claiming such invention was filed. In appropriate circumstances, the Patent Trial and Appeal Board may correct the naming of the inventor in any application or patent at issue.

\section{Priority: Novelty and Statutory Bars}

Priority rules determine which of competing claimants is entitled to an IP right based on an earlier claim. It is rarely as simple as "first in time" because what counts as "first" could be assessed in different ways. Priority rules select one of these ways of determining who is "first" and determine the consequences of this fact. As we shall also see, U.S. patent law mostly creates priority by preventing all but oneor sometimes all - of the potential claimants from obtaining a patent. As we shall also see, the AIA dramatically changed the priority rules of U.S. patent law; it is the single biggest change made by the AIA.

Under Section 102, an applicant "shall be entitled to a patent unless" someone somewhere has done something that makes the invention not patentable. That something is called a prior art reference and it is said to anticipate the applicant's invention. Conceptually, any such rule raises three questions:
Ethicon: 135 F.3d 1456 (Fed. Cir. 1998)

35 U.S.C. § 135

Derivation proceedings 
- Which kinds of activities count as prior art? The present section 102 uses the words "patented, described in a printed publication, or in public use, on sale, or otherwise available to the public." They are broad, but they do not exhaust the universe of human activity. If Alfie files for a patent on an oven of a type that Beth once built and then demolished without using or telling anyone else, Beth's secret use does not quality as prior art and will not stand in the way of Alfie's application. Extensive caselaw glosses the meanings of these phrases, which are far subtler than they may appear at first glance, and which have changed substantially over time.

- What makes a prior art reference sufficiently similar to the applicant's "claimed invention" to make it unpatentable? If Alfie applies to patent an oven, Beth's previous work on metalworking is irrelevant to the novelty of Alfie's oven. Patent law has settled on a remarkably elegant test to capture this idea: the test for anticipation is simply the test for infringement plus the test for enablement. A claim is anticipated by an enabling prior art reference (and hence not novel) if that reference would infringe the claim. "That which infringes, if later, would anticipate, if earlier." Peters v. Active Mfg. Co..

- When must an activity have taken place to qualify as prior art? The present section 102 uses the words "before the effective filing date of the claimed invention," so the patent applicant must not only think of the invention and make it work but must also make it to the Patent Office before anyone else goes public with the same idea. If Alfie invents in January and files in March but Beth publishes (or worse, files her own application) in February, Alfie is out of luck. This is one of the major changes in the America Invents Act: under pre-AIA law, Alfie's March application based off a January invention date would have been good enough. As we dig into the text of the AIA, we will see why it is said to create a rule of "first inventor to file."

Not coincidentally, these are the same kinds of questions one must also ask about infringement: what kinds of conduct are prohibited, what makes a defendant's use too similar, and when does it fall within the term of the plaintiff's rights? This symmetry is baked into patent law, as it is to many other fields of intellectual property law.

\section{a Categories of Prior Art}

Under the new $\S 102(\mathrm{a})(1)$, "A person shall be entitled to a patent unless the claimed invention was patented, described in a printed publication, or in public use, on sale, or otherwise available to the public before the effective filing date of the claimed invention." Most of the caselaw 
bearing on these phrases was developed under the old § 102; significant relevant differences will be noted.

\section{1 "patented"}

U.S. patents pose few conceptual or practical difficulties; they are prior art as of the day they issue. It is not always so easy to tell whether a foreign right is a "patent" within the meaning of $\S 102$. In re Carlson held that a German Geschmacksmuster counted as a patent for prior art purposes. A person may obtain one by "depositing with a local office an application with a drawing, photograph or sample of the article." That was enough, even though "Geschmacksmuster on display for public view in remote cities in a far-away land may create a burden of discovery for one without the time, desire, or resources to journey there in person or by agent to observe that which was registered and protected under German law." Such is life.

\section{2 "described in a printed publication"}

\section{In re Klopfenstein}

Carol Klopfenstein and John Brent appeal a decision from the Patent and Trademark Office's Board of Patent Appeals and Interferences ("Board") upholding the denial of their patent application. The Board upheld the Patent and Trademark Office's ("PTO's") initial denial of their application on the ground that the invention described in the patent application was not novel under 35 U.S.C. § 102(b) because it had already been described in a printed publication more than one year before the date of the patent application. We affirm.

\section{BACKGROUND}

The appellants applied for a patent on October 30, 2000. Their patent application, Patent Application Serial No. 09/699,950 ("the '950 application"), discloses methods of preparing foods comprising extruded soy cotyledon fiber ("SCF"). The '950 application asserts that feeding mammals foods containing extruded SCF may help lower their serum cholesterol levels while raising HDL cholesterol levels. The fact that extrusion reduces cholesterol levels was already known by those of ordinary skill in the art that worked with SCF. What was not known at the time was that double extrusion increases this effect and yielded even stronger results.

In October 1998, the appellants, along with colleague M. Liu, presented a printed slide presentation ("Liu" or "the Liu reference") entitled "Enhancement of Cholesterol-Lowering Activity of Dietary Fibers By Extrusion Processing" at a meeting of the American Association of Cereal Chemists ("AACC"). The fourteen-slide presentation 
was printed and pasted onto poster boards. The printed slide presentation was displayed continuously for two and a half days at the AACC meeting.

In November of that same year, the same slide presentation was put on display for less than a day at an Agriculture Experiment Station ("AES") at Kansas State University.

Both parties agree that the Liu reference presented to the AACC and at the AES in 1998 disclosed every limitation of the invention disclosed in the '950 patent application. Furthermore, at neither presentation was there a disclaimer or notice to the intended audience prohibiting note-taking or copying of the presentation. Finally, no copies of the presentation were disseminated either at the AACC meeting or at the AES, and the presentation was never catalogued or indexed in any library or database.

\section{DISCUSSION}

$B$.

The appellants argue on appeal that the key to establishing whether or not a reference constitutes a "printed publication" lies in determining whether or not it had been disseminated by the distribution of reproductions or copies and/or indexed in a library or database. They assert that because the Liu reference was not distributed and indexed, it cannot count as a "printed publication" for the purposes of 35 U.S.C. $\S 102(b)$. To support their argument, they rely on several precedents from this court and our predecessor court on "printed publications."

Cronyn: F.2d 1158 (Fed. Cir. 1989)

Hall: 781 F.2d 897 (Fed. Cir. 1986) MIT: 774 F.2d 1104 (Fed. Cir. 1985) Wyer: 655 F.2d 221 (CCPA 1981)
They argue that In re Cronyn, In re Hall, Massachusetts Institute of Technology v. AB Fortia, and In re Wyer, among other cases, all support the view that distribution and/or indexing is required for something to be considered a "printed publication."

We find the appellants' argument unconvincing and disagree with their characterization of our controlling precedent. Even if the cases cited by the appellants relied on inquiries into distribution and indexing to reach their holdings, they do not limit this court to finding something to be a "printed publication" only when there is distribution and/or indexing. Indeed, the key inquiry is whether or not a reference has been made "publicly accessible."

The statutory phrase "printed publication" has been interpreted to mean that before the critical date the reference must have been sufficiently accessible to the public interested in the art; dissemination and public accessibility are the keys to the legal determination whether a prior art reference was "published."

For example, a public billboard targeted to those of ordinary skill in the art that describes all of the limitations of an invention and that is on display for the public for months may be neither "distributed" nor 
"indexed" - but it most surely is "sufficiently accessible to the public interested in the art" and therefore, under controlling precedent, a "printed publication."

Furthermore, the cases that the appellants rely on can be clearly distinguished from this case. Cronyn involved college students' presentations of their undergraduate theses to a defense committee made up of four faculty members. Their theses were later catalogued in an index in the college's main library. The index was made up of thousands of individual cards that contained only a student's name and the title of his or her thesis. The index was searchable by student name and the actual theses themselves were neither included in the index nor made publicly accessible. We held that because the theses were only presented to a handful of faculty members and had not been catalogued or indexed in a meaningful way, they were not sufficiently publicly accessible for the purposes of 35 U.S.C. § 102(b).

In Hall, this court determined that a thesis filed and indexed in a university library did count as a "printed publication." The Hall court arrived at its holding after taking into account that copies of the indexed thesis itself were made freely available to the general public by the university more than one year before the filing of the relevant patent application in that case. But the court in Hall did not rest its holding merely on the indexing of the thesis in question. Instead, it used indexing as a factor in determining "public accessibility." As the court asserted:

The "printed publication" bar is grounded on the principle that once an invention is in the public domain, it is no longer patentable by anyone. Because there are many ways in which a reference may be disseminated to the interested public, "public accessibility" has been called the touchstone in determining whether a reference constitutes a "printed publication" bar under 35 U.S.C. § 102(b).

In MIT, a paper delivered orally to the First International Cell Culture Congress was considered a "printed publication." In that case, as many as 500 persons having ordinary skill in the art heard the presentation, and at least six copies of the paper were distributed. The key to the court's finding was that actual copies of the presentation were distributed. The court did not consider the issue of indexing. The MIT court determined the paper in question to be a "printed publication" but did not limit future determinations of the applicability of the "printed publication" bar to instances in which copies of a reference were actually offered for distribution. 4

\footnotetext{
${ }^{4}$ With regard to scientific presentations, it is important to note than an entirely oral presentation at a scientific conference that includes neither slides nor copies of
} 
Finally, the Wyer court determined that an Australian patent application kept on microfilm at the Australian Patent Office was sufficiently accessible to the public and to persons skilled in the pertinent art to qualify as a "printed publication." The court so found even though it did not determine whether or not there was "actual viewing or dissemination" of the patent application. Id. It was sufficient for the court's purposes that the records of the application were kept so that they could be accessible to the public. Id. . According to the Wyer court, the entire purpose of the "printed publication" bar was to "prevent withdrawal" of disclosures already in the possession of the public by the issuance of a patent.

Thus, throughout our case law, public accessibility has been the criterion by which a prior art reference will be judged for the purposes of $\S 102(\mathrm{~b})$. Oftentimes courts have found it helpful to rely on distribution and indexing as proxies for public accessibility. But when they have done so, it has not been to the exclusion of all other measures of public accessibility. In other words, distribution and indexing are not the only factors to be considered in a § 102(b) "printed publication" inquiry.

C.

In this case, the Liu reference was displayed to the public approximately two years before the ' 950 application filing date. The reference was shown to a wide variety of viewers, a large subsection of whom possessed ordinary skill in the art of cereal chemistry and agriculture. Furthermore, the reference was prominently displayed for approximately three cumulative days at AACC and the AES at Kansas State University. The reference was shown with no stated expectation that the information would not be copied or reproduced by those viewing it. Finally, no copies of the Liu display were distributed to the public and the display was not later indexed in any database, catalog or library.

The duration of the display is important in determining the opportunity of the public in capturing, processing and retaining the information conveyed by the reference. The more transient the display, the less likely it is to be considered a "printed publication." Conversely, the longer a reference is displayed, the more likely it is to

the presentation is without question not a "printed publication" for the purposes of 35 U.S.C. § 102(b). Furthermore, a presentation that includes a transient display of slides is likewise not necessarily a "printed publication." See, e.g., Regents of the Univ. of Cal. v. Howmedica, Inc., 530 F.Supp. 846 (D.N.J. 1981) (holding that "the projection of slides at the lecture that was limited in duration and could not disclose the invention to the extent necessary to enable a person of ordinary skill in the art to make or use the invention" was not a "printed publication").

${ }^{5}$ Unlike in Cronyn, it was the actual patent application - and not just an index card searchable by author name only - that was made publicly accessible. 
be considered a "printed publication." In this case, the Liu reference was displayed for a total of approximately three days. It was shown at the AACC meeting for approximately two and a half days and at the AES at Kansas State University for less than one day.

The expertise of the intended audience can help determine how easily those who viewed it could retain the displayed material. As Judge Learned Hand explained in Jockmus v. Leviton, a reference, "however ephemeral its existence," may be a "printed publication" if it "goes direct to those whose interests make them likely to observe and remember whatever it may contain that is new and useful." In this case, the intended target audience at the AACC meeting was comprised of cereal chemists and others having ordinary skill in the art of the ' 950 patent application. The intended viewers at the AES most likely also possessed ordinary skill in the art.

Whether a party has a reasonable expectation that the information it displays to the public will not be copied aids our § 102(b) inquiry. Where professional and behavioral norms entitle a party to a reasonable expectation that the information displayed will not be copied, we are more reluctant to find something a "printed publication." This reluctance helps preserve the incentive for inventors to participate in academic presentations or discussions. Where parties have taken steps to prevent the public from copying temporarily posted information, the opportunity for others to appropriate that information and assure its widespread public accessibility is reduced. These protective measures could include license agreements, non-disclosure agreements, anti-copying software or even a simple disclaimer informing members of the viewing public that no copying of the information will be allowed or countenanced. Protective measures are to be considered insofar as they create a reasonable expectation on the part of the inventor that the displayed information will not be copied. In this case, the appellants took no measures to protect the information they displayed - nor did the professional norms under which they were displaying their information entitle them to a reasonable expectation that their display would not be copied. There was no disclaimer discouraging copying, and any viewer was free to take notes from the Liu reference or even to photograph it outright.

Finally, the ease or simplicity with which a display could be copied gives further guidance to our $\S 102$ (b) inquiry. The more complex a display, the more difficult it will be for members of the public to effectively capture its information. The simpler a display is, the more likely members of the public could learn it by rote or take notes adequate enough for later reproduction. The Liu reference was made up of 14 separate slides. One slide was a title slide; one was an acknowledgement slide; and four others represented graphs and charts of experiment results. The other eight slides contained information pre- 
Suppose that the Liu presentation had not been shown at the AACC meeting but instead been posted to Liu's personal webpage. Printed publication? What if Liu had emailed it to a mailing list for cereal chemists? Are there further questions you would want to ask before committing to an answer on either of these hypotheticals?

It also used the phrase "in this country," which the AIA drops. Don't worry about the geographic issues for now.

93 Tex. L. Rev. 1119 (2015) sented in bullet point format, with no more than three bullet points to a slide. Further, no bullet point was longer than two concise sentences. Finally, as noted earlier, the fact that extrusion lowers cholesterol levels was already known by those who worked with SCF. The discovery disclosed in the Liu reference was that double extrusion increases this effect. As a result, most of the eight substantive slides only recited what had already been known in the field, and only a few slides presented would have needed to have been copied by an observer to capture the novel information presented by the slides.

Upon reviewing the above factors, it becomes clear that the Liu reference was sufficiently publicly accessible to count as a "printed publication" for the purposes of 35 U.S.C. $§ 102(b)$. The reference itself was shown for an extended period of time to members of the public having ordinary skill in the art of the invention behind the ' 950 patent application. Those members of the public were not precluded from taking notes or even photographs of the reference. And the reference itself was presented in such a way that copying of the information it contained would have been a relatively simple undertaking for those to whom it was exposed - particularly given the amount of time they had to copy the information and the lack of any restrictions on their copying of the information. For these reasons, we conclude that the Liu reference was made sufficiently publicly accessible to count as a "printed publication" under $\S 102(\mathrm{~b})$.

\section{3 "in public use"}

The old $\S 102$ got at this concept in two different ways. It denied a patent where the invention was "known or used by others" before the date of invention (a "novelty" rule) or where it was "in public use" more than a year before the filing date (a "statutory bar"). While the two provisions differed in their timing (more on this in the Priority section below), the most fundamental distinction was that "known or used by others" only applied to uses made by third parties, whereas "in public use" also could be triggered by anyone, including the inventor.

\section{Mark A. Lemley}

\section{Does "Public Use" Mean the Same Thing It Did Last Year?}

An inventor can obtain a patent only if the invention is "novel" - that is, that no one has done the same thing before. Rather than adopting an absolute novelty rule, however, patent law has traditionally required that most categories of prior art be "accessible to the public." Thus, while [old] 35 U.S.C. $§ 102(a)$ bars a patent if the invention was "known or used by others" before the applicant invented it, courts have interpreted that term to mean "publicly known or used." At 
the same time, the public accessibility requirement does not require that the public have a realistic chance of accessing the information; "public" seems to mean merely "not secret." An invention performed underground on private property in a rural area, an invention found only inside the walls of a safe, and a single copy of a graduate thesis in the basement of a library in Germany have all been held sufficiently "public" to constitute prior art.

In addition to novelty, the Patent Act of 1952, like its predecessors, created a series of "statutory bars" designed to prevent inventors from making commercial use of their invention while keeping it secret. [Old] section 102(b) provides that even a true first inventor is not entitled to a patent if the invention has been "on sale" or "in public use" more than a year before the inventor files her patent application. As with [old] section 102(a), the courts have interpreted the word "public" quite loosely, so that even uses that are extremely unlikely to be viewed by the public are nonetheless classed as "public uses" so long as they are not affirmatively secret. In the most extreme example, the Supreme Court held that a woman engaged in a public use of a corset invented by her fiancé when she wore it under her clothing.

But even a very broad definition of "public" left a significant loophole - an inventor could avoid the one-year statutory bar by commercializing his invention but treating it as a trade secret. Because a secret use is by definition not a public use, a company could make commercial use of an invention indefinitely without triggering the one-year period for filing. To solve this problem, courts for more than seventy years have created a special rule for secret commercial uses: a secret commercial use is not prior art that bars a third party from later obtaining a patent, but it does start the one-year clock running for the user. This rule originated in a 1940 opinion by Judge Learned Hand in Metallizing Engineering v. Kenyon Bearing \& Auto Parts. The court acknowledged that interpreting the same term ("public use") to have different meanings was hard to reconcile with the statute. But Judge Hand reasoned that it was not the intent of the statute to encourage secrecy, but instead to encourage disclosure. Metallizing's split interpretation of public use served that goal in two ways. First, it encouraged inventors to file a patent quickly rather than relying in trade secrecy, because they would lose the right to patent if they waited longer than a year. Second, the fact that a secret commercial use wouldn't prevent a later patent from issuing to a third party adds to the disclosure incentive, because an inventor who opts for trade secrecy may find that a later inventor has patented their own idea and there is nothing they can do to stop it.
Metallizing: 153 F.2d 516 (2d Cir. 1946)

It is a condition upon an inventor's right to a patent that he shall not exploit his discovery competitively after it is ready for patenting. [If he does,] he forfeits his right regardless of how little the public may have learned about the invention." -Judge Hand 
The PTO takes the position that the AIA, by collapsing the two phrases ("known or used by others" and "in public use"), and by adding the new category of uses "otherwise available to the public," eliminated this per se rule against secret commercialization by the inventor. Some commentators agree; others, including Lemley, vehemently disagreee. The courts have not yet settled on a clear answer.

\section{Egbert v. Lippmann}

This suit was brought for an alleged infringement of the complainant's reissued letters-patent, No. 5216, dated Jan. 7, 1873, for an improvement in corset-springs.

The original letters bear date July 17, 1866, and were issued to Samuel H. Barnes. The reissue was made to the complainant, under her then name, Frances Lee Barnes, executrix of the original patentee.

The specification for the reissue declares:

This invention consists in forming the springs of corsets of two or more metallic plates, placed one upon another, and so connected as to prevent them from sliding off each other laterally or edgewise, and at the same time admit of their playing or sliding upon each other, in the direction of their length or longitudinally, whereby their flexibility and elasticity are greatly increased, while at the same time much strength is obtained.

The second claim is as follows:

A pair of corset-springs, each member of the pair being composed of two or more metallic plates, placed one on another, and fastened together at their centres, and so connected at or near each end that they can move or play on each other in the direction of their length.

[The patent statute in force at the time had a two-year statutory bar, whose] effect is to render letters-patent invalid if the invention which they cover was in public use, with the consent and allowance of the inventor, for more than two years prior to his application.

The evidence on which the defendants rely to establish a prior public use of the invention consists mainly of the testimony of the complainant.

She testifies that Barnes invented the improvement covered by his patent between January and May, 1855; that between the dates named the witness and her friend Miss Cugier were complaining of the breaking of their corset-steels. Barnes, who was present, and was an intimate friend of the witness, said he thought he could make her a pair that would not break. At their next interview he presented her with a pair of corset-steels which he himself had made. The witness 
wore these steels a long time. In 1858 Barnes made and presented to her another pair, which she also wore a long time. When the corsets in which these steels were used wore out, the witness ripped them open and took out the steels and put them in new corsets. This was done several times.

It is admitted, and, in fact, is asserted, by complainant, that these steels embodied the invention afterwards patented by Barnes and covered by the reissued letters-patent on which this suit is brought.

Joseph H. Sturgis, another witness for complainant, testifies that in 1863 Barnes spoke to him about two inventions made by himself, one of which was a corset-steel, and that he went to the house of Barnes to see them. Before this time, and after the transactions testified to by the complainant, Barnes and she had intermarried. Barnes said his wife had a pair of steels made according to his invention in the corsets which she was then wearing, and if she would take them off he would show them to witness. Mrs. Barnes went out, and returned with a pair of corsets and a pair of scissors, and ripped the corsets open and took out the steels. Barnes then explained to witness how they were made and used.

The question for our decision is, whether this testimony shows a public use within the meaning of the statute.

We observe, in the first place, that to constitute the public use of an invention it is not necessary that more than one of the patented articles should be publicly used. The use of a great number may tend to strengthen the proof, but one well-defined case of such use is just as effectual to annul the patent as many. For instance, if the inventor of a mower, a printingpress, or a railway-car makes and sells only one of the articles invented by him, and allows the vendee to use it for two years, without restriction or limitation, the use is just as public as if he had sold and allowed the use of a great number.

We remark, secondly, that, whether the use of an invention is public or private does not necessarily depend upon the number of persons to whom its use is known. If an inventor, having made his device, gives or sells it to another, to be used by the donee or vendee, without limitation or restriction, or injunction of secrecy, and it is so used, such use is public, even though the use and knowledge of the use may be confined to one person.

We say, thirdly, that some inventions are by their very character only capable of being used where they cannot be seen or observed by the public eye. An invention may consist of a lever or spring, hidden in the running gear of a watch, or of a rachet, shaft, or cog-wheel covered from view in the recesses of a machine for spinning or weaving. Nevertheless, if its inventor sells a machine of which his invention forms a part, and allows it to be used without restriction of any kind, the use is a public one. So, on the other hand, a use necessarily open 
to public view, if made in good faith solely to test the qualities of the invention, and for the purpose of experiment, is not a public use within the meaning of the statute. City of Elizabeth $v$. American Nicholson Pavement Co..

Tested by these principles, we think the evidence of the complainant herself shows that for more than two years before the application for the original letters there was, by the consent and allowance of Barnes, a public use of the invention, covered by them. He made and gave to her two pairs of corset-steels, constructed according to his device, one in 1855 and one in 1858 . They were presented to her for use. He imposed no obligation of secrecy, nor any condition or restriction whatever. They were not presented for the purpose of experiment, nor to test their qualities. No such claim is set up in her testimony. The invention was at the time complete, and there is no evidence that it was afterwards changed or improved. The donee of the steels used them for years for the purpose and in the manner designed by the inventor. They were not capable of any other use. She might have exhibited them to any person, or made other steels of the same kind, and used or sold them without violating any condition or restriction imposed on her by the inventor.

According to the testimony of the complainant, the invention was completed and put to use in 1855 . The inventor slept on his rights for eleven years. Letters-patent were not applied for till March, 1866. In the mean time, the invention had found its way into general, and almost universal, use. A great part of the record is taken up with the testimony of the manufacturers and venders of corset-steels, showing that before he applied for letters the principle of his device was almost universally used in the manufacture of corset-steels. It is fair to presume that having learned from this general use that there was some value in his invention, he attempted to resume, by his application, what by his acts he had clearly dedicated to the public.

An abandonment of an invention to the public may be evinced by the conduct of the inventor at any time, even within the two years named in the law. The effect of the law is that no such consequence will necessarily follow from the invention being in public use or on sale, with the inventor's consent and allowance, at any time within two years before his application; but that, if the invention is in public use or on sale prior to that time, it will be conclusive evidence of abandonment, and the patent will be void.

City of Elizabeth We are of opinion that the defence of two years' public use, by the consent and allowance of the inventor, before he made application for letters-patent, is satisfactorily established by the evi- 
dence.

\section{Lough v. Brunswick Corp}

[Lough designed an improved seal for outboard motors.] After some trial and error with his grand-father's metal lathe, he made six usable prototypes in the spring of 1986 . He installed one prototype in his own boat at home. Three months later, he gave a second prototype to a friend who installed it in his boat. He also installed prototypes in the boat of the owner of the marina where he worked and in the boat of a marina customer. He gave the remaining prototypes to longtime friends who were employees at another marina in Sarasota. Lough did not charge anyone for the prototypes. For over a year following the installation of these prototypes, Lough neither asked for nor received any comments about the operability of the prototypes. During this time, Lough did not attempt to sell any seal assemblies.

On June 6, 1988, Lough filed a patent application entitled "Liquid Seal for Marine Stern Drive Gear Shift Shafts," which issued as [U.S. Patent No. 4,848,775A patent on July 18, 1989.

One is entitled to a patent unless, inter alia, "the invention was ... in public use ... in this country, more than one year prior to the date of the application for patent in the United States." . We have defined "public use" as including any use of the claimed invention by a person other than the inventor who is under no limitation, restriction or obligation of secrecy to the inventor. An evaluation of a question of public use depends on how the totality of the circumstances of the case comports with the policies underlying the public use bar. These policies include: (1) discouraging the removal, from the public domain, of inventions that the public reasonably has come to believe are freely available; (2) favoring the prompt and widespread disclosure of inventions; (3) allowing the inventor a reasonable amount of time following sales activity to determine the potential economic value of a patent; and (4) prohibiting the inventor from commercially exploiting the invention for a period greater than the statutorily prescribed time.

Neither party disputes that Lough's prototypes were in use before the critical date. Thus, both parties agree that the issue presented on appeal is whether the jury properly decided that the use of Lough's six prototypes in 1986, prior to the critical date, constituted experimental use so as to negate the conclusion of public use.

"The use of an invention by the inventor himself, or of any other person under his direction, by way of experiment, and in order to bring the invention to perfection, has never been regarded as [a public] use." City of Elizabeth. This doctrine is based on the underlying policy of providing an inventor time to determine if the invention is suitable for its intended purpose, in effect, to reduce the invention 
to practice. See id. ("It is sometimes said that an inventor acquires an undue advantage over the public by delaying to take out a patent, but this cannot be said with justice when the delay is occasioned by a bona fide effort to bring his invention to perfection, or to ascertain whether it will answer the purpose intended."). If a use is experimental, it is not, as a matter of law, a public use within the meaning of section 102.

To determine whether a use is "experimental," a question of law, the totality of the circumstances must be considered, including various objective indicia of experimentation surrounding the use, such as the number of prototypes and duration of testing, whether records or progress reports were made concerning the testing, the existence of a secrecy agreement between the patentee and the party performing the testing, whether the patentee received compensation for the use of the invention, and the extent of control the inventor maintained over the testing.

In order to justify a determination that legally sufficient experimentation has occurred, there must be present certain minimal indicia. The framework might be quite formal, as may be expected when large corporations conduct experiments, governed by contracts and explicit written obligations. When individual inventors or small business units are involved, however, less formal and seemingly casual experiments can be expected. Such less formal experiments may be deemed legally sufficient to avoid the public use bar, but only if they demonstrate the presence of the same basic elements that are required to validate any experimental program.

It cannot be reasonably disputed that Lough's use of the invention was not "experimental" so as to negate a conclusion of public use. It is true that Lough did not receive any compensation for the use of the prototypes. He did not place the seal assembly on sale before applying for a patent. Lough's lack of commercialization, however, is not dispositive of the public use question in view of his failure to present objective evidence of experimentation. Lough kept no records of the alleged testing. Nor did he inspect the seal assemblies after they had been installed by other mechanics. He provided the seal assemblies to friends and acquaintances, but without any provision for followup involvement by him in assessment of the events occurring during the alleged experiments, and at least one seal was installed in a boat that was later sold to strangers. Thus, Lough did not maintain any supervision and control over the seals during the alleged testing.

Lough argues that other evidence supports a finding that his uses were experimental, including his own testimony that the prototypes were installed for experimental purposes and the fact that the prototypes were used in such a manner that they were unlikely to be seen by the public. However, the expression by an inventor of his subjec- 
tive intent to experiment, particularly after institution of litigation, is generally of minimal value. $\mathrm{n}$ addition, the fact that the prototypes were unlikely to be seen by the public does not support Lough's position. As the Supreme Court stated in Egbert:

Some inventions are by their very character only capable of being used where they cannot be seen or observed by the public eye. An invention may consist of a lever or spring, hidden in the running gear of a watch, or of a rachet, shaft, or cogwheel covered from view in the recesses of a machine for spinning or weaving. Nevertheless, if its inventor sells a machine of which his invention forms a part, and allows it to be used without restriction of any kind, the use is a public one.

Moreover, those to whom he gave the prototypes constituted "the public," in the absence of meaningful evidence of experimentation.

We therefore hold that the jury had no legal basis to conclude that the uses of Lough's prototypes were experimental and that the prototypes were not in public use prior to the critical date. Our holding is consistent with the policy underlying the experimental use negation, that of providing an inventor time to determine if the invention is suitable for its intended purpose, i.e., to reduce the invention to practice. Lough's activities clearly were not consistent with that policy. We do not dispute that it may have been desirable in this case for Lough to have had his prototypes installed by mechanics of various levels of skill in boats that were exposed to different conditions. Moreover, Lough was free to test his invention in boats of friends and acquaintances to further verify that his invention worked for its intended purpose; however, Lough was required to maintain some degree of control and feedback over those uses of the prototypes if those tests were to negate public use.

\section{4 "on sale"}

The old $\S 102$ used the phrase "on sale," as does the new $\S 102$, so the AIA would appear to have left the law here unchanged. But, as it does with "public use," the PTO now takes the position that the AIA no longer reaches secret commercialization. In its view, a secret sale - for example, one subject to a confidentiality agreement - is not "available to the public" and thus does not count as prior art. Again, commentators are split and the courts have not yet settled the question. Bracket the issue for now; we still need to understand what it means for something to be "on sale" at all. 
Pfaff: 525 U.S. 55 (1998)

$\S 2133.03(b)$

"On Sale" (describing pre-AIA law)

2133.03(c)

The "Invention" (describing pre-AIA law)
The pre-AIA case law indicates that on sale activity will bar patentability if the claimed invention was: (1) the subject of a commercial sale or offer for sale, not primarily for experimental purposes; and (2) ready for patenting. See Pfaff v. Wells Elecs., Inc.. Contract law principles apply in order to determine whether a commercial sale or offer for sale occurred.

A sale is a contract between parties wherein the seller agrees to give and to pass rights of property in return for the buyer's payment or promise "to pay the seller for the things bought or sold.. A contract for the sale of goods requires a concrete offer and acceptance of that offer. See, e.g., Linear Tech. Corp. v. Micrel, Inc., 275 F.3d at 1040 (2001) (Court held there was no sale where prospective purchaser submitted an order for goods at issue, but received an order acknowledgement reading "will advise-not booked." Prospective purchaser would understand that order was not accepted.).

An assignment or sale of the rights in the invention and potential patent rights is not a sale of "the invention." In re Kollar, 286 F.3d 1326 (Fed. Cir. 2002), distinguishes licenses which trigger the on-sale bar (e.g., a standard computer software license wherein the product is just as immediately transferred to the licensee as if it were sold), from licenses that merely grant rights to an invention which do not per se trigger the on-sale bar (e.g., exclusive rights to market the invention or potential patent rights).

The Supreme Court's "ready for patenting" prong applies in the context of both the on sale and public use bars. "Ready for patenting," the second prong of the Pfaff test, may be satisfied in at least two ways: by proof of reduction to practice before the critical date; or by proof that prior to the critical date the inventor had prepared drawings or other descriptions of the invention that were sufficiently specific to enable a person skilled in the art to practice the invention. In Invitrogen Corp. v. Biocrest Manufacturing L.P., 424 F.3d 1374 (Fed. Cir. 2005), The patent was held invalid because the invention for a computer chip socket was "ready for patenting" when it was offered for sale more than one year prior to the application filing date. Even though the invention had not yet been reduced to practice, the manufacturer was able to produce the claimed computer chip sockets using the inventor's detailed drawings and specifications, and those sockets contained all elements of invention claimed in the patent.

\section{5 "otherwise available to the public"}

The old $\S 102$ had a closed list of prior art categories. The open-ended language "otherwise available to the public" is new with the AIA. In 
the PTO's view, "This 'catch-all' provision permits decision makers to focus on whether the disclosure was 'available to the public,' rather than on the means by which the claimed invention became available to the public or whether a disclosure constitutes a 'printed publication' or falls within another category of prior art."

\section{b Anticipation}

\section{Manual of Patent Examination Procedure}

A claimed invention may be rejected under 35 U.S.C. 102 when the invention is anticipated (or is "not novel") over a disclosure that is available as prior art. To anticipate a claim, the disclosure must teach every element of the claim.

A claim is anticipated only if each and every element as set forth in the claim is found, either expressly or inherently described, in a single prior art reference. "When a claim covers several structures or compositions, either generically or as alternatives, the claim is deemed anticipated if any of the structures or compositions within the scope of the claim is known in the prior art." Brown v. 3M, 265 F.3d 1349 (Fed. Cir. 2001) (claim to a system for setting a computer clock to an offset time to address the Year 2000 (Y2K) problem, applicable to records with year date data in "at least one of two-digit, three-digit, or four-digit" representations, was held anticipated by a system that offsets year dates in only two-digit formats). The elements must be arranged as required by the claim, but this is not an ipsissimis verbis test, i.e., identity of terminology is not required.

A generic claim cannot be allowed to an applicant if the prior art discloses a species falling within the claimed genus. The species in that case will anticipate the genus.

A genus does not always anticipate a claim to a species within the genus. However, when the species is clearly named, the species claim is anticipated no matter how many other species are additionally named. See Ex parte A, 17 USPQ 2d 1716 (BPAI 1990) ("The tenth edition of the Merck Index lists ten thousand compounds. In our view, each and every one of those compounds is 'described' as that term is used in [pre-AIA] 35 U.S.C. § 102(a), in that publication.").

Whether a generic disclosure necessarily anticipates everything within the genusdepends on the factual aspects of the specific disclosure and the particular products at issue. How one of ordinary skill in the art would understand the relative size of a genus or species in a particular technology is of critical importance.

In In re Petering, the prior art disclosed a generic chemical formula "wherein X, Y, Z, P, and R'- represent either hydrogen or alkyl
MPEP § 2152.02(e)

$\S 2131$

Anticipation -- Application of 35 U.S.C. $\S 102$

$\S 2131.02$

Genus-Species Situations 
$\S 2121$

Prior Art; General Level of Operability Required to Make a Prima Facie Case radicals, $\mathrm{R}$ a side chain containing an $\mathrm{OH}$ group." The court held that this formula, without more, could not anticipate a claim to 7methyl-9-[d, l'-ribityl]-isoalloxazine because the generic formula encompassed a vast number and perhaps even an infinite number of compounds. However, the reference also disclosed preferred substituents for $X, Y, Z, P, R$, and $R$. The court determined that this more limited generic class consisted of about 20 compounds. The limited number of compounds covered by the preferred formula in combination with the fact that the number of substituents was low at each site, the ring positions were limited, and there was a large unchanging structural nucleus, resulted in a finding that the reference sufficiently described "each of the various permutations here involved as fully as if he had drawn each structural formula or had written each name." The claimed compound was 1 of these 20 compounds. Therefore, the reference "described" the claimed compound and the reference anticipated the claims.

When the reference relied on expressly anticipates or makes obvious all of the elements of the claimed invention, the reference is presumed to be operable. Once such a reference is found, the burden is on applicant to provide facts rebutting the presumption of operability.

A prior art reference provides an enabling disclosure and thus anticipates a claimed invention if the reference describes the claimed invention in sufficient detail to enable a person of ordinary skill in the art to carry out the claimed invention; proof of efficacy is not required for a prior art reference to be enabling for purposes of anticipation.

\section{Titanium Metals Corp. of America v. Banner}

This appeal is from an Order of the United States District Court for the District of Columbia in a civil action brought pursuant to 35 U.S.C. $\S$ 145 against Donald W. Banner as Commissioner of Patents and Trademarks authorizing the Commissioner to issue to appellee a patent containing claims 1, 2, and 3 of patent application serial No. 598,935 for "TITANIUM ALLOY." The Commissioner has appealed. We reverse.

\section{BACKGROUND}

The inventors, Loren C. Covington and Howard R. Palmer, employees of appellee to whom they have assigned their invention and the application thereon, filed an application on March 29, 1974, serial No. 455,964 , to patent an alloy they developed. The application involved in this appeal contains the three claims on appeal. The alloy is made primarily of titanium (Ti) and contains small amounts of nickel (Ni) and molybdenum (Mo) as alloying ingredients to give the alloy 
certain desirable properties, particularly corrosion resistance in hot brine solutions, while retaining workability so that articles such as tubing can be fabricated from it by rolling, welding and other techniques. The inventors apparently also found that iron content should be limited, iron being an undesired impurity rather than an alloying ingredient. They determined the permissible ranges of the components, above and below which the desired properties were not obtained. A precise definition of the invention sought to be patented is found in the claims, set forth below, claim 3 representing the preferred composition, it being understood, however, that no iron at all would be even more preferred.

1. A titanium base alloy consisting essentially by weight of about 0.6

2. A titanium base alloy as set forth in Claim 1 having up to 0.1

3. A titanium base alloy as set forth in Claim 1 having 0.8

The examiner's final rejection, repeated in his Answer on appeal to the Patent and Trademark Office (PTO) Board of Appeals (board), was on the grounds that claims 1 and 2 are anticipated (fully met) by, and claim 3 would have been obvious from, an article by Kalabukhova and Mikheyew, Investigation of the Mechanical Properties of Ti-Mo-Ni Alloys, Russian Metallurgy (Metally) No. 3, pages 130-133 (1970) (in the court below and hereinafter called "the Russian article") under 35 U.S.C. $\$ \S 102$ and 103, respectively. The board affirmed the examiner's rejection.

The Russian article is short (3 pages), highly technical, and contains 10 graphs as part of the discussion. As its title indicates, it relates to ternary Ti-Mo-Ni alloys, the subject of the application at bar. The examiner and the board both found that it would disclose to one skilled in the art an alloy on which at least claims 1 and 2 read, so that those claims would not be allowable under the statute because of lack of novelty of their subject matter. Since the article does not specifically disclose such an alloy in words, a little thinking is required about what it would disclose to one knowledgeable about Ti-Ni-Mo alloys. The PTO did that thinking as follows:

Figure 1c [a graph] shows data for the ternary titanium alloy which contains $\mathrm{Mo}$ and $\mathrm{Ni}$ in the ratio of 1:3. Amongst the actual points on the graph is one at $1 \% \mathrm{Mo}+\mathrm{Ni}$. At this point, the amounts of $\mathrm{Mo}$ and $\mathrm{Ni}$ would be $0.25 \%$ and $0.75 \%$ respectively. A similar point appears on the graph shown in Figure 2 of the article.

Appellants do not deny that the data points are disclosed in the reference. In fact, the Hall affidavit indicates at least two specific points (at 1\% and 1.25\% $\mathrm{Mo}+$ 
$\mathrm{Ni}$ ) which would represent a description of alloys falling within the scope of the instant claims.

On that basis, the board found that the claimed alloys were not new, because they were disclosed in the prior art. It having been argued that the Russian article contains no disclosure of corrosion-resistant properties of any of the alloys, the board held: "The fact that a particular property or the end use for this alloy as contemplated by appellants was not recognized in the article is of no consequence." It therefore held the Russian article to be an anticipation, noting that although the article does not discuss corrosion resistance, it does disclose other properties such as strength and ductility. The PTO further points out that the authors of the reference must have made the alloys to obtain the data points.

Being dissatisfied with the decision of the board, Titanium Metals Corporation of America, as assignee of the Covington and Palmer application, then brought an action in the District Court for the District of Columbia against the Commissioner pursuant to 35 U.S.C. § 145.

The case came on for trial on January 24, 1980, before the Honorable John G. Penn and was concluded in two and a half hours. The testimony of one witness was heard by the court, Dr. James C. Williams, professor at Carnegie-Mellon University in Pittsburgh and an expert in titanium metallurgy.

The court then concluded that claims 1-3 were not anticipated and that claim 3 was wrongly rejected as directed to obvious subject matter. In the court's view, Dr. Williams' testimony tipped the scales in favor of issuing a patent.

\section{A. Anticipation, $\S 102$}

We are left in no doubt that the court was impressed by the totality of the evidence that the applicants for patent had discovered or invented and disclosed knowledge which is not to be found in the reference, nor do we have any doubt about that ourselves. But those facts are beside the point. The patent law imposes certain fundamental conditions for patentability, paramount among them being the condition that what is sought to be patented, as determined by the claims, be new. The title of the application here involved is "Titanium Alloy," a composition of matter. Surprisingly, in all of the evidence, nobody discussed the key issue of whether the alloy was new, which is the essence of the anticipation issue, including the expert Dr. Williams. Plaintiff's counsel, bringing Dr. Williams' testimony to its climax, after he had explained the nature of the ingredients, the alloys made therefrom, and their superior corrosion resistance in hot brine, etc., repetitively asked him such questions as "Does the [Russian] article direct you as one skilled in the art to a titanium alloy having nickel 
present in an amount between .6 and .9 percent molybdenum in an amount between .2 and .4 percent?" (emphasis ours) followed by "Is there anything mentioned in the article about corrosion resistance?" Of course, the answers were emphatically negative. But this and like testimony does not deal with the critical question: do claims 1 and 2 , to which the questions obviously relate, read on or encompass an alloy which was already known by reason of the disclosure of the Russian article?

Section 102, the usual basis for rejection for lack of novelty or anticipation, lays down certain principles for determining the novelty [of an invention], among which are the provisions in $\S 102(a)$ and (b) that the claimed invention has not been "described in a printed publication in this or a foreign country," either (a) before the invention by the applicant or (b) more than one year before the application date to which he is entitled (strictly a "loss of right" provision similar to novelty). Either provision applies in this case, the Russian article having a date some 5 years prior to the filing date and its status as "prior art" not being questioned. The question, therefore, is whether claims 1 and 2 encompass and, if allowed, would enable plaintiff-appellee to exclude others from making, using, or selling an alloy described in the Russian article.

To answer the question we need only turn to the affidavit of James A. Hall, a metallurgist employed by appellee's TIMET Division, who undertook to analyze the Russian article disclosure by calculating the ingredient percentages shown in the graph data points, which he presented in tabular form. There are 15 items in his table. The second item shows a titanium base alloy containing $0.25 \%$ by weight Mo and $0.75 \% \mathrm{Ni}$ and this is squarely within the ranges of $0.2-0.4 \% \mathrm{Mo}$ and $0.6-0.9 \% \mathrm{Ni}$ of claims 1 and 2 . As to that disclosed alloy of the prior art, there can be no question that claims 1 and 2 read on it and would be infringed by anyone making, using, or selling it. Therefore, the statute prohibits a patent containing them. This seems to be a case either of not adequately considering the novelty requirement of the statute, the true meaning of the correlative term "anticipation," or the meaning of the claims.

By reason of the court's quotations from cases holding that a reference is not an anticipation which does not enable one skilled in the art to practice the claimed invention, it appears that the trial court thought there was some deficiency in the Russian article on that score. Enablement in this case involves only being able to make the alloy, given the ingredients and their proportions without more. The evidence here, however, clearly answers that question in two ways. Appellee's own patent application does not undertake to tell anyone how to make the alloy it describes and seeks to patent. It assumes that those skilled in the art would know how. Secondly, appellee's 
In hindsight, is there a claim that the patentee's counsel could have drafted that would have captured the newlydiscovered properties of the alloy (corrosion resistance in hot brine) without being anticipated by the Russian article? expert, Dr. Williams, testified on cross examination that given the alloy information in the Russian article, he would know how to prepare the alloys "by at least three techniques." Enablement is not a problem in this case.

As we read the situation, the court was misled by the arguments and evidence to the effect that the inventors here found out and disclosed in their application many things that one cannot learn from reading the Russian article and that this was sufficient in law to justify granting them a patent for their contributions - such things as what good corrosion resistance the claimed alloys have against hot brine, which possibly was not known, and the range limits of the $\mathrm{Ni}$ and Mo content, outside of which that resistance diminishes, which are teachings of very useful information. These things the applicants teach the art and the Russian article does not. But throughout the trial counsel never came to grips with the real issues: (1) what do the claims cover and (2) is what they cover new? Under the laws Congress wrote, they must be considered. Congress has not seen fit to permit the patenting of an old alloy, known to others through a printed publication, by one who has discovered its corrosion resistance or other useful properties, or has found out to what extent one can modify the composition of the alloy without losing such properties.

For all of the foregoing reasons, the court below committed clear error and legal error in authorizing the issuance of a patent on claims 1 and 2 since, properly construed, they are anticipated under $\S 102$ by the Russian article which admittedly discloses an alloy on which these claims read.

\section{B. Obviousness, $§ 103$}

Little more need be said in support of the examiner's rejection of claim 3 , affirmed by the board, on the ground that its more specific subject matter would have been obvious at the time the invention was made from the knowledge disclosed in the reference.

As admitted by appellee's affidavit evidence from James A. Hall, the Russian article discloses two alloys having compositions very close to that of claim 3, which is $0.3 \% \mathrm{Mo}$ and $0.8 \% \mathrm{Ni}$, balance titanium. The two alloys in the prior art have $0.25 \% \mathrm{Mo}-0.75 \% \mathrm{Ni}$ and $0.31 \% \mathrm{Mo}-0.94 \% \mathrm{Ni}$, respectively. The proportions are so close that prima facie one skilled in the art would have expected them to have the same properties. Appellee produced no evidence to rebut that prima facie case. The specific alloy of claim 3 must therefore be considered to have been obvious from known alloys. 
c Priority

1 Old $\$ 102$

A person shall be entitled to a patent unless -

(a) the invention was [prior art by someone else] before the invention thereof by the applicant for patent, or

(b) the invention was [prior art by anyone] more than one year prior to the date of the application for patent, or

(g) before such person's invention thereof, the invention was made by another inventor who had not abandoned, suppressed, or concealed it. In determining priority of invention under this subsection, there shall be considered not only the respective dates of conception and reduction to practice of the invention, but also the reasonable diligence of one who was first to conceive and last to reduce to practice, from a time prior to conception by the other.

Pay attention to the structural differences between old subsections (a), (b), and (g). Old $\S 102(a)$ was a novelty provision: it denied a patent where someone else engaged in activity showing that the applicant's invention was not novel when it was supposedly "invented." Old $\S 102(b)$ was a statutory bar: it denied a patent to an applicant who waited too long to apply. And old § 102(g) was a truepriority provision that dealt with the non-uncommon situation in which two parties independently came up with the same invention and neither of them generated prior art that would block the other's application.

To apply old § 102(a), it was necessary to break down the inventive process. The basic concepts were "invention" (i.e. "conception"), "reduction to practice," and "reasonable diligence," which the following materials gloss.

\section{Manual of Patent Examination Procedure}

Pre-AIA 35 U.S.C. 102(g) issues such as conception, reduction to practice and diligence, while more commonly applied to interference matters, also arise in other contexts.

Subsection (g) of pre-AIA 35 U.S.C. $1 \S 02$ is the basis of interference practice for determining priority of invention between two parties. An interference is an inter partes proceeding directed at determining the first to invent as among the parties to the proceeding, involving two or more pending applications naming different inventors or one or more pending applications and one or more unexpired
As hinted above, the categories of prior art under the old $\S 102$ varied significantly from subsection to subsection. It's not necessary to get into the details to understand the modern priority rules. Some additional subsections have been omitted. Old § 102 was absurdly intricate.
$\S 2138$

Pre-AIA 35 U.S.C. 102(g) 
patents naming different inventors. The United States [was] unusual in having a first to invent rather than a first to file system. Upon conclusion of an interference, subject matter claimed by the losing party that was the basis of the interference is rejected under pre-AIA 35 U.S.C. 102(g).

Conception has been defined as "the complete performance of the mental part of the inventive act" and it is "the formation in the mind of the inventor of a definite and permanent idea of the complete and operative invention as it is thereafter to be applied in practice." Conception is established when the invention is made sufficiently clear to enable one skilled in the art to reduce it to practice without the exercise of extensive experimentation or the exercise of inventive skill. Conception has also been defined as a disclosure of an invention which enables one skilled in the art to reduce the invention to a practical form without "exercise of the inventive faculty." It is settled that in establishing conception a party must show possession of every feature recited in the count, and that every limitation of the count must have been known to the inventor at the time of the alleged conception.

Hitzeman: 243 F.3d 1345 (Fed. Cir. 2001)
Conception must be proved by corroborating evidence. In Hitzeman v. Rutter, the inventor's "hope" that a genetically altered yeast would produce antigen particles having the particle size and sedimentation rates recited in the claims did not establish conception, since the inventor did not show that he had a "definite and permanent understanding" as to whether or how, or a reasonable expectation that, the yeast would produce the recited antigen particles. There must be a contemporaneous recognition and appreciation of the invention for there to be conception. On rare occasions conception and reduction to practice occur simultaneously.

Reduction to practice may be an actual reduction or a constructive reduction to practice which occurs when a patent application on the claimed invention is filed. The filing of a patent application serves as conception and constructive reduction to practice of the subject matter described in the application. Thus the inventor need not provide evidence of either conception or actual reduction to practice when relying on the content of the patent application.

In an interference proceeding, a party seeking to establish an actual reduction to practice must satisfy a two-prong test: (1) the party constructed an embodiment or performed a process that met every element of the interference count, and (2) the embodiment or process operated for its intended purpose. Actual reduction to practice requires a showing of the invention in a physical or tangible form that shows every element of the count. For an actual reduction to practice, the invention must have been sufficiently tested to demonstrate that it will work for its intended purpose, but it need not be in a commercially satisfactory stage of development. If a device is so simple, and 
its purpose and efficacy so obvious, construction alone is sufficient to demonstrate workability. The invention must be recognized and appreciated for a reduction to practice to occur. An inventor need not understand precisely why his invention works in order to achieve an actual reduction to practice.

\section{Morway v. Bondi}

[Morway (appellants) conceived on or before April 12, 1945 and filed on December 27, 1946. Bondi (appellees) conceived on June 14, 1945 and filed on October 31, 1945. Both parties were entitled to constructive reduction to practice as of their filing dates.]

Appellants contend that there was a reduction to practice between January 31, 1945 and March 13, 1945. It is claimed that on January 30, 1945 Beerbower, one of the joint appellants herein, compounded a grease containing Carbowax 1500, which grease is said to meet the issue counts. That grease was subjected to a standard Norma-Hoffman oxidation test. It is claimed that the results of this test were good, and counsel for Morway et al. contends that there was an actual reduction to practice when this grease was successfully tested.

Mr. Alan Beerbower, one of the appellants herein, testified on cross-examination that the Norma-Hoffman bomb test merely measures resistance of the grease to oxidation under static or storage conditions, but not under service conditions; and that he would not be able to predict service life from Norma-Hoffman bomb results. In view of the foregoing testimony by appellants' expert witnesses, we think it clear that a successful Norma-Hoffman laboratory test falls far short of simulating actual service tests with sufficient closeness to constitute a reduction to practice.

Thus, appellants, although first to conceive, were last to reduce to practice. If they are to prevail, they must affirmatively establish continuing and reasonable diligence in reducing to practice or reasonable excuse for failure to act. Such diligence must be shown from a date immediately prior to the time that Bondi conceived, on June 14,1945 , until reduction to practice by themselves as first conceivers.

The record shows the following activities by appellants:

- On June 7, August 1, August 15, and September 28, 1945, greases meeting the counts were prepared, and laboratory tests, such as the A.S.T.M. penetration test, were conducted on them.

- On October 2, 1945, Miss O'Halloran conducted a Ford Wheel Bearing Test on the grease prepared September 28.

- On December 26, 1945, a grease meeting the counts was prepared, and laboratory tests conducted on it.

- The record then shows further activities (mainly aimed at possible commercial exploitation of the grease in issue) in February, 
May, August, and November of 1946.

There was no activity at all between June 7 and August 1, 1945, thereby creating a hiatus of one and one-half months right at the outset of the critical period when Bondi entered the field. There is a further hiatus of one and one-half months, during the early part of the critical period, from August 15 to September 28, 1945, when there was no activity at all by Morway et al. It seems manifest from the above chronology that the activities by Morway et al. from early June 1945 to December 1946 were quite sporadic throughout that period.

In our opinion, the foregoing activities by appellants do not constitute reasonable diligence in reducing the invention to practice during the critical period.

Appellants have introduced testimony to the effect that the joint inventors herein and other assisting members of the research team which developed the grease of the issue counts had many other projects and duties. For example, there is testimony indicating that Mr. Morway's primary assignment at the time in question was the development of a carbon black lubricant; and that Mr. Beerbower's primary assignment was the development of a continuous process for manufacturing greases. When the party first to conceive voluntarily lays aside his inventive concept because he is engrossed in pursuit of other projects, this is generally not an acceptable excuse for failure to act diligently in reducing to practice. Clearly there may be circumstances creating exceptions to this rule, but we find no such circumstances in this record.

Morway et al. also seek to explain their lack of diligence by reference to wartime assignments which allegedly took first call on their time. In proper cases, war activities may reasonably excuse the first conceiver's failure to act diligently, but lack of diligence is not excused by a mere assertion that the applicant was engaged in war work. We fail to find in the record before us adequate evidence of such war activities as would excuse appellants' lack of reasonable diligence.

\section{New $\$ 102$}

The AIA's novelty provisions took effect on March 16, 2013. They apply to any applications filed on or after that date. Applications filed before that date are examined under the old pre-AIA rules.

\section{Patent Act}

35 U.S.C. § 102

Conditions for patentability; novelty (a) A person shall be entitled to a patent unless-

(1) the claimed invention was [prior art] before the effective filing date of the claimed invention; or 
(2) the claimed invention was described in a [published patent or application that] names another inventor and was effectively filed before the effective filing date of the claimed invention.

(b) Exceptions. -

(1) A disclosure made 1 year or less before the effective filing date of a claimed invention shall not be prior art to the claimed invention under subsection (a)(1) if-

(A) the disclosure was made by the inventor or joint inventor or by another who obtained the subject matter disclosed directly or indirectly from the inventor or a joint inventor; or

(B) the subject matter disclosed had, before such disclosure, been publicly disclosed by the inventor or a joint inventor or another who obtained the subject matter disclosed directly or indirectly from the inventor or a joint inventor.

Do you see why the passage of the AIA is described as taking the United States from a "first to invent" system to a "first inventor to file" system? And also, in view of Morway, why the AIA's proponents described it as simplifying interference practice and giving inventors greater certainty about their rights? (Who would have won in Morway under the AIA?)

The AIA's proponents also described it as harmonizing the United States with the rest of the world, where priority is assessed strictly on a first-to-file basis. The one-year grace period of new $\S 102(b)(1)(B)$, however, is not typical of true first-to-file systems.

\section{Questions}

1. Suppose that from 1960 to 1972, the Acme Corporation sold the Bait-o-Matic, a grey egg-shaped plastic container containing sharp-grained sand with a grain size of $1 / 25$ of an inch designed to be used to immobilize earthworms. Which claims, if any, of the Lukehart worm-immobilizing patent are invalid because they were anticipated by the Bait-o-Matic?

2. Ivan Inventor is working on a new battery design. Ivan has identified promising materials, but has not yet found a way to combine them safely in a sealed container. Ivan is afraid that others are working on a similar invention. What factors do Ivan and his patent attorney need to consider in deciding when to file? 


\section{Pleistocene Park Problem}

Two biotechnology firms, Crichton Industries and Spielberg Genetics, have been attempting to clone a wooly mammoth (an elephant-like mammal that became extinct about 3,500 years ago) from scattered preserved DNA fragments. The teams made only slow progress at first; the available mammoth DNA fragments were too short and too numerous to combine into a complete DNA sequence using standard laboratory techniques.

Then, on January 1, 2004, mathematician Rube Goldblum published an academic paper describing efficient ways to arrange books in libraries. Crichton's lead researcher read the paper on February 2, 2005 and realized that the method Goldblum was describing could be used to arrange DNA fragments and compile complete DNA sequences.

Goldblum published (on March 3, 2006), a follow-up academic paper explaining how to apply his book-sorting method to the problem of DNA compilation. An executive at Spielberg read the paper on April 4, 2007, and decided to try the technique on the wooly mammoth problem.

On May 5, 2013, in a Crichton laboratory, a modern elephant implanted with a wooly mammoth embryo using standard artificial insemination techniques gave birth to a live wooly mammoth. On June 6, 2013, a Spielberg elephant successfully gave birth to a wooly mammoth. Because both teams started from the same, publicly available sets of wooly mammoth DNA fragments, their DNA sequences were identical. The next day, June 7, 2013, Spielberg held a press conference to announce the birth; it showed video of the baby mammoth and its scientists passed out CDs with the DNA sequence.

On July 12, 2013, Spielberg filed a patent application claiming "a wooly mammoth, having the DNA sequence ..." Crichton filed its own patent application on August 20, 2013 with an identical claim.

Which application, if either, should the PTO allow, and why? Would the answer be different under the old $\S 102$ ?

\section{Nonobviousness}

35 U.S.C. § 103

Conditions for patentability; nonobvious subject matter

\section{Patent Act}

A patent for a claimed invention may not be obtained, notwithstanding that the claimed invention is not identically disclosed as set forth in section 102, if the differences between the claimed invention and the prior art are such that the claimed invention as a whole would have been obvious before the effective filing date of the claimed invention to a person having ordinary skill in the art to which the claimed 
invention pertains. Patentability shall not be negated by the manner in which the invention was made.

KSR Intern. Co. v. Teleflex Inc.

The patent at issue, United States Patent No. 6,237,565 B1, is entitled "Adjustable Pedal Assembly With Electronic Throttle Control." Supplemental App. 1. The patentee is Steven J. Engelgau, and the patent is referred to as "the Engelgau patent." Claim 4 of the Engelgau patent describes a mechanism for combining an electronic sensor with an adjustable automobile pedal so the pedal's position can be transmitted to a computer that controls the throttle in the vehicle's engine.

In Graham v. John Deere Co., the Court set out a framework for applying the statutory language of $\S 103$ :

Under $\S 103$, the scope and content of the prior art are to be determined; differences between the prior art and the claims at issue are to be ascertained; and the level of ordinary skill in the pertinent art resolved. Against this background the obviousness or nonobviousness of the subject matter is determined. Such secondary considerations as commercial success, long felt but unsolved needs, failure of others, etc., might be utilized to give light to the circumstances surrounding the origin of the subject matter sought to be patented.

If a court, or patent examiner, conducts this analysis and concludes the claimed subject matter was obvious, the claim is invalid under $\S$ 103.

Seeking to resolve the question of obviousness with more uniformity and consistency, the Court of Appeals for the Federal Circuit has employed an approach referred to by the parties as the "teaching, suggestion, or motivation" test (TSM test), under which a patent claim is only proved obvious if "some motivation or suggestion to combine the prior art teachings" can be found in the prior art, the nature of the problem, or the knowledge of a person having ordinary skill in the art. KSR challenges that test, or at least its application in this case.

In car engines without computer-controlled throttles, the accelerator pedal interacts with the throttle via cable or other mechanical link. The pedal arm acts as a lever rotating around a pivot point. In a cableactuated throttle control the rotation caused by pushing down the
550 U.S. 398 (2007)

Graham: 383 U.S. 1 (1966) 
pedal pulls a cable, which in turn pulls open valves in the carburetor or fuel injection unit. The wider the valves open, the more fuel and air are released, causing combustion to increase and the car to accelerate. When the driver takes his foot off the pedal, the opposite occurs as the cable is released and the valves slide closed.

In the 1990's it became more common to install computers in cars to control engine operation. Computer-controlled throttles open and close valves in response to electronic signals, not through force transferred from the pedal by a mechanical link. Constant, delicate adjustments of air and fuel mixture are possible. The computer's rapid processing of factors beyond the pedal's position improves fuel efficiency and engine performance.

For a computer-controlled throttle to respond to a driver's operation of the car, the computer must know what is happening with the pedal. A cable or mechanical link does not suffice for this purpose; at some point, an electronic sensor is necessary to translate the mechanical operation into digital data the computer can understand.

Before discussing sensors further we turn to the mechanical design of the pedal itself. In the traditional design a pedal can be pushed down or released but cannot have its position in the footwell adjusted by sliding the pedal forward or back. As a result, a driver who wishes to be closer or farther from the pedal must either reposition himself in the driver's seat or move the seat in some way. In cars with deep footwells these are imperfect solutions for drivers of smaller stature. To solve the problem, inventors, beginning in the 1970's, designed pedals that could be adjusted to change their location in the footwell. Important for this case are two adjustable pedals disclosed in U.S. Patent Nos. 5,010,782 (filed July 28, 1989) (Asano) and 5,460,061 (filed Sept. 17, 1993) (Redding). The Asano patent reveals a support structure that houses the pedal so that even when the pedal location is adjusted relative to the driver, one of the pedal's pivot points stays fixed. The pedal is also designed so that the force necessary to push the pedal down is the same regardless of adjustments to its location. The Redding patent reveals a different, sliding mechanism where both the pedal and the pivot point are adjusted.

We return to sensors. Well before Engelgau applied for his challenged patent, some inventors had obtained patents involving electronic pedal sensors for computer-controlled throttles. These inventions, such as the device disclosed in U.S. Patent No. 5,241,936 (filed Sept. 9, 1991) ('936), taught that it was preferable to detect the pedal's position in the pedal assembly, not in the engine. The '936 patent disclosed a pedal with an electronic sensor on a pivot point in the pedal assembly. U.S. Patent No. 5,063,811 (filed July 9, 1990) (Smith) taught that to prevent the wires connecting the sensor to the computer from chafing and wearing out, and to avoid grime and damage from the 
driver's foot, the sensor should be put on a fixed part of the pedal assembly rather than in or on the pedal's footpad.

In addition to patents for pedals with integrated sensors inventors obtained patents for self-contained modular sensors. A modular sensor is designed independently of a given pedal so that it can be taken off the shelf and attached to mechanical pedals of various sorts, enabling the pedals to be used in automobiles with computer-controlled throttles. One such sensor was disclosed in U.S. Patent No. Ufiled Dec. 18, 1992) ('068). In 1994, Chevrolet manufactured a line of trucks using modular sensors attached to the pedal support bracket, adjacent to the pedal and engaged with the pivot shaft about which the pedal rotates in operation.

The prior art contained patents involving the placement of sensors on adjustable pedals as well. For example, U.S. Patent No. 5,819,593 (filed Aug. 17, 1995) (Rixon) discloses an adjustable pedal assembly with an electronic sensor for detecting the pedal's position. In the Rixon pedal the sensor is located in the pedal footpad. The Rixon pedal was known to suffer from wire chafing when the pedal was depressed and released.

This short account of pedal and sensor technology leads to the instant case.

$B$

Engelgau filed the patent application on August 22, 2000 as a continuation of a previous application for U.S. Patent No. 6,109,241, which was filed on January 26, 1999. He has sworn he invented the patent's subject matter on February 14, 1998. The Engelgau patent discloses an adjustable electronic pedal described in the specification as a "simplified vehicle control pedal assembly that is less expensive, and which uses fewer parts and is easier to package within the vehicle." Claim 4 of the patent, at issue here, describes:

A vehicle control pedal apparatus comprising:

a support adapted to be mounted to a vehicle structure;

an adjustable pedal assembly having a pedal arm moveable in for[e] and aft directions with respect to said support;

a pivot for pivotally supporting said adjustable pedal assembly with respect to said support and defining a pivot axis; and

an electronic control attached to said support for controlling a vehicle system;

said apparatus characterized by said electronic control being responsive to said pivot for providing a signal that cor- 
responds to pedal arm position as said pedal arm pivots about said pivot axis between rest and applied positions wherein the position of said pivot remains constant while said pedal arm moves in fore and aft directions with respect to said pivot.

We agree with the District Court that the claim discloses "a positionadjustable pedal assembly with an electronic pedal position sensor attached to the support member of the pedal assembly. Attaching the sensor to the support member allows the sensor to remain in a fixed position while the driver adjusts the pedal."

Before issuing the Engelgau patent the U.S. Patent and Trademark Office (PTO) rejected one of the patent claims that was similar to, but broader than, the present claim 4 . The claim did not include the requirement that the sensor be placed on a fixed pivot point. The PTO concluded the claim was an obvious combination of the prior art disclosed in Redding and Smith, explaining:

Since the prior art references are from the field of endeavor, the purpose disclosed would have been recognized in the pertinent art of Redding. Therefore it would have been obvious to provide the device of Redding with the means attached to a support member as taught by Smith.

In other words Redding provided an example of an adjustable pedal and Smith explained how to mount a sensor on a pedal's support structure, and the rejected patent claim merely put these two teachings together.

Although the broader claim was rejected, claim 4 was later allowed because it included the limitation of a fixed pivot point, which distinguished the design from Redding's. Engelgau had not included Asano among the prior art references, and Asano was not mentioned in the patent's prosecution. Thus, the PTO did not have before it an adjustable pedal with a fixed pivot point. The patent issued on May 29, 2001 and was assigned to Teleflex.

\section{C}

The District Court determined, in light of the expert testimony and the parties' stipulations, that the level of ordinary skill in pedal design was "an undergraduate degree in mechanical engineering (or an equivalent amount of industry experience) and familiarity with pedal control systems for vehicles." Following Graham's direction, the court compared the teachings of the prior art to the claims of Engelgau. It found "little difference." Asano taught everything contained in claim 4 except the use of a sensor to detect the pedal's position and transmit it to the computer controlling the throttle. That additional aspect was 
revealed in sources such as the ' 068 patent and the sensors used by Chevrolet.

Under the controlling cases from the Court of Appeals for the Federal Circuit, however, the District Court was not permitted to stop there. The court was required also to apply the TSM test. The District Court held KSR had satisfied the test. It reasoned (1) the state of the industry would lead inevitably to combinations of electronic sensors and adjustable pedals, (2) Rixon provided the basis for these developments, and (3) Smith taught a solution to the wire chafing problems in Rixon, namely locating the sensor on the fixed structure of the pedal. This could lead to the combination of Asano, or a pedal like it, with a pedal position sensor.

The conclusion that the Engelgau design was obvious was supported, in the District Court's view, by the PTO's rejection of the broader version of claim 4. Had Engelgau included Asano in his patent application, it reasoned, the PTO would have found claim 4 to be an obvious combination of Asano and Smith, as it had found the broader version an obvious combination of Redding and Smith. As a final matter, the District Court held that the secondary factor of Teleflex's commercial success with pedals based on Engelgau's design did not alter its conclusion.

With principal reliance on the TSM test, the Court of Appeals reversed. It ruled the District Court had not been strict enough in applying the test, having failed to make "findings as to the specific understanding or principle within the knowledge of a skilled artisan that would have motivated one with no knowledge of the invention to attach an electronic control to the support bracket of the Asano assembly." The Court of Appeals held that the District Court was incorrect that the nature of the problem to be solved satisfied this requirement because unless the "prior art references address[ed] the precise problem that the patentee was trying to solve," the problem would not motivate an inventor to look at those references.

Here, the Court of Appeals found, the Asano pedal was designed to solve the "constant ratio problem" - that is, to ensure that the force required to depress the pedal is the same no matter how the pedal is adjusted-whereas Engelgau sought to provide a simpler, smaller, cheaper adjustable electronic pedal. As for Rixon, the court explained, that pedal suffered from the problem of wire chafing but was not designed to solve it. In the court's view Rixon did not teach anything helpful to Engelgau's purpose. Smith, in turn, did not relate to adjustable pedals and did not "necessarily go to the issue of motivation to attach the electronic control on the support bracket of the pedal assembly." When the patents were interpreted in this way, the Court of Appeals held, they would not have led a person of ordinary skill to put a sensor on the sort of pedal described in Asano. 
That it might have been obvious to try the combination of Asano and a sensor was likewise irrelevant, in the court's view, because "'obvious to try' has long been held not to constitute obviousness."

\section{II}

A

We begin by rejecting the rigid approach of the Court of Appeals. Throughout this Court's engagement with the question of obviousness, our cases have set forth an expansive and flexible approach inconsistent with the way the Court of Appeals applied its TSM test here. To be sure, Graham recognized the need for "uniformity and definiteness." Yet the principles laid down in Graham reaffirmed the

Neither the enactment of $\S 103$ nor the analysis in Graham disturbed this Court's earlier instructions concerning the need for caution in granting a patent based on the combination of elements found in the prior art. For over a half century, the Court has held that a patent for a combination which only unites old elements with no change in their respective functions obviously withdraws what is already known into the field of its monopoly and diminishes the resources available to skillful men. This is a principal reason for declining to allow patents for what is obvious. The combination of familiar elements according to known methods is likely to be obvious when it does no more than yield predictable results. Three cases decided after Graham illustrate the application of this doctrine.

In United States v. Adams, a companion case to Graham, the Court considered the obviousness of a "wet battery" that varied from prior designs in two ways: It contained water, rather than the acids conventionally employed in storage batteries; and its electrodes were magnesium and cuprous chloride, rather than zinc and silver chloride. The Court recognized that when a patent claims a structure already known in the prior art that is altered by the mere substitution of one element for another known in the field, the combination must do more than yield a predictable result. It nevertheless rejected the Government's claim that Adams's battery was obvious. The Court relied upon the corollary principle that when the prior art teaches away from combining certain known elements, discovery of a successful means of combining them is more likely to be nonobvious. When Adams designed his battery, the prior art warned that risks were involved in using the types of electrodes he employed. The fact that the elements worked together in an unexpected and fruitful manner supported the conclusion that Adams's design was not obvious to those skilled in the art.

In Anderson's-Black Rock, Inc. v. Pavement Salvage Co., the Court 
elaborated on this approach. The subject matter of the patent before the Court was a device combining two pre-existing elements: a radiant-heat burner and a paving machine. The device, the Court concluded, did not create some new synergy: The radiant-heat burner functioned just as a burner was expected to function; and the paving machine did the same. The two in combination did no more than they would in separate, sequential operation. In those circumstances, "while the combination of old elements performed a useful function, it added nothing to the nature and quality of the radiant-heat burner already patented," and the patent failed under $\S 103$.

Finally, in Sakraida v. Ag Pro, Inc., the Court derived from the precedents the conclusion that when a patent "simply arranges old elements with each performing the same function it had been known to perform" and yields no more than one would expect from such an arrangement, the combination is obvious..

The principles underlying these cases are instructive when the question is whether a patent claiming the combination of elements of prior art is obvious. When a work is available in one field of endeavor, design incentives and other market forces can prompt variations of it, either in the same field or a different one. If a person of ordinary skill can implement a predictable variation, § 103 likely bars its patentability. For the same reason, if a technique has been used to improve one device, and a person of ordinary skill in the art would recognize that it would improve similar devices in the same way, using the technique is obvious unless its actual application is beyond his or her skill. Sakraida and Anderson's Black-Rock are illustrative - a court must ask whether the improvement is more than the predictable use of prior art elements according to their established functions.

Following these principles may be more difficult in other cases than it is here because the claimed subject matter may involve more than the simple substitution of one known element for another or the mere application of a known technique to a piece of prior art ready for the improvement. Often, it will be necessary for a court to look to interrelated teachings of multiple patents; the effects of demands known to the design community or present in the marketplace; and the background knowledge possessed by a person having ordinary skill in the art, all in order to determine whether there was an apparent reason to combine the known elements in the fashion claimed by the patent at issue. To facilitate review, this analysis should be made explicit. As our precedents make clear, however, the analysis need not seek out precise teachings directed to the specific subject matter of the challenged claim, for a court can take account of the inferences and creative steps that a person of ordinary skill in the art would employ.
Compare Adams and Anderson's BlackRock What makes the two cases distinguishable

Sakraida: 425 U.S. 273 (1976) 
When it first established the requirement of demonstrating a teaching, suggestion, or motivation to combine known elements in order to show that the combination is obvious, the Court of Customs and Patent Appeals captured a helpful insight. As is clear from cases such as Adams, a patent composed of several elements is not proved obvious merely by demonstrating that each of its elements was, independently, known in the prior art. Although common sense directs one to look with care at a patent application that claims as innovation the combination of two known devices according to their established functions, it can be important to identify a reason that would have prompted a person of ordinary skill in the relevant field to combine the elements in the way the claimed new invention does. This is so because inventions in most, if not all, instances rely upon building blocks long since uncovered, and claimed discoveries almost of necessity will be combinations of what, in some sense, is already known.

Helpful insights, however, need not become rigid and mandatory formulas; and when it is so applied, the TSM test is incompatible with our precedents. The obviousness analysis cannot be confined by a formalistic conception of the words teaching, suggestion, and motivation, or by overemphasis on the importance of published articles and the explicit content of issued patents. The diversity of inventive pursuits and of modern technology counsels against limiting the analysis in this way. In many fields it may be that there is little discussion of obvious techniques or combinations, and it often may be the case that market demand, rather than scientific literature, will drive design trends. Granting patent protection to advances that would occur in the ordinary course without real innovation retards progress and may, in the case of patents combining previously known elements, deprive prior inventions of their value or utility.

\section{C}

One of the ways in which a patent's subject matter can be proved obvious is by noting that there existed at the time of invention a known problem for which there was an obvious solution encompassed by the patent's claims.

The first error of the Court of Appeals in this case was to foreclose this reasoning by holding that courts and patent examiners should look only to the problem the patentee was trying to solve. The Court of Appeals failed to recognize that the problem motivating the patentee may be only one of many addressed by the patent's subject matter. The question is not whether the combination was obvious to the patentee but whether the combination was obvious to a person with ordinary skill in the art. Under the correct analysis, any need 
or problem known in the field of endeavor at the time of invention and addressed by the patent can provide a reason for combining the elements in the manner claimed.

The second error of the Court of Appeals lay in its assumption that a person of ordinary skill attempting to solve a problem will be led only to those elements of prior art designed to solve the same problem. The primary purpose of Asano was solving the constant ratio problem; so, the court concluded, an inventor considering how to put a sensor on an adjustable pedal would have no reason to consider putting it on the Asano pedal. Common sense teaches, however, that familiar items may have obvious uses beyond their primary purposes, and in many cases a person of ordinary skill will be able to fit the teachings of multiple patents together like pieces of a puzzle. Regardless of Asano's primary purpose, the design provided an obvious example of an adjustable pedal with a fixed pivot point; and the prior art was replete with patents indicating that a fixed pivot point was an ideal mount for a sensor. The idea that a designer hoping to make an adjustable electronic pedal would ignore Asano because Asano was designed to solve the constant ratio problem makes little sense. A person of ordinary skill is also a person of ordinary creativity, not an automaton.

The same constricted analysis led the Court of Appeals to conclude, in error, that a patent claim cannot be proved obvious merely by showing that the combination of elements was obvious to try. When there is a design need or market pressure to solve a problem and there are a finite number of identified, predictable solutions, a person of ordinary skill has good reason to pursue the known options within his or her technical grasp. If this leads to the anticipated success, it is likely the product not of innovation but of ordinary skill and common sense. In that instance the fact that a combination was obvious to try might show that it was obvious under $\S 103$.

\section{III}

When we apply the standards we have explained to the instant facts, claim 4 must be found obvious.

The District Court was correct to conclude that, as of the time Engelgau designed the subject matter in claim 4, it was obvious to a person of ordinary skill to combine Asano with a pivot-mounted pedal position sensor. There then existed a marketplace that created a strong incentive to convert mechanical pedals to electronic pedals, and the prior art taught a number of methods for achieving this advance. The Court of Appeals considered the issue too narrowly by, in effect, asking whether a pedal designer writing on a blank slate would have
In cases in which "common sense" is used to supply a missing limitation, as distinct from a motivation to combine, our search for a reasoned basis for resort to common sense must be searching. Appellees have failed to show why it would be common sense for the "Add to address book" function to operate by first searching for entries with the same telephone number.

Arendi S.A.R.I. v. Apple, Inc., No. 20152073, --- F.3d --- (Fed. Cir Aug. 10, 2016). SRSLY? 
chosen both Asano and a modular sensor similar to the ones used in the Chevrolet truckline and disclosed in the '068 patent. The proper question to have asked was whether a pedal designer of ordinary skill, facing the wide range of needs created by developments in the field of endeavor, would have seen a benefit to upgrading Asano with a sensor.

In automotive design, as in many other fields, the interaction of multiple components means that changing one component often requires the others to be modified as well. Technological developments made it clear that engines using computer-controlled throttles would become standard. As a result, designers might have decided to design new pedals from scratch; but they also would have had reason to make pre-existing pedals work with the new engines. Indeed, upgrading its own pre-existing model led KSR to design the pedal now accused of infringing the Engelgau patent.

For a designer starting with Asano, the question was where to attach the sensor. The consequent legal question, then, is whether a pedal designer of ordinary skill starting with Asano would have found it obvious to put the sensor on a fixed pivot point. The prior art discussed above leads us to the conclusion that attaching the sensor where both KSR and Engelgau put it would have been obvious to a person of ordinary skill.

The '936 patent taught the utility of putting the sensor on the pedal device, not in the engine. Smith, in turn, explained to put the sensor not on the pedal's footpad but instead on its support structure. And from the known wire-chafing problems of Rixon, and Smith's teaching that "the pedal assemblies must not precipitate any motion in the connecting wires," the designer would know to place the sensor on a nonmoving part of the pedal structure. The most obvious nonmoving point on the structure from which a sensor can easily detect the pedal's position is a pivot point. The designer, accordingly, would follow Smith in mounting the sensor on a pivot, thereby designing an adjustable electronic pedal covered by claim 4 .

Just as it was possible to begin with the objective to upgrade Asano to work with a computer-controlled throttle, so too was it possible to take an adjustable electronic pedal like Rixon and seek an improvement that would avoid the wire-chafing problem. Following similar steps to those just explained, a designer would learn from Smith to avoid sensor movement and would come, thereby, to Asano because Asano disclosed an adjustable pedal with a fixed pivot.

Like the District Court, finally, we conclude Teleflex has shown no can holder attached to a foam we'renumber-one finger. Obvious? What about a Sawzie -- a foam can holder attached to a rotary saw? secondary factors to dislodge the determination that claim 4 is obvious. Proper application of Graham and our other precedents to these facts therefore leads to the conclusion that claim 4 encompassed obvious subject matter. As a result, the claim fails to meet the requirement 
of $\S 103$.

IV

We build and create by bringing to the tangible and palpable reality around us new works based on instinct, simple logic, ordinary inferences, extraordinary ideas, and sometimes even genius. These advances, once part of our shared knowledge, define a new threshold from which innovation starts once more. And as progress beginning from higher levels of achievement is expected in the normal course, the results of ordinary innovation are not the subject of exclusive rights under the patent laws. Were it otherwise patents might stifle, rather than promote, the progress of useful arts.

\section{In re Clay}

Clay's invention, assigned to Marathon Oil Company, is a process for storing refined liquid hydrocarbon product in a storage tank having a dead volume between the tank bottom and its outlet port. The process involves preparing a gelation solution which gels after it is placed in the tank's dead volume; the gel can easily be removed by adding to the tank a gel-degrading agent such as hydrogen peroxide.

Two prior art references were applied against the claims on appeal. They were U.S. Patent 4,664,294 (Hetherington), which discloses an apparatus for displacing dead space liquid using impervious bladders, or large bags, formed with flexible membranes; and U.S. Patent 4,683,949 (Sydansk), also assigned to Clay's assignee, Marathon Oil Company, which discloses a process for reducing the permeability of hydrocarbon-bearing formations and thus improving oil production, using a gel similar to that in Clay's invention.

The Board agreed with the examiner that, although neither reference alone describes Clay's invention, Hetherington and Sydansk combined support a conclusion of obviousness. It held that one skilled in the art would glean from Hetherington that Clay's invention "was appreciated in the prior art and solutions to that problem generally involved filling the dead space with something."

The Board also held that Sydansk would have provided one skilled in the art with information that a gelation system would have been impervious to hydrocarbons once the system gelled. The Board combined the references, finding that the "cavities" filled by Sydansk are sufficiently similar to the "volume or void space" being filled by Hetherington for one of ordinary skill to have recognized the applicability of the gel to Hetherington.

\section{DISCUSSION}

The issue presented in this appeal is whether the Board's conclusion was correct that Clay's invention would have been obvious from the combined teachings of Hetherington and Sydansk. 
A prerequisite to making this finding is determining what is "prior art." Although $\S 103$ does not, by its terms, define the "art to which [the] subject matter [sought to be patented] pertains," this determination is frequently couched in terms of whether the art is analogous or not, i.e., whether the art is too remote to be treated as prior art. Clay argues that the claims at issue were improperly rejected over Hetherington and Sydansk, because Sydansk is nonanalogous art.

Two criteria have evolved for determining whether prior art is analogous: (1) whether the art is from the same field of endeavor, regardless of the problem addressed, and (2) if the reference is not within the field of the inventor's endeavor, whether the reference still is reasonably pertinent to the particular problem with which the inventor is involved.

The Board found Sydansk to be within the field of Clay's endeavor because, as the Examiner stated, "one of ordinary skill in the art would certainly glean from Sydansk that the rigid gel as taught therein would have a number of applications within the manipulation of the storage and processing of hydrocarbon liquids and that the gel as taught in Sydansk would be expected to function in a similar manner as the bladders in the Hetherington patent." These findings are clearly erroneous.

The PTO argues that Sydansk and Clay's inventions are part of a common endeavor - "maximizing withdrawal of petroleum stored in petroleum reservoirs." However, Sydansk cannot be considered to be within Clay's field of endeavor merely because both relate to the petroleum industry. Sydansk teaches the use of a gel in unconfined and irregular volumes within generally underground natural oil-bearing formations to channel flow in a desired direction; Clay teaches the introduction of gel to the confined dead volume of a manmade storage tank. The Sydansk process operates in extreme conditions, with petroleum formation temperatures as high as $115^{\circ} \mathrm{C}$ and at significant well bore pressures; Clay's process apparently operates at ambient temperature and atmospheric pressure. Clay's field of endeavor is the storage of refined liquid hydrocarbons. The field of endeavor of Sydansk's invention, on the other hand, is the extraction of crude petroleum. The Board clearly erred in considering Sydansk to be within the same field of endeavor as Clay's.

Even though the art disclosed in Sydansk is not within Clay's field of endeavor, the reference may still properly be combined with Hetherington if it is reasonably pertinent to the problem Clay attempts to solve. A reference is reasonably pertinent if, even though it may be in a different field from that of the inventor's endeavor, it is one which, because of the matter with which it deals, logically would have commended itself to an inventor's attention in considering his problem. Thus, the purposes of both the invention and the prior art are impor- 
tant in determining whether the reference is reasonably pertinent to the problem the invention attempts to solve. If a reference disclosure has the same purpose as the claimed invention, the reference relates to the same problem, and that fact supports use of that reference in an obviousness rejection. An inventor may well have been motivated to consider the reference when making his invention. If it is directed to a different purpose, the inventor would accordingly have had less motivation or occasion to consider it.

Sydansk's gel treatment of underground formations functions to fill anomalies ${ }^{1}$ so as to improve flow profiles and sweep efficiencies of injection and production fluids through a formation, while Clay's gel functions to displace liquid product from the dead volume of a storage tank. Sydansk is concerned with plugging formation anomalies so that fluid is subsequently diverted by the gel into the formation matrix, thereby forcing bypassed oil contained in the matrix toward a production well. Sydansk is faced with the problem of recovering oil from rock, i.e., from a matrix which is porous, permeable sedimentary rock of a subterranean formation where water has channeled through formation anomalies and bypassed oil present in the matrix. Such a problem is not reasonably pertinent to the particular problem with which Clay was involved - preventing loss of stored product to tank dead volume while preventing contamination of such product.

A person having ordinary skill in the art would not reasonably have expected to solve the problem of dead volume in tanks for storing refined petroleum by considering a reference dealing with plugging underground formation anomalies. The Board's finding to the contrary is clearly erroneous. Since Sydansk is non-analogous art, the rejection over Hetherington in view of Sydansk cannot be sustained.

\section{KSR Problem}

In relevant part, claim 4 of the patent in suit in KSR comprises:

- A pedal

- that is adjustable

- and has a fixed pivot,

- and a sensor

- that is in the pedal

- and is and mounted on a fixed position

The Court had before it a number of pieces of prior art, and had

\footnotetext{
${ }^{1}$ Sydansk refers to an anomaly, one of two general region types in an oil-bearing geological formation, as "a volume or void space [e.g., 'streaks, fractures, fracture networks, vugs, solution channels, caverns, washouts, cavities, etc.'] in the formation having very high permeability relative to the matrix [the other region type, consisting of homogeneous porous rock]."
} 
to decide whether claim 4 was obvious in light of them. Please look closely at the Court's descriptions of the following prior art:

- Asano

- Redding

- ‘936

- Smith

- ‘068

- Certain 1994 Chevrolet trucks

- Rixon

Which of the characteristics of claim 4, as listed above, do each of these prior art references disclose? Make a chart. What improvements, if any, does each prior art reference suggest to a person having ordinary skill in the art. Using your chart as a guide, explain whether the Supreme Court's analysis is persuasive.

\section{Infringement: Similarity}

\section{Jeanne C. Fromer \\ Claiming Intellectual Property}

To claim the set of things protected by an intellectual property right, one might be required to delineate to the public the set's bounds so that a third party could determine whether any particular embodiment is a set member thus protected by the right. This sort of claiming is known as peripheral claiming." Alternatively, one might publicly describe only some members of the set, which are clearly protected under the right, and use them to determine whether other items are similar enough to the enumerated members to fall also within the same right. This sort of claiming is known as central claiming, in that the rightsholder describes the central, or prototypical, set members, but the right tends to cover a broader, similar set of items.

There is another important dimension on which claiming can vary, which until now has not been readily appreciated. Either peripheral or central claiming can be done by exemplar or by characteristic. Claiming by exemplar entails enumerating particular members of the set of protected embodiments. In the case of peripheral claiming by exemplar, one would enumerate each set member, while for central claiming by exemplar, one would catalog only some set members. Claiming by characteristic, on the other hand, requires a description of the essential properties of the set's members. For peripheral claiming by characteristic, one would describe the necessary and sufficient features common to all members of the set of protected embodiments. And for central claiming by characteristic, one would 
express the features common to at least some central members of the set of protected embodiments. Claiming by exemplar and by characteristic can be seen as opposing points on a spectrum of how much distillation of the actual works' characteristics is necessary.

TABLE 1

DIFFERENT WAYS TO CLAIM THE FORK

\begin{tabular}{l|l|l|}
\hline \multicolumn{3}{c}{ Central Claiming } \\
Claiming by \\
Exemplar
\end{tabular}

A statutory change in 1870 - requiring a patent applicant to "particularly point out and distinctly claim the part, improvement, or combination which he claims as his invention or discovery" - officially (though gradually) brought peripheral claiming, almost always by characteristic, to American patent law. The Supreme Court held that, pursuant to this statutory language, the articulated bounds of the patent claim would govern the scope of the set of things protected by the patent right. Validity and infringement would thus be measured by construing the claim's bounds and then determining whether particular embodiments fell within those bounds. Characteristic peripheral claiming- - in contrast to central claiming (by characteristic or exemplar) - thus did not require courts to decide which of an invention's properties were essential, as the patentee would delineate these qualities in the patent claims.

At least two vestiges of central claiming have remained in the patent system, namely the doctrine of equivalents and means-plusfunction claims. 
Model Patent Jury Instructions for the Northern District of California

A patent's claims define what is covered by the patent. A [product] [method] directly infringes a patent if it is covered by at least one claim of the patent.

Deciding whether a claim has been directly infringed is a two-step process. The first step is to decide the meaning of the patent claim. I have already made this decision, [and I will instruct you later as to the meaning of the asserted patent claims] [and I have already instructed you as to the meaning of the asserted patent claims]. The second step is to decide whether [alleged direct infringer] has [made,] [used,] [sold,] [offered for sale] or [imported] within the United States a [product] [method] covered by a claim of the [ ] patent. If it has, it infringes. You, the jury, make this decision.

[With one exception,] you must consider each of the asserted claims of the patent individually, and decide whether [alleged direct infringer]'s [product] [method] infringes that claim. [The one exception to considering claims individually concerns dependent claims. A dependent claim includes all of the requirements of a particular independent claim, plus additional requirements of its own. As a result, if you find that an independent claim is not infringed, you must also find that its dependent claims are not infringed. On the other hand, if you find that an independent claim has been infringed, you must still separately decide whether the additional requirements of its dependent claims have also been infringed.]

There are two ways in which a patent claim may be directly infringed. A claim may be "literally" infringed, or it may be infringed under the "doctrine of equivalents."

To decide whether [alleged infringer]'s [product] [method] literally infringes a claim of the [ ] patent, you must compare that [product] [method] with the patent claim and determine whether every requirement of the claim is included in that [product] [method]. If so, [alleged infringer]'s [product] [method] literally infringes that claim. If, however, [alleged infringer]'s [product] [method] does not have every requirement in the patent claim, [alleged infringer]'s [product] [method] does not literally infringe that claim. You must decide literal infringement for each asserted claim separately.

\section{Claim Construction}

415 F.3d 1303 (2005) (en banc)

\section{Phillips v. AWH Corp.}

It is a "bedrock principle" of patent law that the claims of a patent define the invention to which the patentee is entitled the right to exclude. We have frequently stated that the words of a claim are generally given their ordinary and customary meaning. We have made 
clear, moreover, that the ordinary and customary meaning of a claim term is the meaning that the term would have to a person of ordinary skill in the art in question at the time of the invention, i.e., as of the effective filing date of the patent application.

The inquiry into how a person of ordinary skill in the art understands a claim term provides an objective baseline from which to begin claim interpretation. That starting point is based on the wellsettled understanding that inventors are typically persons skilled in the field of the invention and that patents are addressed to and intended to be read by others of skill in the pertinent art. $S$

Importantly, the person of ordinary skill in the art is deemed to read the claim term not only in the context of the particular claim in which the disputed term appears, but in the context of the entire patent, including the specification. This court explained that point well in Multiform Desiccants, Inc. v. Medzam, Ltd.:

It is the person of ordinary skill in the field of the invention through whose eyes the claims are construed. Such person is deemed to read the words used in the patent documents with an understanding of their meaning in the field, and to have knowledge of any special meaning and usage in the field. The inventor's words that are used to describe the invention - the inventor's lexicography must be understood and interpreted by the court as they would be understood and interpreted by a person in that field of technology. Thus the court starts the decisionmaking process by reviewing the same resources as would that person, viz., the patent specification and the prosecution history.

$B$

In some cases, the ordinary meaning of claim language as understood by a person of skill in the art may be readily apparent even to lay judges, and claim construction in such cases involves little more than the application of the widely accepted meaning of commonly understood words. In such circumstances, general purpose dictionaries may be helpful. In many cases that give rise to litigation, however, determining the ordinary and customary meaning of the claim requires examination of terms that have a particular meaning in a field of art. Because the meaning of a claim term as understood by persons of skill in the art is often not immediately apparent, and because patentees frequently use terms idiosyncratically, the court looks to those sources available to the public that show what a person of skill in the art would have understood disputed claim language to mean. Those sources include the words of the claims themselves, the remainder of
Multiform: 133 F.3d 1473 (Fed. Cir. 1998) 
the specification, the prosecution history, and extrinsic evidence concerning relevant scientific principles, the meaning of technical terms, and the state of the art.

Quite apart from the written description and the prosecution history, the claims themselves provide substantial guidance as to the meaning of particular claim terms.

To begin with, the context in which a term is used in the asserted claim can be highly instructive. To take a simple example, the claim in this case refers to "steel baffles," which strongly implies that the term "baffles" does not inherently mean objects made of steel. This court's cases provide numerous similar examples in which the use of a term within the claim provides a firm basis for construing the term. [Cited cases construed the claim term "ingredients" in light of the use of the term "mixture" in the same claim phrase and the claim term "discharge rate" in light of the use of the same term in another limitation of the same claim.]

Other claims of the patent in question, both asserted and unasserted, can also be valuable sources of enlightenment as to the meaning of a claim term. Because claim terms are normally used consistently throughout the patent, the usage of a term in one claim can often illuminate the meaning of the same term in other claims. Differences among claims can also be a useful guide in understanding the meaning of particular claim terms. For example, $1315^{*} 1315$ the presence of a dependent claim that adds a particular limitation gives rise to a presumption that the limitation in question is not present in the independent claim.

The claims, of course, do not stand alone. Rather, they are part of a fully integrated written instrument, consisting principally of a specification that concludes with the claims. For that reason, claims must be read in view of the specification, of which they are a part. The specification is always highly relevant to the claim construction analysis. Usually, it is dispositive; it is the single best guide to the meaning of a disputed term.

The importance of the specification in claim construction derives from its statutory role. The close kinship between the written description and the claims is enforced by the statutory requirement that the specification describe the claimed invention in "full, clear, concise, and exact terms." In light of the statutory directive that the inventor provide a "full" and "exact" description of the claimed invention, the specification necessarily informs the proper construction of the claims. 
Consistent with that general principle, our cases recognize that the specification may reveal a special definition given to a claim term by the patentee that differs from the meaning it would otherwise possess. In such cases, the inventor's lexicography governs. In other cases, the specification may reveal an intentional disclaimer, or disavowal, of claim scope by the inventor. In that instance as well, the inventor has dictated the correct claim scope, and the inventor's intention, as expressed in the specification, is regarded as dispositive.

In addition to consulting the specification, we have held that a court should also consider the patent's prosecution history, if it is in evidence. The prosecution history, which we have designated as part of the "intrinsic evidence," consists of the complete record of the proceedings before the PTO and includes the prior art cited during the examination of the patent. Like the specification, the prosecution history provides evidence of how the PTO and the inventor understood the patent. Furthermore, like the specification, the prosecution history was created by the patentee in attempting to explain and obtain the patent. Yet because the prosecution history represents an ongoing negotiation between the PTO and the applicant, rather than the final product of that negotiation, it often lacks the clarity of the specification and thus is less useful for claim construction purposes. Nonetheless, the prosecution history can often inform the meaning of the claim language by demonstrating how the inventor understood the invention and whether the inventor limited the invention in the course of prosecution, making the claim scope narrower than it would otherwise be.

Although we have emphasized the importance of intrinsic evidence in claim construction, we have also authorized district courts to rely on extrinsic evidence, which consists of all evidence external to the patent and prosecution history, including expert and inventor testimony, dictionaries, and learned treatises. However, while extrinsic evidence can shed useful light on the relevant art, it is less significant than the intrinsic record in determining the legally operative meaning of claim language.

Within the class of extrinsic evidence, dictionaries and treatises can be useful in claim construction. We have especially noted the help that technical dictionaries may provide to a court to better understand the underlying technology and the way in which one of skill in the art might use the claim terms. Because dictionaries, and especially technical dictionaries, endeavor to collect the accepted meanings of terms used in various fields of science and technology, those 
resources have been properly recognized as among the many tools that can assist the court in determining the meaning of particular terminology to those of skill in the art of the invention. Such evidence, may be considered if the court deems it helpful in determining the true meaning of language used in the patent claims.

Extrinsic evidence in the form of expert testimony can be useful to a court for a variety of purposes, such as to provide background on the technology at issue, to explain how an invention works, to ensure that the court's understanding of the technical aspects of the patent is consistent with that of a person of skill in the art, or to establish that a particular term in the patent or the prior art has a particular meaning in the pertinent field. However, conclusory, unsupported assertions by experts as to the definition of a claim term are not useful to a court. Similarly, a court should discount any expert testimony that is clearly at odds with the claim construction mandated by the claims themselves, the written description, and the prosecution history, in other words, with the written record of the patent.

We have viewed extrinsic evidence in general as less reliable than the patent and its prosecution history in determining how to read claim terms, for several reasons. First, extrinsic evidence by definition is not part of the patent and does not have the specification's virtue of being created at the time of patent prosecution for the purpose of explaining the patent's scope and meaning. Second, while claims are construed as they would be understood by a hypothetical person of skill in the art, extrinsic publications may not be written by or for skilled artisans and therefore may not reflect the understanding of a skilled artisan in the field of the patent. Third, extrinsic evidence consisting of expert reports and testimony is generated at the time of and for the purpose of litigation and thus can suffer from bias that is not present in intrinsic evidence. The effect of that bias can be exacerbated if the expert is not one of skill in the relevant art or if the expert's opinion is offered in a form that is not subject to cross-examination. Fourth, there is a virtually unbounded universe of potential extrinsic evidence of some marginal relevance that could be brought to bear on any claim construction question. In the course of litigation, each party will naturally choose the pieces of extrinsic evidence most favorable to its cause, leaving the court with the considerable task of filtering the useful extrinsic evidence from the fluff. Finally, undue reliance on extrinsic evidence poses the risk that it will be used to change the meaning of claims in derogation of the indisputable public records consisting of the claims, the specification and the prosecution history, thereby undermining the public notice function of patents.

In sum, extrinsic evidence may be useful to the court, but it is unlikely to result in a reliable interpretation of patent claim scope unless considered in the context of the intrinsic evidence. Nonetheless, 
because extrinsic evidence can help educate the court regarding the field of the invention and can help the court determine what a person of ordinary skill in the art would understand claim terms to mean, it is permissible for the district court in its sound discretion to admit and use such evidence. In exercising that discretion, and in weighing all the evidence bearing on claim construction, the court should keep in mind the flaws inherent in each type of evidence and assess that evidence accordingly.

Thorner v. Sony Computer Entertainment America LLC Craig Thorner and Virtual Reality Feedback Corporation (Appellants, collectively) accused Sony Computer Entertainment America LLC and number of other Sony entities (Sony, collectively) of infringing claims of U.S. patent no. 6,422,941 ('941 patent) relating to a tactile feedback system for computer video games. The district court construed disputed claim terms and the parties stipulated to a judgment of noninfringement. Because the district court improperly limited the term "attached to said pad" to mean attachment only to an external surface and erred in its construction of the term "flexible", we vacate and remand.

\section{BACKGROUND}

The '941 patent describes a tactile feedback system for use with video games. Figure 2 shows the many different embodiments of the invention:

Tactile feedback controller 110 is part of a larger gaming system that operates one or more of the devices shown above. Each device includes some type of actuator that provides tactile feedback to a user in response to certain game activities. For instance, the actuators in hand-held game controller 598 may vibrate during a crash in a car racing game. Independent claim 1 requires "a flexible pad," "a plurality of actuators attached to said pad" and a control circuit that activates the actuators in response to game activity. The accused products are hand-held game controllers.

Two claim limitations are relevant to this appeal, "flexible pad" and "attached to said pad." The district court held that flexible does not mean simply "capable of being flexed." It reasoned that this definition was inappropriate because "many objects that are capable of being flexed are not flexible. A steel I-beam is capable of being flexed, but no one would call it 'flexible."' The court thus construed the term to mean "capable of being noticeably flexed with ease."

The district court then turned to the construction of "attached to said pad." Appellants argued that attached should be given its plain and ordinary meaning and that an actuator can be attached to the inside of an object. Sony argued that "attached to said pad" should be 
U.S. Patent Jul. 23, 2002 Sheet 2 of $37 \quad$ US 6,422,941 B1

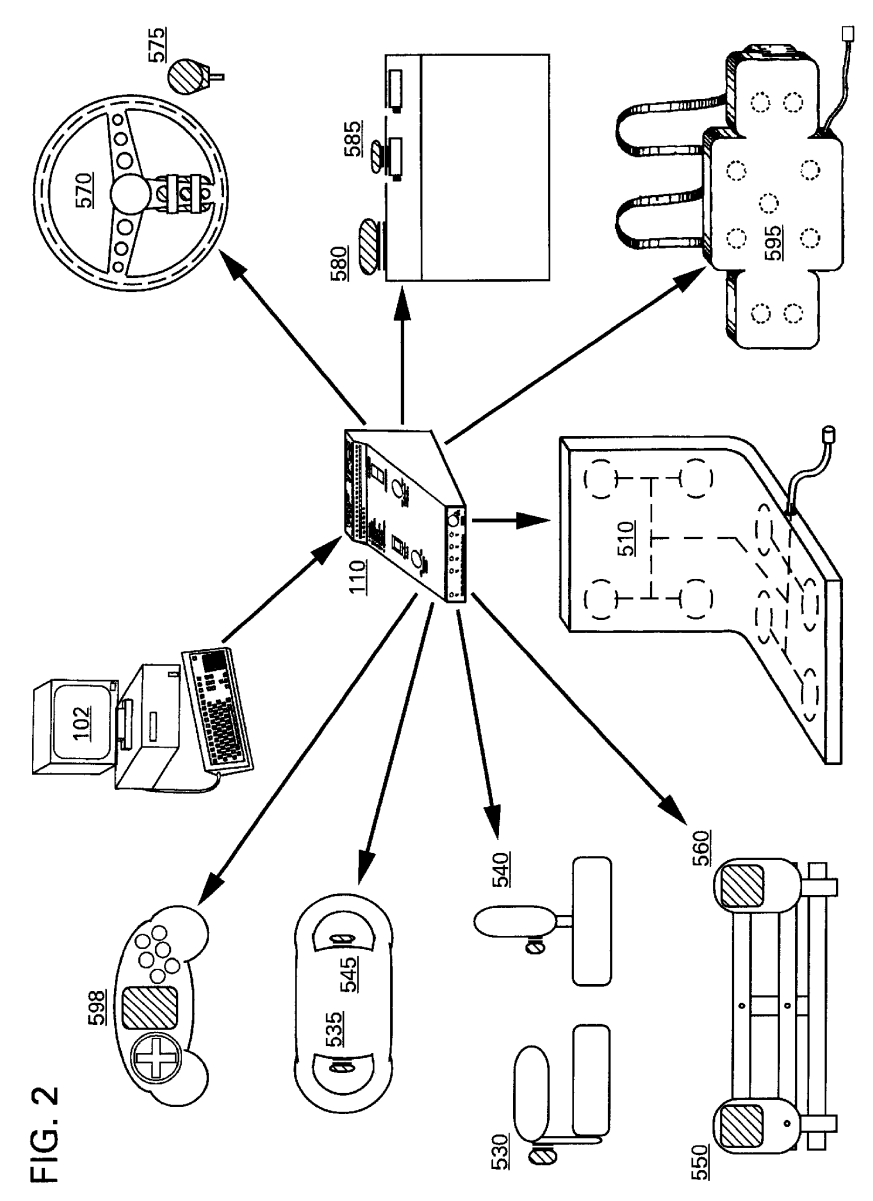

U.S. Patent No. 6,422,941, Universal tactile feedback system for computer video games and simulations 
construed as affixed to the exterior surface of the pad and does not include embedded within said pad. The court held that "the specification redefines 'attached' by implication." The court held that the word attached was limited to attached to the outside of an object because the embodiments in the specification consistently use the term "attached" to indicate affixing an actuator to the outer surface of an object and use the word "embedded" when referring to an actuator inside an object. For additional support for the notion that attached and embedded have different meanings, the court pointed to claim 1 which uses the word "attached" and dependent claim 10 which uses the word "embedded."

Following claim construction, the parties stipulated to noninfringement by the accused products. They stated that "under the Court's construction of the phrase 'attached to said pad,' Defendants have not infringed...." The stipulation further stated that the "parties reserve their rights to challenge this or any other construction of the disputed claim phrases of the "941 patent on appeal."

\section{DISCUSSION}

The words of a claim are generally given their ordinary and customary meaning as understood by a person of ordinary skill in the art when read in the context of the specification and prosecution history. See AWH. There are only two exceptions to this general rule: 1) when a patentee sets out a definition and acts as his own lexicographer, or 2) when the patentee disavows the full scope of a claim term either in the specification or during prosecution. The use of the term "attached" in this specification does not meet either of these exceptions.

To act as its own lexicographer, a patentee must clearly set forth a definition of the disputed claim term other than its plain and ordinary meaning. . It is not enough for a patentee to simply disclose a single embodiment or use a word in the same manner in all embodiments, the patentee must clearly express an intent to redefine the term. For example, in 3M Innovative Properties Co. v. Avery Dennison Corp., we held that the patentee acted as its own lexicographer when the specification stated: “'Multiple embossed' means two or more embossing patterns are superimposed on the web to create a complex pattern of differing depths of embossing."). Similarly, we limited a patentee to particular examples of solubilizers when it stated in the specification that " $\mathrm{t}]$ he solubilizers suitable according to the invention are defined below." Astrazeneca AB v. Mutual Pharm. Co..

The standard for disavowal of claim scope is similarly exacting. Where the specification makes clear that the invention does not include a particular feature, that feature is deemed to be outside the reach of the claims of the patent, even though the language of the claims, read without reference to the specification, might be consid-
3M Innovative Properties: 350 F.3d 1365 (Fed.Cir. 2004)

Astrazeneca: 384 F.3d 1333 (Fed. Cir. 2004) 
ered broad enough to encompass the feature in question. The patentee may demonstrate intent to deviate from the ordinary and accustomed meaning of a claim term by including in the specification expressions of manifest exclusion or restriction, representing a clear disavowal of claim scope. For example, in SciMed Life Sys., Inc. v. Advanced Cardiovascular Sys., Inc., the patentee described two different types of catheters in the prior art, those with dual lumens (side-byside) and those with coaxial lumens. In discussing the prior art, the patentee disparaged the dual lumen configuration as larger than necessary and less pliable than the coaxial type. Further, the specification repeatedly described the "present invention" as a coaxial design. Finally, the specification stated: "The intermediate sleeve structure defined above [coaxial design] is the basic sleeve structure for all embodiments of the present invention contemplated and disclosed herein." This court held that collectively this amounted to disavowal of the dual lumen design.

Mere criticism of a particular embodiment encompassed in the plain meaning of a claim term is not sufficient to rise to the level of clear disavowal. Even where a particular structure makes it particularly difficult to obtain certain benefits of the claimed invention, this does not rise to the level of disavowal of the structure. It is likewise not enough that the only embodiments, or all of the embodiments, contain a particular limitation. We do not read limitations from the specification into claims; we do not redefine words. Only the patentee can do that. To constitute disclaimer, there must be a clear and unmistakable disclaimer.

It is the claims that define the metes and bounds of the patentee's invention. The patentee is free to choose a broad term and expect to obtain the full scope of its plain and ordinary meaning unless the patentee explicitly redefines the term or disavows its full scope.

Claim 1 of the patent at issue includes the disputed claim terms:

In a computer or video game system, apparatus for providing, in response to signals generated by said computer or video game system, a tactile sensation to a user of said computer or video game system, said apparatus comprising:

a flexible pad;

a plurality of actuators, attached to said pad, for selectively generating tactile sensation; and a control circuit ... for generating a control signal to control activation of said plurality of actuators....

\section{I. "attached to said pad"}

Appellants argue that the district court erred by holding that the specification implicitly defined "attached" to mean "affixed to an exterior 
surface." They argue that the term does not require any construction and that the plain and ordinary meaning includes affixing an item to either an exterior or an interior surface. They contend that the specification explicitly states whether an attachment is to an interior or exterior surface: "a vibratory actuator can be attached to [the] outer side of the throttle handle." They argue this shows that when the applicant wished to distinguish an internal from an external attachment, he did so with deliberate, express language. Thus, appellants argue that the specification contemplates "attached" to have its plain and ordinary meaning - attached to either an interior or exterior surface. Finally, appellants argue that the fact that claim 10 includes the word "embedded" does not mean that "attached" can only mean connected to an exterior surface. Rather, appellants argue that "embedded" is merely a narrower term that includes only attachment to an interior surface.

Sony responds that the patent clearly identified two different connections, "attached to" and "embedded within." It argues that in every instance where the specification uses the term "attached," it refers to an attachment to an outer surface. Conversely, in every embodiment where the actuator is placed inside a housing, the specification uses the term "embedded." See, e.g., '941 patent col.32 1.66 ("embedded within or attached to").

Our case law is clear, claim terms must be given their plain and ordinary meaning to one of skill in the art. The plain meaning of the term "attached" encompasses either an external or internal attachment. We must decide whether the patentee has redefined this term to mean only attachment to an external surface. As Sony argues, the specification repeatedly uses the term "attached" in reference to embodiments where the actuators are "attached to [an] outer side." In fact, the specification never uses the word "attached" when referring to an actuator located on the interior of a controller. We hold that this does not rise to the level of either lexicography or disavowal. Both exceptions require a clear and explicit statement by the patentee. It is not enough that the patentee used the term when referencing an attachment to an outer surface in each embodiment. In fact, the specification explains that an actuator was "attached to [an] outer surface." If the applicant had redefined the term "attached" to mean only "attached to an outer surface," then it would have been unnecessary to specify that the attachment was "to [an] outer surface" in the specification. We conclude that the term attached should be given its plain and ordinary meaning. The specification does not redefine attached nor is there any disavowal.

The fact that the specification uses the two terms "attached" and "embedded" as alternatives does not require a different result. There is nothing inconsistent about the applicant's use of the narrower term, 
"embedded," to describe embodiments affixed to an internal surface. The plain and ordinary meaning of embedded, "attached within," is narrower than "attached." Hence it makes sense that the applicant would want to use embedded when it meant to explicitly claim attached to the inside only. That does not mean the word attached automatically means attached to the external surface, as opposed to the broader plain meaning - attached to either the interior or exterior.

Other parts of the claim and specification also support this construction. The claim at issue requires a "flexible pad." The only embodiment in the specification that includes flexible material is the seat cushion 510 shown in Figure 2. The specification states that "the tactile feedback seating unit 510 is a semi-rigid flexible foam structure ... with a plurality of actuators embedded within the foam structure." Thus, the only flexible embodiment in the specification has embedded actuators. If we agreed with Sony that "attached" must mean attached to an outer surface, then the claim would exclude the only flexible embodiment disclosed in the specification. This is further evidence that the term "attached" should have its plain and ordinary meaning which includes either internal or external attachments.

We hold that the term "attached to said pad" should be given its plain and ordinary meaning which encompasses either internal or external attachment. Because the parties based the stipulation of noninfringement on the district court's erroneous construction of this claim term, we vacate and remand.

\section{II. "flexible pad" ...}

Appellants argue that the term "flexible" simply means "capable of being flexed" and that the district court erred by requiring "capable of being noticeably flexed with ease." They note that the specification only uses the term "flexible pad" when referring to a "semi-rigid" structure and that a "semi-rigid" structure would certainly not be "noticeably flexed with ease."

Sony responds that although the specification uses the term to refer to a "semi-rigid" structure, that structure is made out of foam in every embodiment. It argues that foam is capable of being noticeably flexed with ease and thus a rigid, barely bendable material should not be considered "flexible." Sony also points to portions of the Markman hearing where the district court judge inspected one of the accused hard plastic controllers. The judge noted that the controller was rigid and "[i]f I try to flex this thing, I think that you're going to see it snap."

We agree with the appellants that the district court improperly limited the term. Neither the claims nor the specification requires the "flexible pad" to be noticeably flexed with ease. The specification says only that the flexible pad must be a semi-rigid structure. 
The task of determining the degree of flexibility, the degree of rigidity that amounts to "semi-rigid," is part of the infringement analysis, not part of the claim construction. The district court is of course free on summary judgment to decide that there is no genuine issue of material fact that the accused products in this case do not meet the plain and ordinary meaning of the term "flexible." We do not mean to suggest that summary judgment is improper in this case, only that claim construction is the wrong venue for this determination.

\section{Literal Infringement}

Angelo Mongiello's Children, LLC v. Pizza Hut, Inc.

The complaint alleges that defendant's method for making stuffedcrust pizzas, in use between March of 1994 and at least July of 1996, infringed plaintiff's method for making pizza claimed in United States Patent No. 4,661,361 dated April 28, 1987 (the '361 patent).

In essence, plaintiff's method is to create multiple, individually sealed pockets made of dough that are filled with cheese (or other ingredients) and enclosed within the outer rim of a pizza crust or placed on a portion of the pizza crust. Tomato sauce and cheese covers the rest of the pie. The claims describe two basic methods: one uses dough pulled over from the edge of the crust to cover the fillings and form the pockets; the other places a separate piece of dough, not from the edge, over the fillings to form a pocket.

[Claim 1 reads] as follows:

1. A method of making a pizza comprising the steps of:

(a) forming a generally flat dough base;

(b) placing a plurality of separated individual food portions on the dough base such that, when the dough base is cut into substantially equally sized portions, each individual food portion is located upon a portion of each pie;

(c) covering each food portion with an unbaked dough section of sufficient dimensions to cover said food portion thereby forming a separate closed pocket about each food portion;

(d) covering the portions of the dough base which are not covered by said closed pockets with a layer of tomato sauce and cheese to form an unbaked pizza product; and

(e) baking the unbaked product to obtain a pizza.

In early 1988 Anthony Mongiello sent defendant a copy of the'361 patent, offering a license under it. Defendant responded by letter dated May 17, 1988 that it was "not a new concept for Pizza Hut" and rejected the offer.

In March of 1995 defendant launched a cheese "Stuffed Crust 
Pizza." The manager's guide dated February 1995 describes defendant's method as follows:

- Place thumbs on edge of dough.

- Press dough ridge up the sides of pan.

- Dough must extend just above rim of pan $\left(1 / 4^{\prime \prime}\right)$

- Evenly space five pieces of thawed mozzarella string cheese approximately a thumb's width apart along the outside edge of the dough

- Place close to bottom of pan where edge meets.

- Use thumb and index fingers to stretch and fold edge of the dough over string cheese and press firmly to seal.

- Dough overlap should be visible on both sides of thumb.

- Keep stuffed edge at score line etched in pan to keep dough in round shape.

- Use thumbs to press and seal overlapped dough to bottom edge.

- Use thumbs to push stuffed edge out to edge of pan....

- [after applying sauce, toppings, and baking] [a]ll Stuffed Crust Pizzas are cut into 8 slices. If cheese is leaking through small hole in crust, begin cutting pizza at that spot.

An objective of the method was to create "cheese pull," which means that the cheese within the crust joins together during baking so that the consumer receives "cheese in every bite."

Defendant launched a pepperoni and cheese Stuffed Crust Pizza in September of 1995, which contained a continuous layer of pepperoni slices beneath the five pieces of cheese within the outer edge of the pizza. Plaintiff concedes that the pepperoni and cheese version does not infringe the '361 patent.

Shortly after learning of the 1995 launch of defendant's Stuffed Crust Pizza, Anthony Mongiello and his brother Lawrence cut open Stuffed Crust Pizzas purchased from defendant's restaurants. They say that when they cut into the crusts, they observed "pockets" of mozzarella cheese and spots where "a dough wall separated adjacent mozzarella strings."

Based on their observations of randomly occurring dough walls dividing cheese within the crust of defendant's baked product, the Mongiellos believed that the method defendant used to make Stuffed Crust Pizzas infringed on their claimed method.

Defendant argues that its method of making Stuffed Crust Pizza does not infringe the '361 patent, either literally or through substantial equivalence, because it does not perform what it says are three required elements of the claimed method [including]:

(1) The "cutting step" of claim 1: "when the dough base is cut into 
substantially equally sized pieces, each individual food portion is located upon a portion of each piece."

(2) The "forming step" of claim 1: "forming a separate closed pocket about each food portion."

Defendant says that the phrase "such that, when the dough base is cut into substantially equally sized portions, each individual food portion is located upon a portion of each piece" is an essential limitation of the claim requiring that the pizza be cut in a specific manner. Plaintiff contends that the phrase should be construed as an optional step that merely explains where the food portions should be placed, and says that the phrase really means: "if the dough base were cut into equal slices, a food portion would be on each slice." Plaintiff argues that cutting the pizza such that there is an individual filled pocket on each piece is not required, but that "it is enough that it is possible to do so."

But the plain language of the claim says "when," not "if." If the patent applicants had wanted the language to be hypothetical, they would have drafted it in that manner.

In order to find literal infringement, the defendant must practice each and every element of the claimed method

Defendant's method, as described in the February 1995 manager's guide and the affidavit of Patricia Scheibmeir, a manager in defendant's research and development department, does not practice the "cutting" limitation as construed by the court. Although the Stuffed Crust Pizzas in question used five separate pieces of cheese, separated by a thumb's width, the instructions direct that the pizza be cut into eight slices using a "rocker blade," which cuts pizzas into an even number of slices. It is thus impossible for individual portions of cheese to be located on each portion of defendant's pizza.

Since defendant does not practice one of the essential limitations of the '361 patent, the court need not consider the other limitations before making a finding of no literal infringement.

\section{Doctrine of Equivalents}

\section{Freedman Seating Co. v. American Seating Co.}

Freedman Seating Company ("Freedman") sued American Seating Company and Hi-Tech Seating Products (doing business as Kustom Fit) (collectively, "American Seating") for infringement of U.S. Patent No. 5,492,389 (issued Feb. 20, 1996) ("the '389 patent"). Because we conclude that the judgment of infringement under the doctrine of equivalents has the effect of vitiating a limitation of the claims of the ' 389 patent, we reverse the judgment and remand the case to the
Two pages of further claim construction discussion omitted. Focus on what the court does once it has construed the claim language.

This is the court's complete discussion of literal infringement. This is not atypical. Once claim construction is complete, applying the claim language is often (though not always) trivial. Why might that be?

420 F.3d 1350 (Fed. Cir. 2005) 
district court with instructions to enter judgment of non-infringement in favor of American Seating.

\section{BACKGROUND}

Freedman manufactures seats used in public transportation vehicles. Its product line includes stowable seats, which are seats that have the ability to fold away in order to create more interior space in a vehicle. They are particularly useful for accommodating passengers with wheelchairs, but may be used whenever more interior space is needed.

Freedman also owns the "389 patent, titled "Stowable Seat." The figures shown below are representative of the stowable seat claimed in the '389 patent.

Figure 1 shows the stowable seat (10) in the horizontal (or deployed) position, while figure 2 shows the stowable seat in the vertical (or stowed) position. Moving the seat from its horizontal to vertical position involves "folding the seatback (16) flat against the seatbase (14), unlocking the seatbase from its horizontally deployed position and raising the seatbase to its vertically stowed position where it is locked in place."

As shown by figure 1, the invention of the ' 389 patent does not use an aisle leg to support the seat when in the horizontal position. Rather, the invention is based on a cantilever design, which uses a diagonal truss (18), also referred to as a support member, to support the aisle-end of the seat when in the horizontal position. This design, according to the ' 389 patent, avoids difficulties attendant with stowing and deploying seats that have a separate aisle leg.

In addition to providing aisle support, the diagonal truss allows for translational movement of the seatbase between the horizontal and vertical positions. This is due to the truss having a fixed end that is attached to the seat's frame (12) at a pivot point (54), and a movable end (56) that is "slidably mounted" in a runner track (58). When stowing the seat, the movable end of the diagonal truss slides on the runner track toward the middle of the seatbase, while the fixed end of the diagonal truss rotates upward until the seat is in the vertical position. Similarly, when the seat is deployed again, the movable end of the diagonal truss slides toward the aisle end of the seatbase, while the fixed end rotates downward until the seat is in the horizontal position. This folding mechanism created by the slidably mounted moveable end is known in the field of mechanical engineering as a "slider crank," which is a particular type of "four bar mechanism."

Claim 1 is representative of the claims asserted against American Seating; it reads:

A stowable seat for mounting to support member of a vehicle wherein a space may be selectively provided for positioning an 


\section{$\begin{array}{lllr}\text { U.S. Patent } & \text { Feb. 20, } 1996 & \text { Sheet } 1 \text { of } 3 & 5,492,389\end{array}$}
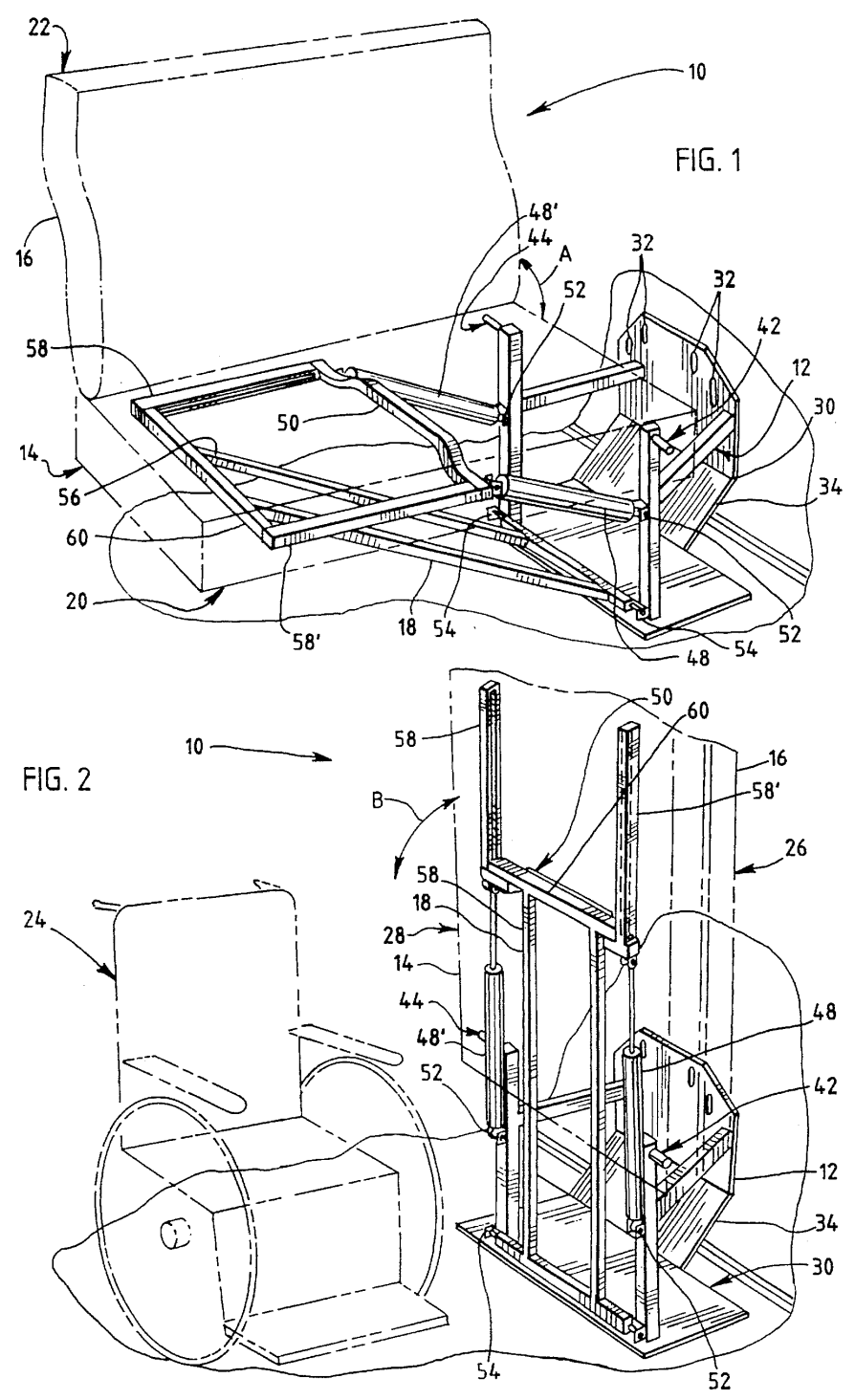

U.S. Patent No. 5,492,389, Stowable seat 
article adjacent to the stowable seat, when stowed the seat comprising:

a frame attached to a support member;

a cantilevered seatbase having a free end, a pivotable end including a pivot mounted thereto for rotatably associating said pivotable end with said frame and for providing said seatbase with a range of motion extending from a horizontally deployed position to a vertically stowed position, a support member for supporting said seatbase in said deployed position including a moveable end slidably mounted to said seatbase and a fixed end journalled with said frame, and a first lock near said free end for releasably locking said movable end to maintain said seatbase in said deployed position; and

a seatback having a pivot for rotatably associating said seatback with said seatbase and for providing said seatback with a range of motion extending from an unfolded position to a folded position, said range of motion of said seatback being perpendicular to said range of motion of said seatbase, said seatback in said unfolded position adapted to be a predetermined angle with respect to said seatbase in said deployed position to provide seating and said seatback in said folded position adapted to be adjacent said seatbase for stowing to provide the space for the article.

American Seating Company and Kustom Fit also manufacture and market seating products for the transportation industry. One particular seat is the Horizon EZ Fold ("EZ Fold"), which is a stowable seat. The EZ Fold is in many respects similar, if not identical, to the invention claimed in the ' 389 patent. Most notably, neither device has an aisle leg. However, and important to this case, the two products use different types of support structures in lieu of the aisle leg. The invention claimed in the ' 389 patent, of course, uses the slider crank, which is described in part by the "slidably mounted" limitation. The EZ Fold, on the other hand, uses what is known as a "fourth link."

Like the slider crank, the fourth link is also a specific type of four bar mechanism. However, the two mechanisms differ in that, where the moveable end of the '389 patent's support member is slidably mounted to the seatbase, the moveable end of the EZ Fold's support member is rotatably mounted to the seatbase. Therefore, the moveable end of the EZ Fold's support member does not slide or otherwise move along the seatbase. Rather, its only range of motion consists of rotation throughout its revolute joints. That said, the EZ Fold's fourth link mechanism still provides the seatbase with fluid translational 
motion, and thereby allows the seat to fold between the deployed and stowed positions. It does this through an extra set of revolute joints located in the midsection of its support member ("mid-joints"). These mid-joints are shown below in two representative illustrations of the EZ Fold product.

The illustration on the left shows the seat in the fully deployed position, and the illustration on the right shows the device in transition between the deployed and stowed positions.
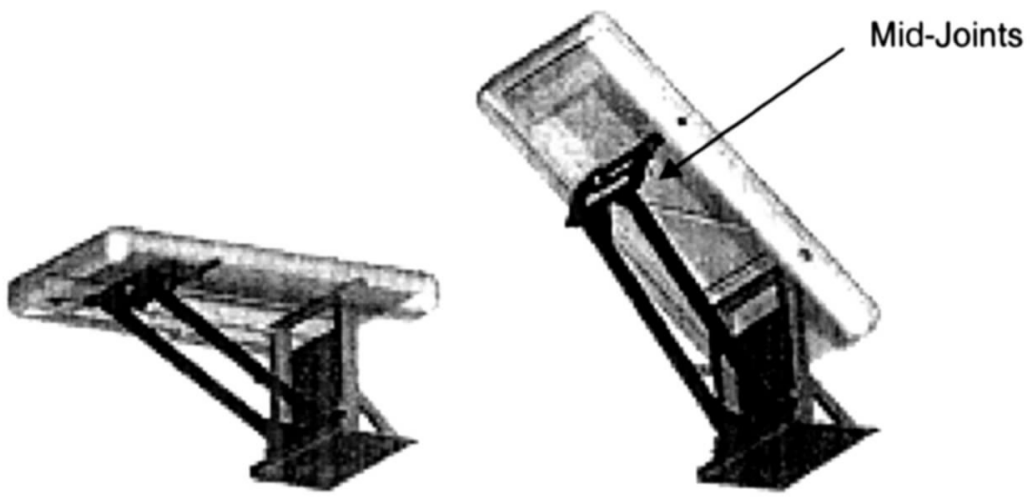

In due course, both parties filed motions for summary judgment on the issue of infringement. The parties generally agreed that the EZ Fold literally meets all of the limitations of claim 1 except for the limitation requiring that the movable end of the support member be "slidably mounted" to the seatbase. The accused product does not literally meet this limitation because the EZ Fold's support member is rotatably mounted, not slidably mounted, to the seatbase.

American Seating argued that its support member and moveable end were not equivalent to the corresponding structure claimed by the ' 389 patent because its system used a fourth link, which created a substantially different support structure than the slider crank of the '389 patent. In particular, American Seating argued that the support structures of the two devices created substantially different distribution forces. The district court disagreed. As an initial matter, the court stated that force distributions were not claimed in the '389 patent and were therefore of minimal relevance. In addition, the court found that any difference in force distributions was insubstantial, and that Freedman's "slider-crank and [American Seating's] fourth link perform substantially the same function in substantially the same manner to achieve substantially the same result." The court therefore granted Freedman summary judgment of infringement by equivalence.

\section{DISCUSSION}

Patent infringement is a two step inquiry. First, the court must construe the asserted claim. Second, the court must determine whether the accused product or process contains each limitation of the prop- 
erly construed claims, either literally or by a substantial equivalent.

Under the doctrine of equivalents, a product or process that does not literally infringe upon the express terms of a patent claim may nonetheless be found to infringe if there is 'equivalence' between the elements of the accused product or process and the claimed elements of the patented invention." Warner-Jenkinson Co. v. Hilton Davis Chem. Co.. The doctrine evolved in recognition of the fact that

The language in the patent claims may not capture every nuance of the invention or describe with complete precision the range of its novelty. If patents were always interpreted by their literal terms, their value would be greatly diminished. Unimportant and insubstantial substitutes for certain elements could defeat the patent, and its value to inventors could be destroyed by simple acts of copying.

Festo. At the same time, the doctrine of equivalents necessarily adds uncertainty to the scope of patent claims, and thereby detracts from the public-notice function of patent claims and risks deterring noninfringing and potentially innovative endeavors. See Festo ("If the range of equivalents is unclear, competitors may be unable to determine what is a permitted alternative to a patented invention and what is an infringing equivalent."); Warner-Jenkinson ("There can be no denying that the doctrine of equivalents, when applied broadly, conflicts with the definitional and public-notice functions of the statutory claiming requirements."). In recognition of this risk, and in an effort to strike the proper balance between protecting patentees while also providing sufficient notice to the public, various rules of law have emerged to constrain when and how the doctrine of equivalents is to be applied.

Of relevance to this case is the "all limitations" rule. The rule holds that an accused product or process is not infringing unless it contains each limitation of the claim, either literally or by an equivalent. This principle has two primary implications for the doctrine of equivalents. First, the all limitations rule requires that equivalence be assessed on a limitation-by-limitation basis, as opposed to from the perspective of the invention as a whole. Second, an element of an accused product or process is not, as a matter of law, equivalent to a limitation of the claimed invention if such a finding would entirely vitiate the limitation.

There is no set formula for determining whether a finding of equivalence would vitiate a claim limitation, and thereby violate the all limitations rule. Rather, courts must consider the totality of the circumstances of each case and determine whether the alleged equivalent can be fairly characterized as an insubstantial change from the claimed subject matter without rendering the pertinent limitation 
meaningless.

In Sage Products, Inc. v. Devon Industries, Inc. we affirmed the district court's grant of summary judgment of non-infringement under the doctrine of equivalents. One of the asserted patents described a container for discarding syringes and other like materials and claimed, among other things, "an elongated slot at the top of the container body" and a barrier means comprised of "a first constriction extending over said slot." We agreed that the district court properly interpreted "top of the container body" to mean "highest point, level, or part of." The accused product differed from the claimed invention in that the slot was located in the interior of the container rather than at the top of the container.

We concluded that finding infringement under these circumstances would vitiate the "slot at the top of the container body" and "extending over said slot" limitations. We reached our conclusion based on several considerations, including the simplicity of the structure, the specificity and narrowness of the claim, and the foreseeability of variations at the time of filing the claim with the PTO:

The claim at issue defines a relatively simple structural device. A skilled patent drafter would foresee the limiting potential of the "over said slot" limitation. No subtlety of language or complexity of the technology, nor any subsequent change in the state of the art, such as laterdeveloped technology, obfuscated the significance of this limitation at the time of its incorporation into the claim. If [the patentee] desired broad patent protection for any container that performed a function similar to its claimed container, it could have sought claims with fewer structural encumbrances. . . . Instead, [the patentee] left the PTO with manifestly limited claims that it now seeks to expand through the doctrine of $1361^{*} 1361$ equivalents. However, as between the patentee who had a clear opportunity to negotiate broader claims but did not do so, and the public at large, it is the patentee who must bear the cost of its failure to seek protection for this foreseeable alteration of its claimed structure.

Compare Hughes Aircraft Co. v. United States, 140 F.3d 1470, 1475 (Fed. Cir. 1998) ("This is a case in which a 'subsequent change in the state of the art, such as later-developed technology, obfuscated the significance of [the] limitation at the time of its incorporation into the claim."').

In Tronzo v. Biomet, Inc., we similarly concluded that a finding of equivalence would vitiate the claimed limitation. The asserted claims related to an artificial hip socket and included a limitation requiring 
Asyst Techs.: 402 F.3d 1188 (Fed. Cir. 2005)

Moore: 229 F.3d 1091 (Fed. Cir. 2000) that the prosthesis's body have "a generally conical outer surface." In finding infringement, the jury concluded that the hemispherical shape of the accused product's hemispherical cup was equivalent to the "generally conical outer surface" limitation. We reversed, finding no infringement as a matter of law. We were particularly troubled by expert testimony submitted by the plaintiff, Tronzo, stating that "when either a hemispherical cup or trapezoidal cup or any other shape cup is successfully implanted into the body, it functions almost exactly the same way." We stated that, according to this theory of infringement, "any shape would be equivalent to the conical limitation." "Such a result," we concluded, "is impermissible under the allelements rule of Warner-Jenkinson because it would write the 'generally conical outer surface' limitation out of the claims." See also Asyst Techs., Inc. v. Emtrak, Inc. (holding that, under the "specific exclusion" principle, "the term 'mounted' can fairly be said to specifically exclude objects that are 'unmounted"'); Moore U.S.A. v Standard Register Co. ("[T] a allow what is undisputedly a minority (i.e., $47.8 \%$ ) to be equivalent to a majority would vitiate the requirement that the "first and second longitudinal strips of adhesive ... extend the majority of the lengths of said longitudinal marginal portions."').

In the instant case, we think the district court's finding of infringement under the doctrine of equivalents had the effect of entirely vitiating the "slidably mounted" limitation. The parties agree that all of the claims require a support member having "a moveable end slidably mounted to" the seatbase. It is also not disputed that the moveable end of the EZ Fold's support member is rotatably mounted, not slidably mounted, to the seatbase. Therefore, while the moveable end of the EZ Fold's support member has the ability to rotate, it cannot slide or otherwise move along the seatbase. It is confined to a fixed location. We think that this structural difference in the mounting of the moveable end to the seatbase is not a subtle difference in degree, but rather, a clear, substantial difference or difference in kind.

Freedman argues that the slider crank claimed in the ' 389 patent and the fourth link mechanism used in the EZ Fold function in the same way to produce identical results. Freedman asserts that this is because "both the infringing seat and the claimed structure of the '389 patent provide the moveable end of the support member with both translational and rotational motion relative to the seatbase." The problem, however, is that taken to its logical conclusion, Freedman's argument would mean that any support member capable of allowing translational and rotational motion would be equivalent to a support member "slidably mounted to said seatbase," which reads "slidably mounted" completely out of the claims. This is the precise type of overextension of the doctrine of equivalents that the claim vitiation 
doctrine is intended to prevent.

Festo Corp. v. Shoketsu Kinzoku Kogyo Kabushiki Co.

Petitioner Festo Corporation owns two patents [4,354,125 (Stoll) and $3,779,401$ (Carroll)] for an improved magnetic rodless cylinder, a piston-driven device that relies on magnets to move objects in a conveying system. The device has many industrial uses and has been employed in machinery as diverse as sewing equipment and the Thunder Mountain ride at Disney World. Petitioner's patent applications, as often occurs, were amended during the prosecution proceedings. Both amended patents added a new limitation - that the inventions contain a pair of sealing rings, each having a lip on one side, which would prevent impurities from getting on the piston assembly. The amended Stoll Patent added the further limitation that the outer shell of the device, the sleeve, be made of a magnetizable material.

Prosecution history estoppel requires that the claims of a patent be interpreted in light of the proceedings in the PTO during the application process. Estoppel is a rule of patent construction that ensures that claims are interpreted by reference to those that have been cancelled or rejected. The doctrine of equivalents allows the patentee to claim those insubstantial alterations that were not captured in drafting the original patent claim but which could be created through trivial changes. When, however, the patentee originally claimed the subject matter alleged to infringe but then narrowed the claim in response to a rejection, he may not argue that the surrendered territory comprised unforeseen subject matter that should be deemed equivalent to the literal claims of the issued patent. On the contrary, by the amendment the patentee recognized and emphasized the difference between the two phrases and the difference which the patentee thus disclaimed must be regarded as material.

A rejection indicates that the patent examiner does not believe the original claim could be patented. While the patentee has the right to appeal, his decision to forgo an appeal and submit an amended claim is taken as a concession that the invention as patented does not reach as far as the original claim. Were it otherwise, the inventor might avoid the PTO's gatekeeping role and seek to recapture in an infringement action the very subject matter surrendered as a condition of receiving the patent.

Prosecution history estoppel ensures that the doctrine of equivalents remains tied to its underlying purpose. Where the original application once embraced the purported equivalent but the patentee narrowed his claims to obtain the patent or to protect its validity, the patentee cannot assert that he lacked the words to describe the subject matter in question. The doctrine of equivalents is premised on language's inability to capture the essence of innovation, but a 
prior application describing the precise element at issue undercuts that premise. In that instance the prosecution history has established that the inventor turned his attention to the subject matter in question, knew the words for both the broader and narrower claim, and affirmatively chose the latter.

We agree with the Court of Appeals that a narrowing amendment made to satisfy any requirement of the Patent Act may give rise to an estoppel. Estoppel arises when an amendment is made to secure the patent and the amendment narrows the patent's scope. A patentee who narrows a claim as a condition for obtaining a patent disavows his claim to the broader subject matter, whether the amendment was made to avoid the prior art or to comply with $\S 112$. We must regard the patentee as having conceded an inability to claim the broader subject matter or at least as having abandoned his right to appeal a rejection. In either case estoppel may apply.

On the record before us, we cannot say petitioner has rebutted the presumptions that estoppel applies and that the equivalents at issue have been surrendered. Petitioner concedes that the limitations at issue - the sealing rings and the composition of the sleeve - were made in response to a rejection for reasons under $\$ 112$, if not also because of the prior art references. As the amendments were made for a reason relating to patentability, the question is not whether estoppel applies but what territory the amendments surrendered.

285 F.3d 1046 (Fed. Cir. 2000) (en banc)

\section{Johnson \& Johnston Associates v. R.E. Service Co.}

Johnson and Johnston Associates (Johnston) asserted United States Patent No. 5,153,050 (the '050 patent) against R.E. Service Co. and Mark Frater (collectively RES). [The patent concerned a method for making printed circuit boards by adhering them to a stiff substrate sheet during processing.]

When a patent drafter discloses but declines to claim subject matter, as in this case, this action dedicates that unclaimed subject matter to the public. Application of the doctrine of equivalents to recapture subject matter deliberately left unclaimed would conflict with the primacy of the claims in defining the scope of the patentee's exclusive right.

Moreover, a patentee cannot narrowly claim an invention to avoid prosecution scrutiny by the PTO, and then, after patent issuance, use the doctrine of equivalents to establish infringement because the specification discloses equivalents. Such a result would merely encourage a patent applicant to present a broad disclosure in the specification of the application and file narrow claims, avoiding examination of broader claims that the applicant could have filed consistent with the specification. By enforcing this rule, the courts avoid the problem of extending the coverage of an exclusive right to encompass more than 
that properly examined by the PTO.

In this case, Johnston's '050 patent specifically limited the claims to "a sheet of aluminum" and "the aluminum sheet." The specification of the ' 050 patent, however, reads: "While aluminum is currently the preferred material for the substrate, other metals, such as stainless steel or nickel alloys may be used." Having disclosed without claiming the steel substrates, Johnston cannot now invoke the doctrine of equivalents to extend its aluminum limitation to encompass steel. Thus, Johnston cannot assert the doctrine of equivalents to cover the disclosed but unclaimed steel substrate.

A patentee who inadvertently fails to claim disclosed subject matter, however, is not left without remedy. Within two years from the grant of the original patent, a patentee may file a reissue application and attempt to enlarge the scope of the original claims to include the disclosed but previously unclaimed subject matter.. In addition, a patentee can file a separate application claiming the disclosed subject matter.. Notably, Johnston took advantage of the latter of the two options by filing two continuation applications that literally claim the relevant subject matter

\section{A Hybrid: Means-Plus-Function Claims}

Kemco Sales, Inc. v. Control Papers Co., Inc.

In order for an accused structure to literally meet a section 112 , paragraph 6 means-plus-function limitation, the accused structure must either be the same as the disclosed structure or be a section 112, paragraph 6"equivalent," i.e., (1) perform the identical function and (2) be otherwise insubstantially different with respect to structure. Under a modified version of the function-way-result methodology, two structures may be "equivalent" for purposes of section 112, paragraph 6 if they perform the identical function, in substantially the same way, with substantially the same result.

If an accused structure is not a section 112, paragraph 6 equivalent of the disclosed structure because it does not perform the identical function of that disclosed structure and hence does not literally infringe, it may nevertheless still be an "equivalent" under the doctrine of equivalents. Thus, if one applies the traditional functionway-result test, the accused structure must perform substantially the same function, in substantially the same way, to achieve substantially the same result, as the disclosed structure. A key feature that distinguishes "equivalents" under section 112, paragraph 6 and "equivalents" under the doctrine of equivalents is that section 112, paragraph 6 equivalents must perform the identical function of the disclosed structure, while equivalents under the doctrine of equivalents need
Reissue: 35 U.S.C. § 251 (2000)

Separate application: 35 U.S.C. § 120 (2000) (allowing filing as a continuation application if filed before all applications in the chain issue)

208 F.3d $1352(2000)$ 
only perform a substantially similar function.

Because the "way" and "result" prongs are the same under both the section 112, paragraph 6 and doctrine of equivalents tests, a structure failing the section 112, paragraph 6 test under either or both prongs must fail the doctrine of equivalents test for the same rea$\operatorname{son}(\mathrm{s})$.
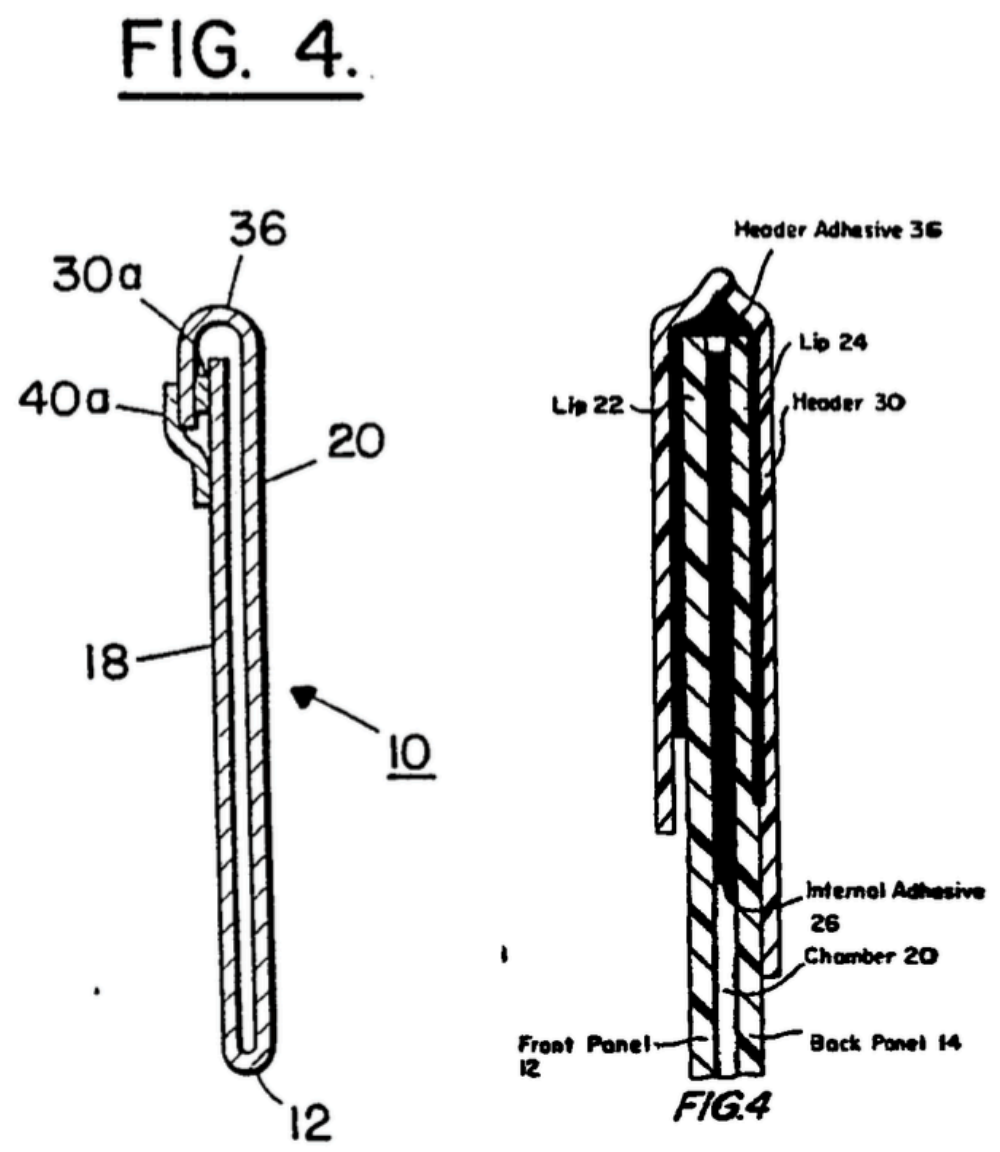

In the present case, we agree with the district court that no reasonable jury could have found that the TripLok infringes, either literally or under the doctrine of equivalents. Turning first to literal infringement, it is clear that the foldover flap structure disclosed in the '197 patent specification is not identical to the dual-lip structure in the accused device, so we must then ask whether the dual-lip structure is an "equivalent" structure under section 112, paragraph 6. In determining this under a modified function-way-result test, we note that both the accused and disclosed structures perform the identical function, which is to close the envelope. However, unlike the disclosed flap, which closes by folding over the envelope, the dual-lip structure closes the accused envelope in a different way by meeting together and binding via the internal adhesive. The accused structure's different way of closing also yields a substantially different result. The first 
and second sealing means in the disclosed structure are ultimately attached to the outside of the envelope. In contrast, the first sealing means in the TripLok envelope is internally attached to the two lips of the dual-lip structure, thereby sealing the envelope.

Based on this analysis, it is also clear that Control Papers does not infringe under the doctrine of equivalents. When a court determines that the "way" and/or "result" is/are substantially different under a section 112, paragraph 6 equivalents analysis, a patentee cannot prevail under the doctrine of equivalents for the same reason(s). In this case, the dual-lip structure is not a section 112, paragraph 6 equivalent of a fold-over flap because the "way" and "result" are substantially different; accordingly, the dual-lip structure also cannot be an equivalent under the doctrine of equivalents.

\section{Super Soaker Problem}

This is claim 1 from U.S. Patent No. 4,239,129:

A toy comprising an elongated housing [case] having a chamber therein for a liquid [tank], a pump including a piston having an exposed rod [piston rod] and extending rearwardly of said toy facilitating manual operation for building up an appreciable amount of pressure in said chamber for ejecting a stream of liquid therefrom an appreciable distance substantially forwardly of said toy, and means for controlling the ejection.

Does the Super Soaker 50 infringe this claim? Note that to use a Super Soaker, one fills it with water through the orange cap at the back top. Sliding the yellow handle back and forth along the white barrel pumps air into the green part, along with water. Pulling the trigger opens a valve that causes the air to press water forward, resulting in the Super Soaker's famed superior soaking ability. (Conventional water pistols didn't store up compressed air; they drove water out the barrel using the force of the trigger pull itself.)

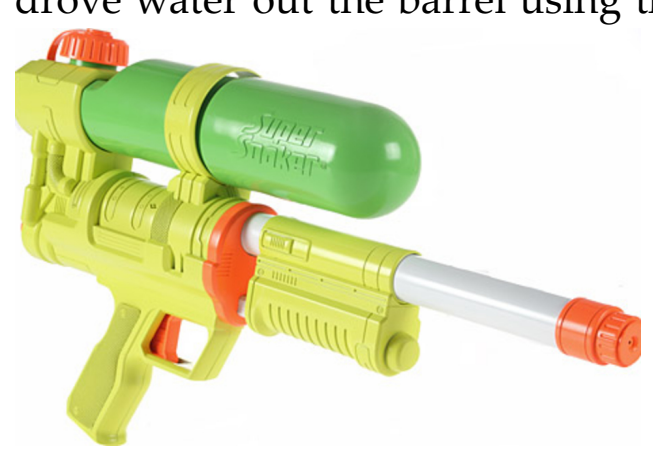

Based on Larami Corp. v. Amron, No. CIV. A. 91-6145, 1993 WL 69581 (E.D. Pa. Mar. 11, 1993) 


\section{E Infringement: Prohibited Conduct}

191 F. 579 (6th Cir. 1911)

Blair v. Westinghouse Elec. Corp., 291 F. Supp. 664 (D.D.C. 1968)

Depuy Spine, Inc. v. Medtronic Sofamor Danek, Inc., 567 F.3d 1314 (Fed Cir. 2009)

35 U.S.C. § 271

Infringement of patent

797 F. 3d 1020 (Fed. Cir. 2015) (en banc)
Herman v. Youngstown Car Mfg. Co.

A patent is not the grant of a right to make or use or sell. It does not, directly or indirectly, imply any such right. It grants only the right to exclude others. The supposition that a right to make is created by the patent grant is obviously inconsistent with the well-known fact that a very considerable portion of the patents granted are in a field covered by a former relatively generic or basic patent, are tributary to such earlier patent, and cannot be practiced unless by license thereunder.

\section{Direct Infringement}

It is typically said that patent infringement is "strict liability." That is, "It is, of course, elementary, that an infringement may be entirely inadvertent and unintentional and without knowledge of the patent." "Similarly, evidence of copying is of no import on the question of whether the claims of an issued patent are infringed, either literally or by equivalents."

\section{Patent Act}

(a) Except as otherwise provided in this title, whoever without authority makes, uses, offers to sell, or sells any patented invention, within the United States or imports into the United States any patented invention during the term of the patent therefor, infringes the patent.

Akamai Technologies, Inc. v. Limelight Networks, Inc.

In 2006, Akamai Technologies, Inc. ("Akamai") filed a patent infringement action against Limelight alleging infringement of U.S. Patent No. 6,108,703 which claims methods for delivering content over the Internet. The case proceeded to trial, at which the parties agreed that Limelight's customers - not Limelight - perform the "tagging" and "serving" steps in the claimed methods. For example, as for claim 34 of the '703 patent, Limelight performs every step save the "tagging" step, in which Limelight's customers tag the content to be hosted and delivered by Limelight's content delivery network.

Direct infringement under $\S 271(\mathrm{a})$ occurs where all steps of a claimed method are performed by or attributable to a single entity. Where more than one actor is involved in practicing the steps, a court must determine whether the acts of one are attributable to the other such that a single entity is responsible for the infringement. We will hold an entity responsible for others' performance of method steps 
in two sets of circumstances: (1) where that entity directs or controls others' performance, and (2) where the actors form a joint enterprise.

The jury heard substantial evidence from which it could find that Limelight directs or controls its customers' performance of each remaining method step, such that all steps of the method are attributable to Limelight. Specifically, Akamai presented substantial evidence demonstrating that Limelight conditions its customers' use of its content delivery network upon its customers' performance of the tagging and serving steps, and that Limelight establishes the manner or timing of its customers' performance. Therefore, Limelight is liable for direct infringement.

\section{Indirect Infringement}

\section{Patent Act}

(b) Whoever actively induces infringement of a patent shall be liable as an infringer.

(c) Whoever offers to sell or sells within the United States or imports into the United States a component of a patented machine, manufacture, combination or composition, or a material or apparatus for use in practicing a patented process, constituting a material part of the invention, knowing the same to be especially made or especially adapted for use in an infringement of such patent, and not a staple article or commodity of commerce suitable for substantial noninfringing use, shall be liable as a contributory infringer.

\section{Limelight Networks, Inc. v. Akamai Technologies, Inc.}

Neither the Federal Circuit nor respondents dispute the proposition that liability for inducement must be predicated on direct infringement. This is for good reason, as our case law leaves no doubt that inducement liability may arise if, but only if, there is direct infringement.

One might think that this simple truth is enough to dispose of this appeal. But the Federal Circuit reasoned that a defendant can be liable for inducing infringement under $\S 271(\mathrm{~b})$ even if no one has committed direct infringement within the terms of $\S 271$ (a) (or any other provision of the patent laws), because direct infringement can exist independently of a violation of these statutory provisions.

The Federal Circuit's analysis fundamentally misunderstands what it means to infringe a method patent. A method patent claims a number of steps; under this Court's case law, the patent is not infringed unless all the steps are carried out. This principle follows
35 U.S.C. § 271

Infringement of patent

134 S. Ct. 2111 (2014)

Watch the dates! This is from an earlier stage of the case. In this 2014 opinion, the Supreme Court reverses a 2012 Federal Circuit opinion. Does seeing this history change your view of the Federal Circuit's 2015 opinion on remand? 
ineluctably from what a patent is: the conferral of rights in a particular claimed set of elements. Each element contained in a patent claim is deemed material to defining the scope of the patented invention, and a patentee's rights extend only to the claimed combination of elements, and no further.

The Federal Circuit seems to have adopted the view that Limelight induced infringement on the theory that the steps that Limelight and its customers perform would infringe the '703 patent if all the steps were performed by the same person. But we have already rejected the notion that conduct which would be infringing in altered circumstances can form the basis for contributory infringement, and we see no reason to apply a different rule for inducement. In Deepsouth Packing Co. v. Laitram Corp., a manufacturer produced components of a patented machine and then exported those components overseas to be assembled by its foreign customers. (The assembly by the foreign customers did not violate U.S. patent laws.) In both Deepsouth and this case, the conduct that the defendant induced or contributed to would have been infringing if committed in altered circumstances: in Deepsouth if the machines had been assembled in the United States, and in this case if performance of all of the claimed steps had been attributable to the same person. In Deepsouth, we rejected the possibility of contributory infringement because the machines had not been assembled in the United States, and direct infringement had consequently never occurred. Similarly, in this case, performance of all the claimed steps cannot be attributed to a single person, so direct infringement never occurred. Limelight cannot be liable for inducing infringement that never came to pass.

\section{Global-Tech Appliances, Inc. v. SEB S.A.}

[SEB held a U.S. patent on a deep fryer whose exterior surface remained cool to the touch. Pentalpha cloned an SEB fryer it purchased in Hong Kong (which did not bear U.S. patent markings). It sold infringing fryers to Sunbeam, Fingerhut, and Montgomery Ward, which resold them in the United States. Pentalpha argued that it did not "induce" these sales under $\S 271(\mathrm{~b})$ because it did not know about the patent.]

[W] now hold that induced infringement under $\S 271(\mathrm{~b})$ requires knowledge that the induced acts constitute patent infringement. We nevertheless affirm the judgment of the Court of Appeals because the evidence was plainly sufficient to support a finding of Pentalpha's knowledge under the doctrine of willful blindeness, [under which] (1) the defendant must subjectively believe that there is a high probability that a fact exists and (2) the defendant must take deliberate actions to avoid learning of that fact. Pentalpha's belief that SEB's fryer embodied advanced technology that would be valuable in the 
U.S. market is evidenced by its decision to copy all but the cosmetic features of SEB's fryer. Even more telling is [a Pentalpha executive's] decision not to inform the attorney from whom Pentalpha sought a right-to-use opinion that the product to be evaluated was simply a knock-off of SEB's deep fryer.

Commil USA, LLC v. Cisco Systems Inc.

The question the Court confronts today concerns whether a defendant's belief regarding patent validity is a defense to a claim of induced infringement. It is not.

Invalidity is an affirmative defense that can preclude enforcement of a patent against otherwise infringing conduct. An accused infringer can, of course, attempt to prove that the patent in suit is invalid; if the patent is indeed invalid, and shown to be so under proper procedures, there is no liability. That is because invalidity is not a defense to infringement, it is a defense to liability. And because of that fact, a belief as to invalidity cannot negate the scienter required for induced infringement.

Lucent Technologies, Inc. v. Gateway, Inc.

In December 1986, three computer engineers at [Lucent's predecessor] AT\&T filed a patent application, which eventually issued as the Day patent. The patent is generally directed to a method of entering information into fields on a computer screen without using a keyboard. A user fills in the displayed fields by choosing concurrently displayed, predefined tools adapted to facilitate the inputting of the information in a particular field, wherein the predefined tools include an on-screen graphical keyboard, a menu, and a calculator.

Lucent asserts that certain features of Outlook, Money, and Windows Mobile, when used, practice the methods of claims 19 and 21. For instance, Outlook includes a calendar tool that allows the user to enter dates in a form when preparing a record of an appointment. The tool displays a monthly calendar as a grid of numbered dates, along with graphical controls that allow the user to scroll to adjacent months or skip directly to a different month and year. Once the user defines a date with the tool, the software enters the numerical day, month, and year into the corresponding field in the appointment form. Similar to the number pad tool illustrated in the Day patent, Outlook's calendar date-picker tool enables the user to select a series of numbers, corresponding to the day, month, and year, using graphical controls. This date-picker calendar tool is incorporated in a few of Outlook's features. Microsoft Money and Windows Mobile have similar functionalities.

According to Microsoft, Lucent did not prove contributory infringement [under $\S 271(\mathrm{c})$ ] because the products have substantial 
noninfringing uses. Lucent counters that the date-picker tool does not have any noninfringing uses. Thus, as framed by the parties, the main issue reduces to whether the "material or apparatus" is the entire software package or just the particular tool (e.g., the calendar date-picker) that performs the claimed method. If the former, then Microsoft prevails because the entire software package has substantial noninfringing uses. If the material or apparatus is the specific date-picker tool, then Lucent wins because that tool was "especially made or especially adapted for" practicing the claimed method.

One example illustrates the problem with Microsoft's approach. Consider a software program comprising five - and only five - features. Each of the five features is separately and distinctly patented using a method claim. That is, the first feature infringes a method claim in a first patent, the second feature infringes a method claim in a second patent, and so forth. Assume also that the company selling the software doesn't provide specific instructions on how to use the five features, thus taking potential liability outside the realm of $\S 271(\mathrm{~b})$. In this scenario, under Microsoft's position, the software seller can never be liable for contributory infringement of any one of the method patents because the entire software program is capable of substantial noninfringing use. This seems both untenable as a practical outcome and inconsistent with both the statute and governing precedent.

Similarly, if, instead of selling Outlook with the date-picker, Microsoft had offered the date-picker for sale as a separate download to be used with Outlook, there would be little dispute that Microsoft was contributing to infringement of the Day patent.

In Hodosh v. Block Drug Co., the patent at issue claimed "a method for desensitizing teeth with a composition containing an alkali metal nitrate." The accused infringer sold toothpaste, e.g., "Sensodyne-F," containing potassium nitrate, an alkali metal nitrate. The accused infringer argued that the sale of the toothpaste, which itself was not patented, could not constitute contributory infringement because the toothpaste contained a staple article, i.e., potassium nitrate. The court rejected this argument. While potassium nitrate, when sold in bulk form, was "a staple article or commodity of commerce suitable for substantial noninfringing use," it was suitable only for the infringing use when sold as an ingredient in the toothpaste specially made to perform the patented method of desensitizing teeth.

Here, the infringing feature for completing the forms, i.e., the date-picker tool, is suitable only for an infringing use. Inclusion of the date-picker feature within a larger program does not change the date-picker's ability to infringe. Because Microsoft included the datepicker tool in Outlook, the jury could reasonably conclude, based on the evidence presented, that Microsoft intended computer users to 
use the tool-perhaps not frequently - and the only intended use of the tool infringed the Day patent.

\section{Questions}

1. Suppose that the Plano Bait Shop is selling empty open-topped rectangular aluminum boxes, with a length slightly less than the width of a bait box, lips at each end that are the right shape to attach to the top edges of a bait box, and a detachable plastic cover. Some buyers take the boxes, fill them with sharp-grained sand, and use it to immobilize earthworms. Others take the boxes and fill them with fish hooks, washcloths, or other items. Who, if anyone, is infringing on the Lukehart patent? Does it matter if Plano includes instructions with the boxes explaining how to fill them with sand to immobilize earthworms?

\section{F Defenses}

\section{Invalidity}

Microsoft Corp. v. i4i Ltd. Partnership

Under $\S 282$ of the Patent Act of 1952, "[a] patent shall be presumed valid" and "[t]he burden of establishing invalidity of a patent or any claim thereof shall rest on the party asserting such invalidity." We consider whether $\S 282$ requires an invalidity defense to be proved by clear and convincing evidence. We hold that it does.

\section{Exhaustion}

\section{Aktiebolag v. E.J. Co.}

The facts in this case are not in dispute. The patents in suit $[4,222,690$ and 4,381,162] are directed to a drill with a shank portion and a unique carbide tip geometry that has specially configured cutting edges resulting in a drill suitable for high-feed machining with improved cutting ability especially at its center portion. The drill tip is not separately patented. 


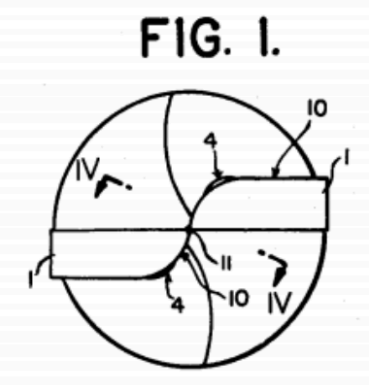

FIG. 2.

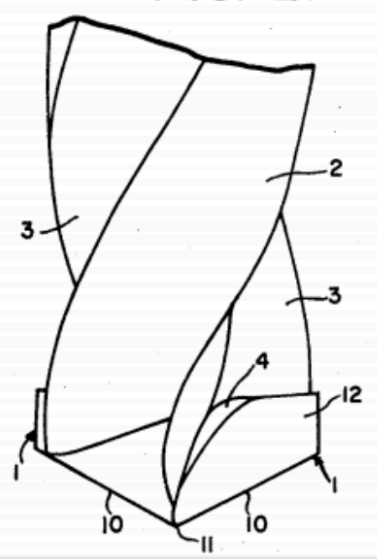

As illustrated in the above drawings from the ' 690 patent, the drill has a tip (1), shank portion (2), twisted grooves (3), projections (4) (these projections bend and break the chips to render them smoothly removable) and a conical end having a center point (11) at the apex of the cone and a pair of cutting edges (10). The drill shank (2) is made of medium carbon steel. The drill tip (1) is made of a more durable carbide and is brazed to the steel shank (2). Brazing is like soldering but with a much higher melting point. It requires a temperature of 1300 degrees Fahrenheit to join the carbide tip to the steel shank.

Sandvik manufactures a commercial embodiment of the patented drill. Although made of durable carbide, over time and use, the drill tip dulls and may require resharpening. Resharpening, also known as regrinding, involves putting a new edge on the drill tip. Normally, the drill can cut through about one thousand inches of material before needing resharpening, depending, of course, upon the hardness of the material being cut. Sandvik expects the drill tip to be resharpened and, in fact, issues guidelines explaining how to resharpen the tip so as to maintain the specially configured cutting edges. Sandvik does not contend that resharpening constitutes infringement.

E.J. offers a drill repair service which includes resharpening and retipping Sandvik drills. E.J. retips, at the request of its customers, when the tip cannot be sharpened because it chips, cracks or simply wears down after being resharpened several times. According to E.J's vice-president, Mr. Robert Hayes, some of E.J.'s customers elect not to have the drill retipped when it cannot be resharpened any longer. E.J. returns the drill to the customer or disposes of it at the customer's request. The parties agree that when the tip is damaged (i.e. chipped, cracked or sufficiently worn down so that it cannot be resharpened), the drill has reached the end of its useful life unless it is retipped.

E.J.'s retipping process includes removing the worn or damaged 
tip by heating the tip to 1300 degrees Fahrenheit using an acetylene torch. E.J. then brazes in a rectangular piece of new carbide onto the drill shank. After the piece of carbide has cooled, E.J. recreates the patented geometry of the cutting edges by machining the carbide. This process includes: (1) grinding the carbide to the proper outside diameter; (2) grinding the carbide to a point; (3) grinding the rake surfaces of the new point; (4) grinding the center of the new point; and (5) honing the edges. In the final steps of the machining process, E.J. creates the cutting edges by following Sandvik's instructions for tip resharpening.

Sandvik claims that E.J.'s retipping service constitutes an infringing reconstruction of its patented drills. Sandvik does not manufacture or sell replacement drill tips. It contends that it never intended for the drills to be retipped. E.J. contends that its retipping service is a lawful repair of the patented drills.

Direct infringement includes the making of a patented article without authority. 35 U.S.C. $§ 271$ (a) (1994). Sandvik contends that E.J. is reconstructing its patented drill and therefore infringing its ' 690 and '162 patents under $\S 271(\mathrm{a})$. However, when Sandvik sold its patented drills to its customers, it granted them an implied license to use the drill for its useful life, see Aro Mfg. Co. v. Convertible Top Replacement Co. ("Aro II"), and the implied license to use includes the right to repair the patented drill.

The Supreme Court has taken an expansive view of what constitutes a permissible repair. In Aro Mfg. Co. v. Convertible Top Replacement Co. ("Aro I"), the Court held that the replacement of the fabric portion of a convertible car top was a permissible repair, not an infringing reconstruction. The Court held: "No element, not itself separately patented, that constitutes one of the elements of a combination patent is entitled to patent monopoly, however essential it may be to the patented combination and no matter how costly or difficult replacement may be." Therefore, even if E.J.'s retipping service cost almost as much as the drill or if the replacement of the tip is difficult and time consuming, as in this case, these factors are not dispositive of reconstruction.

The Court also rejected the "heart of the invention test." See id. (holding that replacement of the distinguishing part of the patented combination does not amount to a reconstruction because a patent covers the totality of the elements in a combination); see also Dawson Chemical Co. v. Rohm \& Haas Co. (This Court has "eschewed the suggestion that the legal distinction between 'reconstruction' and 'repair' should be affected by whether the element of the combination that has been replaced is an 'essential' or 'distinguishing' part of the invention."); Sage Products ("The size or relative importance of the replacement part to the patented combination is not relevant when 
determining whether conduct constitutes repair or replacement."). Therefore, the fact that E.J. may be replacing the novel features of the ' 690 patented invention is also not dispositive of reconstruction.

In Aro 1, the Supreme Court further explained the test for what constitutes a reconstruction: "The decisions of this Court require the conclusion that reconstruction of a patented entity, comprised of unpatented elements, is limited to such a true reconstruction of the entity as to 'in fact make a new article,' after the entity, viewed as a whole, has become spent." Although we question the district court's finding that the tip is, in fact, a separate part of the device, we need not reach this issue because the court nevertheless failed to analyze whether the replacement of this "part" constituted reconstruction consistent with Aro 1.

There are a number of factors to consider in determining whether a defendant has made a new article, after the device has become spent, including the nature of the actions by the defendant, the nature of the device and how it is designed (namely, whether one of the components of the patented combination has a shorter useful life than the whole), whether a market has developed to manufacture or service the part at issue and objective evidence of the intent of the patentee. Under the totality of the circumstances, we hold in this case that E.J.'s actions are a reconstruction.

By E.J.'s own admission, the drill is "spent" when the tip can no longer be resharpened unless it is retipped. In fact, the record reveals that E.J.'s customers may elect not to retip and inform E.J. to discard the drill instead.

Moreover, the nature of the work done by E.J. shows that retipping is more like reconstruction than repair. E.J. does not just attach a new part for a worn part, but rather must go though several steps to replace, configure and integrate the tip onto the shank. It has to break the worn or damaged tip from the shank by heating it to 1300 degrees Fahrenheit. It brazes to the shank a new rectangular block of carbide and grinds and machines it to the proper diameter and creates the point. Thereafter, the tip is honed and sharpened, grinding the rake surfaces and the center of the point and honing the edges. These actions are effectively a re-creation of the patented invention after it is spent.

This is not a case where it is clear that the patented device has a useful life much longer than that of certain parts which wear out quickly. For example, in Wilson $v$. Simpson, in determining that a repair had occurred, the Supreme Court focused specifically on the fact that the machine was designed so that the knives had to be replaced long before the other components:

The proof in the case, is, that one of [the patentee's] ma- 
chines, properly made, will last in use for several years, but that its cutting-knives will wear out and must be replaced at least every sixty or ninety days. [If such a] part of the combination is meant to be only temporary in the use of the whole, and to be frequently replaced, because it will not last as long as the other parts of the combination, its inventor cannot complain.

See also Aro I (noting that the fabric had a much shorter expected life (about three years) than the convertible car top); Porter v. Farmer Supply Serv., Inc. ("The useful life of a disk is measured in weeks, that of a harvester is five or six years. The district court found, and it is undisputed, that a purchaser can expect to wear out many disks during the useful life of the header.").

The drill tip in this case is not a part like the detachable knives in the Wilson that have to be replaced periodically over the useful life of the planing machine. The drill tip was not manufactured to be a replaceable part, although it could be resharpened a number of times to extend its life. It was not intended or expected to have a life of temporary duration in comparison to the drill shank. And finally, the tip was not attached to the shank in a manner to be easily detachable.

In Aro 1, the Supreme Court also noted that "the consequent demand for replacement fabrics has given rise to a substantial industry." Evidence of development in the industry could also be a factor tending to prove that there is a reasonable expectation that the part of the patented combination wears out quickly and requires frequent replacement. In this case, there is no evidence of a substantial market for drill retipping of the sort required for the Sandvik drill. There is no evidence of large numbers of customers retipping these drills or of companies (other than E.J.) offering to retip these drills. No one manufactures replacement tips for Sandvik's drill and although some customers opt to retip the drill only a small percentage of all drills manufactured are retipped.

Finally, there was no intent evidenced by the patentee that would support E.J.'s argument that replacement of the tips is a repair. See Sage Products (evidence that patentee intended the inner containers to be replaced, that it manufactures replacement parts and instructs customers to replace supports holding such replacement a permissible repair); Porter (considering that the patentee sold replacement cutting disks for its tomato harvester). The evidence shows that Sandvik never intended for its drills to be retipped. It did not manufacture or sell replacement drill tips. It did not publish instructions on how to retip its patented drills or suggest that the drills could or should be retipped. Sandvik was aware that the drill tip would need occasional resharpening and instructed its customer on how to resharpen the 
tip. There is, therefore, no objective evidence that Sandvik's drill tip was intended to be a replaceable part. Although the repair or reconstruction issue does not turn on the intention of the patentee alone, the fact that no replacement drill tips have ever been made or sold by the patentee is consistent with the conclusion that replacement of the carbide tip is not a permissible repair.

Although there is no bright-line test for determining whether reconstruction or repair has occurred, we conclude based on all of the facts in this case that E.J. is reconstructing an otherwise spent device when it retips Sandvik's drills. Accordingly, we hold that E.J.'s drill tip replacements infringe the ' 690 and ' 162 patents.

\section{Quanta Computer, Inc. v. LG Electronics, Inc.}

I

Respondent LG Electronics, Inc. (LGE), purchased a portfolio of computer technology patents in 1999 [relating to the storage of data in computer memory.]

LGE licensed a patent portfolio, including the LGE Patents, to Intel Corporation (Intel). The cross-licensing agreement (License Agreement) permits Intel to manufacture and sell microprocessors and chipsets that use the LGE Patents (the Intel Products). The License Agreement authorizes Intel to "'make, use, sell (directly or indirectly), offer to sell, import or otherwise dispose of'" its own products practicing the LGE Patents. Notwithstanding this broad language, the License Agreement contains some limitations. Relevant here, it stipulates that no license

is granted by either party hereto . . . to any third party for the combination by a third party of Licensed Products of either party with items, components, or the like acquired ... from sources other than a party hereto, or for the use, import, offer for sale or sale of such combination.

The License Agreement purports not to alter the usual rules of patent exhaustion, however, providing that, "[n]otwithstanding anything to the contrary contained in this Agreement, the parties agree that nothing herein shall in any way limit or alter the effect of patent exhaustion that would otherwise apply when a party hereto sells any of its Licensed Products."

In a separate agreement (Master Agreement), Intel agreed to give written notice to its own customers informing them that, while it had obtained a broad license "ensuring that any Intel product that you purchase is licensed by LGE and thus does not infringe any patent held by LGE," the license "does not extend, expressly or by implication, to any product that you make by combining an Intel product 
with any non-Intel product." The Master Agreement also provides that "a breach of this Agreement shall have no effect on and shall not be grounds for termination of the Patent License."

Petitioners, including Quanta Computer (collectively Quanta), are a group of computer manufacturers. Quanta purchased microprocessors and chipsets from Intel and received the notice required by the Master Agreement. Nonetheless, Quanta manufactured computers using Intel parts in combination with non-Intel memory and buses in ways that practice the LGE Patents. Quanta does not modify the Intel components and follows Intel's specifications to incorporate the parts into its own systems.

II

The longstanding doctrine of patent exhaustion provides that the initial authorized sale of a patented item terminates all patent rights to that item. In Adams v. Burke, the Court affirmed the dismissal of a patent holder's suit alleging that a licensee had violated postsale restrictions on where patented coffin-lids could be used. "Where a person has purchased a patented machine of the patentee or his assignee," the Court held, "this purchase carries with it the right to the use of that machine so long as it is capable of use."

Although the Court permitted postsale restrictions on the use of a patented article in Henry v. A.B. Dick Co, 昷 that decision was short lived. In 1913, the Court refused to apply A.B. Dick to uphold pricefixing provisions in a patent license. See Bauer E Cie v. O'Donnell. Shortly thereafter, in Motion Picture Patents Co. v. Universal Film Mfg. Co., the Court explicitly overruled A.B. Dick. In that case, a patent holder attempted to limit purchasers' use of its film projectors to show only film made under a patent held by the same company. The Court noted the "increasing frequency" with which patent holders were using A.B. Dick-style licenses to limit the use of their products and thereby using the patents to secure market control of related, unpatented items. Observing that "the primary purpose of our patent laws is not the creation of private fortunes for the owners of patents but is to promote the progress of science and useful arts," the Court held that "the scope of the grant which may be made to an inventor in a patent, pursuant to the patent statute, must be limited to the inven-

\footnotetext{
${ }^{2}$ The A.B. Dick Company sold mimeograph machines with an attached license stipulating that the machine could be used only with ink, paper, and other supplies made by the A.B. Dick Company. The Court rejected the notion that a patent holder "can only keep the article within the control of the patent by retaining the title," and held that "any reasonable stipulation, not inherently violative of some substantive law" was "valid and enforceable." The only requirement, the Court held, was that "the purchaser must have notice that he buys with only a qualified right of use," so that a sale made without conditions resulted in "an unconditional title to the machine, with no limitations upon the use."
} 
tion described in the claims of his patent." Accordingly, it reiterated the rule that "the right to vend is exhausted by a single, unconditional sale, the article sold being thereby carried outside the monopoly of the patent law and rendered free of every restriction which the vendor may attempt to put upon it."

This Court most recently discussed patent exhaustion in United States v. Univis Lens Co.. Univis Lens Company, the holder of patents on eyeglass lenses, licensed a purchaser to manufacture lens blanks ${ }^{B}$ by fusing together different lens segments to create bi- and tri-focal lenses and to sell them to other Univis licensees at agreed-upon rates. Wholesalers were licensed to grind the blanks into the patented finished lenses, which they would then sell to Univis-licensed prescription retailers for resale at a fixed rate. Finishing retailers, after grinding the blanks into patented lenses, would sell the finished lenses to consumers at the same fixed rate. The United States sued Univis under the Sherman Act, alleging unlawful restraints on trade. Univis asserted its patent monopoly rights as a defense to the antitrust suit. The Court granted certiorari to determine whether Univis' patent monopoly survived the sale of the lens blanks by the licensed manufacturer and therefore shielded Univis' pricing scheme from the Sherman Act.

The Court assumed that the Univis patents containing claims for finished lenses were practiced in part by the wholesalers and finishing retailers who ground the blanks into lenses, and held that the sale of the lens blanks exhausted the patents on the finished lenses. The Court explained that the lens blanks "embodi[ed] essential features of the patented device and [were] without utility until . . ground and polished as the finished lens of the patent." The Court noted that:

"where one has sold an uncompleted article which, because it embodies essential features of his patented invention, is within the protection of his patent, and has destined the article to be finished by the purchaser in conformity to the patent, he has sold his invention so far as it is or may be embodied in that particular article."

In sum, the Court concluded that the traditional bar on patent restrictions following the sale of an item applies when the item sufficiently embodies the patent - even if it does not completely practice the patent - such that its only and intended use is to be finished under the terms of the patent.

III

\footnotetext{
${ }^{3}$ Lens blanks are rough opaque pieces of glass of suitable size, design and composition for use, when ground and polished, as multi-focal lenses in eyeglasses.
} 
LGE argues that the exhaustion doctrine is inapplicable here because it does not apply to method claims, which are contained in each of the LGE Patents. LGE reasons that, because method patents are linked not to a tangible article but to a process, they can never be exhausted through a sale. Rather, practicing the patent - which occurs upon each use of an article embodying a method patent-is permissible only to the extent rights are transferred in an assignment contract. Quanta, in turn, argues that there is no reason to preclude exhaustion of method claims, and points out that both this Court and the Federal Circuit have applied exhaustion to method claims. It argues that any other rule would allow patent holders to avoid exhaustion entirely by inserting method claims in their patent specifications.

Quanta has the better of this argument. Nothing in this Court's approach to patent exhaustion supports LGE's argument that method patents cannot be exhausted. It is true that a patented method may not be sold in the same way as an article or device, but methods nonetheless may be "embodied" in a product, the sale of which exhausts patent rights. Our precedents do not differentiate transactions involving embodiments of patented methods or processes from those involving patented apparatuses or materials. To the contrary, this Court has repeatedly held that method patents were exhausted by the sale of an item that embodied the method. In Ethyl Gasoline Corp. v. United States, for example, the Court held that the sale of a motor fuel produced under one patent also exhausted the patent for a method of using the fuel in combustion motors. ${ }^{-1}$ Similarly, as previously described, Univis held that the sale of optical lens blanks that partially practiced a patent exhausted the method patents that were not completely practiced until the blanks were ground into lenses.

These cases rest on solid footing. Eliminating exhaustion for method patents would seriously undermine the exhaustion doctrine. Patentees seeking to avoid patent exhaustion could simply draft their patent claims to describe a method rather than an apparatus. Apparatus and method claims may approach each other so nearly that it will be difficult to distinguish the process from the function of the apparatus. By characterizing their claims as method instead of apparatus claims, or including a method claim for the machine's patented method of performing its task, a patent drafter could shield practi-

\footnotetext{
${ }^{4}$ The patentee held patents for (1) a fluid additive increasing gasoline efficiency, (2) motor fuel produced by mixing gasoline with the patented fluid, and (3) a method of using fuel containing the patented fluid in combustion motors. The patentee sold only the fluid, but attempted to control sales of the treated fuel. The Court held that the sale of the fluid to refiners relinquished the patentee's exclusive rights to sell the treated fuel.
} 
cally any patented item from exhaustion.

This case illustrates the danger of allowing such an end-run around exhaustion. On LGE's theory, although Intel is authorized to sell a completed computer system that practices the LGE Patents, any downstream purchasers of the system could nonetheless be liable for patent infringement. Such a result would violate the longstanding principle that, when a patented item is once lawfully made and sold, there is no restriction on its use to be implied for the benefit of the patentee.

$B$

We next consider the extent to which a product must embody a patent in order to trigger exhaustion. Quanta argues that, although sales of an incomplete article do not necessarily exhaust the patent in that article, the sale of the microprocessors and chipsets exhausted LGE's patents in the same way the sale of the lens blanks exhausted the patents in Univis. Just as the lens blanks in Univis did not fully practice the patents at issue because they had not been ground into finished lenses, Quanta observes, the Intel Products cannot practice the LGE Patents - or indeed, function at all - until they are combined with memory and buses in a computer system. If, as in Univis, patent rights are exhausted by the sale of the incomplete item, then LGE has no postsale right to require that the patents be practiced using only Intel parts. Quanta also argues that exhaustion doctrine will be a dead letter unless it is triggered by the sale of components that essentially, even if not completely, embody an invention. Otherwise, patent holders could authorize the sale of computers that are complete with the exception of one minor step - say, inserting the microprocessor into a socket - and extend their rights through each downstream purchaser all the way to the end user.

We agree with Quanta that Univis governs this case. As the Court there explained, exhaustion was triggered by the sale of the lens blanks because their only reasonable and intended use was to practice the patent and because they "embodie[d] essential features of [the] patented invention." Each of those attributes is shared by the microprocessors and chipsets Intel sold to Quanta under the License Agreement.

C

Having concluded that the Intel Products embodied the patents, we next consider whether their sale to Quanta exhausted LGE's patent rights. Exhaustion is triggered only by a sale authorized by the patent holder.

LGE argues that there was no authorized sale here because the License Agreement does not permit Intel to sell its products for use in 
combination with non-Intel products to practice the LGE Patents. It cites General Talking Pictures Corp. v. Western Elec. Co. I, and General Talking Pictures Corp. v. Western Elec. Co. II, in which the manufacturer sold patented amplifiers for commercial use, thereby breaching a license that limited the buyer to selling the amplifiers for private and home use. The Court held that exhaustion did not apply because the manufacturer had no authority to sell the amplifiers for commercial use, and the manufacturer "could not convey to petitioner what both knew it was not authorized to sell." LGE argues that the same principle applies here: Intel could not convey to Quanta what both knew it was not authorized to sell, i.e., the right to practice the patents with non-Intel parts.

LGE overlooks important aspects of the structure of the Intel-LGE transaction. Nothing in the License Agreement restricts Intel's right to sell its microprocessors and chipsets to purchasers who intend to combine them with non-Intel parts. It broadly permits Intel to "'make, use, [or] sell"' products free of LGE's patent claims. To be sure, LGE did require Intel to give notice to its customers, including Quanta, that LGE had not licensed those customers to practice its patents. But neither party contends that Intel breached the agreement in that respect. In any event, the provision requiring notice to Quanta appeared only in the Master Agreement, and LGE does not suggest that a breach of that agreement would constitute a breach of the License Agreement. Hence, Intel's authority to sell its products embodying the LGE Patents was not conditioned on the notice or on Quanta's decision to abide by LGE's directions in that notice.

LGE points out that the License Agreement specifically disclaimed any license to third parties to practice the patents by combining licensed products with other components. But the question whether third parties received implied licenses is irrelevant because Quanta asserts its right to practice the patents based not on implied license but on exhaustion. And exhaustion turns only on Intel's own license to sell products practicing the LGE Patents.

Alternatively, LGE invokes the principle that patent exhaustion does not apply to postsale restrictions on "making" an article. But this is simply a rephrasing of its argument that combining the Intel Products with other components adds more than standard finishing to complete a patented article. As explained above, making a product that substantially embodies a patent is, for exhaustion purposes, no different from making the patented article itself. In other words, no further "making" results from the addition of standard parts-here, the buses and memory - to a product that already substantially embodies the patent.

The License Agreement authorized Intel to sell products that practiced the LGE Patents. No conditions limited Intel's authority to sell 
816 F. 3d 721 (Fed Cir. 2016) (en banc)

Mallinckrodt: 976 F.2d 700 (Fed. Cir. 1992) products substantially embodying the patents. Because Intel was authorized to sell its products to Quanta, the doctrine of patent exhaustion prevents LGE from further asserting its patent rights with respect to the patents substantially embodied by those products.

Lexmark Intern., Inc. v. Impression Products, Inc.

Lexmark International, Inc. makes and sells printers as well as toner cartridges for its printers. Lexmark owns a number of patents that cover its cartridges and their use.

Lexmark offers buyers a choice. A buyer may purchase a "Regular Cartridge" at full price, in which case the buyer is not subject to any sale terms restricting reuse or resale of the cartridge. Alternatively, a buyer may purchase a "Return Program Cartridge" at a discount of roughly 20 percent, subject to a single-use/no-resale restriction: the buyer may not reuse the cartridge after the toner runs out and may not transfer it to anyone but Lexmark once it is used, i.e., the buyer must "return" the cartridge "only" to Lexmark.

The distinctness of the options for buyers, which produce different revenues for Lexmark, is not just a matter of different terms of sale. It also is reflected in a microchip in the cartridges that, among other things, communicates with the printer. For a Return Program cartridge, the chip and printer, by monitoring toner levels, prevent use of a refilled cartridge. For a Regular cartridge, the toner can be replenished and the cartridge reused. To circumvent this technological measure, however, third parties have "hacked" Lexmark's microchips and created their own "unauthorized replacement" microchips" that, when installed in a Return Program cartridge, fool the printer into allowing reuse of that cartridge. It is undisputed that various companies gather spent cartridges, replace the microchips, refill and "remanufacture" the cartridges, and sell them to resellers like Impression for marketing to consumers for use with Lexmark printers.

Lexmark sells its cartridges in two channels of distribution. It sells directly to end users, and it sells to "re-sellers" (including wholesalers, dealers, and distributors). There is no dispute about the adequacy of notice to resellers as well as end users or the binding nature of the Lexmark-reseller agreements.

We adhere to the holding of Mallinckrodt, Inc. v. Medipart, Inc., that a patentee, when selling a patented article subject to a single-use/noresale restriction that is lawful and clearly communicated to the purchaser, does not by that sale give the buyer, or downstream buyers,

\footnotetext{
${ }^{7}$ We note that the authorized nature of the sale to Quanta does not necessarily limit LGE's other contract rights. LGE's complaint does not include a breach-ofcontract claim, and we express no opinion on whether contract damages might be available even though exhaustion operates to eliminate patent damages.
} 
the resale/reuse authority that has been expressly denied. Such resale or reuse, when contrary to the known, lawful limits on the authority conferred at the time of the original sale, remains unauthorized and therefore remains infringing conduct under the terms of $\S 271$.

Mallinckrodt involved a patentee's sale of its medical device to hospitals, subject to a "single use only" restriction. But some hospital purchasers instead sent used devices to Medipart for reconditioning and for replacement of certain components.

As the Mallinckrodt court observed, in General Talking Pictures II "the patentee had authorized the licensee to make and sell amplifiers embodying the patented invention for a specified use (home radios)," and "the defendant had purchased the patented amplifier from the manufacturing licensee, with knowledge of the patentee's restriction on use," but used it contrary to the restriction. The Supreme Court held that the defendant was liable for infringement; it "observed that a restrictive license to a particular use was permissible, and treated the purchaser's unauthorized use as infringement of the patent." This court noted that the Supreme Court in General Talking Pictures II "did not decide the situation where the patentee was the manufacturer" and seller. This court then held that to distinguish the patentee sale (at issue in Mallinckrodt) from the licensee sale General Talking Pictures II would be to make "formalistic distinctions of no economic consequence."

The court in Mallinckrodt concluded that "unless the condition violates some other law or policy, private parties retain the freedom to contract concerning conditions of sale." Thus, unless a sale restriction is improper under some other body of law, whether within the Patent Act or outside it, a patentee's own sale of its patented article subject to a clearly communicated restriction does not confer authority to sell or use the article in violation of that restriction, i.e., does not exhaust the patentee's $\S 271$ rights against such conduct involving that article.

The district court concluded in this case that Quanta overturned the Mallinckrodt rule as to a patentee's sale of a patented article subject to a clearly communicated single-use/no-resale restriction. But no issue as to such a sale was presented for decision or decided in Quanta. And the Supreme Court in Quanta did not address the distinction between patentee sales and licensee sales on which the argument for overturning Mallinckrodt rests.

Dyk, Circuit Judge, dissenting, with whom Circuit Judge Hughes joins.

I respectfully dissent from the majority's holding that Mallinckrodt remains good law. I agree with the government that Mallinckrodt was wrong when decided, and in any event cannot be reconciled with the Supreme Court's recent decision in Quanta. We exceed our role 
$\S 273(a)$

Defense to infringement based on prior commercial use

Even though thousands of patent cases are filed every year, the prior use defense is only rarely asserted. Why might that be?

307 F.3d 1351 (Fed Cir. (2002)

Embrex: 216 F. 3d 1343 as a subordinate court by declining to follow the explicit domestic exhaustion rule announced by the Supreme Court.

\section{Miscellaneous}

\section{Patent Act}

A person shall be entitled to a defense under section 282(b) with respect to subject matter consisting of a process, or consisting of a machine, manufacture, or composition of matter used in a manufacturing or other commercial process, that would otherwise infringe a claimed invention being asserted against the person if -

(1) such person, acting in good faith, commercially used the subject matter in the United States, either in connection with an internal commercial use or an actual arm's length sale or other arm's length commercial transfer of a useful end result of such commercial use; and

(2) such commercial use occurred at least 1 year before the earlier of either-

(A) the effective filing date of the claimed invention; or

(B) the date on which the claimed invention was disclosed to the public in a manner that qualified for the exception from prior art under section 102(b).

\section{Madey v. Duke University}

[Madey owned a patent on certain laser technology. Duke practiced the patent as part of a research project under a federally funded grant.]

Madey argues, and we agree, that the district court had an overly broad conception of the very narrow and strictly limited experimental use defense. The district court stated that the experimental use defense inoculated uses that "were solely for research, academic, or experimental purposes," and that the defense covered use that "is made for experimental, non-profit purposes only." Both formulations are too broad and stand in sharp contrast to our admonitions in Embrex and Roche that the experimental use defense is very narrow and strictly limited. In Embrex, Inc. v. Service Engineering Corp, we held that the defense was very narrow and limited to actions performed "for amusement, to satisfy idle curiosity, or for strictly philosophical inquiry." Further, use does not qualify for the experimental use defense when it is undertaken in the "guise of scientific inquiry" but has "definite, cognizable, and not insubstantial commercial purposes." 
Our precedent clearly does not immunize use that is in any way commercial in nature. Similarly, our precedent does not immunize any conduct that is in keeping with the alleged infringer's legitimate business, regardless of commercial implications. For example, major research universities, such as Duke, often sanction and fund research projects with arguably no commercial application whatsoever. However, these projects unmistakably further the institution's legitimate business objectives, including educating and enlightening students and faculty participating in these projects. These projects also serve, for example, to increase the status of the institution and lure lucrative research grants, students and faculty.

In the present case, the district court attached too great a weight to the nonprofit, educational status of Duke, effectively suppressing the fact that Duke's acts appear to be in accordance with any reasonable interpretation of Duke's legitimate business objectives. The correct focus should not be on the non-profit status of Duke but on the legitimate business Duke is involved in and whether or not the use was solely for amusement, to satisfy idle curiosity, or for strictly philosophical inquiry. 


\section{4}

\section{Copyright}

Copyright protects creative expression. In some respects it is structurally analogous to patent law: both reward someone who creates valuable information with exclusive rights over it. But in many other respects - including subject matter, novelty, registration, term, and similarity - copyright is almost completely the opposite of patent.

The standard justification for copyright law is a familiar and utilitarian: to maximize public access to the fruits of human creativity. Thus, copyright law provides an economic incentive to create new expressive works, and provides protections to encourage the distribution of those works. Another rationale, with more of a natural-law flavor, is to protect authors' non-economic rights by giving them creative control. One sometimes also sees arguments that link copyright and freedom of speech in a shared goal of creating a diverse society with a healthy culture and healthy democracy.

\section{A Subject Matter}

\section{Copyright Act}

Copyright protection subsists, in accordance with this title, in original works of authorship fixed in any tangible medium of expression, now known or later developed, from which they can be perceived, reproduced, or otherwise communicated, either directly or with the aid of a machine or device. Works of authorship include the following categories:

(1) literary works;

(2) musical works, including any accompanying words;

(3) dramatic works, including any accompanying music;

(4) pantomimes and choreographic works;

(5) pictorial, graphic, and sculptural works;
The standard copyright treatises are Melville B. Nimmer \& David Nimmer, Nimmer on Copyright (Matthew Bender, on Lexis), William F. Patry, Patry on Copyright (Thomson Reuters, on Westlaw), and Paul Goldstein, Goldstein on Copyright (Wolters Kluwer).

17 U.S.C. § 102(a)

Subject matter of copyright: In general 
(6) motion pictures and other audiovisual works;

(7) sound recordings; and

(8) architectural works.

499 U.S. 340 (1991)

We will return to independent creation in the Ownership section.

37 C.F.R. $§ 202.1$

Material not subject to copyright

"The chief similarity between the two works is identity of title [We Who Are Young], but it is well settled that the copyright of a book or play does not give the copyright owner the exclusive right to the use of the title." Becker $v$. Loew's, Inc., 133 F.2d 889 (7th Cir. 1943)
Feist Publications, Inc. v. Rural Telephone Service Co. The sine qua non of copyright is originality. To qualify for copyright protection, a work must be original to the author. Original, as the term is used in copyright, means only that the work was independently created by the author (as opposed to copied from other works), and that it possesses at least some minimal degree of creativity. To be sure, the requisite level of creativity is extremely low; even a slight amount will suffice. The vast majority of works make the grade quite easily, as they possess some creative spark, no matter how crude, humble or obvious it might be. Originality does not signify novelty; a work may be original even though it closely resembles other works so long as the similarity is fortuitous, not the result of copying. To illustrate, assume that two poets, each ignorant of the other, compose identical poems. Neither work is novel, yet both are original and, hence, copyrightable.

Elsewhere, Feist helpfully expresses the elements of originality as "independent creation plus a modicum of creativity." The second prong is the subject (pun intended) of this section. First, we look at it as a threshold test: when are works uncopyrightable because they are uncreative? Then, we ask whether it expresses any exclusions from copyrightability. In one sense, no: courts are not to inquire into a work's quality or morality. In another sense, yes: "ideas" are regarded as uncopyrightable, even if they are original.

\section{Creativity: How Much Is a Modicum?}

\section{Code of Federal Regulations}

The following are examples of works not subject to copyright and applications for registration of such works cannot be entertained:

(a) Words and short phrases such as names, titles, and slogans; familiar symbols or designs; mere variations of typographic ornamentation, lettering or coloring; mere listing of ingredients or contents;

(d) Works consisting entirely of information that is common property containing no original authorship, such as, for example: 
Standard calendars, height and weight charts, tape measures and rulers, schedules of sporting events, and lists or tables taken from public documents or other common sources.

Feist Publications, Inc. v. Rural Telephone Service Co.

This case requires us to clarify the extent of copyright protection avail499 U.S. 340 (1991) able to telephone directory white pages.

I

Rural Telephone Service Company, Inc., is a certified public utility that provides telephone service to several communities in northwest Kansas. It is subject to a state regulation that requires all telephone companies operating in Kansas to issue annually an updated telephone directory. Accordingly, as a condition of its monopoly franchise, Rural publishes a typical telephone directory, consisting of white pages and yellow pages. The white pages list in alphabetical order the names of Rural's subscribers, together with their towns and telephone numbers. The yellow pages list Rural's business subscribers alphabetically by category and feature classified advertisements of various sizes. Rural distributes its directory free of charge to its subscribers, but earns revenue by selling yellow pages advertisements.

[Feist published a telephone directory, containing both white and yellow pages, covering a much larger geographic area. It contained 46,878 white-pages listings. Feist requested a license to Rural's listings; Rural refused.]

Unable to license Rural's white pages listings, Feist used them without Rural's consent. Feist began by removing several thousand listings that fell outside the geographic range of its area-wide directory, then hired personnel to investigate the 4,935 that remained. These employees verified the data reported by Rural and sought to obtain additional information. As a result, a typical Feist listing includes the individual's street address; most of Rural's listings do not. Notwithstanding these additions, however, 1,309 of the 46,878 listings in Feist's 1983 directory were identical to listings in Rural's 19821983 white pages. Four of these were fictitious listings that Rural had inserted into its directory to detect copying.

Rural sued for copyright infringement in the District Court for the District of Kansas taking the position that Feist, in compiling its own directory, could not use the information contained in Rural's white pages. Rural asserted that Feist's employees were obliged to travel door-to-door or conduct a telephone survey to discover the same information for themselves. Feist responded that such efforts were economically impractical and, in any event, unnecessary because the information copied was beyond the scope of copyright protection. The 
District Court granted summary judgment to Rural.

\section{II}

A

This case concerns the interaction of two well-established propositions. The first is that facts are not copyrightable; the other, that compilations of facts generally are. Each of these propositions possesses an impeccable pedigree.

The key to resolving the tension lies in understanding why facts are not copyrightable. No one may claim originality as to facts. This is because facts do not owe their origin to an act of authorship. The distinction is one between creation and discovery: The first person to find and report a particular fact has not created the fact; he or she has merely discovered its existence.

Factual compilations, on the other hand, may possess the requisite originality. The compilation author typically chooses which facts to include, in what order to place them, and how to arrange the collected data so that they may be used effectively by readers. These choices as to selection and arrangement, so long as they are made independently by the compiler and entail a minimal degree of creativity, are sufficiently original that Congress may protect such compilations through the copyright laws.

This inevitably means that the copyright in a factual compilation is thin. Notwithstanding a valid copyright, a subsequent compiler remains free to use the facts contained in another's publication to aid in preparing a competing work, so long as the competing work does not feature the same selection and arrangement.

$B$

As we have explained, originality is a constitutionally mandated prerequisite for copyright protection. The Court's decisions announcing this rule predate the Copyright Act of 1909, but ambiguous language in the 1909 Act caused some lower courts temporarily to lose sight of this requirement.

Making matters worse, these courts developed a new theory to justify the protection of factual compilations. Known alternatively as "sweat of the brow" or "industrious collection," the underlying notion was that copyright was a reward for the hard work that went into compiling facts. The classic formulation of the doctrine appeared

Jeweler's Circular: 281 F. 83 (2d Cir. 1922) in Jeweler's Circular Publishing Co.:

The right to copyright a book upon which one has expended labor in its preparation does not depend upon whether the materials which he has collected consist or 
not of matters which are publici juris, or whether such materials show literary skill or originality, either in thought or in language, or anything more than industrious collection. The man who goes through the streets of a town and puts down the names of each of the inhabitants, with their occupations and their street number, acquires material of which he is the author.

Without a doubt, the "sweat of the brow" doctrine flouted basic copyright principles. Throughout history, copyright law has recognized a greater need to disseminate factual works than works of fiction or fantasy. But "sweat of the brow" courts took a contrary view; they handed out proprietary interests in facts and declared that authors are absolutely precluded from saving time and effort by relying upon the facts contained in prior works.

\section{C}

The definition of "compilation" is found in $\S 101$ of the 1976 Act. It defines a "compilation" in the copyright sense as "a work formed by the collection and assembling of preexisting materials or of data that are selected, coordinated, or arranged in such a way that the resulting work as a whole constitutes an original work of authorship."

As discussed earlier, however, the originality requirement is not particularly stringent. A compiler may settle upon a selection or arrangement that others have used; novelty is not required. Originality requires only that the author make the selection or arrangement independently (i. e., without copying that selection or arrangement from another work), and that it display some minimal level of creativity. Presumably, the vast majority of compilations will pass this test, but not all will. There remains a narrow category of works in which the creative spark is utterly lacking or so trivial as to be virtually nonexistent. Such works are incapable of sustaining a valid copyright.

In summary, the 1976 revisions to the Copyright Act leave no doubt that originality, not "sweat of the brow," is the touchstone of copyright protection in directories and other fact-based works. Nor is there any doubt that the same was true under the 1909 Act. The 1976 revisions were a direct response to the Copyright Office's concern that many lower courts had misconstrued this basic principle, and Congress emphasized repeatedly that the purpose of the revisions was to clarify, not change, existing law. The revisions explain with painstaking clarity that copyright requires originality, § 102(a); that facts are never original, $\S 102(\mathrm{~b})$; that the copyright in a compilation does not extend to the facts it contains, $\S 103(\mathrm{~b})$; and that a compilation is copyrightable only to the extent that it features an original selection, coordination, or arrangement, § 101. 
III

The selection, coordination, and arrangement of Rural's white pages do not satisfy the minimum constitutional standards for copyright protection. As mentioned at the outset, Rural's white pages are entirely typical. Persons desiring telephone service in Rural's service area fill out an application and Rural issues them a telephone number. In preparing its white pages, Rural simply takes the data provided by its subscribers and lists it alphabetically by surname. The end product is a garden-variety white pages directory, devoid of even the slightest trace of creativity.

Rural's selection of listings could not be more obvious: It publishes the most basic information - name, town, and telephone number - about each person who applies to it for telephone service. This is "selection" of a sort, but it lacks the modicum of creativity necessary to transform mere selection into copyrightable expression. Rural expended sufficient effort to make the white pages directory useful, but insufficient creativity to make it original.

We note in passing that the selection featured in Rural's white pages may also fail the originality requirement for another reason. Feist points out that Rural did not truly "select" to publish the names and telephone numbers of its subscribers; rather, it was required to do so by the Kansas Corporation Commission as part of its monopoly franchise. Accordingly, one could plausibly conclude that this selection was dictated by state law, not by Rural.

Nor can Rural claim originality in its coordination and arrangement of facts. The white pages do nothing more than list Rural's subscribers in alphabetical order. This arrangement may, technically speaking, owe its origin to Rural; no one disputes that Rural undertook the task of alphabetizing the names itself. But there is nothing remotely creative about arranging names alphabetically in a white pages directory. It is an age-old practice, firmly rooted in tradition and so commonplace that it has come to be expected as a matter of course. It is not only unoriginal, it is practically inevitable. This time-honored tradition does not possess the minimal creative spark required by the Copyright Act and the Constitution.

Because Rural's white pages lack the requisite originality, Feist's use of the listings cannot constitute infringement. This decision should not be construed as demeaning Rural's efforts in compiling its directory, but rather as making clear that copyright rewards originality, not effort. As this Court noted more than a century ago, "great praise may be due to the plaintiffs for their industry and enterprise in publishing this paper, yet the law does not contemplate their being rewarded in this way." Baken

Arrows Problem 
Is this logo (for a professional sports team) sufficiently creative to be copyrightable?

\section{Baseball Card Price Report Problem}

The Baseball Card Price Report is a comprehensive printed list of collectible baseball cards sold between 1909 and 2011. It lists 32,000 baseball cards and a market price for each of them. The market price is determined by obtaining transaction lists from several dozen large dealers and averaging the sales prices for the card over the past year.

The Report is organized by year: it has a section for 1909, a section for 1910, and so on. Each section is subdivided into a list of manufacturers (Topps, Upper Deck, and so on). Each manufacturer's list is then divided by teams, and players are listed alphabetically by last name within a team section. For each card, the Report gives prices for mint, excellent, very good, good, and fair condition cards. In addition, about 9,000 of the cards are noted with a star to indicate that they are "premium" cards. These cards are considered especially valuable beacuse the player is in the Hall of Fame, played for a famous team, or some other reason that makes the card especially scarce or especially prized by collectors.

An entrepreneur calling himself Tyrone Tyrannosaurus has started a website called the "Collector's Cheat Sheet." The front of the site consists of three drop-down menus: year, team, and player name. Once a user selects all three, he is taken to a page that lists all of the companies that made cards of that player in that year. If a card is considered "premium" by the Report, the Cheat Sheet lists the card in bold.

You represent Mr. Tyrannosaurus, who has received a cease-anddesist letter from the publisher of the Report claiming that the Cheat Sheet is infringing on a copyright in the Report. What is your advice to your client?

\section{Aesthetic Nondiscrimination}

\section{Bleistein v. Donaldson Lithographing Co.}

[The plaintiffs produced three large color posters ("chromolithographs") to be used as advertisements for Wallace's circus. Later, the defendant reproduced the posters in smaller black-and-white versions, as advertisements for the same circus. When sued, the defendants argued that the chromolithographs were not copyrightable.]

We shall do no more than mention the suggestion that painting and engraving unless for a mechanical end are not among the useful arts, the progress of which Congress is empowered by the Con-

188 U.S. 239 (1903)

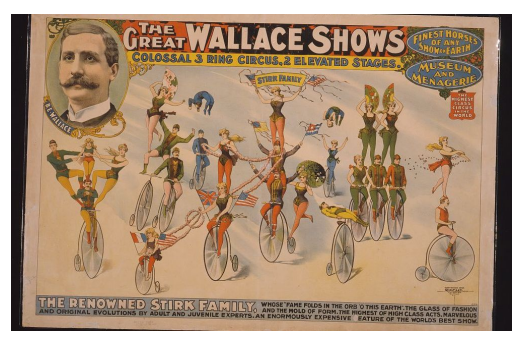

Wallace circus poster

(Holmes, J.) 
stitution to promote. The Constitution does not limit the useful to that which satisfies immediate bodily needs. It is obvious also that the plaintiffs' case is not affected by the fact, if it be one, that the pictures represent actual groups - visible things. They seem from the testimony to have been composed from hints or description, not from sight of a performance. But even if they had been drawn from the life, that fact would not deprive them of protection. The opposite proposition would mean that a portrait by Velasquez or Whistler was common property because others might try their hand on the same face. Others are free to copy the original. They are not free to copy the copy. The copy is the personal reaction of an individual upon nature. Personality always contains something unique. It expresses its singularity even in handwriting, and a very modest grade of art has in it something irreducible, which is one man's alone. That something he may copyright unless there is a restriction in the words of the act.

If there is a restriction it is not to be found in the limited pretensions of these particular works. The least pretentious picture has more originality in it than directories and the like, which may be copyrighted.

[The copyright act in force at the time protected only defined categories of works, one of which was "pictorial illustrations or works connected with the fine arts."] These chromolithographs are "pictorial illustrations." The word "illustrations" does not mean that they must illustrate the text of a book, and that the etchings of Rembrandt or Steinla's engraving of the Madonna di San Sisto could not be protected to-day if any man were able to produce them. Again, the act however construed, does not mean that ordinary posters are not good enough to be considered within its scope. The antithesis to "illustrations or works connected with the fine arts" is not works of tittle merit or of humble degree, or illustrations addressed to the less educated classes; it is "prints or labels designed to be used for any other articles of manufacture." Certainly works are not the less connected with the fine arts because their pictorial quality attracts the crowd and therefore gives them a real use - if use means to increase trade and to help to make money. A picture is none the less a picture and none the less a subject of copyright that it is used for an advertisement. And if pictures may be used to advertise soap, or the theatre, or monthly magazines, as they are, they may be used to advertise a circus. Of course, the ballet is as legitimate a subject for illustration as any other. A rule cannot be laid down that would excommunicate the paintings of Degas.

It would be a dangerous undertaking for persons trained only to the law to constitute themselves final judges of the worth of pictorial illustrations, outside of the narrowest and most obvious limits. At the 
one extreme some works of genius would be sure to miss appreciation. Their very novelty would make them repulsive until the public had learned the new language in which their author spoke. It may be more than doubted, for instance, whether the etchings of Goya or the paintings of Manet would have been sure of protection when seen for the first time. At the other end, copyright would be denied to pictures which appealed to a public less educated than the judge. Yet if they command the interest of any public, they have a commercial value - it would be bold to say that they have not an aesthetic and educational value - and the taste of any public is not to be treated with contempt. It is an ultimate fact for the moment, whatever may be our hopes for a change. That these pictures had their worth and their success is sufficiently shown by the desire to reproduce them without regard to the plaintiffs' rights. We are of opinion that there was evidence that the plaintiffs have rights entitled to the protection of the law.

\section{Compendium of U.S. Copyright Office Practices (3d ed. 2014)}

As a general rule, the Copyright Office will not consider factors that have no bearing on whether the originality requirement has been met. The fact that a work may be novel, distinctive, innovative, or even unique is irrelevant to this analysis. The Copyright Office does not consider the aesthetic value, artistic merit, or intrinsic quality of a work. For example, the Office will not look for any particular style of creative expression. Likewise, the Office will not consider whether a work is visually appealling or written in elegant prose. For the same reasons, the Office will not consider the truth or falsity of the facts set forth in a work of authorship. Nor will the Office consider the soundness of the views expressed in the work.

The Office will focus only on the actual appearance or sound of the work that has been submitted for registration, but will not consider any meaning or significance that the work may evoke. The Office will not consider the author's inspiration for the work, creative intent, or intended meaning. The U.S. Copyright Office will not consider the author's creative skill and experience, because the author's personal or professional history is irrelevant to the determination of copyrightability.

The Office will not consider the amount of time, effort, or expense required to create the work. As a general rule, the Office will not consider possible design alternatives that the author may have considered when he or she created the work. Likewise, the Office will not consider potential variations in the use of the work, such as the fact that the work could be presented in a different color, in a different size, or with a different orientation. As a general rule, the materials
Compare: "The ultimate good desired is better reached by free trade in ideas. The best test of truth is the power of the thought to get itself accepted in the competition of the market." Abrams v. United States, 250 U.S. 616 (1919) (Holmes, J., dissenting).

$\S 310$

Factors That Will Not Be Considered in the Examination of Originality 
604 F.2d 852 (5th Cir. 1979)

"Copyright law is even more pornography-friendly than the First Amendment. The First Amendment will only protect pornography if it is not obscene or illegal for other reasons; for example, if it contains depictions of children. Copyright law offers protections to pornography no matter what material it contains. The First Amendment merely prevents the government from interfering in the creation, distribution and consumption of pornography that is not obscene or otherwise illegal. With the current practice of indiscriminately according pornographic works copyright protection, the government encourages and incentivizes the production of pornography that is non-progressive and non-useful and therefore beyond the scope of the Intellectual Property Clause of the U.S. Constitution. This must cease." Ann Bartow, Copyright Law and Pornography, 91 Or. L. Rev. 1 (2012).

Martinetti: 16 Fed. Cas. 920 (C.C.Cal. 1867) used to create a work have no bearing on the originality analysis. For example, the U.S. Copyright Office will not consider the fact that a jewelry design was constructed with precious metals or gemstones, or the fact that a silk screen was printed on a particular paper stock. The U.S. Copyright Office will not consider the marketability or commercial success of the work, because these issues are irrelevant to the originality analysis.

\section{Mitchell Bros. Film Group v. Cinema Adult Theater}

Plaintiffs-appellants owned a properly registered copyright on a motion picture titled "Behind the Green Door." Two groups of defendants, each group consisting of a theater and several individuals, obtained copies of the movie without plaintiffs' permission and infringed the copyright by exhibiting the film at the theaters. We hold that the district court erred in permitting the assertion of obscenity as an affirmative defense to the claim of infringement, and, accordingly, reverse without reaching the question whether the film is obscene.

The district court did not base its decision on standards found within the [1909 Copyright] Act, which it described as "silent as to works which are subject to registration and copyright." The Act is not "silent." Rather, the statutory language "all the writings of an author" is facially all-inclusive, within itself admitting of no exceptions. There is not even a hint in the language of $\S 4$ that the obscene nature of a work renders it any less a copyrightable "writing."

Society's view of what is moral and immoral continually changes. To give one example, in Martinetti v. Maguire, the play "The Black Crook," because it featured women clad in flesh-colored tights, was held to be "grossly indecent, and calculated to corrupt the morals of the people" and hence uncopyrightable. By the early part of this century, it had become clear that this judgment reflected the moral standards of a bygone era.

Denying copyright protection to works adjudged obscene by the standards of one era would frequently result in lack of copyright protection (and thus lack of financial incentive to create) for works that later generations might consider to be not only non-obscene but even of great literary merit. Many works that are today held in high regard have been adjudged obscene in previous eras. English courts of the nineteenth century found the works of Byron, Southey and Shelley to be immoral. American courts have found these books, among others, obscene: Edmund Wilson, Memories of Hecate County; Henry Miller, Tropic of Cancer and Tropic of Capricorn; Erskine Caldwell, God's Little Acre; Lillian Smith, Strange Fruit; D. H. Lawrence, Lady Chatterly's Lover; Theodore Dreiser, An AmericAN TRAgedy. 


\section{Belcher v. Tarbox}

Defendant's primary contention is that the works were not entitled to copyright protection since they, and the advertising material associated with them, fraudulently represented to the public that users of the system described could beat the horses.

There is nothing in the Copyright Act to suggest that the courts are to pass upon the truth or falsity, the soundness or unsoundness, of the views embodied in a copyrighted work. The gravity and immensity of the problems, theological, philosophical, economic and scientific, that would confront a court if this view were adopted are staggering to contemplate. It is surely not a task lightly to be assumed, and we decline the invitation to assume it.

\section{Idea and Expression}

\section{Copyright Act}

In no case does copyright protection for an original work of authorship extend to any idea, procedure, process, system, method of operation, concept, principle, or discovery, regardless of the form in which it is described, explained, illustrated, or embodied in such work.

It is hornbook law that ideas are not copyrightable, only an author's individual expression of those ideas. But what qualifies as an "idea" can only be learned by seeing what courts treat as one. Sometimes "idea" refers to the general creative concept for a work, as distinguished from its more specific details. Sometimes "idea" is used as a synecdoche for other $\S 102(\mathrm{~b})$ exclusions - "procedure, process, system, method of operation" - that describe functional matter in a work. In addition, two closely related doctrines - merger and scènes à faire help implement these exclusions.

\section{Blehm v. Jacobs}

Appellant Gary Blehm brought this copyright infringement action against brothers Albert and John Jacobs and the Life is Good Company (collectively "Life is Good"). Mr. Blehm is the creator of copyrighted posters featuring cartoon characters called "Penmen." He contends that numerous Life is Good depictions of a cartoon character called "Jake" infringe on his copyrighted works. The district court granted Life is Good's motion for summary judgment, holding that no infringement occurred because the copyrighted and accused works are not substantially similar.
486 F.2d 1087 (9th Cir. 1973)

17 U.S.C. § 102

Subject matter of copyright: In general

702 F. 3d 1193 (10th Cir. 2012) 


\section{BACKGROUND}

Mr. Blehm is a commercial artist who lives in Colorado Springs, Colorado. In the late 1980s, he developed characters called "Penmen." According to Mr. Blehm, each Penman is "a deceptively-simple looking figure" that "engages in a variety of activities pulled directly from his colorful life experiences." The Penmen have "round heads, disproportionately large half-moon smiles, four fingers, large feet, disproportionately long legs, and a message of unbridled optimism."

The Penmen are a product of Mr. Blehm's commercial art training. Through his training, Mr. Blehm learned how to "add a slight bend to a figure's limb to show weight bearing into it" and how, as he puts it, to apply negative space. Eventually, Mr. Blehm developed rules and guidelines for drawing each Penman. These rules and guidelines include a specific shape for each Penman's head, specific length and height requirements for each character, rules on fluidity and perspective, and the "Penmen parallel curve," which Mr. Blehm employs to "create eye-pleasing shapes within the negative space."

In 1990, Mr. Blehm began selling his posters to distributors. From 1990 to 2004, Prints Plus sold his posters nationally.

Starting in 1989, the Jacobs brothers designed and sold t-shirts "infused with a positive undertone as a reflection of their beliefs." The brothers sold t-shirts in areas around Boston, including Harvard Square, not far from the Harvard Coop. During the 1993 holiday season, the Jacobses sold t-shirts from carts in the Cambridgeside Galleria and the Emerald Square Mall, both of which had Prints Plus stores that sold Mr. Blehm's posters.

According to the Jacobses, around April 1994 John Jacobs drew a sketch of a figure with a red face, wide smile, sunglasses, and a beret. The figure was enclosed in two circles. John hung the sketch on the wall of the brothers' apartment.

The Jacobses recall hosting a party in August 1994 at their apartment and soliciting feedback on the sketch from their friends. After a friend stated that the figure in the sketch "really has life figured out," John Jacobs wrote "Life is good" under the image. They named the image "Jake," a spinoff of their last name.

The Jacobses soon made and sold t-shirts featuring Jake at street fairs and to retailers. As demand for the shirts increased, John Jacobs added a torso, arms, and feet to the Jake head. Jake was portrayed engaging in simple activities, such as biking, hiking, golfing, and playing soccer.

The Jacobses incorporated Life is Good in 1997 with the "overarching themes of optimism, simplicity, humor, and humility."

\section{Discussion}




\section{A. Substantial Similarity}

\section{Legal Framework}

In order to prove copying of legally protectable material, a plaintiff must typically show substantial similarity between legally [protectable] elements of the original work and the allegedly infringing work. This commonly stated rule raises two questions: First, what elements of a copyrighted work are legally protectable? Second, how do courts determine whether a copyrighted work's legally protectable elements are "substantially similar" to an accused work?

Section 102(a) of the Copyright Act states that a copyright protects the "original works of authorship fixed in any tangible medium of expression," including pictorial and graphic works. 17 U.S.C. S 102(a). To gain protection, the work must demonstrate at least some minimal degree of creativity, but even a slight amount will suffice. The vast majority of works make the grade quite easily, as they possess some creative spark, no matter how crude, humble or obvious it might be.

But legal protection does not extend to all aspects of a copyrighted work. Section 102(b) provides, "In no case does copyright protection ... extend to any idea ... [or] concept ... regardless of the form in which it is described, explained, illustrated, or embodied in such work." 17 U.S.C. S 102(b). This provision enshrines the fundamental tenet that copyright protection extends only to the author's original expression and not to the ideas embodied in that expression.

Thus, courts comparing works must first distill the protectable elements of the copyrighted work - i.e., determine what aspects constitute protectable expression. But this process, although sound in theory, is difficult to apply in practice. More than 50 years ago, Judge Learned Hand recognized that "[t]he test for infringement of a copyright is of necessity vague." Peter Pan Fabrics, Inc. v. Martin Weiner Corp.. Because "no principle can be stated as to when an imitator has gone beyond copying the 'idea,' and has borrowed its 'expression[,]' [d]ecisions must therefore inevitably be ad hoc." Id.We follow this case-by-case approach, and are mindful that copyright law seeks to achieve a proper balance between competition based on public ideas and incentive to produce original work.

Because the idea/expression distinction is the most complex part of the substantial similarity inquiry, we discuss a few examples where courts have separated the two. In Country Kids 'N City Slicks, Inc. $v$. Sheen, this court held that copyright protection did not "extend to the size, shape and medium" of wooden dolls. We explained that the Copyright Act is concerned with artistic innovation and excludes protection for a work's "utilitarian qualities." The idea of a wooden doll is not copyrightable, nor are "any basic and utilitarian

Peter Pan Fabrics: 274 F.2d 487 (2nd Cir. 1960)

Country Kids: 77 F.3d 1280 (10th Cir. 1996) 
Aliotti: 831 F.2d 898 (9th Cir. 1987)

Sturdza: 281 F.3d 1287 (D.C. Cir. 2002)

Lollytogs: 71 F.3d 996, 1004 (2d Cir.1995)

Tufenkian: 338 F.3d 127 (2nd Cir. 2003) aspects of the dolls, such as the shape of a human body and standard doll poses which are both friendly and inviting and also utilitarian in their ease of manufacture and adaptability to the attachment of various wardrobes."

Similarly, a copyright owner has no monopoly over the idea of fashion dolls with a bratty look or attitude, or dolls sporting trendy clothing. Nor does copyright protection extend to the idea of creating a doll with an upturned nose, bow lips, and widely spaced eyes, even if the allegedly infringing work has explicitly taken this idea from the copyrighted work.

Copyright instead protects the particularized expression of the idea of a doll with such features. For example, although a copyright owner has no monopoly over the idea of a muscular doll in a standard pose, the owner may have a valid infringement claim for copying of the particularized expression of that idea, such as the decision to accentuate certain muscle groups relative to others. A copyright owner's original stylistic choices qualify as protectable expression if the choices are not dictated by the underlying idea. See Aliotti $v$. R. Dakin \& Co. (stuffed dinosaur toys cannot be substantially similar because of shared physiognomy, but a distinctive "eye style and stitching" could qualify as protectable expression if they are "not dictated by the idea of stuffed dinosaur dolls").

In architecture, there is no copyright protection for the idea of using domes, wind-towers, parapets and arches." Sturdza v. United Arab Emirates. "To hold otherwise would render basic architectural elements unavailable to architects generally, thus running afoul of the very purpose of the idea/expression distinction: promoting incentives for authors to produce original work while protecting society's interest in the free flow of ideas." On the other hand, the combination of common architectural elements and use of specific designs may constitute original expression that is protected. An architectural design may infringe if its use of public-domain elements gives off a similar unique effect in decoration and design as the copyrighted work.

Thus, a sweater designer can have copyright protection over an original way of using squirrels as a design element in conjunction with fall colors, stripes, and panels, even though those elements individually constitute ideas in the public domain. See Knitwaves, Inc. $v$. Lollytogs Ltd.. A plaintiff's "selective and particularized" alterations of a public-domain carpet pattern also can constitute protectable expression. Tufenkian Imp./Exp. Ventures, Inc. v. Einstein Moomjy, Inc..

\section{Comparing the Penmen and Jake Images}

The district court was correct that Mr. Blehm has no copyright over the idea of a cartoon figure holding a birthday cake, catching a Fris- 
bee, skateboarding, or engaging in various other everyday activities. Nor can the Jake images infringe on the Penmen because the figures share the idea of using common anatomical features such as arms, legs, faces, and fingers, which are not protectable elements. See Baby Buddies, Inc. v. Toys " $R$ " Us, Inc.. (no copyright protection over common anatomical features of teddy bear). Mr. Blehm's copyright also does not protect Penmen poses that are attributable to an associated activity, such as reclining while taking a bath or lounging in an inner tube. These everyday activities, common anatomical features, and natural poses are ideas that belong to the public domain; Mr. Blehm does not own these elements.

Although we do not consider these unprotected elements in our substantial similarity analysis, we acknowledge that Mr. Blehm's works do contain some protectable expression. The Penmen at first glance might be considered simple stick figures, but they are more nuanced than a child's rudimentary doodling. For example, the prototypical Penman has a rounded, half-moon smile that takes up a substantial portion of the face. Mr. Blehm has chosen to omit any other facial features on the Penmen. Each figure is filled in black, except for the white half-moon smile, and each Penman's head is detached, hovering above the body. Many of the Penmen stand facing the viewer, flashing the half-moon smile.

Mr. Blehm also drew the Penmen according to his own rules and guidelines. The figure's head might be perceived as slightly disproportional to the body. Its arms and legs are thin, long, and disproportionate to the torso, which is relatively short. Mr. Blehm also chose to give the Penmen four fingers - each about as thick as their arms and legs - on each hand, as well as feet that are disproportionately long and thick compared with the rest of the body.

Having identified protectable expression in Mr. Blehm's drawings, we must determine whether that expression is substantially similar to the allegedly infringing Life is Good images. Life is Good is not entitled to summary judgment unless its Jake figures are so dissimilar from the protectable elements of the Penmen that no reasonable jury could find for Mr. Blehm on the question of substantial similarity.

To show substantial similarity, Mr. Blehm provided the district court with an exhibit juxtaposing 67 individual Penmen with a corresponding, allegedly infringing Jake image. We have reviewed these images and agree with the district court's grant of summary judgment in favor of Life is Good. We now address two of Mr. Blehm's proposed comparisons, which he highlights in his appellate brief, and explain why the Life is Good images are so dissimilar from the protectable elements of Mr. Blehm's images that no reasonable jury could find in his favor.
Baby Buddies: 611 F.3d 1308 (11th Cir. 2010) 


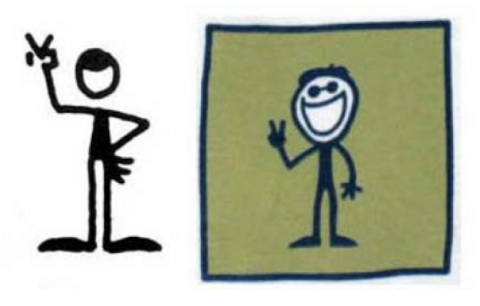

Peace sign images

\section{a. The Peace Sign Images}

The first example in Mr. Blehm's exhibit juxtaposes a Penman and Jake image standing and displaying the peace sign. Because we must separate unprotected ideas from expression, our analysis does not consider that both drawings share the idea of a cartoon figure making a common hand gesture. But we do consider whether the Jake image is substantially similar to Mr. Blehm's expression of this idea.

Mr. Blehm urges us to find certain similarities between the images. He notes that both have round heads. But Mr. Blehm has no copyright protection in general human features. Further, the figures' heads are not similarly round. Jake's head is more oval and somewhat misshapen, whereas the Penman's head is circular and uniform.

Mr. Blehm suggests that the figures have similar proportions, such as the size of the figures' heads, arms, legs, and feet compared with their bodies. A close review of the figures, however, yields the opposite conclusion. Jake's head is very large compared with the body, while the Penman's head is relatively proportional. The Penman's arms and legs are long and disproportionate to its truncated torso. Jake, on the other hand, has more proportional limbs compared with his torso. The figures' feet are distinctly different: the Penman's are thick, long, and roll-shaped, but Jake's are shorter and triangular.

Nevertheless, there are some similarities between the Penman and Jake. Both have black-line bodies, four fingers, and large half-moon smiles, and their feet are pointed outward. But even these similarities have important differences, or are not protectable expression. For example, Jake's fingers appear stubbier. The choice to display the figures' feet outward also naturally flows from the common idea of drawing a two-dimensional stick figure and is thus unprotected.

The figures' smiles thus seem to be the crux of this litigation. The Penman and Jake both face the viewer with disproportionately large half-moon smiles. A smile can be drawn in various ways. Here, they share a crescent shape, but the idea of a crescent-shaped smile is unprotected. Rather, the expression of the smiles must be substantially similar and important to the overall work.

The Penman's smile is all white, as is Jake's. The smiles on both figures take up a large portion of the head. But the Penman's smile is rounded on the tips, whereas the tips of Jake's smile are sharper angled. Jake's smile, by virtue of the size of his head, is much larger compared with his body than is the Penman's. And although both smiles are white, the Penman's is set on an all-black head, making it appear different from Jake's, which is the outline of a smile on a white head with black sunglasses.

Indeed, Mr. Blehm's decision to omit eyes and other facial fea- 
tures on the Penman makes the figure susceptible to an interpretation that the Penman is not smiling at all. One interpretation is that the white space on the head is not a smile, but is the Penman's face with no features. The black above the half-moon shape can be perceived as hair swooping down over the Penman's forehead. Thus, the Penman's lack of facial features make it susceptible to different interpretations. The Jake figure is not susceptible to similar confusion.

Any similarity between smiles also is insubstantial in light of other differences between the figures. Jake's head is attached to the body, and his head is white and has black sunglasses. The Penman's head is detached and is black with no eyes. Jake sports a beret, and his whole figure is displayed on a color background, whereas the Penman has no headwear and is portrayed against a plain white background.

The Jake image's arms are positioned differently from the Penman, with Jake's left arm curved, rather than sharp and angular. Mr. Blehm also chose a unique feature for the Penman's peace-sign expression - white space in the figure's hand - that the Jake image does not share.

We conclude that no reasonable juror could determine that the Jake figure is substantially similar to the protected, expressive choices Mr. Blehm used for the Penman figure.

\section{$b$. The Frisbee Images}

In another example, a Penman and Jake attempt to catch Frisbees between their legs. The two figures' poses are similar - suspended in the air with legs outstretched and a hand descending to catch the disc - but we do not consider the pose in our analysis. Such a pose is common to this activity and is not protected expression. Again, the figures have large, half-moon smiles. And unlike the "peace sign" Jake, this Jake image has legs that are disproportionate to a truncated torso. The Penman's legs also are long with respect to the torso, but not as disproportionate as Jake's.

Jake's legs are curved, but the Penman's are straightened. The Jake image's head differs in the same important ways as in the "peace sign" images. Jake's arms appear to extend from his head, but the Penman's arms attach to the top of the torso. Jake's torso is much thinner (and disproportionately shorter) than the Penman's; Jake has three fingers on each hand (not four); and the Jake image, unlike the Penman image, incorporates color on the canvas and disc. Jake's feet are defined - toes and arches are visible - but the Penman's are not. Although the images share a similar idea of catching a Frisbee between the legs, the protectable expression in the Penman is not substantially similar to the Jake image.

\section{c. Other Images}
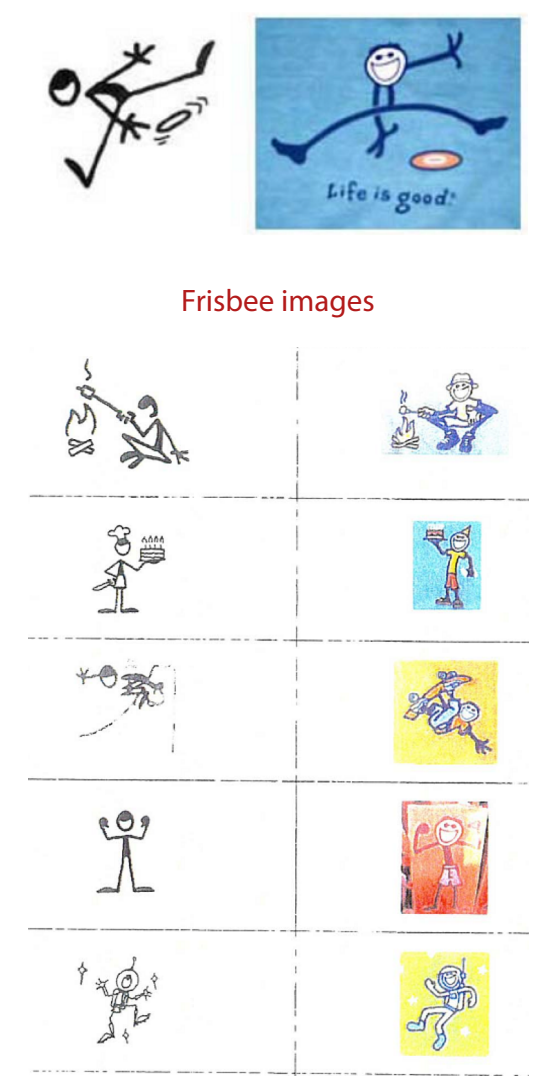

Selected other images 
784 F.2d 44 (2d Cir. 1986)

Based on Reece v. Island Treasures Art Gallery, Inc., 468 F. Supp. 2d 1197 (D. Haw. 2006)

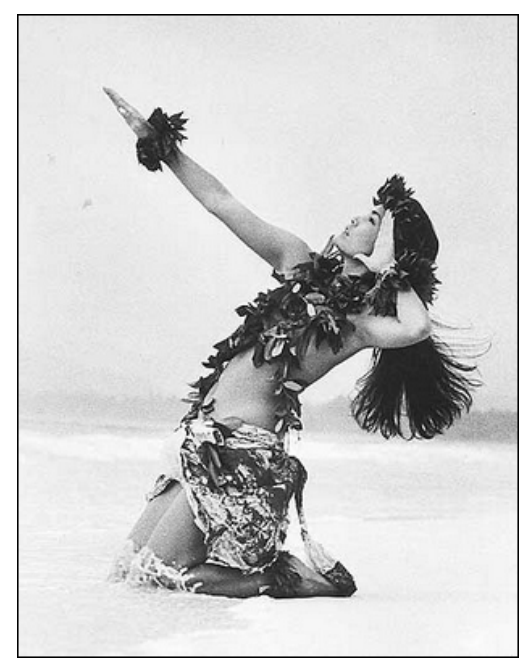

Kim Taylor Reece, Makanani

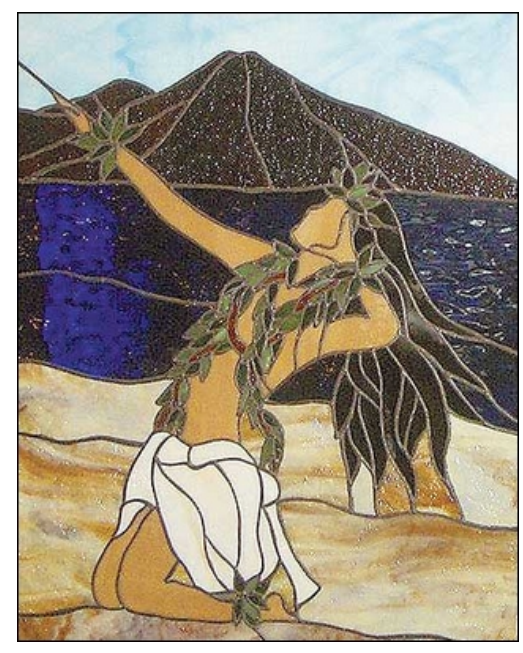

Marylee Colucci, Nohe
Mr. Blehm highlights 65 other Penmen as having been copied. Attached to this opinion is the "Penmen-Jake Chart" Mr. Blehm submitted to the district court in an effort to demonstrate substantial similarity.

We have reviewed these images, and an analysis similar to the discussion above applies.

Copying alone is not infringement. The infringement determination depends on what is copied. Assuming Life is Good copied Penmen images when it produced Jake images, our substantial similarity analysis shows it copied ideas rather than expression, which would make Life is Good a copier but not an infringer under copyright law.

\section{Walker v. Time Life Films, Inc.}

In the district court, appellant proffered lists of specific alleged similarities in an attempt to prove fragmented literal similarity between the book and the film. None of these claims alters our conclusion that the district court properly held that as a matter of law no substantial similarity exists between the protectible elements of the works. For example, appellant notes that both the book and the film depict cockfights, drunks, stripped cars, prostitutes and rats; both feature as central characters third- or fourth-generation Irish policemen who live in Queens and frequently drink; both show disgruntled, demoralized police officers and unsuccessful foot chases of fleeing criminals.

These similarities, however, relate to uncopyrightable material. Elements such as drunks, prostitutes, vermin and derelict cars would appear in any realistic work about the work of policemen in the South Bronx. These similarities therefore are unprotectible as "scènes à faire," that is, scenes that necessarily result from the choice of a setting or situation. Neither does copyright protection extend to copyright or "stock" themes commonly linked to a particular genre. Foot chases and the morale problems of policemen, not to mention the familiar figure of the Irish cop, are venerable and often-recurring themes of police fiction. As such, they are not copyrightable except to the extent they are given unique - and therefore protectible - expression in an original creation.

\section{Hula Problem}

Consider this photograph and stained glass image of hula dancers. The dancers' pose (kneeling, with right arm extended, etc.) is traditional. So is their dress (including the lei, etc.). Does the stained glass infringe on the photograph? Are there further facts it would be helpful to know? 
Charles Selden, the testator of the complainant in this case, in the year 1859 took the requisite steps for obtaining the copyright of a book, entitled "Selden's Condensed Ledger, or Book-keeping Simplified," the object of which was to exhibit and explain a peculiar system of bookkeeping. In 1860 and 1861, he took the copyright of several other books, containing additions to and improvements upon the said system. The bill of complaint was filed against the defendant, Baker, for an alleged infringement of these copyrights.

The book or series of books of which the complainant claims the copyright consists of an introductory essay explaining the system of book-keeping referred to, to which are annexed certain forms or blanks, consisting of ruled lines, and headings, illustrating the system and showing how it is to be used and carried out in practice. This system effects the same results as book-keeping by double entry; but, by a peculiar arrangement of columns and headings, presents the entire operation, of a day, a week, or a month, on a single page, or on two pages facing each other, in an account-book. The defendant uses a similar plan so far as results are concerned; but makes a different arrangement of the columns, and uses different headings. If the complainant's testator had the exclusive right to the use of the system explained in his book, it would be difficult to contend that the defendant does not infringe it, notwithstanding the difference in his form of arrangement; but if it be assumed that the system is open to public use, it seems to be equally difficult to contend that the books made and sold by the defendant are a violation of the copyright of the complainant's book considered merely as a book explanatory of the system. Where the truths of a science or the methods of an art are the common property of the whole world, any author has the right to express the one, or explain and use the other, in his own way. As an author, Selden explained the system in a particular way. It may be conceded that Baker makes and uses account-books arranged on substantially the same system; but the proof fails to show that he has violated the copyright of Selden's book, regarding the latter merely as an explanatory work; or that he has infringed Selden's right in any way, unless the latter became entitled to an exclusive right in the system.

It is contended that he has secured such exclusive right, because no one can use the system without using substantially the same ruled lines and headings which he has appended to his books in illustration of it. In other words, it is contended that the ruled lines and headings, given to illustrate the system, are a part of the book, and, as such, are secured by the copyright; and that no one can make or use similar ruled lines and headings, or ruled lines and headings made and arranged on substantially the same system, without violating the copyright.

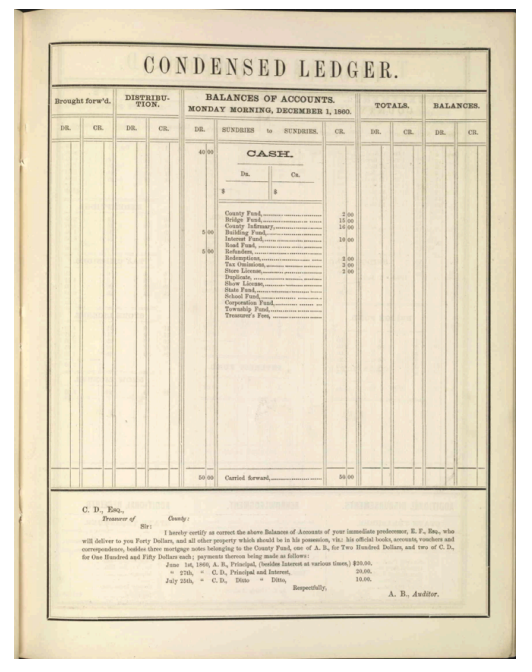

Selden's Condensed Ledger 
There is no doubt that a work on the subject of book-keeping, though only explanatory of well-known systems, may be the subject of a copyright; but, then, it is claimed only as a book. Such a book may be explanatory either of old systems, or of an entirely new system; and, considered as a book, as the work of an author, conveying information on the subject of book-keeping, and containing detailed explanations of the art, it may be a very valuable acquisition to the practical knowledge of the community. But there is a clear distinction between the book, as such, and the art which it is intended to illustrate. The mere statement of the proposition is so evident, that it requires hardly any argument to support it. The same distinction may be predicated of every other art as well as that of book-keeping. A treatise on the composition and use of medicines, be they old or new; on the construction and use of ploughs, or watches, or churns; or on the mixture and application of colors for painting or dyeing; or on the mode of drawing lines to produce the effect of perspective, - would be the subject of copyright; but no one would contend that the copyright of the treatise would give the exclusive right to the art or manufacture described therein. The copyright of the book, if not pirated from other works, would be valid without regard to the novelty, or want of novelty, of its subject-matter. The novelty of the art or thing described or explained has nothing to do with the validity of the copyright. To give to the author of the book an exclusive property in the art described therein, when no examination of its novelty has ever been officially made, would be a surprise and a fraud upon the public. That is the province of letters-patent, not of copyright. The claim to an invention or discovery of an art or manufacture must be subjected to the examination of the Patent Office before an exclusive right therein can be obtained; and it can only be secured by a patent from the government.

The copyright of a work on mathematical science cannot give to the author an exclusive right to the methods of operation which he propounds, or to the diagrams which he employs to explain them, so as to prevent an engineer from using them whenever occasion requires. The very object of publishing a book on science or the useful arts is to communicate to the world the useful knowledge which it contains. But this object would be frustrated if the knowledge could not be used without incurring the guilt of piracy of the book. And where the art it teaches cannot be used without employing the methods and diagrams used to illustrate the book, or such as are similar to them, such methods and diagrams are to be considered as necessary incidents to the art, and given therewith to the public; not given for the purpose of publication in other works explanatory of the art, but for the purpose of practical application.

Of course, these observations are not intended to apply to orna- 
mental designs, or pictorial illustrations addressed to the taste. Of these it may be said, that their form is their essence, and their object, the production of pleasure in their contemplation. This is their final end. They are as much the product of genius and the result of composition, as are the lines of the poet or the historian's periods. On the other hand, the teachings of science and the rules and methods of useful art have their final end in application and use; and this application and use are what the public derive from the publication of a book which teaches them. But as embodied and taught in a literary composition or book, their essence consists only in their statement. This alone is what is secured by the copyright. The use by another of the same methods of statement, whether in words or illustrations, in a book published for teaching the art, would undoubtedly be an infringement of the copyright.

Recurring to the case before us, we observe that Charles Selden, by his books, explained and described a peculiar system of bookkeeping, and illustrated his method by means of ruled lines and blank columns, with proper headings on a page, or on successive pages. Now, whilst no one has a right to print or publish his book, or any material part thereof, as a book intended to convey instruction in the art, any person may practise and use the art itself which he has described and illustrated therein. The use of the art is a totally different thing from a publication of the book explaining it. The copyright of a book on book-keeping cannot secure the exclusive right to make, sell, and use account-books prepared upon the plan set forth in such book. Whether the art might or might not have been patented, is a question which is not before us. It was not patented, and is open and free to the use of the public. And, of course, in using the art, the ruled lines and headings of accounts must necessarily be used as incident to it.

The conclusion to which we have come is, that blank accountbooks are not the subject of copyright; and that the mere copyright of Selden's book did not confer upon him the exclusive right to make and use account-books, ruled and arranged as designated by him and described and illustrated in said book.

\section{Bikram's Yoga College of India v. Evolation Yoga}

We must decide whether a sequence of twenty-six yoga poses and two breathing exercises developed by Bikram Choudhury and described in his 1979 book, Bikram's Beginning Yoga Class, is entitled to copyright protection.

In 1971, Bikram Choudhury, the self-proclaimed "Yogi to the stars," arrived in Beverly Hills, California. He soon became a central figure in the growing popularity of yoga in the United States. Choudhury developed a sequence of twenty-six asanas and two breathing exercises, arranged in a particular order, which he calls the "Se- 
quence." Choudhury opened his own studio, where he began offering "Bikram Yoga" classes. In a Bikram Yoga class, the Sequence is practiced over the course of ninety minutes, to a series of instructions (the "Dialogue"), in a room heated to 105 degrees Fahrenheit to simulate Choudhury's native Indian climate.

Evolation Yoga offers several types and styles of yoga, including "hot yoga," which is similar to "Bikram's Basic Yoga System." Evolation acknowledges that hot yoga "includes 26 postures and two breathing exercises and is done for 90 minutes, accompanied by a series of oral instructions, in a room heated to approximately 105 degrees Fahrenheit." [Choudhury sued.]

Though Choudhury emphasizes the aesthetic attributes of the Sequence's "graceful flow," at bottom, the Sequence is an idea, process, or system designed to improve health. Copyright protects only the expression of this idea - the words and pictures used to describe the Sequence - and not the idea of the Sequence itself.

\section{A. The Sequence Is an Unprotectable Idea.}

Following Baker, and recognizing this vital distinction between ideas and expression, courts have routinely held that the copyright for a work describing how to perform a process does not extend to the process itself. In Palmer v. Braun, for example, the Eleventh Circuit held that meditation exercises described in a copyrighted manual on exploring the consciousness were "a process" unentitled to copyright protection. The court explained that the "exercises, while undoubtedly the product of much time and effort, are, at bottom, simply a process for achieving increased consciousness. Such processes, even if original, cannot be protected by copyright."

As Choudhury describes it, the Sequence is a "system" or a "method" designed to "systematically work every part of the body, to give all internal organs, all the veins, all the ligaments, and all the muscles everything they need to maintain optimum health and maximum function. An essential element of this "system" is the order in which the yoga poses and breathing exercises are arranged. BIKRAM's Beginning Yoga Class instructs readers, "Do the poses in the strict order given in this book. Nothing about Bikram's Beginning Yoga Class is haphazard. It is designed to scientifically warm and stretch muscles, ligaments, and tendons in the order in which they should be stretched." For instance, Choudhury explains, "Camel Pose (Ustrasana) stretches the abdomen and compresses the spine; so for the next posture, I chose the Rabbit Pose (Sasangasana), which does the converse: stretches the back and compresses the abdomen."

Choudhury contends that the Sequence's arrangement of postures is "particularly beautiful and graceful." But beauty is not a basis for copyright protection. The performance of many ideas, systems, 
or processes may be beautiful: a surgeon's intricate movements, a book-keeper's careful notations, or a baker's kneading might each possess a certain grace for at least some viewers. Indeed, from Vermeer's milkmaid to Lewis Hine's power house mechanic, the individual engrossed in a process has long attracted artistic attention. But the beauty of the process does not permit one who describes it to gain, through copyright, the monopolistic power to exclude all others from practicing it. This is true even where, as here, the process was conceived with at least some aesthetic considerations in mind. Just as some steps in a recipe may reflect no more than the author's belief that a particular ingredient is beautiful or that a particular cooking technique is impressive to watch and empowering to practice, some elements in Choudhury's Sequence may reflect his aesthetic preferences. Yet just like the recipe, the Sequence remains unprotectable as a process the design of which primarily reflects function, not expression.

\section{B. The Sequence Is Not a Copyrightable Compilation.}

By claiming copyright protection for the Sequence as a compilation, Choudhury misconstrues the scope of copyright protection for compilations. As we have explained, the Sequence is an idea, process, or system; therefore, it is not eligible for copyright protection. That the Sequence may possess many constituent parts does not transform it into a proper subject of copyright protection. Virtually any process or system could be dissected in a similar fashion. Baker's examples of "how-to" treatises are instructive: "A treatise on the construction and use of ploughs, or watches, or churns, or on the mode of drawing lines to produce the effect of perspective" would likely list the steps necessary to perform the process it describes. The watchmaking treatise's author could not claim a copyright in the process of making a watch, however, by breaking down the process into multiple steps and labeling it a "compilation." Likewise, Choudhury cannot obtain copyright protection for the Sequence as a compilation by separately identifying the poses and breathing exercises it contains.

Moreover, according to Choudhury himself, the medical and functional considerations at the heart of the Sequence compel the very selection and arrangement of poses and breathing exercises for which he claims copyright protection. According to Bikram's Beginning Yoga Class, the "strict order" of the poses "is designed to scientifically warm and stretch muscles, ligaments, and tendons in the order in which they should be stretched." Read in the light most favorable to Choudhury, the record demonstrates that the overarching reason for the organization of the poses and breathing exercises in the Sequence is to further the basic goals of the method: to attain "[p]roper weight, muscle tone, glowing complexion, boundless energy, vibrant

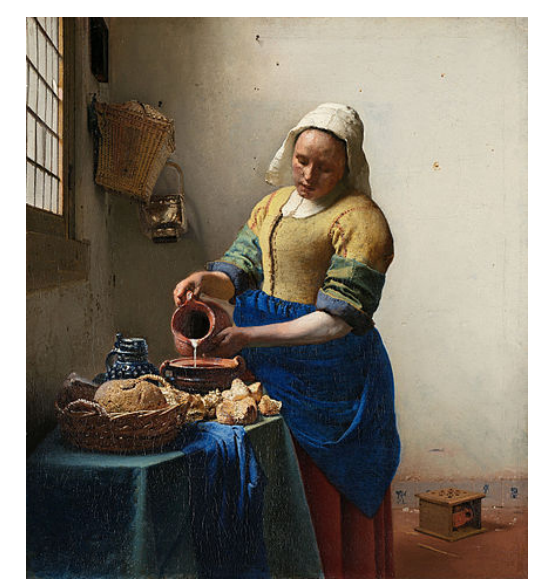

Johannes Vermeer, The Milkmaid

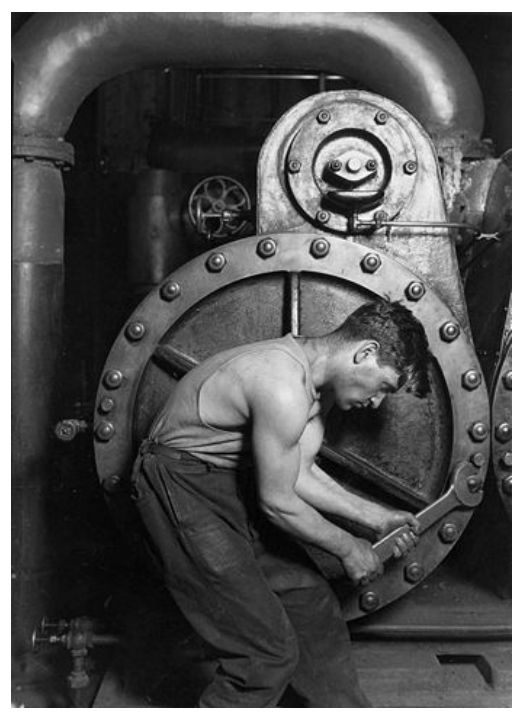

Lewis Hine, Power house mechanic working on steam pump 
Whatever It Takes: 402 F.3d 700, 711-12 (6th Cir. 2005)

Compendium II, S 450.01

"Shake it, shake it like a Polaroid picture."

-OutKast, Hey Ya (LaFace Records 2003) good health, and a sense of well-being." The Sequence's composition renders it more effective as a process or system, but not any more suitable for copyright protection as an original work of authorship.

It makes no difference that similar results could be achieved through a different organization of yoga poses and breathing exercises. Choudhury argues that he could have chosen from "hundreds of postures" and "countless arrangements of these postures" in developing the Sequence. But the possibility of attaining a particular end through multiple different methods does not render the uncopyrightable a proper subject of copyright. See ATC Distribution Group, Inc. v. Whatever It Takes Transmissions \& Parts, Inc. ("To be sure, the publisher of a catalog describing a transmission parts numbering system could have arranged the parts information in other ways that were potentially less clear or useful, but this fact alone is insufficient to demonstrate the creativity necessary for copyright protection."). Though it may be one of many possible yoga sequences capable of attaining similar results, the Sequence is nevertheless a process and is therefore ineligible for copyright protection.

\section{The Sequence Is Not a Copyrightable Choreographic Work.}

The Sequence is not copyrightable as a choreographic work for the same reason that it is not copyrightable as a compilation: it is an idea, process, or system to which copyright protection may "in no case" extend. We recognize that the Sequence may involve "static and kinetic successions of bodily movement in certain rhythmic and spatial relationships.". So too would a method to churn butter or drill for oil. That is no accident: "successions of bodily movement" often serve basic functional purposes. Such movements do not become copyrightable as "choreographic works" when they are part and parcel of a process. Even if the Sequence could fit within some colloquial definitions of dance or choreography, it remains a process ineligible for copyright protection.

Our day-to-day lives consist of many routinized physical movements, from brushing one's teeth to pushing a lawnmower to shaking a Polaroid picture, that could be (and, in two of the preceding examples, have been) characterized as forms of dance. Without a proper understanding of the idea/expression dichotomy, one might obtain monopoly rights over these functional physical sequences by describing them in a tangible medium of expression and labeling them choreographic works.

\section{Conclusion}

Although there is no cause to dispute the many health, fitness, spiritual, and aesthetic benefits of yoga, and Bikram Yoga in particular, they do not bring the Sequence into the realm of copyright protection. 
Concrete Machinery Co. v. Classic Lawn Ornaments

Some ideas admit of only a limited number of expressions. When there is essentially only one way to express an idea, the idea and its expression are inseparable and copyright is no bar to copying that expression. See, e.g., Herbert Rosenthal Jewelry Corp. v. Kalpakian (idea and expression of copyrighted "jeweled bee pin" inseparable and thus copying not prohibited); Morrissey v. Proctor \& Gamble Co. (since few ways to express rules for "sweepstakes," no infringement although defendant's rules only slightly different from plaintiff's rules). When the idea and its expression are not completely inseparable, there may still be only a limited number of ways of expressing the idea. In such a case, the burden of proof is heavy on the plaintiff who may have to show "near identity" between the works at issue. This showing is necessary because, as idea and expression merge, fewer and fewer aspects of a work embody a unique and creative expression of the idea; a copyright holder must then prove substantial similarity to those few aspects of the work that are expression not required by the idea. ...

\section{Cooking for Kids Problem}

Missy Lapine is the author of The Sneaky Chef: Simple Strategies for Hiding Healthy Foods in Kids' Favorite Meals (published 2007), which "presents over 75 recipes that ingeniously disguise the most important superfoods inside kids' favorite meals." Jessica Seinfeld is the author of Deceptively Delicious: Simple Secrets to Get Your Kids Eating Good Food (published 2008), which "is filled with traditional recipes that kids love, except they're stealthily packed with veggies hidden in them so kids don't even know!" Infringement? Are there further facts it would be helpful to know?

\section{B Ownership}

\section{Sheldon v. Metro-Goldwyn Pictures Corp.}

Borrowed the work must indeed not be, for a plagiarist is not himself pro tanto an "author"; but if by some magic a man who had never known it were to compose anew Keats's Ode on a Grecian Urn, he

\footnotetext{
${ }^{7}$ The rationale for this rule, as Judge Aldrich stated, is that "to permit copyrighting [in that case] would mean that a party or parties, by copyrighting a mere handful of forms [of expression], could exhaust all possibilities of future use of the substance ... [and thus] the subject matter would be appropriated by permitting the copyrighting of its expression. We cannot recognize copyright as a game of chess in which the public can be checkmated."
}

843 F.2d 600 (1 st Cir. 1988)

Herbert Rosenthal: 446 F.2d 738 (9th Cir.1971)

Morrissey: 379 F.2d 675 (1st Cir. 1967)

Based on Lapine v. Seinfeld, No. 08cv-128, 2009 WL 2902584 (S.D.N.Y Sept. 10, 2009)

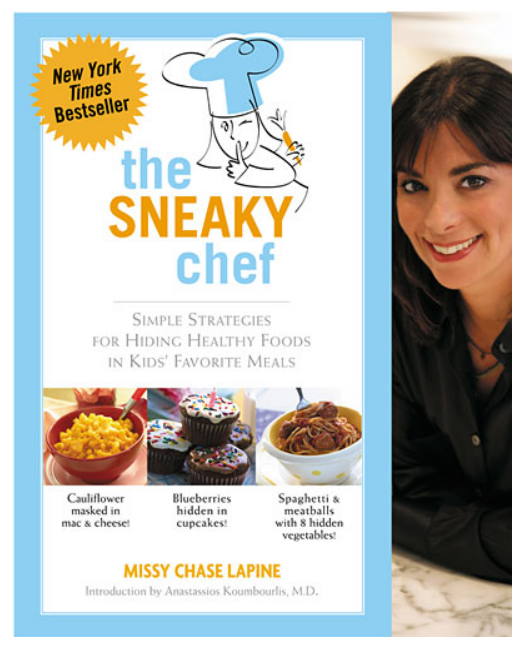

The Sneaky Chef

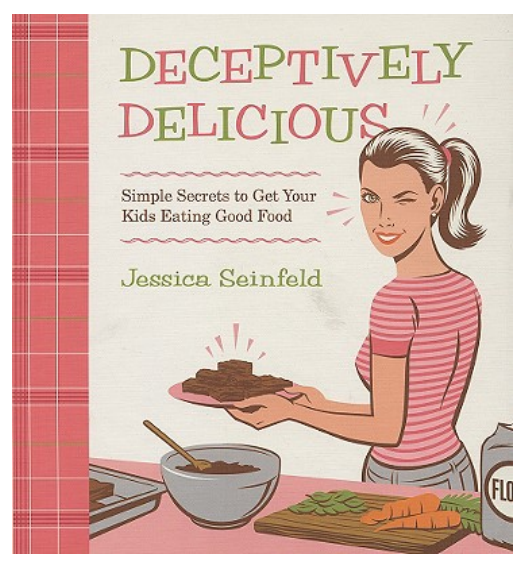

Deceptively Delicious

81 F.2d 49 (2d Cir. 1936)

(Hand, J.) 
Compare: "Pierre Menard did not want to compose another Quixote, which surely is easy enough -- he wanted to compose the Quixote. Nor, surely, need one have to say that his goal was never a mechanical transcription of the original; he had no intention of copying it. His admirable ambition was to produce a number of pages which coincided -word for word and line for line -- with those of Miguel de Cervantes." Jorge Luis Borges, Pierre Menard, Author of the Quixote (1941) (Andrew Hurley trans.).

111 U.S. 53 (1884)

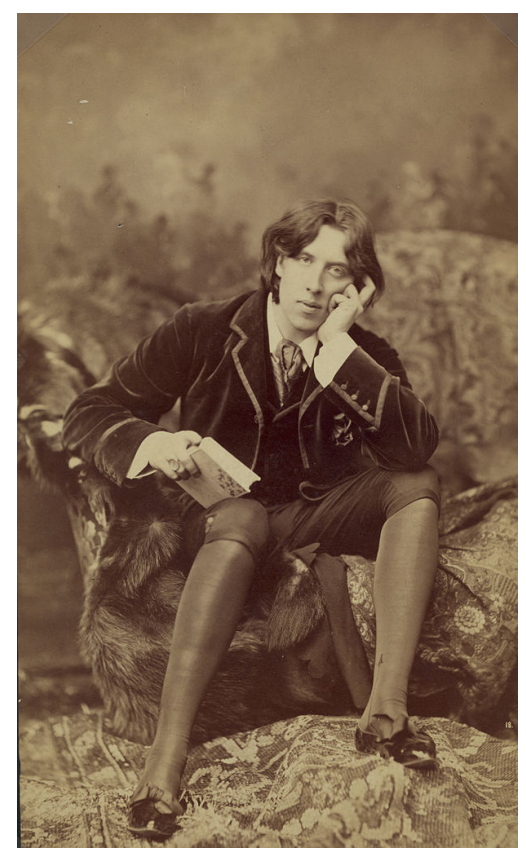

Oscar Wilde No. 18

Napoleon Sarony, 1821-96, was a celebrity photographer: i.e., both a photographer of celebrities and a celebrity in his own right. would be an "author," and, if he copyrighted it, others might not copy that poem, though they might of course copy Keats's.

Because of this rule permitting multiple independent creation, copyright (like trade secret) does not need complicated priority doctrines, as patent and trademark do. The price paid for simplicity here, though, is that copyright (like trade secret) must include proof of copying from the plaintiff as part of its infringement analysis.

Two kinds of issues about initial copyright ownership do arise with some regularity. First, there is the problem of whether certain kinds of allegedly "creative" processes should be regarded as resulting in copyrightable authorship at all. Second, there is the problem of dividing up ownership among multiple parties who do contribute authorship. Copyright slices this problem up along two dimensions: contemporaneous collaborations are addressed as joint works or works made for hire, whereas sequential creation is analyzed in terms of derivative works.

\section{Authorship}

\section{Burrow-Giles Lithographic Co. v. Sarony}

The suit was commenced by an action at law in which Sarony was plaintiff and the lithographic company was defendant, the plaintiff charging the defendant with violating his copyright in regard to a photograph, the title of which is "Oscar Wilde No. 18." A jury being waived, the court made a finding of facts on which a judgment in favor of the plaintiff was rendered for the sum of $\$ 600$ for the plates and 85,000 copies sold and exposed to sale, and $\$ 10$ for copies found in his possession.

The constitutional question is not free from difficulty.

The eighth section of the first article of the Constitution is the great repository of the powers of Congress, and by the eighth clause of that section Congress is authorized:

To promote the progress of science and useful arts, by securing, for limited times to authors and inventors, the exclusive right to their respective writings and discoveries.

It is insisted in argument, that a photograph being a reproduction on paper of the exact features of some natural object or of some person, is not a writing of which the producer is the author.

[The Court reviewed early copyright statutes conferring copyright protection on maps, charts, designs, engravings, etchings, cuts, and other prints.] 
These statutes certainly answer the objection that books only, or writing in the limited sense of a book and its author, are within the constitutional provision. Both these words are susceptible of a more enlarged definition than this. An author in that sense is "he to whom anything owes its origin; originator; maker; one who completes a work of science or literature." Worcester. So, also, no one would now claim that the word writing in this clause of the Constitution, though the only word used as to subjects in regard to which authors are to be secured, is limited to the actual script of the author, and excludes books and all other printed matter. By writings in that clause is meant the literary productions of those authors, and Congress very properly has declared these to include all forms of writing, printing, engraving, etching, \&c., by which the ideas in the mind of the author are given visible expression. The only reason why photographs were not included in the extended list in the act of 1802 is probably that they did not exist, as photography as an art was then unknown, and the scientific principle on which it rests, and the chemicals and machinery by which it is operated, have all been discovered long since that statute was enacted.

But it is said that an engraving, a painting, a print, does embody the intellectual conception of its author, in which there is novelty, invention, originality, and therefore comes within the purpose of the Constitution in securing its exclusive use or sale to its author, while the photograph is the mere mechanical reproduction of the physical features or outlines of some object animate or inanimate, and involves no originality of thought or any novelty in the intellectual operation connected with its visible reproduction in shape of a picture.

The third finding of facts says, in regard to the photograph in question, that it is a "useful, new, harmonious, characteristic, and graceful picture, and that plaintiff made the same ... entirely from his own original mental conception, to which he gave visible form by posing the said Oscar Wilde in front of the camera, selecting and arranging the costume, draperies, and other various accessories in said photograph, arranging the subject so as to present graceful outlines, arranging and disposing the light and shade, suggesting and evoking the desired expression, and from such disposition, arrangement, or representation, made entirely by plaintiff, he produced the picture in suit."

These findings, we think, show this photograph to be an original work of art, the product of plaintiff's intellectual invention, of which plaintiff is the author, and of a class of inventions for which the Constitution intended that Congress should secure to him the exclusive right to use, publish and sell, as it has done by section 4952 of the Revised Statutes. 
Based on Naruto v. Slater, No. 15-cv04324, 2016 WL 362231 (N.D. Cal. Jan. $28,2016)$

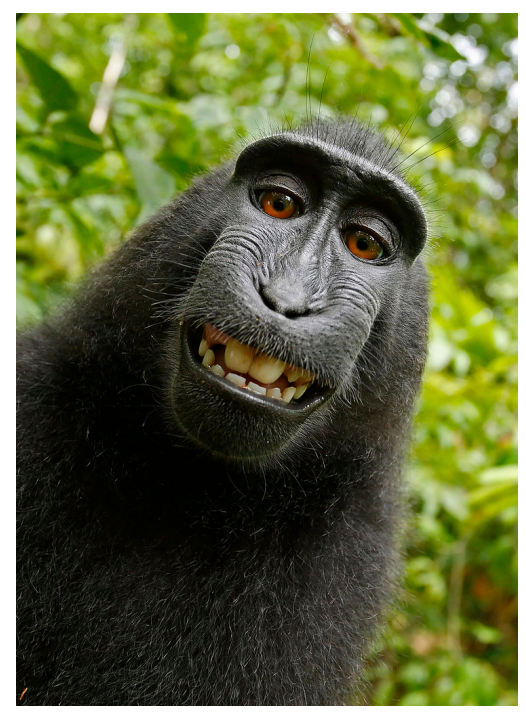

Monkey selfie

17 U.S.C. § 105

Subject matter of copyright: United States Government works

Compare: "There has always been a judicial consensus that no copyright could be secured in the products of the labor done by judicial officers in the discharge of their judicial duties. The whole work done by the judges constitutes the authentic exposition and interpretation of the law, which, binding every citizen, is free for publication to all." Banks v. Manchester, 128 U.S. 244 (1888).

17 U.S.C. § 201

Ownership of copyright

17 U.S.C. § 101

Definitions

\section{Monkey Selfie Problem}

Nature photographer David Slater was traveling in Indonesia when a monkey picked up his camera and pushed the shutter button, resulting in this photograph. Is it copyrightable? If so, who owns the copyright?

Does it matter whether Slater had chosen his camera's settings (e.g., shutter speed, aperture, autofocus) for taking close-up daytime outdoor wildlife photographs? If he was specifically trying to get monkeys to pick up the camera and take selfies? If he took the photograph himself and then falsely passed it off as a monkey selfie?

\section{Copyright Act}

Copyright protection under this title is not available for any work of the United States Government, but the United States Government is not precluded from receiving and holding copyrights transferred to it by assignment, bequest, or otherwise.

\section{Collaborations}

\section{Copyright Act}

(a) Initial Ownership. - Copyright in a work protected under this title vests initially in the author or authors of the work. The authors of a joint work are coowners of copyright in the work.

(b) Works made for hire. - In the case of a work made for hire, the employer or other person for whom the work was prepared is considered the author for purposes of this title, and, unless the parties have expressly agreed otherwise in a written instrument signed by them, owns all of the rights comprised in the copyright.

A "joint work" is a work prepared by two or more authors with the intention that their contributions be merged into inseparable or interdependent parts of a unitary whole.

A "work made for hire" is

(1) a work prepared by an employee within the scope of his or her employment; or

(2) a work specially ordered or commissioned for use as a contribution to a collective work, as a part of a motion picture or other audiovisual work, as a translation, as a supplementary work, as a compilation, as an instructional text, as a test, as answer material for a test, or as an atlas, if the parties expressly agree 
in a written instrument signed by them that the work shall be considered a work made for hire.

Ownership of a copyright, or of any of the exclusive rights under a copyright, is distinct from ownership of any material object in which the work is embodied. Transfer of ownership of any material object, including the copy or phonorecord in which the work is first fixed, does not of itself convey any rights in the copyrighted work embodied in the object; nor, in the absence of an agreement, does transfer of ownership of a copyright or of any exclusive rights under a copyright convey property rights in any material object.

Thomson v. Larson

Plaintiff-appellant Lynn Thomson claims that, along with principal playwright Jonathan Larson, she co-authored a "new version" of the critically acclaimed Broadway musical Rent.

\section{BACKGROUND}

Rent, the Pulitzer Prize and Tony Award-winning Broadway modern musical based on Puccini's opera La Bohème, began in 1989 as the joint project of Billy Aronson and composer Jonathan Larson. Aronson and Larson collaborated on the work until their amicable separation in 1991. At that time, Larson obtained Aronson's permission to develop the play on his own.

In the summer of 1992, Larson's Rent script was favorably received by James Nicola, Artistic Director of the New York Theatre Workshop ("NYTW"), a non-profit theater company in the East Village. Larson continued to develop and revise the "workshop version" of his Rent script. In the spring of 1993, Nicola urged Larson to allow the NYTW to hire a playwright or a bookwriter to help revamp the storyline and narrative structure of the play.

In May 1995, in preparation for Rent's off-Broadway opening scheduled for early 1996, Larson agreed to the NYTW's hiring of Lynn Thomson, a professor of advanced playwrighting at New York University, as a dramaturg ${ }^{6}$ to assist him in clarifying the storyline of the musical. Thomson signed a contract with the NYTW, in which she agreed to provide her services with the workshop production from May 1, 1995, through the press opening, scheduled for early February of 1996. The agreement stated that Thomson's "responsibilities shall include, but not be limited to: Providing dramaturgical assis-

\footnotetext{
${ }^{5}$ Dramaturgs provide a range of services to playwrights and directors in connection with the production and development of theater pieces. According to Thomson's testimony, the role of the dramaturg "can include any number of the elements that go into the crafting of a play," such as "actual plot elements, dramatic structure, character details, themes, and even specific language."
}

17 U.S.C. § 202

Ownership of copyright as distinct from ownership of material object

147 F.3d 195 (2d Cir. 1998) 
tance and research to the playwright and director." In exchange, the NYTW agreed to pay "a fee" of \$2000, "[i]n full consideration of the services to be rendered" and to provide for billing credit for Thomson as "Dramaturg." The Thomson/NYTW agreement was silent as to any copyright interests or any issue of ownership with respect to the final work.

In the summer and fall of 1995, Thomson and Larson worked extremely intensively together on the show. For the most part, the two worked on the script alone in Larson's apartment. Thomson testified that revisions to the text of Rent didn't begin until early August 1995. Larson himself entered all changes directly onto his computer, where he kept the script, and Thomson made no contemporaneous notes of her specific contributions of language or other structural or thematic suggestions. Thomson alludes to the "October Version" of Rent as the culmination of her collaborative efforts with Larson. That new version was characterized by experts as "a radical transformation of the show."

A "sing-through" of the "October Version" of Rent took place in early November 1995. And on November 3, 1995, Larson signed a contract with the NYTW for ongoing revisions to Rent. This agreement identified Larson as the "Author" of Rent and made no reference to Thomson. The contract incorporated by reference an earlier draft author's agreement that set forth the terms that would apply if the NYTW opted to produce Rent. The earlier draft author's agreement gave Larson approval rights over all changes in text, provided that any changes in text would become his property, and assured him billing as "sole author."

The final dress rehearsal was held on January 24, 1996. Just hours after it ended, Larson died suddenly of an aortic aneurysm. Over the next few weeks, Nicola, Greif, Thomson, and musical director Tim Weil worked together to fine-tune the script. The play opened off-Broadway on February 13, 1996, to rave reviews. On February 23, Rent's move to Broadway was announced. Since its opening on Broadway on April 29, 1996, the show has been "an astounding critical, artistic, and commercial success."

Before the Broadway opening, Thomson, in view of her contributions to Rent, sought compensation and title page dramaturgical credit from the Broadway producers. And on April 2, 1996, she signed a contract in which the producers agreed to pay her $\$ 10,000$ plus a nominal $\$ 50 /$ week for her dramaturgical services. Around the same time, upon the producers' advice, Thomson approached Allan S. Larson, Nanette Larson, and Julie Larson McCollum ("Larson Heirs"), the surviving members of Jonathan Larson's family, to request a percentage of the royalties derived from the play. In a letter to the Larson family, dated April 8, 1996, Thomson stated that she 
believed Larson, had he lived, would have offered her a "small percentage of his royalties to acknowledge the contribution I made." In reply, the Larson Heirs offered Thomson a gift of $1 \%$ of the author's royalties. Negotiations between Thomson and the Larson Heirs, however, broke down.

After the parties failed to reach a settlement, Thomson brought suit against the Larson Heirs, claiming that she was a co-author of Rent and that she had never assigned, licensed, or otherwise transferred her rights. Thomson sought declaratory relief and a retroactive and on-going accounting under the Copyright Act. Specifically, she asked that the court declare her a "co-author" of Rent and grant her $16 \%$ of the author's share of the royalties.11

\section{Thomson's Co-Authorship Claim}

The Copyright Act defines a "joint work" as "a work prepared by two or more authors with the intention that their contributions be merged into inseparable or interdependent parts of a unitary whole." 17 U.S.C. $§ 101$ (1994). The touchstone of the statutory definition is the intention at the time the writing is done that the parts be absorbed or combined into an integrated unit.

Joint authorship entitles the co-authors to equal undivided interests in the whole work - in other words, each joint author has the right to use or to license the work as he or she wishes, subject only to the obligation to account to the other joint owner for any profits that are made.

In Childress $v$. Taylor, our court interpreted this section of the Act and set forth "standards for determining when a contributor to a copyrighted work is entitled to be regarded as a joint author" where the parties have failed to sign any written agreement dealing with coauthorship. While the Copyright Act states only that co-authors must intend that their contributions "be merged into ... a unitary whole," Judge Newman explained why a more stringent inquiry than the statutory language would seem to suggest is required:

An inquiry so limited would extend joint author status to many persons who are not likely to have been within the contemplation of Congress. For example, a writer fre-

\footnotetext{
${ }^{11}$ Thomson claims that she seeks $16 \%$ of the proceeds "because of her respect for Larson's role as the principal creator of the work." Thomson derives the $16 \%$ figure in the following way: she alleges that $48 \%$ of the Rent script is new in relation to the 1994 Workshop version (prior to her involvement); as co-author, she is, therefore, entitled to $50 \%$ of this part (or $24 \%$ of the total revenues); but since there are three components to Rent (book, lyrics, and music) and she did not contribute to one (music), she is entitled to $2 / 3$, or $16 \%$ of the total revenues. Thomson also sought the right to quote freely from various versions of Rent in a book that she planned to write.
} 
quently works with an editor who makes numerous useful revisions to the first draft, some of which will consist of additions of copyrightable expression. Both intend their contributions to be merged into inseparable parts of a unitary whole, yet very few editors and even fewer writers would expect the editor to be accorded the status of joint author, enjoying an undivided half interest in the copyright in the published work.

The potential danger of allowing anyone who makes even a minimal contribution to the writing of a work to be deemed a statutory co-author - as long as the two parties intended the contributions to merge - motivated the court to set forth a two-pronged test. A coauthorship claimant bears the burden of establishing that each of the putative co-authors (1) made independently copyrightable contributions to the work; and (2) fully intended to be co-authors.

\section{Independently Copyrightable Contributions}

Childress held that collaboration alone is not sufficient to establish joint authorship. Rather, the contribution of each joint author must be independently copyrightable.

Without making specific findings as to any of Thomson's claims regarding lyrics or other contributions, the district court concluded that Thomson "made at least some non-de minimis copyrightable contribution," and that Thomson's contributions to the Rent libretto were "certainly not zero." Once having said that, the court decided the case on the second Childress prong - mutual intent of coauthorship. It hence did not reach the issue of the individual copyrightability of Thomson's varied alleged contributions (plot developments, thematic elements, character details, and structural components).

\section{Intent of the Parties}

Childress mandates that the parties "entertain in their minds the concept of joint authorship." This requirement of mutual intent recognizes that, since coauthors are afforded equal rights in the coauthored work, the "equal sharing of rights should be reserved for relationships in which all participants fully intend to be joint authors."

Childress and its progeny, however, do not explicitly define the nature of the necessary intent to be co-authors. The court stated that "[i]n many instances, a useful test will be whether, in the absence of contractual arrangements concerning listed authorship, each participant intended that all would be identified as co-authors." But it is also clear that the intention standard is not strictly subjective.

\section{i. Decisionmaking Authority}


An important indicator of authorship is a contributor's decisionmaking authority over what changes are made and what is included in a work. See, e.g., Ericksonv. Trinity Theatre, Inc. (an actor's suggestion of text does not support a claim of co-authorship where the sole author determined whether and where such contributions were included in the work); Maruel $v$. Smith (claimant had a contractual right to control the contents of the opera).

The district court determined that Larson "retained and intended to retain at all times sole decision-making authority as to what went into Rent." In support of its conclusion, the court relied upon Thomson's statement that she was "flattered that [Larson] was asking [her] to contribute actual language to the text" and found that this statement demonstrated that even Thomson understood "that the question whether any contribution she might make would go into the script was within Mr. Larson's sole and complete discretion." Moreover, as the court recognized, the November agreement between Larson and the NYTW expressly stated that Larson had final approval over all changes to Rent and that all such changes would become Larson's property.

\section{ii. Billing}

In discerning how parties viewed themselves in relation to a work, Childress also deemed the way in which the parties bill or credit themselves to be significant. As the district court noted, "billing or credit is ... a window on the mind of the party who is responsible for giving the billing or the credit." And a writer's attribution of the work to herself alone is "persuasive proof ... that she intended this particular piece to represent her own individual authorship" and is "prima facie proof that [the] work was not intended to be joint." Weissmann v. Freeman Thomson claims that Larson's decision to credit her as "dramaturg" on the final page of Rent scripts reflected some coauthorship intent. Thomson concedes that she never sought equal billing with Larson, but argues that she did not need to do so in order to be deemed a statutory co-author.

The district court found, instead, that the billing was unequivocal: Every script brought to [the court's] attention says "Rent, by Jonathan Larson." In addition, Larson "described himself in the biography he submitted for the playbill in January 1996, nine days before he died, as the author/composer, and listed Ms. Thomson on the same document as dramaturg." And while, as Ms. Thomson argues, it may indeed have been highly unusual for an author/composer to credit his dramaturg with a byline, we fail to see how Larson's decision to style her as "dramaturg" on the final page in Rent scripts reflects a co-authorship intent on the part of Larson. The district court properly concluded that "the manner in which [Larson] listed credits on

Weissmann: 868 F.2d 1313 (2d Cir. 1989) 
the scripts strongly supports the view that he regarded himself as the sole author."

\section{iii. Written Agreements with Third Parties}

Just as the parties' written agreements with each other can constitute evidence of whether the parties considered themselves to be coauthors, so the parties' agreements with outsiders also can provide insight into co-authorship intent, albeit to a somewhat more attenuated degree.

The district court found that Larson "listed himself or treated himself as the author in the November 1995 revisions contract that he entered into with the NYTW, which in turn incorporated the earlier draft author's agreement that had not been signed." That agreement identifies Larson as Rent's "Author" and does not mention Thomson. It also incorporates the terms of a September 1995 draft agreement (termed "Author's Agreement") that states that Larson "shall receive billing as sole author." The district court commented, moreover, that "[t]he fact that [Larson] felt free to enter into the November 1995 contract on his own, without the consent of and without any reference to Ms. Thomson quite apart from whatever the terms of the agreements are, indicates that his intention was to be the sole author."

\section{Conclusion}

Based on all of the evidence, the district court concluded that "Mr. Larson never regarded himself as a joint author with Ms. Thomson." We believe that the district court correctly applied the Childress standards to the evidence before it and hold that its finding that Larson never intended co-authorship was not clearly erroneous.

\section{Greene v. Ablon}

Authors who create a joint work co-own the copyright in that work. Joint authors share equal undivided interests in the whole work - in other words, each joint author has the right to use or to license the work as he or she wishes, subject only to the obligation to account to the other joint author for any profits that are made. Even if it is clear that one co-author has contributed more to the work than another co-author, they are nevertheless equal owners of the copyright in the absence of an agreement to the contrary.

A co-owner must account to other co-owners for any profits he earns from licensing or use of the copyright. The duty to account comes from equitable doctrines relating to unjust enrichment and general principles of law governing the rights of co-owners. We acknowledge the theoretical appeal of the notion that if one owner permits free use of the copyright, that owner incurs a debt to his coowner because the use, paid-for or not, partially depletes the value of 
the copyright. However, the duty to account is for profits, not value.

Community for Creative Non-Violence v. Reid

490 U.S. 730 (1989)

I

In the fall of 1985, CCNV decided to participate in the annual Christmastime Pageant of Peace in Washington, D. C., by sponsoring a display to dramatize the plight of the homeless. As the District Court recounted:

"Snyder and fellow CCNV members conceived the idea for the nature of the display: a sculpture of a modern $\mathrm{Na}$ tivity scene in which, in lieu of the traditional Holy Family, the two adult figures and the infant would appear as contemporary homeless people huddled on a streetside steam grate. The family was to be black (most of the homeless in Washington being black); the figures were to be life-sized, and the steam grate would be positioned atop a platform 'pedestal,' or base, within which special-effects equipment would be enclosed to emit simulated 'steam' through the grid to swirl about the figures. They also settled upon a title for the work - 'Third World America' - and a legend for the pedestal: 'and still there is no room at the inn.' "

Snyder made inquiries to locate an artist to produce the sculpture. He was referred to respondent James Earl Reid, a Baltimore, Maryland, sculptor. In the course of two telephone calls, Reid agreed to sculpt the three human figures. CCNV agreed to make the steam grate and pedestal for the statue. Reid proposed that the work be cast in bronze, at a total cost of approximately $\$ 100,000$ and taking six to eight months to complete. Snyder rejected that proposal because CCNV did not have sufficient funds, and because the statue had to be completed by December 12 to be included in the pageant. Reid then suggested, and Snyder agreed, that the sculpture would be made of a material known as "Design Cast 62," a synthetic substance that could meet CCNV's monetary and time constraints, could be tinted to resemble bronze, and could withstand the elements. The parties agreed that the project would cost no more than $\$ 15,000$, not including Reid's services, which he offered to donate. The parties did not sign a written agreement. Neither party mentioned copyright.

After Reid received an advance of \$3,000, he made several sketches of figures in various poses. At Snyder's request, Reid sent CCNV a sketch of a proposed sculpture showing the family in a crechelike setting: the mother seated, cradling a baby in her lap; the father standing behind her, bending over her shoulder to touch the baby's foot. Reid testified that Snyder asked for the sketch to use

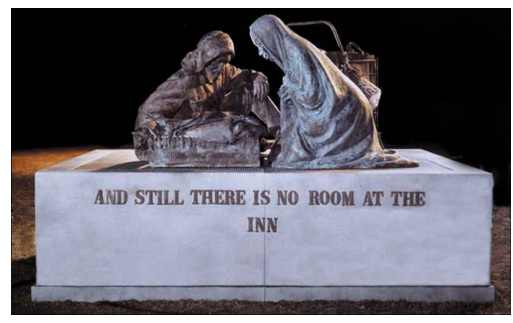

James Earl Reid, Third World America 
in raising funds for the sculpture. Snyder testified that it was also for his approval. Reid sought a black family to serve as a model for the sculpture. Upon Snyder's suggestion, Reid visited a family living at CCNV's Washington shelter but decided that only their newly born child was a suitable model. While Reid was in Washington, Snyder took him to see homeless people living on the streets. Snyder pointed out that they tended to recline on steam grates, rather than sit or stand, in order to warm their bodies. From that time on, Reid's sketches contained only reclining figures.

Throughout November and the first two weeks of December 1985, Reid worked exclusively on the statue, assisted at various times by a dozen different people who were paid with funds provided in installments by CCNV. On a number of occasions, CCNV members visited Reid to check on his progress and to coordinate CCNV's construction of the base. CCNV rejected Reid's proposal to use suitcases or shopping bags to hold the family's personal belongings, insisting instead on a shopping cart. Reid and CCNV members did not discuss copyright ownership on any of these visits.

On December 24, 1985, 12 days after the agreed-upon date, Reid delivered the completed statue to Washington. There it was joined to the steam grate and pedestal prepared by CCNV and placed on display near the site of the pageant. Snyder paid Reid the final installment of the $\$ 15,000$. The statue remained on display for a month. In late January 1986, CCNV members returned it to Reid's studio in Baltimore for minor repairs. Several weeks later, Snyder began making plans to take the statue on a tour of several cities to raise money for the homeless. Reid objected, contending that the Design Cast 62 material was not strong enough to withstand the ambitious itinerary. He urged CCNV to cast the statue in bronze at a cost of $\$ 35,000$, or to create a master mold at a cost of $\$ 5,000$. Snyder declined to spend more of CCNV's money on the project.

In March 1986, Snyder asked Reid to return the sculpture. Reid refused. He then filed a certificate of copyright registration for "Third World America" in his name and announced plans to take the sculpture on a more modest tour than the one CCNV had proposed. Snyder, acting in his capacity as CCNV's trustee, immediately filed a competing certificate of copyright registration.

Snyder and CCNV then commenced this action against Reid.

The Copyright Act of 1976 provides that copyright ownership "vests initially in the author or authors of the work." 17 U. S. C. § 201(a). As a general rule, the author is the party who actually creates the work, 
that is, the person who translates an idea into a fixed, tangible expression entitled to copyright protection. $\S 102$. The Act carves out an important exception, however, for "works made for hire." If the work is for hire, "the employer or other person for whom the work was prepared is considered the author" and owns the copyright, unless there is a written agreement to the contrary. § 201(b). Classifying a work as "made for hire" determines not only the initial ownership of its copyright, but also the copyright's duration, § 302(c), and the owners' renewal rights, $\S 304(\mathrm{a})$, termination rights, $\S 203(\mathrm{a})$, and right to import certain goods bearing the copyright, $\S 601(\mathrm{~b})(1)$. The contours of the work for hire doctrine therefore carry profound significance for freelance creators - including artists, writers, photographers, designers, composers, and computer programmers - and for the publishing, advertising, music, and other industries which commission their works.

The dispositive inquiry in this case therefore is whether "Third World America" is "a work prepared by an employee within the scope of his or her employment" under $\S 101(1)$. The Act does not define these terms. In the absence of such guidance, four interpretations have emerged. The first holds that a work is prepared by an employee whenever the hiring party retains the right to control the product. A second, and closely related, view is that a work is prepared by an employee under $\S 101(1)$ when the hiring party has actually wielded control with respect to the creation of a particular work. A third view is that the term "employee" within § 101(1) carries its common-law agency law meaning. Finally, respondent and numerous amici curiae contend that the term "employee" only refers to "formal, salaried" employees.

Nothing in the text of the work for hire provisions indicates that Congress used the words "employee" and "employment" to describe anything other than the conventional relation of employer and employe. On the contrary, Congress' intent to incorporate the agency law definition is suggested by $\S 101(1)$ 's use of the term, "scope of employment," a widely used term of art in agency law.

We therefore conclude that the language and structure of $\S 101$ of the Act do not support either the right to control the product or the actual control approaches. 8 The structure of $\S 101$ indicates that a

\footnotetext{
${ }^{8} \mathrm{We}$ also reject the suggestion of respondent and amici that the term "employee" refers only to formal, salaried employees. The Act does not say "formal" or "salaried" employee, but simply "employee." Moreover, respondent and those amici who endorse a formal, salaried employee test do not agree upon the content of this test. Compare, e. g., Brief for Respondent 37 (hired party who is on payroll is an employee) with Tr. of Oral Arg. 31 (hired party who receives a salary or commissions regularly is an employee); and Brief for Volunteer Lawyers for the Arts, Inc., et al. as Amici Curiae 4 (hired party who receives a salary and is treated as an
} 
work for hire can arise through one of two mutually exclusive means, one for employees and one for independent contractors, and ordinary canons of statutory interpretation indicate that the classification of a particular hired party should be made with reference to agency law.

In sum, we must reject petitioners' argument. Transforming a commissioned work into a work by an employee on the basis of the hiring party's right to control, or actual control of, the work is inconsistent with the language, structure, and legislative history of the work for hire provisions. To determine whether a work is for hire under the Act, a court first should ascertain, using principles of general common law of agency, whether the work was prepared by an employee or an independent contractor. After making this determination, the court can apply the appropriate subsection of $\S 101$.

\section{$B$}

We turn, finally, to an application of $\S 101$ to Reid's production of “Third World America." In determining whether a hired party is an employee under the general common law of agency, we consider the hiring party's right to control the manner and means by which the product is accomplished. Among the other factors relevant to this inquiry are the skill required; the source of the instrumentalities and tools; the location of the work; the duration of the relationship between the parties; whether the hiring party has the right to assign additional projects to the hired party; the extent of the hired party's discretion over when and how long to work; the method of payment; the hired party's role in hiring and paying assistants; whether the work is part of the regular business of the hiring party; whether the hiring party is in business; the provision of employee benefits; and the tax treatment of the hired party. No one of these factors is determinative.

Examining the circumstances of this case in light of these factors, we agree with the Court of Appeals that Reid was not an employee of CCNV but an independent contractor. True, CCNV members directed enough of Reid's work to ensure that he produced a sculpture that met their specifications. But the extent of control the hiring party exercises over the details of the product is not dispositive. Indeed, all the other circumstances weigh heavily against finding an employment relationship. Reid is a sculptor, a skilled occupation. Reid supplied his own tools. He worked in his own studio in Baltimore, making daily supervision of his activities from Washington practicably impossible. Reid was retained for less than two months, a relatively short period of time. During and after this time, CCNV had no right to assign additional projects to Reid. Apart from the

employee for Social Security and tax purposes is an employee). 
deadline for completing the sculpture, Reid had absolute freedom to decide when and how long to work. CCNV paid Reid $\$ 15,000$, a sum dependent on completion of a specific job, a method by which independent contractors are often compensated. Reid had total discretion in hiring and paying assistants. Creating sculptures was hardly regular business for CCNV. Indeed, CCNV is not a business at all. Finally, CCNV did not pay payroll or Social Security taxes, provide any employee benefits, or contribute to unemployment insurance or workers' compensation funds.

Because Reid was an independent contractor, whether "Third World America" is a work for hire depends on whether it satisfies the terms of $\S 101(2)$. This petitioners concede it cannot do. Thus, CCNV is not the author of "Third World America" by virtue of the work for hire provisions of the Act.

Garcia v. Google, Inc.

In July 2011, Cindy Lee Garcia responded to a casting call for a film titled Desert Warrior, an action-adventure thriller set in ancient Arabia. Garcia was cast in a cameo role, for which she earned $\$ 500$. She received and reviewed a few pages of script. Acting under a professional director hired to oversee production, Garcia spoke two sentences: "Is George crazy? Our daughter is but a child?" Her role was to deliver those lines and to "seem[] concerned."

Garcia later discovered that writer-director Mark Basseley Youssef (a.k.a. Nakoula Basseley Nakoula or Sam Bacile) had a different film in mind: an anti-Islam polemic renamed Innocence of Muslims. The film, featuring a crude production, depicts the Prophet Mohammed as, among other things, a murderer, pedophile, and homosexual. Film producers dubbed over Garcia's lines and replaced them with a voice asking, "Is your Mohammed a child molester?" Garcia appears on screen for only five seconds.

Almost a year after the casting call, in June 2012, Youssef uploaded a 13-minute-and-51-second trailer of Innocence of Muslims to YouTube, the video-sharing website owned by Google, Inc., which boasts a global audience of more than one billion visitors per month. After it was translated into Arabic, the film fomented outrage across the Middle East, and media reports linked it to numerous violent protests. An Egyptian cleric issued a fatwa against anyone associated with Innocence of Muslims, calling upon the "Muslim Youth in America[] and Europe" to "kill the director, the producer[,] and the actors and everyone who helped and promoted this film." Garcia received multiple death threats.

Legal wrangling ensued. Garcia asked Google to remove the film, asserting it was hate speech and violated her state law rights to privacy and to control her likeness. Garcia also sent Google five take-
Is CCNV a joint author?

786 F. 3d 733 (9th Cir. 2015) (en banc) 
down notices under the Digital Millenium Copyright Act, 17 U.S.C. $\S 512$, claiming that YouTube's broadcast of Innocence of Muslims infringed her copyright in her "audio-visual dramatic performance." Google declined to remove the film.

[Garcia sued Google and Youssef for copyright infringement.]

The central question is whether the law and facts clearly favor Garcia's claim to a copyright in her five-second acting performance as it appears in Innocence of Muslims. The answer is no. This conclusion does not mean that a plaintiff like Garcia is without options or that she couldn't have sought an injunction against different parties or on other legal theories, like the right of publicity and defamation.

Innocence of Muslims is an audiovisual work that is categorized as a motion picture and is derivative of the script. Garcia is the author of none of this and makes no copyright claim to the film or to the script. Instead, Garcia claims that her five-second performance itself merits copyright protection.

Garcia's theory of copyright law would result a legal morass splintering a movie into many different "works," even in the absence of an independent fixation. Simply put, as Google claimed, it "make[s] Swiss cheese of copyrights."

Take, for example, films with a large cast - the proverbial "cast of thousands." The silent epic Ben-Hur advertised a cast of 125,000 people. In the Lord of the Rings trilogy, 20,000 extras tramped around Middle-Earth alongside Frodo Baggins (played by Elijah Wood). Treating every acting performance as an independent work would not only be a logistical and financial nightmare, it would turn cast of thousands into a new mantra: copyright of thousands.

The reality is that contracts and the work-made-for-hire doctrine govern much of the big-budget Hollywood performance and production world. Absent these formalities, courts have looked to implied licenses. Indeed, the district court found that Garcia granted Youssef just such an implied license to incorporate her performance into the film. But these legal niceties do not necessarily dictate whether something is protected by copyright, and licensing has its limitations. As filmmakers warn, low-budget films rarely use licenses. Even if filmmakers diligently obtain licenses for everyone on set, the contracts are not a panacea. Third-party content distributors, like YouTube and Netflix, won't have easy access to the licenses; litigants may dispute their terms and scope; and actors and other content contributors can terminate licenses after thirty five years. Untangling the complex, difficult-to-access, and often phantom chain of title to tens, hundreds,

\footnotetext{
${ }^{5}$ Down the road, Garcia also may have a contract claim. She recalls signing some kind of document, though she cannot find a copy. We take no position on this claim.
} 
or even thousands of standalone copyrights is a task that could tie the distribution chain in knots. And filming group scenes like a public parade, or the 1963 March on Washington, would pose a huge burden if each of the thousands of marchers could claim an independent copyright.

\section{Derivative Works}

\section{Copyright Act}

(a) The subject matter of copyright as specified by section 102 includes compilations and derivative works, but protection for a work employing preexisting material in which copyright subsists does not extend to any part of the work in which such material has been used unlawfully.

(b) The copyright in a compilation or derivative work extends only to the material contributed by the author of such work, as distinguished from the preexisting material employed in the work, and does not imply any exclusive right in the preexisting material. The copyright in such work is independent of, and does not affect or enlarge the scope, duration, ownership, or subsistence of, any copyright protection in the preexisting material.

A "compilation" is a work formed by the collection and assembling of preexisting materials or of data that are selected, coordinated, or arranged in such a way that the resulting work as a whole constitutes an original work of authorship. The term "compilation" includes collective works.

A "collective work" is a work, such as a periodical issue, anthology, or encyclopedia, in which a number of contributions, constituting separate and independent works in themselves, are assembled into a collective whole.

A "derivative work" is a work based upon one or more preexisting works, such as a translation, musical arrangement, dramatization, fictionalization, motion picture version, sound recording, art reproduction, abridgment, condensation, or any other form in which a work may be recast, transformed, or adapted. A work consisting of editorial revisions, annotations, elaborations, or other modifications, which, as a whole, represent an original work of authorship, is a "derivative work".

\section{Comics v. Towle}

When a copyright owner authorizes a third party to prepare a derivative work, the owner of the underlying work retains a copyright in
17 U.S.C. § 103

Subject matter of copyright: Compilations and derivative works

17 U.S.C. § 101

Definitions

802 F.3d 1012 (2015)

Towle manufactured and sold replicas of the Batmobiles used in the 1996 television series and the 1989 Tim Burton movie. Because the series and the movie were made under licensing arrangements, the court discussed the scope of derivative-work copyrights. 
that derivative work with respect to all of the elements that the derivative creator drew from the underlying work and employed in the derivative work. By contrast, the creator of the derivative work has a copyright only as to those original aspects of the work that the derivative creator contributed, and only to the extent the derivative creator's contributions are more than trivial. Logically, therefore, if [another] third party copies a derivative work without authorization, it infringes the original copyright owner's copyright in the underlying work to the extent the unauthorized copy of the derivative work also copies the underlying work.

207 F. 3d 402 (7th Cir. 2000)

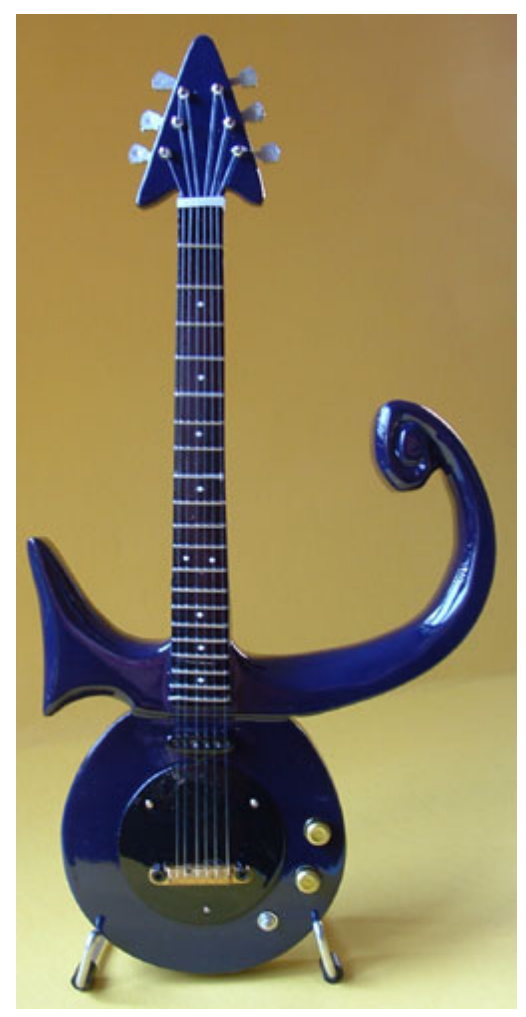

Ferdinand Pickett, Symbol-shaped guitar

\section{Pickett v. Prince}

The defendant, identified only as "Prince" in the caption of the various pleadings, is a well-known popular singer whose name at birth was Prince Rogers Nelson, but who for many years performed under the name Prince (which is what we'll call him) and since 1992 has referred to himself by an unpronounceable symbol. The symbol (which rather strikingly resembles the Egyptian hieroglyph ankh, but the parties make nothing of this, so neither shall we) is his trademark but it is also a copyrighted work of visual art that licensees of Prince have embodied in various forms, including jewelry, clothing, and musical instruments.

In 1993 the plaintiff made a guitar in the shape of the Prince symbol; he concedes that it is a derivative work within the meaning of 17 U.S.C. § 101. The plaintiff claims (truthfully, we assume for purposes of the appeal) to have shown the guitar to Prince. Shortly afterwards Prince appeared in public playing a guitar quite similar to the plaintiff's.

The plaintiff brought this suit for copyright infringement in 1994, but it languished for years in the district court. In January 1997 Prince counterclaimed for infringement of the copyright on his symbol.

Pickett claims the right to copyright a work derivative from another person's copyright without that person's permission and then to sue that person for infringement by the person's own derivative work. Pickett's guitar was a derivative work of the copyrighted Prince symbol, and so was Prince's guitar. Since Prince had (or so we must assume) access to Pickett's guitar, and since the two guitars, being derivatives of the same underlying work, are, naturally, very similar in appearance, Pickett has - if he is correct that one can copyright a derivative work when the original work is copyrighted by someone else who hasn't authorized the maker of the derivative work to copyright it - a prima facie case of infringement. Pickett must, he concedes, show that his derivative work has enough originality to entitle him to a copyright, and also that the copyright is limited to the features that the derivative work adds to the original. But he insists 
that with these limitations his copyright is valid.

We need not pursue the issue of originality of derivative works. The Copyright Act grants the owner of a copyright the exclusive right to prepare derivative works based upon the copyrighted work. So Pickett could not make a derivative work based on the Prince symbol without Prince's authorization even if Pickett's guitar had a smidgeon of originality. This is a sensible result. A derivative work is, by definition, bound to be very similar to the original. Concentrating the right to make derivative works in the owner of the original work prevents what might otherwise be an endless series of infringement suits posing insoluble difficulties of proof. Consider two translations into English of a book originally published in French. The two translations are bound to be very similar and it will be difficult to establish whether they are very similar because one is a copy of the other or because both are copies of the same foreign-language original. Whether Prince's guitar is a copy of his copyrighted symbol or a copy of Pickett's guitar is likewise not a question that the methods of litigation can readily answer with confidence. If anyone can make derivative works based on the Prince symbol, we could have hundreds of Picketts, each charging infringement by the others.

Pickett relies for his implausible theory primarily on section 103(a) of the Copyright Act, which provides that while copyright can be obtained in derivative works, "protection for a work employing preexisting material in which copyright subsists does not extend to any part of the work in which such material has been used unlawfully." Pickett reads this as authorizing a person other than the owner of the original work to make a derivative work, merely forbidding him to infringe the original. It is very difficult to see how a derivative work not made by the owner of the original work could fail to infringe it, given the definition of derivative works.

Pickett relied in the district court on a dictum in Eden Toys, Inc. v. Florelee Undergarment $C_{0}$., that a stranger can make a derivative work without the permission of the owner of the copyright of the original work if the original work does not "pervade" the derivative work. The suggestion, if taken seriously (which it has not been), would inject enormous uncertainty into the law of copyright and undermine the exclusive right that section 106(2) gives the owner of the copyright on the original work. It also rests on a confusion between the determination of whether a work is derivative and the determination of who has the right to make the derivative work. Defined too broadly, "derivative work" would confer enormous power on the owners of copyrights on preexisting works. The BernsteinSondheim musical West Side Story, for example, is based loosely on Shakespeare's Romeo and Juliet, which in turn is based loosely on Ovid's Pyramus and Thisbe, so that if "derivative work" were de-
Eden Toys: 697 F.2d 27 (2d Cir. 1982) 
fined broadly enough (and copyright were perpetual) West Side Story would infringe Pyramus and Thisbe unless authorized by Ovid's heirs. We can thus imagine the notion of pervasiveness being used to distinguish a work fairly described as derivative from works only loosely connected with some ancestral work claimed to be their original. In that sense Prince's symbol clearly "pervades" both guitars. If it did not, the guitars might not be derivative works, but they would not be derivative works that anyone was free to make without obtaining Prince's permission.

809 F.3d 43 (2d Cir. 2015)

\section{Keeling v. Hars}

Plaintiff-Appellee Jaime Keeling is the author of Point Break Live! ("PBL"), a parody stage adaptation of the 1991 Hollywood action movie Point Break, starring Keanu Reeves and Patrick Swayze. In the film, Reeves plays a rookie FBI agent who goes undercover to infiltrate a gang of bank-robbing surfers led by Swayze's character. The Keeling-authored PBL parody parallels the characters and plot elements from Point Break and relies almost exclusively on selected dialogue from the screenplay. To this raw material, Keeling added jokes, props, exaggerated staging, and humorous theatrical devices to transform the dramatic plot and dialogue of the film into an irreverent, interactive theatrical experience. For example, in Keeling's PBL parody, Point Break's death-defying scene in which Reeves's character must pick up bricks, blindfolded, in a swimming pool takes place, instead, in a kiddie pool. Massive waves in the film are replaced by squirt guns in the PBL parody. A central conceit of the PBL parody is that the Keanu Reeves character is selected at random from the audience and reads his lines from cue cards, thereby lampooning Reeves's reputedly stilted performance in the movie. Keeling added to the effect that the audience was watching the making of the film by creating a set of film-production characters in the PBL parody, including a director, cinematographer, and production assistants. Keeling possesses no copyright or license with regard to the Point Break motion picture.

Defendant-Appellant Eve Hars owns production company New Rock Theater Productions, LLC ("New Rock"). In 2007, Keeling executed a production agreement with Hars, pursuant to which New Rock would stage a two-month production run of PBL from October through December 2007. During that time period, Hars conferred with an entertainment attorney and the holder of the copyright to the Hollywood screenplay for Point Break, and eventually Hars came to believe that Keeling did not lawfully own any rights to the PBL parody play. Accordingly, after its initial two-month run, Hars sought to renegotiate the terms of the contract upon its expiration and, in effect, continue to produce PBL without further payment to Keeling. 
Keeling refused renegotiation, threatened suit, and registered a copyright in PBL, without first obtaining permission from the copyright holders of the original Point Break. Keeling's asserted copyright in PBL became effective on January 4, 2008. Hars and New Rock continued to stage performances of PBL for four years thereafter without payment to or authorization from Keeling.

If a work employs preexisting copyrighted material lawfully - as in the case of a "fair use" - nothing in the statute prohibits the extension of the "independent" copyright protection promised by Section 103. A close reading of the statute therefore makes plain that an unauthorized but lawful fair use employing preexisting copyrighted material may itself merit copyright protection. It is not the invocation of fair use that provides the work copyright protection, and perhaps thinking so has created some confusion on the part of the defendant. It is the originality of the derivative work that makes it protectable, and fair use serves only to render lawful the derivative work, such that it may acquire - as would other lawful derivative works - such protection.

\section{Procedures}

Copyright, the statute tells us, subsists as soon as a work is created. The author doesn't need to do anything more to become a copyright owner. But it was not always thus. And this is not to say that copyright has no procedural wrinkles - only that these procedures are not preconditions on copyright protection.

\section{Formalities Then}

\section{Christopher Sprigman \\ Reform(aliz)ing Copyright}

For most of our history, U.S. copyright law has included a system of procedural mechanisms, referred to collectively as "copyright formalities," that helped to maintain copyright's traditional balance between providing private incentives to authors and preserving a robust stock of public domain works from which future creators could draw. From the first copyright statute in 1790, Congress required that authors register their copyrights, give notice (by marking published copies with an indication of copyright status such as the "( $)$ " symbol, as well as other information about copyright ownership), and (perhaps most importantly) renew their rights after a relatively short initial term by reregistering their copyright. Failure to comply with

\footnotetext{
${ }^{7}$ To be sure, the independent copyright protection in the new work is limited to that work's original content.
}

Any who talks about "copyrighting" a work is confused. At best, they are thinking about "registering" the work, which does have several important advantages. At worst, they think that unregistered works are not protected by copyright and may freely be copied. This is wrong, wrong, totally wrong. Correct them.

57 Stan. L. Rev. 485 
these requirements either terminated the copyright (in the case of nonrenewal) or prevented it from arising in the first place.

\section{Estate of Martin Luther King v. CBS, Inc.}

The Estate of Martin Luther King, Jr., Inc. brought this copyright infringement action against CBS, Inc. after CBS produced a video documentary that used, without authorization, portions of civil rights leader Dr. Martin Luther King's famous "I Have a Dream" speech at the March on Washington on August 28, 1963.

On September 30, 1963, approximately one month after the delivery of the Speech, Dr. King took steps to secure federal copyright protection for the Speech under the Copyright Act of 1909, and a certificate of registration of his claim to copyright was issued by the Copyright Office on October 2, 1963. Almost immediately thereafter, Dr. King filed suit in the Southern District of New York to enjoin the unauthorized sale of recordings of the Speech and won a preliminary injunction on December 13, 1963.

Because of the dates of the critical events, the determinative issues in this case are properly analyzed under the Copyright Act of 1909 ("1909 Act"), rather than the Copyright Act of 1976 ("1976 Act") that is currently in effect. The question is whether Dr. King's attempt to obtain statutory copyright protection on September 30, 1963 was effective, or whether it was a nullity because the Speech had already been forfeited to the public domain via a general publication.

Under the regime created by the 1909 Act, an author received state common law protection automatically at the time of creation of a work. This state common law protection persisted until the moment of a general publication. When a general publication occurred, the author either forfeited his work to the public domain, or, if he had therebefore complied with federal statutory requirements, converted his common law copyright into a federal statutory copyright.

In order to soften the hardship of the rule that publication destroys common law rights, courts developed a distinction between a "general publication" and a "limited publication." Only a general publication divested a common law copyright. A general publication occurred when a work was made available to members of the public at large without regard to their identity or what they intended to do with the work. Conversely, a non-divesting limited publication was one that communicated the contents of a work to a select group and for a limited purpose, and without the right of diffusion, reproduction, distribution or sale. The issue before us is whether Dr. King's delivery of the Speech was a general publication.

It appears from the case law that a general publication occurs only in two situations. First, a general publication occurs if tangible copies of the work are distributed to the general public in such 
a manner as allows the public to exercise dominion and control over the work. Second, a general publication may occur if the work is exhibited or displayed in such a manner as to permit unrestricted copying by the general public. See Letter Edged in Black Press, Inc. v. Public Bldg. Comm'n of Chicago (invoking this exception where "there were no restrictions on copying [of a publicly displayed sculpture] and no guards preventing copying" and "every citizen was free to copy the maquette for his own pleasure and camera permits were available to members of the public"). However, the case law indicates that restrictions on copying may be implied, and that express limitations in that regard are deemed unnecessary. See American Tobacco Co. $v$. Werckmeister (holding that there is no general publication where artwork is exhibited and "there are bylaws against copies, or where it is tacitly understood that no copying shall take place, and the public are admitted . . . on the implied understanding that no improper advantage will be taken of the privilege" (emphasis added)); Burke v. National Broadcasting Co. (holding that releasing a film to a professor and host of an educational television program, and authorizing him to copy and broadcast same on public television was a limited publication because the grant of permission to use the film contained an implied condition against distributing copies of the film to others or using it for other purposes); Nutt $v$. National Inst. Incorporated for the Improvement of Memory (lectures were not generally published when delivered because oral delivery is not publication, and "[e]ven where the hearers are allowed to make copies of what was said for their personal use, they cannot later publish for profit that which they had not retained the right to sell").

The case law indicates that distribution to the news media, as opposed to the general public, for the purpose of enabling the reporting of a contemporary newsworthy event, is only a limited publication. This rule comports with common sense; it does not force an author whose message happens to be newsworthy to choose between obtaining news coverage for his work and preserving his common-law copyright.

With the above principles in mind, in the summary judgment posture of this case and on the current state of this record, we are unable to conclude that CBS has demonstrated beyond any genuine issue of material fact that Dr. King, simply through his oral delivery of the Speech, engaged in a general publication making the Speech available to members of the public at large without regard to their identity or what they intended to do with the work. A performance, no matter how broad the audience, is not a publication; to hold otherwise would be to upset a long line of precedent. This conclusion is not altered by the fact that the Speech was broadcast live to a broad radio and television audience and was the subject of extensive con-
Letter Edged in Black: 320 F. Supp. 1303 (N.D. III. 1970)

American Tobacco: 207 U.S. 284 (1907)

Burke: 598 F.2d 688 (1st Cir. 1979)

Nutt: 31 F.2d 236 (2d Cir. 1929) 
13 F. Supp. 2 d 1347 (N.D. Ga. 1998)

This is from the District Court opinion on appeal in the Court of Appeals opinion above. temporaneous news coverage. We follow the above cited case law indicating that release to the news media for contemporary coverage of a newsworthy event is only a limited publication.

\section{Estate of Martin Luther King v. CBS, Inc.}

An advance text of Dr. King's speech was available in the press tent; no copyright notice appeared on the text or was asserted concurrent with the giving of the speech. CBS contends that there were no restrictions regarding entry into the press tent and that individuals outside of the press entered the area and obtained copies of the day's speeches. The Estate argues that Dr. King furnished this advance text for the sole purpose of assisting press coverage of the March and that he had been assured that it would be available only to the press.

Following the March, the SCLC reprinted the speech in its entirety in its September 1963 newsletter with no copyright notice or other restrictions. The newsletter bore Dr. King's name and title as President at the top of its masthead. Generally, the SCLC news-letter had a large national circulation and was also sent to those who asked for copies.

However, material facts are in dispute as to whether the use of Dr. King's speech in the newsletter was authorized and also as to the actual availability of the advance text. Accordingly, for the purposes of summary judgment, this court does not rest its holding upon the newsletter or the advance text but upon the context of Dr. King's speech itself.

\section{Wildman v. New York Times Co.}

This suit arose by reason of a written request sent to defendant's newspaper for the words of the verse "Remember This" by F. Collis Wildman. Several Sundays later in its Queries and Answers page defendant printed the answer to the said request, giving the title, the name of the author and the full text of the verse; followed by "This request was answered by a number of readers, some of whom sent the poem".

Plaintiff claims that this publication in the newspaper without his consent was in derogation of his rights in the copyrighted verse. He wrote it on or about October 4, 1911. Plaintiff applied for a copyright and received the certificate of registration on or about July 3, 1926. On June 23, 1926, he did cause his verse to be printed on a card by a printer in Philadelphia; 3,000 copies of it. At the end of the verse, at the right is the name "F. Collis Wildman". In the lower left corner of card is printed the word "Copyright". Three thousand of these cards, described as above, were sold to the public by the plaintiff.

The law is well settled that the provisions of the statute as to notice must be complied with and by selling a copyrighted article oth- 
erwise there is deication to the public and the copyright protection is lost. Publication with notice of copyright is the essence of compliance with the statute, and publication without proper notice amounts to a dedication to the public sufficient to defeat all subsequent efforts at copyright protection.

With the above principles in mind, I can only come to the conclusion that the plaintiff, when he had printed and sold the cards in June, 1926, dedicated his verse to the public. I can only conclude that there was no sufficient or legal copyright notice attached. There was no date attached. There apparently was no claim of copyright on the printed card by him personally, although this is somewhat questionable in view of the fact that his own name was at the end of the verse. However, he did not comply with the statute; and the alleged notice, if it was intended as a notice of copyright, is insufficient to secure to the plaintiff any right under the copyright registration.

\section{Formalities Now}

Formalities are dramatically less important under contemporary copyright law. The 1976 Copyright Act moderated their impact in some significant ways, and in 1988, the United States joined the international Berne Convention for the Protection of Literary and Artistic Works, which requires that copyright "shall not be subject to any formality." Thus, formalities are important mostly for older works those published before March 1, 1989, when the Berne Convention Implementation Act came into force.

For modern works, the main "formality" is fixation, which is such a thin prerequisite that it is more like the minimal condition required for the legal system to be sure it knows what the copyrighted work even is. But traces of the other formalities remain, and competent copyright practice requires complying with them.

\section{a Fixation}

\section{Compendium of U.S. Copyright Office Practices (3d ed. 2014)}

A work of authorship may be deemed copyrightable, provided that it has been "fixed in any tangible medium of expression, now known or later developed, from which [it] can be perceived, reproduced, or otherwise communicated, either directly or indirectly with the aid of a machine or device." Specifically, the work must be fixed in a copy or phonorecord "by or under the authority of the author" and the work must be "sufficiently permanent or stable to permit it to be perceived, reproduced, or otherwise communicated for a period of more than transitory duration."
But for those works, as the cases above show, the formalities can be vitally important. Copyright due diligence for older works requires a careful investigation of the formalities.

$\S 305$

The Fixation Requirement

17 U.S.C. § 102(a)

17 U.S.C. § 101 
17 U.S.C. § 101

17 U.S.C. § 101
The terms "copy" and "phonorecord" are very broad. They cover all of the material objects in which copyrightable works are capable of being fixed.

- Copies are "material objects, other than phonorecords, in which a work is fixed by any method now known or later developed, and from which the work can be perceived, reproduced, or otherwise communicated, either directly or with the aid of a machine or device," including the material object "in which the work is first fixed."

- Phonorecords are "material objects in which sounds, other than those accompanying a motion picture or other audiovisual work, are fixed by any method now known or later developed, and from which the sounds can be perceived, reproduced, or otherwise communicated, either directly or with the aid of a machine or device," including "the material object in which the sounds are first fixed."

There are countless ways that a work may be fixed in a copy or phonorecord and it makes no difference what the form, manner, or medium of fixation may be. For example, a work may be expressed in words, numbers, notes, sounds, pictures, or any other graphic or symbolic indicia and the author's expression may be fixed in a physical object in written, printed, photographic, sculptural, punched, magnetic, or any other stable form.

Most works are fixed by their very nature, such as an article printed on paper, a song recorded in a digital audio file, a sculpture rendered in bronze, a screenplay saved in a data file, or an audiovisual work captured on film. Nevertheless, some works of authorship may not satisfy the fixation requirement, such as an improvisational speech, sketch, dance, or other performance that is not recorded in a tangible medium of expression. Other works may be temporarily embodied in a tangible form, but may not be sufficiently permanent or stable to warrant copyright protection, such as purely evanescent or transient reproductions such as those projected briefly on a screen, shown electronically on a television, or captured momentarily in the memory of a computer.

The Office rarely encounters works that do not satisfy the fixation requirement because the Office requires applicants to submit copies or phonorecords that contain a visually or aurally perceptible copy of the work. However, the Office may communicate with the applicant or may refuse registration if the work or the medium of expression only exists for a transitory period of time, if the work or the medium is constantly changing, or if the medium does not allow the specific elements of the work to be perceived, reproduced, or otherwise com- 
municated in a consistent and uniform manner.

\section{Stern Electronics, Inc. v. Kaufman}

Video games like "Scramble" can roughly be described as computers programmed to create on a television screen cartoons in which some of the action is controlled by the player. In Stern's "Scramble," for example, the video screen displays a spaceship moving horizontally through six different scenes in which obstacles are encountered. With each scene the player faces increasing difficulty in traversing the course and scoring points. The first scene depicts mountainous terrain, missile bases, and fuel depots. The player controls the altitude and speed of the spaceship, decides when to release the ship's supply of bombs, and fires lasers that can destroy attacking missiles and aircraft. He attempts to bomb the missile bases (scoring points for success), bomb the fuel depots (increasing his own diminishing fuel supply with each hit), avoid the missiles being fired from the ground, and avoid crashing his ship into the mountains. And that is only scene one. In subsequent scenes the hazards include missile-firing enemy aircraft and tunnel-like airspaces. The scenes are in color, and the action is accompanied by battlefield sounds.

The game is built into a cabinet containing a cathode ray tube, a number of electronic circuit boards, a loudspeaker, and hand controls for the player. The electronic circuitry includes memory storage devices called PROMs, an acronym for "programmable read only memory." The PROM stores the instructions and data from a computer program in such a way that when electric current passes through the circuitry, the interaction of the program stored in the PROM with the other components of the game produces the sights and sounds of the audiovisual display that the player sees and hears. The memory devices determine not only the appearance and movement of the images but also the variations in movement in response to the player's operation of the hand controls.

Stern manufactures amusement equipment, including video games, for distribution worldwide. Even in the fast-paced world of video games, "Scramble" quickly became a big success. Approximately 10,000 units were sold at about $\$ 2,000$ each in the first two months for an initial sales volume of about $\$ 20$ million. ...

[Omni was enjoined from distributing its own "Scramble" arcade games. One of its arguments was that Stern's Scramble was not fixed.]

Omni contends that Konami is not entitled to secure a copyright in the sights and sounds of its "Scramble" game because the audiovisual work is neither "fixed in any tangible medium of expression" nor "original" within the meaning of $\S 102(a)$. Both contentions arise from the fact that the sequence of some of the images appearing on the screen during each play of the game will vary depending upon

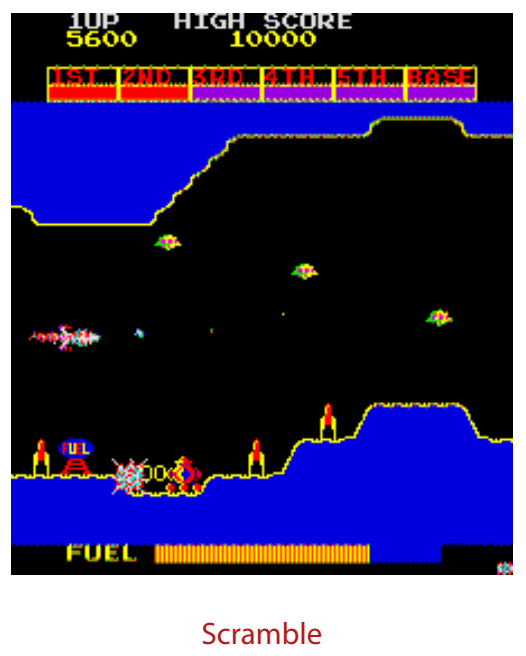


"Audiovisual works' are works that consist of a series of related images which are intrinsically intended to be shown by the use of machines or devices such as projectors, viewers, or electronic equipment, together with accompanying sounds, if any, regardless of the nature of the material objects, such as films or tapes, in which the works are embodied." 17 U.S.C. § 101 the actions taken by the player. For example, if he fails to avoid enemy fire, his spaceship will be destroyed; if he fails to destroy enough fuel depots, his own fuel supply will run out, and his spaceship will crash; if he succeeds in destroying missile sites and enemy planes, those images will disappear from the screen; and the precise course travelled by his spaceship will depend upon his adjustment of the craft's altitude and velocity.

If the content of the audiovisual display were not affected by the participation of the player, there would be no doubt that the display itself, and not merely the written computer program, would be eligible for copyright. The display satisfies the statutory definition of an original "audiovisual work," and the memory devices of the game satisfy the statutory requirement of a "copy" in which the work is "fixed." The audiovisual work is permanently embodied in a material object, the memory devices, from which it can be perceived with the aid of the other components of the game.

We agree with the District Court that the player's participation does not withdraw the audiovisual work from copyright eligibility. No doubt the entire sequence of all the sights and sounds of the game are different each time the game is played, depending upon the route and speed the player selects for his spaceship and the timing and accuracy of his release of his craft's bombs and lasers. Nevertheless, many aspects of the sights and the sequence of their appearance remain constant during each play of the game. These include the appearance (shape, color, and size) of the player's spaceship, the enemy craft, the ground missile bases and fuel depots, and the terrain over which (and beneath which) the player's ship flies, as well as the sequence in which the missile bases, fuel depots, and terrain appears. Also constant are the sounds heard whenever the player successfully destroys an enemy craft or installation or fails to avoid an enemy missile or laser. It is true, as appellants contend, that some of these sights and sounds will not be seen and heard during each play of the game in the event that the player's spaceship is destroyed before the entire course is traversed. But the images remain fixed, capable of being seen and heard each time a player succeeds in keeping his spaceship aloft long enough to permit the appearances of all the images and sounds of a complete play of the game. The repetitive sequence of a substantial portion of the sights and sounds of the game qualifies for copyright protection as an audiovisual work.

\section{Questions}

Which of the following are sufficiently fixed to be copyrightable? In each case where your answer is "yes," identify the material object. 
- A song sung on the sidewalk?

- A song written out as sheet music?

- A song on a CD?

- A diagram on a blackboard?

- A PowerPoint slide?

- A sonnet in your mind?

- A photograph?

- The Fast and the Furious: Tokyo Drift?

- Our class on copyrightable subject matter?

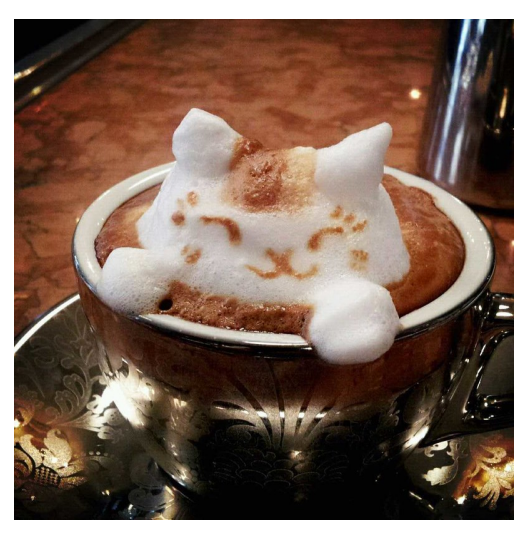

Latte art. Fixed?

\section{Photoshoot Problem}

You represent Shelbyville Stages, a concert promoter. You have booked the eccentric pop musician Plastica for a twelve-city tour in the Northeast. The marketing staff at Shelbyville have recently discovered an image online that they think would be perfect for using on the concert posters. It features Plastica stepping down the landing ramp of a flying saucer, backlit, carrying a pair of cheerleader's pompoms, with a guitar slung over her back, and wearing her trademark disinterested scowl.

A similar photograph was the cover of this month's Them, a celebrity fashion magazine. An unknown party or party unknown, however, extensively Photoshopped it to make it look like a faded, weather-beaten Old West "WANTED" poster. The marketing staff tell you that this was a stroke of genius; the combination of the antique look with the kitschy futuristic technology gives the whole thing what they call a "neo-horsepunk flying-car feel" and the outlaw theme plays off Plastica's expression. Their research has determined that the following people were in some way connected with the image:

- Plastica herself, who has spent years crafting her stage persona, which might be described as "heroin-ravaged all-American girl from outer space."

- Plastica's hair-stylist, Alicia Abt, who produced the complicated multi-layer updo in which she appears in the photograph, with a single side ponytail and a Statute-of-Liberty-style ring of spikes.

- Plastica's personal trainer, Ben Boardwell, who has spent years working with her to develop her musculature to combine strength with a suggestion of wasted potential.

- A celebrity photographer, Charles Carmack, who decided on the flying-saucer theme, chose the placement of props, and instructed Plastica on how to pose. 
- Carmack's salaried assistant, Denyse Dozier, who operated the camera and pushed the button that took the photographs.

- A Photoshop expert, Ernest Eames, who digitally smoothed out the wrinkles in Plastica's face, extended her neck by two inches, and made a hundred other similar tweaks.

- Them magazine, where the modified photograph ran.

- Some unknown person with the username SeePeteyPhotoshop, who added the Old West theme and uploaded the modified photo to the photosharing site AwfulThings.com.

Based on these facts, advise Shelbyville Stages on whether it will be possible to obtain sufficient permissions to use the Old West version of the photo for the concert posters, and, if so how to go about it.

b Registration

\section{Compendium of U.S. Copyright Office Practices (3d ed. 2014)}

$\S 202$

Purposes and Advantages of Registration
Under the current copyright law, a work of authorship is protected by copyright from the moment it is created, provided that the work is original and has been fixed in a tangible medium of expression. Although registration is not required for a work to be protected by copyright, it does provide several important benefits:

- A registration creates a public record that includes key facts relating to the authorship and ownership of the claimed work, as well as information about the work, such as title, year of creation, date of publication (if any), and the type of authorship that the work contains (e.g., photographs, text, sound recordings).

- Registration (or a refusal to register) is a prerequisite to filing a lawsuit for copyright infringement involving a U.S. work. Although registration is permissive, both the certificate and the original work must be on file with the Copyright Office before a copyright owner can sue for infringement.

- To claim statutory damages or attorney's fees in a copyright infringement lawsuit, a work must be registered before the infringement began or within three months after the first publication of the work.

- A registration constitutes prima facie evidence of the validity of the copyright and the facts stated in the certificate of registration, but only if the work is registered before or within five years after the work is first published.

- A registration provides information to prospective licensees, such as the name and address for obtaining permission to use 
the work.

- A document that has been recorded with the U.S. Copyright Office may provide constructive notice of the facts stated therein, but only if the document specifically identifies a work of authorship and only if that work has been registered.

- The deposit copy(ies) submitted with an application for registration of a published work may satisfy the mandatory deposit requirement, provided that the applicant submitted the best edition of the work.

- A registration is necessary to secure the full benefits of a preregistration that has been issued by the U.S. Copyright Office.

- The U.S. Customs and Border Protection Service may seize foreign pirated copies of a copyright owner's work, provided that the work has been registered with the U.S. Copyright Office and the certificate of registration has been recorded with the U.S. Customs and Border Protection Service.

- A registration is required to claim royalties under the compulsory license for making and distributing phonorecords.

\section{Deposit}

\section{Compendium of U.S. Copyright Office Practices (3d ed. 2014)}

The U.S. Copyright Act provides for two separate sets of deposit requirements: deposits submitted in connection with registration applications and those submitted in accordance with the mandatory deposit provisions (or "legal deposit" provisions) of the law. The U.S. Copyright Office administers both sets of provisions.

The Register of Copyrights specifies by regulation the form of deposit that must accompany a copyright claim and registration application. Said regulations reflect and inform the ability of the Office to examine the work for copyrightable authorship, to verify the authorship claimed in the application, and to verify the facts stated in the application. Deposits may also be used for evidentiary purposes in litigation involving a copyrighted work. Since registration is not required as a condition for copyright protection, the Register has the authority to adjust or exempt the deposit requirements as appropriate for certain works or application procedures, weighing the needs or concerns of applicants and the public. Deposits may also be selected by the Library of Congress.

Mandatory deposit is a statutory requirement for the benefit of the national collection of the Library of Congress. The owner of copy-

$\S 1502$

Deposit for Registration Distinguished from Mandatory Deposit 
$\S 1511$

Mandatory Deposit

$\S 2202.2(\mathrm{~A})$

Advantages to Using Notice on PostBerne Works right or the owner of the exclusive right of publication in a work published in the United States must deposit two copies or phonorecords of the work within three months after publication.

In most cases, a deposit submitted for registration may be used to satisfy the mandatory deposit requirement, provided that the applicant submits two complete copies or two complete phonorecords of the best edition of the work. In such cases, there is no need to submit additional copies or phonorecords for the purpose of mandatory deposit.

For some classes of works, the deposit requirements for registration and mandatory deposit are not the same. In such cases, a separate submission of copies, phonorecords, or identifying material may be needed to register the work and to satisfy the mandatory deposit requirements. For example, mandatory deposit for a computer program requires two complete copies of the best edition, while registration may be accomplished with identifying material containing a selection of the source code for that work. In the digital context, such nuance and distinction is even more important, and applicable regulations are therefore subject to change.

Submitting a published work for the use or disposition of the Library is not a condition of copyright protection. However, if compliance with the mandatory deposit requirement is not accomplished within three months of publication, the Register of Copyrights may facilitate, demand, negotiate, or exempt the provision of copies or phonorecords for the Library of Congress at any time after a work has been published in the United States. If the Office issues a written demand and if required copies or phonorecords are not received within three months of receipt of the demand, the copyright owner or owner of the exclusive right of publication in that work may be subject to fines or other monetary liability.

\section{d Notice}

\section{Compendium of U.S. Copyright Office Practices (3d ed. 2014)}

Although notice is optional for unpublished works, foreign works, or works published on or after March 1, 1989, the U.S. Copyright Office strongly encourages copyright owners to use a notice for the following reasons:

- It puts potential users on notice that copyright is claimed in the work.

- In the case of a published work, a notice may prevent a defendant in a copyright infringement action from attempting to limit 
his or her liability for damages or injunctive relief based on an innocent infringement defense.

- It identifies the copyright owner at the time the work was first published for parties seeking permission to use the work.

- It identifies the year of first publication, which may be used to determine the term of copyright protection in the case of an anonymous work, a pseudonymous work, or a work made for hire.

- It may prevent the work from becoming an orphan work by identifying the copyright owner and/or specifying the term of the copyright.

A notice for a work published before March 1, 1989 that has been fixed in copies should include the following elements:

- The symbol (c) or the word "Copyright" or the abbreviation "Copr.";

- The year of first publication for the work; and

- The name of the copyright owner, or an abbreviation by which the name can be recognized, or a generally known alternative designation of the owner.

The elements of the notice should appear as a single continuous statement containing the copyright symbol or the word "Copyright" or the abbreviation "Copr.," followed by the year of first publication, followed by the name of the copyright owner.

Examples:

- (c) 1978 John Doe

- Copyright 1980 John Doe

- Copr. 1982 John Doe

\section{Term}

There is no way around it: copyright terms for older works are a mess and require careful investigation. The details are beyond the scope of this course, but you have been warned.

\section{Copyright Act}

(a) In General. - Copyright in a work created on or after January 1 , 1978 , subsists from its creation and, except as provided by the following subsections, endures for a term consisting of the life of the author and 70 years after the author's death.

(b) Joint Works. - In the case of a joint work prepared by two or more authors who did not work for hire, the copyright endures

17 U.S.C. § 302

Duration of copyright: Works created on or after January 1, 1978
$\S 2204.1$

Notice for Works Fixed in Copies 
17 U.S.C. § 305

Duration of copyright: Terminal date

537 U.S. $186(2003)$ for a term consisting of the life of the last surviving author and 70 years after such last surviving author's death.

(c) Anonymous Works, Pseudonymous Works, and Works Made for Hire. - In the case of an anonymous work, a pseudonymous work, or a work made for hire, the copyright endures for a term of 95 years from the year of its first publication, or a term of 120 years from the year of its creation, whichever expires first. ...

All terms of copyright provided by sections 302 through 304 run to the end of the calendar year in which they would otherwise expire.

\section{Eldred v. Ashcroft}

This case concerns the authority the Constitution assigns to Congress to prescribe the duration of copyrights. In 1998, in the measure here under inspection [the Sonny Bono Copyright Term Extension Act (CTEA)], Congress enlarged the duration of copyrights by 20 years. Petitioners are individuals and businesses whose products or services build on copyrighted works that have gone into the public domain. They seek a determination that the CTEA fails constitutional review under both the Copyright Clause's "limited Times" prescription and the First Amendment's free speech guarantee.

Petitioners do not challenge the "life-plus-70-years" timespan itself. "Whether 50 years is enough, or 70 years too much," they acknowledge, "is not a judgment meet for this Court." Congress went awry, petitioners maintain, not with respect to newly created works, but in enlarging the term for published works with existing copyrights. The "limited Tim[e]" in effect when a copyright is secured, petitioners urge, becomes the constitutional boundary, a clear line beyond the power of Congress to extend.

The Nation's first copyright statute, enacted in 1790, provided a federal copyright term of 14 years from the date of publication, renewable for an additional 14 years if the author survived the first term. The 1790 Act's renewable 14-year term applied to existing works (i. e., works already published and works created but not yet published) and future works alike. Congress expanded the federal copyright term to 42 years in 1831 (28 years from publication, renewable for an additional 14 years), and to 56 years in 1909 (28 years from publication, renewable for an additional 28 years). Both times, Congress applied the new copyright term to existing and future works; to qualify for the 1831 extension, an existing work had to be in its initial copyright term at the time the Act became effective.

In 1976, Congress altered the method for computing federal copyright terms. For works created by identified natural persons, the 1976 
Act provided that federal copyright protection would run from the work's creation, not - as in the 1790, 1831, and 1909 Acts - its publication; protection would last until 50 years after the author's death. In these respects, the 1976 Act aligned United States copyright terms with the then-dominant international standard adopted under the Berne Convention for the Protection of Literary and Artistic Works.

These new copyright terms, the 1976 Act instructed, governed all works not published by its effective date of January 1, 1978, regardless of when the works were created. For published works with existing copyrights as of that date, the 1976 Act granted a copyright term of 75 years from the date of publication, a 19-year increase over the 56-year term applicable under the 1909 Act.

The measure at issue here, the CTEA, installed the fourth major duration extension of federal copyrights. Retaining the general structure of the 1976 Act, the CTEA enlarges the terms of all existing and future copyrights by 20 years. For works created by identified natural persons, the term now lasts from creation until 70 years after the author's death. This standard harmonizes the baseline United States copyright term with the term adopted by the European Union in 1993.

We address first the determination of the courts below that Congress has authority under the Copyright Clause to extend the terms of existing copyrights. The CTEA's baseline term of life plus 70 years, petitioners concede, qualifies as a "limited Tim[e]" as applied to future copyrights. Petitioners contend, however, that existing copyrights extended to endure for that same term are not "limited." Petitioners' argument essentially reads into the text of the Copyright Clause the command that a time prescription, once set, becomes forever "fixed" or "inalterable." The word "limited," however, does not convey a meaning so constricted.

Satisfied that the CTEA complies with the "limited Times" prescription, we turn now to whether it is a rational exercise of the legislative authority conferred by the Copyright Clause. On that point, we defer substantially to Congress. By extending the baseline United States copyright term to life plus 70 years, Congress sought to ensure that American authors would receive the same copyright protection in Europe as their European counterparts. The CTEA may also provide greater incentive for American and other authors to create and disseminate their work in the United States. In addition to international concerns, Congress passed the CTEA in light of demographic, economic, and technological changes and rationally credited projections that longer terms would encourage copyright holders to invest in the restoration and public distribution of their works.

Petitioners separately argue that the CTEA is a content-neutral regulation of speech that fails heightened judicial review under the First Amendment. We reject petitioners' plea for imposition of un- 
commonly strict scrutiny on a copyright scheme that incorporates its own speech-protective purposes and safeguards. In addition to spurring the creation and publication of new expression, copyright law contains built-in First Amendment accommodations. First, it distinguishes between ideas and expression and makes only the latter eligible for copyright protection. Second, the "fair use" defense allows the public to use not only facts and ideas contained in a copyrighted work, but also expression itself in certain circumstances. When, as in this case, Congress has not altered the traditional contours of copyright protection, further First Amendment scrutiny is unnecessary.

\section{Klinger v. Conan Doyle Estate}

Arthur Conan Doyle published his first Sherlock Holmes story in 1887 and his last in 1927. There were 56 stories in all, plus 4 novels. The final 10 stories were published between 1923 and 1927. As a result of statutory extensions of copyright protection culminating in the 1998 Copyright Term Extension Act, the American copyrights on those final stories (copyrights owned by Doyle's estate, the appellant) will not expire until 95 years after the date of original publication between 2018 to 2022, depending on the original publication date of each story. The copyrights on the other 46 stories and the 4 novels, all being works published before 1923, have expired.

Leslie Klinger, the appellee in this case, co-edited an anthology called A Study in Sherlock: Stories Inspired by the Sherlock Holmes Canon (2011). Klinger's anthology consisted of stories written by modern authors but inspired by, and in most instances depicting, the genius detective Sherlock Holmes and his awed sidekick Dr. Watson. Klinger didn't think he needed a license from the Doyle estate to publish these stories, since the copyrights on most of the works in the "canon" had expired. But the estate told Random House, which had agreed to publish Klinger's book, that it would have to pay the estate $\$ 5000$ for a copyright license. Random House bowed to the demand, obtained the license, and published the book.

[Klinger made arrangements to publish a sequel.] Instead of obtaining a license, Klinger sued the estate, seeking a declaratory judgment that he is free to use material in the 50 Sherlock Holmes stories and novels that are no longer under copyright, though he may use nothing in the 10 stories still under copyright that has sufficient originality to be copyrightable.

The issue is whether copyright protection of a fictional character can be extended beyond the expiration of the copyright on it because the author altered the character in a subsequent work. In such a case, the Doyle estate contends, the original character cannot lawfully be copied without a license from the writer until the copyright on the 
later work, in which that character appears in a different form, expires.

We cannot find any basis in statute or case law for extending a copyright beyond its expiration. When a story falls into the public domain, story elements - including characters covered by the expired copyright - become fair game for follow-on authors, as held in Silverman v. CBS Inc., a case much like this one. At issue was the right to copy fictional characters (Amos and Andy) who had appeared in copyrighted radio scripts. The copyrights covered the characters because they were original. As in this case the characters also appeared in subsequent radio scripts that remained under copyright, though the copyrights on the original scripts in which the characters had appeared had expired. The court ruled that "a copyright affords protection only for original works of authorship and, consequently, copyrights in derivative works secure protection only for the incremental additions of originality contributed by the authors of the derivative works."

And so it is in our case. The ten Holmes-Watson stories in which copyright persists are derivative from the earlier stories, so only original elements added in the later stories remain protected. The freedom to make new works based on public domain materials ends where the resulting derivative work comes into conflict with a valid copyright, as Klinger acknowledges. But there is no such conflict in this case.

Lacking any ground known to American law for asserting postexpiration copyright protection of Holmes and Watson in pre-1923 stories and novels going back to 1887, the estate argues that creativity will be discouraged if we don't allow such an extension. It may take a long time for an author to perfect a character or other expressive element that first appeared in his early work. If he loses copyright on the original character, his incentive to improve the character in future work may be diminished because he'll be competing with copiers, such as the authors whom Klinger wishes to anthologize. Of course this point has no application to the present case, Arthur Conan Doyle having died 84 years ago. More important, extending copyright protection is a two-edged sword from the standpoint of inducing creativity, as it would reduce the incentive of subsequent authors to create derivative works (such as new versions of popular fictional characters like Holmes and Watson) by shrinking the public domain. For the longer the copyright term is, the less public-domain material there will be and so the greater will be the cost of authorship, because authors will have to obtain licenses from copyright holders for more material - as illustrated by the estate's demand in this case for a license fee from Pegasus.

Most copyrighted works include some, and often a great deal of, public domain material - words, phrases, data, entire sentences, 
81 F.2d 49 (2nd Cir. 1936)

(Learned Hand, J.)

45 F.2d 119 (2d Cir. 1930)

(Learned Hand, J.) quoted material, and so forth. The smaller the public domain, the more work is involved in the creation of a new work. The defendant's proposed rule would also encourage authors to continue to write stories involving old characters in an effort to prolong copyright protection, rather than encouraging them to create stories with entirely new characters. The effect would be to discourage creativity.

\section{Infringement: Similarity}

This section starts with passages from three classic copyright cases that set out the essential issues in assessing similarity. They are followed by two more recent cases that work through the details in a more concrete setting.

\section{Sheldon v. Metro-Goldwyn Pictures Corp.}

The plaintiffs' originality is necessarily limited to the variants they introduced. Nevertheless, it is still true that their whole contribution may not be protected; for the defendants were entitled to use, not only all that had gone before, but even the plaintiffs' contribution itself, if they drew from it only the more general patterns; that is, if they kept clear of its "expression."

True, much of the picture owes nothing to the play; some of it is plainly drawn from the novel; but that is entirely immaterial; it is enough that substantial parts were lifted; no plagiarist can excuse the wrong by showing how much of his work he did not pirate.

\section{Nichols v. Universal Pictures Corporation}

[The plaintiff's play, Abie's Irish Rose, and the defendant's movie, The Cohens and the Kellys, both concerned the tension between an Irish family and a Jewish family when their children fall in love and marry.]

It is of course essential to any protection of literary property, whether at common-law or under the statute, that the right cannot be limited literally to the text, else a plagiarist would escape by immaterial variations. That has never been the law, but, as soon as literal appropriation ceases to be the test, the whole matter is necessarily at large, so that, as was recently well said by a distinguished judge, the decisions cannot help much in a new case. When plays are concerned, the plagiarist may excise a separate scene or he may appropriate part of the dialogue. Then the question is whether the part so taken is "substantial." It is the same question as arises in the case of any other copyrighted work. But when the plagiarist does not take out a block in situ, but an abstract of the whole, decision is more troublesome. Upon any work, and especially upon a play, a great number of patterns of increasing generality will fit equally well, as more and more 
of the incident is left out. The last may perhaps be no more than the most general statement of what the play is about, and at times might consist only of its title; but there is a point in this series of abstractions where they are no longer protected, since otherwise the playwright could prevent the use of his "ideas," to which, apart from their expression, his property is never extended. Nobody has ever been able to fix that boundary, and nobody ever can. In some cases the question has been treated as though it were analogous to lifting a portion out of the copyrighted work, but the analogy is not a good one, because, though the skeleton is a part of the body, it pervades and supports the whole. In such cases we are rather concerned with the line between expression and what is expressed. As respects plays, the controversy chiefly centers upon the characters and sequence of incident, these being the substance.

But we do not doubt that two plays may correspond in plot closely enough for infringement. How far that correspondence must go is another matter. Nor need we hold that the same may not be true as to the characters, quite independently of the "plot" proper, though, as far as we know, such a case has never arisen. If Twelfth Night were copyrighted, it is quite possible that a second comer might so closely imitate Sir Toby Belch or Malvolio as to infringe, but it would not be enough that for one of his characters he cast a riotous knight who kept wassail to the discomfort of the household, or a vain and foppish steward who became amorous of his mistress. These would be no more than Shakespeare's "ideas" in the play, as little capable of monopoly as Einstein's Doctrine of Relativity, or Darwin's theory of the Origin of Species. It follows that the less developed the characters, the less they can be copyrighted; that is the penalty an author must bear for marking them too indistinctly.

In the two plays at bar we think both as to incident and character, the defendant took no more - assuming that it took anything at all - than the law allowed. The stories are quite different. One is of a religious zealot who insists upon his child's marrying no one outside his faith; opposed by another who is in this respect just like him, and is his foil. Their difference in race is merely an obbligato to the main theme, religion. They sink their differences through grandparental pride and affection. In the other, zealotry is wholly absent; religion does not even appear. It is true that the parents are hostile to each other in part because they differ in race; but the marriage of their son to a Jew does not apparently offend the Irish family at all, and it exacerbates the existing animosity of the Jew, principally because he has become rich, when he learns it. They are reconciled through the honesty of the Jew and the generosity of the Irishman; the grandchild has nothing whatever to do with it. The only matter common to the two is a quarrel between a Jewish and an Irish father, the marriage of 
their children, the birth of grandchildren and a reconciliation.

If the defendant took so much from the plaintiff, it may well have been because her amazing success seemed to prove that this was a subject of enduring popularity. Even so, granting that the plaintiff's play was wholly original, and assuming that novelty is not essential to a copyright, there is no monopoly in such a background. Though the plaintiff discovered the vein, she could not keep it to herself; so defined, the theme was too generalized an abstraction from what she wrote. It was only a part of her "ideas."

Nor does she fare better as to her characters. It is indeed scarcely credible that she should not have been aware of those stock figures, the low comedy Jew and Irishman. The defendant has not taken from her more than their prototypes have contained for many decades. If so, obviously so to generalize her copyright, would allow her to cover what was not original with her. But we need not hold this as matter of fact, much as we might be justified. Even though we take it that she devised her figures out of her brain de novo, still the defendant was within its rights.

We assume that the plaintiff's play is altogether original, even to an extent that in fact it is hard to believe. We assume further that, so far as it has been anticipated by earlier plays of which she knew nothing, that fact is immaterial. Still, as we have already said, her copyright did not cover everything that might be drawn from her play; its content went to some extent into the public domain. We have to decide how much, and while we are as aware as any one that the line, whereever it is drawn, will seem arbitrary, that is no excuse for not drawing it; it is a question such as courts must answer in nearly all cases. Whatever may be the difficulties a priori, we have no question on which side of the line this case falls. A comedy based upon conflicts between Irish and Jews, into which the marriage of their children enters, is no more susceptible of copyright than the outline of Romeo and Juliet.

The plaintiff has prepared an elaborate analysis of the two plays, showing a "quadrangle" of the common characters, in which each is represented by the emotions which he discovers. She presents the resulting parallelism as proof of infringement, but the adjectives employed are so general as to be quite useless. Take for example the attribute of "love" ascribed to both Jews. The plaintiff has depicted her father as deeply attached to his son, who is his hope and joy; not so, the defendant, whose father's conduct is throughout not actuated by any affection for his daughter, and who is merely once overcome for the moment by her distress when he has violently dismissed her lover. "Anger" covers emotions aroused by quite different occasions in each case; so do "anxiety," "despondency" and "disgust." It is unnecessary to go through the catalogue for emotions are too much col- 
ored by their causes to be a test when used so broadly. This is not the proper approach to a solution; it must be more ingenuous, more like that of a spectator, who would rely upon the complex of his impressions of each character.

\section{Arnstein v. Porter}

[The plaintiff, Ira B. Arnstein, alleged that Cole Porter copied numerous songs from him. Arnstein was a serial and vexatious litigant; among his allegations was that Porter "had stooges right along to follow me, watch me, and live in the same apartment with me."]

Assuming that adequate proof is made of copying, that is not enough; for there can be "permissible copying," copying which is not illicit. Whether (if he copied) defendant unlawfully appropriated presents, too, an issue of fact. The proper criterion on that issue is not an analytic or other comparison of the respective musical compositions as they appear on paper or in the judgment of trained musicians. 32 The plaintiff's legally protected interest is not, as such, his reputation as a musician but his interest in the potential financial returns from his compositions which derive from the lay public's approbation of his efforts. The question, therefore, is whether defendant took from plaintiff's works so much of what is pleasing to the ears of lay listeners, who comprise the audience for whom such popular music is composed, that defendant wrongfully appropriated something which belongs to the plaintiff.

Surely, then, we have an issue of fact which a jury is peculiarly fitted to determine. 35

We should not be taken as saying that a plagiarism case can never arise in which absence of similarities is so patent that a summary judgment for defendant would be correct. Thus suppose that Ravel's "Bolero" or Shostakovitch's "Fifth Symphony" were alleged to infringe "When Irish Eyes Are Smiling." But this is not such a case. For, after listening to the playing of the respective compositions, we are, at this time, unable to conclude that the likenesses are so trifling that, on the issue of misappropriation, a trial judge could legitimately direct a verdict for defendant.

At the trial, plaintiff may play, or cause to be played, the pieces in such manner that they may seem to a jury to be inexcusably alike, in terms of the way in which lay listeners of such music would be likely to react. The plaintiff may call witnesses whose testimony may aid the jury in reaching its conclusion as to the responses of such audiences. Expert testimony of musicians may also be received, but it

\footnotetext{
${ }^{32}$ Where plaintiff relies on similarities to prove copying (as distinguished from improper appropriation) paper comparisons and the opinions of experts may aid the court.

${ }^{35}$ It would, accordingly, be proper to exclude tone-deaf persons from the jury.
}

154 F.2d 464 (2d Cir. 1946) 
will in no way be controlling on the issue of illicit copying, and should be utilized only to assist in determining the reactions of lay auditors. The impression made on the refined ears of musical experts or their views as to the musical excellence of plaintiff's or defendant's works are utterly immaterial on the issue of misappropriation; for the views of such persons are caviar to the general - and plaintiff's and defendant's compositions are not caviar.

\section{Children's Book Problem}

You are law clerk to a judge hearing a copyright infringement case. The plaintiff's work is a children's book; the allegedly infringing work is a G-rated animated movie. The plaintiff has offered an expert witness who has made a chart of 83 alleged similarities; the defendant has offered an expert witness who will testify that the book primarily appeals to "verbally oriented" children aged 9-11, while the movie primarily apeals to "visually orented" children aged 6-8.

Will you restrict the jury pool to children? To parents? What special instructions, if any, will you give the jury regarding its task of assessing similarity? Will you allow the plaintiff's expert to testify? The defendant's? If you allow either of them to testify, what will you instruct the jury regarding the relevance of the opinions they offer? How will you allow the parties to present the works to the jury during the trial? Will you allow the jury to have copies of the book and a DVD of the movie with them during deliberations?

\section{Gottlieb Development LLC v. Paramount Pictures}

In the motion picture "What Women Want," released by defendant Paramount Pictures Corporation in 2000, Mel Gibson plays an advertising executive who acquires the ability to "hear" what women are thinking. In one scene, Gibson and his co-star Helen Hunt brainstorm with other employees to develop ideas for marketing certain consumer products to women. At various points during the scene, a pinball machine - the "Silver Slugger" - appears in the background. The Silver Slugger is distributed by plaintiff Gottlieb Development LLC, and Paramount used the pinball machine in the scene without Gottlieb's permission.

The Silver Slugger features three original designs (the "Designs"):

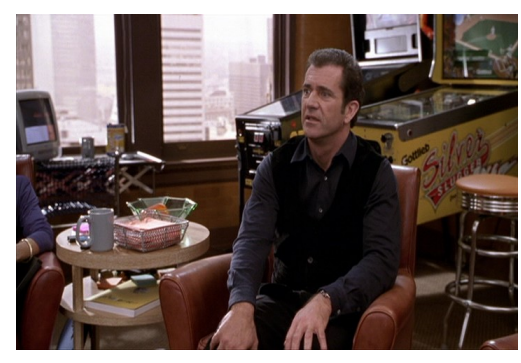

Still from What Women Want (2000)
(1) a depiction of a baseball diamond on the backglass, which is the upright back portion of the pinball machine; (2) another baseball diamond on the playfield, which is the playing surface of the machine; and (3) the layout of the parts of the playfield. The Designs are copyrighted, and Gottlieb has owned the copyrights since 1998.

The legal maxim "de minimis non curat lex" - "the law does not concern itself with trifles" - applies in the copyright context. For example, if the copying is de minimis and so "trivial" as to fall below the 
quantitative threshold of substantial similarity, the copying is not actionable.

There is no plausible claim of copyright infringement here. Although Gottlieb has sufficiently pled unauthorized copying of its Designs, the use of the Silver Slugger was de minimis as a matter of law. Hence, no reasonable juror could find substantial similarity in the legal sense, and thus the copying is not actionable.

The scene in question lasts only three-and-a-half minutes, and the Silver Slugger appears in the scene sporadically, for no more than a few seconds at a time. More importantly, the pinball machine is always in the background; it is never seen in the foreground. It never appears by itself or in a close-up. It is never mentioned and plays no role in the plot. It is almost always partially obscured (by Gibson and pieces of furniture), and is fully visible for only a few seconds during the entire scene. The Designs (on the backglass and playfield of the pinball machine) are never fully visible and are either out of focus or obscured. Indeed, an average observer would not recognize the Designs as anything other than generic designs in a pinball machine.

Gottlieb cites to Ringgold v. Black Entertainment Television, Inc. in support of its claim, but the facts of that case are inapposite. Ringgold involved the unauthorized use of a copyrighted poster in an episode of a HBO television series. The poster was shown, in whole or in part, nine times during a five-minute scene at the end of the episode. The poster (or a portion thereof) was seen for 1.86 to 4.16 seconds at a time, for a total of 26.75 seconds. In some instances, the poster appeared at the center of the screen. As the Second Circuit held, the poster was "plainly observable."

More importantly, there was a qualitative connection between the poster and the show. The poster included a painting depicting a Sunday School picnic held by the Freedom Baptist Church in Atlanta, Georgia, in 1909, and was intended to convey "aspects of the AfricanAmerican experience in the early 1900s." The show was "ROC," a television "sitcom" series about a middle-class African-American family living in Baltimore, and the scene in question was of a gathering in a church hall with a minister. The Second Circuit noted that HBO's production staff "evidently thought that the poster was well suited as a set decoration for the African-American church scene of a ROC episode." The Second Circuit concluded:

From the standpoint of a quantitative assessment of the segments, the principal four-to-five second segment in which almost all of the poster is clearly visible, albeit in less than perfect focus, reenforced by the briefer segments in which smaller portions are visible, all totaling 26 to 27 seconds, are not de minimis copying. The painting compo-
Ringgold: 126 F.3d 70 (2d Cir. 1997)

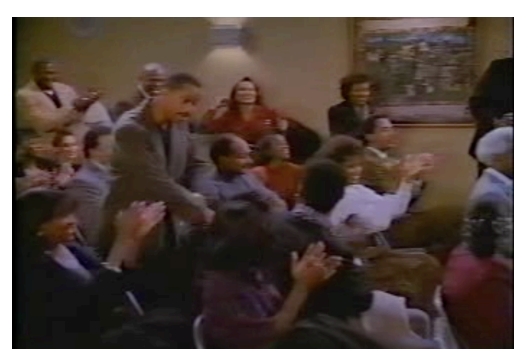

Still from ROC (1992) 
nent of the poster is recognizable as a painting, and with sufficient observable detail for the "average lay observer" to discern African-Americans in Ringold's colorful, virtually two-dimensional style. The de minimis threshold of actionable copying of protected expression has been crossed.

In the present case, the "average lay observer" would not be able to discern any distinctive elements of Gottlieb's Designs - the baseball players clad in stylized, futuristic gear. The best that the average lay observer could make out in the background is a typical home-plate layout with baseball players arrayed around it. The unique expressive element of the Designs is not discernable in those brief moments when the backglass is visible. The only other protected element of the backglass is the "Silver Slugger" logo in the upper left hand corner, which is glimpsed fleetingly, and in poor focus, during the scene. The camera sweeps past the logo without dwelling or focusing on it. The average lay observer would not discern the stylized aspects of the logo attributable to Gottlieb based on the way the logo appears in the background of the scene.

Moreover, while use of a copyrighted work in the background may still be a basis for an infringement claim, where the use is de minimis, the copying will not be actionable, even where the work was chosen to be in the background for some thematic relevance. As the Second Circuit explained in Ringgold, "in some circumstances, a visual work, though selected by production staff for thematic relevance, or at least for its decorative value, might ultimately be filmed at such distance and so out of focus that a typical program viewer would not discern any decorative effect that the work of art contributes to the set." Here, undoubtedly the Silver Slugger was chosen by the production staff because it fit in with the "sporty" theme of the background in the scene; but the Silver Slugger was one of numerous background items, and it was filmed in such a manner and appears so fleetingly that I conclude there is no plausible claim for copyright infringement here. Accordingly, Gottlieb's copyright infringement claim is dismissed.

\section{Boisson v. Banian, Ltd.}

Plaintiffs Judi Boisson and her wholly-owned company, American Country Quilts and Linens, Inc., d/b/a Judi Boisson American Country, brought suit alleging that defendants Vijay Rao and his whollyowned company Banian Ltd., illegally copied two quilt designs.

\section{BACKGROUND}

Judi Boisson has been in the quilt trade for over 20 years, beginning her career by selling antique American quilts - in particular, Amish 
quilts - she purchased in various states throughout the country. By the late 1980s, having difficulty finding antique quilts, she decided to design and manufacture her own and began selling them in 1991 through her company. Boisson published catalogs in 1993 and 1996 to advertise and sell her quilts. Her works are also sold to linen, gift, antique, and children's stores and high-end catalog companies. Various home furnishing magazines have published articles featuring Boisson and her quilts.

In 1991 plaintiff designed and produced two alphabet quilts entitled "School Days I" and "School Days II." Although we later describe the quilts in greater detail, we note each consists of square blocks containing the capital letters of the alphabet, displayed in order. The blocks are set in horizontal rows and vertical columns, with the last row filled by blocks containing various pictures or icons. The letters and blocks are made up of different colors, set off by a white border and colored edging.

Defendant Vijay Rao is the president and sole shareholder of defendant Banian Ltd., incorporated in November 1991. Rao is an electrical engineer in the telecommunications industry who became interested in selling quilts in February 1992. To that end, he imported from India each of the three alphabet quilts at issue in this case. He sold them through boutique stores and catalog companies. The first quilt he ordered was "ABC Green Version I," which he had been shown by a third party. Defendants have not sold this pattern since 1993. "ABC Green Version II" was ordered in September 1994, based upon modifications to "ABC Green Version I" requested by Rao. Defendants reordered this quilt once in April 1995, and then stopped selling it in March 1997. Regarding "ABC Navy," Rao testified that he designed the quilt himself based upon "ABC Green Version II" and imported finished copies in November 1995. Defendants voluntarily withdrew their "ABC Navy" quilts from the market in November 1998 following the initiation of this litigation.

\section{Substantial Similarity: Ordinary Observer v. More}

\section{Discerning ObSERVER}

Generally, an allegedly infringing work is considered substantially similar to a copyrighted work if "the ordinary observer, unless he set out to detect the disparities, would be disposed to overlook them, and regard their aesthetic appeal as the same." Folio Impressions Inc. v. Byer California. Yet in Folio Impressions, the evidence at trial showed the plaintiff designer had copied the background for its fabric from a public domain document and "contributed nothing, not even a trivial variation." Thus, part of the plaintiff's fabric was not original and therefore not protectible. We articulated the need for an ordinary observer to be "more discerning" in such circumstances.

Folio Impressions: 937 F.2d 759 (2d Cir. 1991) 
Key Publications: 945 F.2d 509 (2d Cir. 1991)

Streetwise Maps: 159 F.3d 739 (2d Cir. 1998)

Hamil America: 193 F.3d 92 (2d Cir. 1999)
The ordinary observer would compare the finished product that the fabric designs were intended to grace (women's dresses), and would be inclined to view the entire dress - consisting of protectible and unprotectible elements - as one whole. Here, since only some of the design enjoys copyright protection, the observer's inspection must be more discerning.

We reiterated that a "more refined analysis" is required where a plaintiff's work is not "wholly original," but rather incorporates elements from the public domain. Key Publications, Inc. v. Chinatown Today Publishing Enterprises, Inc.. In these instances, "what must be shown is substantial similarity between those elements, and only those elements, that provide copyrightability to the allegedly infringed compilation." In contrast, where the plaintiff's work contains no material imported from the public domain, the "more discerning" test is unnecessary. In the case at hand, because the alphabet was taken from the public domain, we must apply the "more discerning" ordinary observer test.

In applying this test, a court is not to dissect the works at issue into separate components and compare only the copyrightable elements. To do so would be to take the "more discerning" test to an extreme, which would result in almost nothing being copyrightable because original works broken down into their composite parts would usually be little more than basic unprotectible elements like letters, colors and symbols. This outcome - affording no copyright protection to an original compilation of unprotectible elements - would be contrary to the Supreme Court's holding in Feist.

Although the "more discerning" test has not always been identified by name in our case law, we have nevertheless always recognized that the test is guided by comparing the "total concept and feel" of the contested works. For example, in Streetwise Maps, Inc. v. VanDam, Inc. we found no infringement - not because the plaintiff's map consisted of public domain facts such as street locations, landmasses, bodies of water and landmarks, as well as color - but rather "because the total concept and overall feel created by the two works may not be said to be substantially similar."

In the present case, while use of the alphabet may not provide a basis for infringement, we must compare defendants' quilts and plaintiffs' quilts on the basis of the arrangement and shapes of the letters, the colors chosen to represent the letters and other parts of the quilts, the quilting patterns, the particular icons chosen and their placement. Our analysis of the "total concept and feel" of these works should be instructed by common sense. Cf. Hamil America, Inc. $v$. GFI (noting that the ordinary observer test involves an examination 
of "total concept and feel," which in turn can be guided by "good eyes and common sense").

\section{COMPARISON}

\section{A. "School Days I" v. "ABC Green" Versions}

"School Days I" consists of six horizontal rows, each row containing five blocks, with a capital letter or an icon in each block. The groupings of blocks in each row are as follows: A-E; F-J; K-O; P-T; U-Y; and $\mathrm{Z}$ with four icons following in the last row. The four icons are a cat, a house, a single-starred American flag and a basket. "ABC Green Version I" displays the capital letters of the alphabet in the same formation. The four icons in the last row are a cow jumping over the moon, a sailboat, a bear and a star. "ABC Green Version II" is identical to "ABC Green Version I," except that the picture of the cow jumping over the moon is somewhat altered, the bear is replaced by a teddy bear sitting up and wearing a vest that looks like a singlestarred American flag, and the star in the last block is represented in a different color.

All three quilts use a combination of contrasting solid color fabrics or a combination of solid and polka-dotted fabrics to represent the blocks and letters. The following similarities are observed in plaintiffs' and defendants' designs: " $\mathrm{A}$ " is dark blue on a light blue background; " $\mathrm{B}$ " is red on a white background; " $\mathrm{D}$ " is made of polka-dot fabric on a light blue background; "F" on plaintiffs' "School Days I" is white on a pink background, while the " $\mathrm{F}$ " on defendants" "ABC Green" versions is pink on a white background; " $\mathrm{G}$ " has a green background; " $\mathrm{H}^{\prime \prime}$ and " $\mathrm{L}$ " are each a shade of blue on a white background; " $\mathrm{M}$ " in each quilt is a shade of yellow on a white background. " $\mathrm{N}$ " is green on a white background; " $\mathrm{O}$ " is blue on a polka-dot background; " $\mathrm{P}$ " is polka-dot fabric on a yellow background; " $\mathrm{Q}$ " is brown on a light background; " $R$ " is pink on a gray/purple background. " $S$ " is white on a red background; " $\mathrm{T}$ " is blue on a white background; " $U$ " is gray on a white background; " $\mathrm{V}$ " is white on a gray background; "W" is pink on a white background; " $X$ " is purple in all quilts, albeit in different shades, on a light background; " $Y$ " is a shade of yellow on the same light background; and " $Z$ " is navy blue or black, in all the quilts.

Boisson also testified that defendants utilized the same unique shapes as she had given to the letters "J," " $\mathrm{M}$," " $\mathrm{N}$," "P," "R" and "W." With respect to the quilting patterns, "School Days I" and the "ABC Green" versions feature diamond-shaped quilting within the blocks and a "wavy" pattern in the plain white border that surrounds the blocks. The quilts are also edged with a $3 / 8^{\prime \prime}$ green binding.

From this enormous amount of sameness, we think defendants'

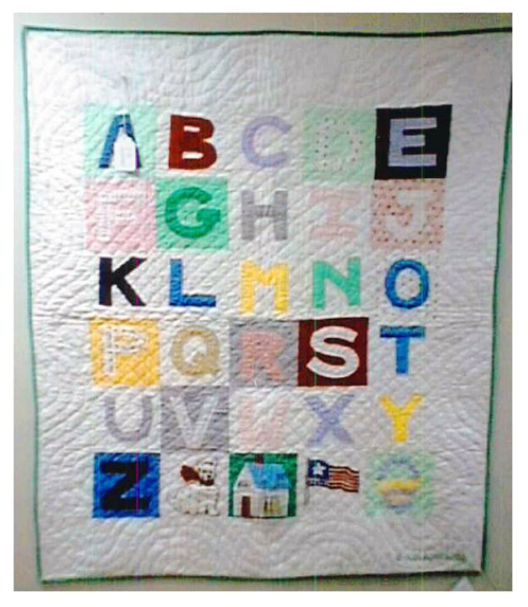

School Days I

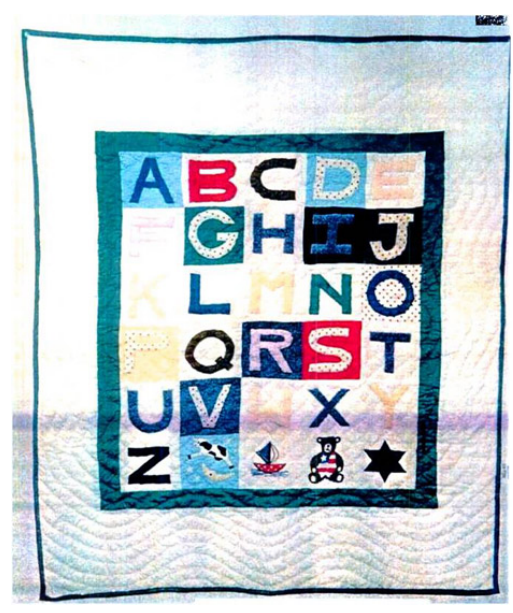

ABC Green 
quilts sufficiently similar to plaintiffs' design as to demonstrate illegal copying. In particular, the overwhelming similarities in color choices lean toward a finding of infringement. Although the icons chosen for each quilt are different and defendants added a green rectangular border around their rows of blocks, these differences are not sufficient to cause even the "more discerning" observer to think the quilts are other than substantially similar insofar as the protectible elements of plaintiffs' quilt are concerned. Moreover, the substitution in "ABC Green Version II" of the teddy bear wearing a flag vest as the third icon causes this version of defendants' quilt to look even more like plaintiffs' quilt that uses a single-starred American flag as its third icon. Consequently, both of defendants' "ABC Green" quilts infringed plaintiffs' copyright on its "School Days I" quilt.

\section{B. "School Days I" v. "ABC Navy"}

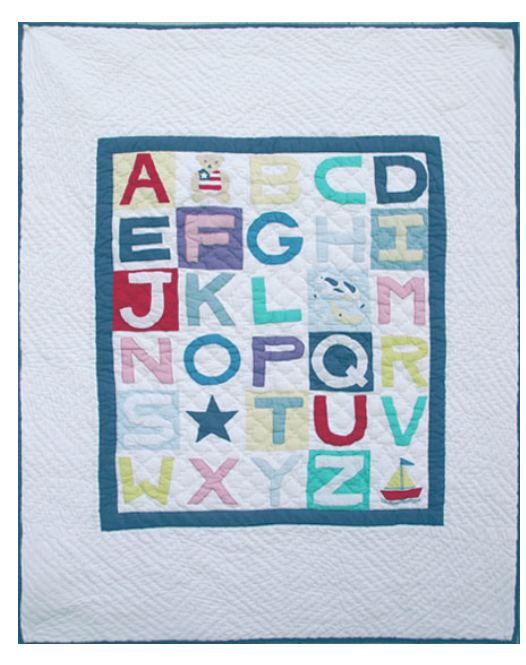

ABC Navy

Based on Steinberg v. Columbia Pictures Industries, Inc., 663 F. Supp. 706 (S.D.N.Y. 1987)
We agree with the district court, however, that Rao did not infringe on plaintiffs' design in "School Days I" when he created "ABC Navy." While both quilts utilize an arrangement of six horizontal rows of five blocks each, "ABC Navy" does not have its four icons in the last row. Rather, the teddy bear with the flag vest is placed after the " $\mathrm{A}$ " in the first row, the cow jumping over the moon is placed after the " $\mathrm{L}$ " in the third row, the star is placed after the " $S$ " in the fifth row, and the sailboat is placed after the " $Z$ " in the last row. Further, the colors chosen to represent the letters and the blocks in "ABC Navy" are, for the most part, entirely different from "School Days I." Defendants dropped the use of polka-dot fabric, and plaintiffs did not even offer a color comparison in their proposed findings of fact to the district court, as they had with each of the "ABC Green" versions. The quilting pattern in the plain white border is changed to a "zig-zag" in "ABC Navy," as opposed to plaintiffs' "wavy" design. Finally, although defendants use a binding around the edge of their quilt, in this instance it is blue instead of green.

Looking at these quilts side-by-side, we conclude they are not substantially similar to one another. Just as we rejected defendants' earlier argument and held that what few differences existed between "School Days I" and the "ABC Green" quilts could not preclude a finding of infringement, plaintiffs' emphasis on the similarity in style between some of the letters between "School Days I" and "ABC Navy" cannot support a finding of infringement. Because no observer, let alone a "more discerning" observer, would likely find the two works to be substantially similar, no copyright violation could properly be found.
New Yorker Problem 
Below you will find a cover from the New Yorker and a poster for the movie Moscow on the Hudson. The copyright owners of the former have sued the producers of the latter for copyright infringement. You are the judge assigned to the case, which you have conducted as a bench trial by the consent of the parties. Write the portion of your opinion finding substantial similarity or the lack thereof. Be as specific as you can.
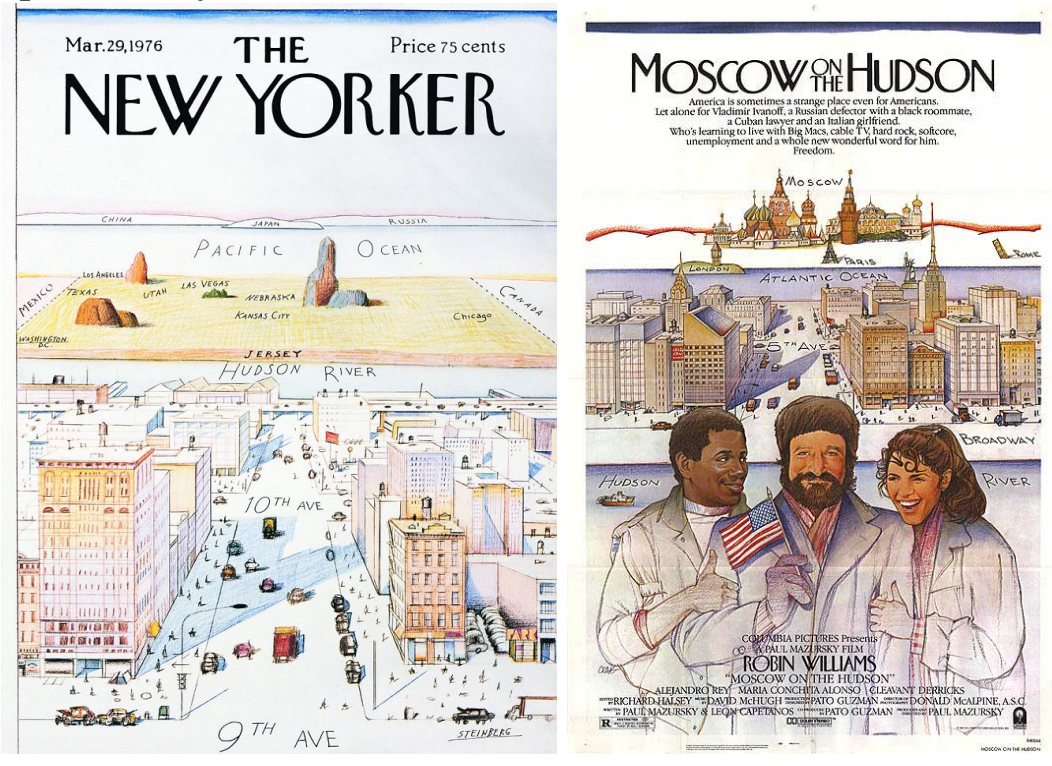

[Ö];:

\section{E Infringement: Prohibited Conduct}

\section{Proof of Copying}

\section{Three Boys Music Corp. v. Bolton}

In 1994, a jury found that Michael Bolton's 1991 pop hit, "Love Is a Wonderful Thing," infringed on the copyright of a 1964 Isley Brothers' song of the same name. The district court denied Bolton's motion for a new trial and affirmed the jury's award of \$5.4 million. Bolton, his co-author, Andrew Goldmark, and their record companies ("Sony Music") appeal.

\section{BACKGROUND}

The Isley Brothers, one of this country's most well-known rhythm and blues groups, have been inducted into the Rock and Roll Hall of Fame. They helped define the soul sound of the 1960s with songs such as "Shout," "Twist and Shout," and "This Old Heart of Mine," and they mastered the funky beats of the 1970s with songs such as "Who's That Lady," "Fight the Power," and "It's Your Thing." In 1964, the Isley Brothers wrote and recorded "Love is a Wonderful Thing" 
"There was nothing wrong with [the name 'Michael Bolton'] until I was about twelve years old and that notalent ass clown became famous and started winning Grammys."

_Office Space (1999)

\footnotetext{
"'Substantial similarity,' while said to be required for indirect proof of copying, is actually required only after copying has been established to show that enough copying has taken place. A similarity, which may or may not be substantial, is probative of copying if, by definition, it is one that under all the circumstances justifies an inference of copying. In order to emphasize the function of such similarity and avoid the confusion of double usage, this Article suggests use of the term probative similarity in place of substantial similarity in this context." Alan Latman, "Probative Similarity" as Proof of Copying: Toward Dispelling Some Myths in Copyright Infringement
}

for United Artists. The Isley Brothers received a copyright for "Love is a Wonderful Thing" from the Register of Copyrights on February 6, 1964.

Hoping to benefit from the Isley Brothers' Motown success, United Artists released "Love is a Wonderful Thing" in 1966. The song was not released on an album, only on a 45-record as a single. Several industry publications predicted that "Love is a Wonderful Thing" would be a hit-"Cash Box" on August 27, 1966, "Gavin Report" on August 26, 1966, and "Billboard" on September 10, 1966. On September 17, 1966, Billboard listed "Love is a Wonderful Thing" at number 110 in a chart titled "Bubbling Under the Hot 100." The song was never listed on any other Top 100 charts. In 1991, the Isley Brothers' "Love is a Wonderful Thing" was released on compact disc.

Michael Bolton is a singer/songwriter who gained popularity in the late 1980s and early 1990s by reviving the soul sound of the 1960s. Bolton has orchestrated this soul-music revival in part by covering old songs such as Percy Sledge's "When a Man Love a Woman" and Otis Redding's "(Sittin' on the) Dock of the Bay." Bolton also has written his own hit songs. In early 1990, Bolton and Goldmark wrote a song called "Love Is a Wonderful Thing." Bolton released it as a single in April 1991, and as part of Bolton's album, "Time, Love and Tenderness." Bolton's "Love Is a Wonderful Thing" finished 1991 at number 49 on Billboard's year-end pop chart.

On February 24, 1992, Three Boys Music Corporation filed a copyright infringement action.

\section{Discussion}

Proof of copyright infringement is often highly circumstantial, particularly in cases involving music. A copyright plaintiff must prove (1) ownership of the copyright; and (2) infringement - that the defendant copied protected elements of the plaintiff's work. Absent direct evidence of copying, proof of infringement involves fact-based showings that the defendant had access to the plaintiff's work and that the two works are substantially similar. Given the difficulty of proving access and substantial similarity, appellate courts have been reluctant to reverse jury verdicts in music cases.

\section{A. Access}

Proof of access requires an opportunity to view or to copy plaintiff's work. This is often described as providing a "reasonable opportunity" or "reasonable possibility" of viewing the plaintiff's work. We have defined reasonable access as "more than a bare possibility." Nimmer has elaborated on our definition: "Of course, reasonable opportunity as here used, does not encompass any bare possibility in the sense that anything is possible. Access may not be inferred 
through mere speculation or conjecture. There must be a reasonable possibility of viewing the plaintiff's work - not a bare possibility." "At times, distinguishing a 'bare' possibility from a 'reasonable' possibility will present a close question."

Circumstantial evidence of reasonable access is proven in one of two ways: (1) a particular chain of events is established between the plaintiff's work and the defendant's access to that work (such as through dealings with a publisher or record company), or (2) the plaintiff's work has been widely disseminated. Goldstein remarks that in music cases the "typically more successful route to proving access requires the plaintiff to show that its work was widely disseminated through sales of sheet music, records, and radio performances." . Nimmer, however, cautioned that "[c]oncrete cases will pose difficult judgments as to where along the access spectrum a given exploitation falls."

Proof of widespread dissemination is sometimes accompanied by a theory that copyright infringement of a popular song was subconscious. Subconscious copying has been accepted since Learned Hand embraced it in a 1924 music infringement case: "Everything registers somewhere in our memories, and no one can tell what may evoke it. Once it appears that another has in fact used the copyright as the source of this production, he has invaded the author's rights. It is no excuse that in so doing his memory has played him a trick." Fred Fisher, Inc. v. Dillingham. In Fred Fisher, Judge Hand found that the similarities between the songs "amount[ed] to identity" and that the infringement had occurred "probably unconsciously, what he had certainly often heard only a short time before."

In modern cases, however, the theory of subconscious copying has been applied to songs that are more remote in time. $A B K C O \mathrm{Mu}-$ sic, Inc. v. Harrisongs Music, Ltd. is the most prominent example. In $A B K C O$, the Second Circuit affirmed a jury's verdict that former Beatle George Harrison, in writing the song "My Sweet Lord," subconsciously copied The Chiffons' "He's So Fine," which was released six years earlier. Harrison admitted hearing "He's So Fine" in 1963, when it was number one on the Billboard charts in the United States for five weeks and one of the top 30 hits in England for seven weeks. The court found: "the evidence, standing alone, by no means compels the conclusion that there was access ... it does not compel the conclusion that there was not." In $A B K C O$, however, the court found that "the similarity was so striking and where access was found, the remoteness of that access provides no basis for reversal." Furthermore, the mere lapse of a considerable period of time between the moment of access and the creation of defendant's work does not preclude a finding of copying.

The Isley Brothers' access argument was based on a theory of
Nimmen \$ 13.02[A]

Goldstein § 8.3.1.1

Nimmen§ 13.02[A]

Fred Fisher: 298 F. 145 (S.D.N.Y. 1924)

ABKCO: 722 F.2d 988 (2d Cir. 1983) 
widespread dissemination and subconscious copying. They presented evidence supporting four principal ways that Bolton and Goldmark could have had access to the Isley Brothers' "Love is a Wonderful Thing":

(1) Bolton grew up listening to groups such as the Isley Brothers and singing their songs. In 1966, Bolton and Goldmark were 13 and 15 , respectively, growing up in Connecticut. Bolton testified that he had been listening to rhythm and blues music by black singers since he was 10 or 11, "appreciated a lot of Black singers," and as a youth was the lead singer in a band that performed "covers" of popular songs by black singers. Bolton also testified that his brother had a "pretty good record collection."

(2) Three disk jockeys testified that the Isley Brothers' song was widely disseminated on radio and television stations where Bolton and Goldmark grew up. First, Jerry Blavitt testified that the Isley Brothers' "Love is a Wonderful Thing" was played five or six times during a 13-week period on the television show, "The Discophonic Scene," which he said aired in Philadelphia, New York, and HartfordNew Haven. Blavitt also testified that he played the song two to three times a week as a disk jockey in Philadelphia and that the station is still playing the song today. Second, Earl Rodney Jones testified that he played the song a minimum of four times a day during an eight to 14 to 24 week period on WVON radio in Chicago, and that the station is still playing the song today. Finally, Jerry Bledsoe testified that he played the song on WUFO radio in Buffalo, and WWRL radio in New York was playing the song in New York in 1967 when he went there. Bledsoe also testified that he played the song twice on a television show, "Soul," which aired in New York and probably in New Haven, Connecticut, where Bolton lived.

(3) Bolton confessed to being a huge fan of the Isley Brothers and a collector of their music. Ronald Isley testified that when Bolton saw Isley at the Lou Rawls United Negro College Fund Benefit concert in 1988, Bolton said, "I know this guy. I go back with him. I have all his stuff." Angela Winbush, Isley's wife, testified about that meeting that Bolton said, "This man needs no introduction. I know everything he's done."

(4) Bolton wondered if he and Goldmark were copying a song by another famous soul singer. Bolton produced a work tape attempting to show that he and Goldmark independently created their version of "Love Is a Wonderful Thing." On that tape of their recording session, Bolton asked Goldmark if the song they were composing was Marvin Gaye's "Some Kind of Wonderful." The district court, in affirming the jury's verdict, wrote about Bolton's Marvin Gaye remark:

This statement suggests that Bolton was contemplating 
the possibility that the work he and Goldmark were creating, or at least a portion of it, belonged to someone else, but that Bolton wasn't sure who it belonged to. A reasonable jury can infer that Bolton mistakenly attributed the work to Marvin Gaye, when in reality Bolton was subconsciously drawing on Plaintiff's song.

The appellants contend that the Isley Brothers' theory of access amounts to a "twenty-five-years-after-the-fact-subconscious copying claim." Indeed, this is a more attenuated case of reasonable access and subconscious copying than $A B K C O$. In this case, the appellants never admitted hearing the Isley Brothers' "Love is a Wonderful Thing." That song never topped the Billboard charts or even made the top 100 for a single week. The song was not released on an album or compact disc until 1991, a year after Bolton and Goldmark wrote their song. Nor did the Isley Brothers ever claim that Bolton's and Goldmark's song is so "strikingly similar" to the Isley Brothers' that proof of access is presumed and need not be proven.

Despite the weaknesses of the Isley Brothers' theory of reasonable access, the appellants had a full opportunity to present their case to the jury. Three rhythm and blues experts (including legendary Motown songwriter Lamont Dozier of Holland-Dozier-Holland fame) testified that they never heard of the Isley Brothers' "Love is a Wonderful Thing." Furthermore, Bolton produced copies of "TV Guide" from 1966 suggesting that the television shows playing the song never aired in Connecticut. Bolton also pointed out that 129 songs called "Love is a Wonderful Thing" are registered with the Copyright Office, 85 of them before 1964.

The Isley Brothers' reasonable access arguments are not without merit. Teenagers are generally avid music listeners. It is entirely plausible that two Connecticut teenagers obsessed with rhythm and blues music could remember an Isley Brothers' song that was played on the radio and television for a few weeks, and subconsciously copy it twenty years later. Furthermore, Ronald Isley testified that when they met, Bolton said, "I have all his stuff." Finally, as the district court pointed out, Bolton's remark about Marvin Gaye and "Some Kind of Wonderful" indicates that Bolton believed he may have been copying someone else's song.

\section{B. Substantial Similarity}

Under our case law, substantial similarity is inextricably linked to the issue of access. In what is known as the "inverse ratio rule," we require a lower standard of proof of substantial similarity when a high degree of access is shown. Furthermore, in the absence of any proof of access, a copyright plaintiff can still make out a case of infringe- 
ment by showing that the songs were "strikingly similar."

\section{Evidence of Substantial Similarity}

Bolton and Goldmark argue that there was insufficient evidence of substantial similarity because the Isley Brothers' expert musicologist, Dr. Gerald Eskelin, failed to show that there was copying of a combination of unprotectible elements. On the contrary, Eskelin testified that the two songs shared a combination of five unprotectible elements: (1) the title hook phrase (including the lyric, rhythm, and pitch); (2) the shifted cadence; (3) the instrumental figures; (4) the verse/chorus relationship; and (5) the fade ending. Although the appellants presented testimony from their own expert musicologist, Anthony Ricigliano, he conceded that there were similarities between the two songs and that he had not found the combination of unprotectible elements in the Isley Brothers' song "anywhere in the prior art." The jury heard testimony from both of these experts and "found infringement based on a unique compilation of those elements." We refuse to interfere with the jury's credibility determination, nor do we find that the jury's finding of substantial similarity was clearly erroneous.

\section{Independent Creation}

Bolton and Goldmark also contend that their witnesses rebutted the Isley Brothers' prima facie case of copyright infringement with evidence of independent creation. By establishing reasonable access and substantial similarity, a copyright plaintiff creates a presumption of copying. The burden shifts to the defendant to rebut that presumption through proof of independent creation.

The appellants' case of independent creation hinges on three factors: the work tape demonstrating how Bolton and Goldmark created their song, Bolton and Goldmark's history of songwriting, and testimony that their arranger, Walter Afanasieff, contributed two of five unprotectible elements that they allegedly copied. The jury, however, heard the testimony of Bolton, Goldmark, Afanasieff, and Ricigliano about independent creation. The work tape revealed evidence that Bolton may have subconsciously copied a song that he believed to be written by Marvin Gaye. Bolton and Goldmark's history of songwriting presents no direct evidence about this case. And Afanasieff's contributions to Bolton and Goldmark's song were described by the appellants' own expert as "very common." Once again, we refuse to disturb the jury's determination about independent creation. The substantial evidence of copying based on access and substantial similarity was such that a reasonable juror could reject this defense.

\section{Inverse-Ratio Rule}


Although this may be a weak case of access and a circumstantial case of substantial similarity, neither issue warrants reversal of the jury's verdict. An amicus brief on behalf of the recording and motion picture industries warns against watering down the requirements for musical copyright infringement. This case presents no such danger. The Ninth Circuit's inverse-ratio rule requires a lesser showing of substantial similarity if there is a strong showing of access. In this case, there was a weak showing of access. We have never held, however, that the inverse ratio rule says a weak showing of access requires a stronger showing of substantial similarity. Nor are we redefining the test of substantial similarity here; we merely find that there was substantial evidence from which the jury could find access and substantial similarity in this case.

\section{Bee Gees Problem}

The plaintiff, Ronald Selle, an amateur musician, recorded a demo tape of his song "Let It End." He performed the song several times with his band in the Chicago area at small local clubs. He sent cassette tapes of the recording to eleven music companies. Eight returned it to him; three never responded. Sometime later, he heard what he thought was his song playing on the radio; it turned out to be "How Deep Is Your Love" by the Bee Gees, which was used on the soundtrack to Saturday Night Fever. Selle sued the Bee Gees and their record company, Polygram.

The Bee Gees were three brothers: Maurice, Robin, and Barry Gibb. They did not read or write music; instead, they composed their songs by playing together in a studio, refining their ideas. In discovery and at trial, they testified that they created "How Deep Is Your Love" during recording sessions at the Chateau d'Herouville near Pontoise, a remote village in France about 25 miles northwest of Paris. Barry Gibb and Blue Weaver, a keyboard player at the sessions, testified that Weaver played a "beautiful chord" at Barry's request, and the two of them refined the idea into a rough "work tape," which was produced in evidence.

Selle provided an musicological analysis of the two songs from Arrand Parsons, a professor of music at Northwestern University. Parsons testified that the first eight bars of each song (Theme A) have twenty-four notes out of thirty-four and forty notes in plaintiff's and defendants' compositions, respectively, that are identical in pitch and symmetrical positions. Out of thirty-five rhythmic impulses in plaintiff's composition and forty in defendants', thirty are identical. In the last four bars of both songs (Theme B), fourteen notes in each are identical in pitch. Of the fourteen rhythmic impulses in Theme B of both songs, eleven are identical. Finally, both Theme A (the first eight bars) and Theme $\mathrm{B}$ (the last four bars) occur in the same position in
Based on Selle v. Gibb, 741 F.2d 896 (7th Cir. 1984) 
each composition. Based on his structural analysis of the two songs, coupled with his detailed analysis of the melodies of Themes A and $\mathrm{B}$ in both of them, Mr. Parsons gave his opinion that the two songs could not have been independently created.

Maurice Gibb was then called by the plaintiff as an adverse party witness. The opening melody from one of the songs was played for him. He identified it as "How Deep Is Your Love." Counsel for the plaintiff then read a stipulation of the parties that the music which had been played to Maurice Gibb was "the melody of Theme B, the first two phrases of Ronald Selle's 'Let It End."' Plaintiff rested his case in chief. Defendants did not call an expert witness to testify.

The jury returned a general verdict of infringement in favor of the plaintiff, Selle, but the District Court judge entered judgment notwithstanding the verdict for the defendants, and the Court of Appeals affirmed. Who was right: the jury or the judges? You may, if you want, listen to the plaintiff's and defendants' songs. (Should you?)

\section{Direct Infringement}

\section{Copyright Act}

17 U.S.C. § 106

Exclusive rights in copyrighted works
17 U.S.C. § 101

Definitions
Subject to sections 107 through 122, the owner of copyright under this title has the exclusive rights to do and to authorize any of the following:

(1) to reproduce the copyrighted work in copies or phonorecords;

(2) to prepare derivative works based upon the copyrighted work;

(3) to distribute copies or phonorecords of the copyrighted work to the public by sale or other transfer of ownership, or by rental, lease, or lending;

(4) in the case of literary, musical, dramatic, and choreographic works, pantomimes, and motion pictures and other audiovisual works, to perform the copyrighted work publicly;

(5) in the case of literary, musical, dramatic, and choreographic works, pantomimes, and pictorial, graphic, or sculptural works, including the individual images of a motion picture or other audiovisual work, to display the copyrighted work publicly;

"Copies" are material objects, other than phonorecords, in which a work is fixed by any method now known or later developed, and from which the work can be perceived, reproduced, or otherwise communicated, either directly or with the aid of a machine or device. The term "copies" includes the material object, other than a phonorecord, in which the work is first fixed. 
To "display" a work means to show a copy of it, either directly or by means of a film, slide, television image, or any other device or process or, in the case of a motion picture or other audiovisual work, to show individual images nonsequentially.

To "perform" a work means to recite, render, play, dance, or act it, either directly or by means of any device or process or, in the case of a motion picture or other audiovisual work, to show its images in any sequence or to make the sounds accompanying it audible.

\section{Capitol Records, LLC v. ReDigi Inc.}

ReDigi markets itself as "the world's first and only online marketplace for digital used music." To sell music on ReDigi's website, a user must first download ReDigi's "Media Manager" to his computer. Once installed, Media Manager analyzes the user's computer to build a list of digital music files eligible for sale.

After the list is built, a user may upload any of his eligible files to ReDigi's "Cloud Locker," an ethereal moniker for what is, in fact, merely a remote server in Arizona. ReDigi asserts that the process involves "migrating" a user's file, packet by packet - "analogous to a train" - from the user's computer to the Cloud Locker so that data does not exist in two places at any one time. Capitol asserts that, semantics aside, ReDigi's upload process "necessarily involves copying" a file from the user's computer to the Cloud Locker. Regardless, at the end of the process, the digital music file is located in the Cloud Locker and not on the user's computer. Moreover, Media Manager deletes any additional copies of the file on the user's computer and connected devices.

If ReDigi determines that the file has not been tampered with or offered for sale by another user, the file is stored in the Cloud Locker, and the user is given the option of simply storing and streaming the file for personal use or offering it for sale in Re-Digi's marketplace. If a user chooses to sell his digital music file, his access to the file is terminated and transferred to the new owner at the time of purchase. Thereafter, the new owner can store the file in the Cloud Locker, stream it, sell it, or download it to her computer and other devices.

\section{Reproduction Rights}

Courts have consistently held that the unauthorized duplication of digital music files over the Internet infringes a copyright owner's exclusive right to reproduce. However, courts have not previously addressed whether the unauthorized transfer of a digital music file over the Internet - where only one file exists before and after the transfer - constitutes reproduction within the meaning of the Copyright Act. The Court holds that it does. 
C.M. Paula: 355 F. Supp. 189 (N.D. Tex. 1973)

Courts are split on whether this process infringes the adaptation right. CompareMirage Editions, Inc. v. Albuquerque ART Co., 856 F.2d 1341 (9th Cir. 1988) (yes), withLee v. A.R.T. Co., 125 F.3d 580 (7th Cir. 1997) (no).

London-Sire: 542 F. Supp. 2d 153 (D. Mass 2008)

Gruebel: 453 F. Supp. 2d 961 (N.D. Tex. 2006)
ReDigi stresses that it "migrates" a file from a user's computer to its Cloud Locker, so that the same file is transferred to the ReDigi server and no copying occurs. However, even if that were the case, the fact that a file has moved from one material object - the user's computer - to another - the ReDigi server - means that a reproduction has occurred. Similarly, when a ReDigi user downloads a new purchase from the ReDigi website to her computer, yet another reproduction is created. It is beside the point that the original phonorecord no longer exists. It matters only that a new phonorecord has been created.

ReDigi struggles to avoid this conclusion by pointing to C.M. Paula Co. v. Logan, where the defendant used chemicals to lift images off of greeting cards and place them on plaques for resale. The court determined that infringement did not occur because "should defendant desire to make one hundred ceramic plaques, defendant would be required to purchase one hundred separate prints." ReDigi argues that, like the defendant in C.M. Paula, its users must purchase a song on iTunes in order to sell a song on ReDigi. Therefore, no "duplication" occurs. ReDigi's argument is unavailing. Ignoring the questionable merits of the court's holding in C.M. Paula, ReDigi's service is distinguishable from the process in that case. There, the copyrighted print, or material object, was lifted from the greeting card and transferred in toto to the ceramic tile; no new material object was created. By contrast, ReDigi's service by necessity creates a new material object when a digital music file is either uploaded to or downloaded from the Cloud Locker.

\section{Distribution Rights}

Like the court in London-Sire Records, Inc. v. John Doe 1, the Court agrees that "an electronic file transfer is plainly within the sort of transaction that $\S 106(3)$ was intended to reach and fits within the definition of 'distribution' of a phonorecord." For that reason, "courts have not hesitated to find copyright infringement by distribution in cases of file-sharing or electronic transmission of copyrighted works." Arista Records LLC v. Greubel (collecting cases).

There is no dispute that sales occurred on ReDigi's website. Capitol has established that it was able to buy more than one-hundred of its own recordings on ReDigi's webite, and ReDigi itself compiled a list of its completed sales of Capitol's recordings. ReDigi, in fact, does not contest that distribution occurs on its website-it only asserts that the distribution is protected by the fair use and first sale defenses.

\section{Performance and Display Rights}

Audio streams are performances because a stream is an electronic transmission that renders the musical work audible as it is received 
by the client-computer's temporary memory. This transmission, like a television or radio broadcast, is a performance because there is a playing of the song that is perceived simultaneously with the transmission.

Public display includes "show[ing] a copy of [a work], either directly or by means of a film, slide, television image, or any other device or process." The Ninth Circuit has held that the display of a photographic image on a computer may implicate the display right, though infringement hinges, in part, on where the image was hosted.

Capitol alleges that ReDigi infringed its copyrights by streaming thirty-second song clips and exhibiting album cover art to potential buyers. ReDigi counters that it only posted such content pursuant to a licensing agreement and within the terms of that agreement. ReDigi also asserts that it promptly removed the content when its licenses were terminated, and instead sent users to YouTube or iTunes for previews. Capitol, in response, claims that ReDigi's use violated the terms of those licenses and did not cease at the time the licenses were terminated. As such, there are material disputes as to the source of the content, whether ReDigi was authorized to transmit the content, when authorization was or was not revoked, and when ReDigi ceased providing the content. Because the Court cannot determine whether ReDigi infringed Capitol's display and performance rights on the present record, ReDigi's motion for summary judgment on its alleged infringement of these exclusive rights is denied.

CoStar Group, Inc. v. LoopNet, Inc.

CoStar is a national provider of commercial real estate information, and it claims to have collected the most comprehensive database of information on commercial real estate markets and commercial properties in the United States and the United Kingdom. LoopNet is an Internet service provider ("ISP") whose website allows subscribers, generally real estate brokers, to post listings of commercial real estate on the Internet. Beginning in early 1998, CoStar became aware that photographs for which it held copyrights were being posted on LoopNet's website by LoopNet's subscribers.

While the Copyright Act does not require that the infringer know that he is infringing or that his conduct amount to a willful violation of the copyright owner's rights, it nonetheless requires conduct by a person who causes in some meaningful way an infringement. Were this not so, the Supreme Court could not have held, as it did in Sony, that a manufacturer of copy machines, possessing constructive knowledge that purchasers of its machine may be using them to engage in copyright infringement, is not strictly liable for infringement. This, of course, does not mean that a manufacturer or owner of machines used for copyright violations could not have some indirect lia-

Perfect 10, Inc. v. Amazon.com, Inc., 508 F.3d 1146 (9th Cir. 2007), held that the operator of the computer from which the image was transmitted for display infringed the display right. 
Netcom: 907 F. Supp. 1361 (N.D. Cal. 1995)

Same case, different opinion

134 S. Ct. 2498 (2014)

17 U.S.C. S 101 bility, such as contributory or vicarious liability. But such extensions of liability would require a showing of additional elements such as knowledge coupled with inducement or supervision coupled with a financial interest in the illegal copying.

But to establish direct liability, something more must be shown than mere ownership of a machine used by others to make illegal copies. There must be actual infringing conduct with a nexus sufficiently close and causal to the illegal copying that one could conclude that the machine owner himself trespassed on the exclusive domain of the copyright owner. Religious Technology Center v. Netcom Online Communication Services, Inc. described this nexus as requiring some aspect of volition or causation. Indeed, counsel for both parties agreed at oral argument that a copy machine owner who makes the machine available to the public to use for copying is not, without more, strictly liable under $\S 106$ for illegal copying by a customer. The ISP in this case is an analogue to the owner of a traditional copying machine whose customers pay a fixed amount per copy and operate the machine themselves to make copies. When a customer duplicates an infringing work, the owner of the copy machine is not considered a direct infringer. Similarly, an ISP who owns an electronic facility that responds automatically to users' input is not a direct infringer. If the Copyright Act does not hold the owner of the copying machine liable as a direct infringer when its customer copies infringing material without knowledge of the owner, the ISP should not be found liable as a direct infringer when its facility is used by a subscriber to violate a copyright without intervening conduct of the ISP.

American Broadcasting v. Aereo, Inc.

The Copyright Act of 1976 gives a copyright owner the "exclusive right" to "perform the copyrighted work publicly." The Act's Transmit Clause defines that exclusive right as including the right to

"transmit or otherwise communicate a performance ... of the [copyrighted] work ... to the public, by means of any device or process, whether the members of the public capable of receiving the performance ... receive it in the same place or in separate places and at the same time or at different times."

We must decide whether respondent Aereo, Inc., infringes this exclusive right by selling its subscribers a technologically complex service that allows them to watch television programs over the Internet at about the same time as the programs are broadcast over the air. We conclude that it does. 
For a monthly fee, Aereo offers subscribers broadcast television programming over the Internet, virtually as the programming is being broadcast.

Aereo's system is made up of servers, transcoders, and thousands of dime-sized antennas housed in a central warehouse. It works roughly as follows: First, when a subscriber wants to watch a show that is currently being broadcast, he visits Aereo's website and selects, from a list of the local programming, the show he wishes to see.

Second, one of Aereo's servers selects an antenna, which it dedicates to the use of that subscriber (and that subscriber alone) for the duration of the selected show. A server then tunes the antenna to the over-the-air broadcast carrying the show. The antenna begins to receive the broadcast, and an Aereo transcoder translates the signals received into data that can be transmitted over the Internet.

Third, rather than directly send the data to the subscriber, a server saves the data in a subscriber-specific folder on Aereo's hard drive. In other words, Aereo's system creates a subscriber-specific copy - that is, a "personal" copy - of the subscriber's program of choice.

Fourth, once several seconds of programming have been saved, Aereo's server begins to stream the saved copy of the show to the subscriber over the Internet. (The subscriber may instead direct Aereo to stream the program at a later time, but that aspect of Aereo's service is not before us.) The subscriber can watch the streamed program on the screen of his personal computer, tablet, smart phone, Internetconnected television, or other Internet-connected device. The streaming continues, a mere few seconds behind the over-the-air broadcast, until the subscriber has received the entire show.

Aereo emphasizes that the data that its system streams to each subscriber are the data from his own personal copy, made from the broadcast signals received by the particular antenna allotted to him. Its system does not transmit data saved in one subscriber's folder to any other subscriber. When two subscribers wish to watch the same program, Aereo's system activates two separate antennas and saves two separate copies of the program in two separate folders. It then streams the show to the subscribers through two separate transmissions - each from the subscriber's personal copy.

\section{II}

History makes plain that one of Congress' primary purposes in amending the Copyright Act in 1976 was to overturn this Court's determination that community antenna television (CATV) systems (the precursors of modern cable systems) fell outside the Act's scope. In Fortnightly Corp. v. United Artists Television, Inc., the Court considered a CATV system that carried local television broadcasting, much of which was copyrighted, to its subscribers in two cities. The CATV 
Teleprompter: 415 U.S. 394 (1974)

Teleprompter extended Fortnightly from local rebroadcasts to rebroadcasts of distant television stations. 17 U.S.C. S 101

17 U.S.C. S 111 provider placed antennas on hills above the cities and used coaxial cables to carry the signals received by the antennas to the home television sets of its subscribers. Asked to decide whether the CATV provider infringed copyright holders' exclusive right to perform their works publicly, the Court held that the provider did not "perform" at all. The Court drew a line: "Broadcasters perform. Viewers do not perform." And a CATV provider "falls on the viewer's side of the line."

In 1976 Congress amended the Copyright Act in large part to reject the Court's holdings in Fortnightly and Teleprompter Corp. $v$. Columbia Broadcasting System, Inc.. The amended statute clarifies that to "perform" an audiovisual work means "to show its images in any sequence or to make the sounds accompanying it audible." Under this new language, both the broadcaster and the viewer of a television program "perform," because they both show the program's images and make audible the program's sounds. Congress also enacted the Transmit Clause, which specifies that an entity performs publicly when it "transmit[s] ... a performance ... to the public." Cable system activities, like those of the CATV systems in Fortnightly and Teleprompter, lie at the heart of the activities that Congress intended this language to cover. The Clause thus makes clear that an entity that acts like a CATV system itself performs, even if when doing so, it simply enhances viewers' ability to receive broadcast television signals. Congress further created a new section of the Act to regulate cable companies' public performances of copyrighted works. Section 111 creates a complex, highly detailed compulsory licensing scheme that sets out the conditions, including the payment of compulsory fees, under which cable systems may retransmit broadcasts.

This history makes clear that Aereo is not simply an equipment provider. Rather, Aereo, and not just its subscribers, "perform[s]" (or "transmit[s]"). Aereo's activities are substantially similar to those of the CATV companies that Congress amended the Act to reach.

III

Next, we must consider whether Aereo performs petitioners' works "publicly," within the meaning of the Transmit Clause. As we have said, an Aereo subscriber receives broadcast television signals with an antenna dedicated to him alone. Aereo's system makes from those signals a personal copy of the selected program. It streams the content of the copy to the same subscriber and to no one else. One and only one subscriber has the ability to see and hear each Aereo transmission. The fact that each transmission is to only one subscriber, in Aereo's view, means that it does not transmit a performance "to the public."

In terms of the Act's purposes, these differences do not distin- 
guish Aereo's system from cable systems, which do perform "publicly." Viewed in terms of Congress' regulatory objectives, why should any of these technological differences matter? They concern the behind-the-scenes way in which Aereo delivers television programming to its viewers' screens. They do not render Aereo's commercial objective any different from that of cable companies. Nor do they significantly alter the viewing experience of Aereo's subscribers. Why would a subscriber who wishes to watch a television show care much whether images and sounds are delivered to his screen via a large multisubscriber antenna or one small dedicated antenna, whether they arrive instantaneously or after a few seconds' delay, or whether they are transmitted directly or after a personal copy is made? And why, if Aereo is right, could not modern CATV systems simply continue the same commercial and consumer-oriented activities, free of copyright restrictions, provided they substitute such new technologies for old? Congress would as much have intended to protect a copyright holder from the unlicensed activities of Aereo as from those of cable companies.

The subscribers to whom Aereo transmits television programs constitute "the public." Aereo communicates the same contemporaneously perceptible images and sounds to a large number of people who are unrelated and unknown to each other. This matters because, although the Act does not define "the public," it specifies that an entity performs publicly when it performs at "any place where a substantial number of persons outside of a normal circle of a family and its social acquaintances is gathered.". The Act thereby suggests that "the public" consists of a large group of people outside of a family and friends.

Neither the record nor Aereo suggests that Aereo's subscribers receive performances in their capacities as owners or possessors of the underlying works. This is relevant because when an entity performs to a set of people, whether they constitute "the public" often depends upon their relationship to the underlying work. When, for example, a valet parking attendant returns cars to their drivers, we would not say that the parking service provides cars "to the public." We would say that it provides the cars to their owners. We would say that a car dealership, on the other hand, does provide cars to the public, for it sells cars to individuals who lack a pre-existing relationship to the cars. Similarly, an entity that transmits a performance to individuals in their capacities as owners or possessors does not perform to "the public," whereas an entity like Aereo that transmits to large numbers of paying subscribers who lack any prior relationship to the works does so perform. 
Aereo and many of its supporting amici argue that to apply the Transmit Clause to Aereo's conduct will impose copyright liability on other technologies, including new technologies, that Congress could not possibly have wanted to reach. We agree that Congress, while intending the Transmit Clause to apply broadly to cable companies and their equivalents, did not intend to discourage or to control the emergence or use of different kinds of technologies. But we do not believe that our limited holding today will have that effect.

Justice SCALIA, with whom Justice THOMAS and Justice ALITO join, dissenting.

Unlike video-on-demand services, Aereo does not provide a prearranged assortment of movies and television shows. Rather, it assigns each subscriber an antenna that - like a library card - can be used to obtain whatever broadcasts are freely available. Some of those broadcasts are copyrighted; others are in the public domain. The key point is that subscribers call all the shots: Aereo's automated system does not relay any program, copyrighted or not, until a subscriber selects the program and tells Aereo to relay it. Aereo's operation of that system is a volitional act and a but-for cause of the resulting performances, but, as in the case of the copy shop, that degree of involvement is not enough for direct liability.

That conclusion does not necessarily mean that Aereo's service complies with the Copyright Act. Quite the contrary. The Networks' complaint alleges that Aereo is directly and secondarily liable for infringing their public-performance rights and also their reproduction rights. Their request for a preliminary injunction - the only issue before this Court - is based exclusively on the direct-liability portion of the public-performance claim (and further limited to Aereo's "watch" function, as opposed to its "record" function). Affirming the judgment below would merely return this case to the lower courts for consideration of the Networks' remaining claims.

\section{Copyright Act}

17 U.S.C. § 110

Limitations on exclusive rights: Exemption of certain performances and displays
Notwithstanding the provisions of section 106, the following are not infringements of copyright:

(1) performance or display of a work by instructors or pupils in the course of face-to-face teaching activities of a nonprofit educational institution, in a classroom or similar place devoted to instruction, unless, in the case of a motion picture or other audiovisual work, the performance, or the display of individual images, is given by means of a copy that was not lawfully made under this title, and that the person responsible for the performance knew or had reason to believe was not lawfully made; 
(2) [similar uses in distance education, subject to numerous conditions]

(3) performance of a nondramatic literary or musical work or of a dramatico-musical work of a religious nature, or display of a work, in the course of services at a place of worship or other religious assembly;

(4) performance of a nondramatic literary or musical work otherwise than in a transmission to the public, without any purpose of direct or indirect commercial advantage and without payment of any fee or other compensation for the performance to any of its performers, promoters, or organizers ... ;

(6) performance ... in the course of an annual agricultural or horticultural fair ...;

(10) [certain private charitable fundraising performances by nonprofit veterans and fraternal organizations]

\section{Secondary Liability}

Fonovisa, Inc. v. Cherry Auction, Inc.

This is a copyright and trademark enforcement action against the operators of a swap meet, sometimes called a flea market, where thirdparty vendors routinely sell counterfeit recordings that infringe on the plaintiff's copyrights and trademarks.

\section{BACKGROUND}

The plaintiff and appellant is Fonovisa, Inc., a California corporation that owns copyrights and trademarks to Latin/Hispanic music recordings. Fonovisa filed this action in district court against defendantappellee, Cherry Auction, Inc., and its individual operators (collectively "Cherry Auction"). For purposes of this appeal, it is undisputed that Cherry Auction operates a swap meet in Fresno, California, similar to many other swap meets in this country where customers come to purchase various merchandise from individual vendors. The vendors pay a daily rental fee to the swap meet operators in exchange for booth space. Cherry Auction supplies parking, conducts advertising and retains the right to exclude any vendor for any reason, at any time, and thus can exclude vendors for patent and trademark infringement. In addition, Cherry Auction receives an entrance fee from each customer who attends the swap meet.

There is also no dispute for purposes of this appeal that Cherry Auction and its operators were aware that vendors in their swap meet were selling counterfeit recordings in violation of Fonovisa's trademarks and copyrights. Indeed, it is alleged that in 1991, the Fresno County Sheriff's Department raided the Cherry Auction swap meet 
and seized more than 38,000 counterfeit recordings. The following year, after finding that vendors at the Cherry Auction swap meet were still selling counterfeit recordings, the Sheriff sent a letter notifying Cherry Auction of the on-going sales of infringing materials, and reminding Cherry Auction that they had agreed to provide the Sheriff with identifying information from each vendor. In addition, in 1993, Fonovisa itself sent an investigator to the Cherry Auction site and observed sales of counterfeit recordings.

Although the Copyright Act does not expressly impose liability on anyone other than direct infringers, courts have long recognized that in certain circumstances, vicarious or contributory liability will be imposed.

\section{VicARious Copyright INFringement}

The concept of vicarious copyright liability was developed in the Second Circuit as an outgrowth of the agency principles of respondeat superior. The landmark case on vicarious liability for sales of counterfeit recordings is Shapiro, Bernstein and Co. v. H.L. Green Co.. In Shapiro, the court was faced with a copyright infringement suit against the owner of a chain of department stores where a concessionaire was selling counterfeit recordings. Noting that the normal agency rule of respondeat superior imposes liability on an employer for copyright infringements by an employee, the court endeavored to fashion a principle for enforcing copyrights against a defendant whose economic interests were intertwined with the direct infringer's, but who did not actually employ the direct infringer.

The Shapiro, court looked at the two lines of cases it perceived as most clearly relevant. In one line of cases, the landlord-tenant cases, the courts had held that a landlord who lacked knowledge of the infringing acts of its tenant and who exercised no control over the leased premises was not liable for infringing sales by its tenant. In the other line of cases, the so-called "dance hall cases," the operator of an entertainment venue was held liable for infringing performances when the operator (1) could control the premises and (2) obtained a direct financial benefit from the audience, who paid to enjoy the infringing performance.

From those two lines of cases, the Shapiro, court determined that the relationship between the store owner and the concessionaire in the case before it was closer to the dance-hall model than to the landlord-tenant model. It imposed liability even though the defendant was unaware of the infringement. Shapiro deemed the imposition of vicarious liability neither unduly harsh nor unfair because the store proprietor had the power to cease the conduct of the concessionaire, and because the proprietor derived an obvious and direct financial benefit from the infringement. The test was more clearly 
articulated in a later Second Circuit case as follows: "even in the absence of an employer-employee relationship one may be vicariously liable if he has the right and ability to supervise the infringing activity and also has a direct financial interest in such activities." Gershwin Publishing Corp. v. Columbia Artists Management, Inc..

The district court in this case agreed with defendant Cherry Auction that Fonovisa did not, as a matter of law, meet either the control or the financial benefit prong of the vicarious copyright infringement test articulated in Gershwin, supra. Rather, the district court concluded that based on the pleadings, Cherry Auction neither supervised nor profited from the vendors' sales. In the district court's view, with respect to both control and financial benefit, Cherry Auction was in the same position as an absentee landlord who has surrendered its exclusive right of occupancy in its leased property to its tenants.

This analogy to absentee landlord is not in accord with the facts as alleged in the district court and which we, for purposes of appeal, must accept. The allegations below were that vendors occupied small booths within premises that Cherry Auction controlled and patrolled. According to the complaint, Cherry Auction had the right to terminate vendors for any reason whatsoever and through that right had the ability to control the activities of vendors on the premises. In addition, Cherry Auction promoted the swap meet and controlled the access of customers to the swap meet area. In terms of control, the allegations before us are strikingly similar to those in Shapiro, and Gershwin.

In Shapiro, for example, the court focused on the formal licensing agreement between defendant department store and the direct infringer-concessionaire. There, the concessionaire selling the bootleg recordings had a licensing agreement with the department store (H.L. Green Company) that required the concessionaire and its employees to "abide by, observe and obey all regulations promulgated from time to time by the H.L. Green Company," and H.L. Green Company had the "unreviewable discretion" to discharge the concessionaires' employees. In practice, H.L. Green Company was not actively involved in the sale of records and the concessionaire controlled and supervised the individual employees. Nevertheless, H.L. Green's ability to police its concessionaire - which parallels Cherry Auction's ability to police its vendors under Cherry Auction's similarly broad contract with its vendors - was sufficient to satisfy the control requirement.

We next consider the issue of financial benefit. The plaintiff's allegations encompass many substantive benefits to Cherry Auction from the infringing sales. These include the payment of a daily rental fee by each of the infringing vendors; a direct payment to Cherry Auc-
Gershwin: 443 F.2d 1159 (2d Cir. 1971) 
tion by each customer in the form of an admission fee, and incidental payments for parking, food and other services by customers seeking to purchase infringing recordings.

Cherry Auction nevertheless contends that these benefits cannot satisfy the financial benefit prong of vicarious liability because a commission, directly tied to the sale of particular infringing items, is required. They ask that we restrict the financial benefit prong to the precise facts presented in Shapiro, where defendant H.L. Green Company received a 10 or 12 per cent commission from the direct infringers' gross receipts. Cherry Auction points to the low daily rental fee paid by each vendor, discounting all other financial benefits flowing to the swap meet, and asks that we hold that the swap meet is materially similar to a mere landlord. The facts alleged by Fonovisa, however, reflect that the defendants reap substantial financial benefits from admission fees, concession stand sales and parking fees, all of which flow directly from customers who want to buy the counterfeit recordings at bargain basement prices. The plaintiff has sufficiently alleged direct financial benefit.

Our conclusion is fortified by the continuing line of cases, starting with the dance hall cases, imposing vicarious liability on the operator of a business where infringing performances enhance the attractiveness of the venue to potential customers. In Polygram International Publishing, Inc. v. Nevada/TIG, Inc., for example, direct infringers were participants in a trade show who used infringing music to communicate with attendees and to cultivate interest in their wares. The court held that the trade show participants "derived a significant financial benefit from the attention" that attendees paid to the infringing music. In this case, the sale of pirated recordings at the Cherry Auction swap meet is a "draw" for customers, as was the performance of pirated music in the dance hall cases and their progeny.

Plaintiffs have stated a claim for vicarious copyright infringement.

\section{Contributory Copyright Infringement}

Contributory infringement originates in tort law and stems from the notion that one who directly contributes to another's infringement should be held accountable. Contributory infringement has been described as an outgrowth of enterprise liability, and imposes liability where one person knowingly contributes to the infringing conduct of another. The classic statement of the doctrine is in Gershwin: "One who, with knowledge of the infringing activity, induces, causes or materially contributes to the infringing conduct of another, may be held liable as a 'contributory' infringer."

There is no question that plaintiff adequately alleged the element of knowledge in this case. The disputed issue is whether plaintiff adequately alleged that Cherry Auction materially contributed to the 
infringing activity. We have little difficulty in holding that the allegations in this case are sufficient to show material contribution to the infringing activity. Indeed, it would be difficult for the infringing activity to take place in the massive quantities alleged without the support services provided by the swap meet. These services include, inter alia, the provision of space, utilities, parking, advertising, plumbing, and customers.

Here again Cherry Auction asks us to ignore all aspects of the enterprise described by the plaintiffs, to concentrate solely on the rental of space, and to hold that the swap meet provides nothing more. Yet Cherry Auction actively strives to provide the environment and the market for counterfeit recording sales to thrive. Its participation in the sales cannot be termed "passive," as Cherry Auction would prefer.

The district court apparently took the view that contribution to infringement should be limited to circumstances in which the defendant "expressly promoted or encouraged the sale of counterfeit products, or in some manner protected the identity of the infringers." Given the allegations that the local sheriff lawfully requested that Cherry Auction gather and share basic, identifying information about its vendors, and that Cherry Auction failed to comply, the defendant appears to qualify within the last portion of the district court's own standard that posits liability for protecting infringers' identities. Moreover, we agree with the Third Circuit's analysis in Columbia Pictures Industries, Inc. v. Aveco, Inc. that providing the site and facilities for known infringing activity is sufficient to establish contributory liability.

Sony Corp. of America v. Universal City Studios, Inc.

Petitioners manufacture and sell home video tape recorders [the "Betamax"]. Respondents own the copyrights on some of the television programs that are broadcast on the public airwaves. Some members of the general public use video tape recorders sold by petitioners to record some of these broadcasts, as well as a large number of other broadcasts. The question presented is whether the sale of petitioners' copying equipment to the general public violates any of the rights conferred upon respondents by the Copyright Act.

If vicarious liability is to be imposed on Sony in this case, it must rest on the fact that it has sold equipment with constructive knowledge of the fact that its customers may use that equipment to make unauthorized copies of copyrighted material. There is no precedent in the law of copyright for the imposition of vicarious liability on such a theory. The closest analogy is provided by the patent law cases to which it is appropriate to refer because of the historic kinship between patent law and copyright law.
Aveco: 800 F.2d 59 (3rd Cir. 1986)

464 U.S. 417 (1984) 
We recognize there are substantial differences between the patent and copyright laws. But in both areas the contributory infringement doctrine is grounded on the recognition that adequate protection of a monopoly may require the courts to look beyond actual duplication of a device or publication to the products or activities that make such duplication possible. The staple article of commerce doctrine must strike a balance between a copyright holder's legitimate demand for effective - not merely symbolic - protection of the statutory monopoly, and the rights of others freely to engage in substantially unrelated areas of commerce. Accordingly, the sale of copying equipment, like the sale of other articles of commerce, does not constitute contributory infringement if the product is widely used for legitimate, unobjectionable purposes. Indeed, it need merely be capable of substantial noninfringing uses.

[The Court held that the Betamax was capable of two substantial nonnfringing uses. The first was recording programs for later viewing ("time-shifting") with the permission of the copyright owner. Religious and educational broadcasters (including Fred Rogers of Mister Rogers' Neighborhood) testified that they did not object to time-shifting. The second noninfringing use was time-shifting even without broadcaster permission, which was protected as fair use.]

\section{Metro-Goldwyn-Mayer Studios Inc. v. Grokster, Ltd.}

The question is under what circumstances the distributor of a product capable of both lawful and unlawful use is liable for acts of copyright infringement by third parties using the product. We hold that one who distributes a device with the object of promoting its use to infringe copyright, as shown by clear expression or other affirmative steps taken to foster infringement, is liable for the resulting acts of infringement by third parties.

\section{Exclusive Rights Problem}

You work for a copyright owner who is determined to bring suit against the following. In each case, identify every theory of copyright liability available. Be sure to consider both the different $\S 106$ rights and the various flavors of secondary liability. Be creative.

- A woman calling herself Makeover Morticia gives tutorials on how to put on makeup effectively, which she livesstreams on a Google Hangout. She is paid by makeup companies to use their products and promote them on her streams. She regularly streams music from Spotify over her computer speakers as she works; this background music is audible to her viewers. Sometimes she turns up the music and tells the audience, "You should totally download this." 
- Terminations is a best-selling dystopian young-adult novel. Fannie Frederickson, a young adult, writes a sequel in the form of a play, which she titles Reversions. Her high school's drama club performs Reversions as its annual fall drama. It gives three performances, for which it charges $\$ 5$ admission; the proceeds are used to pay for a cast party at a local diner.

- The Renton Theater obtains a digital copy of the movie Rager under a license permitting it exhibition at a single theater. But in addition to showing the movie in its own theater, Renton repeatedly duplicates Rager and rents out the copies to ten other movie theaters.

- Diversion Devices sells high-capacity digital video recorders with DVD-R drives. Some buyers of Diversion's DVRs use them to record television programs onto DVRs, which they give as presents to friends, family, and co-workers.

\section{Paracopyright}

\section{Copyright Act}

(a) Violations Regarding Circumvention of Technological Measures. -

(1) (A) No person shall circumvent a technological measure that effectively controls access to a work protected under this title.

(2) No person shall manufacture, import, offer to the public, provide, or otherwise traffic in any technology, product, service, device, component, or part thereof, that -

(A) is primarily designed or produced for the purpose of circumventing a technological measure that effectively controls access to a work protected under this title;

(B) has only limited commercially significant purpose or use other than to circumvent a technological measure that effectively controls access to a work protected under this title; or

(C) is marketed by that person or another acting in concert with that person with that person's knowledge for use in circumventing a technological measure that effectively controls access to a work protected under this title.

MDY Industries, LLC. v. Blizzard Entertainment, Inc.

Blizzard Entertainment, Inc. ("Blizzard") is the creator of World of

629 F.3d 928 (9th Cir. 2010)

17 U.S.C. § 1201

Circumvention of copyright protection systems 
in which players interact in a virtual world while advancing through the game's 70 levels. MDY Industries, LLC and its sole member Michael Donnelly ("Donnelly") (sometimes referred to collectively as "MDY") developed and sold Glider, a software program that automatically plays the early levels of WoW for players.As explained in the Frequently Asked Questions ("FAQ") on MDY's website for Glider:

Glider ... moves the mouse around and pushes keys on the keyboard. You tell it about your character, where you want to kill things, and when you want to kill. Then it kills for you, automatically. You can do something else, like eat dinner or go to a movie, and when you return, you'll have a lot more experience and loot.

Glider does not alter or copy WoW's game client software, does not allow a player to avoid paying monthly subscription dues to Blizzard, and has no commercial use independent of WoW.

The parties dispute Glider's impact on the WoW experience. Blizzard contends that Glider disrupts WoW's environment for nonGlider players by enabling Glider users to advance quickly and unfairly through the game and to amass additional game assets. MDY contends that Glider has a minimal effect on non-Glider players, enhances the WoW experience for Glider users, and facilitates disabled players' access to WoW by auto-playing the game for them.

After MDY began selling Glider, Blizzard launched Warden, its technology designed to prevent players who used bots from connecting to the WoW servers. Blizzard used Warden to ban most Glider users in September 2005. Blizzard claims that MDY is liable under DMCA S 1201(a)(2) and (b)(1) because it thereafter programmed Glider to avoid detection by Warden.

Warden has two components. The first is a software module called "scan.dll," which scans a computer's RAM prior to allowing the player to connect to WoW's servers. If scan.dll detects that a bot is running, such as Glider, it will not allow the player to connect and play. After Blizzard launched Warden, MDY reconfigured Glider to circumvent scan.dll by not loading itself until after scan.dll completed its check. Warden's second component is a "resident" component that runs periodically in the background on a player's computer when it is connected to WoW's servers. It asks the computer to report portions of the WoW code running in RAM, and it looks for patterns of code associated with known bots or cheats. If it detects a bot or cheat, it boots the player from the game, which halts the computer's copying of copyrighted code into RAM.

The district court assessed whether MDY violated DMCA $\S 1201(a)(2)$ and $(b)(1)$ with respect to three WoW components. First, 
the district court considered the game client software's literal elements: the source code stored on players' hard drives. Second, the district court considered the game client software's individual nonliteral elements: the 400,000+ discrete visual and audible components of the game, such as a visual image of a monster or its audible roar. Finally, it considered the game's dynamic non-literal elements: that is, the "real-time experience of traveling through different worlds, hearing their sounds, viewing their structures, encountering their inhabitants and monsters, and encountering other players."

Although the text suffices to resolve the issues before us, we also consider the legislative history in order to address the parties' arguments concerning it. Our review of that history supports the view that Congress created a new anticircumvention right in S 1201(a)(2) independent of traditional copyright infringement.

The Federal Circuit has adopted a different approach to the DMCA. In essence, it requires S 1201(a) plaintiffs to demonstrate that the circumventing technology infringes or facilitates infringement of the plaintiff's copyright (an "infringement nexus requirement"). See Chamberlain Group, Inc. v. Skylink Techs., Inc.; Storage Tech. Corp. v. Custom Hardware Eng'g \& Consulting, Inc..

In Chamberlain, the plaintiff sold garage door openers ("GDOs") with a "rolling code" security system that purportedly reduced the risk of crime by constantly changing the transmitter signal necessary to open the door.Customers used the GDOs' transmitters to send the changing signal, which in turn opened or closed their garage doors.

Plaintiff sued the defendant, who sold "universal" GDO transmitters for use with plaintiff's GDOs, under S 1201(a)(2). The plaintiff alleged that its GDOs and transmitters both contained copyrighted computer programs and that its rolling code security system was a technological measure that controlled access to those programs. Accordingly, plaintiff alleged that the defendant - by selling GDO transmitters that were compatible with plaintiff's GDOs - had trafficked in a technology that was primarily used for the circumvention of a technological measure (the rolling code security system) that effectively controlled access to plaintiff's copyrighted works.

The Federal Circuit rejected the plaintiff's claim, holding that the defendant did not violate $\S 1201(a)(2)$ because, inter alia, the defendant's universal GDO transmitters did not infringe or facilitate infringement of the plaintiff's copyrighted computer programs. The linchpin of the Chamberlain court's analysis is its conclusion that DMCA coverage is limited to a copyright owner's rights under the Copyright Act as set forth in $\S 106$ of the Copyright Act. Thus, it held that $\S 1201$ (a) did not grant copyright owners a new anticircumvention right, but instead, established new causes of action for a defendant's unauthorized access of copyrighted material when
Chamberlain: 381 F.3d 1178 (Fed. Cir. 2004)

Storage Tech: 421 F.3d 1307 (Fed. Cir. 2005) 
it infringes upon a copyright owner's rights under $\S 106$. Id. at 1192, 1194. Accordingly, a § 1201(a)(2) plaintiff was required to demonstrate a nexus to infringement - i.e., that the defendant's trafficking in circumventing technology had a "reasonable relationship" to the protections that the Copyright Act affords copyright owners.

While we appreciate the policy considerations expressed by the Federal Circuit in Chamberlain, we are unable to follow its approach because it is contrary to the plain language of the statute.

We agree with the district court that MDY's Glider does not violate DMCA § 1201(a)(2) with respect to WoW's literal elements and individual non-literal elements, because Warden does not effectively control access to these WoW elements. First, Warden does not control access to WoW's literal elements because these elements - the game client's software code - are available on a player's hard drive once the game client software is installed. Second, as the district court found:

WoW's individual nonliteral components may be accessed by a user without signing on to the server. As was demonstrated during trial, an owner of the game client software may use independently purchased computer programs to call up the visual images or the recorded sounds within the game client software. For instance, a user may call up and listen to the roar a particular monster makes within the game. Or the user may call up a virtual image of that monster. Since a player need not encounter Warden to access WoW's individual non-literal elements, Warden does not effectively control access to those elements.

Our conclusion is in accord with the Sixth Circuit's decision in Lexmark International v. Static Control Components. In Lexmark, the plaintiff sold laser printers equipped with an authentication sequence, verified by the printer's copyrighted software, that ensured that only plaintiff's own toner cartridges could be inserted into the printers. The defendant sold microchips capable of generating an authentication sequence that rendered other manufacturers' cartridges compatible with plaintiff's printers.

The Sixth Circuit held that plaintiff's § 1201(a)(2) claim failed because its authentication sequence did not effectively control access to its copyrighted computer program. Rather, the mere purchase of one of plaintiff's printers allowed "access" to the copyrighted program. Any purchaser could read the program code directly from the printer memory without encountering the authentication sequence. The authentication sequence thus blocked only one form of access: the ability to make use of the printer. However, it left intact another 
form of access: the review and use of the computer program's literal code.

The Sixth Circuit explained:

Just as one would not say that a lock on the back door of a house "controls access" to a house whose front door does not contain a lock and just as one would not say that a lock on any door of a house "controls access" to the house after its purchaser receives the key to the lock, it does not make sense to say that this provision of the DMCA applies to otherwise-readily-accessible copyrighted works. Add to this the fact that the DMCA not only requires the technological measure to "control access" but requires the measure to control that access "effectively," and it seems clear that this provision does not naturally extend to a technological measure that restricts one form of access but leaves another route wide open.

Here, a player's purchase of the WoW game client allows access to the game's literal elements and individual non-literal elements. Warden blocks one form of access to these elements: the ability to access them while connected to a WoW server. However, analogously to the situation in Lexmark, Warden leaves open the ability to access these elements directly via the user's computer. We conclude that Warden is not an effective access control measure with respect to WoW's literal elements and individual non-literal elements, and therefore, that MDY does not violate $\S 1201(a)(2)$ with respect to these elements.

We conclude that MDY meets each of the six textual elements for violating $\S 1201(a)(2)$ with respect to WoW's dynamic non-literal elements. That is, MDY (1) traffics in (2) a technology or part thereof (3) that is primarily designed, produced, or marketed for, or has limited commercially significant use other than (4) circumventing a technological measure (5) that effectively controls access (6) to a copyrighted work.

The first two elements are met because MDY "traffics in a technology or part thereof" - that is, it sells Glider. The third and fourth elements are met because Blizzard has established that MDY markets Glider for use in circumventing Warden, thus satisfying the requirement of $\S 1201(a)(2)(C)$. Indeed, Glider has no function other than to facilitate the playing of WoW. The sixth element is met because, as the district court held, WoW's dynamic non-literal elements constitute a copyrighted work. See, e.g., Atari Games Corp. v. Oman (the audiovisual display of a computer game is copyrightable independently from the software program code, even though the audiovisual display generated is partially dependent on user input).

The fifth element is met because Warden is an effective access con-

Atari Games: 888 F.2d 878 (D.C. Cir. 1989) 
trol measure. Both of Warden's two components "require[] the application of information, or a process or a treatment ... to gain access to the work." For a player to connect to Blizzard's servers which provide access to WoW's dynamic non-literal elements, scan.dll must scan the player's computer RAM and confirm the absence of any bots or cheats. The resident component also requires a "process" in order for the user to continue accessing the work: the user's computer must report portions of WoW code running in RAM to the server. Moreover, Warden's provisions were put into place by Blizzard, and thus, function "with the authority of the copyright owner." Accordingly, Warden effectively controls access to WoW's dynamic non-literal elements. We hold that MDY is liable under $\S 1201(\mathrm{a})(2)$ with respect to WoW's dynamic non-literal elements.

\section{Copyright Act}

17 U.S.C. § 1202

Integrity of copyright management information (a) False Copyright Management Information. - No person shall knowingly and with the intent to induce, enable, facilitate, or conceal infringement -

(1) provide copyright management information that is false, or

(2) distribute ... copyright management information that is false.

(b) Removal or Alteration of Copyright Management Information. - No person shall, without the authority of the copyright owner or the law -

(1) intentionally remove or alter any copyright management information, ...

knowing, or, with respect to civil remedies under section 1203, having reasonable grounds to know, that it will induce, enable, facilitate, or conceal an infringement of any right under this title.

(c) Definition. - As used in this section, the term "copyright management information" means any of the following information conveyed in connection with copies or phonorecords of a work or performances or displays of a work, including in digital form, except that such term does not include any personally identifying information about a user of a work or of a copy, phonorecord, performance, or display of a work:

(1) The title and other information identifying the work, including the information set forth on a notice of copyright.

(2) The name of, and other identifying information about, the author of a work. 
(3) The name of, and other identifying information about, the copyright owner of the work, including the information set forth in a notice of copyright.

(5) With the exception of public performances of works by radio and television broadcast stations, in the case of an audiovisual work, the name of, and other identifying information about, a writer, performer, or director who is credited in the audiovisual work.

(6) Terms and conditions for use of the work.

(7) Identifying numbers or symbols referring to such information or links to such information.

(8) Such other information as the Register of Copyrights may prescribe by regulation.

\section{Murphy v. Millennium Radio Group LLC}

In 2006, Murphy was hired by the magazine New Jersey Monthly ("NJM") to take a photo of Craig Carton and Ray Rossi, who at the time were the hosts of a show on the New Jersey radio station WKXW, which is owned by Millennium Radio Group. NJM used the photo to illustrate an article in its "Best of New Jersey" issue naming Carton and Rossi "best shock jocks" in the state. The photo ("the Image") depicted Carton and Rossi standing, apparently nude, behind a WKXW sign. Murphy retained the copyright to the Image.

An unknown employee of WKXW then scanned in the Image from NJM and posted the resulting electronic copy to the WKXW website and to another website, myspacetv.com. The resulting image, as scanned and posted to the Internet, cut off part of the original NJM caption referring to the "Best of New Jersey" award. It also eliminated NJM's gutter credit (that is, a credit placed in the inner margin, or "gutter," of a magazine page, ordinarily printed in a smaller type and running perpendicular to the relevant image on the page) identifying Murphy as the author of the Image. The WKXW website invited visitors to alter the Image using photo-manipulation software and submit the resulting versions to WKXW. A number of visitors eventually submitted their versions of the photo to WKXW, and it posted 26 of those submissions to its site. The Station Defendants never received Murphy's permission to make use of the Image.

In April 2008, Murphy sued the Station Defendants for violations of $\S 1202$ of the Digital Millennium Copyright Act of 1998 ("DMCA").

Murphy's argument is straightforward. He contends that the NJM gutter credit identifying him as the author of the Image is CMI because it is "the name of ... the author of [the Image]" and was "conveyed in connection with copies of [the Image]." By posting the Image on the two websites without the credit, therefore, the Station De- 
fendants "remove[d] or alter[ed]" CMI and "distribute [d]" a work knowing that its CMI had been "removed or altered" in violation of $\S 1202$.

The Station Defendants, on the other hand, insist that one cannot read $\S 1202$ in isolation, but must interpret it in conjunction with $\S$ 1201 and in light of the legislative history of the DMCA to impose an additional limitation on the definition of CMI. They argue that the chapter as a whole protects various kinds of automated systems which protect and manage copyrights. Specifically, § 1201 covers the systems (the "technological measures" discussed above) that protect copyrighted materials and $\S 1202$ covers the systems that manage copyrighted materials (such as the name of the author of a work). Therefore, they conclude, despite the apparently plain language of $\S 1202$, information like the name of the author of a work is not CMI unless it also functions as part of an "automated copyright protection or management system." In other words, to remove, as the Station Defendants did, a printed credit from a magazine photograph which was then posted to a website does not violate $\S 1202$, because the credit, although apparently meeting the definition of $\S 1202(c)(2)$, was not part of an "automated copyright protection or management system."

Read in isolation, § 1202 simply establishes a cause of action for the removal of (among other things) the name of the author of a work when it has been "conveyed in connection with copies of" the work. The statute imposes no explicit requirement that such information be part of an "automated copyright protection or management system," as the Station Defendants claim. In fact, it appears to be extremely broad, with no restrictions on the context in which such information must be used in order to qualify as CMI. If there is a difficulty here, it is a problem of policy, not of logic.

\section{F Defenses}

\section{First Sale}

\section{Copyright Act}

17 U.S.C. § 109

Limitations on exclusive rights: Effect of transfer of particular copy or phonorecord (a) Notwithstanding the provisions of section 106(3), the owner of a particular copy or phonorecord lawfully made under this title, or any person authorized by such owner, is entitled, without the authority of the copyright owner, to sell or otherwise dispose of the possession of that copy or phonorecord.

(b) Notwithstanding the provisions of subsection (a), unless authorized by the owners of copyright in the sound recording or the 
owner of copyright in a computer program and in the case of a sound recording in the musical works embodied therein, neither the owner of a particular phonorecord nor any person in possession of a particular copy of a computer program may, for the purposes of direct or indirect commercial advantage, dispose of, or authorize the disposal of, the possession of that phonorecord or computer program by rental, lease, or lending.

(c) Notwithstanding the provisions of section 106(5), the owner of a particular copy lawfully made under this title, or any person authorized by such owner, is entitled, without the authority of the copyright owner, to display that copy publicly, either directly or by the projection of no more than one image at a time, to viewers present at the place where the copy is located.

\section{UMG Recordings, Inc. v. Augusto}

Like many music companies, UMG ships specially-produced promotional CDs to a large group of individuals ("recipients"), such as music critics and radio programmers, that it has selected. There is no prior agreement or request by the recipients to receive the CDs. UMG does not seek or receive payment for the CDs, the content and design of which often differs from that of their commercial counterparts. UMG ships the promotional CDs by means of the United States Postal Service and United Parcel Service. Relatively few of the recipients refuse delivery of the CDs or return them to UMG, and UMG destroys those that are returned.

Most of the promotional CDs in issue in this case bore a statement (the "promotional statement") similar to the following:

This CD is the property of the record company and is licensed to the intended recipient for personal use only. Acceptance of this $\mathrm{CD}$ shall constitute an agreement to comply with the terms of the license. Resale or transfer of possession is not allowed and may be punishable under federal and state laws. Some of the CDs bore a more succinct statement, such as "Promotional Use Only - Not for Sale."

Augusto was not among the select group of individuals slated to receive the promotional CDs. He nevertheless managed to acquire numerous such CDs, many of which he sold through online auctions at eBay.com. Augusto regularly advertised the CDs as "rare industry editions" and referred to them as "Promo CDs."

After several unsuccessful attempts at halting the auctions through eBay's dispute resolution program, UMG filed a complaint against Augusto in the United States District Court for the Central District of California, alleging that Augusto had infringed UMG's 
copyrights in eight promotional CDs for which it retained the "exclusive right to distribute."

Although UMG, as the owner of the copyright, has exclusive rights in the promotional CDs, exemptions, compulsory licenses, and defenses found in the Copyright Act narrow those rights. Augusto invokes the "first sale" doctrine embodied in $\S 109$ (a) of the Act. 17 U.S.C. § 109(a). He argues that the circumstances attending UMG's distribution of the discs effected a "sale" (transfer of ownership) of the discs to the original recipients and that, under the "first sale" doctrine, the recipients and subsequent owners of those particular copies were permitted to sell or otherwise dispose of those copies without authorization by the copyright holder.

UMG, on the other hand, contends that the promotional statement effected a license with the recipients and, because the recipients were not owners but licensees of the CDs, neither they nor Augusto were entitled to sell or otherwise transfer the CDs.

Notwithstanding its distinctive name, the first sale doctrine applies not only when a copy is first sold, but when a copy is given away or title is otherwise transferred without the accouterments of a sale. The seminal illustration of the principle is found in Bobbs-Merrill Co. $v$. Straus, where a copyright owner unsuccessfully attempted to restrain the resale of a copyrighted book by including in it the following notice: "The price of this book at retail is $\$ 1$ net. No dealer is licensed to sell it at a less price, and a sale at less price will be treated as an infringement of the copyright." The Court noted that the statutory grant to a copyright owner of the "sole right of vending" the work did not continue after the first sale of a given copy. "The purchaser of a book, once sold by authority of the owner of the copyright, may sell it again, although he could not publish a new edition of it." The attempt to limit resale below a certain price was therefore held invalid.

The rule of Bobbs-Merrill remains in full force, enshrined as it is in $\S 109$ (a) of the Act: a copyright owner who transfers title in a particular copy to a purchaser or donee cannot prevent resale of that particular copy. We have recognized, however, that not every transfer of possession of a copy transfers title. Particularly with regard to computer software, we have recognized that copyright owners may create licensing arrangements so that users acquire only a license to use the particular copy of software and do not acquire title that permits further transfer or sale of that copy without the permission of the copyright owner.

The same question is presented here. Did UMG succeed in creating a license in recipients of its promotional CDs, or did it convey title despite the restrictive labeling on the CDs? We conclude that, under all the circumstances of the CDs' distribution, the recipients 
were entitled to use or dispose of them in any manner they saw fit, and UMG did not enter a license agreement for the CDs with the recipients. Accordingly, UMG transferred title to the particular copies of its promotional CDs and cannot maintain an infringement action against Augusto for his subsequent sale of those copies.

Our conclusion that the recipients acquired ownership of the CDs is based largely on the nature of UMG's distribution. First, the promotional CDs are dispatched to the recipients without any prior arrangement as to those particular copies. The CDs are not numbered, and no attempt is made to keep track of where particular copies are or what use is made of them. As explained in greater detail below, although UMG places written restrictions in the labels of the CDs, it has not established that the restrictions on the CDs create a license agreement.

We also hold that, because the CDs were unordered merchandise, the recipients were free to dispose of them as they saw fit under the Unordered Merchandise Statute, 39 U.S.C. $§ 3009$, which provides in pertinent part that,

(a) [e]xcept for free samples clearly and conspicuously marked as such, the mailing of unordered merchandise constitutes an unfair method of competition and an unfair trade practice.

(b) Any merchandise mailed in violation of subsection (a) of this section may be treated as a gift by the recipient, who shall have the right to retain, use, discard, or dispose of it in any manner he sees fit without any obligation whatsoever to the sender.

There are additional reasons for concluding that UMG's distribution of the CDs did not involve a consensual licensing operation. Some of the statements on the CDs and UMG's purported method of securing agreement to licenses militate against a conclusion that any licenses were created. The sparest promotional statement, "Promotional Use Only-Not for Sale," does not even purport to create a license. But even the more detailed statement is flawed in the manner in which it purports to secure agreement from the recipient. The more detailed statement provides:

This CD is the property of the record company and is licensed to the intended recipient for personal use only. Acceptance of this CD shall constitute an agreement to comply with the terms of the license. Resale or transfer of possession is not allowed and may be punishable under federal and state laws.

It is one thing to say, as the statement does, that "acceptance" of the $\mathrm{CD}$ constitutes an agreement to a license and its restrictions, but it is quite another to maintain that "acceptance" may be assumed when 
the recipient makes no response at all. This record reflects no responses. Even when the evidence is viewed in the light most favorable to UMG, it does not show that any recipients agreed to enter into a license agreement with UMG when they received the CDs.

Because the record here is devoid of any indication that the recipients agreed to a license, there is no evidence to support a conclusion that licenses were established under the terms of the promotional statement. Accordingly, we conclude that UMG's transfer of possession to the recipients, without meaningful control or even knowledge of the status of the CDs after shipment, accomplished a transfer of title.

Because we conclude that UMG's method of distribution transferred the ownership of the copies to the recipients, we have no need to parse the remaining provisions in UMG's purported licensing statement; UMG dispatched the CDs in a manner that permitted their receipt and retention by the recipients without the recipients accepting the terms of the promotional statements. UMG's transfer of unlimited possession in the circumstances present here effected a gift or sale within the meaning of the first sale doctrine.

\section{Capitol Records, LLC v. ReDigi Inc.}

As an initial matter, it should be noted that the first sale defense is, by its own terms, limited to assertions of the distribution right. Because the Court has concluded that ReDigi's service violates Capitol's reproduction right, the first sale defense does not apply to ReDigi's infringement of those rights.

In addition, the first sale doctrine does not protect ReDigi's distribution of Capitol's copyrighted works. This is because, as an unlawful reproduction, a digital music file sold on ReDigi is not "lawfully made under this title." 17 U.S.C. § 109(a). Moreover, the statute protects only distribution by "the owner of a particular copy or phonorecord ... of that copy or phonorecord." Here, a ReDigi user owns the phonorecord that was created when she purchased and downloaded a song from iTunes to her hard disk. But to sell that song on ReDigi, she must produce a new phonorecord on the ReDigi server. Because it is therefore impossible for the user to sell her "particular" phonorecord on ReDigi, the first sale statute cannot provide a defense. Put another way, the first sale defense is limited to material items, like records, that the copyright owner put into the stream of commerce. Here, ReDigi is not distributing such material items; rather, it is distributing reproductions of the copyrighted code embedded in new material objects, namely, the ReDigi server in Arizona and its users' hard drives. The first sale defense does not cover this any more than it covered the sale of cassette recordings of vinyl records in a bygone era. 
Finally, ReDigi feebly argues that the Court's reading of Section 109(a) would in effect exclude digital works from the meaning of the statute. That is not the case. Section 109(a) still protects a lawful owner's sale of her "particular" phonorecord, be it a computer hard disk, iPod, or other memory device onto which the file was originally downloaded. While this limitation clearly presents obstacles to resale that are different from, and perhaps even more onerous than, those involved in the resale of CDs and cassettes, the limitation is hardly absurd - the first sale doctrine was enacted in a world where the ease and speed of data transfer could not have been imagined. There are many reasons for why such physical limitations may be desirable. It is left to Congress, and not this Court, to deem them outmoded.

\section{Fair Use}

\section{Copyright Act}

Notwithstanding the provisions of sections 106 and 106A, the fair use of a copyrighted work, including such use by reproduction in copies or phonorecords or by any other means specified by that section, for purposes such as criticism, comment, news reporting, teaching (including multiple copies for classroom use), scholarship, or research, is not an infringement of copyright. In determining whether the use made of a work in any particular case is a fair use the factors to be considered shall include

(1) the purpose and character of the use, including whether such use is of a commercial nature or is for nonprofit educational purposes;

(2) the nature of the copyrighted work;

(3) the amount and substantiality of the portion used in relation to the copyrighted work as a whole; and

(4) the effect of the use upon the potential market for or value of the copyrighted work.

The fact that a work is unpublished shall not itself bar a finding of fair use if such finding is made upon consideration of all the above factors.

\section{Fair Use Checklist}

The four fair use factors are a checklist of questions to ask about the facts in a given case, not a majority vote. As you see from the readings, they interrelate, and they are not all of equal importance. I find it helpful to break the factors down into a slightly more detailed checklist:

17 U.S.C. § 107

Limitations on exclusive rights: Fair use 
- Factor one ("purpose and character of the [defendant's] use"):

- Is the use for criticism, comment, or another use specifically mentioned in the flush text at the start of section 107 ?

- Is the use commercial or noncommercial?

- Is the use transformative?

- Factor two ("nature of the [plaintiff's] copyrighted work"):

- Is the work primarily informational or primarily expressive?

- Is the work published or unpublished?

- Factor three ("amount and substantiality of the portion used"):

- How much did the defendant copy quantitatively from the plaintiff's work?

- How qualitatively important were the copied portions to the plaintiff's work?

- How extensive was the defendant's copying in light of any proffered justifications?

- Factor four ("effect of the use upon the potential market"):

- What is the relevant market, and is it one the plaintiff can legitimately claim a right to?

- Did the plaintiff suffer losses because the defendant's work substituted for her own, or for some other reason?

- Miscellaneous:

- Did the defendant give appropriate attribution to the plaintiff's work as a source?

- Did either party engage in any dishonest or illegal conduct that bears directly on the copying?

- Is there anything else significant in the facts not already accounted for?

\section{Harper \& Row, Publishers, Inc. v. Nation Enterprises}

In February 1977, shortly after leaving the White House, former President Gerald R. Ford contracted with petitioners Harper \& Row and Reader's Digest, to publish his as yet unwritten memoirs. In addition to the right to publish the Ford memoirs in book form, the agreement gave petitioners the exclusive right to license prepublication excerpts, known in the trade as "first serial rights." Two years later, as the memoirs were nearing completion, petitioners negotiated a prepublication licensing agreement with Time, a weekly news magazine. Time agreed to pay $\$ 25,000, \$ 12,500$ in advance and an additional $\$ 12,500$ at publication, in exchange for the right to excerpt 7,500 words from Mr. Ford's account of the Nixon pardon. The issue featuring the ex- 
cerpts was timed to appear approximately one week before shipment of the full length book version to bookstores. Exclusivity was an important consideration; Harper \& Row instituted procedures designed to maintain the confidentiality of the manuscript, and Time retained the right to renegotiate the second payment should the material appear in print prior to its release of the excerpts.

Two to three weeks before the Time article's scheduled release, an unidentified person secretly brought a copy of the Ford manuscript to Victor Navasky, editor of The Nation, a political commentary magazine. Mr. Navasky knew that his possession of the manuscript was not authorized and that the manuscript must be returned quickly to his "source" to avoid discovery. He hastily put together what he believed was "a real hot news story" composed of quotes, paraphrases, and facts drawn exclusively from the manuscript. Mr. Navasky attempted no independent commentary, research or criticism, in part because of the need for speed if he was to "make news" by "publish[ing] in advance of publication of the Ford book." The 2,250-word article, reprinted in the Appendix to this opinion, appeared on April 3, 1979. As a result of The Nation's article, Time canceled its piece and refused to pay the remaining $\$ 12,500$.

[Harper \& Row sued for copyright infringement.]

The Nation has admitted to lifting verbatim quotes of the author's original language totaling between 300 and 400 words and constituting some $13 \%$ of The Nation article. In using generous verbatim excerpts of Mr. Ford's unpublished manuscript to lend authenticity to its account of the forthcoming memoirs, The Nation effectively arrogated to itself the right of first publication, an important marketable subsidiary right. For the reasons set forth below, we find that this use of the copyrighted manuscript, even stripped to the verbatim quotes conceded by The Nation to be copyrightable expression, was not a fair use within the meaning of the Copyright Act.

Fair use was traditionally defined as "a privilege in others than the owner of the copyright to use the copyrighted material in a reasonable manner without his consent." The statutory formulation of the defense of fair use in the Copyright Act reflects the intent of Congress to codify the common-law doctrine. Section 107 requires a case-bycase determination whether a particular use is fair, and the statute notes four nonexclusive factors to be considered. This approach was intended to restate the pre-existing judicial doctrine of fair use, not to change, narrow, or enlarge it in any way."

As early as 1841, Justice Story gave judicial recognition to the doc-

H. Ball, Law of Copyright and Literary Property (1944) 
trine in a case that concerned the letters of another former President, George Washington.

"[A] reviewer may fairly cite largely from the original work, if his design be really and truly to use the passages for the purposes of fair and reasonable criticism. On the other hand, it is as clear, that if he thus cites the most important parts of the work, with a view, not to criticise, but to supersede the use of the original work, and substitute the review for it, such a use will be deemed in law a piracy."

Folsom v. MarshAs Justice Story's hypothetical illustrates, the fair use doctrine has always precluded a use that "supersede[s] the use of the original."

Perhaps because the fair use doctrine was predicated on the author's implied consent to "reasonable and customary" use when he released his work for public consumption, fair use traditionally was not recognized as a defense to charges of copying from an author's as yet unpublished works. This absolute rule, however, was tempered in practice by the equitable nature of the fair use doctrine. In a given case, factors such as implied consent through de facto publication on performance or dissemination of a work may tip the balance of equities in favor of prepublication use. But it has never been seriously disputed that "the fact that the plaintiff's work is unpublished is a factor tending to negate the defense of fair use." Id.Publication of an author's expression before he has authorized its dissemination seriously infringes the author's right to decide when and whether it will be made public, a factor not present in fair use of published works.

$B$

Respondents, however, contend that First Amendment values require a different rule under the circumstances of this case. The thrust of the decision below is that the scope of fair use is undoubtedly wider when the information conveyed relates to matters of high public concern. Respondents advance the substantial public import of the subject matter of the Ford memoirs as grounds for excusing a use that would ordinarily not pass muster as a fair use - the piracy of verbatim quotations for the purpose of "scooping" the authorized first serialization. Respondents explain their copying of Mr. Ford's expression as essential to reporting the news story it claims the book itself represents. In respondents' view, not only the facts contained in Mr. Ford's memoirs, but "the precise manner in which [he] expressed himself [were] as newsworthy as what he had to say." Respondents argue that the public's interest in learning this news as fast as possible outweighs the right of the author to control its first publication. 
Respondents' theory, however, would expand fair use to effectively destroy any expectation of copyright protection in the work of a public figure. Absent such protection, there would be little incentive to create or profit in financing such memoirs, and the public would be denied an important source of significant historical information. The promise of copyright would be an empty one if it could be avoided merely by dubbing the infringement a fair use "news report" of the book.

Nor do respondents assert any actual necessity for circumventing the copyright scheme with respect to the types of works and users at issue here.[6] Where an author and publisher have invested extensive resources in creating an original work and are poised to release it to the public, no legitimate aim is served by pre-empting the right of first publication. The fact that the words the author has chosen to clothe his narrative may of themselves be "newsworthy" is not an independent justification for unauthorized copying of the author's expression prior to publication.

\section{IV}

Whether The Nation article constitutes fair use under $\S 107$ must be reviewed in light of the principles discussed above. The factors enumerated in the section are not meant to be exclusive: Since the doctrine is an equitable rule of reason, no generally applicable definition is possible, and each case raising the question must be decided on its own facts. The four factors identified by Congress as especially relevant in determining whether the use was fair are: (1) the purpose and character of the use; (2) the nature of the copyrighted work; (3) the substantiality of the portion used in relation to the copyrighted work as a whole; (4) the effect on the potential market for or value of the copyrighted work. We address each one separately.

Purpose of the Use. The Second Circuit correctly identified news reporting as the general purpose of The Nation's use. News reporting is one of the examples enumerated in $\S 107$ to give some idea of the sort of activities the courts might regard as fair use under the circumstances. This listing was not intended to be exhaustive, or to single out any particular use as presumptively a "fair" use. The drafters resisted pressures from special interest groups to create presumptive categories of fair use, but structured the provision as an affirmative defense requiring a case-by-case analysis. The fact that an article arguably is "news" and therefore a productive use is simply one factor in a fair use analysis.

We agree with the Second Circuit that the trial court erred in fixing on whether the information contained in the memoirs was actually new to the public. Courts should be chary of deciding what is and what is not news. The Nation has every right to seek to be the 
first to publish information. But The Nation went beyond simply reporting uncopyrightable information and actively sought to exploit the headline value of its infringement, making a "news event" out of its unauthorized first publication of a noted figure's copyrighted expression.

The fact that a publication was commercial as opposed to nonprofit is a separate factor that tends to weigh against a finding of fair use. Every commercial use of copyrighted material is presumptively an unfair exploitation of the monopoly privilege that belongs to the owner of the copyright. In arguing that the purpose of news reporting is not purely commercial, The Nation misses the point entirely. The crux of the profit/nonprofit distinction is not whether the sole motive of the use is monetary gain but whether the user stands to profit from exploitation of the copyrighted material without paying the customary price.

In evaluating character and purpose we cannot ignore The $\mathrm{Na}$ tion's stated purpose of scooping the forthcoming hard-cover and Time abstracts. The Nation's use had not merely the incidental effect but the intended purpose of supplanting the copyright holder's commercially valuable right of first publication. Also relevant to the "character" of the use is the propriety of the defendant's conduct. "Fair use presupposes good faith and fair dealing. The trial court found that The Nation knowingly exploited a purloined manuscript. Unlike the typical claim of fair use, The Nation cannot offer up even the fiction of consent as justification. Like its competitor newsweekly, it was free to bid for the right of abstracting excerpts from "A Time to Heal." Fair use "distinguishes between a true scholar and a chiseler who infringes a work for personal profit." Wainwright Securities Inc. v. Wall Street Transcript Corp.

Nature of the Copyrighted work. Second, the Act directs attention to the nature of the copyrighted work. "A Time to Heal" may be characterized as an unpublished historical narrative or autobiography. The law generally recognizes a greater need to disseminate factual works than works of fiction or fantasy. See Gorman, Fact or Fancy? The Implications for Copyright:

Even within the field of fact works, there are gradations as to the relative proportion of fact and fancy. One may move from sparsely embellished maps and directories to elegantly written biography. The extent to which one must permit expressive language to be copied, in order to assure dissemination of the underlying facts, will thus vary from case to case."

Even within the field of fact works, there are gradations as to the relative proportion of fact and fancy. One may move from sparsely em- 
bellished maps and directories to elegantly written biography. The extent to which one must permit expressive language to be copied, in order to assure dissemination of the underlying facts, will thus vary from case to case.

Some of the briefer quotes from the memoirs are arguably necessary adequately to convey the facts; for example, Mr. Ford's characterization of the White House tapes as the "smoking gun" is perhaps so integral to the idea expressed as to be inseparable from it. But The Nation did not stop at isolated phrases and instead excerpted subjective descriptions and portraits of public figures whose power lies in the author's individualized expression. Such use, focusing on the most expressive elements of the work, exceeds that necessary to disseminate the facts.

The fact that a work is unpublished is a critical element of its "nature." Our prior discussion establishes that the scope of fair use is narrower with respect to unpublished works. While even substantial quotations might qualify as fair use in a review of a published work or a news account of a speech that had been delivered to the public or disseminated to the press, see House Report, at 65, the author's right to control the first public appearance of his expression weighs against such use of the work before its release. The right of first publication encompasses not only the choice whether to publish at all, but also the choices of when, where, and in what form first to publish a work.

In the case of Mr. Ford's manuscript, the copyright holders' interest in confidentiality is irrefutable; the copyright holders had entered into a contractual undertaking to "keep the manuscript confidential" and required that all those to whom the manuscript was shown also "sign an agreement to keep the manuscript confidential." While the copyright holders' contract with Time required Time to submit its proposed article seven days before publication, The Nation's clandestine publication afforded no such opportunity for creative or quality control. It was hastily patched together and contained "a number of inaccuracies." App. 300b-300c (testimony of Victor Navasky). A use that so clearly infringes the copyright holder's interests in confidentiality and creative control is difficult to characterize as "fair."

Amount and Substantiality of the Portion Used. Next, the Act directs us to examine the amount and substantiality of the portion used in relation to the copyrighted work as a whole. In absolute terms, the words actually quoted were an insubstantial portion of "A Time to Heal." The District Court, however, found that "[T]he Nation took what was essentially the heart of the book." We believe the Court of Appeals erred in overruling the District Judge's evaluation of the qualitative nature of the taking. A Time editor described the chapters on the pardon as "the most interesting and moving parts of the entire manuscript." The portions actually quoted were selected by Mr. 
Navasky as among the most powerful passages in those chapters. He testified that he used verbatim excerpts because simply reciting the information could not adequately convey the "absolute certainty with which [Ford] expressed himself"; or show that "this comes from President Ford,"; or carry the "definitive quality" of the original. In short, he quoted these passages precisely because they qualitatively embodied Ford's distinctive expression.

As the statutory language indicates, a taking may not be excused merely because it is insubstantial with respect to the infringing work. As Judge Learned Hand cogently remarked, "no plagiarist can excuse the wrong by showing how much of his work he did not pirate." Sheldon. Conversely, the fact that a substantial portion of the infringing work was copied verbatim is evidence of the qualitative value of the copied material, both to the originator and to the plagiarist who seeks to profit from marketing someone else's copyrighted expression.

Stripped to the verbatim quotes, the direct takings from the unpublished manuscript constitute at least $13 \%$ of the infringing article. The Nation article is structured around the quoted excerpts which serve as its dramatic focal points. In view of the expressive value of the excerpts and their key role in the infringing work, we cannot agree with the Second Circuit that the "magazine took a meager, indeed an infinitesimal amount of Ford's original language."

Effect on the Market. Finally, the Act focuses on "the effect of the use upon the potential market for or value of the copyrighted work." This last factor is undoubtedly the single most important element of fair use. "Fair use, when properly applied, is limited to copying by others which does not materially impair the marketability of the work which is copied." The trial court found not merely a potential but an actual effect on the market. Time's cancellation of its projected serialization and its refusal to pay the $\$ 12,500$ were the direct effect of the infringement. The Court of Appeals rejected this factfinding as clearly erroneous, noting that the record did not establish a causal relation between Time's nonperformance and respondents' unauthorized publication of Mr. Ford's expression as opposed to the facts taken from the memoirs. We disagree. Rarely will a case of copyright infringement present such clear-cut evidence of actual damage. Petitioners assured Time that there would be no other authorized publication of any portion of the unpublished manuscript prior to April 23, 1979. Any publication of material from chapters 1 and 3 would permit Time to renegotiate its final payment. Time cited The Nation's article, which contained verbatim quotes from the unpublished manuscript, as a reason for its nonperformance.

More important, to negate fair use one need only show that if the challenged use should become widespread, it would adversely affect the potential market for the copyrighted work. This inquiry must 
take account not only of harm to the original but also of harm to the market for derivative works. "If the defendant's work adversely affects the value of any of the rights in the copyrighted work (in this case the adaptation [and serialization] right) the use is not fair."

The Nation conceded that its verbatim copying of some 300 words of direct quotation from the Ford manuscript would constitute an infringement unless excused as a fair use. Because we find that The Nation's use of these verbatim excerpts from the unpublished manuscript was not a fair use, the judgment of the Court of Appeals is reversed, and the case is remanded for further proceedings consistent with this opinion.

Campbell v. Acuff-Rose Music, Inc.

In 1964, Roy Orbison and William Dees wrote a rock ballad called "Oh, Pretty Woman" and assigned their rights in it to respondent Acuff-Rose Music, Inc.

Petitioners Luther R. Campbell, Christopher Wongwon, Mark Ross, and David Hobbs are collectively known as 2 Live Crew, a popular rap music group. In 1989, Campbell wrote a song entitled "Pretty Woman," which he later described in an affidavit as intended, "through comical lyrics, to satirize the original work." On July 5, 1989, 2 Live Crew's manager informed Acuff-Rose that 2 Live Crew had written a parody of "Oh, Pretty Woman," that they would afford all credit for ownership and authorship of the original song to AcuffRose, Dees, and Orbison, and that they were willing to pay a fee for the use they wished to make of it. Enclosed with the letter were a copy of the lyrics and a recording of 2 Live Crew's song. Acuff-Rose's agent refused permission, stating that "I am aware of the success enjoyed by 'The 2 Live Crews', but I must inform you that we cannot permit the use of a parody of 'Oh, Pretty Woman."' Nonetheless, in June or July 1989, 2 Live Crew released records, cassette tapes, and compact discs of "Pretty Woman" in a collection of songs entitled "As Clean As They Wanna Be." The albums and compact discs identify the authors of "Pretty Woman" as Orbison and Dees and its publisher as Acuff-Rose.

Almost a year later, after nearly a quarter of a million copies of the recording had been sold, Acuff-Rose sued 2 Live Crew and its record company, Luke Skyywalker Records, for copyright infringement.

The first factor in a fair use enquiry is "the purpose and character of the use, including whether such use is of a commercial nature or is for nonprofit educational purposes." $§ 107(1)$. The central purpose of this investigation is to see, in Justice Story's words, whether the new work merely "supersede[s] the objects" of the original creation, Folsom, or instead adds something new, with a further purpose or different character, altering the first with new expression, meaning, 
Leval, Toward a Fair Use Standard: 103 Harv. L. Rev. 1105 (1990)

Fisher: 794 F. 2d 432 (9th Cir. 1986)

Elsmere: 482 F. Supp. 741 (S.D.N.Y 1980) or message; it asks, in other words, whether and to what extent the new work is "transformative."Pierre Leval, Toward a Fair Use Standard. Although such transformative use is not absolutely necessary for a finding of fair use, 11 the goal of copyright, to promote science and the arts, is generally furthered by the creation of transformative works. Such works thus lie at the heart of the fair use doctrine's guarantee of breathing space within the confines of copyright, and the more transformative the new work, the less will be the significance of other factors, like commercialism, that may weigh against a finding of fair use.

Suffice it to say now that parody has an obvious claim to transformative value, as Acuff-Rose itself does not deny. Like less ostensibly humorous forms of criticism, it can provide social benefit, by shedding light on an earlier work, and, in the process, creating a new one. We thus line up with the courts that have held that parody, like other comment or criticism, may claim fair use under $\S 107$. See, e.g., Fisher v. Dees ("When Sonny Sniffs Glue," a parody of "When Sunny Gets Blue," is fair use); Elsmere Music, Inc. v. National Broadcasting Co. ("I Love Sodom," a "Saturday Night Live" television parody of "I Love New York," is fair use).

The germ of parody lies in the definition of the Greek parodeia, as "a song sung alongside another." Modern dictionaries accordingly describe a parody as a "literary or artistic work that imitates the characteristic style of an author or a work for comic effect or ridicule," or as a "composition in prose or verse in which the characteristic turns of thought and phrase in an author or class of authors are imitated in such a way as to make them appear ridiculous." For the purposes of copyright law, the nub of the definitions, and the heart of any parodist's claim to quote from existing material, is the use of some elements of a prior author's composition to create a new one that, at least in part, comments on that author's works. If, on the contrary, the commentary has no critical bearing on the substance or style of the original composition, which the alleged infringer merely uses to get attention or to avoid the drudgery in working up something fresh, the claim to fairness in borrowing from another's work diminishes accordingly (if it does not vanish), and other factors, like the extent of its commerciality, loom larger. Parody needs to mimic an original to make its point, and so has some claim to use the creation of its victim's (or collective victims') imagination, whereas satire can stand on its own two feet and so requires justification for the very act of borrowing.

The fact that parody can claim legitimacy for some appropriation

\footnotetext{
11 The obvious statutory exception to this focus on transformative uses is the straight reproduction of multiple copies for classroom distribution.
} 
does not, of course, tell either parodist or judge much about where to draw the line.

We have less difficulty in finding that critical element in 2 Live Crew's song than the Court of Appeals did, although having found it we will not take the further step of evaluating its quality. The threshold question when fair use is raised in defense of parody is whether a parodic character may reasonably be perceived. Whether, going beyond that, parody is in good taste or bad does not and should not matter to fair use. As Justice Holmes explained, "It would be a dangerous undertaking for persons trained only to the law to constitute themselves final judges of the worth of [a work], outside of the narrowest and most obvious limits. At the one extreme some works of genius would be sure to miss appreciation. Their very novelty would make them repulsive until the public had learned the new language in which their author spoke." Bleistein; cf. Yankee Publishing Inc. v. News America Publishing, Inc. ("First Amendment protections do not apply only to those who speak clearly, whose jokes are funny, and whose parodies succeed").

While we might not assign a high rank to the parodic element here, we think it fair to say that 2 Live Crew's song reasonably could be perceived as commenting on the original or criticizing it, to some degree. 2 Live Crew juxtaposes the romantic musings of a man whose fantasy comes true, with degrading taunts, a bawdy demand for sex, and a sigh of relief from paternal responsibility. The later words can be taken as a comment on the naivete of the original of an earlier day, as a rejection of its sentiment that ignores the ugliness of street life and the debasement that it signifies. It is this joinder of reference and ridicule that marks off the author's choice of parody from the other types of comment and criticism that traditionally have had a claim to fair use protection as transformative works. $1 \frac{18}{8}$

\section{City of Inglewood v. Teixeira}

In this action, the City makes two basic allegations. First, that it enjoys a copyright interest in the video recordings it makes of open public meetings of the Inglewood City Council. Second, that Teixeira has

\footnotetext{
${ }^{18}$ Finally, regardless of the weight one might place on the alleged infringer's state of mind, compare Harper $\mathcal{E}$ Row (fair use presupposes good faith and fair dealing) (quotation marks omitted), with Folsom (good faith does not bar a finding of infringement); Leval, Toward a Fair Use Standard (good faith irrelevant to fair use analysis), we reject Acuff-Rose's argument that 2 Live Crew's request for permission to use the original should be weighed against a finding of fair use. Even if good faith were central to fair use, 2 Live Crew's actions do not necessarily suggest that they believed their version was not fair use; the offer may simply have been made in a good-faith effort to avoid this litigation. If the use is otherwise fair, then no permission need be sought or granted. Thus, being denied permission to use a work does not weigh against a finding of fair use.
}

Yankee Publishing: 809 F. Supp. 267 (S.D.N.Y. 1992) (Leval, J.)

No. 15-cv-01815, 2015 WL 5025839 (C.D. Cal. Aug. 20, 2015) 
violated the City's copyright by using portions of these videos in making his own videos that criticize the City and its elected officials (the "Teixeira Videos").

The City alleges that it is the valid copyright owner of video recordings, including six of Inglewood Council meetings from 2011 to 2013 ("the "City Council Videos") for which it has submitted applications for copyright registration by the Register of Copyrights.s

Teixeira is a resident of Inglewood, California. He operates a website, Inglewoodwatchdog.wix.com, and posts videos on YouTube as Dehol Trouth. The City alleges that Teixeira has willfully and intentionally used infringing copies of the City Council Videos in question and distributed them in online media, thereby violating the City's exclusive reproduction and distribution rights.

\section{Discussion}

In his Motion, Teixeira makes two arguments as to why the City's action should be dismissed. First, under California law, the City may not claim and assert a copyright interest in the City Council Videos. Second, even if the City had an enforceable copyright interest in the videos, the Teixeira Videos fall squarely within the fair use protections of $\S 107$ of the Copyright Act.

For the reasons explained below, the Court agrees with both of Teixeira's arguments.

[Although federal law allows states and local government to claim copyright protection in works they create, the court held that California state law did not authorize local governments to do so.]

\section{B. Teixeira's Activity is Protected Fair Use}

Because the Court has determined that the City cannot state a claim it need not address whether Teixeira's copying constitutes fair use. Because the Court is dismissing the action, however, the Court will rule on fair use so that all issues may be appealed now, if the City chooses to do so.

Teixeira argues that he uses small portions of the freely available City Council Videos in order to create his own videos that comment on and criticize activities of the City Council, and in particular Mayor James Butts. This, he contends, falls squarely within the protections of the fair use doctrine as codified at $\S 107$ of the Copyright Act.

The City argues that fair use has never protected "such systematic infringement of copyright works for years at a time" and that "[c]opyrights would become meaningless if such wholesale theft were tolerated." The City contends that it is not trying to impinge on Teixeira's First Amendment but merely seeks to have him "stop posting substantially all of the [City Council Videos] with [Teixeira's] comments posted on top of them." The City continues to say that 
"[w]hat is really going on here is that the Defendant wants to criticize the City without doing his own work." The City also argues that a decision on the basis of fair use is not proper at this stage in the litigation.

A review of the videos is sufficient for the Court to rule that the Teixeira Videos are protected by the fair use doctrine as a matter of law. The Teixeira Videos use brief portions of the larger works in order to comment on, and criticize the political activities of the City Council and its members. He uses carefully chosen portions specifically for the purposes of exercising his First Amendment rights, and in doing so, substantially transforms the purpose and content of the City Council Videos.

\section{Each Statutory Factor Favors a Finding of Fair Use}

The Court determines that each statutory factor in $\S 107$ favors a finding of fair use.

\section{a. Purpose and Character of Use ...}

There is presently no evidence before the Court as to whether Teixeira has produced the videos for a commercial purpose beyond the City's allegation that he uses them to generate income, which the Court must accept as true on a motion under Rule 12(b)(6). Teixeira notes in his Reply that should the case proceed he will show that he does not produce the videos for commercial purposes. Teixeira, however, does not rely on the non-commercial nature of the videos and the Court need not either. As the Supreme Court explained in Campbell, the more transformative the new work, the less will be the significance of other factors, like commercialism, that may weigh against a finding of fair use. See also Hustler Magazine Inc. v. Moral Majority Inc. ("Even assuming that the use had a purely commercial purpose, the presumption of unfairness can be rebutted by the characteristics of the use").

The videos Teixeira produces address local politics in the City of Inglewood. They consist of his narrating his criticism of Mayor Butts over slides or other text, documents-such as a report by the Inglewood city clerk - and video clips, some of which are taken from the City Council Videos over which the City claims a copyright interest. The videos range in time from 3 minutes and 43 second to $15 \mathrm{~min}-$ utes long, and the clips from the City Council Videos are considerably shorter. Some of the clips are used unadorned but they are most often frequently overlaid with Teixeira's oral and written commentary and criticism, as well as music. Even when unadorned, they form only part of longer videos, with the clips contrasted with documents, sound recordings, and other video clips, accompanied with Teixeira's written and oral commentary. 
Free Republic: No. 98-cv07840, 2000 WL 565200 (C.D.Cal. Apr. 4, 2000)
Teixeira's use is highly transformative. His purpose falls directly within two of the categories explicitly referenced in $\S 107$ : criticism and commentary. The Teixeira Videos are also directed at political and other matters of public concern and constitute core First Amendment protected speech. The fair use doctrine generally provides a greater scope of protection when the works involve address matters of public concern.

The City's contention that Teixeira is "simply republishing untransformed, copies of the Copyrighted works, and free-riding on the City's expenses" is plainly incorrect on even the most cursory review of the Teixeira videos. The City's claim that "[t]he facts alleged a complete lack of transformativeness" is also irrelevant given the reference by the Complaint to the videos themselves.

The City's reliance on Los Angeles Times v. Free Republic is also unpersuasive. The defendant hosed an online bulletin board on which "generally, exact copies of whole or substantial portions of articles [we]re posted." The court rejected the arguments by the defendants that the works were transformative because the board did not substitute for the newspapers' websites, and because users added comments. The court noted that "[c]opying portions of a copyrighted work for the purpose of criticism or commentary is often considered fair use." However, the court concluded that limited commentary added to verbatim copies was not sufficient, and the amount of copying - full, verbatim copies - was too great to justify the limited commentary provided on the board. The purpose, the court concluded, was primarily to provide the content of the articles and the ancillary commentary was not sufficient to render the copying transformative because the copied works substituted for the originals. ("For those who visit the site regularly, therefore, the articles posted there serve as substitutes for the originals found on plaintiffs' websites or in their newspapers.")

Teixeira's use of the clips from the City Council Videos is of a wholly different sort. The clips are carefully chosen and heavily edited. Teixeira juxtaposes them with other materials, puts his own commentary over and around them, and uses specific clips to underscore and support the points he makes in his videos. No person wishing to find out what occurred during a lengthy City Council meeting would be satisfied with viewing any of the Teixeira Videos.

Indeed, the videos identified in the Complaint as infringing are quintessential transformative works for the purpose of criticism and commentary on matters of public concern. Even as used for commercial purpose - a fact which the Court assumes to be true - this factor alone would go a substantial way to support a finding of fair use.

\section{b. Nature of the Copyrighted Work}


The purportedly copyright material is not creative in nature. The City Council Videos are straightforward recordings of public proceedings.

The City's arguments address whether there is sufficient creativity to warrant copyright protection at all. While the videos are very likely sufficiently "creative" to fall within the scope of copyright protection, this does not mean that this factor favors the City.

Given the barely creative nature of the City Council Videos, and their informational purpose, they enjoy very narrow copyright protection. This factor therefore weighs in favor of a finding of fair use.

c. Amount and Substantiality of the Portion Used

As described above with regards to the first factor, Teixeira uses only small portions of the total works and uses them for very specific and particular purposes. In five of the six accused videos, he intersperses short clips of the City Council Videos between written slides, pictures, other video clips, and his own commentary.

The first and second videos are approximately 15 minutes long and contain clips from the City Council meeting held on July 20, 2010. The video of the meeting is more than four hours long. The clips used in Teixeira's first two videos, are all under a minute long, and most of them 15 seconds or less. The videos address issues regarding Mayor Butts' Inglewood residency issues that arose while he was running for mayor, and his interactions with the City's Clerk regarding a report she compiled as to his voter registration and qualification to run for mayor.

The third video is the shortest of the Teixeira videos at three minutes and 43 seconds. It is almost wholly comprised of a single clip from the City Council meeting on May 22, 2012, at which Mayor Butts reads a statement regarding a request for information about a shooting. This is the longest clip used by Teixeira in any of the accused videos. Throughout the video there is music added by Teixeira, but more importantly, his commentary runs along the bottom of the screen as Butts talks. Teixeira ridicules Butts' physical tics as he talks, notes his apparent nervousness and stuttering, and specifically identifies points at which Teixeira alleges Butts is lying. The full video of the meeting runs more than three hours.

The City argues that Teixeira fails to meet his supposed burden of showing that it is "essential" to make the copies for his purpose of commenting on it. The City contends that each topic area of the City Council meetings is "an independent and entire work" and Teixeira cannot show why it is necessary to copy these "entire" works. However, a review of the videos makes it clear that Teixeira has copied only the parts of the City Council Videos that serve his purpose of making comment on them, or criticizing very particular statements by Butts. This use of another's material has been frequently recog- 
Northland: 868 F. Supp. 2d 962 (C.D. Cal. 2012)

Cal. Gov. Code § 6253(b) nized as protected fair use. See Northland Family Planning Clinic, Inc. v. Center for Bio-Ethical Reform (holding that using verbatim portions of plaintiff's pro-abortion video in making a video protesting abortion was fair use). The City's exceptionally narrow view of an "entire" work is without merit and contrary to the purpose of the fair use doctrine, which permits the use of reasonable quantities of a work for the purpose of criticism and comment.

Teixeira's use of the clips from the City Council Videos is limited to his purpose of criticizing Butts and the City Council, and commenting on the proceedings of the City Council. Teixeira chooses small and very specific parts of lengthy proceedings to make his point in his videos. The extent of his copying is reasonable in light of his purpose. Accordingly, this factor also strongly favors a finding of fair use.

\section{d. Effect of Use on the Market}

This factor strongly favors Teixeira because there is no market for the City Council Videos and the accused works are not a substitute for the original works.

The City argues that the factor favors its position because Teixeira's copying denies the City of the opportunity to "recoup its expenses" and "deprives [the City] of potential revenue." This argument is without merit and flatly contradicted by the California law that governs the City's creation and use of the City Council Videos.

California law prevents public agencies from charging the public anything more than the "direct costs of duplication" when providing public records.

The City therefore may only collect fees to reimburse for the direct costs of providing copies of any record it creates, including the City Council Videos. It is specifically barred by law from charging any fee to recoup the costs of original production. And it is certainly not permitted to use the City Council Videos to generate any form of revenue. There can therefore be no commercial market for the City Council Videos and no activity by Teixeira can deprive the City of any revenue.

Because copyright's purpose is to protect the commercial interest of authors so as to incentivize the creation of further works the lack of a market for the City Council Videos suggests that the City has no interest in copyright protection of the City Council Videos.

Further, even if the City could generate revenue from its works, Teixeira's videos are not a substitute. The original works are lengthy, unadorned videos of City Council meetings. Teixeira's videos are considerably shorter, contain even shorter portions of the City Council meetings, and are exclusively for the purpose of presenting Teixeira's views and commentary on Inglewood city politics). 
Accordingly, this factor also strongly favors a finding of fair use.

\section{Teixeira's Videos are Fair Use as a Matter of Law}

Having reviewed the accused videos, the Court determines thateven assuming the City has any copyright interest to assert-they are clearly protected by the fair use doctrine. Indeed, the Court can scarcely conceive of works that are more appropriately protected by the fair use doctrine and $\S 107$ than the Teixeira Videos. He is engaged in core First Amendment speech commenting on political affairs and matters of public concern. To do so, he has taken carefully selected and short portions of significantly longer works, and embellished them with commentary and political criticism through music, his voice, and written subtitles. Even if California law allowed the City to assert a copyright claim, Teixeira's activities plainly fall within the protections of fair use.

The City accuses Teixeira of wanting "to criticize the City without doing his own work" by "posting substantially all of the full [City Council Videos] with [his] comments posted on top of them." Even if the City's characterization of the Teixeira Videos were accurate, fair use would allow such use for the purpose of commentary.

Fox Broadcasting Co., Inc. v. Dish Network LLC Plaintiffs Fox Broadcasting Company, Twentieth Century Fox Film Corp., and Fox Television Holdings, Inc. (collectively, "Fox") own the copyrights to television shows that air on the Fox television network. Its primetime lineup includes shows such as Glee, Bones, The Simpsons, and Family Guy. One distributor that Fox contracts with is Dish Network, the third-largest pay television service provider in the United States.

In March 2012, Dish released to its customers the Hopper, a settop box with digital video recorder (DVR) and video on demand capabilities. At the same time it released the Hopper, Dish introduced a feature called PrimeTime Anytime that works only on the Hopper. PrimeTime Anytime allows a subscriber to set a single timer to record any and all primetime programming on the four major broadcast networks (including Fox) every night of the week. To enable PrimeTime Anytime, a Hopper user presses the "*" button on the remote control to reach the PrimeTime Anytime setup screen. The user selects "Enable," and a new menu appears where the viewer can disable recordings of certain networks on certain days of the week and change the length of time that the shows are saved (between two and eight days). By default, PrimeTime Anytime records primetime shows on all four networks each night of the week and saves all recordings for eight days.

In May 2012, Dish started offering a new feature, AutoHop, that al- 
lows users to automatically skip commercials. AutoHop is only available on shows recorded using PrimeTime Anytime, typically on the morning after the live broadcast. It is not available for all primetime programs. When a user plays back a PrimeTime Anytime recording, if AutoHop is available, a pop-up screen appears that allows the user to select the option to "automatically skip over" commercial breaks. By default, AutoHop is not selected.

If a customer enables AutoHop, the viewer sees only the first and last few seconds of each commercial break. A red kangaroo icon appears in the corner of the screen to demonstrate that AutoHop is skipping commercials. Unlike the 30 -second skip feature available on many DVRs, once a user has enabled AutoHop, the user does not press anything to skip through commercials. AutoHop does not delete commercials from the recording. Customers can see the commercials if they manually rewind or fast-forward into a commercial break.

Fox sued Dish for copyright infringement and breach of contract and sought a preliminary injunction. The district court denied the motion.

The district court did not abuse its discretion in concluding that Fox was unlikely to succeed on its claim of secondary copyright infringement for the PrimeTime Anytime and AutoHop programs. Secondary liability for copyright infringement does not exist in the absence of direct infringement by a third party. Therefore, to establish secondary liability, Fox must establish that Dish's users are infringing. There is no dispute that Fox has established a prima facie case of direct infringement by Dish customers because Fox owns the copyrights to its shows and the users make copies. Thus, the burden shifts to Dish to demonstrate that it is likely to succeed on its affirmative defense that its customers' copying was a fair use. Dish has met this burden.

As the district court recognized, the Supreme Court's analysis in Sony provides strong guidance in assessing whether Dish customers' copying of Fox programs is a "fair use." In Sony, the Supreme Court held that Sony was not liable for secondary infringement for manufacturing Betamax VCRs because customers used the machines primarily for time-shifting.

Fox and its amici argue that Dish customers use PrimeTime Anytime and AutoHop for purposes other than time-shifting - namely, commercial-skipping and library-building. These uses were briefly discussed in Sony, in which the Court recognized that some Betamax customers used the device to avoid viewing advertisements and accumulate libraries of tapes. In Sony, about 25 percent of Betamax users fast-forwarded through commercials. Additionally, a "substantial number of interviewees had accumulated libraries of tapes." One 
user owned about 100 tapes and bought his Betamax intending to "build a library of cassettes," but this "proved too expensive." Because the Betamax was primarily used for timeshifting, the Court in Sony never expressly decided whether commercial-skipping and library-building were fair uses.

Yet, as the district court held, commercial-skipping does not implicate Fox's copyright interest because Fox owns the copyrights to the television programs, not to the ads aired in the commercial breaks. If recording an entire copyrighted program is a fair use, the fact that viewers do not watch the ads not copyrighted by Fox cannot transform the recording into a copyright violation. Indeed, a recording made with PrimeTime Anytime still includes commercials; AutoHop simply skips those recorded commercials unless a viewer manually rewinds or fast-forwards into a commercial break. Thus, any analysis of the market harm should exclude consideration of AutoHop because ad-skipping does not implicate Fox's copyright interests.

Analyzing PrimeTime Anytime under the fair use factors, Dish has demonstrated a likelihood of success on its customers' fair use defense. As for the first factor, the "purpose and character of the use, including whether such use is of a commercial nature or is for nonprofit educational purposes," Dish customers' home viewing is noncommercial under Sony, which held that "time-shifting for private home use" was a "noncommercial, nonprofit activity," Here, the district court found that PrimeTime Anytime is used for time-shifting, and that the Hopper is available only to private consumers.

Sony also governs the analysis of the second and third factors, the "nature of the copyrighted work" and "the amount and substantiality of the portion used in relation to the copyrighted work as a whole," Sony held that "when one considers the nature of a televised copyrighted audiovisual work, and that time-shifting merely enables a viewer to see such a work which he had been invited to witness in its entirety free of charge, the fact that the entire work is reproduced, does not have its ordinary effect of militating against a finding of fair use." The same analysis applies here, and thus the fact that Dish users copy Fox's entire copyrighted broadcasts does not have its ordinary effect of militating against a finding of fair use.

Finally, we consider the "effect of the use upon the potential market for or value of the copyrighted work.This is the "most important element of fair use." Harper \& Row Because Dish customers' taping is "for a noncommercial purpose," the likelihood of future market harm is not presumed but "must be demonstrated." Sony Fox "need only show that if the challenged use should become widespread, it would adversely affect the potential market for the copyrighted work." Harper \& Row

Because Fox licenses its programs to distributors such as Hulu and 
Apple, the market harm analysis is somewhat different than in Sony, where no such secondary market existed for the copyright-holders' programs. However, the record before the district court establishes that the market harm that Fox and its amici allege results from the automatic commercial-skipping, not the recording of programs through PrimeTime Anytime. Indeed, Fox often charges no additional license fees for providers to offer Fox's licensed video on demand, so long as providers disable fast-forwarding. This indicates that the ease of skipping commercials, rather than the on-demand availability of Fox programs, causes any market harm. And as we have discussed, the commercial-skipping does not implicate any copyright interest.

Therefore, the district court did not abuse its discretion in concluding that Fox was unlikely to succeed on its secondary infringement claim.

\section{Capitol Records, LLC v. ReDigi Inc.}

934 F. Supp. 2d 640 (S.D.N.Y. 2013)

On the record before it, the Court has little difficulty concluding that ReDigi's reproduction and distribution of Capitol's copyrighted works falls well outside the fair use defense. ReDigi obliquely argues that uploading to and downloading from the Cloud Locker for storage and personal use are protected fair use. Significantly, Capitol does not contest that claim. Instead, Capitol asserts only that uploading to and downloading from the Cloud Locker incident to sale fall outside the ambit of fair use. The Court agrees.

Each of the statutory factors counsels against a finding of fair use. The first factor requires the Court to determine whether ReDigi's use "transforms" the copyrighted work and whether it is commercial. Both inquiries disfavor ReDigi's claim. Plainly, the upload, sale, and download of digital music files on ReDigi's website does nothing to "add[] something new, with a further purpose or different character" to the copyrighted works. Campbell ReDigi's use is also undoubtedly commercial. ReDigi and the uploading user directly profit from the sale of a digital music file, and the downloading user saves significantly on the price of the song in the primary market. ReDigi asserts that downloads for personal, and not public or commercial, use "must be characterized as noncommercial, nonprofit activity." However, ReDigi twists the law to fit its facts. When a user downloads purchased files from the Cloud Locker, the resultant reproduction is an essential component of ReDigi's commercial enterprise. Thus, ReDigi's argument is unavailing.

The second factor - the nature of the copyrighted work - also weighs against application of the fair use defense, as creative works like sound recordings are close to the core of the intended copyright protection and far removed from the ... factual or descriptive work more amenable to fair use. 
The third factor - the portion of the work copied - suggests a similar outcome because ReDigi transmits the works in their entirety.

Finally, ReDigi's sales are likely to undercut the market for or value of the copyrighted work and, accordingly, the fourth factor cuts against a finding of fair use. The product sold in ReDigi's secondary market is indistinguishable from that sold in the legitimate primary market save for its lower price. The clear inference is that ReDigi will divert buyers away from that primary market. ReDigi incredibly argues that Capitol is preempted from making a market-based argument because Capitol itself condones downloading of its works on iTunes. Of course, Capitol, as copyright owner, does not forfeit its right to claim copyright infringement merely because it permits certain uses of its works. This argument, too, is therefore unavailing.

\section{Chicago HOPE Problem}

Compare Shepard Fairey's famous Obama "HOPE" poster with the photograph he used as a starting point. Assume that the photograph's copyright is owned by the Associated Press, which used it to illustrate a news story about a campaign event and then offered it for licensing through a stock photography bureau. Assume further that Fairey created the poster to support Obama, that he then licensed it for free to the Obama campaign, that the campaign has given out tens of thousands of prints to supporters and it has been distributed widely for free online. And finally, note that Fairey became significantly more famous as a result of the poster and the publicity it received, and that he initially lied under oath in trying to conceal the fact that he had used the photograph as a source. Fair use?

\section{Section 512}

\section{Copyright Act}

(c) Information Residing on Systems or Networks At Direction of Users. -

(1) In general. - A service provider shall not be liable for monetary relief, or, except as provided in subsection $(j)$, for injunctive or other equitable relief, for infringement of copyright by reason of the storage at the direction of a user of material that resides on a system or network controlled or operated by or for the service provider, if the service provider - ...

(C) upon notification of claimed infringement as described in paragraph (3), responds expeditiously to re-

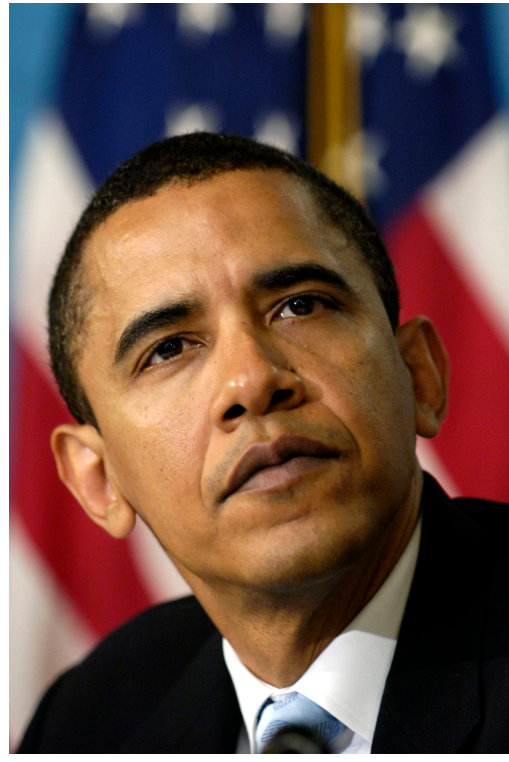

Obama "HOPE" poster by Shepard Fairey

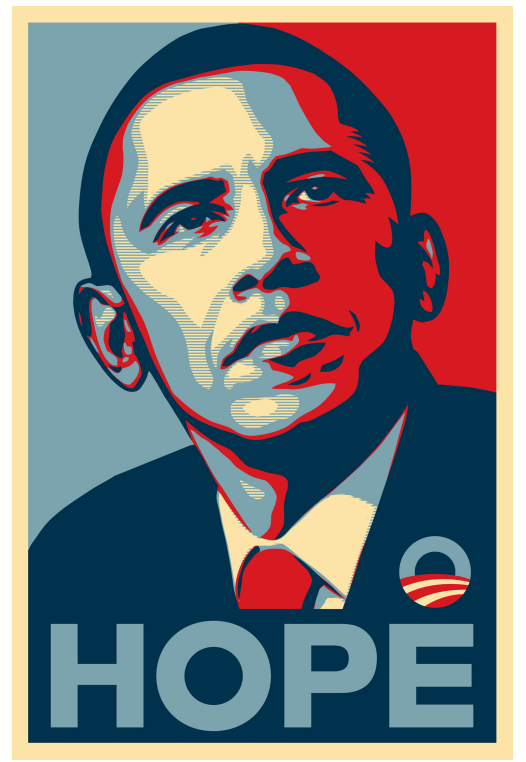

Obama photograph by Mannie Garcia

17 U.S.C. § 512

Limitations on liability relating to material online 
move, or disable access to, the material that is claimed to be infringing or to be the subject of infringing activity.

(2) Designated agent. - The limitations on liability established in this subsection apply to a service provider only if the service provider has designated an agent to receive notifications of claimed infringement described in paragraph (3), by making available through its service, including on its website in a location accessible to the public, and by providing to the Copyright Office, substantially the following information:

(A) the name, address, phone number, and electronic mail address of the agent.

(B) other contact information which the Register of Copyrights may deem appropriate. ...

(3) Elements of notification.-

(A) To be effective under this subsection, a notification of claimed infringement must be a written communication provided to the designated agent of a service provider that includes substantially the following:

(i) A physical or electronic signature of a person authorized to act on behalf of the owner of an exclusive right that is allegedly infringed.

(ii) Identification of the copyrighted work claimed to have been infringed, or, if multiple copyrighted works at a single online site are covered by a single notification, a representative list of such works at that site.

(iii) Identification of the material that is claimed to be infringing or to be the subject of infringing activity and that is to be removed or access to which is to be disabled, and information reasonably sufficient to permit the service provider to locate the material.

(iv) Information reasonably sufficient to permit the service provider to contact the complaining party, such as an address, telephone number, and, if available, an electronic mail address at which the complaining party may be contacted.

(v) A statement that the complaining party has a good faith belief that use of the material in the manner complained of is not authorized by the copyright owner, its agent, or the law. 
(vi) A statement that the information in the notification is accurate, and under penalty of perjury, that the complaining party is authorized to act on behalf of the owner of an exclusive right that is allegedly infringed. ...

\section{UMG Recordings, Inc. v. Shelter Capital Partners}

Veoh Networks (Veoh) operates a publicly accessible website that enables users to share videos with other users. When a video is uploaded, various automated processes take place. Veoh's software automatically breaks down the video file into smaller 256-kilobyte "chunks," which facilitate making the video accessible to others. Veoh's software also automatically converts, or "transcodes," the video file into Flash 7 format. This is done because "the vast majority of internet users have software that can play videos" in this format.

Veoh's computers also automatically extract metadata from information users provide to help others locate the video for viewing. Users can provide a title, as well as tags or keywords that describe the video, and can also select pre-set categories describing the video, such as "music," "faith" or "politics." The Veoh system then automatically assigns every uploaded video a "permalink," or web address, that uniquely identifies the video and makes it available to users. Veoh employees do not review the user-submitted video, title or tags before the video is made available.

Veoh employs various technologies to automatically prevent copyright infringement on its system. In 2006, Veoh adopted "hash filtering" software. Whenever Veoh disables access to an infringing video, the hash filter also automatically disables access to any identical videos and blocks any subsequently submitted duplicates. Veoh also began developing an additional filtering method of its own, but in 2007 opted instead to adopt a third-party filtering solution produced by a company called Audible Magic. Audible Magic's technology takes audio "fingerprints" from video files and compares them to a database of copyrighted content provided by copyright holders. If a user attempts to upload a video that matches a fingerprint from Audible Magic's database of forbidden material, the video never becomes available for viewing. Approximately nine months after beginning to apply the Audible Magic filter to all newly uploaded videos, Veoh applied the filter to its backlog of previously uploaded videos. This resulted in the removal of more than 60,000 videos, including some incorporating UMG's works. Veoh has also implemented a policy for terminating users who repeatedly upload infringing material, and has terminated thousands of user accounts.

Despite Veoh's efforts to prevent copyright infringement on its 
system, both Veoh and UMG agree that some of Veoh's users were able to download unauthorized videos containing songs for which UMG owns the copyright. The parties also agree that before UMG filed its complaint, the only notices Veoh received regarding alleged infringements of UMG's works were sent by the Recording Industry Association of America (RIAA). The RIAA notices listed specific videos that were allegedly infringing, and included links to those videos. The notices did not assert rights to all works by the identified artists, and did not mention UMG. UMG does not dispute that Veoh removed the material located at the links identified in the RIAA notices.

In September 2007, UMG filed suit against Veoh for direct, vicarious and contributory copyright infringement, and for inducement of infringement.

\section{A}

We must first decide whether the functions automatically performed by Veoh's software when a user uploads a video fall within the meaning of "by reason of the storage at the direction of a user." 17 U.S.C. § 512(c)(1). Although UMG concedes that "[s]torage on computers involves making a copy of the underlying data," it argues that "nothing in the ordinary definition of 'storage' encompasses" the automatic processes undertaken to facilitate public access to useruploaded videos. Facilitation of access, UMG argues, goes beyond "storage." Therefore the creation of chunked and Flash files and the streaming and downloading of videos fall outside $\S 512(\mathrm{c})$.

By its terms, §512(c) presupposes that service providers will provide access to users' stored material, and we would thus contravene the statute if we held that such access disqualified Veoh from the safe harbor. Section 512(c) codifies a detailed notice and takedown procedure by which copyright holders inform service providers of infringing material accessible through their sites, and service providers then "disable access to" such materials. This carefully considered protocol, and the statute's attendant references to "disabl[ing] access" to infringing materials would be superfluous if we accepted UMG's constrained reading of the statute. Indeed, it is not clear how copyright holders could even discover infringing materials on service providers' sites to notify them as the protocol dictates if $\S 512$ (c) did not contemplate that there would be access to the materials.

The technological processes involved in providing web hosting services require those service providers to make, transmit and download multiple copies of users' stored materials. To create a website, the user uploads content to the web host's computers, which make an initial copy. Then, when another Internet user wants to access the website by clicking a link or entering the URL, all the website's rel- 
evant content is transmitted to the user's computer, where another copy is automatically made by the user's web browser software in order to assemble the materials for viewing and listening. To carry out their function of making websites available to Internet users, web hosting services thus routinely copy content and transmit it to Internet users. We cannot see how these access-facilitating processes are meaningfully distinguishable from Veoh's for $§ 512$ (c)(1) purposes.

\section{$B$}

It is undisputed that, until the filing of this lawsuit, UMG had not identified to Veoh any specific infringing video available on Veoh's system. Nevertheless, UMG contends that Veoh hosted a category of copyrightable content - music - for which it had no license from any major music company. UMG argues Veoh thus must have known this content was unauthorized, given its general knowledge that its services could be used to post infringing material. UMG urges us to hold that this sufficiently demonstrates knowledge of infringement. We cannot, for several reasons.

As an initial matter, contrary to UMG's contentions, there are many music videos that could in fact legally appear on Veoh. Among the types of videos subject to copyright protection but lawfully available on Veoh's system were videos with music created by users and videos that Veoh provided pursuant to arrangements it reached with major copyright holders, such as SonyBMG. If merely hosting material that falls within a category of content capable of copyright protection, with the general knowledge that one's services could be used to share unauthorized copies of copyrighted material, was sufficient to impute knowledge to service providers, the $\S 512$ (c) safe harbor would be rendered a dead letter: $\S 512$ (c) applies only to claims of copyright infringement, yet the fact that a service provider's website contained copyrightable material would remove the service provider from $\S 512$ (c) eligibility.

These considerations are reflected in Congress' decision to enact a notice and takedown protocol encouraging copyright holders to identify specific infringing material to service providers. They are also evidenced in the "exclusionary rule" that prohibits consideration of substantially deficient $\S 512$ (c)(3)(A) notices for purposes of "determining whether a service provider has actual knowledge or is aware of facts and circumstances from which infringing activity is apparent.. We therefore hold that merely hosting a category of copyrightable content, such as music videos, with the general knowledge that one's services could be used to share infringing material, is insufficient to meet the actual knowledge requirement under $\S 512(\mathrm{c})(1)(\mathrm{A})(\mathrm{i})$.

We reach the same conclusion with regard to the § 512(c)(1)(A)(ii) inquiry into whether a service provider is "aware of facts or cir- 
cumstances from which infringing activity is apparent." The district court's conception of this "red flag test" properly followed our analysis in Perfect 10, Inc. v. CCBill LLC, which reiterated that the burden remains with the copyright holder rather than the service provider. The plaintiffs in CCBill argued that there were a number of red flags that made it apparent infringing activity was afoot, noting that the defendant hosted sites with names such as "illegal.net" and "stolencelebritypics.com," as well as password hacking websites, which obviously infringe. We disagreed that these were sufficient red flags because "we do not place the burden of determining whether materials are actually illegal on a service provider," and "we impose no such investigative duties on service providers." For the same reasons, we hold that Veoh's general knowledge that it hosted copyrightable material and that its services could be used for infringement is insufficient to constitute a red flag.

We are not persuaded that UMG's other purported evidence of Veoh's actual or apparent knowledge of infringement warrants trial. First, UMG points to the tagging of videos on Veoh's service as "music videos." Relying on the theory rejected above, UMG contends that this demonstrates Veoh's knowledge that it hosted a category of infringing content. Relatedly, UMG argues that Veoh's purchase of certain search terms through the Google AdWords program demonstrates knowledge of infringing activity because some of the terms purchased, such as "50 Cent," "Avril Lavigne" and "Britney Spears," are the names of UMG artists. However, artists are not always in exclusive relationships with recording companies, so just because UMG owns the copyrights for some Britney Spears songs does not mean it owns the copyright for all Britney Spears songs. Indeed, 50 Cent, Avril Lavigne and Britney Spears are also affiliated with Sony-BMG, which gave Veoh permission to stream its videos by these artists. Furthermore, even if Veoh had not had such permission, we recognize that companies sometimes purchase search terms they believe will lead potential customers to their websites even if the terms do not describe goods or services the company actually provides. For example, a sunglass company might buy the search terms "sunscreen" or "vacation" because it believed that people interested in such searches would often also be interested in sunglasses. Accordingly, Veoh's search term purchases do little to demonstrate that it knew it hosted infringing material.

UMG comes closer to meeting the $\S 512(\mathrm{c})(1)(\mathrm{A})$ requirements with its evidence of emails sent to Veoh executives and investors by copyright holders and users identifying infringing content. One email, sent by the CEO of Disney, a major copyright holder, to Michael Eisner, a Veoh investor, stated that the movie Cinderella III and various episodes from the television show Lost were available 
on Veoh without Disney's authorization. If this notification had come from a third party, such as a Veoh user, rather than from a copyright holder, it might meet the red flag test because it specified particular infringing material. As a copyright holder, however, Disney is subject to the notification requirements in $\S 512$ (c)(3), which this informal email failed to meet. Accordingly, this deficient notice "shall not be considered under paragraph (1)(A) in determining whether a service provider has actual knowledge or is aware of facts or circumstances from which infringing activity is apparent.". Further, even if this email could have created actual knowledge or qualified as a red flag, Eisner's email in response assured Disney that he would instruct Veoh to "take it down," and Eisner copied Veoh's founder to ensure this happened "right away." UMG nowhere alleges that the offending material was not immediately removed, and accordingly Veoh would be saved by $\S 512(\mathrm{c})(1)(\mathrm{A})(\mathrm{iii})$, which preserves the safe harbor for service providers with such knowledge so long as they "act[] expeditiously to remove, or disable access to, the material."

\section{C}

UMG appeals the district court's determination that Veoh did not have the necessary right and ability to control infringing activity and thus remained eligible for safe harbor protection.

As discussed in the knowledge context, it is not enough for a service provider to know as a general matter that users are capable of posting unauthorized content; more specific knowledge is required. Similarly, a service provider may, as a general matter, have the legal right and necessary technology to remove infringing content, but until it becomes aware of specific unauthorized material, it cannot exercise its "power or authority" over the specific infringing item. In practical terms, it does not have the kind of ability to control infringing activity the statute contemplates.

Our reading of $\S 512(\mathrm{c})(1)(\mathrm{B})$ is informed and reinforced by our concern that the statute would be internally inconsistent were we to interpret the "right and ability to control" language as UMG urges. First, $\S 512(\mathrm{~m})$ cuts against holding that Veoh's general knowledge that infringing material could be uploaded to its site triggered an obligation to "police" its services to the "fullest extent" possible. As we have explained, $\S 512(\mathrm{~m})$ provides that $\S 512(\mathrm{c})$ 's safe harbor protection may not be conditioned on "a service provider monitoring its service or affirmatively seeking facts indicating infringing activity." UMG's reading of the "right and ability to control" language would similarly run afoul of CCBill, , which likewise clarified that § 512(c) "impose[s] no such investigative duties on service providers," and "place[s] the burden of policing copyright infringement ... squarely on the owners of the copyright." We are not persuaded by UMG's 
suggestion that Congress meant this limitation on the duty to monitor to apply only to service providers who do not receive a direct financial benefit under subsection (B). Rather, we conclude that a service provider must be aware of specific infringing material to have the ability to control that infringing activity within the meaning of $\S$ 512(c)(1)(B). Only then would its failure to exercise its ability to control deny it a safe harbor.

Second, §512(c) actually presumes that service providers have the sort of control that UMG argues satisfies the § 512(c)(1)(B) "right and ability to control" requirement: they must "remove[] or disable access to" infringing material when they become aware of it. 17 U.S.C. $\S 512(\mathrm{c})(1)(\mathrm{A})(\mathrm{iii}) \&(\mathrm{C})$. UMG argues that service providers have "the right and ability to control" infringing activity, § 512(c)(1)(B), as long as they have "the ability to locate infringing material" and "terminate users' access." Under that reading, service providers would have the "right and ability to control" infringing activity regardless of their becoming "aware of" the material. Under that interpretation, the prerequisite to $\S 512(\mathrm{c})$ protection under $\S 512(\mathrm{c})(1)(\mathrm{A})(\mathrm{iii})$ and $(\mathrm{C})$, would at the same time be a disqualifier under $\S 512(\mathrm{c})(1)(\mathrm{B})$. Congress could not have intended for courts to hold that a service provider loses immunity under the safe harbor provision of the DMCA because it engages in acts that are specifically required by the DMCA.

Accordingly, we hold that the "right and ability to control" under $\S 512(c)$ requires control over specific infringing activity the provider knows about. A service provider's general right and ability to remove materials from its services is, alone, insufficient. Of course, a service provider cannot willfully bury its head in the sand to avoid obtaining such specific knowledge. Viewing the evidence in the light most favorable to UMG, as we must here, we agree with the district court there is no evidence that Veoh acted in such a manner. Rather, the evidence demonstrates that Veoh promptly removed infringing material when it became aware of specific instances of infringement. Although the parties agree, in retrospect, that at times there was infringing material available on Veoh's services, the DMCA recognizes that service providers who are not able to locate and remove infringing materials they do not specifically know of should not suffer the loss of safe harbor protection.

\section{Statutory Licenses}

691 F.3d 275 (2d Cir. 2012)

WPIX, Inc. v. ivi, Inc.

On September 13, 2010, ivi began streaming plaintiffs' copyrighted programming over the Internet, live, for profit, and without plaintiffs' consent. ivi began by retransmitting signals from approxi- 
mately thirty New York and Seattle broadcast television stations; by February 2, 2011, ivi was also retransmitting signals from stations in Chicago and Los Angeles. Within five months of its launch, ivi had offered more than 4,000 of plaintiffs' copyrighted television programs to its subscribers.

Specifically, ivi captured and retransmitted plaintiffs' copyrighted television programming live and over the Internet to paying ivi subscribers who had downloaded ivi's "TV player" on their computers for a monthly subscription fee of $\$ 4.99$ (following a 30-day free trial). For an additional fee of $\$ 0.99$ per month, subscribers were able to record, pause, fast-forward, and rewind ivi's streams.

Almost immediately after ivi's launch, several affected program owners and broadcast stations sent cease-and-desist letters to ivi. ivi responded to these letters on or about September 17, 2010, purporting to justify its operations on the ground that it was a cable system entitled to a compulsory license under $\S 111$ of the Copyright Act.

Section 111(c)(1) of the Copyright Act provides:

Secondary transmissions to the public by a cable system of a performance or display of a work embodied in a primary transmission made by a broadcast station licensed by the Federal Communications Commission ... shall be subject to statutory licensing upon compliance with the requirements of subsection (d) where the carriage of the signals comprising the secondary transmission is permissible under the rules, regulations, or authorizations of the Federal Communications Commission.

A "cable system" is defined as:

a facility, located in any State, territory, trust territory, or possession of the United States, that in whole or in part receives signals transmitted or programs broadcast by one or more television broadcast stations licensed by the Federal Communications Commission, and makes secondary transmissions of such signals or programs by wires, cables, microwave, or other communications channels to subscribing members of the public who pay for such service. For purposes of determining the royalty fee under subsection $(\mathrm{d})(1)$, two or more cable systems in contiguous communities under common ownership or control or operating from one headend shall be considered as one system.

Based on the statutory text alone, it is simply not clear whether a service that retransmits television programming live and over the Internet constitutes a cable system under $\S 111$. That is, it is unclear 
whether such a service (1) is or utilizes a "facility" (2) that receives and retransmits signals (3) through wires, cables, microwave, or other communication channels.

The legislative history indicates that Congress enacted $\S 111$ with the intent to address the issue of poor television reception, or, more specifically, to mitigate the difficulties that certain communities and households faced in receiving over-the-air broadcast signals by enabling the expansion of cable systems.

Through § 111's compulsory license scheme, Congress intended to support localized - rather than nationwide - systems that use cable or optical fibers to transmit signals through a physical, point-to-point connection between a transmission facility and the television sets of individual subscribers.

Congress did not, however, intend for $\S 111$ 's compulsory license to extend to Internet transmissions. Indeed, the legislative history indicates that if Congress had intended to extend $\S 111$ 's compulsory license to Internet retransmissions, it would have done so expressly either through the language of $\S 111$ as it did for microwave retransmissions or by codifying a separate statutory provision as it did for satellite carriers.

To the extent that there is any doubt as to Congress's intent, however, we conclude that the position of the Copyright Office eliminates such doubt in its entirety. The Copyright Office is the administrative agency charged with overseeing $\S 111$ 's compulsory licensing scheme. Although Congress has not expressly delegated authority to the Copyright Office to make rules carrying the force of law, agencies charged with applying a statute certainly may influence courts facing questions the agencies have already answered.

The Copyright Office has consistently concluded that Internet retransmission services are not cable systems and do not qualify for $\S$ 111 compulsory licenses. The Copyright Office has maintained that $\S 111$ 's compulsory license for cable systems is intended for localized retransmission services; under this interpretation, Internet retransmission services are not entitled to a $\S 111$ license. In light of the Copyright Office's expertise, the validity of its reasoning, the consistency of its earlier and later pronouncements, and the consistency of its opinions with Congress's purpose in enacting $\S 111$, we conclude that the Copyright Office's position is reasonable and persuasive.

\section{Fox Television Stations, Inc. v. AereoKiller}

115 F. Supp. 3d 1152 (C.D. Cal. 2015)

The Copyright Office is not the only agency involved in this issue. As the Copyright Office acknowledged, the FCC is considering new regulations in this area. Those potential regulations are relevant in two ways to this case; one direct and one indirect. The direct way is that $\S 111$ requires that the retransmission be permissible under FCC reg- 
ulations. Currently, Plaintiffs point to no ways in which Defendants are in violation of FCC regulations. There simply do not appear to be any that address Defendants' particular transmissions, and Plaintiffs have made no showing that Defendants are in violation of any more general regulations, for example, of the type we all comply with by operating devices bearing this familiar inscription; "This device complies with part 15 of the FCC Rules. Operation is subject to the following two conditions: (1) This device may not cause harmful interference, and (2) this device must accept any interference received, including interference that may cause undesired operation."

The indirect way that the FCC proceedings are relevant is that the FCC is considering whether internet-based services qualify as "multichannel video programming distributors" under communications law. Plaintiffs argue that the FCC's potential future rules are irrelevant, as they will not extend a $\S 111$ license to anybody. That might be literally true, but nevertheless the Copyright Office thinks the FCC proceedings are relevant to that question. In any event, the proposed rules appear to provide a parallel path to program access for internet retransmitters. The NPM proposes to modernize the FCC's interpretation of the term "multichannel video programming distributor ("MVPD") by including with its scope services that make available for purchase, by subscribers or customers, multiple linear streams of video programming, regardless of the technology used to distribute the programming. This is intended to "enable cable operators to untether their video offerings from their current infrastructure, and could encourage them to migrate their traditional services to Internet delivery." The NPM also requests comment on whether the proposed retransmission consent rules would "force broadcasters to negotiate with and license their signals to potentially large numbers of Internetbased distributors."

Defendants emphasize this second, indirect involvement by the FCC, and represent that they will comply with any applicable regulations that arise out of this rulemaking. What the FCC might or might not do does not directly impact the analysis here, which is necessarily grounded in current law. Nonetheless, the rulemaking again emphasizes that this is not the only forum in which these issues are being debated, and that this is not the only forum for resolving them.

Other notable statutory licenses include a parallel licensing regime for satellite broadcasts, $\S \S 119$ and 121; several music-licensing regimes, § 114 (webcasting), § 115 (cover versions), and § 116 (jukeboxes); and a system of negotiated royalties for works used in noncommercial broadcasting, § 118 . 


\section{Miscellaneous}

\section{Copyright Act}

$\S 108$

Limitations on exclusive rights: Reproduction by libraries and archives
$\S 121(a)$

Limitations on exclusive rights: Reproduction for blind or other people with disabilities (a) Except as otherwise provided in this title, it is not an infringement of copyright for a library or archives, or any of its employees acting within the scope of their employment, to reproduce no more than one copy or phonorecord of a work, except as provided in subsections (b) and (c), or to distribute such copy or phonorecord, under the conditions specified by this section, if -

(1) the reproduction or distribution is made without any purpose of direct or indirect commercial advantage;

(2) the collections of the library or archives are (i) open to the public, or (ii) available not only to researchers affiliated with the library or archives or with the institution of which it is a part, but also to other persons doing research in a specialized field; and

(3) the reproduction or distribution of the work includes a notice of copyright ...

It is not an infringement of copyright for an authorized entity to reproduce or to distribute copies or phonorecords of a previously published, nondramatic literary work if such copies or phonorecords are reproduced or distributed in specialized formats exclusively for use by blind or other persons with disabilities. 


\section{Music}

Music copyright could be a course unto itself. Its doctrines bear the scars of a long and ambivalent history. As you read the chapter, keep three distinctions in mind: between musical works (think sheet music) and sound recordings (think CDs and MP3s), between reproducing a work and performing it, and between state and federal law. Copyright law has explored every possible variation and combination of the three. One does not simply walk into music copyright.

But first, a word on the music industry.

\section{Steve Albini The Problem with Music}

Whenever I talk to a band who are about to sign with a major label, I always end up thinking of them in a particular context. I imagine a trench, about four feet wide and five feet deep, maybe sixty yards long, filled with runny, decaying shit. I imagine these people, some of them good friends, some of them barely acquaintances, at one end of this trench. I also imagine a faceless industry lackey at the other end holding a fountain pen and a contract waiting to be signed. Nobody can see what's printed on the contract. It's too far away, and besides, the shit stench is making everybody's eyes water. The lackey shouts to everybody that the first one to swim the trench gets to sign the contract. Everybody dives in the trench and they struggle furiously to get to the other end. Two people arrive simultaneously and begin wrestling furiously, clawing each other and dunking each other under the shit. Eventually, one of them capitulates, and there's only one contestant left. He reaches for the pen, but the Lackey says "Actually, I think you need a little more development. Swim again, please. Backstroke." And he does of course. ...

The Balance Sheet: This is how much each player got paid at the end of the game.

- Record company: \$710,000
References on music copyright and the music business include Al Kohn \& Bob Kohn, Kohn on Music Licensing, Kohn and Donald S. Passman, All You Need to Know About the Music Business, Passman

(1993) 
- Producer: $\$ 90,000$

- Manager: \$51,000

- Studio: $\$ 52,500$

- Previous label: $\$ 50,000$

- Agent: $\$ 7,500$

- Lawyer: $\$ 12,000$

- Band member net income each: \$4,031.25

The band is now $1 / 4$ of the way through its contract, has made the music industry more than 3 million dollars richer, but is in the hole $\$ 14,000$ on royalties. The band members have each earned about $1 / 3$ as much as they would working at a 7-11, but they got to ride in a tour bus for a month. The next album will be about the same, except that the record company will insist they spend more time and money on it. Since the previous one never "recouped," the band will have no leverage, and will oblige. The next tour will be about the same, except the merchandising advance will have already been paid, and the band, strangely enough, won't have earned any royalties from their T-shirts yet. Maybe the T-shirt guys have figured out how to count money like record company guys. Some of your friends are probably already this fucked.

\section{A Musical Works and Sound Recordings}

\section{Robert Brauneis \\ Musical Work Copyright for the Era of Digital Sound Technology}

Throughout history, plenty of music has been made and transmitted from generation to generation without written scores. Musicians working within what might be called folk traditions learn music by listening to performances and imitating them, often repeatedly with the guidance and corrections of a formal or informal teacher, until they have them more-or-less fixed in memory. At another extreme, mechanical musical devices, such as music boxes, musical clocks, and mechanical organs, have existed for centuries. Such musical automata make music without any human performance at all, and the musical patterns are fixed, not in written notation or human memory, but in physical arrangements such as pins placed on a barrel or perforations made on a disc.

During the nineteenth century and into the early decades of the twentieth century, however, the dominant model of musical practice cast music as a two-stage art, necessarily comprised of two fundamentally different activities: composition and performance. Composition was a deliberative activity that allowed rethinking and editing. 
Its end product was a written score, a stable, visually perceptible set of prescriptions for musicians to follow. Scores virtually universally used a system of notation - Western staff or stave notation - which is mainly discrete: composers choose between an F and an F sharp, or between a quarter note and an eighth note, instead of setting pitches or durations along a continuum. However, staff notation typically indicates relative rather than absolute pitch and duration, and also gives inexact cues about matters such as dynamics (loudness), articulation (legato and staccato rendering of note sequences), timbre, and so on. Thus, it leaves room for - and requires - interpretive choices in performance.

Performance contrasts with composition in many respects. While a score is stable and visually perceptible, performance is unrepeatable, evanescent, and aural. While composition is a deliberative process that allows for trial-and-error editing, performance is a real-time, low-deliberation, no-editing activity.

As printing costs dropped and pianos proliferated in uppermiddle class parlors around the country, printed musical scores began to play an important and profitable role in the dissemination of music into millions of homes. While some of those scores came from the European classical tradition, the biggest sellers were sheet music of popular songs, in simple arrangements that could be performed by a single amateur pianist-vocalist. Most of the music copyright litigation through the middle of the twentieth century was about such popular sheet music, and it is fair to say that the conception of music copyright held by several generations of judges was influenced by sheet music of that type.

White-Smith Music Publishing Co. v. Apollo Co.

The actions were brought to restrain infringement of the copyrights of 209 U.S. 1 (1908) two certain musical compositions, published in the form of sheet music, entitled, respectively, "Little Cotton Dolly" and "Kentucky Babe." The appellee, defendant below, is engaged in the sale of piano players and player pianos, known as the "Apollo," and of perforated rolls of music used in connection therewith.

Without entering into a detailed discussion of the mechanical construction of such instruments and rolls, it is enough to say that the musical rolls consist of perforated sheets, which are passed over ducts in such manner that the same are kept sealed until, by means of perforations in the rolls, air pressure is admitted to sound the notes. This is done with the aid of an operator, upon whose skill and experience the success of the rendition largely depends. As the roll is drawn, the effect is to produce the melody or tune for which the roll has been cut.

Musical compositions have been the subject of copyright protec- 
tion since the statute of February 3, 1831, and laws have been passed including them since that time. The action was brought under the provisions of the copyright act, $\S 4952$, giving to the author, inventor, designer or proprietor of any book, map, chart, dramatic or musical composition the sole liberty of printing, reprinting, publishing, completing, copying, executing, finishing and vending the same.

What is meant by a copy? Various definitions have been given by the experts called in the case. The one which most commends itself to our judgment is perhaps as clear as can be made, and defines a copy of a musical composition to be "a written or printed record of it in intelligible notation." It may be true that in a broad sense a mechanical instrument which reproduces a tune copies it; but this is a strained and artificial meaning. When the combination of musical sounds is reproduced to the ear it is the original tune as conceived by the author which is heard. These musical tones are not a copy which appeals to the eye.

After all, what is the perforated roll? The fact is clearly established in the testimony in this case that even those skilled in the making of these rolls are unable to read them as musical compositions, as those in staff notation are read by the performer. It is true that there is some testimony to the effect that great skill and patience might enable the operator to read his record as he could a piece of music written in staff notation. But the weight of the testimony is emphatically the other way, and they are not intended to be read as an ordinary piece of sheet music, which to those skilled in the art conveys, by reading, in playing or singing, definite impressions of the melody.

These perforated rolls are parts of a machine which, when duly applied and properly operated in connection with the mechanism to which they are adapted, produce musical tones in harmonious combination. But we cannot think that they are copies within the meaning of the copyright act.

It may be true that the use of these perforated rolls, in the absence of statutory protection, enables the manufacturers thereof to enjoy the use of musical compositions for which they pay no value. But such considerations properly address themselves to the legislative and not to the judicial branch of the Government.

\section{Copyright Office}

Federal Copyright Protection for Pre-1972 Sound Recordings The 1909 Copyright Act, passed the following year, granted copyright owners of musical compositions rights with respect to mechanical reproductions of their compositions, for example, in records or piano rolls.

While the 1909 Act provided protection for copyright holders of musical compositions whose works were reproduced in sound 
recordings, it included no explicit protection for sound recordings per se. As a result, over the subsequent decades the courts and the Copyright Office consistently refused to recognize copyright in sound recordings. In the absence of federal protection, states provided protection against duplication of sound recordings under common law theories, usually unfair competition or common law copyright.

The general copyright revision process became stalled in the late 1960s and early 1970s. Congress, persuaded that the situation concerning sound recordings was becoming urgent, decided to bring sound recordings under the federal copyright law without waiting for the overall revision. On November 15, 1971 it passed the Sound Recording Amendment, which for the first time made sound recordings eligible for federal copyright. The effective date of the Sound Recording Amendment was February 15, 1972, four months after it was passed. It applied to sound recordings first fixed on or after that date.

\section{Copyright Act}

... Works of authorship include the following categories:

(2) musical works, including any accompanying words;

(7) sound recordings;

"Sound recordings" are works that result from the fixation of a series of musical, spoken, or other sounds, but not including the sounds accompanying a motion picture or other audiovisual work, regardless of the nature of the material objects, such as disks, tapes, or other phonorecords, in which they are embodied.

\section{Lydia Pallas Loren \\ Untangling the Web of Music Copyrights}

Currently, a sound recording embodies both the work that is protected by the sound recording copyright and the work that is protected by the musical work copyright. In copyright terms, the sound recording is a derivative work based on the musical work.

Courts have recognized that reproducing or publicly performing a derivative work also constitutes a reproduction or performance of the work, or works, on which the derivative work is based. In music, if a webcasting radio station wishes to utilize sound recordings of musical works, the station must obtain permission from both the sound recording copyright owners and the musical work copyright owners.
$\S 102$

Subject matter of copyright; In general

$\S 101$

Definitions

53 Case W. L. Rev. 637 (2003) 
To the extent that music copyright is divided between musical works and sound recordings, it becomes necessary to distinguish them and to allocate authorship between them.

\section{Newton v. Diamond}

The plaintiff and appellant in this case, James W. Newton, is an accomplished avant-garde jazz flutist and composer. In 1978, he composed the song "Choir," a piece for flute and voice intended to incorporate elements of African-American gospel music, Japanese ceremonial court music, traditional African music, and classical music, among others. According to Newton, the song was inspired by his earliest memory of music, watching four women singing in a church in rural Arkansas. In 1981, Newton performed and recorded "Choir" and licensed all rights in the sound recording to ECM Records for $\$ 5,000$. The license covered only the sound recording, and it is undisputed that Newton retained all rights to the composition of "Choir." Sound recordings and their underlying compositions are separate works with their own distinct copyrights.

The defendants and appellees include the members of the rap and hip-hop group Beastie Boys, and their business associates. In 1992, Beastie Boys obtained a license from ECM Records to use portions of the sound recording of "Choir" in various renditions of their song "Pass the Mic" in exchange for a one-time fee of $\$ 1,000$. Beastie Boys did not obtain a license from Newton to use the underlying composition. Pursuant to their license from ECM Records, Beastie Boys digitally sampled the opening six seconds of Newton's sound recording of "Choir." Beastie Boys repeated or "looped" this six-second sample as a background element throughout "Pass the Mic," so that it appears over forty times in various renditions of the song.

The portion of the composition at issue consists of three notes, $\mathrm{C}-\mathrm{D}$ flat $-\mathrm{C}$, sung over a background $\mathrm{C}$ note played on the flute. The score to "Choir" also indicates that the entire song should be played in a "largo/senza-misura" tempo, meaning "slowly/withoutmeasure."

Because the defendants were authorized to use the sound recording, our inquiry is confined to whether the unauthorized use of the composition itself was substantial enough to sustain an infringement claim. Therefore, we may consider only Beastie Boys' appropriation of the song's compositional elements and must remove from consideration all the elements unique to Newton's performance. Stated another way, we must "filter out" the licensed elements of the sound recording to get down to the unlicensed elements of the composition, as the composition is the sole basis for Newton's infringement claim.

In filtering out the unique performance elements from consideration, and separating them from those found in the composition, we 
find substantial assistance in the testimony of Newton's own experts, [who] reveal the extent to which the sound recording of "Choir" is the product of Newton's highly developed performance techniques, rather than the result of a generic rendition of the composition. As a general matter, according to Newton's expert Dr. Christopher Dobrian, "the contribution of the performer is often so great that $\mathrm{s} / \mathrm{he}$ in fact provides as much musical content as the composer." This is particularly true with works like "Choir," given the improvisational nature of jazz performance and the minimal scoring of the composition. Indeed, as Newton's expert Dr. Oliver Wilson explained:

The copyrighted score of "Choir", as is the custom in scores written in the jazz tradition, does not contain indications for all of the musical subtleties that it is assumed the performer-composer of the work will make in the work's performance. The function of the score is more mnemonic in intention than prescriptive.

And it is clear that Newton goes beyond the score in his performance. For example, Dr. Dobrian declared that "Mr. Newton blows and sings in such a way as to emphasize the upper partials of the flute's complex harmonic tone, although such a modification of tone color is not explicitly requested in the score." Dr. Dobrian also concludes that Newton "uses breath control to modify the timbre of the sustained flute note rather extremely" and "uses portamento to glide expressively from one pitch to another in the vocal part." Dr. Dobrian concedes that these elements do not appear in the score, and that they are part of Newton's performance of the piece.

A crucial problem with the testimony of Newton's experts is that they continually refer to the "sound" produced by the "Newton technique." A sound is protected by copyright law only when it is "fixed in a tangible medium." 17 U.S.C. § 102(a). Here, the only time any sound was fixed in a tangible medium was when a particular performance was recorded. Newton's copyright extends only to the elements that he fixed in a tangible medium - those that he wrote on the score. Thus, regardless of whether the average audience might recognize the "Newton technique" at work in the sampled sound recording, those performance elements are beyond consideration in Newton's claim for infringement of his copyright in the underlying composition.

On the undisputed facts of this record, no reasonable juror could find the sampled portion of the composition to be a quantitatively or qualitatively significant portion of the composition as a whole. Quantitatively, the three-note sequence appears only once in Newton's composition. When played, the segment lasts six seconds and is roughly two percent of the four-and-a-half-minute "Choir" sound

The court seems to be either assuming or asserting that Newton's musical work copyright is coextensive with what is in the written score. Is that right? Note that musical works can be fixed in sheet music, in phonorecords, or as part of an audiovisual work (e.g. a movie), and the Copyright Office will allow any of these to be used as a deposit copy. See Copyright Compendium $\S$ 1509.2(A) (3d ed. 2014). Would Newton have been better off never writing out sheet music for "Choir" at all? 
For historical reasons -- which you can probably guess -- these licenses are known as "mechanicals."

$\S 115(a)$

Scope of exclusive rights in nondramatic musical works: Compulsory license for making and distributing phonorecords
$\S 801$ (b)

Copyright Royalty Judges; appointment and functions

The judges are commonly referred to as the "Copyright Royalty Board" or CRB. recording licensed by Beastie Boys. Qualitatively, this section of the composition is no more significant than any other section. Indeed, with the exception of two notes, the entirety of the scored portions of "Choir" consist of notes separated by whole and half-steps from their neighbors and is played with the same technique of singing and playing the flute simultaneously; the remainder of the composition calls for sections of improvisation that range between 90 and 180 seconds in length.

On the undisputed facts of this case, we conclude that an average audience would not discern Newton's hand as a composer, apart from his talent as a performer, from Beastie Boys' use of the sample. The copying was not significant enough to constitute infringement.

\section{B Reproductions}

\section{Musical Works}

The ordinary rules of copyright mostly apply to the reproduction right in musical works. The notable exception is the statutory "cover version" license in $\S 115$ that allows others to record and sell sound recordings if they pay a fixed royalty to the copyright owner of the musical work.

\section{Copyright Act}

(1) When phonorecords of a nondramatic musical work have been distributed to the public in the United States under the authority of the copyright owner, any other person ... may, by complying with the provisions of this section, obtain a compulsory license to make and distribute phonorecords of the work. ...

(2) A compulsory license includes the privilege of making a musical arrangement of the work to the extent necessary to conform it to the style or manner of interpretation of the performance involved, but the arrangement shall not change the basic melody or fundamental character of the work, and shall not be subject to protection as a derivative work under this title, except with the express consent of the copyright owner.

Subject to the provisions of this chapter, the functions of the Copyright Royalty Judges shall be as follows:

(1) To make determinations and adjustments of reasonable terms and rates of royalty payments as provided in sections 112(e), $114,115,116,118,119$, and 1004. The rates applicable under 
sections $114(\mathrm{f})(1)(\mathrm{B}), 115$, and 116 shall be calculated to achieve the following objectives:

(A) To maximize the availability of creative works to the public.

(B) To afford the copyright owner a fair return for his or her creative work and the copyright user a fair income under existing economic conditions.

(C) To reflect the relative roles of the copyright owner and the copyright user in the product made available to the public with respect to relative creative contribution, technological contribution, capital investment, cost, risk, and contribution to the opening of new markets for creative expression and media for their communication.

(D) To minimize any disruptive impact on the structure of the industries involved and on generally prevailing industry practices.

\section{Code of Federal Regulations}

(a) Physical phonorecord deliveries and permanent digital downloads. For every physical phonorecord and permanent digital download made and distributed, the royalty rate payable for each work embodied in such phonorecord shall be either 9.1 cents or 1.75 cents per minute of playing time or fraction thereof, whichever amount is larger.

(b) Ringtones. - For every ringtone made and distributed, the royalty rate payable for each work embodied therein shall be 24 cents.

\section{Lydia Pallas Loren \\ Untangling the Web of Music Copyrights}

Most creators of phonorecords do not use the compulsory license mechanism to obtain permission to use musical works. In 1927 the National Music Publishers Company created the Harry Fox Agency, a wholly owned subsidiary, to issue and administer mechanical licenses. Today, most mechanical licenses are obtainde through the Harry Fox Agency. The Harry Fox Agency has authority to issue licenses only for those musical works for which Harry Fox has been granted authority by the copyright owner to act on the copyright owner's behalf. However, the number of copyright owners that have entered into such agreements is staggering: Harry Fox represents over 27,000 music publishers, who in turn represent the interests of more than 160,000 songwriters, who own more than 2.5 million copy-
37 C.F.R. $\S 385.3$ (2015)

Royalty rates for making and distributing phonorecords.

53 Case W. L. Rev. 637 (2003)

Harry Fox is now owned by SESAC, one of the performing rights organizations discussed below. 
512 F.3d 522 (9th Cir. 2008)

Why a fee for printing lyrics? Does this demand make more sense if you remember that recorded music used to be primarily distributed on black plastic discs in cardboard sleeves? righted musical works.

While the creators of most sound recordings do not utilize the statutory provisions for the compulsory mechanical license, the availability of such a license does affect the rate paid under a license granted by Harry Fox and the terms of the license. The parties to the licenses administered by Harry Fox are negotiating in the shadow of the compulsory license that both parties know could be used instead. Thus, for example, it is rare that the agreed license rate exceeds the rate set by the Copyright Office.

\section{Leadsinger, Inc. v. BMG Music Pub.}

Karaoke devices necessarily involve copyrighted works because both musical compositions and their accompanying song lyrics are essential to their operation. BMG owns or administers copyrights in musical compositions and through its licensing agent, the Harry Fox Agency, has issued to Leadsinger compulsory mechanical licenses to copyrighted musical compositions under $\S 115$ of the Copyright Act. In addition to the mechanical fee required to secure a compulsory license, BMG has demanded that Leadsinger and other karaoke companies pay a "lyric reprint" fee and a "synchronization fee." Leadsinger has refused to pay these additional fees and filed for declaratory judgment to resolve whether it has the right to visually display song lyrics in real time with song recordings without holding anything more than the $\S 115$ compulsory licenses it already possesses.

In its complaint, Leadsinger describes the karaoke device it manufactures as "an all-in-one microphone player" that has recorded songs imbedded in a microchip in the microphone. When the microphone is plugged into a television, the lyrics of the song appear on the television screen in real time as the song is playing, enabling the consumer to sing along with the lyrics. Though most karaoke companies put their recordings on cassettes, compact discs, or use a compact disc + graphic ("CD + G") or DVD format, these other karaoke devices, much like Leadsinger's, display lyrics visually when played in a device that is connected to a television.

While it is true that the microchip in Leadsinger's device stores visual images and visual representations of lyrics in addition to sounds, the plain language of the Copyright Act does not expressly preclude a finding that devices on which sounds and visual images are fixed fall within the definition of phonorecords. The definition of phonorecords is explicit, however, that audiovisual works are not phonorecords and are excluded from $\S 115$ 's compulsory licensing scheme. We need not settle upon a precise interpretation of $\S 101^{\prime} \mathrm{s}$ definition of phonorecords in this case because Leadsinger's karaoke device meets each element of the statutory definition of audiovisual works and, therefore, cannot be a phonorecord. 
As stated above, $\S 101$ of the Copyright Act defines audiovisual works as works consisting of "a series of related images" that are "intrinsically intended to be shown by the use of machines." First, the visual representation of successive portions of song lyrics that Leadsinger's device projects onto a television screen constitutes "a series of related images." Though Leadsinger suggests that its images of song lyrics are not related, the images bear a significant relationship when examined in context. In its complaint, Leadsinger explained that the purpose of karaoke is for the consumer to sing the lyrics to a song "in real time" as the song is playing. To accomplish this purpose, it is necessary that the images of song lyrics be presented sequentially so as to match the accompanying music and make the lyrics readable.

We hold that Leadsinger's device falls within the definition of an audiovisual work. As a result, in addition to any $\S 115$ compulsory licenses necessary to make and distribute phonorecords, Leadsinger is also required to secure synchronization licenses to display images of song lyrics in timed relation with recorded music.

\section{Sound Recordings}

\section{Copyright Act}

The exclusive right of the owner of copyright in a sound recording under clause (1) of section 106 is limited to the right to duplicate the sound recording in the form of phonorecords or copies that directly or indirectly recapture the actual sounds fixed in the recording. The exclusive right of the owner of copyright in a sound recording under clause (2) of section 106 is limited to the right to prepare a derivative work in which the actual sounds fixed in the sound recording are rearranged, remixed, or otherwise altered in sequence or quality. The exclusive rights of the owner of copyright in a sound recording under clauses (1) and (2) of section 106 do not extend to the making or duplication of another sound recording that consists entirely of an independent fixation of other sounds, even though such sounds imitate or simulate those in the copyrighted sound recording.

Everyone agrees that under $\S 114(b)$, reproductions of sound recordings are to be judged by a different standard of similarity than other types of works. But they disagree on what that standard is.

\section{Bridgeport Music, Inc. v. Dimension Films}

This action arises out of the use of a sample from the composition and sound recording "Get Off Your Ass and Jam" ("Get Off") in the

17 U.S.C. § 114(b)

Scope of exclusive rights in sound recordings

410 F.3d 792 (6th Cir. 2005)
"Timed relation" is the crucial operative phrase of the typical "synchronization license" used to license a musical work for use in a movie, television show, or other audiovisual work. The phrase is not in the Copyright Act, but a little thought about the nature of musical and audiovisual works shows why the element of timing is key. The standard phrase used to describe the analogous license for the use of a sound recording as part of an audiovisual work is a "master use license" -- the idea being that the copyright owner allows the licensee to use the "master" recordings, from which the copies sold commercially are made. The phrase is mildly anachronistic in an age of digital production. 
rap song "100 Miles and Runnin"' ("100 Miles"), which was included in the sound track of the movie I Got the Hook Up (Hook Up). The recording "Get Off" opens with a three-note combination solo guitar "riff" that lasts four seconds. According to one of plaintiffs' experts, Randy Kling, the recording "100 Miles" contains a sample from that guitar solo. Specifically, a two-second sample from the guitar solo was copied, the pitch was lowered, and the copied piece was "looped" and extended to 16 beats. Kling states that this sample appears in the sound recording "100 Miles" in five places; specifically, at 0:49, 1:52, $2: 29,3: 20$ and 3:46. By the district court's estimation, each looped segment lasted approximately 7 seconds.

Bridgeport and Westbound claim to own the musical composition and sound recording copyrights in "Get Off Your Ass and Jam" by George Clinton, Jr. and the Funkadelics. We assume, as did the district court, that plaintiffs would be able to establish ownership in the copyrights they claim. There seems to be no dispute either that "Get Off" was digitally sampled or that the recording "100 Miles" was included on the sound track of I Got the Hook Up.

Although musical compositions have always enjoyed copyright protection, it was not until 1971 that sound recordings were subject to a separate copyright. If one were to analogize to a book, it is not the book, i.e., the paper and binding, that is copyrightable, but its contents. There are probably any number of reasons why the decision was made by Congress to treat a sound recording differently from a book even though both are the medium in which an original work is fixed rather than the creation itself. None the least of them certainly were advances in technology which made the "pirating" of sound recordings an easy task. The balance that was struck was to give sound recording copyright holders the exclusive right "to duplicate the sound recording in the form of phonorecords or copies that directly or indirectly recapture the actual sounds fixed in the recording." This means that the world at large is free to imitate or simulate the creative work fixed in the recording so long as an actual copy of the sound recording itself is not made. That leads us directly to the issue in this case. If you cannot pirate the whole sound recording, can you "lift" or "sample" something less than the whole. Our answer to that question is in the negative.

To begin with, there is ease of enforcement. Get a license or do not sample. We do not see this as stifling creativity in any significant way. It must be remembered that if an artist wants to incorporate a "riff" from another work in his or her recording, he is free to duplicate the sound of that "riff" in the studio. Second, the market will control the license price and keep it within bounds. The sound recording copyright holder cannot exact a license fee greater than what it would cost the person seeking the license to just duplicate the sample in the 
course of making the new recording. Third, sampling is never accidental. It is not like the case of a composer who has a melody in his head, perhaps not even realizing that the reason he hears this melody is that it is the work of another which he had heard before. When you sample a sound recording you know you are taking another's work product. 12

This analysis admittedly raises the question of why one should, without infringing, be able to take three notes from a musical composition, for example, but not three notes by way of sampling from a sound recording. Why is there no de minimis taking or why should substantial similarity not enter the equation. Our first answer to this question is what we have earlier indicated. We think this result is dictated by the applicable statute. Second, even when a small part of a sound recording is sampled, the part taken is something of value. No further proof of that is necessary than the fact that the producer of the record or the artist on the record intentionally sampled because it would (1) save costs, or (2) add something to the new recording, or (3) both. For the sound recording copyright holder, it is not the "song" but the sounds that are fixed in the medium of his choice. When those sounds are sampled they are taken directly from that fixed medium. It is a physical taking rather than an intellectual one.

This case also illustrates the kind of mental, musicological, and technological gymnastics that would have to be employed if one were to adopt a de minimis or substantial similarity analysis. The district judge did an excellent job of navigating these troubled waters, but not without dint of great effort. When one considers that he has hundreds of other cases all involving different samples from different songs, the value of a principled bright-line rule becomes apparent.

VMG Salsoul, LLC v. Ciccone

In the early 1990s, pop star Madonna Louise Ciccone, commonly known by her first name only, released the song Vogue to great commercial success. In this copyright infringement action, Plaintiff VMG Salsoul, LLC, alleges that the producer of Vogue, Shep Pettibone, copied a 0.23 -second segment of horns from an earlier song, known as Love Break, and used a modified version of that snippet when recording Vogue. Plaintiff asserts that Defendants Madonna, Pettibone, and others thereby violated Plaintiff's copyrights to Love Break.

Plaintiff has submitted evidence of actual copying. In particular, Tony Shimkin has sworn that he, as Pettibone's personal assistant, helped with the creation of Vogue and that, in Shimkin's presence,

\footnotetext{
${ }^{12}$ The opinion in Grand Upright Music Ltd. v. Warner Bros. Records, Inc., $780 \mathrm{~F}$. Supp. 182 (S.D.N.Y. 1991), one of the first cases to deal with digital sampling, begins with the phrase, "Thou shalt not steal."
} 
Pettibone directed an engineer to introduce sounds from Love Break into the recording of Vogue. Additionally, Plaintiff submitted reports from music experts who concluded that the horn hits in Vogue were sampled from Love Break.

Plaintiff argues that even if the copying here is trivial, that fact is irrelevant because the de minimis exception does not apply to infringements of copyrighted sound recordings. Plaintiff urges us to follow the Sixth Circuit's decision in Bridgeport, which adopted a brightline rule: For copyrighted sound recordings, any unauthorized copying no matter how trivial - constitutes infringement.

We squarely held in Newton that the de minimis exception applies to claims of infringement of a copyrighted composition. But it is an open question in this circuit whether the exception applies to claims of infringement of a copyrighted sound recording.

A straightforward reading of the third sentence in S 114(b) reveals Congress' intended limitation on the rights of a sound recording copyright holder: A new recording that mimics the copyrighted recording is not an infringement, even if the mimicking is very well done, so long as there was no actual copying. That is, if a band played and recorded its own version of Love Break in a way that sounded very similar to the copyrighted recording of Love Break, then there would be no infringement so long as there was no actual copying of the recorded Love Break. But the quoted passage does not speak to the question that we face: whether Congress intended to eliminate the longstanding de minimis exception for sound recordings in all circumstances even where, as here, the new sound recording as a whole sounds nothing like the original.

We disagree [with Bridgeport's "physical taking" analysis] for three reasons. First, the possibility of a "physical taking" exists with respect to other kinds of artistic works as well, such as photographs, as to which the usual de minimis rule applies. See, e.g., Sandoval v. New Line Cinema Corp. (affirming summary judgment to the defendant because the defendant's use of the plaintiff's photographs in a movie was de minimis). A computer program can, for instance, "sample" a piece of one photograph and insert it into another photograph or work of art. We are aware of no copyright case carving out an exception to the de minimis requirement in that context, and we can think of no principled reason to differentiate one kind of "physical taking" from another. Second, even accepting the premise that sound recordings differ qualitatively from other copyrighted works and therefore could warrant a different infringement rule, that theoretical difference does not mean that Congress actually adopted a different rule. Third, the distinction between a "physical taking" and an "intellectual one," premised in part on "saving costs" by not having to hire musicians, does not advance the Sixth Circuit's view. The 
Supreme Court has held unequivocally that the Copyright Act protects only the expressive aspects of a copyrighted work, and not the "fruit of the [author's] labor." Feist. Indeed, the Supreme Court in Feist explained at length why, though that result may seem unfair, protecting only the expressive aspects of a copyrighted work is actually a key part of the design of the copyright laws. Accordingly, all that remains of Bridgeport's argument is that the second artist has taken some expressive content from the original artist. But that is always true, regardless of the nature of the work, and the de minimis test nevertheless applies.

We hold that the "de minimis" exception applies to actions alleging infringement of a copyright to sound recordings.

\section{Performances}

If the only quirk of music copyright were the division between composition and performance, there would be no need for this chapter. Other arts also routinely distinguish between source text and performance: theater, dance, television, and film all routinely split authorship between writer and performer. But music copyright is unique in the degree to which reproduction and performance are governed by startlingly different rules. So we start with a quick hit on the technical difference between reproduction and performance according to the Copyright Act.

\section{United States v. American Society of Composers, Authors, and} Publishers

Yahoo! and RealNetworks offer their customers the ability to download musical works over the Internet. It is undisputed that these downloads create copies of the musical works, for which the parties agree the copyright owners must be compensated. However, the parties dispute whether these downloads are also public performances of the musical works, for which the copyright owners must separately and additionally be compensated. The district court held that these downloads are not public performances, and we agree.

The downloads at issue in this appeal are not musical performances that are contemporaneously perceived by the listener. They are simply transfers of electronic files containing digital copies from an on-line server to a local hard drive. The downloaded songs are not performed in any perceptible manner during the transfers; the user must take some further action to play the songs after they are downloaded. Because the electronic download itself involves no recitation, rendering, or playing of the musical work encoded in the digital transmission, we hold that such a download is not a performance of that work, as defined by $\S 101$.
On performances and copyright, see generally Rebecca Tushnet, Performance Anxiety: Copyright Embodied and Disembodied, $60 \mathrm{~J}$. Copyright Soc'y 209 (2013); Michael W. Carroll, Copyright's Creative Hierarchy in the Performing Arts, 14 Vand. J. Ent. \& Tech. L. 797 (2012).

627 F.3d 64 (2d Cir. 2010) 
Some podcasting apps let you start listening to an episode before it is completely downloaded. Reproduction, performance, or both?
The Internet Companies' stream[ing] transmissions, which all parties agree constitute public performances, illustrate why a download is not a public performance. A stream is an electronic transmission that renders the musical work audible as it is received by the clientcomputer's temporary memory. This transmission, like a television or radio broadcast, is a performance because there is a playing of the song that is perceived simultaneously with the transmission. In contrast, downloads do not immediately produce sound; only after a file has been downloaded on a user's hard drive can he perceive a performance by playing the downloaded song. Unlike musical works played during radio broadcasts and stream transmissions, downloaded musical works are transmitted at one point in time and performed at another. Transmittal without a performance does not constitute a public performance.

\section{Musical Works}

The general rule is that permission of the copyright owner is required to perform a musical work. But in practice, most uses - including broadcasting - are covered by a blanket license issued by one of the "performing rights organizations" (PROs): ASCAP, BMI, and SESAC. Musical-work copyright owners sign up with one of the three PROs, if they wish, which then issues public- performance licenses for all of the works in its "repertory," i.e., one license allows the licensee to perform any musical work available through that PRO. The copyright owners still control the licensing of their other rights, and they are free to negotiate public-performance licenses individually as well. We first discuss the scope of public-performance rights in musical works, then focus on the role of the PROs, and finish with a few miscellaneous cases: jukeboxes and music stores.

\section{a Broadcasting and Receiving}

\section{Buck v. Jewell-LaSalle Realty Co.}

These suits were brought in the federal court for western Missouri by the American Society of Composers, Authors and Publishers, and one of its members, against the Jewell-LaSalle Realty Company, which operates the LaSalle Hotel at Kansas City. The hotel maintains a master radio receiving set which is wired to each of the public and private rooms. As part of the service offered to its guests, loud-speakers or head-phones are provided so that a program received on the master set can, if desired, be simultaneously heard throughout the building. Among the programs received are those transmitted by Wilson Duncan who operates a duly licensed commercial broadcasting station in the same city. Duncan selects his own programs and broadcasts 
them for profit. There is no arrangement of any kind between him and the hotel. Both were notified by the plaintiff society of the existence of its copyrights and were advised that unless a license were obtained, performance of any copyrighted musical composition owned by its members was forbidden. Thereafter, a copyrighted popular song, owned by the plaintiffs, was repeatedly broadcast by Duncan and was received by the hotel company and made available to its guests.

Although the art of radio broadcasting was unknown at the time the Copyright Act of 1909 was passed, and the means of transmission and reception now employed are wholly unlike any then in use, it is not denied that such broadcasting may be within the scope of the Act. The argument here urged, however, is that since the transmitting of a musical composition by a commercial broadcasting station is a public performance for profit, control of the initial radio rendition exhausts the monopolies conferred - both that of making copies (including records) and that of giving public performances for profit (including mechanical performances from a record); and that a monopoly of the reception, for commercial purposes, of this same rendition is not warranted by the Act. The analogy is invoked of the rule under which an author who permits copies of his writings to be made cannot, by virtue of his copyright, prevent or restrict the transfer of such copies. Compare Bobbs-Merrill. This analogy is inapplicable. It is true that control of the sale of copies is not permitted by the Act, but a monopoly is expressly granted of all public performances for profit.

The defendant next urges that it did not perform, because there can be but one actual performance each time a copyrighted selection is rendered; and that if the broadcaster is held to be a performer, one who, without connivance, receives and distributes the transmitted selection cannot also be held to have performed it. But nothing in the Act circumscribes the meaning to be attributed to the term "performance," or prevents a single rendition of a copyrighted selection from resulting in more than one public performance for profit. While this may not have been possible before the development of radio broadcasting, the novelty of the means used does not lessen the duty of the courts to give full protection to the monopoly of public performance for profit which Congress has secured to the composer. No reason is suggested why there may not be more than one liability. And since the public reception for profit in itself constitutes an infringement, we have no occasion to determine under what circumstances a broadcaster will be held to be a performer, or the effect upon others of his paying a license fee.
17 U.S.C. § 110

Limitations on exclusive rights: Exemption of certain performances and displays 
(B) allows "establishments," i.e. businesses open to the public, of less than $2,000 \mathrm{ft}^{2}\left(3,750 \mathrm{ft}^{2}\right.$ for restaurants and bars) to play the musical works in radio and TV broadcasts using any equipment. Larger establishments can use up to 6 loudspeakers or 4 screens of no more than 55区.

441 U.S. 1 (1979)
Notwithstanding the provisions of section 106, the following are not infringements of copyright:

(5) (A) except as provided in subparagraph (B), communication of a transmission embodying a performance or display of a work by the public reception of the transmission on a single receiving apparatus of a kind commonly used in private homes, unless

(i) a direct charge is made to see or hear the transmission; or

(ii) the transmission thus received is further transmitted to the public;

\section{b The Performing Rights Organizations}

Broadcast Music, Inc. v. Columbia Broadcasting System, Inc. Since 1897, the copyright laws have vested in the owner of a copyrighted musical composition the exclusive right to perform the work publicly for profit, but the legal right is not self-enforcing. In 1914, Victor Herbert and a handful of other composers organized ASCAP because those who performed copyrighted music for profit were so numerous and widespread, and most performances so fleeting, that as a practical matter it was impossible for the many individual copyright owners to negotiate with and license the users and to detect unauthorized uses. ASCAP was organized as a "clearing-house" for copyright owners and users to solve these problems associated with the licensing of music. As ASCAP operates today, its 22,000 members grant it nonexclusive rights to license nondramatic performances of their works, and ASCAP issues licenses and distributes royalties to copyright owners in accordance with a schedule reflecting the nature and amount of the use of their music and other factors.

BMI, a nonprofit corporation owned by members of the broadcasting industry, was organized in 1939, is affiliated with or represents some 10,000 publishing companies and 20,000 authors and composers, and operates in much the same manner as ASCAP. Almost every domestic copyrighted composition is in the repertory either of ASCAP, with a total of three million compositions, or of BMI, with one million.

Both organizations operate primarily through blanket licenses, which give the licensees the right to perform any and all of the compositions owned by the members or affiliates as often as the licensees desire for a stated term. Fees for blanket licenses are ordinarily a percentage of total revenues or a flat dollar amount, and do not directly depend on the amount or type of music used. Radio and television broadcasters are the largest users of music, and almost all of them 
hold blanket licenses from both ASCAP and BMI.

The complaint filed by CBS charged various violations of the Sherman Act and the copyright laws. CBS argued that ASCAP and BMI are unlawful monopolies and that the blanket license is illegal price fixing, an unlawful tying arrangement, a concerted refusal to deal, and a misuse of copyrights.

The Department of Justice first investigated allegations of anticompetitive conduct by ASCAP over 50 years ago. In separate complaints in 1941, the United States charged that the blanket license, which was then the only license offered by ASCAP and BMI, was an illegal restraint of trade and that arbitrary prices were being charged as the result of an illegal copyright pool. The Government sought to enjoin ASCAP's exclusive licensing powers and to require a different form of licensing by that organization. The case was settled by a consent decree that imposed tight restrictions on ASCAP's operations. Following complaints relating to the television industry, successful private litigation against ASCAP by movie theaters, and a Government challenge to ASCAP's arrangements with similar foreign organizations, the 1941 decree was reopened and extensively amended in 1950.

Under the amended decree, which still substantially controls the activities of ASCAP, members may grant ASCAP only nonexclusive rights to license their works for public performance. Members, therefore, retain the rights individually to license public performances, along with the rights to license the use of their compositions for other purposes. ASCAP itself is forbidden to grant any license to perform one or more specified compositions in the ASCAP repertory unless both the user and the owner have requested it in writing to do so. ASCAP is required to grant to any user making written application a nonexclusive license to perform all ASCAP compositions, either for a period of time or on a per-program basis. ASCAP may not insist on the blanket license, and the fee for the per-program license, which is to be based on the revenues for the program on which ASCAP music is played, must offer the applicant a genuine economic choice between the per-program license and the more common blanket license. If ASCAP and a putative licensee are unable to agree on a fee within 60 days, the applicant may apply to the District Court for a determination of a reasonable fee, with ASCAP having the burden of proving reasonableness.

CBS would prefer that ASCAP be authorized, indeed directed, to make all its compositions available at standard per-use rates within negotiated categories of use. But if this in itself or in conjunction with blanket licensing constitutes illegal price fixing by copyright owners, CBS urges that an injunction issue forbidding ASCAP to issue any blanket license or to negotiate any fee except on behalf of an individ- 
Available on the ASCAP website

1

Term

2

Definitions. ual member for the use of his own copyrighted work or works. Thus, we are called upon to determine that blanket licensing is unlawful across the board. We are quite sure, however, that the per se rule does not require any such holding.

The blanket license, as we see it, is not a naked restraint of trade with no purpose except stifling of competition, but rather accompanies the integration of sales, monitoring, and enforcement against unauthorized copyright use. As we have already indicated, ASCAP and the blanket license developed together out of the practical situation in the marketplace: thousands of users, thousands of copyright owners, and millions of compositions. Most users want unplanned, rapid, and indemnified access to any and all of the repertory of compositions, and the owners want a reliable method of collecting for the use of their copyrights. Individual sales transactions in this industry are quite expensive, as would be individual monitoring and enforcement, especially in light of the resources of single composers. Indeed, as both the Court of Appeals and CBS recognize, the costs are prohibitive for licenses with individual radio stations, nightclubs, and restaurants, and it was in that milieu that the blanket license arose. ASCAP, in short, made a market in which individual composers are inherently unable to compete fully effectively.

With this background in mind, which plainly enough indicates that over the years, and in the face of available alternatives, the blanket license has provided an acceptable mechanism for at least a large part of the market for the performing rights to copyrighted musical compositions, we cannot agree that it should automatically be declared illegal in all of its many manifestations.

\section{ASCAP 2010 Radio Station License Agreement}

The term of this Agreement commences as of January 1, 2010, and ends on December 31, 2016, unless earlier terminated as hereinafter provided.

A. "ASCAP Repertory" means musical works for which ASCAP has the right to license for public performance now or hereafter during the term of this Agreement. All compositions written and copyrighted by ASCAP members and in the repertory on the date this Agreement is executed are included for the full term of this Agreement. Compositions written or copyrighted by ASCAP members during the license term are included for the full balance of the term.
3. ASCAP Grant of Rights and Limitations. 
A. ASCAP grants LICENSEE a non-exclusive Through-to-theAudience License to perform publicly in the U.S. Territory, by Radio Broadcasting or New Media Transmissions, nondramatic performances of all musical works in the ASCAP Repertory during the Term.

B. If you elect to pay a license fee on the blanket basis for your Radio Broadcasting, subject to the election provisions of Paragraphs 6.A and 6.B below, you agree to pay us a license fee of $1.7 \%$ of your Revenue Subject to Fee from Radio Broadcasting for each year 2012 through 2016 of the Agreement.

G. Minimum Fee. In no event shall your total annual license fee be less than $\$ 588$.

H. Annual Reports. You will submit a report of the license fee due for each year 2012 through 2016 of this Agreement, by April 1st of the following year, by fully completing the Statement of Account that will be made available on ASCAP's website. For the avoidance of any doubt, all Annual Reports must be submitted using the electronic format and Internet-based delivery transmission methodology to be developed by ASCAP.

Range Road Music, Inc. v. East Coast Foods, Inc.

East Coast owns and operates the Roscoe's House of Chicken and Waffles chain of restaurants in Southern California. The codefendant, Herbert Hudson, is the sole officer and director of East Coast.

The Long Beach Roscoe's opened in 2001. Attached to the restaurant is a bar and lounge area called the "Sea Bird Jazz Lounge." Though the parties dispute whether East Coast owns the Long Beach Roscoe's, as it does the other locations, Hudson submitted a signed liquor license application for the Long Beach Roscoe's to the California Department of Alcoholic Beverage Control in 2001, which named the applicant as "East Coast Foods Inc."

Shortly after the Long Beach Roscoe's opened, ASCAP contacted East Coast to offer it a license to perform music by ASCAP members at the restaurant and lounge. East Coast did not purchase a license, and between 2001 and 2007 East Coast ignored repeated requests from ASCAP to pay licensing fees. In 2008, ASCAP engaged an independent investigator, Scott Greene, to visit the Long Beach Roscoe's, make notes of his visit, and prepare a detailed investigative report indicating whether copyright infringement was occurring at the venue. Greene, who considers himself knowledgeable about every genre of music "except heavy metal and explicit rap," had conducted over 300 investigations for ASCAP when he was retained for the Roscoe's job. 
Greene visited Roscoe's on May 30, 2008. During his visit, he surreptitiously noted the musical compositions performed by that night's live musical act, Azar Lawrence \& the L.A. Legends, as well as songs played from a CD over the lounge's sound system. During the live performance, he was able to personally identify the jazz compositions "All or Nothing at All," "It's Easy To Remember," "My Favorite Things," and "Be-Bop," all popularly associated with John Coltrane. In several cases, the band leader announced the titles of the songs before playing them. Greene also identified four songs by the jazzfusion group Hiroshima that played on the venue's CD player: "BopHop," "Once Before I Sleep," "One Fine Day," and "Only Love." He did not personally recognize the Hiroshima songs, but he approached the $\mathrm{CD}$ player and transcribed the titles directly from the $\mathrm{CD}$ jewel case as the songs played.

After Greene submitted his investigative report, ASCAP confirmed that the Music Companies own validly registered copyrights to all eight of the songs Greene identified. The Music Companies sued East Coast and Hudson for eight counts of copyright infringement, corresponding to the eight songs Greene heard publicly performed at the Long Beach Roscoe's.

We agree with the district court that East Coast and Hudson are jointly and severally liable for the infringement. Overwhelming evidence showed that East Coast and Hudson exercised control over both the Long Beach Roscoe's and the Sea Bird Jazz Lounge, and derived a financial benefit from the musical performances in the lounge.

Timothy Rice wrote the libretto for Jesus Christ Superstar and Andrew Lloyd Webber composed the score of the opera's overture and 22 songs which depict the last seven days in the life of Christ. The Robert Stigwood Group Limited ("Stigwood") acquired the rights for stage productions and dramatic presentations of the opera, and its rights are those allegedly infringed.

Each Original American Touring Company ("OATC") so-called concert consists of 20 of the 23 songs from Jesus Christ Superstar, sung sequentially with one exception, and three additional religious works.

OATC's claim that its productions do not infringe Stigwood's rights is based upon the usual and customary agreement between the American Society of Composers, Authors and Publishers ("ASCAP") and Leeds Music Corporation, an ASCAP member. ASCAP is authorized by its members to license only nondramatic performing rights of compositions in its repertory. Consequently, pursuant to the standard ASCAP agreement utilized here, ASCAP was authorized by 
Leeds to give:

1. (b) The non-exclusive right of public performance of the separate numbers, songs, fragments or arrangements, melodies or selections forming part or parts of musical plays and dramatico-musical compositions, the Owner reserving and excepting from this grant the right of performance of musical plays and dramatico-musical compositions in their entirety, or any part of such plays or dramatico-musical compositions on the legitimate stage.

Thus, while ASCAP licensees can perform the individual songs from Jesus Christ Superstar, paragraph 3 of the standard license indicates that it does not extend to presentations of:

(a) Oratorios, choral, operatic, or dramatico-musical works . . . in their entirety or songs or other excerpts from operas or musical plays accompanied either by word, pantomime, dance or visual representation of the work from which the music is taken; but fragments or instrumental selections from such works may be instrumentally rendered without words, dialogue, costume, accompanying dramatic action or scenic accessory and unaccompanied by any stage action or visual representation (by motion picture or otherwise) of the work of which such music forms a part.

The facts before us vividly paint the dramatic nature of OATC's performance. 20 of 23 Superstar selections are performed in defendant's concert, all but one in identical sequence as in the copyrighted opera. The conclusion is inescapable that the story of the last seven days in the life of Christ is portrayed in the OATC performances substantially as in Superstar. One might appropriately ask why, if OATC did not intend that the same story be told, would it insist on preserving the sequence of the songs presented in Jesus Christ Superstar, which when performed in that fashion, tell the story even in the absence of intervening dialogue? As Rice v. American Program Bureau instructed, the lack of scenery or costumes in the OATC production does not ipso facto prevent it from being dramatic. Indeed, radio performances of operas are considered dramatic, because the story is told by the music and lyrics. here can be no question that the OATC concerts, in which singers enter and exit, maintain specific roles and occasionally make gestures, and in which the story line of the original play is preserved by the songsHow does the court know that the full "score" of Jesus Christ Superstar takes 87 minutes to perform? Won't it depend on the performers? which are sung in almost perfect sequence using 78 of the 87 minutes of the original copyrighted score, is dramatic.

In industry parlance, OATC needed "grand rights" -- a license for a dramatic performance -- but ASCAP and other PROs only issue "small rights" -- licenses for nondramatic performances.

Rice: 446 F.2d 685 (2d Cir. 1971) 


\section{c Miscellaneous}

\section{Copyright Act}

$\S 116(b)(1)$

Negotiated licenses for public performances by means of coin-operated phonorecord players

From the JLO website

Berne's strong preference for negotiated licenses is reflected in the current $\S 116$.

17 U.S.C. § 110

Limitations on exclusive rights: Exemption of certain performances and displays
Any owners of copyright in [any nondramatic musical work embodied in a phonorecord] and any operators of coin-operated phonorecord players may negotiate and agree upon the terms and rates of royalty payments for the performance of such works and the proportionate division of fees paid among copyright owners, and may designate common agents to negotiate, agree to, pay, or receive such royalty payments.

\section{History of the Jukebox License Office}

Before 1978, "coin-operated phonorecord players," commonly referred to as jukeboxes, generally were not licensed by ASCAP, BMI, SESAC or the U.S. Government. However, due to revisions of the Copyright Law, a provision was included for a compulsory license from the U.S. Copyright Office for any publicly performed nondramatic musical works by means of a "coin-operated phonorecord player" (jukebox). This act was placed into effect in 1978. At that time jukebox operators submitted payments to the Licensing Division of the U.S. Copyright Office in Washington D.C. Fees were structured on a flat per-box rate.

In 1989, the United States joined an international copyright treaty named the Berne Convention. One aspect of the Berne Convention is to offer "negotiated" licenses as opposed to "compulsory" licenses. Consequently, ASCAP, BMI and SESAC negotiated a license with the Amusement \& Music Operators Association (AMOA), the largest trade association representing jukebox operators.

The result of these negotiations was the 1990 creation of the Jukebox License Office (JLO) and the Jukebox License Agreement, which is administered by the JLO. This agreement provides jukebox operators total access to all songs in the ASCAP, BMI and SESAC repertories. The Jukebox License Agreement is a single, economical, music license that provides the authorization required under the U.S. Copyright Law to publicly play virtually every copyrighted song on a coinoperated jukebox.

The original Jukebox License Agreement was re-negotiated by ASCAP, BMI, SESAC and the AMOA in 1999 and again in 2001. A new Jukebox License Agreement is now in effect as of January 1, 2007. 
Notwithstanding the provisions of section 106, the following are not infringements of copyright:

(7) performance of a nondramatic musical work by a vending establishment open to the public at large without any direct or indirect admission charge, where the sole purpose of the performance is to promote the retail sale of copies or phonorecords of the work, or of the audiovisual or other devices utilized in such performance, and the performance is not transmitted beyond the place where the establishment is located and is within the immediate area where the sale is occurring;

\section{Sound Recordings}

Most performances of sound recordings - including performances in person and traditional "terrestrial" radio broadcasts - are not covered by federal copyright law and do not require permission from the copyright owner. But there is an exclusive right to control the performance of a sound recording via "digital audio transmission," which is subject to an immensely complicated statutory licensing system.

\section{Copyright Act}

The exclusive rights of the owner of copyright in a sound recording do not include any right of performance under section 106(4).

Subject to sections 107 through 122, the owner of copyright under this title has the exclusive rights to do and to authorize any of the following:

(6) in the case of sound recordings, to perform the copyrighted work publicly by means of a digital audio transmission.

\section{Copyright Office \\ Copyright and the Music Marketplace}

In the 1995 The Digital Performance Right in Sound Recordings Act (DPRSRA), Congress gave sound recording owners an exclusive public performance right, but one limited to digital audio transmissions, and created the section 114 statutory license for noninteractive subscription providers, including satellite radio, engaged in digital performances. In 1998, Congress extended the section 114 compulsory license to expressly include webcasting as a covered activity. Traditional over-the-air broadcasts, however, were expressly exempted from the sound recording performance right.

Congress drew this legal distinction based on perceived differences between digital and traditional services, believing at the time
17 U.S.C. § $114(\mathrm{a})$

Scope of exclusive rights in sound recordings

17 U.S.C. § 106

Exclusive rights in copyrighted works

(report of the Register of Copyrights 2015) 
that traditional broadcasters posed "no threat" to the recording industry, in contrast to digital transmission services. A longstanding justification for the lack of a sound recording performance right has been the promotional effect that traditional airplay is said to have on the sale of sound recordings. In the traditional view of the market, broadcasters and labels representing copyright owners enjoy a mutually beneficial relationship whereby terrestrial radio stations exploit sound recordings to attract the listener pools that generate advertising dollars, and, in return, sound recording owners receive exposure that promotes record and other sales.

The section 114 statutory license allows different types of noninteractive digital music services - free and paid internet radio services, "preexisting" satellite radio services, and "preexisting" music subscription services - to perform sound recordings upon compliance with the statutory license requirements, including the payment of royalties as determined by the CRB. In addition, recognizing that such digital services must make server reproductions of sound recordings - sometimes called "ephemeral" copies - to facilitate their digital transmissions, Congress established a related statutory license under section 112 to authorize the creation of these copies. Rates and terms for the section 112 license are also established by the CRB.

The section 112 and 114 licenses for sound recordings are subject to a number of technical limitations. For instance, services relying on the section statutory license are prohibited from publishing an advance program schedule or otherwise announcing or identifying in advance when a specific song, album or artist will be played. Another example is the "sound recording performance complement," which limits the number tracks from a single album or by a particular artist that may be played during a 3-hour period.

Payment and reporting of royalties under the section 112 and 114 licenses are made to a single non-profit agent: SoundExchange. SoundExchange was established by the RIAA in 2000 and in 2003 was spun off as an independent entity. The Copyright Act specifies how royalties collected under section 114 are to be distributed: 50\% go to the copyright owner of the sound recording, typically a record label; $45 \%$ go to the featured recording artist or artists; $21 / 2 \%$ go to an agent representing nonfeatured musicians who perform on sound recordings; and $21 / 2 \%$ to an agent representing nonfeatured vocalists who perform on sound recordings. Section 112 fees are paid by SoundExchange directly to the sound recording owner. Prior to distributing royalty payments, SoundExchange deducts the reasonable costs incurred in carrying out its responsibilities.

The statutory licensing framework applies only to noninteractive (i.e., radio-style) services; interactive or on-demand services are not covered. The distinction between interactive and noninteractive ser- 
vices has been the matter of some debate. The statute provides that an interactive service is one that enables a member of the public to receive either "a transmission of a program specially created for the recipient, " or "on request, a transmission of a particular sound recording, whether or not as part of a program, which is selected by or on behalf of the recipient."

The statutory definition leads to the question of whether so-called "personalized" or "custom" music streaming services-services that tailor the music they play to individual user preferences-transmit programs that are "specially created for the recipient." In Arista Records LLC v. Launch Media, Inc., the Second Circuit held that one such service that played songs for users based on users' individual ratings was not interactive because the service did not displace music sales. Following the Launch Media decision, personalized music streaming services such as Pandora and Rdio have obtained statutory licenses as noninteractive services for their public performance of sound recordings. The CRB-established rates do not currently distinguish between such customized services and other services that simply transmit undifferentiated, radio-style programming over the internet.

Notably, under section 114, the rate standard applicable to "preexisting" satellite radio and music subscription services (i.e., those services that existed as of July 31, 1998) differs from that for other services such as internet radio and newer subscription services. This distinction is a legislative artifact.

Accordingly, because of the staggered enactment of the section 112 and 114 licenses, royalty rates for a limited set of older services Sirius XM, as the only preexisting satellite service, and Music Choice and Muzak, as the only preexisting subscription services - are governed by the four-factor standard in section 801(b) of the Act. Meanwhile, for all internet radio and other newer digital music services, and for all ephemeral recordings regardless of the service, the CRB is to establish rates and terms "that most clearly represent the rates and terms that would have been negotiated in the marketplace between a willing buyer and a willing seller."

In general, the CRB (like the CARP before it) has adopted "perperformance" rates for internet radio, rather than the percentageof-revenue rates that are typical in PRO licenses. That per-stream approach has proven controversial. After the CRB's "Webcasting II" decision in 2007, a number of internet radio services and broadcasters complained that the per-performance rates were unsustainable. These concerns led Congress to pass legislation giving SoundExchange the authority to negotiate and agree to alternative royalty schemes that could be binding on all copyright owners and others entitled to royalty payments in lieu of the CRB-set rates.
Launch Media: 578 F.3d 148 (2d Cir. 2009) 
In the wake of Congress' actions, SoundExchange reached agreement with a number of internet radio services, in general adopting royalty rates that were more closely aligned with the services' revenues. For example, in 2009, SoundExchange negotiated rates with large commercial "pureplay" internet radio services (i.e., services like Pandora that only transmit over the internet). Under that agreement, those services agreed to pay the greater of $25 \%$ of gross revenues or specified per-performance rates.

A streaming service that does not fall under the section 112 and 114 licenses - i.e., an interactive service - must negotiate a license with a record company in order to use the label's sound recordings. Since direct licenses are agreed upon at the discretion of the copyright owner and the potential licensee, the license terms can be vastly different from those that apply under the statutory regime. It is common for a music service seeking a sound recording license from a label to pay a substantial advance against future royalties, and sometimes an administrative fee. Other types of consideration may also be involved. For example, the major labels acquired a reported combined $18 \%$ equity stake in the on-demand streaming service Spotify allegedly based, at least in part, on their willingness to grant Spotify rights to use their sound recordings on its service.

\section{State-Law Protection for Pre-1972 Sound Recordings}

As noted above, Congress did not federalize the copyrights in already existing sound recordings when it added them to the Copyright Act. States are free to apply their own law to such sound recordings until 2067. This bifurcation raises significant questions about the scope of those rights - such as whether there is a public performance right and about whether familiar features of federal copyright law - such as fair use and $\S 512$ - apply to them. The dearth of caselaw does not help.

\section{Copyright Act}

17 U.S.C. § 301 (c)

Preemption with respect to other laws
With respect to sound recordings fixed before February 15, 1972, any rights or remedies under the common law or statutes of any State shall not be annulled or limited by this title until February 15, 2067. The preemptive provisions of subsection (a) shall apply to any such rights and remedies pertaining to any cause of action arising from undertakings commenced on and after February 15, 2067. No sound recording fixed before February 15, 1972, shall be subject to copyright 
under this title before, on, or after February 15, 2067.

RCA Mfg. Co. v. Whiteman

The dispute is as to whether W.B.O. Broadcasting Corporation, as the purchaser of phonographic records prepared by RCA Manufacturing Company, Inc., of Whiteman's orchestral performances, may broadcast them by radio. Whiteman's performances took place in studios of RCA Manufacturing Company, Inc., which arranged for their reproduction upon ordinary phonographic disc records, and which, with the consent of Whiteman, sold the records to the public at large. Of the nine records here in question five were sold between November, 1932, and August 15, 1937, during which period every record bore the legend: "Not Licensed for Radio Broadcast".

It is only in comparatively recent times that a virtuoso, conductor, actor, lecturer, or preacher could have any interest in the reproduction of his performance. Until the phonographic record made possible the preservation and reproduction of sound, all audible renditions were of necessity fugitive and transitory; once uttered they died; the nearest approach to their reproduction was mimicry. Of late, however, the power to reproduce the exact quality and sequence of sounds has become possible, and the right to do so, exceedingly valuable; people easily distinguish, or think they distinguish, the rendition of the same score or the same text by their favorites, and they will pay large sums to hear them. Hence this action.

Copyright in any form, whether statutory or at common-law, is a monopoly; it consists only in the power to prevent others from reproducing the copy-righted work. The records at bar embodied Whiteman's "common-law property" - his contribution as a conductor - in precisely the same way that the record of such a score would embody his composition. Hence the question is no different from whether he might disseminate a musical score to the public at large, but impose a limitation upon it that buyers should not use it to broadcast for profit. It will hardly be argued that if it was a "publication" in the sense that that destroys the "common-law property", the restriction upon the use of the record would be valid notwithstanding. If "the commonlaw property" in the rendition be gone, then anyone may copy it who chances to hear it, and may use it as he pleases.

Certainly when the "common-law property" is in a work which the Copyright Act covers, there can be no doubt; Congress has created the monopoly in exchange for a dedication, and when the monopoly expires the dedication must be complete. If the records were registrable under the act, the restriction would therefore certainly not limit the dedication. The fact that they are not within the act should make no difference. That being true, we see no reason why the same acts that unconditionally dedicate the common-law copy-
114 F.2d 86 (2d Cir. 1940)

(Learned Hand, J.)

"If you are not aware of the Beatles, you cannot not hope to understand any music of the 1960s, because they were ubiquitous and affected all the other music. They were the dominant, inescapable sound of the era. Like the Beatles, Whiteman's orchestra was not only the most popular band of the 1920s, but was also enormously influential in every field of music. When that period is referred to as the 'Jazz Age,' conjuring up pictures of flappers, bearskin coats, and F. Scott Fitzgerald, the band that made that jazz was Whiteman's. In purely musical terms, his innovations were huge: He defined the arranging style that would be used by virtually every later bandleader. If he didn't swing, he appreciated musicians who could and hired many of the most important white jazz artists of that era. And he was the first person to force a broad public to treat jazz as serious, important music rather than just a noisy fad. As the Beatles' Sgt. Pepper was for rock, Whiteman's Rhapsody in Blue [commissioned by Whiteman and composed by George Gershwin] was the breakthrough through work in the struggle to have jazz recognized as art music, bringing it out of the saloons and dance halls and forcing 'serious' music fans to take notice of it as the sound of their time." Elijah Wald, How the Beatles Destroyed Rock ' $n$ ' Roll (2009). 
right in works copyrightable under the act, should not do the same in the case of works not copyrightable. Otherwise it would be possible, at least pro tanto, to have the advantage of dissemination of the work at large, and to retain a perpetual though partial, monopoly in it. That is contrary to the whole policy of the Copyright Act and of the Constitution.

Whiteman and the plaintiff also rest their case upon the theory of unfair competition. In the case at bar if Whiteman and RCA Manufacturing Company, Inc., cannot bring themselves within the law of common-law copyright, there is nothing to justify a priori any continuance of their control over the activities of the public to which they have seen fit to dedicate the larger part of their contribution.

\section{Federal Copyright Protection for Pre-1972 Sound Recordings}

The states provide protection for pre-1972 sound recordings through a patchwork of criminal laws, civil statutes and common law. Early cases relied on common law, principally the tort of unfair competition, to protect sound recordings from unauthorized duplication and sale. By the 1950s, record piracy had become a serious problem, with pirates openly competing with record companies. For that reason, attention shifted to legislation imposing criminal sanctions starting in the 1960s.

In the 1960s, states began to pass laws making it a criminal offense to duplicate and distribute sound recordings, without authorization, for commercial purposes. New York was the first such state in 1967; California was the second, in 1968. Several other states followed, and after the Supreme Court ruled in Goldstein v. California in 1973 that state law protection of sound recordings was constitutional, many additional states passed such laws.

Most state criminal laws prohibit, at a minimum, duplication and sale of recordings done knowingly and willfully with the intent to sell or profit commercially from the copies. Many have express exceptions for activities such as broadcasting, archiving, and personal use. It is unclear how many cases are brought under these statutes, but they inform the protection for sound recordings under state law and provide a backdrop for commercial transactions.

The formulation of prohibited activities varies from state to state. Almost all states prohibit the act of duplicating without authorization (often referred to as "transferring the sounds"). Most states also prohibit advertising or offering for sale, and selling or otherwise distributing the unauthorized recordings. Some states also criminalize activities such as transporting sound recordings within the state (or possessing them) with knowledge that they are unauthorized, with intent to sell them. 
A number of states have civil laws that address protection for pre1972 sound recordings, directly or indirectly. Section 980(a)(2) of the California statute provides civil protection of pre-1972 sound recordings and is a good example:

The author of an original work of authorship consisting of a sound recording initially fixed prior to February 15, 1972, has an exclusive ownership therein until February 15, 2047, as against all persons except one who independently makes or duplicates another sound recording that does not directly or indirectly recapture the actual sounds fixed in such prior sound recording, but consists entirely of an independent fixation of other sounds, even though such sounds imitate or simulate the sounds contained in the prior sound recording.

The few cases decided under $\S 980(a)(2)$ have viewed the section as conferring an intangible property interest in the sound recordings that can be protected in a misappropriation, conversion or unfair competition claim. They have distinguished the property interest protected by this statute from copyright protection which, under California law, terminates upon publication. Some states specifically provide that there is a private right of action for violation of the state criminal piracy provision.

Most states also have some form of non-statutory civil protection, although the precise nature of that protection varies from state to state. The two most prevalent theories for providing protection are common law copyright and misappropriation/unfair competition, but courts have also protected sound recordings under other legal theories, such as conversion.

The most notable case in recent years involving pre-1972 sound recordings was Capitol Records, Inc. v. Naxos of America, Inc.. At issue were recordings of classical music performances by Pablo Casals, Edwin Fischer and Yehudi Menuhin, originally made in the 1930s. Capitol, with a license from EMI, the successor of the original recording company, remastered the recordings, and was distributing them in the United States. Naxos obtained and restored the recordings in the UK, where they were in the public domain, and began marketing them in the United States in competition with Capitol. The New York Court of Appeals held that foreign sound recordings remain protected under "common law copyright" in New York until 2067, even though they may be in the public domain in their home country.

In EMI Records Ltd. v. Premise Media Corp., a New York trial court, ruling on a motion for a preliminary injunction, considered the applicability of the fair use defense to a claim for infringement of common law copyright in a sound recording. Defendants had used an excerpt
Naxos: 4 N.Y.3d 540 (2005)

Premise Media: No. 601209/08, 2008 WL 5027245 (N.Y. Sup. Aug. 8, 2008) 
of John Lennon's "Imagine," a pre-1972 sound recording, in a documentary film entitled "Expelled." The film attempts to counter criticism of the theory of intelligent design. The 99-minute documentary used a 15-second excerpt from Lennon's 3-minute sound recording.

Plaintiffs argued that under common law copyright, any unauthorized use of a sound recording is actionable. Defendants argued that only a reproduction of the complete recording was an infringement. The court rejected both claims, but ultimately concluded that plaintiffs had established a prima facie claim of common law copyright infringement. The court observed that New York cases have acknowledged the existence of a fair use defense to common law infringement claims but that no case had actually applied fair use in that context. The court recognized that fair use was generally unavailable as a defense with respect to unpublished works, principally to protect the copyright owner's right of first publication. In the case of sound recordings, however, common law copyright protection exists regardless of publication, reasoned the court. "Thus, the erosion of the publication distinction in the context of sound recordings vitiates the underlying rationale preventing application of pre-publication fair use." Accordingly, the court held that fair use was available as a defense to plaintiffs' copyright infringement claim.

The court turned for guidance to the federal law of fair use and specifically to the fair use factors in 17 U.S.C. $\S 107$ and the cases interpreting them. The court ruled that defendants were likely to prevail on their fair use defense, primarily because the use of the sound recording excerpt in the film could be seen as transformative, conveying a critical message about the song and the viewpoint it represents, and because there was little likely market effect from defendants' use.

62 F. Supp. 3d 325 (S.D.N.Y. 2014)

Flo \& Eddie, Inc. v. Sirius XM Radio, Inc.

Flo and Eddie is a California corporation, wholly owned by its principals, Mark Volman and Howard Kaylan. Volman and Kaylan are two of the original members of The Turtles, a 1960s rock group whose hits included "Happy Together" and a cover of Bob Dylan's "It Ain't Me Babe."

Master recordings of the Turtles' performances - all of which were made prior to February 15, 1972 - were transferred to the Turtles' members as part of a legal settlement. Volman and Kaylan purchased the remaining Turtles' members' interests in the recordings, and ultimately transferred all ownership interests in the recordings to Flo and Eddie.

Sirius is a Delaware corporation engaged in the satellite radio business. Sirius provides digital audio content to its subscribers, who pay a periodic fee. Sirius acknowledges that it "performs" sound 
recordings, including pre-1972 sound recordings, by broadcasting them over its satellite radio network and streaming them over the internet. The pre-1972 sound recordings Sirius has performed include Turtles recordings.

For all the copying it does do, it's worth noting what Sirius does not do. Sirius does not currently allow users to download and store complete copies of any recordings. In this way, Sirius differs from file-sharing services such as Napster and Limewire. Nor does Sirius allow users to listen to a particular recording whenever they choose to do so. In this way, Sirius differs from some internet radio services like Spotify. Users can customize the programming they receive to a limited extent using the "My SXM" feature. For example, a user could choose to emphasize folk music and deemphasize rock music on a 70s channel. But that user could not choose to listen only to Bob Dylan, much less a particular Bob Dylan recording, while excluding anything by Led Zeppelin.

Sirius has moved for summary judgment. It argues that New York common law copyrights in pre-1972 sound recordings do not afford an exclusive right of public performance.

I conclude that the New York Court of Appeals would recognize the exclusive right to public performance of a sound recording as one of the rights appurtenant to common law copyright in such a recording. The common law typically protects against unauthorized reproduction of copies or phonorecords, unauthorized distribution by publishing or vending, and unauthorized performances. New York courts have long afforded public performance rights to holders of common law copyrights in works such as plays and films. The Second Circuit concluded over three decades ago that New York would recognize a public performance right in compilations of film clips.

Sirius principally argues that no such right exists because New York case law contains no discussion of public performance rights in sound recordings. But the exact same argument could have been made (and undoubtedly was made, and rejected) in Naxos - a case decided only in 2005, more than a century after sound recordings were invented. The very fact that Naxos was decided in favor of the common law copyright holder, after more than a century of judicial silence, means that this court can infer nothing - certainly not that the common law copyright in sound recordings does not encompass all of the rights traditionally accorded to copyright holders in other works, including the right of public performance - from the fact that this is the first case to raise the issue.

An arguably stronger argument can be made that years of judicial silence implies exactly the opposite of what Sirius contends - not that common law copyright in sound recordings carries no right of public performance, but rather that common law copyright in sound record- 
ings comes with the entire bundle of rights that holders of copyright in other works enjoy. No New York case recognizing a common law copyright in sound recordings has so much as suggested that right was in some way circumscribed, or that the bundle of rights appurtenant to that copyright was less than the bundle of rights accorded to plays and musical compositions.

I question whether the investors would be truly surprised if Sirius were to have to pay royalties in order to perform pre-1972 sound recordings. Sirius, which broadcasts exclusively in non-analog form, must pay royalties under federal law in order to broadcast post-1972 sound recordings. All Flo and Eddie seeks here is the right to receive royalties under state law for the digital broadcasting of its pre-1972 recordings - hardly a shocking development in the world of digital broadcasting.

No. $13-\mathrm{cv}-23182,2015$ WL 3852692

(S.D. Fla. 2015)
Flo \& Eddie, Inc. v. Sirius XM Radio, Inc.

At the onset of this litigation, Flo \& Eddie recognized that its property rights were a matter of state law and therefore filed three different actions in Florida, New York, and California. Of the three actions, this one is relatively unique. California's copyright statute has a specific provision that addresses pre-1972 recordings. The New York district court did not have the benefit of legislation, however, it was able to rely on several cases interpreting New York law to find that Flo \& Eddie had an exclusive right to publicly perform the sound recordings.

Florida is different. There is no specific Florida legislation covering sound recording property rights, nor is there a bevy of case law interpreting common law copyright related to the arts.

If this Court adopts Flo \& Eddie's position, it would be creating a new property right in Florida as opposed to interpreting the law. The Court declines to do so. While the Court regularly interprets Florida law to resolve claims in diversity jurisdiction, it is not the Court's place to expand Florida common law by creating new causes of action. Federal courts are entrusted to apply state law, not make it. The Court finds that the issue of whether copyright protection for pre-1972 recordings should include the exclusive right to public performance is for the Florida legislature.

Indeed, if this Court was to recognize and create this broad right in Florida, the music industry - including performers, copyright owners, and broadcasters - would be faced with many unanswered questions and difficult regulatory issues including: (1) who sets and administers the licensing rates; (2) who owns a sound recording when the owner or artist is dead or the record company is out of business; and (3) what, if any, are the exceptions to the public performance right. The Florida legislature is in the best position to address these issues, not the Court. Accordingly, the Court finds that Florida com- 
mon law does not provide Flo \& Eddie with an exclusive right of public performance in The Turtles' sound recordings.

UMG Recordings, Inc. v. Escape Media Group, Inc. Defendant Escape Media Group, Inc. developed, owns and operates an Internet-based music streaming service called Grooveshark. Users of Grooveshark can upload audio files (typically songs) to an archive maintained on defendant's computer servers, and other users can search those servers and stream recordings to their own computers or other electronic devices.

Plaintiff UMG Recordings, Inc. is the owner of the rights in many popular sound recordings that have been uploaded to Grooveshark. Many of those recordings were made prior to February 15, 1972 (the pre-1972 recordings). Defendant concedes that it cannot ensure that each work uploaded to its servers is a non-infringing work. However, it has operated Grooveshark with the assumption that it is shielded from infringement claims by copyright owners by 17 USC $\S 512$, popularly known as the Digital Millenium Copyright Act (DMCA).

Initially, it is clear to us that the DMCA, if interpreted in the manner favored by defendant, would directly violate section 301(c) of the Copyright Act. Had the DMCA never been enacted, there would be no question that UMG could sue defendant in New York state courts to enforce its copyright in the pre-1972 recordings, as soon as it learned that one of the recordings had been posted on Grooveshark. However, were the DMCA to apply as defendant believes, that right to immediately commence an action would be eliminated. Indeed, the only remedy available to UMG would be service of a takedown notice on defendant. This is, at best, a limitation on UMG's rights, and an implicit modification of the plain language of section 301(c). The word "limit" in 301(c) is unqualified, so defendant's argument that the DMCA does not contradict that section because UMG still retains the right to exploit its copyrights, to license them and to create derivative works, is without merit. Any material limitation, especially the elimination of the right to assert a common-law infringement claim, is violative of section 301(c) of the Copyright Act.

For defendant to prevail, we would have to conclude that Congress intended to modify section 301(c) when it enacted the DMCA. However, there is no reason to conclude that Congress recognized a limitation on common-law copyrights posed by the DMCA but intended to implicitly dilute section 301(c) nonetheless. Such an interpretation is disfavored where, as here, the two sections can reasonably co-exist, each in its own field of operation. Congress explicitly, and very clearly, separated the universe of sound recordings into two categories, one for works "fixed" after February 15, 1972, to which it granted federal copyright protection, and one for those
107 A.D.3d 51 (N.Y. App. Div. 2013) 
fixed before that date, to which it did not. Defendant has pointed to nothing in the Copyright Act or its legislative history which prevents us from concluding that Congress meant to apply the DMCA to the former category, but not the latter.

Finally, we reject defendant's argument that the very purpose of the DMCA will be thwarted if it is deemed not to apply to the pre1972 recordings. The statutory language at issue involves two equally clear and compelling Congressional priorities: to promote the existence of intellectual property on the Internet, and to insulate pre1972 sound recordings from federal regulation. Defendant's concerns about interpreting the statutes in the manner advocated by UMG are no more compelling than UMG's concerns about interpreting the statutes in the manner advanced by defendant. Under such circumstances, it would be far more appropriate for Congress, if necessary, to amend the DMCA to clarify its intent, than for this Court to do so by fiat.

This is the Pre-1972 Sound Recordings report excerpted above.

\section{Capitol Records, LLC v. Vimeo, LLC}

Defendant Vimeo, LLC1 is an Internet service provider, which operates a website on which members can post videos of their own creation, which are then accessible to the public at large. Plaintiffs are record companies and music publishing companies, which own copyrights in sound recordings of musical performances. Their complaint alleges that Vimeo is liable to Plaintiffs for copyright infringement by reason of 199 videos posted on the Vimeo website, which contained allegedly infringing musical recordings for which Plaintiffs owned the rights.

The first question we consider is whether the district court erred in granting partial summary judgment to Plaintiffs, rejecting the availability of the DMCA's safe harbor for infringement of sound recordings fixed prior to February 15, 1972. On this question, the district court accepted without discussion the position taken by the United States Copyright Office in a report prepared in 2011 that the safe harbor does not protect against liability for infringement of pre-1972 sound recordings.

The Pre-1972 Sound Recordings Report arrived at its conclusion that § 512(c)'s safe harbor applies only to post-1972 sound recordings by the following reasoning: The term "infringement of copyright," which is employed in § 512(c), "is defined in section 501(a) as the violation of 'any of the exclusive rights of the copyright owner as provided by sections 106 through 122."' Therefore, that term, when used in $\S 512$ (c), "only refers to infringement of rights protected under title 17, and does not include infringement of rights protected under [state] law."

While we unhesitatingly acknowledge the Copyright Office's su- 
perior expertise on the Copyright Act, we cannot accept its reading of $\S 512(\mathrm{c})$. It is based in major part on a misreading of the statute. A literal and natural reading of the text of $\S 512$ (c) leads to the conclusion that its use of the phrase "infringement of copyright" does include infringement of state laws of copyright. One who has been found liable for infringement of copyright under state laws has indisputably been found "liable for infringement of copyright." In this instance, Congress did not qualify the phrase "infringement of copyright" by adding, as it did in other circumstances, the words, "under this title." See, e.g., \& 106 ("Subject to sections 107 through 122, the owner of copyright under this title has the exclusive rights to do and to authorize any of the following ....); § 201(a) ("Copyright in a work protected under this title vests initially in the author or authors of the work."). To interpret $\S 512$ (c)'s guarantee that service providers "shall not be liable ... for infringement of copyright" to mean that they may nonetheless be liable for infringement of copyright under state laws would be, at the very least, a strained interpretation - one that could be justified only by concluding that Congress must have meant something different from what it said.

To construe $\S 512$ (c) as leaving service providers subject to liability under state copyright laws for postings by users of infringements of which the service providers were unaware would defeat the very purpose Congress sought to achieve in passing the statute. Service providers would be compelled either to incur heavy costs of monitoring every posting to be sure it did not contain infringing pre-1972 recordings, or incurring potentially crushing liabilities under state copyright laws. It is not as if pre-1972 sound recordings were sufficiently outdated as to render the potential liabilities insignificant. Some of the most popular recorded music of all time was recorded before 1972, including work of The Beatles, The Supremes, Elvis Presley, Aretha Franklin, Barbra Streisand, and Marvin Gaye.

\section{E Bootlegging}

The Copyright Clause allows protection only for "writings." Under the 1909 Copyright Act, a live performance was not subject to federal copyright; there was nothing to publish with notice of copyright or to register to secure protection. This left a substantial hole, one that states sometimes filled.

The 1976 Copyright Act mostly carried forward the exclusion of live performances, this time because they are not considered "fixed." There was one exception: a work is considered "fixed" if it is being simultaneously recorded and transmitted, thus allowing copyright protection for live broadcasts of concerts, sporting events, etc. Again, states partially filled the gap with so-called anti-bootlegging 
Does the 1976 Copyright Act's treatment of live broadcasts as "fixed" if they are fixed simultaneously with their transmission suffice for the Met's live Saturday afternoon opera radio broadcasts, which continue to this day? statutes. Congress followed their example with the 1994 Uruguay Round Agreements Act, which (among other things) added civil antibootlegging provisions to Title 17 and criminal anti-bootlegging provisions to Title 18.

Metropolitan Opera Assoc. v. Wagner-Nichols Recorder Corp. Metropolitan Opera is an educational membership corporation. Over a period of sixty years it has, by care, skill and great expenditure, maintained a position of pre-eminence in the field of music and grand opera. By reason of this skill and pre-eminence it has created a national and world-wide audience and thereby a large market for radio broadcasts and phonograph recordings of its performances.

Metropolitan Opera has sold the exclusive right to broadcast its opera performances during the 1949-50 season to American Broadcasting, for which Metropolitan Opera receives \$100,000. Under the contract for the 1949-50 season, American Broadcasting broadcast Metropolitan Opera performances of eighteen operas between November 26, 1949, and March 25, 1950.

Since November 26, 1949, the defendants have recorded these broadcast performances of Metropolitan Opera and have used their master recordings to make phonograph records of Metropolitan Opera performances. The defendants have advertised and sold these records as records of broadcast Metropolitan Opera performances.

That defendants' piratical conduct and practices constitute unfair competition both with Metropolitan Opera and Columbia Records is made abundantly clear by the record. Plaintiff Metropolitan Opera derives income from the performance of its operatic productions in the presence of an audience, from the broadcasting of those productions over the radio, and from the licensing to Columbia Records of the exclusive privilege of making and selling records of its own performances. Without any payment to Metropolitan Opera for the benefit of its extremely expensive performances, and without any cost comparable to that incurred by Columbia Records in making its records, defendants offer to the public recordings of Metropolitan Opera's broadcast performances. This constitutes unfair competition.

The performance of the opera in the opera house and the broadcast of the opera performance over the network of American Broadcasting under an exclusive broadcasting contract with Metropolitan Opera did not abandon the plaintiffs' rights to this performance. At common law the public performance of a play, exhibition of a picture or sale of a copy of the film for public presentation did not constitute an abandonment of nor deprive the owner of his common-law rights. The care with which the Metropolitan Opera made its limited grants, granting exclusive right to a single network and restricting the latter's 
right to record and granting exclusive rights to record to Columbia Records, again reserving the right to approve all records before their release, shows clearly no intent to abandon but, on the contrary, an attempt to retain effective control over the broadcasting and recording of its performances. The fact that performances today can take place over the radio as well as in the theatre and thereby reach a wider audience does not change the principle involved.

\section{Copyright Act}

Anyone who, without the consent of the performer or performers involved -

(1) fixes the sounds or sounds and images of a live musical performance in a copy or phonorecord, or reproduces copies or phonorecords of such a performance from an unauthorized fixation,

(2) transmits or otherwise communicates to the public the sounds or sounds and images of a live musical performance, or

(3) distributes or offers to distribute, sells or offers to sell, rents or offers to rent, or traffics in any copy or phonorecord fixed as described in paragraph (1), regardless of whether the fixations occurred in the United States,

shall be subject to the remedies provided in sections 502 through 505, to the same extent as an infringer of copyright.

\section{United States v. Martignon}

This appeal presents a recurring issue in constitutional law: the extent to which Congress can use one of its powers to enact a statute that it could not enact under another of its arguably relevant powers. Here the statute involved is Section 2319A of Title 18 which prohibits the unauthorized recording of performances as well as the copying, distribution, sale, rental, and trafficking of these bootlegged phonorecords. 1

On October 27, 2004, a grand jury charged Martignon, the proprietor of Midnight Records in Manhattan, with one count of violating Section 2319A by reproducing an unauthorized phonorecord and by distributing and selling and offering to distribute and sell phonorecords of performances which had been recorded or fixed without the consent of the performer or performers. Martignon moved to dismiss the indictment, arguing that Section 2319A violated

\footnotetext{
${ }^{1} 17$ U.S.C. § 1101(a) provides that copyright remedies shall be available against persons who commit the same acts. Unlike Section 2319A, Section 1101 does not require any particular mens rea or that the act be performed for commercial gain or private financial gain.
}

17 U.S.C. § 1101 (a)

Unauthorized fixation and trafficking

in sound recordings and music videos

492 F.3d 14 (2d. Cir. 2007) 
the Copyright Clause because live performances are not "Writings" within the meaning of the clause and because live performances were given protection for perpetuity rather than for a "limited Time[]". Martignon also claimed that the statute violated the First Amendment.

Because the government concedes Congress could not have enacted Section 2319A pursuant to the Copyright Clause, we must determine whether the Copyright Clause's limitations also limit Congress's power to regulate creative works under the Commerce Clause.

Section 2319A does not create and bestow property rights upon authors or inventors, or allocate those rights among claimants to them. It is a criminal statute, falling in its codification between the law criminalizing certain copyright infringement and the law criminalizing "trafficking in counterfeit goods or services." It is, perhaps, analogous to the law of criminal trespass. Rather than creating a right in the performer him-or herself, it creates a power in the government to protect the interest of performers from commercial predations. Section 2319A does not grant the performer the right to exclude others from the performance - only the government can do that. Neither may the performer transfer his or her interests under Section 2319A to another. Section 2319A only prevents others from doing something without the authorization of the protected person. It may therefore protect the property interests an individual holds by virtue of other laws, but it does not itself allocate those interests. Section 2319A is not a law "secur[ing] ... rights," nor is it a copyright law. We therefore conclude that it was not enacted under the Copyright Clause. We have no need to examine whether it violates limits of the Copyright Clause and proceed instead to an examination of its sustainability under the Commerce Clause.

It is by now well established that legislative Acts adjusting the burdens and benefits of economic life come to the Court with a presumption of constitutionality. A court may invalidate legislation enacted under the Commerce Clause only if it is clear that there is no rational basis for a congressional finding that the regulated activity affects interstate commerce, or that there is no reasonable connection between the regulatory means selected and the asserted ends. Section 2319A has substantial commercial and economic aspects. Indeed, regulation of bootlegging is necessary at the federal level because of its interstate and international commercial aspects. Without this scope, bootlegging could be adequately regulated, as it has been in the past, by the states. Given the nexus between bootlegging and commerce, it is clear that absent any limitations stemming from the Copyright Clause, Congress would have had the power to enact Section 2319A(a)(1) \& (3) under the Commerce Clause. Further, Section 
2319A regulates only fixing, selling, distributing, and copying with a commercial motive, activities at the core of the Commerce Clause. It would have been eminently reasonable for Congress to conclude that the sale and distribution of bootleg phonorecords will have a substantial interstate effect on the sale and distribution of legitimate phonorecords. Because Section 2319A is not a copyright law and its enactment was well within the scope of Congress's Commerce Clause authority, it is constitutionally permissible unless some other constitutional provision prevents its enforcement.

\section{Questions}

1. The folk singer-songwriter Richard Shindell released the song "The Next Best Western" on his 1997 album Reunion Hill. The musical work copyright (registration no. PA0000967996) is owned by Amalgamated Balladry and is part of the ASCAP repertory. The sound recording copyright (registration no. SR0000297971) is owned by Shanachie Records. For each of the following uses, what licenses (if any) would you need, from whom, and how could you obtain them?

- Playing "The Next Best Western" from a Reunion Hill CD on WTWP, a broadcast radio station.

- Streaming "The Next Best Western" live on the Internet as it plays on WTWP.

- Turning on the radio to WTWP in your home as "The Next Best Western comes on.

- Turning on the radio to WTWP in the coffeeshop you run as "The Next Best Western comes on.

- Using the Reunion Hill version of "The Next Best Western" in a TV commercial.

- Recording a hard-rock cover of "The Next Best Western" which you sell on CDs.

- Selling your hard-rock cover as downloadable MP3s.

- Using your hard-rock cover in a commercial.

- Playing "The Next Best Western" live on guitar at a soldout concert at Carnegie Hall.

- Recording your sold-out Carnegie Hall concert and selling CDs.

\footnotetext{
${ }^{8}$ This commercial purpose distinguishes Section 2319A from Section 1101. A person who recorded a concert for her personal enjoyment would not violate Section 2319A. Further, because no commercial motive is required for a Section 1101 violation, we specifically limit today's holding to Section 2319A and express no opinion on Section 1101's constitutionality.
} 
- Playing the entirety of Reunion Hill live on guitar at a soldout concert at Carnegie Hall.

- Playing "The Next Best Western" on guitar in Central Park on a warm spring day.

- Playing "The Next Best Western" from a Reunion Hill CD on a boombox in Central Park on a warm spring day.

- Singing "The Next Best Western" as you walk down the street.

- Playing "The Next Best Western" from a CD of Reunion Hill

- Setting "The Next Best Western" as your cellphone ringtone.

- Selling ringtones of "The Next Best Western" to other people.

- Sampling "The Next Best Western" from a CD of Reunion Hill and using the sample in a hip-hop track.

- Selling karaoke DVDs that include "The Next Best Western" and its lyrics, set to pictures of trucks and highways.

- Putting a Reunion Hill CD in a folk-music-only coinoperated jukebox.

- Running a streaming-music service that includes the Reunion Hill version of "The Next Best Western" as one of the 3,000,000 tracks users can stream.

- Running a streaming-music service that includes a hardrock cover of "The Next Best Western" as one of the $3,000,000$ tracks users can stream.

- Running a streaming-video service that includes a movie in which the Reunion Hill version of "The Next Best Western" appears on the soundtrack.

2. Which of your answers to the previous question might change if "The Next Best Western" had been released in 1967 rather than 1997 ?

3. How many distinct types of licenses have you encountered in this chapter? Which of these license types would be necessary features of any well-functioning copyright system, and which of them are accidents of history?

4. Is there anything good that can be said aout how United States copyright law deals with music? Or should we burn the whole thing to the ground and start again? 


\section{Trademark}

Trademarks are different.

\section{The Trade-Mark Cases}

Any attempt to identify the essential characteristics of a trademark with inventions and discoveries in the arts and sciences, or with the writings of authors, will show that the effort is surrounded with insurmountable difficulties.

The ordinary trademark has no necessary relation to invention or discovery. The trademark recognized by the common law is generally the growth of a considerable period of use, rather than a sudden invention. It is often the result of accident, rather than design, and when under the act of Congress it is sought to establish it by registration, neither originality, invention, discovery, science, nor art is in any way essential to the right conferred by that act. If we should endeavor to classify it under the head of writings of authors, the objections are equally strong.

The trademark may be, and generally is, the adoption of something already in existence as the distinctive symbol of the party using it. At common law, the exclusive right to it grows out of its use, and not its mere adoption. By the act of Congress, this exclusive right attaches upon registration. But in neither case does it depend upon novelty, invention, discovery, or any work of the brain. It requires no fancy or imagination, no genius, no laborious thought. It is simply founded on priority of appropriation. We look in vain in the statute for any other qualification or condition. If the symbol, however plain, simple, old, or well known, has been first appropriated by the claimant as his distinctive trademark, he may by registration secure the right to its exclusive use.

Suppose that the Knockoff Soda Corporation starts selling a cola in
100 U.S. $82(1879)$

The leading trademark treatises are J. Thomas McCarthy, McCarthy on Trademarks and Unfair Competition (Thomson Reuters, on Westlaw), Callmann. Jerome Gilson \& Anne Gilson LaLonde, Gilson on Trademarks (LexisNexis, on Lexis), and Siegrun D. Kane, Kane on Trademark Law: A Practicioner's Guide (PLI). 
"What's great about this country is that America started the tradition where the richest consumers buy essentially the same things as the poorest. You can be watching TV and see Coca-Cola, and you know that the President drinks Coke, Liz Taylor drinks Coke, and just think, you can drink Coke, too. A Coke is a Coke and no amount of money can get you a better Coke than the one the bum on the corner is drinking. All the Cokes are the same and all the Cokes are good. Liz Taylor knows it, the President knows it, the bum knows it, and you know it."-Andy Warhol

15 U.S.C. § 1127 [Lanham Act § 45] Construction and definitions; intent of chapter

The phrase "even if that source is unknown" was added in 1984 to reverse the holding in Anti-Monopoly, Inc. v. General Mills Fun Group, 684 F. 2d 1316 (9th Cir. 1982) that MONOPOLY was generic for the board game because consumers didn't know and didn't care who made it.

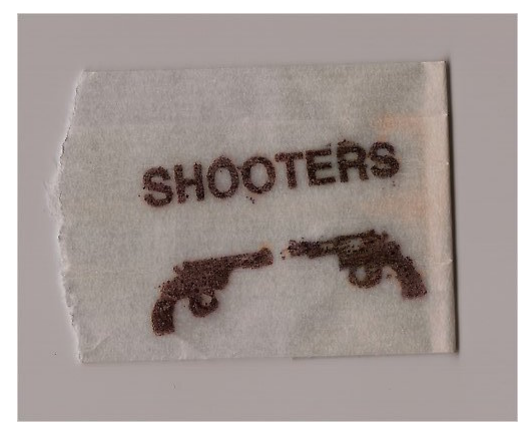

SHOOTERS drug stamp red cans bearing the familiar COCA-COLA name and logo. There are various reasons we might describe this as wrongful:

- Most obviously, there is a consumer protection rationale: some consumers will be deceived into buying a can of soda made by Knockoff rather than by the Coca-Cola Company.

- There is an unfair competition angle: Knockoff unjustifiably free rides on the Coca-Cola Company's reputation for quality.

- More subtly, there is a search costs rationale. If consumers cannot quickly tell the difference between a can of COCA-COLA made by Knockoff and one made by Coca-Cola, they will spend more time inspecting cans in minute detail, or give up entirely.

- And perhaps there is a cultural angle, given the importance of brands like COCA-COLA in modern society.

Trademark law is a large and sprawling thing. It is a hybrid of state and federal protection; the two regimes interrelate so thoroughly that they must be studied together. It has a clear core of liability, surrounded by a messy penumbra of related causes of action. (The boundary between this chapter and the chapter on false advertising, for example, is entirely nebulous.) And its subject matter has expanded so greatly over time that it too, spans multiple chapters.

\section{A Subject Matter}

The basis of trademark protection is distinctiveness: the capacity of a word, phrase, logo, or other symbol to identify to consumers the source of goods or services. We begin with words and phrases and then consider what graphic design elements add. ("Exotic" trademarks, such as scents and product designs, will be considered in the Design chapter.)

\section{Lanham Act}

The term "trademark" includes any word, name, symbol, or device, or any combination thereof used by a person ... to identify and distinguish his or her goods, including a unique product, from those manufactured or sold by others and to indicate the source of the goods, even if that source is unknown.

\section{Drug Stamps Problem}

Drug dealers in many cities sell heroin in single-dose bags for about $\$ 10$. Frequently, the bags are labeled with a "stamp": a phrase, image, or both. Stamps include EXORCIST, FLATLINE, and GET HIGH OR DIE TRYING (this last one is laced with fentanyl). Fans of The Wire may remember PANDEMIC, WMD, and RED TOPS, among others. 
Why would drug dealers mark their bags in this way? What functions do the stamps serve? Does it matter whether these are legally enforceable trademarks?

\section{Word Marks}

\section{Zatarains, Inc. v. Oak Grove Smokehouse, Inc.}

Zatarain's is the manufacturer and distributor of a line of over one hundred food products. Two of these products, "Fish-Fri" and "Chick-Fri," are coatings or batter mixes used to fry foods.

Zatarain's "Fish-Fri" consists of $100 \%$ corn flour and is used to fry fish and other seafood. "Fish-Fri" is packaged in rectangular cardboard boxes containing twelve or twenty-four ounces of coating mix. The legend "Wonderful FISH-FRI ${ }^{\circledR}$." is displayed prominently on the front panel, along with the block Z used to identify all Zatarain's products. The term "Fish-Fri" has been used by Zatarain's or its predecessor since 1950 and has been registered as a trademark since 1962.

Zatarain's "Chick-Fri" is a seasoned corn flour batter mix used for frying chicken and other foods. The "Chick-Fri" package, which is very similar to that used for "Fish-Fri," is a rectangular cardboard container labelled "Wonderful CHICK-FRI." Zatarain's began to use the term "Chick-Fri" in 1968 and registered the term as a trademark in 1976.

Zatarain's products are not alone in the marketplace. At least four other companies market coatings for fried foods that are denominated "fish fry" or "chicken fry." Appellee Oak Grove Smokehouse, Inc. ("Oak Grove") began marketing a "fish fry" and a "chicken fry" in March 1979. Both products are packaged in clear glassine packets that contain a quantity of coating mix sufficient to fry enough food for one meal. The packets are labelled with Oak Grove's name and emblem, along with the words "FISH FRY" OR "CHICKEN FRY."spices. Oak Grove's "FISH FRY" has a corn flour base seasoned with various spices; Oak Grove's "CHICKEN FRY" is a seasoned coating with a wheat flour base.

Appellee Visko's Fish Fry, Inc. ("Visko's") entered the batter mix market in March 1980 with its "fish fry." Visko's product is packed in a cylindrical eighteen-ounce container with a resealable plastic lid. The words "Visko's FISH FRY" appear on the label along with a photograph of a platter of fried fish. Visko's coating mix contains corn flour and added

Other food manufacturing concerns also market coating mixes. Boochelle's Spice Co. ("Boochelle's"), originally a defendant in this lawsuit, at one time manufactured a seasoned "FISH FRY" packaged in twelve-ounce vinyl plastic packets. Pursuant to a settlement be-
698 F.2d 786 (5th Cir. 1983)
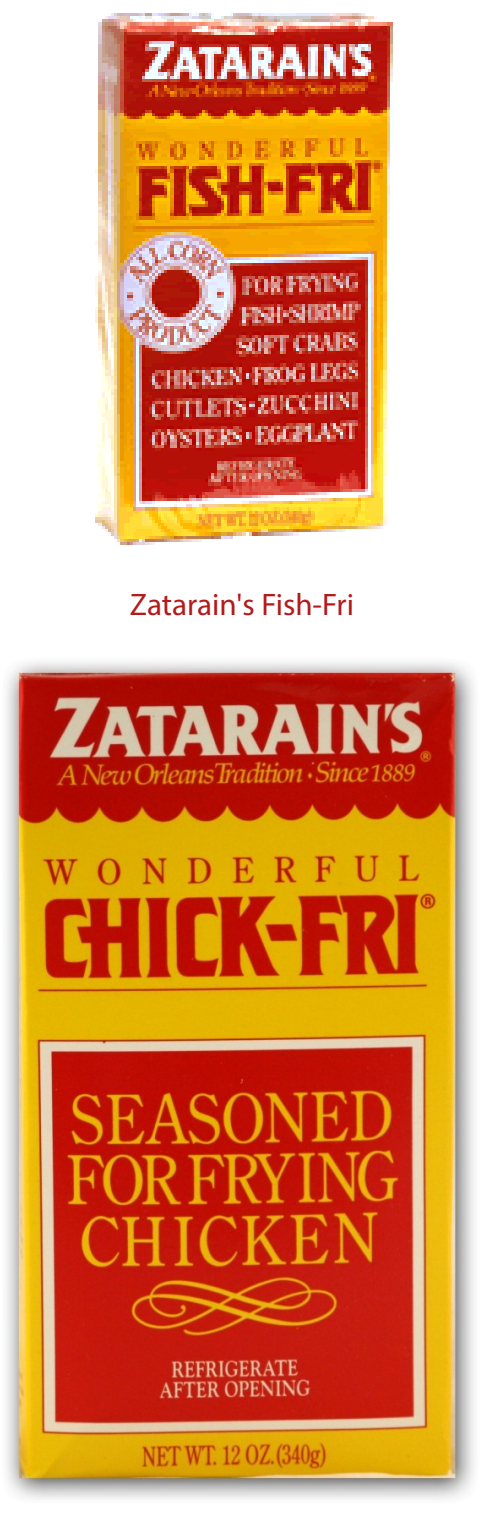

Zatarain's Chick-Fri 


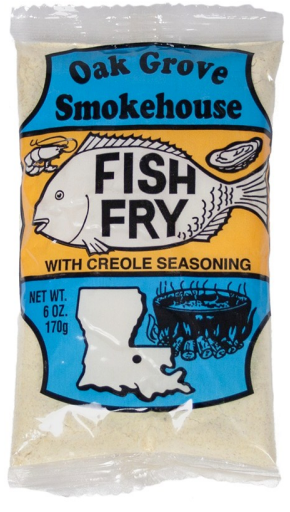

Oak Grove's Fish Fry tween Boochelle's and Zatarain's, Boochelle's product is now labelled "FISH AND VEGETABLE FRY." Another batter mix, "YOGI Brand ${ }^{\circledR}$ OYSTER SHRIMP and FISH FRY," is also available. A product called "Golden Dipt Old South Fish Fry" has recently entered the market as well.

The district court found that Zatarain's trademark "Fish-Fri" was a descriptive term with an established secondary meaning, but held that Oak Grove and Visko's had a "fair use" defense to their asserted infringement of the mark. The court further found that Zatarain's trademark "Chick-Fri" was a descriptive term that lacked secondary meaning, and accordingly ordered the trademark registration cancelled. Additionally, the court concluded that Zatarain's had produced no evidence in support of its claims of unfair competition on the part of Oak Grove and Visko's. [Descriptiveness and secondary meaning are addressed here; the fair use portion of the case is excerpted in the Defenses section.] ...

\section{A. Basic Principles}

The threshold issue in any action for trademark infringement is whether the word or phrase is initially registerable or protectable. Courts and commentators have traditionally divided potential trademarks into four categories. A potential trademark may be classified as (1) generic, (2) descriptive, (3) suggestive, or (4) arbitrary or fanciful. These categories, like the tones in a spectrum, tend to blur at the edges and merge together. The labels are more advisory than definitional, more like guidelines than pigeonholes. Not surprisingly, they are somewhat difficult to articulate and to apply.

A generic term is the name of a particular genus or class of which an individual article or service is but a member. A generic term connotes the "basic nature of articles or services" rather than the more individualized characteristics of a particular product. Generic terms can never attain trademark protection. Furthermore, if at any time a registered trademark becomes generic as to a particular product or service, the mark's registration is subject to cancellation. Such terms as aspirin and cellophane have been held generic and therefore unprotectable as trademarks.

A descriptive term identifies a characteristic or quality of an article or service, such as its color, odor, function, dimensions, or ingredients. Descriptive terms ordinarily are not protectable as trademarks; they may become valid marks, however, by acquiring a secondary meaning in the minds of the consuming public. Examples of descriptive marks would include "Alo" with reference to products containing gel of the aloe vera plant and "Vision Center" in reference to a business offering optical goods and services. As this court has often noted, the distinction between descriptive and generic terms is one of 
degree. The distinction has important practical consequences, however; while a descriptive term may be elevated to trademark status with proof of secondary meaning, a generic term may never achieve trademark protection.

A suggestive term suggests, rather than describes, some particular characteristic of the goods or services to which it applies and requires the consumer to exercise the imagination in order to draw a conclusion as to the nature of the goods and services. A suggestive mark is protected without the necessity for proof of secondary meaning. The term "Coppertone" has been held suggestive in regard to sun tanning products.

Arbitrary or fanciful terms bear no relationship to the products or services to which they are applied. Like suggestive terms, arbitrary and fanciful marks are protectable without proof of secondary meaning. The term "Kodak" is properly classified as a fanciful term for photographic supplies; "Ivory" is an arbitrary term as applied to soap.

As noted earlier, descriptive terms are ordinarily not protectable as trademarks. They may be protected, however, if they have acquired a secondary meaning for the consuming public. The concept of secondary meaning recognizes that words with an ordinary and primary meaning of their own may by long use with a particular product, come to be known by the public as specifically designating that product. In order to establish a secondary meaning for a term, a plaintiff must show that the primary significance of the term in the minds of the consuming public is not the product but the producer. The burden of proof to establish secondary meaning rests at all times with the plaintiff; this burden is not an easy one to satisfy, for a high degree of proof is necessary to establish secondary meaning for a descriptive term. Proof of secondary meaning is an issue only with respect to descriptive marks; suggestive and arbitrary or fanciful marks are automatically protected upon registration, and generic terms are unprotectible even if they have acquired secondary meaning.

B. “FISH-FRI"B

\section{Classification}

Throughout this litigation, Zatarain's has maintained that the term "Fish-Fri" is a suggestive mark. Oak Grove and Visko's assert that "fish fry" is a generic term identifying a class of foodstuffs used to fry fish; alternatively, Oak Grove and Visko's argue that "fish fry" is merely descriptive of the characteristics of the product.

We are mindful that the concept of descriptiveness must be con-

\footnotetext{
${ }^{3}$ We note at the outset that Zatarain's use of the phonetic equivalent of the words "fish fry" - that is, misspelling it - does not render the mark protectable.
} 
strued rather broadly. Whenever a word or phrase conveys an immediate idea of the qualities, characteristics, effect, purpose, or ingredients of a product or service, it is classified as descriptive and cannot be claimed as an exclusive trademark. Courts and commentators have formulated a number of tests to be used in classifying a mark as descriptive.

A suitable starting place is the dictionary, for the dictionary definition of the word is an appropriate and relevant indication 'of the ordinary significance and meaning of words' to the public. Webster's Third New International Dictionary lists the following definitions for the term "fish fry": "1. a picnic at which fish are caught, fried, and eaten; ... 2. fried fish." Thus, the basic dictionary definitions of the term refer to the preparation and consumption of fried fish. This is at least preliminary evidence that the term "Fish-Fri" is descriptive of Zatarain's product in the sense that the words naturally direct attention to the purpose or function of the product.

The "imagination test" is a second standard used by the courts to identify descriptive terms. This test seeks to measure the relationship between the actual words of the mark and the product to which they are applied. If a term requires imagination, thought and perception to reach a conclusion as to the nature of goods, it is considered a suggestive term. Alternatively, a term is descriptive if standing alone it conveys information as to the characteristics of the product. In this case, mere observation compels the conclusion that a product branded "Fish-Fri" is a prepackaged coating or batter mix applied to fish prior to cooking. The connection between this merchandise and its identifying terminology is so close and direct that even a consumer unfamiliar with the product would doubtless have an idea of its purpose or function. It simply does not require an exercise of the imagination to deduce that "Fish-Fri" is used to fry fish. Accordingly, the term "Fish-Fri" must be considered descriptive when examined under the "imagination test."

A third test used by courts and commentators to classify descriptive marks is whether competitors would be likely to need the terms used in the trademark in describing their products. A descriptive term generally relates so closely and directly to a product or service that other merchants marketing similar goods would find the term useful in identifying their own goods. Common sense indicates that in this case merchants other than Zatarain's might find the term "fish fry" useful in describing their own particular batter mixes. While Zatarain's has argued strenuously that Visko's and Oak Grove could have chosen from dozens of other possible terms in naming their coating mix, we find this position to be without merit. The fact that a term is not the only or even the most common name for a product is not determinative, for there is no legal foundation that a product can be 
described in only one fashion. There are many edible fish in the sea, and as many ways to prepare them as there are varieties to be prepared. Even piscatorial gastronomes would agree, however, that frying is a form of preparation accepted virtually around the world, at restaurants starred and unstarred. The paucity of synonyms for the words "fish" and "fry" suggests that a merchant whose batter mix is specially spiced for frying fish is likely to find "fish fry" a useful term for describing his product.

A final barometer of the descriptiveness of a particular term examines the extent to which a term actually has been used by others marketing a similar service or product. This final test is closely related to the question whether competitors are likely to find a mark useful in describing their products. As noted above, a number of companies other than Zatarain's have chosen the word combination "fish fry" to identify their batter mixes. Arnaud's product, "Oyster Shrimp and Fish Fry," has been in competition with Zatarain's "Fish-Fri" for some ten to twenty years. When companies from A to $Z$, from Arnaud to Zatarain's, select the same term to describe their similar products, the term in question is most likely a descriptive one.

\section{Secondary Meaning}

Descriptive terms are not protectable by trademark absent a showing of secondary meaning in the minds of the consuming public. To prevail in its trademark infringement action, therefore, Zatarain's must prove that its mark "Fish-Fri" has acquired a secondary meaning and thus warrants trademark protection. The district court found that Zatarain's evidence established a secondary meaning for the term "Fish-Fri" in the New Orleans area. We affirm.

In assessing a claim of secondary meaning, the major inquiry is the consumer's attitude toward the mark. The mark must denote to the consumer a single thing coming from a single source, to support a finding of secondary meaning. Both direct and circumstantial evidence may be relevant and persuasive on the issue.

Factors such as amount and manner of advertising, volume of sales, and length and manner of use may serve as circumstantial evidence relevant to the issue of secondary meaning. While none of these factors alone will prove secondary meaning, in combination they may establish the necessary link in the minds of consumers between a product and its source. It must be remembered, however, that the question is not the extent of the promotional efforts, but their effectiveness in altering the meaning of the term to the consuming public

Since 1950, Zatarain's and its predecessor have continuously used the term "Fish-Fri" to identify this particular batter mix. Through the expenditure of over $\$ 400,000$ for advertising during the period 
from 1976 through 1981, Zatarain's has promoted its name and its product to the buying public. Sales of twelve-ounce boxes of "FishFri" increased from 37,265 cases in 1969 to 59,439 cases in 1979. From 1964 through 1979, Zatarain's sold a total of 916,385 cases of "FishFri."

In addition to these circumstantial factors, Zatarain's introduced at trial two surveys conducted by its expert witness, Allen Rosenzweig. In one survey, telephone interviewers questioned 100 women in the New Orleans area who fry fish or other seafood three or more times per month. Of the women surveyed, twenty-three percent specified Zatarain's "Fish-Fri" as a product they "would buy at the grocery to use as a coating" or a "product on the market that is especially made for frying fish." In a similar survey conducted in person at a New Orleans area mall, twenty-eight of the 100 respondents answered "Zatarain's 'Fish-Fri"' to the same questions.

The authorities are in agreement that survey evidence is the most direct and persuasive way of establishing secondary meaning. The district court believed that the survey evidence produced by Zatarain's, when coupled with the circumstantial evidence of advertising and usage, tipped the scales in favor of a finding of secondary meaning. Were we considering the question of secondary meaning de novo, we might reach a different conclusion than did the district court, for the issue is close. Mindful, however, that there is evidence in the record to support the finding below, we cannot say that the district court's conclusion was clearly erroneous. Accordingly, the finding of secondary meaning in the New Orleans area for Zatarain's descriptive term "Fish-Fri" must be affirmed. ...

C. "CHICK-FRI"

\section{Classification}

Most of what has been said about "Fish-Fri" applies with equal force to Zatarain's other culinary concoction, "Chick-Fri." "Chick-Fri" is at least as descriptive of the act of frying chicken as "Fish-Fri" is descriptive of frying fish. It takes no effort of the imagination to associate the term "Chick-Fri" with Southern fried chicken. Other merchants are likely to want to use the words "chicken fry" to describe similar products, and others have in fact done so. Sufficient evidence exists

\footnotetext{
${ }^{8}$ The telephone survey also included this question: "When you mentioned 'fish fry,' did you have a specific product in mind or did you use that term to mean any kind of coating used to fry fish?" To this inartfully worded question, 77\% of the New Orleans respondents answered "specific product" and 23\% answered "any kind of coating." Unfortunately, Rosenzweig did not ask the logical follow-up question that seemingly would have ended the inquiry conclusively: "Who makes the specific product you have in mind?" Had he but done so, our task would have been much simpler.
} 
to support the district court's finding that "Chick-Fri" is a descriptive term; accordingly, we affirm.

\section{Secondary Meaning}

The district court concluded that Zatarain's had failed to establish a secondary meaning for the term "Chick-Fri." We affirm this finding. The mark "Chick-Fri" has been in use only since 1968; it was registered even more recently, in 1976. In sharp contrast to its promotions with regard to "Fish-Fri," Zatarain's advertising expenditures for "Chick-Fri" were mere chickenfeed; in fact, Zatarain's conducted no direct advertising campaign to publicize the product. Thus the circumstantial evidence presented in support of a secondary meaning for the term "Chick-Fri" was paltry.

Allen Rosenzweig's survey evidence regarding a secondary meaning for "Chick-Fri" also "lays an egg." The initial survey question was a "qualifier:" "Approximately how many times in an average month do you, yourself, fry fish or other seafood?" Only if respondents replied "three or more times a month" were they asked to continue the survey. This qualifier, which may have been perfectly adequate for purposes of the "Fish-Fri" questions, seems highly unlikely to provide an adequate sample of potential consumers of "Chick-Fri." This survey provides us with nothing more than some data regarding fish friers' perceptions about products used for frying chicken. As such, it is entitled to little evidentiary weight.

It is well settled that Zatarain's, the original plaintiff in this trademark infringement action, has the burden of proof to establish secondary meaning for its term. This it has failed to do.

\section{Innovation Ventures, LLC v. N.V.E., Inc.}

[The plaintiff sold a beverage using the mark 5-HOUR ENERGY. It sued the makers of 6 HOUR POWER.] The 5-HOUR ENERGY mark could be characterized as merely descriptive, in the sense that it simply describes a product that will give someone five hours of energy. But that is not the end of such an inquiry. The first question one would ask is how would the energy be transferred? Through food? Through drink? Through injections? Through pills? Through exercise? Also, one would ask what kind of energy is the mark referring to? Food energy (measured in Calories)? Electrical energy? Nuclear energy? With some thought, one could arrive at the conclusion that the mark refers to an energy shot. But it is not as straightforward as NVE suggests. Such cognitive inferences are indicative of "suggestive" rather than descriptive marks.

The nature of the 5-HOUR ENERGY mark "shares a closer kinship with those marks previously designated as suggestive than those labeled merely descriptive because of the degree of inferential reason-
694 F.3d 723 (6th Cir. 2012)
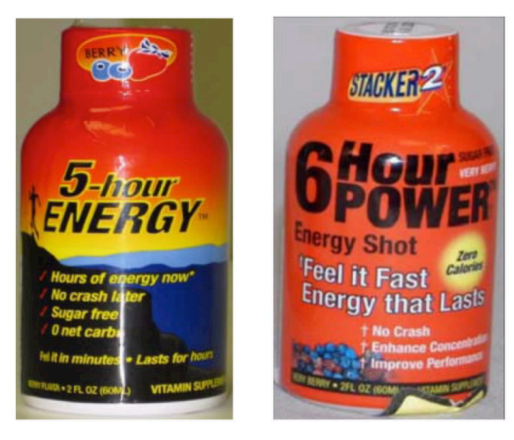

5-Hour Energy and 6 Hour Power 
$\S 1202.08$

Title of a Single Creative Work

Cooper: 254 F.2d 611 (C.C.P.A. 1958)

$\S 1202.18$

Hashtag Marks

45 F.Supp. 3d 1156 (D. Ariz. 2014) ing necessary for a consumer to discern" that the 5-HOUR ENERGY mark relates to an energy shot. The connection between "5-hour" and "ENERGY" is "not so obvious that a consumer seeing 5-HOUR ENERGY in isolation would know that the term refers to" an energy shot rather than, for example, a battery for electronics, an exercise program, a backup generator, or a snack for endurance sports. Connecting the mark 5-HOUR ENERGY with the energy-shot product requires imagination and perception to determine the nature of the goods.

\section{Trademark Manual of Examining Procedure}

The title, or a portion of a title, of a single creative work must be refused registration unless the title has been used on a series of creative works. The title of a single creative work is not registrable. In re Cooper ("A book title identifies a specific literary work and is not associated in the public mind with the publisher, printer or bookseller.").

The addition of the term HASHTAG or the hash symbol (\#) to an otherwise unregistrable mark typically cannot render it registrable. $C f$. TMEP $\S 1209.03(\mathrm{~m})$ and $\S \S 1215-1215.10$ regarding generic top-level domain names.

\section{Elliot v. Google Inc.}

This case concerns two United States registrations of the GOOGLE mark: Number 2884502 (the "'502 Mark") and Number 2806075 (the “"075 Mark"). The '502 Mark covers "computer hardware; computer software for creating indexes of information, indexes of web sites and indexes of other information resources." The '075 Mark covers, inter alia:

Computer services, namely, providing software interfaces available over a network in order to create a personalized on-line information service; extraction and retrieval of information and data mining by means of global computer networks; creating indexes of information, indexes of web sites and indexes of other information sources in connection with global computer networks; providing information from searchable indexes and databases of information, including text, electronic documents, databases, graphics and audio visual information, by means of global computer information networks.

Plaintiffs contend the GOOGLE mark has become generic because a majority of the public understands the word google, when used as a verb, to mean the indiscriminate act of searching on the internet with- 
out regard to the search engine used. Underlying Plaintiffs' argument is the proposition that verbs, as a matter of law, are incapable of distinguishing one service from another, and can only refer to a category of services.

\section{Grammatical Function and Genericness}

A mark is subject to cancellation if it "becomes the generic name for the goods or services, or a portion thereof, for which it is registered.". "The primary significance of the registered mark to the relevant public . . . shall be the test for determining whether the registered mark has become the generic name of goods or services on or in connection with which it has been used." . Under the primary-significance test, a mark is not generic when "he primary significance of the term in the minds of the consuming public is not the product but the producer. See Bayer Co. v. United Drug Co. ("What do the buyers understand by the word for whose use the parties are contending?") If the primary significance of the trademark is to describe the type of product rather than the producer, the trademark is a generic term and cannot be a valid trademark.

The crux of Plaintiffs" argument is the premise "a trademark ceases to function as such when it is used primarily as a verb." This premise is flawed: a trademark performs its statutory function so long as it distinguishes a product or service from those of others and indicates the product's or service's source. Verb use of a trademark is not fundamentally incapable of identifying a producer or denoting source. A mark can be used as a verb in a discriminate sense so as to refer to an activity with a particular product or service, e.g., "I will PHOTOSHOP the image" could mean the act of manipulating an image by using the trademarked Photoshop graphics editing software developed and sold by Adobe Systems. This discriminate mark-asverb usage clearly performs the statutory source-denoting function of a trademark.

However, a mark can also be used as a verb in an indiscriminate sense so as to refer to a category of activity in general, e.g., "I will PHOTOSHOP the image" could be understood to mean image manipulation by using graphics editing software other than Adobe Photoshop. This use commandeers PHOTOSHOP to refer to something besides Adobe's trademarked product. Such indiscriminate mark-as-verb usage does not perform the statutory trademark function; instead, it functions as a synecdoche describing both a particular species of activity (e.g. using Adobe's PHOTOSHOP brand software) and the genus of services to which the species belongs (e.g. using image manipulation software in general).

It cannot be understated that a mark is not rendered generic merely because the mark serves a synecdochian "dual function" of 
Laura A. Heymann, The Grammar of Trademarks, 14 Lewis \& Clark L. Rev. 1313 (2010) identifying a particular species of service while at the same time indicating the genus of services to which the species belongs. Nor is a mark generic merely because it has some significance to the public as an indication of the nature or class of an article. Moreover, casual, non-purchasing uses of marks are not evidence of generic usage"because primary significance is determined by the use and understanding of the mark in the context of purchasing decisions.

The salient question is the primary significance of the term to the consumer. If the term indicates a product of a single producer to the consumer, it is a valid trademark. Thus, even if a mark qua verb is used exclusively in the indiscriminate sense, the mark is not generic if a majority of the consuming public nevertheless uses the mark qua mark to differentiate one particular product or service from those offered by competitors.

It is thus contrary to both the letter and spirit of trademark law to strip a mark of legal protection solely because the mark - cultivated by diligent marketing, enforcement, and quality control - has become so strong and widespread that the public adopts the mark to describe that act of using the class of products or services to which the mark belongs. As one scholar has stated, "top-of-mind use of a trademark in its verb form, far from indicating the mark's generic status, may well indicate the enduring fame of the brand." . This is especially true where the mark in question is arbitrary or fanciful because such terms had a different or no independent meaning before they were adopted as marks.

\section{EXPERT Opinion Evidence}

Defendant's expert linguist, Dr. Geoffrey Nunberg, opined about a linguistic phenomenon observed in some "highly distinctive and famous marks" where "the name of a particular product is used to convey the genus without actually denoting it." Dr. Nunberg's expert report explains:

Trademarks are sometimes used in extended or figurative ways to denote something independent of their proprietary meaning (cf Astroturf for political movements, Band-Aid for social remedies). In a special case of this process, trademarks may be used as verbs to denote the characteristic action associated with the product or service they represent. Examples include TiVo, Fed-Ex, Skype, and Google. Such verbs may be specific in their application but such verbs may also be used in a representative way to connote a more general action. Thus when somebody says, "I need the book tomorrow - can you Fed Ex it to me?" we ordinarily assume that a shipment by UPS will be acceptable as well, without assuming that the verb 
to Fed-Ex simply means to ship by priority courier.

Accordingly, Dr. Nunberg asserts that the use of the word google as a nonspecific verb does not compromise the status of the GOOGLE mark because it literally denotes the use of Google's search engine. Consistent with his report, Dr. Numberg opined that the GOOGLE mark has not become generic and that the phrase "go google it" is not necessarily shorthand for "look it up on the internet."

Defendant's survey expert, Dr. Gerald Ford, conducted a consumer survey modeled after the one used in E. I. DuPont de Nemours $\mathcal{E}$ Co. $v$. Yoshida Int'l, Inc., to prove that the primary significance of the TEFLON mark in the minds of consumers was DuPont's nonstick coating, rather than non-stick coatings in general. In Dr. Ford's "Teflon" survey, 420 randomly selected participants were contacted via telephone and were asked whether "Hewlett Packard" and "computer" were brands names or common names. All 420 respondents successfully identified "Hewlett Packard" as a brand name and "computer" as a common name.

The respondents were then asked to identify six names (STP; Coke; Jello; refrigerator; margarine; aspirin) as either brand names or common names and were told that "don't know" or "no opinion" was an acceptable answer. They were not told that "both" was an acceptable answer, but answers of "both" were nevertheless recorded. The respondents were subsequently asked to apply the brand name/common name distinction to another five names (browser; website; Amazon; Yahoo; Google) specifically with respect to searching on the internet. Last, the respondents were asked whether they conducted searches on the internet - respondents who did not were excluded from the results.

Excluding 19 respondents who answered they do not perform searches on the internet, $93.77 \%$ identified GOOGLE as a brand name and $5.25 \%$ identified GOOGLE as a common name. For purposes of comparison, $93.52 \%$ of consumers identified the YAHOO! mark as a brand name while $5.99 \%$ identified YAHOO! as a common name. Both GOOGLE and YAHOO! beat out COKE: $89.53 \%$ of consumers identified the COKE mark as a brand name while $6.73 \%$ identified $\mathrm{COKE}$ as a common name. The only mark with higher brand name recognition or lower common name misrecognition than GOOGLE was the AMAZON mark at $96.51 \%$ and $2.99 \%$, respectively.

\section{Primary Significance of the Google Mark to the Consuming \\ Public}

As to dictionary usage, Plaintiffs are unable to cite to a single dictionary whose definition of the word "google" neglects to mention the trademark significance of the term. Plaintiffs accuse Defendant of "intimidat[ing] [dictionaries] into submission" because Defendant
Not that Gerald Ford.

Yoshida: 393 F. Supp. 502 (E.D.N.Y. 1975) 
enforces its mark. For example, Defendant asked the website wordspy.com to modify its definition of google as a discriminate verb ("To search for information on the Web, particularly by using the Google search engine") to "take into account the trademark status of Google." Likewise, Plaintiffs contend that the Merriam-Webster dictionary "tempered its definition of google as a result of its fear of Defendant" because the publisher stated "we were trying to be as respectful as we possibly could be about Google's trademark." Plaintiffs also cite the opinions of both of their expert linguists in support of the proposition that the inclusion of a word in dictionaries means that the word carries generic usage. It is undisputed that both of Plaintiffs' linguistic experts testified the GOOGLE mark serves to identify Google as the provider of its search engine services. Viewing the evidence in the light most favorable to Plaintiffs, it establishes the word google carries meaning as an indiscriminate verb.

Shifting to mark-holder usage, Plaintiffs emphasize that Google co-founder Larry Page stated on July 8, 1998, "Have fun and keep googling." Plaintiffs also cite to the fact that entering the search query "define: google" into the Google search engine resulted in a verb definition of: "Use an internet search engine, particularly google.com." Plaintiffs argue that non-enforcement of a mark suggests it is generic and point to the fact that the GOOGLE mark is used in other domain names that Plaintiffs did not purchase. However, it is undisputed that: Defendant uses the GOOGLE mark to identify the Google search engine in national advertising campaigns; has policies in place that set strict standards for third party use of the mark; publishes rules and guidelines for use of the mark; and spends sizeable sums policing and enforcing its rights in the mark. While it is true that non-enforcement of a mark may be evidence the mark is generic, the undisputed facts make it unreasonable to infer that Defendant does not enforce its rights in the mark.

If competitors can accurately describe their products or services without using the mark in question, it suggests the mark is not generic. A corollary of this point is that the existence of a short and simple descriptive term for the genus to which the trademarked species belongs also evidences the mark in question as not generic. E.g., Q-Tips, Inc. v. Johnson $\mathcal{E}$ Johnson (distinguishing the trademarked product "Q-Tips" from the descriptive term for the type of goods "double tipped applicator"). In this case, "internet search engines" is the short and simple descriptive term for the genus to which the Google search engine belongs. It is undisputed that competing search engine providers Yahoo! and Microsoft Bing routinely distinguish their search engine services from Google's search engine service in press releases and advertising campaigns. Thus, there is no evidence of competitors' usage capable of supporting the inference 
that the word google has become the common descriptive term for the category of services to which the Google search engine belongs: internet search engines.

As to media use, Plaintiffs contend that the media often uses the word google as an indiscriminate verb. Some of Plaintiffs' purported evidence of indiscriminate verb use is inadmissible because it was not timely disclosed. As Defendant points out, some of Plaintiffs' media evidence recognizes the trademark significance of the GOOGLE mark and that Plaintiffs have not designated a single instance in which a major media outlet has referred to a competing search engine as a "google." Plaintiffs' media evidence consists mostly of verb usage, some of which is followed by recognition of trademark significance. Like Plaintiffs' other evidence, the media's use of the word google establishes that it is sometimes used as verb to mean search on the internet.

\section{SUMMARY}

The word google has four possible meanings in this case: (1) a trademark designating the Google search engine; (2) a verb referring to the act of searching on the internet using the Google search engine; (3) a verb referring to the act of searching on the internet using any search engine; and (4) a common descriptive term for search engines in general. The '502 and ' 075 marks are subject to cancellation only if the fourth meaning is the primary significance of the word google to a majority of the consuming public.

Accepting Plaintiffs' evidence as true, 51\% of those who utilize internet search engines use the word google as a verb to mean search on the internet. This establishes that the second and third meanings exist. Drawing all reasonable inferences in Plaintiffs' favor, a majority of the consuming public uses google-as-verb in its indiscriminate sense to mean search on the internet without regard to the search engine used. This means that the third meaning is more significant than the second meaning. Plaintiffs then make the leap, without any competent evidence, that the third meaning is the is the most frequently used meaning and seek cancellation of the '502 and '075 Marks because of the frequency with which the word google is used as a verb. This argument is factually and legally flawed. Factually, Plaintiffs offer no competent evidence in support of their assertion that verb use is more frequent than non-verb use. Legally, the test for whether a mark has become generic is not whether its most frequent use is as an indiscriminate verb, but whether its primary significance to a majority of the consuming public is as a common descriptive term. Even if the most frequent use of the word google is its third meaning, Plaintiffs' argument nevertheless fails because there is no evidence to suggest that the primary significance of the word google is the fourth 
meaning because the third meaning is most frequently used.

Plaintiffs' claim for trademark cancellation disappears when the admissible evidence in the record is examined according to the laws enacted by Congress. It is undisputed that well over $90 \%$ of the consuming public understands the word google with respect to searching on the internet as designating not a common name, but a particular brand. This fact establishes that the first meaning (a trademark designating the Google search engine) is more significant than is the fourth meaning (a common descriptive term for search engines in general) to a vast majority of the consuming public. Therefore, the ' 502 and ' 075 marks are not subject to cancellation. This is true even though the Court accepts as true that the $51 \%$ of the public also understands the third meaning (a verb referring to the act of searching on the internet using any search engine) - it is undisputed that the first and third meanings are not mutually exclusive and, in fact, coexist.

\section{CONCLUSION}

Accepting Plaintiffs' evidence as true and drawing all justifiable inferences therefrom in Plaintiffs' favor, a majority of the public uses the word google as a verb to refer to searching on the internet without regard to search engine used. Giving Plaintiffs every reasonable benefit, a majority of the public uses google-as-verb to refer to the act of searching on the internet and uses GOOGLE-as-mark to refer to Defendant's search engine. However, there is no genuine dispute about whether, with respect to searching on the internet, the primary significance of the word google to a majority of the public who utilize internet search engines is a designation of the Google search engine. Therefore, Defendant is entitled to judgment as a matter of law that the ‘ 075 and ‘ 502 Marks are not generic.

\section{Trademark Manual of Examining Procedure}

1209.03(d)

Combined Terms

When two descriptive terms are combined, the determination of whether the composite mark also has a descriptive significance turns upon the question of whether the combination of terms evokes a new and unique commercial impression. If each component retains its descriptive significance in relation to the goods or services, the combination results in a composite that is itself descriptive. [Cases cited found SNAP SIMPLY SAFER merely descriptive for "medical devices, namely, cannulae; medical, hypodermic, aspiration and injection needles; medical, hypodermic, aspiration and injection syringes"), PATENTS.COM merely descriptive of computer software for managing a database of records that could include patents and for tracking the status of the records by means of the Internet), SCREENWIPE generic as applied to premoistened antistatic cloths for cleaning 
computer and television screens), and SUPERJAWS merely descriptive for a variety of machine and hand tools including jaws).]

However, a mark comprising a combination of merely descriptive components is registrable if the combination of terms creates a unitary mark with a unique, nondescriptive meaning, or if the composite has a bizarre or incongruous meaning as applied to the goods. [Cases cited found SUGAR \& SPICE not merely descriptive of bakery products and SNO-RAKE not merely descriptive of a snow removal hand tool.]

The Trademark Trial and Appeal Board has held that the addition of the prefix " $\mathrm{e}$ " does not change the merely descriptive significance of a term in relation to goods or services sold or rendered electronically, where the record showed that the " $\mathrm{e}$ " prefix has become commonly recognized as a designation for goods or services sold or delivered electronically. In re Int'l Bus. Machs. Corp. ("We see no difference in the meaning or connotation of 'e-server' and 'eserver,' and consider them both to be an abbreviated form of 'electronic server."'). Similarly, with appropriate evidence, the prefix "i" or "I" was held to be understood by purchasers to signify Internet, when used in relation to Internet-related products or services. In re Zanova, Inc. (ITOOL merely descriptive of computer software for use in creating web pages, and custom design of websites for others). In these situations, the examining attorney should provide evidence of use of the prefix " $\mathrm{e}$ " or " $\mathrm{i}$ " in relation to the goods or services.

The foreign equivalent of a merely descriptive English word is no more registrable than the English word itself. A word taken from a well-known foreign modern language, which is, itself, descriptive of a product, will be so considered when it is attempted to be registered as a trade-mark in the United States for the same product. [Cases cited held AYUMI and its Japanese-character equivalent held merely descriptive for footwear where the evidence, including applicant's own admissions, indicated that the primary meaning of applicant's mark is "walking," Chinese characters that mean ORIENTAL DAILY NEWS merely descriptive of newspapers), and SAPORITO, an Italian word meaning "tasty," merely descriptive because it describes a desirable characteristic of applicant's dry sausage.]

Although words from modern languages are generally translated into English, the doctrine of foreign equivalents is not an absolute rule, but merely a guideline. The doctrine should be applied only when it is likely that the ordinary American purchaser would stop and translate the foreign word into its English equivalent. The "ordinary American purchaser" in this context refers to the ordinary American purchaser who is knowledgeable in the foreign language. Defining "ordinary American purchaser" as the "average American buyer"
IBM: 81 USPQ 2d 1677 (TTAB 2006)

Zaonova: 59 USPQ 2d 1300 (TTAB 2000)

1209.03(g)

Foreign Equivalents 
1209.03(h)

Acronyms

412 F.3d 373 (2d Cir. 2005)

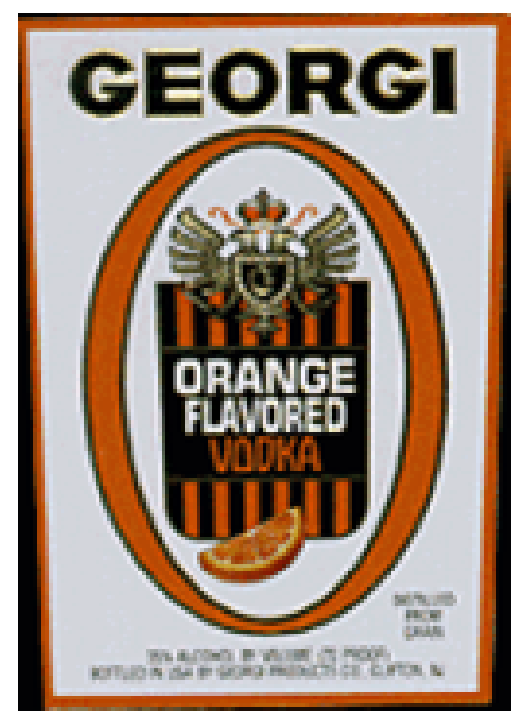

Georgi O

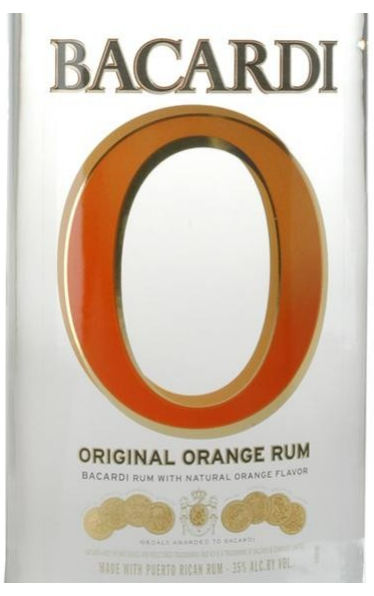

Bacardi O would write the doctrine out of existence." The "ordinary American purchaser" includes all American purchasers, including those proficient in a non-English language who would ordinarily be expected to translate words into English.

As a general rule, an acronym or initialism cannot be considered descriptive unless the wording it stands for is merely descriptive of the goods or services, and the acronym or initialism is readily understood by relevant purchasers to be "substantially synonymous" with the merely descriptive wording it represents. [Cases cited held CMS not substantially synonymous with the grape varietals cabernet, merlot, and syrah and therefore not merely descriptive for wine, and NKJV substantially synonymous with merely descriptive term "New King James Version" and thus merely descriptive of bibles.]

\section{Designs}

Star Industries, Inc. v. Bacardi \& Co. Ltd.

In June 1996, inspired by the success of flavored vodkas introduced by leading international companies such as Stolichnaya, Star's president decided to develop an orange-flavored Georgi vodka. A new label was designed, consisting of the traditional Georgi label, which contains a coat of arms and a logo consisting of stylized capital letters spelling 'Georgi' on a white background, together with three new elements: an orange slice, the words "orange flavored," and a large elliptical letter "O" appearing below the "Georgi" logo and surrounding all of the other elements. The " $\mathrm{O}$ " was rendered as a vertical oval, with the outline of the "O" slightly wider along the sides (about one quarter inch thick) and narrowing at the top and bottom (about one eighth inch thick); the outline of the " $\mathrm{O}$ " is colored orange and decorated with two thin gold lines, one bordering the inside and one bordering the outside of the outline. Star was apparently the first company to distribute an orange-flavored alcoholic beverage packaged in a bottle bearing a large elliptical orange letter "O."

In 2000 Bacardi began to develop an orange-flavored rum, which it ultimately introduced nationally in 2001 under the name "Bacardi O." Bacardi's line of flavored rums originated in 1995 with "Bacardi Limon." Unlike Bacardi's other flavored rums, however, Bacardi $\mathrm{O}$ was produced and marketed bearing a distinct label consisting of the Bacardi logo and bat symbol above a large elliptical letter " $\mathrm{O}$ " against a clear background.

After sending a cease and desist letter to Bacardi in September 2001, Star filed the instant lawsuit in May 2002.

The district court erred when it described the Star "O" as a ba- 
sic geometric shape or letter, and therefore rejected inherent distinctiveness and required a showing of secondary meaning. The Star "O" is not a "common basic shape" or letter, and the district court's holding to the contrary was premised on a misunderstanding of this trademark law concept. Unshaded linear representations of common shapes or letters are referred to as "basic." They are not protectable as inherently distinctive, because to protect them as trademarks would be to deprive competitors of fundamental communicative devices essential to the dissemination of information to consumers. However, stylized letters or shapes are not "basic," and are protectable when original within the relevant market. See Courtenay Communications Corp. v. Hall (distinguishing case of mark consisting of word displayed with distinctive "typeface, color, and other design elements," which was protectable, from cases holding generic words not protectable); compareIn re W.B. Roddenbery Co. (holding design consisting of colored circle attached to differently colored rectangle protectable as inherently distinctive) withIn re Hillerich \& Bradsby Co. (noting that applicant conceded that unshaded line oval was not inherently distinctive). Star's " $\mathrm{O}$ " is sufficiently stylized to be inherently distinctive and therefore protectable as a trademark. It is stylized with respect to shading, border, and thickness, and each of these design elements distinguishes it from the simple or basic shapes and letters that have been held unprotectable.

The Star "O" design had sufficient shape and color stylization to render it slightly more than a simply linear representation of an ellipse or the letter "O." It was, furthermore, a unique design in the alcoholic beverage industry at the time it was introduced. This suffices to establish its inherent distinctiveness and thus its protectability. Furthermore, the Star " $\mathrm{O}$ " design is protectable separately from the other design elements on the Georgi orange-flavored vodka label precisely because the "O" design is itself inherently distinctive. However, the extent of stylization was marginal at best. The outline of the " $\mathrm{O}$," though not uniform, is ordinary in its slightly varying width, and the interior and exterior borders are also ordinary. The result is a "thin" or weak mark, which will be entitled to only limited protection.

\section{Melting Bad Problem}

You are the general counsel of Blancorp, a medium-sized scientific and industrial chemical supply firm named for its founder and CEO, Walter Blanco. He has been hoping for years to break in to the snowand-ice melter market with his own line of salts for homeowners, businesses, and cities to spread on streets and sidewalks after snowstorms. Blancorp's research chemists have been studying a type of naturally occurring rock salt from Quebec, Canada. Known locally as
Courtenay: 334 F.3d 210 (2d Cir. 2003)

Roddenberry: 135 U.S.P.Q. 215, (TTAB 1962)

Hillerich: 204 F.2d 287 (CCPA 1953) 
le loup bleu (French for "the blue wolf"), this particular variety is notable for its cobalt blue color and its remarkable resistance to clumping. (Some other melters are either naturally or dyed blue, but they all have lighter shades, Blanco assures you.)

Blanco has informed you that his chemists have succeeded in replicating le loup bleu in the lab, with high purity, the same blue color, and the same resistance to clumping. He has asked them to start fullscale production immediately, and has come to you to discuss potential trademarks. Give Blanco your advice on which of the following would be good choices from a legal and business perspectives:

- ALL-NATURAL BLUE

- ICE MELT

- LOUP BLEU

- CLUMPLESS

- COBALT WOLF

- QUIZMARUNK

- Sell the salt in a bag with a line drawing of a wolf

Do you have any other ideas or advice?

\section{B Ownership}

Ownership of trademarks is determined, in the first instance, by state common law. Federal registration is an overlay onto this system; it mostly assumes, rather than displaces, state law.

\section{Priority at Common Law}

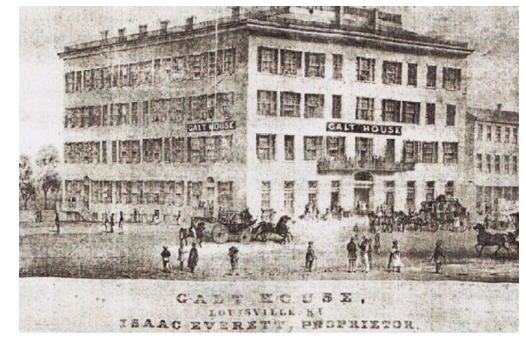

The second Galt House

\section{Galt House Inc. v. Home Supply Company}

The plaintiff, Galt House, Inc., instituted this action to enjoin the defendants, Home Supply Company, and its principal officer and stockholder, Al J. Schneider, from operating a new hotel in Louisville, Kentucky, under the assumed trade name "Galt House."

During the Nineteenth Century the Galt House Hotel was a famous hostelry in Louisville with an excellent and widely recognized reputation. In 1838 the bar-room at the Galt House was the scene of a killing as a result of which an attorney and judge and his two companions were indicted for murder. The trial itself is famous in the annals of Kentucky history.

In 1842 Charles Dickens toured America. In his account in "American Notes," he was characteristically uncomplimentary in his description of Louisville; he was impressed, however, with the Galt House. He wrote: "We slept at the Galt House; a splendid hotel; and were as handsomely lodged as though we had been in Paris, rather 
than hundreds of miles beyond the Alleghanies." In 1858 Charles Mackay, an English writer, passed through Louisville. In his account in "Life and Liberty in America" he remarked: "We crossed in the steamer to Louisville, and once more found ourselves in a land of plenty and comfort, in a flourishing city, in an excellent hotel - the Galt House, one of the best conducted establishments in America."'"

The Galt House, located on Main Street at Second Street, occupied separate buildings during its existence as a hotel. The second Galt House was destroyed by fire in January 1865 at a reported loss of $\$ 1,000,000$. The third Galt House, a magnificent structure in its day, was abandoned as a hotel and ceased operations in 1920. Belknap Hardware Company thereafter occupied the site of the last Galt House.

Thus, it would appear that since 1920 there has been no use of the name Galt House in connection with or to describe a hotel. The name doubtless strikes interest when used in the presence of history buffs and among those familiar with the folklore of Louisville. Among such cognoscenti the name encourages remembrance of things past.

In February 1964, the plaintiff, Galt House, Inc., incorporated under the laws of this state. In its articles of incorporation it adopted as its corporate name the term "Galt House." The plaintiff has no assets and no liabilities; neither does it have corporate books or records. Plaintiff's president and sole shareholder is Arch Stallard, Sr., a real estate broker in Louisville, Kentucky, who specializes in hotel and motel real estate. Mr. Stallard has on occasions since the date of the filing of plaintiff's articles of incorporation made a few sporadic inquiries concerning possible locations for a hotel and considered engaging in an enterprise by which a franchise operation would be effected. These few efforts came to naught and Mr. Stallard testified that because of illness and death in his family he had been "laying dormant."

The defendant, Home Supply Company, is a Kentucky corporation organized sometime prior to 1950. The defendant, Al J. Schneider, is its president and controlling shareholder. Home Supply Company is active in the business of constructing and operating hotels in this state. It presently operates a hotel on the Kentucky State Fair Board property under the assumed name "Executive Inn." It is presently engaged in the construction and completion of a high-rise hotel on riverfront-development property belonging to an agency of the City of Louisville.

In April 1969, Home Supply Company, through its president Schneider, submitted to the city agency plans of a hotel bearing the name Galt House. Construction commenced in May 1970. A new hotel, 26 stories in height with 714 rooms, is now nearly completed and has affixed a sign bearing the name "The Galt House." The ho-

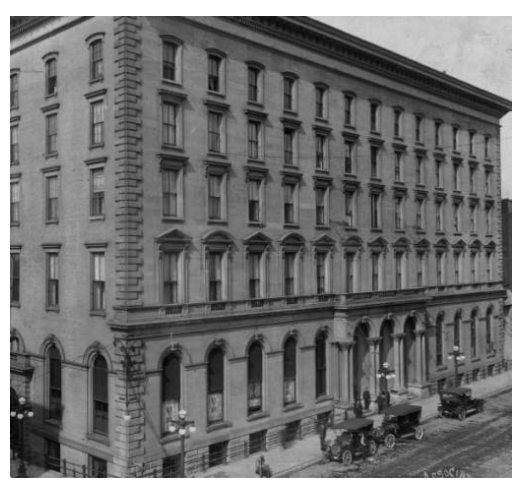

The third Galt House

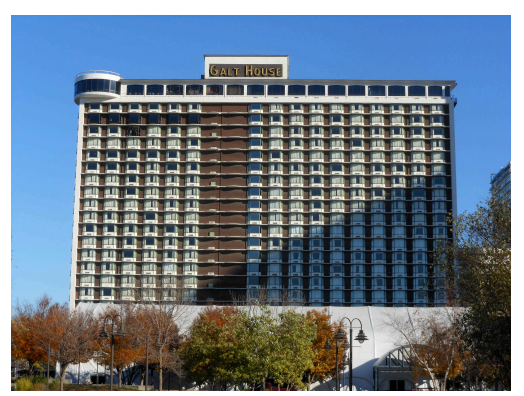

The fourth (and current) Galt House 
Kansas City Star: 299 F.2d 320 (8th Cir. 1962) tel already has scheduled future conventions and room reservations, although it will not open until after May 1972. In April 1971, Home Supply Company applied for and received from the Secretary of State of Kentucky a registration and service mark of the name "The Galt House."

Plaintiff filed suit in August 1971, seeking to enjoin the defendants from any use of the name Galt House.

As found by the circuit judge, the corporation which operated the last Galt House was formed in 1911 and its formal corporate existence expired in 1961. From 1920 to 1961, however, it did not engage in the hotel business. Therefore, the name Galt House had not been used in connection with a going business for 49 years when defendants undertook to use it as the name of their new hotel in 1969.

The primary argument asserted by the plaintiff actually rests upon a premise that by mere incorporation under a corporate name it retains the right to exclude others from the use of that name so long as the corporation legally exists.

In Duff v. Kansas City Star Company, the court held that there is no such thing as property in a trade-mark except as a right appurtenant to an established business or trade with which the mark is employed. This principle was applied to the trade name of a newspaper which had not been published for eight years. The court decided that since there was no established business (good will) to which the contested name attached, the plaintiff had no right to prevent another from using the name in an active, going business. The court pointed out that the contested name was no more than the common name of a oncepublished newspaper.

We are also unable to find that plaintiff has any standing to enjoin under the theory that it was placed on the same footing with the former Galt House Corporation whose existence expired by operation of law in 1961. There was no transfer of the name from the expiring Galt House Corporation to plaintiff. The former Galt House Corporation at the end of its corporate term of existence as fixed by its articles terminated its right to do business in 1961. It had not engaged in the hotel business under its corporate name since 1920. The former Corporation was incapable of possessing a business with a good will or a corporate trade name. The name did not survive, for there was nothing to which it could be attached.

We must only determine whether the plaintiff has the right to prohibit the defendants from using the name. We agree with the trial judge that the plaintiff has no standing to enjoin the use of the name by the defendants under the facts of this case. 
The essential facts are as follows: About the year 1877 Ellen M. Regis, a resident of Haverhill, Massachusetts, began to compound and distribute in a small way a preparation for medicinal use in cases of dyspepsia and some other ailments, to which she applied as a distinguishing name the word "Rex" - derived from her surname. The word was put upon the boxes and packages in which the medicine was placed upon the market, after the usual manner of a trade-mark. Subsequently, in the year 1911, petitioner purchased the business with the trade-mark right, and has carried it on in connection with its other business, which consists in the manufacture of medicinal preparations, and their distribution and sale through retail drug stores, known as "Rexall stores," situate in the different States of the Union, four of them being in Louisville, Kentucky.

Meanwhile, about the year 1883, Theodore Rectanus, a druggist in Louisville, familiarly known as "Rex," employed this word as a trade-mark for a medicinal preparation known as a "blood purifier." He continued this use to a considerable extent in Louisville and vicinity, spending money in advertising and building up a trade, so that - except for whatever effect might flow from Mrs. Regis' prior adoption of the word in Massachusetts, of which he was entirely ignorant - he was entitled to use the word as his trade-mark. In the year 1906 he sold his business, including the right to the use of the word, to respondent; and the use of the mark by him and afterwards by respondent was continuous from about the year 1883 until the filing of the bill in the year 1912.

Petitioner's first use of the word "Rex" in connection with the sale of drugs in Louisville or vicinity was in April, 1912, when two shipments of "Rex Dyspepsia Tablets," aggregating 150 boxes and valued at $\$ 22.50$, were sent to one of the "Rexall" stores in that city. Shortly after this the remedy was mentioned by name in local newspaper advertisements published by those stores. In the previous September, petitioner shipped a trifling amount - five boxes - to a drug store in Franklin, Kentucky, approximately 120 miles distant from Louisville. There is nothing to show that before this any customer in or near Kentucky had heard of the Regis remedy, with or without the description "Rex," or that this word ever possessed any meaning to the purchasing public in that State except as pointing to Rectanus and the Rectanus Company and their "blood purifier." That it did and does convey the latter meaning in Louisville and vicinity is proved without dispute.

The entire argument for the petitioner is summed up in the contention that whenever the first user of a trade-mark has been reasonably diligent in extending the territory of his trade, and as a result of such extension has in good faith come into competition with a later user of the same mark who in equal good faith has extended his trade

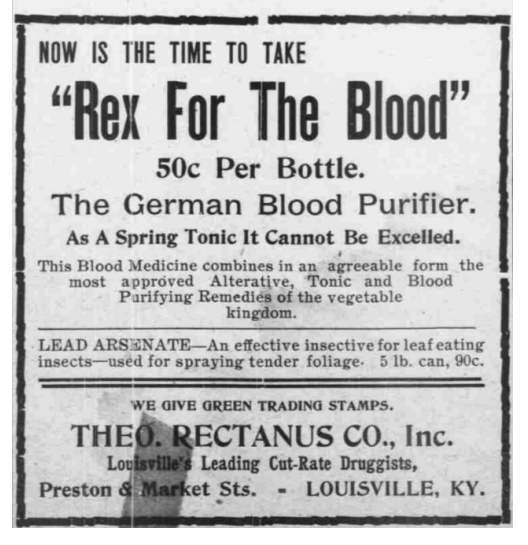

Rex blood purifier advertisement

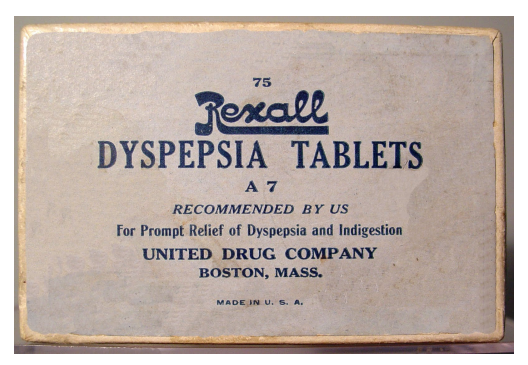

Rexall dyspepsia tablets label 
locally before invasion of his field by the first user, so that finally it comes to pass that the rival traders are offering competitive merchandise in a common market under the same trade-mark, the later user should be enjoined at the suit of the prior adopter, even though the latter be the last to enter the competitive field and the former have already established a trade there.

The asserted doctrine is based upon the fundamental error of supposing that a trade-mark right is a right in gross or at large, like a statutory copyright or a patent for an invention, to either of which, in truth, it has little or no analogy. There is no such thing as property in a trade-mark except as a right appurtenant to an established business or trade in connection with which the mark is employed. The law of trade-marks is but a part of the broader law of unfair competition; the right to a particular mark grows out of its use, not its mere adoption; its function is simply to designate the goods as the product of a particular trader and to protect his good will against the sale of another's product as his; and it is not the subject of property except in connection with an existing business.

The owner of a trade-mark may not, like the proprietor of a patented invention, make a negative and merely prohibitive use of it as a monopoly. In truth, a trade-mark confers no monopoly whatever in a proper sense, but is merely a convenient means for facilitating the protection of one's good-will in trade by placing a distinguishing mark or symbol - a commercial signature - upon the merchandise or the package in which it is sold.

It results that the adoption of a trade-mark does not, at least in the absence of some valid legislation enacted for the purpose, project the right of protection in advance of the extension of the trade, or operate as a claim of territorial rights over areas into which it thereafter may be deemed desirable to extend the trade. And the expression, sometimes met with, that a trade-mark right is not limited in its enjoyment by territorial bounds, is true only in the sense that wherever the trade goes, attended by the use of the mark, the right of the trader to be protected against the sale by others of their wares in the place of his wares will be sustained.

Conceding everything that is claimed in behalf of the petitioner, the entire business conducted by Mrs. Regis and her firm prior to April, 1911, when petitioner acquired it, was confined to the New England States with inconsiderable sales in New York, New Jersey, Canada, and Nova Scotia. There was nothing in all of this to give her any rights in Kentucky, where the principles of the common law obtain.

Undoubtedly, the general rule is that, as between conflicting claimants to the right to use the same mark, priority of appropriation determines the question. But the reason is that purchasers have 
come to understand the mark as indicating the origin of the wares, so that its use by a second producer amounts to an attempt to sell his goods as those of his competitor. The reason for the rule does not extend to a case where the same trade-mark happens to be employed simultaneously by two manufacturers in different markets separate and remote from each other, so that the mark means one thing in one market, an entirely different thing in another. It would be a perversion of the rule of priority to give it such an application in our broadly extended country that an innocent party who had in good faith employed a trade-mark in one State, and by the use of it had built up a trade there, being the first appropriator in that jurisdiction, might afterwards be prevented from using it, with consequent injury to his trade and good-will, at the instance of one who theretofore had employed the same mark but only in other and remote jurisdictions, upon the ground that its first employment happened to antedate that of the first-mentioned trader.

In this case, as already remarked, there is no suggestion of a sinister purpose on the part of Rectanus or the Rectanus Company. And it results, as a necessary inference from what we have said, that petitioner, being the newcomer in that market, must enter it subject to whatever rights had previously been acquired there in good faith by the Rectanus Company and its predecessor. In that market, until petitioner entered it, "Rex" meant the Rectanus product, not that of Regis.

Planetary Motion, Inc. v. Techsplosion, Inc.

[In 1994, Byron Darrah released an email program he named Coolmail. Darrah made Coolmail available by posting it to a service named Sunsite, where users with an Internet connection could download it for free. Darrah made Coolmail available under the GNU General Public License, which allows users to copy, distribute, and modify the software as long as they adhere to various conditions, such as releasing any modified versions under the GPL.]

We find that, under these principles, Darrah's activities under the COOLMAIL mark constitute a "use in commerce" sufficiently public to create ownership rights in the mark. The distribution was widespread, and there is evidence that members of the targeted public actually associated the mark COOLMAIL with the Software to which it was affixed. Darrah made the software available not merely to a discrete or select group (such as friends and acquaintances, or at a trade show with limited attendance), but to numerous end-users via the Internet. The Software was posted under a filename bearing the COOLMAIL mark on a site accessible to anyone who had access to the Internet. End-users communicated with Darrah regarding the Software by referencing the COOLMAIL mark in their e-mails. Ap- 
pellants argue that only technically-skilled UNIX users made use of the Software, but there is no evidence that they were so few in number to warrant a finding of de minimis use.

The mark served to identify the source of the Software. The COOLMAIL mark appeared in the subject field and in the text of the announcement accompanying each release of the Software, thereby distinguishing the Software from other programs that might perform similar functions available on the Internet or sold in software compilations. The announcements also apparently indicated that Darrah was the "Author/Maintainer of Coolmail" and included his e-mail address. The user manual also indicated that the Software was named "Coolmail." The German company S.u.S.E. was able to locate Darrah in order to request permission to use his Software in its product under the mark "Coolmail." Appellants do not assert that S.u.S.E. was unaware that the Software was called COOLMAIL when it contacted Darrah.

Software is commonly distributed without charge under a GNU General Public License. The sufficiency of use should be determined according to the customary practices of a particular industry. That the Software had been distributed pursuant to a GNU General Public License does not defeat trademark ownership, nor does this in any way compel a finding that Darrah abandoned his rights in trademark. Appellants misconstrue the function of a GNU General Public License. Software distributed pursuant to such a license is not necessarily ceded to the public domain and the licensor purports to retain ownership rights, which may or may not include rights to a mark. 16

Appellants cite Heinemann v. General Motors Corp. for the proposition that Darrah was a "hobbyist" unworthy of common law trademark protection. Heinemann is factually distinguishable from the case at hand. The plaintiff in Heinemann used a mark in connection with his automobile before an automobile manufacturer independently had adopted the same name for a new model. The court held that the plaintiff had not established common law ownership rights based on two findings. First, the court found that because Heinemann's purpose in using the mark was to "open [at a later date] an automobile equipment shop which would have capitalized upon the slogan," he merely attempted to "reserve a trade or service mark pending the creation of a trade or business ...." The court reasoned as follows:

While the law does not require a nationwide business; an old, established business; or even a profitable business

\footnotetext{
${ }^{16}$ Because a GNU General Public License requires licensees who wish to copy, distribute, or modify the software to include a copyright notice, the license itself is evidence of Darrah's efforts to control the use of the COOLMAIL mark in connection with the Software.
} 
for the acquisition of property interests in trade or service marks, it does require a presently existing trade or business for such acquisition. The exhibits disclose that Plaintiff had only a desire to open a business in futuro. To hold otherwise would make a trade mark a property right in gross, instead of a right appurtenant.

The Heinemann court also found that plaintiff Heinemann's activities consisted merely of occasionally racing or displaying the automobile at fairs as a hobby, as evidenced by his testimony that he was employed at an oil company. Here, Darrah did not attempt to "warehouse" the mark by promoting a product he merely intended to develop and distribute at a later date. Darrah's use of the mark to designate the distributed Software and each subsequent version thereof indicates that his use was not mere sporadic or token use. Furthermore, unlike Heinemann, Darrah activities pertained to his chosen profession. Darrah is employed as a computer systems administrator, which entails the management and oversight of computer networks and systems as well as the development of software in support thereof.

Appellants also rely on DeCosta v. Columbia Broad. Sys., Inc. to argue that Darrah is an eleemosynary individual and therefore unworthy of protection under unfair competition laws. The DeCosta court did not hold that the that the absence of a profit-oriented enterprise renders one an eleemosynary individual, nor did it hold that such individuals categorically are denied protection. 18 Common law unfair competition protection extends to non-profit organizations because they nonetheless engage in competition with other organizations. Thus, an eleemosynary individual that uses a mark in connection with a good or service may nonetheless acquire ownership rights in the mark if there is sufficient evidence of competitive activity.

Here, Darrah's activities bear elements of competition, notwithstanding his lack of an immediate profit-motive. By developing and distributing software under a particular mark, and taking steps to avoid ceding the Software to the public domain, Darrah made efforts to retain ownership rights in his Software and to ensure that his Software would be distinguishable from other developers who may have distributed similar or related software. Competitive activity need not be fueled solely by a desire for direct monetary gain. Darrah derived value from the distribution because he was able to improve his Software based on suggestions sent by end-users. Just as any other

\footnotetext{
${ }^{18}$ It is unlikely that the plaintiff's activities in De Costa-costumed performances and distribution of his picture at local rodeos, parades, hospitals, etc. - would generate a "public association" sufficient to confer him common law trademark ownership rights.
}

DeCosta: 520 F.2d 499, 513 (1st Cir. 1975) 
585 F. Supp. 2d 433 (W.D.N.Y. 2008)

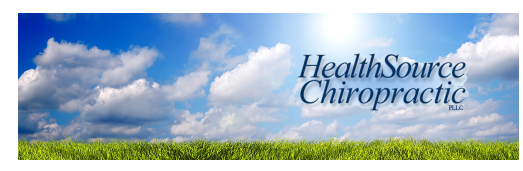

Plaintiff's website logo, at http://healthsourcechiropractic.com/

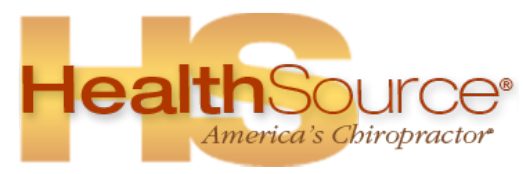

Defendant's website logo, at http://healthsourcechiro.com/ consumers, these end-users discriminate among and share information on available software. It is logical that as the Software improved, more end-users used his Software, thereby increasing Darrah's recognition in his profession and the likelihood that the Software would be improved even further.

In light of the foregoing, the use of the mark in connection with the Software constitutes significant and substantial public exposure of a mark sufficient to have created an association in the mind of public.

\section{Dudley v. HealthSource Chiropractic, Inc.}

[Plaintiff used the mark HEALTHSOURCE CHIROPRACTIC for his chiropractic practice in Rochester, New York starting in 2003. Defendant started franchising chiropractic practices under the name HEALTHSOURCE CHIROPRACTIC in 2006, initially in Ohio. It quickly expanded to 325 franchisees nationwide. It awarded a franchise in Rochster to one Dr. Divito, which opened in April 2007.]

The Plaintiff contends that he is the senior user of the HealthSource Chiropractic mark not only in the greater Rochester area but also on the internet.

Geographical zones of exclusivity developed to protect the rights of concurrent, innocent adopters who used the same mark in different geographic areas. There is little likelihood of confusion, deception, or mistake when a mark is used by different businesses in distinct regions of the country. Common law trademark rights only extend to the territories in which the mark's adopter sells its products, renders its services, establishes recognition of its mark, or draws its trade. A user of a mark who does not seek federal registration risks the possibility that another user will independently adopt the same mark and establish exclusive rights to use the mark in a remote area. The trademark laws allow concurrent use of the same mark by multiple adopters so long as each adopter's use of the mark does not unreasonably intrude on another user's geographic zone of exclusivity. By allowing concurrent use of a mark, the trademark laws tolerate a certain amount of confusion.

By claiming exclusivity to the HealthSource Chiropractic mark on the internet, the Plaintiff assumes that the internet is a territory in which he can establish exclusive rights. The internet is not, however, a geographic territory to be subdivided; instead, it is a global communication medium that is accessible from anywhere on the planet. The internet has become vital for local, regional, national, and international communication. It is used for selling, advertising, and marketing products and services as well as communicating with clients and customers. An internet presence has become crucial for businesses of all sizes, whether they operate locally or nationally. 
The rights of concurrent users would be substantially harmed if one user were able to monopolize the internet to the exclusion of other lawful users of the same mark. Unlike national advertising which would often be cost-prohibitive for a local or regional user, the internet is an almost-necessary tool for a user to develop its business and remain competitive within its exclusive territory. Consequently, this Court concludes that neither party can claim exclusive rights to the internet.

Even though concurrent, lawful users of a mark should be allowed to use their marks on the internet, use on the internet cannot be manipulated to intrude on another's territory in bad faith. For instance, it would be improper for a user to target internet advertisements to consumers within another user's exclusive territory or to advertise on locally focused web sites that target that market.

In this case, the Defendants have taken reasonable measures to ensure that they are not using the HealthSource Chiropractic mark on the internet to intrude into the Plaintiff's territory. The Defendants have removed Dr. Divito's practice completely from HealthSource Inc.'s web site. Dr. Divito maintains his own web site, rochesterspinalcare.com, for his Rochester practice and only uses the HealthQuest mark on his web site. The Plaintiff has presented no evidence that indicates the Defendants have used the HealthSource mark on the internet to specifically target the Rochester market.

A trademark owner cannot reasonably expect to have exclusive use of a term on the internet. Defendants presented evidence that as of 2008 there were 754 registered domain names with that included the term "healthsource." Users of a mark must develop ways to distinguish themselves on the internet beyond resorting to the trademark laws.

CreAgri, Inc. v. USANA Health Sciences, Inc.

In a contest involving competing products claiming trademark priority, the district court determined, in order to acquire priority, a "use in commerce" means a lawful use - here, a use compliant with federal labeling requirements. We agree.

In the spring of 2001, Appellant CreAgri began selling Olivenol, a dietary supplement containing an apparently beneficial antioxidant found in olives called hydroxytyrosol. At the time, Olivenol's label indicated that each tablet contained $25 \mathrm{mg}$ of hydroxytyrosol, the product's primary active ingredient. CreAgri now admits that each tablet contains at most $3 \mathrm{mg}$ of hydroxytyrosol and that Olivenol was, therefore, inaccurately labeled.

On June 18, 2002 - more than a year after CreAgri began selling Olivenol - Appellee USANA filed an intent to use application with the Patent and Trademark Office asserting that it intended to begin 
selling a series of vitamins, minerals, and nutritional supplements containing an ingredient called Olivol, which - like Olivenol - is an olive extract containing apparently beneficial polyphenols. USANA began selling these products in August 2002, the PTO granted USANA's application, and OLIVOL is now listed on the principal register with a priority date of June 18, 2002. The present suit arises because, according to CreAgri, the name of USANA's Olivol ingredient is confusingly similar to the name of its own Olivenol product and, therefore USANA is infringing upon the trademark rights CreAgri acquired when it began selling Olivenol more than a year earlier.

If "use in commerce" were the only requirement for acquiring trademark rights, 9 then CreAgri would have an easier path to establishing priority of its mark because it began selling Olivenol more than one year before USANA's intent to use application was filed. But the inquiry does not stop with use in commerce. It has long been the policy of the PTO's Trademark Trial and Appeal Board that use in commerce only creates trademark rights when the use is lawful.

The rationale for this rule is twofold. First, as a logical matter, to hold otherwise would be to put the government in the anomalous position of extending the benefits of trademark protection to a seller based upon actions the seller took in violation of that government's own laws. Second, as a policy matter, to give trademark priority to a seller who rushes to market without taking care to carefully comply with the relevant regulations would be to reward the hasty at the expense of the diligent.

By CreAgri's own admission, each tablet sold under the Olivenol name before June 18, 2002 contained, at most, 3mg of hydroxytyrosol, while Olivenol's label claimed that each tablet contained either $25 \mathrm{mg}$ or $5 \mathrm{mg}$ of this nutrient. 21 C.F.R. $\S 101.9(\mathrm{~g})(4)(\mathrm{i})$, however, requires that the actual amount of a nutrient added to a product be "at least equal to the value for that nutrient declared on the label." Because the actual amount of hydroxytyrosol (at most 3mg) was less than the values for hydroxytyrosol declared on Olivenol's labels $(25 \mathrm{mg}$ and $5 \mathrm{mg}$ ), CreAgri's product was, at all relevant times, in violation.

\section{Nexus}

There must be some nexus between use of a mark and an alleged violation before it can be said that the unlawfulness of a sale or shipment has resulted in a trademark's invalidity. CreAgri argues that its labeling violation was collateral to its use of the Olivenol mark and, thushe former should not render the latter "unlawful."

We neither adopt nor reject this rule because, even if the rule were adopted, CreAgri could not benefit from it. While it may be possible to conceive of a situation in which violation of a law in connection with a trademarked product would have no effect on the rights inur- 
ing in that trademark, the nexus between a misbranded product and that product's name, particularly one designed for human consumption, is sufficiently close to justify withholding trademark protection for that name until and unless the misbranding is cured.

\section{Potential Exemption}

We also reject CreAgri's argument that, because there was no accepted method for determining the hydroxytyrosol content of a given substance at the time Olivenol's labels were in error, Olivenol was exempt from the FDCA's labeling requirements. See 21 C.F.R. $\S 101.36(f)(2)$ (allowing a seller to apply for an exemption from these regulations if it is technologically infeasible or otherwise impracticable to comply with them). While it is unclear, as a factual matter, whether appropriate testing was technologically feasible at the time, section 101.36(f)(2) does not provide for an automatic exemption but, rather, expressly requires sellers to apply for and receive an exemption from the FDA. CreAgri did neither

If CreAgri had applied for, and if the FDA had exercised its discretion by granting, an exemption on the basis of technological infeasibility, then CreAgri's violation would be properly excused. CreAgri, however, offered no evidence to show that it so much as applied to the Office of Nutritional Products for an exemption, much less that the FDA granted CreAgri "special allowances" from the FDCA's labeling requirements.

\section{Materiality}

CreAgri's final argument with respect to the apparent unlawfulness of its use of "Olivenol" in commerce prior to USANA's priority date is that the labeling defect was so harmless or de minimis that it should be excused as "immaterial" under General Mills, Inc. v. Health Valley Foods(holding that a labeling defect is "material" only when it is "of such gravity and significance that the usage must be considered unlawful - so tainted that, as a matter of law, it can create no trademark rights").

General Mills involved a dispute between Health Valley Foods (seller of Fiber 7 Flakes cereal) and General Mills, Inc. (seller of Fiber One cereal), in which the former accused the latter of not having lawfully used "Fiber One" in commerce when the latter applied for trademark registration. Although the first eighteen boxes of Fiber One - indeed, all boxes sold before General Mills applied for trademark registration of the Fiber One mark - were mislabeled under the FDCA, General Mills noticed the error, promptly corrected it, and then sold over 600,000 correctly labeled boxes to consumers before Health Valley Foods even applied to register "Fiber 7 Flakes." Under

General Mills: 24 U.S.P.Q.2d 1270 (TTAB 1992) 
these facts, the Trademark Trial and Appeal Board concluded that cancelling Fiber One's registration based on the original eighteen mislabeled boxes would be "Draconian."

This case is categorically different. Whereas General Mills corrected its labeling error before its competitor's priority date - thus eventually establishing the "lawful use in commerce" necessary for trademark protection - CreAgri did not correct its labeling error before USANA's priority date, and thus, there is not a single instance of "lawful use in commerce" prior to June 18, 2002 upon which CreAgri can base its claim of priority. Accordingly, we need not decide whether to adopt the generamills test for materiality; by any definition, Olivenol's defect - which existed as to every bottle of Olivenol sold prior to the competing registrant's priority date - was material.

\section{Conclusion}

Because CreAgri's admitted violation cannot be deemed collateral to use of the Olivenol mark, excused, or overlooked as immaterial, it follows that the Olivenol mark was not lawfully used in commerce prior to Olivol's June 18, 2002 priority date. As such, USANA's mark has priority over CreAgri's mark, and a trademark infringement action by CreAgri against USANA cannot stand.

\section{Bilgewater Bill's Problem}

Consider the following sequence of events. Who has priority in Baltimore? In Seattle? In Chicago?

- A uses BILGEWATER BILL'S in Baltimore.

- B uses BILGEWATER BILL'S in Seattle.

\section{Federal Registration}

a Registration

15 U.S.C. § 1051

Lanham Act § 1

Application for registration ...

Who is the "owner" of a trademark?

35 U.S.C. § 1057

Lanham Act $§ 7$

Certificates of registration

\section{Lanham Act}

(a) Application for use of trademark. -

(1) The owner of a trademark used in commerce may request registration of its trademark on the principal register hereby established by paying the prescribed fee and filing in the Patent and Trademark Office an application and a verified statement, in such form as may be prescribed by the Director, and such number of specimens or facsimiles of the mark as used as may be required by the Director.

(b) Certificate as prima facie evidence. - A certificate of registration of a mark upon the principal register provided by this chapter 
shall be prima facie evidence of the validity of the registered mark and of the registration of the mark, of the owner's ownership of the mark, and of the owner's exclusive right to use the registered mark in commerce on or in connection with the goods or services specified in the certificate, subject to any conditions or limitations stated in the certificate.

(c) Application to register mark considered constructive use. - Contingent on the registration of a mark on the principal register provided by this chapter, the filing of the application to register such mark shall constitute constructive use of the mark, conferring a right of priority, nationwide in effect, on or in connection with the goods or services specified in the registration.

\section{Burger King of Florida, Inc. v. Hoots}

Plaintiff Burger King of Florida, Inc. opened the first BURGER KING restaurant in Jacksonville, Florida, in 1953. In July, 1961, plaintiffs opened their first Illinois BURGER KING restaurant in Skokie. Thereafter, on October 3, 1961, plaintiffs' certificate of federal registration of the mark was issued. Subsequently, plaintiffs opened a restaurant in Champaign, Illinois, and at the time of the trial in November, 1967, were operating more than fifty BURGER KING restaurants in the state of Illinois.

In 1957 the defendants, who had been operating an ice cream business in Mattoon, Illinois, opened a BURGER KING restaurant there. In July, 1959, they registered that name under Illinois law as their trade mark, without notice of plaintiffs' prior use of the same mark. On September 26, 1962, the defendants, with constructive knowledge of plaintiffs' federal trade mark, opened a second similar restaurant, in Charleston, Illinois.

We hold that plaintiffs' federal registration of the trade mark BURGER KING gave them the exclusive right to use the mark in Illinois except in the Mattoon market area in Illinois where the defendants, without knowledge of plaintiffs' prior use, actually used the mark before plaintiffs' federal registration. The defendants did not acquire the exclusive right they would have acquired by their Illinois registration had they actually used the mark throughout Illinois prior to the plaintiffs' federal registration.

Plaintiffs agree that the defendants as prior good faith users are to be protected in the area that they had appropriated. Thus, the question narrows to what area in Illinois the defendants have appropriated by virtue of their Illinois registration.

At common law, defendants were entitled to protection in the Mattoon market area because of the innocent use of the mark prior to plaintiffs' federal registration. They argue that the Illinois Trade
403 F.2d 904 (7th Cir. 1968)

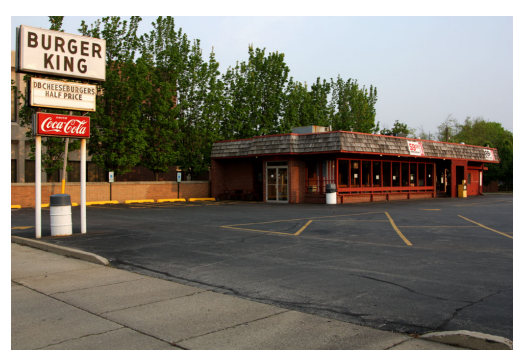

Defendant's restaurant

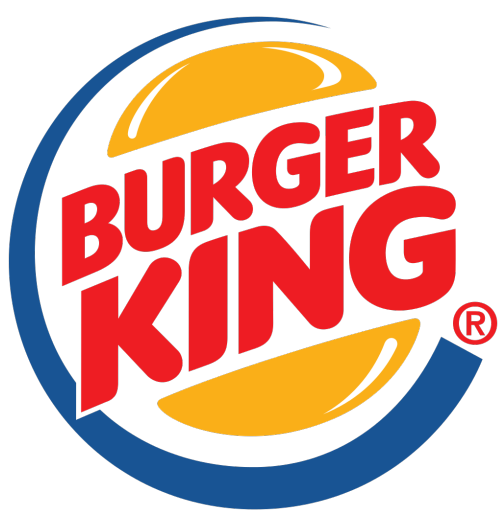

Plaintiff's logo

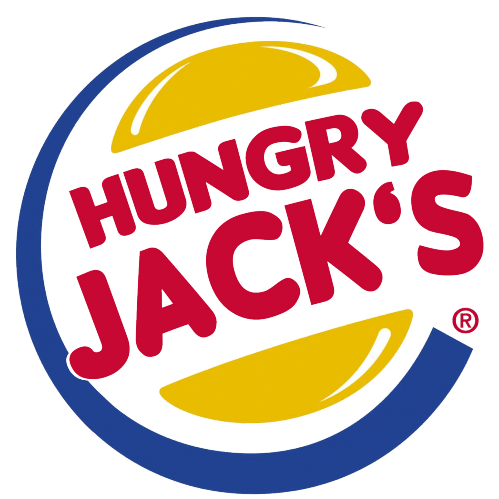

Logo used by plaintiff's franchisee in Australia. Can you guess the backstory? 
Mark Act was designed to give more protection than they already had at common law, and that various provisions of the Illinois Act indicate an intention to afford Illinois registrants exclusive rights to use trade marks throughout the state, regardless of whether they actually used the marks throughout the state or not. However, the Act itself does not express any such intention. Moreover, we think that whether or not Illinois intended to enlarge the common law with respect to a right of exclusivity in that state, the Illinois Act does not enlarge its right in the area where the federal mark has priority.

The defendants argue also that unless they are given the right to exclusive use throughout Illinois, many persons from all parts of Illinois in our current mobile society will come in contact with the defendants' business and will become confused as to whether they are getting the defendants' product, as they intended.

We are not persuaded by this argument. Defendants have not shown that the Illinois public is likely to confuse the products furnished by plaintiffs and by defendants. We are asked to infer that confusion will exist from the mere fact that both trade marks co-exist in the state of Illinois. The mere fact that some people will travel from one market area to the other does not, of itself, establish that confusion will result.

Bilgewater Bill's Problem, Redux

1. Consider the following sequence of events. Who has priority in Baltimore? In Seattle? In Chicago?

- A uses BILGEWATER BILL'S in Baltimore.

- B uses BILGEWATER BILL'S in Seattle.

- A files for federal trademark registration under $\S 1(a)$.

2. Consider the following sequence of events. Who has priority in Baltimore? In Seattle? In Chicago?

- A uses BILGEWATER BILL'S in Baltimore.

- B uses BILGEWATER BILL'S in Seattle.

- B files for federal trademark registration under $\S 1(\mathrm{a})$.

3. Consider the following sequence of events. Who has priority in Baltimore? In Seattle? In Chicago?

- A uses BILGEWATER BILL'S in Baltimore.

- B uses BILGEWATER BILL'S in Seattle.

- A files for federal trademark registration under $\S 1(\mathrm{a})$.

- B files for federal trademark registration under $\S 1(\mathrm{a})$. 
b Intent-to-Use Applications

\section{Lanham Act}

(b) Application for bona fide intention to use trademark. -

(1) A person who has a bona fide intention, under circumstances showing the good faith of such person, to use a trademark in commerce may request registration of its trademark on the principal register hereby established by paying the prescribed fee and filing in the Patent and Trademark Office an application and a verified statement, in such form as may be prescribed by the Director.

(d) Verified statement that trademark is used in commerce. -

(1) Within six months after the date on which the notice of allowance with respect to a mark is issued to an applicant under subsection (b) of this section, the applicant shall file in the Patent and Trademark Office, together with such number of specimens or facsimiles of the mark as used in commerce as may be required by the Director and payment of the prescribed fee, a verified statement that the mark is in use in commerce and specifying the date of the applicant's first use of the mark in commerce and those goods or services specified in the notice of allowance on or in connection with which the mark is used in commerce. Subject to examination and acceptance of the statement of use, the mark shall be registered.

(2) The Director shall extend, for one additional 6-month period, the time for filing the statement of use under paragraph (1), upon written request of the applicant before the expiration of the 6-month period provided in paragraph (1). In addition to an extension under the preceding sentence, the Director may, upon a showing of good cause by the applicant, further extend the time for filing the statement of use under paragraph (1) for periods aggregating not more than 24 months, pursuant to written request of the applicant made before the expiration of the last extension granted under this paragraph.

Kelly Services, Inc. v. Creative Harbor, LLC [I]

This is a trademark dispute. Plaintiffs/Counter-Defendants Kelly Services, Inc. and Kelly Properties, LLC (collectively, "Kelly") and Defendant/Counter-Plaintiff Creative Harbor, LLC ("Creative Harbor") each developed a mobile application that provides job search-

15 U.S.C. § 1051

Lanham Act § 1

Application for registration ... 
ing and job placement tools. Now, Kelly and Creative Harbor dispute which company has priority to the trademark "WorkWire." Creative Harbor has filed two "intent to use" applications with the United States Patent and Trademark Office (the "Creative ITUs"), and Creative Harbor claims priority based upon those filings. Kelly counters that it has priority because it used the mark in commerce before Creative Harbor filed the Creative ITUs.

\section{FACTUAL BACKGROUND}

\section{A. The Kelly Workwire App}

Kelly provides career development information and job placement tools to employers and prospective employees. In early 2013, Kelly began developing an iPad application that would provide users with access to personnel placement services, career information, job searching tools, and a Kelly branch office locator. Kelly intended to distribute the application through the Apple App Store. Kelly decided to call its application "WorkWire" (the "Kelly WorkWire App").

Kelly completed the development of the Kelly WorkWire App on February 4, 2014. That same day, Kelly submitted the Kelly WorkWire App to Apple's iTunes Connect, an Internet-based tool that allows a software developer to submit an application for sale in the Apple App Store, pending Apple's approval of the application.

Approximately one week later, on February 10, 2014, Apple informed Kelly that the Kelly WorkWire App was rejected because of a problem with the application's metadata. The next day, Kelly resubmitted the Kelly WorkWire App for Apple's review.

On February 17, 2014, Apple informed Kelly that the Kelly WorkWire App had been approved and was "ready for sale." However, Apple's designation of the Kelly WorkWire App as "ready for sale" did not immediately make the Kelly WorkWire App available for the public to download from the Apple App Store. The Kelly WorkWire App was first released to the public via the Apple App Store on Febru-

KELLY. SERVICES

Kelly's WorkWire app logo ary 19, 2014, sometime after 8:11 p.m. Eastern Standard Time. A consumer first downloaded the Kelly WorkWire App from the Apple App Store on February 20, 2014.

\section{B. The Creative WorkWire App}

In September 2013, Christian Jurgensen (“Jurgensen"), an entrepreneur based in Los Angeles, California, independently came up with an idea for a mobile application for use by employers and prospective employees. Jurgensen decided to call his application "WorkWire" (the "Creative Workwire App"). 
In early February 2014, Jurgensen formed Creative Harbor as the limited liability company responsible for the Creative WorkWire App. At approximately the same time, Creative Harbor hired an intellectual property attorney to provide advice on trademark protection. On February 16, 2014, the attorney informed Creative Harbor that the trademark for "WorkWire" was available.

Three days later, on February 19, 2014, Creative Harbor filed the Creative ITUs with the United States Patent and Trademark Office (the "USPTO"). (hereinafter the "Mark"). The Creative ITUs were filed at 6:28 p.m. and 7:56 p.m. Eastern Standard Time.

Creative Harbor has tried to make the Creative WorkWire App available for download by the public through the Apple App Store. However, Apple will not accept the Creative WorkWire App for posting in the Apple App Store because the "WorkWire" name is already being used by the Kelly WorkWire App. Creative Harbor acknowledges that it has not used the Mark in commerce and therefore has not completed registration of the Mark.

\section{PROCEDURAL HISTORY}

On March 10, 2014, Creative Harbor's counsel sent a "cease and desist" letter to Kelly. Creative Harbor stated that Kelly's use of the Mark in connection with the Kelly WorkWire App "constitutes trademark infringement and unfair competition under federal and state law." Creative Harbor therefore "demand[ed] that Kelly ... cease all use of the term 'WorkWire'...." In response, Kelly filed this declaratory judgment action against Creative Harbor.

\section{ANALYSIS \\ A. Kelly Did Not Use the Mark in Commerce Before Creative Filed the Creative ITUs, and Thus Kelly Does Not Have Priority Based on Its Alleged Prior Use}

Ordinarily, priority to a mark is established "as of the first actual use of [the] mark" in commerce. . However, the Lanham Act allows a person not yet using a mark to file an anticipatory application for registration - i.e., an ITU application - on the basis of an intent to use the mark in the future. If the ITU applicant later uses the mark in a commercial transaction and files a statement of use with the USPTO within the prescribed time frame, the mark is registered and the date

\footnotetext{
${ }^{1}$ As explained further below, an intent to use ("ITU") application is an anticipa-
tory application for registration of a trademark based on the applicant's intent to
use the mark in the future. Under certain circumstances, an ITU application estab-
lishes the applicant's priority to the trademark over another person who adopted
the trademark after the ITU was filed.

${ }^{1}$ As explained further below, an intent to use ("ITU") application is an anticipa-
tory application for registration of a trademark based on the applicant's intent to
use the mark in the future. Under certain circumstances, an ITU application estab-
lishes the applicant's priority to the trademark over another person who adopted
the trademark after the ITU was filed.

${ }^{1}$ As explained further below, an intent to use ("ITU") application is an anticipa-
tory application for registration of a trademark based on the applicant's intent to
use the mark in the future. Under certain circumstances, an ITU application estab-
lishes the applicant's priority to the trademark over another person who adopted
the trademark after the ITU was filed.

${ }^{1}$ As explained further below, an intent to use ("ITU") application is an anticipa-
tory application for registration of a trademark based on the applicant's intent to
use the mark in the future. Under certain circumstances, an ITU application estab-
lishes the applicant's priority to the trademark over another person who adopted
the trademark after the ITU was filed.

${ }^{1}$ As explained further below, an intent to use ("ITU”) application is an anticipa-
tory application for registration of a trademark based on the applicant's intent to
use the mark in the future. Under certain circumstances, an ITU application estab-
lishes the applicant's priority to the trademark over another person who adopted
the trademark after the ITU was filed.
}

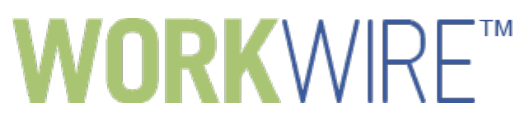

Creative Harbor's WorkWire logo 
15 U.S.C. $\S 1127$

Allard: 146 F.3d 350 (6th Cir. 1998) the ITU application was filed becomes the applicant's constructiveuse date. This gives the [ITU] applicant priority-of-use over anyone who adopts the mark after the constructive-use date.

Kelly argues that it used the Mark in commerce before Creative Harbor filed the Creative ITUs and that Kelly therefore has priority to the Mark over Creative Harbor. Creative Harbor contends that Kelly did not use the Mark in commerce before the Creative ITUs were filed and, thus, that Kelly does not have priority over Creative Harbor. Accordingly, the issue with respect to priority is whether Kelly actually used the Mark in commerce before Creative Harbor filed the Creative ITUs. The Court holds that Kelly did not.

Under the Lanham Act, " $t \mathrm{t}]$ he term 'use in commerce' means the bona fide use of a mark in the ordinary course of trade, and not made merely to reserve a right in a mark.". Use in commerce requires a genuine commercial transaction or an attempt to complete a genuine commercial transaction. The use need not be extensive nor result in deep market penetration or widespread recognition. However, there has to be an "open" use, that is to say, a use has to be made to the relevant class of purchasers or prospective purchasers. An "internal" use cannot give rise to priority rights to a mark. S Indeed, the talismanic test for use in commerce is whether or not the use was sufficiently public to identify or distinguish the marked goods in an appropriate segment of the public mind as those of the adopter of the mark. Applying this test in Allard Enters., Inc. v. Advanced Programming Resources, Inc., the Sixth Circuit found sufficient public use when a claimant offered its services to potential customers through "numerous solicitations" bearing the mark.

Kelly contends that it used the Mark in commerce on February 4, 2014, when it submitted the Kelly Workwire App to iTunes Connect for Apple's review. Kelly argues that its submission constitutes use in commerce because it "engaged Apple, an unrelated company, at arms-length, in the ordinary course of trade and subject to Apple's software developer's requirements." But Kelly has not shown that its submission of the Kelly WorkWire App to Apple was sufficiently open or public to identify or distinguish its application in the minds of consumers. To the contrary, the bilateral exchange between Kelly and iTunes Connect provided no notice of the Kelly WorkWire App to potential consumers - i.e., persons who might eventually download the Kelly WorkWire App from the Apple App Store. Indeed, by merely submitting the Kelly WorkWire App for Apple's review, Kelly did not make the Kelly WorkWire App available for download by the public. At best, Kelly's submission was a preparatory step to making the Kelly WorkWire App available to consumers. an applicant's preparations to use a mark in commerce are insufficient to constitute use in commerce. 
B. Creative Harbor is Not Entitled to a Declaration That it Has Priority At this Time

In its Motion, Creative Harbor seeks summary judgment "on the issue of priority in its right to use the Mark." But Creative Harbor has not yet established its priority. All that Creative Harbor has done is file the Creative ITUs. The Creative ITUs - in and of themselves - do not establish Creative Harbor's priority to the Mark. Rather, the Creative ITUs merely establish Creative Harbor's constructive-use date, contingent on Creative Harbor's registration of the Mark. Thus, in order to establish its priority, Creative Harbor must actually complete the registration of the Mark by using the Mark in commerce and filing a statement of use with the USPTO within the prescribed time frame. Creative Harbor acknowledges that it has not yet used the Mark. Accordingly, while Creative Harbor may establish its priority at some point in the future, it is not now entitled to the declaration that it seeks here.

\section{Creative Harbor's Additional Counterclaims Fail as a Matter of Law}

As noted above, Creative Harbor asserts Additional Counterclaims against Kelly for unfair competition, trademark dilution, and intentional interference with prospective business. Each of the Additional Counterclaims is based on Creative Harbor's assertion that Kelly infringed on Creative Harbor's alleged priority rights to the Mark. Creative Harbor says that it established those rights by filing the Creative ITUs. But an intent-to-use application does not, by itself, confer any rights enforceable against others.

Kelly Services, Inc. v. Creative Harbor, LLC [II]

The evidence makes clear that Creative Harbor had a "firm" intent to use the Mark in connection with an iPhone application that connected job seekers with employers. But evidence that Creative Harbor intended to use the Mark with respect to some of the goods and services listed in the Creative ITUs does not contradict Kelly's evidence that Creative Harbor lacked a firm intent to use the Mark on several of the other services and goods listed in the ITUs. Kelly has identified sworn deposition testimony by Creative Harbor's CEO Christian Jurgensen indicating that (1) in many respects, Creative Harbor merely intended to reserve a right in the Mark and (2) Creative Harbor lacked a firm intent to use the Mark with respect to several of the goods and services listed in the Creative ITUs. Kelly directs the Court to the following representative portions of Mr. Jurgensen's testimony:

- Mr. Jurgensen conceded that at the time his attorney drafted the Creative ITUs he (Jurgensen) "had clear ideas for some of them, and some of them were meant for future exploration." 
Spirits Int'l: 99 U.S.P.Q.2d 1545 (T.T.A.B. 2011)

Where does this leave the parties in the courts? And in the Apple App Store?
- In the Goods ITU, Creative Harbor stated that it intended to use the Mark with "computer game software," but Mr. Jurgensen testified that Creative Harbor did "not" intend to use the Mark "with a game."

- In the Services ITU, Creative Harbor said that it intended to use the Mark in connection with "business consulting" services, but Mr. Jurgensen conceded that he "wanted to make sure [that] was there included" because the company "could" perhaps perform those services "at some point" in the future.

Critically, Creative Harbor has not identified any objective evidence that it had a bona fide intent to use the Mark in connection with many of services and goods listed on the Creative ITUs, such as employee relations information services, business consulting services, professional credentialing verification services, computer game software, and/or computer hardware for integrating text and audio.

Absent fraud, an ITU applicant may cure an overbroad listing of goods and/or services by deleting from its application the goods and/or services on which it lacks a bona fide intent to use the mark. In Spirits Int l, B.V. v. S.S. Taris Zeytin Ve Zeytinyagi Tarim Satis Kooperatifleri Birligi, the TTAB did not suggest that a tribunal may properly delete items that an applicant has not, itself, undertaken to delete. Instead, the TTAB said that because the applicant had failed to make the required deletions, the appropriate remedy was to void the entire classes containing the goods for which the required intent was lacking. Application of the Spirits Int'] framework leads the Court to invalidate the Creative ITUs in their entirety.

\section{Bilgewater Bill's Problem, Re-Redux}

Consider the following sequence of events. Who has priority in Baltimore? Who has priority in Seattle? Who has priority in Chicago?

- B files a $\S 1(b)$ intent-to-use application for BILGEWATER BILL'S.

- A uses BILGEWATER BILL'S in Baltimore

- B uses BILGEWATER BILL'S in Seattle.

- B files a $\S 1(\mathrm{~d})$ statement of use.

\section{Collaborations}

\section{Boogie Kings v. Guillory}

In this action, plaintiff seeks to enjoin the defendant, Clinton Guillory, who is also known and sometimes referred to herein as "Clint West," from using the trade name "The Boogie Kings." The suit was instituted by "The Boogie Kings," an unincorporated association doing 
business under that trade name, represented herein by three of the officers or representatives of that association. The defendant filed an answer and a reconventional demand, in which he alleges that he has the exclusive right to use that trade name, and he prays for judgment enjoining plaintiff from using it.

The evidence shows that in 1955 Douglas Ardoin and Harris Miller formed a dance band or orchestra, and they mutually agreed to call themselves "The Boogie Kings." Other musicians joined the band thereafter, and in 1964 it was composed of ten members. The band was never incorporated and no formal partnership agreement, oral or written, was ever entered into. The band functioned as an organization with a definite membership, however, and as an organized band it acquired movable property and entered into contracts for playing engagements and other matters. The evidence shows that since the initial creation of the orchestra, the members from time to time have elected one of their number to serve as "leader." Although there is some conflict in the testimony, we think the evidence establishes that all major decisions affecting the organization, the assets and the operations of the band have been made by a majority vote of the members.

Ardoin was elected and served as the first leader of the band, and he was succeeded by Miller. Later, Ardoin was reelected to be the leader, and he served as such until he withdrew completely from the band in 1963. Thereafter, he discontinued his career as a musician. Miller succeeded Ardoin as leader in 1963, and he served as such until May, 1964, when a dispute arose between Miller and most of the other members relative to a playing engagement. As the result of that dispute, Miller withdrew as a member of the band.

Defendant, Guillory, joined the band as a drummer and vocalist in 1963. Immediately after Miller withdrew in May, 1964, Guillory was elected by the other members as leader. As the featured vocalist in the band, he was known professionally as "Clint West." In order to capitalize on his popularity as a singer, the name of the band was changed to "Clint West and the Boogie Kings," this change of name being made after defendant became the leader and with the approval of a majority of the members.

During the latter part of the year 1964, or the first part of 1965, this band was playing regularly at the Bamboo Club in Lake Charles and occasionally at other places. Guillory acquired an interest in the Moulin Rouge Club at that time, however, and he prevailed upon the other members to discontinue playing at the Bamboo Club and to begin playing regularly at the Moulin Rouge instead. A relatively short time after making this change, all of the members except Guillory became dissatisfied with the arrangement, and nine of the ten members voted to go back to playing at the Bamboo Club. Guillory was the

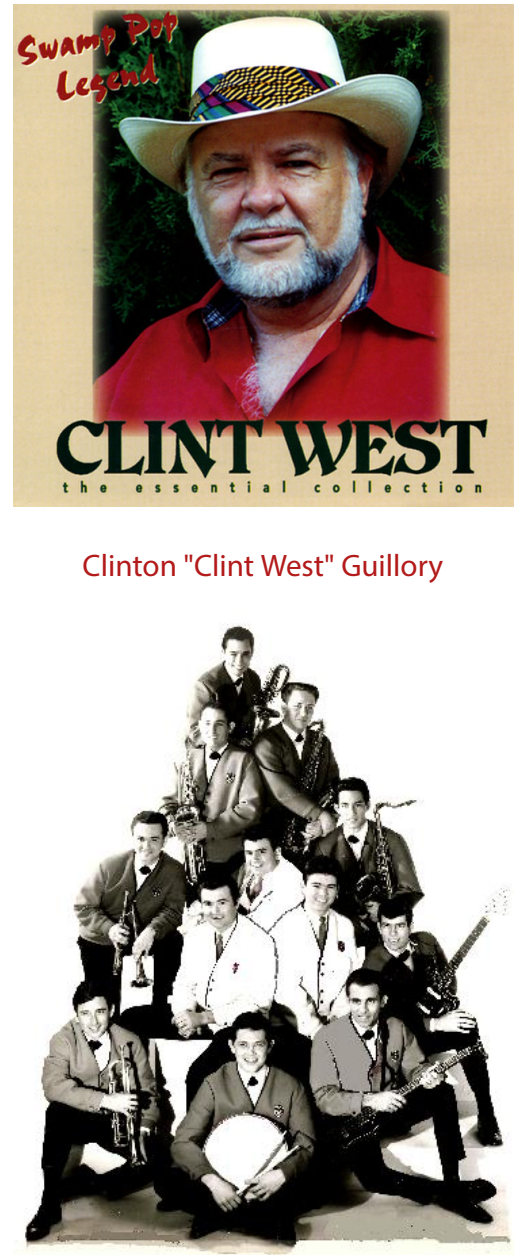

The Boogie Kings, circa 1965 
only member who refused to join them in this decision, and he thereupon separated or disassociated himself from the other members.

Immediately after this split in the band occurred, the nine original members elected a new leader, a new member came into the band to take Guillory's place, and the orchestra resumed playing regularly at the Bamboo Club, and other places, under the name of "The Boogie Kings." Also, immediately after the split, Guillory joined with nine other musicians to form a new orchestra, and this new group resumed playing at the Moulin Rouge Club, and other places, and they called themselves "Clint West and The Boogie Kings."

Defendant contends that the band, as an organization or association, never acquired a proprietary interest in this trade name, that the right to use that name was vested originally in Ardoin and Miller, that Miller acquired the exclusive right to use it when Ardoin abandoned any claim to it, and that shortly prior to the "split" Miller specifically gave to defendant Guillory the exclusive right to use the name, "The Boogie Kings."

In the instant suit, the evidence shows that during the period from 1955 to 1964 the band known by the trade name of "The Boogie Kings" acquired a considerable amount of popularity. Because of its reputation as a musical organization or dance band, its trade name has acquired some significance and value. The person or organization first appropriating the name or having the legal right to use it, therefore, has a proprietary interest in that name and is entitled to judgment enjoining another from appropriating it.

In our opinion, this band, when first organized in 1955, became an unincorporated association, and it has continued to be such an organization since that time. The evidence convinces us, as it apparently did the trial judge, that the original trade name, "The Boogie Kings," was adopted by mutual agreement of the members of the band, that a proprietary interest in that name became vested in the band, as an unincorporated association, and that it did not become vested in any individual member of that band. Miller, therefore, had no right or authority to "give" or to transfer to defendant Guillory the exclusive right to use that name.

Dissatisfied members of an association cannot deprive it of the right to use its own name by incorporating themselves thereunder, and enjoining it from using the same. We conclude that Guillory acquired no right to use the trade name of the band, either from Miller or from the circumstance that he had been elected as leader of the band. The trial judge, therefore, correctly enjoined defendant from continuing to use that name. 
Section 5 of the Trademark Act, 15 U.S.C. $\S 1055$, states, in part, as follows:

Where a registered mark or a mark sought to be registered is or may be used legitimately by related companies, such use shall inure to the benefit of the registrant or applicant for registration, and such use shall not affect the validity of such mark or of its registration, provided such mark is not used in such manner as to deceive the public.

Section 45 of the Act, 15 U.S.C. § 1127, defines "related company" as follows:

The term "related company" means any person whose use of a mark is controlled by the owner of the mark with respect to the nature and quality of the goods or services on or in connection with which the mark is used.

Thus, $\S 5$ of the Act permits applicants to rely on use of the mark by related companies. Either a natural person or a juristic person may be a related company. 15 U.S.C. $\S 1127$.

The essence of related-company use is the control exercised over the nature and quality of the goods or services on or in connection with which the mark is used. When a mark is used by a related company, use of the mark inures to the benefit of the party who controls the nature and quality of the goods or services. This party is the owner of the mark and, therefore, the only party who may apply to register the mark.

\section{Duff Problem}

Duff beer is, or was, a fictional beer on the animated cartoon sitcom The Simpsons. Varieties mentioned on the show include Duff, Duff Dry, Duff Light, Duff Adequate, Raspberry Duff, Lady Duff, and Tartar Control Duff. Recently, the Fudd Corporation has started selling beer under the DUFF name. Fudd is unaffiliated with Twentieth Century Fox (which produces The Simpsons) and has not obtained permission to sell DUFF beer. Trademark infringement? What if Fox sold a line of Simpsons-themed beers including Duff? What if Fox gave away "Duff beer" (actually ginger ale) to fans at conventions?

\section{Procedures}

\section{Registration}


No trademark ... shall be refused registration on the principal register on account of its nature unless it -

(e) Consists of a mark which (1) when used on or in connection with the goods of the applicant is merely descriptive ... of them,

(f) Except as expressly excluded in subsections (a), (b), (c), (d), (e)(3), and (e)(5) of this section, nothing in this chapter shall prevent the registration of a mark used by the applicant which has become distinctive of the applicant's goods in commerce.

15 U.S.C. § 1052

Lanham Act § 2

Trademarks registrable on principal register
808 F.3d 1321 (Fed. Cir. 2015) (en banc)

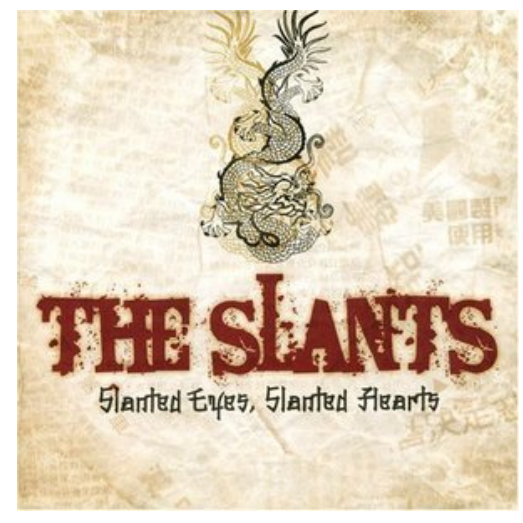

THE SLANTS logo
Note that $\S \S 2(e)(1)$ and (f) of the Lanham Act restate the common-law doctrine of descriptive and generic trademarks. "Merely" descriptive marks are not protectable, but marks that have "become distinctive" (i.e. acquired secondary meaning) are. A generic mark is considered incapable of acquiring secondary meaning as a matter of law.

\section{Lanham Act}

No trademark shall be refused registration on the principal register on account of its nature unless it-

(a) Consists of or comprises immoral ... or scandalous matter; or matter which may disparage or falsely suggest a connection with persons, living or dead, institutions, beliefs, or national symbols, or bring them into contempt, or disrepute; ...

\section{In re Tam}

Section 2(a) of the Lanham Act bars the Patent and Trademark Office ("PTO") from registering scandalous, immoral, or disparaging marks. The government enacted this law - and defends it today - because it disapproves of the messages conveyed by disparaging marks. It is a bedrock principle underlying the First Amendment that the government may not penalize private speech merely because it disapproves of the message it conveys. That principle governs even when the government's message-discriminatory penalty is less than a prohibition.

Courts have been slow to appreciate the expressive power of trademarks. Words-even a single word-can be powerful. Mr. Simon Shiao Tam named his band THE SLANTS to make a statement about racial and cultural issues in this country. With his band name, Mr. Tam conveys more about our society than many volumes of undisputedly protected speech. Another rejected mark, STOP THE ISLAMISATION OF AMERICA, proclaims that Islamisation is 
undesirable and should be stopped. Many of the marks rejected as disparaging convey hurtful speech that harms members of oftstigmatized communities. But the First Amendment protects even hurtful speech.

The government cannot refuse to register disparaging marks because it disapproves of the expressive messages conveyed by the marks. It cannot refuse to register marks because it concludes that such marks will be disparaging to others. The government regulation at issue amounts to viewpoint discrimination, and under the strict scrutiny review appropriate for government regulation of message or viewpoint, we conclude that the disparagement proscription of $\S 2$ (a) is unconstitutional. Because the government has offered no legitimate interests justifying $\S 2(a)$, we conclude that it would also be unconstitutional under the intermediate scrutiny traditionally applied to regulation of the commercial aspects of speech. We therefore vacate the Trademark Trial and Appeal Board's holding that Mr. Tam's mark is unregistrable, and remand this case to the Board for further proceedings.

In re Boulevard Entertainment, Inc.

The Boulevard Entertainment, Inc. seeks to register "1-800-JACKOFF" and "JACK-OFF" as marks on the Principal Register for "entertainment in the nature of adult-oriented conversations by telephone." The TTAB affirmed the refusal to register on the ground that the marks consist of or comprise scandalous matter. Because substantial evidence supports the TTAB's finding that the term "jack-off" is an offensive and vulgar reference to masturbation and that Boulevard's use of the marks refers to that meaning, we affirm.

\section{Trademark Manual of Examining Procedure}

Section 45 of the Trademark Act, 15 U.S.C. §1127, defines "collective mark" as follows:

The term "collective mark" means a trademark or service mark-

(1) used by the members of a cooperative, an association, or other collective group or organization, or

(2) which such cooperative, association, or other collective group or organization has a bona fide intention to use in commerce and applies to register on the principal register established by this [Act], and includes marks indicating membership in a union, an association, or other organization.

Under the Trademark Act, a collective mark is owned by a collective entity even though the mark is used by the members of the collective.

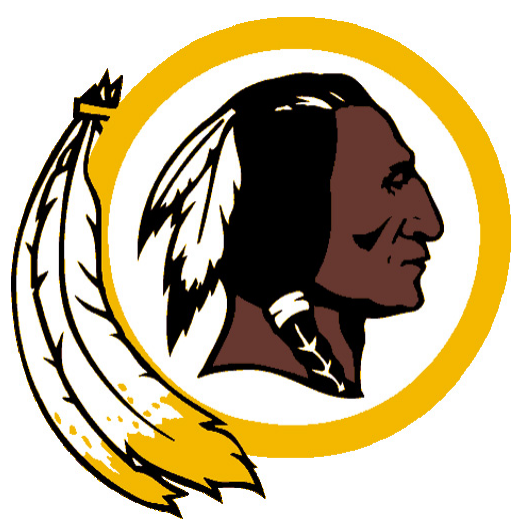

WASHINGTON REDSKINS logo. Distinguishable?

334 F.3d 1336 (Fed. Cir. 2003)

Does the exclusion for immoral or scandalous marks survive Tam?

$\S 1302$

1302 Collective Marks Generally 
Aloe Creme: 192 USPQ 170 (TTAB 1976)

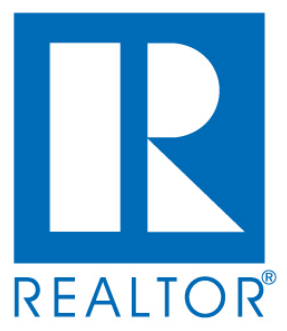

REALTOR collective service mark.

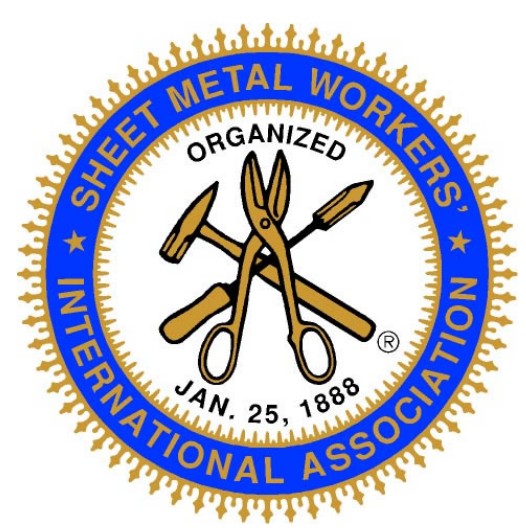

Sheet Metal Workers International Association collective membership mark.

$\S 1401.03$

Designation of Class

$\S 1401.02$ (a)

Headings of International Trademark Classes

$\S 1402.01$

Specifying the Goods and/or Services in General
There are basically two types of collective marks: (1) collective trademarks or collective service marks; and (2) collective membership marks. The distinction between these types of collective marks is explained in Aloe Creme Labs., Inc. v. Am. Soc'y for Aesthetic Plastic Surgery, Inc. as follows:

A collective trademark or collective service mark is a mark adopted by a "collective" (i.e., an association, union, cooperative, fraternal organization, or other organized collective group) for use only by its members, who in turn use the mark to identify their goods or services and distinguish them from those of nonmembers. The "collective" itself neither sells goods nor performs services under a collective trademark or collective service mark, but the collective may advertise or otherwise promote the goods or services sold or rendered by its members under the mark. A collective membership mark is a mark adopted for the purpose of indicating membership in an organized collective group, such as a union, an association, or other organization. Neither the collective nor its members uses the collective membership mark to identify and distinguish goods or services; rather, the sole function of such a mark is to indicate that the person displaying the mark is a member of the organized collective group.

\section{Trademark Manual of Examining Procedure}

In an application for registration of a mark, the applicant should designate the international class number(s) that are appropriate for the identified goods and/or services whenever the information is known.

International trademark classification, and the headings of the international trademark classes, are established by the Committee of Experts of the Nice Union and set forth in the International Classification of Goods and Services for the Purposes of the Registration of Marks (Nice Classification) published annually by the World Intellectual Property Organization ("WIPO") on its website.

A written application must specify the particular goods and/or services on or in connection with which the applicant uses, or has a bona fide intention to use, the mark in commerce. To "specify" means to name in an explicit manner. The identification should set forth common names, using terminology that is generally understood.

The applicant must identify the goods and services specifically to provide public notice and to enable the USPTO to classify the goods 
and services properly and to reach informed judgments concerning likelihood of confusion. The USPTO has discretion to require the degree of particularity deemed necessary to clearly identify the goods and/or services covered by the mark.

Terminology that includes items in more than one class is considered indefinite.

Example: "Blankets" is not acceptable without qualifying wording because it is not particular enough to identify the kind of blanket on which the mark is used, e.g., fire blankets (Class 9), electric blankets (Class 11), horse blankets (Class 18), and bed blankets (Class 24).

The accuracy of identification language in the original application is important because the identification cannot later be expanded.

Specimens are required because they show the manner in which the mark is seen by the public. Specimens also provide supporting evidence of facts recited in the application.

A trademark or service mark application for registration under $\S 1$ (a) of the Trademark Act must include one specimen for each class, showing use of the mark in commerce on or in connection with the goods, or in the sale or advertising of the services.

For a trademark application under $\S 1(a)$, allegation of use in an application under $\S 1(\mathrm{~b})$, or affidavit of use under $\S 8$ or $\S 71$ of the Trademark Act, the specimen must show the mark as used on or in connection with the goods in commerce. A trademark specimen should be a label, tag, or container for the goods, or a display associated with the goods. A photocopy or other reproduction of a specimen of the mark as used on or in connection with the goods is acceptable.

\section{Trademark Manual of Examining Procedure}

The owner of a mark registered in the United States Patent and Trademark Office may give notice that the mark is registered by displaying with the mark the words "Registered in United States Patent and Trademark Office," the abbreviation "Reg. U.S. Pat. \& Tm. Off.," or the letter $\mathrm{R}$ enclosed within a circle, ${ }^{\circledR}$. A party may use terms such as "trademark," "trademark applied for," "TM" and "SM" regardless of whether a mark is registered. These are not official or statutory symbols of federal registration.

\section{Opposition}

§ 904

Specimens

$\S 904.03$

Material Appropriate as Specimens for Trademarks

§ TMEP 906

Federal Registration Notice

35 U.S.C. § 1057

Lanham Act § 2

Trademarks registrable on principal register; concurrent registration 
15 U.S.C § 1062

Lanham Act § 12

Publication
15 U.S.C. § 1063

Lanham Act § 13

Opposition to registration

135 S.Ct. 1293 (2015)
No trademark by which the goods of the applicant may be distinguished from the goods of others shall be refused registration on the principal register on account of its nature unless it -

(d) Consists of or comprises a mark which so resembles a mark registered in the Patent and Trademark Office, or a mark or trade name previously used in the United States by another and not abandoned, as to be likely, when used on or in connection with the goods of the applicant, to cause confusion, or to cause mistake, or to deceive:

Provided, That if the Director determines that confusion, mistake, or deception is not likely to result from the continued use by more than one person of the same or similar marks under conditions and limitations as to the mode or place of use of the marks or the goods on or in connection with which such marks are used, concurrent registrations may be issued to such persons when they have become entitled to use such marks as a result of their concurrent lawful use in commerce prior to (1) the earliest of the filing dates of the applications pending or of any registration issued under this chapter. Use prior to the filing date of any pending application or a registration shall not be required when the owner of such application or registration consents to the grant of a concurrent registration to the applicant.

(a) Examination and publication. - Upon the filing of an application for registration and payment of the prescribed fee, the Director shall refer the application to the examiner in charge of the registration of marks, who shall cause an examination to be made and, if on such examination it shall appear that the applicant is entitled to registration the Director shall cause the mark to be published in the Official Gazette of the Patent and Trademark Office.

(a) Any person who believes that he would be damaged by the registration of a mark upon the principal register may, upon payment of the prescribed fee, file an opposition in the Patent and Trademark Office, stating the grounds therefor, within thirty days after the publication of the mark sought to be registered.

B\&B Hardware, Inc. v. Hargis Industries, Inc.

This case concerns the application of issue preclusion in the context of trademark law. Petitioner, B\&B Hardware, Inc. (B\&B), and respondent Hargis Industries, Inc. (Hargis), both use similar trademarks; B\&B owns SEALTIGHT while Hargis owns SEALTITE. Under the 
Lanham Act, an applicant can seek to register a trademark through an administrative process within the United States Patent and Trademark Office (PTO). But if another party believes that the PTO should not register a mark because it is too similar to its own, that party can oppose registration before the Trademark Trial and Appeal Board (TTAB).

The TTAB consists of administrative trademark judges and highranking PTO officials, including the Director of the PTO and the Commissioner of Trademarks. Opposition proceedings before the TTAB are in many ways similar to a civil action in a federal district court. These proceedings, for instance, are largely governed by the Federal Rules of Civil Procedure and Evidence. The TTAB also allows discovery and depositions. The party opposing registration bears the burden of proof, and if that burden cannot be met, the opposed mark must be registered.

The primary way in which TTAB proceedings differ from ordinary civil litigation is that proceedings before the Board are conducted in writing, and the Board's actions in a particular case are based upon the written record therein. In other words, there is no live testimony. Even so, the TTAB allows parties to submit transcribed testimony, taken under oath and subject to cross-examination, and to request oral argument.

Here, Hargis tried to register the mark SEALTITE, but B\&B opposed SEALTITE's registration. After a lengthy proceeding, the TTAB agreed with B\&B that SEALTITE should not be registered.

In addition to permitting a party to object to the registration of a mark, the Lanham Act allows a mark owner to sue for trademark infringement. Both a registration proceeding and a suit for trademark infringement, moreover, can occur at the same time. In this case, while the TTAB was deciding whether SEALTITE should be registered, $B \& B$ and Hargis were also litigating the SEALTIGHT versus SEALTITE dispute in federal court. In both registration proceedings and infringement litigation, the tribunal asks whether a likelihood of confusion exists between the mark sought to be protected (here, SEALTIGHT) and the other mark (SEALTITE).

The question before this Court is whether the District Court in this case should have applied issue preclusion to the TTAB's decision that SEALTITE is confusingly similar to SEALTIGHT. Here, the Eighth Circuit rejected issue preclusion for reasons that would make it difficult for the doctrine ever to apply in trademark disputes. We disagree with that narrow understanding of issue preclusion. Instead, consistent with principles of law that apply in innumerable contexts, we hold that a court should give preclusive effect to TTAB decisions if 
the ordinary elements of issue preclusion are met.

Justice GINSBURG, concurring.

The Court rightly recognizes that "for a great many registration decisions issue preclusion obviously will not apply." That is so because contested registrations are often decided upon a comparison of the marks in the abstract and apart from their marketplace usage. When the registration proceeding is of that character, there will be no preclusion of the likelihood of confusion issue in a later infringement suit. On that understanding, I join the Court's opinion.

B\&B Hardware, Inc. v. Hargis Industries, Inc.

This matter is on remand from the United States Supreme Court. We directed the parties to submit supplemental briefing. Having reviewed the briefing, we now determine that the ordinary elements of issue preclusion have been met and the usages of the marks adjudicated before the TTAB were materially the same as the usages before the district court. As noted in our prior opinions, the TTAB compared the marks in question in the marketplace context when it determined the likelihood of confusion issue for purposes of trademark registration.

\section{Maintenance}

\section{Lanham Act}

(a) Time periods for required affidavits. - Each registration shall remain in force for 10 years, except that the registration of any mark shall be canceled by the Director unless the owner of the registration files in the United States Patent and Trademark Office affidavits that meet the requirements of subsection (b), within the following time periods:

(1) Within the 1-year period immediately preceding the expiration of 6 years following the date of registration under this chapter or the date of the publication under section 1062(c) of this title.

(2) Within the 1-year period immediately preceding the expiration of 10 years following the date of registration, and each successive 10-year period following the date of registration.

(b) Requirements for affidavit. - The affidavit referred to in subsection (a) shall-

(1) (A) state that the mark is in use in commerce; 
(B) set forth the goods and services recited in the registration on or in connection with which the mark is in use in commerce;

(C) be accompanied by such number of specimens or facsimiles showing current use of the mark in commerce as may be required by the Director; and

(D) be accompanied by the fee prescribed by the Director;

(a) Period of renewal; time for renewal. - Subject to the provisions of section 1058 of this title, each registration may be renewed for periods of 10 years at the end of each successive 10-year period following the date of registration upon payment of the prescribed fee and the filing of a written application, in such form as may be prescribed by the Director.

\section{Cancellation and Incontestability}

\section{Lanham Act}

A petition to cancel a registration of a mark, stating the grounds relied upon, may, upon payment of the prescribed fee, be filed as follows by any person who believes that he is or will be damaged by the registration of a mark on the principal register established by this chapter

Within five years from the date of the registration of the mark under this chapter.

(3) At any time if the registered mark becomes the generic name for the goods or services, or a portion thereof, for which it is registered, or is functional, or has been abandoned, or its registration was obtained fraudulently or contrary to the provisions of section 1054 of this title or of subsection (a), (b), or (c) of section 1052 of this title for a registration under this chapter ... or with the permission of, the registrant so as to misrepresent the source of the goods or services on or in connection with which the mark is used. ... A registered mark shall not be deemed to be the generic name of goods or services solely because such mark is also used as a name of or to identify a unique product or service. The primary significance of the registered mark to the relevant public rather than purchaser motivation shall be the test for determining whether the registered mark has become the generic name of goods or services on or in connection with which it has been used.

15 U.SC. § 1065

Lanham Act § 15

Incontestability of right to use mark under certain conditions
15 U.S.C. § 1059

Lanham Act § 9

Renewal of registration

Trick question: what is the maximum possible term a trademark could be in effect?

15 U.S. Code $\S 1064$

Lanham Act § 14

Cancellation of registration 
$\S 1064(5)$ pertains to certification marks. See the False Advertising chapter.

469 U.S. 189 (1985)

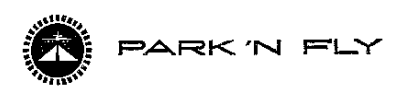

Park 'N Fly service mark
Except on a ground for which application to cancel may be filed at any time under paragraphs (3) and (5) of section 1064 of this title ... the right of the owner to use such registered mark in commerce for the goods or services on or in connection with which such registered mark has been in continuous use for five consecutive years subsequent to the date of such registration and is still in use in commerce, shall be incontestable: ...

Park ‘N Fly, Inc. v. Dollar Park \& Fly, Inc.

Petitioner operates long-term parking lots near airports. After starting business in St. Louis in 1967, petitioner subsequently opened facilities in Cleveland, Houston, Boston, Memphis, and San Francisco. Petitioner applied in 1969 to the United States Patent and Trademark Office (Patent Office) to register a service mark consisting of the logo of an airplane and the words "Park'N Fly." The registration issued in August 1971. Nearly six years later, petitioner filed an affidavit with the Patent Office to establish the incontestable status of the mark. As required by $\S 15$ of the Trademark Act of 1946 (Lanham Act), the affidavit stated that the mark had been registered and in continuous use for five consecutive years, that there had been no final adverse decision to petitioner's claim of ownership or right to registration, and that no proceedings involving such rights were pending.

Respondent also provides long-term airport parking services, but only has operations in Portland, Oregon. Respondent calls its business "Dollar Park and Fly." Petitioner filed this infringement action in 1978 in the United States District Court for the District of Oregon and requested the court permanently to enjoin respondent from using the words "Park and Fly" in connection with its business.

After a bench trial, the District Court found that petitioner's mark is not generic and observed that an incontestable mark cannot be challenged on the grounds that it is merely descriptive.

An incontestable mark that becomes generic may be canceled at any time pursuant to $\S 14$ (c). That section also allows cancellation of an incontestable mark at any time if it has been abandoned, if it is being used to misrepresent the source of the goods or services in connection with which it is used, or if it was obtained fraudulently or contrary to the provisions of $\S 4,15$ U.S.C. $\S 1054$, or $\S \S 2$ (a)-(c), 15 U.S.C. $\S \S 1052(a)-(c)$.

The language of the Lanham Act also refutes any conclusion that an incontestable mark may be challenged as merely descriptive. The Lanham Act expressly provides that before a mark becomes incontestable an opposing party may prove any legal or equitable defense which might have been asserted if the mark had not been registered. Thus, § 33(a) would have allowed respondent to challenge petitioner's mark as merely descriptive if the mark had not become 
incontestable. With respect to incontestable marks, however, § 33(b) provides that registration is conclusive evidence of the registrant's exclusive right to use the mark, subject to the conditions of $\S 15$ and the seven defenses enumerated in $\S 33(b)$ itself. Mere descriptiveness is not recognized as a basis for challenging an incontestable mark.

JUSTICE STEVENS, dissenting.

Congress enacted the Lanham Act "to secure trade-mark owners in the goodwill which they have built up." But without a showing of secondary meaning, there is no basis upon which to conclude that petitioner has built up any goodwill that is secured by the mark "Park' $\mathrm{N}$ Fly." In fact, without a showing of secondary meaning, we should presume that petitioner's business appears to the consuming public to be just another anonymous, indistinguishable parking lot.

It is perfectly clear that the failure to include mere descriptiveness among the grounds for challenging incontestability was based on the understanding that such a mark would not be registered without a showing of secondary meaning.

Because it would be demonstrably at odds with the intent of Congress to grant incontestable status to a mark that was not eligible for registration in the first place, the Court is surely authorized to require compliance with $\S 2(\mathrm{f})$ before granting relief on the basis of $\S$ 33(b).

\section{Abandonment}

\section{Lanham Act}

A mark shall be deemed to be "abandoned" if either of the following occurs:

(1) When its use has been discontinued with intent not to resume such use. Intent not to resume may be inferred from circumstances. Nonuse for 3 consecutive years shall be prima facie evidence of abandonment. "Use" of a mark means the bona fide use of such mark made in the ordinary course of trade, and not made merely to reserve a right in a mark.

Procter \& Gamble Co. v. Johnson \& Johnson Inc.

This is an action for trademark infringement, false designation of origin, unfair competition and trademark dilution. The plaintiff, Procter \& Gamble Co. ("P\&G"), an Ohio corporation, is one of the country's largest manufacturers of household and personal use products. The defendants are Johnson \& Johnson Incorporated ("J\&J") and its wholly-owned subsidiary Personal Products Company ("PPC"). PPC
15 U.S.C. § 1127

Lanham Act § 45

Construction and definitions ...

485 F.Supp. 1185 (S.D.N.Y. 1979)

(Leval, J.) 
is the leading manufacturer of women's external menstrual protection products.

The defendants' trademarks which are alleged to infringe rights of the plaintiff are "Assure!" as used on a woman's menstrual tampon, and "Sure \& Natural", as used on an external menstrual protection shield. The plaintiff's marks alleged to be infringed are SURE for an underarm anti-perspirant deodorant and for a woman's tampon, and ASSURE for a mouthwash and a shampoo.

SURE for tampons, since 1964, and ASSURE for mouthwash and shampoo, since 1970, have been carried by P\&G in its "minor brands program". The minor brands program is designed by P\&G to establish and maintain ownership rights over trademarks which have not been assigned by P\&G to any commercially marketed product.

In 1974 P\&G's office of legal counsel circulated a memorandum institutionalizing the procedures to be followed for this brand maintenance program. The memorandum was revised in 1976 and was received in evidence at the trial. The memorandum begins by stating that the failure to use a trademark for two consecutive years may result in its loss. "The Minor Brands Sales Program is intended", it states, "to rebut any such inference of abandonment and thus maintain the company's ability to subsequently use the marks on goods in question as major brands." The memorandum directs that the trademark section of the legal division will annually prepare a list of every mark owned by the company. The list will be divided into three categories, to be designated as Major Brand, Minor Brand and No Value. A major brand is one which is currently marketed on a day to day basis. "A 'No Value' mark is one in which there is no current commercial interest . . . All others automatically fall into the Minor Brand category." The memorandum goes on to state that each year the list will be reviewed with each division. "A diligent assessment will be made each year to place any marks which are in the Minor Brand category but which are unlikely to be selected for Major Brand usage within a reasonable period of time into the No Value category so as to keep Minor Brands to a minimum." The memorandum further instructs that when the list of minor brands has been reviewed each year, the trademark coordinator will pack 50 units of each product in the Minor Brand category and ship the 50 units to at least 10 states with a recommendation of alternation of states in succeeding years so as to achieve wide distribution. The shipments are made to normal customers for each type of product.

The evidence showed that the system functioned as follows. The distribution of goods in the Minor Brands Program is not handled by persons normally involved in $P \& G^{\prime}$ s merchandising operation. Indeed few employees at any level of P\&G are even aware of the minor brands' existence. In each division of the company, one employee is 
charged with the distribution of minor brands. This "Minor Brands Coordinator" causes labels to be made and simple packages to be prepared for each minor brand. He then ships in accordance with the standing written instructions from trademark counsel. For all items in the Minor Brands Program regardless of size, cost or any other feature, the price billed is $\$ 2$ per case.

As there are no products of $P \& G$ covered by these minor brands, the coordinator takes some other $P \& G$ product in the brand category to be shipped under the minor brand's label. P\&G's Prell Shampoo is bottled under 13 different minor brand labels for annual shipment at $\$ 2$ a case. $P \& G^{\prime}$ s Scope Mouthwash is bottled under 7 different minor brand labels for annual shipment. The situation as to tampons is particularly curious. Prior to 1974 when Rely was introduced, P\&G had no such product. Accordingly, it was the practice to buy the tampons of other manufacturers and to repackage them under $P \& G^{\prime}$ s various minor brand tampon labels. PPC learned through documents produced at the trial that in the 1960's, its own Modess tampons had been purchased by P\&G and repackaged and shipped under a "Sure" Tampon label. In recent years for its minor brand tampons, P\&G has been purchasing and shipping Tampax. Although since 1974 P\&G has had a tampon product of its own, the Minor Brands Coordinator for the paper goods division has continued to ship Tampax rather than $P \& G^{\prime}$ s own product, apparently through oversight.

None of $P \& G^{\prime}$ 's catalogues, price lists or other published materials make any reference to the minor brands. Indeed it appears that virtually none of P\& G's personnel is aware of their existence. No steps are taken to see whether these goods are actually sold by the recipients of the shipments. The only evidence received in the trial concerning any such resale was to the effect that once in 1977 the president of PPC had seen some P\&G minor brands including Sure Tampons on the shelves of a store in Milwaukee and had bought a box.

P\&G defends the validity of the Minor Brands Program on the grounds that it is commercially necessary. It argues that the development of new brands is an enormously lengthy process; numerous products are under development at any one time; and it is very hard to tell how soon a product under development will be ready for market. The process of name selection and registration is also timeconsuming. If a product should become ready for market without prior provision having been made for a name, the product could be held up for quite some time while the name was being secured.

P\&G has claimed rights to the Sure Tampon brand since 1964. Taking the facts in the light most favorable to $P \& G$, the Sure Tampon brand has resided in the Minor Brands Program for nearly 12 years, with approximately 50 cases being shipped once a year. While there may well be persons at $P \& G$ who would like to use the Sure name on 
a tampon to be marketed in the future, I find it most unlikely that the Sure name will be assigned to a tampon while P\&G's uses that name on an anti-perspirant.

P\&G has owned the ASSURE mark for shampoo and mouthwash since 1970. The shampoo mark has been maintained as a minor brand since 1970 bringing in total revenues of $\$ 491.30$. The mouthwash brand has been in the program for only three years bringing in total revenues of \$161.50; apparently for the first six years the ASSURE mouth wash brand was not utilized at all. P\&G has introduced a new mouthwash and a shampoo into test markets without selecting the name ASSURE.

Usage which is sporadic, nominal and intended solely for trademark maintenance is insufficient to establish and maintain trademark rights. Upon detailed review of all the pertinent facts, I have concluded that P\&G does not own a protectable interest in the marks in question. I find that $P \& G$ has never put (these brands) on the market in any meaningful way; indeed, it has given no indication (which I would regard as convincing) that it has any current plans to do so. Trademark rights are not created by sporadic, casual, and nominal shipments of goods bearing a mark. There must a trade in the goods sold under the mark or at least an active and public attempt to establish such a trade.

While P\&G's annual shipment of 50 cases for periods of nine to twelve years may not be sporadic or casual, it is certainly nominal and does not represent a bona fide attempt to establish a trade in any meaningful way. A trademark maintenance program obviously cannot in itself justify a minimal sales effort, or the requirement of good faith commercial use would be read out of trademark law altogether.

I recognize that $P \& G^{\prime}$ s minor brands program might well be legally effective in other circumstances, as where a brand is reserved in connection with reasonably well-formulated plans to use it on a particular product under development, especially if the artificial maintenance does not continue for an unreasonably long time. But there must be a present intent to market the trademarked product. P\&G's vague, remote and almost abstract intentions for the SURE and ASSURE marks are not satisfactory. P\&G's personnel testified, for example, as to each of its 13 minor shampoo brands (including ASSURE), that it held a present intention to utilize them on a commercially marketed product. At present, P\&G offers only 3 shampoos on the commercial market. While there are several shampoos under development, I find no firm intention to use ASSURE on any of these. Intentions which are so vague and remote and so unlikely to come to fruition within a reasonable near future are not sufficient to meet the test.

I conclude that P\&G owns no enforceable rights in SURE tampon 
brand or in the ASSURE mark and that its action on behalf of those interests must fail. P\&G has failed to show that it established trademark rights through bona fide commercial use.

\section{Trademark Throwback Problem}

In 1984, to great local anger, the Baltimore Colts of the National Football League moved to Indianapolis. In 1993, a team in the Canadian Football League proposed to play in Baltimore and to call itself the "Baltimore CFL Colts." The NFL Colts sued, and won an injunction against the CFL Colts' use of the name. Properly decided? Does it matter whether the NFL Colts were selling merchandise with the old team name and insignia? If the defendants proposed instead to open up a bar in Baltimore under the name The Baltimore Colt?

\section{Infringement: Confusion}

Unlike in other areas of IP, it is not so easy to divide trademark infringement into "similarity" and "prohibited conduct." The reason is that trademark liability turns on consumer perceptions, and similarity of marks is only one factor going into what consumers believe. Their familiarity with the plaintiff and its trademark, the care they take when shopping, and the similarity or difference between plaintiff's and defendant's goods, are all among the factors that can determine whether consumers are confused when confronted with the defendant's trademark in an actual marketplace context.

Instead, it is more helpful to divide (direct) trademark infringement into the factual question of whether the defendant's activities create a likelihood of confusion among consumers, and the legal question of what kinds of confusion are legally actionable. The former typically turns on multifactor balancing tests and empirical questions about consumer perception. The later typically are stated as categorial rules that certain kinds of conduct can and cannot give rise to liability. This approach preserves the standards-vs.-rules distinction in breaking down infringement in other areas.

The paradigm theory of trademark confusion is point-of-sale confusion about the source of goods: at the moment the consumer hands over her money, she thinks she's getting the plaintiff's goods or services, but is actually receiving the defendant's. So we begin by studying the standard multi-factor test for point-of-sale confusion about source. Every circuit has its own list of factors; they differ in the details but mostly ask the same questions.

The next section will take up other theories of confusion. For the most part, we will not separately consider the multi-factor balancing tests they employ. First, the tests are generally variations on the basic test described in this section; getting into the details of the differences
Based on Major League Baseball v. Sed Non Olet Denarius, 817 F. Supp. 1103 (S.D.N.Y. 1993) (finding abandonment) and Indianapolis Colts, Inc. v. Metro. Baltimore Football, 34 F.3d 410 (7th Cir. 1994) (finding no abandonment).

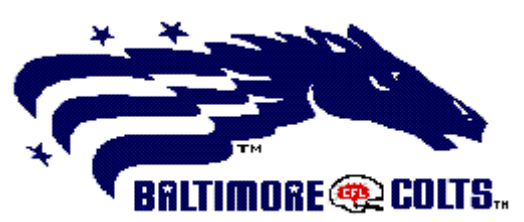

Baltimore CFL Colts logo

It is commonly said that dilution is not a confusion-based theory of liability, since the gravamen is the harm is harm to the mark itself. I have never understood this claim. Consumers are still confused, they're just confused about something else: the mark itself. The same goes for other supposedly "nonconfusion based" theories of liability. 
15 U.S.C. § 1114 [Lanham Act § 32] Remedies; infringement ... adds little insight. Second, once one leaves the calm waters of pointof-sale confusion about source for the choppy seas of other theories of liability, the multi-factor tests are mostly bullshit.

\section{Lanham Act}

(1) Any person who shall, without the consent of the registrant-

(a) use in commerce any reproduction, counterfeit, copy, or colorable imitation of a registered mark in connection with the sale, offering for sale, distribution, or advertising of any goods or services on or in connection with which such use is likely to cause confusion, or to cause mistake, or to deceive; or

(b) reproduce, counterfeit, copy, or colorably imitate a registered mark and apply such reproduction, counterfeit, copy, or colorable imitation to labels, signs, prints, packages, wrappers, receptacles or advertisements intended to be used in commerce upon or in connection with the sale, offering for sale, distribution, or advertising of goods or services on or in connection with which such use is likely to cause confusion, or to cause mistake, or to deceive,

shall be liable in a civil action by the registrant for the remedies hereinafter provided.

Note that while $\S 32$ of the Lanham Act speaks of infringement of registered marks, $\S 43$ (discussed in more detail below) also gives a federal cause of action for infringement of unregistered marks - and both of them coexist with state-law causes of action for trademark infringement. In practice, the tests for consumer confusion about source based on the defendant's use of a mark under all of these causes of action are effectively identical. The substantive and jurisdictional distinctions between state and federal causes of action are discussed in the Preemption and Litigation chapters, respectively.

\section{Virgin Enterprises Ltd. v. Nawab}

\section{Leval, Circuit Judge:}

Plaintiff Virgin Enterprises Limited ("VEL" or "plaintiff") appeals from the denial of its motion for a preliminary injunction. This suit, brought under $\S 32$ of the Lanham Act, alleges that defendants infringed plaintiff's rights in the registered mark VIRGIN by operating retail stores selling wireless telephones and related accessories and 
services under the trade name VIRGIN WIRELESS. We find that the plaintiff is likely to succeed on the merits and was entitled to a preliminary injunction.

\section{BACKGROUND}

Plaintiff VEL, a corporation with its principal place of business in London, owns U.S. Registration No. 1,851,817 (“the 817 Registration"), filed on May 5, 1991, and registered on August 30, 1994, for the VIRGIN mark as applied to "retail store services in the fields of ... computers and electronic apparatus" (emphasis added). Plaintiff filed an affidavit of continuing use, pursuant to 15 U.S.C. $\S 1058(a)$, on April 27,2000 , which averred that plaintiff had used the mark in connection with retail store services selling computers and electronic apparatus. Plaintiff also owns U.S. Registration No. 1,852,776 ("the 776 Registration"), filed on May 9, 1991, and registered on September 6, 1994, for a stylized version of the VIRGIN mark for use in connection with "retail store services in the fields of ... computers and electronic apparatus," and U.S. Registration No. 1,863,353 ("the 353 Registration"), filed on May 19, 1992, and registered on November 15, 1994, for the VIRGIN MEGASTORE mark. It is undisputed that these three registrations have become incontestable pursuant to 15 U.S.C. § 1065.

VEL, either directly or through corporate affiliates, operates various businesses worldwide under the trade name VIRGIN, including an airline, large-scale record stores called Virgin Megastores, and an internet information service. Plaintiff or its affiliates also market a variety of goods branded with the VIRGIN name, including music recordings, computer games, books, and luggage. Three of plaintiff's megastores are located in the New York area. According to an affidavit submitted to the district court in support of plaintiff's application for preliminary injunction, Virgin Megastores sell a variety of electronic apparatus, including video game systems, portable CD players, disposable cameras, and DVD players. These stores advertise in a variety of media, including radio.

Defendants Simon Blitz and Daniel Gazal are the sole shareholders of defendants Cel-Net Communications, Inc. ("Cel-Net"); The Cellular Network Communications, Inc., doing business as CNCG ("CNCG"); and SD Telecommunications, Inc. ("SD Telecom”). Blitz and Gazal formed Cel-Net in 1993 to sell retail wireless telephones and services in the New York area. Later, they formed CNCG to sell wireless phones and services on the wholesale level. CNCG now sells wireless phones and services to more than 400 independent wireless retailers. In 1998, Cel-Net received permission from New York State regulators to resell telephone services within the state.

Around 1999, Andrew Kastein, a vice-president of CNCG, began to develop a Cel-Net brand of wireless telecommunications products. 
In early 1999, Cel-Net entered into negotiations with the Sprint PCS network to provide telecommunications services for resale by CelNet. In August 1999, Cel-Net retained the law firm Pennie \& Edmonds to determine the availability of possible service marks for CelNet. Pennie \& Edmonds associate Elizabeth Langston researched for Kastein a list of possible service marks; among the marks CelNet asked to have researched was VIRGIN. Defendants claim that Langston told Cel-Net officer Simon Corney that VIRGIN was available for use in the telecommunications field. Plaintiff disputed this, offering an affidavit from Langston that she informed defendants that she would not search the VIRGIN mark because her firm represented plaintiff.

According to defendants, in December 1999, Cel-Net retained Corporate Solutions, LLC and its principals Nathan Erlich and Tahir Nawab as joint venture partners to help raise capital to launch CelNet's wireless telephone service. On December 2, 1999, Erlich and Nawab filed four intent-to-use applications with the U.S. Patent and Trademark Office ("PTO") to register the marks VIRGIN WIRELESS, VIRGIN MOBILE, VIRGIN COMMUNICATIONS, and VIRGIN NET in the field of telecommunications services, class 38. On December 24, 1999, Corporate Solutions incorporated defendant Virgin Wireless, Inc. ("VWI") and licensed to VWI the right to use the marks VIRGIN WIRELESS and VIRGIN MOBILE. Meanwhile, one of plaintiff's affiliates had begun to offer wireless telecommunication services bearing the VIRGIN mark in the United Kingdom. A press release dated November 19, 1999, found on plaintiff's website, stated that its Virgin Mobile wireless services were operable in the United States.

On June 23, 2000, defendant Blitz signed a lease under the name Virgin Wireless for a kiosk location in South Shore Mall in Long Island from which to re-sell AT\&T wireless services, telephones, and accessories under the retail name Virgin Wireless. Defendants CelNet and VWI later expanded their telecommunications re-sale operations to include two retail stores and four additional retail kiosks in malls in the New York area and in Pennsylvania. All of these stores have been run by VWI under the trade name VIRGIN WIRELESS. VWI also has leases and bank accounts in its name, and has shown evidence of actual retail transactions and newspaper advertisements.

In August 2000, plaintiff licensed Virgin Mobile USA, LLC, to use the VIRGIN mark for wireless telecommunications services in the United States. On August 10, 2000, plaintiff filed an intent-touse application with the PTO for use of the VIRGIN mark in the United States on telecommunications services and mobile telephones. On October 11, 2001, the PTO suspended this mark's registration in international class 9, which covers wireless telephones, and class 38 , which covers telecommunications services, because the VIRGIN 
mark was already reserved by a prior filing, presumably defendants'. On August 16, 2001, plaintiff filed another intent-to-use application for the mark VIRGIN MOBILE to brand telecommunications services. The PTO issued a non-final action letter for both of plaintiff's pending new registrations on October 31, 2001, which stated that defendant Corporation Solutions' pending applications for similar marks in the same class could give rise to "a likelihood of confusion." The PTO suspended action on plaintiff's application pending the processing of Corporation Solutions' applications.

In October 2001, plaintiff issued a press release announcing that it was offering wireless telecommunications services and mobile telephones in the United States.

Plaintiff became aware of Corporation Solutions' application for registration of the VIRGIN WIRELESS and VIRGIN MOBILE marks by May 2000. In October 2001 and December 2001, defendant VWI filed suits against plaintiff in the federal district courts in Arizona and Delaware, alleging that plaintiff was using VWI's mark. Plaintiff maintains (and the district court found) that it learned in January 2002 that VWI and Cel-Net were operating kiosks under the VIRGIN WIRELESS name and two days later filed the present suit seeking to enjoin defendants from selling mobile phones in VIRGIN-branded retail stores.

\section{Discussion}

We believe the district court accorded plaintiff too narrow a scope of protection for its famous, arbitrary, and distinctive mark. There could be no dispute that plaintiff prevailed as to the first prong of the test - prior use and ownership. For years, plaintiff had used the VIRGIN mark on huge, famous stores selling, in addition to music recordings, a variety of consumer electronic equipment. At the time the defendants began using VIRGIN, plaintiff owned rights in the mark. The focus of inquiry thus turns to the second prong of the test - whether defendants' use of VIRGIN as a mark for stores selling wireless telephone services and phones was likely to cause confusion. There can be little doubt that such confusion was likely.

The landmark case of Polaroid Corp. v. Polarad Electronics Corp., outlined a series of nonexclusive factors likely to be pertinent in addressing the issue of likelihood of confusion, which are routinely followed in such cases.

Six of the Polaroid factors relate directly to the likelihood of consumer confusion. These are the strength of the plaintiff's mark; the similarity of defendants' mark to plaintiff's; the proximity of the products sold under defendants' mark to those sold under plaintiff's; where the products are different, the likelihood that plaintiff will bridge the gap by selling the products being sold by defendants; the
Polaroid: 287 F.2d 492 (2d Cir.1961) (Friendly, J.) 
existence of actual confusion among consumers; and the sophistication of consumers. Of these six, all but the last (which was found by the district court to be neutral) strongly favor the plaintiff. The remaining two Polaroid factors, defendants' good or bad faith and the quality of defendants' products, are more pertinent to issues other than likelihood of confusion, such as harm to plaintiff's reputation and choice of remedy. We conclude that the Polaroid factors powerfully support plaintiff's position.

Strength of the mark. The strength of a trademark encompasses two different concepts, both of which relate significantly to likelihood of consumer confusion. The first and most important is inherent strength, also called "inherent distinctiveness." This inquiry distinguishes between, on the one hand, inherently distinctive marks marks that are arbitrary or fanciful in relation to the products (or services) on which they are used - and, on the other hand, marks that are generic, descriptive or suggestive as to those goods. The former are the strong marks. The second sense of the concept of strength of a mark is "acquired distinctiveness," i.e., fame, or the extent to which prominent use of the mark in commerce has resulted in a high degree of consumer recognition.

Considering first inherent distinctiveness, the law accords broad, muscular protection to marks that are arbitrary or fanciful in relation to the products on which they are used, and lesser protection, or no protection at all, to marks consisting of words that identify or describe the goods or their attributes. The reasons for the distinction arise from two aspects of market efficiency. The paramount objective of the trademark law is to avoid confusion in the marketplace. The purpose for which the trademark law accords merchants the exclusive right to the use of a name or symbol in their area or commerce is identification, so that the merchants can establish goodwill for their goods based on past satisfactory performance, and the consuming public can rely on a mark as a guarantee that the goods or services so marked come from the merchant who has been found to be satisfactory in the past. At the same time, efficiency and the public interest require that every merchant trading in a class of goods be permitted to refer to the goods by their name, and to make claims about their quality. Thus, a merchant who sells pencils under the trademark Pencil or Clear Mark, for example, and seeks to exclude other sellers of pencils from using those words in their trade, is seeking an advantage the trademark law does not intend to offer. To grant such exclusivity would deprive the consuming public of the useful market information it receives where every seller of pencils is free to call them pencils. The trademark right does not protect the exclusive right to an advertising message - only the exclusive right to an identifier, to protect against confusion in the marketplace. Thus, as a matter of 
policy, the trademark law accords broader protection to marks that serve exclusively as identifiers and lesser protection where a grant of exclusiveness would tend to diminish the access of others to the full range of discourse relating to their goods.

The second aspect of efficiency that justifies according broader protection to marks that are inherently distinctive relates directly to the likelihood of confusion. If a mark is arbitrary or fanciful, and makes no reference to the nature of the goods it designates, consumers who see the mark on different objects offered in the marketplace will be likely to assume, because of the arbitrariness of the choice of mark, that they all come from the same source. For example, if consumers become familiar with a toothpaste sold under an unusual, arbitrary brand name, such as ZzaaqQ, and later see that same inherently distinctive brand name appearing on a different product, they are likely to assume, notwithstanding the product difference, that the second product comes from the same producer as the first. The more unusual, arbitrary, and fanciful a trade name, the more unlikely it is that two independent entities would have chosen it. In contrast, every seller of foods has an interest in calling its product "delicious." Consumers who see the word delicious used on two or more different food products are less likely to draw the inference that they must all come from the same producer. In short, the more distinctive the mark, the greater the likelihood that the public, seeing it used a second time, will assume that the second use comes from the same source as the first. The goal of avoiding consumer confusion thus dictates that the inherently distinctive, arbitrary, or fanciful marks, i.e., strong marks, receive broader protection than weak marks, those that are descriptive or suggestive of the products on which they are used.

The second sense of trademark strength, fame, or "acquired distinctiveness," also bears on consumer confusion. If a mark has been long, prominently and notoriously used in commerce, there is a high likelihood that consumers will recognize it from its prior use. Widespread consumer recognition of a mark previously used in commerce increases the likelihood that consumers will assume it identifies the previously familiar user, and therefore increases the likelihood of consumer confusion if the new user is in fact not related to the first. A mark's fame also gives unscrupulous traders an incentive to seek to create consumer confusion by associating themselves in consumers' minds with a famous mark. The added likelihood of consumer confusion resulting from a second user's use of a famous mark gives reason for according such a famous mark a broader scope of protection, at least when it is also inherently distinctive.

Plaintiff's VIRGIN mark undoubtedly scored high on both concepts of strength. In relation to the sale of consumer electronic equip- 
ment, the VIRGIN mark is inherently distinctive, in that it is arbitrary and fanciful; the word "virgin" has no intrinsic relationship whatsoever to selling such equipment. Because there is no intrinsic reason for a merchant to use the word "virgin" in the sale of consumer electronic equipment, a consumer seeing VIRGIN used in two different stores selling such equipment will likely assume that the stores are related.

Plaintiff's VIRGIN mark was also famous. The mark had been employed with world-wide recognition as the mark of an airline and as the mark for megastores selling music recordings and consumer electronic equipment. The fame of the mark increased the likelihood that consumers seeing defendants' shops selling telephones under the mark VIRGIN would assume incorrectly that defendants' shops were a part of plaintiff's organization.

There can be no doubt that plaintiff's VIRGIN mark, as used on consumer electronic equipment, is a strong mark, as the district court found. It is entitled as such to a broad scope of protection, precisely because the use of the mark by others in connection with stores selling reasonably closely related merchandise would inevitably have a high likelihood of causing consumer confusion.

Similarity of marks. When the secondary user's mark is not identical but merely similar to the plaintiff's mark, it is important to assess the degree of similarity between them in assessing the likelihood that consumers will be confused. Plaintiff's and defendants' marks were not merely similar; they were identical to the extent that both consisted of the same word, "virgin."

The district court believed this factor did not favor plaintiff because it found some differences in appearance. Defendants' logo used a difference typeface and different colors from plaintiff's. While those are indeed differences, they are quite minor in relation to the fact that the name being used as a trademark was the same in each case.

Advertisement and consumer experience of a mark do not necessarily transmit all of the mark's features. Plaintiff, for example, advertised its Virgin Megastores on the radio. A consumer who heard those advertisements and then saw the defendants' installation using the name VIRGIN would have no way of knowing that the two trademarks looked different. A consumer who had visited one of plaintiff's Virgin Megastores and remembered the name would not necessarily remember the typeface and color of plaintiff's mark. The reputation of a mark also spreads by word of mouth among consumers. One consumer who hears from others about their experience with Virgin stores and then encounters defendants' Virgin store will have no way knowing of the differences in typeface.

In view of the fact that defendants used the same name as plaintiff, 
we conclude the defendants' mark was sufficiently similar to plaintiff's to increase the likelihood of confusion. This factor favored the plaintiff as a matter of law. We conclude that the district court erred in concluding otherwise on the basis of comparatively trivial and often irrelevant differences.

Proximity of the products and likelihood of bridging the gap. The next factor is the proximity of the products being sold by plaintiff and defendant under identical (or similar) marks. This factor has an obvious bearing on the likelihood of confusion. When the two users of a mark are operating in completely different areas of commerce, consumers are less likely to assume that their similarly branded products come from the same source. In contrast, the closer the secondary user's goods are to those the consumer has seen marketed under the prior user's brand, the more likely that the consumer will mistakenly assume a common source.

While plaintiff had not sold telephones or telephone service prior to defendant's registration evincing intent to sell those items, plaintiff had sold quite similar items of consumer electronic equipment. These included computer video game systems, portable cassette-tape players, compact disc players, MP3 players, mini-disc players, and disposable cameras. Like telephones, many of these are small consumer electronic gadgets making use of computerized audio communication. They are sold in the same channels of commerce. Consumers would have a high expectation of finding telephones, portable CD players, and computerized video game systems in the same stores. We think the proximity in commerce of telephones to CD players substantially advanced the risk that consumer confusion would occur when both were sold by different merchants under the same trade name, VIRGIN.

Our classic Polaroid test further protects a trademark owner by examining the likelihood that, even if the plaintiff's products were not so close to the defendants' when the defendant began to market them, there was already a likelihood that plaintiff would in the reasonably near future begin selling those products. VEL's claim of proximity was further strengthened in this regard because, as the district court expressly found, "plans had been formulated [for VEL] to enter [the market for telecommunications products and services] shortly in the future." VEL had already begun marketing telephone service in England which would operate in the United States, and, as the district court found, had made plans to sell telephones and wireless telephone service under the VIRGIN name from its retail stores.

The district court, nonetheless, found in favor of the defendants with respect to the proximity of products and services. We would ordinarily give considerable deference to a factual finding on this issue. Here, however, we cannot do so because it appears the district court 
applied the wrong test. The court did not assess the proximity of defendants' VIRGIN-branded retail stores selling telephone products to plaintiff's VIRGIN-branded retail stores selling other consumer electronic products. It simply concluded that, because defendants were selling exclusively telephone products and services, and plaintiff's electronic products did not include telephones or related services, the defendants must prevail as to the proximity factor.

This represents a considerable misunderstanding of the Polaroid test. The famous list of factors of likely pertinence in assessing likelihood of confusion in Polaroid was specially designed for a case like this one, in which the secondary user is not in direct competition with the prior user, but is selling a somewhat different product or service. In Polaroid, the plaintiff sold optical and camera equipment, while the defendant sold electronic apparatus. The test the court discussed was expressly addressed to the problem "how far a valid trademark shall be protected with respect to goods other than those to which its owner has applied it." 287 F.2d at 495 (emphasis added). The very fact that the test includes the "proximity" between the defendant's products and the plaintiff's and the likelihood that the plaintiff will "bridge the gap" makes clear that the trademark owner does not lose, as the district court concluded, merely because it has not previously sold the precise good or service sold by the secondary user.

In our view, had the district court employed the proper test of proximity, it could not have failed to find a high degree of proximity as between plaintiff VEL's prior sales of consumer electronic audio equipment and defendants' subsequent sales of telephones and telephone services, which proximity would certainly contribute to likelihood of consumer confusion. And plaintiff was all the more entitled to a finding in its favor in respect of these matters by virtue of the fact, which the district court did find, that at the time defendants began using the VIRGIN mark in the retail sale of telephones and telephone services, plaintiff already had plans to bridge the gap by expanding its sales of consumer electronic equipment to include sales of those very goods and services in the near future. Consumer confusion was more than likely; it was virtually inevitable.

Actual confusion. It is self-evident that the existence of actual consumer confusion indicates a likelihood of consumer confusion. We have therefore deemed evidence of actual confusion "particularly relevant" to the inquiry.

Plaintiff submitted to the district court an affidavit of a former employee of defendant Cel-Net, who worked at a mall kiosk branded as Virgin Wireless, which stated that individuals used to ask him if the kiosk was affiliated with plaintiff's VIRGIN stores. The district court correctly concluded that this evidence weighed in plaintiff's favor.

Sophistication of consumers. The degree of sophistication of con- 
sumers can have an important bearing on likelihood of confusion. Where the purchasers of a products are highly trained professionals, they know the market and are less likely than untrained consumers to be misled or confused by the similarity of different marks. The district court recognized that "[r]etail customers, such as the ones catered to by both the defendants and [plaintiff], are not expected to exercise the same degree of care as professional buyers, who are expected to have greater powers of discrimination." On the other hand, it observed that purchasers of cellular telephones and the service plans were likely to give greater care than self-service customers in a supermarket. Noting that neither side had submitted evidence on the sophistication of consumers, the court made no finding favoring either side. We agree that the sophistication factor is neutral in this case.

Bad faith and the quality of the defendants' services or products. Two factors remain of the conventional Polaroid test: the existence of bad faith on the part of the secondary user and the quality of the secondary user's products or services. Neither factor is of high relevance to the issue of likelihood of confusion. A finding that a party acted in bad faith can affect the court's choice of remedy or can tip the balance where questions are close. It does not bear directly on whether consumers are likely to be confused. The district court noted some evidence of bad faith on the defendants' part, but because the evidence on the issue was scant and equivocal, the court concluded that such a finding "at this stage [would be] speculative." The court therefore found that this factor favored neither party.

The issue of the quality of the secondary user's product goes more to the harm that confusion can cause the plaintiff's mark and reputation than to the likelihood of confusion. In any event, the district court found this factor to be "neutral" with respect to likelihood of confusion.

$* * * * * *$

In summary we conclude that of the six Polaroid factors that pertain directly to the likelihood of consumer confusion, all but one favor the plaintiff, and that one - sophistication of consumers - is neutral. The plaintiff is strongly favored by the strength of its mark, both inherent and acquired; the similarity of the marks; the proximity of the products and services; the likelihood that plaintiff would bridge the gap; and the existence of actual confusion. None of the factors favors the defendant. The remaining factors were found to be neutral. Although we do not suggest that likelihood of confusion may be properly determined simply by the number of factors in one party's favor, the overall assessment in this case in our view admits only of a finding 
Giant Food: 710 F. 2d 1565 (Fed. Cir. 1983) in plaintiff's favor that defendants' sale of telephones and telephonerelated services under the VIRGIN mark was likely to cause substantial consumer confusion.

We conclude that, as a matter of law, plaintiff demonstrated irreparable harm and likelihood of success on the merits and was entitled to a preliminary injunction.

\section{Sally Beauty Co., Inc. v. Beautyco, Inc.}

Sally Beauty Co., Inc. ("Sally Beauty") and Marianna Imports, Inc. ("Marianna"), collectively "Plaintiffs," sued Beautyco, Inc. ("Beautyco") for trademark infringement, trade dress infringement, and false advertising. Beautyco markets a line of hair care products under the trade name GENERIX, which the Plaintiffs claim infringes the trademark and trade dress of their competing line of hair care products called Generic Value Products.

The degree of similarity between marks rests on sight, sound, and meaning. This court must determine whether the allegedly infringing mark will confuse the public when singly presented, rather than when presented side by side with the protected trademark. In so doing, similarities are weighed more heavily than differences, particularly when the competing marks are used in virtually identical products packaged in a similar manner.

The district court concluded that the similarity of marks weighed in favor of Marianna. "Generic Value Products," however, is not visually similar to "GENERIX." Marianna's mark consists of three words, while Beautyco's consists of only one. Although both marks begin with the same six letters, this similarity is not enough to outweigh the visual differences in the marks.

The sound of the marks is also different. "Generic Value Products" does not sound similar to "GENERIX." In considering this subfactor, the district court erred by shortening "Generic Value Products" to simply "Generic" in comparing aural similarities between the marks. The district court cited no authority which would permit the shortening of the trademark for the likelihood of confusion analysis. Marianna relies on Giant Food, Inc. v. Nation's Foodservice, Inc., in support, but that case involved marks consisting of pictorial designs with clearly dominant visual elements. In this case, however, the Generic Value Products mark consists of words alone and no one word takes precedence over the others.

In contrast, the meanings of "Generic Value Products" and "GENERIX" are similar. Although "GENERIX" has no inherent meaning, Beautyco admits in its motion for summary judgment that the use of the word is obviously intended to convey the idea that its product is inexpensive. Beautyco further concedes that Sally Beauty's use of "Generic" conveys the same idea. Taken as a whole, Generic 
Value Products conveys the same meaning as GENERIX.

On balance, the similarity in meaning between the marks favors Marianna, but the differences in both sight and sound favor Beautyco. Although similarities are to be weighed more heavily than differences, the differences in this case are significant enough to lead us to conclude that this factor weighs in favor of Beautyco.

\section{Cheat Sheet Problem}

Barton Beebe, An Empirical Study of the Multifactor Tests for Trademark Infringement, 94 CAL. L. Rev. 1581 (2006) reports on an empirical study of 331 litigated trademark cases and concludes that the factors do not have equal importance. According to Beebe, the following flowchart correctly decides every case in the sample set:

- Are the marks similar? If NO, then the defendant wins.

- Did the defendant act in bad faith? If YES, then the plaintiff wins.

- Was there actual confusion? If YES, then the plaintiff wins.

- Were the goods proximate? If NO, then the defendant wins.

- Is the plaintiff's mark strong? If YES, then the plaintiff wins; if $\mathrm{NO}$, then the defendant wins.

How should Professor Beebe's findings influence our thinking about trademark infringement? Should it change how lawyers argue cases, how judges decide them, or how we study them in class?

\section{Boats Problem}

Following are the facts as stated in AMF Inc. v. Sleekcraft Boats. Assuming a jury verdict in favor of the plaintiff on a claim of trademark infringement at trial, how should the court rule on the defendant's motion for judgment notwithstanding the verdict?

AMF and appellee Nescher both manufacture recreational boats. AMF uses the mark Slickcraft, and Nescher uses Sleekcraft.

AMF's predecessor used the name Slickcraft Boat Company from 1954 to 1969 when it became a division of AMF. The mark SLICKCRAFT was federally registered on April 1,1969 , and has been continuously used since then as a trademark for this line of recreational boats.

Slickcraft boats are distributed and advertised nationally. AMF has authorized over one hundred retail outlets to sell the Slickcraft line. For the years 1966-1974, promotional expenditures for the Slickcraft line averaged approximately $\$ 200,000$ annually. Gross sales for the same period approached $\$ 50,000,000$.
AMF: 599 F.2d 341 (9th Cir. 1979)
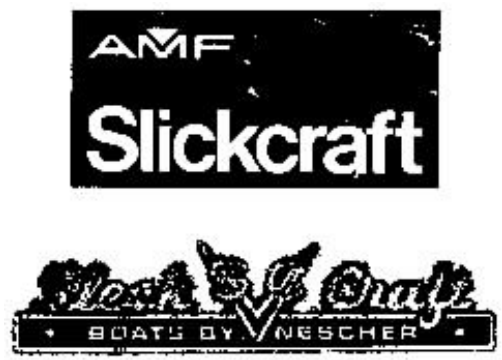

Slickcraft (top) and Sleekcraft (bottom) logos 


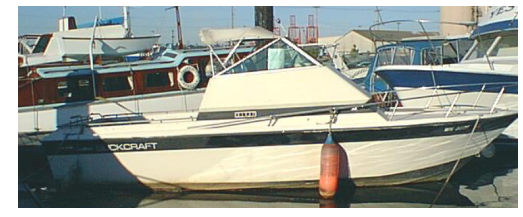

AMF boat

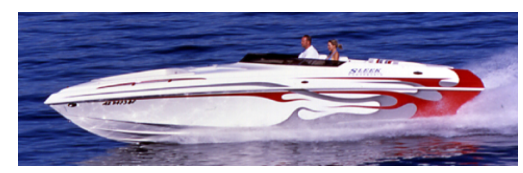

Nescher boat

\section{E Infringement: Prohibited Conduct}

\section{Threshold Conditions}

\section{Rescuecom Corp. v. Google Inc.}

Appeal by Plaintiff Rescuecom Corp. from a judgment of the United States District Court for the Northern District of New York (Mordue, Chief Judge) dismissing its action against Google, Inc., under Rule 12(b)(6) for failure to state a claim upon which relief may be granted. Rescuecom's Complaint alleges that Google is liable under $\$ \S 32$ and 43 of the Lanham Act, 15 U.S.C. \$§ 1114 \& 1125, for infringement, false designation of origin, and dilution of Rescuecom's eponymous trademark. The district court believed the dismissal of the action was compelled by our holding in 1-800 Contacts, Inc. v. WhenU. Com, Inc., because, according to the district court's understanding of that opinion, Rescuecom failed to allege that Google's use of its mark was a "use in commerce" within the meaning of $\S 45$ of the Lanham Act, 15 U.S.C. $\S 1127$. We believe this misunderstood the holding of 1800. While we express no view as to whether Rescuecom can prove a Lanham Act violation, an actionable claim is adequately alleged in 
its pleadings. Accordingly, we vacate the judgment dismissing the action and remand for further proceedings.

\section{BACKGROUND}

Rescuecom is a national computer service franchising company that offers on-site computer services and sales. Rescuecom conducts a substantial amount of business over the Internet and receives between 17,000 to 30,000 visitors to its website each month. It also advertises over the Internet, using many web-based services, including those offered by Google. Since 1998, RESCUECOM has been a registered federal trademark, and there is no dispute as to its validity.

Google's proprietary system responds to such a search request in two ways. First, Google provides a list of links to websites, ordered in what Google deems to be of descending relevance to the user's search terms based on its proprietary algorithms. The second way Google responds to a search request is by showing context-based advertising.

AdWords is Google's program through which advertisers purchase terms (or keywords). When entered as a search term, the keyword triggers the appearance of the advertiser's ad and link. An advertiser's purchase of a particular term causes the advertiser's ad and link to be displayed on the user's screen whenever a searcher launches a Google search based on the purchased search term. Advertisers pay Google based on the number of times Internet users "click" on the advertisement, so as to link to the advertiser's website. For example, using Google's AdWords, Company Y, a company engaged in the business of furnace repair, can cause Google to display its advertisement and link whenever a user of Google launches a search based on the search term, "furnace repair." Company Y can also cause its ad and link to appear whenever a user searches for the term "Company $\mathrm{X}$," a competitor of Company $\mathrm{Y}$ in the furnace repair business. Thus, whenever a searcher interested in purchasing furnace repair services from Company $X$ launches a search of the term X (Company X's trademark), an ad and link would appear on the searcher's screen, inviting the searcher to the furnace repair services of X's competitor, Company Y. And if the searcher clicked on Company Y's link, Company Y's website would open on the searcher's screen, and the searcher might be able to order or purchase Company Y's furnace repair services.

In addition to AdWords, Google also employs Keyword Suggestion Tool, a program that recommends keywords to advertisers to be purchased. The program is designed to improve the effectiveness of advertising by helping advertisers identify keywords related to their area of commerce, resulting in the placement of their ads before users who are likely to be responsive to it. Thus, continuing the example given above, if Company Y employed Google's Keyword Sug- 
gestion Tool, the Tool might suggest to Company $Y$ that it purchase not only the term "furnace repair" but also the term " $X$," its competitor's brand name and trademark, so that Y"s ad would appear on the screen of a searcher who searched Company $X^{\prime}$ 's trademark, seeking Company X's website.

Once an advertiser buys a particular keyword, Google links the keyword to that advertiser's advertisement. The advertisements consist of a combination of content and a link to the advertiser's webpage. Google displays these advertisements on the search result page either in the right margin or in a horizontal band immediately above the column of relevance-based search results. These advertisements are generally associated with a label, which says "sponsored link." Rescuecom alleges, however, that a user might easily be misled to believe that the advertisements which appear on the screen are in fact part of the relevance-based search result and that the appearance of a competitor's ad and link in response to a searcher's search for Rescuecom is likely to cause trademark confusion as to affiliation, origin, sponsorship, or approval of service. This can occur, according to the Complaint, because Google fails to label the ads in a manner which would clearly identify them as purchased ads rather than search results. The Complaint alleges that when the sponsored links appear in a horizontal bar at the top of the search results, they may appear to the searcher to be the first, and therefore the most relevant, entries responding to the search, as opposed to paid advertisements.

Google's objective in its AdWords and Keyword Suggestion Tool programs is to sell keywords to advertisers. Rescuecom alleges that Google makes $97 \%$ of its revenue from selling advertisements through its AdWords program. Google therefore has an economic incentive to increase the number of advertisements and links that appear for every term entered into its search engine.

Many of Rescuecom's competitors advertise on the Internet. Through its Keyword Suggestion Tool, Google has recommended the Rescuecom trademark to Rescuecom's competitors as a search term to be purchased. Rescuecom's competitors, some responding to Google's recommendation, have purchased Rescuecom's trademark as a keyword in Google's AdWords program. This practice allegedly allows Rescuecom's competitors to deceive and divert users searching for Rescuecom's website.

\section{DISCUSSION}

Our court ruled in 1-800 that a complaint fails to state a claim under the Lanham Act unless it alleges that the defendant has made "use in commerce" of the plaintiff's trademark as the term "use in commerce" is defined in 15 U.S.C. $\$ 1127$. The district court believed that this case was on all fours with 1-800, and that its dismissal was re- 
quired for the same reasons as given in 1-800. We believe the cases are materially different. The allegations of Rescuecom's complaint adequately plead a use in commerce.

In 1-800, the plaintiff alleged that the defendant infringed the plaintiff's trademark through its proprietary software, which the defendant freely distributed to computer users who would download and install the program on their computer. The program provided contextually relevant advertising to the user by generating pop-up advertisements to the user depending on the website or search term the user entered in his browser. For example, if a user typed "eye care" into his browser, the defendant's program would randomly display a pop-up advertisement of a company engaged in the field of eye care. Similarly, if the searcher launched a search for a particular company engaged in eye care, the defendant's program would display the pop-up ad of a company associated with eye care. The pop-up ad appeared in a separate browser window from the website the user accessed, and the defendant's brand was displayed in the window frame surrounding the ad, so that there was no confusion as to the nature of the pop-up as an advertisement, nor as to the fact that the defendant, not the trademark owner, was responsible for displaying the ad, in response to the particular term searched.

Sections 32 and 43 of the Act, which we also refer to by their codified designations, 15 U.S.C. $\S \S 1114$ \& 1125, inter alia, impose liability for unpermitted "use in commerce" of another's mark which is "likely to cause confusion, or to cause mistake, or to deceive," $\S 1114$, "as to the affiliation... or as to the origin, sponsorship or approval of his or her goods [or] services... by another person." § 1125(a)(1)(A). The 1-800 opinion looked to the definition of the term "use in commerce" provided in $\S 45$ of the Act, 15 U.S.C. $\S 1127$. That definition provides in part that "a mark shall be deemed to be in use in commerce... (2) on services when it is used or displayed in the sale or advertising of services and the services are rendered in commerce." 15 U.S.C. § 1127. Our court found that the plaintiff failed to show that the defendant made a "use in commerce" of the plaintiff's mark, within that definition.

At the outset, we note two significant aspects of our holding in 1-800, which distinguish it from the present case. A key element of our court's decision in 1-800 was that under the plaintiff's allegations, the defendant did not use, reproduce, or display the plaintiff's mark at all. The search term that was alleged to trigger the pop-up ad was the plaintiff's website address. 1-800 noted, notwithstanding the similarities between the website address and the mark, that the website address was not used or claimed by the plaintiff as a trademark. Thus, the transactions alleged to be infringing were not transactions involving use of the plaintiff's trademark. 1-800 suggested in dictum that is 
S\&L Vitamins: 521 F. Supp. 2d 188 (E.D.N.Y.2007)

Merck: 425 F. Supp. 2d 402 (S.D.N.Y. 2006) highly relevant to our case that had the defendant used the plaintiff's trademark as the trigger to pop-up an advertisement, such conduct might, depending on other elements, have been actionable.

Second, as an alternate basis for its decision, 1-800 explained why the defendant's program, which might randomly trigger pop-up advertisements upon a searcher's input of the plaintiff's website address, did not constitute a "use in commerce," as defined in $\S 1127$. In explaining why the plaintiff's mark was not "used or displayed in the sale or advertising of services," 1-800 pointed out that, under the defendant's program, advertisers could not request or purchase keywords to trigger their ads. Even if an advertiser wanted to display its advertisement to a searcher using the plaintiff's trademark as a search term, the defendant's program did not offer this possibility. The defendant's program relied upon categorical associations such as "eye care" to select a pop-up ad randomly from a predefined list of ads appropriate to that category. To the extent that an advertisement for a competitor of the plaintiff was displayed when a user opened the plaintiff's website, the trigger to display the ad was not based on the defendant's sale or recommendation of a particular trademark.

The present case contrasts starkly with those important aspects of the 1-800 decision. First, in contrast to 1-800, where we emphasized that the defendant made no use whatsoever of the plaintiff's trademark, here what Google is recommending and selling to its advertisers is Rescuecom's trademark. Second, in contrast with the facts of 1-800 where the defendant did not "use or display," much less sell, trademarks as search terms to its advertisers, here Google displays, offers, and sells Rescuecom's mark to Google's advertising customers when selling its advertising services. In addition, Google encourages the purchase of Rescuecom's mark through its Keyword Suggestion Tool.

Google, supported by amici, argues that 1-800 suggests that the inclusion of a trademark in an internal computer directory cannot constitute trademark use. Several district court decisions in this Circuit appear to have reached this conclusion. See, e.g., SEL Vitamins, Inc. v. Australian Gold, Inc. (holding that use of a trademark in metadata did not constitute trademark use within the meaning of the Lanham Act because the use "is strictly internal and not communicated to the public"); Merck E Co., Inc. v. Mediplan Health Consulting, Inc. (holding that the internal use of a keyword to trigger advertisements did not qualify as trademark use). This over-reads the 1-800 decision. First, regardless of whether Google's use of Rescuecom's mark in its internal search algorithm could constitute an actionable trademark use, Google's recommendation and sale of Rescuecom's mark to its advertising customers are not internal uses. We did not imply in 1-800 that an alleged infringer's use of a trademark in an internal software pro- 
gram insulates the alleged infringer from a charge of infringement, no matter how likely the use is to cause confusion in the marketplace. If we were to adopt Google and its amici's argument, the operators of search engines would be free to use trademarks in ways designed to deceive and cause consumer confusion. 1 This is surely neither within the intention nor the letter of the Lanham Act.

Google and its amici contend further that its use of the RESCUECOM trademark is no different from that of a retail vendor who uses "product placement" to allow one vender to benefit from a competitors' name recognition. An example of product placement occurs when a store-brand generic product is placed next to a trademarked product to induce a customer who specifically sought out the trademarked product to consider the typically less expensive, generic brand as an alternative. Google's argument misses the point. From the fact that proper, non-deceptive product placement does not result in liability under the Lanham Act, it does not follow that the label "product placement" is a magic shield against liability, so that even a deceptive plan of product placement designed to confuse consumers would similarly escape liability. It is not by reason of absence of a use of a mark in commerce that benign product placement escapes liability; it escapes liability because it is a benign practice which does not cause a likelihood of consumer confusion. In contrast, if a retail seller were to be paid by an off-brand purveyor to arrange product display and delivery in such a way that customers seeking to purchase a famous brand would receive the off-brand, believing they had gotten the brand they were seeking, we see no reason to believe the practice would escape liability merely because it could claim the mantle of "product placement."

Unlike the practices discussed in 1-800, the practices here attributed to Google by Rescuecom's complaint are that Google has made use in commerce of Rescuecom's mark. Needless to say, a defendant must do more than use another's mark in commerce to violate the Lanham Act. We have no idea whether Rescuecom can prove that Google's use of Rescuecom's trademark in its AdWords program causes likelihood of confusion or mistake. Rescuecom has alleged that it does, in that would-be purchasers (or explorers) of its services who search for its website on Google are misleadingly directed to the

\footnotetext{
${ }^{4}$ For example, instead of having a separate "sponsored links" or paid advertisement section, search engines could allow advertisers to pay to appear at the top of the "relevance" list based on a user entering a competitor's trademark - a functionality that would be highly likely to cause consumer confusion. Alternatively, sellers of products or services could pay to have the operators of search engines automatically divert users to their website when the users enter a competitor's trademark as a search term. Such conduct is surely not beyond judicial review merely because it is engineered through the internal workings of a computer program.
} 
ads and websites of its competitors in a manner which leads them to believe mistakenly that these ads or websites are sponsored by, or affiliated with Rescuecom. Whether Google's actual practice is in fact benign or confusing is not for us to judge at this time. We consider at the 12(b)(6) stage only what is alleged in the Complaint.

We conclude that the district court was mistaken in believing that our precedent in 1-800 requires dismissal.

\section{Radiance Foundation, Inc. v. NAACP}

The Radiance Foundation published an article online entitled "NAACP: National Association for the Abortion of Colored People" that criticized the NAACP's stance on abortion. In response to a cease-and-desist letter from the NAACP, Radiance sought a declaratory judgment that it had not infringed any NAACP trademarks. The NAACP then filed counterclaims alleging trademark infringement and dilution.

The National Association for the Advancement of Colored People, better known by its acronym "NAACP," is this country's oldest and largest civil rights organization, and one that holds a place of honor in our history. It champions political, educational, social, and economic equality of all citizens while working to eliminate racial and other forms of prejudice within the United States. The NAACP owns several trademarks, among them NAACP (federally registered) and NATIONAL ASSOCIATION FOR THE ADVANCEMENT OF COLORED PEOPLE.

The Radiance Foundation, established by Ryan Bomberger, is also a non-profit organization focused on educating and influencing the public about issues impacting the African American community. Radiance addresses social issues from a Christian perspective. It uses as its platform two websites, TheRadianceFoundation.org and TooManyAborted.com, where it posts articles on topics such as race relations, diversity, fatherlessness, and the impact of abortion on the black community. Radiance also runs a billboard campaign for TooManyAborted.com; individuals may sponsor these billboards, licensing the artwork from Radiance. In addition to its billboard campaign, Radiance funds its endeavors through donations from visitors to its websites, which are facilitated by "Donate" buttons on the webpages that link to a PayPal site.

In January 2013, Bomberger authored an article criticizing the NAACP's annual Image Awards, entitled "NAACP: National Association for the Abortion of Colored People." The piece lambasted the NAACP for sponsoring an awards event to recognize Hollywood figures and products that Radiance alleged defied Christian values and perpetuated racist stereotypes. The article then criticized other of the NAACP's public stances and actions. It particularly targeted the 
NAACP's ties to Planned Parenthood and its position on abortion. Though the NAACP has often claimed to be neutral on abortion, Radiance maintains that the NAACP's actions actually demonstrate support for the practice.

The article appeared on three websites: the two owned by Radiance - TheRadianceFoundation.com and TooManyAborted.com and a third-party site called Life-News.com. Though the text of the article was identical across the sites, the headlines and presentation varied slightly. On TheRadianceFoundation.com, directly below the headline was an image of a Too-ManyAborted billboard with the headline "NAACP: National Association for the Abortion of Colored People" repeated next to it. The TooManyAborted.com site posted the headline "The National Association for the Abortion of Colored People" with a graphic below of a red box with the words "CIVIL WRONG" followed by the modified NAACP name. Adjacent to the article on both pages was an orange button with "CLICK HERE TO GIVE ONE-TIME GIFT TO THE RADIANCE FOUNDATION" printed around the word "DONATE." Finally on LifeNews.com, the third-party site, the NAACP's Scales of Justice appeared as a graphic underneath the headline.

II.

The first element of trademark infringement at issue is thus whether Radiance's use of the NAACP's marks was "in connection with the sale, offering for sale, distribution, or advertising of any goods or services.". The NAACP urges us to give this requirement a "broad construction," but that construction would expose to liability a wide array of noncommercial expressive and charitable activities. Such an interpretation would push the Lanham Act close against a First Amendment wall, which is incompatible with the statute's purpose and stretches the text beyond its breaking point. We decline to reach so far.

At least five of our sister circuits have interpreted this element as protecting from liability all noncommercial uses of marks. At the very least, reading the "in connection with" element to take in broad swaths of noncommercial speech would be an overextension of the Lanham Act's reach that would intrude on First Amendment values. It is true that neither of the Lanham Act's infringement provisions explicitly mentions commerciality. Still, this provision must mean something more than that the mark is being used in commerce in the constitutional sense, because the infringement provisions include a separate Commerce Clause hook.

Although this case does not require us to hold that the commercial speech doctrine is in all respects synonymous with the "in connection with" element, we think that doctrine provides much the best guid- 
Bolger: 463 U.S. 60 (1983)

United We Stand: 128 F.3d 86 (2d Cir. 1997) ance in applying the Act.

Use of a protected mark as part of speech that does no more than propose a commercial transaction thus plainly falls within the Lanham Act's reach. Courts also look to the factors outlined in Bolger v. Youngs Drug Products Corp.: whether the speech is an advertisement; whether the speech references a particular good or service; and whether the speaker (the alleged infringer) has a demonstrated economic motivation for his speech.

In the context of trademark infringement, the Act's purpose, as noted, is to protect consumers from misleading uses of marks by competitors. Thus if in the context of a sale, distribution, or advertisement, a mark is used as a source identifier, we can confidently state that the use is "in connection with" the activity. Even the Second Circuit, which rejected noncommerciality as an invariable defense to Lanham Act liability, conceded that a "crucial" factor is that the infringer "used the Mark not as a commentary on its owner, but instead as a source identifier." United We Stand Am., Inc. v. United We Stand, Am. New York, Inc.. The danger of allowing the "in connection with" element to suck in speech on political and social issues through some strained or tangential association with a commercial or transactional activity should thus be evident. Courts have uniformly understood that imposing liability under the Lanham Act for such speech is rife with the First Amendment problems.

III.

In finding that Radiance's use of the NAACP's marks was "in connection with" goods or services, the district court erred in several respects. To begin, the court held that because the Radiance article appeared in a Google search for the term "NAACP," it diverted "Internet users to Radiance's article as opposed to the NAACP's websites," which thereby created a connection to the NAACP's goods and services. But typically the use of the mark has to be in connection with the infringer's goods or services, not the trademark holder's.

The district court proceeded to find that Radiance's use of the NAACP's marks was also in connection with Radiance's goods or services. The court first found that there was a sufficient nexus "with Radiance's own information services" because Radiance "provided information" on its website. That ruling, however, neuters the First Amendment. The provision of mere "information services" without any commercial or transactional component is speech - nothing more.

In the alternative, the court held that Radiance's use of the NAACP's marks was in connection with goods or services, because the use was "part of social commentary or criticism for which they solicit donations and sponsorship." We need not address this point 
with absolute pronouncements. Suffice it to say that the specific use of the marks at issue here was too attenuated from the donation solicitation and the billboard campaign to support Lanham Act liability. Although present on the article page, the Donate button was off to the side and did not itself use the NAACP's marks in any way. The billboard campaign was displayed on a different page altogether. A visitor likely would not perceive the use of the NAACP's marks in the article as being in connection with those transactional components of the website.

Again, this is not to say that in all instances a solicitation by a nonprofit is immune from Lanham Act liability. A solicitation may satisfy the "in connection with" element if the trademark holder demonstrates a sufficient nexus between the unauthorized use of the protected mark and clear transactional activity. Such a nexus may be present, for example, where the protected mark seems to denote the recipient of the donation. However, where, as here, the solicitations are not closely related to the specific uses of the protected marks, we are compelled to conclude that the district court erred in ruling that the "in connection element" was met.

\section{IV.}

The district court further held that Radiance diluted the "NAACP" and "National Association for the Advancement of Colored People" trademarks by tarnishing them. We respectfully disagree. Radiance's use of the marks was undeniably to criticize the NAACP's perceived position on abortion, thus falling squarely within the statute's explicit exclusions.

The final exclusion protects "[a]ny noncommercial use of a mark.". The term "noncommercial" refers to the First Amendment commercial speech doctrine. Commercial speech is speech that does no more than propose a commercial transaction.

The district court held that because Radiance "offered various opportunities for visitors to donate to Radiance, pay to sponsor billboards, secure license content, or erect state-specific webpages for a fee," the use of the NAACP's marks was commercial. We think however, that the above [Bolger] factors mitigate against a finding of commerciality. The article in contention was not an advertisement. Nowhere in the piece did it offer the reader anything for sale. The article did not even mention Radiance's services. The only point "Radiance" even appeared in the article was as part of a passing reference to conservatives that the NAACP purportedly targets. The fact that the websites provided opportunities to engage in financial transactions does not demonstrate that the article itself was commercial. The key here is the viewpoint of a reasonable reader. A person navigating to the article, even if through a Google search for "NAACP,"
The substance of dilution law will be discussed in due course. For now, the important part is that it is subject to an explicit statutory commerciality threshold.

15 U.S.C. § $1125(c)(3)(C)$ 
is highly unlikely to read the article as advertising a Radiance service or proposing a transaction of any kind.

Trademark law in general and dilution in particular are not proper vehicles for combatting speech with which one does not agree. Trademarks do not give their holders under the rubric of dilution the rights to stymie criticism. Criticism of large and powerful entities in particular is vital to the democratic function. Under appellee's view, many social commentators and websites would find themselves victims of litigation aimed at silencing or altering their message, because, as noted, "it is often virtually impossible to refer to a particular product for purposes of comparison, criticism, point of reference or any other such purpose without using the mark." New Kids on the Block The article in this case was harsh. But that did not forfeit its author's First Amendment liberties. The most scathing speech and the most disputable commentary are also the ones most likely to draw their intended targets' ire and thereby attract Lanham Act litigation. It is for this reason that law does not leave such speech without protection.

\section{Theories of Confusion}

Now we begin in earnest our safari to observe exotic forms of liability in their natural habitat. We have already met point-of-sale confusion about source.

\section{a Reverse Confusion}

Standard ("forward") confusion involves consumers confused into thinking that the defendant's goods came from the plaintiff. But what if consumers are confused into thinking that the plaintiff's goods came from the defendant? How could that even happen? Read on.

$\S 20 \mathrm{cmt}$. $\mathrm{f}$

Standard of Infringement

"Potential customers came to Big O dealers asking for BIGFOOT tires as a result of Goodyear's commercials. Big O salesmen then had to explain the difference in the construction of these tires." Big O Tire Dealers, Inc. v. Goodyear Tire \& Rubber Co., 408 F. Supp. 1219 (D. Colo. 1976). "If consumers believe that Doc's runs Fuddruckers, and they are disappointed with the quality of Doc's food or service, they may be deterred from patronizing Fuddruckers." Fuddruckers, Inc. v. Doc's B.R. Others, Inc.826 F.2d 837 (9th Cir. 1987). Are these harms plausible? Are they really harms? Should trademark law try to prevent them?

\section{Restatement (Third) of Unfair Competition}

f. Reverse confusion. - In the typical case of trademark infringement, consumers are led to believe that the goods sold by the subsequent user of the mark are associated in some manner with the trademark owner. However, in some cases the subsequent user's promotion of the mark may so overwhelm the use by the prior user that most purchasers come to associate the mark with the subsequent user. This can result in reverse confusion - purchasers are likely to believe that the goods sold by the prior user are actually those of the subsequent user.

The injury to the trademark owner caused by a likelihood of reverse confusion is more subtle than that resulting from direct confusion. Reverse confusion does not ordinarily threaten a direct diversion of trade from the trademark owner; indeed, the owner's sales 
may benefit to some extent from the infringer's promotion of the mark. On the other hand, because of the infringer's concurrent use of the mark, the reputation of the trademark owner's goods or services among prospective purchasers is no longer within the owner's exclusive control. Failure to protect against reverse confusion would also permit large subsequent users to undermine by extensive advertising the investments of smaller firms in their trade symbols. Because these potential injuries result from a likelihood of confusion as to the source of goods or services, the creation of reverse confusion falls within the traditional rules governing the infringement of trademarks.

\section{Illustration:}

8. A, a small tire manufacturer, sells BIGTRACK tires in a regional market. Consumers in that market associate BIGTRACK with A. B, a prominent tire manufacturer, subsequently begins selling BIGTRACK tires and engages in an extensive promotional campaign on national television. B's advertising overwhelms A's promotional efforts with the result that consumers encountering $A^{\prime}$ s tires now think that the tires are actually produced by B. B is subject to liability to A under the rule stated in this Section.

\section{b Initial Interest Confusion}

Standard point of sale confusion takes place at the moment of purchase. What if consumers are confused before then?

\section{Grotrian, Helfferich, Schultz, Th. Steinweg Nachf v. Steinway \& Sons}

The issue here is not the possibility that a purchaser would buy a Grotrian-Steinweg thinking it was actually a Steinway or that Grotrian had some connection with Steinway and Sons. The harm to Steinway, rather, is the likelihood that a consumer, hearing the "Grotrian-Steinweg" name and thinking it had some connection with "Steinway", would consider it on that basis. The "Grotrian-Steinweg" name therefore would attract potential customers based on the reputation built up by Steinway in this country for many years. Misled into an initial interest, a potential Steinway buyer may satisfy himself that the less expensive Grotrian-Steinweg is at least as good, if not better, than a Steinway. Deception and confusion thus work to appropriate defendant's good will.

\section{Brookfield Communications v. West Coast Entertainment}

Suppose West Coast's competitor (let's call it "Blockbuster") puts up a billboard on a highway reading-"West Coast Video: 2 miles ahead at Exit 7"- where West Coast is really located at Exit 8 but Blockbuster is located at Exit 7. Customers looking for West Coast's store will pull 
Blockbuster: 869 F. Supp. 505 (E.D. Mich 1994)

603 F. Supp. 2d 274 (D. Mass. 2009) off at Exit 7 and drive around looking for it. Unable to locate West Coast, but seeing the Blockbuster store right by the highway entrance, they may simply rent there. Even consumers who prefer West Coast may find it not worth the trouble to continue searching for West Coast since there is a Blockbuster right there. Customers are not confused in the narrow sense: they are fully aware that they are purchasing from Blockbuster and they have no reason to believe that Blockbuster is related to, or in any way sponsored by, West Coast. Nevertheless, the fact that there is only initial consumer confusion does not alter the fact that Blockbuster would be misappropriating West Coast's acquired goodwill. See Blockbuster Entertainment Group v. Laylco, Inc. (finding trademark infringement where the defendant, a video rental store, attracted customers' initial interest by using a sign confusingly to its competitor's even though confusion would end long before the point of sale or rental).

Hearts on Fire Company, LLC v. Blue Nile, Inc.

[This was a keyword advertising case. Consult Rescuecom for a description of keyword advertising. The plaintiff alleged that the defendant purchased its HEARTS ON FIRE trademark as a keyword on the Webcrawler search engine.]

Rarely are cases so clear as the Ninth Circuit's billboard - particularly on the internet - and certainly not this one.

Infringement is not nearly so obvious from this vantage point. Rather than a misleading billboard, this analogy is more akin to a menu - one that offers a variety of distinct products, all keyed to the consumer's initial search. Sponsored linking may achieve precisely this result, depending on the specific product search and its context. When a consumer searches for a trademarked item, she receives a search results list that includes links to both the trademarked product's website and a competitor's website. Where the distinction between these vendors is clear, she now has a simple choice between products, each of which is as easily accessible as the next. If the consumer ultimately selects a competitor's product, she has been diverted to a more attractive offer but she has not been confused or misled. 9 While she may have gotten to the search-results list via the trademarked name, once there, the advertised products are easily distinguished.

In much the same way, keyword purchasing may, in many cases, be analogized to a drug store that typically places its own store-

\footnotetext{
${ }^{9}$ Consider, for instance, if Pepsi were to purchase sponsored links to its website triggered by an internet user's search for the "Coca-Cola" trademark. Coca-Cola would have difficulty suing Pepsi for infringement on an initial interest theory because these two products are widely recognized as competitors and, accordingly, the likelihood of consumer confusion is exceedingly small.
} 
brand generic products next to the trademarked products they emulate in order to induce a customer who has specifically sought out the trademarked product to consider the store's less-expensive alternative. The generic product capitalizes on the recognizable brand name but the consumer benefits by being offered a lower-cost product. At no point is the consumer confused about the alternatives presented to her. The goodwill invested in the protected mark remains undisturbed while the consumer reaps the benefit of competing goods. Trademark infringement would seem to be unsupportable in this scenario. Mere diversion, without any hint of confusion, is not enough.

To be sure, the sponsored links appearing on a search-results page will not always be a menu of readily distinguished alternatives. With the intense competition for internet users' attention and mouseclicks, online merchants may well be tempted to blur these distinctions, hoping to create and capitalize on initial consumer confusion. Such conduct undoubtedly begins to sound in trademark infringement. Thus, where a plaintiff has plausibly alleged some consumer confusion, even at an initial stage of his product search, the question is a far closer one.

Based on the twin goals of trademark protection, the Court concludes that initial interest confusion can support a claim under the Lanham Act - but only where the plaintiff has plausibly alleged that consumers were confused, and not simply diverted. Many cases, including this one, will fall somewhere between the incarnations of so-called initial interest confusion discussed above - the misleading billboard or the choice-enhancing menu. The Court's task is to distinguish between them. As a preliminary matter, the Court agrees with the many scholars who find the deceptive billboard analogy often inapt in the internet context. Unlike the deceived shopper who is unlikely to get back on the highway, the internet consumer can easily click the 'back' button on her web browser and return almost instantly to the search results list to find the sought-after brand. Her added search costs, in other words, may often be very low while her comparative choice among products is greatly expanded.

The crucial question in these cases is one of degree: Whether the consumer is likely confused in some sustained fashion by the sponsored link and the defendant's website, or whether the link serves instead as a benign and even beneficial form of comparison shopping. The menu analogy described above - where the competing products are clearly distinguished - is not, in and of itself, truly a case of confusion at all, and therefore cannot support an infringement claim. In fact, in order for a plaintiff pleading initial interest confusion to prevail, that confusion must be more than momentary and more than a "mere possibility." Grotrian As with any alleged trademark violation, 
Mobil Oil: 818 F.2d 254 (2d Cir. 1987)

453 F.3d 351 (6th Cir. 2006)

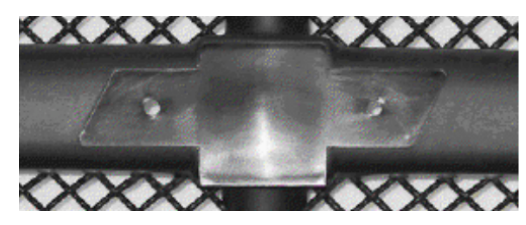

Tong Yang Chevrolet grille placeholder plaintiffs must show a genuine and substantial likelihood of confusion.

This principle was implicit in the bricks-and-mortar cases that laid the groundwork for initial interest confusion as well as the Ninth Circuit's billboard analogy, which assumed that the deceived shopper, once diverted, would not get back on the highway. See Mobil Oil Corp. v. Pegasus Petroleum Corp. (competitor's logo confused oil traders into investing a considerable amount of time and effort into pre-sale negotiations with the defendant); Grotrian (similar mark would entice even sophisticated consumers to consider defendant's pianos, even if any confusion was resolved prior to any purchase). Where, as here, a plaintiff has alleged a plausible likelihood of confusion based on the overall context in which a consumer performs his internet search, he has stated a claim for trademark infringement and may proceed on an initial interest theory.

\section{c Post-Sale Confusion}

Standard point of sale confusion takes place at the moment of purchase. What if consumers are confused after then?

\section{General Motors Corp. v. Keystone Automotive Industries, Inc.}

$\mathrm{GM}$, currently the world's largest automaker, owns registered trademarks in the Chevrolet "bow tie" design and the "GMC" design. The instant case arose out of Tong Yang's manufacturing and Keystone's distribution of replacement grilles with "placeholders" bearing these two designs.

For Chevrolets, the placeholder is a recessed space on the front of the grille in the shape of a bow tie in which a heavy plastic GM "bow tie" emblem is inserted. Each emblem is a separate part always purchased from GM and is secured to the placeholder with studs or pins extending from the back of the emblem so as to pass through holes in the placeholder. After inserted and secured in the placeholder of a Chevrolet grille, the "bow tie" emblem partially or wholly fills the "bow tie" recess. [Similarly for GMC vehicles.]

\section{A. Point-of-Sale Confusion}

Likelihood of confusion at the point of sale involves a purchaser's confusion as to a product's origin or sponsorship occurring at the time of purchase. The points of sale for most of Tong Yang's grilles are collision repair shops, but some are sold directly to individuals over the internet. We need not exhaustively apply the eight-factor test to reach the rather obvious conclusion that there is no likelihood of confusion at the point of sale because buyers are expressly informed that they are not purchasing GM grilles. 
In Ferrari S.P.A. Esercizio v. Roberts, this Court noted that there was no likelihood of point-of-sale confusion where a manufacturer of "knockoff" Ferraris informed his purchasers that his significantly cheaper cars were not genuine Ferraris. Similarly, customers knowing they are purchasing a knockoff designer purse or Rolex watch simply do not confuse the counterfeit with the original.

Likewise, in the instant case, no purchaser has reason to be confused as to the origin of the replacement grilles. Collision repair shops ordering Tong Yang parts do so intentionally and generally at the bidding of insurance companies because non-original equipment is less expensive and reduces the cost of repairing a vehicle. Moreover, GM grilles are made by Siegel-Robert, Inc., and carry the molded letters "SRI" to identify their origin, whereas Tong Yang grilles are marked "OTN" and "Made in Taiwan." In addition, Tong Yang grilles are shipped in boxes and packaging markedly different from those containing GM grilles with conspicuous logos of Tong Yang and/or Keystone. The invoice accompanying Tong Yang parts conspicuously carries the following disclaimer:

THESE REPLACEMENT PARTS ARE NOT MANUFACTURED BY THE ORIGINAL MANUFACTURER. THESE PARTS ARE REPLACEMENT FOR THE OEM PARTS, AND MANUFACTURED IN TAIWAN FOR NORTH AMERICA MARKET.

An automobile owner would have to possess complete ignorance of this disclaimer, her insurance contract, and ordinary automobile repair practices to be confused as to the origin of a Tong Yang grille when getting her vehicle repaired. Individuals purchasing grilles directly from Keystone over the internet receive the same source information as collision repair shops and likewise could scarcely be confused. In short, the transparent and conspicuous indications that Tong Yang manufactured its grilles make confusion at the point of sale all but impossible.

\section{B. Downstream Confusion}

In addition to point-of-sale confusion, the Sixth Circuit recognizes that a likelihood of downstream confusion, also called "post-sale" confusion, is actionable. Thus, injection of knockoffs into the stream of commerce may lead to a likelihood of confusion among the general public.

Our review of cases discussing the harm of injecting knockoffs into the stream of commerce further signals the likelihood of downstream confusion in this case. Even without point-of-sale confusion, knockoffs can harm the public and the original manufacturer in a number of ways, including: (1) the viewing public, as well as sub- 
sequent purchasers, may be deceived if expertise is required to distinguish the original from the counterfeit; (2) the purchaser of an original may be harmed if the widespread existence of knockoffs decreases the original's value by making the previously scarce commonplace; (3) consumers desiring high quality products may be harmed if the original manufacturer decreases its investment in quality in order to compete more economically with less expensive knockoffs; (4) the original manufacturer's reputation for quality may be damaged if individuals mistake an inferior counterfeit for the original; (5) the original manufacturer's reputation for rarity may be harmed by the influx of knockoffs onto the market; and (6) the original manufacturer may be harmed if sales decline due to the public's fear that what they are purchasing may not be the original. On the other hand, courts should be wary of overprotecting public domain ideas and works whose exploitation can lead to economic efficiency, greater competition, and lower costs for consumers.

The instant case carries potential for downstream confusion and corresponding harm to GM and the public. Unaided by the defendants' conspicuously marked packaging, the invoice disclaimer, or a collision shop's expertise, the viewing public could mistake a Tong Yang grille for a GM grille. Such confusion could damage GM's reputation for quality if the public associates any inferior attributes (e.g., improper fit or cracking) of Tong Yang's grilles with GM. Other types of possible downstream harm, such as that resulting from a product's reduced scarcity, however, are largely inapplicable to this case. Nonetheless, visibility of the placeholder after the automobile is repaired and returned to the road may harm the public and GM.

If the placeholder cannot be seen after the Chevrolet "bow tie" or "GMC" emblem is affixed, the wholly hidden placeholder cannot cause downstream confusion as to origin or sponsorship. After all,

Polo Fashions: 816 F.2d 145 (4th Cir 1987) that which defies perception cannot confuse. Cf. Polo Fashions, Inc. v. Craftex, Inc. (In a suit involving knockoff Polo shirts, the placement of the defendant's mark inside the back of the neck of each shirt did not prevent a likelihood of confusion stemming from the defendant's placement of the Polo trademark on the front of each shirt.).

The parties dispute whether the placeholder can be seen after the emblem is secured. The District Court improperly resolved in favor of the defendants this factual dispute regarding the visibility of the placeholders after each emblem is affixed. If the placeholders remain visible, the related question is raised whether the placeholders are sufficiently visible to cause a likelihood of confusion. These genuine

\footnotetext{
${ }^{2}$ It is worth emphasizing that GM seeks relief only under the laws of trademark and unfair competition. Other legal theories, such as the laws of patent and trade dress, also offer protection for certain attributes of products.
} 
disputes of material fact render summary judgment inappropriate, a common disposition in evaluating likelihood of confusion.

\section{Section 43(a)}

Our safari continues with Section 43(a) of the Lanham Act.

\section{Lanham Act}

(a) Civil action. -

(1) Any person who, on or in connection with any goods or services, or any container for goods, uses in commerce any word, term, name, symbol, or device, or any combination thereof, or any false designation of origin, false or misleading description of fact, or false or misleading representation of fact, which -

(A) is likely to cause confusion, or to cause mistake, or to deceive as to the affiliation, connection, or association of such person with another person, or as to the origin, sponsorship, or approval of his or her goods, services, or commercial activities by another person ...

shall be liable in a civil action by any person who believes that he or she is or is likely to be damaged by such act.

What does Section 43(a) do? Quite a lot:

- It provides a federal cause of action for infringement even of unregistered marks.

- It provides a federal cause of action for infringement of trade dress.

- It provides a federal cause of action for false advertising.defer them to the Design and False Advertising chapters, respectively.

- It provides a federal cause of action for unfair competition.

- It provides a federal cause of action for confusion about sponsorship or affiliation.

The first of these requires little discussion. The second and third require so much discussion that we We consider the fourth and fifth in this subsection, along with another theory of liability not supported by Section 43(a): failure to attribute (or "reverse passing off").
15 U.S.C. § 1125

Lanham Act § 43

False designations of origin, false descriptions, and dilution forbidden

"Homer: Are you saying you're never going to eat any animal again? What about bacon? Ham? Pork chops? Lisa: Dad, those all come from the same animal. Homer: Ooh, yeah, right, Lisa. A wonderful, magical animal." The Simpsons episode 3F03 ("Lisa the Vegetarian"). Section 43(a) is the wonderful magical animal of intellectual property law.

To be precise, the false advertising cause of action comes from $\S 43(\mathrm{a})(1)(B)$, while the present section discusses § 43(a)(1)(A). See Rebecca Tushnet, Running the Gamut from $A$ to $B$ : Federal Trademark and False Advertising Law, 159 U. Pa. L. Rev. 1305 (2011). 


\section{a Unfair Competition}

To understand the unfair-competition tort and how it differs from trademark infringement, a page of history is helpful.

\section{Margreth Barrett}

Finding Trademark Use

At common law in the late 1800s and early 1900s, courts distinguished between "technical trademarks," which were protected through a suit for trademark infringement, and "trade names" (or "secondary meaning marks"), which were protected (if at all) through a suit for unfair competition.

Technical trademarks were what we would call "inherently distinctive" marks today - words and symbols that were "fanciful, arbitrary, unique, distinctive, and nondescriptive in character," and which the claimant had physically affixed to articles of merchandise. Trade names, by contrast, consisted of words and symbols that described their user's product or service, constituted geographical terms, personal names, or designations common to the trade, or constituted business or corporate names.

The courts distinguished between technical trademarks and secondary meaning marks on the reasoning that a business could legitimately appropriate a fanciful or arbitrary word or symbol to its sole, exclusive use, with no harm to others. A technical trademark, by definition, was either made up (and thus had no meaning) or had a meaning that bore no descriptive or other logical relationship to the user's product. Accordingly, competitors had no legitimate reason to adopt the same word or symbol to identify or describe their similar goods. If they did so, they likely did it for the purpose of perpetrating a fraud on the mark owner or the public. Their action could be characterized as an invasion of the first user's property rights.

In contrast, trade names consisted of descriptive, surname, geographic, and other words and symbols commonly used in the trade, such as colors, squares, circles, stripes, or other common shapes. Numerous competitors might legitimately want to use such words and symbols in their own marketing activities. A business that adopted such a word or symbol as its mark or name had no right to expect exclusivity.

When competitors intentionally used a secondary meaning mark for the purpose of confusing consumers about the source of their goods, thus diverting trade from an earlier user, courts would intervene - not on the ground that the plaintiff had property rights in the word or symbol (as might be the case with regard to a technical trademark), but because the defendant/competitor was engaged in fraudulent conduct. 
Plaintiffs in secondary meaning infringement cases generally had to demonstrate that the defendant acted with fraudulent intent, while courts would presume fraud in technical trademark infringement cases.

Today, the Lanham Act for the most part does not draw any distinctions in the protections it accords to inherently distinctive marks and to marks with acquired distinctiveness. They are all protected under the same likelihood-of-confusion standard. That would seem to obliterate the need for a separate unfair-competition tort. Not quite so fast.

William R. Warner \& Co. v. Eli Lilly \& Co.

Respondent is a corporation engaged in the manufacture and sale of pharmaceutical and chemical products. In 1899 it began and has ever since continued to make and sell a liquid preparation of quinine, in combination with other substances, including yerba-santa and chocolate, under the name of Coco-Quinine. Petitioner also is a pharmaceutical and chemical manufacturer[, which] in 1906 began the manufacture of a liquid preparation which is substantially the same as respondent's preparation and which was put upon the market under the name of Quin-Coco.

This suit was brought in the Federal District Court for the Eastern District of Pennsylvania by respondent to enjoin petitioner from continuing to manufacture and sell the preparation if flavored or colored with chocolate; and also from using the name Quin-Coco, on the ground that it was an infringement of the name Coco-Quinine, to the use of which respondent had acquired an exclusive right.

First. We agree with the courts below that the charge of infringement was not sustained. The name Coco-Quinine is descriptive of the ingredients which enter into the preparation. The same is equally true of the name Quin-Coco. A name which is merely descriptive of the ingredients, qualities or characteristics of an article of trade cannot be appropriated as a trademark and the exclusive use of it afforded legal protection. The use of a similar name by another to truthfully describe his own product does not constitute a legal or moral wrong, even if its effect be to cause the public to mistake the origin or ownership of the product.

Second. The issue of unfair competition, on which the courts below differed, presents a question of more difficulty.

It is apparent, from a consideration of the testimony, that the efforts of petitioner to create a market for Quin-Coco were directed not so much to showing the merits of that preparation as they were to

265 U.S. 526 (1924)

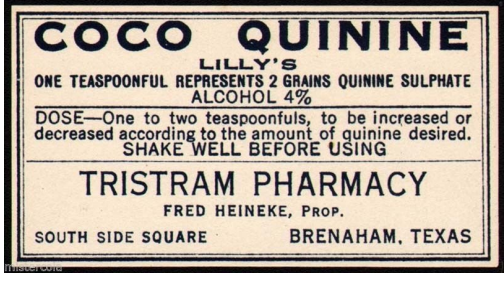

Coco-Quinine advertisement 
demonstrating its practical identity with Coco-Quinine, and, since it was sold at a lower price, inducing the purchasing druggist, in his own interest, to substitute, as far as he could, the former for the latter. In other words, petitioner sought to avail itself of the favorable repute which had been established for respondent's preparation in order to sell its own. Petitioner's salesmen appeared more anxious to convince the druggists with whom they were dealing that Quin-Coco was a good substitute for Coco-Quinine and was cheaper, than they were to independently demonstrate its merits. The evidence establishes by a fair preponderance that some of petitioner's salesmen suggested that, without danger of detection, prescriptions and orders for Coco-Quinine could be filled by substituting Quin-Coco. More often, however, the feasibility of such a course was brought to the mind of the druggist by pointing out the identity of the two preparations and the enhanced profit to be made by selling Quin-Coco because of its lower price. There is much conflict in the testimony; but on the whole it fairly appears that petitioner's agents induced the substitution, either in direct terms or by suggestion or insinuation. Sales to druggists are in original bottles bearing clearly distinguishing labels and there is no suggestion of deception in those transactions; but sales to the ultimate purchasers are of the product in its naked form out of the bottle; and the testimony discloses many instances of passing off by retail druggists of petitioner's preparation when respondent's preparation was called for. That no deception was practiced on the retail dealers, and that they knew exactly what they were getting is of no consequence. The wrong was in designedly enabling the dealers to palm off the preparation as that of the respondent. One who induces another to commit a fraud and furnishes the means of consummating it is equally guilty and liable for the injury.

Blinded Veterans Association v. Blinded American Veterans Foundation

The Blinded Veterans Association (BVA or the Association) sought to enjoin the Blinded American Veterans Foundation (BAVF or the Foundation) from using the words "blinded" and "veterans" in its name and from using the initials "BAV" as an acronym. We hold that BVA's name is not a protectable trademark because the term "blinded veterans" is generic. BVA, however, may be entitled to protection against BAVF's passing itself off as BVA.

Appellee Blinded Veterans Association is a nonprofit organization founded in 1945 by a group of blinded World War II veterans. Appellant BAVF is a nonprofit District of Columbia corporation founded in September 1985 by three former officials of BVA. In 1986, BAVF applied to 552 local campaign organizations involved in the Combined Federal Campaign (CFC). Those organizations listed BAVF, alphabet- 
ically ahead of BVA, as a prospective recipient of CFC funds. Despite its lack of significant accomplishments at that point, BAVF did rather well in its initial fundraising foray: the Foundation's 1986 income totalled between $\$ 35,000$ and $\$ 40,000$, half from CFC pledges and half from corporate contributions.

If the name of one manufacturer's product is generic, a competitor's use of that name, without more, does not give rise to an unfair competition claim under section 43(a) of the Lanham Act. Nevertheless, such a claim might be supportable if consumer confusion or a likelihood of consumer confusion arose from the failure of the defendant to adequately identify itself as the source of the product.

The subsequent competitor cannot be prevented from using the generic term to denote itself or its product, but it may be enjoined from passing itself or its product off as the first organization or its product. Thus, a court may require the competitor to take whatever steps are necessary to distinguish itself or its product from the first organization or its product. In the paradigm case, Kellogg Co. v. National Biscuit Co., for example, the Supreme Court held that the term "shredded wheat" is generic; the National Biscuit Company therefore was not entitled to exclusive use of the term. Because National Biscuit had been the only manufacturer of shredded wheat for many years, however, the public had come to associate the product and the term "shredded wheat" with that company. The Court therefore stated that the Kellogg Company, which also produced a shredded wheat cereal, could be required to "use reasonable care to inform the public of the source of its product." 19 See also, e.g., Singer Mfg. Co. v. June Mfg. Co. (holding that "Singer" had become generic denotation of type of sewing machine, but requiring that defendant not use the word on its product or in advertisements "without clearly and unmistakably stating ... that the machines are made by the defendant, as distinguished from the sewing machines made by the Singer Manufacturing Company"); King-Seeley Thermos Co. v. Aladdin Indus., Inc. (finding "thermos" generic denotation of vacuum-insulated container, but affirming requirement that defendant distinguish its product from plaintiff's by preceding "thermos" with "Aladdin's," by using only the lower case " $t$ ", and by never using the words "original" or "genuine" in describing its product); G.EC. Merriam Co. v. Saalfield (requiring defendant to accompany generic term "Webster's Dictionary" with sufficient explanation to avoid giving false impression that his book was plaintiff's).

Under the approach set forth in these cases, a court will not act

\footnotetext{
${ }^{19}$ The Court then determined that Kellogg had sufficiently distinguished its product by selling it in cartons different from National Biscuit's in size, form, and color, with a different label, a different number of biscuits in each carton, and the name "Kellogg" displayed prominently.
}

Kellogg: 305 U.S. 111 (1938)

Singer Mfg.: 163 U.S. 169 (1896)

King-Seeley: 321 F.2d 577 (2d Cir. 1963)

Merriam: 198 F.369, 373-76 (6th Cir. 1912) 


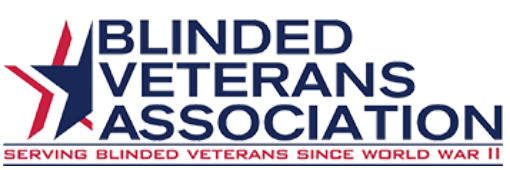

BVA logo, circa 2016

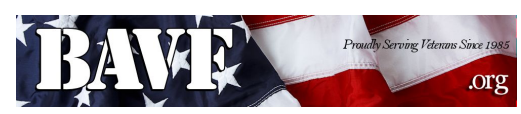

BAVF website banner, circa 2016 to remedy or prevent "confusion generated by a mere similarity of names. If a consumer confuses two manufacturers' shredded wheat cereal, for example, because both products share the same name and the consumer has a general appetite for crunchy, pillow-shaped wheat biscuits, there is no cause for judicial action. Such confusion results merely from the manufacturers' concurrent use of a generic term to designate their products, and the late entrant into the shredded wheat field cannot be said to have engaged in unfair competition. If, however, the consumer associates "shredded wheat" with a particular manufacturer, there is a risk that the consumer may erroneously assume that any product entitled "shredded wheat" comes from that manufacturer. A second manufacturer may increase the risk of confusion by, for example, using a similar label, similar packaging, misleading advertisements, or simply by failing to state the product's source. Only when there is a likelihood that the newcomer might thus pass its product off as the original manufacturer's may a court require the newcomer to distinguish its product or to notify consumers explicitly that its product does not come from the original manufacturer.

Ultimately, to succeed on its passing off claim, BVA must prove that the likely effect of BAVF's actions is to induce the public to think that BAVF is BVA. The evidence now in the record appears insufficient to establish this type of confusion. To prevail in this action, however, it is not enough for BVA to show confusion that is the natural consequence of the two organizations' use of generic names. What is essential, we underscore, is evidence that people associate "blinded veterans" with BVA per se and that, because of specific actions by BAVF that increase the risk of confusion, people are likely to think BAVF is BVA.

We think it proper to permit the parties to submit additional evidence trained on the question whether people are likely to think that BAVF is actually BVA. It would fill out and sharpen the record to prove (or disprove), for instance, that people who have contributed to BVA in the past have contributed, or are likely to contribute, to BAVF thinking it was BVA, or that people familiar with BVA's long service on behalf of blinded veterans are likely to think any group with a name containing "blinded veterans" or with the letters " $\mathrm{B}$ " " $\mathrm{A}$ " and " $\mathrm{V}$ " in its logo is the same as, or is associated with, BVA.

If the district court, on remand, finds from the evidence that BAVF is passing itself off as BVA, the court may order that BAVF distinguish itself from BVA to avoid confusion. This case obviously differs from Kellogg and other cases cited above because it involves the name of an organization rather than the name of a particular product. This difference precludes such a ready remedy as attaching the manufacturer's name to the generic name of the product. The district court 
could, however, require BAVF to attach a prominent disclaimer to its name alerting the public that it is not the same organization as, and is not associated with, the Blinded Veterans Association. Alternatively, the court could order that BAVF adopt another name containing the term "blinded veterans" that is less likely to confuse.

\section{b False Endorsement}

Another way that $\S 43(a)$ is useful to trademark owners is by supplying a cause of action for the false suggestion of "affiliation," "connection," "sponsorship" or "approval." Again, a little history is useful. At common law at the start of the 20th century, only trademark infringements involving directly competing goods were actionable - a rule following directly from the conceptual logic of technical trademark infringement and unfair competition, which focused on the defendant's diversion of the plaintiff's customers via deception.

As in Yale Electrid, courts began to allow trademark infringement suits against related but not directly competing goods. This had two effects. First, it made relatedness of the goods into one of the factors for the standard trademark-infringement likelihood-ofconfusion test. Second, it opened up a new and independent theory of harm to the plaintiff, one not necessarily grounded in confusion about source. Indeed, as in Conan Properties, the theory now works even against wholly different goods, where no reasonable consumer could think they originated from the plaintiff. There still must be a likelihood of confusion; it is just confusion about something else.. Also watch out for the trademark defenses, which often limit liability in such cases. Section 43(a) now incorporates this wider second understanding of confusion, which must be pleaded as a distinct cause of action. The most controversial cases involve merchandising: use of the trademark on apparel and other items purchased by people who care about the mark because of what it signifies rather than as a signal of who made the goods.

\section{Yale Electric Corp. v. Robertson}

The record contains many instances where the defendant's buyers did, or said that they should, suppose the plaintiff's flash-lights to be one of the defendant's products, and it is extremely probable that mistakes will continue unless the practice ceases.

Therefore, so far as we can see, only [one] point[] of law need be considered: whether, in view of the fact that it makes no flash-lights or batteries, it may complain of the plaintiff's use of its name. The law of unfair trade comes down very nearly to this - as judges have repeated again and again - that one merchant shall not divert customers from another by representing what he sells as emanating from

But see Mark A. Lemley \& Mark McKenna, Irrelevant Confusion, 62 Stan. L. Rev. 412 (2010) ("We think trademark law needs to refocus on confusion that is actually relevant to purchasing decisions.")

26 F.2d 972 (2d Cir. 1928)

(Learned Hand, J.)

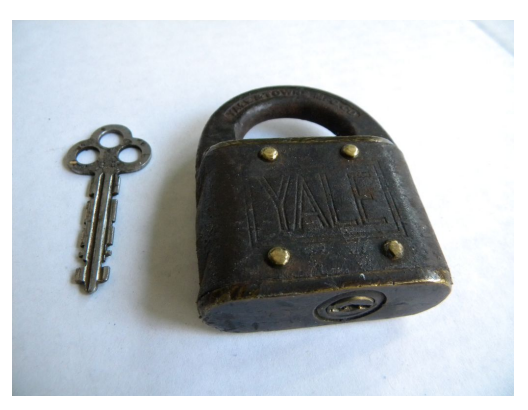

Defendant's YALE lock

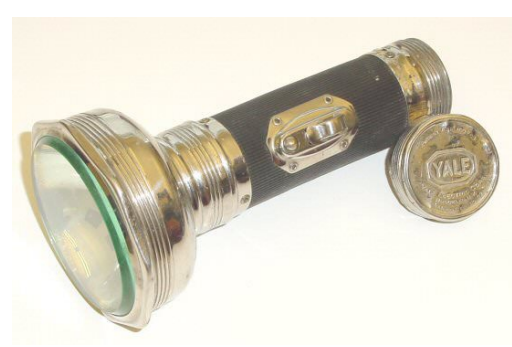

Plaintiff's YALE flashlight 
the second. This has been, and perhaps even more now is, the whole Law and the Prophets on the subject, though it assumes many guises. Therefore it was at first a debatable point whether a merchant's good will, indicated by his mark, could extend beyond such goods as he sold. How could be lose bargains which he had no means to fill? What harm did it do a chewing gum maker to have an ironmonger use his trade-mark?

However, it has of recent years been recognized that a merchant may have a sufficient economic interest in the use of his mark outside the field of his own exploitation to justify interposition by a court. His mark is his authentic seal; by it he vouches for the goods which bear it; it carries his name for good or ill. If another uses it, he borrows the owner's reputation, whose quality no longer lies within his own control. This is an injury, even though the borrower does not tarnish it, or divert any sales by its use; for a reputation, like a face, is the symbol of its possessor and creator, and another can use it only as a mask. And so it has come to be recognized that, unless the borrower's use is so foreign to the owner's as to insure against any identification of the two, it is unlawful. The defendant need not permit another to attach to its good will the consequences of trade methods not its own.

Conan Properties, Inc. v. Conans Pizza, Inc.

Conan Properties, Inc. (CPI) owns the literary property rights in the fictional character CONAN THE BARBARIAN and licenses others to use the character in various commercial and entertainment works. CPI sued Conans Pizza, Inc. (Conans) for infringement of its federal trademark and for unfair competition and misappropriation of its property under Texas common law.

The CONAN character was created in 1929 by Robert Howard. But the character remained relatively dormant until the 1950's, when L. Sprague deCamp, a contemporary author, rediscovered and began writing books featuring CONAN THE BARBARIAN. As the title might suggest, deCamp's CONAN THE BARBARIAN series told the tales of a gigantic, sword and battle-ax wielding barbarian adventurer who roamed the world in search of foes. Many of deCamp's works were illustrated by Frank Frazetta, an artist famous for his "sword and sorcery" style artwork. In 1970, the Howard estate licensed Marvel Comics to publish a series of comic books featuring CONAN THE BARBARIAN . To avoid litigation over who had rights in CONAN THE BARBARIAN, the Howard estate and deCamp united their interests in the CONAN character in 1976 and formed CPI. In that same year the United States Patent and Trademark Office (USPTO) granted CPI a federally registered trademark for the title CONAN THE BARBARIAN for comic books. 
Also in this same year, Scott Leist and Jerry Strader opened "Conans Pizza", a restaurant in Austin, Texas.The restaurant's menus, signs, promotional material, specialty items, and general decor featured a barbarian-like man who closely resembled CPI's CONAN character. For example, Conans Pizza's menus depicted a loinclothclad, sword wielding, sandal wearing, barbarian-like muscleman, and they described one of the featured pizzas as the "Savage, Barbaric, All the Way Pizza." The owners decorated the restaurant with dozens of reproductions of Frank Frazetta's artwork, although only a few of the reproductions actually represented CONAN THE BARBARIAN.

To prevail on its trademark infringement and unfair competition claims, CPI needed to demonstrate that Conans' use of the CONAN THE BARBARIAN mark and image was likely to create confusion in the mind of the ordinary consumer as to the source, affiliation, or sponsorship of Conans' service and product. A nonexhaustive list of factors to be considered in determining whether a likelihood of confusion exists includes: (1) the type of trademark alleged to have been infringed, (2) the similarity of design between the two marks, (3) similarity of the products or services, (4) the identity of the retail outlets and purchasers, (5) the identity of the advertising medium utilized, (6) the defendant's intent, and (7) evidence of actual confusion. Armco, Inc. v. Armco Burglar Alarms Co.. The absence or presence of any one factor ordinarily is not dispositive; indeed, a finding of likelihood of confusion need not be supported by even a majority of the seven factors.

We conclude that CPI presented sufficient evidence related to these seven factors to permit the jury to find that Conans' conduct created a likelihood of confusion as to the source, sponsorship, or affiliation of its service and product. The evidence adduced at trial revealed that Conans was aware of the CONAN THE BARBARIAN character prior to its adoption of the name Conans Pizza. Additionally, Conans' menus, advertising material, specialty items, and general decor featured a character unmistakably similar if not identical to CONAN THE BARBARIAN.

Conans answers that no reasonable person could have believed that its restaurants were related to CPI's CONAN THE BARBARIAN, since the products and services each provided were different. We must disagree. Although CPI never licensed any entity to use its mark in connection with restaurant services, ordinary consumers may well believe that Conans was in fact licensed by CPI. At the trial CPI presented evidence of numerous cartoon and other characters whose names, marks, or images were used in extensive licensing programs to promote everything from children's toys to fast-food restaurants. These characters included SNOOPY, POPEYE, DICK TRACY,

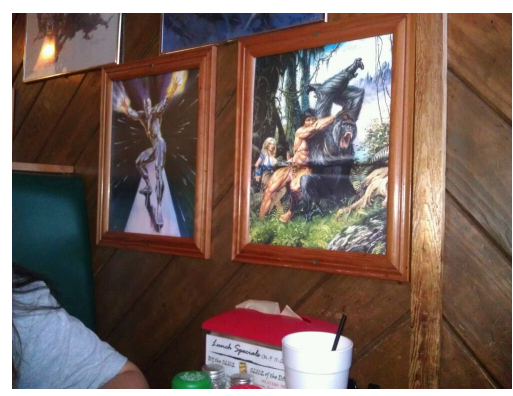

Conans Pizza interior, circa 2016

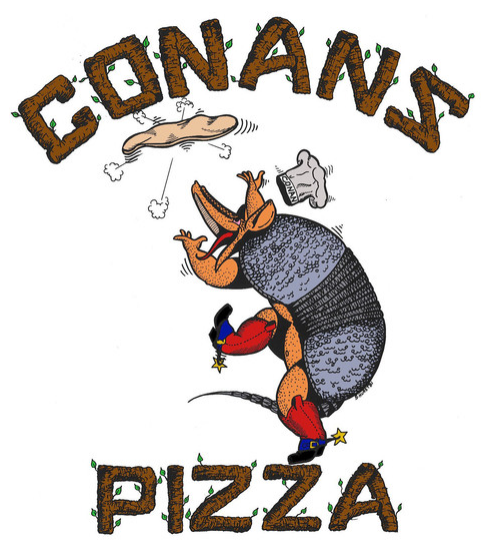

Conans Pizza logo, circa 2016 Armco: 693 F.2d 1155 (5th Cir. 1983) 
633 F.2d 912 (9th Cir. 1980)

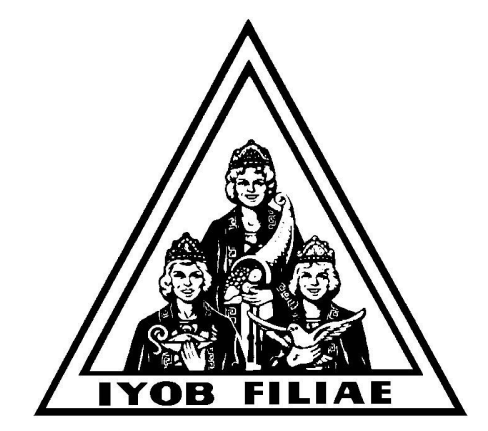

Job's Daughters emblem

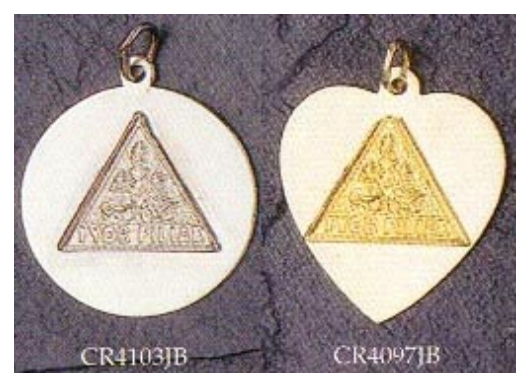

Lindeburg jewelry
PETER PAN, E.T., and ROY ROGERS. Many of today's consumers expect such endorsements and act favorably toward them. It is reasonable to assume, as the jury found, that ordinary consumers who patronized Conans Pizza and experienced the pervasive, inescapable aura of CONAN THE BARBARIAN in those restaurants were likely to believe that the restaurants were in some way licensed by or affiliated with CPI. We therefore leave undisturbed the jury's findings of trademark infringement and unfair competition.

\section{International Order of Job's Daughters v. Lindeburg \& Co.} Appellee, the International Order of the Daughters of Job (Job's Daughters), sued appellant Lindeburg and Co. (Lindeburg), for trademark infringement arising out of Lindeburg's manufacture and sale of jewelry bearing the Job's Daughters insignia.

Job's Daughters is a young women's fraternal organization. Since its establishment in 1921 it has used its name and emblem ${ }^{1}$ as collective marks. Since its inception Job's Daughters has licensed at least one jeweler to produce jewelry for it. Job's Daughters sells some of the licensed jewelry directly to its members. Jewelry bearing the name or emblem is also sold by approximately 31,000 retailers across the nation. Most of these retailers presumably have no connection with the Job's Daughters organization. Some sell jewelry manufactured by Job's Daughters' licensees; others sell jewelry manufactured by jewelers not licensed by the organization.

Lindeburg makes and sells fraternal jewelry. In 1954 it began selling jewelry and related items bearing the Job's Daughters insignia. In 1957 Lindeburg asked the Job's Daughters trademark committee to designate it an "official jeweler." The committee refused and in 1964 and 1966 asked Lindeburg to stop manufacturing and selling unlicensed jewelry. Lindeburg did not comply with this request. In 1973 Lindeburg again sought permission to act as an official jeweler for Job's Daughters. Permission was granted for one year and then withdrawn.

The name JOB'S DAUGHTERS and the Job's Daughters insignia are indisputably used to identify the organization, and members of Job's Daughters wear the jewelry to identify themselves as members. In that context, the insignia are trademarks of Job's Daughters. But in the context of this case, the name and emblem are functional aesthetic components of the jewelry, in that they are being merchandised on the basis of their intrinsic value, not as a designation of origin or sponsorship.

It is not uncommon for a name or emblem that serves in one con-

\footnotetext{
${ }^{1}$ The emblem consists of a representation of three girls within a double triangle. The girls carry a dove, an urn, and a cornucopia. Between the bases of the two triangles are the words "Iyob Filiae," the Latin translation of "Daughters of Job."
} 
text as a collective mark or trademark also to be merchandised for its own intrinsic utility to consumers. We commonly identify ourselves by displaying emblems expressing allegiances. Our jewelry, clothing, and cars are emblazoned with inscriptions showing the organizations we belong to, the schools we attend, the landmarks we have visited, the sports teams we support, the beverages we imbibe. Although these inscriptions frequently include names and emblems that are also used as collective marks or trademarks, it would be naive to conclude that the name or emblem is desired because consumers believe that the product somehow originated with or was sponsored by the organization the name or emblem signifies.

Job's Daughters relies on Boston Professional Hockey Ass'n, Inc. $v$. Dallas Cap \& Emblem Mfg., Inc., in which the Boston Bruins and other National Hockey League clubs brought a trademark infringement suit against a company that sold replicas of the NHL team emblems. The Fifth Circuit, applying the Lanham Act infringement test and focusing on the "likelihood of confusion," found infringement:

The confusion or deceit requirement is met by the fact that the defendant duplicated the protected trademarks and sold them to the public knowing that the public would identify them as being the teams' trademarks. The certain knowledge of the buyer that the source and origin of the trademark symbols were the plaintiffs satisfies the requirement of the act. The argument that confusion must be as to the source of the manufacture of the emblem itself is unpersuasive, where the trademark, originated by the team, is the triggering mechanism for the sale of the emblem.

We reject the reasoning of Boston Hockey

Interpreted expansively, Boston Hockey holds that a trademark's owner has a complete monopoly over its use in commercial merchandising. But our reading of the Lanham Act and its legislative history reveals no congressional design to bestow such broad property rights on trademark owners. Its scope is much narrower: to protect consumers against deceptive designations of the origin of goods and, conversely, to enable producers to differentiate their products from those of others. The Boston Hockey decision transmogrifies this narrow protection into a broad monopoly. It does so by injecting its evaluation of the equities between the parties and of the desirability of bestowing broad property rights on trademark owners. A trademark is, of course, a form of business property. But the "property right" or protection accorded a trademark owner can only be understood in the context of trademark law and its purposes. A trademark owner has a property right only insofar as is necessary to prevent consumer confu-
Boston Hockey: 510 F.2d 1004 (5th Cir. 1975) 
sion as to who produced the goods and to facilitate differentiation of the trademark owner's goods. The Boston Hockey court decided that broader protection was desirable. In our view, this extends the protection beyond that intended by Congress and beyond that accorded by any other court.

Our holding does not mean that a name or emblem could not serve simultaneously as a functional component of a product and a trademark. That is, even if the Job's Daughters' name and emblem, when inscribed on Lindeburg's jewelry, served primarily a functional purpose, it is possible that they could serve secondarily as trademarks if the typical customer not only purchased the jewelry for its intrinsic functional use and aesthetic appeal but also inferred from the insignia that the jewelry was produced, sponsored, or endorsed by Job's Daughters. We recognize that there is some danger that the consumer may be more likely to infer endorsement or sponsorship when the consumer is a member of the group whose collective mark or trademark is being marketed. Accordingly, a court must closely examine the articles themselves, the defendant's merchandising practices, and any evidence that consumers have actually inferred a connection between the defendant's product and the trademark owner.

We conclude from our examination of the trial judge's findings and of the underlying evidence that Lindeburg was not using the Job's Daughters name and emblem as trademarks. The insignia were a prominent feature of each item so as to be visible to others when worn, allowing the wearer to publicly express her allegiance to the organization. Lindeburg never designated the merchandise as "official" Job's Daughters' merchandise or otherwise affirmatively indicated sponsorship. Job's Daughters did not show a single instance in which a customer was misled about the origin, sponsorship, or endorsement of Lindeburg's jewelry, nor that it received any complaints about Lindeburg's wares. Finally, there was evidence that many other jewelers sold unlicensed Job's Daughters jewelry, implying that consumers did not ordinarily purchase their fraternal jewelry from only "official" sources. We conclude that Job's Daughters did not meet its burden of proving that a typical buyer of Lindeburg's merchandise would think that the jewelry was produced, sponsored, or endorsed by the organization. The name and emblem were functional aesthetic components of the product, not trademarks. There could be, therefore, no infringement.

\section{c Failure to Attribute}

Section $43(a)$ is not infinitely elastic. 
In this case, we are asked to decide whether $\S 43(a)$ of the Lanham Act prevents the unaccredited copying of a work.

In 1948, three and a half years after the German surrender at Reims, General Dwight D. Eisenhower completed Crusade in Europe, his written account of the allied campaign in Europe during World War II. Doubleday published the book, registered it with the Copyright Office in 1948, and granted exclusive television rights to an affiliate of respondent Twentieth Century Fox Film Corporation (Fox). Fox, in turn, arranged for Time, Inc., to produce a television series, also called Crusade in Europe, based on the book, and Time assigned its copyright in the series to Fox. The television series, consisting of 26 episodes, was first broadcast in 1949. It combined a soundtrack based on a narration of the book with film footage from the United States Army, Navy, and Coast Guard, the British Ministry of Information and War Office, the National Film Board of Canada, and unidentified "Newsreel Pool Cameramen." In 1975, Doubleday renewed the copyright on the book as the "proprietor of copyright in a work made for hire." Fox, however, did not renew the copyright on the Crusade television series, which expired in 1977, leaving the television series in the public domain.

[The respondents held the television rights to General Eisenhower's book and reissued a videotape version of the original television series.]

Enter petitioner Dastar. Anticipating renewed interest in World War II on the 50th anniversary of the war's end, Dastar released a video set entitled World War II Campaigns in Europe. To make Campaigns, Dastar purchased eight beta cam tapes of the original version of the Crusade television series, which is in the public domain, copied them, and then edited the series. Dastar's Campaigns series is slightly more than half as long as the original Crusade television series. Dastar substituted a new opening sequence, credit page, and final closing for those of the Crusade television series; inserted new chapter-title sequences and narrated chapter introductions; moved the "recap" in the Crusade television series to the beginning and retitled it as a "preview"; and removed references to and images of the book. Dastar created new packaging for its Campaigns series and (as already noted) a new title.

Dastar manufactured and sold the Campaigns video set as its own product. The advertising states: "Produced and Distributed by: Entertainment Distributing " (which is owned by Dastar), and makes no reference to the Crusade television series. Similarly, the screen credits state "DASTAR CORP presents" and "an ENTERTAINMENT DISTRIBUTING Production," and list as executive producer, pro-

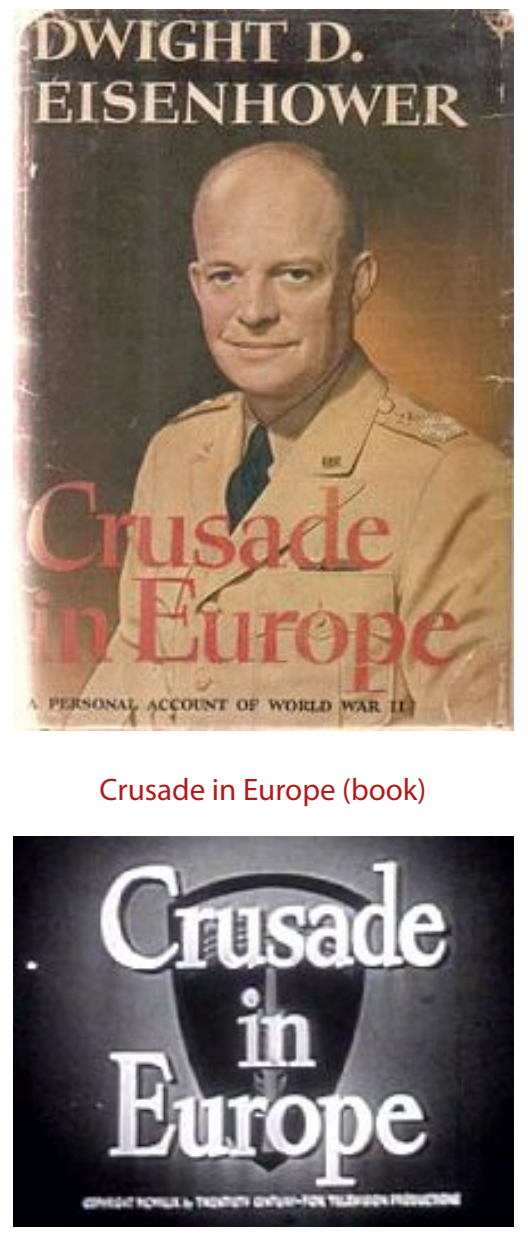

Crusade in Europe (television series)

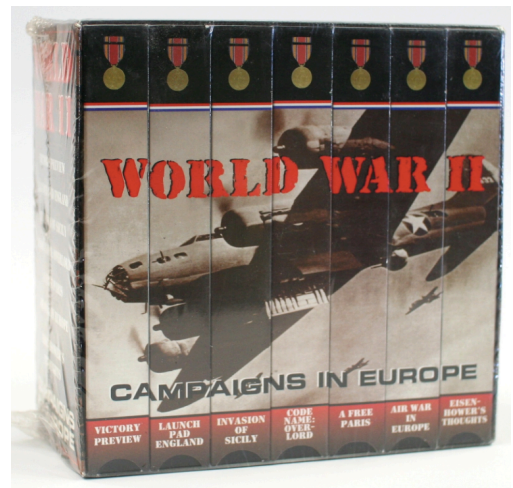

Campaigns in Europe box set 
ducer, and associate producer employees of Dastar. The Campaigns videos themselves also make no reference to the Crusade television series, New Line's Crusade videotapes, or the book. Dastar sells its Campaigns videos to Sam's Club, Costco, Best Buy, and other retailers and mail-order companies for $\$ 25$ per set, substantially less than New Line's video set. In 1998, respondents Fox, SFM, and New Line brought this action alleging that Dastar's sale of its Campaigns video set infringes Doubleday's copyright in General Eisenhower's book and, thus, their exclusive television rights in the book. Respondents later amended their complaint to add claims that Dastar's sale of Campaigns "without proper credit" to the Crusade television series constitutes "reverse passing off" 1 in violation of $\S 43(\mathrm{a})$ of the Lanham Act and in violation of state unfair-competition law.

\section{II}

As it comes to us, the gravamen of respondents' claim is that, in marketing and selling Campaigns as its own product without acknowledging its nearly wholesale reliance on the Crusade television series, Dastar has made a "false designation of origin, false or misleading description of fact, or false or misleading representation of fact, which . . . is likely to cause confusion . . . as to the origin . . . of his or her goods." § 43(a). That claim would undoubtedly be sustained if Dastar had bought some of New Line's Crusade videotapes and merely repackaged them as its own. Dastar's alleged wrongdoing, however, is vastly different: It took a creative work in the public domain - the Crusade television series - copied it, made modifications (arguably minor), and produced its very own series of videotapes. If "origin" refers only to the manufacturer or producer of the physical "goods" that are made available to the public (in this case the videotapes), Dastar was the origin. If, however, "origin" includes the creator of the underlying work that Dastar copied, then someone else (perhaps Fox) was the origin of Dastar's product. At bottom, we must decide what $\S 43(\mathrm{a})(1)(\mathrm{A})$ of the Lanham Act means by the "origin" of "goods."

\section{III}

The dictionary definition of "origin" is "[t]he fact or process of coming into being from a source," and "[t]hat from which anything pri-

Webster's New International Dictionary (2d ed. 1949) marily proceeds; source." . And the dictionary definition of "goods" (as relevant here) is "[w]ares; merchandise." We think the most natural understanding of the "origin" of "goods" - the source of wares - is the producer of the tangible product sold in the marketplace, in

\footnotetext{
${ }^{1}$ Passing off (or palming off, as it is sometimes called) occurs when a producer misrepresents his own goods or services as someone else's. "Reverse passing off," as its name implies, is the opposite: The producer misrepresents someone else's goods or services as his own.
} 
this case the physical Campaigns videotape sold by Dastar. The concept might be stretched to include not only the actual producer, but also the trademark owner who commissioned or assumed responsibility for ("stood behind") production of the physical product. But as used in the Lanham Act, the phrase "origin of goods" is in our view incapable of connoting the person or entity that originated the ideas or communications that "goods" embody or contain.

Section 43(a) of the Lanham Act prohibits actions like trademark infringement that deceive consumers and impair a producer's goodwill. It forbids, for example, the Coca-Cola Company's passing off its product as Pepsi-Cola or reverse passing off Pepsi-Cola as its product. But the brand-loyal consumer who prefers the drink that the CocaCola Company or PepsiCo sells, while he believes that that company produced (or at least stands behind the production of) that product, surely does not necessarily believe that that company was the "origin" of the drink in the sense that it was the very first to devise the formula. The consumer who buys a branded product does not automatically assume that the brand-name company is the same entity that came up with the idea for the product, or designed the product - and typically does not care whether it is. The words of the Lanham Act should not be stretched to cover matters that are typically of no consequence to purchasers.

It could be argued, perhaps, that the reality of purchaser concern is different for what might be called a communicative product - one that is valued not primarily for its physical qualities, such as a hammer, but for the intellectual content that it conveys, such as a book or, as here, a video. The purchaser of a novel is interested not merely, if at all, in the identity of the producer of the physical tome (the publisher), but also, and indeed primarily, in the identity of the creator of the story it conveys (the author). And the author, of course, has at least as much interest in avoiding passing off (or reverse passing off) of his creation as does the publisher. For such a communicative product (the argument goes) "origin of goods" in $\S 43$ (a) must be deemed to include not merely the producer of the physical item (the publishing house Farrar, Straus and Giroux, or the video producer Dastar) but also the creator of the content that the physical item conveys (the author Tom Wolfe, or - assertedly - respondents).

The problem with this argument according special treatment to communicative products is that it causes the Lanham Act to conflict with the law of copyright, which addresses that subject specifically. The right to copy, and to copy without attribution, once a copyright has expired, like the right to make an article whose patent has expired - including the right to make it in precisely the shape it carried when patented - passes to the public. The rights of a patentee or copyright holder are part of a carefully crafted bargain, under which, once the 
patent or copyright monopoly has expired, the public may use the invention or work at will and without attribution. Assuming for the sake of argument that Dastar's representation of itself as the "Producer" of its videos amounted to a representation that it originated the creative work conveyed by the videos, allowing a cause of action under $\S 43(\mathrm{a})$ for that representation would create a species of mutant copyright law that limits the public's federal right to copy and to use expired copyrights.

Reading "origin" in $\S 43(\mathrm{a})$ to require attribution of uncopyrighted materials would pose serious practical problems. Without a copyrighted work as the basepoint, the word "origin" has no discernable limits. A video of the MGM film Carmen Jones, after its copyright has expired, would presumably require attribution not just to MGM, but to Oscar Hammerstein II (who wrote the musical on which the film was based), to Georges Bizet (who wrote the opera on which the musical was based), and to Prosper Mérimée (who wrote the novel on which the opera was based). In many cases, figuring out who is in the line of "origin" would be no simple task. Indeed, in the present case it is far from clear that respondents have that status. Neither SFM nor New Line had anything to do with the production of the Crusade television series - they merely were licensed to distribute the video version. While Fox might have a claim to being in the line of origin, its involvement with the creation of the television series was limited at best. Time, Inc., was the principal, if not the exclusive, creator, albeit under arrangement with Fox. And of course it was neither Fox nor Time, Inc., that shot the film used in the Crusade television series. Rather, that footage came from the United States Army, Navy, and Coast Guard, the British Ministry of Information and War Office, the National Film Board of Canada, and unidentified "Newsreel Pool Cameramen." If anyone has a claim to being the original creator of the material used in both the Crusade television series and the Campaigns videotapes, it would be those groups, rather than Fox. We do not think the Lanham Act requires this search for the source of the Nile and all its tributaries.

Another practical difficulty of adopting a special definition of "origin" for communicative products is that it places the manufacturers of those products in a difficult position. On the one hand, they would face Lanham Act liability for failing to credit the creator of a work on which their lawful copies are based; and on the other hand they could face Lanham Act liability for crediting the creator if that should be regarded as implying the creator's "sponsorship or approval" of the copy. In this case, for example, if Dastar had simply copied the television series as Crusade in Europe and sold it as Crusade in Europe, without changing the title or packaging (including the original credits to Fox), it is hard to have confidence in respondents' assurance 
that they "would not be here on a Lanham Act cause of action,"

In sum, reading the phrase "origin of goods" in the Lanham Act in accordance with the Act's common-law foundations (which were not designed to protect originality or creativity), and in light of the copyright and patent laws (which were), we conclude that the phrase refers to the producer of the tangible goods that are offered for sale, and not to the author of any idea, concept, or communication embodied in those goods. To hold otherwise would be akin to finding that $\S 43$ (a) created a species of perpetual patent and copyright, which Congress may not do.

The creative talent of the sort that lay behind the Campaigns videos is not left without protection. The original film footage used in the Crusade television series could have been copyrighted, as was copyrighted (as a compilation) the Crusade television series, even though it included material from the public domain. Had Fox renewed the copyright in the Crusade television series, it would have had an easy claim of copyright infringement. And respondents' contention that Campaigns infringes Doubleday's copyright in General Eisenhower's book is still a live question on remand. If, moreover, the producer of a video that substantially copied the Crusade series were, in advertising or promotion, to give purchasers the impression that the video was quite different from that series, then one or more of the respondents might have a cause of action - not for reverse passing off under the "confusion . . . as to the origin" provision of $\S 43(\mathrm{a})(1)(\mathrm{A})$, but for misrepresentation under the "misrepresents the nature, characteristics [or] qualities" provision of $\S 43(\mathrm{a})(1)(\mathrm{B})$. For merely saying it is the producer of the video, however, no Lanham Act liability attaches to Dastar. [oojes]

\section{Dilution}

Now we move from section 43(a) to section 43(c). We start with some background on the history and theory of dilution, then the statute, then an example.

\section{Frank I. Schechter}

\section{The Rational Basis of Trademark Protection}

We have seen that the proper expansion of trademark law has been hampered by obsolete conceptions both as to the function of a trademark and as to the need for its protection. Commencing with the assumption that a trademark designates either origin or ownership - in other words, source- - he law, even in its most liberal interpretation at the present time, will prevent the misuse of that mark only where there is an actual confusion created by such misuse, resulting in either diversion of trade or other concrete financial liability or injury to 
trade repute. However, we have intimated the possibility that the use of trademarks on entirely non-related goods may of itself concretely injure the owner of the mark even in the absence of those elements of damage noted above. If so, what is the injury, and to what extent, if any, should the law take cognizance of such injury?

Trademark pirates are growing more subtle and refined. They proceed circumspectly, by suggestion and approximation, rather than by direct and exact duplication of their victims' wares and marks. The history of important trademark litigation within recent years shows that the use of similar marks on non-competing goods is perhaps the normal rather than the exceptional case of infringement. In the famous English Kodak case, cameras and bicycles were the articles in question; in the Aunt Jemima's case, pancake flour and syrup; in the Vogue case, fashion magazines and hats; in the Rolls-Royce case, automobiles and radio parts; in the Beech-Nut case, food products and cigarettes. In each in- stance the defendant was not actually diverting custom from the plaintiff, and where the courts conceded the absence of diversion of custom they were obliged to resort to an exceedingly laborious spelling out of other injury to the plaintiff in order to support their decrees. The real injury in all such cases can only be gauged in the light of what has been said concerning the function of a trade- mark. It is the gradual whittling away or dispersion of the identity and hold upon the public mind of the mark or name by its use upon non-competing goods. The more distinctive or unique the mark, the deeper is its impress upon the public consciousness, and the greater its need for protection against vitiation or dissociation from the particular product in connection with which it has been used.

The following principles necessarily emerge: (1) that the value of the modern trademark lies in its selling power; (2) that this selling power depends for its psychological hold upon the public, not merely upon the merit of the goods upon which it is used, but equally upon its own uniqueness and singularity; (3) that such uniqueness or singularity is vitiated or impaired by its use upon either related or nonrelated goods; and (4) that the degree of its protection depends in turn upon the extent to which, through the efforts or ingenuity of its owner, it is actually unique and different from other marks.

Jeremy N. Sheff

\section{The (Boundedly) Rational Basis of Trademark Liability}

Schechter's theory of dilution rested on the premise that the ability of a trademark to serve as a vehicle for creating and perpetuating goodwill depends on its "uniqueness," and that multiple unrelated uses of an unusual or distinctive mark will prevent that mark from developing a strong, unique hold on the public consciousness. This the- 
ory would give the first user of a particularly unique or distinctive mark the right to enforce her mark broadly-not merely within the geographic markets in which she operated, but also in neighboring regions; not merely against competing products, but also against sellers of non-competing goods-all on the theory that any interference with her efforts to build and retain the association of goodwill with her trademark threatens gradually to weaken that association, thereby reducing her incentive to cultivate such goodwill.

Ty Inc. v. Perryman

But what is "dilution"? There are (at least) three possibilities relevant to this case, each defined by a different underlying concern. First, there is concern that consumer search costs will rise if a trademark becomes associated with a variety of unrelated products. Suppose an upscale restaurant calls itself "Tiffany." There is little danger that the consuming public will think it's dealing with a branch of the Tiffany jewelry store if it patronizes this restaurant. But when consumers next see the name "Tiffany" they may think about both the restaurant and the jewelry store, and if so the efficacy of the name as an identifier of the store will be diminished. Consumers will have to think harder - incur as it were a higher imagination cost - to recognize the name as the name of the store. Cf. Mead Data Central, Inc. v. Toyota Motor Sales, U.S.A., Inc. ("The [legislative] history [of New York's antidilution statute] disclosed a need for legislation to prevent such 'hypothetical anomalies' as 'Dupont shoes, Buick aspirin tablets, Schlitz varnish, Kodak pianos, Bulova gowns"'). So "blurring" is one form of dilution.

Now suppose that the "restaurant" that adopts the name "Tiffany" is actually a striptease joint. Again, and indeed even more certainly than in the previous case, consumers will not think the striptease joint under common ownership with the jewelry store. But because of the inveterate tendency of the human mind to proceed by association, every time they think of the word "Tiffany" their image of the fancy jewelry store will be tarnished by the association of the word with the strip joint. So "tarnishment" is a second form of dilution.

\section{Lanham Act}

(c) Dilution by blurring; dilution by tarnishment. -

(1) Injunctive relief. - Subject to the principles of equity, the owner of a famous mark that is distinctive, inherently or through acquired distinctiveness, shall be entitled to an injunction against another person who, at any time after the owner's mark has become famous, commences use of a mark or trade name in commerce that is likely to cause
306 F.3d 509 (7th Cir. 2002)

(Posner, J.)

Mead Data Centra: 875 F.2d 1026 (2d Cir. 1989)

15 U.S.C. § 1125

Lanham Act § 43

False designations of origin, false descriptions, and dilution forbidden 
dilution by blurring or dilution by tarnishment of the famous mark, regardless of the presence or absence of actual or likely confusion, of competition, or of actual economic injury.

\section{(2) Definitions. -}

(A) For purposes of paragraph (1), a mark is famous if it is widely recognized by the general consuming public of the United States as a designation of source of the goods or services of the mark's owner. In determining whether a mark possesses the requisite degree of recognition, the court may consider all relevant factors, including the following:

(i) The duration, extent, and geographic reach of advertising and publicity of the mark, whether advertised or publicized by the owner or third parties.

(ii) The amount, volume, and geographic extent of sales of goods or services offered under the mark.

(iii) The extent of actual recognition of the mark.

(iv) Whether the mark was registered ...

(B) For purposes of paragraph (1), "dilution by blurring" is association arising from the similarity between a mark or trade name and a famous mark that impairs the distinctiveness of the famous mark. In determining whether a mark or trade name is likely to cause dilution by blurring, the court may consider all relevant factors, including the following:

(i) The degree of similarity between the mark or trade name and the famous mark.

(ii) The degree of inherent or acquired distinctiveness of the famous mark.

(iii) The extent to which the owner of the famous mark is engaging in substantially exclusive use of the mark.

(iv) The degree of recognition of the famous mark.

(v) Whether the user of the mark or trade name intended to create an association with the famous mark.

(vi) Any actual association between the mark or trade name and the famous mark.

(C) For purposes of paragraph (1), "dilution by tarnishment" is association arising from the similarity between a mark or trade name and a famous mark that 
harms the reputation of the famous mark.

Nike, Inc. v. Nikepal Intern., Inc.

The following findings of fact and conclusions of law issue as a result of a bench trial conducted in this trademark action. Plaintiff Nike, Inc. ("Nike"), a company headquartered in Beaverton, Oregon which uses the mark NIKE, contests the use of the mark NIKEPAL by Defendant Nikepal International, Inc. ("Nikepal"), a company located in Sacramento, California.

Nike seeks an injunction preventing Nikepal from using the term "Nike" (or any term confusingly similar thereto) alone or as part of any trademark, domain name or business name under which Nikepal offers goods or services in commerce.

Findings OF FACT

\section{The Parties And their Businesses}

\section{A. Nike}

Nike was incorporated in 1968 under the original company name Blue Ribbon Sports. In 1971, it adopted the NIKE mark to brand its footwear products and in May 1978, the company's name was officially changed to "Nike, Inc." Today, Nike is the largest seller of athletic footwear and apparel in the world. Nike sells around 180 million pairs of shoes annually in the United States alone. Nike's principal business activity is the design, development, and worldwide marketing and distribution of high quality and technologically advanced footwear, apparel, equipment, and accessories. Nike has continuously used the NIKE mark on and in connection with the various products offered by the company since the 1970s. Sometimes, the word mark NIKE is the only brand used; sometimes, Nike's Swoosh design mark (i.e. the logo which frequently appears on products along with NIKE, and in some instances alone) is also placed on the product.

\section{B. Nikepal}

Nikepal was incorporated on May 18, 1998 by the company's founder and president, Palminder Sandhu ("Mr. Sandhu"), who then began using the NIKEPAL mark in commerce. Nikepal provides services and products to analytical, environmental, and scientific laboratories. Nikepal's trademark application to the PTO requested registration for: "import and export agencies and wholesale distributorships featuring scientific, chemical, pharmaceutical, biotechnology testing instruments and glassware for laboratory use, electrical instruments, paper products and household products and cooking appliances."

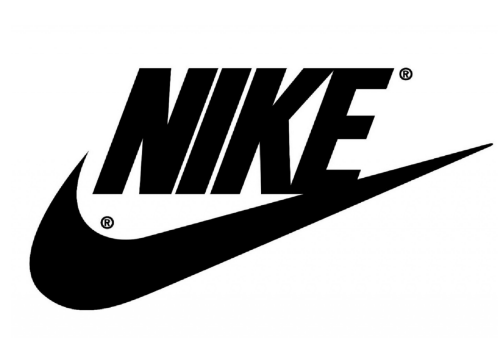

Nike logo

No. 2:05-CV-1468-GEB-JFM, 2007 WL 2782030 (E.D. Cal. Sept. 18, 2007) 
Nikepal distributes glass syringes in varying volumes and other laboratory products to testing and power companies and also distributes paper boxes (syringe carrying cases) and nylon valves and caps for use with the syringes. Nikepal only distributes its products to laboratories, not to individuals.

Nikepal does not have a retail office, but operates its business through its website (located at www.nikepal.com), via email, and via telephone. Nikepal is run by Mr. Sandhu, who also works as a transportation engineer. Currently, Nikepal has one other part-time employee. Nikepal has only a few hundred customers, but it has a list of thousands of prospective customers, some of whom receive materials from Nikepal advertising its product and service offerings under the mark NIKEPAL.

\section{The Parties' Marks}

\section{A. NIKE}

Nike first registered the NIKE mark with the PTO in February 1974. Nike owns ten (10) federal trademark registrations for the NIKE mark alone, covering footwear, clothing, bags, timepieces, paper products such as notebooks and binders, sport balls, swim accessories, and retail store services, all of which related to pre-May 1998 uses of the mark. By May 1998, Nike was also using and applied for trademark registrations covering the use of the NIKE mark in combination with other terms or designs for footwear, clothing, bags, timepieces, posters, sport balls, swim accessories, weights, gloves, headgear, and retail store services. For example, Nike owns nineteen (19) federal registrations for NIKE composite marks such as: NIKE and the Swoosh design which has been in use since 1971; NIKE NIKE AIR which has been in use since 1987; NIKE-FIT which has been in use since 1990; NIKE TOWN which has been in use since 1990; NIKE SHOP which has been in use since 1991; and NIKE GOLF which has been in use since 1993. From 1998 to the present, Nike has continued to use the mark NIKE alone and in combination with other terms or designs.

\section{B. NIKEPAL}

Mr. Sandhu testified that he conceived of the term Nikepal when he wanted to create a vanity license plate for his car. He testified that he selected the word "Nike" by opening a dictionary to a random page and choosing the first word he saw, and then combined it with the first three letters of his first name "Pal." ("Pal" means friend or benefactor. Mr. Sandhu admits he knew of the existence of the company Nike and its use of the NIKE mark at the time he devised the term NIKEPAL. Despite Mr. Sandhu's trial testimony concerning the 
manner in which he conceived of the term NIKEPAL, the court does not find it to be credible.

The "Nike" portion of the NIKEPAL mark is pronounced the same way as the NIKE mark is pronounced: with a hard " $\mathrm{i}$ " (like bike) in the first syllable and a hard "e" (like in "key") in the second syllable. The articles of incorporation signed by Mr. Sandhu for Nikepal in 1998 display the company name as "NikePal International, Inc.," with the first word of the company name spelled "NikePal," with a capital "N" and a capital "P."

In addition to using Nikepal as the company name, NIKEPAL appears directly on some of Nikepal's products, including on its syringe products, and on its marketing materials. Nikepal also places www.nikepal.com on its syringes to identify the source of the syringe. Nikepal also uses the NIKEPAL mark in a vanity phone number (1877-N-I-K-E-P-A-L), on its website, and in its domain names, including nikepal.com, nikepal.biz, nikepal.us, nikepal.tv, nikepal.info, and nikepal.net.

\section{NIKE's SALES}

By the late 1980s, United States sales of NIKE branded products were over one billion dollars per year. Starting in 1991 and through the mid 1990s, sales of NIKE products in the United States were approximately two billion dollars per year, and were above five billion dollars per year by 1997. By 1997, Nike was the largest seller of athletic footwear and apparel in the world. The geographic area of Nike's sales includes the United States and 140 countries throughout the world. Since 1997, Nike has sold over 100,000,000 pairs of NIKE shoes each year.

\section{Advertising and Promotion of the NIKE Mark}

Nike has undertaken significant expense to promote the NIKE mark. Nike advertises in various types of media, including traditional print advertising, such as magazines (of both special and general interest), newspapers (of general circulation), leaflets, and billboards. Nike also advertises in electronic media, including radio, television, cable and internet, on sides of buildings, on taxi cabs, and through direct mailings. Nike's television advertisements have run on network

\footnotetext{
${ }^{2} \mathrm{Nikepal}$ 's attorney attempted to convince the court that there is a pronunciation difference between NIKE and NIKEPAL. In her questions during trial, for example, she pronounced Nikepal's mark as "nik-a-pal." However, in answering her questions at trial, Mr. Sandhu, the president of Nikepal, alternated between the pronunciation of NIKEPAL as "nik-a-pal" and as "Ny-key-pal." Further, Nike's witness, Joseph Sheehan, a former FBI agent and now a private investigator, provided a tape recording of the outgoing message heard on Nikepal's answering machine which clearly pronounced the term "Nike" with long, or hard, vowels, that is an "i" like in "bike" and "e" like in "key" identical to the pronunciation of the Nike's trademark.
} 
channels and have reached national audiences. Nike has also promoted its mark by associating with athletes through endorsement arrangements. By 1991, Nike was spending in excess of one hundred million dollars per year in the United States alone to advertise products bearing the NIKE mark. By 1997, Nike had spent at least $\$ 1,567,900,000.00$ to promote the NIKE mark in the United States.

\section{Notoriety OF NIKE}

The NIKE mark has been consistently ranked as a top brand in publications that survey the top brands each year. Since at least 1990, Nike has been named one of the top forty (40) brands in the United States based on the EquiTrend and other studies published in BrandWeek and Financial World Magazine. Other brands ranked in such studies include FRITO LAY, LEVI'S, CAMPBELLS', HEWLETT-PACKARD, SONY, PEPSI, and VISA. One story printed in Forbes magazine, reported a survey conducted by Young \& Rubicam that ranked the NIKE brand among the top ten (10) in the United States in 1996 with COKE, DISNEY, and HALLMARK.

\section{Evidence of Actual Association}

A survey conducted by Phillip Johnson of Leo J. Shapiro and Associates ("Mr. Johnson's survey"), a Chicago-based market research firm, determined that a significant number of Nikepal's potential laboratory customers actually associated NIKE with NIKEPAL. Mr. Johnson is an expert at designing surveys that measure consumer behavior.

In designing his study, Mr. Johnson used a universe of survey participants randomly selected from lists of companies that Mr. Sandhu's deposition testimony identified as the sources for Nikepal's current and prospective customers. Mr. Johnson conducted the survey by phone and asked respondents about their perception of a website called nikepal.com. In designing his survey, Mr. Johnson chose one of the ways that the NIKEPAL mark is used in commerce which allowed him to reasonably recreate a purchasing context while obtaining a controlled and accurate measurement. Mr. Johnson testified that this survey replicated the circumstances in which people typically encountered the NIKEPAL mark.

Once survey respondents were screened to confirm that they were the persons most responsible for ordering laboratory equipment at their business, they were asked: "What if anything, came to your mind when I first said the word Nikepal?" Many survey respondents who were not actually confused about the source of the Nikepal website nonetheless identified Nike. Mr. Johnson testified that his survey revealed that the vast majority of respondents, $87 \%$, associated Nikepal with Nike; that is, when they encounter the mark NIKEPAL, 
they think of Nike and/or its offerings.

Conclusions of Law

\section{Dilution}

Under the Federal Trademark Dilution Revision Act

The owner of a famous mark that is distinctive, inherently or through acquired distinctiveness, shall be entitled to an injunction against another person who, at any time after the owner's mark has become famous, commences use of a mark or trade name in commerce that is likely to cause dilution by blurring or dilution by tarnishment of the famous mark, regardless of the presence or absence of actual or likely confusion, of competition, or of actual economic injury.

15 U.S.C. § 1125(c)(1) ("TDRA"). To prevail on its dilution claim, Nike must prove 1) that its mark was famous as of a date prior to the first use of the NIKEPAL mark and 2) that Nikepal's use of its allegedly diluting mark creates a likelihood of dilution by blurring or tarnishment.

\section{A. Whether NIKE Was Famous Prior to the First Use of NIKEPAL}

A "famous" mark is one that "is widely recognized by the general consuming public of the United States as a designation of source of the goods or services of the mark's owner." 15 U.S.C. §1125(c)(2)(A). [The court quoted the four statutory factors.]

Since Nikepal's first use of NIKEPAL commenced in May 1998, Nike must show that NIKE was famous before that date.

\footnotetext{
${ }^{5}$ The TDRA, signed into law on October 6, 2006, amended the previous federal anti-dilution statute (the Federal Trademark Dilution Act ("FTDA")). The TDRA revises the FTDA in three ways: it establishes that likelihood of dilution, and not actual dilution, is a prerequisite to establish a dilution claim; it sets forth four relevant factors courts may consider in determining famousness; and it also lists six relevant factors that courts may consider in determining whether a likelihood of dilution exists.

${ }^{6}$ California's anti-dilution statute, under which Nike also brings a claim, prescribes:

Likelihood of injury to business reputation or a dilution of the distinctive quality of a mark registered under this chapter, or a mark valid at common law, or a trade name valid at common law, shall be a ground for injunctive relief notwithstanding the absence of competition between parties or the absence of confusion as to the source of goods or services.
}

Cal. Bus. \& Prof.Code $\S 14330$. If Nike prevails on its federal dilution claim, it will also prevail on its dilution claim under California law. 
With regard to the first factor, the evidence clearly establishes that through various combinations of athlete endorsements, television, radio, print media, and billboard placements, NIKE was promoted nationally for more than two decades before 1998. By the 1990s, Nike was had spent in excess of a billion dollars for promotion of NIKE products in the United States.

With regard to the second factor, Nike's sales of NIKE products reached the billion dollar per year level in the United States well before May 1998. By 1997, Nike had spent in excess of one billion dollars to promote the NIKE mark in the United States.

Nike also satisfies the third factor, since recognition of the success of NIKE has been recorded by various publications in surveys and articles written prior to May 1998. Since the early 1990s, NIKE has been consistently ranked as a top brand in brand surveys in the United States and the world. Mr. Johnson, who in his professional capacity is familiar with the reputation and methodology used in various brand surveys and literature, opined that these sources evinced that NIKE was famous during the mid 1990s, before Nikepal adopted its mark in 1998. Nikepal counters that only Nike's Swoosh design mark, and not the NIKE mark itself, is famous. However, Mr. Johnson's survey revealed that when participants were exposed solely to the word "Nike" without the Swoosh, the response overwhelmingly indicated recognition of the NIKE mark.

Finally, with regard to the fourth factor, the NIKE mark is registered on the PTO's principal register. Nike owns ten federal registrations for NIKE covering uses prior to 1998 which include retail services, bags, footwear, apparel, heart monitors, electrical items and paper products. Accordingly, the court concludes that NIKE was famous prior to Nikepal's first use of the NIKEPAL mark.

\section{B. Likelihood of Dilution by Blurring}

The TDRA defines dilution by blurring as an "association arising from the similarity between a mark or trade name and a famous mark that impairs the distinctiveness of the famous mark." 15 U.S.C. § 1125(c)(2)(A). [The court quoted the six statutory factors.]

(i) The Degree of Similarity

Marks in a dilution analysis must be identical or nearly identical. For marks to be nearly identical to one another, they must be similar enough that a significant segment of the target group of customers sees the two marks as essentially the same.

The parties' marks are nearly identical. The NIKEPAL mark is a composite of the word "Nike" with the term of affinity, "pal." The composite nature of the NIKEPAL mark is evident in the logo selected by the company which clearly features an "N" and a "P." In each 
case the dominant feature of the mark is the term "Nike." In addition, the term "Nike" in both marks is pronounced identically with an "i" like in "bike" and an "e" like in "key." See Porsche Cars N. Am. Inc. $v$. Spencer (finding that the trademark PORSCHE was diluted by PORCHESOURCE.COM); see also Jada Toys, Inc. v. Mattel, Inc. (concluding "that a reasonable trier of fact could find that the HOT WHEELS and HOT RIGZ marks are nearly identical.").

Further, as shown by Mr. Johnson's survey, the vast majority of the survey respondents, representing a significant segment of Nikepal's target customer group, associate Nike and/or its products and services when they encounter the mark NIKEPAL, thus perceiving the two marks as essentially the same. Accordingly, this factor favors Nike.

\section{(ii) Distinctiveness}

Nikepal does not dispute that NIKE is, at the very least, suggestive. Accordingly, NIKE is inherently distinctive and this factor favors Nike.

\section{(iii) Substantially Exclusive Use}

The law does not require that use of the famous mark be absolutely exclusive, but merely "substantially exclusive." Therefore, a limited amount of third party use is insufficient to defeat a showing of substantially exclusive use.

Nike asserts that its use of the NIKE mark is substantially exclusive. Nikepal introduced evidence of use of the term "Nike" in the company name "Nike Hydraulics, Inc.," through a bottle jack purchased from the company and a 1958 trademark registration for "Nike" owned by Nike Hydraulics. However, this evidence is insufficient to disprove Nike's claim that its use of NIKE is substantially exclusive. Even Nikepal's witness, Roger Smith, admitted that he had not encountered Nike Hydraulics before hearing that name in connection with this action. Accordingly, the court finds that Nike's use of the NIKE mark is substantially exclusive and this factor therefore favors Nike. . $^{-1}$

\section{(iv) Degree of Recognition}

\footnotetext{
${ }^{9}$ Nikepal also introduced evidence that the term "Nike" appears in dictionaries referring to the Greek goddess of victory, that the image of Nike the goddess appeared on some Olympic medals, and that the United States Government named one of its missile programs "Nike." However, Nikepal did not show that these uses were made in commerce in association with the sale or marketing of goods or services as required under the TDRA. (See 15 U.S.C. § 1125(c) (1) (providing that under the TDRA, only "use of a mark or trade name in commerce" is actionable as diluting a famous mark.).)
}

Porsche Cars: No. Civ. S-00-471, 2000

WL 641209 (E.D. Cal. 2000)

Jada Toys: 496 F.3d 974 (2007) 
The degree of recognition of NIKE is quite strong. Millions of NIKE products are sold in the United States annually and the evidence demonstrates that NIKE is readily recognized. This factor therefore favors Nike.

\section{(v) Intent to Create Association}

Mr. Sandhu admitted that he was aware of the existence of the NIKE mark before he adopted the company name. Although he testified at trial that he came up with the term Nikepal by opening the dictionary to a random page and essentially finding that word by "fate," his testimony was not credible. Therefore, this factor favors Nike.

\section{(vi) Actual Association}

Nikepal registered the domain names nikepal.biz, nikepal.net, nikepal.us, nikepal.info and nikepal.tv. The evidence shows that the domain registrar assigned the domain names an "under construction" page and then associated with that page promotions and advertisement links to a number of web pages that offered NIKE products (or products of Nike's competitors in the shoe and apparel field). Thus, in the internet context, there is actual association between NIKEPAL and NIKE.

Further, Mr. Johnson's survey also evinced that there is a strong degree of association between NIKEPAL and NIKE. Mr. Johnson's survey showed over $87 \%$ of the people in Nikepal's own customer pool associated the stimulus "Nikepal" with NIKE. The survey presents ample proof of association between the marks to support a finding that such exists in the general public. Accordingly, the court finds that there is actual association between the NIKEPAL and NIKE marks and this factor favors Nike.

In conclusion, since the six factors considered in the likelihood of dilution analysis favor Nike, there is a likelihood that NIKE will suffer dilution if Nikepal is allowed to continue its use of NIKEPAL. Accordingly, Nike prevails on its federal and state dilution claims.

\section{Dilution Lightning Round}

In each case, what kind or kinds of trademark infringement are at stake: confusion about source, confusion about sponsorship, dilution by blurring, or dilution by tarnishment? Should a court find a violation of the trademark owner's rights. (The respective marks are TIFFANY'S for jewelry, I CAN'T BELIEVE IT'S NOT BUTTER! for margarine, and NEW YORK STOCK EXCHANGE for securitiestrading services.) 

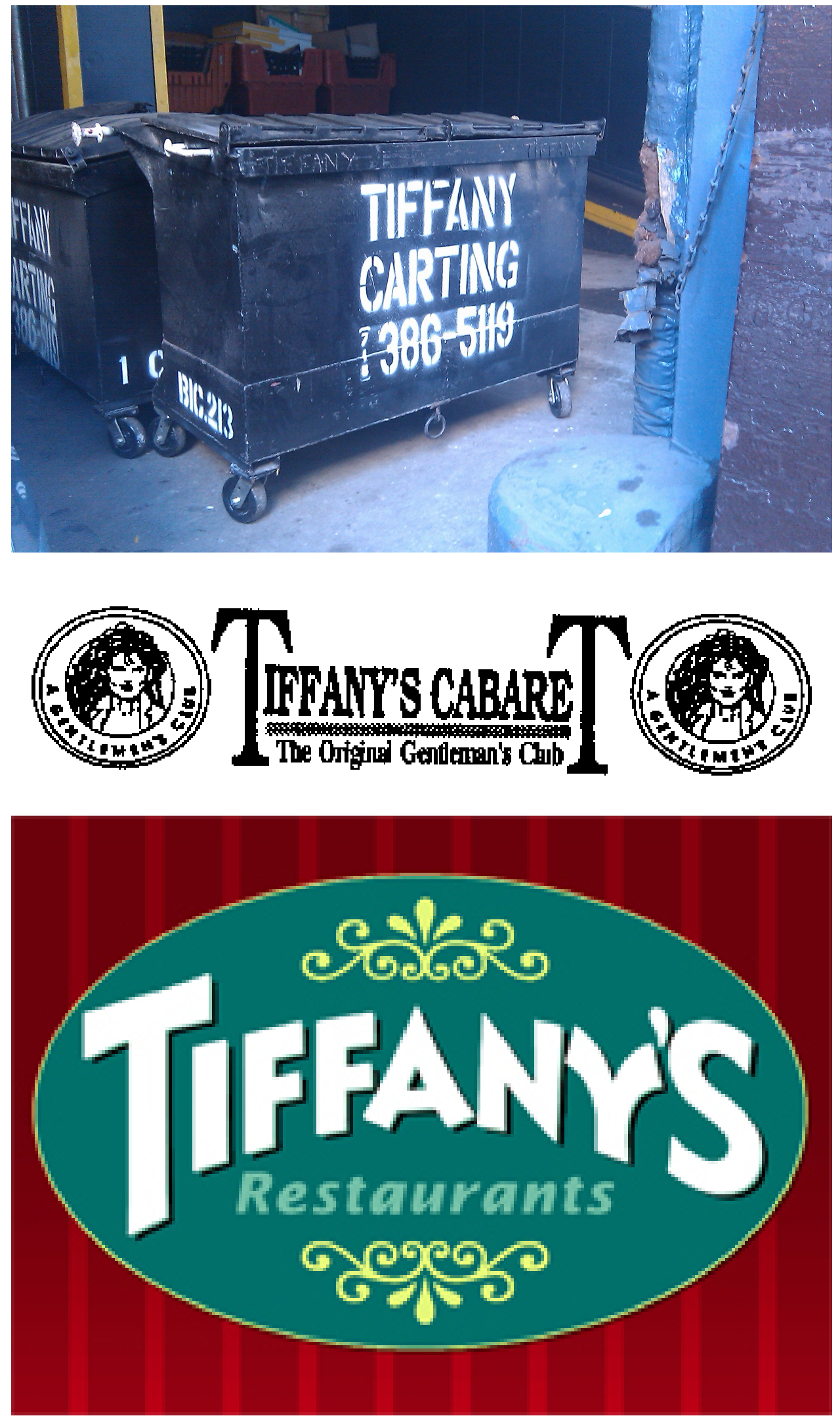

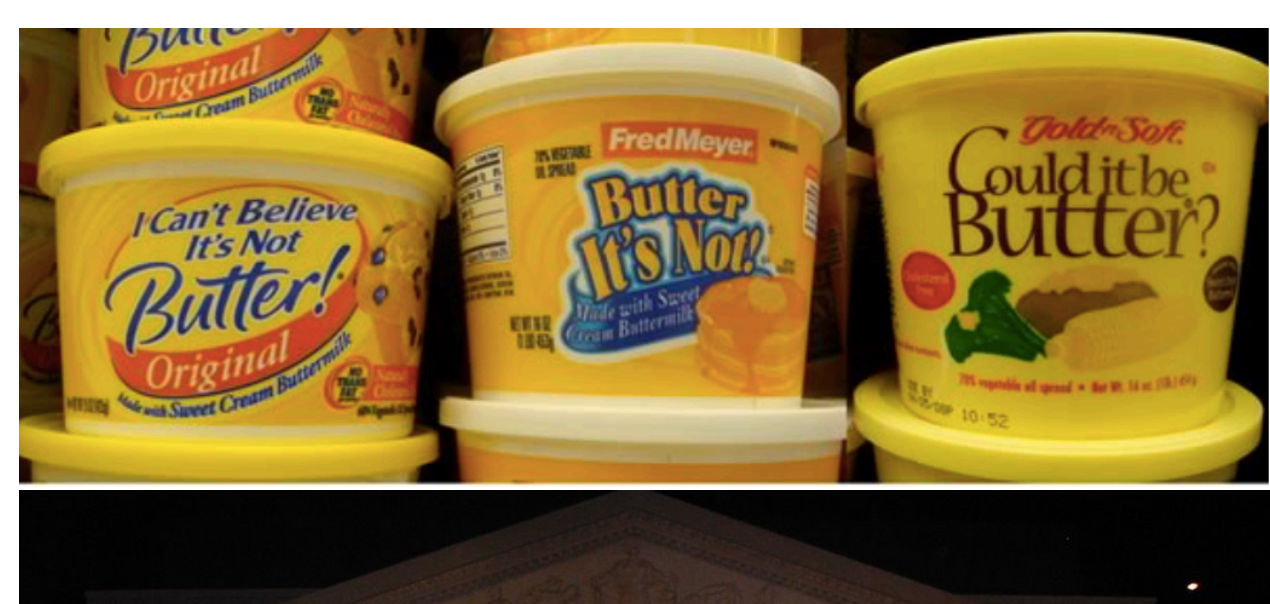

\section{Problems}

\section{Ambush Marketing Problem}

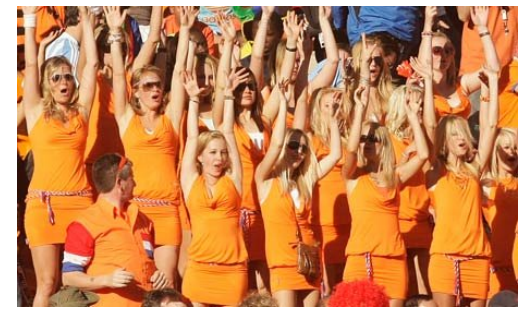

Women wearing orange
Section 15A of South Africa's Merchandise Marks Act, as amended in 2002, provides that certain events may be designated as "protected" and that

For the period during which an event is protected, no person may use a trade mark in relation to such event in a manner which is calculated to achieve publicity for that trade mark and thereby to derive special promotional benefit from the event, without the prior authority of the organiser of such event.

Note that "a trade mark" need not be the mark of the event's orga- 
nizer - section 15A prohibits the use of any trademark in this manner.

In 2010, South Africa was the host nation for the FIFA World Cup.Thirty-six women attended the Netherlands-Denmark game wearing orange dresses. Orange is the national color of the Netherlands, and also is used prominently in advertising for the Dutch beer company Bavaria. Did Bavaria or the women violate section 15A? If they had done this in the United States, would they have violated any provisions of the Lanham Act?

\section{Jack Daniel's Problem}

The image on the top is the world-famous label from JACK DANIEL'S whiskey. The image on the right is the front cover of a novel by Patrick Wensink. Infringement?

\section{Paper Handbag Problem}

These "handbags" bearing the GUCCI logo are actually made of paper. In Chinese religious traditions, people burn them - along with other paper effigies of luxury goods and paper "money" in denominations up to $\$ 5,000,000,00$ - as offerings to deceased relatives. Very loosely, the idea is that doing so provides for the relatives' comfort in the afterlife. Does Gucci have the right under trademark law to prevent the sale of these items bearing its trademarks?

\section{Secondary Liability}

Inwood Laboratories, Inc. v. Ives Laboratories, Inc.

[Ives sold the drug cyclandelate under the trademark CYCLOSPASMOL. Ives marketed the drug, a white powder, to wholesalers, retail pharmacists, and hospitals in colored gelatin capsules. It used a blue capsule, imprinted with "Ives 4124," for its $200 \mathrm{mg}$ dosage and a combination blue-red capsule, imprinted with "Ives 4148," for its $400 \mathrm{mg}$ dosage. After Ives' patent on cyclandelate expired, several generic manufacturers, including the respondents, marketed cyclandelate in $200 \mathrm{mg}$ and $400 \mathrm{mg}$ capsules in colors identical to those selected by Ives, but with no identifying marks or different ones than Ives used.]

The generic manufacturers also follow a normal industry practice by promoting their products primarily by distribution of catalogs to wholesalers, hospitals, and retail pharmacies, rather than by contacting physicians directly. The catalogs truthfully describe generic cyclandelate as "equivalent" or "comparable" to CYCLOSPASMOL. In addition, some of the catalogs include price comparisons of the generic drug and CYCLOSPASMOL and some refer to the color of the generic capsules. The generic products reach wholesalers, hospitals, and pharmacists in bulk containers which correctly indicate the manufacturer of the product contained therein.

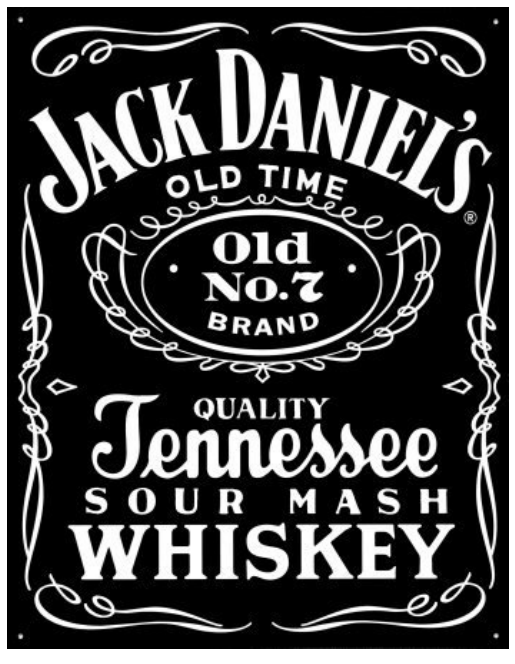

Jack Daniel's logo

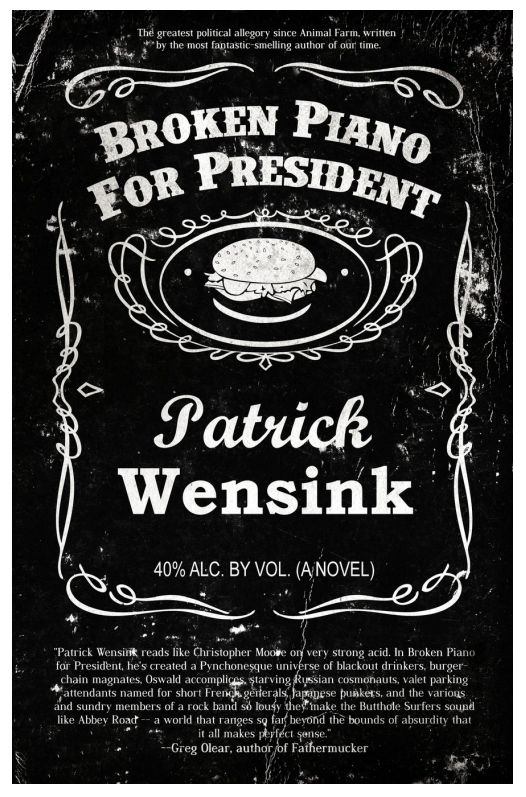

Broken Piano for President cover

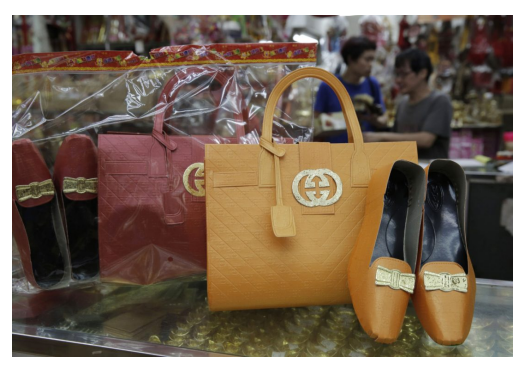

GUCCI "handbags"

456 U.S. 844 (1982) 


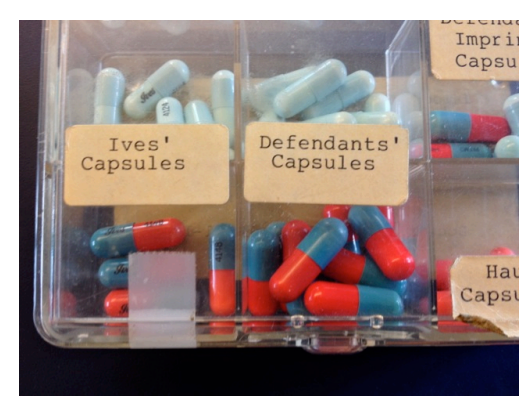

Cyclandelate capsules

547 F. Supp. 2d 667 (W.D. Tex 2008)

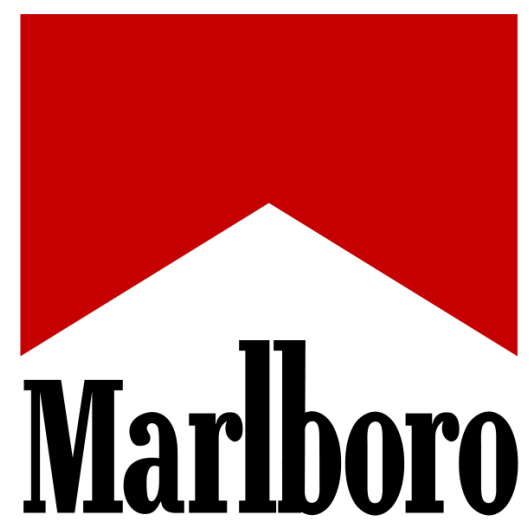

MARLBORO logo
A pharmacist, regardless of whether he is dispensing CYCLOSPASMOL or a generic drug, removes the capsules from the container in which he receives them and dispenses them to the consumer in the pharmacist's own bottle with his own label attached. Hence, the final consumer sees no identifying marks other than those on the capsules themselves.

[Ives sued for trademark infringement. It alleged that some druggists ignored physicians' written instructions to dispense only CYCLOSPASMOL and dispensed generic products instead, and that some druggists mislabeled generic drugs as CYCLOSPASMOL.] Ives contended that the generic manufacturers' use of look-alike capsules and of catalog entries comparing prices and revealing the colors of the generic capsules induced pharmacists illegally to substitute a generic drug for CYCLOSPASMOL and to mislabel the substitute drug CYCLOSPASMOL. Although Ives did not allege that the petitioners themselves applied the Ives trademark to the drug products they produced and distributed, it did allege that the petitioners contributed to the infringing activities of pharmacists who mislabeled generic cyclandelate.

As the lower courts correctly discerned, liability for trademark infringement can extend beyond those who actually mislabel goods with the mark of another. Even if a manufacturer does not directly control others in the chain of distribution, it can be held responsible for their infringing activities under certain circumstances. Thus, if a manufacturer or distributor intentionally induces another to infringe a trademark, or if it continues to supply its product to one whom it knows or has reason to know is engaging in trademark infringement, the manufacturer or distributor is contributorially responsible for any harm done as a result of the deceit.

It is undisputed that those pharmacists who mislabeled generic drugs with Ives' registered trademark violated $\S 32$. However, whether these petitioners were liable for the pharmacists' infringing acts depended upon whether, in fact, the petitioners intentionally induced the pharmacists to mislabel generic drugs or, in fact, continued to supply cyclandelate to pharmacists whom the petitioners knew were mislabeling generic drugs.

\section{Philip Morris USA Inc. v. Lee}

\section{FACTUAL AND PROCEDURAL BACKGROUND}

Plaintiff is the registered owner of the Marlboro word mark and the Marlboro Roof Design label mark (collectively, the "Marlboro Marks"), which it uses in connection with its tobacco products. Plaintiff initiated the present suit against numerous defendants, including Defendant Motohiro Miyagi ("Miyagi”). 
Evidence submitted by Plaintiff, along with the Affidavits, indicates that Miyagi is a sales and distribution agent for Metrich International Company, a Chinese company that manufactures counterfeit cigarettes. Miyagi admits that, since 1999, he has been managing and arranging for the sale of these goods, which he knows are counterfeit. For his services, Miyagi receives a $\$ 10.00$ commission per case.

Plaintiff alleges that Miyagi orchestrated a conspiracy to illegally import 978 master cases of counterfeit Marlboro cigarettes into the United States. In August 2003, Miyagi obtained control over a large quantity of counterfeit Marlboro cigarettes manufactured by Metrich. The goods were stored in a warehouse in Curaçao, Netherlands Antilles. Miyagi was responsible for finding people to purchase the goods. To assist him, Miyagi contacted Florida-based Julian Balea and arranged for Balea, and his company, Synergy Trading Group, Inc., to advertise and offer the counterfeit cigarettes for sale to buyers in the United States. Acting as Miyagi's agent, Balea advertised the counterfeit Marlboro cigarettes for sale on an Internet website.

William Lee and Felipe Castaneda, partners doing business together in El Paso, Texas, as the Kagro Company, responded to the Internet advertisement, and offered to buy the counterfeit cigarettes. According to the sales invoice, Balea, Lee, and Castaneda reached a deal whereby Kagro agreed to purchase 1,960 master cases of counterfeit Marlboro cigarettes. At his deposition, Balea testified that Miyagi dictated the terms of the deal and retained final authority to approve the transaction.

Once the deal was negotiated, Miyagi prepared to ship the counterfeit cigarettes from Curaçao to the United States. He enlisted the services of John Tominelli ("Tominelli") and his company, Southeastern Cargo Services, Inc. ("Southeastern"), to inspect the goods in Curaçao. Miyagi traveled to Curaçao and attended the inspection. After inspecting the goods, Tominelli issued a report that listed their quantity, packaging, and freshness. In the report, the cigarettes were falsely described as "Made Under Authority of Philip Morris Products S.A., Neuchatel, Switzerland." Once the inspection was complete, Miyagi released the counterfeit cigarettes to Tominelli, who shipped them to Lee and Castaneda in El Paso, Texas.

On October 8, 2003, the United States Bureau of Customs and Border Protection ("Customs") notified Plaintiff that it seized a shipment of counterfeit Marlboro cigarettes at the Port of Houston, Texas. The cigarettes had been shipped from Curaçao and were destined for El Paso, Texas.

\section{ANALYSIS}

\footnotetext{
${ }^{6}$ In each master case, there are fifty cartons, and in each carton, there are ten packages of cigarettes. Each package contains twenty cigarettes.
} 
Taylor Made: 265 F.Supp.2d, 732 (N.D. Tex. 2003)

Webbworld: 991 F.Supp. 543 (N.D. Tex. 1997)
Plaintiff submits that Miyagi used the Marlboro Marks in commerce when he offered for sale, sold, and imported counterfeit cigarettes. The extent of Miyagi's participation in this venture, and specifically in these activities, remains unclear. It is well established that persons other than Miyagi directly conducted the relevant transactions. For example, Balea individually, and through his company, Synergy, organized the sales transaction by advertising the availability of the goods, contacting the buyers, and receiving the payment of funds. At his deposition, Lee testified that he dealt only with Synergy, and was unaware of Miyagi's existence. Tominelli performed the inspection and shipped the goods. Indeed, Miyagi's name appears on neither the sales invoice nor the inspection report. Thus, one may arguably question whether Miyagi directly imported counterfeit cigarettes. This finding, however, does not shield Miyagi from liability. The Court must look to whether Miyagi is liable for conduct that constitutes unlawful infringement under a theory of vicarious liability.

To hold a party liable for the infringing activities of another, a plaintiff must prove that the party had (1) a direct financial interest in the infringing activity, and (2) the right and ability to supervise the infringing party's acts or activities which caused the infringement. Taylor Made Golf Co. v. MJT Consulting Group (holding a defendant personally liable for infringement where he procured and inspected the goods and signed the purchase agreement, though another entity ultimately sold the goods); Playboy Enters. v. Webbworld, Inc. (holding an employer liable for an employee's infringement where the former had supervisory authority over the latter's activities).

There is undisputed evidence that Miyagi had a direct financial interest and control over the sale and importation of the counterfeit cigarettes into the United States. Miyagi admits Metrich paid him a commission for each case of cigarettes he sold.

There is also evidence that Miyagi had a right and ability to supervise Balea's unlawful activities. Miyagi admits that he controlled the counterfeit Marlboro cigarettes as part of his responsibility to maintain and sell them for Metrich. It is Miyagi who hired Balea and Synergy to assist him with the sale, retaining significant authority over the transaction. At his deposition, Balea testified about his belief that Miyagi was the actual seller of the goods. Balea understood that Miyagi dictated the price of the goods and could exercise control over the terms of the sale to Lee and Castaneda. Miyagi selected Tominelli and Southeastern to perform an inspection and verify the goods. In fact, Miyagi was present at the inspection and authorized the release of goods upon verification. Miyagi's attempted disclaimer of responsibility on the grounds that he did not know the identity of the buyers or that they lived in the United States is undercut by his admission 
that he knew that "the buyers [were] located in Texas." Thus, there is evidence that Miyagi used the Marlboro Marks in commerce when he, acting through Balea, sold and imported counterfeit cigarettes into the United States. Accordingly, the Court holds Miyagi actions constitute "use in commerce."

Having shown that Miyagi used the Marlboro Marks in commerce when he sold and imported counterfeit cigarettes, Plaintiff is entitled to summary judgment against Miyagi for violating $\S \S 32$ and 43(a) of the Lanham Act.

\section{F Defenses}

\section{Lanham Act}

(c) $\quad \ldots$

(3) Exclusions. - The following shall not be actionable as dilution by blurring or dilution by tarnishment under this subsection:

(A) Any fair use, including a nominative or descriptive fair use, or facilitation of such fair use, of a famous mark by another person other than as a designation of source for the person's own goods or services, including use in connection with -

(i) advertising or promotion that permits consumers to compare goods or services; or

(ii) identifying and parodying, criticizing, or commenting upon the famous mark owner or the goods or services of the famous mark owner.

(B) All forms of news reporting and news commentary.

(C) Any noncommercial use of a mark.

Note that these are statutory defenses to trademark dilution. They are all based on well-established defenses to trademark infringement first recognized by the courts. As you read the materials in this section, consider the extent to which the statutory codification does or does not track the common-law defenses recognized by the courts.

\section{Descriptive Fair Use}

Zatarains, Inc. v. Oak Grove Smokehouse, Inc.
15 U.S.C. § 1125

Lanham Act $§ 43$

False designations of origin, false descriptions, and dilution forbidden 
Even when a descriptive term has acquired a secondary meaning sufficient to warrant trademark protection, others may be entitled to use the mark without incurring liability for trademark infringement. When the allegedly infringing term is "used fairly and in good faith only to describe to users the goods or services of [a] party, or their geographic origin," Lanham Act § 33(b)(4), 15 U.S.C. § 1115(b)(4), a defendant in a trademark infringement action may assert the "fair use" defense. The defense is available only in actions involving descriptive terms and only when the term is used in its descriptive sense rather than its trademark sense. In essence, the fair use defense prevents a trademark registrant from appropriating a descriptive term for its own use to the exclusion of others, who may be prevented thereby from accurately describing their own goods. The holder of a protectable descriptive mark has no legal claim to an exclusive right in the primary, descriptive meaning of the term; consequently, anyone is free to use the term in its primary, descriptive sense so long as such use does not lead to customer confusion as to the source of the goods or services.

Zatarain's term FISH-FRI is a descriptive term that has acquired a secondary meaning in the New Orleans area. Although the trademark is valid by virtue of having acquired a secondary meaning, only that penumbra or fringe of secondary meaning is given legal protection. Zatarain's has no legal claim to an exclusive right in the original, descriptive sense of the term; therefore, Oak Grove and Visko's are still free to use the words "fish fry" in their ordinary, descriptive sense, so long as such use will not tend to confuse customers as to the source of the goods.

The record contains ample evidence to support the district court's determination that Oak Grove's and Visko's use of the words "fish fry" was fair and in good faith. Testimony at trial indicated that the appellees did not intend to use the term in a trademark sense and had never attempted to register the words as a trademark. Oak Grove and Visko's apparently believed "fish fry" was a generic name for the type of coating mix they manufactured. In addition, Oak Grove and Visko's consciously packaged and labelled their products in such a way as to minimize any potential confusion in the minds of consumers. The dissimilar trade dress of these products prompted the district court to observe that confusion at the point of purchase - the grocery shelves - would be virtually impossible. Our review of the record convinces us that the district court's determinations are correct. We hold, therefore, that Oak Grove and Visko's are entitled to fair use of the term "fish fry" to describe their products; accordingly, Zatarain's claim of trademark infringement must fail.

\footnotetext{
${ }^{9}$ The district court also rejected Zatarain's claims of unfair competition under
} 


\section{Nominative Fair Use}

New Kids on the Block v. New America Pub., Inc.

The individual plaintiffs perform professionally as The New Kids on the Block, reputedly one of today's hottest musical acts. This case requires us to weigh their rights in that name against the rights of others to use it in identifying the New Kids as the subjects of public opinion polls.

\section{BACKGROUND}

No longer are entertainers limited to their craft in marketing themselves to the public. This is the age of the multi-media publicity blitzkrieg: Trading on their popularity, many entertainers hawk posters, T-shirts, badges, coffee mugs and the like - handsomely supplementing their incomes while boosting their public images. The New Kids are no exception; the record in this case indicates there are more than 500 products or services bearing the New Kids trademark. Among these are services taking advantage of a recent development in telecommunications: 900 area code numbers, where the caller is charged a fee, a portion of which is paid to the call recipient. Fans can call various New Kids 900 numbers to listen to the New Kids talk about themselves, to listen to other fans talk about the New Kids, or to leave messages for the New Kids and other fans.

The defendants, two newspapers of national circulation, conducted separate polls of their readers seeking an answer to a pressing question: Which one of the New Kids is the most popular? USA Today's announcement contained a picture of the New Kids and asked, "Who's the best on the block?" The announcement listed a 900 number for voting, noted that "any USA Today profits from this phone line will go to charity," and closed with the following:

New Kids on the Block are pop's hottest group. Which of the five is your fave? Or are they a turn off? ... Each call costs 50 cents. Results in Friday's Life section.

The Star's announcement, under a picture of the New Kids, went to the heart of the matter: "Now which kid is the sexiest?" The announcement, which appeared in the middle of a page containing a story on a New Kids concert, also stated:

the Lanham Act § 43(a) and La. Rev. Stat. Ann. § 51:1405(A), relying upon the absence of any likelihood of confusion between the products of Zatarain's, Oak Grove, and Visko's. We affirm these conclusions also.

It would make no sense to characterize defendant's use as "fair" within the meaning of the Lanham Act for the purposes of a trademark infringement claim and at the same time characterize his use as "unfair" for the purpose of a section 43(a) unfair competition claim under the same statute. 
Which of the New Kids on the Block would you most like to move next door? STAR wants to know which cool New Kid is the hottest with our readers.

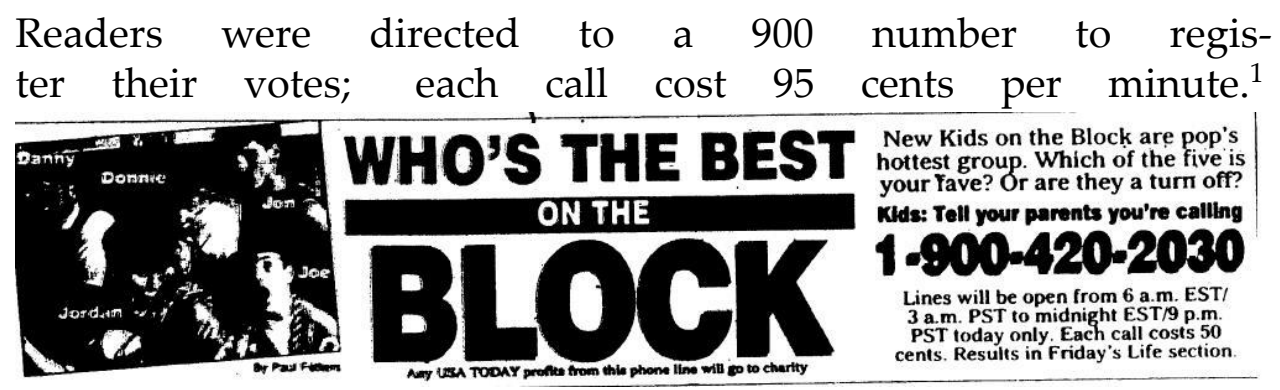

Discussion

A.

San Francisco Arts \& Athletics: 483 U.S. 522 (1987)
A trademark is a limited property right in a particular word, phrase or symbol. And although English is a language rich in imagery, we need not belabor the point that some words, phrases or symbols better convey their intended meanings than others. See San Francisco Arts E Athletics, Inc. v. U.S.O.C. (Brennan, J., dissenting) ("[A] jacket reading 'I Strongly Resent the Draft' would not have conveyed Cohen's message."). Indeed, the primary cost of recognizing property rights in trademarks is the removal of words from (or perhaps nonentrance into) our language. Thus, the holder of a trademark will be denied protection if it is (or becomes) generic, i.e., if it does not relate exclusively to the trademark owner's product. [Examples cited: "shredded wheat" for cereal and "air shuttle" for hourly airline service.] This requirement allays fears that producers will deplete the stock of useful words by asserting exclusive rights in them. When a trademark comes to describe a class of goods rather than an individual product, the courts will hold as a matter of law that use of that mark does not imply sponsorship or endorsement of the product by the original holder.

A related problem arises when a trademark also describes a person, a place or an attribute of a product. If the trademark holder were allowed exclusive rights in such use, the language would be depleted in such the same way as if generic words were protectable. Thus trademark law recognizes a defense where the mark is used only "to describe the goods or services of [a] party, or their geographic origin." 15 U.S.C. $§ 1115(b)(4)$. The "fair-use" defense, in essence, for-

\footnotetext{
${ }^{1}$ The USA Today poll generated less than $\$ 300$ in revenues, all of which the newspaper donated to the Ber- klee College of Music. The Star's poll generated about $\$ 1600$.
} 
bids a trademark registrant to appropriate a descriptive term for his exclusive use and so prevent others from accurately describing a characteristic of their goods. Once again, the courts will hold as a matter of law that the original producer does not sponsor or endorse another product that uses his mark in a descriptive manner. [Example cited: "ribbed" condoms.]

With many well-known trademarks, such as JELL-O, SCOTCH TAPE and KLEENEX, there are equally informative non-trademark words describing the products (gelatin, cellophane tape and facial tissue). But sometimes there is no descriptive substitute, and a problem closely related to genericity and descriptiveness is presented when many goods and services are effectively identifiable only by their trademarks. For example, one might refer to "the two-time world champions" or "the professional basketball team from Chicago," but it's far simpler (and more likely to be understood) to refer to the Chicago Bulls. In such cases, use of the trademark does not imply sponsorship or endorsement of the product because the mark is used only to describe the thing, rather than to identify its source.

Indeed, it is often virtually impossible to refer to a particular product for purposes of comparison, criticism, point of reference or any other such purpose without using the mark. For example, reference to a large automobile manufacturer based in Michigan would not differentiate among the Big Three; reference to a large Japanese manufacturer of home electronics would narrow the field to a dozen or more companies. Much useful social and commercial discourse would be all but impossible if speakers were under threat of an infringement lawsuit every time they made reference to a person, company or product by using its trademark.

A good example of this is Volkswagenwerk Aktiengesellschaft $v$. Church, where we held that Volkswagen could not prevent an automobile repair shop from using its mark. We recognized that in "advertising [the repair of Volkswagens, it] would be difficult, if not impossible, for [Church] to avoid altogether the use of the word 'Volkswagen' or its abbreviation 'VW,' which are the normal terms which, to the public at large, signify appellant's cars." Church did not suggest to customers that he was part of the Volkswagen organization or that his repair shop was sponsored or authorized by VW; he merely used the words "Volkswagen" and "VW" to convey information about the types of cars he repaired. Therefore, his use of the Volkswagen trademark was not an infringing use.

The First Circuit confronted a similar problem when the holder of the trademark "Boston Marathon" tried to stop a television station from using the name:

The words "Boston Marathon" do more than call atten-

Vokswagenwerk: 411 F.2d 350 (9th Cir. 1969) 
WCVB-TV v. Boston Athletic Ass'n. Similarly, competitors may use a rival's trademark in advertising and other channels of communication if the use is not false or misleading..

Cases like these are best understood as involving a non-trademark use of a mark - a use to which the infringement laws simply do not apply, just as videotaping television shows for private home use does not implicate the copyright holder's exclusive right to reproduction. Indeed, we may generalize a class of cases where the use of the trademark does not attempt to capitalize on consumer confusion or to appropriate the cachet of one product for a different one. Such nominative use of a mark - where the only word reasonably available to describe a particular thing is pressed into service - lies outside the strictures of trademark law: Because it does not implicate the sourceidentification function that is the purpose of trademark, it does not constitute unfair competition; such use is fair because it does not imply sponsorship or endorsement by the trademark holder. "When the mark is used in a way that does not deceive the public we see no such sanctity in the word as to prevent its being used to tell the truth." Prestonettes, Inc. v. Coty (Holmes, J.).

To be sure, this is not the classic fair use case where the defendant has used the plaintiff's mark to describe the defendant's own product. Here, the NEW KIDS trademark is used to refer to the New Kids themselves. We therefore do not purport to alter the test applicable in the paradigmatic fair use case. If the defendant's use of the plaintiff's trademark refers to something other than the plaintiff's product, the traditional fair use inquiry will continue to govern. But, where the defendant uses a trademark to describe the plaintiff's product, rather than its own, we hold that a commercial user is entitled to a nominative fair use defense provided he meets the following three requirements: First, the product or service in question must be one not readily identifiable without use of the trademark; second, only so much of the mark or marks may be used as is reasonably necessary to identify the product or service; 7 and third, the user must do noth-

\footnotetext{
${ }^{7}$ Thus, a soft drink competitor would be entitled to compare its product to Coca-
} 
ing that would, in conjunction with the mark, suggest sponsorship or endorsement by the trademark holder.

$B$.

The New Kids do not claim there was anything false or misleading about the newspapers' use of their mark. Rather, the first seven causes of action, while purporting to state different claims, all hinge on one key factual allegation: that the newspapers' use of the New Kids name in conducting the unauthorized polls somehow implied that the New Kids were sponsoring the polls. It is no more reasonably possible, however, to refer to the New Kids as an entity than it is to refer to the Chicago Bulls, Volkswagens or the Boston Marathon without using the trademark. Indeed, how could someone not conversant with the proper names of the individual New Kids talk about the group at all? While plaintiffs' trademark certainly deserves protection against copycats and those who falsely claim that the New Kids have endorsed or sponsored them, such protection does not extend to rendering newspaper articles, conversations, polls and comparative advertising impossible. The first nominative use requirement is therefore met.

Also met are the second and third requirements. Both The Star and USA Today reference the New Kids only to the extent necessary to identify them as the subject of the polls; they do not use the New Kids' distinctive logo or anything else that isn't needed to make the announcements intelligible to readers. Finally, nothing in the announcements suggests joint sponsorship or endorsement by the New Kids. The USA Today announcement implies quite the contrary by asking whether the New Kids might be "a turn off." The Star's poll is more effusive but says nothing that expressly or by fair implication connotes endorsement or joint sponsorship on the part of the New Kids.

The New Kids argue that, even if the newspapers are entitled to a nominative fair use defense for the announcements, they are not entitled to it for the polls themselves, which were money-making enterprises separate and apart from the newspapers' reporting businesses. According to plaintiffs, defendants could have minimized the intrusion into their rights by using an 800 number or asking readers to call in on normal telephone lines which would not have resulted in a profit to the newspapers based on the conduct of the polls themselves.

The New Kids see this as a crucial difference, distinguishing this case from Vokswagenwerk, WCVB-TV and other nominative use cases. The New Kids' argument in support of this distinction is not entirely

Cola or Coke, but would not be entitled to use Coca-Cola's distinctive lettering. 
Ideal Publishing: 195 U.S.P.Q. 761 (S.D.N.Y. 1977) implausible: They point out that their fans, like everyone else, have limited resources. Thus a dollar spent calling the newspapers' 900 lines to express loyalty to the New Kids may well be a dollar not spent on New Kids products and services, including the New Kids' own 900 numbers. In short, plaintiffs argue that a nominative fair use defense is inapplicable where the use in question competes directly with that of the trademark holder.

We reject this argument. While the New Kids have a limited property right in their name, that right does not entitle them to control their fans' use of their own money. Where, as here, the use does not imply sponsorship or endorsement, the fact that it is carried on for profit and in competition with the trademark holder's business is beside the point. See, e.g., Universal City Studios, Inc. v. Ideal Publishing Corp. (magazine's use of TV program's trademark "Hardy Boys" in connection with photographs of show's stars not infringing). Voting for their favorite New Kid may be, as plaintiffs point out, a way for fans to articulate their loyalty to the group, and this may diminish the resources available for products and services they sponsor. But the trademark laws do not give the New Kids the right to channel their fans' enthusiasm (and dollars) only into items licensed or authorized by them. See Iob's Daughters. The New Kids could not use the trademark laws to prevent the publication of an unauthorized group biography or to censor all parodies or satires which use their name. We fail to see a material difference between these examples and the use here.

Summary judgment was proper as to the first seven causes of action because they all hinge on a theory of implied endorsement; there was none here as the uses in question were purely nominative.

Smith v. Chanel, Inc.

Appellant R. G. Smith, doing business as Ta'Ron, Inc., advertised a fragrance called 'Second Chance' as a duplicate of appellees' ‘Chanel No. 5,' at a fraction of the latter's price.1 Appellees were granted a preliminary injunction prohibiting any reference to Chanel No. 5 in the promotion or sale of appellants' product. This appeal followed.

\footnotetext{
${ }^{9}$ Consider, for example, a cartoon which appeared in a recent edition of a humor magazine: The top panel depicts a man in medieval garb hanging a poster announcing a performance of "The New Kids on the Block" to an excited group of onlookers. The lower panel shows the five New Kids, drawn in caricature, hands tied behind their backs, kneeling before "The Chopping Block" awaiting execution. Cracked \# 17 (inside back cover) (Aug. 1992). Cruel? No doubt - but easily within the realm of satire and parody.
} 

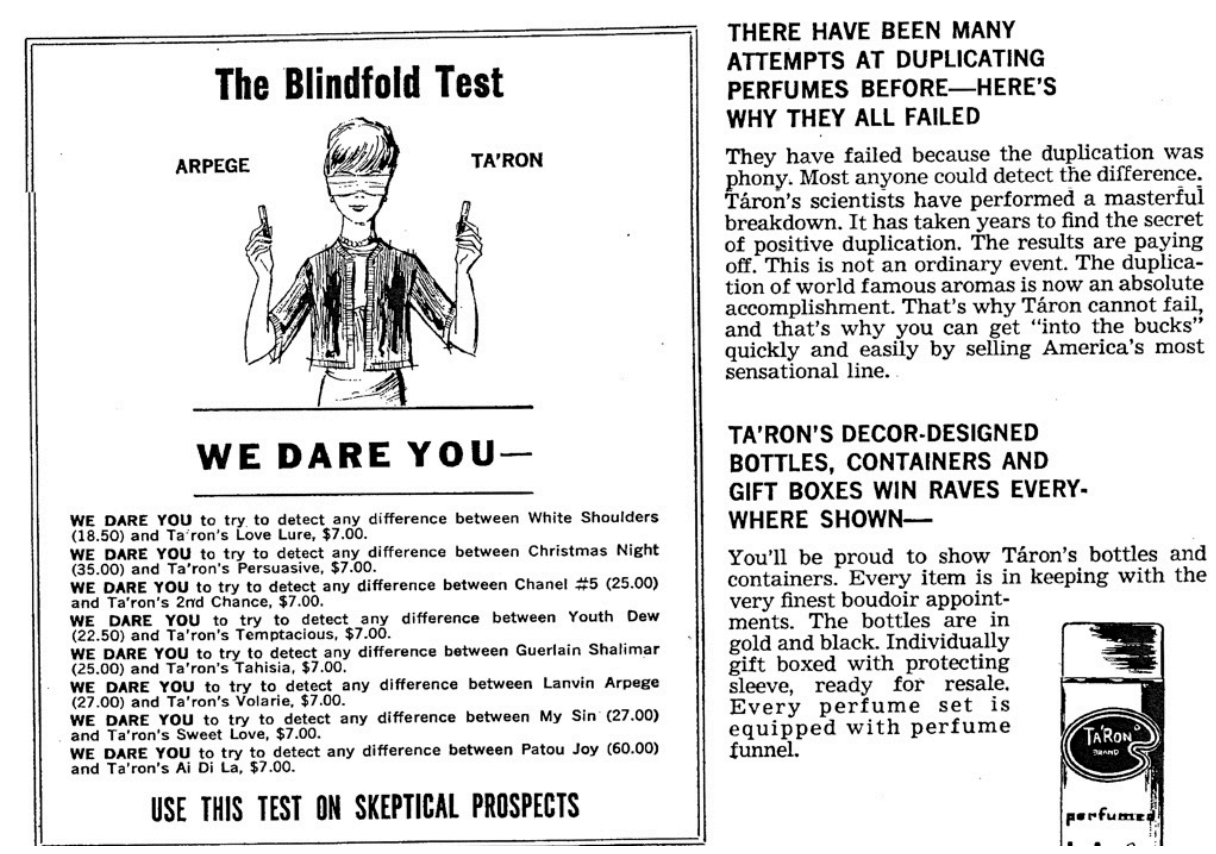

The action rests upon a single advertisement published in 'Specialty Salesmen,' a trade journal directed to wholesale purchasers. The advertisement offered 'The Ta'Ron Line of Perfumes' for sale. It gave the seller's address as 'Ta'Ron Inc., 26 Harbor Cove, Mill Valley, Calif.' It stated that the Ta' Ron perfumes 'duplicate $100 \%$ Perfect the exact scent of the world's finest and most expensive perfumes and colognes at prices that will zoom sales to volumes you have never before experienced.' It repeated the claim of exact duplication in a variety of forms.

The advertisement suggested that a 'Blindfold Test' be used 'on skeptical prospects,' challenging them to detect any difference between a well known fragrance and the Ta'Ron 'duplicate.' One suggested challenge was, 'We dare you to try to detect any difference between Chanel \#5 (25.00) and Ta'Ron's 2nd Chance. \$7.00.'

In an order blank printed as part of the advertisement each Ta'Ron fragrance was listed with the name of the well known fragrance which it purportedly duplicated immediately beneath. Below 'Second Chance' appeared '*(Chanel \#5).' The asterisk referred to a statement at the bottom of the form reading 'Registered Trade Name of Original Fragrance House.'

Appellees conceded below and concede here that appellants 'have the right to copy, if they can, the unpatented formula of appellees' product.' Moreover, for the purposes of these proceedings, appellees assume that 'the products manufactured and advertised by (appellants) are in fact equivalents of those products manufactured by appellees.' Finally, appellees disclaim any contention that the packaging or labeling of appellants' 'Second Chance' is misleading or con- 
fusing. 田

Saxlehner: 216 U.S. 375 (1910)

Societe Comptoir: 299 F.2d 33 (2d Cir. 1962)

\section{I}

The principal question presented on this record is whether one who has copied an unpatented product sold under a trademark may use the trademark in his advertising to identify the product he has copied. We hold that he may, and that such advertising may not be enjoined under either the Lanham Act or the common law of unfair competition, so long as it does not contain misrepresentations or create a reasonable likelihood that purchasers will be confused as to the source, identity, or sponsorship of the advertiser's product.

This conclusion is supported by direct holdings in Saxlehner $v$. Wagner and Societe Comptoir de L'Industrie Cotonniere Etablissements Boussac v. Alexander's Dept. Stores, Inc..

In Saxlehner the copied product was a 'bitter water' drawn from certain privately owned natural springs. The plaintiff sold the natural water under the name 'Hunyadi Janos,' a valid trademark. The defendant was enjoined from using plaintiff's trademark to designate defendant's 'artificial' water, but was permitted to use it to identify plaintiff's natural water as the product which defendant was copying. Justice Holmes wrote:

We see no reason for disturbing the finding of the courts below that there was no unfair competition and no fraud. The real intent of the plaintiff's bill, it seems to us, is to extend the monopoly of such trademark or tradename as she may have to a monopoly of her type of bitter water, by preventing manufacturers from telling the public in a way that will be understood, what they are copying and trying to sell. But the plaintiff has no patent for the water, and the defendants have a right to reproduce it as nearly as they can. They have a right to tell the public what they are doing, and to get whatever share they can in the popularity of the water by advertising that they are trying to make the same article, and think that they succeed. If they do not convey, but, on the contrary, exclude, the notion that they are selling the plaintiff's goods, it is a strong proposition that when the article has a well-known name they have not the right to explain by that name what they imitate. By doing so, they are not trying to get the good will of the name, but the good will of the goods.

${ }^{4}$ Appellants' product was packaged differently from appellees', and the only words appearing on the outside of appellants' packages were 'Second Chance Perfume by Ta'Ron.' The same words appeared on the front of appellants' bottles; the words 'Ta'Ron trademark by International Fragrances, Inc., of Dallas and New York' appeared on the back. 
In Societe Comptoin, the defendant used plaintiff's registered trademarks 'Dior' and 'Christian Dior' in defendant's advertising in identifying plaintiff's dresses as the original creations from which defendant's dresses were copied. The district court refused to grant a preliminary injunction.

The appellate court considered plaintiff's rights under both the Lanham Act and common law. Noting that the representation that defendant's dresses were copies of 'Dior' originals was apparently truthful and that there was no evidence of deception or confusion as to the origin or sponsorship of defendant's garments, the court disposed of the claim of right under the Lanham Act as follows:

The Lanham Act does not prohibit a commercial rival's truthfully denominating his goods a copy of a design in the public domain, though he uses the name of the designer to do so. Indeed it is difficult to see any other means that might be employed to inform the consuming public of the true origin of the design.

We have found no holdings by federal or California appellate courts contrary to the rule of these cases. Moreover, the principle for which they stand - that use of another's trademark to identify the trademark owner's product in comparative advertising is not prohibited by either statutory or common law, absent misrepresentation regarding the products or confusion as to their source or sponsorship - is also generally approved by secondary authorities.

The rule rests upon the traditionally accepted premise that the only legally relevant function of a trademark is to impart information as to the source or sponsorship of the product. Appellees argue that protection should also be extended to the trademark's commercially more important function of embodying consumer good will created through extensive, skillful, and costly advertising. The courts, however, have generally confined legal protection to the trademark's source identification function for reasons grounded in the public policy favoring a free, competitive economy.

Preservation of the trademark as a means of identifying the trademark owner's products, implemented both by the Lanham Act and the common law, serves an important public purpose. It makes effective competition possible in a complex, impersonal marketplace by providing a means through which the consumer can identify products which please him and reward the producer with continued pa-

\footnotetext{
${ }^{1}$ Defendant described its dresses in newspaper advertisements as copies of Dior's original creations. Tags were hung on each garment reading 'Original by Christian Dior - Alexander's Exclusive - Paris-Adaptation.' 'Dior' or 'Christian Dior' appeared more than a dozen times in a singing commercial on defendant's television fashion show.
} 
tronage. Without some such method of product identification, informed consumer choice, and hence meaningful competition in quality, could not exist. On the other hand, it has been suggested that protection of trademark values other than source identification would create serious anti-competitive consequences with little compensating public benefit.

As Justice Holmes wrote in Saxlehner, the practical effect of such a rule would be to extend the monopoly of the trademark to a monopoly of the product. The monopoly conferred by judicial protection of complete trademark exclusivity would not be preceded by examination and approval by a governmental body, as is the case with most other government-granted monopolies. Moreover, it would not be limited in time, but would be perpetual.

A large expenditure of money does not in itself create legally protectable rights. Appellees are not entitled to monopolize the public's desire for the unpatented product, even though they themselves created that desire at great effort and expense.

Disapproval of the copyist's opportunism may be an understandable first reaction, but this initial response to the problem has been curbed in deference to the greater public good. By taking his free ride, the copyist, albeit unintentionally, serves an important public interest by offering comparable goods at lower prices. Appellants' advertisement makes it clear that the product they offer is their own. If it proves to be inferior, they, not appellees, will bear the burden of consumer disapproval.25

We are satisfied, therefore, that both authority and reason require a holding that in the absence of misrepresentation or confusion as to source or sponsorship a seller in promoting his own goods may use the trademark of another to identify the latter's goods.

\section{Exhaustion}

\section{Champion Spark Plug Co. v. Sanders}

Petitioner is a manufacturer of spark plugs which it sells under the trade mark 'Champion.' Respondents collect the used plugs, repair and recondition them, and resell them. Respondents retain the word 'Champion' on the repaired or reconditioned plugs. The outside box or carton in which the plugs are packed has stamped on it the word

\footnotetext{
${ }^{25}$ In addition, if appellants' specific claims of equivalence are false, appellees may have a remedy under $\S 43(\mathrm{a})$ of the Lanham Act, 15 U.S.C. $\S 1125(\mathrm{a})$. [Ed: On remand, the District Court found that "The results of gas chromatograph tests prove that the chemical composition of 'Second Chance' is not identical to that of 'Chanel No. 5,"' and thus the defendant had violated § 43(a). Smith v. Chanel, No. 45647 GBH, 1973 WL 19871, at*3 (N.D. Cal. May 22, 1973).]
} 
'Champion,' together with the letter and figure denoting the particular style or type. They also have printed on them 'Perfect Process Spark Plugs Guaranteed Dependable' and 'Perfect Process Renewed Spark Plugs.' Each carton contains smaller boxes in which the plugs are individually packed. These inside boxes also carry legends indicating that the plug has been renewed. But respondent company's business name or address is not printed on the cartons. On each individual plug is stamped in small letters, blue on black, the word 'Renewed,' which at time is almost illegible.

We are dealing here with second-hand goods. The spark plugs, though used, are nevertheless Champion plugs and not those of another make. There is evidence to support what one would suspect, that a used spark plug which has been repaired or reconditioned does not measure up to the specifications of a new one. But the same would be true of a second-hand Ford or Chevrolet car. And we would not suppose that one could be enjoined from selling a car whose valves had been reground and whose piston rings had been replaced unless he removed the name Ford or Chevrolet. Prestonettes was a case where toilet powders had as one of their ingredients a powder covered by a trade mark and where perfumes which were trade marked were rebottled and sold in smaller bottles. The Court sustained a decree denying an injunction where the prescribed labels told the truth. Mr. Justice Holmes stated, "A trade-mark only gives the right to prohibit the use of it so far as to protect the owner's good will against the sale of another's product as his. ${ }^{*}$ When the mark is used in a way that does not deceive the public we see no such sanctity in the word as to prevent its being used to tell the truth. It is not taboo."

Cases may be imagined where the reconditioning or repair would be so extensive or so basic that it would be a misnomer to call the article by its original name, even though the words 'used' or 'repaired' were added. But no such practice is involved here. The repair or reconditioning of the plugs does not give them a new design. It is no more than a restoration, so far as possible, of their original condition. The type marks attached by the manufacturer are determined by the use to which the plug is to be put. But the thread size and size of the cylinder hole into which the plug is fitted are not affected by the reconditioning. The heat range also has relevance to the type marks. And there is evidence that the reconditioned plugs are inferior so far as heat range and other qualities are concerned. But inferiority is expected in most second-hand articles. Indeed, they generally cost the customer less. That is the case here. Inferiority is immaterial so long as the article is clearly and distinctively sold as repaired or reconditioned rather than as new. The result is, of course, that the second-hand dealer gets some advantage from the trade mark. But

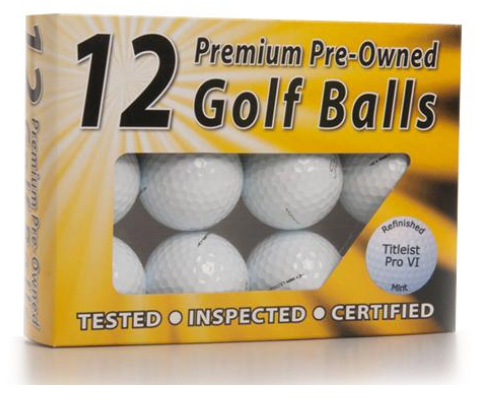

Adequately disclosed and disclaimed? 
--- F.3d ---, 2016 WL 3360639 (June 13, 2016)

507 F.3d 252 (4th Cir. 2007) under the rule of Prestonettes that is wholly permissible so long as the manufacturer is not identified with the inferior qualities of the product resulting from wear and tear or the reconditioning by the dealer. Full disclosure gives the manufacturer all the protection to which he is entitled.

Hart v. Amazon.com, Inc.

Plaintiff's pro se complaint is at times difficult to understand, but his claims ultimately revolve around the same conduct: Amazon allegedly engaged in counterfeiting and displayed and sold counterfeit copies of his books featuring his tradename and trademark. Plaintiff claims that his trademarks include the name "Henrietta Press" and a symbol "comprised of an open book with pages emerging therefrom."

Plaintiff does not plausibly allege that the books sold through Amazon were anything other than authentic original copies protected under the first-sale doctrine. Even if Amazon's actions were not protected by the first-sale doctrine, Plaintiff's claim alleging consumer confusion fails for additional reasons. Amazon argues that the allegation that Amazon caused confusion by suggesting that Plaintiff is affiliated with Amazon fails to state a "false endorsement" claim under the Lanham Act.

Plaintiff's claim centers on individuals re-selling copies of his books through Amazon's website without Plaintiff's permission. The mere fact that Amazon offers a platform to third-party sellers to sell various products and, subsequently, those individuals sold Plaintiff's books, does not imply that Plaintiff has endorsed Amazon or has any specific affiliation with Amazon. This is not the reality of commerce. As a comparison, a shopper at a bookstore does not automatically believe that just because a used book is appearing at the store, the author is expressly endorsing that store. The same is true for a book that is resold on Amazon.

\section{Expressive Use}

\section{Louis Vuitton Malletier v. Haute Diggity Dog}

Louis Vuitton Malletier S.A., a French corporation located in Paris, that manufactures luxury luggage, handbags, and accessories, commenced this action against Haute Diggity Dog, LLC, a Nevada corporation that manufactures and sells pet products nationally, alleging trademark infringement under 15 U.S.C. §1114(1)(a), trademark dilution under 15 U.S.C. $\$ 1125(\mathrm{c})$, copyright infringement under 17 U.S.C. $\S 501$, and related statutory and common law violations. Haute Diggity Dog manufactures, among other things, plush toys on which 
dogs can chew, which, it claims, parody famous trademarks on luxury products, including those of Louis Vuitton Malletier. The particular Haute Diggity Dog chew toys in question here are small imitations of handbags that are labeled "Chewy Vuiton" and that mimic Louis Vuitton Malletier's LOUIS VUITTON handbags.

I

Louis Vuitton Malletier S.A. ("LVM") is a well known manufacturer of luxury luggage, leather goods, handbags, and accessories, which it markets and sells worldwide. In connection with the sale of its products, LVM has adopted trademarks and trade dress that are well recognized and have become famous and distinct. Indeed, in 2006, Business Week ranked LOUIS VUITTON as the 17th "best brand" of all corporations in the world and the first "best brand" for any fashion business.

LVM has registered trademarks for "LOUIS VUITTON," in connection with luggage and ladies" handbags (the "LOUIS VUITTON mark"); for a stylized monogram of "LV," in connection with traveling bags and other goods (the "LV mark"); and for a monogram canvas design consisting of a canvas with repetitions of the LV mark along with four-pointed stars, four-pointed stars inset in curved diamonds, and four-pointed flowers inset in circles, in connection with traveling bags and other products (the "Monogram Canvas mark"). In 2002, LVM adopted a brightly-colored version of the Monogram Canvas mark in which the LV mark and the designs were of various colors and the background was white (the "Multicolor design"), created in collaboration with Japanese artist Takashi Murakami. For the Multicolor design, LVM obtained a copyright in 2004. In 2005, LVM adopted another design consisting of a canvas with repetitions of the LV mark and smiling cherries on a brown background (the "Cherry design").

As LVM points out, the Multicolor design and the Cherry design attracted immediate and extraordinary media attention and publicity in magazines such as Vogue, W, Elle, Harper's Bazaar, Us Weekly, Life and Style, Travel \& Leisure, People, In Style, and Jane. The press published photographs showing celebrities carrying these handbags, including Jennifer Lopez, Madonna, Eve, Elizabeth Hurley, Carmen Electra, and Anna Kournikova, among others. When the Multicolor design first appeared in 2003, the magazines typically reported, "The Murakami designs for Louis Vuitton, which were the hit of the summer, came with hefty price tags and a long waiting list." People Magazine said, "the wait list is in the thousands." The handbags retailed in the range of $\$ 995$ for a medium handbag to $\$ 4500$ for a large travel bag. The medium size handbag that appears to be the model for the "Chewy Vuiton" dog toy retailed for $\$ 1190$. The Cherry design ap-

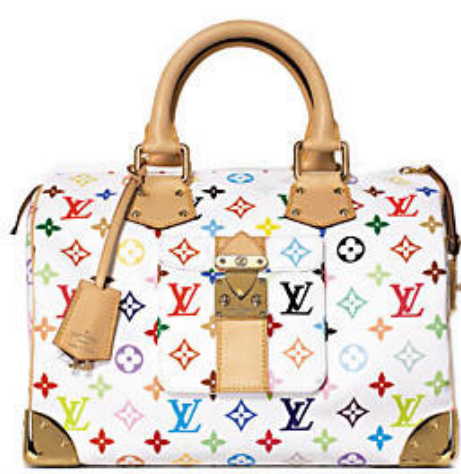

LVM Multiculor bag 
peared in 2005, and the handbags including that design were priced similarly - in the range of $\$ 995$ to $\$ 2740$. LVM does not currently market products using the Cherry design.

The original LOUIS VUITTON, LV, and Monogram Canvas marks, however, have been used as identifiers of LVM products continuously since 1896.

During the period 2003-2005, LVM spent more than $\$ 48$ million advertising products using its marks and designs, including more than $\$ 4$ million for the Multicolor design. It sells its products exclusively in LVM stores and in its own instore boutiques that are contained within department stores such as Saks Fifth Avenue, Bloomingdale's, Neiman Marcus, and Macy's. LVM also advertises its products on the Internet through the specific websites www.louisvuitton.com and www.eluxury.com.

Although better known for its handbags and luggage, LVM also markets a limited selection of luxury pet accessories - collars, leashes, and dog carriers - which bear the Monogram Canvas mark and the Multicolor design. These items range in price from approximately $\$ 200$ to $\$ 1600$. LVM does not make dog toys.

Haute Diggity Dog, LLC, which is a relatively small and relatively new business located in Nevada, manufactures and sells nationally - primarily through pet stores - a line of pet chew toys and beds whose names parody elegant high-end brands of products such as perfume, cars, shoes, sparkling wine, and handbags. These include - in addition to Chewy Vuiton (LOUIS VUITTON) - Chewnel No. 5 (Chanel No. 5), Furcedes (Mercedes), Jimmy Chew (Jimmy Choo), Dog Perignonn (Dom Perignon), Sniffany \& Co. (Tiffany \& Co.), and Dogior (Dior). The chew toys and pet beds are plush, made of polyester, and have a shape and design that loosely imitate the signature product of the targeted brand. They are mostly distributed and sold through pet stores, although one or two Macy's stores carries Haute Diggity Dog's products. The dog toys are generally sold for less than $\$ 20$, although larger versions of some of Haute Diggity Dog's plush dog beds sell for more than $\$ 100$.

Haute Diggity Dog's "Chewy Vuiton" dog toys, in particular, loosely resemble miniature handbags and undisputedly evoke LVM handbags of similar shape, design, and color.

In lieu of the LOUIS VUITTON mark, the dog toy uses "Chewy Vuiton"; in lieu of the LV mark, it uses "CV"; and the other symbols and colors employed are imitations, but not exact ones, of those used in the LVM Multicolor and Cherry designs.

\section{II}

LVM contends first that Haute Diggity Dog's marketing and sale of Chewy Vuitton dog toy its "Chewy Vuiton" dog toys infringe its trademarks because the ad- 
vertising and sale of the "Chewy Vuiton" dog toys is likely to cause confusion.

To prove trademark infringement, LVM must show (1) that it owns a valid and protectable mark; (2) that Haute Diggity Dog uses a "re-production, counterfeit, copy, or colorable imitation" of that mark in commerce and without LVM's consent; and (3) that Haute Diggity Dog's use is likely to cause confusion. The validity and protectability of LVM's marks are not at issue in this case, nor is the fact that Haute Diggity Dog uses a colorable imitation of LVM's mark. Therefore, we give the first two elements no further attention. To determine whether the "Chewy Vuiton" product line creates a likelihood of confusion, we have identified several nonexclusive factors to consider: (1) the strength or distinctiveness of the plaintiff's mark; (2) the similarity of the two marks; (3) the similarity of the goods or services the marks identify; (4) the similarity of the facilities the two parties use in their businesses; (5) the similarity of the advertising used by the two parties; (6) the defendant's intent; and (7) actual confusion. See Pizzeria Uno Corp. v. Temple. These Pizzeria Uno factors are not always weighted equally, and not all factors are relevant in every case.

Because Haute Diggity Dog's arguments with respect to the Pizzeria Uno factors depend to a great extent on whether its products and marks are successful parodies, we consider first whether Haute Diggity Dog's products, marks, and trade dress are indeed successful parodies of LVM's marks and trade dress.

For trademark purposes, a parody is defined as a simple form of entertainment conveyed by juxtaposing the irreverent representation of the trademark with the idealized image created by the mark's owner. A parody must convey two simultaneous - and contradictory - messages: that it is the original, but also that it is not the original and is instead a parody. This second message must not only differentiate the alleged parody from the original but must also communicate some articulable element of satire, ridicule, joking, or amusement. Thus, a parody relies upon a difference from the original mark, presumably a humorous difference, in order to produce its desired effect. Jordache Enterprises, Inc. v. Hogg Wyld, Ltd. (finding the use of "Lardashe" jeans for larger women to be a successful and permissible parody of "Jordache" jeans).

When applying the PETA criteria to the facts of this case, we agree with the district court that the "Chewy Vuiton" dog toys are successful parodies of LVM handbags and the LVM marks and trade dress used in connection with the marketing and sale of those handbags. First, the pet chew toy is obviously an irreverent, and indeed intentional, representation of an LVM handbag, albeit much smaller and coarser. The dog toy is shaped roughly like a handbag; its name "Chewy Vuiton" sounds like and rhymes with LOUIS VUITTON; its
Pizzeria Uno: 747 F.2d 1522 (4th Cir. 1984)

Jordache: 828 F.2d 1482 (10th Cir. 1987) 
monogram CV mimics LVM's LV mark; the repetitious design clearly imitates the design on the LVM handbag; and the coloring is similar. In short, the dog toy is a small, plush imitation of an LVM handbag carried by women, which invokes the marks and design of the handbag, albeit irreverently and incompletely. No one can doubt that LVM handbags are the target of the imitation by Haute Diggity Dog's "Chewy Vuiton" dog toys.

At the same time, no one can doubt also that the "Chewy Vuiton" dog toy is not the "idealized image" of the mark created by LVM. The differences are immediate, beginning with the fact that the "Chewy Vuiton" product is a dog toy, not an expensive, luxury LOUIS VUITTON handbag. The toy is smaller, it is plush, and virtually all of its designs differ. Thus, "Chewy Vuiton" is not LOUIS VUITTON ("Chewy" is not "LOUIS" and "Vuiton" is not "VUITTON," with its two Ts); CV is not LV; the designs on the dog toy are simplified and crude, not detailed and distinguished. The toys are inexpensive; the handbags are expensive and marketed to be expensive. And, of course, as a dog toy, one must buy it with pet supplies and cannot buy it at an exclusive LVM store or boutique within a department store. In short, the Haute Diggity Dog "Chewy Vuiton" dog toy undoubtedly and deliberately conjures up the famous LVM marks and trade dress, but at the same time, it communicates that it is not the LVM product.

Finally, the juxtaposition of the similar and dissimilar - the irreverent representation and the idealized image of an LVM handbag immediately conveys a joking and amusing parody. The furry little "Chewy Vuiton" imitation, as something to be chewed by a dog, pokes fun at the elegance and expensiveness of a LOUIS VUITTON handbag, which must not be chewed by a dog. The LVM handbag is provided for the most elegant and well-to-do celebrity, to proudly display to the public and the press, whereas the imitation "Chewy Vuiton" "handbag" is designed to mock the celebrity and be used by a dog. The dog toy irreverently presents haute couture as an object for casual canine destruction. The satire is unmistakable. The dog toy is a comment on the rich and famous, on the LOUIS VUITTON name and related marks, and on conspicuous consumption in general. This parody is enhanced by the fact that "Chewy Vuiton" dog toys are sold with similar parodies of other famous and expensive brands “Chewnel No. 5" targeting "Chanel No. 5"; "Dog Perignonn" targeting "Dom Perignon"; and "Sniffany \& Co." targeting "Tiffany \& Co."

We conclude that the PETA criteria are amply satisfied in this case and that the "Chewy Vuiton" dog toys convey just enough of the original design to allow the consumer to appreciate the point of parody, but stop well short of appropriating the entire marks that LVM 
claims.

Finding that Haute Diggity Dog's parody is successful, however, does not end the inquiry into whether Haute Diggity Dog's "Chewy Vuiton" products create a likelihood of confusion. See McCarthy ("There are confusing parodies and non-confusing parodies. All they have in common is an attempt at humor through the use of someone else's trademark"). The finding of a successful parody only influences the way in which the Pizzeria Uno factors are applied. Indeed, it becomes apparent that an effective parody will actually diminish the likelihood of confusion, while an ineffective parody does not. We now turn to the Pizzeria Uno factors.

As to the first Pizzeria Und factor, the parties agree that LVM's marks are strong and widely recognized. They do not agree, however, as to the consequences of this fact. LVM maintains that a strong, famous mark is entitled, as a matter of law, to broad protection. While it is true that finding a mark to be strong and famous usually favors the plaintiff in a trademark infringement case, the opposite may be true when a legitimate claim of parody is involved. As the district court observed, "In cases of parody, a strong mark's fame and popularity is precisely the mechanism by which likelihood of confusion is avoided."

We agree with the district court. It is a matter of common sense that the strength of a famous mark allows consumers immediately to perceive the target of the parody, while simultaneously allowing them to recognize the changes to the mark that make the parody funny or biting. See Tommy Hilfiger Licensing, Inc. v. Nature Labs, LLC (noting that the strength of the TOMMY HILFIGER fashion mark did not favor the mark's owner in an infringement case against TIMMY HOLEDIGGER novelty pet perfume). In this case, precisely because LOUIS VUITTON is so strong a mark and so well recognized as a luxury handbag brand from LVM, consumers readily recognize that when they see a "Chewy Vuiton" pet toy, they see a parody. Thus, the strength of LVM's marks in this case does not help LVM establish a likelihood of confusion.

\section{$B$}

With respect to the second Pizzeria Und factor, the similarities between the marks, the usage by Haute Diggity Dog again converts what might be a problem for Haute Diggity Dog into a disfavored conclusion for LVM.

Haute Diggity Dog concedes that its marks are and were designed to be somewhat similar to LVM's marks. But that is the essence of a

Tommy Hilfiger: 221 F.Supp.2d 410 (S.D.N.Y. 2002) 
parody - the invocation of a famous mark in the consumer's mind, so long as the distinction between the marks is also readily recognized. While a trademark parody necessarily copies enough of the original design to bring it to mind as a target, a successful parody also distinguishes itself and, because of the implicit message communicated by the parody, allows the consumer to appreciate it.

In concluding that Haute Diggity Dog has a successful parody, we have impliedly concluded that Haute Diggity Dog appropriately mimicked a part of the LVM marks, but at the same time sufficiently distinguished its own product to communicate the satire. The differences are sufficiently obvious and the parody sufficiently blatant that a consumer encountering a "Chewy Vuiton" dog toy would not mistake its source or sponsorship on the basis of mark similarity.

This conclusion is reinforced when we consider how the parties actually use their marks in the marketplace. The record amply supports Haute Diggity Dog's contention that its "Chewy Vuiton" toys for dogs are generally sold alongside other pet products, as well as toys that parody other luxury brands, whereas LVM markets its handbags as a top-end luxury item to be purchased only in its own stores or in its own boutiques within department stores. These marketing channels further emphasize that "Chewy Vuiton" dog toys are not, in fact, LOUIS VUITTON products.

\section{C}

Nor does LVM find support from the third Pizzeria Uno factor, the similarity of the products themselves. It is obvious that a "Chewy Vuiton" plush imitation handbag, which does not open and is manufactured as a dog toy, is not a LOUIS VUITTON handbag sold by LVM. Even LVM's most proximate products - dog collars, leashes, and pet carriers - are fashion accessories, not dog toys. As Haute Diggity Dog points out, LVM does not make pet chew toys and likely does not intend to do so in the future. Even if LVM were to make dog toys in the future, the fact remains that the products at issue are not similar in any relevant respect, and this factor does not favor LVM.

\section{D}

The fourth and fifth Pizzeria Und factors, relating to the similarity of facilities and advertising channels, have already been mentioned. LVM products are sold exclusively through its own stores or its own boutiques within department stores. It also sells its products on the Internet through an LVM-authorized website. In contrast, "Chewy Vuiton" products are sold primarily through traditional and Internet pet stores, although they might also be sold in some department stores. The record demonstrates that both LVM handbags and 
"Chewy Vuiton" dog toys are sold at a Macy's department store in New York. As a general matter, however, there is little overlap in the individual retail stores selling the brands.

Likewise with respect to advertising, there is little or no overlap. LVM markets LOUIS VUITTON handbags through high-end fashion magazines, while "Chewy Vuiton" products are advertised primarily through pet-supply channels.

The overlap in facilities and advertising demonstrated by the record is so minimal as to be practically nonexistent. "Chewy Vuiton" toys and LOUIS VUITTON products are neither sold nor advertised in the same way, and the de minimis overlap lends insignificant support to LVM on this factor.

\section{E}

The sixth factor, relating to Haute Diggity Dog's intent, again is neutralized by the fact that Haute Diggity Dog markets a parody of LVM products. As other courts have recognized, An intent to parody is not an intent to confuse the public. Despite Haute Diggity Dog's obvious intent to profit from its use of parodies, this action does not amount to a bad faith intent to create consumer confusion. To the contrary, the intent is to do just the opposite - to evoke a humorous, satirical association that distinguishes the products. This factor does not favor LVM.

On the actual confusion factor, it is well established that no actual confusion is required to prove a case of trademark infringement, although the presence of actual confusion can be persuasive evidence relating to a likelihood of confusion.

While LVM conceded in the district court that there was no evidence of actual confusion, on appeal it points to incidents where retailers misspelled "Chewy Vuiton" on invoices or order forms, using two Ts instead of one. Many of these invoices also reflect simultaneous orders for multiple types of Haute Diggity Dog parody products, which belies the notion that any actual confusion existed as to the source of "Chewy Vuiton" plush toys. The misspellings pointed out by LVM are far more likely in this context to indicate confusion over how to spell the product name than any confusion over the source or sponsorship of the "Chewy Vuiton" dog toys. We conclude that this factor favors Haute Diggity Dog.

In sum, the likelihood-of-confusion factors substantially favor Haute Diggity Dog. But consideration of these factors is only a proxy for the ultimate statutory test of whether Haute Diggity Dog's marketing, sale, and distribution of "Chewy Vuiton" dog toys is likely 
to cause confusion. Recognizing that "Chewy Vuiton" is an obvious parody and applying the Pizzeria Uno factors, we conclude that LVM has failed to demonstrate any likelihood of confusion. Accordingly, we affirm the district court's grant of summary judgment in favor of Haute Diggity Dog on the issue of trademark infringement.

III

LVM also contends that Haute Diggity Dog's advertising, sale, and distribution of the "Chewy Vuiton" dog toys dilutes its LOUIS VUITTON, LV, and Monogram Canvas marks, which are famous and distinctive. It argues, "Before the district court's decision, Vuitton's famous marks were unblurred by any third party trademark use." "Allowing defendants to become the first to use similar marks will obviously blur and dilute the Vuitton Marks." It also contends that "Chewy Vuiton" dog toys are likely to tarnish LVM's marks because they "pose a choking hazard for some dogs."

We address first LVM's claim for dilution by blurring.

We begin by noting that parody is not automatically a complete defense to a claim of dilution by blurring where the defendant uses the parody as its own designation of source, i.e., as a trademark. Although the TDRA does provide that fair use is a complete defense and allows that a parody can be considered fair use, it does not extend the fair use defense to parodies used as a trademark.

The TDRA, however, does not require a court to ignore the existence of a parody that is used as a trademark, and it does not preclude a court from considering parody as part of the circumstances to be considered for determining whether the plaintiff has made out a claim for dilution by blurring. Indeed, the statute permits a court to consider "all relevant factors," including the six factors supplied in $\S 1125(\mathrm{c})(2)(\mathrm{B})$.

In sum, while a defendant's use of a parody as a mark does not support a "fair use" defense, it may be considered in determining whether the plaintiff-owner of a famous mark has proved its claim that the defendant's use of a parody mark is likely to impair the distinctiveness of the famous mark.

In the case before us, when considering factors (ii), (iii), and (iv), it is readily apparent, indeed conceded by Haute Diggity Dog, that LVM's marks are distinctive, famous, and strong. The LOUIS VUITTON mark is well known and is commonly identified as a brand of the great Parisian fashion house, Louis Vuitton Malletier. So too are its other marks and designs, which are invariably used with the LOUIS VUITTON mark. It may not be too strong to refer to these famous marks as icons of high fashion. 
While the establishment of these facts satisfies essential elements of LVM's dilution claim, the facts impose on LVM an increased burden to demonstrate that the distinctiveness of its famous marks is likely to be impaired by a successful parody. Even as Haute Diggity Dog's parody mimics the famous mark, it communicates simultaneously that it is not the famous mark, but is only satirizing it. And because the famous mark is particularly strong and distinctive, it becomes more likely that a parody will not impair the distinctiveness of the mark. In short, as Haute Diggity Dog's "Chewy Vuiton" marks are a successful parody, we conclude that they will not blur the distinctiveness of the famous mark as a unique identifier of its source.

It is important to note, however, that this might not be true if the parody is so similar to the famous mark that it likely could be construed as actual use of the famous mark itself. Factor (i) directs an inquiry into the "degree of similarity between the junior mark and the famous mark." If Haute Diggity Dog used the actual marks of LVM (as a parody or otherwise), it could dilute LVM's marks by blurring, regardless of whether Haute Diggity Dog's use was confusingly similar, whether it was in competition with LVM, or whether LVM sustained actual injury. Thus, the use of DUPONT shoes, BUICK aspirin, and KODAK pianos would be actionable under the TDRA because the unauthorized use of the famous marks themselves on unrelated goods might diminish the capacity of these trademarks to distinctively identify a single source. This is true even though a consumer would be unlikely to confuse the manufacturer of KODAK film with the hypothetical producer of KODAK pianos.

But in this case, Haute Diggity Dog mimicked the famous marks; it did not come so close to them as to destroy the success of its parody and, more importantly, to diminish the LVM marks' capacity to identify a single source. Haute Diggity Dog designed a pet chew toy to imitate and suggest, but not use, the marks of a high-fashion LOUIS VUITTON handbag. It used "Chewy Vuiton" to mimic "LOUIS VUITTON"; it used "CV" to mimic "LV"; and it adopted imperfectly the items of LVM's designs. We conclude that these uses by Haute Diggity Dog were not so similar as to be likely to impair the distinctiveness of LVM's famous marks.

\section{$B$}

LVM's claim for dilution by tarnishment does not require an extended discussion. To establish its claim for dilution by tarnishment, LVM must show, in lieu of blurring, that Haute Diggity Dog's use of the "Chewy Vuiton" mark on dog toys harms the reputation of the LOUIS VUITTON mark and LVM's other marks. LVM argues that the possibility that a dog could choke on a "Chewy Vuiton" toy causes this harm. LVM has, however, provided no record support for its as- 
sertion. It relies only on speculation about whether a dog could choke on the chew toys and a logical concession that a $\$ 10$ dog toy made in China was of "inferior quality" to the $\$ 1190$ LOUIS VUITTON handbag. There is no record support, however, that any dog has choked on a pet chew toy, such as a "Chewy Vuiton" toy, or that there is any basis from which to conclude that a dog would likely choke on such a toy.

We agree with the district court that LVM failed to demonstrate a claim for dilution by tarnishment.

\section{Louis Vuitton Mallatier v. Warner Bros.}

On December 22, 2011, Louis Vuitton Malletier, S.A. ("Louis Vuitton") filed a complaint against Warner Bros. Entertainment Inc. ("Warner Bros."), focusing on Warner Bros.' use of a travel bag in the film The Hangover: Part II that allegedly infringes upon Louis Vuitton's trademarks. Plaintiff's complaint asserts three claims for relief: (1) false designation of origin/unfair competition in violation of $\S$ 43(a) of the Lanham Act; (2) common law unfair competition; and (3) trademark dilution in violation N.Y. Gen. Bus. Law 360-1. On March 14,2012 , defendant filed a motion to dismiss the complaint with prejudice for failure to state a claim upon which relief can be granted pursuant to Fed.R.Civ.P. 12(b). The court has fully considered the parties' arguments, and for the reasons set forth below, defendant's motion is granted.

\section{BACKGROUND}

Louis Vuitton is one of the premier luxury fashion houses in the world, renowned for, among other things, its high-quality luggage, trunks, and handbags. Louis Vuitton's principle trademark is the highly-distinctive and famous Toile Monogram. Registered in 1932, this trademark, along with its component marks (collectively, the "LVM Marks"), are famous, distinctive, and incontestable.

Louis Vuitton has invested millions of dollars and decades of time and effort to create a global recognition that causes consumers to associate the LVM Marks with high-quality, luxury goods emanating exclusively from Louis Vuitton.

Warner Bros. is one of the oldest and most respected producers of motion pictures and television shows in the country and the world. In the summer of 2011, Warner Bros. released The Hangover: Part II ("the Film"), the sequel to the 2009 hit bachelor-party-gone-awrycomedy The Hangover. The Film has grossed roughly \$580 million globally as of the date of the Complaint, becoming the highest-gross $\mathrm{R}$-rated comedy of all time and one of the highest grossing movies in 2011.

Diophy is a company that creates products which use a mono- 
gram design that is a knock-off of the famous Toile Monogram (the "Knock-Off Monogram Design"). The Diophy products bearing the Knock-Off Monogram Design have been extensively distributed throughout the United States, causing enormous harm to Louis Vuitton. Despite the inferior quality of Diophy's products, demand for its products bearing the Knock-Off Monogram Design remains high because they are far less expensive than genuine Louis Vuitton products.

\section{A. The Airport Scene}

As alleged in the complaint, in one early scene in the Film the "four main characters in Los Angeles International Airport before a flight to Thailand for the character Stu's bachelor party and wedding." "[A]s the characters are walking through the airport, a porter is pushing on a dolly what appears to be Louis Vuitton trunks, some hard-sided luggage, and two Louis Vuitton Keepall travel bags.") Alan, one of the characters, is carrying what appears to be a matching over-theshoulder Louis Vuitton "Keepall" bag, but it is actually an infringing Diophy bag. Moments later, Alan is seen sitting on a bench in the airport lounge and places his bag (i.e., the Diophy bag) on the empty seat next to him. Stu, who is sitting in the chair to the other side of the bag, moves the bag so that Teddy, Stu's future brother-in-law, can sit down between him and Alan. (Id.) Alan reacts by saying: "Careful that is ... that is a Lewis Vuitton." No other reference to Louis Vuitton or the Diophy bag is made after this point.

After the movie was released in theaters, Louis Vuitton sent Warner Bros. a cease and desist letter noting its objection to the use of the Diophy bag in the Film. Despite being informed of its objection, on December 6, 2011, Warner Bros. released the Film in the United States on DVD and Blu-Ray. The complaint alleges that "many consumers believed the Diophy [b]ag" used in the Film "was, in fact, a genuine Louis Vuitton," and that Louis Vuitton consented to Warner Bros.' "misrepresentation" that the Diophy bag was a genuine Louis Vuitton product. Louis Vuitton claims that its harm has been "exacerbated by the prominent use of the aforementioned scenes and the LVM Marks in commercials and advertisements for the [F]ilm," and that Alan's "Lewis Vuitton" line has "become an oft-repeated and hallmark quote from the movie." Louis Vuitton attaches to the complaint, as Exhibit E, what it claims are "[r]epresentative Internet references and blog excerpts" demonstrating that consumers mistakenly believe that the Diophy bag is a genuine Louis Vuitton bag.

\footnotetext{
${ }^{1}$ Warner Bros. does not dispute for the purposes of this motion that Louis Vuitton's representations with respect to the source of the bag are accurate.

${ }^{2}$ Although the Court takes as true the allegations of the complaint, none of the
}

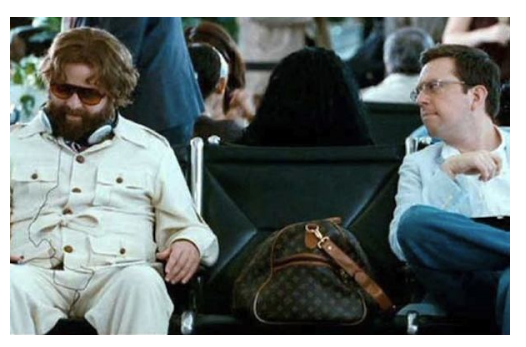

Still from The Hangover: part II 


\section{B. The Present Motion}

It is instructive to consider what this case is about and what it is not. Louis Vuitton does not object to Warner Bros.' unauthorized use of the LVM Marks or reference to the name Louis Vuitton in the Film. Nor does Louis Vuitton claim that Warner Bros. misled the public into believing that Louis Vuitton sponsored or was affiliated with the Film. Rather, Louis Vuitton contends that Warner Bros. impermissibly used a third-party's bag that allegedly infringes on the LVM Marks. On the basis of Warner Bros.' use of the allegedly infringing Diophy bag in the Film, Louis Vuitton asserts three causes of action: (1) false designation of origin/unfair competition in violation of 15 U.S.C. $\$ 1125(\mathrm{a})$, (2) common law unfair competition, 1 and (3) trademark dilution in violation of New York General Business Law § 360-1.

Warner Bros. now moves to dismiss the complaint in its entirety on the ground that its use of the Diophy bag in the Film is protected by the First Amendment under the framework established by Rogers v. Grimaldi.

\section{DISCUSSION ...}

\section{First Amendment}

In Rogers, the Second Circuit held that the Lanham Act is inapplicable to "artistic works" as long as the defendant's use of the mark is (1) "artistically relevant" to the work and (2) not "explicitly misleading" as to the source or content of the work. Louis Vuitton does not dispute that Warner Bros.' challenged use of the mark is noncommercial, placing it firmly within the purview of an "artistic work" under Rogers. a. Artistic Relevance

The threshold for "artistic relevance" is purposely low and will be satisfied unless the use has no artistic relevance to the underlying work whatsoever. The artistic relevance prong ensures that the defendant intended an artistic - i.e., noncommercial - association with the plaintiff's mark, as opposed to one in which the defendant intends to associate with the mark to exploit the mark's popularity and good will. See Rogers (finding that the defendant satisfied the artistic relevance prong where its use of the trademark was "not arbitrarily chosen just

Internet references and blog excerpts attached to the complaint in Exhibit E show that anyone is confused or mistaken into believing that the Diophy bag was a real Louis Vuitton bag. In one blog post, a commenter notes that the luggage on the cart is real, but the bag carried by Alan is a "replica." Although a few other posts and comments refer to the bags generally as Louis Vuitton bags, no one else specifically writes about Alan's bag, let alone its authenticity.

${ }^{4}$ The standards for $\S 43$ (a) claims of the Lanham Act and common law unfair competition claims are almost indistinguishable. 
to exploit the publicity value of [the plaintiffs' mark] but instead ha[d] genuine relevance to the film's story").

Warner Bros.' use of the Diophy bag meets this low threshold. Alan's terse remark to Teddy to "[be] [c]areful" because his bag "is a Lewis Vuitton" comes across as snobbish only because the public signifies Louis Vuitton - to which the Diophy bag looks confusingly similar - with luxury and a high society lifestyle. His remark also comes across as funny because he mispronounces the French "Louis" like the English "Lewis," and ironic because he cannot correctly pronounce the brand name of one of his expensive possessions, adding to the image of Alan as a socially inept and comically misinformed character. This scene also introduces the comedic tension between Alan and Teddy that appears throughout the Film.

Louis Vuitton contends that the Court cannot determine that the use of the Diophy bag was artistically relevant until after discovery. Specifically, Louis Vuitton maintains that it should be able to review the script and depose the Film's creators to determine whether Warner Bros. intended to use an authentic Louis Vuitton bag or Diophy's knock-off bag. However, the significance of the airport scene relies on Alan's bag - authentic or not - looking like a Louis Vuitton bag. Louis Vuitton does not dispute this was Warner Bros.' intention, and therefore the discovery it seeks is irrelevant. The Court is satisfied that Warner Bros.' use of the Diophy bag (whether intentional or inadvertent) was intended to create an artistic association with Louis Vuitton, and there is no indication that its use was commercially motivated. 11

Accordingly, the Court concludes that the use of the Diophy bag has some artistic relevance to the plot of the Film.

\section{b. Explicitly Misleading}

\footnotetext{
${ }^{11}$ For this reason, the present case is distinguishable from the cases cited by Louis Vuitton. In those cases, the court disbelieved the defendant's claim that a communicative message was intended and/or expressed concern that the mark's use was commercially motivated. See Am. Dairy Queen Corp. v. New Line Prods., Inc., 35 F. Supp. 2d 727, (D. Minn. 1998) (defendant movie producers' position was that their proposed movie title [Ed: Dairy Queens] was not "designed to evoke or even suggest any relationship at all to [plaintiff's] trademarked name or any of its products"); Sherwood 48 Assocs. v. Sony Corp. of Am., 76 Fed. Appx. 389, 392 (2d Cir. 2003) (plaintiffs alleged that the defendant altered the plaintiffs' marks "to generate revenue for their film," and the defendant had not pled that the alteration had "at least some artistic relevance in order to assert a valid First Amendment defense" [Ed: the producers of the movie Spider-Man digitally altered the exterior of three buildings in a scene filmed in New York's Times Square.]); Parks v. LaFace Records, 329 F.3d 437, (6th Cir 2003) (finding that "reasonable persons could conclude that there is no relationship of any kind between Rosa Park's name and the content of the song [Ed: "Rosa Parks" by OutKast]," and noting that the "marketing power" of the song's title "unquestionably enhanced the song's potential sale to the consuming public").
} 
Since using the Diophy bag has some relevance to the Film, Warner Bros.' use of it is unprotected only if it explicitly misleads as to the source or the content of the work. The relevant question is whether the defendant's use of the mark is misleading in the sense that it induces members of the public to believe the work] was prepared or otherwise authorized by the plaintiff. Only a particularly compelling finding of likelihood of confusion can overcome the First Amendment interests.

Rogers and the cases adopting its holding have consistently framed the applicable standard in terms of confusion as to the defendant's artistic work. See Rogers ("The title 'Ginger and Fred' contains no explicit indication that Rogers endorsed the [defendant's] film or had a role in producing it.").

It is not a coincidence that courts frame the confusion in relation to the defendant's artistic work, and not to someone else's. This narrow construction of the Lanham Act accommodates the public's interest in free expression by restricting its application to those situations that present the greatest risk of consumer confusion: namely, when trademarks are used to dupe consumers into buying a product they mistakenly believe is sponsored by the trademark owner. When this concern is present it will generally outweigh the public's interest in free expression. However, if a trademark is not used, in any direct sense, to designate the source or sponsorship of the defendant's work, then "he consumer interest in avoiding deception is too slight to warrant application of the Lanham Act.

Here, the complaint alleges two distinct theories of confusion: (1) that consumers will be confused into believing that the Diophy bag is really a genuine Louis Vuitton bag; and (2) that Louis Vuitton approved the use of the Diophy bag in the Film. However, even drawing all reasonable inferences in the light most favorable to Louis Vuitton, as the Court is required to do, neither of these allegations involves confusion as to Warner Bros.' artistic work. Specifically, Louis Vuitton does not allege that Warner Bros. used the Diophy bag in order to mislead consumers into believing that Louis Vuitton produced or endorsed the Film. Therefore, the complaint fails to even allege the type of confusion that could potentially overcome the Rogers protection.

Even if the Court assumes, arguendo, that Louis Vuitton has stated a cognizable claim of confusion, its claim would fail anyway. The Second Circuit in Rogers emphasized that when First Amendment values are involved, courts should narrowly construe the Lanham Act and weigh the public interest in free expression against the public interest in avoiding customer confusion. As such, where an expressive work is alleged to infringe a trademark, the likelihood of confusion must be particularly compelling. 
The Court concludes that Louis Vuitton's allegations of confusion are not plausible, let alone "particularly compelling." First, it is highly unlikely that an appreciable number of people watching the Film would even notice that Alan's bag is a knock-off. Cf. . Gottlieb (no confusion of plaintiff sponsoring defendant's film where "it would be difficult for even a keen observer to pick out [plaintiff's] trademark" since "it appears in the background of the scene" and "occupies only a minute fraction [of] the frame for three segments lasting approximately three seconds each"). In this regard, Louis Vuitton is trying to have it both ways: arguing that the Diophy bags are so similar as to create consumer confusion but at the same time so obviously dissimilar that someone watching the Film would notice the slightly different symbols used on the Diophy bag. Yet, the Diophy bag appears on screen for no more than a few seconds at a time and for less than thirty seconds in total, and when it is on screen, it is usually in the background, out of focus, or partially obscured by other things. Like the appearance of the plaintiff's mark in Gottlieb, the Court finds that the difference between the authentic and knock-off bag is so difficult to even notice, that a claim of confusion under the Lanham Act is simply not plausible. Furthermore, Louis Vuitton's position assumes that viewers of the Film would take seriously enough Alan's statements about designer handbags (even about those he does not correctly pronounce) that they would attribute his views to the company that produced the Film. This assumption is hardly conceivable, and it does not cross the line into the realm of plausibility. Lastly, Louis Vuitton is objecting to a statement made by a fictional character in a fictional movie, which it characterizes as an affirmative misrepresentation. However, this assumes that the fictional Alan character knew that his bag was a knock-off; otherwise, he would simply be (innocently) misinformed about the origin of his bag. For these reasons, the Court concludes that the likelihood of confusion is at best minimal, and when balanced against the First Amendment concerns implicated here, it is not nearly significant enough to be considered particularly compelling.

Louis Vuitton maintains that the Rogers test cannot be assessed on a motion to dismiss. The Court disagrees. Although many courts have considered the Rogers test on a summary judgment motion, not on a motion to dismiss, the circuit has never stated that a court cannot properly apply the Rogers test (or the likelihood of confusion factors) on a motion to dismiss. In fact, the Second Circuit has suggested that it would be appropriate where the court is satisfied that the products or marks are so dissimilar that no question of fact is presented. In the context of a motion to dismiss, courts have disposed of trademark claims where simply looking at the work itself, and the context in which it appears, demonstrates how implausible it is that a viewer 
Stewart Surfboards: No. 10-cv-2982, slip. op. (C.D. Cal. May 11, 2011)

Burnett: 491 F.Supp.2d 962 (C.D. Cal. 2007)

Wham-O: 286 F. Supp. 2d 1254 (N.D. Cal. 2003)

$\S 32$

... innocent infringement by printers and publishers will be confused into believing that the plaintiff endorsed the defendant's work (and without relying on the likelihood of confusion factors to do so). See, e.g., Stewart Surfboards, Inc. v. Disney Book Group, LLC (no likelihood of confusion that readers would believe that plaintiff surfboard manufacturer endorsed a Hannah Montana book because one of its surfboards appeared on the back cover); Gottlieb (no likelihood of confusion that viewers would believe plaintiff pinball machine owner endorsed the movie "What Women Want" because it appeared in the background of a few scenes); Burnett $v$. Twentieth Century Fox Film Corp. (no likelihood of confusion that viewers would believe plaintiff Carol Burnett endorsed a Family Guy sketch making fun of her); cf. Wham-O, Inc. v. Paramount Pictures Corp. (denying preliminary injunction without discovery where no likelihood of confusion that viewers would believe that plaintiff maker of the Slip ' $N$ Slide endorsed the movie "Dickie Roberts: Former Child Star" because the protagonist (mis)used the toy water slide in one scene of the movie).

Here, there is no likelihood of confusion that viewers would believe that the Diophy bag is a real Louis Vuitton bag just because a fictional character made this claim in the context of a fictional movie. Neither is there a likelihood of confusion that this statement would cause viewers to believe that Louis Vuitton approved of Warner Bros.' use of the Diophy bag. In a case such as this one, no amount of discovery will tilt the scales in favor of the mark holder at the expense of the public's right to free expression.

Therefore, even assuming, arguendo, that Louis Vuitton could state a cognizable claim of confusion, Warner Bros.' use of the Diophy bag is protected under Rogers because it has some artistic relevance to the Film and is not explicitly misleading.

\section{Miscellaneous}

\section{Lanham Act}

(2) Notwithstanding any other provision of this chapter, the remedies given to the owner of a right ... of this title shall be limited as follows:

(A) Where an infringer or violator is engaged solely in the business of printing the mark or violating matter for others and establishes that he or she was an innocent infringer or innocent violator, the owner of the right infringed ... shall be entitled as against such infringer or violator only to an injunction against future printing. 
(B) Where the infringement or violation complained of is contained in or is part of paid advertising matter in a newspaper, magazine, or other similar periodical or in an electronic communication, the remedies of the owner of the right infringed shall be limited to an injunction against the presentation of such advertising matter in future issues of such newspapers, magazines, or other similar periodicals or in future transmissions of such electronic communications. The limitations of this subparagraph shall apply only to innocent infringers and innocent violators.

\section{Trademark Defenses Lightning Round}

Do the following uses qualify for any trademark defenses? For your reference, the relevant marks are LITTLE LEAGUE for children's sports; FORD for cars; 7-11 for groceries; FEDEX for delivery services; GOT MILK for milk; MARLBORO for cigarettes; LISTERINE for mouthwash; M\&MS for chocolate candy, and the angry monkey design for an "on-line retailer store featuring clothing, namely, patches, t-shirts, hats, bags and pouches and tactical gear." It may help to note that "I wish I knew how to quit you" is a line of dialogue from Brokeback Mountain, and observe that black text on the white portion of Target bottle of mouthwash reads "Compare to FRESHBURST® LISTERINE®." (Hint: it never hurts to start by articulating the applicable theory or theories of infringement against which a defense is needed.)

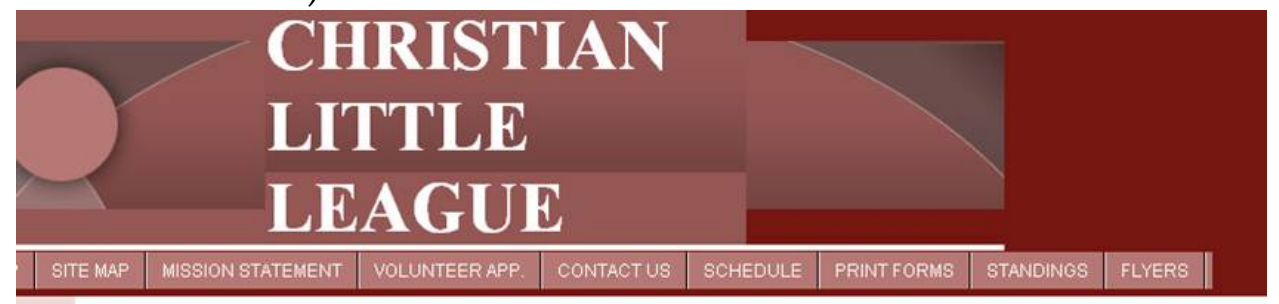

WHERE FAMILY AND FRIENDS ARE MORE IMPORTANT THAN WINNING AND THERE ARE NO LOSERS!!!

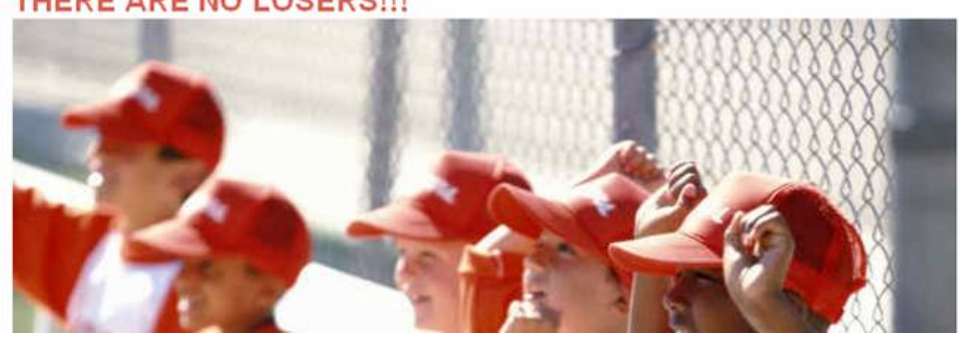




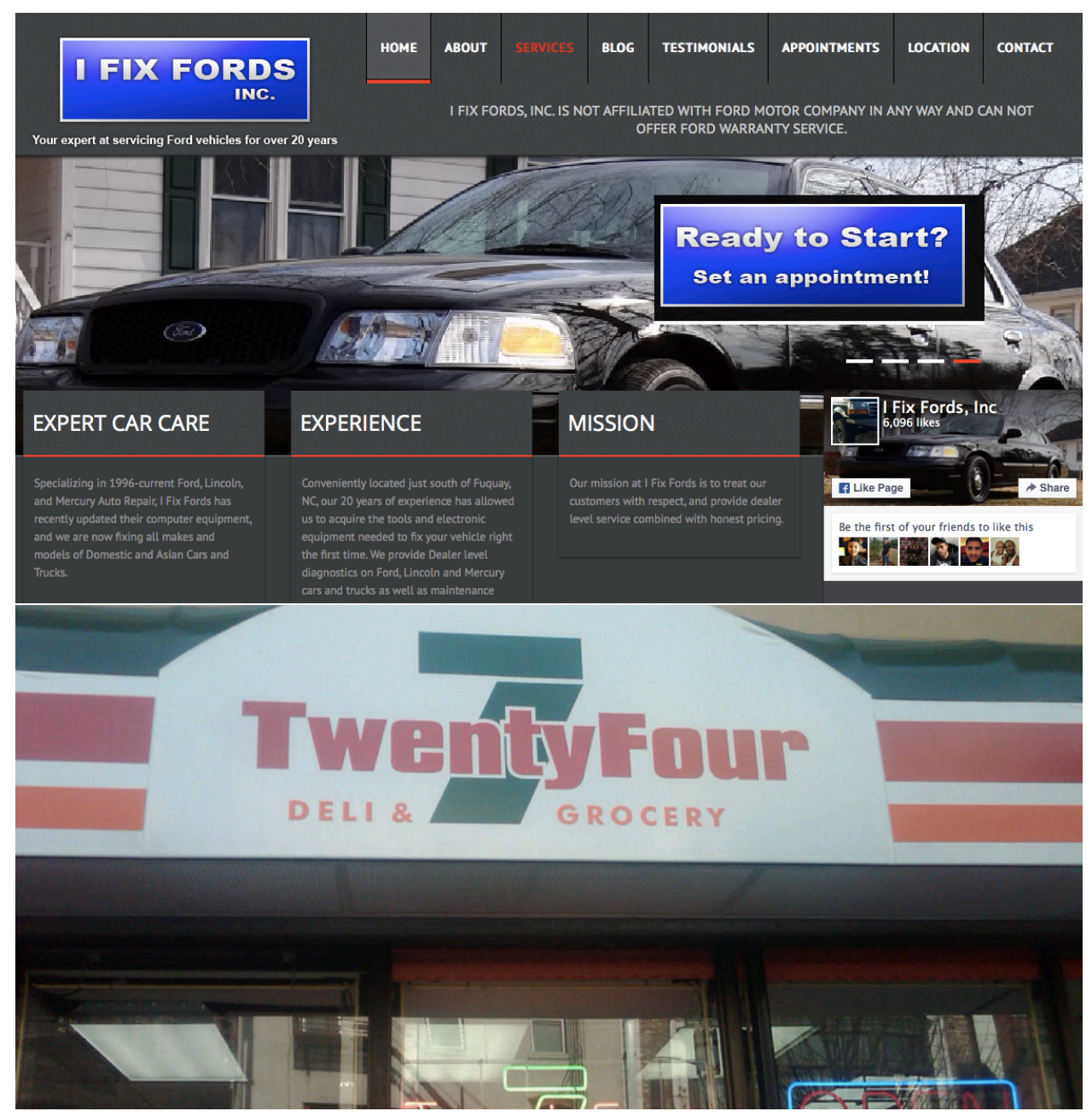




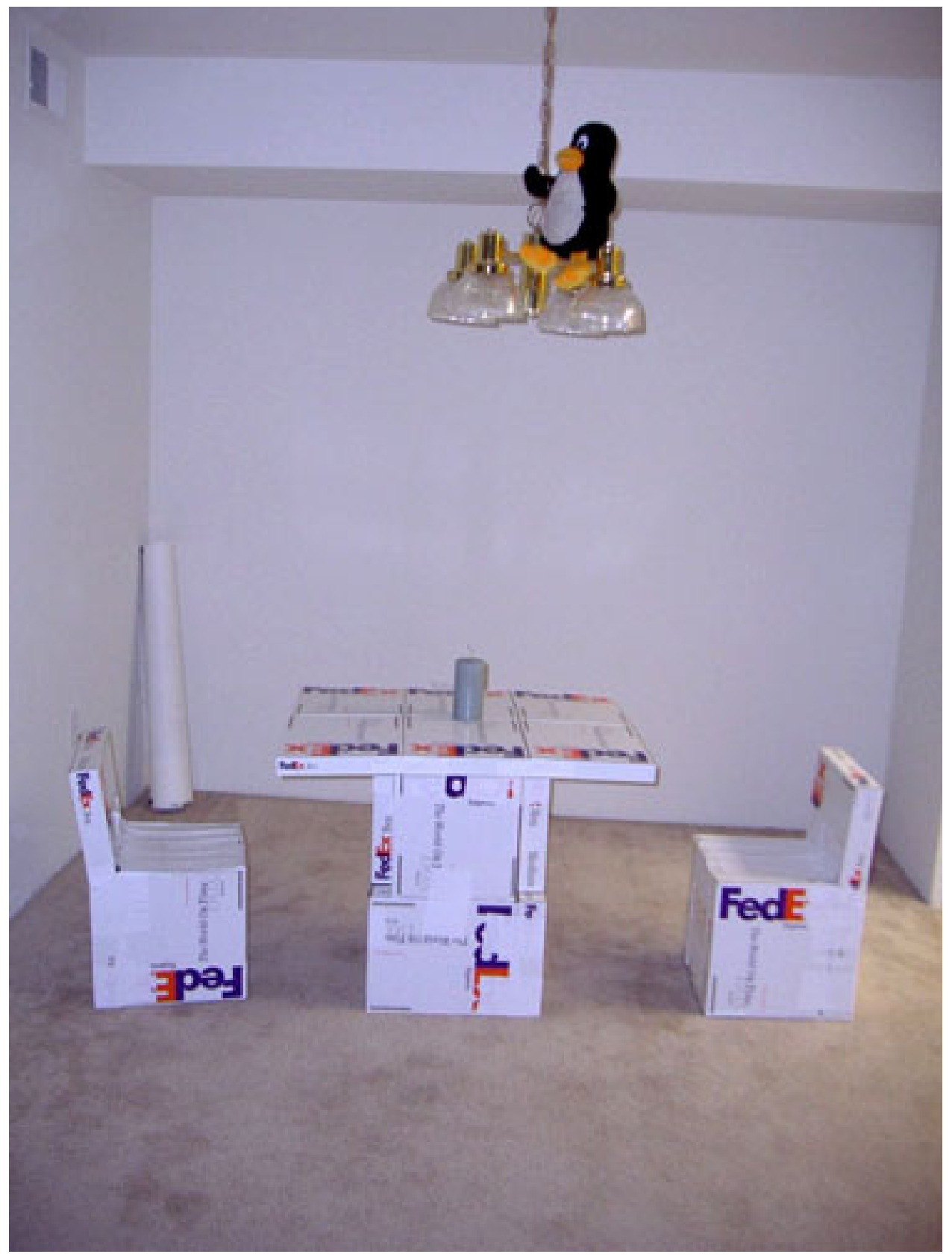




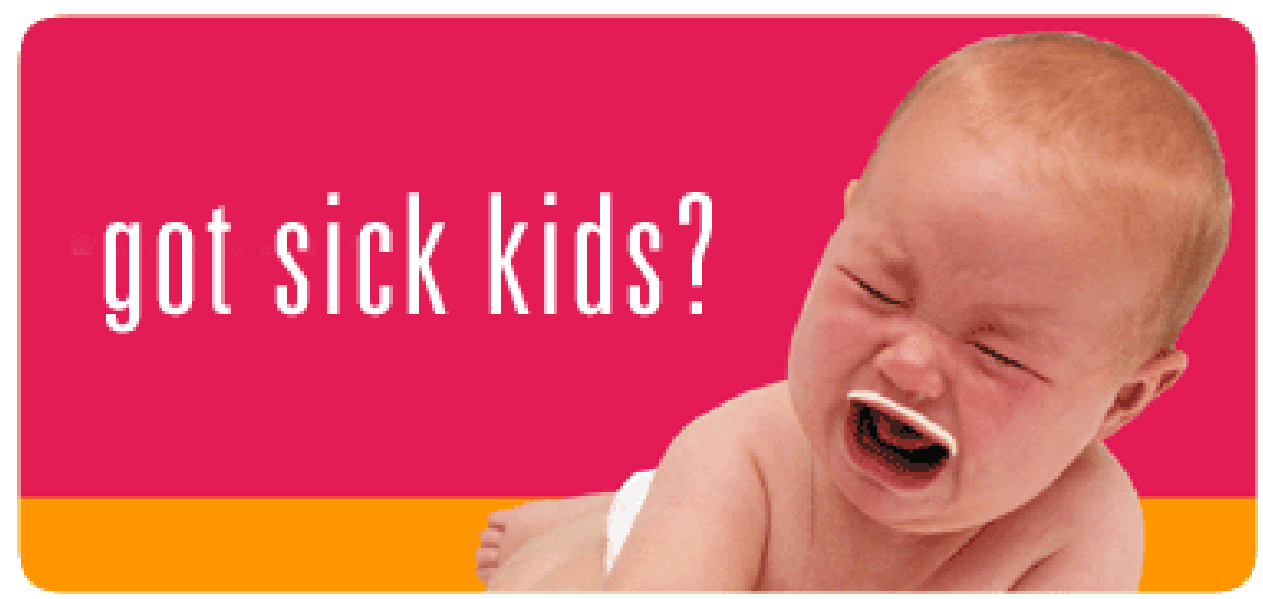

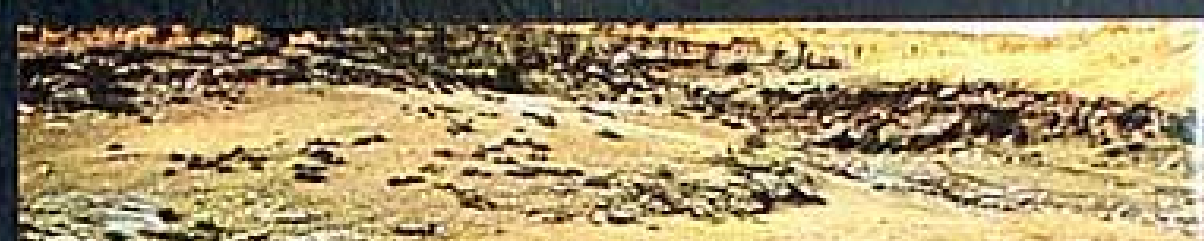

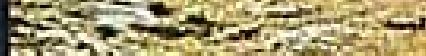
I Wish I Knew How to Quit You

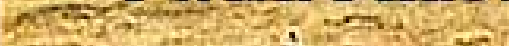

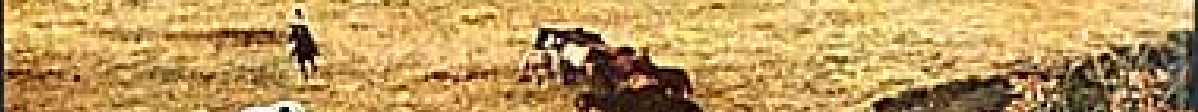

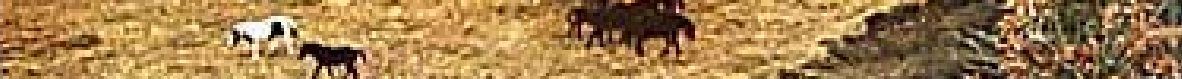

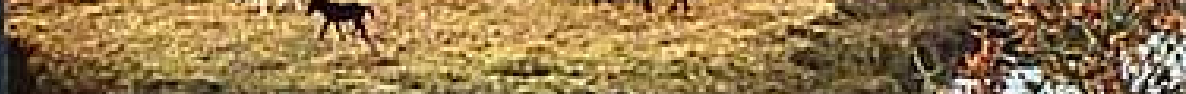

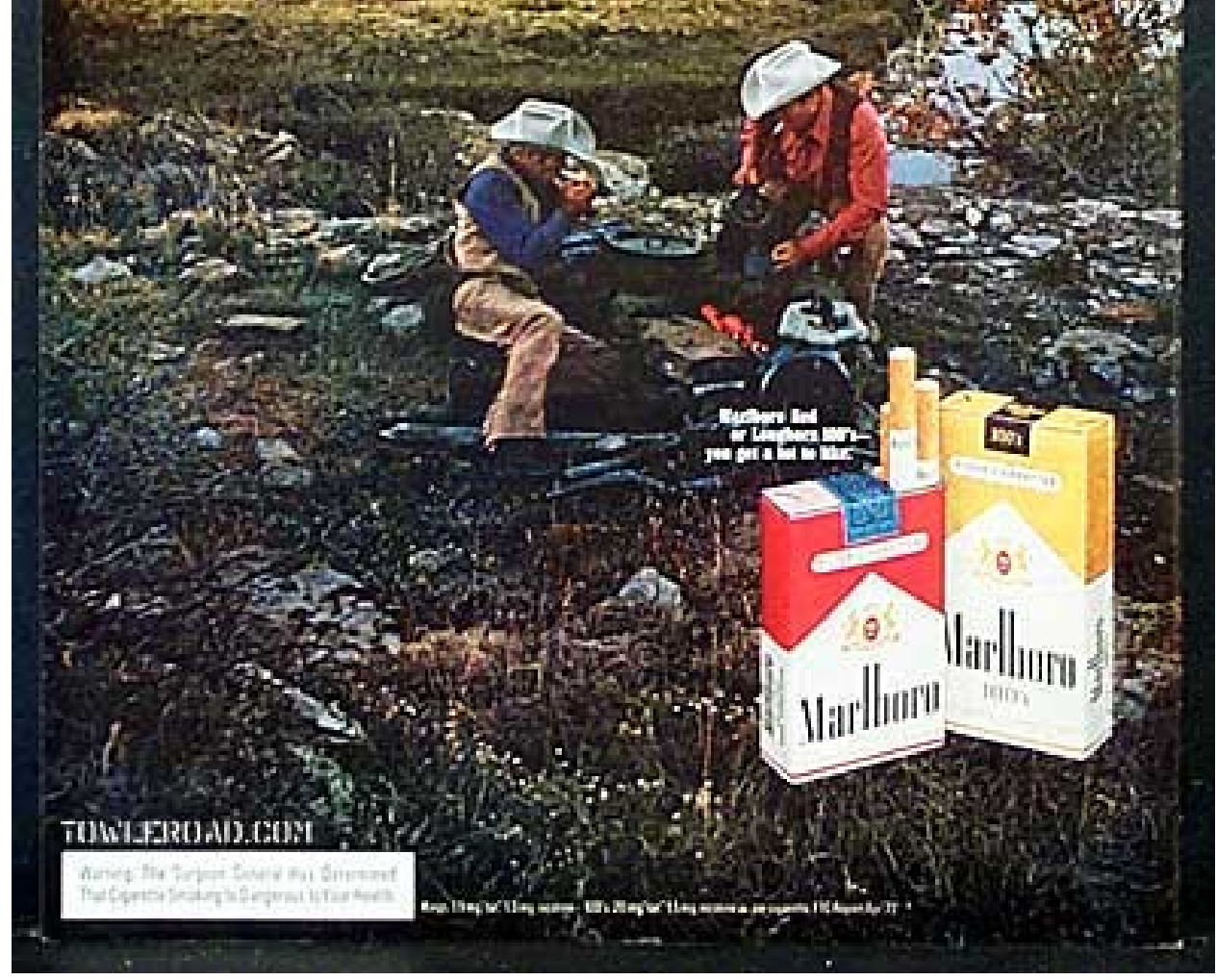




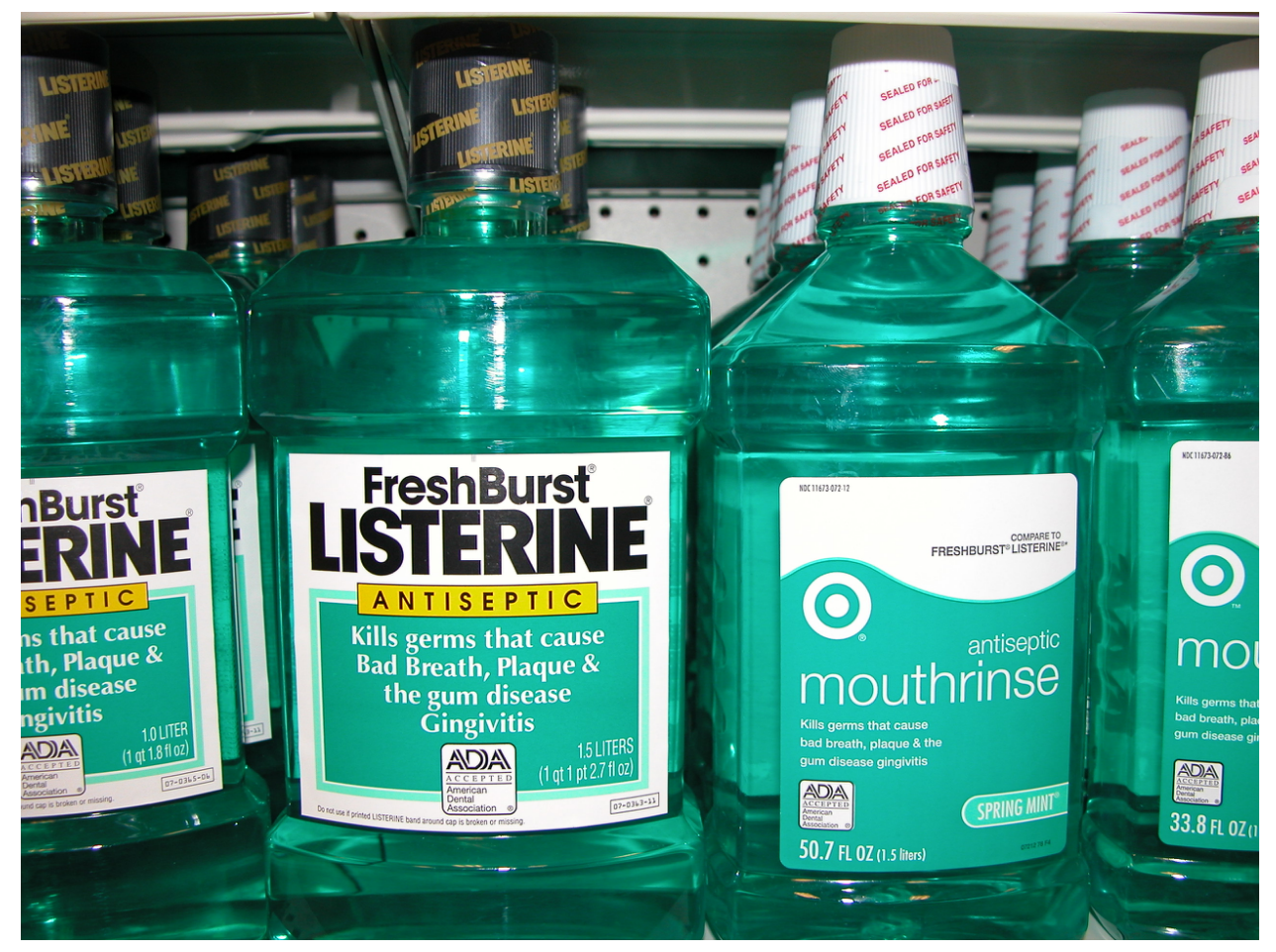




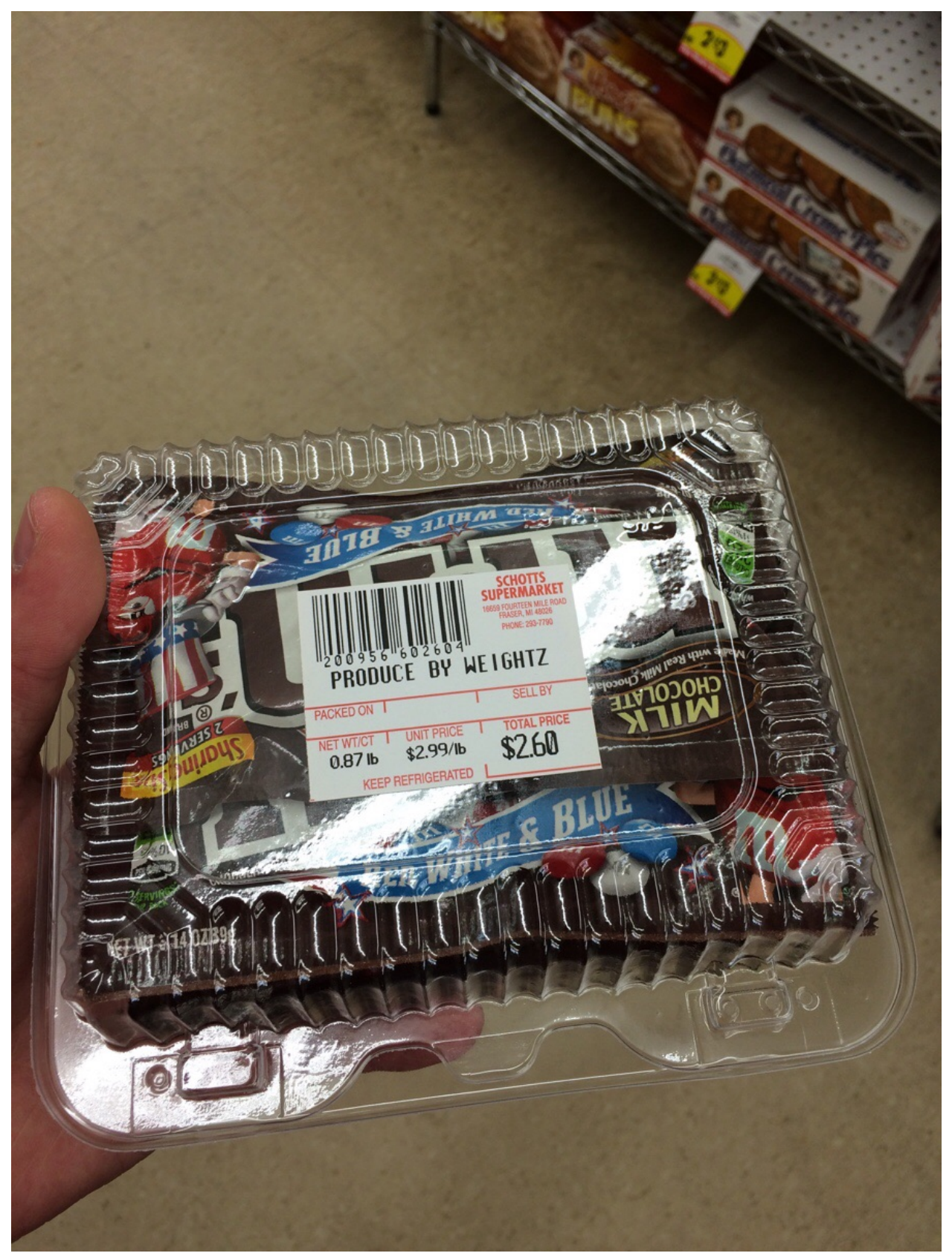




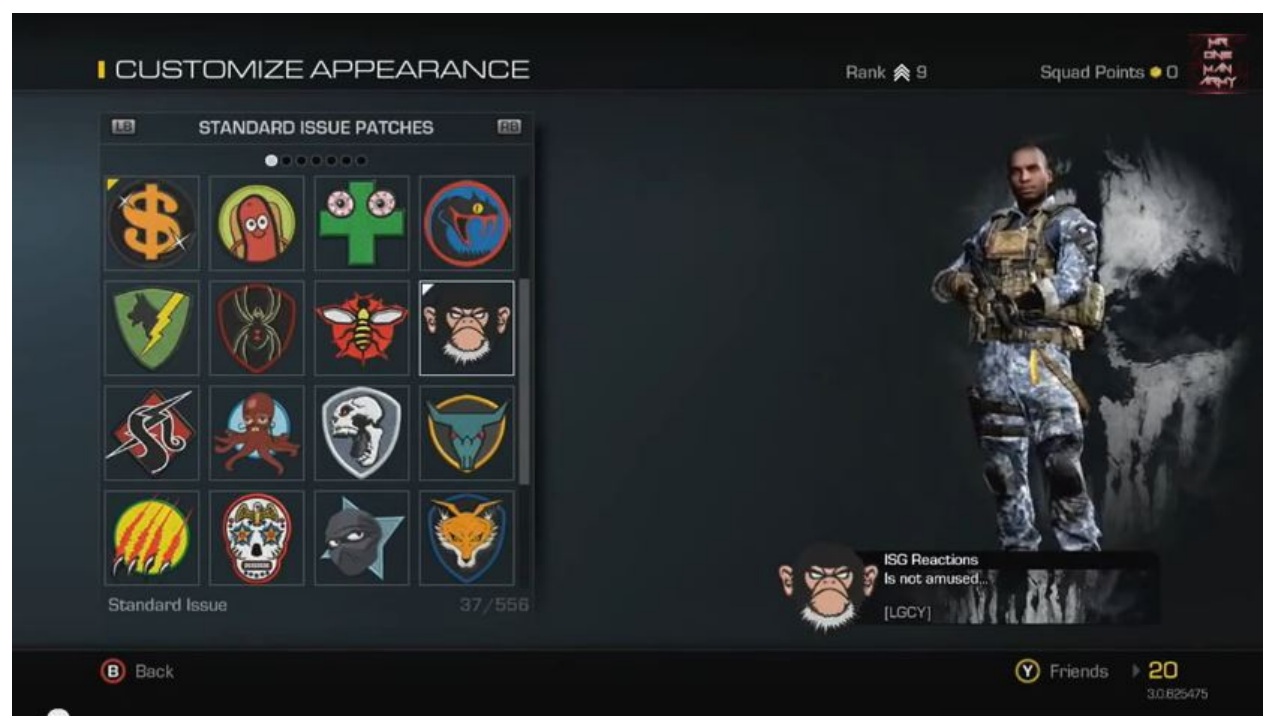

\section{G Other Identifier Registries}

One of the core concepts of trademark law - a registry that assigns exclusive rights in names or other identifiers - shows up in some other contexts, as well. In each case, query what work if any trademark law is doing and what lessons if any trademark law can teach.

\section{Phone Numbers}

Holiday Inns, Inc. v. 800 Reservation, Inc.

Holiday Inns, Inc., filed this Lanham Act suit against the defendants, alleging unfair competition and infringement of its trademark telephone number, 1-800-HOLIDAY, known as a "vanity number." Since 1952, Holiday Inns has operated an international chain of hotels through both franchise agreements and on its own, utilizing the name "Holiday Inn." Holiday Inns, Inc. owns registration in the United States Patent and Trademark Office for several service marks, including the "Holiday Inn" mark, which was registered in 1954. Holiday Inns has invested a great deal of time, money, and effort to increase the traveling public's awareness of its 1-800-HOLIDAY phone number, which can be dialed to secure reservations or to obtain information about lodging facilities. According to the vice president of Holiday Inns's marketing, the company's vanity number is included in virtually all of its extensive media, print, and radio advertisements. The telephone number is not, however, officially registered as a trademark.

The defendants, Call Management Systems, Inc. (a consulting firm that obtains and services 1-800 telephone numbers for busi- 
Dial-a-Mattress: 880 F.2d 675 (2d Cir. 1989) nesses), 800 Reservations, Inc. (an agency that makes reservations for a number of hotel chains, including Holiday Inns), and Earthwinds Travel, Inc. (a travel agency) had secured the use and were engaged in using a telephone number that potential Holiday Inns customers frequently dial by mistake when they unintentionally substitute the number zero for the letter "O." That number, 1-800-405-4329, corresponds to the alphanumeric 1-800-H[zero]LIDAY, known in the trade as a "complementary number." It is referred to in this opinion as "the 405 number" to distinguish it from the Holiday Inns numeric, 1-800465-4329.

Albert H. Montreuil, the 50

When Montreuil discovered that numbers complementing 1-800HOLIDAY had not been reserved, he decided, in May 1993, to reserve them for Call Management. In fact, Montreuil freely admitted during the preliminary injunction hearing that his "sole purpose" in choosing the 405 number was to intercept calls from misdialed customers who were attempting to reach Holiday Inns, and he acknowledged that his company reaped benefits in direct proportion to Holiday Inns's efforts at marketing 1-800-HOLIDAY for securing reservations.

The few courts that have addressed similar issues have agreed that telephone numbers may be protected as trademarks and that a competitor's use of a confusingly similar telephone number may be enjoined as both trademark infringement and unfair competition. See, e.g., Dial-A-Mattress Franchise Corp. v. Page. In Dial-a-Mattress, the plaintiff was the customer of record for the local telephone number 628-8737 in the various area codes of the New York metropolitan region. Dial-A-Mattress Franchise Corp. had advertised extensively its services and its phone number in the area with the phrase "DIALA-MATTRESS and drop the last 'S' for savings." The defendant, Page, obtained the right to use 1-800-628-8737 (or 1-800-MATTRES) and promoted his number as 1-800-MATTRESS.

The Second Circuit held that although the term "mattress" is a generic term generally not entitled to protection under trademark law, telephone numbers that correlate with generic terms may be entitled to protection. It further determined:

Defendant's use of the telephone number 1-800-628-8737 was confusingly similar to plaintiff's telephone number 628-8737 in those area code regions in which plaintiff solicited telephone orders, especially in view of defendant's identification of its number as 1-800-MATTRESS after plaintiff had promoted identification of its number as (area code)-MATTRES.

Despite Holiday Inns's reliance upon the Dial-a-Mattress decision, we find the instant case and the Second Circuit opinion clearly distin- 
guishable. In Dial-a-Mattress, for example, the defendant intentionally promoted his vanity number and actively caused confusion; in our case, the defendants engaged in only minimal advertisement of their travel agency and never promoted a vanity number.

The defendants, on the other hand, cite cases which suggest that the active promotion of a deceptively similar vanity number is necessary before the trial court can conclude that unlawful infringement has occurred. In American Airlines, Inc. v. A 1-800-A-M-E-R-I-C-A-N Corp, for example, the defendant falsely advertised its airline reservation service as an airline company in the yellow pages and listed its company name as "A 1-800-A-M-E-R-I-C-A-N." In finding a Lanham Act violation, the court clarified that the defendant's "wrongful conduct lies in its misleading use of the 'Airline Companies' yellowpages listing rather than its mere use of its telephone number [1-800AMERICAN] as such." In other words, the court issued an injunction because the defendant's publicity efforts misled the public and not because the defendant activated a 1-800 number that appeared confusingly similar to the trademark, "American Airlines." See also Murrin v. Midco Communications, Inc. (granting a limited injunction forbidding the advertisement or use of the vanity number 1-800-LAWYER with "dial" or with any symbols resembling dots or hyphens between the letters "LAWYERS" but explicitly rejecting the argument that any use of the phone number 529-9377 - which spells "lawyers" on the telephone keypad - constitutes infringement upon Murrin's "Dial L.A.W.Y.E.R.S." service mark).

We conclude that although Holiday Inns owns trademark rights in its vanity number 1-800-HOLIDAY, it cannot claim such rights to the 405 number. It follows that the defendant, Call Management, is the rightful assignee of the telephone number 1-800-405-4329.

\section{Radio Callsigns}

In re WSM, Inc.

WSM, Incorporated adopted the call letters "WSM" for its radio station in 1925 and claims use of "WSM" as a service mark for radio broadcasting services in interstate commerce since 1925. Its application to register the letters as a service mark was refused. The Examining Attorney concedes that the letters sought to be registered are used by applicant as a service mark, but takes the position that applicant is not the owner of the mark because the Federal Communications Commission (FCC) licenses applicant to broadcast, approves applicant's call letters, and retains the power to revoke the license to broadcast along with the call letters used to identify the station. Thus under the Examining Attorney's theory the applicant cannot control the use of
American Airlines: 622 F.Supp. 673 (N.D. III. 1985)

Murrin: 726 F. Supp. 1195 (D. Minn. 1989)

225 U.S.P.Q. 883 (TTAB 1985) 
the mark, and as such is not its owner. Applicant appealed when the refusal was made final.

The Examining Attorney has apparently misunderstood the nature of the relationship between the FCC and applicant. The FCC licenses applicant to broadcast from a specified geographic location on a specified frequency at a specified power during specified times. The FCC exercises its authority to "designate" call letters for licensed broadcasters by permitting the broadcasters to request whatever call letters they like. Prior to 1984 the requests were granted unless: (1) another station had the same call letters, (2) the requested call letters were not in good taste, or (3) the requested letters were phonetically and rythmically similar to existing call letters of stations in the same area, so that the stations would likely be confused. Prior to 1984 the FCC administered a system whereby one licensed station could object to the approval of another station's call letters, but only if both stations were to serve the same area. These disputes between broadcasters were resolved by the FCC. The interests of anyone who was not a broadcaster were never considered by the FCC.

In 1984 the FCC rules regarding call letter approval and conflicts were changed. The agency will now grant a request for particular call signs if the identical call sign is not already in use by someone else, and the FCC is no longer a forum for the resolution of disputes between stations. Section 73.3550(g) of the FCC Rules now provides as follows:

Applicants may request call signs of their choice if the combination is available. Objections to the assignment of requested call signs will not be entertained at the FCC. However, this does not hamper any party from asserting such rights as it may have under private law in some other forum. Should it be determined by an appropriate forum that a station should not utilize a particular call sign, the initial assignment of a call sign will not serve as a bar to the making of a different assignment.

It is clear that the FCC is not the owner of the call letters used by the broadcasters which it regulates. The right to broadcast is what the agency licenses to broadcasters. The right to use the call letters is not licensed in a trademark sense. The FCC neither adopts nor uses call letters as service marks, so it does not own any such marks. Even prior to its new rules the agency did not assert ownership of call letters. It acted only as a third party to resolve disputes between the owners of the call letters, the broadcasters who actually use them.

The relationship between broadcasters and the FCC is analogous to other areas of commerce where businesses are regulated by government agencies. Pharmaceutical manufacturers, for example, operate 
under complex regulations established and administered by a federal agency. The right to market a particular drug is granted by the agency and may be withdrawn by the agency for particular health or safety reasons at any time. The ownership of the trademarks used to identify these goods is obtained by the manufacturers through adoption and use, just as with any other trademark or service mark. The fact that sales are regulated by the agency and the agency may withdraw the right to market the goods has no bearing on the manufacturers' ownership of, and right to register, these trademarks during the time while they are in lawful use. If and when the agency rules that a manufacturer may no longer sell a particular product, the use of the mark in connection with that product ceases. If that or a similar product is not sold again the manufacturer will no longer be able to maintain trademark rights with respect to that particular kind of product. As with any other goods or services, the rights in the marks are tied to use.

In the case at hand the applicant obtained whatever rights it has in its serivce mark by adopting it and using it to identify its broadcasting services. The FCC neither selected the mark for applicant nor used it to identify any services. While the agency may withdraw applicant's license to broadcast, it cannot, under its rules, unilaterally direct applicant to change its service mark or adopt another one. If the FCC withdraws the broadcast license and applicant is therefore unable to continue rendering broadcast services under the mark, the issue of abandonment of the mark would arise, but as long as applicant uses the mark to identify its services which are lawfully rendered in commerce, applicant is the owner of its service mark.

In summary, we hold that through the adoption and use of the service mark "WSM" the applicant is the owner of the mark within the meaning of Section 1(a) of the Act and is therefore entitled to register it.

\section{Business Names}

States regulate the official names of corporations. and other organizations, and they also regulate assumed names people use when they're in business under a name other than their own (also referred to as "doing business as" or "d/b/a"). Typically, both kinds of names must be registered; in fact, official names are part of the incorporation paperwork. In both cases there aren't many limits on the names that can be registered - but there are a few.

Model Business Corporation Act (2010)
Recall also Galt House's discussion of the trademark-priority effect of incorporating a business name, viz. absolutely nothing.

$\S 4.01$ (b)

Corporate Name 
[A] corporate name must be distinguishable upon the records of the secretary of state from (1) the corporate name of a corporation incorporated or authorized to transact business in this state ...

cmt. 2 Names That Are "Distinguishable upon the Records of the Secretary of State". -

The revision of the Model Act is based on the fundamental premise that its name provisions should only ensure that each corporation has a sufficiently distinctive name so that it may be distinguished from other corporations upon the records of the secretary of state. The general business corporation statute should not be a partial substitute for a general assumed name, unfair competition, or antifraud statute. As a result, the Model Act does not restrict the power of a corporation to adopt or use an assumed or fictitious name with the same freedom as an individual or impose a requirement that an "official" name not be "deceptively similar" to another corporate name (a requirement of earlier versions of the Model Act). Principles of unfair competition, not the business corporation act, provide the limits on the competitive use of similar names.

The phrase "distinguishable upon the records of the secretary of state" is drawn from section 102(a)(1) of the Delaware General Corporation Law. The principal justifications for requiring a distinguishable official name are (1) to prevent confusion within the secretary of state's office and the tax office and (2) to permit accuracy in naming and serving corporate defendants in litigation. Thus, confusion in an absolute or linguistic sense is the appropriate test under the Model Act, not the competitive relationship between the corporations, which is the test for fraud or unfair competition. The precise scope of "distinguishable upon the records of the secretary of state" is an appropriate subject of regulation by the office of secretary of state in order to ensure uniformity of administration. Corporate names that differ only in the words used to indicate corporateness are generally not distinguishable. Thus, if $\mathrm{ABC}$ Corporation is in existence, the names "ABC Inc.," "ABC Co.," or "ABC Corp." should not be viewed as distinguishable. Similarly, minor variations between names that are unlikely to be noticed, such as the substitution of a "," for a "." or the substitution of an Arabic numeral for a word, such as "2" for "Two," or the substitution of a lower case letter for a capital, such as " $\mathrm{d}$ " for " $\mathrm{D}$," generally should not be viewed as being distinguishable.

The elimination of the "deceptively similar" requirement that appeared in earlier versions of the Model Act is based on the fact that the secretary of state does not generally police the unfair competitive use of names and, indeed, usually has no resources to do so. For example, assume that "ABC Corporation" operates a retail furniture store in Albany, New York, and another group wants to use the same name to engage in a business involving imports of textiles in New York 
City. An attempt to incorporate a second "ABC Corporation" (or a very close variant such as "ABC Corp." or "ABC Inc.") should be rejected because the names are not distinguishable upon the records of the secretary of state. If the second group uses a distinguishable official name, like "ABD Corporation," it probably may lawfully assume the fictitious name "ABC Corporation" to import goods in New York City if it files the assumed name certificate required by $\mathrm{New}$ York law. In these situations, the secretary of state will usually not know in what business or in what geographical area "ABC Corporation" is active or what name ABD Corporation is actually using in its business; the secretary of state simply maintains an alphabetical list of "official" corporate names as they appear from corporate records and decides whether a proposed name is distinguishable from other "official names" by comparing the proposed name with those on the list. This assumes that there is either no assumed name statute or that if there is such a statute it requires only local filing in counties or, as in New York, a central filing which does not become part of the corporate records maintained by the secretary of state's office. These assumptions are generally if not universally correct.

\section{Harvard Business Services v. Coyle}

Plaintiff is a corporation engaged in the business of incorporating companies and of acting as registered agent for such corporations. Harvard has sought a writ of mandamus from this Court to compel Defendants, the Director of the Division of Corporations and the Secretary of State, to accept for filing a restated certificate of incorporation of a corporation proposed by Harvard to be called "Bank Financial Services, Inc."

Generally, the formation of banking companies is governed by special statutes and such businesses are not permitted to incorporate under general incorporation acts. Notably, 8 Del. C. $\S 395$ precludes the use of the word "trust" in the name of any corporation other than those regulated under the banking laws. At least one commentator has found it "curious" that there is no statutory prohibition on the use of the word "bank" similar to the "trust" prohibition.

The Secretary has an interest in furthering this general legislative goal of preventing misconceptions by the public about the functions of Delaware corporations. To further that goal, the Secretary has an interest in restricting the use of the word "bank."

Surely, if an incorporator attempted to incorporate in Delaware using obscene or libelous language in the proposed corporate name, the Secretary would have the discretion to refuse such a filing. Similarly, if a proposed corporation's name consisted of five hundred words, the Secretary would have the authority to refuse to accept the certificate of incorporation for filing if the overly lengthy corporate 
name would cause undue confusion or difficulty in administration. This discretion is not delineated in the statute, but seems implicit in the Secretary's duty to accept corporate filings.

This Court finds that although there is no explicit statutory restriction on the use of the word "bank" in the name of a corporation not in fact exercising banking powers, the Secretary does possess some limited, implied discretion when considering a proposed corporate name which includes the word "bank" but where that corporation cannot engage in the business of banking.

\section{Cooper v. Goodman}

Petitioner offered for filing certificates of doing business under the names of 'The Brothel', 'The Garden of Erotic Pleasures', 'Theatre O', and 'Club Orgy'. Section 130 of the General Business Law requires that a person doing business under an assumed name must file a certificate designating the person conducting such business.

The County, Clerk refused to file said certificates because they would be employed for deceptive purposes indicating that some kind of illegal or otherwise obscene activity may be expected within the establishments so described.

Obviously, the assumed names on the certificates were adopted for the purpose of obtaining publicity, public attention, and curiosity with the expectation they would promote business for the establishments. In fact, they may invite the attention of the Police Department, which would cause the establishments to be under police surveillance. In such case the public would be protected from illegal activities.

The filing of a certificate does not imply governmental approval

"The obvious purpose of the Fictitious Names Act is to protect persons giving credit in reliance on the assumed or fictitious name and to definitely establish the identity of the individuals owning the business for the information of those who might have dealings with the concern." textitFremd v. Horne, 1990 WL 362051 (Pa. Com. PI. 1990)

440 U.S. 1 (1979)

Virginia Pharmacy: 425 U.S. 748 (1976) of the assumed name or of the business acitivity. The filing is statutorily required for the purpose of identifying the person operating the business under such assumed name.

It has not been shown that the assumed names are in contravention of any provision of law. While the names are distasteful, that is not a sufficient reason to deny their filing.

\section{Friedman v. Rogers}

The Texas Legislature approved the Texas Optometry Act (Act) in 1969. Section 5.13 (d), at issue here, prohibits the practice of optometry under an assumed name, trade name, or corporate name.

Once a trade name has been in use for some time, it may serve to identify an optometrical practice and also to convey information about the type, price, and quality of services offered for sale in that practice. In each role, the trade name is used as part of a proposal of a commercial transaction. Like the pharmacist who desired to advertise his prices in Virginia Pharmacy Board v. Virginia Citizens Consumer Council, the optometrist who uses a trade name "does not wish to ed- 
itorialize on any subject, cultural, philosophical, or political. He does not wish to report any particularly newsworthy fact, or to make generalized observations even about commercial matters." His purpose is strictly business. The use of trade names in connection with optometrical practice, then, is a form of commercial speech and nothing more.

A trade name is, however, a significantly different form of commercial speech from that considered in Virginia Pharmacy and Bates. In those cases, the State had proscribed advertising by pharmacists and lawyers that contained statements about the products or services offered and their prices. These statements were self-contained and self-explanatory. Here, we are concerned with a form of commercial speech that has no intrinsic meaning. A trade name conveys no information about the price and nature of the services offered by an optometrist until it acquires meaning over a period of time by associations formed in the minds of the public between the name and some standard of price or quality. Because these ill-defined associations of trade names with price and quality information can be manipulated by the users of trade names, there is a significant possibility that trade names will be used to mislead the public.

The possibilities for deception are numerous. The trade name of an optometrical practice can remain unchanged despite changes in the staff of optometrists upon whose skill and care the public depends when it patronizes the practice. Thus, the public may be attracted by a trade name that reflects the reputation of an optometrist no longer associated with the practice. A trade name frees an optometrist from dependence on his personal reputation to attract clients, and even allows him to assume a new trade name if negligence or misconduct casts a shadow over the old one. By using different trade names at shops under his common ownership, an optometrist can give the public the false impression of competition among the shops. The use of a trade name also facilitates the advertising essential to large-scale commercial practices with numerous branch offices, conduct the State rationally may wish to discourage while not prohibiting commercial optometrical practice altogether.

The concerns of the Texas Legislature about the deceptive and misleading uses of optometrical trade names were not speculative or hypothetical, but were based on experience in Texas with which the legislature was familiar when in 1969 it enacted $\S 5.13$ (d). The forerunner of $\S 5.13$ (d) was adopted as part of a "Professional Responsibility Rule" by the Texas State Board of Examiners in Optometry in 1959. In a decision upholding the validity of the Rule, the Texas Supreme Court reviewed some of the practices that had prompted its adoption. Texas State Bd. of Examiners in Optometry v. Carp. One of the plaintiffs in that case, Carp, operated 71 optometrical offices in Texas under at 
least 10 different trade names. From time to time, he changed the trade names of various shops, though the licensed optometrists practicing in each shop remained the same. He purchased the practices of other optometrists and continued to practice under their names, even though they were no longer associated with the practice. In several instances, Carp used different trade names on offices located in close proximity to one another and selling the same optical goods and services. The offices were under common management, and had a common staff of optometrists, but the use of different trade names facilitated advertising that gave the impression of competition among the offices.

The Texas court found that Carp used trade names to give a misleading impression of competitive ownership and management of his shops. It also found that Rogers, a party to this suit and a plaintiff in Carp, had used a trade name to convey the impression of standardized optometrical care. All 82 of his shops went under the trade name "Texas State Optical" or "TSO," and he advertised "scientific TSO eye examination[s]" available in every shop. The TSO advertising was calculated as well, the court found, to give "the impression that [Rogers or one of his brothers] is present at a particular office. Actually they have neither been inside nor seen some of their eightytwo offices distributed generally over Texas." Even if Rogers' use and advertising of the trade name were not in fact misleading, they were an example of the use of a trade name to facilitate the large-scale commercialization which enhances the opportunity for misleading practices.

It is clear that the State's interest in protecting the public from the deceptive and misleading use of optometrical trade names is substantial and well demonstrated. We are convinced that $\S 5.13$ (d) is a constitutionally permissible state regulation in furtherance of this interest.

\section{Ticker Symbols}

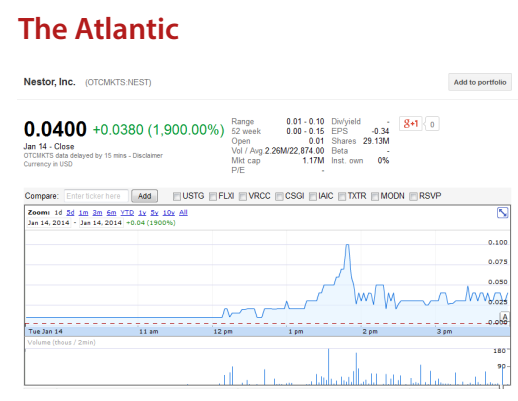

Nestor stock price before and after Nest acquisition announcement

\section{Eric Levenson}

Investors Buy Up Worthless Stock After Confusing It for an Actual Successful Company

Shortly after Google announced its deal to acquire thermostat-maker Nest Labs for $\$ 3.2$ billion, shares of NEST started trading like gangbusters. Unfortunately, NEST is not the stock symbol for Nest Labs.

NEST actually represents the stock of Nestor Inc, an essentially bankrupt company that has seen almost no stock activity since selling off its assets in 2009. No one is quite sure why the stock is even still available to trade, but confused investors (or perhaps some un- 
scrupulous ones) rushed to buy it up, mistakenly believing they were getting in on Google's Next Big Thing. Nestor's stock price went up 1900 percent for the day, and reached a high of 10 cents after years of trading for less than a penny a share. Economics blogger Kid Dynamite noticed the stark increase in trading, and posted this graph on his site. Notice the volatile rise after a long period of quiet.

\section{FINRA Uniform Practice Advisory \# 39 -13}

On Friday, October 4, 2013, the Financial Industry Regulatory Authority, Inc. halted trading in the securities of Tweeter Home Entertainment Group (former OTC Symbol: TWTRQ). FINRA determined to impose a temporary halt because FINRA believed that trading in the TWTRQ security demonstrated a widespread misunderstanding related to the possible initial public offering of an unrelated security.

For the avoidance of further confusion, FINRA has determined to effect a symbol change for the common stock of Tweeter Home Entertainment Group. Members hereby are advised that the symbol for Tweeter Home Entertainment Group has been changed from TWTRQ to THEGQ and that quoting and trading in Tweeter Home Entertainment Group's securities will resume under the new symbol, THEGQ, effective October 8, 2013 at 9:30:00 a.m. E.T.

\section{Central Parking Corp. v. Park One Inc.}

In July, 1997, Southern Parking System, Inc., a parking lot management services company, became Park One Incorporated. The selection of the name "Park One Incorporated" and the use of "pk1" as its symbol came as the result of an extensive name search. Numerous names were suggested; one name, "Trans Park," was eventually decided on and pursued until it was discovered that another company held a federal trademark on the name. The second efforts at a name search produced the "Park One Incorporated" name and the "pk1" logo, an abbreviation of the full length name. Prior to final selection, Park One's attorney did a trademark search to ascertain that the logo was not identical to nor too closely related to an existing trademark.

Central Parking Corporation is also engaged in parking management services. The letters "PK" designate Central's stock on the New York Stock Exchange; since October of 1995, Central has used the "PK" mark in its advertising and marketing to show the symbol under which its stock is traded. There is no evidence that Central has used this mark outside its reference as its NYSE symbol. Central has sued Park One for service mark infringement and seeks Park One's cessation of use of the "pk1" logo in its Motion for Preliminary Injunction.

By Central's own admission the letters "PK" were selected as the NYSE symbol because of its association with "parking" and because
(Oct. 7, 2013)

Twitter's IPO prospectus, which proposed the symbol TWTR, was dated October 3, 2013.

No. Civ.A. 97-2638, 1997 WL 655925 (E.D. La. Oct. 20, 1997) 
it was the closest combination of letters approximating the word. While Central argues that "PK" is a service mark, the evidence shows that "PK" designates its New York Stock Exchange listing and is not a service mark of the company. To the contrary, the "converging arrowhead" mark has been federally registered by Central and is the pervasive logo in its business. The "PK" mark tends to describe the services offered rather than to identify or distinguish a particular company.

Central's clients are typically savvy business people who require more than a logo before entering into complex and long term contracts. Thus, they are not likely to be confused by Park One's use of "pk1" while "PK" is the NYSE symbol for Central.

\section{Exxon Corp. v. Xoil Energy Resources, Inc.}

EXXON is one of the world's larger business enterprises, engaged in virtually every aspect of the oil and gas business, from exploratory and developmental well drilling to refining and retail marketing. In 1972 plaintiff adopted the trade name "EXXON", a coined term first registered as a trademark in 1968.

XOIL Energy Resources, Inc. are in the business of providing interests in tax shelters related to exploratory and developmental oil and gas well drilling. Plaintiff claims that defendants' use of the name XOIL in connection with oil and gas (or energy) enterprises, will cause irreparable harm because it will be likely to cause the public to confuse the name XOIL with EXXON.

The symbol "XON" is used by the various stock exchanges where Exxon securities are traded as a ticker symbol to designate those securities. Plaintiff contends that "XON" has come to identify goods (viz., stock and other securities) sold by, sponsored by or originating with the plaintiff, and is entitled to protection from marks or designations which are confusingly similar. Plaintiff also argues that defendants' securities are traded in the over-the-counter market, and that the symbols for defendants' securities, "XOIL" and "XPLR", will be confused with Exxon's ticker symbol "XON". In the absence of any evidence that the symbol "XON" is known at all outside of that small segment of the public which consists of the employees of stock exchanges, investment brokerage firms and their customers, and investment advisors and their advisees, I continue my examination of the degree of similarity of the ticker symbols "XON", "XOIL", and "XPLR" to their usage in the stock business.

The securities of at least six companies (other than plaintiff or defendants) traded on various exchanges or in the over-thecounter market are designated by symbols involving the letter " $X$ ". At least one of these companies is engaged in the oil business: 


\begin{tabular}{lll} 
Company Name & Exchanges on Which Traded & Ticker Symbol \\
\hline Excel Energy & Over-the-Counter & EXLL \\
Ex-Cello-Corp. & New York, Boston & XLO \\
Exolon Co. & Boston & EXL \\
XOMOX Corp. & Over-the-Counter & XOMX \\
XONICS, INC. & Philadelphia, American & XOX \\
Xtra Corp. & New York, Boston & XTR
\end{tabular}

For those who recognize and use such symbols, the addition, deletion or change of a single letter is obviously more than sufficient to enable those active in the securities field to differentiate between the various symbols. I also note that most of the symbols cannot be pronounced easily, and infer that they are used primarily in written communications, or are spelled out whenever spoken. Obviously these two forms of usage would tend to reduce the likelihood of confusion stemming from visual similarity.

"XPLOR" and "XOIL" are much more similar to plaintiff's marks aurally than visually. "Exxon", "XOIL", and "Xplor" all commence with an " $X$ " or "ex" sound: " $X$ " and "ex" are phonetically indistinguishable. "Exxon" and "Xplor" are also easily distinguishable when heard. While there is a degree of aural similarity between "XOIL" on the one hand, and "Exxon" on the other, the nature of defendants' business is such that every transaction involves, at some point, a written instrument. There could not be, under such circumstances, such reliance on the sounding of the name "XOIL" as to make aural similarity an important factor.

The symbol "XON" is used in the securities markets to identify securities of the plaintiff. Plaintiff did not create this symbol, nor has it registered or promoted this symbol as a trademark. No products other than securities are identified by this symbol. Nor has any evidence been introduced that plaintiff itself uses this mark on securities when it sells them. Thus unlike the trademarks involved in this case, the symbol "XON" is not owned by, used to sell products by, or even created by plaintiff. Furthermore, while the symbol "XON" has a well-established secondary meaning in the investment community, it has no significance outside that community, the size of which must be considered small in relation to the general population. I find the strength of the symbol "XON" to be quite strong in the investment community but so small as to be insignificant in the general population.

As to the ticker symbol "XON", the relevant public is accustomed to distinguishing ticker symbols one from another. In the context of the securities market and those who are active in that market, there are not such similarities between the symbol for plaintiff's securities ("XON") and the symbols for those of defendants ("XOIL" and "XPLR") as to lead to any confusion. 
Quite apart from other infirmities in plaintiff's claims of infringement with respect to the ticker symbol " $\mathrm{XON}$ " there is a lack of proximity of product between the stocks and securities to which that symbol pertains and the securities of defendants with the symbol "XOIL". XOIL is a non-listed stock and trades in the over-the-counter market while Exxon stock is listed on the principal exchanges. Plaintiff's stock has sold in the $\$ 70$ per share range during this suit, while the price of defendants' XOIL stock has ranged from $\$ 4$ per share at issuance to $\$ 16$ per share. Since the securities of these two companies do not sell in the same price range or in the same markets, I conclude that they are not in close proximity.

Plaintiff argues that purchasers over-the-counter of XOIL Energy Resources, Inc. stock, at a relatively low price, do not partake of the sophistication of investors in limited partnerships. Plaintiff also suggests that those who invest in defendants' over-the-counter stock and in its limited partnerships may in fact be quite unsophisticated, and be directed to those investments by their brokers. I do not credit these arguments. A market is not rendered less sophisticated because business in that market is ordinarily transacted through brokers. To the contrary, the brokers render a market, if anything, more sophisticated: professional buyers are less likely to be subject to confusion.

\section{MDT Corp. v. New York Stock Exchange, Inc.}

Trading symbols are used within the securities business to identify a specific publicly traded security; in particular trading symbols play an important role in the technical execution of trading transactions on the floor of the NYSE.

Medtronic was founded in 1949. It manufactures and sells a variety of medical products, including cardiac pacemakers, artificial heart valves, cardiopulmonary products and interventional vascular products.

Since the early 1960s, Medtronic's securities have been publicly traded. At first they were traded over the counter. Then, beginning on February 5, 1971, Medtronic's securities were traded on NASDAQ under the trading symbol MDTR.

On November 21, 1977 Medtronic began the listing of its stock on the NYSE and its listing has remained there until the present time. All stocks listed on the NYSE are assigned a unique trading symbol which must comprise three or fewer letters. Since they were first listed on the NYSE, Medtronic's securities have been identified by the trading symbol MDT.

When a company is accepted for listing on the NYSE, it is asked to submit three alternative choices for a three letter trading symbol. If the requested symbol is available, the NYSE assigns it to the list- 
ing company. A trading symbol is not available if it is already in use by a listing company on either the NYSE or a number of other regional exchanges. Approximately two-thirds of the first choices for NYSE trading symbols are not available because they are already in use. The sole criterion used by the NYSE in assigning a trading symbol and the only ground on which a trading symbol will be denied is the availability of a symbol.

The parties do not dispute that Medtronic's motive for choosing the MDT trading symbol was to obtain a trading symbol as close as possible to its former NASDAQ trading symbol. The parties also do not dispute that the assignment of the MDT trading symbol to Medtronic was made in good faith, without any intent by either Medtronic or the NYSE to violate any trademark or trade name held by MDT Corp.

On July 1, 1988, MDT Corp. applied to list its publicly traded securities on the New York Stock Exchange and on August 5, 1988, the NYSE accepted MDT Corp.'s securities for listing. At that time, the NYSE informed MDT Corp. that its first choice for a trading symbol was not available because it was already being used to identify the stock of Medtronic.

Starting in February of 1989, MDT Corp. began attempts to convince Medtronic to change its NYSE trading symbol. Medtronic never agreed to MDT Corp.'s demands, and since March 1989 has consistently and repeatedly expressed to MDT Corp. that it was unwilling to relinquish the MDT trading symbol. Similarly, since 1988, NYSE has consistently and repeatedly expressed to MDT Corp. that it would not change Medtronic's MDT trading symbol without Medtronic's consent.

In November 1977, when the MDT trading symbol was assigned to Medtronic by the NYSE, MDT Corp. was not publicly traded and was little known in the public securities industry. MDT Corp. did not go public until January 1987 when it listed its securities on NASDAQ under the trading symbol MDTC. That was ten years after the MDT trading symbol was assigned to Medtronic by the NYSE.

Until January 1987, MDT Corp. shares were never publicly traded, there $1032^{*} 1032$ were no publicly available reports from brokerage or investment firms concerning trading in MDT Corp. shares, there were no third party listings or brokerage reports of trades of MDT Corp. shares, no trading symbol existed to identify MDT Corp. shares, and MDT Corp. did not participate as an issuer in the market for publicly traded securities.

Although MDT Corp. is the senior user of the MDT mark in the medical products field, Medtronic, not MDT Corp., is the senior user of the MDT mark within the context of the publicly traded securities market. 
The doctrine of Inwood Laboratories requires that, to be liable for contributory infringement, a party must have actively "suggested, even if only by implication" the infringement. MDT Corp. has not argued, and indeed cannot argue, that either Medtronic or the NYSE has in any way suggested, or even implied, that anyone should use MDT the trading symbol as anything but a trading symbol. Instead, MDT Corp. appears to interpret Inwood Laboratories to impose an affirmative duty on innocent third party users of a mark to police the mark for its owner. No such duty exists.

\section{Comments of James Angel on General Portability Filing}

As both an empirical researcher in finance and a personal investor, I deal with stock exchange ticker symbols almost every day. I am pleased that the topic of ticker symbols has come up, because there is a need for improvements in the present system to prevent consumer confusion. Here are my comments on the exchange symbology plans. In brief:

- Just as with phone numbers, the rights to a particular ticker symbol should belong to the issuers, not the exchanges. Issuers generally expend considerable resources to associate their corporate brand image with a particular set of characters, and their claims should prevail over the far weaker claims of any particular exchange.

- Changing ticker symbols cause investor confusion, leading to errors in both research and trading. Allowing issuers to keep their ticker symbols when they change exchanges will lead to fewer costly trading mistakes.

- Perpetual reservation of unused ticker symbols is a bad idea. Unused tickers should be available to any legitimate issuer seeking to use them on a first come, first served basis.

\section{Introduction: Who owns the alphabet?}

In the beginning, there was the stock ticker. Each exchange used its own symbology for the instruments it traded. A stock traded on multiple exchanges could have multiple tickers. Or the same ticker could mean different stocks on different exchanges. For example, AT\&T (then known as American Bell) first traded on the Boston Exchange under the ticker symbol T in 1888. When AT\&T listed on the NYSE, it used the ticker symbol ATT and did not use the single letter T on the NYSE until 1931.

This is still the international practice today. For example, the ticker symbol FUN on the NYSE represents Cedar Fair, L.P., a maker of amusement parks. The symbol FUN on the TSX in Toronto is Fun Technologies PLC. This creates a lot of fun for investors and re- 
searchers who deal with the stocks that are dually listed in the U.S. and Canada.

To deal with this confusion in the United States, Standard and Poor's came up with a standard alphabet-only system of U.S. ticker symbols which became the industry standard.

The NYSE, AMEX, and regional exchanges traditionally used one, two, or three character ticker symbols to identify stocks. The NASDAQ has traditionally used four or five character ticker symbols. When a firm switched its stock listing from the NASDAQ to the AMEX or NYSE, it would have to change its ticker symbol to a shorter ticker symbol. Likewise, when a stock moved from the NYSE or AMEX to the NASDAQ, it had to adopt a longer four or five character ticker symbol. However, when stocks switched from the AMEX to the NYSE they usually kept their shorter ticker symbol. Thus, there is a long precedent of firms keeping their ticker symbols when they switch exchanges.

Now NASDAQ wants to use shorter ticker symbols and its competitors don't want to let it. NASDAQ and its allies have proposed setting up a plan under the NMS rules to divvy up stock symbols among the exchanges. The NYSE and its allies have proposed a competing plan to keep the shorter ticker symbols all to themselves. This brings up an interesting question: Who owns the alphabet, the exchanges or the issuers?

Issuers have the strongest claim to any particular ticker symbol.

The economic issues involved are very similar to those involved with trademarks. I am not now, nor have I ever been, an attorney, so I will not make a legal argument here. I will instead make an economic argument as to how the rights to a particular ticker symbol should be decided.

Trademark protection is quite broad and covers the use of such a trademark in many other applications. The same economic considerations that led society to create trademark protection can also be applied to the more limited case of who should have the right to a particular letter combination for use as a ticker symbol.

There are two issues here: First, should an issuer that moves its listing from one exchange to another exchange have the right to take its ticker symbol with it? Does the ticker symbol belong to the exchange or the firm? And second, should a group of exchanges, or anyone else for that matter, have an exclusive right to certain letter combinations even when those combinations are not in use? Is a one, two-, or three- character ticker symbol such a unique signal of the AMEX, NYSE, and regional exchanges that they should be able to preclude NASDAQ-listed firms from using them? The proposed NMS 
plans give certain exchanges the right to reserve some symbols indefinitely even through they have no current plans to use them.

Companies often go to great efforts to come up with ticker symbols that appeal to investors. Sometimes ticker symbols reflect the name of the company (AAPL or IBM for example). Other ticker symbols have other associations with the issuer. Dynamic Materials, which is engaged in explosive metal working, has ticker symbol BOOM while Anheuser-Busch, the maker of Budweiser, uses ticker symbol BUD. Southwest Airlines started its operations at Love Field and thus uses the ticker LUV. The post- bankruptcy US Airways chose LCC to signify that it is a Low Cost Carrier. Oftentimes these symbols are seen as part of a firm's identity.

Corporations sometimes include their ticker symbols in their advertising campaigns as a way to alert their customers that their stock is publicly traded. When companies change their names, they often change their ticker symbols as well. Sometimes the firm's identity and ticker symbol have become so intertwined that the company changes its name to match its ticker. X was used for U.S. Steel long before it changed its name to USX.

Over time, investors tend to associate a particular ticker symbol far more with a particular company than with a particular exchange. Thus, in terms of reducing investors' search and transaction costs, it makes sense to award the rights to a particular ticker symbol to the issuer that has been using the ticker symbol.

It also makes economic sense to expand the pool of potential ticker symbols for all issuers by giving all exchange-listed issuers full access to all combinations of ticker symbols from one to five characters. Ford Motor Company may well prefer the ticker FORD as it will cause less confusion to investors than F. This will allow issuers to pick tickers that better match the issuer to the symbol, thus reducing communication costs and search costs.

Thus, the claim of any particular exchange or group of exchanges to the entire class of shorter ticker symbols is quite weak. In general, listed companies have expended far more resources in associating a particular ticker symbol with their company than has anyone else. It thus makes sense to allow issuers to keep their ticker symbols if they choose to switch their listing from one market to another. There is no good reason why an Amex or NYSE-listed firm should not be able to keep its ticker symbol if it moves to NASDAQ. Likewise, there is no good reason why a NASDAQ-listed firm should not be able to keep its longer ticker if wants to move to the AMEX or NYSE.

Shorter ticker symbols should go to the more actively traded stocks, if they want them. 
In any language, the most frequently used words are typically the shortest ones. This reduces the "cost" of using the language. Similarly, the shortest ticker symbols should be used for the most frequently traded securities, as shorter ticker symbols require less typing and may be easier to remember. This reduces the time it takes investors to type in ticker symbols and reduces the mental bandwidth needed to remember the tickers. Some of the most actively traded securities are NASDAQ listed, so economic efficiency would dictate that such actively-traded NASDAQ stocks could also be able to use shorter ticker symbols if they want them.

Traditionally, the exchanges used shorter ticker symbols for the larger and more actively traded stocks. T stands for ATT ("Telephone") and F for Ford. Thus, shorter ticker symbols have a certain cachet associated with larger issues. However, the shorter ticker symbols are no longer exclusively used by the most actively traded shares. Barnes Group Inc., ticker symbol B, has a three-month average daily volume of only 384,863 shares.

Shorter ticker symbols can also lead to investor confusion as well. Automated news search engines that search for a stock symbol sometimes bring up numerous false hits when searching for shorter ticker symbols. Longer ticker symbols that are not recognized words yield fewer false hits. Googling the letters MSFT yields 7.3 million hits, most of which are relevant to Microsoft. Googling the letter A yields 7.3 billion hits, most of which have nothing to do with Agilent. Thus, some issuers will wisely choose to avoid shorter ticker symbols.

Ticker symbol portability is a good because it will reduce investor confusion.

Speaking as both an investor and researcher, I can attest that mutating ticker symbols can be a large source of confusion and costly investment mistakes. When a ticker symbol changes, data vendors do not always catch the change. I have personally run across many instances in which data vendors have proffered up incorrect charts or incorrect accounting information because of a missed symbol change. Reducing the number of ticker symbol changes will be a plus for investors, and will reduce costs to the legions of unsung heroes in the back offices who keep track of these things.

Ticker symbol portability will reduce the confusion to investors and researchers that comes from changing ticker symbols. This is similar to the rights to a particular telephone number. In the bad old days, a phone company (either landline or mobile) would assign a number to a customer. If a customer switched to another provider, the customer had to give up the old number and get a new number from the new provider. This was, to say the least, a nuisance. Now the practice is that customers can keep their phone numbers when 
they switch providers. This is in line with economic efficiency as it reduces the overall costs to the economy when everyone has to keep track of new phone numbers. It also enhances competition between phone companies. In the same manner, companies should be able to take their ticker symbols with them when they switch exchanges. This ticker symbol portability will result in fewer costs for issuers and investors.

As such, I don't think that NASDAQ's proposal for threecharacter portability goes far enough, and that such exchange ticker symbol portability should extend to one- and two- (as well as three-, four-, and five-) character tickers.

\section{Exchanges should not be allowed to sit on unused symbols.}

However, in order for trademarks to be recognized as intellectual property (in which case others are precluded others from using them), they generally need to be used. This makes economic sense because parking unused trademarks reduces the potential benefits to consumers and producers that would occur if someone else used the unused property. Thus, NASDAQ should not be allowed to park the symbol FORD if Ford Motor Company wanted to use it on another exchange. The features in both proposed plans that allow the exchanges to permanently reserve ticker symbols should not be approved.

Symbols should be allocated on a "first-come, first-served" basis.

If a ticker symbol is not in use, then it should be available to any legitimate issuer that wants to use it. Symbols should be available to issuers on a "first-come, first served" basis with a "Use it or lose it" feature.

An issuer wishing to use a symbol could request the symbol, and then would have a given length of time in which to actually use the symbol. Use of the symbol would include actually trading the security, or filing a listing application with an exchange, or a registration statement with the SEC in anticipation of trading on an exchange.

\section{Some tickers should be off limits.}

Although issuers should, in general, be able to choose any symbol they want, there are legitimate reasons why some tickers should not be issued.

One exception to the "first-come, first-served" principle would be for tickers that are so close to existing trademarks that allowing others to grab them would sow confusion among investors. Thus, it should not be permissible for someone other than Ford Motor Company to grab the ticker FORD. 
Words that many people find offensive should not be used as ticker symbols. Thus, examples include ${ }^{* * *},{ }^{* * *},{ }^{* * *}$, and $<$ expletive deleted.>

Symbols that are too close to an existing symbol, either in meaning or on the keyboard, could also be precluded if common typos would cause traders to make more "fat fingers" mistakes. For example, it would not be a good idea to use both "FORM" and "FROM" as ticker symbols.

\section{Abandoned tickers should be unavailable for a six-month waiting period to prevent confusion.}

When a company abandons a desirable ticker, it is often recycled quickly. For example, when Chrysler was taken over by Daimler to become DaimlerChrysler, its ticker symbol $\mathrm{C}$ was in use for Citigroup within a few weeks. Many investors keep track of portfolios as lists of ticker symbols, and reassigned ticker symbols cause lots of headaches. I have personally experienced situations in which data vendors did not catch the switch, and supplied bad data to in the way of bad price charts, or worse yet, bad accounting data.

When a ticker symbol is abandoned, there should be a six-month waiting period before it can be reassigned. This will give investors time to adapt to the switch.

\section{The Plan needs a dispute resolution mechanism.}

There will be inevitable disputes that arise over the rights to various ticker symbols, and the Plan should come up with a method for resolving disputes. For example, one issuer may claim that it should have the rights to a particular ticker symbol as it has already trademarked that word. Or there may be a dispute as to whether a particular claimant has actually used a ticker symbol to retain rights to it. The dispute resolution mechanism of the plan should look at the facts and circumstances in each particular case.

The National Market System Plan for the Selection and Reservation of Securities Symbols, a/k/a the "Symbols Reservation System," is a joint agreement among fifteen national exchanges. It is operated by the Options Clearing Corporation. It allows for symbols of up to five characters. One-to-three character symbols are reserved for stocks traded on a national exchange; four-and-five character symbols can

Not to be confused with the Office of the Comptroller of the Currency. be used for any security or index. In general, symbols are portable between exchanges:

If an [exchange] lists a security or product that previously was listed on another [exchange], the New [exchange] 
shall have the rights to that symbol unless, in its discretion, it consents to the symbol being retained by the Former [exchange].

Each exchange may have up to 40 perpetual reservations and 3,000 temporary reservations - the symbol must be either used or released within two years. If an exchange stops using a symbol (i.e. because a company has merged or been delisted), it can retain the symbol for up to two years. As for reuse:

A symbol, nonetheless, may not be reused to identify a new security (other than the security that has been trading under such symbol) within 90 calendar days from the last day of its use to identify the old security, without the consent of the party that released the symbol. A party may not reuse (or consent to the reuse of) a symbol to identify a new security unless the party reasonably determines that such use would not cause investor confusion.

\section{ISBNs}

\section{ISBN.org FAQs: General Questions}

What is an ISBN?

The International Standard Book Number (ISBN) is a 13-digit number that uniquely identifies books and book-like products published internationally.

What is the purpose of an ISBN?

The purpose of the ISBN is to establish and identify one title or edition of a title from one specific publisher and is unique to that edition, allowing for more efficient marketing of products by booksellers, libraries, universities, wholesalers and distributors.

What is the format of the ISBN?

Every ISBN consists of thirteen digits and whenever it is printed it is preceded by the letters ISBN. The thirteen-digit number is divided into four parts of variable length, each part separated by a hyphen.

- Group or country identifier which identifies a national or geographic grouping of publishers;

- Publisher identifier which identifies a particular publisher within a group;

- Title identifier which identifies a particular title or edition of a title; 
- Check digit is the single digit at the end of the ISBN which validates the ISBN.

What is the format of the new ISBN-13?

Every ISBN will consist of thirteen digits in 2007. The thirteen digit number is divided into five parts of variable length, each part separated by a hyphen.

- The current ISBN-13 will be prefixed by "978"

- Group or country identifier which identifies a national or geographic grouping of publishers;

- Publisher identifier which identifies a particular publisher within a group;

- Title identifier which identifies a particular title or edition of a title;

- Check digit is the single digit at the end of the ISBN which validates the ISBN.

Who can assign ISBNs to a publisher?

There are over 160 ISBN Agencies worldwide, and each ISBN Agency is appointed as the exclusive agent responsible for assigning ISBNs to publishers residing in their country or geographic territory. The United States ISBN Agency is the only source authorized to assign ISBNs to publishers supplying an address in the United States, U.S. Virgin Islands, Guam and Puerto Rico and its database establishes the publisher of record associated with each prefix.

Once an ISBN publisher prefix and associated block of numbers has been assigned to a publisher by the ISBN Agency, the publisher can assign ISBNs to publications it holds publishing rights to. However, after the ISBN Agency assigns ISBNs to a publisher, that publisher cannot resell, re-assign, transfer, or split its list of ISBNs among other publishers. These guidelines have long been established to ensure the veracity, accuracy and continued utility of the international ISBN standard.

As defined by the ISO Standard, the ISBN publisher prefix (or "root" of the ISBN) identifies a single publisher. If a second publisher subsequently obtains an ISBN from the assigned publisher's block of ISBNs, there will be no change in the publisher of record for any ISBN in the block as originally assigned.

If you are a new publisher, you should apply for your own ISBN publisher prefix and plan to identify and circulate your books properly in the industry supply chain. You may encounter offers from other sources to purchase single ISBNs at special offer prices; you should be wary of purchasing from these sources for the reasons 
noted above. There are unauthorized re-sellers of ISBNs and this activity is a violation of the ISBN standard and of industry practice. A publisher with one of these re-assigned ISBNs will not be correctly identified as the publisher of record in Books In Print or any of the industry databases such as Barnes and Noble or Amazon or those of wholesalers such as Ingram. If you have questions, contact the US ISBN Agency for further advice.

\section{License Plates}

\section{Wooley v. Maynard}

Since 1969 New Hampshire has required that noncommercial vehicles bear license plates embossed with the state motto, "Live Free or Die."

Another New Hampshire statute makes it a misdemeanor "knowingly to obscure the figures or letters on any number plate." The term "letters" in this section has been interpreted by the State's highest court to include the state motto.

Appellees George Maynard and his wife Maxine are followers of the Jehovah's Witnesses faith. The Maynards consider the New Hampshire State motto to be repugnant to their moral, religious, and political beliefs,, and therefore assert it objectionable to disseminate this message by displaying it on their automobiles. Pursuant to these beliefs, the Maynards began early in 1974 to cover up the motto on their license plates.

We are thus faced with the question of whether the State may constitutionally require an individual to participate in the dissemination of an ideological message by displaying it on his private property in a manner and for the express purpose that it be observed and read by the public. We hold that the State may not do so.

We begin with the proposition that the right of freedom of thought protected by the First Amendment against state action includes both the right to speak freely and the right to refrain from speaking at all.

The State points out that passenger vehicles, but not commercial, trailer, or other vehicles are required to display the state motto. Thus,

${ }^{2} \mathrm{Mr}$. Maynard described his objection to the state motto:

By religious training and belief, I believe my "government" - Jehovah's Kingdom - offers everlasting life. It would be contrary to that belief to give up my life for the state, even if it meant living in bondage. Although I obey all laws of the State not in conflict with my conscience, this slogan is directly at odds with my deeply held religious convictions.

I also disagree with the motto on political grounds. I believe that life is more precious than freedom. 
the argument proceeds, officers of the law are more easily able to determine whether passenger vehicles are carrying the proper plates. However, the record here reveals that New Hampshire passenger license plates normally consist of a specific configuration of letters and numbers, which makes them readily distinguishable from other types of plates, even without reference to the state motto. .13

\section{Mitchell v. Maryland Motor Vehicle Administration}

What does Petitioner, John T. Mitchell, have in common with "Seinfeld's" Cosmo Kramer? Both received and displayed on their respective motor vehicles, for a period of time, vanity license plates bearing words that had arguably scatological meanings. 1 Mitchell did not give up without a fight when the Maryland Motor Vehicle Administration (MVA) recalled his vanity plates; hence, this litigation.

The MVA granted in 2009 John T. Mitchell's application for vanity license plates bearing the word "MIERDA." Two years later, the MVA received a complaint about "MIERDA" on the plates displayed on Mitchell's vehicle. The MVA determined then that "mierda" translates into English as "shit" and rescinded the plates according to a State regulation authorizing the denial or recall of vanity plates containing "profanities, epithets, or obscenities."

\section{BACKGROUND}

Maryland requires the obtention and display of registration plates on in-state registered motor vehicles. The plates must contain an individualized registration number, consisting of letters, numerals, or both, which is assigned typically by the MVA. For an additional annual fee of $\$ 50$, an applicant may select a special, personalized registration number, subject to the MVA's approval. Known as "vanity plates," these plates allow the display of "a message with at least 2 and up to 7 characters," unless the chosen message "has already been issued or ... is objectionable." Indeed, Maryland regulations empower the MVA to deny or rescind vanity plates whose messages bear "profanities, epithets, or obscenities."

The MVA offers also two options for customizing a license plate's general theme, which may, but need not, be combined with a vanity message. First, "background scene plates," or "commemorative plates," display images and text associated with issues the State

\footnotetext{
${ }^{13}$ New Hampshire passenger vehicle license plates generally consist of two letters followed by four numbers. No other license plate category displays this combination, and no other category bears the state motto. However, of the approximately 325,000 passenger plates in New Hampshire, 9,999 do not follow the regular pattern, displaying numbers only, preceded by no letters.

${ }^{1}$ In "Seinfeld" (Episode 107 (27 April 1995)), Kramer was sent erroneously vanity plates bearing the words "ASSMAN," which plates had been applied for by a proctologist.
}

--- A.3d --- (Md. 2016)

Md. Motor Vehicle Admin., Personalized (Vanity) License Plates, Maryland.gov 
wishes to promote through both its speech and fee revenue. Commemorative plates are available presently to support the Chesapeake Bay and agriculture. Second, Maryland allows the customization of "specialty plates" for members of nonprofit organizations who pay a fee to express their organizations' messages via logos, emblems, the organization's name, or another combination of characters. § 13-619. The MVA sells specialty plates for a diverse range of issues from medical and military interests to educational institution alumni associations, and hobbies.

I. Under the Supreme Court's articulation of the First

Amendment Public Forum doctrine, the vanity plate message

"MIERDA" CONSTITUTES PRIVATE SPEECH IN A NONPUBLIC FORUM, WHEREIN GOVERNMENT RESTRICTIONS ON SPEECH MUST BE REASONABLE

AND VIEWPOINT NEUTRAL.

In its most recent case elucidating the distinction between private speech and government speech, the U.S. Supreme Court determined that a Texas-issued specialty license plate displaying a Confederate flag constituted speech by the government, not speech by the Texas Division of the Sons of Confederate Veterans, the organization that sought the plate design. Walker v. Texas Div., Sons of Confederate Veterans, Inc.. A court's identification of speech as either that of the government or of a private person or entity determines whether the First Amendment applies at all: government statements (and government actions and programs that take the form of speech) do not normally trigger the First Amendment rules designed to protect the marketplace of ideas. The First Amendment protects, however, private speech on government property, with some limitations.

The Court used three factors to disambiguate government speech from private speech. The Court considered first whether the government used historically the mechanism of communication in question "to speak to the public." Many States, including Texas, used specialty plate slogans for nearly a century "to urge action, to promote tourism, and to tout local industries." Second, the Court considered to whom the audience of the communications would tend reasonably to attribute the speech: a private speaker or the public owner of the property on which the speech takes place. Because of their well-understood "governmental purposes of vehicle registration and identification," the display of "TEXAS" on each plate, and the State's ownership of specialty plate designs, "Texas license plate designs are often closely identified in the public mind with the State." Finally, the Court looked to whether the government exercises control over the communication, for example, by retaining "final approval authority." Texas had "direct control" over specialty plate messages, including "the design, typeface, color, and alphanumeric pattern for all li- 
cense plates," as well as "final approval authority" over the content of a specialty plate design. These considerations, taken together, persuaded the Court to find the specialty plates at issue to be government speech.

In the present case, a message on a vanity plate, such as "MIERDA," is private speech. Applying the Supreme Court's first analytical factor, historical usage, although license plates in general function historically as government IDs for vehicles, vanity plates display additionally a personalized message with intrinsic meaning (sometimes clear, sometimes abstruse) that is independent of mere identification and specific to the owner. The unique, personalized messages communicated via vanity plates contrast with the generic, depersonalized speech conveyed by a specialty plate: many Maryland vehicles display identical specialty plates; only the registration numbers, which on a specialty plate have no intrinsic meaning and carry no message, will vary. Additionally, private citizens, not the State of Maryland, create and submit prospective vanity plate messages. So, historically, vehicle owners have used vanity plates to communicate their own personal messages and the State has not used vanity plates to communicate any message at all. Unlike the license plate slogans that States use 'to urge action, to promote tourism, and to tout local industries, vanity plates are personal to the vehicle owner, and are perceived as such.

Turning to the factor of audience perception, the personal nature of a vanity plate message makes it unlikely that members of the public, upon seeing the vanity plate, will think the message comes from the State. Unlike the specialty plates at issue in Walker, vanity plates bear unique, personalized, user-created messages that cannot be attributed reasonably to the government. The fact that this kind of speech takes place on government property - a license plate - is not transformative in this context of private speech into government speech. Although perhaps the perception of a governmental imprimatur is what makes "MIERDA" arguably clever or humorous in the first place, this stems from the public perception of State permission of private speech, not State endorsement or State expression. A fellow motorist who understood the primary Spanish meaning or English translation of "mierda" might think: "the MVA let you get away with that?," or "you pulled a fast one on the MVA!" Even these sentiments are rooted in an understanding that the vehicle owner, not the government, is the speaker, and that the speaker implicated the State in a private message that, surprisingly, the government permitted, but certainly did not endorse.

Considering the third factor of the government speech analysis, the MVA's statutory and regulatory authority to deny or rescind a vanity plate based on the content of its message, does not rise to the 
level of such tight control that the personalized messages become government speech. Maryland does not exercise "direct control" over the "alphanumeric pattern" displayed on vanity plates in the same or similar way that Texas controlled specialty plates. In Walker, the State had sole control over the content of a specialty plate. With respect to vanity plates in Maryland, vehicle owners, not the State, create the proposed messages and apply for them. Although the MVA retains discretion to deny a prospective vanity message, its authority to recall vanity plates (but not specialty plates) issued erroneously suggests that the MVA's control over vanity plates does not rise to the rigorous level required to transmogrify its regulatory approach into government speech.

Contrarily, a recent ruling by the Indiana Supreme Court held that vanity plates constitute government speech because "license plates have long been used for government purposes" such as vehicle identification, their messages are perceived to be communicated on behalf of the State, and the State maintains direct control over the messages they display. Comm'r of Indiana Bureau of Motor Vehicles v. Vawter We reject the Vawter court's reasoning because vanity plates represent more than an extension by degree of the government speech found on regular license plates and specialty plates. Vanity plates are, instead, fundamentally different in kind from the aforementioned plate formats. Maryland has not communicated historically to the public with vanity messages. Observers of vanity plates understand reasonably that the messages come from vehicle owners.

[Long discussion of public-forum doctrine.]

Maryland's vanity plates constitute a nonpublic forum. The purpose of the statutory mandate for license plates on vehicles registered in Maryland is identification of vehicles on the road. Maryland began offering vanity plates in 1971. From the vanity plate program's inception, Maryland has required applicants to pay a revenue-generating fee to the State. The purpose of the program was, and still is, to raise money. This purpose does not evidence a State intent to facilitate the full and free expression of ideas, but rather to tap into the egocentricities of vehicle owners, to the State's financial benefit. Admittedly, Maryland did intend to open a public space for limited private expression via vanity plates, but only in the sense that it did not establish accidentally the procedures for vehicle owners to submit prospective vanity messages and procure vanity plates. This does not mean, however, that the State intended vanity plates to serve as a public forum, but rather, that they happen to afford a limited space for speech as an incentive to lure vehicle owners into paying for vanity plates, thereby achieving the MVA's purpose of raising revenue.

Maryland constrains the expressive potential of vanity plates in accordance with the State's purposes for license plates in general and 
vanity plates in particular. The combination of characters on a plate, whether a vanity plate or otherwise, must be unique to serve as a government ID. The State limits vanity messages to seven characters, presumably because that is sufficient to register a unique combination of characters to each vehicle. Of course, pithy and clever individuals find invariably a way to express themselves in such a constrained space, but that does not bear on whether the State intended to open a public forum.

\section{The State's Ultimate Rejection of "MiERDA" was Reasonable and Viewpoint Neutral.}

The prohibition of "profanities, epithets, or obscenities" on vanity plates relates reasonably to Maryland's purposes of vehicle identification and revenue generation, which involve the public display of license plates. Because the State requires motorists to display license plates on their vehicles, the public is exposed to the messages that appear on vanity plates. For better or worse, our society sets apart particular words as out-of-bounds; their utterance or display can be understood reasonably as indecent or offensive, especially in the presence of minors. "Shit" is one of these words, and that is an English translation, admitted by Mitchell, of "mierda." It is reasonable, therefore, for the State to protect knowledgeable observers of vanity plates from the perception of such a term. Even though a witness to a vanity plate message will discern easily the vehicle owner as the speaker, because the speech takes place on government property and only with State permission, the message will be associated with the State. The state has a legitimate interest in not communicating the message that it approves of the public display of offensive scatological terms on state license plates, and it is reasonable, therefore, for Maryland to prohibit "profanities, epithets, or obscenities," content with which it does not wish to associate.

Neither the MVA's content-restricting regulation, nor its actions in accordance with that regulation, constitute viewpoint discrimination. Viewpoint discrimination occurs when the government targets particular views taken by speakers on a subject, for example, to discourage one viewpoint and advance another. Here, the Maryland regulation targets only content-profanities, epithets, and obscenities - not a speaker's viewpoint about such terms or any viewpoint expressed with such terms. Clearly, the regulation does not target viewpoints in support of organic agriculture. If Maryland wished to suppress pro-agriculture speech, it probably would not speak in favor of agriculture via commemorative plates, and it would restrict the use on vanity plates of terms such as "FARM," "COMPOST," and "CROPS." This is not the case. Moreover, Maryland did not "impute an offensive intent" on the part of Mitchell, as he claims. Mitchell's 
Nev. Admin. Code § 482.320

Nomenclature used

Which provisions of Nevada's vanity plate rules are constitutional given Tam, Wooley, and Walker? subjective intent is irrelevant because the regulation restricts outright and objectively profanities, not specific viewpoints for or against profanity. The MVA rescinded Mitchell's plates not because of Mitchell's real or presumed intent, but based on the content with which Maryland is not willing to be associated, and the content the State is not willing to inflict upon the discerning public.

Substantial evidence supported the MVA's determination. Wikipedia research (received in evidence by the ALJ without objection) revealed "mierda" to be an expletive in Spanish slang that translates in its primary sense into "shit," an expletive in English. Mitchell's testimony corroborated that "mierda" means "shit," among other things, in English. Finally, the MVA maintained that it received a complaint from an observer of the vanity plate at issue about the inappropriateness of "MIERDA." This evidence is adequate in an administrative law context for a "reasonable mind" to conclude, as did the MVA, that the State could rescind permissibly Mitchell's "MIERDA" vanity plates.

\section{Nevada Administrative Code}

1. The letter " $\mathrm{O}$," the letter " $\mathrm{I}$ " and the letter " $\mathrm{Q}$ " must not be used alone but may be used with a combination of other letters and numbers if the combination does not create confusion between the letter " $\mathrm{O}$ " or " $\mathrm{Q}$ " and the number " 0 " or between the letter "I" and the number " 1. "

2. Only letters, numbers and spaces may be used on personalized prestige license plates. Letters, numbers and spaces may be used in any combination not prohibited by this section or NRS 482.3667.

3. A blank plate will not be issued.

5. No more than seven characters may be on any one personalized prestige license plate.

6. No combination of letters, numbers or spaces is allowed if it:

(a) Creates confusion with any combination on other license plates.

(b) Expresses contempt, ridicule or superiority of: (1) Race; (2) Ethnic heritage; (3) Religion; or (4) Gender.

(c) Contains any connotation that is sexual, vulgar, derogatory, profane or obscene.

(d) Contains a direct or indirect reference to a (1) Drug or drug paraphernalia; or (2) Gang.

(e) Makes a defamatory reference to a person or group. 
7. The person who first applies for a particular letter or number or combination of letters, numbers or spaces and pays the prescribed fee for registration and for the personalized prestige license plates has priority to receive plates with that particular letter or number or combination of letters, numbers or spaces once the application has been accepted by the Department.

Any letter or number or combination of letters, numbers or spaces which is available for issuance may be reserved for a period of 30 days after the date on which the applicant makes his or her reservation with the Department. If license plates are to be manufactured in a new format, the Director will extend the period of a reservation long enough to allow an applicant to receive plates in the new format.

\section{Domain Names}

\section{Anticybersquatting Consumer Protection Act}

(1) (A) A person shall be liable in a civil action by the owner of a mark, including a personal name which is protected as a mark under this section, if, without regard to the goods or services of the parties, that person-

(i) has a bad faith intent to profit from that mark, including a personal name which is protected as a mark under this section; and

(ii) registers, traffics in, or uses a domain name that-

(I) in the case of a mark that is distinctive at the time of registration of the domain name, is identical or confusingly similar to that mark;

(II) in the case of a famous mark that is famous at the time of registration of the domain name, is identical or confusingly similar to or dilutive of that mark; or

(III) is a trademark, word, or name protected by reason of section 706 of title 18 [i.e. the Olympics name, logo, and related indicia] or section 220506 of title 36 [i.e. the Red Cross sign].

(B) (i) In determining whether a person has a bad faith intent described under subparagraph (A), a court may consider factors such as, but not limited to -

(I) the trademark or other intellectual property rights of the person, if any, in the domain name;
Nev. Admin. Code § 482.340

Reservations

Lanham Act § 43(d)

15 U.S.C. § 1125(d)

Cyberpiracy prevention

See, e.g., Sporty's Farm LLC v. Sportsman's Market, Inc., 202 F.3d 489 (2d Cir. 2000) (discussing ACPA and applying factors). 
(II) the extent to which the domain name consists of the legal name of the person or a name that is otherwise commonly used to identify that person;

(III) the person's prior use, if any, of the domain name in connection with the bona fide offering of any goods or services;

(IV) the person's bona fide noncommercial or fair use of the mark in a site accessible under the domain name;

(V) the person's intent to divert consumers from the mark owner's online location to a site accessible under the domain name that could harm the goodwill represented by the mark, either for commercial gain or with the intent to tarnish or disparage the mark, by creating a likelihood of confusion as to the source, sponsorship, affiliation, or endorsement of the site;

(VI) the person's offer to transfer, sell, or otherwise assign the domain name to the mark owner or any third party for financial gain without having used, or having an intent to use, the domain name in the bona fide offering of any goods or services, or the person's prior conduct indicating a pattern of such conduct;

(VII) the person's provision of material and misleading false contact information when applying for the registration of the domain name, the person's intentional failure to maintain accurate contact information, or the person's prior conduct indicating a pattern of such conduct;

(VIII) the person's registration or acquisition of multiple domain names which the person knows are identical or confusingly similar to marks of others that are distinctive at the time of registration of such domain names, or dilutive of famous marks of others that are famous at the time of registration of such domain names, without regard to the goods or services of the parties; and

(IX) the extent to which the mark incorporated in the person's domain name registration is or is not distinctive and famous within the meaning of subsection (c).

(ii) Bad faith intent described under subparagraph (A) 
shall not be found in any case in which the court determines that the person believed and had reasonable grounds to believe that the use of the domain name was a fair use or otherwise lawful.

(C) In any civil action involving the registration, trafficking, or use of a domain name under this paragraph, a court may order the forfeiture or cancellation of the domain name or the transfer of the domain name to the owner of the mark.

(2) [Provides an in rem action against the domain name if personal jurisdiction over a suitable defendant is not available.]

(3) The civil action established under paragraph (1) and the in rem action established under paragraph (2), and any remedy available under either such action, shall be in addition to any other civil action or remedy otherwise applicable.

\section{Uniform Domain-Name Dispute Resolution Policy}

4. Mandatory Administrative Proceeding. -

a. Applicable Disputes. - You are required to submit to a mandatory administrative proceeding in the event that a third party (a "complainant") asserts that

(i) your domain name is identical or confusingly similar to a trademark or service mark in which the complainant has rights; and

(ii) you have no rights or legitimate interests in respect of the domain name; and

(iii) your domain name has been registered and is being used in bad faith.

b. Evidence of Registration and Use in Bad Faith. - For the purposes of Paragraph 4(a)(iii), the following circumstances, in particular but without limitation, if found by the Panel to be present, shall be evidence of the registration and use of a domain name in bad faith:

(i) circumstances indicating that you have registered or you have acquired the domain name primarily for the purpose of selling, renting, or otherwise transferring the domain name registration to the complainant who is the owner of the trademark or service mark or to a competitor of that complainant, for valuable consideration in excess of your documented out-of-pocket costs directly related to the domain name; or

(ii) you have registered the domain name in order to pre-
UDRP

This language is required to be included in all contracts to register domain names in most top-level domains (e.g. . com). "You" refers to the the party registering a domain-name; "we" is the domain-name registrar (e.g. Google Domains or Namecheap). 
vent the owner of the trademark or service mark from reflecting the mark in a corresponding domain name, provided that you have engaged in a pattern of such conduct; or

(iii) you have registered the domain name primarily for the purpose of disrupting the business of a competitor; or

(iv) by using the domain name, you have intentionally attempted to attract, for commercial gain, Internet users to your web site or other on-line location, by creating a likelihood of confusion with the complainant's mark as to the source, sponsorship, affiliation, or endorsement of your web site or location or of a product or service on your web site or location.

c. How to Demonstrate Your Rights to and Legitimate Interests in the Domain Name in Responding to a Complaint. - Any of the following circumstances, in particular but without limitation, if found by the Panel to be proved based on its evaluation of all evidence presented, shall demonstrate your rights or legitimate interests to the domain name for purposes of Paragraph 4(a)(ii):

(i) before any notice to you of the dispute, your use of, or demonstrable preparations to use, the domain name or a name corresponding to the domain name in connection with a bona fide offering of goods or services; or

(ii) you (as an individual, business, or other organization) have been commonly known by the domain name, even if you have acquired no trademark or service mark rights; or

(iii) you are making a legitimate noncommercial or fair use of the domain name, without intent for commercial gain to misleadingly divert consumers or to tarnish the trademark or service mark at issue.

i. Remedies. - The remedies available to a complainant pursuant to any proceeding before an Administrative Panel shall be limited to requiring the cancellation of your domain name or the transfer of your domain name registration to the complainant.

k. Availability of Court Proceedings. - The mandatory administrative proceeding requirements set forth in Paragraph 4 shall not prevent either you or the complainant from submitting the dispute to a court of competent jurisdiction for 
independent resolution before such mandatory administrative proceeding is commenced or after such proceeding is concluded. If an Administrative Panel decides that your domain name registration should be canceled or transferred, we will wait ten (10) business days (as observed in the location of our principal office) after we are informed by the applicable Provider of the Administrative Panel's decision before implementing that decision. We will then implement the decision unless we have received from you during that ten (10) business day period official documentation (such as a copy of a complaint, file-stamped by the clerk of the court) that you have commenced a lawsuit against the complainant in a jurisdiction to which the complainant has submitted. (In general, that jurisdiction is either the location of our principal office or of your address as shown in our Whois database.) If we receive such documentation within the ten (10) business day period, we will not implement the Administrative Panel's decision, and we will take no further action, until we receive (i) evidence satisfactory to us of a resolution between the parties; (ii) evidence satisfactory to us that your lawsuit has been dismissed or withdrawn; or (iii) a copy of an order from such court dismissing your lawsuit or ordering that you do not have the right to continue to use your domain name.

1. Definitions. -

Panel means an administrative panel appointed by a UDRP Rules Provider to decide a complaint concerning a domain-name registration.

Provider means a dispute-resolution service provider approved by ICANN. A list of such Providers appears at http://www.icann.org/en/dndr/udrp/approvedproviders.htm.

3. The Complaint. -

(a) Any person or entity may initiate an administrative proceeding by submitting a complaint [in electronic form] in accordance with the Policy and these Rules to any Provider approved by ICANN.

4. Notification of Complaint. -

(a) The Provider shall review the complaint for administrative compliance with the Policy and these Rules and, if in compliance, shall forward the complaint, including any annexes, electronically to the Respondent and shall send 
WIPO's current fee schedule is $\$ 1,500$ for 1 to 5 domain names, or $\$ 4,000$ for a three-member panel
Written Notice of the complaint to the Respondent within three (3) calendar days following receipt of the fees to be paid by the Complainant in accordance with Paragraph 19.

5. The Response. -

(a) Within twenty (20) days of the date of commencement of the administrative proceeding the Respondent shall submit a response [in electronic form] to the Provider.

6. Appointment of the Panel and Timing of Decision. -

(a) Each Provider shall maintain and publish a publicly available list of panelists and their qualifications.

(b) If neither the Complainant nor the Respondent has elected a three-member Panel, the Provider shall appoint, within five (5) calendar days following receipt of the response by the Provider, or the lapse of the time period for the submission thereof, a single Panelist from its list of panelists.

7. Impartiality and Independence. - A Panelist shall be impartial and independent and shall have, before accepting appointment, disclosed to the Provider any circumstances giving rise to justifiable doubt as to the Panelist's impartiality or independence. If, at any stage during the administrative proceeding, new circumstances arise that could give rise to justifiable doubt as to the impartiality or independence of the Panelist, that Panelist shall promptly disclose such circumstances to the Provider. In such event, the Provider shall have the discretion to appoint a substitute Panelist.

15. Panel Decisions

(a) A Panel shall decide a complaint on the basis of the statements and documents submitted and in accordance with the Policy, these Rules and any rules and principles of law that it deems applicable.

(b) In the absence of exceptional circumstances, the Panel shall forward its decision on the complaint to the Provider within fourteen (14) days of its appointment.

\section{Online Accounts}

\section{Twitter Rules}

We reserve the right to reclaim usernames on behalf of businesses or individuals that hold legal claim or trademark on those usernames. Accounts using business names and/or logos to mislead others may be permanently suspended. 
You may not engage in username squatting. Accounts that are inactive for more than six months may also be removed without further notice. Some of the factors we take into consideration when determining what conduct is considered to be username squatting are:

- the number of accounts created;

- creating accounts for the purpose of preventing others from using those account names;

- creating accounts for the purpose of selling those accounts; and

- using feeds of third-party content to update and maintain accounts under the names of those third parties.

Using another's trademark in a manner that may mislead or confuse others about your brand affiliation may be a violation of our trademark policy.

Referencing another's trademark is not automatically a violation of Twitter's trademark policy. Examples include:

- Using a trademark in a way that is outside the scope of the trademark registration (e.g. territory, or goods and services identified in the registration).

- Nominative and other fair uses of trademarks are protected uses under our trademark policy, so long as the account is clearly distinguished from the trademark owner. This includes use by resellers in certain regions and accounts engaging in parody, commentary, or news.

Twitter accounts portraying another person in a confusing or deceptive manner may be permanently suspended under the Twitter impersonation policy.

An account will not be removed if:

- the user shares your name but has no other commonalities, or

- the profile clearly states it is not affiliated with or connected to any similarly-named individuals.

Accounts with similar usernames or that are similar in appearance (e.g. the same avatar image) are not automatically in violation of the impersonation policy. In order to be impersonation, the account must also portray another person in a misleading or deceptive manner.

Users are allowed to create parody, newsfeed, commentary, and fan accounts on Twitter, provided that the accounts follow the requirements below.

Parody, commentary, and fan account policy

https://support.twitter.com/articles/106373

- Bio: The bio should indicate that the user is not affiliated with the account subject by stating a word such as "parody," "fake," 
"fan," or "commentary," and be done so in a way that would be understood by the intended audience.

- Account name: The name should not be the exact name of the account subject without some other distinguishing word, such as "not," "fake," or "fan," and be done so in a way that would be understood by the intended audience.

\section{Stage Names}

\section{Professional Name Policy}

The Association shall not enroll an applicant under a name, nor shall a member use a name which is the same as, or resembles (so closely as to tend to be confused with), the name of an existing enrolled member, except that an applicant may enroll under and use such name professionally upon proof of consent by the existing member, or a finding by the National Council that under the circumstances there is no likelihood of confusion, or that there are extenuating circumstances.

Administratively, the following procedures will be followed:

- If an applicant or member must change or alter his/her name to distinguish it from an existing member, he/she may change the first and/or last name completely or add a full middle name. (Note: The use of a middle initial under these circumstances is not acceptable.)

- If a member requests a Temporary Withdrawal/Suspended Payment inactive status, and if after (5) years he/she has not returned to active status with AEA, any claim to the sole use and possession which he/she may have to any name or names within the jurisdiction of Actors' Equity Association is hereby declared null and void.

- If a member loses or resigns membership for any reason, he/she may lose the exclusive right to the professional name.

Please note:

- All contracts, billings, programs and insurance cards must show your professional name as recorded with Actors' Equity Association.

- The use by a member of a name in violation of the above rules shall be an offense for which a member may be disciplined in accordance with the pertinent Constitution Article. 
Nicknames are common in all sports, but contemporary women's roller derby has taken this to a new level by publicly identifying skaters almost exclusively by means of facetious pseudonyms called "derby names" or "skate names." An ideal derby name typically has three components: it sounds something like a real name (i.e., has a plausible first name-last name construction), it connects to derby in some meaningful way (i.e., it suggests that the skater is fierce, fast, or tough), and it creates some sense of an overall persona. L.A. Derby Dolls blocker Tara Armov furnishes an example of a derby "Aname." "Tara" is a standard woman's first name, while "Armov" is a plausible-sounding last name. The name also suggests that Tara is tough enough that she'll tear your arm off. And the vaguely Slavic overtones of her moniker suggest an Eastern Bloc motif that Tara plays up by using faux Cyrillic lettering on her helmet.

The practice of using pseudonyms has created a patchwork of derby names that are simultaneously fierce and funny. Derby names may refer to great actresses (Grace Killy, Sophia LoRenegade), notso-great actresses (Gori Spelling), or miscreant heiresses (Paris Killton) 19 Pseudonyms invoke ancient art (Venus de Maul'r) and pop culture (Killo Kitty) alike. Skaters name-check favorite bands (Joy Collision) or musicians both popular (Beonslay) and niche (Stiv Skator49). Multiple monikers may reference the same public figure (Kristi Yamagotcha, Kristi Imahootchie). Some names don't refer to people or things but are just amusing puns (Anne R. Kissed, Anna Notherthing). A skate name may refer back to derby itself (Helen Wheels, Axles of Evil). Names can emphasize a skater's fierceness (Eva Destruction, Anita Kill) or downplay it (Sparkle Plenty). Some derby sobri- quets could function easily as porn names (Tae Kwon Ho), a few are outright gynecological (Vulvarine), and still others are just gross (Emma Rhoids). Political events both happy (Paris Troika) and tragic (Blanche Davidian) may be invoked. A few require a bit of historical knowledge (Reyna Terror) or literary awareness (Penny Dreadful, Madame Ovary) to decode. Derby names may pay homage to the spirit of a place you love (Louise Ze Animal, Fleur de Lethal, Dumaine Attraction50). Almost all skate names are in English, but some allude to phrases more familiar to foreign ears (Bette Noir, Fox Sake). Names chosen at the early dawn of derby's resurgence tended to be more abstract and conceptual (Suzy Snakeeyes, Tawdry Tempest), while a few are simply inscrutable (Lux, V. Lee). My personal favorite is Raven Seaward of the L.A. Derby Dolls, whose name was inspired by the television show Arrested Development.

\footnotetext{
${ }^{48}$ The celebrities who are name-checked by derby girls have not, to my knowledge, complained about the unauthorized plays on their names. Tori Spelling has actually reached out to Gori Spelling and seems enthusiastic about having a derby doppelganger.
} 
Derby pseudonyms are at least as important to the skaters who adopt them as they are to the viewing public. First, nicknames serve a simple, trademark-like function of facilitating derby girls' notoriety to the viewing public by differentiating skaters from one another. Obviously, standard government names can serve this function as well, but derby names are often particularly good source identifiers because they are tied to aesthetic features that fill out distinct personas. And unlike real names (and standard trademarks), derby names also serve an identity-concealing function in that they can separate a competitor's derby persona from her real-life identity, obscuring the latter from derby fans and the world more generally. This is important for skaters who have professional careers (law, medicine) in which participating in derby as an extracurricular activity may be looked down on.61 Relatedly, made-up names can also decrease the chances that overzealous fans (or, more concerningly, stalkers) will be able to identify and track down skaters.

Second, skate names facilitate skaters' abilities to develop identities within the roller derby world. Many participants are drawn to derby because it provides a welcome contrast to the everyday grind and provides a space that permits them to explore aspects of their personalities that cannot find expression in their daily lives.

Finally, derby names are inextricably bound up with the sense of community that the sport provides for its participants. Once a skater secures a name, it's how other people in the derby world will refer to her in all settings - not only during bouts, but at practices, social events, and online - so much so that even teammates may not know one another's real names. You know you've left workaday life behind and entered the insular derby community (whether at a practice, a team dinner, or a night out at a bar) when people stop calling you "Jane Smith" and instead refer to you as "Sasha Haughtbich."

Even though derby names are theoretically unlimited, skaters frequently choose names that turn out to be identical (or very similar to) ones that other derby girls have thought of first. Countless skaters have likely thought of the outstanding name "Princess Slay-Ya," for example, but it was first used by (and thus exclusively belongs to, for reasons we shall shortly see) one of the Kansas City Roller Warriors. One might suppose that because derby comprises a basically decent community where people share common interests and make close friends, there would be no objections if other skaters decided to use names identical or very similar to preexisting ones.

Nope. However much derby may embody communal sharing norms in many respects, name usage represents a glaring exception.

\footnotetext{
${ }^{61}$ One skater who works as a lawyer explained that when she appears in court, she doesn't want the judge imagining her in skates and fishnets.
} 
Derby girls react with anxiety and rancor to the discovery that others have sought to skate under names similar to theirs. Name repetition, and even similarity, triggers rage in skaters who feel they have superior rights in their derby aliases: "When you bite on someone's style you look like a douche and so uncool. Just imagine finding out at 2:30am in a bar when you are not completely sober that the person you are talking to has an almost identical name as yours. SUPER ANNOYING."

Derby girls care about maintaining the uniqueness of their aliases for three primary reasons. First, names in derby function as trademarks do in the commercial world: they ensure that skaters will not be confused with one another and that the viewing public can tell skaters apart. This is particularly true in the context of actual bouts, when announcers rely on derby names to relay action to spectators over a public-address system. As competition becomes increasingly interleague, the chances that two identically named skaters in leagues thousands of miles apart could skate against one another no longer seem so slim.

Second, and probably more importantly, though, skaters care about the uniqueness of their names despite their lack of discernible market value because skate names are a repository for the identities that skaters work so hard to create in a subculture that is profoundly important to them. Using a skater's preexisting name - or even using a name very similar to a skater's preexisting name - effects a dignitary harm on several levels. First, it may detract from the hardearned social capital that a skater has built up within the derby world, even where the senior skater's fame is sufficiently strong that no one is likely to confuse the junior skater with her. Second, overlapping name use violates one of the central tenets of the derby world, the "don't be a douchebag rule," so that not honoring the uniqueness of a preexisting skate name communicates disrespect in the same way as an intentional, if costless, trespass to land. Finally, names are typically a product of careful thought and effort, so that they express not just the holder's identity, but also her cleverness. Having multiple skaters use the same sobriquet dilutes that sense of ingenuity by making it seem commonplace.

Third, the gravity with which name infringement is treated in the derby world may seem puzzling because derby nicknames are theoretically infinite, so that overlap need only spur skaters to pick a new one from an inexhaustible commons. Many skaters contest whether derby names actually do comprise an inexhaustible commons. Newer rollergirls in particular often complain that with existing names numbering in the five figures, it's often necessary to think of many possible nicknames before finding one that is unclaimed, so that newer skaters often have to settle for a sixth-choice skate name. 
Not all names are created equal. Even if there is an infinitude of possible names, only some of those names will suit a skater's personality and style, so that a world in which skate names must be unique may well cause a newer skater to experience a much lower chance of being able to claim a name that truly suits her.

The roller derby world has eschewed trademark and other IP law almost completely as a means of protecting skate names, turning instead to its own skater-created and -operated system of name regulation and registration.

As demand for names increased, and casual enforcement increasingly failed, derby name regulation godmother and former Women's Flat Track Derby Association president Hydra stepped in to create the ur-version of what has since become known as the Master Roster. The Master Roster began as a humble Excel spreadsheet that noted the same basic data about names that it still does today: a skater's derby name, the date that the name was entered on the Master Roster, and the skater's team affiliation. In early 2006, there were 2,585 registered names on the Master Roster, and the increasing pace of submission required the Roster's administrators to release an updated version of the spreadsheet every week. Soon after, the administrators released an online version of the Master Roster with a search algorithm that enabled skaters to evaluate whether their proposed name was similar to a preexisting one and even how close the proximity was. This new functionality and increased accessibility enhanced the efficiency of name registration significantly, and by late 2007, the number of registered names had already exceeded 10,000. This version of the Master Roster remains publicly available online.

Three core principles govern derby name regulation. First is a uniqueness requirement: only one skater can skate under a given name. The second instantiates the idea of priority: where two names are identical or excessively similar, the skater with the earlier claim to the name has the right to use it. The third creates elemental standards for resolving overlapping name conflicts: where two names are reasonably similar, the second skater must ask the first skater for permission to use the name. This permission must be in writing and submitted to the Master Roster's administrators in order to authenticate it. Names that are very similar to preexisting names but that have been approved via written permission by the senior skater are listed on the Master Roster with the note "(cleared)."

The Master Roster's name search feature allows users to determine the degrees of similarity between a proposed name and existing names, and this result strongly determines the likelihood that a name will be accepted or rejected. The derby name checker returns one of five results, alerting users that a proposed moniker's degree of similarity to preexisting ones is either "very high," "high," "medium," 
"low," or "very low." Names of very high similarity are "almost guaranteed to be rejected," while names of very low similarity are likely to be accepted. For example, inputting the name "Nurse Wretched" into the name checker returns the result that the name is identical to a preexisting name ("Nurse Wretched"), of high similarity to another preexisting name ("Nurse Ratchet"), and of low similarity to yet another one ("Wretched"). This name would almost certainly be rejected by the Master Roster's administrators. These results are advisory rather than dispositive, though: the administrators retain discretion over the acceptance and rejection of all proposed derby names, which is particularly salient in cases where a name has a nontrivial degree of similarity to a preexisting one.

The Master Roster's substantive rules are supported by a number of formal registration procedures. For instance, skaters are advised not to submit a name until they have been participating in derby for at least a couple of months in order to avoid wastefully registering a name to beginning skaters who end up dropping out or failing to make a team. The submission of names to the Master Roster is initially organized by a designated skater within each league, a "name wrangler," who aggregates the names of qualifying new skaters, vets them for validity, and submits them in batches to the Master Roster administrators. Priority in cases of identical submissions is determined by the date stamp on the e-mail received by the Master Roster's administrators. In other words, registration is a matter of filing priority, not actual use, so that if two skaters simultaneously seek to register the same name, the Master Roster's administrators will register the first submission they receive, regardless of which skater adopted the name first.

The process of adding names to the registry raises a correlative problem: what to do with names of skaters who have quit or retired? This problem looms more and more as the number of derby girls grows ever larger and names grow ever scarcer. Skaters (and name wranglers) are encouraged to notify the Master Roster's administrators when they are no longer using their names, and leagues often submit lists of names to the Master Roster that are to be deleted. Name removal does not happen as often as it should, and certainly not as often as name addition happens, for several reasons. First, incentives to retire one's own name are weak. There are no ways to sanction skaters who have left derby without doing the courtesy of notifying the Master Roster that their names are now available. Second, skaters often change their minds about retirement, so any derby girl who has even a sliver of interest in returning to the sport will be disinclined to give up her name. And third, even when disused names are purged from the Master Roster, skaters may not want a "used" name because using it may seem derivative rather than orig- 
inal and because it may have unwanted associations with its prior user. As a result of all this, turnover in names tends to be slow, and the Master Roster contains many names of skaters who have become inactive, despite best efforts by name wranglers and list administrators.

Assuming that there is agreement that two names are in conflict (i.e., where they are either identical or substantially similar), an additional issue remains: How are a skater's superior name rights enforced? The Master Roster administrators can decline to register a name, but as an informal organization, they lack any coercive force, so a skater who consciously uses an overlapping name cannot be fined or thrown in jail. And yet despite the total absence of formal coercive sanctions, the incidence of repetitive name use is small, thanks to informal enforcement norms. This raises two related puzzles: How do skaters enforce rules governing derby name uniqueness, and why is the level of compliance so high?

The answer to the how question is straightforward. The primary means of enforcement is simply personal contact and interaction that relies on skaters' strong incentives to maintain the uniqueness of their own names. These exchanges usually take the form of an e-mail exchange between the skater who wants to use a name and the one who has registered a similar one. Skaters exhibit a high degree of deference to the first-to-register rule. The dog that didn't bark in this context is the number of times that skaters use the Master Roster to determine that their proposed name is too similar to a preexisting one and defer to the system by simply seeking another name. While it's impossible to measure absence of evidence, the number of times the Master Roster (while far from perfectly effective) successfully fends off name conflicts is almost certainly far greater than the number of name conflicts it fails to deter.

the informal sanctions that skat- ers inflict on one another for violating name-uniqueness norms effectuate compliance to a large extent. Skaters unanimously agree that choosing a name that has clearly been adopted by another skater-even a skater in another league - without permission would be egregiously socially unacceptable within the derby community and lead to ostracism. And since being part of a community is central to the derby experience, the kind of shaming that flouting name-priority norms would engender would undermine entirely the advantages of being part of derby in the first place.

If these sanctions do not work, there is always the oldest form of self-help: violence. Skaters have (perhaps facetiously) invoked threats of physical harm against those who fail to respect the derby world's rules and norms of name usage. As one rollergirl put it, "sure there's no laws in place - you don't even have to register your derby 
name - it's COURTESY. Ref might not see you smash me in the facebut I know, and trust me baby, I'm comin for ya." Added another, "I totally agree with the not stealing/copying of names . . . Someone once said imitation was the best form of flattery. . . . So flatter me and then let me kick your a $\$$." These threats are just talk, after all, and should be taken with a grain of salt. There is no evidence (that I've seen, anyway) of a derby girl beating up someone who used her name without permission. But in a sport where skaters are skilled at using full-body blocks at high speeds in the course of competition, the idea of using violence to lay down the law against those who flout shared norms about name usage certainly does not seem completely implausible.

Instances of formal regulation represent attempts to protect derby girls' names and identities from infringement by actors external to the derby world. Ivanna S. Pankin registered her name as a trademark largely because she wanted to make sure that competitors outside the derby world could not free ride on her business goodwill. Babe Ruthless's concern about unauthorized use of her moniker was directed at a film production company, not at another roller derby girl. In these and other instances, the Master Roster did sufficient work to assure the skaters that no one else would compete under their derby names. It remains necessary to invoke formal law only outside contexts that, and against individuals who, are not governed by roller derby's name-exclusivity norms. 


\section{Advertising}

False advertising law is not, strictly speaking, intellectual property law, but it is a close relative. At the very lest, we need to say a bit about adveritisng law to complete our survey of trademark law. Competitor suits for false advertising have a lot in common with competitor suits for trademark infringement and unfair competition, and trademark law incorporates several devices to discourage misleading uses of trademarks. But a slightly deeper dive - exploring advertising law as a body of law devoted to controlling information - casts new light on other areas of intellectual property as well.

Three issues are pervasive in advertising law: falsity, materiality and commerciality. Falsity is important because true statements about one's products (or others) generally enjoy robust First Amendment protections. Not every false statement is actionable; only those that is material to consumers' purchasing decisions. And advertising law only generally applies to statements "in commercial advertising or promotion," to quote the Lanham Act. Falsity, materiality, and commerciality all raise conceptual questions about the control information that go well beyond advertising law. So we start with the tort law of competitor suits for false advertising, then discuss its close tort and tort-like substitutes, and then look more broadly at other sources of advertising law.

The central concern of false advertising law is to prevent the dissemination of false commercial information. Note that this task necessarily requires courts to distinguish true statements from false ones. At least five different conceptions of truth butt heads in the caselaw:

- Scientific truth exists in the world and can be determined through objective investigation.

- Linguistic truth is conventional; the true meaning of a term is the meaning a reasonable listener (e.g., a reasonable consumer) would regard it as having.

- Legal truth is a matter of authority; courts must defer to what 
The leading advertising treatises are David H. Bernstein \& Bruce P. Keller, The Law of Advertising, Marketing, and Promotions (Law Journal Press) and James Astrachan, The Law of Advertising (Matthew Bender, on Lexis, current through 2014). See also the casebook Rebecca Tushnet \& Eric Goldman, Advertising \& Marketing Law: Cases and Materials (self-published, available in a variety of convenient and inexpensive formats)

15 U.S.C. § 1125 [Lanham Act § 43] False designations of origin, false descriptions, and dilution forbidden
See Rebecca Tushnet, Running the Gamut from A to B: Federal Trademark and False Advertising Law, 159 U. Pa. L. Rev. 1305 (2011). legislatures and agencies assert.

- Trademark truth is determined by priority of appropriation; the owner of a mark is entitled to say definitively what it means.

- In a pluralistic society committed to free speech, there is no absolute truth; everyone is entitled to express their own opinions. As you read the cases, always ask which conception or conceptions the courts are appealing to.

\section{A False Advertising}

As with trademark and unfair competition, state and federal law provide overlapping - and often redundant - protections against false advertising. We will focus on our old federal friend, section 43(a), except that now our attention turns to a different subparagraph.

\section{Lanham Act}

(a) Civil action. -

(1) Any person who, on or in connection with any goods or services, or any container for goods, uses in commerce any word, term, name, symbol, or device, or any combination thereof, or any false designation of origin, false or misleading description of fact, or false or misleading representation of fact, which - ...

(B) in commercial advertising or promotion, misrepresents the nature, characteristics, qualities, or geographic origin of his or her or another person's goods, services, or commercial activities,

shall be liable in a civil action by any person who believes that he or she is or is likely to be damaged by such act.

In a sense, false advertising law shares the tort structure of trademark law, but without the requirement that the plaintiff own a trademark. The false advertising tort lacks anything corresponding to procedural rules, and subject matter and "similarity" are so interwoven that it makes sense to treat them together.

\section{1 "Ownership": Competitor Standing}

One gains tort protection against competitors' false advertising competitors simply by having competitors - by engaging in a commercial activity that has customers capable of being diverted by lies. This requirement of competitor standing functions as a kind of ownership 
rule. Modern standing law under $\S 43(a)$ is considerably more liberal than its common-law precursors.

American Washboard Co. v. Saginaw Mfg. Co.

[The plaintiff sold aluminum washboards marked "aluminum." It alleged that it had "contracted for and purchased ... the entire output of sheet aluminum suitable for forming the rubbing sheets of washboards." The defendant sold zinc washboards, falsely marked "aluminum."]

We do not find it anywhere averred that the defendant, by means of its imitation of complainant's trade-mark, is palming off its goods on the public as and for the goods of complainant. The bill is not predicated upon that theory. It undertakes to make a case, not because the defendant is selling its goods as and for the goods of complainant, but because the defendant is deceiving the public by selling to it a board not made of aluminum, although false branded as such.

It is doubtless morally wrong and improper to impose upon the public by the sale of spurious goods, but this does not give rise to a private right of action unless the property rights of the plaintiff are thereby invaded. There are many wrongs which can only be righted through public prosecution, and for which the legislature, and not the courts, must provide a remedy.

Take the metal which is the subject-matter of the controversy in this case. Many articles are now being put upon the market under the name of aluminum, because of the attractive qualities of that metal, which are not made of pure aluminum, yet they answer the purpose for which they are made and are useful. Can it be that the courts have the power to suppress such trade at the instance of others starting in the same business who use only pure aluminum?

Nor do we find anything in the allegations of the bill as to complainant's monopoly in the use of the metal aluminum for washboard purposes which would extend its rights. We are not referred to any case, nor can we think of any reason why one who has obtained a monopoly in the material of which his goods are made should have any broader rights in protecting his trade-name than another who is engaged in competition in the same line of business.

\section{Ely-Norris Safe Co. v. Mosler Safe Co.}

[The plaintiff held a patent [No. 827,351] for a safe with an "explosion chamber" - a design "to prevent burglarious entrances to safes, vaults, and the like through the doors by the use of explosives." Its safes had a metal band around the door to cover the explosion chamber. The defendant sold safes with a metal band around the door, but no explosion chamber beneath.]
103 F. 281 (6th Cir. 1900)

(Taft, J.)

Why didn't the plaintiff sue for trademark infringement?

7 F.2d 603 (2d Cir. 1925)

(Learned Hand, J.) 
There is no part of the law which is more plastic than unfair competition, and what was not reckoned an actionable wrong 25 years ago may have become such today. While a competitor may, generally speaking, take away all the customers of another that he can, there are means which he must not use. One of these is deceit. We conceive that in the end the questions which arise are always two: Has the plaintiff in fact lost customers? And has he lost them by means which the law forbids? The false use of the plaintiff's name is only an instance in which each element is clearly shown.

The reason, as we think, why such deceits have not been regarded as actionable by a competitor, depends only upon his inability to show any injury for which there is a known remedy. In an open market it is generally impossible to prove that a customer, whom the defendant has secured by falsely describing his goods, would have bought of the plaintiff, if the defendant had been truthful. Without that, the plaintiff, though aggrieved in company with other honest traders, cannot show any ascertainable loss. The law does not allow him to sue as a vicarious avenger of the defendant's customers.

But, if it be true that the plaintiff has a monopoly of the kind of wares concerned, and if to secure a customer the defendant must represent his own as of that kind, it is a fair inference that the customer wants those and those only. Had he not supposed that the defendant could supply him, presumably he would have gone to the plaintiff, who alone could. If a tradesman falsely foists on a customer a substitute for what the plaintiff alone can supply, it can scarcely be that the plaintiff is without remedy, if he can show that the customer would certainly have come to him, had the truth been told.

273 U.S. 132 (1927)

(Holmes, J.)

134 S. Ct. 1377 (2014)

\section{Mosler Safe Co. v. Ely-Norris Safe Co.}

It is consistent with every allegation in the bill and the defendant in argument asserted it to be a fact, that there are other safes with explosion chambers beside that for which the plaintiff has a patent. There is nothing to show that customers had they known the facts would have gone to the plaintiff rather than to other competitors in the market, or to lay a foundation for the claim for a loss of sales. The bill is so framed as to seem to invite the decision that was obtained from the Circuit Court of Appeals, but when scrutinized is seen to have so limited its statements as to exclude the right to complain.

Lexmark International, Inc. v. Static Control Components, Inc. This case requires us to decide whether respondent, Static Control Components, Inc., may sue petitioner, Lexmark International, Inc., for false advertising under the Lanham Act.

\section{BACKGROUND}


Lexmark manufactures and sells laser printers. It also sells toner cartridges for those printers (toner being the powdery ink that laser printers use to create images on paper). Lexmark designs its printers to work only with its own style of cartridges, and it therefore dominates the market for cartridges compatible with its printers. That market, however, is not devoid of competitors. Other businesses, called "remanufacturers," acquire used Lexmark toner cartridges, refurbish them, and sell them in competition with new and refurbished cartridges sold by Lexmark.

Lexmark would prefer that its customers return their empty cartridges to it for refurbishment and resale, rather than sell those cartridges to a remanufacturer. So Lexmark introduced what it called a "Prebate" program, which enabled customers to purchase new toner cartridges at a 20-percent discount if they would agree to return the cartridge to Lexmark once it was empty. To enforce the Prebate terms, Lexmark included a microchip in each Prebate cartridge that would disable the cartridge after it ran out of toner; for the cartridge to be used again, the microchip would have to be replaced by Lexmark.

Static Control is not itself a manufacturer or remanufacturer of toner cartridges. It is, rather, the market leader in making and selling the components necessary to remanufacture Lexmark cartridges. In addition to supplying remanufacturers with toner and various replacement parts, Static Control developed a microchip that could mimic the microchip in Lexmark's Prebate cartridges. By purchasing Static Control's microchips and using them to replace the Lexmark microchip, remanufacturers were able to refurbish and resell used Prebate cartridges.

As relevant to its Lanham Act claim, Static Control alleged two types of false or misleading conduct by Lexmark. First, it alleged that through its Prebate program Lexmark "purposefully misleads end-users" to believe that they are legally bound by the Prebate terms and are thus required to return the Prebate-labeled cartridge to Lexmark after a single use. Second, it alleged that upon introducing the Prebate program, Lexmark "sent letters to most of the companies in the toner cartridge remanufacturing business" falsely advising those companies that it was illegal to sell refurbished Prebate cartridges and, in particular, that it was illegal to use Static Control's products to refurbish those cartridges.

\section{Static Control's Right To Sue Under § 1125(A)}

Thus, this case presents a straightforward question of statutory interpretation: Does the cause of action in $\S 1125$ (a) extend to plaintiffs like Static Control? The statute authorizes suit by "any person who believes that he or she is likely to be damaged" by a defendant's false advertising. 


\section{A. Zone of Interests}

First, we presume that a statutory cause of action extends only to plaintiffs whose interests fall within the zone of interests protected by the law invoked.

We thus hold that to come within the zone of interests in a suit for false advertising under $\S 1125(a)$, a plaintiff must allege an injury to a commercial interest in reputation or sales. A consumer who is hoodwinked into purchasing a disappointing product may well have an injury-in-fact cognizable under Article III, but he cannot invoke the protection of the Lanham Act - a conclusion reached by every Circuit to consider the question. Even a business misled by a supplier into purchasing an inferior product is, like consumers generally, not under the Act's aegis.

\section{B. Proximate Cause}

Second, we generally presume that a statutory cause of action is limited to plaintiffs whose injuries are proximately caused by violations of the statute.

Put differently, the proximate-cause requirement generally bars suits for alleged harm that is "too remote" from the defendant's unlawful conduct. That is ordinarily the case if the harm is purely derivative of misfortunes visited upon a third person by the defendant's acts. In a sense, of course, all commercial injuries from false advertising are derivative of those suffered by consumers who are deceived by the advertising; but since the Lanham Act authorizes suit only for commercial injuries, the intervening step of consumer deception is not fatal to the showing of proximate causation required by the statute.

We thus hold that a plaintiff suing under $§ 1125(a)$ ordinarily must show economic or reputational injury flowing directly from the deception wrought by the defendant's advertising; and that that occurs when deception of consumers causes them to withhold trade from the plaintiff. That showing is generally not made when the deception produces injuries to a fellow commercial actor that in turn affect the plaintiff. For example, while a competitor who is forced out of business by a defendant's false advertising generally will be able to sue for its losses, the same is not true of the competitor's landlord, its electric company, and other commercial parties who suffer merely as a result of the competitor's inability to meet its financial obligations.

\section{Application}

Applying those principles to Static Control's false-advertising claim, we conclude that Static Control comes within the class of plaintiffs whom Congress authorized to sue under $\S 1125(\mathrm{a})$. 
To begin, Static Control's alleged injuries - lost sales and damage to its business reputation - are injuries to precisely the sorts of commercial interests the Act protects. Static Control is suing not as a deceived consumer, but as a "perso[n] engaged in" "commerce within the control of Congress" whose position in the marketplace has been damaged by Lexmark's false advertising. $\S 1127$. There is no doubt that it is within the zone of interests protected by the statute.

Static Control also sufficiently alleged that its injuries were proximately caused by Lexmark's misrepresentations. This case, it is true, does not present the classic Lanham Act false-advertising claim in which one competitor directly injures another by making false statements about his own goods or the competitor's goods and thus inducing customers to switch. But although diversion of sales to a direct competitor may be the paradigmatic direct injury from false advertising, it is not the only type of injury cognizable under $\S 1125(\mathrm{a})$. For at least two reasons, Static Control's allegations satisfy the requirement of proximate causation.

First, Static Control alleged that Lexmark disparaged its business and products by asserting that Static Control's business was illegal. When a defendant harms a plaintiff's reputation by casting aspersions on its business, the plaintiff's injury flows directly from the audience's belief in the disparaging statements. Courts have therefore afforded relief under $§ 1125$ (a) not only where a defendant denigrates a plaintiff's product by name but also where the defendant damages the product's reputation by, for example, equating it with an inferior product.

In addition, Static Control adequately alleged proximate causation by alleging that it designed, manufactured, and sold microchips that both (1) were necessary for, and (2) had no other use than, refurbishing Lexmark toner cartridges. It follows from that allegation that any false advertising that reduced the remanufacturers' business necessarily injured Static Control as well. Taking Static Control's assertions at face value, there is likely to be something very close to a 1:1 relationship between the number of refurbished Prebate cartridges sold (or not sold) by the remanufacturers and the number of Prebate microchips sold (or not sold) by Static Control. Where the injury alleged is so integral an aspect of the violation alleged, there can be no question that proximate cause is satisfied.

Although we conclude that Static Control has alleged an adequate basis to proceed under $\S 1125(a)$, it cannot obtain relief without evidence of injury proximately caused by Lexmark's alleged misrepresentations. We hold only that Static Control is entitled to a chance to prove its case. 


\section{2 "Infringement": Prohibited Conduct}

Notice the threshold condition in $\S 43(\mathrm{a})(1)(\mathrm{B})$ : the challenged false statement must be "in commercial advertising or promotion." This threshold condition is heavily influenced by First Amendment concerns. In addition, the statement must concern "the nature, characteristics, qualities, or geographic origin of his or her or another person's goods, services, or commercial activities," a phrase that is expansive but not infinitely so.

Greater Houston Transportation Company v. Uber Technologies, Inc.

Plaintiffs are taxicab permit-holders in Houston and San Antonio, who claim that Uber is unfairly competing with the taxicab industry by misrepresenting the safety of its services to consumers.

First, Plaintiff cites Uber's Senior Communications Associate, Lauren Altmin's statement on an NBC Detroit affiliate's website, in a post titled, "Local 4 Defenders: Is Uber X safe?". The article on the website republished Uber's statement as follows:

What I can tell you is that Uber takes passenger safety very seriously. We work every day to connect riders with the safest rides on the road and go above and beyond local requirements in every city we operate. Uber only partners with drivers who pass an industry-leading screening that includes a criminal background check at the county, federal and multistate level going back as far as the law allows. We also conduct ongoing reviews of drivers' motor vehicle records during their time as an Uber partner.

For more information on what makes Uber the safest rides on the road, please see our website ...

Plaintiffs also point to a statement by Uber's Head of Communications for North America, Lane Kasselman, in an April 24, 2014 article on Mashable.com entitled "Faulty Background Checks May Put Uber X Passengers at Risk, Report Says." The statement quoted in the article reads:

Uber's industry-leading background checks help connect consumers with the safest ride on the road.... Our driver partner background checks are more thorough than those of taxi [sic] in most cities and include county, state and federal screens going back seven years. We continue to improve and are always working hard to tighten our policies and processes to ensure that Uber remains the safest transportation option available.

In addition, Plaintiffs take issue with a quote by Kasselman in an 
April 24, 2014, NBCBayArea.com news article, titled "Is Uber Keeping Riders Safe?". In the article, Kasselman states, "We're confident that every ride on the Uber platform is safer than a taxi." Plaintiffs also allege that a similar email response from Kasselman included in a news story on NBCLosAngeles.com, was false or misleading: "We're confident that every ride on Uber is safer than a taxi."

Plaintiffs allege that Uber's statements quoted in online news articles were misleading to potential consumers. Defendant argues that false-advertising claims under the Lanham Act must be based on "commercial advertising or promotion," and contends that statements contained in news articles do not qualify as commercial advertising.

Uber argues that each of its statements quoted in news articles are "inextricably intertwined with the reporters' coverage" in each article, citing Boulé $v$. Hutton (affirming dismissal of a Lanham Act claim based on the defendant's statements as quoted in a news article). Defendant further argues that the alleged statements are not commercial speech, because commercial speech is speech which does no more than propose a commercial transaction.

This area of law is currently evolving. The Second Circuit recently explored the commercial and non-commercial speech dichotomy in Ony, Inc. v. Cornerstone Therapeutics, Inc.. The Ony, Inc court found that publication and dissemination of a scientific study that had the effect of touting a company's product is noncommercial speech and was thereby immune from the false advertising provisions of the Lanham Act. The Fifth Circuit recently highlighted the difficulties in separating commercial from non-commercial speech, holding that the dissemination of an article as part of a company's marketing campaign is in fact commercial speech. Eastman Chemical Co. v. PlastiPure, Inc.

Each of Uber's statements was issued by its corporate spokesperson or on Uber's own official website as part of a concerted campaign by the company in response to incidents that had been publicized in the media. Three of the statements quoted in the media were made by Uber's Head of Communications for North America. Two more were by other corporate representatives: Uber's Senior Communications Associate and Uber's Public Policy representative. One statement was published on Uber's own website, and then quoted in the media.

Because Uber's statements as a whole are issued with the intent to influence consumer opinion, they thereby become commercial speech even though they were contained in news media. In the modern age of hybrid advertising and advertising in social media, Courts must remain vigilant in order to separate commercial from non-commercial speech, regardless of the form in which it was dis-
Boulé: 328 F.3d 84 (2d Cir.2003)

In Boule, the plaintiffs and defendants competed in selling paintings by Lazar Khidekel. Two defendants, who were Khidekel's son and daughter-in-law, defendants were quoted in ARTnews claiming that paintings being sold by the plaintiff were not authentic Khidekels.

Ony, Inc.: 720 F.3d 490 (2d Cir. 2013)

Eastman Chemical: . 


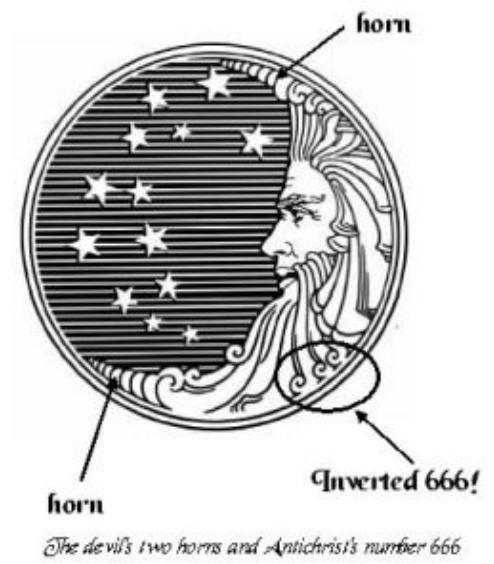

The allegedly Satanic P\&G logo seminated. The comments issued by Uber's communication executives demonstrate a careful, uniform, and orchestrated message designed to encourage and facilitate the commercial use of its product and service. Thus, the Court finds that the disputed statements contained in media articles are commercial speech, and are potentially actionable under the Lanham Act.

\section{Procter \& Gamble Co. v. Haugen}

[Randy Haugen, an Amway distributor, distributed a voice message to other distributors saying

I wanna run something by you real quick that I think you will find pretty interesting. Just talking to a guy the other night about this very subject and it just so happens that a guy brings information in and lays it on my desk this morning, so here it goes.

It says the president of Procter \& Gamble appeared on the Phil Donahue Show on March 1, '95. He announced that due to the openness of our society, he was coming out of the closet about his association with the church of satan. He stated that a large portion of the profits from [P\&G] products go to support his satanic church. When asked by Donahue if stating this on television would hurt his business, his reply was, "There are not enough Christians in the United States to make a difference." And below it has a list of the [P\&G] products which I'll read: [the subject message then lists 43 P\&G products].

It says if you are not sure about a product, look for the symbol of the ram's horn that will appear on each product beginning in April. The ram's horn will form the 666 which is known as satan's number. I'll tell you it really makes you count your blessings to have available to all of us a business that allows us to buy all the products that we want from our own shelf and I guess my real question is, if people aren't being loyal to themselves and buying from their own business, then whose business are they supporting and who are they buying from. Love you. Talk to you later. Bye.

Needless to say, the claims about P\&G were entirely false.]

The district court granted defendants-appellees' motion for summary judgment on P\&G's Lanham Act claim because it found the subject message, although "identiflying] . . . [P\&G] products," did not "contain false representations about the qualities or characteristics of those products," and so did "not relate to a product within the meaning of the Lanham Act." We agree with the district court that the sub- 
ject message did not implicate the nature, characteristics, or qualities of $P \& G^{\prime}$ s products because it impugned no feature of the products themselves, such as price, regulatory approval, scope of copyright, or substitutability for another product.

However, in addition to challenging on appeal the district court's conclusion that there was no genuine issue as to misrepresentation of the qualities or characteristics of its goods or services, $P \& G$ argues that the district court erred in granting summary judgment because the subject message's representations regarding the infernal affiliation of $P \& G$ and the use of its profits misrepresented "the nature, characteristics, [or] qualities . . . of . . . [its] commercial activities."

The subject message linking P\&G to Beelzebub clearly concerned the "nature, characteristics, [or] qualities ... of . . [P\&G's] commercial activities," under the plain meaning of that phrase. In particular, the subject message asserted that "a large portion of the profits from $[P \& G]$ products go to support [the church of Satan]." Given the common association of Satan and immorality, a direct affiliation with the church of Satan could certainly undermine a corporation's reputation and goodwill by suggesting the corporation conducts its commercial activities in an unethical or immoral manner. There can be little doubt that products are often marketed and purchased not only on the basis of their inherent utility, but also for the images they project and the values they promote. In that regard, the subject message itself implies that recipients should question the values promoted by the businesses from whom they purchase goods. In light of the foregoing reality of the marketplace, corporations cultivate their images and values through a wide array of activities, including celebrity endorsements, sponsorships, and charitable giving. Allegations that P\&G tithes the church of Satan concern just such commercial activities.

\section{3 "Infringement": Falsity and Materiality}

With no specific information as such to protect, false advertising law lacks a similarity test. Instead, because it protects the truth, it asks whether the challenged statements are false, and if so, whether the lies are ones that are material to consumers.

Pizza Hut, Inc. v. Papa John's Intern., Inc.

This appeal presents a false advertising claim under section 43(a) of 227 F.3d 489 (5th Cir. 2000) the Lanham Act, resulting in a jury verdict for the plaintiff, Pizza Hut. At the center of this appeal is Papa John's four word slogan "Better Ingredients. Better Pizza."

The appellant, Papa John's International Inc. ("Papa John's"), argues that the slogan "cannot and does not violate the Lanham Act" because it is "not a misrepresentation of fact." The appellee, Pizza 
Hut, Inc., argues that the slogan, when viewed in the context of Papa John's overall advertising campaign, conveys a false statement of fact actionable under section 43(a) of the Lanham Act. The district court, after evaluating the jury's responses to a series of special interrogatories and denying Papa John's motion for judgment as a matter of law, entered judgment for Pizza Hut stating:

When the "Better Ingredients. Better Pizza." slogan is considered in light of the entirety of Papa John's post-May 1997 advertising which violated provisions of the Lanham Act and in the context in which it was juxtaposed with the false and misleading statements contained in Papa John's print and broadcast media advertising, the slogan itself became tainted to the extent that its continued use should be enjoined.

We conclude that (1) the slogan, standing alone, is not an objectifiable statement of fact upon which consumers would be justified in relying, and thus not actionable under section 43(a); and (2) while the slogan, when utilized in connection with some of the post-May 1997 comparative advertising - specifically, the sauce and dough campaignsconveyed objectifiable and misleading facts, Pizza Hut has failed to adduce any evidence demonstrating that the facts conveyed by the slogan were material to the purchasing decisions of the consumers to which the slogan was directed. Thus, the district court erred in denying Papa John's motion for judgment as a matter of law. We therefore reverse the judgment of the district court denying Papa John's motion for judgment as a matter of law, vacate its final judgment, and remand the case to the district court for entry of judgment for Papa John's.

Pizza Hut is a wholly owned subsidiary of Tricon Global Restaurants. With over 7000 restaurants (both company and franchisee-owned), Pizza Hut is the largest pizza chain in the United States. In 1984, John Schnatter founded Papa John's Pizza in the back of his father's tavern. Papa John's has grown to over 2050 locations, making it the third largest pizza chain in the United States.

In May 1995, Papa John's adopted a new slogan: "Better Ingredients. Better Pizza." In 1996, Papa John's filed for a federal trademark registration for this slogan with the United States Patent \& Trademark Office ("PTO"). Its application for registration was ultimately granted by the PTO. Since 1995, Papa John's has invested over $\$ 300$ million building customer goodwill in its trademark "Better Ingredi- 
ents. Better Pizza." The slogan has appeared on millions of signs, shirts, menus, pizza boxes, napkins and other items, and has regularly appeared as the "tag line" at the end of Papa John's radio and television ads, or with the company logo in printed advertising.

On May 1, 1997, Pizza Hut launched its "Totally New Pizza" campaign. This campaign was the culmination of "Operation Lightning Bolt," a nine-month, \$50 million project in which Pizza Hut declared "war" on poor quality pizza. From the deck of a World War II aircraft carrier, Pizza Hut's president, David Novak, declared "war" on "skimpy, low quality pizza." National ads aired during this campaign touted the "better taste" of Pizza Hut's pizza, and "dared" anyone to find a "better pizza."

In early May 1997, Papa John's launched its first national ad campaign. The campaign was directed towards Pizza Hut, and its "Totally New Pizza" campaign. In a pair of TV ads featuring Pizza Hut's co-founder Frank Carney, Carney touted the superiority of Papa John's pizza over Pizza Hut's pizza. Although Carney had left the pizza business in the 1980's, he returned as a franchisee of Papa John's because he liked the taste of Papa John's pizza better than any other pizza on the market. The ad campaign was remarkably successful. During May 1997, Papa John's sales increased 11.7 percent over May 1996 sales, while Pizza Hut's sales were down 8 percent.

On the heels of the success of the Carney ads, in February 1998, Papa John's launched a second series of ads touting the results of a taste test in which consumers were asked to compare Papa John's and Pizza Hut's pizzas. In the ads, Papa John's boasted that it "won big time" in taste tests. The ads were a response to Pizza Hut's "dare" to find a "better pizza." The taste test showed that consumers preferred Papa John's traditional crust pizzas over Pizza Hut's comparable pizzas by a 16 -point margin ( $58 \%$ to $42 \%$ ). Additionally, consumers preferred Papa John's thin crust pizzas by a fourteen-point margin $(57 \%$ to $43 \%)$.

Following the taste test ads, Papa John's ran a series of ads comparing specific ingredients used in its pizzas with those used by its "competitors." During the course of these ads, Papa John's touted the superiority of its sauce and its dough. During the sauce campaign, Papa John's asserted that its sauce was made from "fresh, vine-ripened tomatoes," which were canned through a process called "fresh pack," while its competitors - including Pizza Hut-make their sauce from remanufactured tomato paste. During the dough campaign, Papa John's stated that it used "clear filtered water" to make its pizza dough, while the "biggest chain" uses "whatever comes out of the tap." Additionally, Papa John's asserted that it gives its yeast "several days to work its magic," while "some folks" use "frozen dough or dough made the same day." At or near the close of each of these 


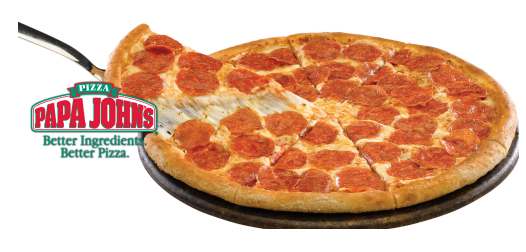

"Better Ingredients. Better Pizza" ad ads, Papa John's punctuated its ingredient comparisons with the slogan "Better Ingredients. Better Pizza."

Pizza Hut does not appear to contest the truthfulness of the underlying factual assertions made by Papa John's in the course of these ads. Pizza Hut argues, however, that its own independent taste tests and other "scientific evidence" establishes that filtered water makes no difference in pizza dough, that there is no "taste" difference between Papa John's "fresh-pack" sauce and Pizza Hut's "remanufactured" sauce, and that fresh dough is not superior to frozen dough. In response to Pizza Hut's "scientific evidence," Papa John's asserts that "each of these 'claims' involves a matter of common sense choice (fresh versus frozen, canned vegetables and fruit versus remanufactured paste, and filtered versus unfiltered water) about which individual consumers can and do form preferences every day without 'scientific' or 'expert' assistance."

In November 1997, Pizza Hut filed a complaint regarding Papa John's “Better Ingredients. Better Pizza." advertising campaign with the National Advertising Division of the Better Business Bureau, an industry self-regulatory body. This complaint, however, did not produce satisfactory results for Pizza Hut.

\section{$B$}

On August 12, 1998, Pizza Hut filed a civil action in the United States District Court for the Northern District of Texas charging Papa John's with false advertising in violation of Section 43(a)(1)(B) of the Lanham Act. The suit sought relief based on the above-described TV ad campaigns, as well as on some 249 print ads. On March 10, 1999, Pizza Hut filed an amended complaint. Papa John's answered the complaints by denying that its advertising and slogan violated the Lanham Act. Additionally, Papa John's asserted a counterclaim, charging Pizza Hut with engaging in false advertising. The parties consented to a jury trial before a United States magistrate judge. The parties further agreed that the liability issues were to be decided by the jury, while the equitable injunction claim and damages award were within the province of the court.

The trial began on October 26, 1999, and continued for over three weeks. At the close of Pizza Hut's case, and at the close of all evidence, Papa John's moved for a judgment as a matter of law. The motions were denied each time. The district court, without objection, submitted the liability issue to the jury through special interrogatories. The special issues submitted to the jury related to (1) the slogan and (2) over Papa John's objection, certain classes of groups of advertisements referred to as "sauce claims," "dough claims," "taste test claims," and "ingredients claims." 
On November 17, 1999, the jury returned its responses to the special issues finding that Papa John's slogan, and its "sauce claims" and "dough claims" were false or misleading and deceptive or likely to deceive consumers. The jury also determined that Papa John's "taste test" ads were not deceptive or likely to deceive consumers, and that Papa John's "ingredients claims" were not false or misleading. As to Papa John's counterclaims against Pizza Hut, the jury found that two of the three Pizza Hut television ads at issue were false or misleading and deceptive or likely to deceive consumers.

On January 3, 2000, the trial court, based upon the jury's verdict and the evidence presented by the parties in support of injunctive relief and on the issue of damages, entered a Final Judgment and issued a Memorandum Opinion and Order. The court concluded that the "Better Ingredients. Better Pizza." slogan was "consistent with the legal definition of non-actionable puffery" from its introduction in 1995 until May 1997. However, the slogan "became tainted . . . in light of the entirety of Papa John's post-May 1997 advertising." Based on this conclusion, the magistrate judge permanently enjoined Papa John's from "using any slogan in the future that constitutes a recognizable variation of the phrase 'Better Ingredients. Better Pizza.' or which uses the adjective 'Better' to modify the terms 'ingredients' and/or 'pizza'." Additionally, the court enjoined Papa John's from identifying Frank Carney as a co-founder of Pizza Hut, "unless such advertising includes a voice-over, printed statement or a superimposed message which states that Frank Carney has not been affiliated with Pizza Hut since 1980," and enjoined the dissemination of any advertising that was produced or disseminated prior to the date of this judgment and that explicitly or implicitly states or suggested that "Papa John's component is superior to the same component of Pizza Hut's pizzas." Finally, the court enjoined Papa John's from "explicitly or implicitly claim[ing] that a component of Papa John's pizza is superior to the same component of Pizza Hut's unless the superiority claim is supported by either (1) scientifically demonstrated attributes of superiority or (2) taste test surveys." Additionally, the injunction required that if the claim is supported by taste test surveys, the advertising shall include a printed statement, voice-over or "super," whichever is appropriate, stating the localities where the tests were conducted, the inclusive dates on which the surveys were performed, and the specific pizza products that were tested. The court also awarded Pizza Hut $\$ 467,619.75$ in damages for having to run corrective ads.

III 
"Although factfinders usually base literal falsity determinations upon the explicit claims made by an advertisement, they may also consider any claims the advertisement conveys by necessary implication. A claim is conveyed by necessary implication when, considering the advertisement in its entirety, the audience would recognize the claim as readily as if it had been explicitly stated. For instance, a factinder found that an advertisement that claimed a motor oil provided "longer engine life and better engine protection" without explicitly mentioning competitors nonetheless drew a comparison by necessary implication vis a vis those competitors." Clorox Co. P.R. v. Procter \& Gamble Commercial Co.228 F.3d 24 (1st Cir. 2000)
A prima facie case of false advertising under section 43(a) requires the plaintiff to establish:

(1) A false or misleading statement of fact about a product;

(2) Such statement either deceived, or had the capacity to deceive a substantial segment of potential consumers;

(3) The deception is material, in that it is likely to influence the consumer's purchasing decision;

(4) The product is in interstate commerce; and

(5) The plaintiff has been or is likely to be injured as a result of the statement at issue.

The failure to prove the existence of any element of the prima facie case is fatal to the plaintiff's claim.

$B$

The law governing false advertising claims under section 43(a) of the Lanham Act is well settled. In order to obtain monetary damages or equitable relief in the form of an injunction, a plaintiff must demonstrate that the commercial advertisement or promotion is either literally false, or that if the advertisement is not literally false it is likely to mislead and confuse consumers. If the statement is shown to be misleading, the plaintiff must also introduce evidence of the statement's impact on consumers, referred to as materiality.

(a)

Essential to any claim under section 43(a) of the Lanham Act is a determination of whether the challenged statement is one of fact actionable under section 43(a) - or one of general opinion - not actionable under section 43(a). Bald assertions of superiority or general statements of opinion cannot form the basis of Lanham Act liability. Rather the statements at issue must be a specific and measurable claim, capable of being proved false or of being reasonably interpreted as a statement of objective fact. A statement of fact is one that (1) admits of being adjudged true or false in a way that (2) admits of empirical verification.

(b)

One form of non-actionable statements of general opinion under section 43(a) of the Lanham Act has been referred to as "puffery." Puffery has been discussed at some length by other circuits. The Third Circuit has described "puffing" as "advertising that is not deceptive for no one would rely on its exaggerated claims." Similarly, the Ninth Circuit has defined "puffing" as "exaggerated advertising, 
blustering and boasting upon which no reasonable buyer would rely and is not actionable under 43(a)."

These definitions of puffery are consistent with the definitions provided by the leading commentaries in trademark law. A leading authority on unfair competition has defined "puffery" as an "exaggerated advertising, blustering, and boasting upon which no reasonable buyer would rely," or "a general claim of superiority over a comparative product that is so vague, it would be understood as a mere expression of opinion." McCarthy Similarly, Prosser and Keeton on Torts defines "puffing" as "a seller's privilege to lie his head off, so long as he says nothing specific, on the theory that no reasonable man would believe him, or that no reasonable man would be influenced by such talk."

Drawing guidance from the writings of our sister circuits and the leading commentators, we think that non-actionable "puffery" comes in at least two possible forms: (1) an exaggerated, blustering, and boasting statement upon which no reasonable buyer would be justified in relying; or (2) a general claim of superiority over comparable products that is so vague that it can be understood as nothing more than a mere expression of opinion.

(a)

With respect to materiality, when the statements of fact at issue are shown to be literally false, the plaintiff need not introduce evidence on the issue of the impact the statements had on consumers. In such a circumstance, the court will assume that the statements actually misled consumers. On the other hand, if the statements at issue are either ambiguous or true but misleading, the plaintiff must present evidence of actual deception. The plaintiff may not rely on the judge or the jury to determine, based solely upon their own intuitive reactions, whether the advertisement is deceptive. Instead, proof of actual deception requires proof that consumers were actually deceived by the defendant's ambiguous or true-but-misleading statements.

IV

We turn now to consider the case before us. Reduced to its essence, the question is whether the evidence, viewed in the most favorable light to Pizza Hut, established that Papa John's slogan "Better Ingredients. Better Pizza." is misleading and violative of section 43(a) of the Lanham Act. In making this determination, we will first consider

\footnotetext{
${ }^{7}$ McCarthy on Trademarks goes on to state: "Vague advertising claims that one's product is 'better' than that of competitors' can be dismissed as mere puffing that is not actionable as false advertising."
} 
the slogan "Better Ingredients. Better Pizza." standing alone to determine if it is a statement of fact capable of deceiving a substantial segment of the consuming public to which it was directed. Second, we will determine whether the evidence supports the district court's conclusion that after May 1997, the slogan was tainted, and therefore actionable, as a result of its use in a series of ads comparing specific ingredients used by Papa John's with the ingredients used by its "competitors."

The jury concluded that the slogan itself was a "false or misleading" statement of fact, and the district court enjoined its further use. Papa John's argues, however, that this statement "quite simply is not a statement of fact, [but] rather, a statement of belief or opinion, and an argumentative one at that." Papa John's asserts that because "a statement of fact is either true or false, it is susceptible to being proved or disproved. A statement of opinion or belief, on the other hand, conveys the speaker's state of mind, and even though it may be used to attempt to persuade the listener, it is a subjective communication that may be accepted or rejected, but not proven true or false." Papa John's contends that its slogan "Better Ingredients. Better Pizza." falls into the latter category, and because the phrases "better ingredients" and "better pizza" are not subject to quantifiable measures, the slogan is non-actionable puffery.

We will therefore consider whether the slogan standing alone constitutes a statement of fact under the Lanham Act. Bisecting the slogan "Better Ingredients. Better Pizza.," it is clear that the assertion by Papa John's that it makes a "Better Pizza." is a general statement of opinion regarding the superiority of its product over all others. This simple statement, "Better Pizza.," epitomizes the exaggerated advertising, blustering, and boasting by a manufacturer upon

Boston Beer Co.: 198 F.3d 1370 (Fed. Cir. 1999)

3D0: 1994 WL 723601 (N.D.Cal. 1994)

Nikkal: 735 F. Supp. 1227 (S.D.N.Y. 1990) which no consumer would reasonably rely. See, e.g., In re Boston Beer Co. (stating that the phrase "The Best Beer in America" was "trade puffery" and that such a general claim of superiority "should be freely available to all competitors in any given field to refer to their products or services"); Atari Corp. v. 3D0 Co. (stating that a manufacturer's slogan that its product was "the most advanced home gaming system in the universe" was non-actionable puffery); Nikkal Indus., Ltd. v. Salton, Inc. (stating that a manufacturers claim that its ice cream maker was "better" than competition ice cream makers is nonactionable puffery). Consequently, it appears indisputable that Papa John's assertion "Better Pizza." is non-actionable puffery.

\footnotetext{
${ }^{8}$ It should be noted that Pizza Hut uses the slogan "The Best Pizza Under One Roof." Similarly, other nationwide pizza chains employ slogans touting their pizza
} 
Moving next to consider separately the phrase "Better Ingredients.," the same conclusion holds true. Like "Better Pizza.," it is typical puffery. The word "better," when used in this context is unquantifiable. What makes one food ingredient "better" than another comparable ingredient, without further description, is wholly a matter of individual taste or preference not subject to scientific quantification. Indeed, it is difficult to think of any product, or any component of any product, to which the term "better," without more, is quantifiable. As our court stated in e Presidio Enterprises, Inc. v. Warner Brothers Distribution Corp.:

The law recognizes that a vendor is allowed some latitude in claiming merits of his wares by way of an opinion rather than an absolute guarantee, so long as he hews to the line of rectitude in matters of fact. Opinions are not only the lifestyle of democracy, they are the brag in advertising that has made for the wide dissemination of products that otherwise would never have reached the households of our citizens. If we were to accept the thesis set forth by the appellees, [that all statements by advertisers were statements of fact actionable under the Lanham Act,] the advertising industry would have to be liquidated in short order.

Thus, it is equally clear that Papa John's assertion that it uses "Better Ingredients." is one of opinion not actionable under the Lanham Act.

Finally, turning to the combination of the two non-actionable phrases as the slogan "Better Ingredients. Better Pizza.," we fail to see how the mere joining of these two statements of opinion could create an actionable statement of fact. Each half of the slogan amounts to little more than an exaggerated opinion of superiority that no consumer would be justified in relying upon. It has not been explained convincingly to us how the combination of the two phrases, without more, changes the essential nature of each phrase so as to make it actionable. We assume that "Better Ingredients." modifies "Better Pizza." and consequently gives some expanded meaning to the phrase "Better Pizza," i.e., our pizza is better because our ingredients are better. Nevertheless, the phrase fails to give "Better Pizza." any more quantifiable meaning. Stated differently, the adjective that continues to describe "pizza" is "better," a term that remains unquantifiable, especially when applied to the sense of taste. Consequently, the slogan as a whole is a statement of non-actionable opinion. Thus, there is no

as the "best": (1) Domino's Pizza uses the slogan "Nobody Delivers Better."; (2) Danato's uses the slogan "Best Pizza on the Block."; (3) Mr. Gatti's uses the slogan "Best Pizza in Town: Honest!"; and (4) Pizza Inn uses the slogans "Best Pizza Ever." and "The Best Tasting Pizza." 
legally sufficient basis to support the jury's finding that the slogan standing alone is a "false or misleading" statement of fact.

We next will consider whether the use of the slogan "Better Ingredients. Better Pizza." in connection with a series of comparative ads found by the jury to be misleading - specifically, ads comparing Papa John's sauce and dough with the sauce and dough of its competitors - "tainted" the statement of opinion and made it misleading under section 43(a) of the Lanham Act. Before reaching the ultimate question of whether the slogan is actionable under the Lanham Act, we will first examine the sufficiency of the evidence supporting the jury's conclusion that the comparison ads were misleading.

After the jury returned its verdict, Papa John's filed a post-verdict motion under Federal Rule of Civil Procedure 50 for a judgment as a matter of law. In denying Papa John's motion, the district court, while apparently recognizing that the slogan "Better Ingredients. Better Pizza." standing alone is non-actionable puffery under the Lanham Act, concluded that after May 1997, the slogan was transformed as a result of its use in connection with a series of ads that the jury found misleading. These ads had compared specific ingredients used by Papa John's with the ingredients used by its competitors. In essence, the district court held that the comparison ads in which the slogan appeared as the tag line gave objective, quantifiable, and fact-specific meaning to the slogan. Consequently, the court concluded that the slogan was misleading and actionable under section 43(a) of the Lanham Act and enjoined its further use.

We are obligated to accept the findings of the jury unless the facts point so overwhelmingly in favor of one party that no reasonable person could arrive at a different conclusion. In examining the record evidence, we must view it the way that is most favorable to upholding the verdict. Viewed in this light, it is clear that there is sufficient evidence to support the jury's conclusion that the sauce and dough ads were misleading statements of fact actionable under the Lanham Act.

Turning first to the sauce ads, the evidence establishes that despite the differences in the methods used to produce their competing sauces: (1) the primary ingredient in both Pizza Hut and Papa John's sauce is vine-ripened tomatoes; (2) at the point that the competing sauces are placed on the pizza, just prior to putting the pies into the oven for cooking, the consistency and water content of the sauces are 
essentially identical; and (3) as noted by the district court, at no time "prior to the close of the liability phase of trial was any credible evidence presented [by Papa John's] to demonstrate the existence of demonstrable differences" in the competing sauces. Consequently, the district court was correct in concluding that: "Without any scientific support or properly conducted taste preference test, by the written and/or oral negative connotations conveyed that pizza made from tomato paste concentrate is inferior to the 'fresh pack' method used by Papa John's, its sauce advertisements conveyed an impression which is misleading. . . ." Turning our focus to the dough ads, while the evidence clearly established that Papa John's and Pizza Hut employ different methods in making their pizza dough, again, the evidence established that there is no quantifiable difference between pizza dough produced through the "cold or slow-fermentation method" (used by Papa John's), or the "frozen dough method" (used by Pizza Hut). 10 Further, although there is some evidence indicating that the texture of the dough used by Papa John's and Pizza Hut is slightly different, this difference is not related to the manufacturing process used to produce the dough. Instead, it is due to a difference in the wheat used to make the dough. Finally, with respect to the differences in the pizza dough resulting from the use of filtered water as opposed to tap water, the evidence was sufficient for the jury to conclude that there is no quantifiable difference between dough produced with tap water, as opposed to dough produced with filtered water.

We should note again that Pizza Hut does not contest the truthfulness of the underlying factual assertions made by Papa John's in the course of the sauce and dough ads. Pizza Hut concedes that it uses "remanufactured" tomato sauce to make its pizza sauce, while Papa John's uses "fresh-pack." Further, in regard to the dough, Pizza Hut concedes the truth of the assertion that it uses tap water in making its pizza dough, which is often frozen, while Papa John's uses filtered water to make its dough, which is fresh - never frozen. Consequently, because Pizza Hut does not contest the factual basis of Papa John's factual assertions, such assertions cannot be found to be factually false, but only impliedly false or misleading.

Thus, we conclude by saying that although the ads were true about the ingredients Papa John's used, it is clear that there was sufficient evidence in the record to support the jury's conclusion that Papa John's sauce and dough ads were misleading - but not false - in their suggestion that Papa John's ingredients were superior.

\footnotetext{
${ }^{10}$ The testimony of Pizza Hut's expert, Dr. Faubion, established that although consumers stated a preference for fresh dough rather than frozen dough, when taste tests were conducted, respondents were unable to distinguish between pizza made on fresh as opposed to frozen dough.
} 


\section{(3)}

Thus, having concluded that the record supports a finding that the sauce and dough ads are misleading statements of fact, we must now determine whether the district court was correct in concluding that the use of the slogan "Better Ingredients. Better Pizza." in conjunction with these misleading ads gave quantifiable meaning to the slogan making a general statement of opinion misleading within the meaning of the Lanham Act.

In support of the district court's conclusion that the slogan was transformed, Pizza Hut argues that "in construing any advertising statement, the statement must be considered in the overall context in which it appears." Building on the foundation of this basic legal principle, Pizza Hut argues that " $\mathrm{t}]$ he context in which Papa John's slogan must be viewed is the $2 \frac{1}{2}$ year campaign during which its advertising served as 'chapters' to demonstrate the truth of the 'Better Ingredients. Better Pizza.' book." Pizza Hut argues, that because Papa John's gave consumers specific facts supporting its assertion that its sauce and dough are "better" - specific facts that the evidence, when viewed in the light most favorable to the verdict, are irrelevant in making a better pizza - Papa John's statement of opinion that it made a "Better Pizza" became misleading. In essence, Pizza Hut argues, that by using the slogan "Better Ingredients. Better Pizza." in combination with the ads comparing Papa John's sauce and dough with the sauce and dough of its competitions, Papa John's gave quantifiable meaning to the word "Better" rendering it actionable under section 43(a) of the Lanham Act.

We agree that the message communicated by the slogan "Better Ingredients. Better Pizza." is expanded and given additional meaning when it is used as the tag line in the misleading sauce and dough ads. The slogan, when used in combination with the comparison ads, gives consumers two fact-specific reasons why Papa John's ingredients are "better." Consequently, a reasonable consumer would understand the slogan, when considered in the context of the comparison ads, as conveying the following message: Papa John's uses "better ingredients," which produces a "better pizza" because Papa John's uses "fresh-pack" tomatoes, fresh dough, and filtered water. In short, Papa John's has given definition to the word "better." Thus, when the slogan is used in this context, it is no longer mere opinion, but rather takes on the characteristics of a statement of fact. When used in the context of the sauce and dough ads, the slogan is misleading for the same reasons we have earlier discussed in connection with the sauce and dough ads. 
Concluding that when the slogan was used as the tag line in the sauce and dough ads it became misleading, we must now determine whether reasonable consumers would have a tendency to rely on this misleading statement of fact in making their purchasing decisions. We conclude that Pizza Hut has failed to adduce evidence establishing that the misleading statement of fact conveyed by the ads and the slogan was material to the consumers to which the slogan was directed. Consequently, because such evidence of materiality is necessary to establish liability under the Lanham Act, the district court erred in denying Papa John's motion for judgment as a matter of law.

As previously discussed, none of the underlying facts supporting Papa John's claims of ingredient superiority made in connection with the slogan were literally false. Consequently, in order to satisfy its prima facie case, Pizza Hut was required to submit evidence establishing that the impliedly false or misleading statements were material to, that is, they had a tendency to influence the purchasing decisions of, the consumers to which they were directed.13 We conclude that the evidence proffered by Pizza Hut fails to make an adequate showing.

In its appellate brief and during the course of oral argument, Pizza Hut directs our attention to three items of evidence in the record that it asserts establishes materiality to consumers. First, Pizza Hut points to the results of a survey conducted by an "independent expert" (Dr. Dupont) regarding the use of the slogan "Better Ingredients. Better Pizza." as written on Papa John's pizza box (the box survey). The results of the box survey, however, were excluded by the district court. Consequently, these survey results provide no basis for the jury's finding.

Second, Pizza Hut points to two additional surveys conducted

\footnotetext{
${ }^{13}$ In Johnson E Johnson v. Smithkline Beecham Corp., 960 F.2d 294 (2d Cir. 1992), the Second Circuit discussed this requirement in some detail:

Where, as here, a plaintiff's theory of recovery is premised upon a claim of implied falsehood, a plaintiff must demonstrate, by extrinsic evidence, that the challenged commercials tend to mislead or confuse consumers. It is not for the judge to determine, based solely upon his or her own intuitive reaction whether the advertisement is deceptive. Rather, as we have reiterated in the past, "the question in such cases is - what does the person to whom the advertisement is addressed find to be the message?" That is, what does the public perceive the message to be.

The answer to this question is pivotal because, where the advertisement is literally true, it is often the only measure by which a court can determine whether a commercial's net communicative effect is misleading. Thus, the success of a plaintiff's implied falsity claim usually turns on the persuasiveness of a consumer survey.
}

Id. at 287-98. 
by Dr. Dupont that attempted to measure consumer perception of Papa John's "taste test" ads. This survey evidence, however, fails to address Pizza Hut's claim of materiality with respect to the slogan. Moreover, the jury rejected Pizza Hut's claims of deception with regard to Papa John's "taste test" ads - the very ads at issue in these surveys.

Finally, Pizza Hut attempts to rely on Papa John's own tracking studies and on the alleged subjective intent of Papa John's executives “to create a perception that Papa John's in fact uses better ingredients" to demonstrate materiality. Although Papa John's 1998 Awareness, Usage \& Attitude Tracking Study showed that $48 \%$ of the respondents believe that "Papa John's has better ingredients than other national pizza chains," the study failed to indicate whether the conclusions resulted from the advertisements at issue, or from personal eating experiences, or from a combination of both. Consequently, the results of this study are not reliable or probative to test whether the slogan was material. Further, Pizza Hut provides no precedent, and we are aware of none, that stands for the proposition that the subjective intent of the defendant's corporate executives to convey a particular message is evidence of the fact that consumers in fact relied on the message to make their purchases. Thus, this evidence does not address the ultimate issue of materiality.

In short, Pizza Hut has failed to offer probative evidence on whether the misleading facts conveyed by Papa John's through its slogan were material to consumers: that is to say, there is no evidence demonstrating that the slogan had the tendency to deceive consumers so as to affect their purchasing decisions. Thus, the district court erred in denying Papa John's motion for judgment as a matter of law.

\section{$\mathrm{V}$}

In sum, we hold that the slogan "Better Ingredients. Better Pizza." standing alone is not an objectifiable statement of fact upon which consumers would be justified in relying. Thus, it does not constitute a false or misleading statement of fact actionable under section 43(a) of the Lanham Act.

Additionally, while the slogan, when appearing in the context of some of the post-May 1997 comparative advertising - specifically, the sauce and dough campaigns - was given objectifiable meaning and thus became misleading and actionable, Pizza Hut has failed to adduce sufficient evidence establishing that the misleading facts conveyed by the slogan were material to the consumers to which it was directed. Thus, Pizza Hut failed to produce evidence of a Lanham Act violation. 
McNeil-PPC, Inc. v. Pfizer Inc.

In June 2004, defendant Pfizer Inc. ("Pfizer") launched a consumer advertising campaign for its mouthwash, Listerine Antiseptic Mouthrinse. Print ads and hang tags featured an image of a Listerine bottle balanced on a scale against a white container of dental floss.

The campaign also featured a television commercial called the "Big Bang." In its third version, which is still running, the commercial announces that "Listerine's as effective as floss at fighting plaque and gingivitis. Clinical studies prove it."

In this case, plaintiff McNeil-PPC, Inc. ("PPC"), the market leader in sales of string dental floss and other interdental cleaning products, alleges that Pfizer has engaged in false advertising in violation of $\S$ 43(a) of the Lanham Act and unfair competition in violation of state law.

Before the Court is PPC's motion for a preliminary injunction enjoining Pfizer from continuing to make these claims in its advertisements.

Pfizer sponsored two clinical studies involving Listerine and floss: the "Sharma Study" and the "Bauroth Study." These studies purported to compare the efficacy of Listerine against dental floss in controlling plaque and gingivitis in subjects with mild to moderate gingivitis.

In proving an advertising claim literally false, a plaintiff bears a different burden depending on whether the advertisement purports to be based on test results. Hence, where a defendant's advertisement contends that "clinical tests" prove the superiority of its product (an "establishment claim"), the plaintiff need only prove that the tests referred to were not sufficiently reliable to permit one to conclude with reasonable certainty that they established the proposition for which they were cited. On the other hand, where a superiority claim does not purport to rest on test results, the plaintiff may prove falsity only upon adducing evidence that affirmatively shows defendant's claim to be false.

Pfizer's advertisements make the explicit claim that "clinical studies prove that Listerine is as effective as floss against plaque and gingivitis." As Pfizer purports to rely on "clinical studies," this is an "establishment claim" and PPC need only prove that the studies referred to were not sufficiently reliable to permit one to conclude with reasonable certainty that they established the proposition for which they were cited. Two questions are presented: first, whether the Sharma and Bauroth Studies stand for the proposition that "Listerine is as effective as floss against plaque and gingivitis"; and second, assuming they do, whether the studies are sufficiently reliable to permit one to draw that conclusion with "reasonable certainty." 
First, even putting aside the issue of their reliability, the two studies do not stand for the proposition that "Listerine is as effective as floss against plaque and gingivitis." The two studies included in their samples only individuals with mild to moderate gingivitis. They excluded individuals with severe gingivitis or with any degree of periodontitis, and they did not purport to draw any conclusions with respect to these individuals. Hence, the literal claim in Pfizer's advertisements is overly broad, for the studies did not purport to prove that Listerine is as effective as floss "against plaque and gingivitis," but only against plaque and gingivitis in individuals with mild to moderate gingivitis. The advertisements do not specify that the "as effective as floss" claim is limited to individuals with mild to moderate gingivitis. Consequently, consumers who suffer from severe gingivitis or periodontitis (including mild periodontitis) may be misled by the ads into believing that Listerine is just as effective as floss in helping them fight plaque and gingivitis, when the studies simply do not stand for that proposition.

Second, the two studies were not sufficiently reliable to permit one to conclude with reasonable certainty that Listerine is as effective as floss in fighting plaque and gingivitis, even in individuals with mild to moderate gingivitis. What the two studies showed was that Listerine is as effective as floss when flossing is not done properly. The authors of both studies recognized that the plaque reductions in the flossing groups were lower than would be expected and hypothesized that "behavioral or technical causes" were the reason. Significantly, in some of the plaque reduction scores for the flossing groups there was greater improvement at three months than at six months, suggesting a deterioration in flossing technique with the passage of time.

Hence, the studies did not "prove" that Listerine is "as effective as floss." Rather, they proved only that Listerine is "as effective as improperly-used floss." The studies showed only that Listerine is as effective as floss when the flossing is not performed properly. As one of the ADA consultants observed in objecting to the advertising when it was proposed, "for a substitute product to be 'as good as' or 'better' than flossing it must be compared against the data of subjects who demonstrate they can and are flossing effectively."

Pfizer and its experts argue that the two studies are reliable, notwithstanding the indications that the participants in the flossing group did not floss properly, because these conditions reflect "realworld settings." But the ads do not say that "in the real world," where most people floss rarely or not at all and even those who do floss have difficulty flossing properly, Listerine is "as effective as floss." Rather, the ads make the blanket assertion that Listerine works just as well as floss, an assertion the two studies simply do not prove. Although 
it is important to determine how a product works in the real world, it is probably more important to first determine how a product will work when it is used properly.

Accordingly, I hold that PPC is likely to succeed on its claim of literal false advertisement.

\section{Satellite TV Problem}

This advertisement for DirecTV ran on the Internet; it was shown to customers in markets served by Time Warner Cable. Some of Time Warner's channels are analog; others are digital HD. DirecTV offers only digital HD channels. The parties agree that the HD channels are equivalent in quality. They also agree that the pixelated portions of the ads are not accurate depictions of cable TV signals, either digital or analog. Is the advertisement actionable?
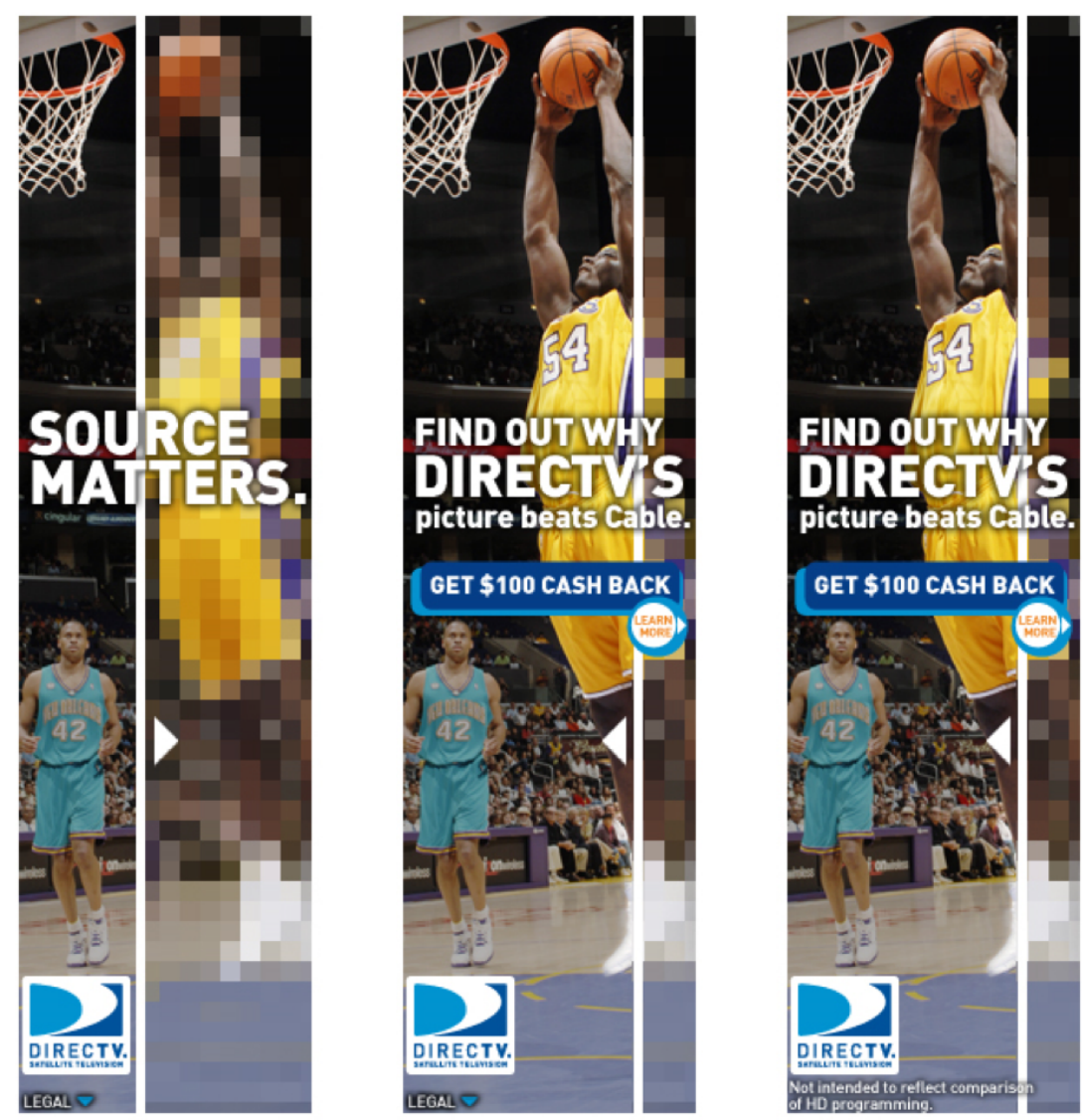


\section{Secondary Liability}

There's not a lot of caselaw on secondary liability for false advertising - but there is some.

\section{Duty Free Americas, Inc. v. Estee Lauder Companies, Inc.}

[DFA operates duty free stores in airports. It previously sold Estée Lauder cosmetics. DFA purchased those cosmetics at wholesale prices that were lower than the wholesale prices charged to traditional retailers, such as department stores. As a result, it was able to offer its customers lower retail prices. In 2007, Estée Lauder announced plans to eliminate the difference and move to a system with a single suggested retail price. As a result, DFA ended its relationship with Estée Lauder and devoted the shelf space to other products. Some of its competitors continued to sell Estée Lauder products and announced this fact to airport authorities during the bidding processes to operate duty-free concessions at airports in Newark, Boston, Orlando, and Atlanta. They also allegedly made various false statements about DFA. It sued Estée Lauder on a number of theories, including contributory false advertising.]

Whether $\S 43(\mathrm{a})$ of the Lanham Act includes within its ambit a claim for false advertising based on contributory liability is a question of first impression.

The rationale for allowing contributory trademark infringement actions supports recognizing a similar theory of liability in the false advertising context. For starters, § 43(a) of the Lanham Act contains two different classes of prohibitions: one banning trademark infringement and one prohibiting false advertising.

These prohibitions are found in the same statutory provision, and they share the same introductory clause. The placement of the two prohibitions in the same statutory section-and correspondingly, the fact that the introductory language banning both practices is identical-suggests the two causes of action should be interpreted to have the same scope.

Moreover, while the two causes of action are derived from the same principles and contained in the same statute, the Supreme Court has recognized that the false advertising provision of the Lanham Act entails broader protections. See POM Wonderful ("The Lanham Act's trademark provisions are the primary means of achieving [the statute's] ends. But the Act also creates a federal remedy [for false advertising] that goes beyond trademark protection. The broader remedy is at issue here."). It would be odd indeed for us to narrow the scope of the false advertising provision - a cause of action plainly intended to encompass a broader spectrum of protectionand hold that it could be enforced only against a smaller class of de- 
fendants. Absent congressional direction, we are reluctant to limit the statute's scope in this way. Thus, we hold that a plaintiff may bring a claim for contributory false advertising under $\S 43(\mathrm{a})$ of the Lanham Act.

What, then, must a plaintiff establish in order to state a contributory false advertising claim? First, the plaintiff must show that a third party in fact directly engaged in false advertising that injured the plaintiff. Second, the plaintiff must allege that the defendant contributed to that conduct either by knowingly inducing or causing the conduct, or by materially participating in it.

Once the plaintiff establishes the elements of a direct false advertising claim against a third party, it must allege that the defendant contributed to that conduct. This means that the plaintiff must allege that the defendant had the necessary state of mind - in other words that it intended to participate in or actually knew about the false advertising. The plaintiff must also allege that the defendant actively and materially furthered the unlawful conduct - either by inducing it, causing it, or in some other way working to bring it about.

Analogies from trademark infringement, in which contributory liability is more developed, can be instructive. Thus, for example, a plaintiff may be able to make out the participation prong of a contributory false advertising claim by alleging that the defendant directly controlled or monitored the third party's false advertising. It is also conceivable that there could be circumstances under which the provision of a necessary product or service, without which the false advertising would not be possible, could support a theory of contributory liability. In determining whether a plaintiff has adequately alleged facts to support such a claim, we look to whether the complaint suggests a plausible inference of knowing or intentional participation, examining the nature and extent of the communication" between the third party and the defendant regarding the false advertising; "whether or not the defendant explicitly or implicitly encouraged the false advertising; whether the false advertising is serious and widespread, making it more likely that the defendant knew about and condoned the acts; and whether the defendant engaged in bad faith refusal to exercise a clear contractual power to halt the false advertising.

The district court identified four allegedly false claims in the complaint, each of which was made by a duty free operator to representatives of an airport and each of which DFA says we should attribute to Estée Lauder. First, Nuance stated in a letter to Atlanta officials: "Given that Estée Lauder brands account for 20\% of cosmetic and fragrance sales, at least in Orlando, and cosmetic and fragrance sales constitute one of the largest sources of revenue for duty free stores, a lack of access to Estée Lauder brands would cast doubt on the validity 
of DFA's projected revenue streams." Second, Travel Retail told Orlando officials: "[W]e strongly believe that Estée Lauder is a product which you have to sell, also, to domestic passengers." Third, Nuance said during the Orlando appeal hearing: "With respect to DFA, I'd like to echo Travel Retail's concerns on DFA's rents. ... DFA sales project[ions] are deemed to be unreasonable and not sustainable in light of the history." Finally, Travel Retail informed the Orlando Airport Authority: "[F]ailure to offer the Estée Lauder product line will negatively impact duty free and duty paid sales revenue for both international and domestic travelers." DFA argues that it also alleged that Nuance, in its letter protesting the Atlanta award, stated "DFA may have made misrepresentations about its ability to carry Estée Lauder brands," and we agree that this is an allegedly false claim the district court failed to consider.

As for the first element, Estée Lauder claims that the duty free operators did not engage in any false advertising. Estée Lauder urges us to hold that DFA's complaint is devoid of any false or misleading statements cognizable under the Lanham Act, but we need not answer this fact-intensive question. We agree that DFA did not adequately allege Estée Lauder contributed to any of the statements, and thus affirm the district court's dismissal on this ground.

We are unable to find in DFA's complaint any facts that would enable the court to draw the reasonable inference that Estée Lauder induced or knowingly or intentionally participated in any of the allegedly false statements made by the other duty free operators. In its complaint, DFA based its claim for contributory liability on the fact that "[Estée Lauder] knew or should have known of the False Claims, but [it] continued to supply [Estée Lauder] product [s] to its favored duty free operators.... In doing so, [Estée Lauder] provided its favored duty free operators with the means to continue making the False Claims...." We cannot see how the mere sale of Estée Lauder products can serve as a basis for holding the manufacturer liable for any disparaging statements its customers make in the course of their own separate business relations. In our view, selling Estée Lauder products is too unrelated to the making of the allegedly false or misleading statements to form a basis for liability - under either an inducement or participation theory.

Moreover, contrary to DFA's argument, there are simply no facts in the complaint that suggest the existence of coordinated action or encouragement, much less inducement, between Estée Lauder and the operators on the decision to make the disputed claims to airport authorities. There has been no allegation that by selling its products to the duty free operators, Estée Lauder monitored, controlled, or participated in operators' statements to airport authorities during a competitive bidding process for which Estée Lauder was not even present. 
More generally, there are no facts to suggest that Estée Lauder commonly exercises any level of control over or involvement in the duty free operators' conduct during airport RFP bidding.

In short, although we agree with DFA that a plaintiff may state a claim against a defendant for contributory false advertising, we are unwilling to extend the doctrine as far as DFA urges. The mere sale of products in the course of an ordinary business relationship, without more, cannot justify a finding that a defendant induced, encouraged, caused, procured, or brought about false advertising. Contributory false advertising claims are cognizable under the Lanham Act, but a plaintiff must allege more than an ordinary business relationship between the defendant and the direct false advertiser in order to plausibly plead its claim. DFA has failed to do so here.

\section{B Alternatives to Competitor Suits}

Other models relax the Lanham Act standing rules in various ways. The Lanham Act generally only allows competing businesses to sue each other. But various speech torts permit businesses to sue for certain false statements by non-competitors. On the other side of the v, consumers and government agencies can sue businesses for certain false statements. In each case, the substantive rules of liability (especially the treatment of falsity) are tweaked to account for the different party configurations.

\section{Commercial Disparagement and Related Torts}

An unruly bundle of common-law torts try to protect individuals and businesses from injurious falsehoods. The following materials are not meant to be representative of this sprawling and doctrinally intricate mess, only to give another take on falsity and to illustrate the complete absence of anything resembling the competitor- or purchaserin-reliance- standing requirements.

\section{HipSaver, Inc. v. Kiel}

An action for commercial disparagement is similar in many respects to an action for defamation, but there are important differences. Both torts seek to impose liability on a defendant for harm sustained by a plaintiff as a result of the publication of a false statement about the plaintiff to others. A defamation action, which encompasses libel and slander, affords a remedy for damage to the reputation of the injured party. By comparison, an action for commercial disparagement affords a remedy for harm to the economic interests of the injured party that results in pecuniary loss. A plaintiff asserting such a claim seeks 
to recover damages for false disparaging statements about the plaintiff's property, often a product or service being sold.

This court adopted the language of the Restatement (Second) of Torts $\S 623 \mathrm{~A}$, regarding liability for commercial disparagement: "One who publishes a false statement harmful to the interests of another is subject to liability for pecuniary loss resulting to the other if (a) he intends for publication of the statement to result in harm to the interests of the other having a pecuniary value, or either recognizes or should recognize that it is likely to do so, and (b) he knows that the statement is false or acts in reckless disregard of its truth or falsity." Thus, in order to prevail on a claim alleging commercial disparagement, a plaintiff must prove that a defendant: (1) published a false statement to a person other than the plaintiff; (2) "of and concerning" the plaintiff's products or services; (3) with knowledge of the statement's falsity or with reckless disregard of its truth or falsity; (4) where pecuniary harm to the plaintiff's interests was intended or foreseeable; and (5) such publication resulted in special damages in the form of pecuniary loss.

\section{Aviation Charter, Inc. v. Aviation Research}

Aviation Charter, Inc. (Aviation Charter), appeals from the district court's grant of summary judgment to Aviation Research Group/US (ARGUS) on Aviation Charter's claims of defamation and alleged violations of the Minnesota Deceptive Trade Practices Act (MDTPA), and the Lanham Act

ARGUS publishes and sells safety ratings of air charter service providers. It bases its ratings on a methodology called the Charter Evaluation and Qualifications (CHEQ) system, which has "three major components: Historical Safety Ratings, Current Aircraft and Pilot Data, and On-Site Safety Audits." June 12, 2003, CHEQ Report on Aviation Charter. ARGUS maintains that it:

... conducts in-depth research into multiple public databases to uncover accidents, incidents, enforcement actions, and certification data relating to the operator. Records that are discovered are assigned a score based on the official cause, violation, or other data on record. Older records have less impact on the score and are omitted after

\footnotetext{
${ }^{7}$ Notwithstanding many similarities between the torts of commercial disparagement and defamation, it has been recognized that from the beginning, more stringent requirements were imposed upon the plaintiff seeking to recover for commercial disparagement in three important respects - falsity of the statement, fault of the defendant and proof of damage. For purposes of this opinion, we need not elaborate at length on these particular distinctions, other than to note that as the common law of defamation has become infused with principles of the First Amendment to the United States Constitution, these distinctions have narrowed.
} 
ten years. The total of all found records results in a Historical Safety Record score, with the higher score reflecting a greater number of negative events.

Carriers are grouped into four classes of operation based on the number of aircraft they operate. ARGUS assigns carriers one of four ratings: Does Not Qualify (DNQ), Silver, Gold, and Platinum. The Silver rating is assigned to "[t]hose operators with CHEQ scores within one standard deviation of the median score for their class of operation." The DNQ rating is the lowest possible rating.

In 2001, ARGUS assigned a DNQ rating to Aviation Charter. The following year, Senator Paul Wellstone and seven others died in an Aviation Charter crash. Following the Wellstone crash, the Minneapolis Star Tribune published an article entitled "Wellstone charter firm got poor safety evaluation." The Star Tribune article referred to ARGUS's report on Aviation Charter and quoted ARGUS's president, Joe Moeggenberg.

After the Star Tribune article was published, Aviation Charter contacted ARGUS and inquired about the basis of its rating. Aviation Charter concluded that ARGUS's rating system was fundamentally flawed and, when ARGUS refused to retract its rating, Aviation Charter initiated this lawsuit.

A.

A statement is defamatory under Minnesota law if it is communicated to a third party, is false, and tends to harm the plaintiff's reputation in the community. It is well recognized in Minnesota that the First Amendment absolutely protects opinion that lacks a provably false statement of fact. Statements about matters of public concern that are not capable of being proven true or false and statements that reasonably cannot be interpreted as stating facts are protected from defamation actions by the First Amendment.

We have characterized the balance of Aviation Charter's defamation claim as derivative of ARGUS's comparison that "Aviation Charter, relative to other carriers of its size, has an unfavorable safety record." We must examine whether this comparison is "sufficiently factual to be susceptible of being proved true or false." Milkovich If ARGUS had offered a wholly subjective basis for its conclusion, or even no basis whatsoever, then the comparison would likely have lacked objectively verifiable criteria. ARGUS, however, asserted that its comparative rating was derived from "multiple public databases to uncover accidents, incidents, enforcement actions, and certification data relating to the operator." Nonetheless, although ARGUS's comparison relies in part on objectively verifiable data, the interpretation of those data was ultimately a subjective assessment, not an 
Cf. Mayfair Farms, Inc. v. Socony Mobil Oil Co., Inc.172 A.2d 26 (N.J. Super. 1961) ("If the plaintiffs are convinced they deserve three stars or better and the defendants (through their editorial group) that two stars for Mayfair and one star for Pal's are enough, those are matters of judgment and opinion on which the court should not try to say that either party is right or wrong.") Should the same standard apply to restaurant reviews and aviation safety ratings?

Haynes: 8 F.3d 1222 (7th Cir.1993) objectively verifiable fact. ARGUS's description of its process illustrates the subjective component of its assessment:

Incidents are rated on a scale of 1-10. ARGUS has trained its analysts to follow general guidelines for the type of incident and severity of the action. The analysts then make independent judgments based on the information in the database regarding the report. They review the facts in the documents and can "hyper link" to the specific regulation that was violated. If they believe that a drastic variation from the computer assigned score is warranted, the three analysts can caucus and discuss the incident and draw on outside scores if necessary. The individual "scores" for each incident are then weighted so that the scores in the most recent 36 months are more significant than those that occurred more than three years ago. The weighted scores are added together and compared to like-sized carriers.

ARGUS chose which underlying data to prioritize, performed a subjective review of those data, and defined "safety" relative to its own methodology.

ARGUS's interpretation of the public database information available on Aviation Charter is not sufficiently factual to be susceptible of being proved true or false. It is a subjective interpretation of multiple objective data points leading to a subjective conclusion about aviation safety. Cf. . Haynes v. Alfred A. Knopf, Inc. ("A statement of fact is not shielded from an action for defamation by being prefaced with the words 'in my opinion,' but if it is plain that the speaker is expressing a subjective view, an interpretation, a theory, conjecture, or surmise, rather than claiming to be in possession of objectively verifiable facts, the statement is not actionable."). Because ARGUS's comparative rating is not a provably false statement of fact, Aviation Charter's defamation claim fails with respect to that rating and the derivative statements in the Star Tribune article.

$B$.

Aviation Charter asserts that ARGUS violated the Lanham Act because ARGUS's statements to the Star Tribune were made to advertise the fact that ARGUS was in the business of rating carriers like Aviation Charter. The Lanham Act requires that a false statement, in order to be actionable, must be made in commercial advertising or promotion. For a statement to constitute commercial advertising or promotion, it must be made, inter alia, by a defendant who is in commercial competition with the plaintiff. The district court correctly found that Aviation Charter's Lanham Act action failed because ARGUS was not in commercial competition with Aviation Charter. 
C.

The district court concluded that Aviation Charter's MDTPA action, like its Lanham Act action, failed because ARGUS was not in competition with Aviation Charter. As ARGUS concedes, however, the district court erred in so holding because the MDTPA provides that "a complainant need not prove competition between the parties."

The MDTPA provides that a person engages in a deceptive trade practice when, inter alia, the person "disparages the goods, services, or business of another by false or misleading representation of fact." As set forth above, ARGUS's statement that Aviation Charter had fifteen FAA enforcement actions was false. Accordingly, that statement would violate the MDTPA if it disparaged Aviation Charter. We conclude, however, that Aviation Charter cannot demonstrate that the statement disparaged its business, given the full context of the Star Tribune article.

\section{Consumer Suits}

Consumers can sometimes bring actions for common-law fraud or under state unfair-competition laws that provide for consumer suits. But these causes of action tend to have more stringent elements than competitor suits, and can be especially difficult to maintain on a classwide basis.

Perrine v. Sega of America, Inc.

In this consumer class action, plaintiff John Locke has moved for class certification and defendant Gearbox has moved for dismissal or judgment on the pleadings. The Court denies both motions.

The product at issue in this case is the video game "Aliens: Colonial Marines" ("ACM"). The game, developed by Gearbox Software, L.L.C. ("Gearbox") and produced by Sega of America, Inc. ("Sega"), was "held out as the canon sequel to James Cameron's 1986 film 'Aliens."' Named plaintiff John Locke is an "avid fan of the series" who pre-purchased a copy prior to its release. Damion Perrine, the other named plaintiff, is also a "fan of the Aliens franchise," and purchased a copy of the game on its release date, February 13, 2013.

The complaint alleges a "classic bait-and-switch." Plaintiffs allege that defendants developed a "non-retail but technically superior version" of the game that featured, among other things, "advanced artificial intelligence programming, certain gameplay sequences drawn from the Aliens movie," and "a highly advanced graphics engine (the 'Demo Engine')," and presented this version and described it to the public as "actual gameplay." The retail version that was ultimately sold, however, allegedly "utilized different programming altogether and a different-and much less advanced-graphics engine." The
Minn.Stat. § 325D.44, subd. 2.

No. 13-cv-01962-JD, 2015 WL 2227846 (N.D. Cal. May 12, 2015) 
complaint alleges that because of these differences, videogame industry critics expressed "disappointment and surprise" following the public release of the game, and that even Randy Pitchford, President of Gearbox, "acknowledged the discrepancy between the Aliens: Colonial Marines hands-off demo and the final game." On this basis, the complaint asserts six claims for relief: (1) violation of the Consumer Legal Remedies Act, Cal. Civil Code § 1750 ("CLRA"); (2) violation of the Unfair Competition Law, Cal. Bus. \& Prof.Code $\S$ 17200 ("UCL"); (3) violation of the False Advertising Law, Cal. Bus. \& Prof.Code § 17500 ("FAL"); (4) breach of express warranties; (5) fraud in the inducement; and (6) negligent misrepresentation.

As an initial matter, the proposed class as framed by the complaint - "all persons in the United States who paid for a copy of the Aliens: Colonial Marines video game either on or before February 12, 2013" - is not certifiable. At a minimum, common questions of fact would not predominate in the class as defined by the complaint; rather, individualized. And while it is true that "class members do not need to demonstrate individualized reliance" for plaintiff's claims under the UCL and FAL, even for those claims, a presumption of reliance does not arise when class members were exposed to quite disparate information from various representatives of the defendant. For the presumption to apply, it is necessary for everyone in the class to have viewed the allegedly misleading advertising. Plaintiff's original definition makes no attempt to limit the class to those who were exposed to the allegedly misleading advertising here, and consequently it is overbroad and not certifiable.

The obviousness of these principles is underscored by the fact that plaintiff rapidly retreated at the hearing to "limit the class to people who viewed an advertisement." Plaintiff proposed to do this "by affidavit and claim form." The Court directed the parties to submit supplemental briefs on this issue, namely "whether the Court can and should certify a class allowing class membership to be established by assertion of the class members by way of, e.g., affidavits swearing that a consumer viewed a certain video or trailer prior to placing a pre-order for the game at issue."

The parties responded, and the Court now concludes that the answer to its question is no. The problem with plaintiff's suggestion is that the revised class lacks ascertainability. Ascertainability is an important requirement because it is needed for properly enforcing the preclusive effect of final judgment. The class definition must be clear in its applicability so that it will be clear later on whose rights are merged into the judgment, that is, who gets the benefit of any relief and who gets the burden of any loss.

The factual record in the case shows why ascertainability is a pipe dream here. As the complaint acknowledges, this is not a case about 
a single misrepresentation. Rather, the non-retail version of the ACM game is alleged to have been presented to the public "through a series of 'actual gameplay' demonstrations." The first demonstration is alleged to have occurred "at the annual 'E3' conference in early June 2011." At the hearing, plaintiff explained that the ad campaign at issue "started at the E3 2011 conference and concluded ... right before the release date [of the game in] February of 2013."

It is undisputed in the record that many trailers and commercials were released during that time period, primarily via the Internet but also through television. It is further undisputed that several videos for ACM shown before the game's release contain footage from only the final retail version, rather than from the alleged non-retail version. When pressed at the hearing to identify which specific videos or trailers included the allegedly problematic E3 2011 video or portions of it, plaintiff's counsel answered that he could not "say with certainty which ones" and that he "just [didn't] have the information." Counsel added, ineffectually, that it does not "matter that each and every video didn't have a specific scene from the 2011 reenactment," because the E3 2011 video "was accessible through this time period" and remains so today. And Mr. Locke, the only named plaintiff moving for class certification and seeking appointment as a class representative, compounded the ascertainability problem by testifying in deposition that he could not "answer ... with any degree of certainty" a question regarding which videos he saw before he preordered his copy of the game.

These facts distinguish this case from others in which selfidentification through affidavits was found to be permissible, and places it in the camp of cases where such a proposal failed for lack of ascertainability. As was the case in Xavier, there is "no good way to identify" individuals who "have been exposed to Defendants' atissue advertising before February 12, 2003 - the day that all ACM preorders were made 'final."' Putting aside the fact that plaintiff has failed to carry his burden of identifying which videos and trailers actually comprise defendants' "at-issue advertising" here, there is no good way to identify which purchasers viewed which videos prior to purchasing the game. Certainly, defendants have no records of who viewed what when, and plaintiff has not identified any documentbased method of identifying this information. Instead, plaintiff's suggestion is to permit class members to self-identify through the submission of affidavits, but those affidavits would be highly unreliable and likely to embody the "subjective memory problem" that was found to exist in Xavier v. Philip Morris USA Inc.. As Judge Alsup noted in that case, "[s]wearing 'I smoked 146,000 Marlboro cigarettes' is categorically different from swearing 'I have been to Paris, France,' or 'I am Jewish,' or even 'I was within ten miles of the toxic explosion

Xavier: 787 F. Supp. 2d 1075 (N.D.Cal. 2011) 
on the day it happened," and the "memory problem is compounded by incentives individuals would have to associate with a successful class or dissociate from an unsuccessful one."

The reality of this memory problem is beyond meaningful dispute. One of the two named plaintiffs here has already admitted under oath that he cannot identify "with any degree of certainty" which videos he saw before he placed his pre-order of the game at issue. The other named plaintiff, who no longer seeks to be a class representative but whose testimony is relevant nevertheless, also testified under oath that he could "not with certainty" remember all the videos he saw for Aliens: Colonial Marines. He further affirmed that there were "no records or no way for you to be able to recreate all of the different videos or demonstrations you may have seen for the game."

On this record, the Court finds that "persons who viewed an advertisement for ACM incorporating the Demoed Version," cannot be identified through any reliable and manageable means, and that the proposed class lacks ascertainability.

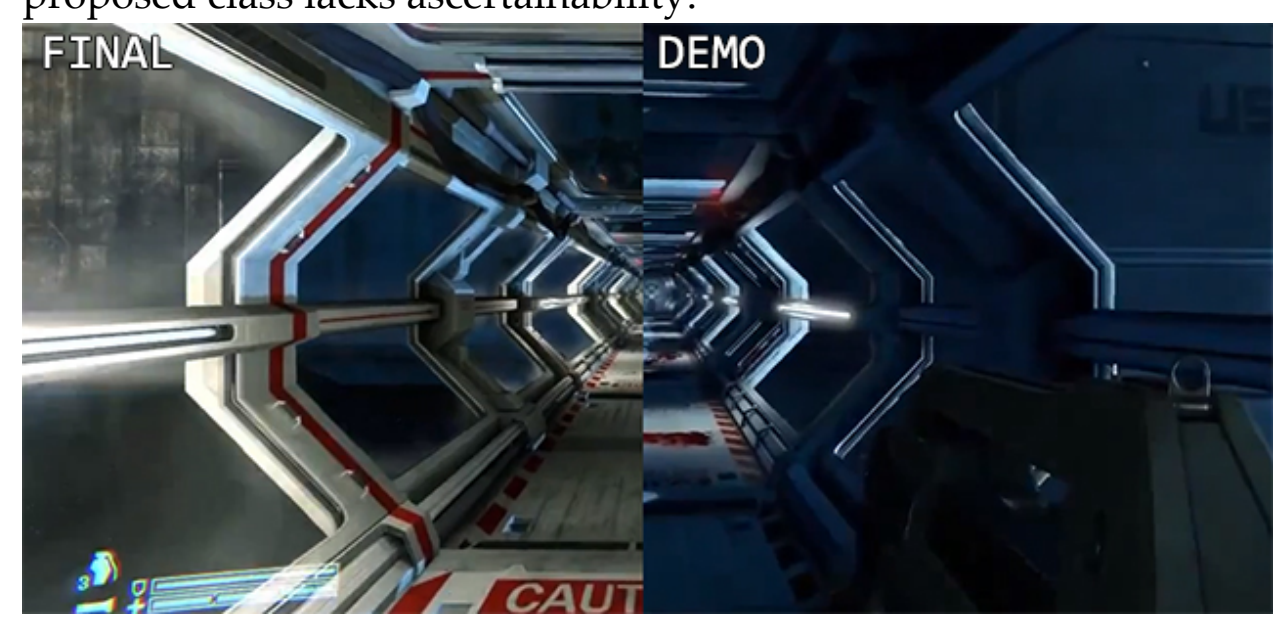

\section{FTC Enforcement}

Section 5 of the Federal Trade Commission Act authorizes the FTC to prevent "unfair or deceptive acts or practices in or affecting commerce." In some respects, this authority parallels the tests applied to competitor suits under the Lanham Act. In other respects, it is broader. State law often also provides for public enforcement by state officials, typically state attorneys general. (We will not discuss these "Baby FTC Acts" further here, other than to note their nickname.)

\section{Federal Trade Commission v. Winsted Hosiery Company}

The Winsted Hosiery Company has for many years manufactured underwear which it sells to retailers throughout the United States. It brands or labels the cartons in which the underwear is sold, as "Nat- 
ural Merino", "Gray Wool", "Natural Wool", "Natural Worsted", or "Australian Wool". None of this underwear is all wool. Much of it contains only a small percentage of wool; some as little as ten per cent. The Federal Trade Commission instituted a complaint under $\S 5$, and called upon the company to show cause why use of these brands and labels alleged to be false and deceptive should not be discontinued.

It is contended that the method of competition complained of is not unfair within the meaning of the act, because labels such as the Winsted Company employs, and particularly those bearing the word "Merino", have long been established in the trade and are generally understood by it as indicating goods partly of cotton; that the trade is not deceived by them; that there was no unfair competition for which another manufacturer of underwear could maintain a suit against the Winsted Company; and that even if consumers are misled because they do not understand the trade signification of the label or because some retailers deliberately deceive them as to its meaning, the result is in no way legally connected with unfair competition.

This argument appears to have prevailed with the Court of Appeals; but it is unsound. The labels in question are literally false, and, except those which bear the word "Merino", are palpably so. All are, as the Commission found, calculated to deceive and do in fact deceive a substantial portion of the purchasing public. That deception is due primarily to the words of the labels, and not to deliberate deception by the retailers from whom the consumer purchases. While it is true that a secondary meaning of the word "Merino" is shown, it is not a meaning so thoroughly established that the description which the label carries has ceased to deceive the public; for even buyers for retailers, and sales people, are found to have been misled. The facts show that it is to the interest of the public that a proceeding to stop the practice be brought. And they show also that the practice constitutes an unfair method of competition as against manufacturers of all wool knit underwear and as against those manufacturers of mixed wool and cotton underwear who brand their product truthfully. For when misbranded goods attract customers by means of the fraud which they perpetrate, trade is diverted from the producer of truthfully marked goods. That these honest manufacturers might protect their trade by also resorting to deceptive labels is no defense to this proceeding brought against the Winsted Company in the public interest.

The fact that misrepresentation and misdescription have become so common in the knit underwear trade that most dealers no longer accept labels at their face value, does not prevent their use being an unfair method of competition. A method inherently unfair does not cease to be so because those competed against have become aware of the wrongful practice. Nor does it cease to be unfair because the fal-
Would any of these "honest manufacturers" have had a private cause of action against Winsted? Note the date of the opinion 
sity of the manufacturer's representation has become so well known to the trade that dealers, as distinguished from consumers, are no longer deceived. The honest manufacturer's business may suffer, not merely through a competitor's deceiving his direct customer, the retailer, but also through the competitor's putting into the hands of the retailer an unlawful instrument, which enables the retailer to increase his own sales of the dishonest goods, thereby lessening the market for the honest product. As a substantial part of the public was still misled by the use of the labels which the Winsted Company employed, the public had an interest in stopping the practice as wrongful; and since the business of its trade rivals who marked their goods truthfully was necessarily affected by that practice, the Commission was justified in its conclusion that the practice constituted an unfair method of competition; and it was authorized to order that the practice be discontinued.

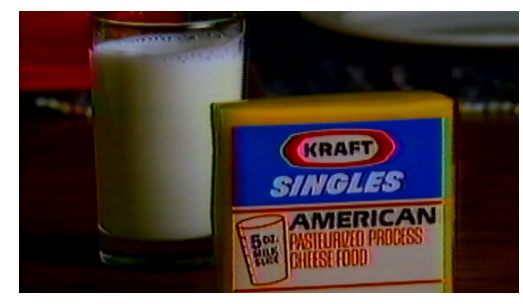

\section{Kraft, Inc. v. FTC}

[Kraft Singles were classified as "processed cheese": part cheese and part other ingredients. To differentiate them from "imitation cheese" slices, which contain little or no cheese, Kraft advertised its Singles as having "five ounces of milk" per slice and emphasized their calcium content. But $30 \%$ of the calcium in the milk in Kraft Singles was lost during processing.]

In determining what claims are conveyed by a challenged advertisement, the Commission relies on two sources of information: its own viewing of the ad and extrinsic evidence. Its practice is to view the ad first and, if it is unable on its own to determine with confidence what claims are conveyed in a challenged ad, to turn to extrinsic evidence. The most convincing extrinsic evidence is a survey of what consumers thought upon reading the advertisement in question, but the Commission also relies on other forms of extrinsic evidence including consumer testimony, expert opinion, and copy tests of ads.

Kraft has no quarrel with this approach when it comes to determining whether an ad conveys express claims, but contends that the FTC should be required, as a matter of law, to rely on extrinsic evidence rather than its own subjective analysis in all cases involving allegedly implied claims. The basis for this argument is that implied claims, by definition, are not self-evident from the face of an ad. This, combined with the fact that consumer perceptions are shaped by a host of external variables - including their social and educational backgrounds, the environment in which they view the ad, and prior experiences with the product advertised - makes review of implied claims by a five-member commission inherently unreliable.

Kraft buttresses its argument by pointing to the use of extrinsic evidence in an analogous context: cases brought under $\S 43(\mathrm{a})$ of the 
Lanham Act. Courts hearing deceptive advertising claims under that Act, which provides a private right of action for deceptive advertising, generally require extrinsic proof that an advertisement conveys an implied claim. Were this a Lanham Act case, a reviewing court in all likelihood would have relied on extrinsic evidence of consumer perceptions. While this disparity is sometimes justified on grounds of advertising "expertise" - the FTC presumably possesses more of it than courts - Kraft maintains this justification is an illusory one in that the FTC has no special expertise in discerning consumer perceptions. While Kraft's arguments may have some force as a matter of policy, they are unavailing as a matter of law. Courts, including the Supreme Court, have uniformly rejected imposing such a requirement on the FTC, FTC v. Colgate-Palmolive Co. (FTC not required to conduct consumer surveys before determining that a commercial has a tendency to mislead), and we decline to do so as well. We hold that the Commission may rely on its own reasoned analysis to determine what claims, including implied ones, are conveyed in a challenged advertisement, so long as those claims are reasonably clear from the face of the advertisement.

The Commission's expertise in deceptive advertising cases, Kraft's protestations notwithstanding, undoubtedly exceeds that of courts as a general matter. That false advertising cases constitute a small percentage of the FTC's overall workload does not negate the fact that significant resources are devoted to such cases in absolute terms, nor does it account for the institutional expertise the FTC gains through investigations, rulemakings, and consent orders.

We find substantial evidence in the record to support the FTC's finding. Although Kraft downplays the nexus in the ads between milk and calcium, the ads emphasize visually and verbally that five ounces of milk go into a slice of Kraft Singles; this image is linked to calcium content, strongly implying that the consumer gets the calcium found in five ounces of milk.

Kraft asserts that the literal truth of the Class Picture ads - they are made from five ounces of milk and they do have a high concentration of calcium - makes it illogical to render a finding of consumer deception. The difficulty with this argument is that even literally true statements can have misleading implications. Here, the average consumer is not likely to know that much of the calcium in five ounces of milk (30\%) is lost in processing, which leaves consumers with a misleading impression about calcium content. The critical fact is not that reasonable consumers might believe that a $3 / 4$ ounce slice of cheese actually contains five ounces of milk, but that reasonable consumers might believe that a $3 / 4$ ounce slice actually contains the calcium in five ounces of milk. 


\section{Letter from Federal Trade Commission to Microsoft Corp. and Starcom} MediaVest Group

Dear Counsel:

As you know, the staff of the Federal Trade Commission's Northwest Region has conducted an investigation into whether Microsoft Cmporation and its advertising agency, Starcom MediaVest Group ("Starcom"), violated Section 5 of the Federal Trade Commission Act, 15 U.S.C. $\S 45$, in connection with the promotion of Xbox One video game consoles and certain Microsoft video game titles.

Our inquiry focused on an advertising campaign conducted by Machinima, Inc., in late 2013 at the request of Starcom, acting on behalf of Microsoft.

As part of that advertising campaign, Machinima, a multi-channel network on YouTube, paid several of its network partners (video bloggers known as "influencers") significant amounts of money to produce and upload Xbox One gameplay videos. The videos, which were posted to YouTube in the days immediately prior to and after the launch of the Xbox One, were intended to generate buzz around and drive sales of the newly released Xbox One and the Microsoft video game titles.

At Machinima's direction, the influencers spoke favorably of the Xbox One and the game titles in their videos.

The videos were uploaded by the influencers to their individual YouTube channels, where they appeared to be independently produced by, and to reflect the personal views of, the influencers.

Machinima did not require the influencers to disclose in their videos that they were being compensated for producing and uploading the videos, and when the videos were uploaded, many (if not most) of the influencers failed to make any kind of disclosure.

Section 5 of the FTC Act requires the disclosure of a material connection between an advertiser and an endorser when such a relationship is not apparent from the context of the communication that contains the endorsement. In this case, the payment of significant sums to video bloggers to post specific content promoting the Xbox One and Microsoft's game titles is a material connection that would not be reasonably expected by YouTube viewers. As the advertiser, Microsoft bears responsibility for the influencers' failure to disclose such material connections. Starcom, as Microsoft's agent and the advertising agency that managed the relationship with Machinima, also bears responsibility for the influencers' failure to disclose.

However, upon careful review of this matter, including nonpublic information submitted to the FTC, we have determined not to recommend enforcement action against Microsoft or Starcom at this time. We considered several factors in reaching this decision.

The failures to disclose here appear to be isolated incidents that oc- 
curred in spite of, and not in the absence of, policies and procedures designed to prevent such lapses. Microsoft had a robust compliance program in place when the Xbox One campaign was launched, including specific legal and marketing guidelines concerning the FTC's Endorsement Guides and relevant training made available to employees, vendors and Starcom personnel. Since the Xbox One campaign, Microsoft and Starcom have adopted additional safeguards regarding sponsored endorsements, and they have committed to, among other steps, specifically requiring their employees to monitor influencer campaigns conducted by subcontractors in the future. In addition, Microsoft and Starcom took swift action to require that Machinima insert disclosures into the campaign videos once they learned that Machinima had paid the influencer and that no disclosures had been made.

Our decision not to pursue enforcement action is not to be construed as a determination that a violation may not have occurred, just as the pendency of an investigation should not be construed as a determination that a violation has occurred. The Commission reserves the right to take further action as the public interest may warrant.

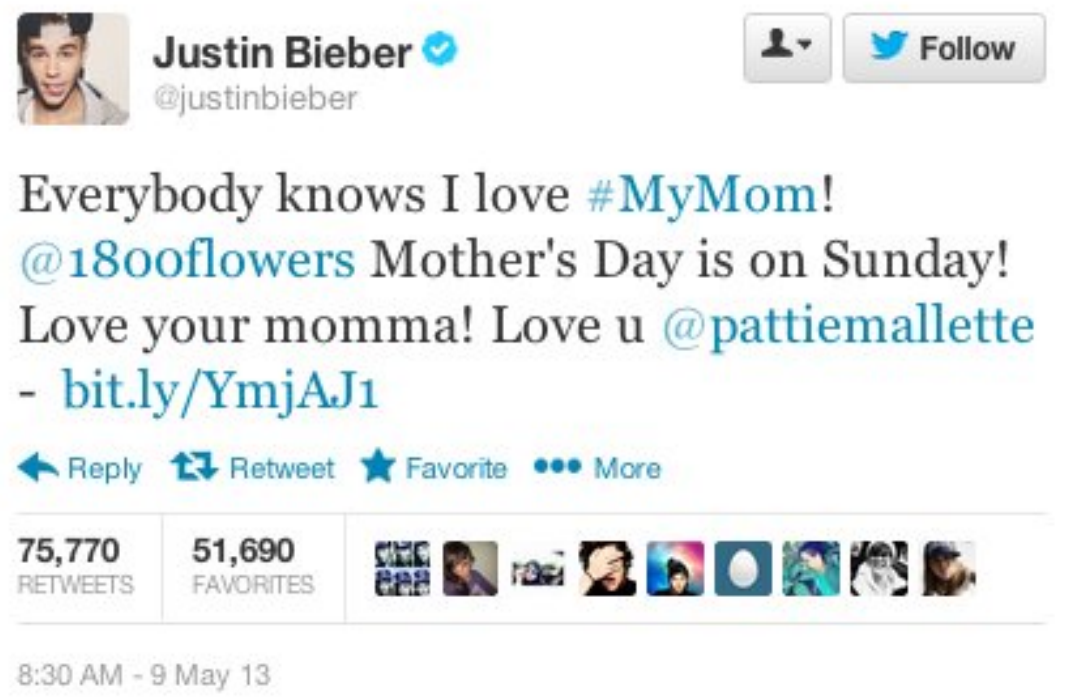

See also 16 C.F.R. pt. 255 ("Guides Concerning the Use of Endorsements and Testimonials in Advertising"); Federal Trade Commission, .com Disclosures: How to Make Effective Disclosures in Digital Advertising (Mar. 2013). In addition to disclosure, endorsements can also raise falsity and substantiation issues about the endorser's experience with the product - and endorsement claims without the endorser's permission can raise $\S 43$ (a) false-endorsement and right of publicity issues. 


\section{Other Sources of Advertising Law}

\section{Trademark}

In a sense, trademark law treats consumer understandings - i.e. secondary meaning and goodwill - as a source of truth. A trademark refers to its owner's goods or services; using it to refer to something else is false as a matter of law. But in another, more accurate sense, trademark law defers to consumer understandings only so long as the mark owner is not using them to deceive. Arbitrary trademarks like APPLE for computers are acceptable only because no one really thinks the computers are made of apples.

\section{Lanham Act}

15 U.S.C. § 1052 [Lanham Act § 2] Trademarks registrable on principal register...

857 F.2d 773 (Fed. Cir. 1988)

Automatic Radio: 404 F.2d 1391 (CCPA 1969)
No trademark ... shall be refused registration on the principal register on account of its nature unless it-

(a) Consists of or comprises ... deceptive ... matter; ...

(e) Consists of a mark which (1) when used on or in connection with the goods of the applicant is merely ... deceptively misdescriptive of them ....

\section{In re Budge Mfg. Co.}

Budge Manufacturing Co., Inc., appeals from the final decision of the United States Trademark Trial and Appeal Board refusing registration of LOVEE LAMB for "automotive seat covers," application Serial No. 507,974 filed November 9,1984 . The basis for rejection is that the term LAMB is deceptive matter within the meaning of section 2(a) of the Lanham Act as applied to Budge's goods which are made wholly from synthetic fibers. We affirm.

Section 2(a) of the Lanham Act bars registration of a mark which: "Consists of or comprises ... deceptive ... matter...." As stated in In re Automatic Radio Mfg. Co.: "The proscription [of section 2(a)] is not against misdescriptive terms unless they are also deceptive." Thus, that a mark or part of a mark may be inapt or misdescriptive as applied to an applicant's goods does not make it "deceptive." Id.(AUTOMATIC RADIO not a deceptive mark for air conditioners, ignition systems, and antennas).

Where the issue relates to deceptive misdescriptiveness within the meaning of 2(a), we are in general agreement with the standard set out by the board:

(1) Is the term misdescriptive of the character, quality, function, composition or use of the goods? 
(2) If so, are prospective purchasers likely to believe that the misdescription actually describes the goods?

(3) If so, is the misdescription likely to affect the decision to purchase?

In ex parte prosecution, the burden is initially on the Patent and Trademark Office (PTO) to put forth sufficient evidence that the mark for which registration is sought meets the above criteria of unregistrability. Mindful that the PTO has limited facilities for acquiring evidence - it cannot, for example, be expected to conduct a survey of the marketplace or obtain consumer affidavits - we conclude that the evidence of record here is sufficient to establish a prima facie case of deceptiveness. That evidence shows with respect to the three-pronged test:

(1) Budge admits that its seat covers are not made from lamb or sheep products. Thus, the term LAMB is misdescriptive of its goods.

(2) Seat covers for various vehicles can be and are made from natural lambskin and sheepskin. Applicant itself makes automobile seat covers of natural sheepskin. Lambskin is defined, inter alia, as fine-grade sheep skin. The board's factual inference is reasonable that purchasers are likely to believe automobile seat covers denominated by the term LAMB or SHEEP are actually made from natural sheep or lamb skins.

(3) Evidence of record shows that natural sheepskin and lambskin is more expensive than simulated skins and that natural and synthetic skins have different characteristics. Thus, the misrepresentation is likely to affect the decision to purchase.

Faced with this prima facie case against registration, Budge had the burden to come forward with countering evidence to overcome the rejection. It wholly failed to do so.

Budge argues that its use of LAMB as part of its mark is not misdescriptive when considered in connection with the text in its advertising, which states that the cover is of "simulated sheepskin."

We conclude that the board properly discounted Budge's advertising and labeling which indicate the actual fabric content. Misdescriptiveness of a term may be negated by its meaning in the context of the whole mark inasmuch as the combination is seen together and makes a unitary impression. A.F. Gallun \& Sons Corp. v. Aristocrat Leather Prods., Inc. (COPY CALF not misdescriptive, but rather suggests imitation of calf skin). The same is not true with respect to explanatory statements in advertising or on labels which purchasers may or may not note and which may or may not always be provided. The statutory provision bars registration of a mark comprising deceptive mat- 
ter. Congress has said that the advantages of registration may not be extended to a mark which deceives the public. Thus, the mark standing alone must pass muster, for that is what the applicant seeks to register, not extraneous explanatory statements.

Budge next argues that no reasonable purchaser would expect to purchase lambskin automobile seat covers because none made of lambskin are on the market. Only sheepskin automobile seat covers are being made, per Budge. Not only was no evidence submitted on the point Budge seeks to make, only statements of Budge's attorney, but also the argument is without substance. The board properly equated sheepskin and lambskin based on the dictionary definition which indicates that the terms may be used interchangeably. In addition, while Budge would discount the evidence presented that bicycle and airline seat coverings are made of lambskin, we conclude that it does support the board's finding that there is nothing incongruous about automobile seat covers being made from lambskin. We also agree with the board's conclusion that any differences between sheepskin and lambskin would not be readily apparent to potential purchasers of automobile seat covers. The board's finding here that purchasers are likely to believe the misrepresentation is not clearly erroneous.

Finally, we note the evidence of Budge's extensive sales since 1974 under the mark. However, it is too well established for argument that a mark which includes deceptive matter is barred from registration and cannot acquire distinctiveness.

None of the facts found by the board have been shown to be clearly erroneous nor has the board erred as a matter of law. Accordingly, we affirm the board's decision that Budge's mark LOVEE LAMB for automobile seat covers made from synthetic fibers is deceptive and is, thus, barred from registration.

\section{Certifications}

Certifications come in various forms. We start with Lanham Act certification marks (like the Fair Trade mark) because they draw heavily from trademark law. There are also government-administered certifications, some of which are mandatory (like the FCC's equipment labeling rules) and some of which are voluntary (like the USDA's food-grading certifications).

\section{Lanham Act}

15 U.S.C. § 1127 [Lanham Act § 45] Construction and definitions; intent of chapter
The term "certification mark" means any word, name, symbol, or device, or any combination thereof-

(1) used by a person other than its owner, or 
(2) which its owner has a bona fide intention to permit a person other than the owner to use in commerce and files an application to register on the principal register established by this [Act], to certify regional or other origin, material, mode of manufacture, quality, accuracy, or other characteristics of such person's goods or services or that the work or labor on the goods or services was performed by members of a union or other organization.

\section{Trademark Manual of Examining Procedure}

... Based on the statute, there are generally three types of certification marks, that is, those that certify:

1. Geographic origin. Certification marks may be used to certify that authorized users' goods or services originate in a specific geographic region (e.g., SUNSHINE TREE for citrus from Florida).

2. Standards met with respect to quality, materials, or mode of manufacture. Certification marks may be used to certify that authorized users' goods or services meet certain standards in relation to quality, materials, or mode of manufacture (e.g., approval by Underwriters Laboratories) (UL certifies, among other things, representative samplings of electrical equipment meeting certain safety standards).

3. Work/labor performed by member or that worker meets certain standards. Certification marks may also be used to certify that authorized users' work or labor on the products or services was performed by a member of a union or other organization, or that the performer meets certain standards.

A certification mark may not be used, in the trademark sense of "used," by the owner of the mark; it may be used only by a person or persons other than the owner of the mark. That is, the owner of a certification mark does not apply the mark to his or her goods or services and, in fact, usually does not attach or apply the mark at all. The mark is generally applied by other persons to their goods or services, with authorization from the owner of the mark.

The owner of a certification mark does not produce the goods or perform the services in connection with which the mark is used, and thus does not control their nature and quality. Therefore, it is not appropriate to inquire about control over the nature and quality of the goods or services. What the owner of the certification mark does control is use of the mark by others on their goods or services. This control consists of taking steps to ensure that the mark is applied only to goods or services that contain the characteristics or meet the re-
$\S 1306.1$

Types of Certification Marks

§ 1306.01 (a)

Use Is by Person Other than Owner of Certification Mark 
$\S 1306.01$ (b)

Purpose Is to Certify, Not to Indicate Source

Version 1.11 (2014)

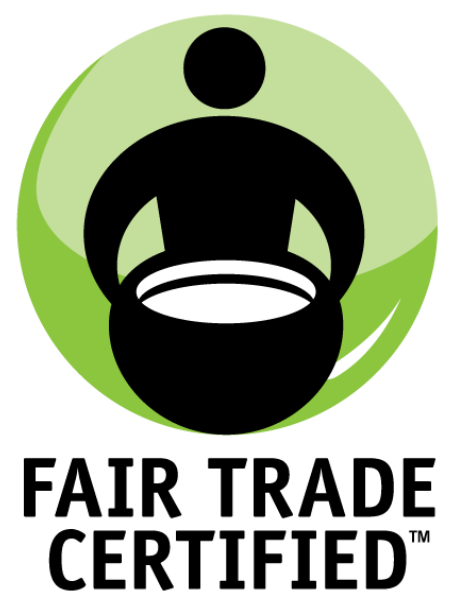

Fair Trade Certified certification mark quirements that the certifier/owner has established or adopted for the certification.

A certification mark is a special creature created for a purpose uniquely different from that of an ordinary service mark or trademark That is, the purpose of a certification mark is to inform purchasers that the goods or services of a person possess certain characteristics or meet certain qualifications or standards established by another person. A certification mark does not indicate origin in a single commercial or proprietary source the way a trademark or service mark does. Rather, the same certification mark is used on the goods or services of many different producers.

The message conveyed by a certification mark is that the goods or services have been examined, tested, inspected, or in some way checked by a person who is not their producer, using methods determined by the certifier/owner. The placing of the mark on goods, or its use in connection with services, thus constitutes a certification by someone other than the producer that the prescribed characteristics or qualifications of the certifier for those goods or services have been met.

\section{Fair Trade USA Farm Workers Standard}

The Fair Trade USA Farm Workers Standard takes a development approach in that it differentiates between minimum criteria and progress criteria. Minimum criteria are assessed during the first certification audit and represent minimum practices in social empowerment, economic development, and environmental responsibility. These criteria are met prior to initial certification. Progress criteria are fulfilled after the first year of certification and represent continuous development towards increased social empowerment and economic development as well as best practices in environmental responsibility. ...

ED-CE 1 Conditions of employment, including wages, either meet or exceed the following standards: sector regulations, Collective Bargaining Agreements that are in place with the employer, the regional average minimum wage, and official minimum wages for similar occupations. The employer specifies wages for all functions. ...

ED-CE 20 If the company provides the workers with housing, the conditions and the infrastructure of the house must be such as to ensure sanitation, safety, ventilation, reasonable protection from heat and cold, privacy and security. Housing must be provided at reasonable cost. Fire extinguishers are provided and workers should be trained on how to use them. ...

SR-ND 1 There is no discrimination, particularly on the basis of race, color, gender, sexual orientation, disability, marital status, family 
obligations, age, religion, political opinion, union or worker's representative bodies or Fair Trade Committee membership, national extraction or social origin or any other condition that could give rise to discrimination, in: recruitment, promotion, access to training, remuneration, allocation of work, termination of employment, retirement or other activities. ...

ES-AC 1 Materials on the red list (prohibited materials) on the Fair Trade USA Prohibited Materials List (see annex 1) are not used or otherwise sold, handled, or distributed by the company.

ES-AC 2 The decision to use herbicides is based on the presence of weeds and lack of alternative controls. If used, herbicides are only one element of an integrated strategy against weeds, and are only used in spot applications. ...

\section{Special Price and Premium Terms \\ Produce - Banana}

At FOB level, prices include the costs for the following packing material:

- standard carton box,

- one plastic per carton box (banavac or polypack),

- pallet,

- edge corners,

- strips,

- up to 3 labels per banana hand

The costs for these standard packing and palletization materials are covered by the exporter. However, the service related to packing (labor costs) of above defined standard packing material is included in the Ex Works prices and provided by the producer. Neither the Ex Works nor the FOB prices include costs for additional or special packing materials such as "clusterbags" or "parafilm" and related services. Costs for those packing materials and any associated labor must be paid on top of the Fair Trade Minimum Prices to producers at Ex Works or FOB level and be defined in the contract. Fair Trade Minimum Prices in any case refer to $18.14 \mathrm{~kg}$ of ripened fruit. If boxes with different weight are used, Fair Trade Minimum Prices and Fair Trade Premiums are calculated pro rata.

\section{Understanding the FCC Regulations for Low-Power, Non-Licensed Transmitter}

Low-power, non-licensed transmitters are used virtually everywhere. Cordless phones, baby monitors, garage door openers, wireless home security systems, keyless automobile entry systems and hundreds of
Federal Communications Commission Office of Engineering and Technology Bulleting No. 63 (1993) 
So-called because they comply with the rules in 47 C.F.R. pt. 15.

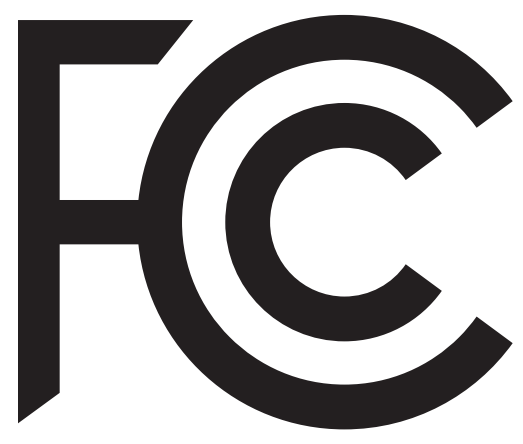

Required FCC logo

U.S. Department of Agriculture Food Safety \& Inspection Service fact sheet (last modified June 3, 2014)

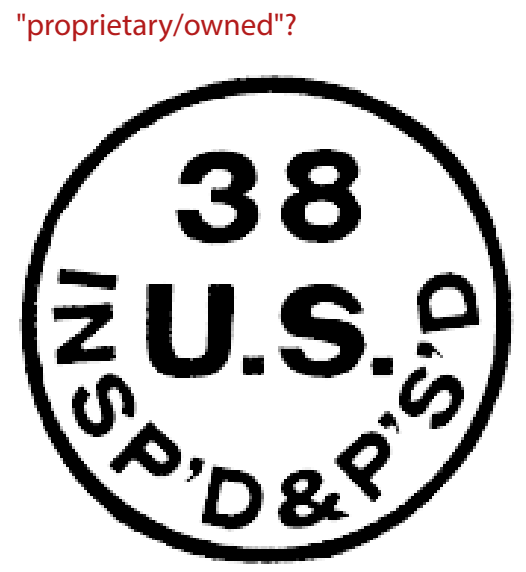

USDA inspected mark other types of common electronic equipment rely on such transmitters to function. At any time of day, most people are within a few meters of consumer products that use low-power, non-licensed transmitters. Part 15 transmitters use very little power, most of them less than a milliwatt. They are "non-licensed" because their operators are not required to obtain a license from the FCC to use them.

The Federal Communications Commission (FCC) has rules to limit the potential for harmful interference to licensed transmitters by low-power, non-licensed transmitters. The certification procedure requires that tests be performed to measure the levels of radio frequency energy that are radiated by the device into the open air or conducted by the device onto the power lines. results, and some additional information about the device including design drawings.

Certified transmitters also are required to have two labels attached: an FCC ID label and a compliance label. The FCC ID label identifies the FCC equipment authorization file that is associated with the transmitter, and serves as an indication to consumers that the transmitter has been authorized by the FCC. The compliance label indicates to consumers that the transmitter was authorized under Part 15 of the FCC rules and that it may not cause, nor is it protected from, harmful interference.

\section{Inspection \& Grading of Meat and Poultry: What Are the Differences?} The inspection and grading of meat and poultry are two separate programs within the U.S. Department of Agriculture (USDA). Inspection for wholesomeness is mandatory and is paid for with public funds. Grading for quality is voluntary, and the service is requested and paid for by meat and poultry producers/processors.

Meat that has been federally inspected and passed for wholesomeness is stamped with a round purple mark. The dye used to stamp the grade and inspection marks onto a meat carcass is made from a food-grade vegetable dye and is not harmful. (The exact formula is proprietary/owned by the maker of the dye.) The mark is put on carcasses and major cuts. After trimming, the mark might not appear on retail cuts such as roasts and steaks. However, meat that is packaged in an inspected facility will have an inspection mark which identifies the plant on the label.

After meat and poultry are inspected for wholesomeness, producers and processors may request that they have products graded for quality by a licensed Federal grader. The USDA's Agricultural Marketing Service (http://www.ams.usda.gov) is the agency responsible for grading meat and poultry. Those who request grading must pay for the service. Grading for quality means the evaluation of traits related to tenderness, juiciness, and flavor of meat; and, for poultry, a normal shape that is fully fleshed and meaty and free of defects. 
USDA grades are based on nationally uniform Federal standards of quality. No matter where or when a consumer purchases graded meat or poultry, it must have met the same grade criteria. The grade is stamped on the carcass or side of beef and is usually not visible on retail cuts. However, retail packages of beef, as well as poultry, will show the U.S. grade mark if they have been officially graded.

The grade symbol and wording are no longer copyrighted; however, according to the Truth in Labeling Law, it is illegal to mislead or misrepresent the shield or wording.

Quality Grades:

- Prime grade is produced from young, well-fed beef cattle. It has abundant marbling and is generally sold in restaurants and hotels. Prime roasts and steaks are excellent for dry-heat cooking (broiling, roasting, or grilling).

- Choice grade is high quality, but has less marbling than Prime. Choice roasts and steaks from the loin and rib will be very tender, juicy, and flavorful and are, like Prime, suited to dry-heat cooking. Many of the less tender cuts, such as those from the rump, round, and blade chuck, can also be cooked with dry heat if not overcooked. Such cuts will be most tender if "braised" roasted, or simmered with a small amount of liquid in a tightly covered pan.

- Select grade is very uniform in quality and normally leaner than the higher grades. It is fairly tender, but, because it has less marbling, it may lack some of the juiciness and flavor of the higher grades. Only the tender cuts (loin, rib, sirloin) should be cooked with dry heat. Other cuts should be marinated before cooking or braised to obtain maximum tenderness and flavor.

- Standard and Commercial grades are frequently sold as ungraded or as "store brand" meat.

- Utility, Cutter, and Canner grades are seldom, if ever, sold at retail but are used instead to make ground beef and processed products.

\section{Geographic Indications}

Some countries have sui generis systems for protecting geographical indications. The United States mostly does not; we protect them primarily - but not exclusively - with trademarks and certification marks.

Justin Hughes

Champagne, Feta, and Bourbon -- The Spirited Debate About

Geographical Indications

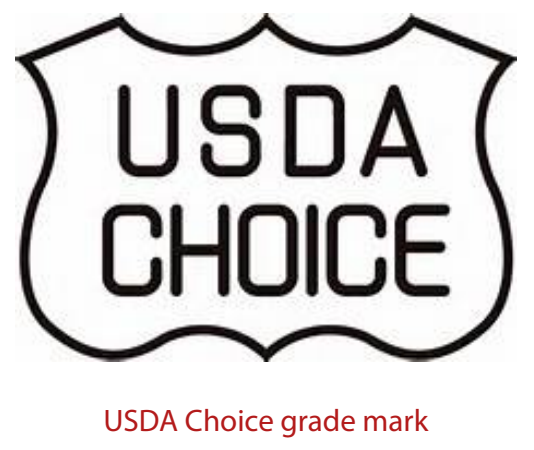

"copyrighted"? 
The French system of appellations d'origine contrôlées (AOC) is founded on the idea of terroir. Terroir has no direct English translation, but the notion behind the Latinate word is simple: the product's qualities come with the territory. As one Australian wine critic describes it: 'terroir . . . translates roughly as 'the vine's environment[,]' but has connotations that extend right into the glass: in other words, if a wine tastes of somewhere, if the flavours distinctly make you think of a particular place on the surface of this globe, then that wine is expressing its terroir."

Beliefs about terroir run deep in France, but not too deep, for if they did there might not be a justification for the elaborate regulatory structure governing production of AOC foodstuffs. The INAO regulates not just the geographic boundaries for each AOC, but all "conditions of production," including, for wine, the grape varietals, hectare production quotas, natural alcohol content during vinification, permitted irrigation, etc. The Institut National des Appellations d'Origine (INAO) regulations for AOC cheese place varying legal requirements on rennet used in coagulation, curd drainage, milk temperature at different points in curing, salting, and the use of lactic proteins.

In contrast to a separate system for protecting appellations, some countries, like the United States, subsume protection of geographical indications under trademark law. This is achieved through the categories of "certification marks" and "collective marks." ...

Geographical words in product names (that is, labeling and advertising) have three basic purposes. These are (1) to communicate geographic source, (2) to communicate (non- geographic) product qualities, and (3) to create evocative value. The first of these is simple. "Industria Argentina" or "Made in England" communicate a product's geographic origins. Second, geographic words are often used to communicate product characteristics other than geographic origin. This second use often leads to the geographic words becoming "generic." The word loses its geographic meaning and acquires another meaning based on non-geographic qualities of the product, as when people go into a restaurant chinois off the Champs-Elysées or, nine time zones away, Californians order French fries with their hamburger.

A third, more overlooked, category for use of geographical words in product names is their use for evocative and aesthetic purposes. These are typically uses of words which, in American trademark doctrine, would be "fanciful" or "arbitrary." The evocative value of geographic words is most evident with geographic names of fictional or no-longer existent places: ATLANTIS waterproofing services, POMPEII game machines, 23 and SHANGRI-LA hotels.

Armed with this framework, we will see that the classical justification for geographical indications is that they serve a special combina- 
tion of (1) and (2): to communicate a product's geographical source and non-geographic qualities of the product that are related to its geographic origin. This is the idea of terroir: that the particular geography produces particular product characteristics that cannot be imitated by other regions. The idea of terroir undergirds the European Union claim for stronger protection of geographical indications. This concept helps justify the European Union's demand, since 2004, for the "return" of over forty words that have become generic names for foodstuffs in other countries (e.g., Parmesan cheese, Champagne, Chablis, Gorgonzola cheese, Parma ham, etc.). Although terroir and a claim for a unique communications function for geographical indications is the European Union's public rhetoric, this Article concludes that the European Commission has a simpler goal: control of geographic words for their evocative value in the marketplace. The monopoly rents available from exclusive control of this evocative value drive the EU position in the debates over geographical indications.

Trade-Related Aspects of Intellectual Property (TRIPS), Uruguay Round Agreement (1991)

1. Geographical indications are, for the purposes of this Agreement, indications which identify a good as originating in the territory of a Member, or a region or locality in that territory, where a given quality, reputation or other characteristic of the good is essentially attributable to its geographical origin.

2. In respect of geographical indications, Members shall provide the legal means for interested parties to prevent:

(a) the use of any means in the designation or presentation of a good that indicates or suggests that the good in question originates in a geographical area other than the true place of origin in a manner which misleads the public as to the geographical origin of the good;

(b) any use which constitutes an act of unfair competition within the meaning of Article 10bis of the Paris Convention (1967) [i.e., "in the course of trade is liable to mislead the public as to the nature, the manufacturing process, the characteristics, the suitability for their purpose, or the quantity, of the goods"]

3. A Member shall, ex officio if its legislation so permits or at the request of an interested party, refuse or invalidate the registration of a trademark which contains or consists of a geographical indication with respect to goods not originating in the territory indicated, if use of the indication in the trademark for such goods in that Member is of such a nature as to mislead the public as to
Art. 22

Protection of Geographical Indications 
Art. 23

Additional Protection for Geographical Indications for Wines and Spirits

Art. 24

International Negotiations, Exceptions

15 U.S.C. § 1052 [Lanham Act § 2] Trademarks registrable on principal register... the true place of origin.

1. Each Member shall provide the legal means for interested parties to prevent use of a geographical indication identifying wines for wines not originating in the place indicated by the geographical indication in question or identifying spirits for spirits not originating in the place indicated by the geographical indication in question, even where the true origin of the goods is indicated or the geographical indication is used in translation or accompanied by expressions such as "kind", "type", "style", "imitation" or the like.

2. The registration of a trademark for wines which contains or consists of a geographical indication identifying wines or for spirits which contains or consists of a geographical indication identifying spirits shall be refused or invalidated, ex officio if a Member's legislation so permits or at the request of an interested party, with respect to such wines or spirits not having this origin.

6. Nothing in this Section shall require a Member to apply its provisions in respect of a geographical indication of any other Member with respect to goods or services for which the relevant indication is identical with the term customary in common language as the common name for such goods or services in the territory of that Member. ...

\section{Lanham Act}

No trademark ... shall be refused registration on the principal register on account of its nature unless it-

(a) Consists of or comprises ... a geographical indication which, when used on or in connection with wines or spirits, identifies a place other than the origin of the goods ...

(e) Consists of a mark which ... (2) when used on or in connection with the goods of the applicant is primarily geographically descriptive of them, except as indications of regional origin may be registrable under section 1054 of this title [pertaining to collective marks and certification marks], (3) when used on or in connection with the goods of the applicant is primarily geographically deceptively misdescriptive of them, ... . 


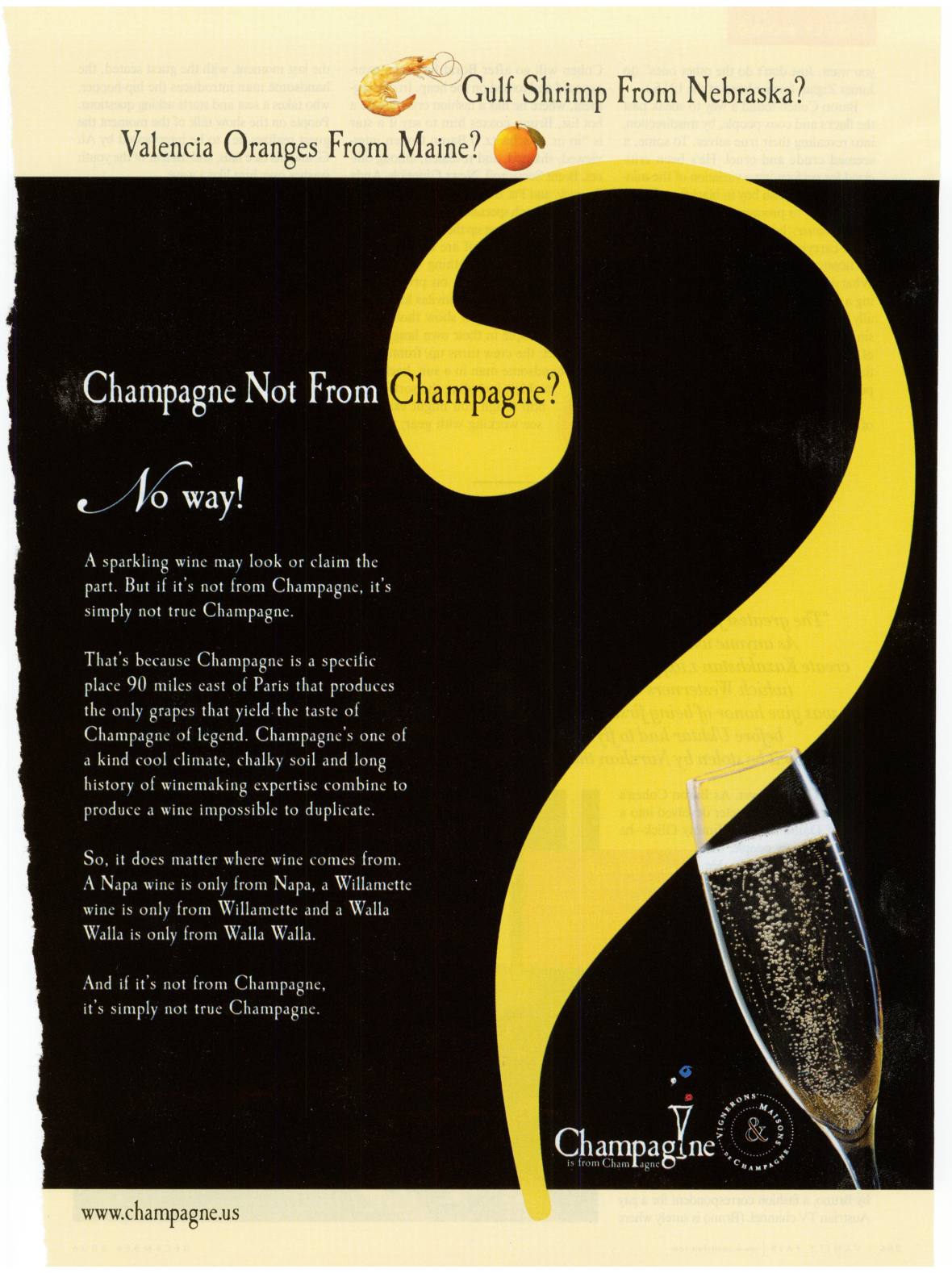

Guantanamera Cigar Co. v. Corporacion Habanos

This case comes before the Court on cross motions for summary judgment filed by plaintiff Guantanamera Cigar Company's ("GCC") and defendant Corporacion Habanos, S.A. ("Habanos"). Upon reviewing the motions, the Court concludes that the Trademark Trial and Appeal Board ("TTAB") erred as a matter of law in applying the three-part test for primarily geographically deceptively misdescriptive marks, which are barred from registration by the Lanham Act, 15 U.S.C. $§ 1052(e)(3)$. Therefore, the Court grants the plaintiff's motion for summary judgment. 


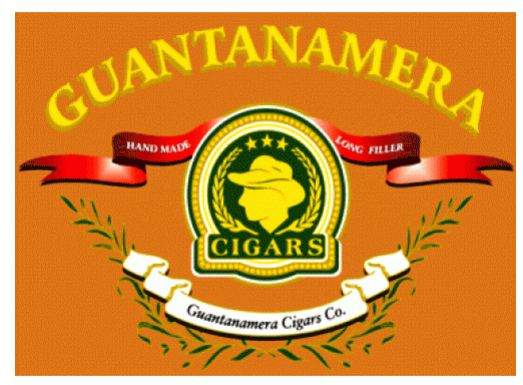

GCC's GUANTANAMERA logo

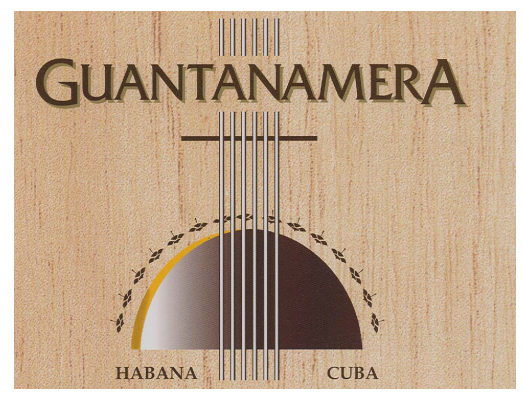

Habanos's GUANTANAMERA logo

California Innovations: 329 F.3d 1334 (Fed. Cir. 2003)

\section{FACTUAL BACKGROUND}

GCC is a small company based in Coral Gables, Florida. GCC manufactures cigars in Honduras from non-Cuban seeds, then sells and distributes them mainly in the Miami area, as well as other parts of the United States. GCC filed a trademark application for the mark GUANTANAMERA for use in connection with cigars on May, 14, 2001. When translated, "guantanamera" means "(i) the female adjectival form of GUANTANAMO, meaning having to do with or belonging to the city or province of Guantanamo, Cuba; and/or (ii) a woman from the city or province of Guantanamo, Cuba." Many people are also familiar with the Cuban folk song, Guantanamera, which was originally recorded in 1966.

Habanos, jointly owned by the Cuban government and a Spanish entity, manufactures cigars. The Cuban embargo prohibits Habanos from exporting cigars into the U.S. Habanos, however, owns trademarks on many cigar brands outside the U.S., including registrations or applications for GUANTANAMERA in more than 100 countries in the world. On December 29, 1998, Habanos applied for the mark in Cuba, and registered the mark on March 13, 2001. Habanos applied for a U.S. Trademark on April 15, 2002, but its application remains suspended because of GCC's prior application.

Shortly after the TTAB published GCC's application, Habanos filed an opposition, which asserted that GUANTANAMERA was primarily geographically deceptively misdescriptive, and therefore barred from registration. The TTAB agreed and found that GUANTANAMERA was primarily geographically deceptively misdescriptive and that Habanos had standing to oppose registration.

\section{Discussion}

The TTAB improperly denied registration of GUANTANAMERA for cigars because it used an incorrect legal standard. The TTAB must deny registration of marks "which when used on or in connection with the goods of the applicant is primarily geographically deceptively misdescriptive of them." 15 U.S.C. $\$ 1052(\mathrm{e})(3)$. A mark is "primarily geographically deceptively misdescriptive" when:

(1) the primary significance of the mark is a generally known geographic location, (2) the consuming public is likely to believe the place identified by the mark indicates the origin of the goods bearing the mark, when in fact the goods do not come from that place, and (3) the misrepresentation was a material factor in the consumer's decision.

In re California Innovations, Inc.. The TTAB cited the proper legal standard, but erred in its application of the third part. The Court reviews 
the three parts of the test-geographic location, goods-place association, and materiality - as applied by the TTAB.

\section{a. Geographic Location}

There is significant evidence in the record to find that Cuba or Guantanamo, Cuba is the primary significance of GUANTANAMERA. The primary significance of a mark is a finding of fact. Guantanamera literally means "girl from Guantanamo." The Plaintiff argues that the primary meaning of GUANTANAMERA is the famous Cuban song by Joseito Fernandez. The TTAB recognized that the folk song's history reinforces the geographic connection to Guantanamo and Cuba. Based on the deferential standard of review, the Court finds that the Plaintiff produced insufficient evidence to disturb the TTAB's factual finding that GUANTANAMERA's primary significance is a geographic location.

\section{b. Goods-Place Association}

There is sufficient evidence to find that the consuming public is likely to believe that the Plaintiff's cigars originate from Cuba. If consumers are likely to believe that the place identified on the mark is the origin of the goods, when in fact the goods do not come from that place, the element is satisfied. See also In re Spirits International N.V. (leaving the TTAB's analysis of the goods-place association unaltered when the TTAB found that Moscow was well known for vodka). The Federal Circuit characterized this element as a "relatively easy burden of showing a naked goods-place association."

The record contains ample evidence that cigar tobacco is produced in the Guantanamo province. There is also ample evidence to support the finding that Cuba is well-known for cigars. The TTAB did not err in finding that the goods-place association was met.

\section{c. Materiality}

The TTAB erred as a matter of law in its analysis of materiality. To establish a prima facie case, the TTAB or the opposition must show that a significant portion of the relevant consumers would be materially influenced in the decision to purchase the product or service by the geographic meaning of the mark. Accordingly, the Court holds that Habanos never established a prima facie case for the third part of the test before the TTAB.

In Spirits, the TTAB refused to register the mark MOSKOVSKAYA for vodka because it was primarily geographically deceptively misdescriptive. MOSKOVSKAYA literally means "of or from Moscow," but the registrant admitted that the vodka is not manufactured, produced, or sold in Moscow and has no connection to Moscow. The TTAB found that the primary significance of the mark was a gen- 
erally known geographic location and recognized that Moscow is renowned for vodka. Thus, the first two elements of the test were satisfied. The Court took issue with the TTAB's application of the third element, the materiality requirement.

The TTAB reasoned that because 706,000 people in the United States speak Russian, and because 706,000 is "an appreciable number," the materiality requirement was satisfied. The Court remanded the case without ruling on the merits because the TTAB failed to consider whether Russia speakers were a "substantial portion" of the intended audience. The Court noted that only $0.25 \%$ of the U.S. population speaks Russian. To satisfy the materiality requirement, a substantial portion of relevant consumers must be likely to be deceived, not an absolute number or particular segment (such as foreign language speakers).

Here, the TTAB erred as a matter of law in applying the materiality requirement. The TTAB decided this case before the Federal Circuit decided Spirits. The portion of the TTAB's opinion that addressed the materiality factor was only four sentences and did not make any findings regarding a "substantial proportion" of materially deceived consumers. The TTAB stated two reasons why the misrepresentation is material in the minds of consumers: (1) Cuba's "renown and reputation for high quality cigars" and (2) the plaintiff's subjective intent to deceive customers evidenced by previously placing "Guantanamera, Cuba" and "Genuine Cuban Tobacco" on the packaging.

Spirits plainly demands more than a finding of Cuba's reputation for high quality cigars. In Spirits, Moscow's renown reputation for vodka was not enough to affirm the TTAB's legal conclusion; likewise, Cuba's renown reputation for cigars is not enough in this case.

The Court finds the plaintiff's false claims on the packaging equally inadequate to satisfy Spirits. First, the registrant's subjective intent provides little, if any, insight into the minds of consumers. Consumers could have numerous reasons as to why they purchase Guantanamera cigars, but without any objective findings, it is difficult to make an accurate conclusion as to whether the geographic misdescription will materially affect a "substantial portion" of consumers. Second, the Court does not consider extraneous and out-dated marketing material particularly relevant in determining a mark's ability to satisfy the $\S 1052(\mathrm{e})(3)$ registration bar. The Lanham Act bars registration of marks that are primarily geographically deceptively misdescriptive, not marks that are accompanied by deceptive packaging material. See 15 U.S.C. \$ 1052.

Habanos attempts to distinguish Spirits by asserting that this case meets the "substantial proportion" requirement. It argues that there are millions of Spanish speakers in the U.S., that the English speaking public recognizes "guantanamera" to mean Guantanamo, Cuba, and 
that GCC targeted Spanish speaking consumers. Nevertheless, this evidence fails to determine that a substantial proportion of the target audience would be deceived into purchasing the cigars because of the false goods-place association. Habanos never introduced evidence that suggested material deception of a substantial proportion of the relevant consuming public.

\section{Conclusion}

Therefore, this case is remanded to the TTAB so it may apply the proper legal standard to the third part of the test for primarily geographically deceptively misdescriptive terms.

\section{C.F.R. Part 5}

\section{Labeling and Advertising of Distilled Spirits}

No person engaged in business as a distiller, rectifier, importer, wholesaler, or warehouseman and bottler ... shall sell or ship ... any distilled spirits in bottles, unless such bottles are marked, branded, labeled, or packaged, in conformity with $\S \S 5.31$ through 5.42 [which require, in pertinent part, that the "class and type of distilled spirits shall be stated in conformity with $\S 5.22$ if defined therein"].

(b) Class 2; whisky. - "Whisky" is an alcoholic distillate from a fermented mash of grain produced at less than $190^{\circ}$ proof in such manner that the distillate possesses the taste, aroma, and characteristics generally attributed to whisky, stored in oak containers (except that corn whisky need not be so stored), and bottled at not less than $80^{\circ}$ proof $\ldots$

(6) "Spirit whisky" is a mixture of neutral spirits and not less than 5 percent on a proof gallon basis of whisky, or straight whisky, or straight whisky and whisky, if the straight whisky component is less than 20 percent on a proof gallon basis.

(7) "Scotch whisky" is whisky which is a distinctive product of Scotland, manufactured in Scotland in compliance with the laws of the United Kingdom regulating the manufacture of Scotch whisky for consumption in the United Kingdom: Provided, That if such product is a mixture of whiskies, such mixture is "blended Scotch whisky"

(d) Class 4; brandy. - ...

(9) "Pisco" is grape brandy manufactured in Peru or Chile in accordance with the laws and regulations of the country of manufacture governing the manufacture of Pisco for consumption in the country of manufacture.
27 C.F.R. $§ 5.31$ (a)

General

27 C.F.R. § 5.22

The standards of identity

Notice the tight interleaving of geographic and nongeographic standards. 
(k) Class 11; geographical designations. -

(1) Geographical names for distinctive types of distilled spirits (other than names found by the appropriate TTB officer under paragraph $(\mathrm{k})(2)$ of this section to have become generic) shall not be applied to distilled spirits produced in any other place than the particular region indicated by the name, unless (i) in direct conjunction with the name there appears the word "type" or the word "American" or some other adjective indicating the true place of production, in lettering substantially as conspicuous as such name, and (ii) the distilled spirits to which the name is applied conform to the distilled spirits of that particular region. The following are examples of distinctive types of distilled spirits with geographical names that have not become generic: Eau de Vie de Dantzig (Danziger Goldwasser), Ojen, Swedish punch.

(2) Only such geographical names for distilled spirits as the appropriate TTB officer finds have by usage and common knowledge lost their geographical significance to such extent that they have become generic shall be deemed to have become generic. Examples at London dry gin, Geneva (Hollands) gin.

(3) Geographical names that are not names for distinctive types of distilled spirits, and that have not become generic, shall not be applied to distilled spirits produced in any other place than the particular place or region indicated in the name. Examples are Armagnac, Greek brandy, , Jamaica rum, Puerto Rico rum, Demerara rum.

(1) Class 12; products without geographical designations but distinctive of a particular place. -

(1) The whiskies of the types specified in paragraphs (b) (1), (4), (5), and (6) of this section are distinctive products of the United States and if produced in a foreign country shall be designated by the applicable designation prescribed in such paragraphs, together with the words "American type" or the words "produced (distilled, blended) in __", the blank to be filled in with the name of the foreign country: Provided, That the word "bourbon" shall not be used to describe any whisky or whisky-based distilled spirits not produced in the United States. 
(b) Except as otherwise provided in this subchapter, a textile fiber product shall be misbranded if a stamp, tag, label, or other means of identification, or substitute therefor authorized by section 70c of this title, is not on or affixed to the product showing in words and figures plainly legible, the following:

(1) The constituent fiber or combination of fibers in the textile fiber product, designating with equal prominence each natural or manufactured fiber in the textile fiber product by its generic name in the order of predominance by the weight thereof if the weight of such fiber is 5 per centum or more of the total fiber weight of the product, but nothing in this section shall be construed as prohibiting the use of a nondeceptive trademark in conjunction with a designated generic name ...

(2) The percentage of each fiber present, by weight, in the total fiber content of the textile fiber product ...

(3) The name of the manufacturer of the product ...

(4) If it is an imported textile fiber product the name of the country where processed or manufactured.

(5) If it is a textile fiber product processed or manufactured in the United States, it be so identified.

\section{Melting Bad Problem, Redux}

Blancorp has come to you with a few more ideas for trademarks for its clumpless ice-melter. The product is factory-made in the United States (in Duluth, Minnesota, to be precise). Recall that it mimics the properties of a naturally occurring rock salt from Quebec, Canada. Give your opinion on the following names as trademarks:

- DULUTH

- HAWAIIAN

- ATLANTIS

- QUEBEC SALT

- CANADIAN BLUE

\section{Regulation}

In addition to the FTC's (and state regulators') general power to prevent deceptive marketing, statutes and regulations sometimes give authoritative meanings to particular terms. This raises two problems of interest. First, when the legislative and executive branches have said what a term means, how much room is there left for the judicial branch to interpret it in a false advertising suit? And second, can the 
government say what words mean?

134 S. Ct. 2228 (2014)

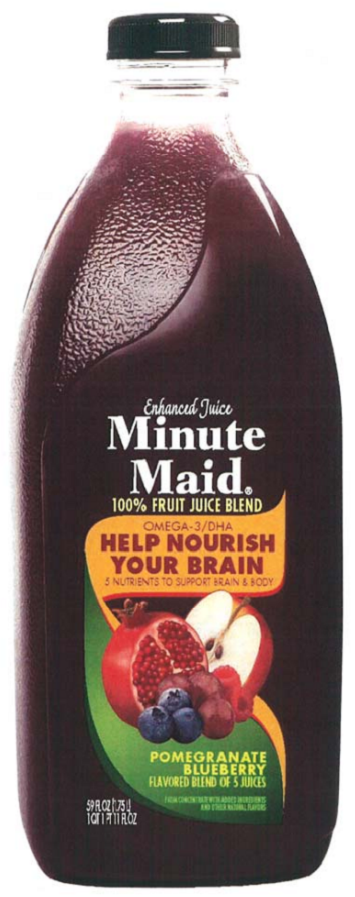

Minute Maid "Pomegranate Blueberry" bottle

21 U.S.C. §§ 331, 343

21 U.S.C. § 343(a)

21 U.S.C § 343(f)

21 U.S.C. § 343(i)

See 21 C.F.R. § 102.33

\section{POM Wonderful LLC v. The Coca-Cola Company}

Coca-Cola, under its Minute Maid brand, created a juice blend containing $99.4 \%$ apple and grape juices, $0.3 \%$ pomegranate juice, $0.2 \%$ blueberry juice, and $0.1 \%$ raspberry juice. Despite the minuscule amount of pomegranate and blueberry juices in the blend, the front label of the Coca-Cola product displays the words "pomegranate blueberry" in all capital letters, on two separate lines. Below those words, Coca-Cola placed the phrase "flavored blend of 5 juices" in much smaller type. And below that phrase, in still smaller type, were the words "from concentrate with added ingredients" - and, with a line break before the final phrase - "and other natural flavors." The product's front label also displays a vignette of blueberries, grapes, and raspberries in front of a halved pomegranate and a halved apple.

POM Wonderful LLC makes and sells pomegranate juice products, including a pomegranate-blueberry juice blend.

Alleging that the [Minute Maid] label is deceptive and misleading, POM sued Coca-Cola under $\S 43$ of the Lanham Act. That provision allows one competitor to sue another if it alleges unfair competition arising from false or misleading product descriptions. The Court of Appeals for the Ninth Circuit held that, in the realm of labeling for food and beverages, a Lanham Act claim like POM's is precluded by a second federal statute. The second statute is the Federal Food, Drug, and Cosmetic Act (FDCA), which forbids the misbranding of food, including by means of false or misleading labeling.

The FDCA statutory regime is designed primarily to protect the health and safety of the public at large. The FDCA prohibits the misbranding of food and drink. A food or drink is deemed misbranded if, inter alia, "its labeling is false or misleading,", information required to appear on its label "is not prominently placed thereon," , or a label does not bear "the common or usual name of the food, if any there be,". To implement these provisions, the Food and Drug Administration (FDA) promulgated regulations regarding food and beverage labeling, including the labeling of mixes of different types of juice into one juice blend. . One provision of those regulations is particularly relevant to this case: If a juice blend does not name all the juices it contains and mentions only juices that are not predominant in the blend, then it must either declare the percentage content of the named juice or "[i]ndicate that the named juice is present as a flavor or flavoring," e.g., "raspberry and cranberry flavored juice drink."

Unlike the Lanham Act, which relies in substantial part for its enforcement on private suits brought by injured competitors, the FDCA and its regulations provide the United States with nearly exclusive enforcement authority, including the authority to seek criminal sanc- 
tions in some circumstances. Private parties may not bring enforcement suits.

Beginning with the text of the two statutes, it must be observed that neither the Lanham Act nor the FDCA, in express terms, forbids or limits Lanham Act claims challenging labels that are regulated by the FDCA.

The structures of the FDCA and the Lanham Act reinforce the conclusion drawn from the text.The Lanham Act and the FDCA complement each other in major respects, for each has its own scope and purpose. Although both statutes touch on food and beverage labeling, the Lanham Act protects commercial interests against unfair competition, while the FDCA protects public health and safety. The two statutes impose different requirements and protections.

The two statutes complement each other with respect to remedies in a more fundamental respect. Enforcement of the FDCA and the detailed prescriptions of its implementing regulations is largely committed to the FDA. The FDA, however, does not have the same perspective or expertise in assessing market dynamics that day-to-day competitors possess. Competitors who manufacture or distribute products have detailed knowledge regarding how consumers rely upon certain sales and marketing strategies. Their awareness of unfair competition practices may be far more immediate and accurate than that of agency rulemakers and regulators. Lanham Act suits draw upon this market expertise by empowering private parties to sue competitors to protect their interests on a case-by-case basis. By serving a distinct compensatory function that may motivate injured persons to come forward, Lanham Act suits, to the extent they touch on the same subject matter as the FDCA, provide incentives for manufacturers to behave well. Allowing Lanham Act suits takes advantage of synergies among multiple methods of regulation. This is quite consistent with the congressional design to enact two different statutes, each with its own mechanisms to enhance the protection of competitors and consumers.

A holding that the FDCA precludes Lanham Act claims challenging food and beverage labels would not only ignore the distinct functional aspects of the FDCA and the Lanham Act but also would lead to a result that Congress likely did not intend. Unlike other types of labels regulated by the FDA, such as drug labels, it would appear the FDA does not preapprove food and beverage labels under its regulations and instead relies on enforcement actions, warning letters, and other measures. Because the FDA acknowledges that it does not necessarily pursue enforcement measures regarding all objectionable labels, if Lanham Act claims were to be precluded then commercial interests - and indirectly the public at large - could be left with less effective protection in the food and beverage labeling realm than in 
41 Loy. L.A. L. Rev. 227 (2007)

Benson v. Kwikset Corp., 62 Cal. Rptr. 3d 284 (Ct. App. 2007).
Piazza's Seafood World: 448 F.3d 744, 753 (5th Cir. 2006)

The statute made it a crime to "advertise, sell, offer or expose for sale, or distribute food or food products as 'Cajun', 'Louisiana Creole', or any derivative thereof unless the food or food product ... [was] produced, processed, or manufactured in Louisiana. many other, less regulated industries. It is unlikely that Congress intended the FDCA's protection of health and safety to result in less policing of misleading food and beverage labels than in competitive markets for other products.

\section{Rebecca Tushnet \\ It Depends on What the Meaning of "False" is: Falsity and Misleadingness in Commercial Speech Doctrine}

A key issue in advertising law is whether regulation of deception can be wholesale or retail. California has a particularly restrictive law that bars labeling products as "Made in U.S.A." unless the overall product and the parts are substantially made in the U.S. In a recent case, a California appeals court sustained this law against a First Amendment challenge. The court ruled that the legislature could determine that, as a general matter, merchandise not meeting the statute's restrictive definition would be deceptively labeled if advertised as "Made in U.S.A." Thus, though the plaintiff had to meet standing requirements showing that he'd been harmed by the misrepresentation, he could rely on the statutory definition to establish that the defendants violated the law by using "Made in U.S.A." and "All American-Made" on products using Taiwanese- made screws and parts sub-assembled in Mexico.

To the extent that the law is directed at consumer protection, calibrating it to promote domestic production will be extremely difficult. Producers who could use "Made in U.S.A." if their products had 40 percent or even 10 percent U.S. content might also keep some jobs in the U.S. that would otherwise go overseas. Yet if consumers expect "Made in U.S.A." products to be made entirely or almost entirely of U.S.-made parts, then a label that incentivizes producers to keep some jobs in the U.S. might still be deceptive. Because regulations on the advertising use of particular terms often aim both to protect consumers from deception and to encourage producers to make products with certain components, this problem is a recurrent one. If, however, legislatures choose definitions that protect consumer expectations, the fact that regulations might not be efficient is not a free speech argument against them. The First Amendment is not industrial policy.

By contrast to the California appeal court's deference to legislative judgment, a recent Fifth Circuit case, Piazza's Seafood World, LLC v. Odom decided that it was not inherently misleading to label Chinese catfish "Cajun." The Fifth Circuit affirmed the district court's finding that Louisiana's Cajun Statute was an unconstitutional regulation of commercial speech. As a result, a seafood importer was free to use "Cajun" as a trademark for its catfish, even though they are from China, not Louisiana, and even though they are actually of 
a different species than the domestic fish known as catfish. Despite the widespread success of the proposition that fixing the meaning of geographical indications protects and informs consumers, the Fifth Circuit did not give any weight to the Louisiana legislature's specific judgment about the meaning of "Cajun."

The Cajun case's refusal to accept blanket bans on terms is in tension with the "Made in U.S.A." decision, which accepted a legislative determination that "Made in U.S.A." and similar terms would invariably be misleading unless used according to the statutory definition. Similarly, the Supreme Court, in San Francisco Arts $\mathcal{E}$ Athletics accepted that "Congress reasonably could conclude that most commercial uses of the Olympic words and symbols are likely to be confusing," which justified upholding a special law giving complete control over commercial uses of the term "Olympic" to the U.S. Olympic Committee, regardless of whether confusion or other harm was shown in a particular case.

These categorical determinations of misleadingness are far from isolated incidents. Regulation-by-definition is common, and requires lawmakers to endorse one meaning at the expense of others. Consider moral and environmental claims such as "dolphin-free tuna": one possible definition of dolphin-free tuna is tuna caught in a net that didn't happen to kill any dolphins. If the net brings up a dolphin, you throw out the whole catch. This understanding of "dolphin-free tuna" doesn't address the fundamental objection that the method of catching the tuna routinely and predictably kills a lot of dolphins. However, it remains the case that the cans of tuna don't have any dolphins in them and did not even need to have dead dolphins picked out of them. Because of likely audience understanding, tuna caught this way is not "dolphin-free." In order to end semantic disputes, Congress passed a law defining dolphin- free tuna.

There has also been substantial debate over the proper definition of "organic," an official definition of which has now been adopted by the United States Department of Agriculture ("USDA"). Historically, organic foods faced market difficulties because of a proliferation of standards, which led to consumer suspicion that the organic label was meaningless. Currently, products not meeting USDA standards, but meeting some other definition of "organic," cannot be labeled organic. Organic products must have at least 95 percent organic content, but the remainder can be non-organic if it is on an approved list of ingredients without reasonably available organic substitutes. That list is itself controversial, since interested parties dispute whether or not various ingredients are available in organic form. In addition, "made with organic" is a separate standard, requiring at least percent organic content.

The issue of consumer response to standard-setting is worth fur-
The Dolphin Protection Consumer Information Act, 16 U.S.C. § 1385(d)

Organic Production and Handling Requirements, 7 C.F.R. §§ 205.200-.299 (2007)

Arguably, this is the case with "natural" claims. 
Int'l Dairy Foods Ass'n v. Amestoy, 92 F.3d 67 (2d Cir. 1996) ther discussion to show just how hard the problem is. By setting a standard, the government establishes what "organic" means. If people misunderstand the term - in other words, if they continue to give a different meaning to it - there is an information problem that leads to inefficient results. If people do not understand the term but nonetheless rely on it, then a key question is whether the government has gotten the social policy producing the underlying definition right. Moreover, the correctness of the government's definition has to be compared to the situation without regulation, in which producers could give the term multiple meanings as long as they were not intentionally fraudulent. If consumers still relied on the term without understanding it or understanding that different producers were using different definitions, the welfare effects would change, but not obviously in any particular direction. To this must be added the likelihood that consumers would discount the term "organic" if they believed it to be self-defined, moderating both the harms and benefits of varying definitions. Only if consumers carefully research multiple meanings of unregulated terms - and only if they do this again and again, for each term that makes a difference to them - can we expect the unregulated market to beat the government systematically in shaping meaning.

Labels can also function as warnings, even without explicit evaluative statements. Dairy producers who use recombinant bovine growth hormone ("rBST", also known as "rBGH") convinced the Second Circuit to strike down a rBST labeling requirement for milk that, they argued, functioned as a scarlet letter. Labeling may encourage otherwise uninterested consumers to think, mistakenly, that rBST involves health risks - they may reason that there would be no label if it didn't make a difference. Thus, Monsanto, the major producer of rBST, resisted labeling and also brought false advertising claims against smaller dairies with non-treated cows who voluntarily labeled their own milk. In addition, Monsanto recently asked the Food and Drug Administration ("FDA") to act against other voluntary labeling. "Not treated with rBST" is a factual statement, but its truth or falsity is not the key question. The dispute is over whether the implications of "not treated with rBST" mislead consumers and distort their purchases.

\section{Commack Self-Service Kosher Meats, Inc. v. Weiss}

Plaintiffs-appellees are Commack Self-Service Kosher Meats, Inc., $\mathrm{d} / \mathrm{b} / \mathrm{a}$ Commack Kosher, an entity in Commack, Long Island engaged in the meat business, and its owners, Brian and Jeffrey Yarmeisch. Over the last sixteen years, the Yarmeisches have been cited for violations of New York's kosher fraud laws on at least four occasions.

[For example,] the Department of Agriculture and Markets in- 
spected Commack Kosher on January 7, 1987, and seized two packages of beef chuck side steaks, each of which was marked "soaked and salted." The Department's "laboratory analysis did not reveal a significantly greater salt content in the outside surface of the steak than in the inside." The Department asserted that "had the steak been properly soaked and salted, the analysis would have indicated that the outside surface of the steak had a measurably higher salt content than the inner part of the meat." The Department therefore concluded that "the defendant's steak was not soaked and salted according to orthodox Hebrew religious requirements and was improperly offered for sale and represented as such." Accordingly, the Department alleged violations of New York Agriculture and Markets Law section 201-a(1), which prohibits the sale of any food product represented to be "kosher" that has not been prepared "in accordance with the orthodox Hebrew religious requirements. The Yarmeisches responded to the claimed violations in a letter dated April 29, 1987, which contained the following explanation of their soaking and salting method:

We take the side steak with the top and bottom fat left on the meat and soak it in water for one half hour, salt for one hour, and then rinse thoroughly. We then proceed to remove the fat and then face the meat (remove dark meat before packaging).

This is the procedure for all meat that is labeled soaked and salted, all of which is done under the direction of Rabbi Berman who has been supervising this establishment for approximately five years.

Rabbi Berman is a rabbi who adheres to the teachings of the Conservative branch of Judaism. The Yarmeisches' letter further explained that they believed their procedures for soaking and salting were in accordance with kosher requirements and requested that the Department "explain how [any problem with their procedures] can be rectified."

The Yarmeisches claimed that by defining "kosher" to mean food that is "prepared in accordance with orthodox Hebrew religious requirements," New York's kosher fraud laws violate the Establishment Clause. In cases involving facial challenges on Establishment Clause grounds, we assess the constitutionality of an enactment by reference to the three factors first articulated in Lemon $v$. Kurtzman: that a challenged law (1) have a valid secular purpose; (2) have a primary effect that neither advances nor inhibits religion; and (3) not foster excessive state entanglement with religion.

It appears to us that the challenged laws excessively entangle government and religion because they (1) take sides in a religious matter, effectively discriminating in favor of the Orthodox Hebrew view of dietary requirements; (2) require the State to take an official position
Leviticus 7:26 prohibits eating blood. Rabbinical authorities generally hold that implementing this commandment requires deveining meat, soaking it in water, salting it to draw out the blood, and then rinsing it.

Cf. State v. Rachleff Kosher Provisions, Inc., 188 A.D.2d 458 (N.Y. App. Div. 1992) (defendant "purchased nonkosher meat which he processed, packaged, and sold as kosher"); Barghout v. Bureau of Kosher Meat and Food Control, 66 F.3d 1337 (4th Cir. 1995) (defendant repeatedly "placed kosher hot dogs on a rotisserie next to nonkosher hot dogs," which "allowed grease from the nonkosher meat to contaminate the kosher hot dogs, rendering them nonkosher").

Lemon: 403 U.S. 602 (1971) 
on religious doctrine; and (3) create an impermissible fusion of governmental and religious functions by delegating civic authority to individuals apparently chosen according to religious criteria.

The Department argues that the challenged laws do not excessively entangle the government with religion because "no one disputes the meaning of the term 'kosher."' There is ample evidence in the record to support the opposite conclusion. In a guide to observance of Jewish dietary law, published by the United Synagogue Commission on Jewish Education, author Samuel H. Dresner notes that

Over the years and in varying locales, rabbinic authorities differed in their interpretations of specific laws of kashrut. To cite a famous example: Sephardic Jews eat rice and legumes on Passover, Ashkenazic Jews do not. Ashkenazic Jews, by and large, do not eat the hindquarters of beef; Sephardic Jews do.

Some of the decisions recorded in this book are not accepted by all authorities on Jewish law, notably decisions about wine, cheese, gelatin, swordfish and sturgeon. This is not a novel situation in the history of Jewish law. There have always been disagreements on various points.

Samuel H. Dresner, The Jewish Dietary Laws 55-56 (1982).

We find it indisputable that there are differences of opinion within Judaism regarding the dietary requirements of kashrut. As a result, because the challenged laws interpret "kosher" as synonymous with the views of one branch, those of Orthodox Judaism, the State has effectively aligned itself with one side of an internal debate within Judaism. This it may not do.

In order to assert that a food article does not conform to kosher requirements, New York must take an official position as to what are the kosher requirements. In doing so, the Department must either interpret religious doctrine or defer to the interpretations of religious officials in reaching its official position.

We also find that the challenged laws fail the second prong of the Lemon test, which mandates that, to avoid conflict with the Establishment Clause, a principal or primary effect of a challenged law must neither advance nor inhibit religion. The challenged laws violate this prohibition because they (1) have a primary effect that both advances religion, by preferring the dietary restrictions of Orthodox Judaism over those of other branches, and inhibits religion, by effectively prohibiting other branches from using the kosher label in accordance with their religious beliefs, and (2) create an impermissible joint exercise of religious and civic authority that advances religion. We reach this conclusion for reasons similar to those that demonstrate exces- 
sive entanglement of government and religion.

Finally, because the secular purpose prong of the Lemon test is often easily satisfied, and is uncontested by the parties here, we address it last. The parties here do not dispute that the challenged laws were enacted for the secular purpose of protecting consumers from fraud in the kosher food market.

We agree with the New Jersey Supreme Court that a state has "a valid interest in preventing fraud in the sale of any foods, including kosher foods." Ran-Dav's County Kosher, Inc. v. State. This interest in protecting against fraud in the kosher food market extends to the general public. Indeed, Jewish consumers reportedly now make up less than thirty percent of the consumers of kosher food. The remainder are Muslims and others with similar religious requirements, persons with special dietary restrictions, and those who simply prefer food bearing the kosher label as a symbol of purity. The State clearly has a valid secular interest in protecting from fraud all those who choose to consume kosher food products. We do note, however, that the challenged laws imperfectly accomplish this secular purpose because their avowed purpose is amply covered by the existing general fraud laws. For example, section 199-a(1) prohibits any misbranding of food, and therefore would penalize vendors who falsely represented their products to be kosher according to the standard described on the label. In other words, under the general statutory scheme governing fraud in the food industry, the State can prevent fraud in the sale of kosher food in a less restrictive and neutral manner by simply requiring that any vendor engaged in the sale of kosher food state the basis on which the food is labeled kosher. Thus, the valid secular purpose articulated by the State can be accomplished by nondiscriminatory means that do not advance religion.

\section{Levy v. Kosher Overseers Ass'n of America, Inc.}

Kosher certification marks are used to designate food items that comply with Judaism's strict dietary laws. A kosher certification mark informs the consumer that a certification agency has examined the manufacturing process, the ingredients, and the cleanliness of the production facilities of a product to insure that the product is kosher. Because the various kosher certification agencies employ their own standards for accepting products as kosher, according to their particular interpretation of Judaism's dietary requirements, it is important for a consumer to recognize the marks of the certification agencies
Ran-Dav's: 608 A.2d 1353 (N.J. 1992)

In Commack Self-Service Kosher Meats, Inc. v. Hooker, 680 F.3d 194 (2d Cir. 2012), the court rejected an Establishment Clause challenge by the same plaintiffs against New York's revised kosher certification laws, which require that anyone marketing food as kosher identify the individuals certifying the food as kosher. Certifiers must register with the Department and provide "a statement of such person's qualifications for providing such certification." A casual perusal of the statements on file at the Department's website shows that most of them run to one or sometimes two sentences; they commonly mention the certifier's rabbinical ordination, years of experience performing kosher inspections, and occasionally a bit about the standards applied.

Cf. Wallace v. ConAgra Foods, Inc., 920 F. Supp. 2d 995 (D. Minn. 2013), rev'd on other grounds, 747 F.3d 1025 (8th Cir. 2014) (dismissing on Establishment Clause grounds a consumer class action under state consumer protection laws against Hebrew National for calling its hot dogs "100\% Kosher" when it allegedly used quotas for how much beef would be certified as kosher, regardless of the cows' status as clean or unclean).

104 F.3d 38 (2d Cir. 1997) 
that he trusts.

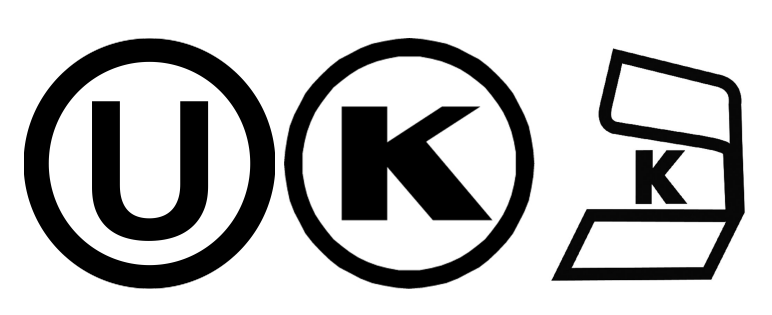

\section{Mandatory Disclosures}

Regulations sometimes tell companies what they must say, rather than what they must not say.

760 F.3d 18 (D.C. Cir. 2014) (en banc)

7 U.S.C. $\S 1638,1638 a$

\section{American Meat Institute v. Dept. of Agriculture}

Congress has required country-of-origin labels on a variety of foods, including some meat products and tasked the Secretary of Agriculture with implementation. [Yadda yadda yadda.] The Secretary responded with a rule in 2013 requiring more precise information revealing the location of each production step. For example, meat derived from an animal born in Canada and raised and slaughtered in the United States, which formerly could have been labeled "Product of the United States and Canada," would now have to be labeled "Born in Canada, Raised and Slaughtered in the United States."

The plaintiffs, a group of trade associations representing livestock producers, feedlot operators, and meat packers, whom we'll collectively call American Meat Institute ("AMI"), challenged the 2013 rule in district court as a violation of both the statute and the First Amendment. AMI argues that the 2013 rule violates its First Amendment right to freedom of speech by requiring it to disclose country-oforigin information to retailers, who will ultimately provide the information to consumers.

The starting point common to both parties is that Zauderer $v$. Office of Disciplinary Counsel of Supreme Court of Ohio applies to government mandates requiring disclosure of "purely factual and uncontroversial information" appropriate to prevent deception in the regulated party's commercial speech. The key question for us is whether the principles articulated in Zauderen apply more broadly to factual and uncontroversial disclosures required to serve other government interests. [The court held that it does.] All told, Zauderer's characterization of the speaker's interest in opposing forced disclosure of such information as "minimal" seems inherently applicable beyond the problem of deception.

In applying Zauderen, we first must assess the adequacy of the interest motivating the country-of-origin labeling scheme. AMI argues that, even assuming Zauderen applies here, the government has utterly failed to show an adequate interest in making country-of-origin information available to consumers. AMI disparages the govern- 
ment's interest as simply being that of satisfying consumers' "idle curiosity." But here we think several aspects of the government's interest in country-of-origin labeling for food combine to make the interest substantial: the context and long history of country-of-origin disclosures to enable consumers to choose American-made products; the demonstrated consumer interest in extending country-of-origin labeling to food products; and the individual health concerns and market impacts that can arise in the event of a food-borne illness outbreak.

Supporting members of Congress identified the statute's purpose as enabling customers to make informed choices based on characteristics of the products they wished to purchase, including United States supervision of the entire production process for health and hygiene. Some expressed a belief that with information about meat's national origin, many would choose American meat on the basis of a belief that it would in truth be better. Even though the production steps abroad for food imported into the United States are to a degree subject to U.S. government monitoring, it seems reasonable for Congress to anticipate that many consumers may prefer food that had been continuously under a particular government's direct scrutiny.

Some legislators also expressed the belief that people would have a special concern about the geographical origins of what they eat. This is manifest in anecdotes appearing in the legislative record, such as the collapse of the cantaloupe market when some imported cantaloupes proved to be contaminated and consumers were unable to determine whether the melons on the shelves had come from that country. Of course the anecdote more broadly suggests the utility of these disclosures in the event of any disease outbreak known to have a specific country of origin, foreign or domestic.

The record is further bolstered by surveys the Agricultural Marketing Service reviewed, such as one indicating that 71-73 percent of consumers would be willing to pay for country-of-origin information about their food. The AMS quite properly noted the vulnerabilities in such data. Most obvious is the point that consumers tend to overstate their willingness to pay; after all, the data sound possibly useful, and giving a "Yes" answer on the survey doesn't cost a nickel. But such studies, combined with the many favorable comments the agency received during all of its rulemakings, reinforce the historical basis for treating such information as valuable.

The self-evident tendency of a disclosure mandate to assure that recipients get the mandated information may in part explain why, where that is the goal, many such mandates have persisted for decades without anyone questioning their constitutionality. In this long-lived group have been not only country-of-origin labels but also many other routine disclosure mandates about product attributes, in- 
Fiber content: 16 C.F.R. pt. 303

Clothing care instructions: 16 C.F.R. pt. 423

Ingredients: 21 C.F.R. § 101.4

748 F.3d 359 (D.C. Cir. 2014)

15 U.S.C. $\S \S 78 m(p), 78 m$ note cluding, for instance, disclosures of fiber content, care instructions for clothing items, , and listing of ingredients .

AMI does not contest that country-of-origin labeling qualifies as factual, and the facts conveyed are directly informative of intrinsic characteristics of the product AMI is selling. As to whether it is "controversial," AMI objected to the word "slaughter" in its reply brief. Though it seems a plain, blunt word for a plain, blunt action, we can understand a claim that "slaughter," used on a product of any origin, might convey a certain innuendo. But we need not address such a claim because the 2013 rule allows retailers to use the term "harvested" instead, and AMI has posed no objection to that. And AMI does not disagree with the truth of the facts required to be disclosed, so there is no claim that they are controversial in that sense.

We also do not understand country-of-origin labeling to be controversial in the sense that it communicates a message that is controversial for some reason other than dispute about simple factual accuracy. Leaving aside the possibility that some required factual disclosures could be so one-sided or incomplete that they would not qualify as "factual and uncontroversial," country-of-origin facts are not of that type. AMI does not suggest anything controversial about the message that its members are required to express.

\section{National Ass'n of Mfrs. v. Securities and Exchange Commission [I]} For the last fifteen years, the Democratic Republic of the Congo has endured war and humanitarian catastrophe. Millions have perished, mostly civilians who died of starvation and disease. Communities have been displaced, rape is a weapon, and human rights violations are widespread.

Armed groups fighting the war finance their operations by exploiting the regional trade in several kinds of minerals. Those mineralsgold, tantalum, tin, and tungsten 1 - are extracted from technologically primitive mining sites in the remote eastern Congo. They are sold at regional trading houses, smelted nearby or abroad, and ultimately used to manufacture many different products. Armed groups profit by extorting, and in some cases directly managing, the minimally regulated mining operations.

In 2010, Congress devised a response to the Congo war. Section 1502 of the Dodd-Frank Wall Street Reform and Consumer Protection Act,, requires the Securities and Exchange Commission - the agency normally charged with policing America's financial markets - to issue regulations requiring firms using "conflict minerals" to investigate and disclose the origin of those minerals. [Securities issuers must state in reports to the SEC and on their websites which of their products have "not been found to be 'DRC conflict free."']

[The panel struck down the rule as constituting compelled speech. 
Then American Meat Institute overruled NAM 1 . The panel issued the following opinion on rehearing.]

National Ass'n of Mfrs. v. Securities and Exchange Commission [II] "Unncontroversial," as a legal test, must mean something different than "purely factual." Perhaps the distinction is between fact and opinion. But that line is often blurred, and it is far from clear that all opinions are controversial. Is Einstein's General Theory of Relativity fact or opinion, and should it be regarded as controversial? If the government required labels on all internal combustion engines stating that "USE OF THIS PRODUCT CONTRIBUTES TO GLOBAL WARMING" would that be fact or opinion? It is easy to convert many statements of opinion into assertions of fact simply by removing the words "in my opinion" or removing "in the opinion of many scientists" or removing "in the opinion of many experts."

We agree with NAM that the statutory definition of "conflict free" cannot save this law. As NAM forcefully puts it, "if the law were otherwise, there would be no end to the government's ability to skew public debate by forcing companies to use the government's preferred language. For instance, companies could be compelled to state that their products are not 'environmentally sustainable' or 'fair trade' if the government provided 'factual' definitions of those sloganseven if the companies vehemently disagreed that their [products] were 'unsustainable' or 'unfair.' "

In our initial opinion we stated that the description at issue whether a product is "conflict free" or "not conflict free" - was hardly "factual and non-ideological." We put it this way:

Products and minerals do not fight conflicts. The label "[not] conflict free" is a metaphor that conveys moral responsibility for the Congo war. It requires an issuer to tell consumers that its products are ethically tainted, even if they only indirectly finance armed groups. An issuer, including an issuer who condemns the atrocities of the Congo war in the strongest terms, may disagree with that assessment of its moral responsibility. And it may convey that message through silence. By compelling an issuer to confess blood on its hands, the statute interferes with that exercise of the freedom of speech under the First Amendment.

We see no reason to change our analysis in this respect. And we continue to agree with NAM that "requiring a company to publicly condemn itself is undoubtedly a more 'effective' way for the government to stigmatize and shape behavior than for the government to have to convey its views itself, but that makes the requirement more consti- 
tutionally offensive, not less so."

\section{Self-Regulation}

The National Advertising Division of the Advertising Self-Regulatory Council runs an ADR system, based entirely on written filings and with decisions within 60 days. Participation is voluntary, and the NAD takes no enforcement actions by itself. Given its subject-matter expertise, the FTC tends to accord the NAD's decisions substantial deference, even though they are not by themselves binding. Another arm of the ASRC, the Children's Advertising Review Unit, operates a similar program under standards that are "deliberately subjective, going beyond the issues of truthfulness and accuracy to take into account the uniquely impressionable and vulnerable child audience."

\section{Mead Johnson Nutritionals (Enfamil LIPIL)}

This is the third compliance report stemming from a challenge in which print, packaging and point of sale advertising claims made by Mead Johnson Nutritionals for its Enfamil LIPIL infant formula were challenged by Abbott Nutrition, a manufacturer of a competing infant formula. The following claims were representative are representative of those at issue: "Enfamil ${ }^{\circ}$ LIPIL $®$ is the only infant formula shown in independent clinical studies to improve baby's brain and eye development. ${ }^{*}{ }^{*}$ vs. same routine formula without DHA and ARA. Studied to 18 months.]"; "Enfamil LIPIL* improves mental development by 7 points vs. same formula without LIPIL [ + vs. same routine formula without LIPIL. Studied at 18 months for brain and 12 months for eye. Longer term impact not measured.]"; "shown in independent clinical studies to improve baby's brain and eye development" versus unsupplemented Enfamil."

\section{BACKGROUND}

In its underlying decision, NAD recommended that the advertiser either discontinue its "improve brain and eye development" claimsor modify them by making clear that (a) the advertised improvements are limited to only the first 18 months of an infant's life; and (b) the touted "improve[ment]" is with respect to a discontinued, or prior, version of the product. With respect to the consumer-directed coupon featuring a comparison to breastfed babies, NAD recommended that the advertiser either discontinue the advertising, or modify it by making clear that the advertised improvement is not shown at four years, and that the comparison is with respect to the now-discontinued Enfamil product. NAD further recommended that the advertiser make clear that Enfamil Lipil has not been shown to outperform Similac Advance with respect to mental and/or visual de- 
velopment. With respect to the consumer-directed coupon that features a chart that invites consumers to "compare the differences" between Enfamil Lipil and Similac Advance, NAD recommended that the advertiser either discontinue this comparative advertisement, or modify it by removing the comparison to Similac Advance.

With respect to the advertiser's compositional comparison to median levels of DHA and ARA in breast milk, NAD determined that there was no basis for it to examine this claim anew. With respect to the health-care provider-directed claims, NAD recommended that the advertiser discontinue side-by-side IQ graphs, and modify the materials to ensure that they no longer convey the unsupported message that Enfamil Lipil outperforms Similac with respect to the formulas' effects on IQ. NAD further recommended that the advertiser discontinue any express or implied claims that based on the fouryear data, Enfamil Lipil makes a "difference" (as compared to unsupplemented Enfamil.) Likewise, NAD recommended that the advertiser no longer claim that "new 4-year follow-up data" shows an "impact" of Enfamil Lipil on cognitive development. NAD did find, however, that the advertiser had a reasonable basis to claim a similar performance to breastfed babies at four years. Finally, NAD noted that nothing in this decision prevents the advertiser from presenting health care professionals with clinical results from the Birch four-year data, provided that it is done in an accurate and non-misleading manner.

In June 2008, the challenger contacted the NAD to raise concerns about advertising which it believed did not comply with NAD's underlying decision. The advertiser explained that all of the website materials submitted by the challenger were printed prior to NAD's decision and that it had already begun modifying this page prior to the receipt of the challenger's compliance inquiry. The advertiser notified NAD that the claim, as revised, would now read: "The only infant formula clinically shown to promote baby's brain and eye development ${ }^{* \prime \prime ~ " ~}\left({ }^{*}\right.$ Versus prior formulation of same product without DHA and ARA, with improvement demonstrated to 18 months.") The advertiser further noted that it is in the process of comprehensively reviewing its entire website to ensure all relevant language has been modified and that all new materials would comply with NAD's decision. Based on the advertiser's assurances, NAD closed its compliance review.

In November 2008, the challenger again contacted NAD about concerns it had about advertising it alleged to be noncompliant with NAD's decision. The advertiser informed NAD that the professional advertisement in question was distributed in error and will no longer be disseminated. The advertiser noted that it has taken substantial steps to comply with NAD's decision. While expressing its deep dis- 
appointment that noncompliant advertising had continued to be disseminated, NAD noted that the current advertisements comply with NAD's recommendations but cautioned that any noncompliant advertisements that are brought to its attention after the issuance of the instant decision will result in an automatic referral to the appropriate government agency for possible law enforcement action pursuant to section 4.1(B) of the NAD/NARB Procedures.

In February 2009, the challenger contacted NAD with concerns it had about advertising for Enfamil LIPIL which it believed contravened NAD's decision.

\section{DeCISION}

NAD is incredulous that after two compliance proceedings, with the second compliance proceeding making explicit that any noncompliant advertising would result in a referral to the appropriate government agency, that the advertiser would disseminate advertising that clearly does not comply with NAD's decision. For example, in its underlying decision, NAD noted that with respect to the consumerdirected coupon that features a chart that invites consumers to "compare the differences" between Enfamil LIPIL and Similac Advance, NAD recommended that the advertiser either discontinue this comparative advertisement or modify it by removing the comparison to Similac Advance. In one of the current advertisements, the advertiser features the claim "Enfamil LIPIL is now clinically shown to support cognitive development ${ }^{*}$ and immune balancet" next to which is a chart with one column for Similac Advance and one for Enfamil LIPIL and has a check mark for Enfamil Lipil and "NO" for Similac for, among other things, "Only Enfamil LIPIL has been shown in published independent clinical studies to improve BRAIN and EYE development $t^{* \prime}$ The faint asterisks refer to a inconspicuous disclosure to the left of the claim and chart which states "vs. the prior version of the product without DHA and ARA with improvement shown to 18 months." This advertisement does not comply with NAD's decision, and NAD need look no further to determine noncompliance. The selfregulatory process cannot function properly when advertisers state, on the one hand, that they respect the process and will comply with NAD's decision, and then do the opposite. Accordingly, NAD has no choice but to refer this matter to the appropriate government agency for possible law enforcement action pursuant to section 4.1(B) of the NAD/NARB Procedures. 
Keep nourishing them with a full year of Enfamil LIPIL.

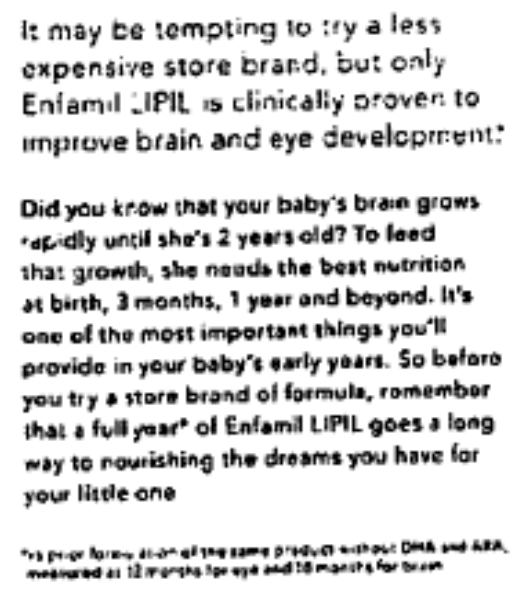

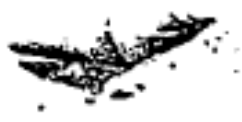

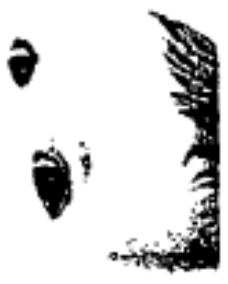

\section{CARU Press Release}

The Children's Advertising Review Unit (CARU) of the Council of Better Business Bureaus, Inc., has recommended that Lego Systems Inc., maker of the Lego Racers: Crash Collection line of playsets, modify advertising to make it clear to the child audience that the toys sold do not make sounds.

Broadcast advertising for Lego Racers: Crash Collection came to the attention of CARU, the children's advertising industry's selfregulatory forum, through CARU's ongoing monitoring efforts.

Commercials for the playsets feature two children playing with LEGO pull-back motor racers. A voice-over states that the toys are "built to crash." When the cars hit each other, loud crashing noises are heard and a voice-over screams "CRASH" in a long, drawn-out manner while a bubble visual of the word "CRASH" appears on the screen in large, cartoon-like letters. The commercial features numerous loud crash scenes, with the cars hitting each other and various other objects. On impact, in addition to the sounds synchronized with the collision and the video and audio supers, special effects dramatize the cars breaking apart and pieces flying off in slow-motion.

CARU was concerned that the synchronization of the "crashing" sound effects accompanying the colliding of the cars could potentially mislead children into believing that the toys were equipped with sound-effects equipment. CARU was also concerned that, because the toys do not have any sound capabilities, the commercials would create unrealistic performance expectations that children would not be able to duplicate.

In order to avoid potentially misleading the child audience,

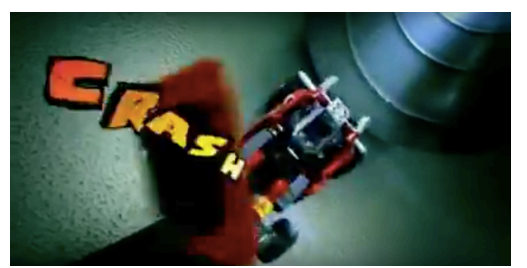

Still from challenged Lego Racers ad 
CARU recommended that the advertiser modify the commercial. CARU further recommended that the advertiser include scenes of real action play without special effects, which would serve to demonstrate how much noise the toys do make.

The company, in its advertiser's statement, said that it is a strong supporter of CARU and "appreciates the opportunity to participate in the self-regulatory process."

"LSI will continue to remain sensitive to CARU's concerns and do its best to follow the Guidelines in future advertisements. LSI does not plan to appeal this decision," the company said.

\section{Problems}

\section{Scavenger Hunt Problem}

Find as many of the following as you can in the wild:

- An advertisement containing non-actionable puffery

- A literally false advertisement

- An advertisement that is not literally false but is misleading

- An establishment claim (bonus point if it is unsubstantiated)

- A registered certification mark

- A regulatory certification mark

- A deceptive trademark (not necessarily registered)

- A food label regulated by the FDA under the FDCA, together with a citation to the specific section in the Code of Federal Regulations that governs the label. Highlight the portion of the label that is required by the regulation you cite.

- An endorsement on social media containing an advertising disclosure.

- An endorsement on social media not containing an advertising disclosure, but which should have had one

- An advertisement directed at children that is misleading under the standards applied by CARU

You are allowed one entry per category. All your submissions should be examples you are comfortable having shown in class.

You get one point for each one you find on the Internet, and two points for each one you find offline (submit a photo). You get a bonus point for each of your entries that is unique, i.e., no one else in the class submitted it. Whoever gets the highest score will win bragging rights and a prize of negligible value.

problems/fortunetelling 


\section{Personality Rights}

One body of intellectual property law - the right of publicity squarely protects people's names, appearances, and other aspects of their personal identities. The policies underlying the right of publicity overlap substantially with those of copyright, trademark, and false advertising. It is helpful, therefore, to compare how these other bodies of law deal with personal identity. In addition, the law of naming and name changes sheds light both on right of publicity and trademark, and the tort law of defamation also bears on the issues.

\section{A Right of Publicity}

Two closely related theories of the right of publicity should be familiar. One is that it facilitates contracting over a type of information - people's fame, talent, and ability to make endorsements - that has significant commercial value. The other is that it incentivizes the creation of these valuable personas in the first place. But the right of publicity is also closely linked to privacy. Historically, it grew out of privacy torts, and it helps to protect people's interest in not being involuntarily exposed to the public eye.

\section{Ownership}

Who has publicity rights? Conceptually, the answer depends on the reason(s) to recognize them. If publicity rights are privacy rights, then arguably ordinary citizens have them but celebrities who have voluntarily stepped out upon the public stage don't. But if publicity rights are property rights, then arguably celebrities have them but ordinary citizens who have done nothing to monetize their identities don't. The history of the rise of the right of publicity in the twentieth century shows courts wrestling with both kinds of theories. 


\section{a Privacy Theories}

The different paths taken by New York (after Roberson) and Georgia (in Pavesich) illustrate the two typical routes to the right of publicity in the states that recognize it: by statute and by common law, respectively. (Some states, like California, have both.) Pavesich hints and $O^{\prime}$ Brien confirms that a privacy-focused rationale doesn't work for celebrities.

64 N.E. 442 (N.Y. 1902)

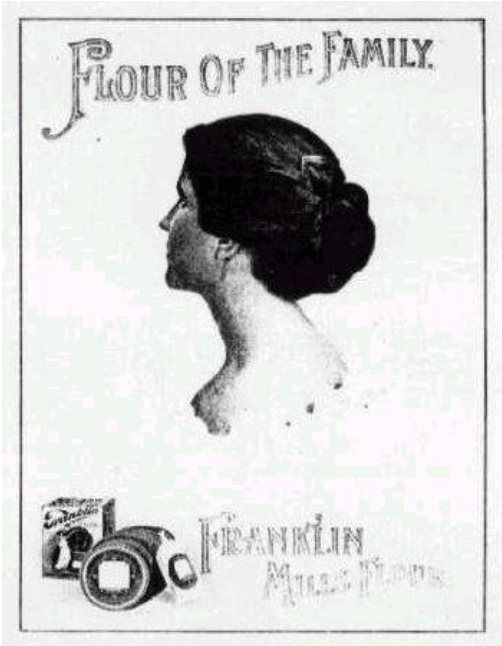

Flour of the Family advertisement

\section{Roberson v. Rochester Folding Box Co.}

The complaint alleges that the Franklin Mills Company, one of the defendants, was engaged in a general milling business and in the manufacture and sale of flour; that before the commencement of the action, without the knowledge or consent of plaintiff, defendants, knowing that they had no right or authority so to do, had obtained, made, printed, sold, and circulated about 25,000 lithographic prints, photographs, and likenesses of plaintiff, made in a manner particularly set up in the complaint; that upon the paper upon which the likenesses were printed and above the portrait there were printed, in large, plain letters, the words, 'Flour of the Family,' and below the portrait, in large capital letters, 'Franklin Mills Flour,' and in the lower right-hand corner, in smaller capital letters, 'Rochester Folding Box Co., Rochester, N. Y.'; that upon the same sheet were other advertisements of the flour of the Franklin Mills Company; that those 25,000 likenesses of the plaintiff thus ornamented have been conspicuously posted and displayed in stores, warehouses, saloons, and other public places; that they have been recognized by friends of the plaintiff and other people, with the result that plaintiff has been greatly humiliated by the scoffs and jeers of persons who have recognized her face and picture on this advertisement, and her good name has been attacked, causing her great distress and suffering, both in body and mind; that she was made sick, and suffered a severe nervous shock, was confined to her bed, and compelled to employ a physician, because of these facts; that defendants had continued to print, make, use, sell, and circulate the said lithographs, and that by reason of the foregoing facts plaintiff had suffered damages in the sum of $\$ 15,000$. The complaint prays that defendants be enjoined from making, printing, publishing, circulating, or using in any manner any likenesses of plaintiff in any form whatever; for further relief (which it is not necessary to consider here); and for damages.

It will be observed that there is no complaint made that plaintiff was libeled by this publication of her portrait. The likeness is said to be a very good one, and one that her friends and acquaintances were able to recognize. Indeed, her grievance is that a good portrait of her, and therefore one easily recognized, has been used to attract atten- 
tion toward the paper upon which defendant mill company's advertisements appear. Such publicity, which some find agreeable, is to plaintiff very distasteful, and thus, because of defendants' impertinence in using her picture, without her consent, for their own business purposes, she has been caused to suffer mental distress where others would have appreciated the compliment to their beauty implied in the selection of the picture for such purposes; but, as it is distasteful to her, she seeks the aid of the courts to enjoin a further circulation of the lithographic prints containing her portrait made as alleged in the complaint, and, as an incident thereto, to reimburse her for the damages to her feelings, which the complaint fixes at the sum of $\$ 15,000$. There is no precedent for such an action to be found in the decisions of this court.

Nevertheless the Appellate Division reached the conclusion that plaintiff had a good cause of action against defendants, in that defendants had invaded what is called a 'right of privacy'; in other words, the right to be let alone. Mention of such a right is not to be found in Blackstone, Kent, or any other of the great commentators upon the law; nor, so far as the learning of counsel or the courts in this case have been able to discover, does its existence seem to have been asserted prior to about the year 1890, when it was presented with attractiveness, and no inconsiderable ability, in the Harvard Law Review in an article entitled 'Rights of a Citizen to His Reputation.' The so-called 'right of privacy' is, as the phrase suggests, founded upon the claim that a man has the right to pass through this world, if he wills, without having his picture published, his business enterprises discussed, his successful experiments written up for the benefit of others, or his eccentricities commented upon either in handbills, circulars, catalogues, periodicals, or newspapers; and, necessarily, that the things which may not be written and published of him must not be spoken of him by his neighbors, whether the comment be favorable or otherwise. While most persons would much prefer to have a good likeness of themselves appear in a responsible periodical or leading newspaper rather than upon an advertising card or sheet, the doctrine which the courts are asked to create for this case would apply as well to the one publication as to the other, for the principle which a court of equity is asked to assert in support of a recovery in this action is that the right of privacy exists and is enforceable in equity, and that the publication of that which purports to be a portrait of another person, even if obtained upon the street by an impertinent individual with a camera, will be restrained in equity on the ground that an individual has the right to prevent his features from becoming known to those outside of his circle of friends and acquaintances. If such a principle be incorporated into the body of the law through the instrumentality of a court of equity, the attempts to logically ap-
Samuel D. Warren \& Louis D. Brandeis, The Right to Privacy, 4 Harv. L. Rev. 193 (1890). 
ply the principle will necessarily result not only in a vast amount of litigation, but in litigation bordering upon the absurd, for the right of privacy, once established as a legal doctrine, cannot be confined to the restraint of the publication of a likeness, but must necessarily embrace as well the publication of a word picture, a comment upon one's looks, conduct, domestic relations or habits. And, were the right of privacy once legally asserted, it would necessarily be held to include the same things if spoken instead of printed, for one, as well as the other, invades the right to be absolutely let alone. An insult would certainly be in violation of such a right, and with many persons would more seriously wound the feelings than would the publication of their picture. And so we might add to the list of things that are spoken and done day by day which seriously offend the sensibilities of good people to which the principle which the plaintiff seeks to have imbedded in the doctrine of the law would seem to apply. I have gone only far enough to barely suggest the vast field of litigation which would necessarily be opened up should this court hold that privacy exists as a legal right enforceable in equity by injunction, and by damages where they seem necessary to give complete relief.

An examination of the authorities leads us to the conclusion that the so-called 'right of privacy' has not as yet found an abiding place in our jurisprudence, and, as we view it, the doctrine cannot now be incorporated without doing violence to settled principles of law by which the profession and the public have long been guided. I do not say that, even under the existing law, in every case of the character of the one before us, or, indeed, in this case, a party whose likeness is circulated against his will is without remedy. By section 242 of the Penal Code any malicious publication by picture, effigy, or sign, which exposes a person to contempt, ridicule, or obloquy, is a libel, and it would constitute such at common law. There are many articles, especially of medicine, whose character is such that using the picture of a person, particularly that of a woman, in connection with the advertisement of those articles, might justly be found by a jury to cast ridicule or obloquy on the person whose picture was thus published. The manner or posture in which the person is portrayed might readily have a like effect. In such cases both a civil action and a criminal prosecution could be maintained. But there is no allegation in the complaint before us that this was the tendency of the publication complained of, and the absence of such an allegation is fatal to the maintenance of the action, treating it as one of libel.

New York Civil Rights Law

$\S 51$

Action for injunction and for damages
Any person whose name, portrait, picture or voice is used within this state for advertising purposes or for the purposes of trade without the 
written consent first obtained as above provided may maintain an equitable action in the supreme court of this state against the person, firm or corporation so using his name, portrait, picture or voice, to prevent and restrain the use thereof; and may also sue and recover damages for any injuries sustained by reason of such use.

Pavesich v. New England Life Ins. Co.

Paolo Pavesich brought an action against the New England Mutual Life Insurance Company, a nonresident corporation, Thomas B. Lumpkin, its general agent, and J. Q. Adams, a photographer, both residing in the city of Atlanta. The allegations of the petition were, in substance, as follows: In an issue of the Atlanta Constitution, a newspaper published in the city of Atlanta, there appeared a likeness of the plaintiff, which would be easily recognized by his friends and acquaintances, placed by the side of the likeness of an ill-dressed and sickly looking person. Above the likeness of the plaintiff were the words: "Do it now. The man who did." Above the likeness of the other person were the words: "Do it while you can. The man who didn't." Below the two pictures were the words: "These two pictures tell their own story." Under the plaintiff's picture the following appeared: "In my healthy and productive period of life I bought insurance in the New England Mutual Life Insurance Co., of Boston, Mass., and to-day my family is protected and I am drawing an annual dividend on my paid-up policies." Under the other person's picture was a statement to the effect that he had not taken insurance, and now realized his mistake. The statements were signed, "Thomas B. Lumpkin, General Agent." The picture of the plaintiff was taken from a negative obtained by the defendant Lumpkin, or some one by him authorized, from the defendant Adams, which was used with his consent, and with knowledge of the purpose for which it was to be used. The picture was made from the negative without the plaintiff's consent, at the instance of the defendant insurance company, through its agent, Lumpkin. Plaintiff is an artist by profession, and the publication is peculiarly offensive to him. He never made any such statement, and has not, and never has had, a policy of life insurance with the defendant company. The publication is malicious, and tends to bring plaintiff into ridicule before the world, and especially with his friends and acquaintances, who know that he has no policy in the defendant company.

The right of privacy has its foundation in the instincts of nature. It is recognized intuitively, consciousness being the witness that can be called to establish its existence. Any person whose intellect is in a normal condition recognizes at once that as to each individual member of society there are matters private, and there are matters public so far as the individual is concerned. Each individual as instinctively
50 S.E. 68 (Ga. 1905)

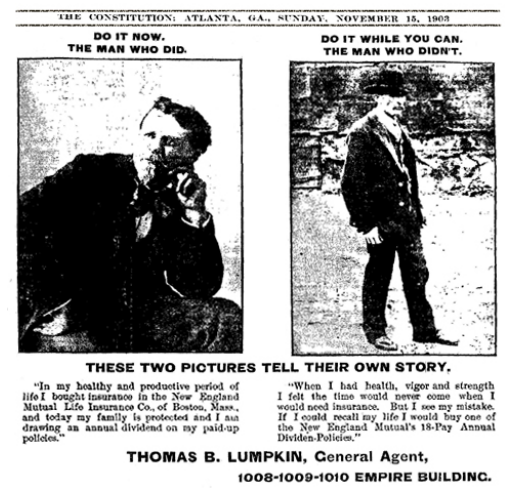

New England Mutual Life Insurance ad 
resents any encroachment by the public upon his rights which are of a private nature as he does the withdrawal of those of his rights which are of a public nature. A right of privacy in matters purely private is therefore derived from natural law.

All will admit that the individual who desires to live a life of seclusion cannot be compelled, against his consent, to exhibit his person in any public place, unless such exhibition is demanded by the law of the land. He may be required to come from his place of seclusion to perform public duties - to serve as a juror and to testify as a witness, and the like; but, when the public duty is once performed, if he exercises his liberty to go again into seclusion, no one can deny him the right. One who desires to live a life of partial seclusion has a right to choose the times, places, and manner in which and at which he will submit himself to the public gaze. Subject to the limitation above referred to, the body of a person cannot be put on exhibition at any time or at any place without his consent. The right of one to exhibit himself to the public at all proper times, in all proper places, and in a proper manner is embraced within the right of personal liberty. The right to withdraw from the public gaze at such times as a person may see fit, when his presence in public is not demanded by any rule of law, is also embraced within the right of personal liberty. Publicity in one instance, and privacy in the other, are each guarantied.

The right of privacy, however, like every other right that rests in the individual, may be waived. This waiver may be either express or implied, but the existence of the waiver carries with it the right to an invasion of privacy only to such an extent as may be legitimately necessary and proper in dealing with the matter which has brought about the waiver. It may be waived for one purpose, and still asserted for another; it may be waived in behalf of one class, and retained as against another class; it may be waived as to one individual, and retained as against all other persons. The most striking illustration of a waiver is where one either seeks or allows himself to be presented as a candidate for public office. He thereby waives any right to restrain or impede the public in any proper investigation into the conduct of his private life which may throw light upon his qualifications for the office, or the advisability of imposing upon him the public trust which the office carries. But even in this case the waiver does not extend into those matters and transactions of private life which are wholly foreign, and can throw no light whatever upon the question as to his competency for the office, or the propriety of bestowing it upon him.

Cases may arise where it is difficult to determine on which side of the line of demarkation which separates the right of privacy from the well-established rights of others they are to be found; but we have little difficulty in arriving at the conclusion that the present case is one 
in which it has been established that the right of privacy has been invaded, and invaded by one who cannot claim exemption under the constitutional guaranties of freedom of speech and of the press. The form and features of the plaintiff are his own. The defendant insurance company and its agent had no more authority to display them in public for the purpose of advertising the business in which they were engaged than they would have had to compel the plaintiff to place himself upon exhibition for this purpose. Nothing appears from which it is to be inferred that the plaintiff has waived his right to determine himself where his picture should be displayed in favor of the advertising right of the defendants. The mere fact that he is an artist does not of itself establish a waiver of this right, so that his picture might be used for advertising purposes. If he displayed in public his works as an artist, he would, of course, subject his works and his character as an artist, and possibly his character and conduct as a man, to such scrutiny and criticism as would be legitimate and proper to determine whether he was entitled to rank as an artist, and should be accorded recognition as such by the public. But it is by no means clear that even this would have authorized the publication of his picture. The constitutional right to speak and print does not necessarily carry with it the right to reproduce the form and features of man. The plaintiff was in no sense a public character, even if a different rule in regard to the publication of one's picture should be applied to such characters.

It is now to be determined whether first count in the petition set forth a cause of action for libel. The publication did not mention the plaintiff's name, but it did contain a likeness of him that his friends and acquaintances would readily recognize as his, and the words of the publication printed under the likeness were put into the mouth of him whose likeness was published. These words are harmless in themselves. Standing alone, they contain nothing, and carry no inference of anything that is disgraceful, to be ashamed of, or calculated to bring one into reproach.

It is alleged that the plaintiff did not have, and never had had, a policy of insurance with the defendant company, and that this fact was known to his friends and acquaintances. In the light of these allegations, the words attributed to the plaintiff become absolutely false, and those who are acquainted with the facts, upon reading the statement, would naturally ask, "For what purpose was this falsehood written?" It was either gratuitous, or it was for a consideration; and, whichever conclusion might be reached, the person to whom the words were attributed would become contemptible in the mind of the reader. He would become at once a self-confessed liar. If he lied gratuitously, he would receive and merit the contempt of all persons having a correct conception of moral principles. If he lied for a 
consideration, he would become odious to every decent individual. It seems clear to us that a jury could find from the facts alleged that the publication, in the light of the extrinsic facts, was libelous, and the plaintiff was entitled to have this question submitted to the jury.

\section{O'Brien v. Pabst Sales Co.}

Plaintiff, in physique as in prowess as a hurler, a modern David, is a famous football player. Defendant, in bulk, if not in brass and vulnerability, a modern Goliath, is a distributor of Pabst beer. Plaintiff, among other honors received during the year 1938, was picked by Grantland Rice on his Collier's All American Football Team. Defendant, as a part of its advertising publicity for 1939, following its custom of getting out football schedule calendars, placed an order with the Inland Lithographing Company, to prepare for and furnish to it, 35,000 Pabst 1939 football calendars. The calendars were to carry complete schedules of all major college games; professional schedules; and pictures of Grantland Rice's 1938 All American Football Team, the Inland Company to furnish photographs and necessary releases.

At the top of the calendar, as thus printed and circulated, were the words "Pabst Blue Ribbon." Directly underneath were the words "Football Calendar, 1939"; to the left of these words was a photograph of $\mathrm{O}^{\prime}$ Brien in football uniform characteristically poised for the throw; to the right of them was a glass having on it the words "Pabst Breweries, Blue Ribbon Export Beer"; and to the right of the glass still, a bottle of beer, having on it "Pabst Blue Ribbon Beer." Directly below these was the intercollegiate football schedule for 1939 , and in the center of the calender were pictures, including that of O'Brien, of Grantland Rice's All American Football Team for 1938. Near the bottom was the schedule of the national football league and on the very bottom margin, were the words "Pabst Famous Blue Ribbon Beer."

Claiming that this use of his photograph as part of defendant's advertising was an invasion of his right of privacy and that he had been damaged thereby, plaintiff brought this suit.

The defenses were three. The first was that if the mere use of one's picture in truthful and respectable advertising would be an actionable invasion of privacy in the case of a private person, the use here was not, as to plaintiff, such an invasion, for as a result of his activities and prowess in football, his chosen field, and their nationwide and deliberate publicizing with his consent and in his interest, he was no longer, as to them, a private but a public person, and as to their additional publication he had no right of privacy. The second defense was that plaintiff, in his own interest and that of Texas Christian University, had posed for and had authorized the publicity department of T. C. U. to distribute his picture and biographical data to newspapers, 
magazines, sports journals and the public generally, and that the particular picture whose use is complained of had been in due course obtained from and payment for it had been made to the T. C. U. publicity department. Third, no injury to appellant's person, property or reputation had been or could be shown and there was therefore no basis for a recovery. The testimony fully supported these defenses.

Assuming then, what is by no means clear, that an action for right of privacy would lie in Texas at the suit of a private person, we think it clear that the action fails; because plaintiff is not such a person and the publicity he got was only that which he had been constantly seeking and receiving; and because the use of the photograph was by permission, and there were no statements or representations made in connection with it, which were or could be either false, erroneous or damaging to plaintiff.

\section{b Property Theories}

Haelan shows the courts how courts overcame the conceptual obstacles to developing a property theory of the right of publicity that works for celebrities. Fraley shows how they turned it around to work for ordinary people as well.

\section{Haelan Laboratories v. Topps Chewing Gum}

The plaintiff maintains that defendant invaded plaintiff's exclusive right to use the photographs of leading baseball-players. Probably because the trial judge ruled against plaintiff's legal contentions, some of the facts were not too clearly found.

1. So far as we can now tell, there were instances of the following kind:

(a). The plaintiff, engaged in selling chewing-gum, made a contract with a ballplayer providing that plaintiff for a stated term should have the exclusive right to use the ball-player's photograph in connection with the sales of plaintiff's gum; the ball-player agreed not to grant any other gum manufacturer a similar right during such term; the contract gave plaintiff an option to extend the term for a designated period.

(b). Defendant, a rival chewing-gum manufacturer, knowing of plaintiff's contract, deliberately induced the ball-player to authorize defendant, by a contract with defendant, to use the player's photograph in connection with the sales of defendant's gum either during the original or extended term of plaintiff's contract, and defendant did so use the photograph.

Defendant argues that, even if such facts are proved, they show no actionable wrong, for this reason: The contract with plaintiff was no more than a release by the ballplayer to plaintiff of the liability which,

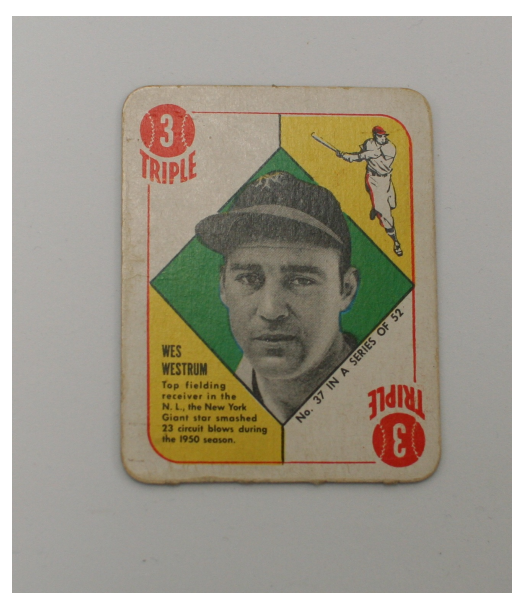

Wes Westrum baseball card 
absent the release, plaintiff would have incurred in using the ballplayer's photograph, because such a use, without his consent, would be an invasion of his right of privacy under Section 50 and Section 51 of the New York Civil Rights Law; this statutory right of privacy is personal, not assignable; therefore, plaintiff's contract vested in plaintiff no "property" right or other legal interest which defendant's conduct invaded.

Both parties agree, and so do we, that, on the facts here, New York "law" governs. And we shall assume, for the moment, that, under the New York decisions, defendant correctly asserts that any such contract between plaintiff and a ballplayer, in so far as it merely authorized plaintiff to use the player's photograph, created nothing but a release of liability. On that basis, were there no more to the contract, plaintiff would have no actionable claim against defendant. But defendant's argument neglects the fact that, in the contract, the ballplayer also promised not to give similar releases to others. If defendant, knowing of the contract, deliberately induced the ball-player to break that promise, defendant behaved tortiously.

2. The foregoing covers the situations where defendant, by itself or through its agent, induced breaches. But in those instances where [another company] induced the breach, we have a different problem; and that problem also confronts us in instances where defendant, with knowledge of plaintiff's exclusive rights, used a photograph of a ball-player without his consent during the term of his contract with plaintiff.

With regard to such situations, we must consider defendant's contention that none of plaintiff's contracts created more than a release of liability, because a man has no legal interest in the publication of his picture other than his right of privacy, i. e., a personal and nonassignable right not to have his feelings hurt by such a publication.

A majority of this court rejects this contention. We think that, in addition to and independent of that right of privacy (which in New York derives from statute), a man has a right in the publicity value of his photograph, i. e., the right to grant the exclusive privilege of publishing his picture, and that such a grant may validly be made "in gross," i. e., without an accompanying transfer of a business or of anything else. Whether it be labelled a "property" right is immaterial; for here, as often elsewhere, the tag "property" simply symbolizes the fact that courts enforce a claim which has pecuniary worth.

This right might be called a "right of publicity." For it is common knowledge that many prominent persons (especially actors and ballplayers), far from having their feelings bruised through public exposure of their likenesses, would feel sorely deprived if they no longer received money for authorizing advertisements, popularizing their countenances, displayed in newspapers, magazines, busses, trains 
and subways. This right of publicity would usually yield them no money unless it could be made the subject of an exclusive grant which barred any other advertiser from using their pictures.

We think the New York decisions recognize such a right.

Plaintiff, in its capacity as exclusive grantee of a player's "right of publicity," has a valid claim against defendant if defendant used that player's photograph during the term of plaintiff's grant and with knowledge of it. It is no defense to such a claim that defendant is the assignee of a subsequent contract. For the prior grant to plaintiff renders that subsequent grant invalid during the period of the grant to plaintiff.

\section{Joseph R. Grodin}

Note: The Right of Publicity: A Doctrinal Innovation

Haelan's right of publicity probably gives a famous person more than the right to assign a protectible interest in his name or picture. By allowing an individual to make a grant of the publicity value of his name or photograph, the Haelan case gave protection to persons' commercial interest in their personality independent of their privacy interest. In so doing, Haelan implied that such commercial interest, aside from any privacy interest, might justify legal protection of an individual against unauthorized use of his name or picture. While a famous person can generally invoke the right of privacy against an advertiser who appropriates his name or picture without permission, this right may not always afford adequate protection to his commercial interest in his personality. Celebrities complaining of the unauthorized use of their names or likenesses have sometimes been held, in effect, to have waived their right of privacy because they sought and received publicity in the past. And where relief has been granted under the privacy doctrine it is not clear whether plaintiffs have recovered damages for injury to the commercial interest in their popularity. But if the publicity value of a famous person's name or picture is to be shielded without reference to the right of privacy, these celebrities will be fully protected: prior publicity will enhance rather than bar relief. They will be able to obtain an injunction or recover damages commensurate with the advertising value of their names or pictures.

And the right of publicity may be extended beyond advertising cases. A famous person may wish to prevent appropriation of the public appeal of his personality by a telecast reproduction of his performance, a biography, or by use of his photograph for illustrating newspapers or magazines. Here, as in the advertising situation, the right of privacy has sometimes been considered waived because of plaintiff's past exposure in the public limelight, but this would not be a ground for denying relief under the right of publicity. And, where
In 1984, the New York Court of Appeals disagreed. "Since the 'right of publicity' is encompassed under the Civil Rights Law as an aspect of the right of privacy, which is exclusively statutory in this State, the plaintiff cannot claim an independent common-law right of publicity." Stephang

62 Yale L.J. 1123 (1953) 
Cal. Civ. Code $\S 3344$

Cal. Bus. Prof. Code § 17200, which grants broader consumer standing than Lanham Act § 43(a) courts have sometimes held that plaintiff's privacy interest was outweighed by the public's interest in news or information, the balance may now swing in plaintiff's favor if both his privacy and publicity interests are considered.

In applying the right of privacy, courts have confused commercial interests with privacy interests. The result of making one doctrine do the work of two has been inadequate protection for both these interests in personality. The right of privacy gives inadequate protection to the commercial interest in one's personality because courts have placed upon the right limitations which are appropriate only to the privacy interest. Similarly, in some states the right of privacy gives inadequate protection even to the privacy interest because courts and legislatures have implied that commercial benefit to the defendant is an element of the cause of action. If courts wish to protect both interests to at least some extent, they should do so under separate doctrines, so that limitations appropriate to each interest may be imposed. The Haelan case takes a long step in this direction.

Fraley v. Facebook, Inc.

At issue here is one of Facebook's advertising practices, "Sponsored Stories," which appear on a member's Facebook page, and which typically consist of another member's name, profile picture, and an assertion that the person "likes" the advertiser, coupled with the advertiser's logo. Sponsored Stories are generated when a member interacts with the Facebook website or affiliated sites in certain ways, such as by clicking on the "Like" button on a company's Facebook page.

In this putative class action, plaintiffs allege that Facebook's Sponsored Stories violate California's Right of Publicity Statute, California's Unfair Competition Law, and the common law doctrine of unjust enrichment.

Here, Plaintiffs allege not that they suffered mental anguish as a result of Defendant's actions, but rather that they suffered economic injury because they were not compensated for Facebook's commercial use of their names and likenesses in targeted advertisements to their Facebook Friends. Defendant does not deny that Plaintiffs may assert economic injury, but insists that, because they are not celebrities, they must demonstrate some preexisting commercial value to their names and likenesses, such as allegations that they previously received remuneration for the use of their name or likeness, or that they have ever sought to obtain such remuneration.

First, the Court finds nothing in the text of the statute or in case law that supports Defendant's interpretation of $\S 3344$ as requiring a plaintiff pleading economic injury to provide proof of preexisting commercial value and efforts to capitalize on such value in order to survive a motion to dismiss. In cases involving celebrity plaintiffs, 
the mere allegation that the plaintiff was not compensated has been deemed sufficient to satisfy the injury prong. Nor does the Court find any reason to impose a higher pleading standard on non-celebrities than on celebrities. California courts have clearly held that the statutory right of publicity exists for celebrity and non-celebrity plaintiffs alike.

Although generally, the greater the fame or notoriety of the identity appropriated, the greater will be the extent of the economic injury suffered, the appropriation of the identity of a relatively unknown person may result in economic injury or may itself create economic value in what was previously valueless. Thus, courts have long recognized that a person's name, likeness, or other attribute of identity can have commercial value, even if the individual is relatively obscure. In Downing v. Abercrombie \& Fitch, the Ninth Circuit sustained the $\S 3344$ claim of a surfer alleging that a clothing retailer had unlawfully used a photograph of him surfing for advertising purposes. As explained by the California appellate court, Although the unauthorized appropriation of an obscure plaintiff's name, voice, signature, photograph, or likeness would not inflict as great an economic injury as would be suffered by a celebrity plaintiff, California's appropriation statute is not limited to celebrity plaintiffs.

Admittedly, these previous non-celebrity plaintiffs have typically been models, entertainers, or other professionals who have cultivated some commercially exploitable value through their own endeavors. Nevertheless, the Court finds nothing requiring that a plaintiff's commercially exploitable value be a result of his own talents or efforts in order to state a claim for damages under $\S 3344$. In a society dominated by reality television shows, YouTube, Twitter, and online social networking sites, the distinction between a "celebrity" and a "noncelebrity" seems to be an increasingly arbitrary one.

Moreover, even if non-celebrities are subject to a heightened pleading standard under $\S 3344$, the Court finds that Plaintiffs' allegations satisfy the requirements for pleading a claim of economic injury under $§ 3344$. Plaintiffs quote Facebook CEO Mark Zuckerberg stating that "nothing influences people more than a recommendation from a trusted friend. A trusted referral influences people more than the best broadcast message. A trusted referral is the Holy Grail of advertising."

Thus, Plaintiffs have alleged that, in the same way that celebrities enjoy commercially exploitable opportunities among consumers at large, they enjoy commercially exploitable opportunities to advertise among their immediate friends and associates because in essence, Plaintiffs are celebrities - to their friends. While traditionally, advertisers had little incentive to exploit a non-celebrity's likeness because such endorsement would carry little weight in the economy at large, 
Plaintiffs' allegations suggest that advertisers' ability to conduct targeted marketing has now made friend endorsements a valuable marketing tool, just as celebrity endorsements have always been so considered.

\section{Subject Matter}

Typically the right of publicity covers at least one's name and likeness. How much further it extends is more controversial.

\section{Midler v. Ford Motor Co.}

This case centers on the protectibility of the voice of a celebrated chanteuse from commercial exploitation without her consent. Ford Motor Company and its advertising agency, Young \& Rubicam, Inc., in 1985 advertised the Ford Lincoln Mercury with a series of nineteen 30 or 60 second television commercials in what the agency called "The Yuppie Campaign." The aim was to make an emotional connection with Yuppies, bringing back memories of when they were in college. Different popular songs of the seventies were sung on each commercial. The agency tried to get "the original people," that is, the singers who had popularized the songs, to sing them. Failing in that endeavor in ten cases the agency had the songs sung by "sound alikes." Bette Midler, the plaintiff and appellant here, was done by a sound alike.

Midler is a nationally known actress and singer. She won a Grammy as early as 1973 as the Best New Artist of that year. Records made by her since then have gone Platinum and Gold. She was nominated in 1979 for an Academy award for Best Female Actress in The Rose, in which she portrayed a pop singer. Newsweek in its June 30, 1986 issue described her as an "outrageously original singer/comedian." Time hailed her in its March 2, 1987 issue as "a legend" and "the most dynamic and poignant singer-actress of her time."

When Young \& Rubicam was preparing the Yuppie Campaign it presented the commercial to its client by playing an edited version of Midler singing "Do You Want To Dance," taken from the $1973 \mathrm{Mi}-$ dler album, "The Divine Miss M." After the client accepted the idea and form of the commercial, the agency contacted Midler's manager, Jerry Edelstein. The conversation went as follows: "Hello, I am Craig Hazen from Young and Rubicam. I am calling you to find out if Bette Midler would be interested in doing ...? Edelstein: "Is it a commercial?" "Yes." "We are not interested."

Undeterred, Young \& Rubicam sought out Ula Hedwig whom it knew to have been one of "the Harlettes" a backup singer for Midler for ten years. Hedwig was told by Young \& Rubicam that "they 
wanted someone who could sound like Bette Midler's recording of [Do You Want To Dance]." She was asked to make a "demo" tape of the song if she was interested. She made an a capella demo and got the job.

At the direction of Young \& Rubicam, Hedwig then made a record for the commercial. The Midler record of "Do You Want To Dance" was first played to her. She was told to "sound as much as possible like the Bette Midler record," leaving out only a few "aahs" unsuitable for the commercial. Hedwig imitated Midler to the best of her ability.

After the commercial was aired Midler was told by "a number of people" that it "sounded exactly" like her record of "Do You Want To Dance." Hedwig was told by "many personal friends" that they thought it was Midler singing the commercial. Ken Fritz, a personal manager in the entertainment business not associated with Midler, declares by affidavit that he heard the commercial on more than one occasion and thought Midler was doing the singing.

Neither the name nor the picture of Midler was used in the commercial; Young \& Rubicam had a license from the copyright holder to use the song. At issue in this case is only the protection of Midler's voice. The district court described the defendants' conduct as that "of the average thief." They decided, "If we can't buy it, we'll take it." The court nonetheless believed there was no legal principle preventing imitation of Midler's voice and so gave summary judgment for the defendants. Midler appeals.

Nancy Sinatra once sued Goodyear Tire and Rubber Company on the basis of an advertising campaign by Young \& Rubicam featuring "These Boots Are Made For Walkin'," a song closely identified with her; the female singers of the commercial were alleged to have imitated her voice and style and to have dressed and looked like her. The basis of Nancy Sinatra's complaint was unfair competition; she claimed that the song and the arrangement had acquired a secondary meaning which, under California law, was protectible. This court noted that the defendants "had paid a very substantial sum to the copyright proprietor to obtain the license for the use of the song and all of its arrangements." To give Sinatra damages for their use of the song would clash with federal copyright law. Summary judgment for the defendants was affirmed. Sinatra $v$. Goodyear Tire E Rubber Co. If Midler were claiming a secondary meaning to "Do You Want To Dance" or seeking to prevent the defendants from using that song, she would fail like Sinatra. But that is not this case. Midler does not seek damages for Ford's use of "Do You Want To Dance," and thus her claim is not preempted by federal copyright law. Copyright protects original works of authorship fixed in any tangible medium of expression. A voice is not copyrightable. The sounds are not fixed.
Why couldn't Midler sue for copyright infringement for imitating her recorded version?

If these two cases are indication, Young \& Rubicam seems to have had a steady line of business making commercials with sound-alikes of famous female singers.

Sinatra: 435 F.2d 711 (9th Cir. 1970) 
Lahr: 300 F.2d 256 (1st Cir. 1962)

Cal. Civ. Code. $§ 990(b)$

Motschenbacher: 498 F.2d 821 (9th Cir. 1974)
What is put forward as protectible here is more personal than any work of authorship.

Bert Lahr once sued Adell Chemical Co. for selling Lestoil by means of a commercial in which an imitation of Lahr's voice accompanied a cartoon of a duck. Lahr alleged that his style of vocal delivery was distinctive in pitch, accent, inflection, and sounds. The First Circuit held that Lahr had stated a cause of action for unfair competition, that it could be found "that defendant's conduct saturated plaintiff's audience, curtailing his market." Lahr v. Adell Chemical Co.. That case is more like this one. But we do not find unfair competition here. One-minute commercials of the sort the defendants put on would not have saturated Midler's audience and curtailed her market. Midler did not do television commercials. The defendants were not in competition with her.

California Civil Code section 3344 is also of no aid to Midler. The statute affords damages to a person injured by another who uses the person's "name, voice, signature, photograph or likeness, in any manner." The defendants did not use Midler's name or anything else whose use is prohibited by the statute. The voice they used was Hedwig's, not hers. The term "likeness" refers to a visual image not a vocal imitation. The statute, however, does not preclude Midler from pursuing any cause of action she may have at common law.

The companion statute protecting the use of a deceased person's name, voice, signature, photograph or likeness states that the rights it recognizes are "property rights." By analogy the common law rights are also property rights. Appropriation of such common law rights is a tort in California. In Motschenbacher v. R.J. Reynolds Tobacco Co., what the defendants used in their television commercial for Winston cigarettes was a photograph of a famous professional racing driver's racing car. The number of the car was changed and a wing-like device known as a "spoiler" was attached to the car; the car's features of white pinpointing, an oval medallion, and solid red coloring were retained. The driver, Lothar Motschenbacher, was in the car but his features were not visible. Some persons, viewing the commercial, correctly inferred that the car was his and that he was in the car and was therefore endorsing the product. The defendants were held to have invaded a "proprietary interest" of Motschenbacher in his own identity.

Midler's case is different from Motschenbacher's. He and his car were physically used by the tobacco company's ad; he made part of his living out of giving commercial endorsements. But, as Judge Koelsch expressed it in Motschenbacher, California will recognize an injury from "an appropriation of the attributes of one's identity." It was irrelevant that Motschenbacher could not be identified in the ad. The ad suggested that it was he. The ad did so by emphasizing signs 
or symbols associated with him. In the same way the defendants here used an imitation to convey the impression that Midler was singing for them.

Why did the defendants ask Midler to sing if her voice was not of value to them? Why did they studiously acquire the services of a sound-alike and instruct her to imitate Midler if Midler's voice was not of value to them? What they sought was an attribute of Midler's identity. Its value was what the market would have paid for Midler to have sung the commercial in person.

A voice is more distinctive and more personal than the automobile accouterments protected in Motschenbacher. A voice is as distinctive and personal as a face. The human voice is one of the most palpable ways identity is manifested. We are all aware that a friend is at once known by a few words on the phone. At a philosophical level it has been observed that with the sound of a voice, "the other stands before me.". A fortiori, these observations hold true of singing, especially singing by a singer of renown. The singer manifests herself in the song. To impersonate her voice is to pirate her identity.

We need not and do not go so far as to hold that every imitation of a voice to advertise merchandise is actionable. We hold only that when a distinctive voice of a professional singer is widely known and is deliberately imitated in order to sell a product, the sellers have appropriated what is not theirs and have committed a tort in California. Midler has made a showing, sufficient to defeat summary judgment, that the defendants here for their own profit in selling their product did appropriate part of her identity.

White v. Samsung Electronics America, Inc.

Plaintiff Vanna White is the hostess of "Wheel of Fortune," one of the most popular game shows in television history. An estimated forty million people watch the program daily. Capitalizing on the fame which her participation in the show has bestowed on her, White markets her identity to various advertisers.

The dispute in this case arose out of a series of advertisements prepared for Samsung by Deutsch. The series ran in at least half a dozen publications with widespread, and in some cases national, circulation. Each of the advertisements in the series followed the same theme. Each depicted a current item from popular culture and a Samsung electronic product. Each was set in the twenty-first century and conveyed the message that the Samsung product would still be in use by that time. By hypothesizing outrageous future outcomes for the cultural items, the ads created humorous effects. For example, one lampooned current popular notions of an unhealthy diet by depicting a raw steak with the caption: "Revealed to be health food. 2010 A.D." Another depicted irreverent "news"-show host Morton
D. Ihde, Listening and Voice 77 (1976)

971 F.2d 1395 (9th Cir. 1992) 


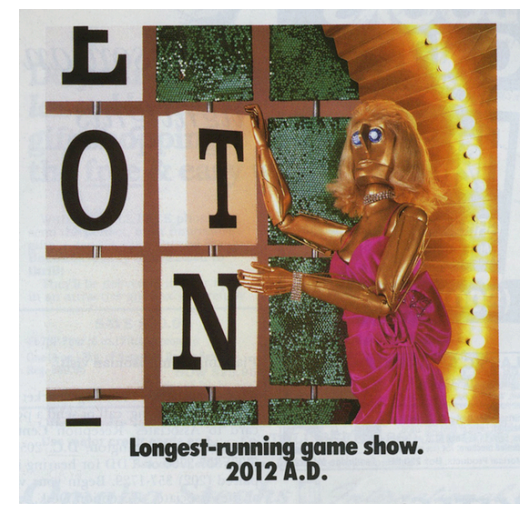

Samsung game show ad
Downey Jr. in front of an American flag with the caption: "Presidential candidate. 2008 A.D."

The advertisement which prompted the current dispute was for Samsung videocassette recorders (VCRs). The ad depicted a robot, dressed in a wig, gown, and jewelry which Deutsch consciously selected to resemble White's hair and dress. The robot was posed next to a game board which is instantly recognizable as the Wheel of Fortune game show set, in a stance for which White is famous. The caption of the ad read: "Longest-running game show. 2012 A.D." Defendants referred to the ad as the "Vanna White" ad. Unlike the other celebrities used in the campaign, White neither consented to the ads nor was she paid.

Following the circulation of the robot ad, White sued Samsung and Deutsch in federal district court under: (1) California Civil Code S 3344; (2) the California common law right of publicity; and (3) S 43(a) of the Lanham Act.

\section{SECTION 3344}

White first argues that the district court erred in rejecting her claim under section 3344. Section 3344(a) provides, in pertinent part, that "[a]ny person who knowingly uses another's name, voice, signature, photograph, or likeness, in any manner, ... for purposes of advertising or selling, ... without such person's prior consent ... shall be liable for any damages sustained by the person or persons injured as a result thereof."

White argues that the Samsung advertisement used her "likeness" in contravention of section 3344. In Midler, this court rejected Bette Midler's section 3344 claim concerning a Ford television commercial in which a Midler "sound-alike" sang a song which Midler had made famous. In rejecting Midler's claim, this court noted that "the defendants did not use Midler's name or anything else whose use is prohibited by the statute. The voice they used was another person's, not hers. The term 'likeness' refers to a visual image not a vocal imitation."

In this case, Samsung and Deutsch used a robot with mechanical features, and not, for example, a manikin molded to White's precise features. Without deciding for all purposes when a caricature or impressionistic resemblance might become a "likeness," we agree with the district court that the robot at issue here was not White's "likeness" within the meaning of section 3344. Accordingly, we affirm the court's dismissal of White's section 3344 claim.

\section{Right of Publicity}

In Carson v. Here's Johnny Portable Toilets, Inc., the defendant had marketed portable toilets under the brand name "Here's Johnny" - 
Johnny Carson's signature "Tonight Show" introduction - without Carson's permission. The sixth circuit held that the right was implicated because the defendant had appropriated Carson's identity by usin the phrase "Here's Johnny."

It is not important how the defendant has appropriated the plaintiff's identity, but whether the defendant has done so. Motschenbacher, Midler, and Carson teach the impossibility of treating the right of publicity as guarding only against a laundry list of specific means of appropriating identity. A rule which says that the right of publicity can be infringed only through the use of nine different methods of appropriating identity merely challenges the clever advertising strategist to come up with the tenth.

Indeed, if we treated the means of appropriation as dispositive in our analysis of the right of publicity, we would not only weaken the right but effectively eviscerate it. The right would fail to protect those plaintiffs most in need of its protection. Advertisers use celebrities to promote their products. The more popular the celebrity, the greater the number of people who recognize her, and the greater the visibility for the product. The identities of the most popular celebrities are not only the most attractive for advertisers, but also the easiest to evoke without resorting to obvious means such as name, likeness, or voice.

Consider a hypothetical advertisement which depicts a mechanical robot with male features, an African-American complexion, and a bald head. The robot is wearing black hightop Air Jordan basketball sneakers, and a red basketball uniform with black trim, baggy shorts, and the number 23 (though not revealing "Bulls" or "Jordan" lettering). The ad depicts the robot dunking a basketball one-handed, stiff-armed, legs extended like open scissors, and tongue hanging out. Now envision that this ad is run on television during professional basketball games. Considered individually, the robot's physical attributes, its dress, and its stance tell us little. Taken together, they lead to the only conclusion that any sports viewer who has registered a discernible pulse in the past five years would reach: the ad is about Michael Jordan.

Viewed separately, the individual aspects of the advertisement in the present case say little. Viewed together, they leave little doubt about the celebrity the ad is meant to depict. The female-shaped robot is wearing a long gown, blond wig, and large jewelry. Vanna White dresses exactly like this at times, but so do many other women. The robot is in the process of turning a block letter on a game-board. Vanna White dresses like this while turning letters on a game-board but perhaps similarly attired Scrabble-playing women do this as well. The robot is standing on what looks to be the Wheel of Fortune game show set. Vanna White dresses like this, turns letters, and does this on the Wheel of Fortune game show. She is the only one. Indeed, 
defendants themselves referred to their ad as the "Vanna White" ad. We are not surprised.

Television and other media create marketable celebrity identity value. Considerable energy and ingenuity are expended by those who have achieved celebrity value to exploit it for profit. The law protects the celebrity's sole right to exploit this value whether the celebrity has achieved her fame out of rare ability, dumb luck, or a combination thereof. We decline Samsung and Deutch's invitation to permit the evisceration of the common law right of publicity through means as facile as those in this case. Because White has alleged facts showing that Samsung and Deutsch had appropriated her identity, the district court erred by rejecting, on summary judgment, White's common law right of publicity claim.

ALARCON, Circuit Judge, concurring in part, dissenting in part

The common theme in these federal cases is that identifying characteristics unique to the plaintiffs were used in a context in which they were the only information as to the identity of the individual. The commercial advertisements in each case showed attributes of the plaintiff's identities which made it appear that the plaintiff was the person identified in the commercial. No effort was made to dispel the impression that the plaintiffs were the source of the personal attributes at issue. The commercials affirmatively represented that the plaintiffs were involved. The proper interpretation of Motschenbacher, Midler, and Carson is that where identifying characteristics unique to a plaintiff are the only information as to the identity of the person appearing in an ad, a triable issue of fact has been raised as to whether his or her identity as been appropriated.

The case before this court is distinguishable from the factual showing made in Motschenbacher, Midlen, and Carson. It is patently clear to anyone viewing the commercial advertisement that Vanna White was not being depicted. No reasonable juror could confuse a metal robot with Vanna White.

\section{White v. Samsung Electronics America, Inc.}

KOZINSKI, Circuit Judge, dissenting from the order rejecting the suggestion for rehearing en banc

The majority isn't, in fact, preventing the "evisceration" of Vanna White's existing rights; it's creating a new and much broader property right, a right unknown in California law. It's replacing the existing balance between the interests of the celebrity and those of the public by a different balance, one substantially more favorable to the celebrity. Instead of having an exclusive right in her name, likeness, signature or voice, every famous person now has an exclusive right 
to anything that reminds the viewer of her. After all, that's all Samsung did: It used an inanimate object to remind people of White, to "evoke [her identity].1.7

Consider how sweeping this new right is. What is it about the ad that makes people think of White? It's not the robot's wig, clothes or jewelry; there must be ten million blond women (many of them quasi-famous) who wear dresses and jewelry like White's. It's that the robot is posed near the "Wheel of Fortune" game board. Remove the game board from the ad, and no one would think of Vanna White. But once you include the game board, anybody standing beside it a brunette woman, a man wearing women's clothes, a monkey in a wig and gown - would evoke White's image, precisely the way the robot did. It's the "Wheel of Fortune" set, not the robot's face or dress or jewelry that evokes White's image. The panel is giving White an exclusive right not in what she looks like or who she is, but in what she does for a living. .18

This is entirely the wrong place to strike the balance. Intellectual property rights aren't free: They're imposed at the expense of future creators and of the public at large. Where would we be if Charles Lindbergh had an exclusive right in the concept of a heroic solo aviator? If Arthur Conan Doyle had gotten a copyright in the idea of the detective story, or Albert Einstein had patented the theory of relativity? If every author and celebrity had been given the right to keep people from mocking them or their work? Surely this would have made the world poorer, not richer, culturally as well as economically.

Future Vanna Whites might not get the chance to create their personae, because their employers may fear some celebrity will claim the

\footnotetext{
${ }^{17}$ Some viewers might have inferred White was endorsing the product, but that's a different story. The right of publicity isn't aimed at or limited to false endorsements; that's what the Lanham Act is for.

${ }^{18}$ Once the right of publicity is extended beyond specific physical characteristics, this will become a recurring problem: Outside name, likeness and voice, the things that most reliably remind the public of celebrities are the actions or roles they're famous for. A commercial with an astronaut setting foot on the moon would evoke the image of Neil Armstrong. Any masked man on horseback would remind people (over a certain age) of Clayton Moore. And any number of songs - "My Way," "Yellow Submarine," "Like a Virgin," "Beat It," "Michael, Row the Boat Ashore," to name only a few - instantly evoke an image of the person or group who made them famous, regardless of who is singing.

See also Carlos V. Lozano, West Loses Lawsuit over Batman TV Commercial, L.A. Times, Jan. 18, 1990, at B3 (Adam West sues over Batmanlike character in commercial); Nurmi v. Peterson, 10 U.S.P.Q.2d 1775, 1989 WL 407484 (C.D. Cal. 1989) (1950s TV movie hostess "Vampira" sues 1980s TV hostess "Elvira"); text accompanying notes 7-8 (lawsuits brought by Guy Lombardo, claiming big bands playing at New Year's Eve parties remind people of him, and by Uri Geller, claiming psychics who can bend metal remind people of him). Cf. Motschenbacher, where the claim was that viewers would think plaintiff was actually in the commercial, and not merely that the commercial reminded people of him.
} 
persona is too similar to her own.21

\section{Procedures}

There are no procedural prerequisites to owning a right of publicity, other perhaps than the vestigial suggestion (rejected in Fraley) that one must have commercially exploited one's likeness to sue for its appropriation. The most interesting procedural issue raised by the right of publicity is its duration.

903 F. Supp. 2d 932 (C.D. Cal. 2012)

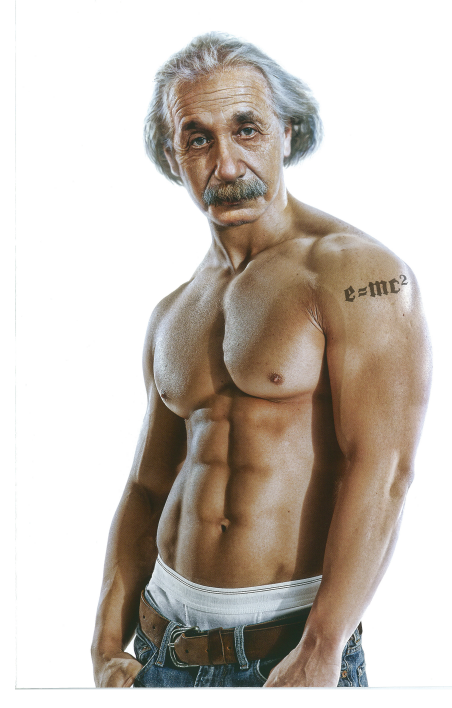

GM Terrain ad

McCarthy S 9:16

Presley: 513 F. Supp. at 1339 (D.N.J. 1981)

\section{Hebrew University of Jerusalem v. General Motors}

\section{INTRODUCTION}

Defendant General Motors LLC ("GM") used an image of Albert Einstein in a November 2009 advertisement for its 2010 Terrain vehicle. The ad depicted Einstein's face digitally pasted onto a muscled physique, accompanied by the written message "Ideas are sexy too." The ad ran in only one issue of People magazine. Plaintiff Hebrew University of Jerusalem ("HUJ"), which claims to own Einstein's right of publicity as a beneficiary under Einstein's will and thus exclusive control of the exploitation of his name and likeness, brought suit against GM for this unauthorized use of Einstein's image.

For the reasons set forth below, the Court concludes that the New Jersey Supreme Court would likely find that the postmortem right of publicity endures for no more than 50 years after death.

\section{AnAlysis}

J. Thomas McCarthy, the leading commentator on the right of publicity, has characterized the determination of the right's duration as "by nature almost arbitrary." An "almost arbitrary" ruling is unacceptable, however. The following analysis seeks to avoid one.

\section{B. Status of Existing New Jersey Law Concerning the Duration of the Postmortem Right of Publicity}

Only one court in New Jersey, a federal district court, has ever discussed the question of duration, and it did not decide the issue. Estate of Presley The primary question in Presley was whether New Jersey

\footnotetext{
${ }^{21}$ If Christian Slater, star of "Heathers," "Pump up the Volume," "Kuffs," and "Untamed Heart" - and alleged Jack Nicholson clone - appears in a commercial, can Nicholson sue? Of 54 stories on LEXIS that talk about Christian Slater, 26 talk about Slater's alleged similarities to Nicholson. Apparently it's his nasal wisecracks and killer smiles, St. Petersburg Times, Jan. 10, 1992, at 13, his eyebrows, Ottawa Citizen, Jan. 10, 1992, at E2, his sneers, Boston Globe, July 26, 1991, at 37, his menacing presence, USA Today, June 26, 1991, at 1D, and his sing-song voice, Gannett News Service, Aug. 27, 1990 (or, some say, his insinuating drawl, L.A. Times, Aug. 22, 1990, at F5). That's a whole lot more than White and the robot had in common.
} 
recognized a descendible, postmortem right of publicity. The court found that it does, holding that "Elvis Presley's right of publicity survived his death and became part of Presley's estate." With respect to the duration of the right of publicity, however, the Presley court merely stated that the state legislature should determine that question, although it also noted that the federal Copyright Act, which at that time provided for a copyright term of life plus 50 years, could provide guidance. No state court in New Jersey has ever addressed the issue.

Although the New Jersey Legislature has considered at least two bills that would create a statutory right of publicity, it has thus far not seen fit to enact such a right. See A.3536, 213th Legis. (N.J. 2008) (proposing the "Celebrity Image Protection Act," with a postmortem duration of 70 years); A.4476, 212th Legis. (N.J. 2007) (same). There is nothing stopping HUJ from petitioning the New Jersey Legislature to pass a statute, with retroactive applicability, that would create a definitive postmortem right of publicity with the extended duration that HUJ seeks here.

\section{Aspects of the Right of Publicity that Should Affect Its Duration}

\section{The Right of Publicity's Origins in the Right of Privacy}

The right of publicity originally developed within the array of privacy rights that are considered personal, are based on dignitary interests and are not descendible.

Now, however, the right of publicity is widely understood, including in New Jersey, to be akin to intellectual property. Additionally, "[w]ith its emphasis on commercial interests, the right of publicity also secures for plaintiffs the commercial value of their fame and prevents the unjust enrichment of others seeking to appropriate that value for themselves."

Notwithstanding the trend toward treating the right of publicity as a commercial property right, HUJ contends that the right of publicity is a deeply personal right. It is true that one of the rationales for recognizing a right of publicity remains its protection of an individual's interest in personal dignity and autonomy. Surely, however, the personal interest that is at stake becomes attenuated after the personality dies.

A maximum 50-year postmortem duration here would be a reasonable middle ground that is long enough for a deceased celebrity's heirs to take advantage of and reap the benefit of the personal aspects of the right. See Restatement (Third) of Unfair Competition S $46 \mathrm{cmt}$. $\mathrm{h}$ ("As a general matter, however, the dignitary and proprietary interests that support the recognition of a right of publicity become substantially attenuated after death. Post mortem uses are also less likely
Restatement (Third) of Unfair Competition S $46 \mathrm{cmt}$. c. 
to create a false suggestion of endorsement or sponsorship."). The obviously humorous ad for the 2010 Terrain having been published 55 years or more after Einstein's death, it is unlikely that any viewer of it could reasonably infer that Einstein or whoever succeeded to any right of publicity that Einstein may have had was endorsing the GMC Terrain.

\section{Copyright Law Considerations}

HUJ argues that, if the Court must set a limit on the postmortem right of publicity, it should be coterminus with the current federal Copyright Act, which protects copyrights for 70 years after death. This Court disagrees. The purpose of the right and its underlying policies do not warrant a mechanical application of the Copyright Act's term of life plus 70 years. Indeed, although McCarthy ultimately recognizes that using the federal Copyright Act as a model will "more often than not provide the tie-breaking solution to the problem" of determining the postmortem duration of the right of publicity, , it is clear that such an analogy is inconsistent with McCarthy's own views about the purpose and policies underlying the right. In fact, he would prefer to limit the extent of the right to 10-20 years after death, despite noting that other commentators have proposed longer durations, including a life-plus-50-year term modeled after the former version of the federal Copyright Act.

The current 70-year postmortem term was enacted by the 1998 Copyright Term Extension Act, which increased the length of copyright protection from its former duration of life plus 50 years. HUJ acquired Einstein's right of publicity in 1982, at which time the 1976 Copyright Act was in place - with a 50-year postmortem duration. HUJ's reasonable expectation at that time, based on the same theory of analogy to copyright that it advocates today, necessarily would have been that any rights it acquired would not last more than 50 years after Einstein's death. Similarly, when the Presley court suggested that the New Jersey Legislature consider the Copyright Act as a guide in setting a postmortem duration for the right of publicity, that statute had only a life-plus-50-year duration. This was approximately one year before HUJ acquired its interest.

There are certain similarities between the goals of copyright and those of the right of publicity. In a sense, both rights evolve from an act of creation, whether it is the creation of a "work" such as a writing or the creation of a cultivated persona. These acts of creation are the product of an individual's choices and self-expression. Some courts, accordingly, have analogized between copyright and the right of publicity in the context of balancing the interests protected by those rights with the interests protected under the First Amendment.

Despite the intersecting similarities between copyright and the 
right of publicity, however, that the right of publicity is an outgrowth of the right of privacy suggests that the term of copyright protection is far from a perfect precedent for determining the duration of the right of publicity. First, as HUJ itself has argued, the right of publicity is an intensely personal right meant, to some extent, to protect against personal and dignitary harms, such as having one's persona associated with a product or idea of which he disapproves.

Moreover, the protection of copyright is designed to encourage the future creation of works of art, whereas the interest sought to be protected by the right of publicity is usually the byproduct of a different and earlier endeavor. The commercial value of a person's identity often results from success in endeavors such as entertainment or sports that offer their own substantial rewards. Any additional incentive attributable to the right of publicity may have only marginal significance. For this reason, it is questionable whether those interests should be protected for as long a period after the death of the person to whom they belong as are his copyrighted works.

\section{Other States' Laws}

\section{Common Law}

Looking beyond New Jersey, in none of the five other states that recognize a common law postmortem right of publicity has any court addressed the issue of the right's duration, or even raised it as a question needing to be answered. In none of those cases, however, was the interval between the death of the person whose right of publicity was at stake and the date of the alleged infringement of that right 50 years or longer. Indeed, in most of the cases the period was 10 years or less. See, e.g., , Gignilliat v. Gignilliat, Savitz \& Bettis, LLP (maximum of 7 years at issue); Jim Henson Productions v. John T. Brady \& Assoc. (maximum of 4 years at issue); Nature's Way Products, Inc. v. NaturePharma, Inc.; (maximum of 7 years at issue); Presley (permitting right of publicity claim brought three years after Elvis's death).

\section{Statutes}

The majority of states with statutory rights of publicity limit the right's postmortem duration to 50 years or less. Seven states have statutory rights of publicity that permit the right to endure for up to 50 years.

Six states allow the postmortem right of publicity to reach 60 years or more.

Of the states whose statutes were enacted prior to the revision of the Copyright Act in 1998, only California amended its statute to reflect the extended copyright term.

Thus, of the states with currently enacted statutory rights of pub-
Gignilliat: 684 S.E.2d 756 (S.C. 2009)

Jim Henson Productions: 867 F. Supp. 175 (S.D. Neb. 1994)

Nature's Way: 736 F. Supp. 245 (D. Utah 1990)

Florida: 40 years

Illinois: 50 years

Kentucky: 50 years

Nevada: 50 years

Pennsylvania: 30 years

Texas: 50 years

Virginia: 20 years

California: 70 years

Indiana: 100 years

Ohio: 60 years

Oklahoma: 100 years

Tennessee: indefinite

Washington: up to 75 years 
licity, a slight majority limits the duration of that right to 50 years or less. Although this does not provide overwhelming support for such a length of time, it does tip the balance slightly in that direction.

\section{E. Public Policy Counsels in Favor of Limiting the Postmortem Right of Publicity to Not More Than 50 Years}

One of the overarching policy concerns in enforcing intellectual property rights is the balance that must be struck between protecting an individual's right to reap the benefits of his creative endeavors and the public's freedom of expression. This policy concern extends to the right of publicity.

An open-ended right of publicity, or even a postmortem duration longer than 50 years, raises considerable First Amendment concerns and creates a potentially infinite curb on expression. Additionally, an extended right of publicity may interfere with or decrease the value of copyrighted works, such as photographs, thereby pitting one form of protected property against another.

In addition to First Amendment implications, there is another consideration. In the 57 years since Albert Einstein died, the means of communication have increased and so has the proclivity of people to use them frequently. Journalists, academics and politicians frequently issue pronouncements about the impact on society, both in the United States and around the globe, of the dizzying explosion in the tools of communication. New devices and platforms have been developed, including smart phones, personal computers, social networks, email, Twitter, blogs, etc. These technologies have caused a swift and dramatic, but still developing, impact on ordinary life. It has become a truism that their speed, their accessibility, and their popularity appear to have changed social norms regarding privacy and public expression. But it is not yet clear what this should mean for the protection of such rights as the right of privacy, the right of expression and the right of publicity. For example, on balance should the law increasingly protect people's right of expression, now that we enjoy so many fora in which to broadcast our views? Similarly, should the law value the right of privacy less than before, given that many social media devotees, especially young people, are said to have little compunction about revealing intimate information about themselves? Conversely, should the law afford celebrities greater rights in controlling publicity about themselves, to protect against what appears to be a growing tendency of people to not just exalt but even to exploit the fame and celebrity of others?

The Court does not profess to have answers to these questions, but what is clear is that since the full impact of these rapid changes remains uncertain, it would be imprudent to issue any ruling that 
strengthens (or at least lengthens) one right - that of the right of publicity - to the potentially significant detriment of these other rights.

\section{Conclusion}

Absent a legislative directive to the contrary, to extend the right of publicity beyond a half century would be inconsistent with the Court's responsibility to balance all of the interests that are at stake. It also would risk having that right treated as an open-ended heredity right. See McCarthy (noting the need "to avoid descendants or heirs unto the nth generation reaping the commercial rewards of a distant and famous ancestor, a 'favored bloodline' concept out of step with a society that has abolished hereditary titles" and that at some point, the interests of free speech outweigh the interests of the heirs and "the person's identity should enter the public domain as a part of history and folklore").

A maximum duration of 50 years appropriately reflects the balance between meaningful enforcement of the right of publicity after a famous individual's death and the public's interest in free expression. It aligns with the majority of current state statutes limiting the right's postmortem duration. And it approximates the period evidently contemplated by the Presley court - the one court in New Jersey to have discussed the duration of the right - when it encouraged that state's legislature to consider the issue with guidance from the then-current Copyright Act.

The Ninth Circuit recently noted that Marilyn Monroe considered herself to belong "to the Public and to the world." Milton H. Greene Archives, Inc. v. Marilyn Monroe LLC. There is no evidence that Albert Einstein saw himself that way, but he did become the symbol and embodiment of genius. His persona has become thoroughly ingrained in our cultural heritage. Now, nearly 60 years after his death, that persona should be freely available to those who seek to appropriate it as part of their own expression, even in tasteless ads.

\section{Infringement: Similarity}

For a use to infringe, the plaintiff must be identifiable. This is effectively a similarity test between the defendant's use and the plaintiff's persona. Also, look back at the subject matter cases and the cases they discuss, especially Motschenbachen, which illustrate some variations on identifiability. Have the courts there conflated similarity with subject matter? Or is that precisely the point, that once identifiability is shown, there is no need for limiting subject-matter doctrines?

\section{Hooker v. Columbia Pictures Industries, Inc.}

Plaintiff is a professional woodcarver from Woodstock, Illinois. Examining the host of exhibits appended to the affidavit which he has
McCarthy S 9:16

Milton H. Greene Archives: 692 F.3d 983 (9th Cir 2012)

551 F. Supp. 1060 (N.D. III. 1982) 


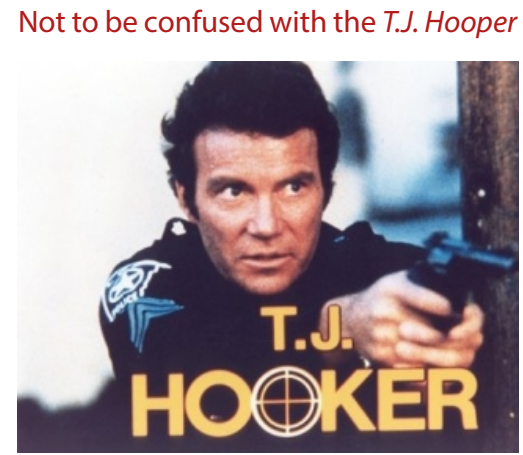

William Shatner in T.J. Hooker submitted, it appears that while plaintiff does carve other birds, he specializes in ducks. Plaintiff's ducks are of the highest quality. Some of them are described as "exquisite" and sell for a great deal of money. Plaintiff's name is T.J. Hooker.

The defendants produce and broadcast a television series about a fictional policeman in California. Never having heard of plaintiff or his celebrated ducks, the defendants happened to name their imaginary policeman "T.J. Hooker." Not surprisingly, the series is also entitled "T.J. Hooker."

Count I of the complaint is based upon the common law tort of appropriation of the plaintiff's name or likeness for the defendants' benefit or advantage. $n$ order to state a claim for relief based on this theory, it is vital that some "appropriation" be alleged. See W. Prosser, Law of Torts $\S 117$ (4th ed. 1971). "Appropriation" in this context means more than the mere coincidental use of a name that happens to be the same as that of the plaintiff. Dean Prosser explained this as follows:

It is the plaintiff's name as a symbol of his identity that is involved here, and not as a mere name. Unless there is some tortious use made of it, there is no such thing as an exclusive right to the use of a name; and any one can be given or assume any name he likes. It is only when he makes use of the name to pirate the plaintiff's identity for some advantage of his own, as by impersonation to obtain credit or secret information, or by posing as the plaintiff's wife, or providing a father for a child on a birth certificate, that he becomes liable. It is in this sense that "appropriation" must be understood. It is therefore not enough that a name which is the same as the plaintiff's is used in a novel, or the title of a corporation, unless the context or the circumstances indicate that the name is that of the plaintiff.... Nor is there any liability when the plaintiff's character, occupation, and the general outline of his career, with many real incidents in his life, are used as the basis for a figure in a novel who is still clearly a fictional one.

Similarly, the Restatement of Torts makes it clear that it is not the use of the plaintiff's name which constitutes a tort but rather the appropriation of the value of his name and reputation:

It is not enough that the defendant has adopted for himself a name that is the same as that of the plaintiff, so long as he does not pass himself off as the plaintiff or otherwise seek to obtain for himself the values or benefits of the plaintiff's name or identity. Unless there is such an appropriation, 
the defendant is free to call himself by any name he likes, whether there is only one person or a thousand others of the same name. Until the value of the name has in some way been appropriated, there is no tort.

Examining Count I in light of the foregoing principles, it is apparent that plaintiff has failed to allege a tortious appropriation of his name. Plaintiff does allege that "[d]efendants' ... use of plaintiff's name appropriates the right of publicity in plaintiff's celebrated name." But this broad, conclusory allegation cannot substitute for allegations of facts showing that the defendants used the name "T.J. Hooker" as a means of pirating plaintiff's identity. By his own admission, the commercial value of plaintiff's name is in the field of wildlife art. Hunters, sportsmen, and collectors identify plaintiff's name with fine carvings of ducks and other fowl. There is nothing in the complaint which can be construed as an allegation that the defendants adopted the name "T.J. Hooker" in order to avail themselves of plaintiff's reputation as an extraordinary woodcarver.

Plaintiff admits that the fictional television series at issue here is a "police drama." It is difficult to imagine a subject further removed for the life of T.J. Hooker the artisan. The facts and circumstances alleged by plaintiff provide no basis upon which it can be found that the name "T.J. Hooker," as used in the defendants' fictional television series, in any way refers to the real T.J. Hooker.

There being no well-pleaded allegation of appropriation of the value of plaintiff's name, plaintiff has failed to state a claim upon which relief can be granted.

\section{Infringement: Prohibited Conduct}

\section{a Direct Infringement}

The usual threshold rule is that the right of publicity only applies to commercial and advertising uses. The caselaw is thin on whether violations need to be intentional.

\section{Stephano v. News Group Publications, Inc.}

The plaintiff, a professional model, claims that the defendant used his picture for trade or advertising purposes without his consent, and thus violated his statutory right to privacy (Civil Rights Law, § 51), by publishing a picture of him modeling a "bomber jacket" in a magazine article containing information regarding the approximate price of the jacket, the name of the designer, and the names of three stores where the jacket might be purchased. Plaintiff also claims that the defendant's conduct violated a common-law right of publicity. The trial court granted summary judgment to the defendant concluding that
Suppose that the plaintiff were the star of a long-running top-rated reality show about woodcarving. Same result?

64 N.Y.2d 174 (1984) 


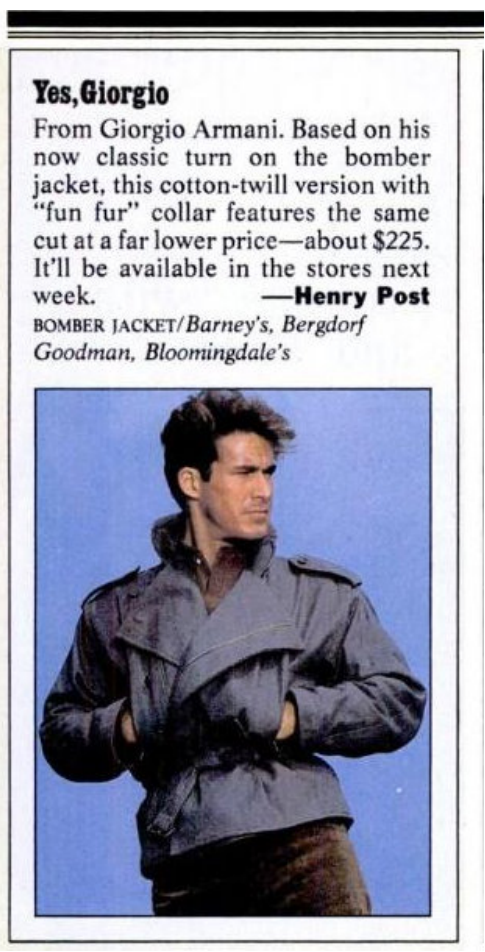

The "Best Bets" item featuring Stephano the article reported a newsworthy event of fashion news, and was not published for trade or advertising purposes. A divided Appellate Division reversed and denied summary judgment finding that factual questions were presented as to whether the defendant had used the plaintiff's picture for trade purposes and whether the article constituted an advertisement in disguise.

In the summer of 1981 the plaintiff agreed to model for an article on men's fall fashions. The photographic session took place on August 11, 1981. The defendant used two of the photographs taken during that session to illustrate an article entitled "Classic Mixes", which appeared under the heading "Fall Fashions" in the September 7, 1981 issue of New York magazine. Another photograph taken during the session was used, a week earlier, in the August 31, 1981 issue of New York magazine, in a column entitled "Best Bets". That column, a regular feature in the magazine, contains information about new and unusual products and services available in the metropolitan area. One of the items included in the August 31 column was a bomber jacket modeled by the plaintiff. The text above the picture states: "Yes Giorgio - From Giorgio Armani. Based on his now classic turn on the bomber jacket, this cotton-twill version with 'fun fur' collar features the same cut at a far lower price - about $\$ 225$. It'll be available in the stores next week. - Henry Post Bomber Jacket/Barney's, Bergdorf Goodman, Bloomingdale's."

It is the plaintiff's contention that he agreed to model for one article only - the September 7, 1981 article on Fall Fashions - and that the defendant violated his rights by publishing his photograph in the August 31 "Best Bets" column. The complaint alleges two causes of action. First the plaintiff claims that the defendant violated his civil rights by using his photograph for trade or advertising purposes without his consent. In his second cause of action the plaintiff claims that the defendant's conduct "invaded plaintiff's right of publicity". On each cause of action the plaintiff seeks \$350,000 in compensatory damages and an equal amount in exemplary damages.

The only question is whether the defendant used the plaintiff's picture for trade or advertising purposes within the meaning of the statute when it published his picture in the "Best Bets" column with-

\footnotetext{
${ }^{1}$ In his brief to this court the plaintiff claims that the defendant's use of his photographs in both articles is in issue because the plaintiff did not give his written consent to use them in either article. It appears that the plaintiff was injured at the photographic session and subsequently refused to sign a release in order to avoid compromising the unrelated action for physical injuries. Nevertheless, in his complaint, he only objected to the August 31 "Best Bets" article. Similarly, in his papers in opposition to the motion for summary judgment, the plaintiff identified that publication alone as the basis for the complaint. Thus the only question properly before us concerns the defendant's liability for publishing the plaintiff's photograph in the "Best Bets" article of August 31, 1981.
} 
out his consent.

The statute does not define trade or advertising purposes. However, the courts have consistently held, from the time of its enactment, that these terms should not be construed to apply to publications concerning newsworthy events or matters of public interest. The exception reflects Federal and State constitutional concerns for free dissemination of news and other matters of interest to the public, but essentially requires an interpretation of the statute to give effect to the legislative intent. We have recently noted that this exception should be liberally applied.

The newsworthiness exception applies not only to reports of political happenings and social trends but also to news stories and articles of consumer interest including developments in the fashion world. Nevertheless, the plaintiff contends that the photograph in this case did not depict a newsworthy event because it is a posed picture of a professional model taken at a photographic session staged by the defendant. However, the event or matter of public interest which the defendant seeks to convey is not the model's performance, but the availability of the clothing item displayed. A fashion display is, of necessity, posed and arranged. Obviously the picture of the jacket does not lose its newsworthiness simply because the defendant chose to employ a person to model it in a controlled or contrived setting.

The fact that the defendant may have included this item in its column solely or primarily to increase the circulation of its magazine and therefore its profits, as the Appellate Division suggested, does not mean that the defendant has used the plaintiff's picture for trade purposes within the meaning of the statute. Indeed, most publications seek to increase their circulation and also their profits. It is the content of the article and not the defendant's motive or primary motive to increase circulation which determines whether it is a newsworthy item, as opposed to a trade usage, under the Civil Rights Law. It is settled that a picture illustrating an article on a matter of public interest is not considered used for the purposes of trade or advertising within the prohibition of the statute unless it has no real relationship to the article or unless the article is an advertisement in disguise. A contrary rule would unreasonably and unrealistically limit the exception to nonprofit or purely altruistic organizations which are not the only, or even the primary, source of information concerning newsworthy events and matters of public interest.

The plaintiff's primary contention is that his picture was used for advertising purposes within the meaning of the statute. Although the article was not presented to the public as an advertisement, and was published in a column generally devoted to newsworthy items, the plaintiff claims that it is in fact an advertisement in disguise.

The facts on which the plaintiff relies are entirely circumstantial. 
He does not claim to have personal knowledge, or direct proof, that this particular article was actually published by the defendant for advertisement purposes. The circumstances on which he bases his claim are (1) the fact that the news column contains information normally included in an advertisement identifying the designer of the jacket, the approximate price, and three places where the jacket may be purchased, and (2) the fact that some or all of those stores mentioned in the article had previously advertised products in the magazine. Those circumstances are not enough to raise a jury question as to whether the article was published for advertising purposes.

The plaintiff does not dispute the fact that the information provided in the article is of legitimate reader interest. Indeed, similar information is frequently provided in reviews or news announcements of books, movies, shows or other new products including fashions. Nor does the plaintiff contend that it is uncommon for commercial publishers to print legitimate news items or reviews concerning products by persons or firms who have previously advertised in the publisher's newspaper or magazine. In short, the plaintiff has not presented any facts which would set this particular article apart from the numerous other legitimate news items concerning new products. He offers only his speculative belief that in this case the information on the jacket was included in the defendant's column for advertising purposes or perhaps, more vaguely, to promote additional advertising. That, in our view, is insufficient to defeat the defendant's motion for summary judgment. The rule exempting articles of public interest from the operation of the Civil Rights Law would, as a practical matter, lose much of its force if publishers of articles which are at least prima facie newsworthy were required to incur the expense of a trial to meet such general and insubstantial accusations of disguised advertising. ...

Finally, it should be emphasized that we do not mean to suggest that a publisher who has employed a professional model to pose for pictures to be used in an article may avoid the agreed fee, or otherwise ignore contractual arrangements, if the model's pictures are used to illustrate a newsworthy article or one involving matters of public interest. Although the complaint alludes to an agreement between the parties, the plaintiff has not sought to enforce a contract or recover damages for a breach. Since the plaintiff chose to frame his complaint entirely in terms of rights covered by the Civil Rights Law, which we have concluded is not applicable in this case, the complaint should be dismissed.

1984 WL 63629223, U.S.P.Q. 1116 (E.D. Pa. 1984)
Washington v. Brown \& Williamson Tobacco Corp.

Grover Washington, Jr., a well-known jazz saxophonist, alleges an advertising campaign invaded his right of publicity and contains false 
representation of sponsorship. The advertisements at issue were prepared as part of a "Kool" cigarette campaign and include photographs of an individual whom plaintiff claims looks like him. As a result of this alleged resemblance, it is asserted that the defendants have falsely represented to the public that the plaintiff endorses Kools and have appropriated for themselves the commercial value of plaintiff's image and likeness. Plaintiff has asserted claims for false representation and designation of sponsorship under section 43(a) of the Lanham Act, 15 U.S.C. § 1125(a), and has also asserted pendent state claims for violation of his right of publicity, unjust enrichment, and quantum meruit.

The gist of the campaign was to display various musicians photographed playing instruments with the Kool logo and advertising copy superimposed upon the photographs. The music theme was selected because of the perception that music conveyed a positive image that would appeal to a broad selection of consumers. In particular, jazz was believed to offer the broadest possible appeal because it allowed the most personal interpretation for the viewer. (Dearth dep. at 33).

After the theme had been decided upon, studio photographs were taken of various musicians playing their instruments. Actual musicians were used, rather than models, because it was believed that musicians would enhance the realism of the advertisements.

Among those picked was Ronald L. Brown, the individual whose photograph the plaintiff alleges bears a likeness to him. Brown is a professional musician who is accomplished in playing the saxophone, among other instruments. He was selected to appear in the advertisements because he looked "appropriate." [Three employees,] Lewis, Dearth, and Vail, had the primary responsibility for the creation and development of the campaign. None had ever seen Grover Washington or his photographs. In fact, of these three individuals only Lewis had ever heard of the plaintiff prior to the commencement of this litigation.

In January, 1982, the defendants began their music campaign nationwide, with advertisements appearing in newspapers, magazines, and on bill boards. The two advertisements at issue were among those initially circulated. These advertisements show a black male, with short hair and a beard playing the saxophone. In one, Brown is photographed from the side and is standing relatively erect in an open collar white shirt. In the other, he is again photographed from the side, but is bent forward and is wearing a tweed coat. After viewing these advertisements, plaintiff commenced this action.

Defendants have premised their motion for summary judgment upon their assertion that it is undisputed the resemblance between the photograph of Ronald Brown and plaintiff was wholly coinciden-

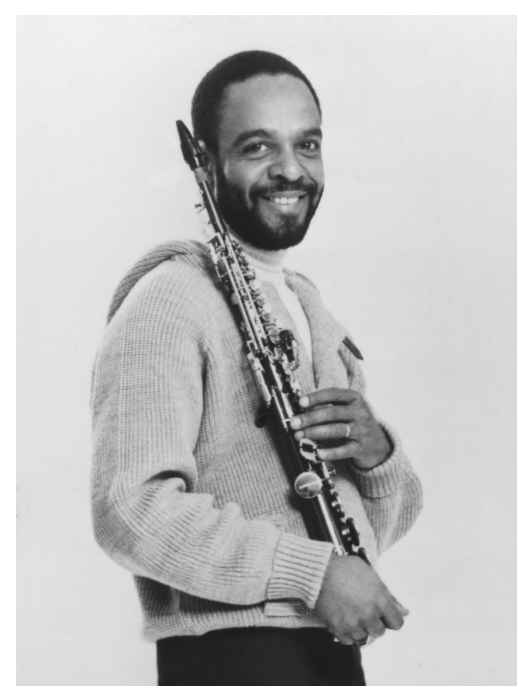

Grover Washington, Jr.

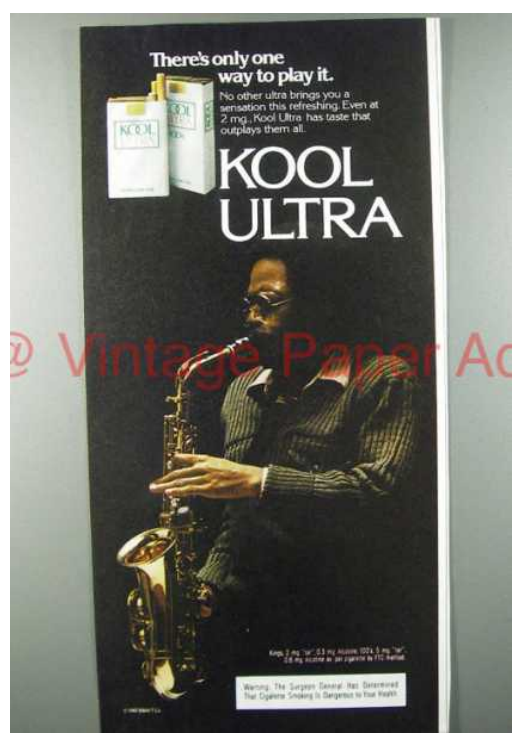

Kool ad featuring Ronald L. Brown 
Compare Flake v. Greensboro News Co., 195 S.E. 55 (N.C. 1938), where the defendant published an ad reading "Keep that Sylph-Like Figure by eating more of Melt's Rye and Whole Wheat Bread, says Mlle. Sally Payne, exotic red haired Venus" but by mistake used a photograph of Nancy Flake rather than one of Sally Payne. The court held, "Upon the present record, from which it appears that said photograph was used by mistake and without malice and that the defendants immediately desisted from the use thereof upon the discovery of the mistake and made due apology therefor, the plaintiff would be entitled to a judgment for nominal damages only."

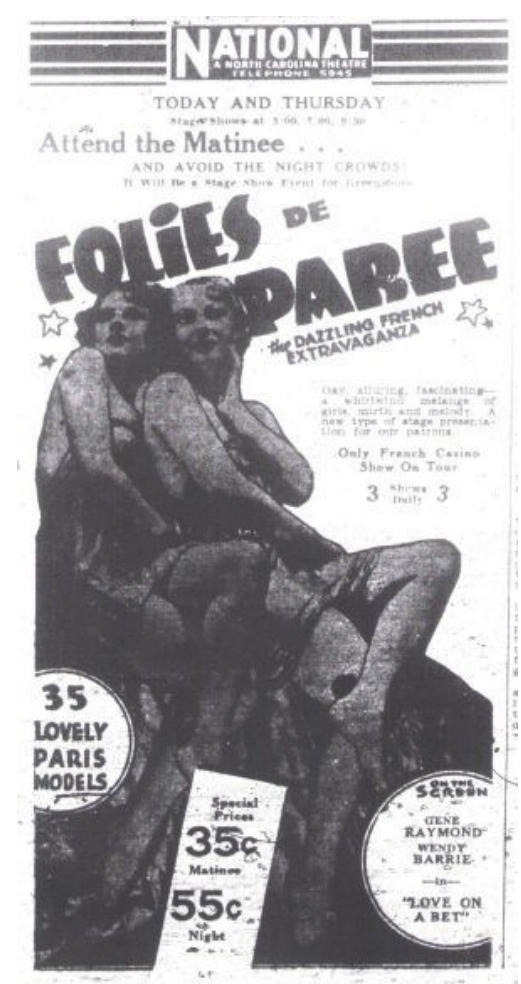

Greensboro Daily News ad misidentifying Nancy Flake as Sally Payne

213 F.Supp.2d 1146 (C.D. Cal. 2002) tal because the individuals responsible for the creation and development of the campaign had never seen the plaintiff or his picture prior to the commencement of this litigation. Therefore, they argue, there was no intent to either confuse the public as to the plaintiff's sponsorship of their product or invade plaintiff's right of publicity.

Admittedly, the case at bar presents a close question. In their depositions, Vail, Dearth, and Lewis stated that they had never seen plaintiff or his photograph at the time they were developing the Kool advertising campaign. Not surprisingly, plaintiff has been unable to rebut this assertion directly since information relating to an individual's state of mind is generally within that person's exclusive knowledge. Instead, plaintiff relies upon circumstantial evidence which he contends demonstrates that in fact the defendants intentionally chose Ronald Brown's photograph to lead the public to believe that plaintiff endorsed the advertised products. Specifically, plaintiff points to his solicitation by agents of Brown \& Williamson to perform in the Kool Jazz Festival, an alleged pattern of displaying the disputed advertisement in cities in which plaintiff performed during the summer of 1982, and the use of Milt Jackson, another renowned jazz musician, as a model for the advertising campaign, as well as a host of other relatively minor factual issues. However speculative they may be, the inferences to be drawn from such facts are not questions for the court to resolve. The task of making factual inferences must be done by the jury. Moreover, because the issue of intent is a material fact, the jury must be given an opportunity to observe the demeanor of Vail, Dearth, and Lewis to evaluate the credibility of each.

One final issue must be addressed. Defendants argue that the first amendment protects against liability where the cause of action is based on a coincidental, unintended resemblance. Obviously, this begs the question of whether the resemblance is in fact coincidental. If it is ultimately determined that the defendants intentionally chose the photographs of Ronald Brown in an effort to avail themselves of the commercial value of plaintiff's likeness, the first amendment would not provide the absolute protection defendants seek. False or misleading advertising is not within the ambit of absolute first amendment protection.

\section{b Secondary Liability}

As with false advertising, there's not a think body of caselaw on secondary liability for right of publicity violations, but there is enough to sketch its contours. 
[Perfect 10 sold "'classy' pictures of nude women without breast implants, cosmetic surgery, or the like" in a magazine and website. Cybernet provided age-verification services for more than 300,000 pornographic websites. According to Perfect 10, approximately 900 of those sites displayed Perfect 10's images without permission. Many of the models in those photographs had assigned their rights of publicity to Perfect 10.

On copyright, the court held that Cybernet did not directly infringe Perfect 10 's copyrights but could potentially be liable as a contributory or a vicarious infringer, and that it was unlikely that Cybernet qualified for the $\S 512$ (c) safe harbor for various reasons, including that it had failed to reasonably implement a policy to terminate repeat infringers.]

Neither party contests that third parties operating under the Adult Check name have infringed the rights of publicity assigned to Perfect 10 by a number of models. . Nor does either party suggest that direct liability would not be appropriate against those third-parties under either theory. Similarly, Perfect 10 does not assert any direct liability theory against Cybernet. The likelihood of success thus boils down to a question of "aiding and abetting."

California has adopted the joint liability principle laid out in the Restatement (Second) of Torts $\S 876$. Under the Restatement,

For harm resulting to a third person from the tortious conduct of another, one is subject to liability if he:

a) does a tortious act in concert with the other in pursuit to a common design with him, or

b) knows that the other's conduct constitutes a breach of duty and gives substantial assistance or encouragement so to conduct himself, or

c) gives substantial assistance to the other in accomplishing a tortious result and his own conduct, separately considered, constitutes a breach of duty to the third person.

Cybernet argues that there is no case directly recognizing the applicability of this doctrine to the right of publicity torts. The Court finds this argument unpersuasive, as the Restatement provides a background principle for all tort liability in the state of California.

Nor does the Court find convincing Cybernet's argument that the right of publicity itself contains an actual knowledge requirement. Cybernet's citations refer to the requirement that broadcasters of advertisements must have actual knowledge before they can be held liable. Cybernet does not claim to be a medium used for advertising, and the Court only focuses on rights of publicity infringements lo- 
cated on the websites, not infringements associated with webmaster banner ads. Rather, Cybernet argues that the knowledge requirement of section 3344(f) is a requirement for "aider and abettor" liability under the statute.

The Court concludes otherwise. Although section 3344(f) provides clear evidence that secondary liability can be imposed for violations of publicity rights, it also provides evidence that the California legislature created a heightened knowledge requirement limited to broadcasters of advertisements. The California legislature has not extended this requirement to defendants like Cybernet. The Court therefore defaults to the background assumption that secondary liability applies to right of publicity claims and it is to be found in conformance with the requirements established in the Restatement.

Perfect 10 has primarily focused its secondary theory of liability on the second branch of the Restatement, requiring actual knowledge of the tortious conduct and substantial participation. The Court agrees with Perfect 10 that there is a serious question on the merits of the substantial participation prong. As it stands, in the absence of argument to the contrary, the Court looks to the contributory infringement framework of copyright trademark law, where it has already found just such participation, thus leading the Court to conclude Perfect 10 has established a strong likelihood of success with regard to Cybernet's substantial participation.

The Court recognizes that application of secondary liability principles is particularly applicable for claims of unfair competition, as the California Supreme Court recognized as far back as 1935: "When a scheme is evolved which on its face violates the fundamental rules of honesty and fair dealing, a court of equity is not impotent to frustrate the consummation because the scheme is an original one." American Philatelic Soc'y v. Claibourne

In American Philatelic, a purveyor of stamps altered his normal stamps to resemble rare perforated stamps. He then sold these stamps to stamp dealers with clear notice that the stamps were not of the rare variety. Nevertheless, his sales brochures and pricing established that he both anticipated and effectively encouraged these dealers to sell the stamps to the public as rare stamps. The California Supreme Court had no problem finding these claims stated a claim under the unfair competition law. American Philatelic's equity language reinforce the Court's conclusion that Perfect 10's theory of aiding and abetting liability for Cybernet based on third-party violations of various rights of publicity has a strong likelihood of success. 


\section{Defenses}

The types of defenses to the right of publicity should be familiar by now. First sale applies, but pay attention to the details. And there are also defenses for newsworthy uses and for creative ones. Very, very, very loosely, newsworthiness incorporates some of the same concerns as descriptive and nominative fair uses. Again, pay attention to the details; things may be different here than elsewhere.

\section{Allison v. Vintage Sports Plaques}

The issue presented in this case is whether the "first-sale doctrine," a well-established limitation on intellectual property rights, applies to the common-law right of publicity. We hold that it does. Accordingly, we affirm the district court, which granted summary judgment to the defendant.

Elisa Allison is the widow of Clifford Allison, a well-known racecar driver. Orel Hershisher is a well-known professional baseball player. [Both Clifford Allison and Hershisher had licensing contacts for trading cards.]

Vintage Sports Plaques ("Vintage") purchases trading cards from licensed card manufacturers and distributors and, without altering the cards in any way, frames them by mounting individual cards between a transparent acrylic sheet and a wood board. Vintage then labels each plaque with an identification plate bearing the name of the player or team represented. In addition to the mounted trading card, some of the plaques feature a clock with a sports motif. Vintage markets each plaque as a "Limited Edition" and an "Authentic Collectible." Vintage is not a party to any licensing agreement that grants it the right to use the appellants' names or likenesses for commercial purposes and has never paid a royalty or commission to the appellants for its use of their names or images. Appellants presumably have received, however, pursuant to their respective licensing agreements, royalties from the card manufacturers and distributors for the initial sale of the cards to Vintage.

Appellants argue that we should not apply the first-sale doctrine to common-law actions to enforce the right of publicity. There is virtually no case law in any state addressing the application of the firstsale doctrine to the right of publicity, perhaps because the applicability of the doctrine is taken for granted.

Appellants argue that the right of publicity differs from other forms of intellectual property because the former protects "identity," whereas the latter protect "a particular photograph or product." The first-sale doctrine should not apply, they reason, because a celebrity's

\footnotetext{
${ }^{8}$ We note that some states that statutorily have recognized a right of publicity have codified the first-sale doctrine.
}

136 F.3d 1443 (11th Cir. 1998)

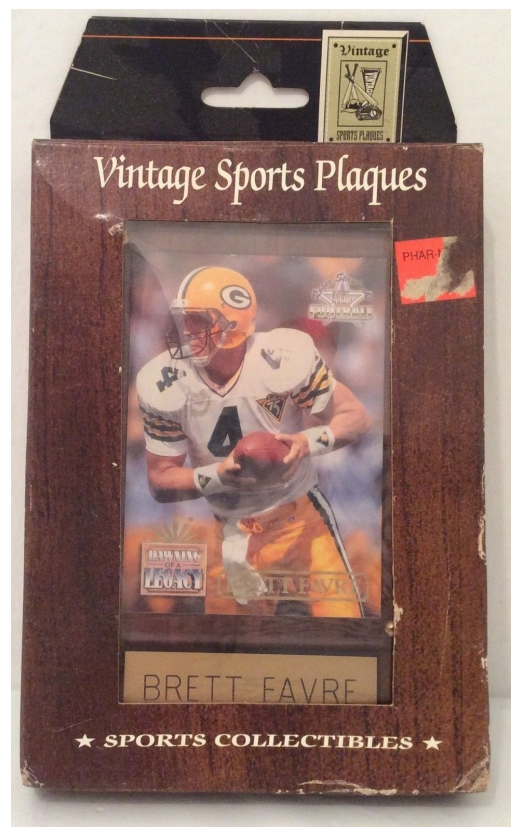

Vintage Sports Plaque 
identity continues to travel with the tangible property in which it is embodied after the first sale. We find two significant problems with appellants' argument. First, the distinction that appellants draw between what is protected by the right of publicity and what is protected by other forms of intellectual property rights, such as copyright, is not sound. Copyright law, for example, does not exist merely to protect the tangible items, such as books and paintings, in which the underlying expressive material is embodied; rather, it protects as well the author's or artist's particular expression that is included in the tangible item. The copyright law thus would be violated not only by directly photocopying a protected work, but also by publishing language or images that are substantially similar to that contained in the copyrighted work.

Second, and more important in our view, accepting appellants' argument would have profoundly negative effects on numerous industries and would grant a monopoly to celebrities over their identities that would upset the delicate balance between the interests of the celebrity and those of the public. Indeed, a decision by this court not to apply the first-sale doctrine to right of publicity actions would render tortious the resale of sports trading cards and memorabilia and thus would have a profound effect on the market for trading cards, which now supports a multi-billion dollar industry. Such a holding presumably also would prevent, for example, framing a magazine advertisement that bears the image of a celebrity and reselling it as a collector's item, reselling an empty cereal box that bears a celebrity's endorsement, or even reselling a used poster promoting a professional sports team. Refusing to apply the first-sale doctrine to the right of publicity also presumably would prevent a child from selling to his friend a baseball card that he had purchased, a consequence that undoubtedly would be contrary to the policies supporting that right.

A holding that the first-sale doctrine does limit the right of publicity, on the other hand, would not eliminate completely a celebrity's control over the use of her name or image; the right of publicity protects against unauthorized use of an image, and a celebrity would continue to enjoy the right to license the use of her image in the first instance - and thus enjoy the power to determine when, or if, her image will be distributed.

The issue before us, then, is whether the district court properly resolved as a matter of law that Vintage's plaques merely are the cards themselves repackaged, rather than products separate and distinct from the trading cards they incorporate. If they are the latter, as appellants contend that they are, then arguably Vintage is selling a product by commercially exploiting the likenesses of appellants intending to engender profits to their enterprise, a practice against which the right of publicity seems clearly to protect. 
We conclude that the district court properly determined that, as a matter of law, Vintage merely resells cards that it lawfully obtains. We think it unlikely that anyone would purchase one of Vintage's plaques for any reason other than to obtain a display of the mounted cards themselves. Although we recognize that the plaques that include a clock pose a closer case, we conclude that it is unlikely that anyone would purchase one of the clock plaques simply to obtain a means of telling time, believing the clock to be, for example, a "Hershisher Clock" or an "Allison Clock."

Rosa and Raymond Parks Institute for Self Development v. Target Corp. The Parks Institute is a Michigan 501(c)(3) corporation that owns the name and likeness of the late Rosa Parks. Rosa Parks, who was African-American, became an icon of the Civil Rights movement when she refused to surrender her seat to a white passenger on a racially segregated Montgomery, Alabama bus. Her actions ignited the Montgomery Bus Boycott. Target is a national retail corporation headquartered in Minneapolis, Minnesota. Target operates more than 1,800 retail stores across the United States, as well as an e-commerce website.

Beginning in 2009, Target offered for sale a collage-styled plaque in a limited number of its retail stores. The plaque contained the following images, as described by its creator Stephanie Workman Marrott: (1) a stylized rendering of the phrase "Civil Rights"; (2) an illustrated exhibit submitted in Browder v. Gayle, depicting where Rosa Parks was sitting on the bus prior to her arrest; (3) a stylized rendering of the word "Change"; (4) an illustration of the Cleveland Avenue bus; (5) a stylized rendering of Rosa Parks's name and dates of birth and death; (6) a picture of Rosa Parks's Congressional Gold Medal; (7) a photograph of Rosa Parks and Martin Luther King, Jr.; and (8) an inspirational statement made by Rosa Parks. It was this plaque that Elaine Steele, co-founder of the Parks Institute, and Anita Peek, Executive Director of the Parks Institute, discovered when they visited a number of Target retail stores located in the state of Michigan.

Upon realizing that Target was selling a plaque adorned with images of and related to Rosa Parks, the Parks Institute filed this lawsuit on November 6, 2013. Following a period of discovery, it became clear that the lawsuit challenged Target's sale of eight items in addition to the plaque: 1) the book Rosa Parks: My Story, by authors Rosa Parks and Jim Haskins; 2) the book Who Was Rosa Parks?, by author Yona Zeldis McDonough and illustrator Nancy Harrison; 3) the book Rosa Parks (Childhood of Famous Americans), by author Kathleen Kudlinkski and illustrator Maryl Henderson; 4) the book Rosa Parks, by author Eloise Greenfield and illustrator Gil Ashby; 5) the book $A$ Picture Book of Rosa Parks, by author David A. Adler and illustrator

Browder: 142 F. Supp. 707 (M.D. Ala. 1956)

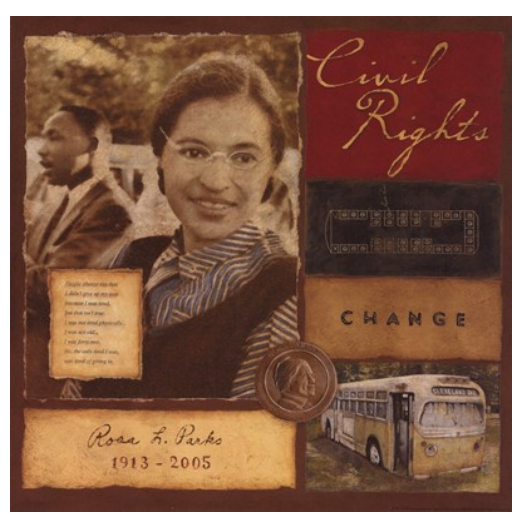

Rosa Parks plaque 
Ruffin-Steinback: 82 F. Supp. 2d 723 (E.D. Mich. 2000)
Robert Casilla; 6) the book, The Rebellious Life of Mrs. Rosa Parks, by author Jeanne Theoharis; 7) the book The Story of Rosa Parks, by author Patricia A. Pingry and illustrator Steven Walker; and 8) the American television movie The Rosa Parks Story, written by Paris Qualles and directed by Julie Dash.

Target argues that under Michigan law - and Alabama law - summary judgment is proper as to all of the Parks Institute's claims because the plaque and biographical works are protected fully by the First Amendment as biographical works that concern matters of legitimate public interest. In opposition, the Parks Institute argues that Target's "reliance on the First Amendment as protection for its action in this case is misplaced." Specifically, the Parks Institute avers that there is no legal precedent that would allow Target to exploit Rosa Parks's image or likeness for its own commercial purposes.

Michigan law is fairly limited with regard to actions alleging the unlawful commercial exploitation of a celebrity or public figure's identity. See Ruffin-Steinback $v$. dePasse (discerning how Michigan courts would address a claim for unlawfully depicting a public figure's life story without consent by looking to "all available sources" because the Michigan Supreme Court had not spoken to the issue). In 2000, however, the Michigan federal district court in Ruffin-Steinback addressed "state law tort claims for violation of the right of publicity, unjust enrichment, negligence, conspiracy, invasion of privacy, defamation and intentional infliction of emotional distress" brought by the heirs and personal representatives of members of the Temptations music group and associated individuals. In that case, the plaintiffs challenged the National Broadcasting Company's airing of a two-night mini-series covering the story of the Temptations. The mini-series was told from the perspective of Otis Williams, one of the group's founding members, but covered the lives of each of the group's members in detail.

[The Ruffin-Steinback court referred to Restatement (Third) of Unfair Competition § 47]:

The name, likeness, and other indicia of a person's identity are used for the purposes of trade under the rule stated in $\S 46$ if they are used in advertising the user's goods or services, or are placed on merchandise marketed by the user, or are used in connection with services rendered by the user. However, use for the purposes of trade does not ordinarily include the use of a person's identity in news reporting, commentary, entertainment, works of fiction or nonfiction, or in advertising that is incidental to such uses.

The court also noted that comment c to S 47 states that "the right of 
publicity is not infringed by the dissemination of an unauthorized print or broadcast biography."

After looking to the Restatement, the court surveyed case law and confirmed that courts in various jurisdictions treated unlicensed works of biography similarly. Across jurisdictions, courts had been reluctant "to extend the right of publicity to depictions of life-stories based on First Amendment considerations." Id. Accordingly, the court concluded that "Michigan courts would not extend [the] right of publicity tort" to prohibit biographical works and, ultimately, dismissed all of the derivative claims - unjust enrichment, conspiracy, and negligence - finding that they were dependent on the plaintiffs' right of publicity claims.

In this case, the Parks Institute is challenging Target's sale of eight biographical works, the majority of which are simplified accounts of Rosa Parks's life and accomplishments written to educate children about the Civil Rights movement and to demonstrate how one courageous individual can bring about significant change. The Parks Institute does not claim that any of the biographical works cast Rosa Parks in a false or defamatory light - separate causes of action for the dissemination of inaccurate information. Rather, it bases the entirety of its lawsuit on the idea that the First Amendment does not extend to protect the unapproved commercial sale of items that depict the name, likeness, story, or image of Rosa Parks.

For the reasons discussed at length in Ruffin-Steinback, however, the Parks Institute is mistaken. The depiction of Rosa Parks's life story without the Parks Institute's consent does not violate the Parks Institute's ownership rights to Rosa Parks's name or likeness. To quote from one of the biographical works at issue, Rosa Parks is perhaps the most iconic heroine of the civil rights movement. And, as both parties agree, one cannot talk about the Civil Rights movement without including Rosa Parks. The importance of her story serves as an apt reminder of why First Amendment protection for biographical works is so vital.

Target's sale of the seven books and one movie does not violate the Parks Institute's ownership rights in Rosa Parks's name or likeness because they are biographical works. Accordingly, summary judgment is due to be entered in favor of Target as to those eight items on the Parks Institute's right of publicity claim, as well as the unjust enrichment and misappropriation claims since they are derivative causes of action.

Because the collage-styled plaque is less of a biographical work and more akin to a work of art, the legality of Target's sale of the plaque requires a separate analysis. The Michigan Supreme Court has recognized that a plaintiff may bring suit for the misappropriation of his or her name or likeness under its invasion of privacy tort. 
Battaglieri: 680 N.W.2d 915 (Mich. Ct. App. 2004)

Restatement (Second) Torts S 652D, comment j

Armstrong: 655 F. Supp. 2d 779 (E.D. Mich. 2009)
This cause of action is founded upon the interest of the individual in the exclusive use of his own identity, in so far as it is represented by his name or likeness, and in so far as the use may be of benefit to him or to others. Because the tort has the potential to offer a troublingly broad swath of protection, however, courts that have recognized the appropriation tort have also uniformly held that the First Amendment bars appropriation liability for the use of a name or likeness in a publication that concerns matters that are newsworthy or of legitimate public concern.

The question whether a publication is sufficiently a matter of public interest to be protected by the privilege is ordinarily decided by the court as a question of law. To make the decision, a court must examine the nature of the appropriation. For while a defendant can be liable for the tort of misappropriation of likeness if defendant's use of plaintiff's likeness was for a predominately commercial purpose, the First Amendment will protect the appropriation if it has a redeeming public interest, news, or historical value.

No doubt Target's sale of the plaque served a commercial purpose. Michigan courts, however, have applied the legitimate public interest privilege to instances where the misappropriation occurred for the purposes of making a profit. See, e.g., Battaglieri v. Mackinac Center For Public Policy (finding that a fundraising letter was within the privilege when it used quotes from the plaintiff without his consent because the quotes spoke to important policy issues). Additionally, the legitimate public interest exception does not merely extend to cover current events, as matters related to education and information are within the scope of legitimate concern. As provided by the Restatement (Second) of Torts:

The scope of a matter of legitimate concern to the public is not limited to "news," in the sense of current events or activities. It extends also to the use of names, likenesses or fact in giving information to the public for purposes of education, amusement or enlightenment, when the public may reasonably be expected to have a legitimate interest in what is published.

Expanding on this idea, a federal district court applying Michigan law explained that the "First Amendment privilege does not only extend to news in the sense of current events, but extends far beyond to include all types of factual, educational, and historical data, or even entertainment and amusement, concerning interesting phases of human activity in general." Armstrong v. Eagle Rock Entm't, Inc.

Applying these principles, the court found that Eagle Rock Entertainment's decision to use Louis Armstrong's picture on the cover liner of its DVD entitled, "Mahavishnu Orchestra, Live at Montreux, 
1984, 1974," without consent was protected by the First Amendment. Specifically, under Michigan law, the court concluded that the DVD and its packaging had an historical and entertainment value for jazz fans everywhere. Michigan law and the First Amendment require a similar determination in this case.

The collage-styled plaque contains several elements reminiscent of the historic Civil Rights movement. In fact, by including a picture of Rosa Parks and Martin Luther King, Jr., alongside stylized renderings of the words "Civil Rights" and "Change," Stephanie Workman Marrott, the plaque's creator, sought to inspire viewers to "stand up for what they believe is right" while telling the important story of Rosa Parks's courage during the Civil Rights movement. There can be no doubt that Rosa Parks and her involvement in the Civil Rights movement are matters of utmost importance, both historically and educationally. Accordingly, just as Louis Armstrong's image is significant to the history of jazz, Rosa Parks's name and image are historically significant to the fight for equality in the South. Because Target's sale of the collage-style plaque is protected by the First Amendment, Target is entitled to summary judgment on all of the Parks Institute's claims regarding the plaque, in addition to the biographical works.

No Doubt v. Activision Publishing, Inc.

The rock band No Doubt brought suit against the video game publisher Activision Publishing, Inc. (Activision), based on Activision's release of the Band Hero video game featuring computer-generated images of the members of No Doubt. Applying the transformative use test first adopted in Comedy III Productions, Inc. v. Gary Saderup, Inc., we conclude that the creative elements of the Band Hero video game do not transform the images of No Doubt's band members into anything more than literal, fungible reproductions of their likenesses. Therefore, we reject Activision's contention that No Doubt's right of publicity claim is barred by the First Amendment. In addition, we disagree with Activision's contention that No Doubt must demonstrate that Activision used the likenesses of the band members in an "explicitly misleading" way in order to prevail on its unfair competition claim.

\section{Factual and Procedural Background}

Defendant Activision is a leading international video game distributor and the creator and owner of the interactive Band Hero video game. The game allows players to simulate performing in a rock band in time with popular songs. By choosing from a number of playable characters, known as "avatars," players can "be" a guitarist, a singer, or a drummer. Some of the available avatars are fictional
122 Cal. Rptr. 3d 397 (Ct. App. 2011)

Comedy III: 21 P.3d 797 (2001) 


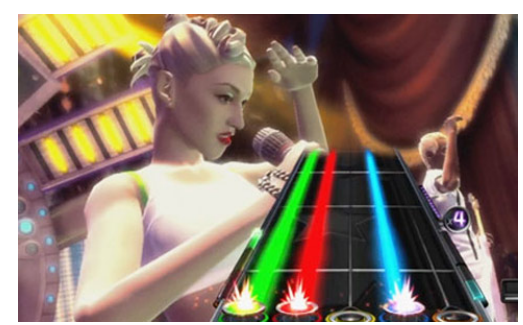

Band Hero screenshot characters created and designed by Activision while others are digital representations of real-life rock stars. Players can also design their own unique fictional avatars. Represented by the avatars of their choosing, players "perform" in various settings, such as venues in Paris and Madrid, a rock show at a shopping mall, and even outer space.

In addition to allowing players to perform over 60 popular songs, Band Hero permits players to create their own music and then play their compositions using an avatar. As with all the Guitar Hero video games, as players advance in the Band Hero game, they can "unlock" characters and use them to play songs of the players' choosing, including songs the players have composed as well as songs made famous by other artists.

Plaintiff No Doubt is an internationally recognized rock band featuring Gwen Stefani as its lead singer. No Doubt entered into a professional services and character licensing agreement (Agreement) with Activision permitting Activision to include No Doubt as one of the rock bands featured in Band Hero.

As part of the Agreement, Activision agreed to license no more than three No Doubt songs for use in Band Hero, subject to No Doubt's approval over the song choice. (Ultimately, the game included two No Doubt songs.)

Pursuant to the Agreement, the members of No Doubt participated in a full-day motion capture photography session at Activision's studios so that the band members' Band Hero avatars would accurately reflect their appearances, movements, and sounds. No Doubt then closely reviewed the motion capture photography and the details related to the appearance and features of their avatars to ensure the representations would meet their approval.

Approximately two weeks prior to the release of Band Hero, No Doubt became aware of the "unlocking" feature of the game that would permit players to use No Doubt's avatars to perform any of the songs included in the game, including songs that No Doubt maintains it never would have performed. The band also learned that female lead singer Gwen Stefani's avatar could be made to sing in a male voice, and the male band members' avatars could be manipulated to sing songs in female voices. The individual band member avatars could be made to perform solo, without their band members, as well as with members of other groups. No Doubt contends that in the numerous communications with No Doubt, Activision never communicated its intention to permit such manipulations of the No Doubt avatars. Rather, No Doubt insists, Activision represented that No Doubt's likenesses within Band Hero would be used only in conjunction with the selected No Doubt songs.

When No Doubt complained about the additional exploitation of 
their likenesses, Activision admitted that it had hired actors to impersonate No Doubt in order to create the representations of the band members' performances of the additional musical works other than the No Doubt songs licensed for the game. No Doubt demanded that Activision remove the "unlocking" feature for No Doubt's avatars, but Activision refused. Activision contends that No Doubt's request came only after the programming had been finalized and the manufacturers had approved the game for manufacture.

No Doubt filed a complaint against Activision in superior court, seeking injunctive relief and damages for Activision's allegedly unauthorized exploitation of No Doubt's name, performances and likenesses. No Doubt alleged six causes of action: (1) fraudulent inducement; (2) violation of statutory and common law right of publicity; (3) breach of contract; (4) unfair business practices in violation of Business and Professions Code section 17200; (5) injunctive relief; and (6) rescission.

\section{No Doubt's Claims Arose from Protected Activity}

Video games generally are considered "expressive works" subject to First Amendment protections. Further, Activision's use of No Doubt's likenesses in Band Hero is a matter of public interest because of the widespread fame No Doubt has achieved; there is a public interest which attaches to people who, by their accomplishments, mode of living, professional standing or calling, create a legitimate and widespread attention to their activities. Accordingly, the use of No Doubt's likenesses in the Band Hero video game meets the first requirement of the anti-SLAPP statute.

III. No Doubt's Probability of Success on the Merits of the Claims

\section{A. Right of Publicity Claim}

No Doubt has alleged a claim for violation of the right of publicity under Civil Code section 3344 as well as under common law. Section 3344 provides in pertinent part: "Any person who knowingly uses another's name, voice, signature, photograph, or likeness, in any manner, on or in products, merchandise, or goods, or for purposes of advertising or selling, or soliciting purchases of, products, merchandise, goods or services, without such person's prior consent . . . shall be liable for any damages sustained by the person or persons injured as a result thereof." The common law claim for misappropriation of the right of publicity is similar, except there is no requirement that the misappropriation have been done knowingly.

\section{1. "Transformative Use" Defense}

"Like the protected books, plays, and movies that preceded them, video games communicate ideas-and even social messages - through many familiar literary devices (such as characters, dialogue, plot, and music) and through features distinctive to the medium (such as the player's interaction with the virtual world). That suffices to confer First Amendment protection." Brown v. Entertainment Merchant's Ass'n, 131 S. Ct. 2729 (2011) 
Activision contends that its use of No Doubt's likenesses in Band Hero constitutes "protected First Amendment activity involving an artistic work," and thus No Doubt's right of publicity claim is completely barred. However, Activision's First Amendment right of free expression is in tension with the rights of No Doubt to control the commercial exploitation of its members' likenesses.

In Comedy III, our Supreme Court directly confronted this tension. The court in articulated

what is essentially a balancing test between the First Amendment and the right of publicity based on whether the work in question adds significant creative elements so as to be transformed into something more than a mere celebrity likeness or imitation.

[Thus,] when artistic expression takes the form of a literal depiction or imitation of a celebrity for commercial gain, directly trespassing on the right of publicity without adding significant expression beyond that trespass, the state law interest in protecting the fruits of artistic labor outweighs the expressive interests of the imitative artist.

[A celebrity may enforce] the right to monopolize the production of conventional, more or less fungible, images of that celebrity. On the other hand, a work claimed to violate a celebrity's right of publicity is entitled to First Amendment protection where added creative elements significantly transform the celebrity depiction.

Another way of stating the inquiry is whether the celebrity likeness is one of the "raw materials" from which an original work is synthesized, or whether the depiction or imitation of the celebrity is the very sum and substance of the work in question. We ask, in other words, whether a product containing a celebrity's likeness is so transformed that it has become primarily the defendant's own expression rather than the celebrity's likeness. [The inquiry boils down to] whether the literal and imitative or the creative elements predominate in the work.

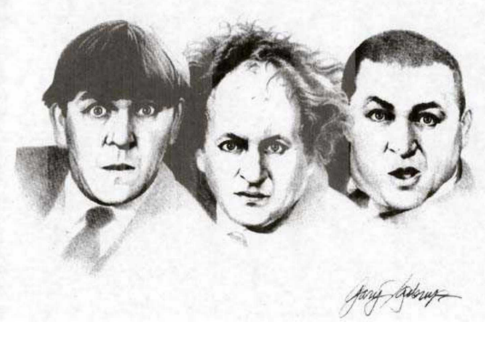

Saderup's Three Stooges drawing

The court then applied its newly minted "transformative use" test to the facts before it. The plaintiff was the owner of the rights to the comedy act known as The Three Stooges. The defendant was an artist who sold lithographs and T-shirts bearing a likeness of The Three Stooges reproduced from a charcoal drawing the artist had created. The owner sued for violation of the right of publicity under Civil Code section 3344.1, the companion statute to section 3344 that extends the right of publicity to the heirs and assignees of deceased 
personalities. 目

The court rejected the artist's contention that the plaintiff's claim was barred by the First Amendment. The court could "discern no significant transformative or creative contribution" in the artist's literal reproduction of the likenesses of The Three Stooges in its charcoal drawing. The artist's "undeniable skill is manifestly subordinated to the overall goal of creating literal, conventional depictions of The Three Stooges so as to exploit their fame."

The court was careful to note that, in some circumstances, literal reproductions of celebrity portraits may be protected by the First Amendment. The court used the example of silk screens created by artist Andy Warhol using images of celebrities such as Marilyn Monroe, Elizabeth Taylor, and Elvis Presley. "Through distortion and the careful manipulation of context, Warhol was able to convey a message that went beyond the commercial exploitation of celebrity images and became a form of ironic social comment on the dehumanization of celebrity itself."

The Supreme Court again addressed the balance between the First Amendment and celebrities' rights of publicity in Winter $v$. DC Comics in which the defendant was sued for misappropriation under section 3344 after publishing a series of comic books featuring two villainous half-worm, half-human characters named the "Autumn brothers." The characters were quite obviously based on the musician brothers Edgar and Johnny Winter, sharing their same long white hair and albino features.

Applying the "transformative use" test set forth in Comedy III, the court held that the Winter brothers' claim was barred by the First Amendment as a matter of law. The court found that the comic depictions at issue were

not just conventional depictions of plaintiffs but contain significant expressive content other than plaintiffs' mere likenesses. Although the fictional characters Johnny and Edgar Autumn are less-than-subtle evocations of Johnny and Edgar Winter, the books do not depict plaintiffs literally. Instead, plaintiffs are merely part of the raw materials from which the comic books were synthesized. To the extent the drawings of the Autumn brothers resemble plaintiffs at all, they are distorted for purposes of lampoon, parody, or caricature. And the Autumn brothers are but cartoon characters - half-human and half-worm - in a larger story, which is itself quite expressive.

The comic books featured "fanciful, creative characters, not pictures
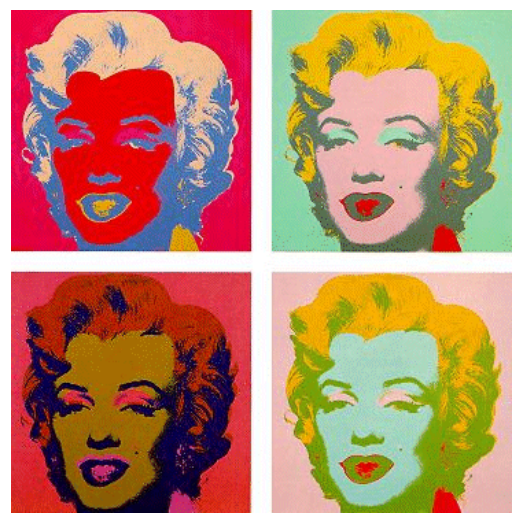

Andy Warhol silkscreen of Marilyn Monroe

Winter: 69 P.3d 473 (Cal. 2003)

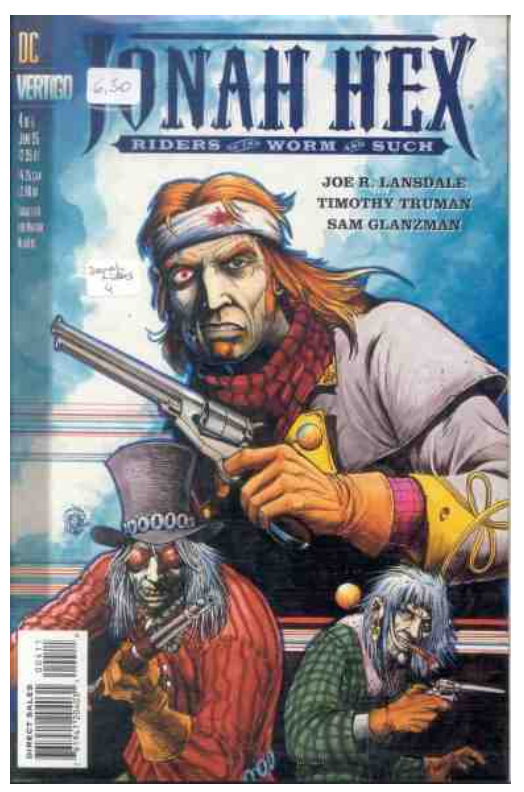

Jonah Hex cover from Winter

\footnotetext{
${ }^{5}$ The test developed in Comedy III applies equally to claims under section 3344.
} 
Kirby: 50 Cal. Rptr. 3d 607 (Ct. App. 2006)

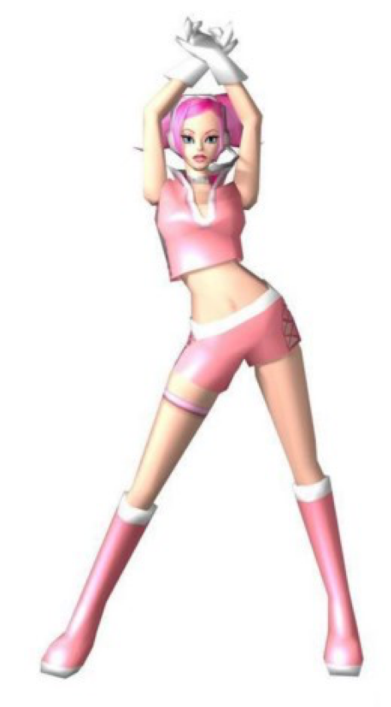

Ulala from Space Channel 5 of the Winter brothers," in stark contrast to Comedy III, where the artist "essentially sold, and devoted fans bought, pictures of The Three Stooges, not transformed expressive works by the artist."

In Kirby v. Sega of America, Inc., the Court of Appeal applied the "transformative use" test in a case involving the alleged use of a celebrity's likeness in a video game. The plaintiff, Kierin Kirby, achieved fame as the lead singer of the musical group Deee-Lite which was popular in the early 1990's. Kirby alleged that video game distributor Sega violated her common law and statutory rights of publicity when it released the video game Space Channel 5 that included as its main character a computer-generated woman named "Ulala" allegedly based on Kirby.

SC5 is set in outer space, in the 25th century, and Ulala is a reporter who is sent to "investigate an invasion of Earth by dance-loving aliens who shoot earthlings with ray guns, causing them to dance uncontrollably." To advance in the game, players attempt to have Ulala match the dance moves of various aliens and competitor reporters. A Japanese choreographer and dancer created Ulala's six main dance moves.

Kirby contended that Sega misappropriated her likeness by giving Ulala similar facial features to her own as well as by borrowing her distinctive look that combines retro and futuristic elements, including red or pink hair, platform shoes, brightly colored formfitting clothes, and short skirts. In addition, Ulala's name is a phonetic variation of "ooh la la," which Kirby alleged was her "signature" lyrical expression included in three of her songs.

The Court of Appeal concluded that there was a question of fact as to whether Sega had misappropriated Kirby's likeness in creating the character Ulala. However, the court found that even assuming Sega used Kirby's likeness, the First Amendment provided a complete defense. "Notwithstanding certain similarities, Ulala is more than a mere likeness or literal depiction of Kirby," as Ulala's physique, primary hairstyle and costumes, and dance moves differed from Kirby's. "Moreover, the setting for the game that features Ulala-as a spaceage reporter in the 25th century-is unlike any public depiction of Kirby. . . . Taken together, these differences demonstrate Ulala is 'transformative,' and respondents added creative elements to create a new expression" such that the First Amendment barred Kirby's claim. Ulala was not merely "an imitative character contrived of minor digital enhancements and manipulations", and unlike the use of the likenesses of The Three Stooges in Comedy III, any imitation of Kirby's likeness was not "the sum and substance" of Ulala's character Rather, like the "Autumn brothers" comic book characters in Winter, "Ulala is a "fanciful, creative character" who exists in the context of a unique and expressive video game." 


\section{Use of No Doubt's Likenesses in Band Hero Is Not "Transformative"}

Activision does not dispute that the avatars of No Doubt are computer-generated recreations of the real band members, painstakingly designed to mimic their likenesses. Indeed, as part of the licensing agreement between Activision and No Doubt, No Doubt posed for motion-capture photography to enable Activision to reproduce their likenesses, movements, and sounds with precision. Activision intentionally used these literal reproductions so that players could choose to "be" the No Doubt rock stars. The game does not permit players to alter the No Doubt avatars in any respect; they remain at all times immutable images of the real celebrity musicians, in stark contrast to the fanciful, creative characters in Winter and Kirby.

No Doubt asserts that such realistic depictions categorically disqualify their Band Hero avatars from First Amendment protection. However, as Comedy III held, even literal reproductions of celebrities can be "transformed" into expressive works based on the context into which the celebrity image is placed (noting, for instance, the Warhol silk screens featuring celebrity portraits, through "careful manipulation of context," convey an ironic message about the "dehumanization of celebrity" through reproductions of celebrity images); see also ETW Corp. v. Jireh Publishing, Inc. [a painting featuring three literal likenesses of Tiger Woods in different poses in the foreground, with the Augusta National Clubhouse behind him and the likenesses of other famous golfing champions looking down on him, found worthy of First Amendment protection because it was a "panorama" of Woods's historic 1997 victory at the world-famous Masters Tournament and conveyed a message about the significance of Woods's achievement through images suggesting that Woods would eventually join the ranks of the world's best golfers].) Thus, when the context into which a literal celebrity depiction is placed creates something new, with a further purpose or different character, altering the first likeness with new expression, meaning, or message, the depiction is protected by the First Amendment.

Nonetheless, although context may create protected expression in the use of a celebrity's literal likeness, the context in which Activision uses the literal likenesses of No Doubt's members does not qualify the use of the likenesses for First Amendment protection. Activision contends that as in Kirby, where Sega used Kirby's likeness in a unique and expressive video game, Activision's use of No Doubt's likenesses in Band Hero is transformative because the video game shows the No Doubt avatars "surrounded by unique, creative elements, including in fanciful venues such as outer space . . . and performing songs that No Doubt avowedly would never perform in real life." Indeed, according to Activision, No Doubt's objection that the band can be
ETW: 332 F.3d 915 (6th Cir. 2003)

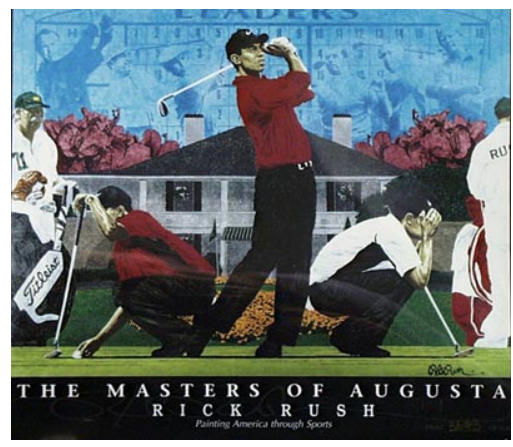

Rick Rush portrait of Tiger Woods from ETW 


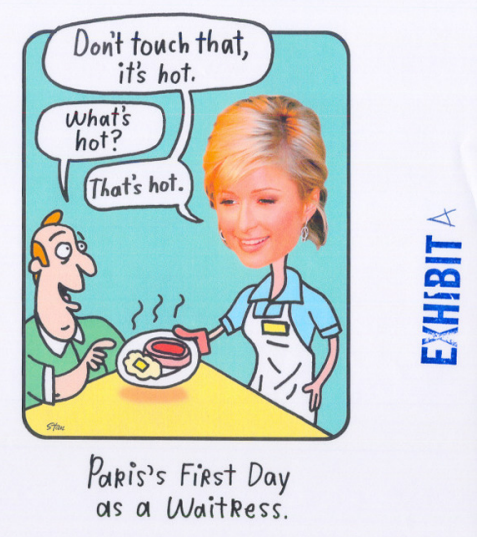

Hallmark card from Hilton

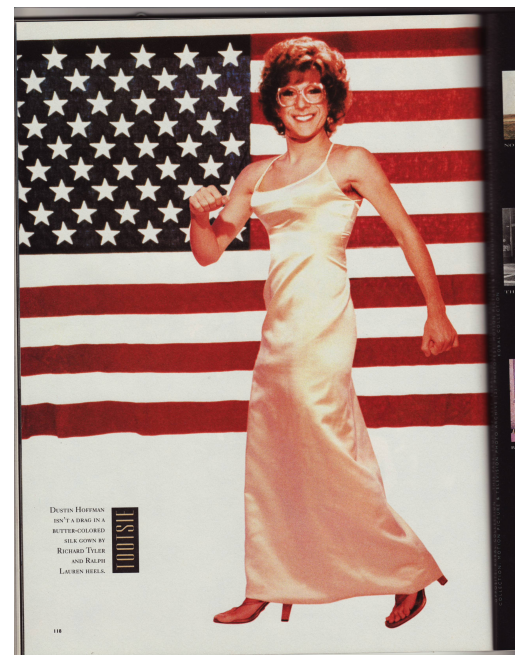

L.A. Magazine article from Hoffman made to perform songs it would never perform demonstrates that the use of the No Doubt avatars is transformative.

However, that the members of No Doubt object to being shown performing certain songs is irrelevant to whether that element of Band Hero combined with others transforms the literal depictions of No Doubt's members into expression that is more Activision's than pure mimicry. In that inquiry, it is the differences between Kirby and the instant case, not the similarities, which are determinative. In Kirby, the pop singer was portrayed as an entirely new character - the space-age news reporter Ulala. In Band Hero, by contrast, no matter what else occurs in the game during the depiction of the No Doubt avatars, the avatars perform rock songs, the same activity by which the band achieved and maintains its fame. Moreover, the avatars perform those songs as literal recreations of the band members. That the avatars can be manipulated to perform at fanciful venues including outer space or to sing songs the real band would object to singing, or that the avatars appear in the context of a video game that contains many other creative elements, does not transform the avatars into anything other than exact depictions of No Doubt's members doing exactly what they do as celebrities. Hilton $v$. Hallmark Cards [Hallmark card featuring Paris Hilton's head on a cartoon waitress's body was not a "transformative use" as in Kirby because, despite some differences, the "basic setting" was the same as an episode of Hilton's television show in which she is depicted as "born to privilege, working as a waitress" $]$;

Moreover, Activision's use of lifelike depictions of No Doubt performing songs is motivated by the commercial interest in using the band's fame to market Band Hero, because it encourages the band's sizeable fan base to purchase the game so as to perform as, or along-

${ }^{6}$ An earlier Ninth Circuit decision, Hoffman v. Capital Cities/ABC, Inc., 255 F.3d 1180 (9th Cir. 2001), arguably reached a different conclusion on facts somewhat similar to those in Hilton. In Hoffman, the court found that the First Amendment barred Dustin Hoffman's claim that Los Angeles Magazine had violated his right of publicity when it published an article that included a photographic image of the head of Hoffman in his "Tootsie" character superimposed on the body of a cartoon male who was wearing an evening gown and high heels. The court only briefly addressed the transformative use defense, finding that "even if we were to consider LAM an 'artist' and the altered 'Tootsie' photograph 'artistic expression' subject to the Comedy III decision, there is no question that LAM's publication of the 'Tootsie' photograph contained 'significant transformative elements'" because "Hoffman's body was eliminated and a new, differently clothed body was substituted in its place." In Hilton, the Ninth Circuit noted that Hoffman had not addressed the transformative use defense in great depth because the Supreme Court decided Comedy III only after oral argument in the Hoffman case had taken place. Thus, Hilton concluded that Hoffman was not controlling Ninth Circuit authority on the issue of the transformative use defense. We similarly do not find Hoffman's brief discussion or application of the transformative use defense compelling. 
side, the members of No Doubt. Thus, insofar as the depiction of No Doubt is concerned, the graphics and other background content of the game are secondary, and the expressive elements of the game remain manifestly subordinated to the overall goal of creating a conventional portrait of No Doubt so as to commercially exploit its fame. In other words, nothing in the creative elements of Band Hero elevates the depictions of No Doubt to something more than "conventional, more or less fungible, images" of its members that No Doubt should have the right to control and exploit. Thus, the trial court did not err in denying Activision's motion to strike the right of publicity claim based on Activision's assertion of a First Amendment defense.

\section{B. Unfair Competition Claim}

To state a claim for unfair competition under Business and Professions Code section 17200, a plaintiff must show that members of the public are likely to be deceived"' by a particular business practice. No Doubt alleges that Activision violated section 17200 by deceiving the public into believing that No Doubt authorized the use of its name and likeness for the unlocking feature of Band Hero and that "No Doubt approves and endorses the appearance of its members individually performing songs that are wholly inappropriate and out of character for No Doubt."

When the challenged use of a trademark appears in an artistic work that implicates First Amendment protections, some courts have concluded that the standard "likelihood of confusion" test under the Lanham Act is inadequate to address First Amendment concerns. The seminal case is Rogers, in which the Second Circuit developed an alternative to the "likelihood of confusion" test to be used for titles of artistic works that borrow names protected by trademark.

Activision contends that we should construe section 17200 to incorporate the Rogers standard as an element of No Doubt's unfair competition claim, because the claim is "substantially congruent" to a trademark infringement claim under the Lanham Act, given that for both the "ultimate test" is whether the public is likely to be deceived or confused by the similarity of the marks.

Even if the Rogers "explicitly misleading" test might be applied to some section 17200 claims involving the unauthorized use of a celebrity's likeness (a conclusion we do not reach), the test does not apply to No Doubt's section 17200 claim. Activision overlooks the overarching conclusion in Rogers that the public interest in avoiding consumer confusion must be balanced against the public interest

\footnotetext{
${ }^{8}$ Although the "explicitly misleading" requirement of the Rogers test makes obvious sense when the title of an artistic work is at issue, and thus conventional "speech" is involved, we question whether it should apply when the actionable wrong is the misappropriation of a celebrity's likeness in a video game.
} 
in free expression. The "explicitly misleading" standard comes into play only after a determination has been made that a challenged use of a trademark is worthy of heightened First Amendment protection.

Here, we have already concluded that Activision's use of No Doubt's avatars is not "transformative" because the avatars are simply precise computer-generated reproductions of the band members that do not meld with the other elements of Band Hero to become, in essence, Activision's own artistic expression. In the case of such a "nontransformative" use of celebrity likenesses, the public interest in avoiding consumer confusion outweighs the public interest in free expression, and it would make little sense to require No Doubt to make the almost impossible showing that Activision's nontransformative use of the No Doubt avatars was "explicitly misleading." Of course, to prevail on its section 17200 claim, No Doubt will still have to demonstrate that members of the public are likely to be deceived by Activision's use of the likenesses.

In sum, the trial court did not err in denying Activision's motion to strike No Doubt's section 17200 claim based on Activision's contention that its challenged use of the No Doubt avatars was not explicitly misleading.

\section{Problems}

\section{Governator Problem}

Does this bobblehead doll violate Arnold Schwarzenegger's right of publicity? (As a reminder, following his action-movie acting career, Schwarzenegger went into politics and served as Governor of California from 2003 to 2011.) 


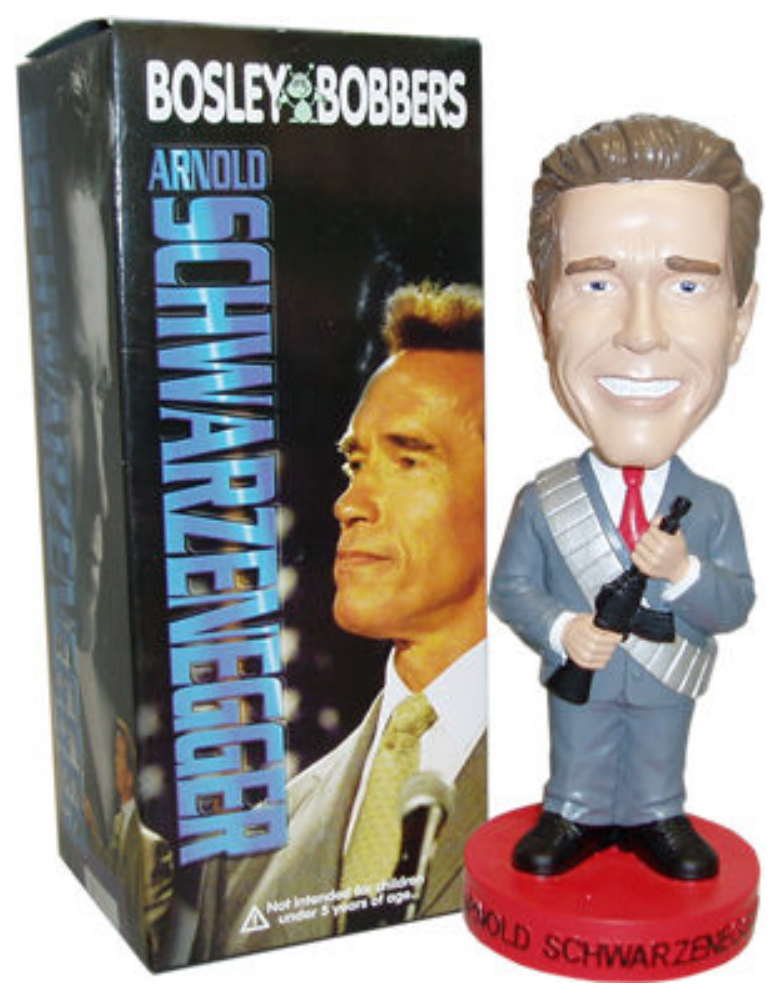

Tony Twist Problem

Anthony Rory Twist was a hockey player who played for the St. Louis Blues and the Quebec Nordiques. He was known as an "enforcer" who would pummel players from the opposing team if they disrespected or acted too aggressively toward his teammates.

Antonio Carlo Twistarelli a/k/a Tony Twist is a villain who appears in thirty-six issues of the Spawn comic book series by Todd McFarlane. MacFarlane has sometimes given away copies of Spawn comic books as promotions at hockey games.

Does Anthony Twist have a right of publicity case against McFarlane? 


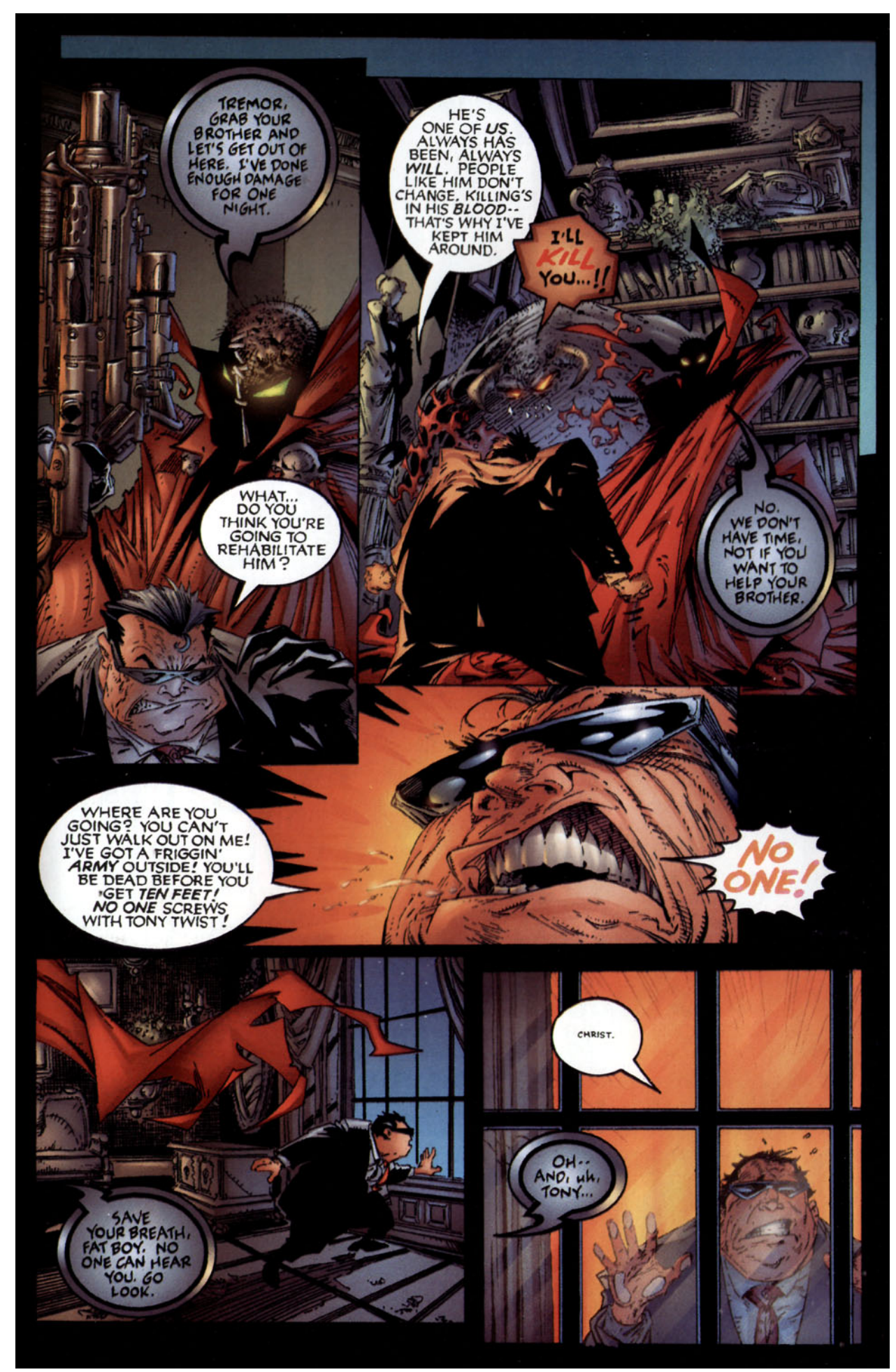

\section{B Moral Rights}

Moral rights give authors strong and often inalienable rights against uses of their works that could be harmful to their reputations that of- 
fend their artistic visions. Moral rights are usually described as a part of copyright. In some respects, so they are. But the underlying theory of moral rights derives more from natural-law considerations about personal dignity than from any utilitarian balancing of incentives.

Some countries have well-developed moral rights traditions. The United States does not. The clearest instantiation of something resembling moral rights is in the federal Visual Artists Rights Act and state analogues.

\section{Peter Baldwin \\ The Copyright Wars: Three Centuries of Trans-Atlantic Battle}

The laws governing how artists, writers, musicians, choreographers, directors, and other authors relate to their works are usually called "copyright." But this one word covers two very different approaches. The very terms used to designate the European "authors' rights" alternative - Urheberrecht in German and droit d'auteur in French - voice a more encompassing approach.

Seen historically over its long development, copyright has focused on the audience and its hopes for an expansive public domain. Authors' rights, in contrast, have targeted creators and their claims to ensure the authenticity of their works. For its detractors, copyright is philistine and commercial, treating noble creation as a mere commodity. It regards the creator as an entrepreneur and the work as a product. The authors' rights tradition, in turn, valiantly protects the creators vision from commercialization and exploitation.

Authors' rights derive from natural rights. The Continental approach defends creators and their work. In a sense, it seeks no other interest - public or otherwise. Authors' rights, says a distinguished French jurist, seek to protect the author, not society. Because it sets the author before all, writes a French law professor, balancing interests, on the model of the copyright system, is foreign to the French tradition. The author, in the words of a standard French legal textbook, "owes society nothing. He has no more obligations in this respect than the mason who builds or the farmer who ploughs. Quite the contrary, society owes him."

\section{Roberta Rosenthal Kwall}

Copyright and the Moral Right: Is an American Marriage Possible?

The moral right doctrine generally is said to encompass three major components: the right of disclosure, the right of paternity, and the right of integrity. Some formulations of the moral right doctrine also include the right of withdrawal, the right to prevent excessive criticism, and the right to prevent assaults upon one's personality. For purposes of illustration, these components will be explored briefly in the context of the following hypothetical. A playwright, enthralled 
with the idea of writing a piece poking fun at the evangelical segment of society, suddenly envisions a story line through which she can communicate her ideas. In one day she outlines the plot and sketches some dialogue so that she will have a rough draft which she can develop further when inspiration strikes again. At this point, the playwright's interest in her work would be protected by an aspect of the moral right doctrine known as the right of disclosure or divulgation. Underlying this component of the moral right is the idea that the creator, as the sole judge of when a work is ready for public dissemination, is the only one who can possess any rights in an uncompleted work. Prior to the time the playwright places her work into circulation, therefore, she retains the same right to determine both the form of her play before it is distributed and the timing of public circulation.

Suppose that a few days after the playwright had finished her rough draft, she entered into an agreement with a publisher in which she promised to produce the final publication version of the play within six months. Subsequently, a personal crisis in the playwright's life triggers a deep sense of religious conviction and she no longer wishes to finish the play. In these circumstances her refusal to complete the play would be supported by her right to refuse to disclose, a corollary to the right of disclosure. Application of this right would preclude a judgment ordering the playwright to complete the play, although a court might award the publisher damages for breach of contract.

Some scholars believe that a second component of the moral right doctrine, known as the right of withdrawal, would allow the play in our hypothetical situation to recall all existing copies of her work if, following actual publication, she experienced a radical change of the convictions that originally provided the impetus for the play. Other commentators, however, have expressed doubts regarding the viability of the moral right of withdrawal because of the practical inconsistency in assuming that the public will forget works to which it has already been exposed.

To continue the illustration, now assume that the playwright completes her work and subsequently visits a publisher with her manuscript in hand and offers it to the publisher for $\$ 1500$. The publisher conditionally agrees to this arrangement, providing the playwright makes certain revisions. When the playwright tenders the revised manuscript to the publisher, the publisher refuses to publish it with the playwright's name, notwithstanding the appearance of the playwright's name on the original manuscript. In these circumstances the playwright would be protected by another component of the moral right, the right of paternity. As its name suggests, the right of paternity safeguards a creator's right to compel recognition for his work and prevents others from naming anyone else as the creator. 
Therefore, the playwright would be able to force publication of the work under her name. Additionally, the right of paternity protects a creator in the event that someone falsely attributes to him a work that is not his creation.

Two other aspects of the moral right doctrine are the creator's right to prevent excessive criticism and the creator's right to relief from other assaults on his personality. To appreciate fully the theoretical basis for these two rights, one must recall that the moral right doctrine safeguards rights of personality rather than pecuniary rights. The creator projects his personality into his work, and thus is entitled to be free from vexatious or malicious criticism and from unwanted assaults upon his honor and professional standing By virtue of the prohibition against attacks on the creator's personality, the creator also is protected against misuse of his name and work. In the context of our hypothetical situation, such misuse would occur if an antireligious organization claimed that the playwright subscribed to antireligious views solely by virtue of her authorship of the play.

In the hypothetical situation, now suppose the playwright enters into an agreement with a movie producer authorizing the producer to write a screenplay based upon her play. The final version of the screenplay, however, distorts considerably the playwright's theme and mutilates her story line. The component of the moral right doctrine that would grant relief to the paywright in this situation is called the right of integrity. This right lies at the heart of the moral right doctrine. In our hypothetical case the adaptation process naturally would require certain modifications in the playwright's manuscript, but the right of integrity prevents those who make such alterations from destroying the spirit and character of the author's work. Although adaptations of a work from one medium to another present the most obvious potential for violations of a creator's right of integrity, in reality, any modification of a work can be problematic from an integrity standpoint. Any distortion that misrepresents an artist's expression constitutes a violation of the creator's right of integrity.

There is, however, one rather incongruous aspect of the right of integrity. If the artist in our hypothetical situation was a painter rather than a playwright, the right of integrity probably would not allow her to prevent the destruction of one of her paintings by its owner. Perhaps the underlying rationale for this exception is that a work which has been destroyed completely cannot reflect adversely upon the creator's honor or reputation. Nevertheless, some commentators have criticized the destruction exception on the ground that it negates the creator's right of paternity and frustrates the public's interest in enjoying the artist's work.

All nations that have adopted the moral right doctrine statutorily include at least some of the above protections, but the contours of the 
doctrine vary among the adhering countries.

\section{Berne Convention for the Protection of Literary and Artistic Works}

(1979)

Art. 6bis

Moral Rights

17 U.S.C. § $106 \mathrm{~A}$

Rights of certain authors to attribution and integrity
(1) Independently of the author's economic rights, and even after the transfer of the said rights, the author shall have the right to claim authorship of the work and to object to any distortion, mutilation or other modification of, or other derogatory action in relation to, the said work, which would be prejudicial to his honor or reputation.

(2) The rights granted to the author in accordance with the preceding paragraph shall, after his death, be maintained, at least until the expiry of the economic rights, and shall be exercisable by the persons or institutions authorized by the legislation of the country where protection is claimed.

\section{Copyright Act}

(a) Rights of Attribution and Integrity. - Subject to section 107 and independent of the exclusive rights provided in section 106, the author of a work of visual art-

(1) shall have the right-

(A) to claim authorship of that work, and

(B) to prevent the use of his or her name as the author of any work of visual art which he or she did not create;

(2) shall have the right to prevent the use of his or her name as the author of the work of visual art in the event of a distortion, mutilation, or other modification of the work which would be prejudicial to his or her honor or reputation; and

(3) subject to the limitations set forth in section 113 (d), shall have the right-

(A) to prevent any intentional distortion, mutilation, or other modification of that work which would be prejudicial to his or her honor or reputation, and any intentional distortion, mutilation, or modification of that work is a violation of that right, and

(B) to prevent any destruction of a work of recognized stature, and any intentional or grossly negligent destruction of that work is a violation of that right. ...

(c) Exceptions. -

(1) The modification of a work of visual art which is a result 
of the passage of time or the inherent nature of the materials is not a distortion, mutilation, or other modification described in subsection (a)(3)(A).

(2) The modification of a work of visual art which is the result of conservation, or of the public presentation, including lighting and placement, of the work is not a destruction, distortion, mutilation, or other modification described in subsection (a)(3) unless the modification is caused by gross negligence.

(3) The rights described in paragraphs (1) and (2) of subsection (a) shall not apply to any reproduction, depiction, portrayal, or other use of a work in, upon, or in any connection with any item described in subparagraph (A) or (B) of the definition of "work of visual art" in section 101, and any such reproduction, depiction, portrayal, or other use of a work is not a destruction, distortion, mutilation, or other modification described in paragraph (3) of subsection (a).

(e) Transfer and Waiver. -

(1) The rights conferred by subsection (a) may not be transferred, but those rights may be waived if the author expressly agrees to such waiver in a written instrument signed by the author. Such instrument shall specifically identify the work, and uses of that work, to which the waiver. ...

(2) Ownership of the rights conferred by subsection (a) with respect to a work of visual art is distinct from ownership of any copy of that work, or of a copyright or any exclusive right under a copyright in that work. Transfer of ownership of any copy of a work of visual art, or of a copyright or any exclusive right under a copyright, shall not constitute a waiver of the rights conferred by subsection (a).

A "work of visual art" is -

(1) a painting, drawing, print, or sculpture, existing in a single copy, in a limited edition of 200 copies or fewer that are signed and consecutively numbered by the author, or, in the case of a sculpture, in multiple cast, carved, or fabricated sculptures of 200 or fewer that are consecutively numbered by the author and bear the signature or other identifying mark of the author; or

(2) a still photographic image produced for exhibition purposes only, existing in a single copy that is signed by the author, or in a limited edition of 200 copies or fewer that are signed and 
consecutively numbered by the author.

A work of visual art does not include-

(A) (i) any poster, map, globe, chart, technical drawing, diagram, model, applied art, motion picture or other audiovisual work, book, magazine, newspaper, periodical, data base, electronic information service, electronic publication, or similar publication;

(ii) any merchandising item or advertising, promotional, descriptive, covering, or packaging material or container;

(iii) any portion or part of any item described in clause (i) or (ii);

(B) any work made for hire; or

(C) any work not subject to copyright protection under this title.

\section{Integrity}

Start with the right of integrity. VARA protects it explicitly, copyright law implicitly.

\section{Massachusetts Museum of Contemporary Art Foundation v. Büchel}

Artist Christoph Büchel conceived of an ambitious, football-fieldsized art installation entitled "Training Ground for Democracy," which was to be exhibited at the Massachusetts Museum of Contemporary Art ("MASS MoCA"). Unfortunately, the parties never memorialized the terms of their relationship or their understanding of the intellectual property issues involved in the installation in a written agreement. Even more unfortunately, the project was never completed. Numerous conflicts and a steadily deteriorating relationship between the artist and the Museum prevented the completion of "Training Ground for Democracy" in its final form.

I.

MASS MoCA opened in 1999 as a center for the creation and display of contemporary art. The Museum "seeks to catalyze and support the creation of new art, expose [its] visitors to bold visual and performing art in all stages of production, and re-invigorate the life of a region in socioeconomic need." In its expansive facility in North Adams, Massachusetts, the Museum strives to "make the whole cloth of art making, presentation and public participation a seamless continuum." Over the last decade, the Museum has hosted the production and presentation of over sixty exhibits of visual art, including over 600 works of art by more than 250 individual artists. Some of 
these works have been displayed in Building 5, the Museum's signature exhibition space, which spans the length of a football field.

Christoph Büchel is a Swiss visual artist who lives and works in Basel, Switzerland. He is known for building elaborate, politically provocative environments for viewers to wander, and sometimes to crawl, through. One critic has stated that "Mr. Büchel's environments are huge in scale," "like bristling three-dimensional history paintings," yet are "so obsessively detailed that they might best be described as panoramic collage."

Büchel proposed, and the Museum agreed to, a project entitled "Training Ground for Democracy." Büchel conceived of the exhibit as "essentially a village, ... contain[ing] several major architectural and structural elements integrated into a whole, through which a visitor could walk (and climb)." According to an affidavit submitted to the district court, Büchel envisioned the work in the following way:

It was to adopt the role-play of U.S. military training for its visitors, who would be given the opportunity to "virtually" change their own various identities in relation to the collective project called "democracy": training to be an immigrant, training to vote, protest, and revolt, training to loot, training iconoclasm, training to join a political rally, training to be the objects of propaganda, training to be interrogated and detained and to be tried or to judge, training to reconstruct a disaster, training to be in conditions of suspended law, and training various other social and political behavior. In August 2006, Büchel spent ten days in residence at MASS MoCA. During this time, he and a partner prepared a basic schematic model of the proposed installation. MASS MoCA agreed to acquire, at Büchel's direction but its own expense, the materials and items necessary for the project.

Unfortunately, the parties never formalized the contours of their relationship or firmly established the project's financial scope and precise specifications by executing any written instrument. The parties set an opening date of December 16, 2006 for the exhibit.

Over the course of the fall, tensions began to develop between the artist and MASS MoCA employees, particularly Joseph Thompson. The museum felt the artist's directions were vague, and his financial and logistical demands were increasingly unreasonable; the artist felt the museum was compromising his artistic integrity and failing to follow his instructions. One frequent source of conflict between the parties was the budget, with the Museum understandably concerned about keeping its costs for the massive project under control, and Büchel understandably insistent that his vision for "Training 


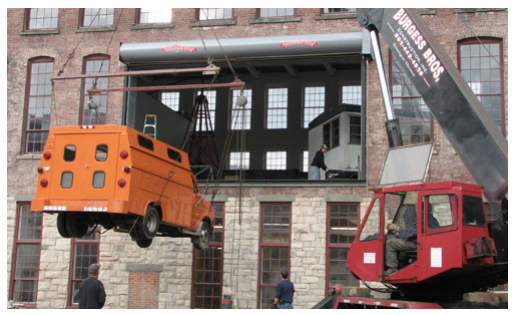

Installation of "Training Ground for Democracy" at MASS MoCA in 2006

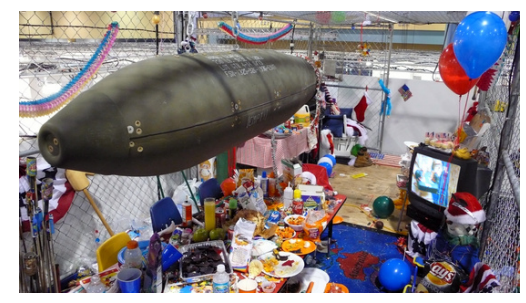

Christoph Buchel, "Training Ground for Training Ground for Democracy", installation at Art Basel Miami Beach, 2007
Ground" be fully realized.

For our purposes, the key conflict between MASS MoCA and the artist involved Büchel's dissatisfaction with the way in which the Museum was implementing his instructions and procuring the items necessary for the installation. At various points in the development of the installation, Büchel proposed several major components, some but not all of which later became part of the installation "as its elements evolved through discussions with MASS MoCA during the construction process. These major components included a movie theater, a house, a bar, a mobile home, various sea containers, a bomb carousel, and an aircraft fuselage. The Museum had begun seeking out some of these materials and others for potential use in the installation as soon as Büchel left North Adams at the end of August 2006, and continued to do so throughout the fall. One of the Museum's curators described the search for these items (at Büchel's direction) as "the ultimate scavenger hunt." However, problems soon arose, especially between Thompson and Büchel, as to the progress of the project, particularly when, as Thompson explained in an internal Museum email dated October 28, 2006, he had tried to "move the project along" by "making a few decisions in [Büchel's] stead." Thompson noted that Büchel, whom he described as having "clear vision" and "rock solid integrity," had taken "extreme, mortal[] offense" to Thompson's efforts.

Büchel remained onsite at the Museum working on "Training Ground" until December 17, 2006, when he left for the holidays. In Büchel's estimation, "Training Ground" was then only about $40 \%$ complete. At the time, he planned to return on January 8, 2007, in order to finish the work in time for a March 3 opening. Meanwhile, the Museum was running out of money for the project. In Büchel's absence, MASS MoCA staff continued to work on the installation. The parties disagree as to whether the employees were merely executing instructions left by the artist or whether their actions represented independent artistic judgment, exercised in direct contravention of Büchel's express wishes.

As the vitriolic exchanges between the parties continued, and negotiations over the project's eventual completion became hopeless, "Training Ground" languished in its unfinished state. It became clear that Büchel would not complete the installation. On May 22, 2007, MASS MoCA announced the cancellation of "Training Ground," and contemporaneously publicized the opening of a new exhibit entitled "Made at MASS MoCA," which was to be "a documentary project exploring the issues raised in the course of complex collaborative projects between artists and institutions." The press release noted that this lawsuit had been filed the previous day; it also highlighted the Museum's desire to use its "other experiences working with 
artists" to "provide [its] audience with thought-provoking insights into the complexities of the art-making process." The release further explained that, due to "space constraints imposed by the materials assembled for Training Ground for Democracy," the exhibition would be presented in the Museum's "only remaining available gallery space"; therefore, in order to enter the exhibit, visitors would have to pass through Building 5, "housing the materials and unfinished fabrications that were to have comprised elements of Training Ground for Democracy." The Museum represented that "[r]easonable steps [had] been taken to control and restrict the view of these materials, pending a court ruling."

When "Made at MASS MoCA" opened, many in the art world disagreed with the Museum's handling of its dispute with Büchel, though the parties have different views on whether the Museum's actions ultimately tarnished the artist's reputation. Moreover, the parties differ on whether the "reasonable steps ... taken to control and restrict the view of the[] materials" - the placement of yellow tarpaulins over the unfinished work - actually concealed all of the individual components and vital design elements of "Training Ground," or whether the tarpaulins simply "hid[] an elephant behind a napkin," effectively inviting individuals to peek behind the cloth coverings and view the unfinished work. See Charles Giuliano, Christoph Buchel's Tarp Art at Mass MoCA: Crap Under Wrap (July 31,

The Museum sued Büchel on May 21, 2007, in the United States District Court for the District of Massachusetts. The complaint asserted a single claim for declaratory relief under VARA. The Museum sought a declaration that it was "entitled to present to the public the materials and partial constructions assembled in connection with an exhibit planned with the Swiss artist Büchel." Büchel responded by asserting five counterclaims against the Museum. The first sought a declaratory judgment and an injunction under VARA prohibiting the Museum from publicly displaying "the unfinished Work of Art or any of its component elements." The second sought damages for MASS MoCA's alleged violations of Büchel's VARA rights by "intentionally distort[ing] and modif[ying] the Work of Art" and allowing members of the public to "see and pass through" the unfinished work, both with and without the yellow tarpaulins. The third, fourth and fifth counterclaims sought damages and injunctive relief under the Copyright Act based on alleged violations of Büchel's right to publicly display and create derivative works from his work.

The district court ruled in favor of the Museum, noting that nothing in VARA prevented MASS MoCA from showing the incomplete project. Therefore, MASS MoCA was "entitled to present" the unfinished installation to the public as long as it posted a disclaimer that 
would "inform anyone viewing the exhibit that the materials assembled in Building 5 constitute an unfinished project that [did] not carry out the installation's original intent." The court correspondingly denied the artist's request for injunctive relief barring public display of the unfinished installation, ruling that he had failed to prove a likelihood of success on the merits of his VARA claim.

However, several days after obtaining the ruling in its favor, MASS MoCA changed course. The Museum posted an announcement on its website stating that it had "begun removing materials gathered for Training Ground for Democracy and [would] not permit the public to enter the planned installation."

II.

Büchel argues that VARA applies with equal force to incomplete artistic endeavors that would otherwise be subject to VARA protection. The text of VARA itself does not state when an artistic project becomes a work of visual art subject to its protections. However, VARA is part of the Copyright Act. Not surprisingly, based on section 101's general definitions, courts have held that the Copyright Act's protections extend to unfinished works. Reading VARA in accordance with the definitions in section 101, it too must be read to protect unfinished, but "fixed," works of art that, if completed, would qualify for protection under the statute.

III.

The right of attribution under VARA gives an artist a claim for injunctive relief to, inter alia, assert or disclaim authorship of a work. We agree that VARA does not provide a damages remedy for an attribution violation. Where the statutory language is framed as a right "to prevent" conduct, it does not necessarily follow that a plaintiff is entitled to damages once the conduct occurs. The question is whether "doing" the act the artist has a right to prevent also triggers a damages remedy, and the statutory language indicates that Congress answered that question for the attribution right differently from the integrity right.

By dismantling "Training Ground," the Museum prevented the

Did MASS MoCA violate Büchel's VARA right against destruction in $\S 106 \mathrm{~A}(\mathrm{a})(3)(B)$ ? further use of Büchel's name in connection with the work, eliminating any basis for injunctive relief, and we therefore do not address the attribution claim in our VARA analysis.

Büchel alleges that MASS MoCA violated his right to integrity in three distinct ways: first, by continuing to work on the installation without his authorization, particularly in early 2007, and by then exhibiting the distorted artwork to the public; second, by using tarpaulins to "partially cover" - and thus modify and distort - the installation, and allowing Museum visitors to see it in that condition; 
and third, merely by showing Büchel's work in its unfinished state, which he claims was a distortion. Büchel asserts that these actions caused prejudice to his honor or reputation.

As we shall explain, we conclude that summary judgment was improperly granted to MASS MoCA because material disputes of fact exist concerning the first of Büchel's integrity claims - i.e., that MASS MoCA modified "Training Ground" over his objections, to his detriment. We further conclude that the record contains sufficient evidence to allow a jury to find that MASS MoCA's actions caused prejudice to Büchel's honor or reputation. The other integrity claims, however, are unavailing.

\section{Continuing Work on "Training Ground"}

Büchel asserts that, in the months following his departure from North Adams in December 2006, the Museum encroached on his artistic vision by making modifications to the installation that in some instances were directly contrary to his instructions. In rejecting Büchel's VARA claims, the district court described the Museum's actions as perhaps "occasionally misguided" attempts "to implement Büchel's long-distance instructions." The court found that these "[f]umbled efforts to assist in creating, or failing to create, a work of art are not equivalent to distortion, modification, or mutilation of the art."

Although a jury might agree with the court's assessment, the evidence viewed in the light most favorable to Büchel would allow a finding that at least some of the Museum's actions violated VARA. The record permits the inference that, even during his time as an artist-in-residence at MASS MoCA, Museum staff members were disregarding his instructions and intentionally modifying "Training Ground" in a manner that he did not approve.

Both in his deposition and in his affidavit, Büchel described ways in which he felt the Museum had knowingly disregarded his specific instructions. For example, MASS MoCA's decision to build a cinderblock wall through the Cape Codstyle house in the installation, despite Büchel's expressed desire that the construction await his return, resulted in what Büchel considered a "big distortion of the meaning of that element." The record is replete with similar allegations concerning other components of the installation, including the cinema, the bomb carousel, the Saddam spiderhole, the police car and the mobile home. Indeed, even the Museum, in its August 31, 2007 memorandum of law in support of its motion for summary judgment, admitted that the installation "[m]aterials as they now stand reflect significant aesthetic and design choices by MASS MoCA personnel, including with respect to the layout of the [m]aterials, and with respect to the selection and procurement of pre-existing build- 
ings and vehicles that have been modified and incorporated into the [m]aterials."

The record also contains evidence from which a jury could conclude that the Museum's alterations had a detrimental impact on Büchel's honor or reputation. An article in the Boston Globe reported that, in February, Museum officials had shown the unfinished project to a group of Museum directors and curators who were attending an arts conference in the area. Although the commentary generated by these visits is not all negative, there was sufficient evidence for a jury to find that the changes to "Training Ground" caused prejudice to Büchel. The New York Times noted that the exhibition would "certainly give people unfamiliar with his obsessive, history-driven aesthetic an inaccurate sense of his art, and this is indeed a form of damage." A critic for the Boston Globe similarly observed that "many people are going to judge Büchel and his work on the basis of this experience." A review published in Berkshire Fine Arts - subtitled "Crap Under Wrap" - concluded that it would be a "huge mistake" to uncover the installation, which offered "virtually nothing of substance or interest."

In concluding that Büchel has adduced sufficient evidence to support a right-of-integrity claim, we reject the Museum's assertion that to find a violation of Büchel's right of integrity in these circumstances would make it impossible for parties to collaborate on large-scale artistic works. The Museum warns that, under Büchel's interpretation, "no one other than the artist himself ... may ever perform any work in fabricating visual art unless that specific task has been authorized by the artist." We disagree. Although the artist's vision must govern, that principle does not prevent collaboration at the implementation level so long as the artist's vision guides that implementation. Here, Büchel alleges a campaign of intentional distortion and modification to his work in which Museum personnel repeatedly ignored his express wishes. Our holding that the summary judgment record precludes an affirmance of the district court on this claim may serve as a cautionary tale to museums contemplating similar installations in the future - guiding them to document the terms of their relationship and obtain VARA waivers where necessary - but it does not prevent museums or other collaborators from working cooperatively with artists on such non-traditional artworks.

\section{Showing "Training Ground" Covered with Tarpaulins}

Büchel also claims that MASS MoCA improperly modified and distorted "Training Ground" when it partially covered it with the yellow tarpaulins and displayed it in that condition. He asserts that the record shows beyond dispute that visitors looked behind the tarps, that the tarp-adorned installation was "judged by others to be 
Büchel's work, and that his honor and reputation were harmed by it." In response, the Museum argues that the yellow tarpaulins were merely functional - a way of keeping people "out" of the installation - rather than an aesthetic modification of the artwork that gave MASS MoCA patrons a distorted view of it.

Although the tarpaulins did prevent visitors to the Museum from seeing the entire unfinished installation, the record shows that a number of people were able to form an impression of "Training Ground" despite the partial covering. For example, according to one observer,

[the tarps] don't reach the floor, and they rise only about two feet above eye level, so they don't cover much. You can easily crouch down to slip your head underneath or peek through the slits between the vinyl sheets. Beyond the passageway formed by the tarps, the monumental elements of the installation rise all around you, plain as day - the cinderblock walls, the two-story house, the guard tower, the trailers, the carnival ride, all compacted together in a claustrophobic, politically surreal borough of hell, George Orwell by way of David Lynch.

Thomas Micchelli, Christoph Büchel Training Ground for Democracy, The Brooklyn Rail (September 2007). Another critic noted that the installation "under all the tarps is really kind of a conceptual peep show. It doesn't take much effort or imagination to see most of the work.... Mass MoCA is hiding an elephant behind a napkin," and called it a "wink, wink, wrap show." Photographs in the record confirm that the covers did not obscure the general path and layout of the installation. Indeed, given the location of "Training Ground," visitors to "Made at MASS MoCA" could not avoid seeing the unfinished "Training Ground" bedecked in tarpaulins.

Nonetheless, although the installation unquestionably looked different with the tarpaulins partially covering it, we agree with the district court that the mere covering of the artwork by the Museum, its host, cannot reasonably be deemed an intentional act of distortion or modification of Büchel's creation. To conclude otherwise would be to say that, even if all had gone well, the Museum would have been subject to a right-of-integrity claim if it had partially covered the work before its formal opening to prevent visitors from seeing it prematurely.

This is not to say that MASS MoCA was necessarily acting with pure intentions when it created "Made at MASS MoCA" in close proximity to the tarped "Training Ground." It might be a fair inference that the Museum was deliberately communicating its anger with Büchel by juxtaposing his unfinished work with the successful artistic collaborations depicted in its new exhibition. The partial covering of 
"Training Ground" may have been intended to highlight, rather than hide, the failed collaboration. The right of integrity under VARA, however, protects the artist from distortions of his work, not from disparaging commentary about his behavior.

\section{Exhibiting "Training Ground" in Its Unfinished State}

Büchel maintains that, even aside from the alleged modifications to "Training Ground," merely exhibiting the work of art in its unfinished state, without the artist's consent, constitutes a distortion. We reject this claim. A separate moral right of disclosure (also known as the right of divulgation) protects an author's authority to "prevent third parties from disclosing [his or her] work to the public without the author's consent," and is not covered by VARA.

Although Büchel proffered an expert who opined that showing an unfinished work without the artist's permission is inherently a distortion, we decline to interpret VARA to include such a claim where a separate moral right of disclosure is widely recognized in other jurisdictions and Congress explicitly limited the statute's coverage to the rights of attribution and integrity. Any right Büchel possesses to withhold display of his artwork must be found outside VARA.

IV.

We now assess Büchel's challenge to the grant of summary judgment for MASS MoCA on his Copyright Act claims. Büchel's undeveloped argument [that Mass MoCA violated the derivative works right] is so perfunctory that we deem the claim waived. [But his public display claim survived summary judgment.] The record reveals disputed issues of fact with respect to whether the Museum's copy was "lawfully made," as it may have been created in violation of the artist's rights under VARA. Moreover, Büchel introduced evidence to rebut the Museum's assertion that "the installation's various components" all belonged to, or were purchased by, MASS MoCA. Finally, Büchel presented evidence that the Museum understood that the physical copy of the installation belonged to him.

443 Mass. 110 (2004)

\section{Philips v. Pembroke Real Estate, Inc.}

David Phillips is a sculptor who has gained national recognition for his site-specific artwork. In 1999, Pembroke Real Estate, Inc. commissioned Phillips to work on Eastport Park, a public green space in the South Boston waterfront section of Boston. Phillips created approximately twenty-seven sculptures for the park, including abstract bronze and granite works and a dozen realistic bronze sculptures of hermit crabs, shrimp, and frogs. Phillips was responsible for the design and installation of rough stone walls, split granite paving stones, and other landscape design elements. Most of Phillips's sculpture 
and landscape elements are organized along a diagonal sight line, or axis, passing through the park, and are unified by a theme of spiral and circular forms. At the center of the axis is a large spherical sculpture entitled "Chords."

Soon after the park was completed in the spring of 2000, Pembroke determined that it was in need of alteration. A redesign scheme was prepared by British landscape architect Elizabeth Banks. It called for the removal and relocation of Phillips's sculptures. Phillips protested and, in January, 2003, Pembroke agreed to retain all but one of Phillips's sculptures. Phillips objected to Pembroke's revised plan and subsequently filed suit in the United States District Court for the District of Massachusetts, seeking injunctive relief under the Federal Visual Artists Rights Act and MAPA.

On August 21, 2003, at the conclusion of a nonevidentiary hearing, the United States District Court judge issued a temporary restraining order enjoining Pembroke from altering the park. Subsequently, Pembroke announced its intention to return to the original redesign scheme, which called for the removal of all of Phillips's sculptures. After a two-day evidentiary hearing, the United States District Court judge issued a memorandum and order in which she found "that the environment of Phillips' integrated sculpture along the axis of the Park is a critical element of those works, and changing the location of the sculpture constitutes an alteration" under MAPA. Accordingly, she ordered that Pembroke "not alter, destroy, move or remove any of the sculptures along the northeast-southwest axis of the Park until the conclusion of this litigation or further order of the Court. With respect to the other sculptures, Defendant may move the sculptures but shall not destroy or alter them."

Both parties filed interlocutory appeals with the United States Court of Appeals for the First Circuit pursuant to 28 U.S.C. \& 1292(a)(1) (2000). In the interim, the District Court judge certified the present question:

"Under the facts and circumstances described in the District Court's October 24, 2003 Memorandum and Order, to what extent does the Massachusetts Art Preservation Act protect the placement of 'site specific' art?"

The term "site-specific" art does not appear in any applicable Massachusetts statute. It is a term that has been defined in the art world as art "[that] is conceived and created in relation to the particular conditions of a specific site." Serra v. United States Gen. Servs. Admin. (quoting sculptor Richard Serra). It has also been described as "a combination of readymade work and a crafted work: the site is the readymade work, from which the artist draws her inspiration, and upon which the artist adds a crafted material. Together, the ready-

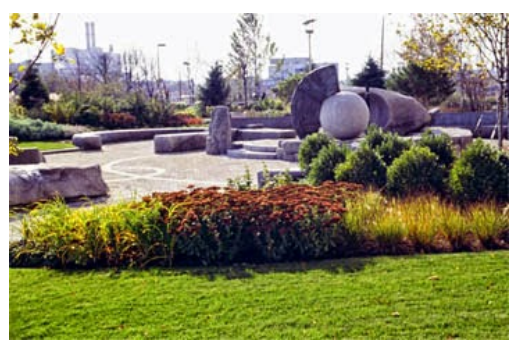

David Phillips installation in Eastport Park

Mass. Gen. Laws ch. 231, § $85 S$ (1984)

Serra: 847 F.2d 1045 (2d Cir. 1988) 
made and the crafted material exist as the artwork." Garson, Before That Artist Came Along, It Was Just a Bridge: The Visual Artists Rights Act and the Removal of Site-Specific Artwork, 11 Cornell J.L. \& Pub. Pol'y 203, 230 (2001). The term "site-specific" is also admittedly a sort of catchall phrase for a variety of artworks that elevate, in varying degrees, the importance of the relationship between context and object. In some works of site-specific art, the landscape provides the context necessary to give full meaning to otherwise free-standing crafted objects. In other works, such as "earthworks," the artwork is completely inextricable from its site because it is literally made from and imbedded in nature." The facts of this case present the former and not the latter type of site-specific art.

After considering all the language used in MAPA, construed as a whole, consistent with what we can glean of the Legislature's intentions in its enactment, we answer the question as follows: MAPA does not protect the placement of the type of site-specific art at issue here. Although it prohibits the physical destruction of the crafted components of such art, MAPA does not protect it against the conceptual destruction or decontextualization that may result from the removal of those components from the physical environment in which they have been placed. If the crafted components of site-specific art can be extracted from their surroundings without physical damage to them, the statute is not violated by their removal.

MAPA followed the lead of similar legislation in California and New York in attempting to graft onto a generally inhospitable common law tradition the civil law concept of droit moral, whereby a creative artist retains certain inalienable rights with respect to his or her creation before and after publication, display or sale. To accomplish its ends, MAPA protects both an artist's "right of integrity" (an artist's right not to have his or her creations altered), and an artist's "right of paternity" (an artist's right to claim or disclaim authorship of a work of art). The rights of integrity and paternity continue for fifty years after the artist's death and are enforceable by the artist or by his duly authorized representative by an action in the Superior Court.

It is apparent that in drafting the statute, the Legislature was concerned not only with creating new rights for artists, but also with protecting the rights of property owners who commission artworks that become attached to real property. This concern manifests itself in the way $\S 85 S(\mathrm{~h})$ of MAPA addresses "fine art" attached to buildings. If the art can be removed from the building without causing "substantial harm" to the art, the building owner may remove the art after giving the artist notice and ninety days to reclaim and remove it himself (at his own expense). If the artwork cannot be removed from the building without causing the "substantial physical defacement, mutilation, alteration, or destruction" of the art, the owner may pro- 
ceed to remove it unless the artist has expressly reserved his rights under the statute "by an instrument in writing signed by the owner of such building and properly recorded, prior to the installation of such art"

This provision serves two purposes. First, it ensures that the owner of a building will be able to remove unwanted art from his property even if the removal would cause physical damage to the art in ways otherwise prohibited by MAPA (unless the property owner has signed a written instrument reserving the artist's rights). Thus, it prevents the artist from holding the building hostage to the artworks. Second, by requiring that any enforceable reservation of rights be "properly recorded," the statute protects the integrity of the real property conveyancing system and guards against the establishment of unnoticed, undetectable, and indeterminate encumbrances.

If the Legislature intended to include the type of site-specific art at issue here within MAPA's protections, it would entail a radical consequence for owners of land, that the Legislature directly averted for owners of buildings. Specifically, rights afforded artists would encumber private and public land with restrictions lasting for the life of the artist plus fifty years, without the need for such restrictions to be recorded in a registry of deeds. We do not lightly read such an intent into a legislative act given the recognized legislative policy of discouraging land restrictions (especially unrecorded ones), the common-law doctrine disapproving the long-term burdening of property, and the corollary judicial practice of construing statutory provisions regarding land restrictions in favor of freedom of alienation.

The failure of the statute to address specifically the removal of fine art from land suggests that the Legislature either did not intend the statute's protection to extend to the land upon which works of art have been placed, or did not perceive the removal of free-standing works of art from their sites as causing their "physical defacement, mutilation, alteration, or destruction." Either way, there was no need for it to consider the possibility that land might be also "held hostage" to attached artworks. Given the Legislature's evident concern that works of fine art not burden buildings, and that restrictions encumbering buildings be properly recorded, it is apparent to us that if the Legislature had understood that MAPA would have that same encumbering effect on the sites of site-specific art, it would have addressed the subject directly.

This interpretation is also consistent with our view that the statutory protection afforded fine art is protection from physical rather than conceptual harm. In application, moving Phillips's sculptures will not result in their physical destruction, nor will it cause a physical alteration to the actual sculptures. The harm presented is decon- 
433 F. Supp. 2d 1236 (D. Colo. 2006)

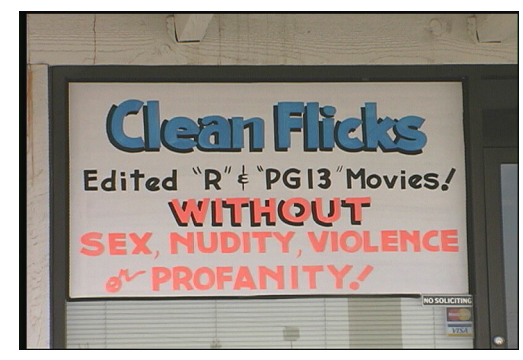

Sign from CleanFlicks' window textualization. That this harm is significant to Phillips (and possibly to the public) is not to be understated, but it is not the same harm as the actual physical alteration or physical destruction of the artworks crafted by the artist. The balance struck by the Legislature in 1984 deals only with the latter.

\section{Clean Flicks of Colorado, LLC v. Soderbergh}

CleanFlicks is a limited liability company in Utah, owned by Ray and Sharon Lines. It has created and publicly distributed copies of the Studios' movies that it altered by deleting "sex, nudity, profanity and gory violence," using its own guidelines. CleanFlicks began editing movies on VHS videocassettes in June, 2000, added DVDs at some time and now does only DVDs. The deletions are from both audio and visual content of the movies. The editing techniques used include redaction of audio content, replacing the redaction with ambient noise, "blending" of audio and visual content to provide transition of edited scenes, cropping, fogging or the use of a black bar to obscure visual content.

CleanFlicks first obtains an original copy of the movie from its customer or by its own purchase from an authorized retailer. It then makes a digital copy of the entire movie onto the hard drive of a computer, overcoming such technology as a digital content scrambling protection system in the acquired DVD, that is designed to prevent copying. After using software to make the edits, the company downloads from the computer an edited master copy which is then used to create a new recordable DVD-R to be sold to the public, directly or indirectly through a retailer. Thus, the content of the authorized DVD has been changed and the encryption removed. The DVD-R bears the CleanFlicks trademark. CleanFlicks makes direct sales and rentals to consumers online through its web-site requiring the purchaser to buy both the authorized and edited copies. CleanFlicks purchases an authorized copy of each edited copy it rents. CleanFlicks stops selling to any retailer that makes unauthorized copies of an edited movie.

The Studios claim that CleanFlicks is infringing their exclusive right to reproduce the copyrighted works under § 106(1), the Studios' right to create derivative works under $\S 106(2)$, and the exclusive right of distribution of copies under $\S 106(3)$.

[CleanFlicks argued fair use.]

Under the purpose and character of use factor, the counterclaim defendants concede that their use of the copyrighted works is for commercial gain, but argue, correctly, that under Campbell, that fact is not determinative. They seek to establish a public policy test that they are criticizing the objectionable content commonly found in current movies and that they are providing more socially acceptable alternatives to enable families to view the films together, without exposing 
children to the presumed harmful effects emanating from the objectionable content.

The accused parties make much of their public policy argument and have submitted many communications from viewers expressing their appreciation for the opportunity to view movies in the setting of the family home without concern for any harmful effects on their children. This argument is inconsequential to copyright law and is addressed in the wrong forum. This Court is not free to determine the social value of copyrighted works. What is protected are the creator's rights to protect its creation in the form in which it was created.

During the pendency of this case Congress enacted the Family Movie Act of 2005, amending $\S 110$ to provide an exemption for the editing of motion pictures by a member of a private household if no fixed copy of the altered version of the motion picture is created. That statute eliminated from this case those parties selling technology enabling such private editing. The legislative history shows that the amendment was not intended to exempt actions resulting in fixed copies of altered works which the House Committee believed illegal. Thus, the appropriate branch of government had the opportunity to make the policy choice now urged and rejected it.

The primary argument on the fair use defense is the fourth statutory factor. The counterclaim defendants contend that there is no adverse effect from their use of the movies on the value of the copyrighted work to the Studios. They suggest that the Studios benefit because they are selling more copies of their movies as a result of the editing parties' practice of maintaining a one-to-one ratio of the original and edited versions. It is assumed that the consumers of the edited versions would not have themselves purchased the authorized versions because of the objectionable content and the Studios do not compete in this alternative market.

The argument has superficial appeal but it ignores the intrinsic value of the right to control the content of the copyrighted work which is the essence of the law of copyright. Whether these films should be edited in a manner that would make them acceptable to more of the public playing them on DVD in a home environment is more than merely a matter of marketing; it is a question of what audience the copyright owner wants to reach.

\section{Prepared Statement of Taylor Hackford on Behalf of the Directors Guild of America}

Directors put their full vision and often years of hard work into the creation of a film. That film is not only their vision, but it carries their name and reflects on their reputation. Their ability to have their names used to identify and market their films is of great economic consequence. No matter how many warnings or disclaimers some-
At 17 U.S.C. § 110(11)

Derivative Rights, Moral Rights, and Movie Filtering Technology, Hearing Before the Subcommittee on Courts, the Internet, and Intellectual Property of the Committee on the Judiciary, House of Representatives (May 20, 2004) 
one puts on the film, it still has the director's name on it. So directors have great passion about protecting their work, which is their signature and brand identification, against unauthorized editing, and an abiding belief that contracts and the law will prevent others from illegally profiting from or altering their work.

Because directors and their names are inextricably and prominently linked with the movies they direct, the conduct of companies that sell unauthorized software filters or edited versions of movies is particularly harmful to directors. These companies are undoing, undermining and superseding the artistic work in which a director has invested a great deal of effort, and become closely associated by the public. Removing scenes and dialogue from films interferes with the story a director is trying to tell, and in so doing, can take away from the narrative structure and overall vision that audiences associate with a director. This editing can make movies into nonsense, completely changing their meaning. The director's reputation is likely to suffer when people viewing the film may believe they are watching a version of the film that has been edited and authorized for release by the director.

Proof of Life, starring Meg Ryan and Russell Crowe, told the story of an American oil executive who was kidnapped for ransom by insurgents in a fictional South American country. At its core, this movie centered on the kidnapping, the struggles of the kidnapped executive, and the impact of the event on his wife (Ryan) and his would-be rescuer (Crowe).

Despite the utter centrality of the kidnapping to the story, I was amazed to learn that at least one company, without any authorization or contractual right to alter the film, removed the entire kidnapping scene when it created a filter specifically designed to alter the viewing of this film. It is important to note that this scene was shown on television and airline versions virtually in its entirety, with only eleven seconds removed. These types of minor, authorized edits are acceptable, because, as the film's director, I agreed to them for a particular use.

In this case, the company had no authorization from the studio or me, yet they unilaterally removed the entire kidnapping scene and altered my film in a way that was extremely harmful to the basic telling of the story. It also was harmful to the way viewers perceive me as a director. This unauthorized version may lead viewers to believe Taylor Hackford directs movies that just don't make sense. Let me explain why.

First, the subject of kidnapping for ransom is pivotal to the film, and as the film's director, I went to great lengths to portray it as realistically as possible. In the theatrical, airline, and television version of the film, the audience sees how the abduction was carried out, and 
witnesses the organizational skill of the abductors and the depth of their cruelty. All of these essential details, and the overall tension and desperation of the scene, have been ripped from the film.

Second, the kidnapping scene, which takes place early in the movie, establishes the foundation for the entire story that follows, and is crucial to the overall dramatic purposes of the film. This scene enables the audience to empathize with an ordinary person, who is driving to work thinking about everyday problems on the job and at home. This "everyman" suddenly is wrenched from his daily life and plunged into a nightmare that he had never imagined possible. Removing this scene in its entirety leaves the audience unable to understand the context and meaning of the story, and renders the audience unable to connect emotionally to the character's plight. In short, removing the early kidnapping scene, from a movie about a kidnapping, changes the basic nature of the movie.

\section{Attribution}

Given Büchel, VARA's attribution right isn't much good, is it? And given Dastar, trademark law isn't much good for attribution either, is it? But there are a few ways in which the law prioritizes attribution: recall 1202

Unsurprisingly, private parties frequently insist on attribution by contract.

\section{Williams v. UMG Recordings, Inc.}

Plaintiff Kelvin Williams styles himself as "a talented young film director/writer/editor." Defendant Cash Money is a record label [which has a distribution contract with UMG].

In February of 2000, Plaintiff, Panzer and the Cash Money Defendants collaborated on the production of a documentary. A dispute over Plaintiff's compensation subsequently developed, apparently resulting in bad blood between Plaintiff and Panzer. In the meantime, around March 2000, Plaintiff got involved in another project with Panzer and the Cash Money Defendants involving post-production work on a film entitled "Baller Blockin'."

The parties disagree as to the nature and extent of Plaintiff's involvement in the Baller Blockin' project. Plaintiff claims that Defendants contracted with him to restructure the entire film. Plaintiff contends that he re-edited and re-scored the entire film and that it incorporates his copyrighted narration script ("Narration Script"). After Baller Blockin' was released, Plaintiff discovered his name was not listed in the film's credits and initiated this lawsuit.

Defendants argue that Dastar invalidates Plaintiff's Lanham Act claim. This Court agrees with Defendants. Plaintiff's Lanham Act

281 F. Supp. 2d 1177 (C.D. Cal. 2003)

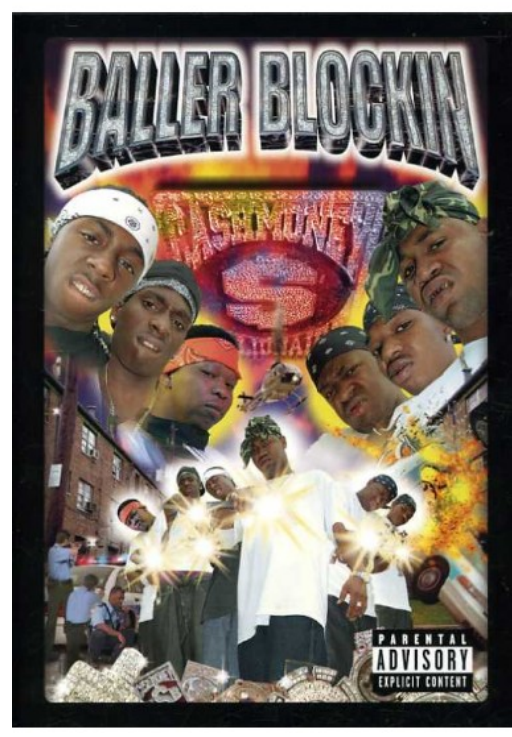

Baller Blockin' poster 
claim is based on the misattribution of credits for "story/screenplay" and "editing" on the Baller Blockin' film. Plaintiff alleges that he should be given credit for "the authoring of the 'Narration Script' . . ., editing film sequences and re-scoring the music." Under Dastar, however, the Supreme Court specifically held that the phrase "origin of goods" "refers to the producer of tangible goods that are offered for sale, and not to the author of any idea, concept, or communication embodied in those goods." As such, Plaintiff would have a claim if Defendants purchased copies of Plaintiff's goods (i.e. the film) and repackaged them as their own. By contrast, Plaintiff does not have a claim for his authorship and direction embodied in that film. His claim, therefore, is barred as a matter of law.

Plaintiff then asserts that "[i]f defendants [sic] argument were accepted, a talented director who directs a Summer blockbuster for example can be deprived of the immense value of such a credit in the entertainment industry, simply because the producer decides to name himself as the director .... A reading that the Lanham Act does not protect those people who provide services on films permits a form of anarchy in the entertainment industry, where anybody could be credited for anyone else's work and have their credit obliterated." In Plaintiff's hypothetical, the director has options to protect his interest - obtaining a contractual right to a credit, relying on the regulation of credits in union collective bargaining agreements (e.g., the Directors Guild) or maintaining the copyright in the film. In light of Dastar, this hypothetical director cannot bring a claim under the Lanham Act.

95 Geo. L.J. 49 (2006)

\section{Catherine L. Fisk \\ Credit Where It's Due: The Law and Norms of Attribution}

Hollywood (both motion picture and television production) has a highly formal attribution system that is thoroughly infused with legally enforceable rules for granting screen credit. Elaborate rules govern whose name will appear and whose will not, who can be listed under which job title (director, screenplay by, key grip, etc.), and the order and size of the print in which names are listed. The credit rules are the subject of negotiations between the guilds representing various workers and the production companies, but currently the administration of credit is left entirely to the guilds representing each of the forms of talent. One of the most important things that Hollywood guilds do is to administer the credit system.

The Writers Guild of America (WGA), the union representing 12,000 writers, administers the credit system for screenwriters. The collective bargaining agreement between the WGA and the Alliance of Motion Picture \& Television Producers states that "credits for screen authorship shall be given only pursuant to the terms of and 
in the manner prescribed in" the Theatrical Schedule A, a thirty page addendum to the Basic Agreement. Theatrical Schedule A specifies the criteria for screen credit. Disputes over credit are resolved pursuant to the WGA Credits Manual, which is not part of Theatrical Schedule A but is approved by the WGA's board of directors and by a vote of the WGA membership. The WGA has a committee that decides which names to submit to the studios to list as screenwriters. Theatrical Schedule A limits screen credit to no more than two writers "except that in unusual cases, and solely as a result of arbitration," three writers or "two writing teams" (each of which can be no more than two writers) may be credited. It also states, however, that the writers may agree among themselves as to screen credit if they agree unanimously and so long as the number of credited writers and the form of credit are consistent with Theatrical Schedule A. Writers who disagree with the Guild's determination can seek arbitration. In 2002, 67 of 210 feature film writing credits were arbitrated.

Notwithstanding the formality and legally enforceable nature of screen credit rights, informal norms also play a significant role. Producer credits, one of the most important on a movie, are not governed by collective bargaining agreements because the studios do not recognize the Producers Guild as a union. Therefore, some (including a producer of the 2006 Academy Award winning movie Crash) complain that producer screen credits are accorded by the Producers Guild unfairly. Because the guild agreements limit the number of people who can be credited in some roles on any one film, power relations among various possible contenders for credit affect who is listed. Individual workers with significant bargaining power (actors, directors, writers, and producers) negotiate for specific treatment on each project, which may or may not reflect the same level of artistic contribution as compared to others who receive a similar type of credit on a different film or who receive the same credit (or no credit) on the same film.

Other contributors to a project (lawyers, caterers, and animal trainers) may be credited even though they are not subject to guild agreements providing for credit. They may negotiate for credit in the contract in which they agree to work on the project, or they may be given credit at the whim of the producer or director as a form of thanks. There are significant differences in the processes of credit attribution for star actors, directors, producers, and writers than for the best boys, grips, set painters, and still another set of norms governing credit for caterers, assistants, lawyers, and accountants. 


\section{People as Trademarks}

Trademark law has a few rules that explicitly apply to names and other attributes of personal identity. Are these special rules for special subject matter, or just the predictable application of trademark's usual principles?

\section{Lanham Act}

35 U.S.C. § 1052 [Lanham Act § 2] Trademarks registrable on principal register; concurrent registration
362 F.3d 986 (7th Cir. 2004)

Both companies sold plush camel toys named "Niles." Trademark litigation ensued, giving Judge Posner an opportunity to discuss the considerations applicable to personal names as trademarks
No trademark by which the goods of the applicant may be distinguished from the goods of others shall be refused registration on the principal register on account of its nature unless it-

(c) Consists of or comprises a name, portrait, or signature identifying a particular living individual except by his written consent, or the name, signature, or portrait of a deceased President of the United States during the life of his widow, if any, except by the written consent of the widow.

(e) Consists of a mark which ... (4) is primarily merely a surname

Peaceable Planet, Inc. v. Ty, Inc.

Although cases and treatises commonly describe personal names as a subset of descriptive marks, it is apparent that the rationale for denying trademark protection to personal names without proof of secondary meaning can't be the same as the rationale just sketched for marks that are "descriptive" in the normal sense of the word. Names, as distinct from nicknames like "Red" or "Shorty," are rarely descriptive. "Niles" may evoke but it certainly does not describe a camel, any more than "Pluto" describes a dog, "Bambi" a fawn, "Garfield" a cat, or "Charlotte" a spider. (In the Tom and Jerry comics, "Tom," the name of the cat, could be thought descriptive, but "Jerry," the name of the mouse, could not be.) So anyone who wanted to market a toy camel, dog, fawn, cat, or spider would not be impeded in doing so by having to choose another name.

The reluctance to allow personal names to be used as trademarks reflects valid concerns (three such concerns, to be precise), but they are distinct from the concern that powers the rule that descriptive marks are not protected until they acquire secondary meaning. One of the concerns is a reluctance to forbid a person to use his own name in his own business. Supposing a man named Brooks opened a clothing store under his name, should this prevent a second Brooks from opening a clothing store under his own (identical) name even though consumers did not yet associate the name with the first Brooks's store? It should not. 
Another and closely related concern behind the personal-name rule is that some names are so common - such as "Smith," "Jones," "Schwartz," "Wood," and "Jackson" - that consumers will not assume that two products having the same name therefore have the same source, and so they will not be confused by their bearing the same name. If there are two bars in a city that are named "Steve's," people will not infer that they are owned by the same Steve.

The third concern, which is again related but brings us closest to the rule regarding descriptive marks, is that preventing a person from using his name to denote his business may deprive consumers of useful information. Maybe "Steve" is a well-known neighborhood figure. If he can't call his bar "Steve's" because there is an existing bar of that name, he is prevented from communicating useful information to the consuming public.

David B. Findlay, Inc. v. Findlay

When should a man's right to use his own name in his business be limited? This is the question before us.

The individual plaintiff David B. Findlay ("David") and the individual defendant Walstein C. Findlay ("Wally") are brothers. The Findlay art business was founded in 1870 by their grandfather in Kansas City. Their father continued and expanded the business with a Chicago branch managed by Wally and a New York branch established and managed by David on East 57th Street. In 1936 the Kansas City gallery was closed and in 1938, after a dispute, the brothers separated. By agreement David, as president of Findlay Galleries, Inc., and owner of nearly all of the stock of the original Missouri corporation, sold to Wally individually the Chicago gallery and allowed Wally to use the name "Findlay Galleries, Inc." in the conduct of his business in Chicago. Wally organized an Illinois corporation under the name "Findlay Galleries, Inc." in 1938 and has since operated his Chicago gallery. He also opened, in 1961, a Palm Beach, Florida, gallery.

David, since the separation, has operated his gallery on East 57th Street in Manhattan. For many years he has conducted his business on the second floor of 11-13 East 57th Street.

In October, 1963, Wally purchased the premises at 17 East 57th Street and informed David of his plans to open an art gallery. David objected to Wally's use of the name "Findlay" on 57th Street and by letter announced he would "resist any appropriation by you in New York of the name Findlay in connection with a gallery *** any funds spent by you to establish a gallery at 17 East 57th Street under the name Findlay Galleries, Inc. (or any variation thereof using the name Findlay) are spent at your peril." David also, in self-defense and in an effort to survive, rented additional space at 15 East 57th Street so 
as to have a street level entrance.

David's objections and pleas seemed to have some effect on Wally. As renovation on the building was carried on from October, 1963 to September, 1964, a large sign proclaimed the coming opening of "W.C.F. Galleries, Inc." There was also a display and listing in the New York Telephone directory under the same name and similar advertisements in other publications. However, in September, 1964 the sign was suddenly changed to announce the imminent opening of "Wally Findlay Galleries" affiliated with "Findlay Galleries, Inc." David immediately sought an injunction. Wally went ahead with his opening and erected a sidewalk canopy from the curb to the building displaying the name "Wally Findlay Galleries."

The trial court made very detailed findings and, based on them, enjoined defendant from using the names "Wally Findlay Galleries", "Findlay Galleries" and any other designation including the name "Findlay" in the conduct of an art gallery on East 57th Street. The Appellate Division has affirmed on the trial court's findings and we find evidence to sustain them.

In his quarter of a century on East 57th Street David has established a valuable good will and reputation as an art dealer. Through hard work, business ability and expenditure of large sums of money, David has reached the level where a significant portion of his business comes from people who have been referred to him by others and told to go to "Findlay's on 57th St."

The effect of Wally's new gallery, with its long canopy, can only be that those looking for "Findlay's on 57th St." will be easily confused and find their way into Wally's rather than David's gallery. Though Wally perhaps did not deliberately set out to exploit David's good will and reputation, the trial court found, and we agree, that such a result would follow if Wally were permitted to operate a gallery under the name "Wally Findlay Galleries" next door to David.

There were numerous instances of people telephoning or asking at David's for personnel of Wally's or for art work exhibited at Wally's. Many regular customers congratulated David on the opening of "his" new gallery next door. Moreover, advertisements frequently appeared on the same pages of the local press for "Findlay Galleries", "Findlay's", or "Wally Findlay Galleries" thus making it very difficult to tell whose advertisement it was. Even the art editors and reporters referred to Wally as "Findlay Galleries" - the name used for many years by David - or as "the new Findlay Gallery."

It is apparent that confusion has and must result from Wally's opening next to David. This is compounded by the fact that both brothers have for years specialized in French impressionist and postimpressionist painters. Therefore, quite naturally, both brothers have in the past dealt in the works of such famous deceased painters as 
Modigliani, Degas, Renoir, Gauguin, Bonnard, Braque, Monet and many others.

Although someone seeking a Renoir from David is unlikely to purchase a Degas from Wally, it is likely that with respect to some of the lesser-known impressionists such diversion might happen. More important, someone wishing to own a nude by Modigliani, a dancer by Degas or a portrait of a girl by Renoir would not necessarily have a particular painting in mind and would likely purchase any of these species, whether it be in Wally's or David's. The items sold by the two brothers are not unique, nonsubstitutional works.

Moreover, art, particularly modern art, is sold only to those who see it. Works of art are sold to those who cross the threshold of the art gallery and the more people you get into your gallery, the more art you will sell. To this end David has worked hard to develop the name "Findlay's on 57th St." and bring in customers. Many people who have the finances to purchase art do not necessarily have the knowledge to distinguish between the works of all the various painters represented by galleries such as Wally's or David's. For this reason they rely on the reputation of the gallery. David has spent over 25 years in developing satisfied customers who will tell others to go to "Findlay's on 57th St." This good will brings in customers who look for a work of art that suits their fancy and, if Wally were to continue to use the name Findlay, it is inevitable that some would walk into Wally's by mistake and would have their tastes satisfied there, to David's great harm.

The so-called "sacred right" theory that every man may employ his own name in his business is not unlimited. Moreover, fraud or deliberate intention to deceive or mislead the public are not necessary ingredients to a cause of action.

The present trend of the law is to enjoin the use even of a family name when such use tends or threatens to produce confusion in the public mind. Whether this confusion should be satisfied by misplaced phone calls or confusing advertisements alone we do not decide because there has been a finding that diversion, as well as confusion, will exist if Wally is not enjoined. Thus it is clear that the "confusion" with which we are dealing includes impairment of good will of a business.

In Meneely v. Meneely this court noted that one can use his own name provided he does not resort to any artifice or contrivance for the purpose of producing the impression that the establishments are identical, or do anything calculated to mislead the public.

Thirty-five years later, we noted that, as a general principle of law, one's name is his property and he is entitled to its use. However, it was equally a principle of law that no man can sell his goods as those of another. "He may not through unfairness, artifice, misrepresenta- 
World's Dispensary: 96 N.E. 738 (N.Y. 1911)

Ryan \& Son: 205 N.E.2d 859 (N.Y. 1965)
Today, the "Wally Findlay Gallery" and the "David Findlay Jr. Gallery" are under combined ownership and operate from the same address at 724 Fifth Avenue, between 56th and 57th Streets. The business is owned by James Borynack, who bought Wally's gallery after Wally's death in 1996, and bought David Jr.'s gallery from David Jr.s' daughter in 2016. tion or fraud injure the business of another or induce the public to believe his product is the product of that other." World's Dispensary Med. Assn. v. Pierce

Ryan $\mathcal{E}$ Son $v$. Lancaster Homes is distinguishable from the present case because there was lacking the crucial finding that in the absence of relief plaintiff would be damaged by confusion and diversion. There was no real competition between the two businesses. Again, unlike the instant case where "Findlay's on 57th St." is synonymous in New York City with quality art galleries, "Homes by Ryan" had not become a trade name with a secondary meaning. The court reviewed the law and cited the rule in Meneely. "This rule has been qualified, as we have said, only to the extent that use of a family name will be restricted where such use tends or threatens to induce confusion in the public mind".

In the present case Wally knew that David had conducted his business and built a reputation under the names "Findlay Galleries" and "Findlay's on 57th St." and that many years of effort and expenses had gone into promoting the name of "Findlay" in the art business on 57th Street. He also knew that people would come into his gallery looking for "Findlay Galleries" and even instructed his employees on this matter before he opened. Nonetheless he opened his gallery next door to David dealing in substantially similar works and using the name Findlay. The bona fides of Wally's intentions do not change the applicable principles. The objective facts of this unfair competition and injury to plaintiff's business are determinative, not the defendant's subjective state of mind. Wally's conduct constituted unfair competition and an unfair trade practice, and it is most inequitable to permit Wally to profit from his brother's many years of effort in promoting the name of "Findlay" on 57th Street. Wally should use any name other than "Findlay" in the operation of his business next door to his brother.

In framing its injunction the trial court went no farther than was necessary to avoid the harm threatened. It prevented the use of the name Findlay but limited this to the particular area in which its use would cause confusion and diversion - East 57th Street. It resolved the conflict with as little injury as possible to Wally. The proof showed and the trial court found that many, if not most of the leading art galleries, are now located on Madison Avenue and in the area of the 60's, 70's and 80's in New York City. Wally could probably have found an appropriate place for his New York gallery other than at 17 East 57th Street and can now either find such another location or remain where he is under some name such as "W.C.F. Galleries".

The decision in this case is in accord with the directions of our court: "The defendant has the right to use his name. The plaintiff has the right to have the defendant use it in such a way as will not injure 
his business or mislead the public. Where there is such a conflict of rights, it is the duty of the court so to regulate the use of his name by the defendant that, due protection to the plaintiff being afforded, there will be as little injury to him as possible." World's Dispensary

\section{Hebrew University of Jerusalem v. General Motors LLC}

Plaintiff's First Cause of Action asserts a claim for unfair competition and false endorsement under the Lanham Act. Unlike the broader right of publicity, which is infringed by the unpermitted use of a person's identity containing no false inference that plaintiff endorses or approves the product, $\S 1125$ (a) prohibits only false endorsement, not mere use of an image or name. A false endorsement claim based on the unauthorized use of a celebrity's identity is a type of false association claim for it alleges misuse of a trademark which is likely to confuse consumers as to the plaintiff's sponsorship or approval of the product. Only uses which suggest sponsorship or approval are prohibited.

Here, as defendant emphasizes, a minimal association exists between Plaintiff and the mark, which greatly reduces the likelihood that consumers viewing the Advertisement will conclude that Plaintiff endorsed the product. "The Advertisement does not state expressly (or even imply) that Dr. Einstein (or HUJ) endorsed the Terrain, nor would any reasonable reader reach that conclusion. Instead, the Advertisement uses Dr. Einstein's face, superimposed on someone else's body, as a play on People magazine's "Sexiest Man Alive" edition, and to make a light-hearted point about the smart (but "sexy") features of the Terrain."

Plaintif fails to point to any evidence in the record that establishes a genuine dispute of material fact regarding consumer confusion. Plaintiff "disputes" the facts relating to the Advertisement merely by citing to the Advertisement itself and claiming that it "implies and creates the false impression that Dr. Einstein's estate and/or [Plaintiff] were associated with the Advertisement." . Even if that is plausible - doubtful - this is a motion for summary judgment, not a motion to dismiss, and the Court will not sift through the record attempting to find evidence to support Plaintiff's case.

The Court will assume, for purposes of this analysis, that Einstein's likeness constitutes a strong mark. Since the Advertisement contains a photographic image of Einstein, the marks here are identical. However, Plaintiff has not even shown a tenuous connection between the "goods" at issue. At most, the Terrain draws its value from Einstein's image only indirectly and remotely; the ad was not for an Einstein product. Einstein is famous largely due to his tower-

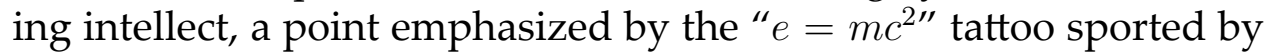
the Advertisement's Einstein doppelganger. "So what the Advertise-
903 F. Supp. 2d 932 (C.D. Cal. 2012)

This is a trademark false-endorsement claim under § 43(a)(1)(A). Why not a false-advertising claim under $\S 43(\mathrm{a})(1)(B)$, which would drop the requirement that the defendant use plaintiff's trademark and the likelihood-of-confusion analysis? 
ment suggests is that the Terrain vehicle is endowed with "smart (but 'sexy') features." So what? Einstein = smart. Terrain = smart. Ergo, does Einstein = Approval of Terrain? In short, any link between the "hunky" model in the ad, Einstein's image and the vehicle is too weak to create a link between two "goods."

Plaintiff points to no evidence of the strength of association between the mark and The Hebrew University of Jerusalem. Plaintiff points to no evidence regarding the degree of care consumers are likely to exercise when purchasing a car. Plaintiff points to no evidence that Defendant intended to profit by confusing consumers into believing Plaintiff endorsed the Terrain. Plaintiff points to no evidence that it markets products bearing the image of Einstein through the same marketing channels as Defendant or that any of its approved product lines will expand to overlap with Defendant's product lines. Finally, Plaintiff points to no evidence of actual consumer confusion.

Plaintiff has failed to meet its burden of producing evidence sufficient to create a genuine dispute of material fact. Accordingly, Defendant's motion for summary judgment is GRANTED on Plaintiff's claim for unfair competition and false endorsement under the Lanham Act.

Brown v. Electronic Arts, Inc.

Plaintiff-Appellant James "Jim" Brown alleges that DefendantAppellee Electronic Arts, Inc. has violated § 43(a) of the Lanham Act, through the use of Brown's likeness in EA's Madden NFL series of football video games.

Jim Brown is widely regarded as one of the best professional football players of all time. He starred for the Cleveland Browns from 1957 to 1965 and was inducted into the National Football League Hall of Fame after his retirement. After his NFL career, Brown also achieved success as an entertainer and public servant. There is no question that he is a public figure whose persona can be deployed for economic benefit.

EA is a manufacturer, distributor and seller of video games and has produced the Madden NFL series of football video games since 1989. The Madden NFL series allows users of the games to control avatars representing professional football players as those avatars participate in simulated NFL games. In addition to these simulated games, Madden NFL also enables users to participate in other aspects of a simulated NFL by, for example, creating and managing a franchise. Each version of Madden NFL includes the current year's NFL teams with the teams' current rosters. Each avatar on a current team is designed to mirror a real current NFL player, including the player's name, jersey number, physical attributes, and physical skills. Some versions of the game also include historical and all-time teams. Un- 
like for players on the current NFL teams, no names are used for the players on the historical and all-time teams, but these players are recognizable due to the accuracy of their team affiliations, playing positions, ages, heights, weights, ability levels, and other attributes. Although EA enters into licensing agreements with the NFL and NFL Players Association for its use of the names and likenesses of current NFL players, Brown, as a former player, is not covered by those agreements and has never entered into any other agreement allowing EA to use his likeness in Madden NFL. Brown asserts that EA has used his likeness in several versions of the game dating back at least to 2001 but that he has never been compensated.

A decade ago, we adopted the Rogers test as our method for balancing the trademark and similar rights protected by $\S 43$ (a) of the Lanham Act against First Amendment rights in cases involving expressive works. We agree with the district court that the use of Brown's likeness is artistically relevant to the Madden NFL games. As Brown points out in trying to undermine the status of the games as expressive works, EA prides itself on the extreme realism of the games. As Brown emphasizes in arguing that it is in fact his likeness in the games: "[I]t is axiomatic the '65 Cleveland Browns simply, by definition, cannot be the ' 65 Cleveland Browns without the players who played for the '65 Cleveland Browns. This fundamental truth applies especially to that team's most famous player, Jim Brown." Given the acknowledged centrality of realism to EA's expressive goal, and the importance of including Brown's likeness to realistically recreate one of the teams in the game, it is obvious that Brown's likeness has at least some artistic relevance to EA's work.

Brown questions the artistic relevance of his likeness to Madden NFL in part by pointing us to the Sixth Circuit's decision in Parks $v$. LaFace Records. In Rosa and Raymond Parks Institute, civil rights hero Rosa Parks sued the musical duo Outkast under § 43(a) after Outkast released a song called Rosa Parks. Partially due to the fact that one of the members of Outkast had said that the song was not "intended ... to be about Rosa Parks or the civil rights movement," the Sixth Circuit concluded that the district court should have at least considered additional evidence before deciding that the use of Ms. Parks' name was artistically relevant to the song.

One of the Sixth Circuit's animating concerns in Rosa and Raymond Parks Institute was that a celebrity's name could be "appropriated solely because of the vastly increased marketing power of a product bearing the name of [the celebrityl." 329 F.3d at 454 . This is a legitimate concern, but the facts in Rosa and Raymond Parks Institute - specifically, the court's determination that the lyrics of Outkast's song may very well have nothing to do with Rosa Parks or the civil rights movement - made that concern much more realistic in that case

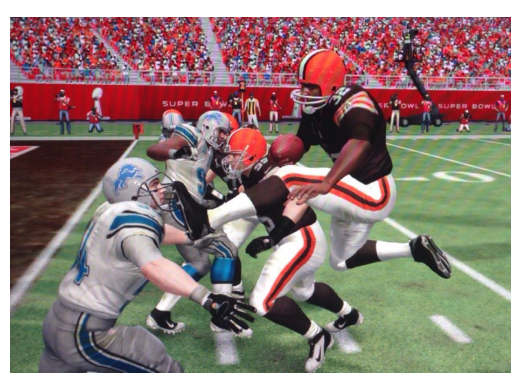

Madden NFL screenshot. The player with the ball has Jim Brown's uniform number.

Once the court adopts the Rogers test, it's pretty much fourth-and-forty for Brown. But consider In re NCAA Student-Athlete Name \& Likeness Licensing Litigation, 724 F.3d 1268 (9th Cir. 2013), which applied No Doubt and the transformative-use test to athletes' right of publicity claims against another EA sports video game and found no transformation because the game replicated their "physical characteristics," "users manipulate the characters in the performance of the same activity for which they are known in real life," and the context was "similarly realistic." Same court, same panel, same day. Also compare CBC Distribution \& Marketing v. Major League Baseball Advanced Media, 505 F.3d 818 (8th Cir.), which held that fantasy baseball competitions were shielded by the First Amendment from right of publicity liability when they used actual players' names and statistics.

LaFace: 329 F.3d 437 (6th Cir. 2003) 
than in this one. EA did not produce a game called Jim Brown Presents Pinball with no relation to Jim Brown or football beyond the title; it produced a football game featuring likenesses of thousands of current and former NFL players, including Brown. Comparing this case to Rosa and Raymond Parks Institute does not further Brown's cause.

[The court found nothing explicitly misleading about Madden NFL.]

\section{Melting Bad Problem, Re-Redux}

Walter Blanco from Blancorp is back again with yet more ideas for possible trademarks for his clumpless ice-melter. Give your opinion on the following potential trademarks:

- JONES

- BETTE MIDLER

- JAY Z

- WALTER BLANCO

- ROBIN HOOD

- CALVIN COOL EDGE

- BLANCO'S BLUE

\section{Personal Names}

Personal names are to the right of publicity as business names are to trademark. The law on permissible personal names is for the most part a free-for-all: you can call yourself almost anything you want. The occasional exceptions express some familiar policies.

\section{Laura A. Heymann}

\section{Naming, Identity, and Trademark Law}

Like trademarks, personal names serve denotative, connotative, and associative functions. A name denotes in that it allows us to refer to or identify a particular person who is not immediately present (and thus could be pointed to), akin to trademark's "source." Indeed, as one court noted, a name is, at root, "the label or appellation which [an individual] bears for the convenience of the world at large in addressing him or in speaking of him or in dealing with him." A personal name also connotes, in that it brings to mind a certain set of qualities or attributes about the individual to whom the name is attached. A personal name suggests that an individual is either male or female, that he or she is of a particular ethnicity or from a particular region, or that he or she is young or old.

Finally, personal names also have an associational function. In the same way the shared mark "Mercedes" can indicate a family 
of related goods, a surname can indicate a family of related people and an indication of one's social identity. Initiation into other social structures, such as fraternities or gangs, may be accompanied by new names that represent the new associations; indeed, as early as fifteenth-century Italy, virtually the only Tuscan family names were those of a handful of great families whose kin, including affines, adopted the name as a way of claiming the backing of a powerful corporate group.

\section{Carlton F.W. Larson}

Naming Baby: The Constitutional Dimensions of Parental Naming Rights In some states, parents may only choose surnames that are directly connected to their own. Louisiana's law is the most restrictive, requiring that a child of a married couple bear the surname of the husband. However, if both the husband and the wife agree, the surname "may be the maiden name of the mother or a combination of the surname of the husband and the maiden name of the mother." Any other surname, such as the surname of the mother's mother, is prohibited.

Although many state laws are silent on this point, I suspect most states would require parents to select a first name and a surname, rather than just one name. Hawaii, for example, requires married parents to select "both a family name and a given name chosen by one of the child's parents."

Curiously, very few states explicitly impose a duty on parents to name their child anything at all. Connecticut is not alone in not requiring a child's name to be entered on the birth certificate. For example, Michigan statutory law does not explicitly require that a child's given name be included on the birth certificate, and indeed a Michigan official has stated that "a child does not have to be given a name at all." Under Nevada law, a birth certificate need not include the child's name, but parents are given a form to submit "as soon as the child shall have been named."

A number of states, either through statute or administrative practice, prohibit the use of ideograms or pictograms as part of a child's name. This would preclude, for example, parents from naming their child using the symbol denoting The Artist Formerly Known as Prince.

As far as I can determine, no state prohibits the use of a numeral if it is spelled out. It would be permissible, for example, to name a child "Eight." But several states prohibit the use of a numerical symbol, which would prohibit naming a child "8." New Jersey, for example, permits the State Registrar to reject names that contain "numerals" or a "combination of letters, numerals, or symbols." In Illinois, administrative practice prohibits numerals when used as the first character in a child's name. Texas prohibits numerals as part of
80 Geo. Wash. L. Rev. 159 (2011)

See also Patrick McKenzie, Falsehoods Programmers Believe About Names; Julia Shear Kushner, The Right to Control One's Name, 57 UCLA L. Rev. 313 (2009)

But see Jennifer 8 . Lee, Yes, 8 Is My Middle Name, Boston Globe, Aug. 8, 1996 
the name or suffix, although Roman numerals may be used for suffixes. Thus, a child could be named "John William Turner III," but not "John William Turner 3" or "John William 3 Turner."

Some states explicitly limit the length of names, whereas others undoubtedly do so informally. Iowa administrative practice, for example, prohibits names over a certain number of characters due to technological limitations associated with its electronic data systems.52 In Massachusetts, the first, last, and middle names are limited to forty characters because of software limitations.

Prohibitions of accent marks and other diacritical marks are common. For example, the California Office of Vital Records provides a handbook to county vital records departments that states birth names can be recorded using only "the 26 alphabetical characters of the English language with appropriate punctuation if necessary." The handbook further specifies that "no pictographs, ideograms, diacritical marks" (including "é," "ñ," and "ç") are allowed. Hence the prohibition on "Lucía" discussed in the Introduction. In Massachusetts, the "characters have to be on the standard american [sic] keyboard. So dashes and apostrophes are fine, but not accent marks and the such." New Hampshire prohibits all special characters other than an apostrophe or dash. Accordingly, "O'Connor" is a permissible name in New Hampshire, but "Chacón" is not.

At least two states explicitly prohibit obscenities, and I suspect many other states would prohibit obscene names as well. New Jersey statutory law permits the State Registrar to reject any chosen names or surnames that contain an obscenity. Under Nebraska statutory law, the selection of a surname is the "parents' prerogative, except that the department [of Health and Human Services] shall not accept a birth certificate with a child's surname that implies any obscene or objectionable words or abbreviations." The statute is curiously sillent with respect to an obscenity in the child's first name.

Some states ostensibly impose no restrictions at all upon parents' choice of names. For example, under Kentucky statutory law, the child's surname is "any name chosen by the parents." A Kentucky official has stated that the mother can give her child "any name she wishes." In response to e-mail inquiries, state officials in Delaware, Maryland, and Montana all asserted that their states imposed no restrictions on parents' choice of names.65 A Washington statute states that an unmarried mother may "give any surname she so desires to her child." There is no similar statutory language with respect to married parents or with respect to first names. South Carolina formerly required that every child be given the surname of the father; now, however, a state official asserts that the state "does allow a mother to name her child without any restrictions."

Yet one wonders if these statements are literally true. It seems 
unlikely that state officials would passively accept an expletive, a 700letter name, or a name written entirely in Greek characters. Put to the acid test, these general statements about parents' unfettered ability to select a name may well prove unreliable.

Many foreign jurisdictions are significantly more restrictive with respect to naming practices. Portugal, for example, requires governmental approval of names; a list of previously approved and rejected names is available on the Internet. It makes for fascinating reading, displaying a relentless enforcement of "authentic" Portuguese names. Not surprisingly, "Svetlana," "Johann," "Ethel," and "Andy" all fail to make the cut, but so do "Carmencita," "Catelina," and "Iglesias." Portugal also prohibits names that "raise doubts about the sex of the registrant." In 2007, Venezuelan lawmakers proposed legislation that would limit parents to 100 approved names, perhaps because at least 60 Venezuelans bore the first name "Hitler." Spain specifically prohibits "extravagant" or "improper" names. French law permits officials to reject first names that are considered contrary to the welfare of the child. One such name was "Fleur de Marie," rejected by French courts as too eccentric. Argentina prohibits names that are "extravagant, ridiculous, contrary to [its] customs, [or] that express or signify political or ideological tendencies." It has in the past also rejected certain non-Spanish names, such as "Malcolm."

The need for further prohibitions is at least debatable. After all, most parents do not give their children ridiculous and hurtful names. But it does happen. When I started researching this topic several years ago, I assumed that no one would name his or her child "Adolf Hitler." But it happened. Indeed, at least sixty Venezuelans of voting age bear the first name "Hitler." Similarly, at least one child is alleged to be named for a venereal disease, and other American children have been named "Satan." Parents in Japan sought to name their child, "Akuma," which means "devil" or "demon." Since 1984, two children in the United Kingdom have been named "Superman," and six have been named "Gandalf." A New Zealand judge ordered a girl named "Talula Does The Hula From Hawaii" into court guardianship so that her name could be changed. The judge stated, "It makes a fool of the child and sets her up with a social disability and handicap." Other children in New Zealand have been named "Number 16 Bus Shelter," and "Violence." Similarly, Swedish officials have rejected attempts by parents to name children "Metallica" and "Brfxxccxxmnpccclllmmnprxvclmnckssqlbb11116." Danish officials rejected the proposed names "Anus" and "Monkey."

In re Mokiligon

Petitioner, acting pro se, appeals the district court's order denying his request to change his name from "Snaphappy Fishsuit Mokiligon" to 


\section{"Variable."}

Petitioner argued in his docketing statement that NMSA 1978, § 40-8-1 (1989) grants him the right to change his name. Section 40-8-1 reads, in pertinent part, as follows:

Any resident of this state over the age of fourteen years may, upon petition to the district court of the district in which the petitioner resides and upon filing the notice required with proof of publication, if no sufficient cause is shown to the contrary, have his [or her] name changed or established by order of the court.

We stated in our notice of proposed disposition that although it has been held that a court has discretion to deny a name change under statutes similar to ours, it is generally held that denial is limited to a showing of an "unworthy motive, the possibility of fraud on the public, or the choice of a name that is bizarre, unduly lengthy, ridiculous or offensive to common decency and good taste."

The court summarily denied Petitioner's request without providing sufficient factual support for the denial. The docketing statement represented that Petitioner did not receive a hearing, but was informed by mail that his request was denied. Thus, there appears to have been no showing of wrongful or fraudulent purpose, and the name "Variable" does not appear obviously offensive.

We clarify, however, that Petitioner is restricted to using the word 'variable' as his legal name. The court is not granting him the power to actually vary his legal name at will and he is limited to using 'variable,' unless or until he changes his name again through a recognized legal process.

\section{Petition of Variable}

Petitioner filed a request in district court to change his name to "Fuck Censorship!" " The district court denied the request stating that the "proposed name change would be obscene, offensive and would not comport with common decency."

Petitioner argues on appeal that he is entitled to call himself whatever he wishes. He argues that the First Amendment to the United States Constitution gives him that right and that it is improper government censorship to deny him that right.

We do not believe that the district court's action infringes on Petitioner's right to free speech. Petitioner has a right under the common law to assume any name that he wants so long as no fraud or misrepresentation is involved. He may do so without making any application to the state. Thus, under the common law, Petitioner may exercise his right to free speech and use any name at all. However, once Petitioner files an application for a name change and seeks the 
approval of the courts for a name, it becomes the responsibility of the courts to ensure that there are no lawful objections to the name change.

Petitioner may make a political statement by changing his name, but once he seeks the state's imprimatur he is subject to the court's discretion in granting the government's approval of the name. As the court in Lee v. Ventura County Superior Court, stated in denying the petition of Lee to change his name to "nigger," one has a common law right to assume any name, and a right to engage in a social experiment, but one does not have a right to require the state to participate in the experiment.

\section{In re Ravitch}

On October 26, 1998, Appellant filed a petition to change her name from "Mary Ravitch" to "Mary R." At the hearing, Appellant testified briefly that she no longer wished to use her ex-husband's surname "Ravitch" and did not want to revert to her premarital surname "Gon." Instead, she preferred to assume the "nice and simple" letter "R" as her surname.

The primary purpose of the Judicial Change of Name Statute, other than with regard to minor children, is to prohibit fraud by those attempting to avoid financial obligations. Inquiry extends beyond the intentions of the petitioner, however, and a court may properly exercise its wide discretion to refuse a requested name if the name is bizarre or unduly lengthy or difficult to pronounce or possessive of a ridiculous offensive connotation.

While there is naturally some confusion attendant to all name changes, Appellant's desired surname is so bizarre that it would likely be met with repeated suspicion and distrust in both business and social settings. Indeed, far from being a "nice and simple" identifier, an initialized surname has traditionally been used to preserve one's anonymity in various contexts. We thus associate Appellant's request with routinely denied requests for numerical or symbolized surnames rather than with those accepted requests for non-western or gender-transitional names. Finally, we must note that if courts were to permit initialized official names as a matter of course, we would invite surname replication at an exponential rate, greatly in excess of what is currently experienced with common surnames, so as to make informal identification burdensome at best.

We find, therefore, that the trial court properly exercised its discretion when it ruled that the public interest overrides Appellant's personal interest in choosing the letter " $R$ " as her official surname. Where, as here, the desired name is devoid of any significance to the petitioner and would likely spawn insurmountable difficulties affecting both the petitioner and the general population, its denial is proper.
Lee: 11 Cal. Rptr. 2d 763 (1992)

754 A.2d 1287 (Pa. Super. 2000) 
Though we are to interpret the Judicial Change of Name Statute liberally, we will not extend the statute to permit one to officially identify oneself by use of a mere alphabetical symbol instead of by a meaningful word or name.

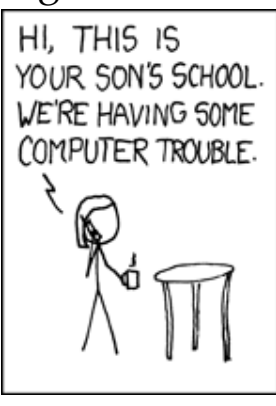

285 Ga. App. 325 (2007)
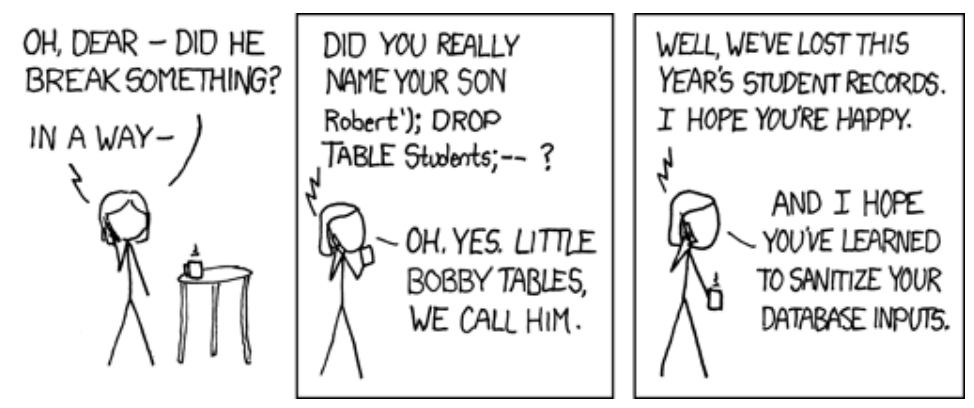

In re Serpentfoot

Pro se appellant Serpentfoot appeals the superior court's order denying her third amended petition to change her name to Ann Serpentfoot-Mooney and awarding \$2,500 in attorney fees to Burgett Mooney III, who objected to the petition.

The record shows that Mooney is the publisher of the Rome News Tribune. Appellant's current name, as well as her former name, Anne Otwell, appear in the newspaper on occasion in an unflattering light. In her first petition, appellant sought to change her name to "Blowdjett Mooney, IV." Mooney objected on the ground that appellant intended to defraud him and that this name change would cause him embarrassment and ridicule. Appellant amended her petition three times, on each occasion seeking an order to utilize the Mooney surname.

At the hearing held on the petition, appellant testified that the newspaper refuses to stop using her former name, even though she changed it to Serpentfoot after her arrest for protesting in the nude during Christian prayers at government meetings; that the newspaper is blackmailing her and prints the name Otwell in order to hurt her family and alienate her from her children; and that she chose the surname Mooney, although she is "not particularly fond of the name," because she believes that Burgett Mooney will not likely print the name Otwell if it is associated with Mooney's name. In her third amended petition, appellant set forth the reason for seeking the name change as follows:

\footnotetext{
${ }^{3}$ This is due to various criminal and other newsworthy acts committed by appellant. See Serpentfoot v. State, 524 S.E.2d 516 (Ga. App. 1999) (appellant's suspended sentence for public indecency revoked because she shot and killed her neighbors' ten-year-old, crippled dog because it was annoying her).

${ }^{4}$ Appellant chose "Bridgett S. Mooney, IV," then "S.S. Serpentfoot-Mooney," and finally, "Ann Serpentfoot-Mooney.
} 
I would like for our newspaper owner, Burgett Mooney, III to treat my name and the name of my previous husband's family, the same way he would like his name treated. Since they, and I, pleaded with him and it did no good, I see no solution to get him to practice "The Golden Rule" as to my name unless my surname is the same as his surname.

Given the probable harm to Burgett Mooney and appellant's improper motives, the trial court exercised sound legal discretion in denying the petition. Also, a person is not authorized to change his name "with a view to deprive another fraudulently of any right under the law." Every individual has a common law right to the protection of his own good name. Based on her testimony and the pleadings appellant has included in the record, the court could have found that she intended to deprive Mooney of his good name.

\section{Weingand v. Lorre}

Appellant Eugene Weingand appeals from the judgment ('Order') entered herein (1) denying appellant's petition for change of name, and (2) permanently restraining petitioner from using the name Peter Lorie in either his personal or business activities unless petitioner first obtains in writing the express written consent of Peter Lorre.

[The court discussed In re Ross.] There one Ross, an actor, had used the name of Ian Keith as a stage name for some fifteen years; it had become valuable to him and he desired it to be legally made his name. There was no opposition but the trial court denied his petition upon determining that he had once been adjudicated a bankrupt and had not subsequently paid such debts. In reversing the judgment the court held that a lawful bankruptcy proceeding without subsequent payment of the discharged debts was not a substantial reason to justify the denial. The court then said:

The common law recognizes the right to change one's personal name without the necessity of legal proceedings, and the purpose of the statutory procedure is simply to have, wherever possible, a record of the change. Hence Mr. Ross may, regardless of the present petition, use the name of Keith if he desires. And in keeping with the object of the statute, a court to which he applies should normally make its decree recording such change of name.

In light of the evidence herein and the substantial showing made in opposition to the petition no abuse of discretion was exercised by the trial court in denying the petitioner a legal record for change of name. The evidence fully supports the findings of the court to the
OCGA § 19-12-4.

41 Cal. Rptr. 778 (1964)

Ross: 67 P.2d 94 (1937) 
effect that it is not true petitioner's last name is hard to pronounce; it is true that petitioner has been engaged in show business and his associates have called him by his proposed name for about one year; petitioner has no family connection with the name Lorre or with any other name sounding like Lorre or Lorie; that petitioner bears a physical resemblance of sorts to, and affects a manner of speech similar to that for which Peter Lorre is known; that for more than one year petitioner, in the course of his business transactions, has held himself out to the public to be Peter Lorre, Peter Lorie, Peter Lorie, Jr., and also as the son of Peter Lorre, the well-known actor. Petitioner, before moving to California, was active in theater groups in Germany and New York City. For about one year he has been attending an acting school in Hollywood, California. That Peter Lorre is a world-famous actor in motion pictures and television. His name is unique in the entertainment industry and has acquired a secondary meaning in that it cannotes the unique characterization, style, manner of speaking and appearance of Mr. Lorre. That the appearance in the entertainment industry of an actor bearing the name Peter Lorie would confuse the public in that advertising and publicity for a performance of Peter Lorie would draw members of the public expecting to see a performance of Peter Lorre. This would directly affect the commercial and professional value of the services and performances of Peter Lorre both present and future. That petitioner has not acted in good faith in filing his petition to change his name to Peter Lorie and his purpose in seeking an order of the court authorizing such name change is to 'cash in' on the reputation of Peter Lorre. These findings, based upon credible evidence, constitute substantial reasons for the denial by the court of the petition herein for a change of name.

The final matter before us concerns the voluntary inclusion in the conclusions of law and the judgment of a permanent injunction. As pointed out in Ross, the common law recognizes the right of a person to change his name without the necessity of legal proceedings. The trial court therefore exceeded its jurisdiction in permanently enjoining petitioner from using the name Peter Lorie.

\section{Application of Clark}

Identical applications are presented by Maxine Sheppard and Nancy Clark for leave, by each, to assume the name of Nancy ClarkSheppard. Petitioners are actresses, radio and television artists and desire to engage in television work as a partnership. Each avers that "The theatre and its allied arts is justly famous throughout the ages for its generosity. Unfortunately, this generosity does not always extend within its own ranks. Especially is this true in regard to publicity and personal fame. We are about to launch this theatrical partnership. Realizing the human frailities of woman, in particular her petty jeal- 
ousies over career, we feel that by thus bearing the same name much of this will be eliminated. Therefore, we wish to circumvent the possibility of having the spotlight of publicity trained more upon one of us than the other. We wish to share and share alike in publicity, the life blood of a performer." To approve these requests would, it seems to me, create a situation which may veritably lead to a "Comedy of Errors" and may tend to prejudice persons having business and commercial relations with petitioners. The applications are denied.

\section{In re Name Change of Handley}

The petitioner filed an application with the court on December 29, 1999 to change his name to Santa Robert Claus. In his application, he stated that children have called him "Santa Bob" year round and that he lives his life for the children. The petitioner is a rotund gentleman with a full white beard and wears wire glasses, which he says attributes to people commenting on his resemblance of Santa Claus. The petitioner has been acting the role of Santa Claus for over forty years, initially playing the role in a school play at age fourteen. The petitioner receives gratuity for his portrayal of Santa Claus at various events, but it does not cover his expenses incurred. The petitioner stated in his application, "I don't want people to say you look like Santa, I want to be Santa."

The court finds that there is an economic value to the name of Santa Claus. The court finds no fraudulent intent of the petitioner to take advantage of the economic value for the use of the name. However, the court finds public policy reasons to deny the petitioner's request, particularly the interference with the rights of others. The petitioner is seeking more than a name change, he is seeking the identity of an individual that this culture has recognized throughout the world, for well over one hundred years. Thus, the public has a proprietary interest, a proprietary right in the identity of Santa Claus, both in the name and the persona. Santa Claus is really an icon of our culture; he exists in the minds of millions of children as well as adults.

The history of Santa Claus - the North Pole, the elves, Mrs. Claus, reindeer - is a treasure that society passes on from generation to generation, and the petitioner seeks to take not only the name of Santa Claus, but also to take on the identity of Santa Claus. Although thousands of people every year do take on the identity of Santa Claus around Christmas, the court believes it would be very misleading to the children in the community, particularly the children in the area that the petitioner lives, to approve the applicant's name change petition.

Therefore, for the foregoing reasons, the court finds that it would
736 N.E.2d 125 (Ohio Probate Ct. 2000) 
be against public policy to grant the application of the petitioner.

The issue before us is whether the trial court erred in denying David Lynn Porter's petition to change his name to "Santa Claus." We conclude it did and reverse.

The reasons offered by the district court for denying Porter's petition included that the name "Santa Claus" would likely "create confusion, misunderstanding and intended or unintended, could allow for substantial mischief." The district court also feared that the name could cause a substantial chilling effect for persons otherwise entitled to exercise access to the courts but who would be hesitant to sue Santa Claus.

On the record before us, we simply disagree with the district court. Porter's proposed name may be thought by some to be unwise, and it may very well be more difficult for him to conduct his business and his normal everyday affairs as a result. However, Porter has the right to select the name by which he is known, within very broad limits. Significantly, Porter already tells others that he is Santa Claus. Allowing him to legally change his name to reflect his practice of doing so is more likely to avoid greater confusion than to create it by making Porter legally responsible for his actions in the name Santa Claus.

\section{E Defamation and False Light}

Finally, while the tort law of defamation and false light is not strictly speaking a body of intellectual property law, our survey would be incomplete without it. Unlike the right of publicity (but like commercial disparagement and false advertising), these torts are deeply concerned with truth and falsity.

\section{Milkovich v. Lorain Journal Co.}

Respondent J. Theodore Diadiun authored an article in an Ohio newspaper implying that petitioner Michael Milkovich, a local high school wrestling coach, lied under oath in a judicial proceeding about an incident involving petitioner and his team which occurred at a wrestling match. [The article stated, for example, "Anyone who attended the meet, whether he be from Maple Heights, Mentor, or impartial observer, knows in his heart that Milkovich and Scott lied at the hearing after each having given his solemn oath to tell the truth." Milkovich sued for defamation. The Ohio courts concluded that the article constituted constitutionally protected "opinion."]

Since the latter half of the 16th century, the common law has afforded a cause of action for damage to a person's reputation by the 
publication of false and defamatory statements. In Shakespeare's Othello, Iago says to Othello:

Good name in man and woman, dear my lord, Is the immediate jewel of their souls. Who steals my purse steals trash; 'Tis something, nothing; 'Twas mine, 'tis his, and has been slave to thousands; But he that filches from me my good name Robs me of that which not enriches him, And makes me poor indeed."

Defamation law developed not only as a means of allowing an individual to vindicate his good name, but also for the purpose of obtaining redress for harm caused by such statements. As the common law developed in this country, apart from the issue of damages, one usually needed only allege an unprivileged publication of false and defamatory matter to state a cause of action for defamation. The common law generally did not place any additional restrictions on the type of statement that could be actionable. Indeed, defamatory communications were deemed actionable regardless of whether they were deemed to be statements of fact or opinion. As noted in the 1977 Restatement (Second) of Torts § 566, Comment a:

Under the law of defamation, an expression of opinion could be defamatory if the expression was sufficiently derogatory of another as to cause harm to his reputation, so as to lower him in the estimation of the community or to deter third persons from associating or dealing with him. The expression of opinion was also actionable in a suit for defamation, despite the normal requirement that the communication be false as well as defamatory.... This position was maintained even though the truth or falsity of an opinion-as distinguished from a statement of fact-is not a matter that can be objectively determined and truth is a complete defense to a suit for defamation.

However, due to concerns that unduly burdensome defamation laws could stifle valuable public debate, the privilege of "fair comment" was incorporated into the common law as an affirmative defense to an action for defamation. The principle of fair comment afforded legal immunity for the honest expression of opinion on matters of legitimate public interest when based upon a true or privileged statement of fact. As this statement implies, comment was generally privileged when it concerned a matter of public concern, was upon true or privileged facts, represented the actual opinion of the speaker, and was not made solely for the purpose of causing harm. According to the majority rule, the privilege of fair comment applied only to an expression of opinion and not to a false statement of fact, whether it 
was expressly stated or implied from an expression of opinion. Thus under the common law, the privilege of "fair comment" was the device employed to strike the appropriate balance between the need for vigorous public discourse and the need to redress injury to citizens wrought by invidious or irresponsible speech.

In 1964, we decided in New York Times Co. v. Sullivan that the First Amendment to the United States Constitution placed limits on the application of the state law of defamation. There the Court recognized the need for "a federal rule that prohibits a public official from recovering damages for a defamatory falsehood relating to his official conduct unless he proves that the statement was made with 'actual malice' - that is, with knowledge that it was false or with reckless disregard of whether it was false or not." This rule was prompted by a concern that, with respect to the criticism of public officials in their conduct of governmental affairs, a state-law rule compelling the critic of official conduct to guarantee the truth of all his factual assertions' would deter protected speech.

Three years later, in Curtis Publishing Co. v. Butts, a majority of the Court determined that the New York Times test should apply to criticism of "public figures" as well as "public officials." The Court has also determined that both for public officials and public figures, a showing of New York Times malice is subject to a clear and convincing standard of proof.

The next step in this constitutional evolution was the Court's consideration of a private individual's defamation actions involving statements of public concern. Although the issue was initially in doubt, the Court ultimately concluded that the New York Times malice standard was inappropriate for a private person attempting to prove he was defamed on matters of public interest. Gertz v. Robert Welch, Inc. As we explained:

Public officials and public figures usually enjoy significantly greater access to the channels of effective communication and hence have a more realistic opportunity to counteract false statements than private individuals normally enjoy.

More important, public officials and public figures have voluntarily exposed themselves to increased risk of injury from defamatory falsehood concerning them. No such assumption is justified with respect to a private individual.

Nonetheless, the Court believed that certain significant constitutional protections were warranted in this area. First, we held that the States could not impose liability without requiring some showing of fault. Second, we held that the States could not permit recovery of pre- 
sumed or punitive damages on less than a showing of New York Times malice.

Still later, in Philadelphia Newspapers, Inc. v. Hepps, we held that "the common-law presumption that defamatory speech is false cannot stand when a plaintiff seeks damages against a media defendant for speech of public concern." In other words, the Court fashioned a constitutional requirement that the plaintiff bear the burden of showing falsity, as well as fault, before recovering damages.

Respondents would have us recognize, in addition to the established safeguards discussed above, still another First-Amendmentbased protection for defamatory statements which are categorized as "opinion" as opposed to "fact." For *18 this proposition they rely principally on the following dictum from our opinion in Gert:

Under the First Amendment there is no such thing as a false idea. However pernicious an opinion may seem, we depend for its correction not on the conscience of judges and juries but on the competition of other ideas. But there is no constitutional value in false statements of fact.

Judge Friendly appropriately observed that this passage "has become the opening salvo in all arguments for protection from defamation actions on the ground of opinion, even though the case did not remotely concern the question." Cianciv. New Times Publishing Co. Read in context, though, the fair meaning of the passage is to equate the word "opinion" in the second sentence with the word "idea" in the first sentence. Under this view, the language was merely a reiteration of Justice Holmes' classic "marketplace of ideas" concept.

Thus, we do not think this passage from Gertz was intended to create a wholesale defamation exemption for anything that might be labeled "opinion." Not only would such an interpretation be contrary to the tenor and context of the passage, but it would also ignore the fact that expressions of "opinion" may often imply an assertion of objective fact.

If a speaker says, "In my opinion John Jones is a liar," he implies a knowledge of facts which lead to the conclusion that Jones told an untruth. Even if the speaker states the facts upon which he bases his opinion, if those facts are either incorrect or incomplete, or if his assessment of them is erroneous, the statement may still imply a false assertion of fact. Simply couching such statements in terms of opinion does not dispel these implications; and the statement, "In my opinion Jones is a liar," can cause as much damage to reputation as the statement, "Jones is a liar." As Judge Friendly aptly stated: "It would be destructive of the law of libel if a writer could escape liability for accusations of defamatory conduct simply by using, explicitly or implicitly, the words 'I think."' Cianci 
Foremost, we think Hepps stands for the proposition that a statement on matters of public concern must be provable as false before there can be liability under state defamation law, at least in situations, like the present, where a media defendant is involved. Thus, unlike the statement, "In my opinion Mayor Jones is a liar," the statement, "In my opinion Mayor Jones shows his abysmal ignorance by accepting the teachings of Marx and Lenin," would not be actionable. Hepps ensures that a statement of opinion relating to matters of public concern which does not contain a provably false factual connotation will receive full constitutional protection. ${ }^{\text {. }}$

Next, [another] line of cases provides protection for statements that cannot "reasonably [be] interpreted as stating actual facts" about an individual. Hustler Magazine, Inc. v. Falwell. This provides assurance that public debate will not suffer for lack of "imaginative expression" or the "rhetorical hyperbole" which has traditionally added much to the discourse of our Nation.

We are not persuaded that, in addition to these protections, an additional separate constitutional privilege for "opinion" is required to ensure the freedom of expression guaranteed by the First Amendment. The dispositive question in the present case then becomes whether a reasonable factfinder could conclude that the statements in the Diadiun column imply an assertion that petitioner Milkovich perjured himself in a judicial proceeding. We think this question must be answered in the affirmative. As the Ohio Supreme Court itself observed: "The clear impact in some nine sentences and a caption is that Milkovich 'lied at the hearing after . . . having given his solemn oath to tell the truth."' This is not the sort of loose, figurative, or hyperbolic language which would negate the impression that the writer was seriously maintaining that petitioner committed the crime of perjury. Nor does the general tenor of the article negate this impression.

We also think the connotation that petitioner committed perjury is sufficiently factual to be susceptible of being proved true or false. A determination whether petitioner lied in this instance can be made on a core of objective evidence by comparing, inter alia, petitioner's testimony before the OHSAA board with his subsequent testimony before the trial court.

The numerous decisions discussed above establishing First Amendment protection for defendants in defamation actions surely

\footnotetext{
${ }^{7}$ We note that the issue of falsity relates to the defamatory facts implied by a statement. For instance, the statement, "I think Jones lied," may be provable as false on two levels. First, that the speaker really did not think Jones had lied but said it anyway, and second that Jones really had not lied. It is, of course, the second level of falsity which would ordinarily serve as the basis for a defamation action, though falsity at the first level may serve to establish malice where that is required for recovery.
} 
demonstrate the Court's recognition of the Amendment's vital guarantee of free and uninhibited discussion of public issues. But there is also another side to the equation; we have regularly acknowledged the "important social values which underlie the law of defamation," and recognized that "[s]ociety has a pervasive and strong interest in preventing and redressing attacks upon reputation." Rosenblatt $v$. Baer. Justice Stewart in that case put it with his customary clarity:

Rosenblatt: 383 U.S. 75 (1966)

The right of a man to the protection of his own reputation from unjustified invasion and wrongful hurt reflects no more than our basic concept of the essential dignity and worth of every human being - a concept at the root of any decent system of ordered liberty. ...

The destruction that defamatory falsehood can bring is, to be sure, often beyond the capacity of the law to redeem. Yet, imperfect though it is, an action for damages is the only hope for vindication or redress the law gives to a man whose reputation has been falsely dishonored."

We believe our decision in the present case holds the balance true.

\section{Restatement (Second) of Torts}

One who gives publicity to a matter concerning another that places the other before the public in a false light is subject to liability to the other for invasion of his privacy, if

(a) the false light in which the other was placed would be highly offensive to a reasonable person, and

(b) the actor had knowledge of or acted in reckless disregard as to the falsity of the publicized matter and the false light in which the other would be placed.

cmt. b. Relation to Defamation. - The interest protected by this Section is the interest of the individual in not being made to appear before the public in an objectionable false light or false position, or in other words, otherwise than as he is. In many cases to which the rule stated here applies, the publicity given to the plaintiff is defamatory, so that he would have an action for libel or slander under the rules stated in Chapter 24. In such a case the action for invasion of privacy will afford an alternative or additional remedy, and the plaintiff can proceed upon either theory, or both, although he can have but one recovery for a single instance of publicity.

It is not, however, necessary to the action for invasion of privacy that the plaintiff be defamed. It is enough that he is given unreasonable and highly objectionable publicity that attributes to him characteristics, conduct or beliefs that are false, and so is placed before 
the public in a false position. When this is the case and the matter attributed to the plaintiff is not defamatory, the rule here stated affords a different remedy, not available in an action for defamation.

Illustrations:

5. A is a war hero, distinguished for bravery in a famous battle. B makes and exhibits a motion picture concerning A's life, in which he inserts a detailed narrative of a fictitious private life attributed to $\mathrm{A}$, including a non-existent romance with a girl. $\mathrm{B}$ knows this matter to be false. Although $\mathrm{A}$ is not defamed by the motion picture, B is subject to liability to him for invasion of privacy.

cmt. c. Highly offensive to a reasonable person. - The rule stated in this Section applies only when the defendant knows that the plaintiff, as a reasonable man, would be justified in the eyes of the community in feeling seriously offended and aggrieved by the publicity. Complete and perfect accuracy in published reports concerning any individual is seldom attainable by any reasonable effort, and most minor errors, such as a wrong address for his home, or a mistake in the date when he entered his employment or similar unimportant details of his career, would not in the absence of special circumstances give any serious offense to a reasonable person.

Illustrations:

6. A is a noted musician. B writes and publishes a biography of A, which is in general a correct and favorable portrayal. Included in the book are a number of minor mistakes concerning details of A's career, together with accounts of a few fictitious but quite unimportant incidents in which $\mathrm{A}$ is reported to have been involved and conversations he is reported to have had with others. These are not defamatory and nothing in the book casts any adverse reflection upon A's character or reputation. B's attention is called to these errors, but he nevertheless publishes the book. $B$ has not invaded A's privacy.

Tyne ex rel. Tyne v. Time Warner Entertainment Co., L.P.

In October 1991, the fishing vessel the Andrea Gail was caught in a severe storm, and lost at sea. All of the crewmembers aboard the vessel were presumed dead. Due to interest in the unusual meteorological forces that caused the storm, the loss of the Andrea Gail became the subject of news stories and a best-selling book, The Perfect Storm, by Sebastian Junger. In June 2000, Warner Bros. released The Perfect Storm ("the Picture"), a motion picture based on the book and the events that occurred during the "storm of the century."

[Plaintiffs were the surviving children and spouses of some of the crew members. They sued the filmmakers of The Perfect Storm for] 
(1) unauthorized commercial appropriation of decedents' likenesses, in violation of Florida Statute § 540.08; (2) unauthorized commercial appropriation of Plaintiffs' likenesses, also in violation of $\S 540.08$; (3) common law invasion of privacy -false light; and (4) common law invasion of privacy based on disclosure of private facts.

\section{A. Section 540.08 Claims}

Defendants concede that they did not obtain authorization to include characters based on Plaintiffs and the decedents prior to the production of The Perfect Storm. However, they argue that they did not violate $\S 540.08$ by failing to obtain such authorization, because The Perfect Storm is an expressive work that has no commercial advertising purpose, and is, therefore, outside the scope of the rights protected by $\S 540.08$.

Despite Plaintiffs' protestations to the contrary, the Court believes that this case is squarely on point with the case of Loft $v$. Fuller. In that case, decedent Robert Loft was a commercial pilot who died in the crash of Eastern Airlines Flight 401. In the weeks and months following the crash, there were reported sightings of apparitions of Flight 401 crew members, including Loft. These reports were extensively covered by the news media. In 1976, John Fuller wrote a nonfiction book about the crash, "The Ghost of Flight 401," which was later made into a motion picture. Loft's family filed an action for invasion of privacy and unauthorized publication of Loft's name and likeness, based on the movie's depiction of Loft as a "reappearing ghost."

The Fourth District Court of Appeal held:

In our view, Section 540.08, by prohibiting the use of one's name or likeness for trade, commercial or advertising purposes, is designed to prevent the unauthorized use of a name to directly promote the product or service of the publisher. Thus, the publication is harmful not simply because it is included in a publication that is sold for a profit, but rather because of the way it associates the individual's name or his personality with something else. Such is not the case here. While we agree that at least one of the purposes of the author and publisher in releasing the publication in question was to make money through sales of copies of the book and that such a publication is commercial in that sense, this in no way distinguished this book from almost all other books, magazines or newspapers and simply does not amount to the kind of commercial exploitation prohibited by the statute.

The court's statement makes it clear that merely using an individual's 
"We think it does not matter whether the book is properly described as a biography, a fictional biography, or any other kind of literary work. It is not for a court to pass on literary categories, or literary judgment. It is enough that the book is a literary work and not simply a disguised commercial advertisement for the sale of goods or services. The protection of the right of free expression is so important that we should not extend any right of publicity, if such exists, to give rise to a cause of action against the publication of a literary work about a deceased person." Frosch v. Grosset \& Dunlap, Inc.427 N.Y.S.2d 828 (N.Y. App. Div. 1980) (dismissing suit by Marilyn Monroe's estate against the publisher of Norman Mailer's Marilyn) name or likeness in a publication is not actionable under $\S 540.08$. A motion picture is not, therefore, in and of itself, a "commercial purpose." Furthermore, the promotion and advertising of the picture also do not constitute a commercial purpose.

In the instant case, Plaintiffs have failed to raise a genuine issue of material fact as to whether the use of decedents' likenesses and their own likenesses were used for the purposes of trade or a commercial purpose. Plaintiffs have presented no evidence showing that their names and likenesses were used to directly promote The Perfect Storm. In the absence of such evidence, Plaintiffs have no cause of action under $\S 540.08$.

Finally, the Court addresses Plaintiffs' argument that Defendants are liable under $\S 540.08$ because the Picture contains fictionalized elements even though it purports to be "a true story." This argument has no merit. No Florida court has interpreted $\S 540.08$ to include an element of falsity. It is therefore immaterial whether The Perfect Storm claims to be a work of fiction or nonfiction. Plaintiffs' arguments regarding the alleged fictionalization of the Picture suggest that they have confused the statutory action of unauthorized publication with the common law action of false light invasion of privacy. The Court, however, has no such problem distinguishing those two causes of action. Consequently, the Court determines that the truth or falsity of the events depicted in the Picture is of no import to the issue of whether there was unauthorized publication of the Plaintiffs' and decedents' likenesses.

\section{B. False Light Invasion of Privacy}

Plaintiffs Erica and Billie-Jo Tyne do not have standing to bring an action for false light invasion of privacy on their father's behalf. It is well-settled that:

a cause of action for invasion of the common law right of privacy is strictly personal and may be asserted only by the person who is the subject of the challenged publication. Relatives of a deceased person have no right of action for invasion of privacy of the deceased person regardless of how close such personal relationship was with the deceased.

Loft The only recognized exception to this rule occurs when plaintiffs experience an independent violation of their own personal privacy rights other than the violation alleged to have occurred indirectly by virtue of the publicity given to the deceased.

Plaintiffs argue that they have experienced an independent violation of their own personal privacy rights by having been individually depicted in the Picture. It is true that both Erica and Billie-Jo Tyne 
are portrayed in the Picture. However, neither actress portraying Erica or Billie-Jo speaks any lines at any point during the film. In the film, the actresses are shown in a photograph in the wheelhouse of the Andrea Gail; both Erica and Billie-Jo admitted in requests for admissions that their father kept such a photograph in the wheelhouse of the vessel. The Picture also includes a scene depicting Erica and Billie-Jo attending their father's memorial service. Both Erica and Billie-Jo admit that they attended the memorial service. Thus, the Picture cannot be said to have portrayed Erica and Billie-Jo in a false light, because they have admitted to the factual accuracy of the scenes depicting them. The Picture's portrayal of the Tyne daughters is not sufficiently egregious in nature to establish a claim of invasion of privacy against Defendants.

\section{Invasion of Privacy - Public Disclosure of Private Facts}

Plaintiffs Debra Tigue and Dale R. Murphy, Jr. assert claims for invasion of privacy based on public disclosure of private facts. The complaint alleges that The Perfect Storm falsely portrays Tigue and Murphy, Jr. as living in Massachusetts. In their memorandum in opposition to the motion for summary judgment, Plaintiffs further contend that "the depiction in the Picture of Debra Tigue as being intimately involved with another man who is about to supplant the role of decedent Murphy in the lives of both Debra Tipe and Dale R. Murphy, Jr. is likewise entirely fabricated and has been advanced by Warner, as alleged in the Complaint, in knowing or reckless disregard of the truth."

In response to the motion for summary judgment, Plaintiffs primarily argue that the details of Tigue and Murphy, Jr.'s lives, as depicted in the Picture, are of no concern to the public. The Court need not address this issue, however, because it is clear that the Picture did not disclose private facts about Tigue and Murphy, Jr.

The Restatement (Second) of Torts has recognized that an essential element of the tort of public disclosure of private facts is that the facts at issue be true. However, Plaintiffs argue that the Picture's entire depiction of Tigue and Murphy, Jr. is fabricated and false. Because none of the facts disclosed by the picture are alleged to be true, Plaintiffs have no cause of action for invasion of privacy based on public disclosure of private facts. In a situation where the "facts" disclosed in a publication are, in actuality, false, the interest invaded is that protected by the defamation and false-light torts: the interest in being represented truthfully to the world. However, because Tigue and Murphy, Jr. did not assert claims for defamation or false light invasion of privacy, they do not have a valid cause of action, and Defendants are entitled to summary judgment on their claims. 


\section{Restatement (Second) of Torts}

$\S 564$

Applicability of Defamatory Communication to Plaintiff cmt d. Fictitious character. - A libel may be published of an actual person by a story or essay, novel, play or moving picture that is intended to deal only with fictitious characters if the characters or plot bear such a resemblance to actual persons or events as to make it reasonable for its readers or audience to understand that a particular character is intended to portray that person. The fact that the author or producer states that his work is exclusively one of fiction and in no sense applicable to living persons is not decisive if readers actually and reasonably understand otherwise. Such a statement, however, is a factor to be considered by the jury in determining whether readers did so understand it, or, if so, whether the understanding was reasonable.

\section{Illustration:}

1. The A motion picture producing company produces a film based upon historical events but offered as a fictitious play. In the film, B, a young woman who was a participant in some of these events, is represented as having yielded to the hypnotic power of the villain. In spite of the deviations of the film from the exact historical facts, B's friends reasonably understand that she is portrayed in the picture. The film is defamatory of $B$.

\section{Jessica Litman \\ Information Privacy/Information Property}

The entire house of cards represented by Hollywood's recognition of property rights in subjects' life stories is an illusory creation impelled by the realities of financing. If one seeks either loans or investors, it helps to have a piece of property to offer as collateral. Producers of works based loosely on truth rather than fiction have no property rights in their subjects. If the central actors in the story can be persuaded to "sell" the exclusive rights to film what happened to them, then those rights become property that a producer can take to the bank, even though no court would enjoin such a production on the ground that its principals lacked such a property right or had created their production despite the fact that the relevant life story rights had been sewn up by someone else. 


\section{Design}

This chapter deals with IP protections for the designs of threedimensional objects. The fundamental conceptual challenge such objects present is that they can be both useful and beautiful, and the bodies of IP law we have studied so far tend to insist either that the only protect the useful aspects or only that they don't protect the useful aspects. Thus, the doctrinal challenge in each IP area is how to draw the line between the utilitarian/functional/useful/applied aspects of an object's design and everything else. As we will see, design patents cut the Gordian knot by defining utility extraordinarily narrowly. But to understand how that solution works, we first need to see the difficulties other approaches face. And, as we will see, the design-patent solution creates its own difficulties.

\section{A Patent}

There are no per se rules preventing the issuance of utility patents on three-dimensional designs; they are just not usually an effective tool for protecting design as such. One problem is utility: if the design's only improvement over the prior art is that it looks better, this might not qualify even under the permissive Juicy Whip standard. Another is claim drafting: to twist the phrase, writing about design is like dancing about architecture. Indefiniteness and enablement are likely to hem in the applicant's ability to capture the design in words. So while utility patents are well adapted to capturing the functional aspects of a design, they are so awkward as to be useless at capturing everything else.

\section{B Copyright}

Copyright deals with the functionality problem for threedimensional objects in three different ways, depending on whether 
If you add in Baker and the variations introduced for computer software, there are at least five different functionality tests.

347 U.S. 201 (1954)

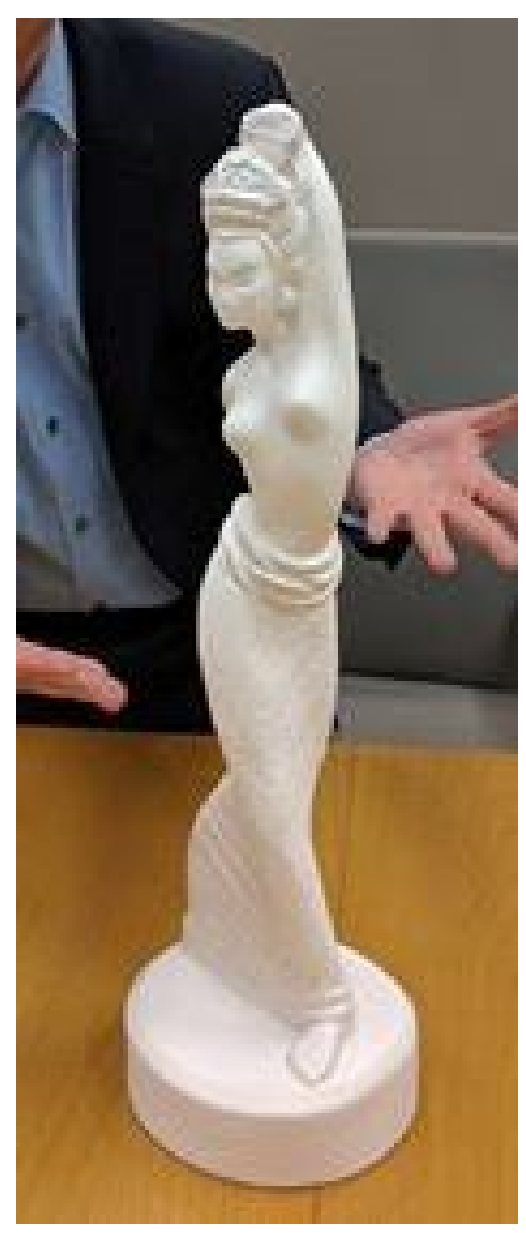

Lamp base the work is sculptural or architectural, and on whether VARA is in play.

\section{Useful Articles}

One could imagine drawing a distinction between fine art (like paintings and novels) and non-art (like boats and tools). Bleistein, however, dooms any inquiry into a work's artistry. Instead, the modern test focuses on utility; if a work is useful at all, the question is how much of the work is infected by its utility. You already know the answer in two dimensions: it is given by Baker and the merger doctrine. In three dimensions, the test is somewhat more stringent.

\section{Mazer v. Stein}

Respondents are partners in the manufacture and sale of electric lamps. One of the respondents created original works of sculpture in the form of human figures by traditional clay-model technique. From this model, a production mold for casting copies was made. The resulting statuettes, without any lamp components added, were submitted by the respondents to the Copyright Office for registration as "works of art" or reproductions thereof and certificates of registration issued. Thereafter, the statuettes were sold in quantity throughout the country both as lamp bases and as statuettes. Petitioners are partners and, like respondents, make and sell lamps. Without authorization, they copied the statuettes, embodied them in lamps and sold them.

[Under the 1909 Copyright Act, copyright extended to "all the writings of an author," and the two potentially applicable classes of works were "Works of art; models or designs for works of art" and "Reproductions of a work of art".]

The case requires an answer, not as to a manufacturer's right to register a lamp base but as to an artist's right to copyright a work of art intended to be reproduced for lamp bases. Petitioners question the validity of a copyright of a work of art for "mass" production. "Reproduction of a work of art" does not mean to them unlimited reproduction. Their position is that a copyright does not cover industrial reproduction of the protected article.

It is not the right to copyright an article that could have utility that petitioners oppose. Their brief accepts the copyrightability of the great carved golden saltcellar of Cellini but adds:

If, however, Cellini designed and manufactured this item in quantity so that the general public could have salt cellars, then an entirely different conclusion would be reached. In such case, the salt cellar becomes an article of manufacture having utility in addition to its ornamental 
value and would therefore have to be protected by design patent.

The [longstanding] practice of the Copyright Office was to allow registration "as works of the fine arts" of articles of the same character as those of respondents now under challenge. It is clear Congress intended the scope of the copyright statute to include more than the traditional fine arts. Individual perception of the beautiful is too varied a power to permit a narrow or rigid concept of art. We find nothing in the copyright statute to support the argument that the intended use or use in industry of an article eligible for copyright bars or invalidates its registration.

We hold that the [design] patentability of the statuettes, fitted as lamps or unfitted, does not bar copyright as works of art. Neither the Copyright Statute nor any other says that because a thing is patentable it may not be copyrighted.

The economic philosophy behind the clause empowering Congress to grant patents and copyrights is the conviction that encouragement of individual effort by personal gain is the best way to advance public welfare through the talents of authors and inventors in "Science and useful Arts." Sacrificial days devoted to such creative activities deserve rewards commensurate with the services rendered.

Douglas, J., concurring:

An important constitutional question underlies this case-a question which was stirred on oral argument but not treated in the briefs. The Copyright Office has supplied us with a long list of such articles which have been copyrighted - statuettes, book ends, clocks, lamps, door knockers, candlesticks, inkstands, chandeliers, piggy banks, sundials, salt and pepper shakers, fish bowls, casseroles, and ash trays. Perhaps these are all "writings" in the constitutional sense. But to me, at least, they are not obviously so.

Mazen frames the question. Here is how Congress tried to answer it in the 1976 Copyright Act.

\section{Copyright Act}

- "Pictorial, graphic, and sculptural works" include twodimensional and three-dimensional works of fine, graphic, and applied art, photographs, prints and art reproductions, maps, globes, charts, diagrams, models, and technical drawings, including architectural plans. Such works shall include works of

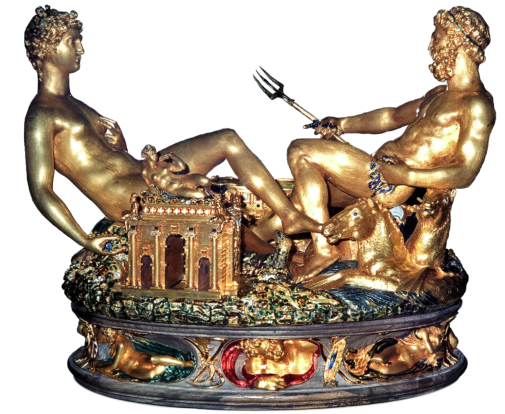

Salt cellar by Benvenuto Cellini.

The Cellini Salt Cellar, worth an estimated \$60 million, was stolen in 2003 from the Kunsthistorisches Museum in Vienna and recovered in 2006 after the thief was identified.

17 U.S.C. § 101

Definitions 
artistic craftsmanship insofar as their form but not their mechanical or utilitarian aspects are concerned; the design of a useful article, as defined in this section, shall be considered a pictorial, graphic, or sculptural work only if, and only to the extent that, such design incorporates pictorial, graphic, or sculptural features that can be identified separately from, and are capable of existing independently of, the utilitarian aspects of the article.

- A "useful article" is an article having an intrinsic utilitarian function that is not merely to portray the appearance of the article or to convey information. An article that is normally a part of a useful article is considered a "useful article".

\section{H.R. Rep No. 94-1476}

1976 U.S.C.C.A.N. 5659

The Committee is seeking to draw as clear a line as possible between copyrightable works of applied art and uncopyrighted works of industrial design. A two-dimensional painting, drawing, or graphic work is still capable of being identified as such when it is printed on or applied to utilitarian articles such as textile fabrics, wallpaper, containers, and the like. The same is true when a statue or carving is used to embellish an industrial product or, as in the Mazer case, is incorporated into a product without losing its ability to exist independently as a work of art. On the other hand, although the shape of an industrial product may be aesthetically satisfying and valuable, the Committee's intention is not to offer it copyright protection under the bill. Unless the shape of an automobile, airplane, ladies' dress, food processor, television set, or any other industrial product contains some element that, physically or conceptually, can be identified as separable from the utilitarian aspects of that article, the design would not be copyrighted under the bill. The test of separability and independence from 'the utilitarian aspects of the article' does not depend upon the nature of the design - that is, even if the appearance of an article is determined by esthetic (as opposed to functional) considerations, only elements, if any, which can be identified separately from the useful article as such are copyrightable. And, even if the three-dimensional design contains some such element (for example, a carving on the back of a chair or a floral relief design on silver flatware), copyright protection would extend only to that element, and would not cover the over-all configuration of the utilitarian article as such.

In reporting S. 22, the House Judiciary Committee has deleted Title II, which would create a new limited form of copyright protection for "original" designs which are clearly a part of a useful article, regardless of whether such designs could stand by themselves, sepa- 
rate from the article itself. Thus designs of useful articles which do not meet the design patent standard of "novelty" would for the first time be protected. The Committee chose to delete Title II in part because the new form of design protection provided by Title II could not truly be considered copyright protection and therefore appropriately within the scope of copyright revision. In addition, Title II left unanswered at least two fundamental issues which will require further study by the Congress. These are: first, what agency should administer this new design protection system and. second, should typeface designs be given the protections of the title? The issues raised by Title II have not been resolved by its deletion from the Copyright Revision Bill. Therefore, the Committee believes that it will be necessary to reconsider the question of design protection in new legislation during the 95th Congress. At that time more complete hearings on the subject may be held.

\section{Brandir Intern., Inc. v. Cascade Pacific Lumber Co.}

The courts have had difficulty framing tests by which the fine line establishing what is and what is not copyrightable can be drawn. Once again we are called upon to draw such a line, this time in a case involving the "RIBBON Rack," a bicycle rack made of bent tubing that is said to have originated from a wire sculpture.

Against the history of copyright protection well set out in the majority opinion in , and in

One aspect of the distinction that has drawn considerable attention is the reference in the House Report to "physically or conceptually" separable elements. The District of Columbia Circuit in Esquire, Inc. v. Ringer, (holding outdoor lighting fixtures ineligible for copyright), called this an "isolated reference" and gave it no significance. In Kieselstein-Cord v. Accessories by Pearl, Inc., this court accepted the idea that copyrightability can adhere in the "conceptual" separation of an artistic element. Indeed, the court went on to find such conceptual separation in reference to ornate belt buckles that could be and were worn separately as jewelry.

In Carol Barnhart Inc. v. Economy Cover Corp., a divided panel of this circuit affirmed a district court grant of summary judgment of noncopyrightability of four life-sized, anatomically correct human torso forms. Carol Barnhart distinguished Kieselstein-Cord, but it surely did not overrule it. The distinction made was that the ornamented surfaces of the belt buckles "were not in any respect required by their utilitarian functions," but the features claimed to be aesthetic or artistic in the Carol Barnhart forms were "inextricably intertwined with the utilitarian feature, the display of clothes." As Judge Newman's dissent made clear, the Carol Barnhart majority did not dispute "that conceptual separability is distinct from 'physical separability'
834 F.2d 1142 (2d Cir. 1987)

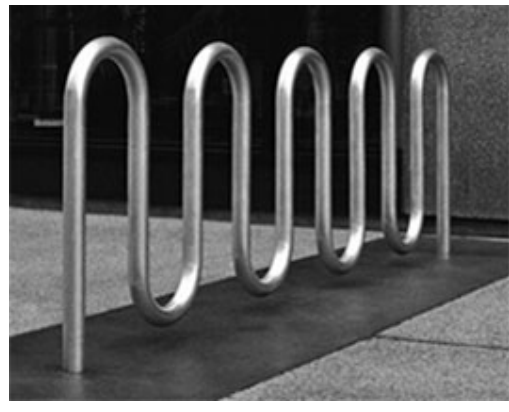

RIBBON Rack

Esquire: 591 F.2d 796 (D.C. Cir. 1978)

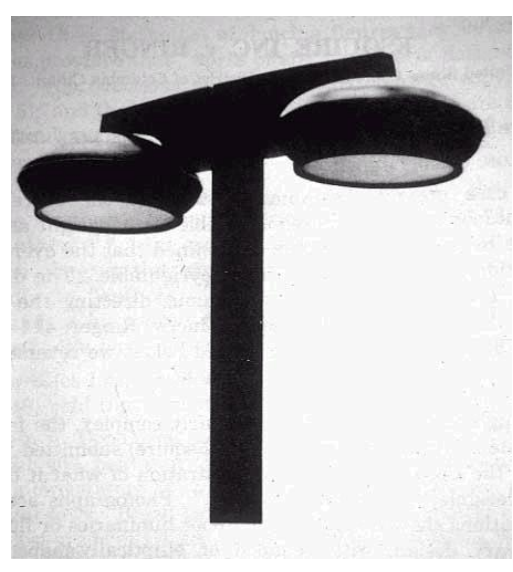

Lighting fixture in Esquire

Kieselstein-Cord: 632 F.2d 989 (2d Cir. 1980)

Carol Barnhart: 773 F.2d 411 (2d Cir. 1985) 
and, when present, entitles the creator of a useful article to a copyright on its design."

"Conceptual separability" is thus alive and well, at least in this circuit. The problem, however, is determining exactly what it is and how it is to be applied. Judge Newman's illuminating discussion in dissent in Carol Barnhart proposed a test that aesthetic features are conceptually separable if "the article stimulates in the mind of the beholder a concept that is separate from the concept evoked by its utilitarian function." This approach is to be distinguished from other possible ways in which conceptual separability can be tested, including whether the primary use is as a utilitarian article as opposed to an artistic work, whether the aesthetic aspects of the work can be said to be "primary," and whether the article is marketable as art, none of which is very satisfactory. But Judge Newman's test was rejected outright by the majority as "a standard so ethereal as to amount to a 'nontest' that would be extremely difficult, if not impossible, to administer or apply."

Perhaps the differences between the majority and the dissent in Carol Barnhart might have been resolved had they had before them Robert C. Denicola, Applied Art and Industrial Design: A Suggested Approach to Copyright in Useful Articles. There, Professor Denicola points out that although the Copyright Act of 1976 was an effort "to draw as clear a line as possible," in truth "there is no line, but merely a spectrum of forms and shapes responsive in varying degrees to utilitarian concerns." Denicola argues that "the statutory directive requires a distinction between works of industrial design and works whose origins lie outside the design process, despite the utilitarian environment in which they appear." He views the statutory limitation of copyrightability as "an attempt to identify elements whose form and appearance reflect the unconstrained perspective of the artist," such features not being the product of industrial design. "Copyrightability, therefore, should turn on the relationship between the proffered work and the process of industrial design." He suggests that "the dominant characteristic of industrial design is the influence of nonaesthetic, utilitarian concerns" and hence concludes that copyrightability "ultimately should depend on the extent to which the work reflects artistic expression uninhibited by functional considerations." To state the Denicola test in the language of conceptual separability, if design elements reflect a merger of aesthetic and functional considerations, the artistic aspects of a work cannot be said to be conceptually separable from the utilitarian elements. Conversely, where design elements can be identified as reflecting the designer's artistic judgment exercised independently of functional influences, conceptual separability exists.

We believe that Professor Denicola's approach provides the best 
test for conceptual separability and, accordingly, adopt it here for several reasons. First, the approach is consistent with the holdings of our previous cases. In Kieselstein-Cord, for example, the artistic aspects of the belt buckles reflected purely aesthetic choices, independent of the buckles' function, while in Carol Barnhart the distinctive features of the torsos - the accurate anatomical design and the sculpted shirts and collars - showed clearly the influence of functional concerns. Though the torsos bore artistic features, it was evident that the designer incorporated those features to further the usefulness of the torsos as mannequins. Second, the test's emphasis on the influence of utilitarian concerns in the design process may help, as Denicola notes, to "alleviate the de facto discrimination against nonrepresentational art that has regrettably accompanied much of the current analysis." 目 Finally, and perhaps most importantly, we think Denicola's test will not be too difficult to administer in practice. The work itself will continue to give "mute testimony" of its origins. In addition, the parties will be required to present evidence relating to the design process and the nature of the work, with the trier of fact making the determination whether the aesthetic design elements are significantly influenced by functional considerations.

Turning now to the facts of this case, we note first that Brandir contends, and its chief owner David Levine testified, that the original design of the RIBBON Rack stemmed from wire sculptures that Levine had created, each formed from one continuous undulating piece of wire. These sculptures were, he said, created and displayed in his home as a means of personal expression, but apparently were never sold or displayed elsewhere. He also created a wire sculpture in the shape of a bicycle and states that he did not give any thought to the utilitarian application of any of his sculptures until he accidentally juxtaposed the bicycle sculpture with one of the self-standing wire sculptures. It was not until November 1978 that Levine seriously began pursuing the utilitarian application of his sculptures, when a friend, G. Duff Bailey, a bicycle buff and author of numerous articles about urban cycling, was at Levine's home and informed him that the sculptures would make excellent bicycle racks, permitting bicycles to be parked under the overloops as well as on top of the underloops. Following this meeting, Levine met several times with Bailey

\footnotetext{
${ }^{3}$ We are reminded not only by Judge Gesell in the district court in Esquire but by Holmes in Bleistein, by Mazer, and by numerous other opinions, that we judges should not let our own view of styles of art interfere with the decisionmaking process in this area. Denicola suggests that the shape of a Mickey Mouse telephone is copyrightable because its form is independent of function, and "a telephone shape owing more to Arp, Brancusi, or Moore than Disney may be equally divorced from utilitarian influence." This is true, of course, of the artist Christo's "Running Fence," approved as an example of conceptual separability in Kieselstein-Cord.
}

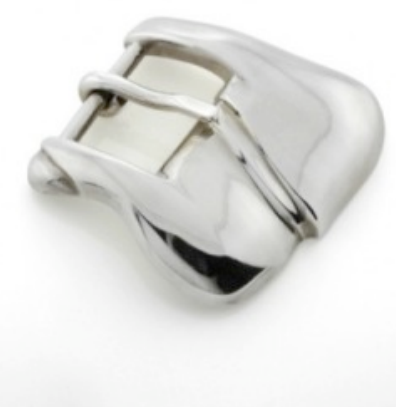

Belt buckle from Kieselstein-Cora

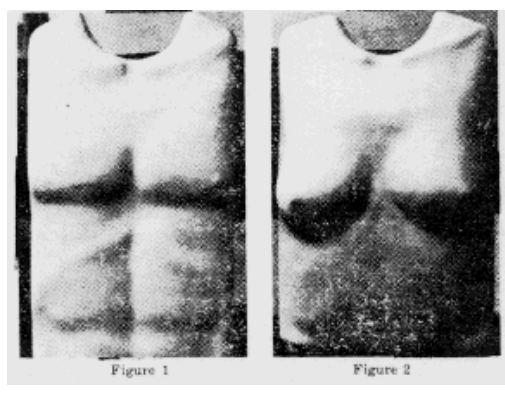

Torso from CarolBarnhart

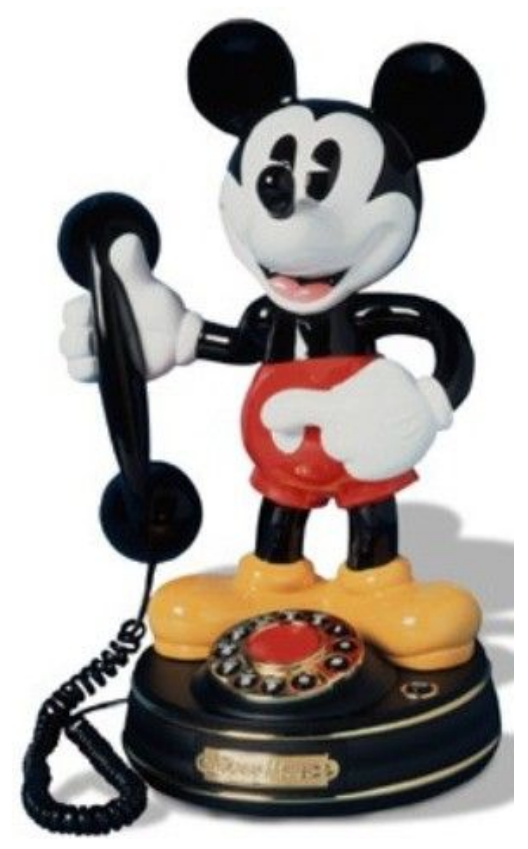

Mickey Mouse telephone 


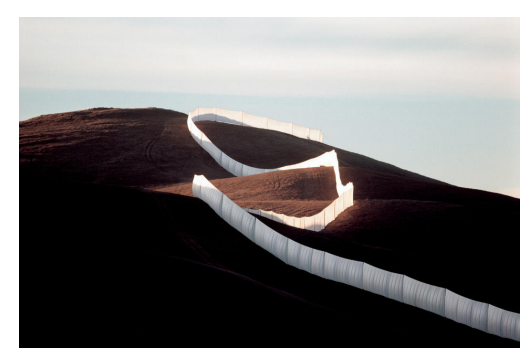

Christo and Jeanne-Claude, Running Fence (1972-76) and others, completing the designs for the RIBBON Rack by the use of a vacuum cleaner hose, and submitting his drawings to a fabricator complete with dimensions. The Brandir RIBBON Rack began being nationally advertised and promoted for sale in September 1979.

Between September 1979 and August 1982 Brandir spent some $\$ 38,500$ for advertising and promoting the RIBBON Rack, including some 85,000 pieces of promotional literature to architects and landscape architects. Additionally, since October 1982 Brandir has spent some $\$ 66,000$, including full-, half-, and quarter-page advertisements in architectural magazines such as Landscape Architecture, Progressive Architecture, and Architectural Record, indeed winning an advertising award from Progressive Architecture in January 1983. The RIBBON Rack has been featured in Popular Science, Art and Architecture, and Design 384 magazines, and it won an Industrial Designers Society of America design award in the spring of 1980. In the spring of 1984 the RIBBON Rack was selected from 200 designs to be included among 77 of the designs exhibited at the Katonah Gallery in an exhibition entitled "The Product of Design: An Exploration of the Industrial Design Process," an exhibition that was written up in the New York Times.

Sales of the RIBBON Rack from September 1979 through January 1985 were in excess of $\$ 1,367,000$. Prior to the time Cascade Pacific began offering for sale its bicycle rack in August 1982, Brandir's sales were $\$ 436,000$. The price of the RIBBON Rack ranges from $\$ 395$ up to $\$ 2,025$ for a stainless steel model and generally depends on the size of the rack, one of the most popular being the RB-7, selling for $\$ 485$.

In November 1982 Levine discovered that another company, Cascade Pacific Lumber Co., was selling a similar product.

Applying Professor Denicola's test to the RIBBON Rack, we find that the rack is not copyrightable. It seems clear that the form of the rack is influenced in significant measure by utilitarian concerns and thus any aesthetic elements cannot be said to be conceptually separable from the utilitarian elements. This is true even though the sculptures which inspired the RIBBON Rack may well have been the issue of originality aside - copyrightable.

Brandir argues correctly that a copyrighted work of art does not lose its protected status merely because it subsequently is put to a functional use. The Supreme Court so held in Mazer, and Congress specifically intended to accept and codify Mazer in section 101 of the Copyright Act of 1976.

Had Brandir merely adopted one of the existing sculptures as a bicycle rack, neither the application to a utilitarian end nor commercialization of that use would have caused the object to forfeit its copyrighted status. Comparison of the RIBBON Rack with the earlier sculptures, however, reveals that while the rack may have been de- 
rived in part from one of more "works of art," it is in its final form essentially a product of industrial design. In creating the RIBBON Rack, the designer has clearly adapted the original aesthetic elements to accommodate and further a utilitarian purpose. These altered design features of the RIBBON Rack, including the spacesaving, open design achieved by widening the upper loops to permit parking under as well as over the rack's curves, the straightened vertical elements that allow in- and above-ground installation of the rack, the ability to fit all types of bicycles and mopeds, and the heavy-gauged tubular construction of rustproof galvanized steel, are all features that combine to make for a safe, secure, and maintenance-free system of parking bicycles and mopeds. Its undulating shape is said in Progressive Architecture, January 1982, to permit double the storage of conventional bicycle racks. Moreover, the rack is manufactured from $23 / 8$ inch standard steam pipe that is bent into form, the six-inch radius of the bends evidently resulting from bending the pipe according to a standard formula that yields bends having a radius equal to three times the nominal internal diameter of the pipe.

Brandir argues that its RIBBON Rack can and should be characterized as a sculptural work of art within the minimalist art movement. Minimalist sculpture's most outstanding feature is said to be its clarity and simplicity, in that it often takes the form of geometric shapes, lines, and forms that are pure and free of ornamentation and void of association. As Brandir's expert put it, "The meaning is to be found in, within, around and outside the work of art, allowing the artistic sensation to be experienced as well as intellectualized." People who use Foley Square in New York City see in the form of minimalist art the "Tilted Arc," which is on the plaza at 26 Federal Plaza. Numerous museums have had exhibitions of such art, and the school of minimalist art has many admirers.

It is unnecessary to determine whether to the art world the RIBBON Rack properly would be considered an example of minimalist sculpture. The result under the copyright statute is not changed. Using the test we have adopted, it is not enough that, to paraphrase Judge Newman, the rack may stimulate in the mind of the reasonable observer a concept separate from the bicycle rack concept. While the RIBBON Rack may be worthy of admiration for its aesthetic qualities alone, it remains nonetheless the product of industrial design. Form and function are inextricably intertwined in the rack, its ultimate design being as much the result of utilitarian pressures as aesthetic choices. Indeed, the visually pleasing proportions and symmetricality of the rack represent design changes made in response to functional concerns. Judging from the awards the rack has received, it would seem in fact that Brandir has achieved with the RIBBON Rack the highest goal of modern industrial design, that is, the harmo-

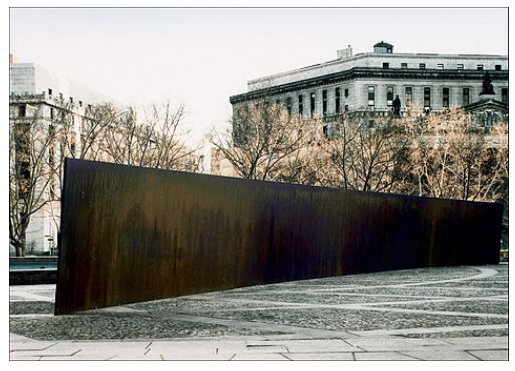

Richard Serra, Tilted Arc (1981)

Tilted Arc was dismantled and removed in 1989, i.e., the year before VARA's moral right against destruction of a work of recognized stature. 
nious fusion of function and aesthetics. Thus there remains no artistic element of the RIBBON Rack that can be identified as separate and "capable of existing independently, of, the utilitarian aspects of the article." Accordingly, we must affirm on the copyright claim

WINTER, Circuit Judge, concurring in part and dissenting in part:

The grounds of my disagreement are that: (1) my colleagues' adaptation of Professor Denicola's test diminishes the statutory concept of "conceptual separability" to the vanishing point; and (2) their focus on the process or sequence followed by the particular designer makes copyright protection depend upon largely fortuitous circumstances concerning the creation of the design in issue.

In my view, Carol Barnhart and Kieselstein-Cord are not reconcilable. Carol Barnhart paid only lip service to the fact that the "conceptual separability" of an article's aesthetic utilitarian aspects may render the design of a "useful article" a copyrightable "sculptural work." Actually, the Carol Barnhart majority applied a test of physical separability. They thus stated:

What distinguishes [the Kieselstein-Cord] buckles from the Barnhart forms is that the ornamented surfaces of the buckles were not in any respect required by their utilitarian functions; the artistic and aesthetic features could thus be conceived of as having been added to, or superimposed upon, an otherwise utilitarian article. The unique artistic design was wholly unnecessary to performance of the utilitarian function. In the case of the Barnhart forms, on the other hand, the features claimed to be aesthetic or artistic, e.g., the life-size configuration of the breasts and the width of the shoulders are inextricably intertwined with the utilitarian feature, the display of clothes.

In contrast, Kieselstein-Cord focused on the fact that the belt buckles at issue could be perceived as objects other than belt buckles:

We see in appellant's belt buckles conceptually separable sculptural elements, as apparently have the buckles' wearers who have used them as ornamentation for parts of the body other than the waist.

My colleagues' adaptation of the Denicola test tracks the Carol Barnhart approach, whereas I would adopt that taken in Kieselstein-Cord, which allows for the copyrightability of the aesthetic elements of useful articles even if those elements simultaneously perform utilitarian functions. ${ }^{1}$ The latter approach received its fullest elaboration in

\footnotetext{
${ }^{1}$ Indeed, Kieselstein-Cord approved Professor Nimmer's example of Christo's "Running Fence" as an object whose sculptural features were conceptually, but not
} 
Judge Newman's dissent in Carol Barnhart, where he explained that "for the artistic design features to be 'conceptually separate' from the utilitarian aspects of the useful article that embodies the design, the article must stimulate in the mind of the beholder a concept that is separate from the concept evoked by its utilitarian function."

In other words, the relevant question is whether the design of a useful article, however intertwined with the article's utilitarian aspects, causes an ordinary reasonable observer to perceive an aesthetic concept not related to the article's use. The answer to this question is clear in the instant case because any reasonable observer would easily

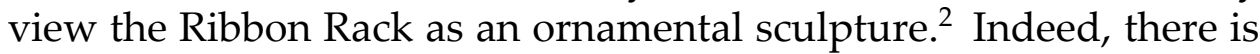
evidence of actual confusion over whether it is strictly ornamental in the refusal of a building manager to accept delivery until assured by the buyer that the Ribbon Rack was in fact a bicycle rack. Moreover, Brandir has received a request to use the Ribbon Rack as environmental sculpture, and has offered testimony of art experts who claim that the Ribbon Rack may be valued solely for its artistic features. As one of those experts observed: "If one were to place a Ribbon Rack on an island without access, or in a park and surround the work with a barrier, its status as a work of art would be beyond dispute."

My colleagues also allow too much to turn upon the process or sequence of design followed by the designer of the Ribbon Rack. They thus suggest that copyright protection would have been accorded "had Brandir merely adopted as a bicycle rack" an enlarged version of one of David Levine's original sculptures rather than one that had wider upper loops and straightened vertical elements. I cannot agree that copyright protection for the Ribbon Rack turns on whether Levine serendipitously chose the final design of the Ribbon Rack during his initial sculptural musings or whether the original design had to be slightly modified to accommodate bicycles.

\section{Eames Chair Problem}

This is the Eames Lounge Chair by Charles and Ray Eames. Is its design copyrightable?

\section{Copyright Act}

(a) Subject to the provisions of subsections (b) and (c) of this section, the exclusive right to reproduce a copyrighted pictorial,

physically, separable from its utilitarian aspects. The fact that the Running Fence's aesthetic features were "inextricably intertwined" with its functional aspects, however, creates doubt as to whether it is a copyrightable "sculptural work" under Carol Barnhart or the instant decision.

${ }^{2}$ The reasonable observer may be forgiven, however, if he or she does not recognize the Ribbon Rack as an example of minimalist art.

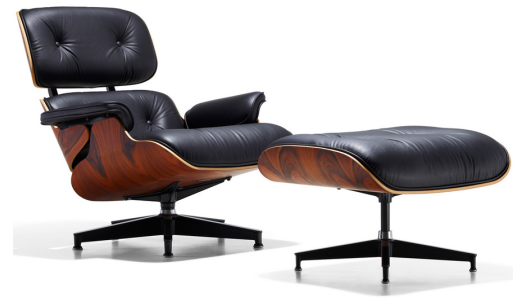

Eames Lounge Chair

17 U.S.C. § 113

Scope of exclusive rights in pictorial, graphic, and sculptural works 
graphic, or sculptural work in copies under section 106 includes the right to reproduce the work in or on any kind of article, whether useful or otherwise.

(b) This title does not afford, to the owner of copyright in a work that portrays a useful article as such, any greater or lesser rights with respect to the making, distribution, or display of the useful article so portrayed than those afforded to such works under the law, whether title 17 or the common law or statutes of a State, in effect on December 31, 1977, as held applicable and construed by a court in an action brought under this title.

(c) In the case of a work lawfully reproduced in useful articles that have been offered for sale or other distribution to the public, copyright does not include any right to prevent the making, distribution, or display of pictures or photographs of such articles in connection with advertisements or commentaries related to the distribution or display of such articles, or in connection with news reports. ...

\section{Report of the Register of Copyrights on the General Revision of the Copyright Law (1961)}

§II.C.1.c

Relationship between copyright and the designs of useful articles

The present $\S 113$ may be inartfully worded, but do you see how it adopts the Register's recommendations?
There remains the question of protection to be given to a copyrighted work of art that is utilized as a design in the manufacture of useful articles. We believe that, where the copyrighted work is used as a design or decoration of a useful article, it should continue, as under the present law, to be protected by copyright if the owner wishes. However, where the "work of art" actually portrays the useful article as such - as in a drawing, scale model, advertising sketch, or photograph of the article - existing court decisions indicate that copyright in the "work of art" does not protect against manufacture of the useful article portrayed. We agree with these decisions and the distinctions made in them.

Some examples will illustrate these points.

(3) Since the protection available to a copyrighted pictorial, graphic, or sculptural work is not affected by use of the work as a design or decoration of a useful article, the foilowing works would continue to be accorded full protection under the copyright statute:

- A copyrighted painting reproduced on textile fabrics;

- A copyrighted cartoon drawing or photograph reproduced on fabrics or in the form of toys or dolls;

- A copyrighted drawing of a chair reproduced on a lampshade; 
- A copyrighted sculptured figure used as a lamp base.

(4) Under distinotions indicated in existing court decisions, that the copyright in a work portraying a useful article as such would not protect against manufacture of that article, copyright protection would not extend to the following cases:

- A copyrighted drawing of a chair, used to manufacture chairs of that design;

- A copyrighted scale model of an automobile, used to manufacture automobiles of that design;

- A copyrighted technical drawing showing the construction of a machine, used to manufacture the machine;

- A copyrighted picture of a dress, used to manufacture the dress.

\section{Model Car Problem}

You represent Schafer Software, creator of the hit Out of Control series of racing video games. Sterling normally pays car companies licensing fees to include their cars in the Out of Control games as part of the licensing agreement. Negotiations with Corley Motors have broken down over Corley's excessive licensing fee demands for its Corley Polecat - ten times higher than any other company is demanding per vehicle.

Marketing is desparate to include the Polecat in Out of Control 2017 and has asked the development team to think of ways to include the Polecat without Corley's cooperation. They have suggested two ways of doing so. First, they could rent a Polecat and scan it with a high-resolution laser scanner that would generate an extremely detailed three-dimensional model. Second, it appears that digital copies of Corley's engineering diagrams for the Polecat have leaked onto car-enthusiast websites, where they have been available for months (with Corley's tacit acquiescence, it appears). The diagrams contain extremely detailed specifications for every part in the Polecat, as well as renderings showing a fully assembled Polecat from numerous angles. The developers believe that although both approaches would require significant work by Corley's 3D modeling artists, either approach would work for generating the files they would need to put the Polecat in Out of Control 2017.

Should Schafer proceed, and if so, how?

\section{Architecture}

Initially, the 1976 Copyright Act treated buildings as useful articles. The 1990 Architectural Works Copyright Protection Act changed that, adding "architectural works" to the list of types of copyrightable sub-
Loosely based on Meshwerks, Inc. v. Toyota Motor Sales USA, Inc., 528 F.3d 1258 (10th Cir. 2008)

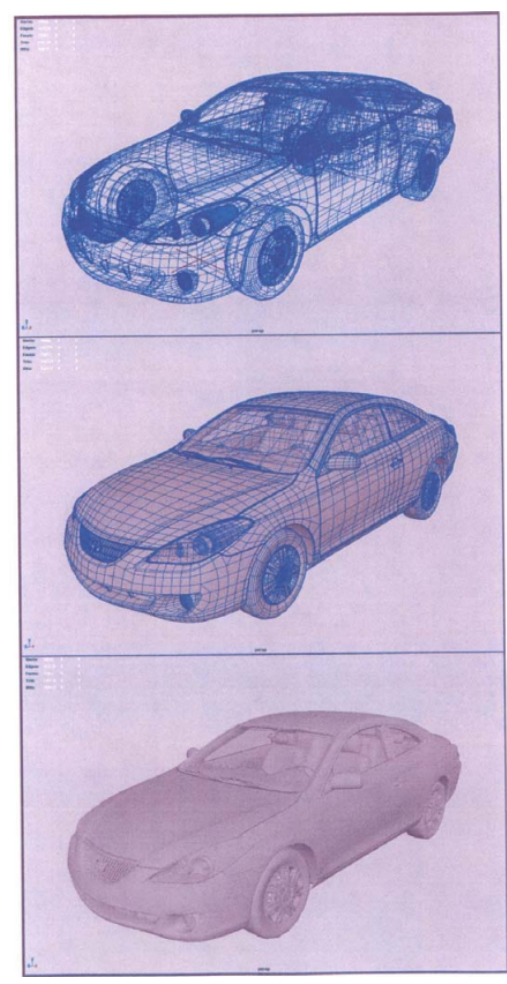

3D car model 
(unpublished draft 2015)

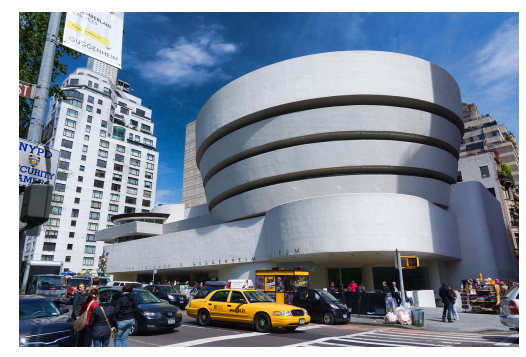

Frank Lloyd Wright, Guggenheim Museum ject matter in $\S 102$ (a) and adding a few special rules for them. The AWCPA is purely prospective; it applies only to architectural works created on or after December 1, 1990.

\section{Kevin Emerson Collins}

Economically Defeasible Rights to Facilitate Information Disclosure: The Hidden Wisdom of Pre-AWCPA Copyright

Architects were not entitled to rights on par with the rights to which other creative professionals were entitled. Most importantly, architectural drawings and buildings received different treatment: the former were protected but the latter were not. Pre- AWCPA copyright recognized architectural drawings as copyrightable subject matter. Duplicating the original expression embodied in a drawing in copy that is also a drawing violated pre-AWCPA copyright if performed without authorization. However, pre-AWCPA copyright did not protect original expression when that expression was embodied in a constructed building. Copying a constructed building did not constitute infringement before the AWCPA, even if the building was constructed from copyrighted drawings and regardless of whether the copy took the form of a drawing or a building. Constructed buildings were simply not copyrightable subject matter, so they could be freely copied. One architect was free to make "measured drawings" of an original building constructed by another architect and use those drawings to construct a copy of the building, even when the drawings that were used to build the original building were copyrighted. In other words, copying original expression from a constructed building was permitted even though copying the exact same original expression from a drawing was not.

The doctrinal reasoning that supported the unprotectability of constructed buildings has been viewed by some as suspect, but this limit on pre-AWCPA copyright was never seriously challenged. Constructed buildings were classified as useful articles, so, in theory, they could have been protected insofar as they had aesthetic aspects that were conceptually separable from their utilitarian aspects. However, apart from sculptures like gargoyles that were attached to architectural works, the aesthetic features of constructed buildings never came to be viewed as separable from the buildings' functional features, so copyright protection never protected the architectural designs embodied in constructed buildings. Even a highly original building like Frank Lloyd Wright's Guggenheim Museum was not protectable at all under pre-AWCPA because the building's originality was not embodied in add-on ornamentation.

Pre-AWCPA copyright also disprivileged constructed buildings in another way. Although architectural drawings were copyrightable subject matter, constructing the building depicted in an architectural 
drawing was not actionable because it was not considered to involve the creation of a derivative work.

\section{Copyright Act}

(a) Pictorial Representations Permitted. - The copyright in an architectural work that has been constructed does not include the right to prevent the making, distributing, or public display of pictures, paintings, photographs, or other pictorial representations of the work, if the building in which the work is embodied is located in or ordinarily visible from a public place.

(b) Alterations to and Destruction of Buildings. - Notwithstanding the provisions of section 106(2), the owners of a building embodying an architectural work may, without the consent of the author or copyright owner of the architectural work, make or authorize the making of alterations to such building, and destroy or authorize the destruction of such building.

An "architectural work" is the design of a building as embodied in any tangible medium of expression, including a building, architectural plans, or drawings. The work includes the overall form as well as the arrangement and composition of spaces and elements in the design, but does not include individual standard features.

\section{Code of Federal Regulations}

(b) Definitions. -

(2) The term building means humanly habitable structures that are intended to be both permanent and stationary, such as houses and office buildings, and other permanent and stationary structures designed for human occupancy, including but not limited to churches, museums, gazebos, and garden pavilions.

(d) Works excluded. - The following structures, features, or works cannot be registered:

(1) Structures other than buildings. - Structures other than buildings, such as bridges, cloverleafs, dams, walkways, tents, recreational vehicles, mobile homes, and boats.

\section{Intervest Construction., Inc. v. Canterbury Estate Homes}

The definition of an architectural work closely parallels that of a "compilation" under the statute. Accordingly, any similarity comparison of the works at issue here must be accomplished at the level of protected expression - that is, the arrangement and coordination of
17 U.S.C. § 120

Scope of exclusive rights in architectural works

17 U.S.C. § 101

Definitions

37 C.F.R. § 202.11

Architectural works

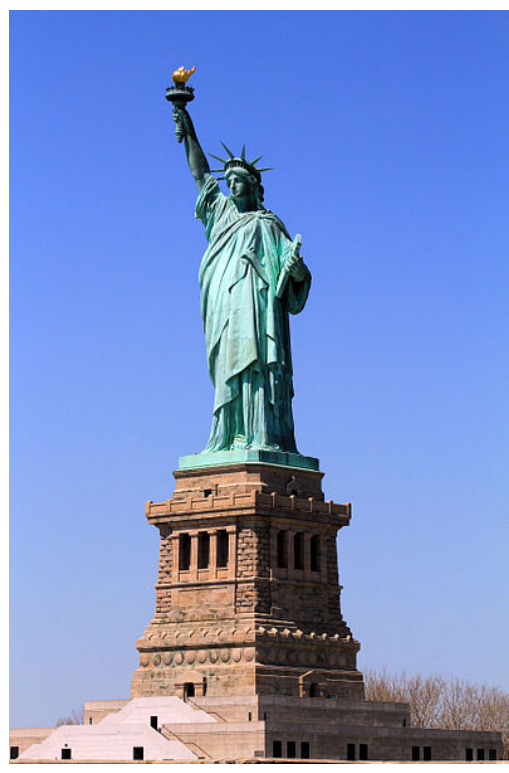

Is the Statue of Liberty an architectural work?

554 F.3d 914 (11th Cir. 2008)

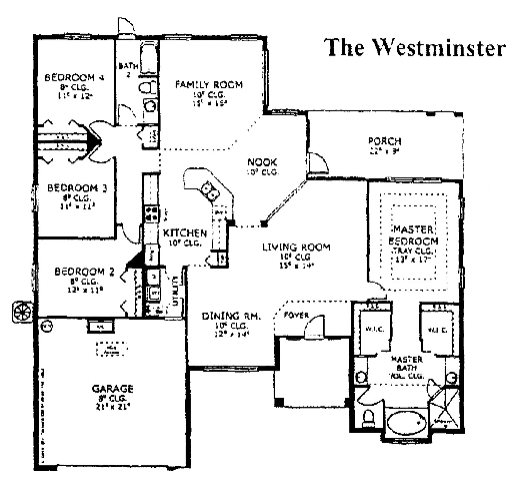

Plaintiff's plan 


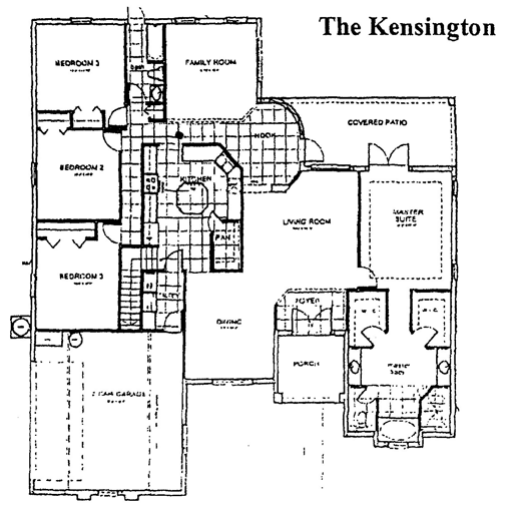

Defendant's plan

754 F.3d 95 (2d Cir. 2014) those common elements ("selected" by the market place, i.e., rooms, windows, doors, and "other staple building components"). In undertaking such a comparison it should be recalled that the copyright protection in a compilation is "thin." Feist Thus, when viewed through the narrow lens of compilation analysis only the original, and thus protected arrangement and coordination of spaces, elements and other staple building components should be compared.

Given that the plans at issue were protected by compilation copyrights which were "thin," the district court correctly determined that the differences in the protectable expression were so significant that, as a matter of law, no reasonable properly-instructed jury of lay observers could find the works substantially similar. Accordingly, the district court did not err in granting summary judgment to the appellee, the putative infringer.

\section{Zalewski v. Cicero Builder Dev., Inc.}

What aspects of Zalewski's designs are protectable? A fundamental rule of copyright law is that it protects only "original works of authorship," those aspects of the work that originate with the author himself. Everything else in the work, the history it describes, the facts it mentions, and the ideas it embraces, are in the public domain free for others to draw upon. It is the peculiar expressions of that history, those facts, and those ideas that belong exclusively to their author. Thus, any author may draw from the history of English-speaking peoples, but no one may copy from A History of the English-Speaking Peoples. Any artist may portray the Spanish Civil War, but no one may paint another Guernica. And anyone may draw a cartoon mouse, but there can be only one Mickey.

While we agree with the outcome in Intervest, we disagree with its reasoning. Every kind of work at some level is a compilation, an arrangement of uncopyrightable "common elements." No individual word is copyrightable, but the arrangement of words into a book is. No color is copyrightable, but the arrangement of colors on canvas is. Likewise, doors and walls are not copyrightable, but their arrangement in a building is. Some architectural designs, like that of a singleroom log cabin, will consist solely of standard features arranged in standard ways; others, like the Guggenheim, will include standard features, but also present something entirely new. Architecture, in this regard, is like every art form.

Labeling architecture a compilation obscures the real issue. Every work of art will have some standard elements, which taken in isolation are un-copyrightable, but many works will have original elements - or original arrangements of elements. The challenge in adjudicating copyright cases is not to determine whether a work is a creative work, a derivative work, or a compilation, but to determine 
what in it originated with the author and what did not. Intervest fails to do this. It compares the floor plans of the two houses, "focusing only on the narrow arrangement and coordination" of what it deems "standard ... features" and intuits that there was no copying of the arrangement. But it fails to provide any analysis of what made a feature "standard" and unprotectable. Hence, we find it of little assistance here.

Courts should treat architectural copyrights no differently than other copyrights. This is what Congress envisioned, and it is an approach we have employed before. In Attia $v$. Society of the New York Hospital, for example, the plaintiff had been retained by New York Hospital to design an expansion of its facility over FDR Drive. The hospital rejected his preliminary sketches, but ultimately went with a similar design by another firm. The plaintiff admitted that his drawings were "preliminary and generalized" "outlines" of "concepts." Although there were some similarities between the plaintiff's and the defendant's designs, there were also significant differences. Thus, we held that any copying went to unprotected ideas, "concepts," rather than concrete expression.

In Peter F. Gaito Architecture, LLC v. Simone Development Corp., on a similar set of facts, we held that copying of "architecture that was light, airy, and transparent," as well as design parameters and "generalized notions of where to place functional elements," went only to ideas and not protected expression. Finally, in Sparaco v. Lawler, Matusky, Skelly, Engineers LLP, we held that although a construction site preparation plan was preliminary in the sense that it pertained to the early phases of construction, it was extremely detailed and thus more than a mere idea.

Efficiency is an important architectural concern. Any design elements attributable to building codes, topography, structures that already exist on the construction site, or engineering necessity should therefore get no protection.

There are scènes-à-faire in architecture. Neoclassical government buildings, colonial houses, and modern high-rise office buildings are all recognized styles from which architects draw. Elements taken from these styles should get no protection. Likewise, there are certain market expectations for homes or commercial buildings. Design features used by all architects, because of consumer demand, also get no protection.

Our prior architecture cases support this approach. In Sparaco, we held that there can be no copyright in a plan insofar as it merely represents the topography of a building site. Topography is an uncopyrightable "fact." In Attia we recognized that "generalized notions of where to place functional elements, how to route the flow of traffic, and methods of construction" are un-protectable. Architects

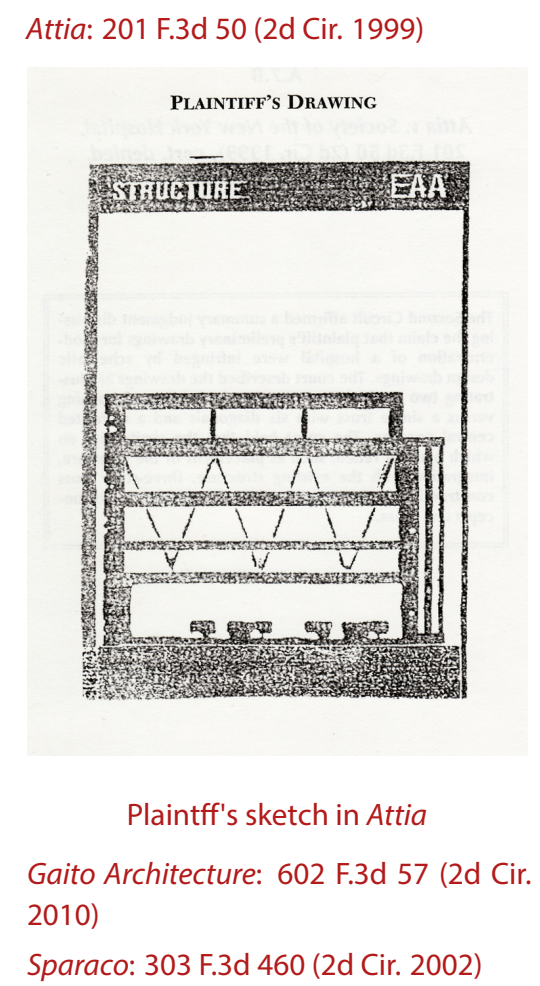




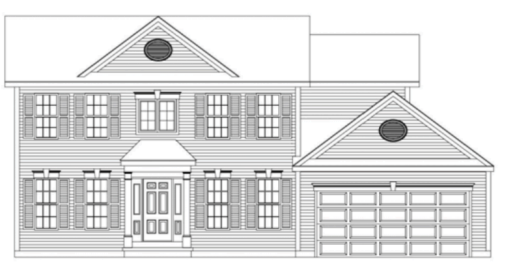

One of Zalewski's colonial designs cannot claim that good engineering is original to them - or at least can get no copyright protection for it. Finally, in Gaito Architecture, we held that there is no copyright in a building plan's design parameters. Constraints placed on an architect by the way her client plans to use the building do not originate with the architect.

After considering these principles and reviewing the designs in question, we conclude that even if Defendants copied Zalewski's plans, they copied only the unprotected elements of his designs. Plaintiff's principal argument is that Defendants' designs are so close to his that Defendants must have infringed. He is correct that the designs are, in many respects, quite close, but this is not enough. It proves at most copying, not wrongful copying.

First, many of the similarities are a function of consumer expectations and standard house design generally. Plaintiff can get no credit for putting a closet in every bedroom, a fireplace in the middle of an exterior wall, and kitchen counters against the kitchen walls. Furthermore, the overall footprint of the house and the size of the rooms are "design parameters" dictated by consumer preferences and the lot the house will occupy, not the architect.

Finally, most of the similarities between Plaintiff's and Defendants' designs are features of all colonial homes, or houses generally. So long as Plaintiff was seeking to design a colonial house, he was bound to certain conventions. He cannot claim copyright in those conventions. Great artists often express themselves through the vocabulary of existing forms. Shakespeare wrote his Sonnets; Brahms composed his Hungarian Dances; and Plaintiff designed his colonial houses. Because we must preserve these forms for future artists, neither iambic pentameter, nor European folk motifs, nor clapboard siding are copyrightable.

Plaintiff makes no attempt to distinguish those aspects of his designs that were original to him from those dictated by the form in which he worked. For example, Zalewski claims that the "front porches are the same design, size, and in the same location." But a door centered on the front of the house is typical of many homes, and colonials in particular. Moreover, there are subtle differences in the paneling, size, and framing of Plaintiff's and Defendants' doors. These differences are not great, but given the constraints of a colonial design, they are significant. The same is true of the windows and garage doors that Plaintiff claims are identical. They are quite similar in location, size, and general design, but again, the similarities are due primarily to the shared colonial archetype. The window panes, shutters, and garage-door paneling all have subtle differences. Likewise, the designs' shared footprint and general layout are in keeping with the colonial style. There are only so many ways to arrange four bedrooms upstairs and a kitchen, dining room, living room, and 
study downstairs. Beyond these similarities, Plaintiff's and Defendants' layouts are different in many ways. The exact placement and sizes of doors, closets, and countertops often differ as do the arrangements of rooms.

Although he undoubtedly spent many hours on his designs, and although there is certainly something of Plaintiff's own expression in his work, as long as Plaintiff adhered to a pre-existing style his original contribution was slight-his copyright very thin. Only very close copying would have taken whatever actually belonged to Plaintiff. Copying that is not so close would-and in this case did-only capture the generalities of the style in which Plaintiff worked and elements common to all homes. Defendants' houses shared Plaintiff's general style, but took nothing from his original expression.

\section{Embassy Problem}

Here are sketches front and side elevations of plaintiff's and defendant's designs for a proposed embassy. If the defendant had access to the plaintiff's plans, are the similarities strong enough that a jury could find infringement? Are they so strong that a jury must find infringement?
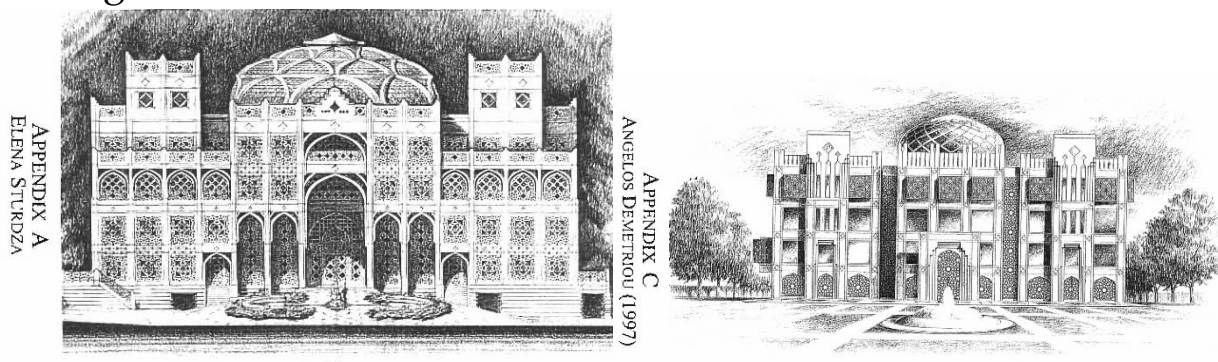

FRONT ELEVATION

FRONT HEVATION

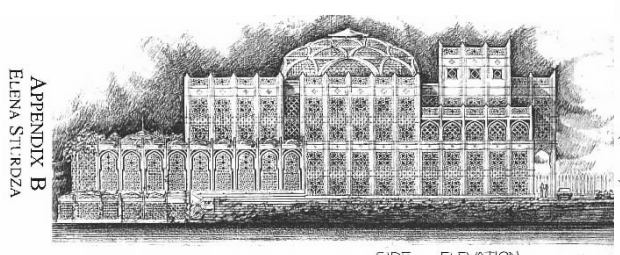

side eleVATION

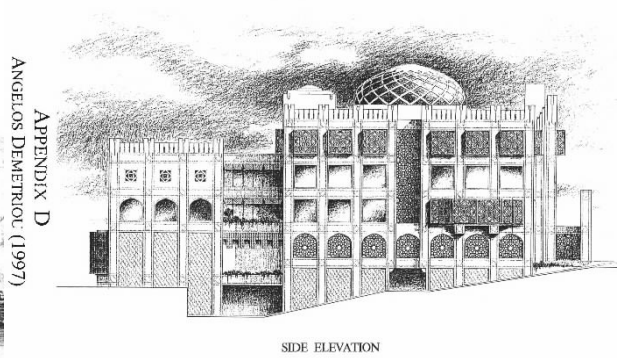

SIDE FIEVATION

\section{Moral Rights}

VARA excludes from its coverage works of "applied art." Query how this standard differs from the tests applicable to the scope of copyright in a "useful article" or an "architectural work."

\section{Cheffins v. Stewart}

We must decide whether the Visual Artists Rights Act applies to a used school bus transformed into a mobile replica of a 16th-century

Based on Sturdza v. United Arab Emirates, 281 F.3d 1287 (D.C. Cir. 2002) 


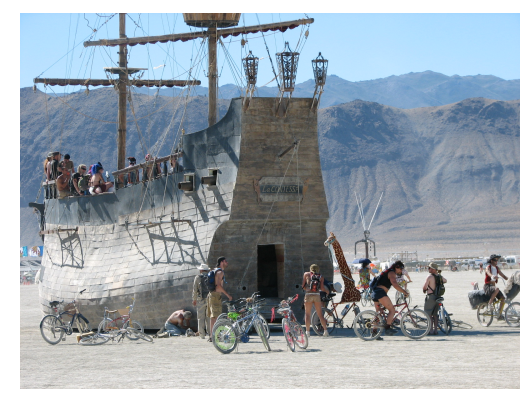

La Contessa

Helmsley-Spear: 71 F.3d 77 (2d Cir. 1995)

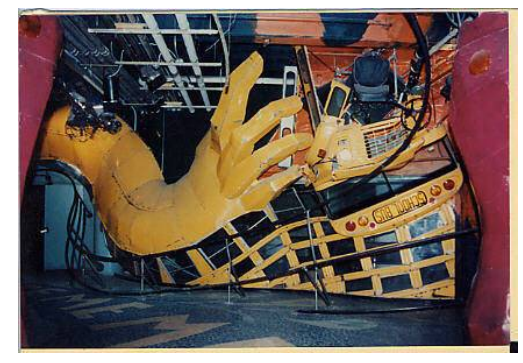

Installation by Jx3 from Helmsley-Spear
Spanish galleon.

Plaintiffs Simon Cheffins and Gregory Jones, along with a number of volunteers, built the La Contesssa, a replica of a 16th-century Spanish galleon for use at the Burning Man Festival. ${ }^{1}$ Cheffins began his creation by acquiring a used school bus. He and Jones then designed and constructed the galleon facade, including a hull, decking, masts, and a handcrafted figurehead. These elements and the bus were then transported to the Black Rock Desert in northern Nevada, the site of Burning Man, and assembled. When completed, the La Contesssa was approximately sixty feet wide and sixteen feet long with a mast over fifty feet tall.

The La Contesssa first appeared at the Festival in 2002. Festival participants took rides on the La Contesssa, and at least two weddings were performed on its deck. It reappeared in 2003 and 2005. In 2003, it was used as part of a marching band performance, and, in 2005, it was the centerpiece of a children's treasure hunt, among other things.

After the 2003 and 2005 Festivals, Cheffins and Jones stored the $L a$ Contesssa on land in Nevada held in life estate by one Joan Grant, who had given them permission to do so. In late 2005, however, Grant's home burned down, causing her to abandon the life estate. Thereafter, defendant Michael Stewart took possession of the land in fee simple through a limited liability company.

Cheffins and Jones did not relocate the La Contesssa after the change of property ownership. Rather, it sat unmoved on Stewart's land until December 2006. Sometime during that month, Stewart intentionally burned the wooden structure of the La Contesssa so that a scrap metal dealer could remove the underlying school bus from his property.

As the text of the statute shows, the VARA only applies to "works of visual art." On summary judgment, Stewart asserted, and the trial court subsequently concluded, that the La Contesssa was not a "work of visual art" because it was "applied art."

The VARA does not define the term "applied art," and federal courts have rarely had occasion to interpret its meaning. In Carter v. Helmsley-Spear, Inc., the Second Circuit held that a sculpture constructed of portions of a school bus and affixed to a wall in a building lobby was not "applied art." It explained that the term "applied art" means "two-and threedimensional ornamentation or decoration that is affixed to otherwise utilitarian objects." The court further explained that the sculpture was not "applied art" simply because it was affixed to "the lobby's floor, walls, and ceiling" because "interpreting applied art to include such works would render meaningless

\footnotetext{
${ }^{1}$ Burning Man is an art and countercultural festival held each year for the week preceding Labor Day.
} 
VARA's protection for works of visual art installed in buildings."

The Second Circuit provided an additional gloss on what constitutes a "work of visual art," and by extension what constitutes "applied art," in Pollara v. Seymour, where it explained that the "VARA may protect a sculpture that looks like a piece of furniture, but it does not protect a piece of utilitarian furniture, whether or not it could arguably be called a sculpture." The court went on to hold that an elaborate painted banner was not a "work of visual art" eligible for protection under the VARA.

We agree in large part with the Second Circuit's analysis. As the Second Circuit suggested, the focus of our inquiry should be on whether the object in question originally was - and continues to be - utilitarian in nature. Dictionary definitions suggest that, in its ordinary meaning, applied art consists of an object with a utilitarian function that also has some artistic or aesthetic merit.

Further, this approach makes sense in the statutory context in which "applied art" is used in 17 U.S.C. § 101. "Applied art" is enumerated in a list that also contains, inter alia, maps, globes, charts, technical drawings, diagrams, models, newspapers, periodicals, data bases, and electronic information services. The fact that the other items in the list are utilitarian objects leads us to conclude that the listed items are related by their practical purposes and utilitarian functions, requiring a focus on utility when construing the term "applied art."

We therefore hold that an object constitutes a piece of "applied art" - as opposed to a "work of visual art" - where the object initially served a utilitarian function and the object continues to serve such a function after the artist made embellishments or alterations to it. This test embraces the circumstances both where a functional object incorporates a decorative design in its initial formulation, and where a functional object is decorated after manufacture but continues to serve a practical purpose. Conversely, "applied art" would not include a piece of art whose function is purely aesthetic or a utilitarian object which is so transformed through the addition of artistic elements that its utilitarian functions cease.

We respond briefly to the concern expressed in the concurrence that the standard we adopt today may not be workable - that it raises difficult questions regarding where exactly the line defining "applied art" will be drawn. The analysis we adopt today directs the court's attention away from assessments of an object's artistic merit and in-

\footnotetext{
${ }^{6}$ With recognition that nearly every object on which art is installed will be in some sense "utilitarian," we caution that the utilitarian function must be something other than mere display of the work in question. See also 17 U.S.C. §101 ("A 'useful article' is an article having an intrinsic utilitarian function that is not merely to portray the appearance of the article or to convey information.").
}

Pollara: 344 F.3d 265, 269 (2d Cir. 2003)

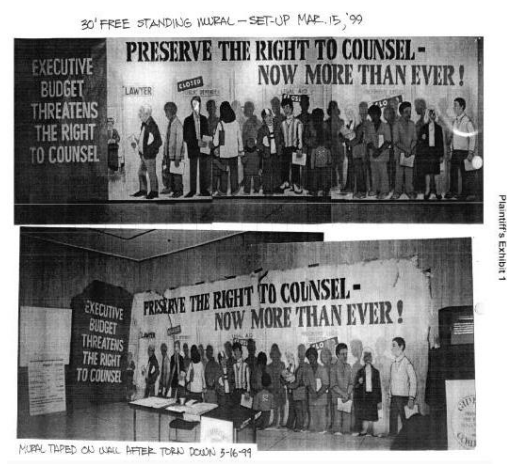

Banner by Joanne Pollara 
stead toward the object's practical utility.

We now apply this standard to the facts of this case.

The La Contesssa began as a simple school bus - an object which unquestionably served the utilitarian function of transportation. To transform the bus into the La Contesssa, Cheffins and Jones adorned it with the visual trappings of a 16th-century Spanish galleon. While the La Contesssa's elaborate decorative elements may have had many artistic qualities, the La Contesssa retained a largely practical function even after it had been completed. At Burning Man, the La Contesssa was used for transportation, providing rides to festival-goers, hosting musical performances and weddings, and serving as a stage for poetry and acrobatics shows. Indeed, the La Contesssa often was driven about the Festival grounds and was banned from the Festival in 2004 because "its unsafe driving practices far exceeded community tolerance and out-weighed the visual contribution" it made.

Under the definition we adopt today, the La Contesssa plainly was "applied art." It began as a rudimentary utilitarian object, and despite being visually transformed through elaborate artistry, it continued to serve a significant utilitarian function upon its completion. As "applied art," the La Contesssa was not a work of visual art under the VARA and therefore not eligible for its protection. Therefore, the trial court properly granted summary judgment to Stewart on Cheffins and Jones's VARA claim.

McKeown, Circuit Judge, concurring:

To better effectuate the purpose of VARA, we need a more nuanced definition of "applied art" that balances between the risk of unduly restricting VARA's reach and the risks of turning judges into art critics or consigning to litigation every work of art that includes some utilitarian function. In determining whether a work is "applied art," the right question to ask is whether the primary purpose of the work as a whole is to serve a practical, useful function, and whether the aesthetic elements are subservient to that utilitarian purpose.Because the bus/Spanish galleon La Contesssa is applied art under either standard, I concur in the judgment.

Although many court decisions have addressed applied art, these cases provide little guidance on how to distinguish applied from visual art. The issue in nearly all applied art cases is whether the work was copyrightable applied art or instead a noncopyrightable work of "industrial design."

The analysis in these cases is driven by the principle that works may unquestionably be applied art, such as a detailed carving on the back of a chair - an obviously utilitarian object - but may also enjoy certain copyright protection. 1 . Whether such a work falls under

\footnotetext{
${ }^{4}$ Indeed, examples of original "pictoral, graphic, and sculptural works" pro-
} 
VARA's protections is a different question. Thus, while these opinions have coalesced around a definition of applied art for the purpose of copyright protection as pictorial, graphic, and sculptural works that are intended to be or have been embodied in useful articles, they do not provide an answer under VARA because VARA protects a new and different genus of "works of visual art."

VARA's protections cannot be limited only to works entirely devoid of any utilitarian purpose. Many outstanding sculptures, including the Caryatids of the Acropolis and the monumental carvings of Ramses at the temple of Karnak are in fact columns that provided buildings with structural integrity. Medieval tapestries not only represented a form of fine art, but also kept castles and cathedrals free from drafts. Of course, the famous Bayeux tapestries, which depict events leading to the Battle of Hastings, retain their utilitarian function to some extent: they could still be used to keep a drafty castle warm. Likewise, Tracy Emin's My Bed, displayed at the Tate Britain, incorporates Emin's real bed as a "monument to the heartache of a relationship breakdown." The bed arguably retains its original utilitarian function - it remains a bed, and could still be slept in - but it is no longer meant or used for this utilitarian purpose. Rather, like the Bayeux tapestries, My Bed is now appreciated and viewed as a work of creative expression and, when viewed as a whole, the utilitarian object has become part of a visual art piece.

The modern era abounds with examples of fine art that serve some utility. Perhaps the most famous sculpture of the modern era - Rodin's The Thinker - was conceived when the artist was designing a set of monumental doors titled The Gates of Hell. Doors, of course, are utilitarian objects that facilitate the movement of people into and out of buildings. Likewise, a young Pablo Picasso painted a massive background piece for the ballet Le Tricorne. Although that painting surely served some utilitarian purpose as a stage curtain, following that debut, it has been displayed as a painting for half a century. The painting was the focus of intense debate when it was removed last year from the Four Seasons restaurant in New York's Seagram Building, where it had hung since 1959. Some sculptures designed by Dale Chihuly are fantastically artistic and original and yet could also serve a utilitarian purpose of diffusing fresh water or serving as a room divider. The artistic and utilitarian aspects are entwined in some of Chihuly's pieces.

It is easy to imagine a sculpture composed of an array of utilitarian objects. Indeed, a Florida plumber/artist who created a sculpture with auto parts, plumbing fixtures and scrap wiring, found himself in

tected by copyright include dolls and toys, mosaics, and stained glass designs.

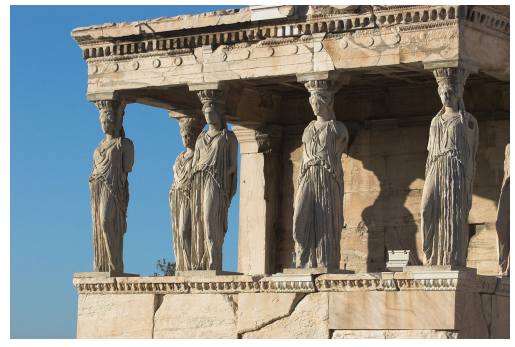

Caryatid Porch of the Erechtheum

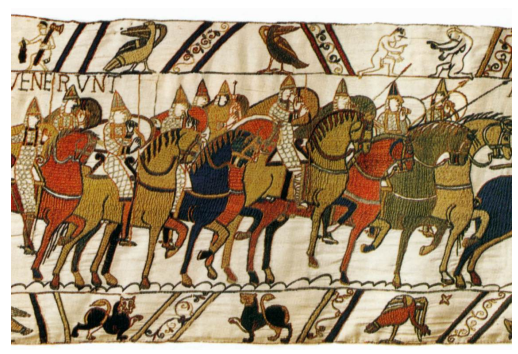

Portion of the Bayeux tapestry

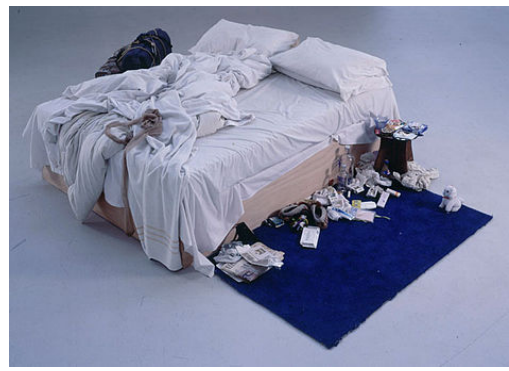

Tracy Emin, My Bed (1998)

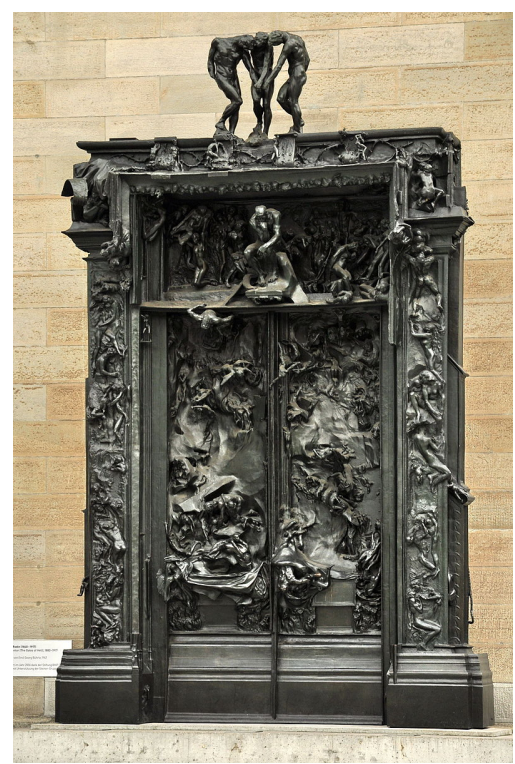

Auguste Rodin, The Gates of Hell (18801917) 


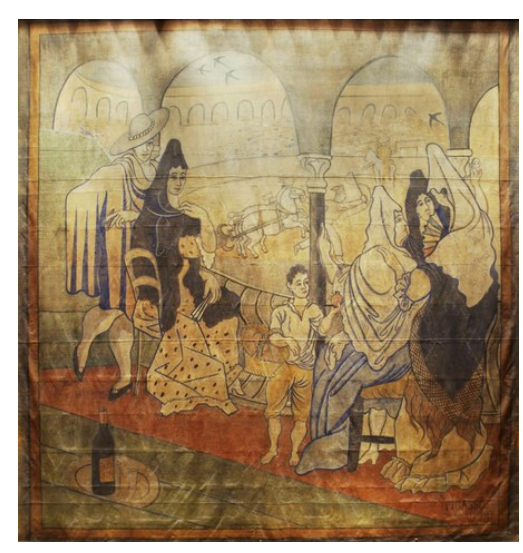

Pablo Picasso, Stage Curtain for the Ballet "Le Tricorne" (1919)

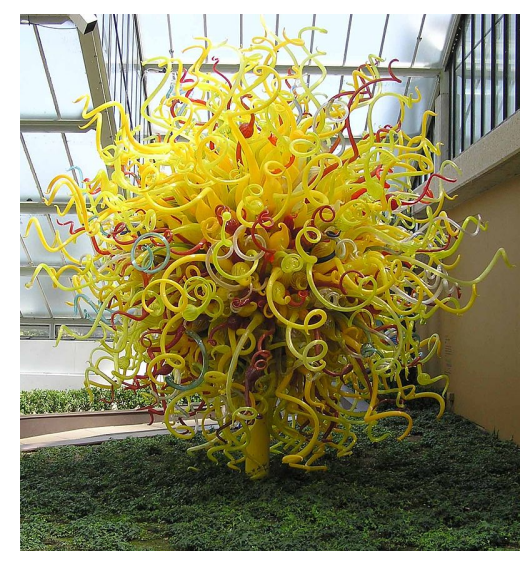

Dale Chihuly, The Sun

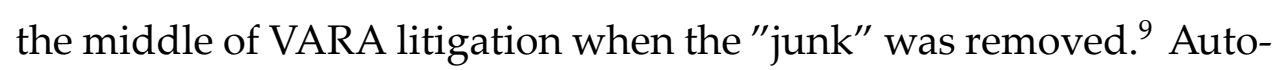
matically relegating these pieces - which are unquestionably works of visual art - beyond the scope of VARA simply because they may serve some practical function would undermine the purpose of the law.

To effect the purpose of VARA and provide guidance for the art community, I believe courts should evaluate the work as a whole, asking whether its primary purpose is to serve a useful function and whether the artistic creation is subservient to that purpose. If the primary purpose is for the work to be viewed and perceived as art, then any incidental utilitarian function will not push it outside the scope of VARA. If a work's primary purpose is functional, however, no amount of aesthetic appeal will transfer it into visual art subject to VARA's protections. Determining a work's primary purpose need not constitute a judicial inquiry into the nature of art. Rather, as in other legal contexts, courts should ask whether "a reasonable observer" would "consider [the work] designed to a practical degree" for a utilitarian or artistic purpose.

In this case, applying the analysis I outline yields the same result as the majority: La Contesssa was applied art. The school bus-turnedgalleon was designed for, and employed as, a performance venue, restaurant, and means of transportation around the Burning Man festival. Poets, acrobats, and bands performed on its decks. It drove revelers from party to party within Nevada's Black Rock desert. On various occasions, the galleon was driven at high speeds, prompting festival organizers to send Cheffins and Jones a letter condemning its "unsafe driving practices." When La Contesssa was not serving this purpose, it was dragged to a field, covered with a tarp, and left to sit idle for months at a time. Taken as a whole, this is powerful evidence that the primary purpose of La Contesssa was to serve the utilitarian functions of performance venue, gathering space, and peoplemover. Although Cheffins and Jones testified passionately about $L a$ Contesssa's beauty and the artistic expression they felt it embodied and it is an impressive work of art in many respects - I conclude it is applied art because its aesthetic appeal was subservient to its primary utilitarian purpose. Thus, the VARA claim fails.

\section{Trademark}

Trademark protects designs under the general heading of trade dress, using the same general distinctiveness analysis as it does for word

\footnotetext{
${ }^{9}$ The story of this fascinating dispute is outlined in Christopher J. Robinson's note The "Recognized Stature" Standard in the Visual Artists Rights Act, 68 Fordham L. Rev. 1935 (2000). The parties did not contest that the work was a sculpture, but fought bitterly over whether the visual art was of "recognized stature."
} 
marks and logos. But two very important limiting doctrines apply. One is that product design is effectively always at most descriptive: it can have acquired distinctiveness (via secondary meaning) but not inherent distinctiveness. The other is that functional aspects of a design are never protectable, even if they have secondary meaning.

Wal-Mart Stores, Inc. v. Samara Brothers, Inc.

In this case, we decide under what circumstances a product's design is distinctive, and therefore protectible, in an action for infringement of unregistered trade dress under $\S 43$ (a) of the Lanham Act.

Respondent Samara Brothers, Inc., designs and manufactures children's clothing. Its primary product is a line of spring/summer onepiece seersucker outfits decorated with appliques of hearts, flowers, fruits, and the like. A number of chain stores, including JCPenney, sell this line of clothing under contract with Samara.

In 1995, Wal-Mart contracted with one of its suppliers, JudyPhilippine, Inc., to manufacture a line of children's outfits for sale in the 1996 spring/summer season. Wal-Mart sent Judy-Philippine photographs of a number of garments from Samara's line, on which JudyPhilippine's garments were to be based; Judy-Philippine duly copied, with only minor modifications, 16 of Samara's garments, many of which contained copyrighted elements. In 1996, Wal-Mart briskly sold the so-called knockoffs, generating more than $\$ 1.15$ million in gross profits.

The breadth of the definition of marks registrable under $\S 2$, and of the confusion-producing elements recited as actionable by $\S 43(\mathrm{a})$, has been held to embrace not just word marks, such as "Nike," and symbol marks, such as Nike's "swoosh" symbol, but also "trade dress" - a category that originally included only the packaging, or "dressing," of a product, but in recent years has been expanded by many Courts of Appeals to encompass the design of a product. [Cases cited protected the designs of bedroom furniture, sweaters, and notebooks.] These courts have assumed, often without discussion, that trade dress constitutes a "symbol" or "device" for purposes of the relevant sections, and we conclude likewise.

The text of $\S 43(\mathrm{a})$ provides little guidance as to the circumstances under which unregistered trade dress may be protected. Nothing in $\S$ 43(a) explicitly requires a producer to show that its trade dress is distinctive, but courts have universally imposed that requirement, since without distinctiveness the trade dress would not "cause confusion ... as to the origin, sponsorship, or approval of [the] goods," as the section requires.

In evaluating the distinctiveness of a mark under $\S 2$ (and therefore, by analogy, under $\S 43(\mathrm{a})$ ), courts have held that a mark can be distinctive in one of two ways. First, a mark is inherently distinc-
529 U.S. 205 (2000)

(Scalia, J.)

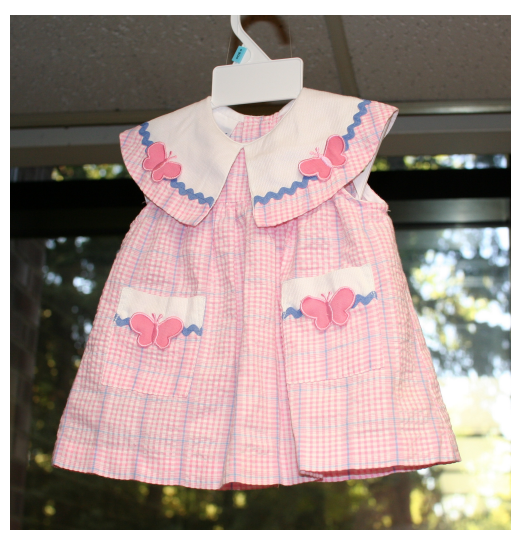

Samara Brothers dress 
Qualitex: 514 U.S. 159 (1995)

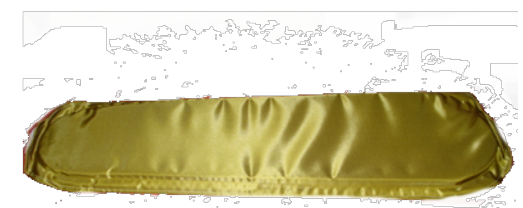

Qualitex dry-cleaning pad

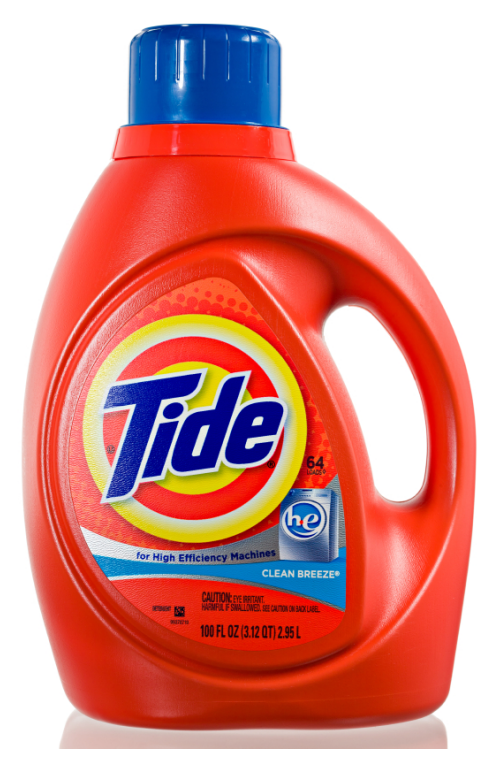

Tide bottle tive if its intrinsic nature serves to identify a particular source. In the context of word marks, courts have applied the now-classic test originally formulated by Judge Friendly, in which word marks that are "arbitrary" ("Camel" cigarettes), "fanciful" ("Kodak" film), or "suggestive" ("Tide" laundry detergent) are held to be inherently distinctive. See Abercrombie $\mathcal{E}$ Fitch. Second, a mark has acquired distinctiveness, even if it is not inherently distinctive, if it has developed secondary meaning, which occurs when, in the minds of the public, the primary significance of a mark is to identify the source of the product rather than the product itself.

The judicial differentiation between marks that are inherently distinctive and those that have developed secondary meaning has solid foundation in the statute itself. Nothing in $\S 2$, however, demands the conclusion that every category of mark necessarily includes some marks "by which the goods of the applicant may be distinguished from the goods of others" without secondary meaning - that in every category some marks are inherently distinctive.

Indeed, with respect to at least one category of mark - colors - we have held that no mark can ever be inherently distinctive. In Qualitex Co. v. Jacobson Products Co., petitioner manufactured and sold greengold dry-cleaning press pads. After respondent began selling pads of a similar color, petitioner brought suit under $\S 43(a)$, then added a claim under $\S 32$ after obtaining registration for the color of its pads. We held that a color could be protected as a trademark, but only upon a showing of secondary meaning. Reasoning by analogy to the Abercrombie $\mathcal{E}$ Fitch test developed for word marks, we noted that a product's color is unlike a "fanciful," "arbitrary," or "suggestive" mark, since it does not "almost automatically tell a customer that it refers to a brand," and does not "immediately signal a brand or a product source." However, we noted that, "over time, customers may come to treat a particular color on a product or its packaging ... as signifying a brand." Because a color, like a "descriptive" word mark, could eventually "come to indicate a product's origin," we concluded that it could be protected upon a showing of secondary meaning.

It seems to us that design, like color, is not inherently distinctive. The attribution of inherent distinctiveness to certain categories of word marks and product packaging derives from the fact that the very purpose of attaching a particular word to a product, or encasing it in a distinctive packaging, is most often to identify the source of the product. Although the words and packaging can serve subsidiary functions - a suggestive word mark (such as "Tide" for laundry detergent), for instance, may invoke positive connotations in the consumer's mind, and a garish form of packaging (such as Tide's squat, brightly decorated plastic bottles for its liquid laundry detergent) may attract an otherwise indifferent consumer's attention on 
a crowded store shelf - their predominant function remains source identification. Consumers are therefore predisposed to regard those symbols as indication of the producer, which is why such symbols almost automatically tell a customer that they refer to a brand, and immediately signal a brand or a product source. And where it is not reasonable to assume consumer predisposition to take an affixed word or packaging as indication of source - where, for example, the affixed word is descriptive of the product ("Tasty" bread) or of a geographic origin ("Georgia" peaches) - inherent distinctiveness will not be found. That is why the statute generally excludes, from those word marks that can be registered as inherently distinctive, words that are "merely descriptive" of the goods or "primarily geographically descriptive of them. In the case of product design, as in the case of color, we think consumer predisposition to equate the feature with the source does not exist. Consumers are aware of the reality that, almost invariably, even the most unusual of product designs such as a cocktail shaker shaped like a penguin - is intended not to identify the source, but to render the product itself more useful or more appealing.

The fact that product design almost invariably serves purposes other than source identification not only renders inherent distinctiveness problematic; it also renders application of an inherentdistinctiveness principle more harmful to other consumer interests. Consumers should not be deprived of the benefits of competition with regard to the utilitarian and esthetic purposes that product design ordinarily serves by a rule of law that facilitates plausible threats of suit against new entrants based upon alleged inherent distinctiveness.

Respondent contends that our decision in Two Pesos, Inc. v. Taco Cabana, Inc. forecloses a conclusion that product-design trade dress can never be inherently distinctive. In that case, we held that the trade dress of a chain of Mexican restaurants, which the plaintiff described as "a festive eating atmosphere having interior dining and patio areas decorated with artifacts, bright colors, paintings and murals," could be protected under $\S 43$ (a) without a showing of secondary meaning. Two Pesos unquestionably establishes the legal principle that trade dress can be inherently distinctive, but it does not establish that product-design trade dress can be. Two Pesos is inapposite to our holding here because the trade dress at issue, the decor of a restaurant, seems to us not to constitute product design. It was either product packaging - which, as we have discussed, normally is taken by the consumer to indicate origin - or else some tertium quid that is akin to product packaging and has no bearing on the present case.

Respondent replies that this manner of distinguishing Two Pesos will force courts to draw difficult lines between product-design and

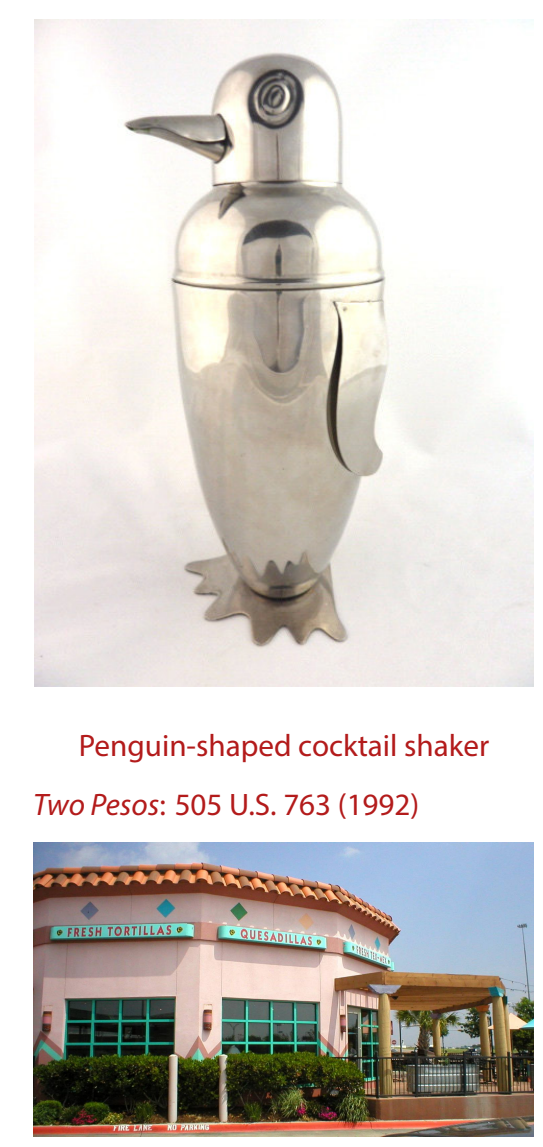

Taco Cabana exterior 


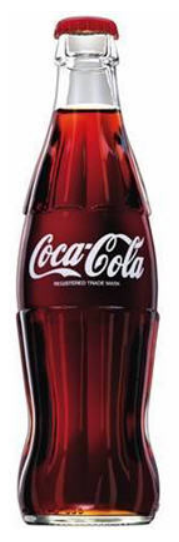

Earl Dean's Coca-Cola bottle design

15 U.S.C. § 1052 [Lanham Act § 2] Trademarks registrable on principal register...

15 U.S.C. § 1125 [Lanham Act § 43] False designations of origin, false descriptions, and dilution forbidden

532 U.S. 23 (2001)

No. 3,646,696 and No. 3,662,482

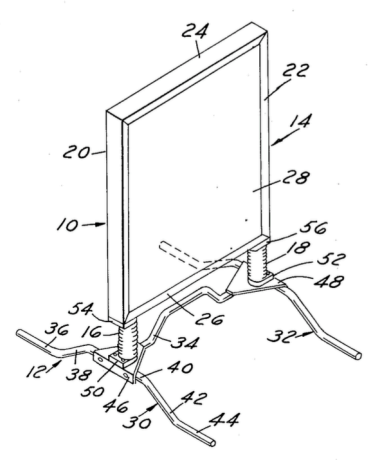

Patented dual-spring design product-packaging trade dress. There will indeed be some hard cases at the margin: a classic glass Coca-Cola bottle, for instance, may constitute packaging for those consumers who drink the Coke and then discard the bottle, but may constitute the product itself for those consumers who are bottle collectors, or part of the product itself for those consumers who buy Coke in the classic glass bottle, rather than a can, because they think it more stylish to drink from the former. We believe, however, that the frequency and the difficulty of having to distinguish between product design and product packaging will be much less than the frequency and the difficulty of having to decide when a product design is inherently distinctive. To the extent there are close cases, we believe that courts should err on the side of caution and classify ambiguous trade dress as product design, thereby requiring secondary meaning. The very closeness will suggest the existence of relatively small utility in adopting an inherent-distinctiveness principle, and relatively great consumer benefit in requiring a demonstration of secondary meaning.

We hold that, in an action for infringement of unregistered trade dress under $\S 43$ (a) of the Lanham Act, a product's design is distinctive, and therefore protectible, only upon a showing of secondary meaning.

\section{Lanham Act}

No trademark ... shall be refused registration on the principal register on account of its nature unless it-

(e) Consists of a mark which ... (5) comprises any matter that, as a whole, is functional.

\section{(a) Civil Action}

(3) In a civil action for trade dress infringement under this chapter for trade dress not registered on the principal register, the person who asserts trade dress protection has the burden of proving that the matter sought to be protected is not functional.

\section{TrafFix Devices, Inc. v. Marketing Displays, Inc.}

Temporary road signs with warnings like "Road Work Ahead" or "Left Shoulder Closed" must withstand strong gusts of wind. An inventor named Robert Sarkisian obtained two utility patents for a mechanism built upon two springs (the dual-spring design) to keep these and other outdoor signs upright despite adverse wind conditions. The holder of the now-expired Sarkisian patents, respondent Marketing Displays, Inc. (MDI), established a successful business in 
the manufacture and sale of sign stands incorporating the patented feature. MDI's stands for road signs were recognizable to buyers and users (it says) because the dual-spring design was visible near the base of the sign.

This litigation followed after the patents expired and a competitor, TrafFix Devices, Inc., sold sign stands with a visible spring mechanism that looked like MDI's. MDI and TrafFix products looked alike because they were. When TrafFix started in business, it sent an MDI product abroad to have it reverse engineered, that is to say copied. Complicating matters, TrafFix marketed its sign stands under a name similar to MDI's. MDI used the name "WindMaster," while TrafFix, its new competitor, used "WindBuster."

\section{II}

It is well established that trade dress can be protected under federal law. The design or packaging of a product may acquire a distinctiveness which serves to identify the product with its manufacturer or source; and a design or package which acquires this secondary meaning, assuming other requisites are met, is a trade dress which may not be used in a manner likely to cause confusion as to the origin, sponsorship, or approval of the goods. In these respects protection for trade dress exists to promote competition. Congress confirmed this statutory protection for trade dress by amending the Lanham Act to recognize the concept. Lanham Act S 43(a)(3) provides: "In a civil action for trade dress infringement under this chapter for trade dress not registered on the principal register, the person who asserts trade dress protection has the burden of proving that the matter sought to be protected is not functional." [The Court discussed Qualitex, Two Pesos, and Wal-Mart Stores.]

Trade dress protection must subsist with the recognition that in many instances there is no prohibition against copying goods and products. In general, unless an intellectual property right such as a patent or copyright protects an item, it will be subject to copying. Copying is not always discouraged or disfavored by the laws which preserve our competitive economy. Allowing competitors to copy will have salutary effects in many instances. Reverse engineering of chemical and mechanical articles in the public domain often leads to significant advances in technology.

The principal question in this case is the effect of an expired patent on a claim of trade dress infringement. A prior patent, we conclude, has vital significance in resolving the trade dress claim. A utility patent is strong evidence that the features therein claimed are functional. If trade dress protection is sought for those features the strong evidence of functionality based on the previous patent adds great weight to the statutory presumption that features are deemed func-

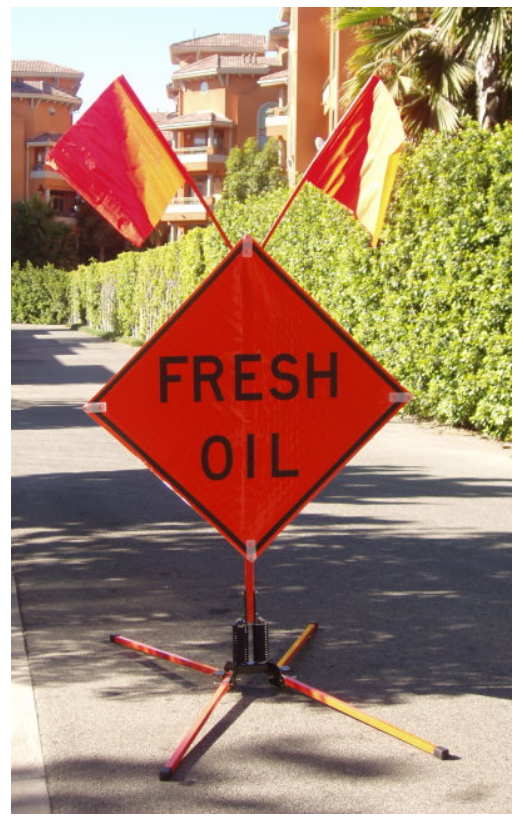

TrafFix "Little Buster" sign with dualspring base 
tional until proved otherwise by the party seeking trade dress protection. Where the expired patent claimed the features in question, one who seeks to establish trade dress protection must carry the heavy burden of showing that the feature is not functional, for instance by showing that it is merely an ornamental, incidental, or arbitrary aspect of the device.

In the case before us, the central advance claimed in the expired utility patents is the dualspring design; and the dual-spring design is the essential feature of the trade dress MDI now seeks to establish and to protect. MDI did not, and cannot, carry the burden of overcoming the strong evidentiary inference of functionality based on the disclosure of the dual-spring design in the claims of the expired patents.

The dual springs shown in the Sarkisian patents were well apart (at either end of a frame for holding a rectangular sign when one full side is the base) while the dual springs at issue here are close together (in a frame designed to hold a sign by one of its corners). As the District Court recognized, this makes little difference. The point is that the springs are necessary to the operation of the device. The fact that the springs in this very different-looking device fall within the claims of the patents is illustrated by MDI's own position in earlier litigation. In the late 1970's, MDI engaged in a long-running intellectual property battle with a company known as Winn-Proof. Although the precise claims of the Sarkisian patents cover sign stands with springs "spaced apart," the Winn-Proof sign stands (with springs much like the sign stands at issue here) were found to infringe the patents by the United States District Court for the District of Oregon, and the Court of Appeals for the Ninth Circuit affirmed the judgment. Sarkisian v. WinnProof Corp. Although the WinnProof traffic sign stand (with dual springs close together) did not appear, then, to infringe the literal terms of the patent claims (which called for "spaced apart" springs), the WinnProof sign stand was found to infringe the patents under the doctrine of equivalents. In light of this past ruling - a ruling procured at MDI's own insistence - it must be concluded the products here at issue would have been covered by the claims of the expired patents.

The rationale for the rule that the disclosure of a feature in the claims of a utility patent constitutes strong evidence of functionality is well illustrated in this case. The dual-spring design serves the important purpose of keeping the sign upright even in heavy wind conditions; and, as confirmed by the statements in the expired patents, it does so in a unique and useful manner. As the specification of one of the patents recites, prior art "devices, in practice, will topple under the force of a strong wind." The dual-spring design allows sign stands to resist toppling in strong winds. Using a dual-spring design rather than a single spring achieves important operational advantages. For 
example, the specifications of the patents note that the "use of a pair of springs as opposed to the use of a single spring to support the frame structure prevents canting or twisting of the sign around a vertical axis," and that, if not prevented, twisting "may cause damage to the spring structure and may result in tipping of the device." In the course of patent prosecution, it was said that "the use of a pair of spring connections as opposed to a single spring connection forms an important part of this combination" because it "forc[es] the sign frame to tip along the longitudinal axis of the elongated groundengaging members." The dual-spring design affects the cost of the device as well; it was acknowledged that the device "could use three springs but this would unnecessarily increase the cost of the device." These statements made in the patent applications and in the course of procuring the patents demonstrate the functionality of the design. MDI does not assert that any of these representations are mistaken or inaccurate, and this is further strong evidence of the functionality of the dual-spring design.

III

In finding for MDI on the trade dress issue the Court of Appeals gave insufficient recognition to the importance of the expired utility patents, and their evidentiary significance, in establishing the functionality of the device. The error likely was caused by its misinterpretation of trade dress principles in other respects.

Discussing trademarks, we have said "in general terms, a product feature is functional, and cannot serve as a trademark, if it is essential to the use or purpose of the article or if it affects the cost or quality of the article. Qualitex. Expanding upon the meaning of this phrase, we have observed that a functional feature is one the "exclusive use of which would put competitors at a significant nonreputation-related disadvantage." Id.The Court of Appeals in the instant case seemed to interpret this language to mean that a necessary test for functionality is "whether the particular product configuration is a competitive necessity." This was incorrect as a comprehensive definition. A feature is also functional when it is essential to the use or purpose of the device or when it affects the cost or quality of the device. The Qualitex decision did not purport to displace this traditional rule. It is proper to inquire into a "significant non-reputation-related disadvantage" in cases of esthetic functionality, the question involved in Qualitex. Where the design is functional under the traditional formulation there is no need to proceed further to consider if there is a competitive necessity for the feature. In Qualitex, by contrast, esthetic functionality was the central question, there having been no indication that the green-gold color of the laundry press pad had any bearing on the use or purpose of the product or its cost or quality. 
The Court has allowed trade dress protection to certain product features that are inherently distinctive. In Two Pesos, however, the Court at the outset made the explicit analytic assumption that the trade dress features in question decorations and other features to evoke a Mexican theme in a restaurant) were not functional. The trade dress in those cases did not bar competitors from copying functional product design features. In the instant case, beyond serving the purpose of informing consumers that the sign stands are made by MDI (assuming it does so), the dual-spring design provides a unique and useful mechanism to resist the force of the wind. Functionality having been established, whether MDI's dual-spring design has acquired secondary meaning need not be considered.

There is no need, furthermore, to engage, as did the Court of Appeals, in speculation about other design possibilities, such as using three or four springs which might serve the same purpose. Here, the functionality of the spring design means that competitors need not explore whether other spring juxtapositions might be used. The dual-spring design is not an arbitrary flourish in the configuration of MDI's product; it is the reason the device works. Other designs need not be attempted.

Because the dual-spring design is functional, it is unnecessary for competitors to explore designs to hide the springs, say, by using a box or framework to cover them, as suggested by the Court of Appeals. The dual-spring design assures the user the device will work. If buyers are assured the product serves its purpose by seeing the operative mechanism that in itself serves an important market need. It would be at cross-purposes to those objectives, and something of a paradox, were we to require the manufacturer to conceal the very item the user seeks.

In a case where a manufacturer seeks to protect arbitrary, incidental, or ornamental aspects of features of a product found in the patent claims, such as arbitrary curves in the legs or an ornamental pattern painted on the springs, a different result might obtain. There the manufacturer could perhaps prove that those aspects do not serve a purpose within the terms of the utility patent. The inquiry into whether such features, asserted to be trade dress, are functional by reason of their inclusion in the claims of an expired utility patent could be aided by going beyond the claims and examining the patent and its prosecution history to see if the feature in question is shown as a useful part of the invention. No such claim is made here, however. MDI in essence seeks protection for the dual-spring design alone. The asserted trade dress consists simply of the dual-spring design, four legs, a base, an upright, and a sign. MDI has pointed to nothing arbitrary about the components of its device or the way they are assembled. The Lanham Act does not exist to reward manufacturers for their innovation 
in creating a particular device; that is the purpose of the patent law and its period of exclusivity. The Lanham Act, furthermore, does not protect trade dress in a functional design simply because an investment has been made to encourage the public to associate a particular functional feature with a single manufacturer or seller. The Court of Appeals erred in viewing MDI as possessing the right to exclude competitors from using a design identical to MDI's and to require those competitors to adopt a different design simply to avoid copying it. MDI cannot gain the exclusive right to produce sign stands using the dual-spring design by asserting that consumers associate it with the look of the invention itself.

\section{In re Florists' Transworld Delivery, Inc.}

Florists' Transworld Delivery, Inc. appealed from the final refusal of the trademark examining attorney to register the proposed mark shown [in the margin] for "flowers and live cut floral arrangements." The specimen of use is reproduced [in the margin]. The description of the mark is:

The mark consists of the color black as applied to a substantial portion of the outside surface of a box which serves as a container or packaging for the goods and in part forms a background to design and literal elements applied thereto.

Section 2(e)(5) of the Trademark Act prohibits registration of a mark if it "comprises any matter that, as a whole, is functional." There are two forms of functionality, utilitarian functionality and aesthetic functionality. A feature that is not essential to the use or purpose of the article, or does not affect the cost or quality of the article - in other words, would not be considered as utilitarian functional - is still prohibited from registration if the exclusive appropriation of that feature would put competitors at a significant non-reputation related disadvantage.

In Brunswick Corp. v. British Seagull Ltd., the applicant sought to register the color black for outboard engines. In affirming the Board's finding that the color black is de jure functional for outboard motors, the Federal Circuit reasoned:

The color black does not make the engines function better as engines. The paint on the external surface of an engine does not affect its mechanical purpose. Rather, the color black exhibits both color compatibility with a wide variety of boat colors and ability to make objects appear smaller. With these advantages for potential customers, there is competitive need for engine manufacturers to use
106 U.S.P.Q.2d (TTAB 2013)

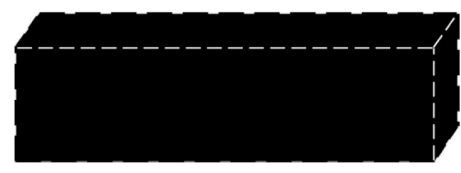

Proposed mark

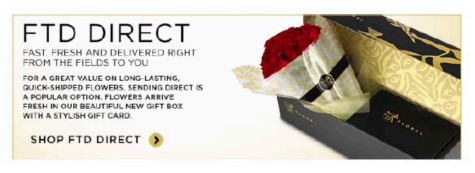

Specimen of use

Brunswick Corp.: 35 F.3d 1527 (Fed. Cir. 1994) 
black on outboard engines.

Kichler: 192 F.3d 1349 (Fed. Cir. 1999)

"The color is functional because it indicates the flavor of the ice cream, for example, pink signifies strawberry, white signifies vanilla, brown signifies chocolate, etc." Dippin' Dots, Inc. v. Frosty Bites Distribution, 369 F.3d 1197 (11th Cir. 2004). Is that right?
The Federal Circuit also focused on competitive need in L.D. Kichler Co. v. Davoil, Inc.. There, the Federal Circuit reversed a district court's cancellation on summary judgment of a registration for the "Olde Brick" finish of a lighting fixture backplate. The Federal Circuit found a genuine issue of material fact as to whether there was a competitive need for others to use the "Olde Brick" finish and remanded. In particular, the Court noted:

There is evidence that many customers prefer Olde Brick and other composite "rust-type" colors. It is not clear, however, that Olde Brick is one of a few colors that are uniquely superior for use in home decorating. Thus, the district court erred in granting summary judgment that Olde Brick was de jure functional.

In the present case, applicant seeks to register a single-color mark, black, for the outside of the box which serves as the container or packaging for its goods. We therefore determine factually whether registration of the color black for boxes for flowers and live cut floral arrangements serves a non-trademark purpose that would hinder the ability of others to effectively compete with the registrant.

The evidence in the record reflects that, indeed, in the floral industry, color has significance and communicates particular messages. It is commonly known that a dozen red roses are given as a message of love, particularly for Valentine's Day. [Numerous florist websites referred to the importance of the color of flowers in a bouquet and its packaging, e.g. red roses in a white box. Numerous websites also stated that black in connection with flowers connotes elegance or luxury.]

In addition, the evidence reflects that black has significance on somber occasions such as in the context of death. Office action at 8), states "Black has been ... often associated with death." Black is the traditional sign of mourning; it is common knowledge that black clothing is traditionally worn at funerals. Flowers and floral displays play an important role in the context of funerals and mourning; flowers are ubiquitous at funerals and it is also common knowledge that flowers are commonly presented as an expression of condolence. With regard to floral packaging, black is an appropriate color for floral packaging, and is used as floral packaging in bereavement bouquets

When we consider the evidence in the record, we find that the examining attorney has demonstrated prima facie that there is a competitive need for others in the industry to use the color black in connection with floral arrangements and flowers. Competitors who, for example, want to offer flowers for bereavement purposes, Halloween 
or to imbue an element of elegance or luxury to their presentations through packaging therefor will be disadvantaged if they must avoid using the color black in such packaging. As the examining attorney stated, "competitors will need to use black packaging to convey an appropriate message or sentiment, whether that is elegance, style, festivity, grief or sympathy" and "allowing singular entities to control certain colors, in a field where color is both dynamic and has significance, would severely limit the availability of appropriate color choices to consumers seeking particular floral arrangement gifts."

Maker's Mark Distillery, Inc. v. Diageo North America, Inc. Plaintiff Maker's Mark is a Kentucky-based distiller specializing in bourbon whisky. Since 1958, when it first began producing bourbon, the company has capped its bottles with a red dripping wax seal that partially covers the neck of the bottle and drips down to the bottle's shoulder. Since 1985, Maker's Mark has held a federally registered trademark, U.S. Trademark Reg. No. 1,370,465, consisting of the "wax-like coating covering the cap of the bottle and trickling down the neck of the bottle in a freeform irregular pattern."Notably, the trademark does not mention the color red - it is silent as to color. [During the course of litigation, Maker's Mark narrowed its argument to assert protection only for a red dripping wax seal.]

The facts giving rise to this case began in the mid-1990s, when [Jose] Cuervo executives decided to create a high-end tequila to celebrate the company's 200th anniversary of producing tequila products legally. They designed the new product, Reserva de la Familia, in conjunction with a U.S. marketing firm and production began in 1995. Initially, the Reserva bottle design included a straight-edge, non-dripping wax seal capping the bottle, along with a stamp of the Cuervo crest imprinted into the wax and a small blue ribbon extending from underneath the wax.

Juan Domingo Beckmann, now Chief Executive Officer of Casa Cuervo, testified that sometime around 1997, he decided to alter the wax seal to include dripping wax after seeing such a bottle in midproduction, before its drips were cut off. Beckmann thought the uncut seal, with its drips, created a unique and artisanal look. By 2001, Reserva, with its red dripping wax seal, had entered the U.S. market. Packaged in a wooden box designed each year by a different Mexican artist, it retailed for about $\$ 100$ per bottle.

Defendants argue the red dripping wax seal is functional because it protects a cork from air, moisture and contaminants, thus preserving the contents of the bottle on some bottles of alcohol. They further argue that drips are a natural byproduct of such a coating, and are costly to remove. In the Court's view, Cuervo completely failed to show that wax seals are functional. Not only did Cuervo fall short of
703 F. Supp. 2d 671 (W.D Ky. 2010), aff'd, 679 F.3d 41 (6th Cir. 2012)

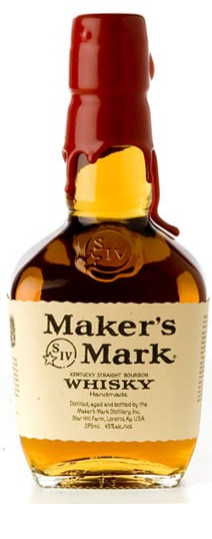

Maker's Mark

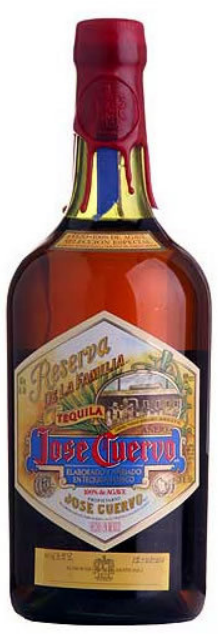

Cuervo Reserva 
proving that the wax seal on the Reserva bottle was functional, it also did not prove that any current wax seal users employ the method for a functional purpose. For example, Cuervo's production manager, $\mathrm{Al}-$ fredo Guerrero, acknowledged that the company seals other Cuervo products with plastic caps or shrink wrap, and that some of those methods are less expensive than creating a wax seal.

Even assuming that the Sixth Circuit would apply the aesthetic functionality doctrine, the Court finds the case for its application here is unpersuasive. None of Cuervo's witnesses convinced the Court that it would be difficult or costly for competitors to design around the red dripping wax trademark. Furthermore, red wax is not the only pleasing color of wax that competitors may employ on their product, nor does it put competitors at a significant non-reputation related disadvantage to be prevented from using red dripping wax. There are other ways of making a bottle look artisanal or unique. Therefore, the doctrine of aesthetic functionality is inapplicable here.

\section{Eames Chair Problem, Revisited}

Look again at the Eames Lounge Chair. Is its design protectable trade dress?

\section{Pez Dispenser Problem}

Make yourself familiar, if you are not already, with PEZ dispensers. To what extent can Patrafico AG (the PEZ corporate parent) obtain trademark or trade dress protection in the appearance of PEZ dispensers? Can it trademark the spring-loaded flip-top design? The number of candies in a pack? The fluted front and footed base of a dispenser? Does it matter what heads the PEZ dispensers have? Against what products and uses will these rights be effective?

\section{Design Patent}

Design patent law has, until recently, been one of the most academically neglected fields of intellectual property law. The immense importance of design patents in smartphone litigation, however, has thrust them on the public stage again. As you read this section, pay close attention to how they deal with the limits on protections for functional matter hard-wired into copyright and trademark. There is a functionality test for design patents, but it is far more forgiving.

Design patents are an interesting hybrid of IP concepts we have

There are no canonical design patent treatises. Chisum's patent-law treatise has a chapter on design patents, and Matthew A. Smith has a draft treatise availble online. seen elsewhere. They borrow their basic structure from utility patent law: a designer obtains exclusive rights to a design by filing an application that is examined under the same substantive and procedural rules as a utility patent application would be. But the subject mat- 
ter that is actually protected, and the infringement test used to measure similarity, looks much more like copyright. There are even hints of tradmark-law confusion concepts in the historical infringement tests for design patents, although recent cases insist that whether consumers are confused is (mostly) not the right question to ask.

\section{Patent Act}

Whoever invents any new, original and ornamental design for an article of manufacture may obtain a patent therefor, subject to the conditions and requirements of this title.

The provisions of this title relating to patents for inventions shall apply to patents for designs, except as otherwise provided.

Patents for designs shall be granted for the term of fourteen years from the date of grant.

35 U.S.C. § 171

Patents for designs

35 U.S.C. § 173

Term of design patent 
[54] AUTOMOBILE

[75] Inventor: Giorgetto Giugiaro, Turin, Italy

[73] Assignee: Delorean Motor Company

[**] Term: 14 Years

[21] Appl. No.: 273,091

[22] Filed: Jun. 12, 1981

[52] U.S. Cl.

[58] Field of Search D12/91 D12/91, 92; 296/185
[56]

\author{
References Cited \\ PUBLICATIONS
}

Road \& Track, 3/73, p. 50, Lamborghini P250 Uracco, top right side of page.

Primary Examiner-James M. Gandy Attorney, Agent, or Firm-David A. Maxon

[57]

\section{CLAIM}

The ornamental design for an automobile, as shown and described.

\section{DESCRIPTION}

FIG. 1 is a front perspective view of an automobile showing my new design;

FIG. 2 is a rear perspective view thereof;

FIG. 3 is a front elevational view thereof; and

FIG. 4 is a rear elevational view thereof.

The side opposite to that shown in FIGS. 1 and 2 of the drawing is substantially a mirror image thereof.

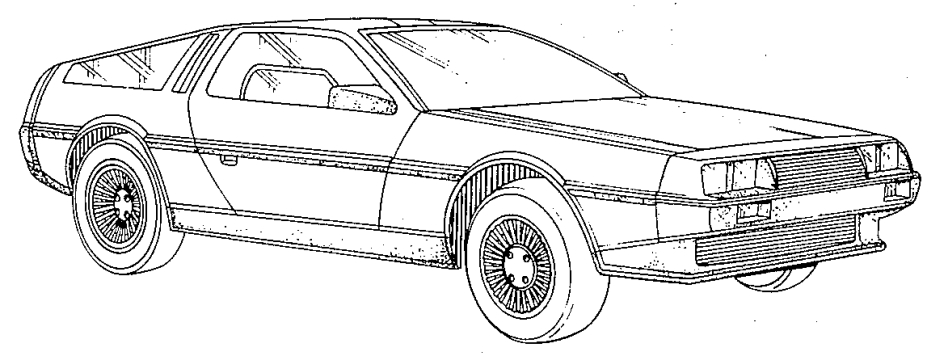


U.S. Patent May 20, 1986 Sheet 1 of 3 Des. 283,882

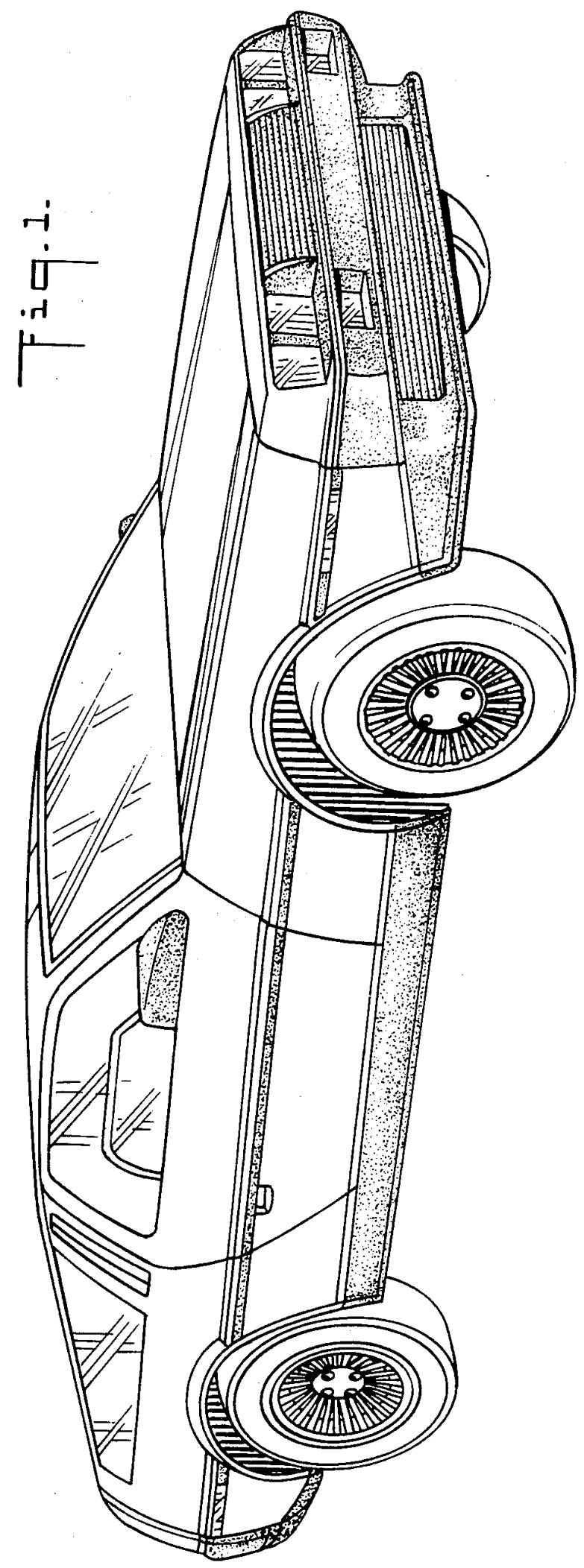


U.S. Patent May 20,1986 Sheet 2 of 3 Des. 283,882

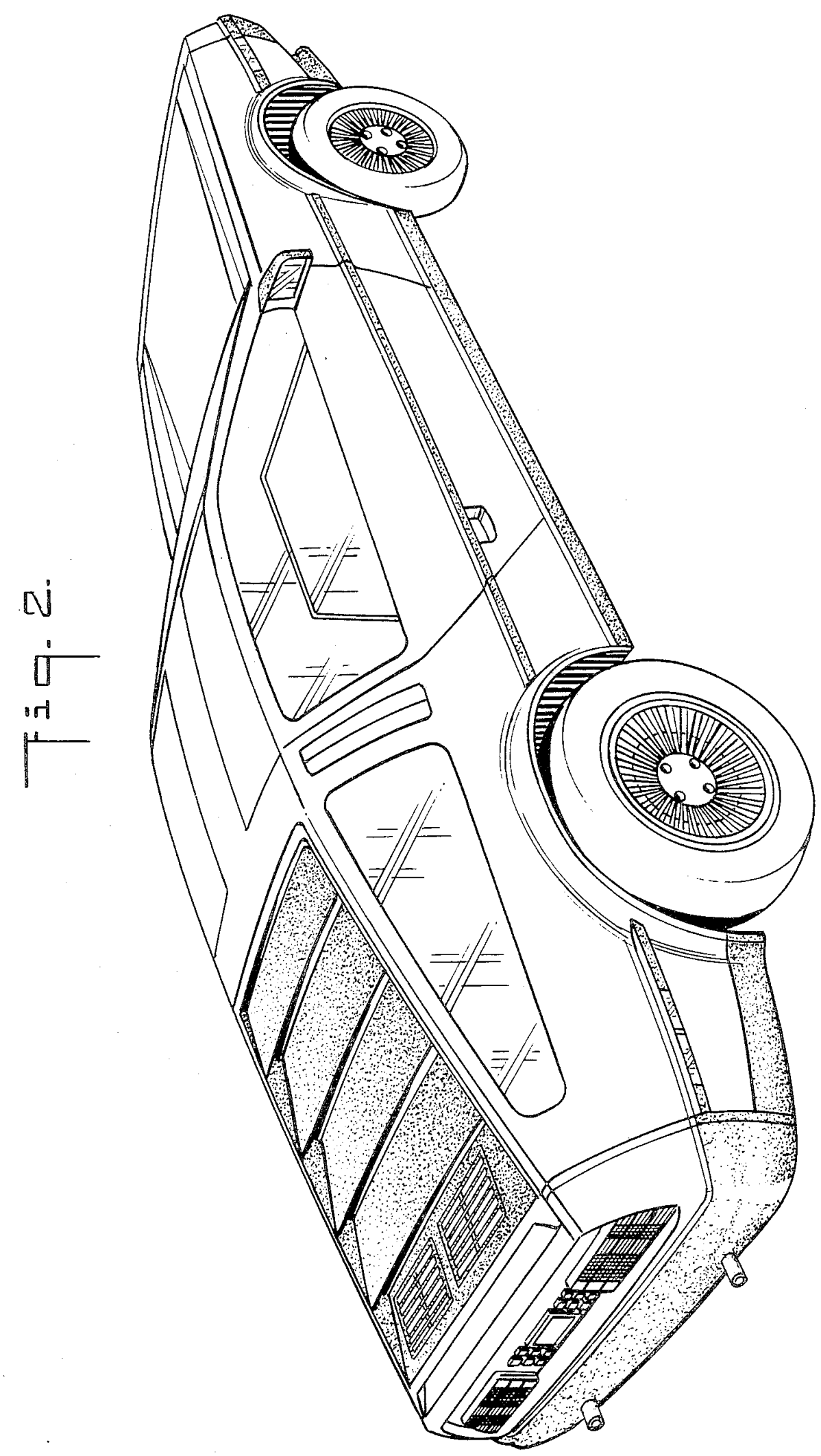




\section{U.S. Patent May 20, 1986 Sheet 3 of 3 Des. 283,882}

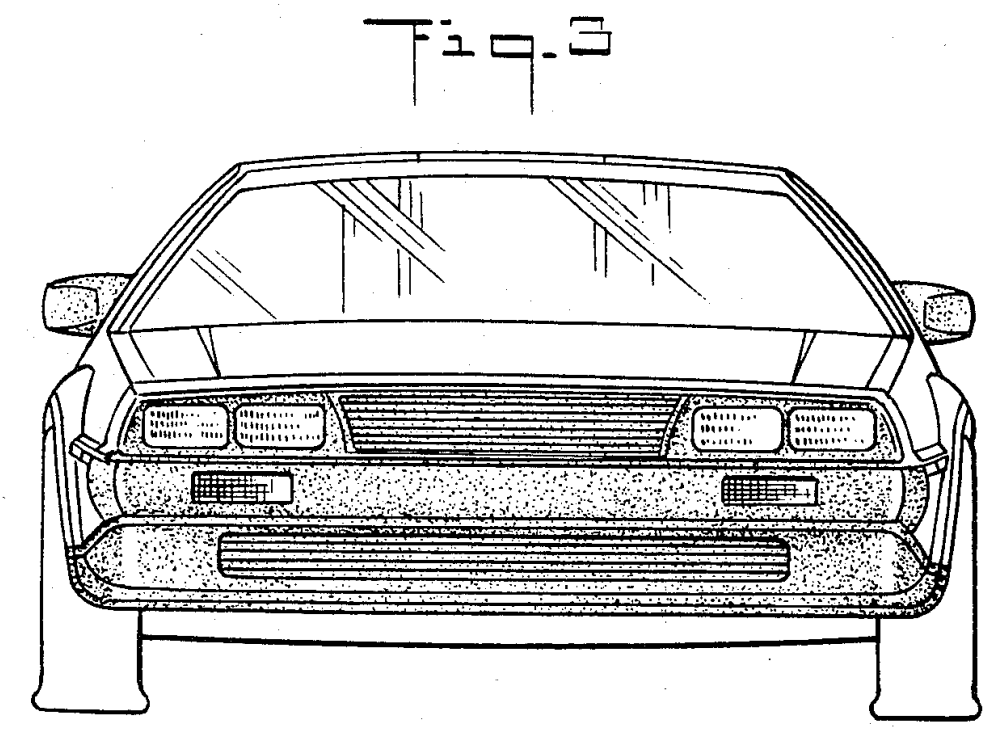

Fiqu. 4 .

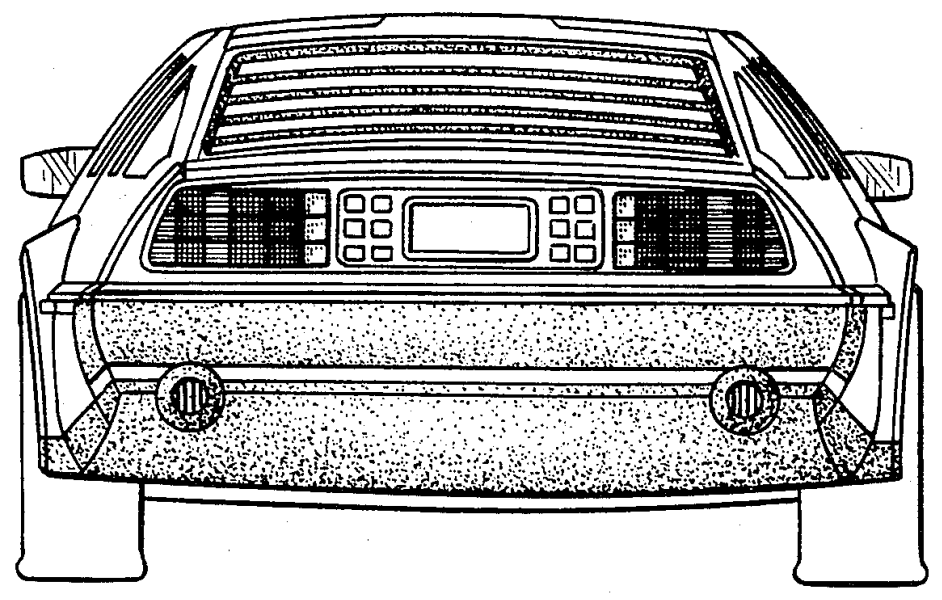




\section{Subject Matter}

Section 171 provides two subject matter threshold conditions: a design patent can apply only to a design for "an article of manufacture" and the design must be "ornamental."

\section{a Articles of Manufacture}

373 F.2d 997 (CCPA 1967)

(Rich, J.)

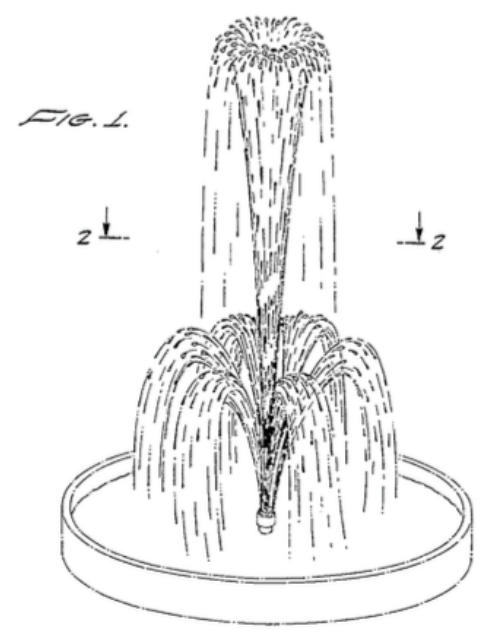

Figure 1 from Hruby's application

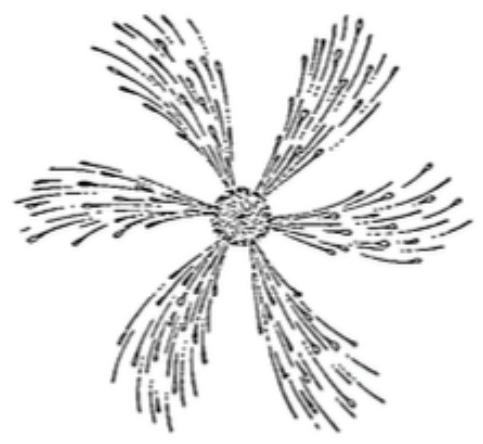

Figure 2 from Hruby's application

\section{In re Hruby}

These appeals are from split decisions of the Patent Office Board of Appeals wherein the majority affirmed the rejection of appellant's claims in four design patent applications. The single claim in each application reads:

The ornamental design for a water fountain as shown and described.

The sole rejection was that the claim in each case does not define an article of manufacture. The precise question before us, therefore, is whether that portion of a water fountain which is composed entirely of water in motion is within the statutory term "article of manufacture."

The board said, "we appreciate that the forms created in water by fountains are a well recognized and much used decorative device" and that it "is evident as urged by appellant that the shape created in a specific fountain is manufactured by man in the sense that water as a raw material is put into planned patterns of motion for accomplishment of a decorative purpose." The majority further expressed disagreement with the examiner's objection that the water of which the designs are produced is a "natural" product, and wisely so as that argument would apply to every article made of wood or stone. Nor did it think much of the argument that the water droplets constantly changed position. Nevertheless the board majority concluded that the water display itself is not "an article of manufacture." The only reasons we can perceive for this conclusion in the board's opinion are that "the pattern created is wholly a fleeting product of nozzle arrangements and control of operating pressure or pressures" and that "the pattern exists only as a product or 'effect' of the mechanical organization during its continued operation."

The dissenting member of the board soundly answered the "fleeting" argument as follows:

Although appellant did not disclose the particular means for producing the fountain effect, it is recognized that if certain parameters such as orifice configuration, water pressure and freedom from disturbing atmospheric conditions are maintained, the ornamental shape of the foun- 
tain will remain substantially constant and will at such times present an over-all appearance virtually the same from day to day.

We agree with the dissenter on that and would add that the permanence of any design is a function of the materials in which it is embodied and the effects of the environment thereon. Considering the fact that the Romans and the French built now famous fountains hundreds of years ago which still produce the same water designs today, the notion that a fountain is "fleeting" is not one which will "hold water."

The dissenting member continued:

It is true that a particular droplet or droplets may be "a fleeting product" but the fountain itself is not. The fountain in its entirety under proper conditions presents a product of constant appearance rather than a fleeting product. I assume that the majority would find no objection if a design effect would be produced in the form of frozen water. Is it logical or reasonable to find objection to a related design effect also having a constant appearance merely because of continuous movement of water droplets? I am unable to find any logical or legal basis for such a distinction. It must be remembered that in a design it is the over-all appearance due to the form or shape of the product that is determinative of patentability and not the minutia of the details that form the design.

Again we agree. The physicists and philosophers teach us that what we think we see is not really there at all; that the very concept of "solid" is something of an illusion and objects are mostly empty space, "substance" consisting of nuclei with electrons orbiting about them. In common parlance, however, what we see here are fountains, not droplets of water moving in space, any more than we see nuclei and electrons or atoms or molecules in solid objects.

Fountains are what appellant (or someone connected with him) sells. At oral argument, counsel presented us with a stereoscopic filmslide card, a sales device showing fountains like those here involved in three-dimensional pictures as offered for sale. There is no doubt in our minds that prospective buyers of these fountains would select them for the decoration of buildings or grounds according to specific, reproducible $\mathrm{e}^{\mathrm{B}}$ designs, intending to us them as permanent decoration.

\footnotetext{
${ }^{3}$ We use the term "reproducible" in the practical sense of making another thing which has the same appearance to the average viewer. The examiner was concerned about the obvious fact that "the exact arrangement and configuration of droplets" could not be reproduced by a person skilled in the art. We do not
} 


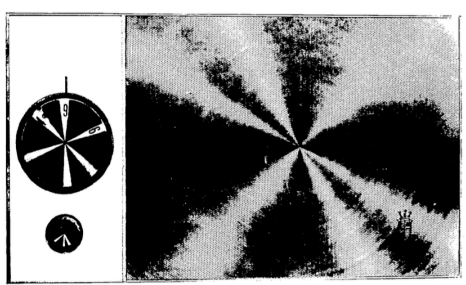

Boldt's radio cabinet. Unfortunately, the same moiré effect remarked on by the court also makes the image in Boldt's filing hard to copy or scan faithfully.

Boldt: 344 F.2d 990 (1965)
The fountains are certainly made by man (manufactured) for sale to and use by such buyers. They certainly carry into effect the plain intent of the design patent statute, which is to give encouragement to the decorative arts.

The brief for the Patent Office makes but a single argument in support of the contention the fountains should not be considered to be "an article of manufacture." It is, as the examiner contended, that water sprays "cannot exist of themselves," being dependent on the existence of the nozzles and the water under pressure. Only because of this dependence are we asked to affirm the rejection.

We fail to see any force in this argument. It is not denied that designs exist. It is perfectly clear that these designs are of the threedimensional or configuration-of-goods type. The "goods" in this instance are fountains, so they are made of the only substance fountains can be made of - water. We see no necessary relation between the dependence of these designs made of water upon the means for producing them and their being articles of manufacture. A majority of this court recently held patentable a grille for a radio cabinet with a circularly brushed appearance which also had evenly-spaced small perforations. The peculiarity of this grille was that "with variations in viewing angle and ambient lighting" (emphasis added) a varying moire effect was produced and the majority felt that this effect made the ornamental appearance unobvious and patentable. The design was thus dependent, insofar as the feature which made it patentable was concerned, on something outside itself, it did not exist alone, because without the proper angles of ambient lighting and viewing there was no moire effect.In re Boldt We do not see that the dependence of the existence of a design on something outside itself is a reason for holding it is not a design "for an article of manufacture." Many such designs depend upon outside factors for the production of the appearance which the beholder observes. The design of a lampshade may not be apparent unless the lamp is lighted. The design of a woman's hosiery is not apparent unless it is in place on her legs. The designs of inflated articles such as toy balloons, water toys, air mattresses, and now even buildings are not apparent in the absence of the compressed air which gives them form, as the water pressure

think this important. The same problem exists to some degree with most everything made of such variable materials as wood, cloth, clay and many others which minutely vary from piece to piece. What matters with an ornamental design is only the ultimate over-all appearance of the article which embodies it. Technically, "exact" reproduction is an impossibility. It is always an approximation. We see no reason why design law - law being one of the greatest approximations of all - should be any more concerned with the "exact arrangement" of water droplets than it is with the exact arrangement of molecules, grains of sand, or even grosser building blocks so long as the general appearance is not affected. 
here gives shape to the fountain. Even the design of wall paper is not always fully apparent in the commodity as it is sold and requires a wall and the services of a paperhanger to put it into condition for enjoyment by the beholder, which is the ultimate purpose of all ornamental design.

Worley, Chief Judge, dissenting:

It is inconceivable that Congress could possibly have intended Sec. 171, in letter or spirit, to allow an individual to remove from the public domain and monopolize mere sprays of water. To do so, one must necessarily rely on strained semantics at the expense of common sense. The instant sprays, so evanescent and fugitive in nature, presumably subject to the whims of wind and weather, incapable of existing in and of themselves, are merely the effect flowing from articles of manufacture, but certainly are no more articles of manufacture per se than are the vapor trails of jets, wakes of ships or steam from engines.

It appears that appellant presently enjoys patent protection on the mechanical elements of the fountains, but apparently not satisfied with that, now seeks to monopolize certain configurations of moving water, whether produced by a garden hose or otherwise. It is not difficult to imagine the potential harassment that could result from such a monopoly.

\section{In re AISabah}

AlSabah seeks a design patent on, "The ornamental design for a Teaching Aid for Teaching Arabic as shown and described." AlSabah's design is a table of synopsized Arabic letters divided into numbered groups and arranged in eleven rows and two columns.

The Board properly found that AlSabah's design is directed to nonstatutory subject matter as provided under 35 U.S.C. $\S 171$ because the design is not embodied in or applied to an article of manufacture. Specifically, AlSabah seeks a design patent on a design for a teaching aid, where the design is a table of information (synopsized Arabic letters divided into groups arranged in an eleven rows and two columns). AlSabah's design can theoretically be applied to a variety of articles, from poster boards to coffee mugs, but has not yet been applied to any article. In other words, AlSabah seeks to improperly patent an abstract design.

A design patent may be obtained for a "new, original and ornamental design for an article of manufacture." An article of manufacture is a tangible man-made object. For example, a computergenerated icon shown on a computer screen is a patentable design on an article of manufacture. The icon itself is not patentable, but when claimed as an icon embodied on a computer screen, monitor,

No. 2015-1264 (Fed. Cir. 2015)

The examiner rejected AISabah's application, and the PTAB affirmed. This is the brief for the USPTO in AISabah's appeal to the Federal Circuit, which affirmed the PTAB without opinion. 621 Fed. Appx. 659, 2015 WL 6080577 (Fed. Cir. 2015).

\begin{tabular}{|c|c|}
\hline Group & Lateefa Grolips \\
\hline $1^{\text {st }}$ & 1 \\
\hline $2^{n d}$ & 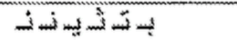 \\
\hline $3^{\text {fe }}$ & " \\
\hline $4^{\text {th }}$ & jo \\
\hline $5^{\text {thi }}$ & $j 3$ \\
\hline 6 th & $\omega$ \\
\hline $7^{\text {th }}$ & صد ضت ط ال \\
\hline $8^{\text {th }}$ & $\hat{s} \dot{s}=$ \\
\hline gith & 4 \\
\hline $10^{6 h}$ & 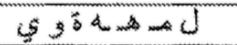 \\
\hline
\end{tabular}

AISabah's design 
or other display panel, the combination of the icon and the display panel (or portion thereof) is patentable as a design.

The phrase "design for an article of manufacture" encompasses three categories of designs: (1) a design for an ornament, impression, print or picture to be applied to an article of manufacture (surface ornamentation); (2) a design for the shape or configuration of an article of manufacture; and (3) a combination of the first two categories. In re Schnell With respect to the sort of surface ornamentation at issue in this appeal, this Court's predecessor, the United States Court of Customs and Patent Appeals held that section 171 requires that "design must be shown not to be the mere invention of a picture, irrespective of its manner of use, but that the applicant should be required to show by an appropriate drawing the manner of its application." The court went on to state that "it is the application of the design to an article of manufacture that Congress wishes to promote, and an applicant has not reduced his invention to practice and has been of little help to the art if he does not teach the manner of applying his design."

The title of AlSabah's application and claim generically describe the claimed design as being "for a Teaching Aid for Teaching Arabic." The drawing in AlSabah's application fails to identify an article of manufacture to which the claimed design must be affixed.Rather, the drawing simply shows synopsized Arabic letters in an eleven row by two column table and nothing more - i.e., a mere abstract design.

AlSabah argues that her application is in "full compliance" with section 171 because teaching aids and tables are articles of manufacture. While a design for a teaching aid is patentable subject matter, the problem for AlSabah is that her so-called design is the teaching aid. And, although AlSabah's design can be applied to an unlimited number of articles of manufacture, there is no way for a person looking at AlSabah's claim and drawing to discern whether the claimed design is applied, for example, to a paper handout, a computer icon, or even a coffee mug. Without application to a defined article of manufacture, AlSabah's design is nothing more than an abstract idea.

AlSabah erroneously argues that her design is "applied to or embodied in an article of manufacture" because "the design is printed on a piece of white paper, and a piece of white paper is an article of manufacture." More specifically, AlSabah argues that her design is "applied to or embodied" in paper because her design patent application was printed on paper and submitted to the USPTO for examination in paper form. According to AlSabah, an applicant can put any printed material in a design patent application, submit it to the USPTO, and because the application is transmitted to the Office on paper the application should not get rejected for not claiming a design for an article of manufacture. Following AlSabah's logic, all such proposed design patents would be embodied in paper just because they 
were submitted to the USPTO for examination. But that makes little sense, what matters is the context of the application itself. AlSabah's design is not depicted as being a table on paper nor is it described as being on paper in her application.

If AlSabah wanted to claim the design in Figure 1 as applied to paper, AlSabah could have done so using broken or dotted lines to represent the paper. But AlSabah's Figure 1 "as shown and described" does not depict any article of manufacture, let alone paper. For all these reasons, AlSabah's arguments regarding paper are inapt.

\section{b Ornamentality}

\section{In re Webb}

This is an appeal from a decision of the U.S. Patent and Trademark Office Board of Patent Appeals and Interferences affirming the final rejection of the sole claim of appellants' U.S. Design Patent Application Serial No. 833,470. The Board affirmed the Examiner's holding that the design, "clearly not intended to be visible in actual use," "is not proper subject matter under 35 U.S.C. § 171." The Board's decision creates a per se rule that a design for an article which will not be visible in the final use for which the article was created is nonstatutory subject matter even if the design is observed at some stage of the article's commercial life. We reverse and remand.

Hip stem prostheses of the design invented by Webb are metallic implants that are generally used by orthopedic surgeons to supplant the functioning of a diseased or broken femur, near the hip, where the femur is joined to the pelvis. According to Webb, and not disputed by the Patent and Trademark Office ("PTO"), surgeons are made aware of differing brands and types of prostheses through advertisements in professional journals and through trade shows, where the prostheses themselves are displayed. Advertisements that were put in the record prominently and visually display the features of the prostheses. Furthermore, the applicant's agent submitted that "an implant's appearance is observed by potential and actual purchasers, surgeons, nurses, operating room staff, and other hospital personnel." After purchase, the prosthesis is surgically implanted into a patient's body where the implant is to remain indefinitely. Neither party disputes that, after implantation, the prosthesis is no longer visible to the naked eye.

In the Final Office Action, the Examiner stated:

There is not sound reason or logic for "normal use" to include the repair, service, replacement, sale or display of the article which incorporates the claimed design. While such occasions are of course "normal" in the sense of com-

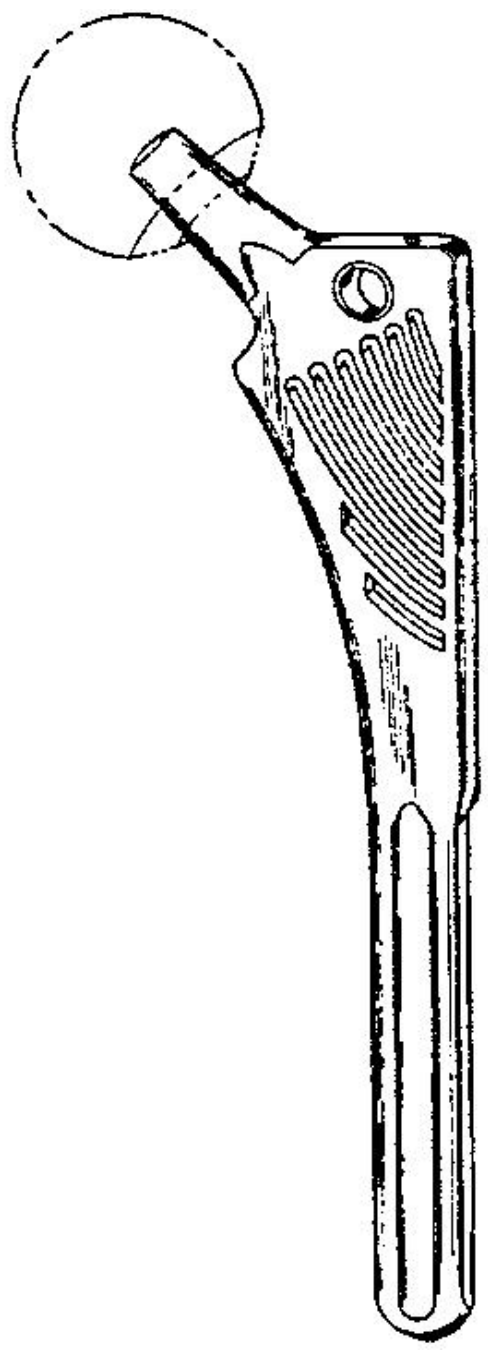


Cornwall: 230 F.2d 457 (CCPA 1956)

Stevens: 173 F.2d 1015, (CCPA 1949) monplace or routine occasions of an item's use, for patent purposes "normal use" should be limited to the ordinary functioning for which it was designed, not incidents in the article's life which are not integral to its function or purpose. Items are not designed for sale, display, replacement or repair.

The issuance of design patents is limited by statute to designs that are ornamental. Our predecessor court has affirmed the rejection of design applications that cannot be perceived in their normal and intended uses. For instance, the Court of Customs and Patent Appeals affirmed the rejection of a design claim for a vent tube placed in the wall of a frame house, stating that "it is well-settled that patentability of a design cannot be based on elements which are concealed in the normal use of the device to which the design is applied."In re Cornwall. Even earlier, that court affirmed the rejection of a design claim for a vacuum cleaner brush. In re Stevens. There the court noted:

Articles which are concealed or obscure are not proper subjects for design patents, since their appearance cannot be a matter of concern. Almost every article is visible when it is made and while it is being applied to the position in which it is to be used. Those special circumstances, however, do not justify the granting of a design patent on an article such as here under consideration which is always concealed in its normal and intended use.

We read those cases to establish a reasonable general rule that presumes the absence of ornamentality when an article may not be observed. This is a sound rule of thumb, but it is not dispositive. In each case, the inquiry must extend to whether at some point in the life of the article an occasion (or occasions) arises when the appearance of the article becomes a "matter of concern."

Here, we read the Board's decision to have established a per se rule under $\S 171$ that if an article is hidden from the human eye when it arrives at the final use of its functional life, a design upon that article cannot be ornamental. The rule in Stevens does not compel the Board's decision. Instead, Stevens instructs us to decide whether the "article such as here under consideration" - a hip stem implant - "is always concealed in its normal and intended use." The issue before us, then, is whether "normal and intended use" of these prosthetic devices is confined to their final use.

Although we agree that "normal and intended use" excludes the time during which the article is manufactured or assembled, it does not follow that evidence that an article is visible at other times is legally irrelevant to ascertaining whether the article is ornamental for 
purposes of $\S 171$. Contrary to the reasoning of the Examiner in this case, articles are designed for sale and display, and such occasions are normal uses of an article for purposes of $\S 171$. The likelihood that articles would be observed during occasions of display or sale could have a substantial influence on the design or ornamentality of the article.

In short, we construe the "normal and intended use" of an article to be a period in the article's life, beginning after completion of manufacture or assembly and ending with the ultimate destruction, loss, or disappearance of the article. Although the period includes all commercial uses of the article prior to its ultimate destination, only the facts of specific cases will establish whether during that period the article's design can be observed in such a manner as to demonstrate its ornamentality.

It is possible, as in Stevens, that although an article may be sold as a replacement item, its appearance might not be of any concern to the purchaser during the process of sale. Indeed, many replacement items, including vacuum cleaner brushes, are sold by replacement or order number, or they are noticed during sale only to assess functionality. In such circumstances, the PTO may properly conclude that an application provides no evidence that there is a period in the commercial life of a particular design when its ornamentality may be a matter of concern. However, in other cases, the applicant may be able to prove to the PTO that the article's design is a "matter of concern" because of the nature of its visibility at some point between its manufacture or assembly and its ultimate use. Many commercial items, such as colorful and representational vitamin tablets, or caskets, have designs clearly intended to be noticed during the process of sale and equally clearly intended to be completely hidden from view in the final use. Here, for example, there was ample evidence that the features of the device were displayed in advertisements and in displays at trade shows. That evidence was disregarded by the Board because, in its view, doctors should select implants solely for their functional characteristics, not their design. It is not the task of the Board to make such presumptions.

Rosco, Inc. v. Mirror Lite Co.

Rosco, Inc. ("Rosco") appeals the decision of the United States District Court for the Eastern District of New York finding Rosco's design patent, United States Design Patent No. 346,357 ("the '357 patent"), invalid as functional.

Rosco and Mirror Lite are competitors in the school bus mirror market. This dispute involves "cross-view" mirrors, which are convex, three-dimensional, curved surface mirrors mounted on the front fender of a school bus, enabling the bus driver to view the front and 


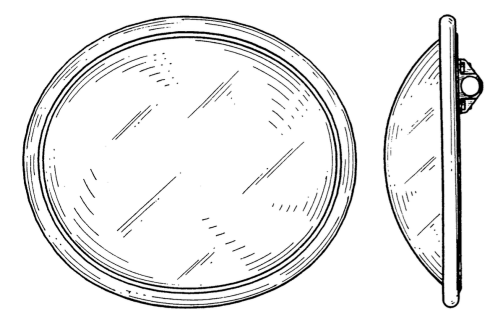

Rosco's '357 design passenger side of a school bus. Rosco's '357 design patent shows a highly convex, curved-surface, three-dimensional oval mirror with a black, flat metal backing. In May 1992, Rosco began manufacturing the mirror of the '357 patent under the name "Eagle Eye." Rosco alleged that Mirror Lite infringed the ' 357 patent by manufacturing and selling a duplicate of Rosco's mirror under the name "Hawk Eye."

We apply a stringent standard for invalidating a design patent on grounds of functionality: the design of a useful article is deemed functional where the appearance of the claimed design is dictated by the use or purpose of the article. [For a design patent to be valid,] the design must not be governed solely by function, i.e., that this is not the only possible form of the article that could perform its function. When there are several ways to achieve the function of an article of manufacture, the design of the article is more likely to serve a primarily ornamental purpose. That is, if other designs could produce the same or similar functional capabilities, the design of the article in question is likely ornamental, not functional.

The district court found that because the mirror's oval shape, the asserted point of novelty of the ' 357 patent, "of necessity dictates its function," the '357 patent was invalid as functional. The court based its determination of functionality on its findings that the mirror of the '357 patent offered a unique field of view (when compared to Mirror Lite's Bus Boy mirror); that Rosco represented to the Patent and Trademark Office that its mirror provided a superb field of view; and that Rosco marketed the mirror of the ' 357 patent as more "aerodynamic" than other cross-view mirrors.

The mere fact that the invention claimed in the design patent exhibited a superior field of view over a single predecessor mirror (here, the Bus Boy) does not establish that the design was "dictated by" functional considerations, as required by L.A. Gear. The record indeed reflects that other mirrors that have non-oval shapes also offer that particular field of view. Similarly, nothing in the record connects the oval shape of the patented design with aerodynamics, and the record shows that other non-oval shaped mirrors have the same aerodynamic effect.

Mirror Lite has not shown by clear and convincing evidence that there are no designs, other than the one shown in Rosco's '357 patent, that have the same functional capabilities as Rosco's oval mirror. Under these circumstances it cannot be said that the claimed design of the '357 patent was dictated by functional considerations.

\section{In re Koehring}

This appeal from the decision of the Commissioner of Patents, refusing a patent for a design for a concrete mixer truck body and frame, presents as its main issue the very interesting, and oftimes trouble- 
some, question as to what articles of manufacture may constitute the subject-matter of design patents. Before us the Commissioner urges that it must be held, under In re Stimpson that this character of machine is not "inventively ornamental." The riveting machine in controversy in Stimpson was held not to be ornamental, because the drawing showed that it was

purely utilitarian, and without ornamentation of any kind. There is nothing about the assembled mechanical device which serves to beautify, embellish, or adorn it. The several parts of the mechanism, whether circular, curved, rounded, or spiral, are assembled into an entirety which is lacking in symmetry, wanting in grace, and destitute of any appeal to the senses or emotions. The design has no human interest, other than that aroused by the utilitarian nature of the machine.

In our view of the case, the beauty and ornamentation requisite in design patents is not confined to such as may be found in the "aesthetic or fine arts." It is not reasonable to presume that Congress, in basing a patent right upon the ornamentation or beauty of a tool or mechanical device, intended that such beauty and ornamentation should be limited to such as is found in paintings, sculpture, and artistic objects, and which excites the aesthetic sense of artists alone.

By the enactment of the design patent law, Congress expressed a desire to promote more beauty, grace, and ornamentation in things used, observed, and enjoyed by our people. Appellant's design of a truck body and frame for a concrete mixer shows the frame to be so designed as to place the different elements of the whole machine, including the hood, gas tank, mixer, etc., into a more symmetrical and compact whole than was known in the prior art. Aside from this arrangement, which removes much of the unsightliness from the machine, the covering of the motor is made to resemble, in appearance, an automobile hood, and the angular bars and framework of the same are given a rounded or oval appearance. By the plan of assembly of the more or less rounded hood, round gas tank, and rounded frame corners into a compact and more symmetrical whole, an article, possessing more grace and pleasing appearance than existed in the prior art, has been produced. This effect in the design as a whole is ornamental and inventive.

Since it is clear that Congress meant the design patent law to apply to tools and mechanisms of utilitarian character, it follows, we think, that it had in mind the elimination of much of the unsightly repulsiveness that characterizes many machines and mechanical devices which have a tendency to depress rather than excite the esthetic sense. In this mechanical age, when machines, engines, and various
Stimpson: 24 F.2d 1012 (D.C. Ct. App.)

"Design applications which disclose subject matter which could be deemed offensive to any race, religion, sex, ethnic group, or nationality, such as those which include caricatures or depictions, should be rejected as nonstatutory subject matter." MPEP § 1504.01(e).

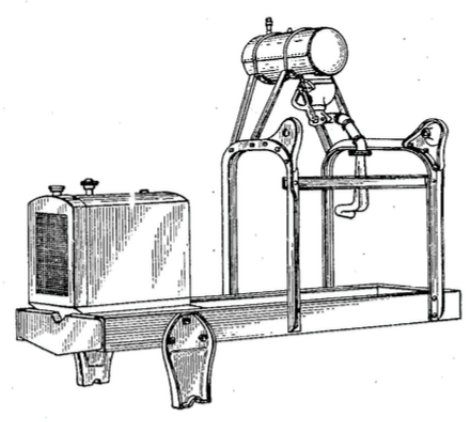

Koehring's design 
kinds of mechanisms are transported on our public highways and streets and moved by their own momentum from place to place, it is certainly not undesirable that some of the unsightliness - and, as frequently occurs, frightfulness - of such contrivances be eliminated, if possible.

\section{Procedures}

Most of the mechanics of obtaining a design patent are the same as for a utility patent. The principal difference is that designs are claimed by illustration rather than in words. This creates some distinctive drafting issues. Design patents also have a shorter term. (In addition, design patent prosecution is procedurally simpler in several ways not here relevant.)

\section{Manual of Patent Examining Procedure}

MPEP $§ 1503$

Elements of a Design Patent Application Filed Under 35 U.S.C. ch. 16
A preamble, if included, should state the name of the applicant, the title of the design, and a brief description of the nature and intended use of the article in which the design is embodied.

No description of the design in the specification beyond a brief description of the drawing is generally necessary, since as a rule the illustration in the drawing views is its own best description. However, while not required, such a description is not prohibited and may be incorporated, at applicant's option, into the specification or may be provided in a separate paper. Descriptions of the figures are not required to be written in any particular format, however, if they do not describe the views of the drawing clearly and accurately, the examiner should object to the unclear and/or inaccurate descriptions and suggest language which is more clearly descriptive of the views.

The following types of statements are not permissible in the specification:

(1) A disclaimer statement directed to any portion of the claimed design that is shown in solid lines in the drawings.

(2) Statements which describe or suggest other embodiments of the claimed design which are not illustrated in the drawing disclosure, except one that is a mirror image of that shown or has a shape and appearance that would be evident from the one shown.

(3) Statements describing matters that are directed to function or are unrelated to the design.

A design patent application may only include a single claim. The single claim should normally be in formal terms to "The ornamental design for (the article which embodies the design or to which it is 
applied) as shown." The description of the article in the claim should be consistent in terminology with the title of the invention.

When the specification includes a proper descriptive statement of the design, or a proper showing of modified forms of the design or other descriptive matter has been included in the specification, the words "and described" must be added to the claim following the term "shown"; i.e., the claim must read "The ornamental design for (the article which embodies the design or to which it is applied) as shown and described."

Full lines in the drawing show the claimed design. Broken lines are used for numerous purposes. Under some circumstances, broken lines are used to illustrate the claimed design (i.e., stitching and fold lines). Broken lines are not permitted for the purpose of identifying portions of the claimed design which are immaterial or unimportant. There are "no portions of a design which are "immaterial" or "not important." A design is a unitary thing and all of its portions are material in that they contribute to the appearance which constitutes the design.

Every design patent application must include either a drawing or a photograph of the claimed design. As the drawing or photograph constitutes the entire visual disclosure of the claim, it is of utmost importance that the drawing or photograph be clear and complete, and that nothing regarding the design sought to be patented is left to conjecture.

When inconsistencies are found among the views, the examiner should object to the drawings and request that the views be made consistent. When the inconsistencies are of such magnitude that the overall appearance of the design is unclear, the claim should be rejected under 35 U.S.C. 112(a) and (b) as nonenabling and indefinite.

The drawings or photographs should contain a sufficient number of views to disclose the complete appearance of the design claimed, which may include the front, rear, top, bottom and sides. Perspective views are suggested and may be submitted to clearly show the appearance of three dimensional designs.

Views that are merely duplicative of other views of the design or that are flat and include no surface ornamentation may be omitted from the drawing if the specification makes this explicitly clear. For example, if the left and right sides of a design are identical or a mirror image, a view should be provided of one side and a statement made in the drawing description that the other side is identical or a mirror image. If the design has a flat bottom, a view of the bottom may be omitted if the specification includes a statement that the bottom is flat and devoid of surface ornamentation.

Sectional views presented solely for the purpose of showing the internal construction or functional/ mechanical features are unneces-
Are enablement and definiteness the same for design patents? 
sary and may lead to confusion as to the scope of the claimed design. The examiner should object to such views and require their cancellation.. However, where the exact contour or configuration of the exterior surface of a claimed design is not apparent from the views of the drawing, and no attempt is made to illustrate features of internal construction, a sectional view may be included to clarify the shape of said design.

While surface shading is not required, it may be necessary in particular cases to shade the figures to show clearly the character and contour of all surfaces of any 3-dimensional aspects of the design. Surface shading is also necessary to distinguish between any open and solid areas of the article. Lack of appropriate surface shading in the drawing as filed may render the design nonenabling and indefinite under 35 U.S.C. 112(a) and (b). Solid black surface shading is not permitted except when used to represent the color black as well as color contrast. Oblique line shading must be used to show transparent, translucent and highly polished or reflective surfaces, such as a mirror. Contrast in materials may be shown by using line shading in one area and stippling in another. By using this technique, the claim will broadly cover contrasting surfaces unlimited by colors.

The two most common uses of broken lines are to disclose the environment related to the claimed design and to define the bounds of the claim. Structure that is not part of the claimed design, but is considered necessary to show the environment in which the design is associated, may be represented in the drawing by broken lines. This includes any portion of an article in which the design is embodied or applied to that is not considered part of the claimed design. Unclaimed subject matter may be shown in broken lines for the purpose of illustrating the environment in which the article embodying the design is used. Unclaimed subject matter must be described as forming no part of the claimed design or of a specified embodiment thereof. A boundary line may be shown in broken lines if it is not intended to form part of the claimed design.

35 U.S.C. § 173

Term of design patent

\section{Patent Act}

Patents for designs shall be granted for the term of 15 years from the date of grant.

\section{Ownership}

Skip this section. Not forever, just for a bit. Read the following section on the similarity analysis in design patent infringement. Then come back. Don't worry. This section will still be here, and it will make much more sense.

Inventorship for design patents is much the same as for utility 
patents and initial ownership. Design patents pose more difficult questions when it comes to the tests for anticipation under $\S 102$ and for nonobviousness under $\S 103$. The difficulty flows from the fact that design patents use depictions rather than verbal claims, so that the claim-based tests used for utility patents simply map cleanly onto design patents.

\section{a Novelty}

For the most part, the are the rules for priority and for what counts as prior art are thes same for design patents and utility patents. The test for experimental use is a little diffrent because what counts as necessary experimentation is different for ornamentation than for function. In In re Mann, for example, the applicant exhibited a wrought-iron table embodying the design at a trade show, but argued that it was an "experimental use." The court disagreed, writing, "Obtaining the reactions of people to a design - whether or not they like it - is not 'experimentation' in that sense. In the case of a design, if market testing shows that it has no appeal and the design is changed, the result is a new and different design; the original design remains just what it was." It is the test for anticipation that requires modification.

\section{International Seaway Trading Corp. v. Walgreens Corp.}

Plaintiff International Seaway filed suit against Walgreens Corporation and Touchsport Footwear claiming infringement of Seaway's patents, U.S. Design Patents Nos. D529,263, D545,032, and D545,033. The district court granted summary judgment for defendants, finding that the claims of the asserted patents were invalid under 35 U.S.C. § 102 as anticipated by a patent assigned to Crocs, Inc., U.S. Design Patent No. D517,789.

Seaway's patents claim designs for casual, lightweight footwear, which are typically referred to as "clogs." Seaway asserted that Touchsport had imported and continued to import shoes that infringed the Seaway patents and that Walgreens had sold and continued to sell the allegedly infringing shoes. The district court granted summary judgment of anticipation, finding that the three Seaway patents were anticipated by the Crocs '789 patent.

It has been well established for over a century that the same test must be used for both infringement and anticipation. his general rule derives from the Supreme Court's proclamation 120 years ago in the context of utility patents: "that which infringes, if later, would anticipate, if earlier." Peters The same rule applies for design patents. In Egyptian Goddess, we abandoned the point of novelty test for design patent infringement and held that the ordinary observer test should serve as the sole test for design patent infringement. we now con-
Mann: 861 F.2d 1581 (Fed. Cir. 1988) (Rich, J.)

589 F.3d 1233 (Fed. Cir. 2009) 
The test for anticipation of a utility patent is the mirror image of the literal infringement test. But the design patent infringement test bears more than a passing resemblance to the doctrine of equivalents in utility patents. What does this do to the symmetry argument? Should anticipation in design patents be confined to identical designs? Or is it all irrelevant, since obviousness under $\S 103$ will take care of such cases?

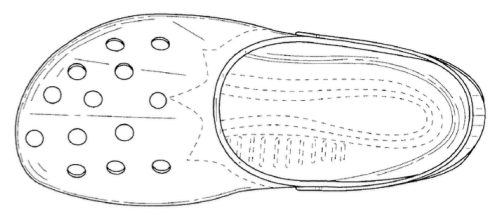

'789 insole

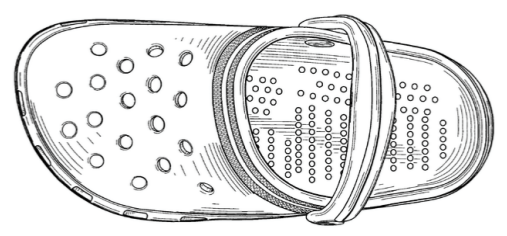

'263 insole

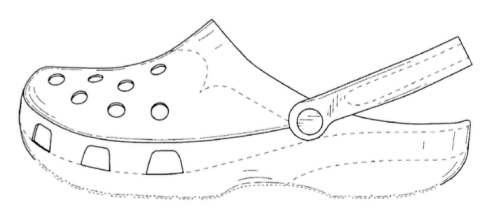

'789 side view

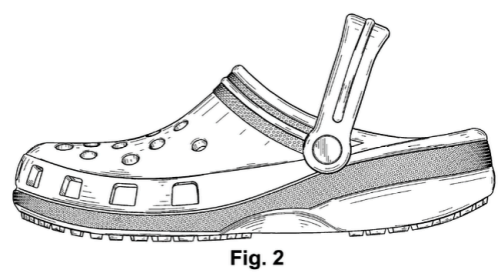

'263 side view clude that the ordinary observer test must logically be the sole test for anticipation as well.

Walgreens and Touchsport argue that the asserted differences between the insoles of the patents-in-suit and the prior art "were at most slight variations of design elements already present in the Crocs prior art." We disagree. The insole pattern for the patents-in-suit is distinctly different than the Crocs insole pattern.

The Crocs'789 patent contains a long, U-shaped dimpling pattern on the insole. In contrast, the patents-in-suit have a dimpling pattern that includes multiple short rows of dimples. Because we cannot say that these differences are insignificant as a matter of law, a genuine issue of material fact exists as to whether the designs would be viewed as substantially similar in the eyes of the ordinary observer armed with the knowledge of the prior art.

Beyond the insole features of its patented designs, Seaway argues that a genuine issue of material fact exists as to whether the exterior features of its designs preclude a finding of anticipation. It claims that four exterior features differ from the prior art to the degree necessary to preclude summary judgment: (1) the number and arrangement of the circular openings on the upper of the clog; (2) the number and position of the rectangular cut-outs in the lower portion of the upper of the clog; (3) the shape of the toe portion of the clog; and (4) the raised pattern of the outsole of the clog. These features are identical in all three of Seaway's patents-in-suit. With regard to these alleged dissimilarities, the district court stated:

Slight variations on the number and position of the circular holes on the top of the shoe, the rectangular holes on the toe of the shoe as well as the design of different shaped rectangles on the sole of the shoe would not convince a reasonable jury, or an ordinary observer with knowledge of the prior art, that the limitations were not inherently disclosed in the '789 patent. This conclusion does not change merely because plaintiff slightly changed the arrangement of the textured portions on the top and around the bottom portion of the sides of the shoe.

We agree with the district court that these minor variations in the shoe are insufficient to preclude a finding of anticipation because they do not change the overall visual impression of the shoe. Although the ordinary observer test requires consideration of the design as a whole, this does not prevent the district court on summary judgment from determining that individual features of the design are insignificant from the point of view of the ordinary observer and should not be considered as part of the overall comparison. The mandated overall comparison is a comparison taking into account significant differ- 
ences between the two designs, not minor or trivial differences that necessarily exist between any two designs that are not exact copies of one another. Just as minor differences between a patented design and an accused article's design cannot, and shall not, prevent a finding of infringement," so too minor differences cannot prevent a finding of anticipation.

\section{b Obviousness}

The Graham framework is nominally the same for design patents and for utility patents. But the application is very different. Query whether the tests used by the Federal Circuit survive KSR.

\section{MRC Innovations, Inc. v. Hunter Mfg., LLP,}

MRC Innovations, Inc. appeals from a final judgment of the U.S. District Court for the Northern District of Ohio granting summary judgment of invalidity with respect to U.S. Design Patent No. D634,488. The ' 488 patent claims an ornamental design for a football jersey for a dog.

The district court concluded that the ' 488 patent would have been obvious in view of several prior art pet jerseys. MRC now appeals that determination. Obviousness is a question of law based on underlying factual questions. The underlying factual inquiries include: (1) the scope and content of the prior art; (2) the level of ordinary skill in the art; (3) the differences between the claimed invention and the prior art; and (4) objective evidence of non-obviousness. Graham.

In the context of design patents, the ultimate inquiry under section 103 is whether the claimed design would have been obvious to a designer of ordinary skill who designs articles of the type involved. To answer this question, a court must first determine whether one of ordinary skill would have combined teachings of the prior art to create the same overall visual appearance as the claimed design. That inquiry involves a two-step process. First, the court must identify a single reference, something in existence, the design characteristics of which are basically the same as the claimed design. The "basically the same" test requires consideration of the visual impression created by the patented design as a whole. The trial court judge may determine almost instinctively whether the two designs create basically the same visual impression, but "must communicate the reasoning behind that decision.

Once the primary reference is found, other "secondary" references may be used to modify it to create a design that has the same overall visual appearance as the claimed design. These secondary references must be so related to the primary reference that the appearance of certain ornamental features in one would suggest the ap-
747 F.3d 1326 (Fed. Cir. 2014)
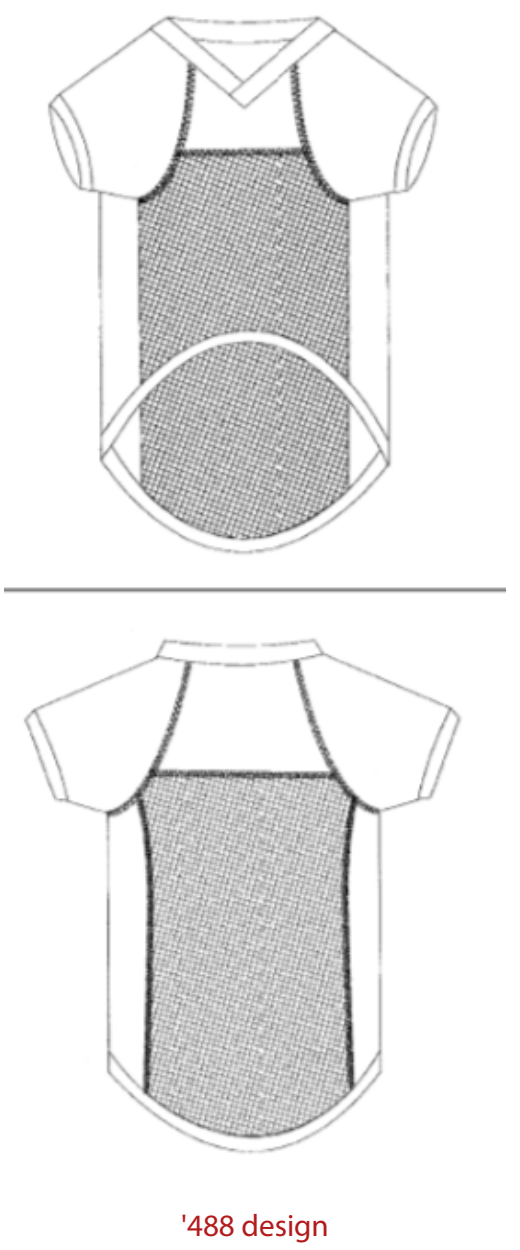

"The 'ordinary designer' means one who brings certain background and training to the problems of developing designs in a particular field, comparable to the 'mechanic' or 'routineer' in non-design arts. We do not have a name for that person in the design field other than 'designer' which is also the name we must use for the person who creates a patentable design." $\mathrm{Nal}$ bandian 
"For design patents, the role of one skilled in the art in the obviousness context lies only in determining whether to combine earlier references to arrive at a single piece of art for comparison with the potential design or to modify a single prior art reference. Once that piece of prior art has been constructed, obviousness, like anticipation, requires application of the ordinary observer test, not the view of one skilled in the art." nternationalseaway
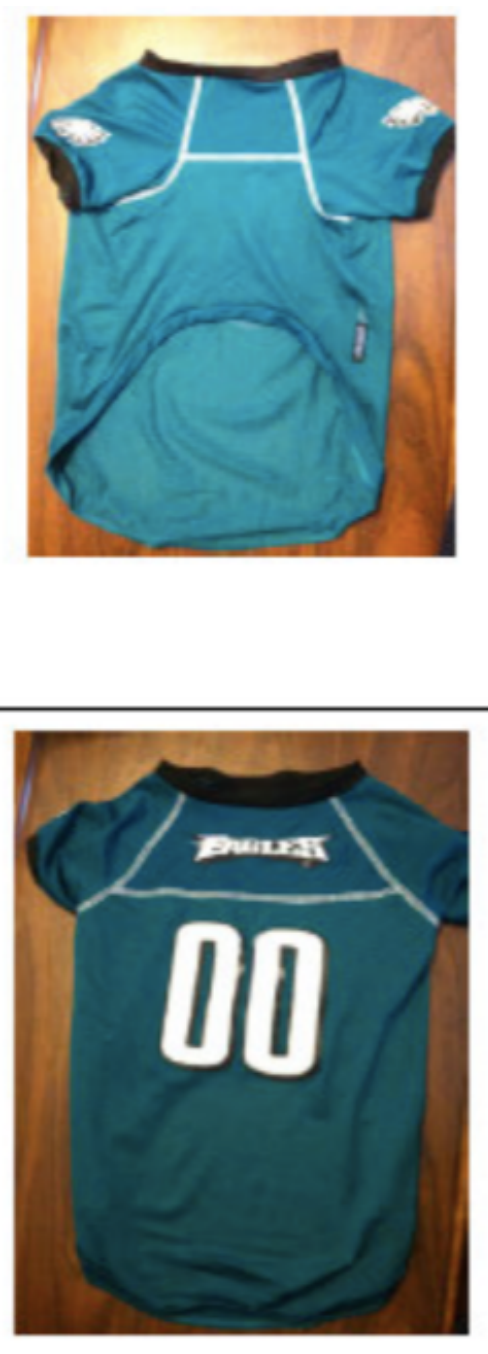

"Eagles" design plication of those features to the other.

\section{A. Primary Reference}

The district court used the "Eagles" pet jersey as the "primary reference" under step one of the analysis. MRC argues that this was legally erroneous because there are significant differences between the Eagles jersey and the patented design of the ' 488 patent. Specifically, there are three differences: (1) the patented design has a V-neck collar where the Eagles jersey has a round neck; (2) the patented design contains an interlock fabric panel on the side portion of the design rather than mesh; and (3) the patented design contains additional ornamental surge stitching on the rear portion of the jersey. MRC argues that the district court overlooked these differences by focusing on the claimed design at too high a level of abstraction. If the district court had translated the claimed design into a verbal description as required by High Point, MRC insists, it would have concluded that neither the Eagles jersey nor any other prior art reference contained design characteristics that were basically the same as the claimed design.

As an initial matter, it is true that the district court did not expressly undertake to translate the claimed design into a verbal description. However, the purpose of requiring district courts to describe the claimed design in words is so that the parties and appellate courts can discern the trial court's reasoning in identifying a primary reference. It is entirely clear from the district court's opinion what it considered to be the relevant design characteristics of the ' 488 patented design.

First, the district court pointed out three key similarities between the claimed design and the Eagles jersey: an opening at the collar portion for the head, two openings and sleeves stitched to the body of the jersey for limbs, and a body portion on which a football logo is applied. If the district court's analysis had ended there, it might indeed have failed to meet the verbal description requirement. However, the district court went on to point out two additional similarities between the two designs: first, the Eagles jersey is made "primarily of a mesh and interlock fabric"; and second, it contains at least some ornamental surge stitching - both features found in the ' 488 claimed design. The district court also went on to acknowledge the three major differences between the two designs that are enumerated above. Taking all of those things together (the at least five design characteristics that the claimed design shares with the Eagles jersey and three design characteristics that differ from it), the district court painted a clear picture of the claimed design. The district court did far more than merely ask whether the Eagles jersey disclosed the general concept of a pet jersey; it thoroughly considered the "dstinctive visual ap- 
pearances of the reference and the claimed design. Thus, the district court did not err by failing to provide an express verbal description of the claimed design; rather, it described the claimed design in the context of comparing it to the prior art.

Nor did the district court err in finding that the design characteristics of the ' 488 design created basically the same overall visual impression as the Eagles jersey prior art reference. As the district court noted, both designs contain the same overall shape, similar fabric, and ornamental surge stitching. That there are slight differences in the precise placement of the interlock fabric and the ornamental stitching does not defeat a claim of obviousness; if the designs were identical, no obviousness analysis would be required. 1 Indeed, we have permitted prior art designs to serve as "primary references" when their differences are as great or greater than the differences in this case. See Jore Corp. v. Kouvato, Inc. (finding prior art drill bit to be a primary reference despite containing a smooth cylindrical shaft rather than the grooved hexagonal shaft of the claimed design); In re Nalbandian (finding tweezer design obvious in light of prior art reference that contained vertical rather than horizontal fluting and straight rather than curved pincers).

\section{B. Secondary References}

After concluding that the Eagles jersey could be a "primary reference," the district court determined that the V2 jersey and another reference known as the "Sporty K9" jersey were "so related to the

\footnotetext{
${ }^{1}$ This conclusion is not inconsistent with the law of this circuit on design patent infringement. In that context, we have often noted that design patents have "almost no scope" beyond the precise images shown in the drawings. Mann. However, in practice, our focus on the "overall visual appearance" of a claimed design rather than on individual features has led us to find products infringing despite differences in specific ornamental features. For example, in Crocs, Inc. v. International Trade Commission, 598 F.3d 1294 (Fed. Cir. 2010), we concluded that all of the accused products infringed the asserted design patents despite the fact that two of the infringing products (the Groovy DAWGSTM shoes and Big DAWGSTM shoes) contained a wider shoe front with an additional row of holes, and another infringing product (the Effervescent Waldies AT shoe) contained square holes on the top of the shoe rather than round ones.

${ }^{3}$ Alternatively, the district court could have relied on the V2 jersey as the primary reference. The only differences between the V2 jersey and the claimed design are: (1) that the V2 jersey does not contain an "interlock" fabric panel; (2) it has "drop" sleeves while the claimed jersey has "raglan-style" sleeves; and (3) the V2 jersey lacks any ornamental surge stitching. A side-by-side comparison of the two designs demonstrates that of those three differences, only the ornamental surge stitching truly alters the "overall visual appearance" of the design. Moreover, the ornamental stitching on the claimed design is suggested by the seam lines on the V2 jersey, further minimizing the difference in overall appearance. Thus, either the "Eagles" jersey or the V2 jersey could have served as a "primary reference" for purposes of the obviousness analysis.
}
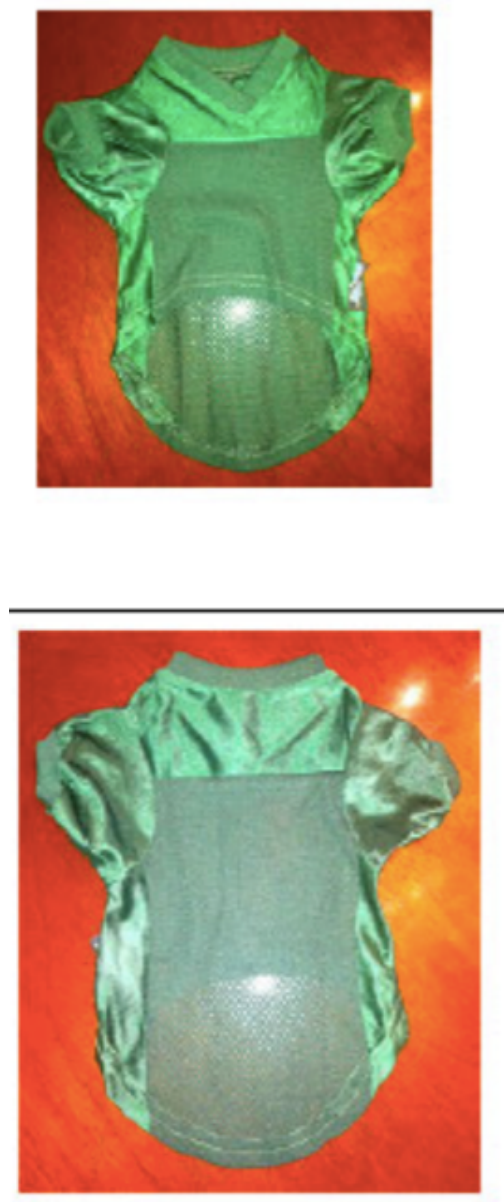

"V2" design

Jore: 117 Fed. Appx. 761 (Fed. Cir. 2005)

Nalbandian: 661 F.2d 1214 (CCPA 1981) 


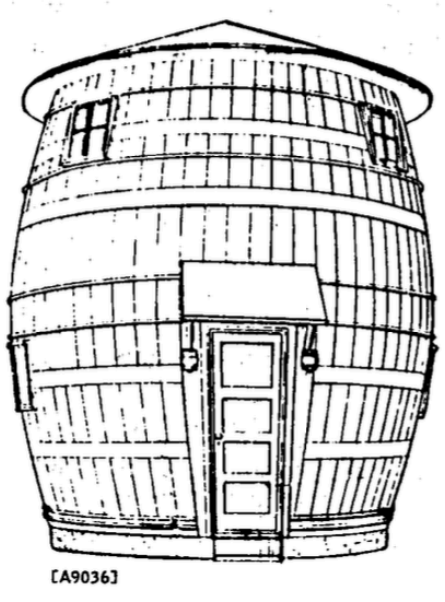

Prior art barrel-shaped building

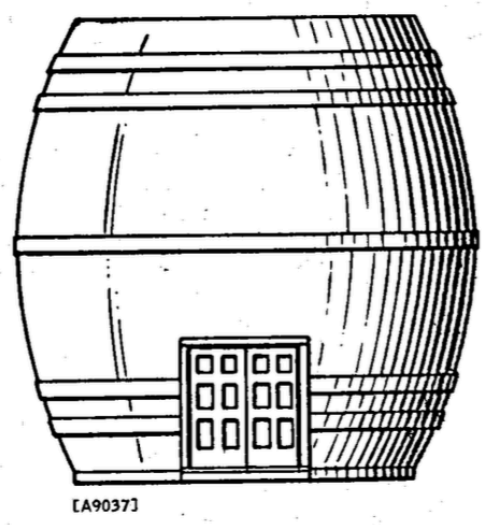

Barrel-shaped building design held obvious in light of prior art primary reference" that they could serve as "secondary references" that would motivate the skilled artisan to make the claimed design.

The district court found that both jerseys suggested the use of a $\mathrm{V}$-neck pattern and non-mesh fabric on the side panels - the first two differences described above. MRC argues that the district court erred by failing to explain why a skilled artisan would have chosen to incorporate those features of the V2 and Sporty K9 jerseys with the Eagles jersey.

We disagree. It is true that in order for secondary references to be considered, there must be some suggestion in the prior art to modify the basic design with features from the secondary references. However, the teachings of prior art designs may be combined only when the designs are so related that the appearance of certain ornamental features in one would suggest the application of those features to the other. In other words, it is the mere similarity in appearance that itself provides the suggestion that one should apply certain features to another design.

In re Borden discussed what is required for a reference to be considered sufficiently "related" for that test to apply. There, we noted that the secondary references were "closely akin" to the claimed design, and relied heavily on the fact that "the two missing design elements [were] not taken from unrelated references, but [were] found in other dual-chamber containers." Thus, those references could be used "to bridge the small gap between the [primary] container and Borden's claimed design." So too, here, the secondary references that the district court relied on were not furniture, or drapes, or dresses, or even human football jerseys; they were football jerseys designed to be worn by dogs. Moreover, as discussed above, the V2 could easily have served as a primary reference itself, so similar is its overall visual appearance to that of the claimed design and the Eagles jersey. We therefore agree that those references were "so related" to the Eagles jersey that the striking similarity in appearance across all three jerseys would have motivated a skilled designer to combine features from one with features of another.

With respect to the only remaining difference between the Eagles jersey and the ' 488 claimed design - the presence of additional ornamental surge stitching running down the rear of the jersey - the district court acknowledged that no prior art reference contained exactly that same stitching on the rear of the jersey, but nevertheless concluded that this was not a "substantial" difference that created a patentably distinct design, but rather was a "de minimis change[] which would be well within the skill of an ordinary designer in the art."

MRC argues that adding any ornamental feature to a primary reference that is not suggested by the prior art is, by definition, more 
than de minimis. But our case law plainly contradicts that position; on numerous occasions we have invalidated design patents despite the inclusion of ornamental features that were entirely absent from prior art designs. See, e.g., Nalbandian different shape of fluting on finger grips and different shape of pincers were de minimis differences in design for tweezers); In re Cooper (affirming Board's conclusion that numerous changes to the design of a prior art building - including a single rather than double door and the addition of windows - were de minimis because the overall impression was still a building that looked like a barrel).

Here, the Eagles jersey had already disclosed the use of ornamental surge stitching. The only additional step needed was to extend the stitching down the sides of the rear of the jersey. Moreover, the V2 jersey plainly suggested the addition of vertical lines down the rear of the jersey through the use of the seams between the two types of fabric. We agree with the district court that adding ornamental surge stitching on top of a preexisting seam was an insubstantial change that would have been obvious to a skilled designer.

\section{Infringement: Similarity}

The "ordinary observer" analysis used to assess the similarity of designs actually predates its use in copyright law, which borrowed the term and some of the concepts from design patent law. Egyptian Goddess sets out the modern test. Wing Shing shows the test in action and deals with the problem of filtering out unoriginal elements of a design; $O d d z O n$ deals with the related problem of filtering out unprotectable functional elements. L.A. Gear clears up a couple of conceptual points about how the analysis actually works.

\section{Egyptian Goddess, Inc. v. Swisa, Inc.}

\section{I}

The starting point for any discussion of the law of design patents is the Supreme Court's decision in Gorham Co. v. White. That case involved a design patent for the handles of tablespoons and forks. In its analysis of claim infringement, the Court stated that the test of identity of design "must be sameness of appearance, and mere difference of lines in the drawing or sketch ... or slight variances in configuration... will not destroy the substantial identity." Identity of appear-

\footnotetext{
${ }^{6}$ To be clear, we do not intend to suggest that merely because one prior art reference used ornamental surge stitching, any use of such stitching would have been a de minimis change. Rather, the addition of the surge stitching in this case was de minimis because it merely followed the visual lines created by the seams of the V2 jersey; in other words, it served only to highlight a design feature that had already existed in the V2 prior art jersey.
}

Cooper: 480 F.2d 900 (CCPA 1973)

"Judges and lawyers in general are highly uncomfortable with images, yet design patents force direct legal engagement with images." Rebecca Tushnet, The Eye Alone Is the Judge: Images and Design Patents, 19 J. Intell. Prop. L. 409 (2012)

543 F.3d 665 (Fed. Cir. 2008)

Gorham: 81 U.S. 511 (1871) 
Litton Systems: 728 F.2d 1423 (Fed. Cir. 1984) ance, the Court explained, or "sameness of effect upon the eye, is the main test of substantial identity of design"; the two need not be the same "to the eye of an expert," because if that were the test, "there never could be piracy of a patented design, for human ingenuity has never yet produced a design, in all its details, exactly like another, so like, that an expert could not distinguish them."

The Gorham Court then set forth the test that has been cited in many subsequent cases: "If, in the eye of an ordinary observer, giving such attention as a purchaser usually gives, two designs are substantially the same, if the resemblance is such as to deceive such an observer, inducing him to purchase one supposing it to be the other, the first one patented is infringed by the other." In the case before it, the Court concluded that "whatever differences there may be between the plaintiffs' design and those of the defendant in details of ornament, they are still the same in general appearance and effect, so much alike that in the market and with purchasers they would pass for the same thing - so much alike that even persons in the trade would be in danger of being deceived."

Since the decision in Gorham, the test articulated by the Court in that case has been referred to as the "ordinary observer" test and has been recognized by lower courts, including both of this court's predecessors, as the proper standard for determining design patent infringement. However, in a series of cases tracing their origins to Litton Systems, Inc. v. Whirlpool Corp., this court has held that proof of similarity under the ordinary observer test is not enough to establish design patent infringement. Rather, the court has stated that the accused design must also appropriate the novelty of the claimed design in order to be deemed infringing. The court in Litton Systems wrote as follows:

For a design patent to be infringed, no matter how similar two items look, the accused device must appropriate the novelty in the patented device which distinguishes it from the prior art. That is, even though the court compares two items through the eyes of the ordinary observer, it must nevertheless, to find infringement, attribute their similarity to the novelty which distinguishes the patented device from the prior art.

After identifying the combination of features in the design that it considered novel, the court in Litton Systems held that the accused design had none of those features and therefore did not infringe.

In a number of cases decided after Litton Systems, this court has interpreted the language quoted above to require that the test for design patent infringement consider both the perspective of the ordinary observer and the particular novelty in the claimed design. 
The extent to which the point of novelty test has been a separate test has not always been clear in this court's case law. In cases decided shortly after Litton, the court described the ordinary observer test and the point of novelty test as "conjunctive." It has not been until much more recently that this court has described the ordinary observer and point of novelty tests as "two distinct tests" and has stated that the merger of the point of novelty test and the ordinary observer test is legal error.

Regardless of the differences in the way it has been characterized, the point of novelty test has proved reasonably easy to apply in simple cases in which the claimed design is based on a single prior art reference and departs from that reference in a single respect. In such cases, it is a simple matter to identify the point of novelty and to determine whether the accused design has appropriated the point of novelty, as opposed to copying those aspects of the claimed design that were already in the prior art. However, the point of novelty test has proved more difficult to apply where the claimed design has numerous features that can be considered points of novelty, or where multiple prior art references are in issue and the claimed design consists of a combination of features, each of which could be found in one or more of the prior art designs. In particular, applying the point of novelty test where multiple features and multiple prior art references are in play has led to disagreement over whether combinations of features, or the overall appearance of a design, can constitute the point of novelty of the claimed design. In light of the questions surrounding the status and application of the point of novelty test, we use this case as a vehicle for reconsidering the place of the point of novelty test in design patent law generally.

\section{II}

[The court reviewed previous caselaw in detail.]

As noted, this court has cited Litton Systems for the proposition that the point of novelty test is separate from the ordinary observer test and requires the patentee to point out the point of novelty in the claimed design that has been appropriated by the accused design. We think, however, that Litton Systems and the predecessor cases on which it relied are more properly read as applying a version of the ordinary observer test in which the ordinary observer is deemed to view the differences between the patented design and the accused product in the context of the prior art. When the differences between the claimed and accused design are viewed in light of the prior art, the attention of the hypothetical ordinary observer will be drawn to those aspects of the claimed design that differ from the prior art. And when the claimed design is close to the prior art designs, small differences between the accused design and the claimed design are likely to be 
important to the eye of the hypothetical ordinary observer. It was for that reason that the Supreme Court in Smith v. Whitman Saddle Co. focused on the one feature of the patented saddle design that departed from the prior art - the sharp drop at the rear of the pommel. To an observer familiar with the multitude of prior art saddle designs, including the design incorporating the Granger pommel and the Jenifer cantle, "an addition frequently made," the sharp drop at the rear of the pommel would be important to the overall appearance of the design and would serve to distinguish the accused design, which did not possess that feature, from the claimed design.

Applying the ordinary observer test with reference to prior art designs also avoids some of the problems created by the separate point of novelty test. One such problem is that the point of novelty test has proved difficult to apply in cases in which there are several different features that can be argued to be points of novelty in the claimed design. In such cases, the outcome of the case can turn on which of the several candidate points of novelty the court or fact-finder focuses on. The attention of the court may therefore be focused on whether the accused design has appropriated a single specified feature of the claimed design, rather than on the proper inquiry, i.e., whether the accused design has appropriated the claimed design as a whole.

In addition, the more novel the design, and the more points of novelty that are identified, the more opportunities there are for a defendant to argue that its design does not infringe because it does not copy all of the points of novelty, even though it may copy most of them and even though it may give the overall appearance of being identical to the claimed design. In such cases, a test that asks how an ordinary observer with knowledge of the prior art designs would view the differences between the claimed and accused designs is likely to produce results more in line with the purposes of design patent protection.

This court has characterized the purpose of the point of novelty test as being "to focus on those aspects of a design which render the design different from prior art designs." That purpose can be equally well served, however, by applying the ordinary observer test through the eyes of an observer familiar with the prior art. If the accused design has copied a particular feature of the claimed design that departs conspicuously from the prior art, the accused design is naturally more likely to be regarded as deceptively similar to the claimed design, and thus infringing. At the same time, unlike the point of novelty test, the ordinary observer test does not present the risk of assigning exaggerated importance to small differences between the claimed and accused designs relating to an insignificant feature simply because that feature can be characterized as a point of novelty.

This approach also has the advantage of avoiding the debate over the extent to which a combination of old design features can serve 
as a point of novelty under the point of novelty test. An ordinary observer, comparing the claimed and accused designs in light of the prior art, will attach importance to differences between the claimed design and the prior art depending on the overall effect of those differences on the design. If the claimed design consists of a combination of old features that creates an appearance deceptively similar to the accused design, even to an observer familiar with similar prior art designs, a finding of infringement would be justified. Otherwise, infringement would not be found.

On the basis of the foregoing analysis, we hold that the "point of novelty" test should no longer be used in the analysis of a claim of design patent infringement. In accordance with Gorham and subsequent decisions, we hold that the "ordinary observer" test should be the sole test for determining whether a design patent has been infringed.

In some instances, the claimed design and the accused design will be sufficiently distinct that it will be clear without more that the patentee has not met its burden of proving the two designs would appear "substantially the same" to the ordinary observer, as required by Gorham. In other instances, when the claimed and accused designs are not plainly dissimilar, resolution of the question whether the ordinary observer would consider the two designs to be substantially the same will benefit from a comparison of the claimed and accused designs with the prior art, as in many of the cases discussed above and in the case at bar. Where there are many examples of similar prior art designs, as in a case such as Whitman Saddle, differences between the claimed and accused designs that might not be noticeable in the abstract can become significant to the hypothetical ordinary observer who is conversant with the prior art.

We emphasize that although the approach we adopt will frequently involve comparisons between the claimed design and the prior art, it is not a test for determining validity, but is designed solely as a test of infringement.

\section{III}

One of the issues raised by this court in its order granting en banc review was whether trial courts should conduct claim construction in design patent cases. While this court has held that trial courts have a duty to conduct claim construction in design patent cases, as in utility patent cases, the court has not prescribed any particular form that the claim construction must take. To the contrary, the court has recognized that design patents typically are claimed as shown in drawings, and that claim construction is adapted accordingly. For that reason, this court has not required that the trial court attempt to provide a detailed verbal description of the claimed design, as is typically done in 
the case of utility patents. Given the recognized difficulties entailed in trying to describe a design in words, the preferable course ordinarily will be for a district court not to attempt to "construe" a design patent claim by providing a detailed verbal description of the claimed design.

While it may be unwise to attempt a full description of the claimed design, a court may find it helpful to point out, either for a jury or in the case of a bench trial by way of describing the court's own analysis, various features of the claimed design as they relate to the accused design and the prior art. Apart from attempting to provide a verbal description of the design, a trial court can usefully guide the finder of fact by addressing a number of other issues that bear on the scope of the claim. Those include such matters as describing the role of particular conventions in design patent drafting, such as the role of broken lines; assessing and describing the effect of any representations that may have been made in the course of the prosecution history; and distinguishing between those features of the claimed design that are ornamental and those that are purely functional,

Wing Shing Products (BVI) Co. v. Sunbeam Products, Inc. Plaintiff Wing Shing owns United States Design Patent No. D348,585 for the ornamental design of a coffeemaker. Defendant Sunbeam is a Delaware corporation that sells coffee makers under the MR. COFFEE brand. The subject of this action is a line of MR. COFFEE automatic coffee-making devices called the "AR series," which defendants manufactured and sold between 2001 and 2006.

Sunbeam argues that the ' 585 patent and the primary accused device - the AR 10/12 - are so plainly dissimilar that, even without considering any prior art, no reasonable fact-finder could conclude that they would appear "substantially the same" to an ordinary observer. The argument is not without merit. The two designs are pictured below: 


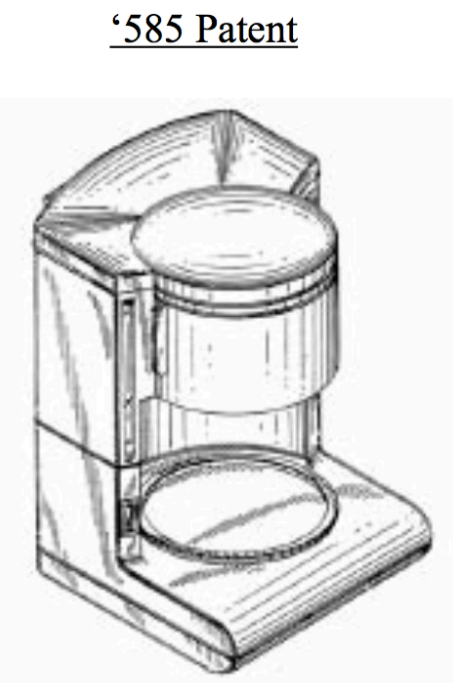

$\underline{\text { AR 10/12 (Accused) }}$

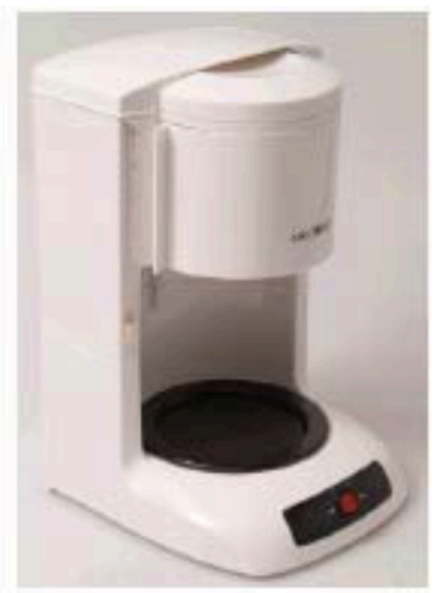

Two major differences between the designs are apparent. First, they have different bases: the '585 has a "bullnose" base - it is flat with a rectangular cross section up to the tip, where the top and bottom meet on a curve - while the AR 10/12 has a smooth base that slopes gradually from the heating plate. The designs also have dramatically different tops: the ' 585 's is flat, whereas the AR's has a circular indent partially overhung by the lid to the water reservoir. As Sunbeam points out, these differences come at "focal points" in the designs: the top and base are the most visually commanding features of a coffeemaker, along perhaps with the brew basket. At least one district court applying Egyptian Goddess has granted summary judgment without considering prior art where two designs differed primarily at one highly significant feature. Here, however, in the cluttered world of the drip-coffeemakers, it seems senseless to attempt to determine whether the "ordinary observer" would confuse two designs without looking to the prior art for a point of reference. That "a purchaser of things of similar design," as the ordinary observer has been defined, could be deceived by the devices' similarities seems unlikely to the Court, but resolution of the inquiry would benefit from a concrete guidepost. Thus, though the Court acknowledges manifest differences in the overall appearance of the ' 585 and the AR 10/12, it turns to the prior art for context.

Defendants identify numerous examples of prior art. The primary piece is a coffeemaker called the "Accel" that Sunbeam itself developed in the early 1990's. The Accel and the ' 585 are pictured below: 
‘585 patent
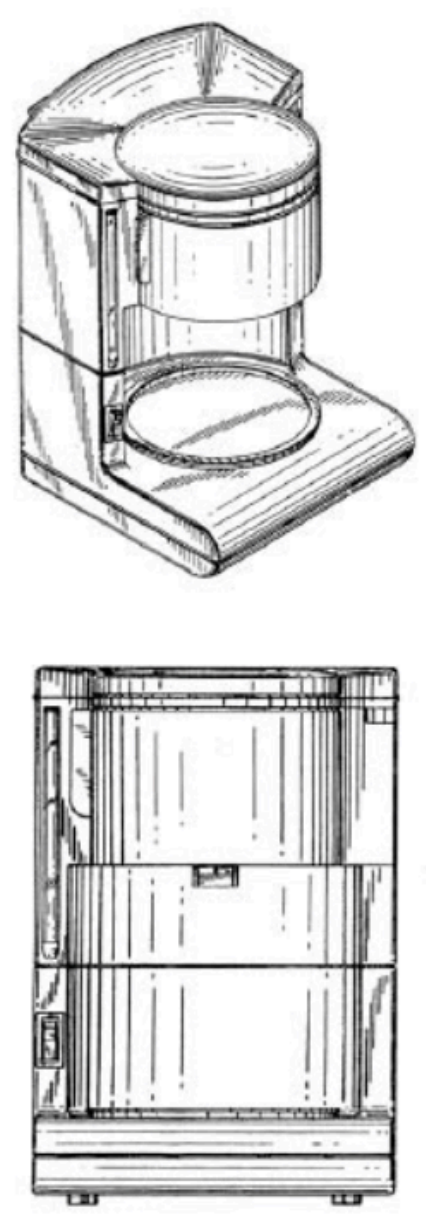

Accel (Prior Art)
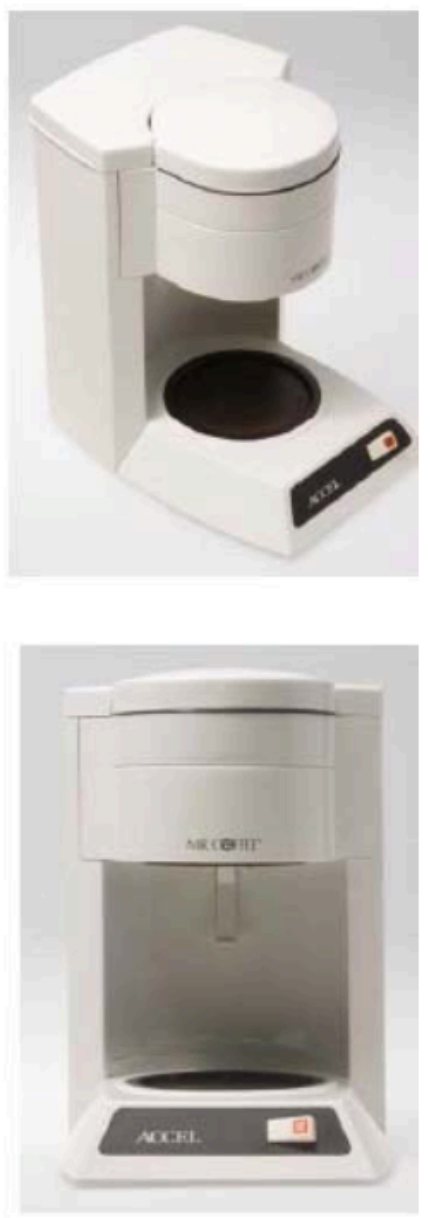

The two designs are quite similar. Each has a large, smooth brew basket with a circular cross section that is partially encased by vertical shafts connecting the brew basket to the base of the machine. Each has a similarly shaped recess for the carafe. Both designs call to mind the familiar white or black coffeemaker that graces most American kitchens. As will be noted, differences exist, but on the whole the claimed design when compared to the prior art bespeaks "a field ... crowded with many references relating to the design of the same type of appliance." Egyptian Goddess. Accordingly, the scope of protection afforded the ' 585 patent falls in a narrow range.

As for dissimilarities, the base is surely the most prominent observable difference between the designs. In contrast to the "bullnose" on the ' 585 , the Accel has an angular base with a trapezoidal cross section. To the extent the devices have distinct overall appearances, their different bases supply them. There are additional minor differences - the top of the Accel is slightly crowned, while the '585's is flat; and the water reservoir on the ' 585 extends further around the circumfer- 
ence of the brew basket - but these small details do not make nearly the visual impression that the distinct bases do.

If the AR 10/12 (the accused design) had copied the '585's bullnose base - the one feature of the ' 585 that departs conspicuously from the prior art as depicted in the Accel - an inference of infringement might arise. Instead, the AR 10/12 has its own, unique base, as is all the more apparent when viewed alongside both the '585 and the Accel:

Accel
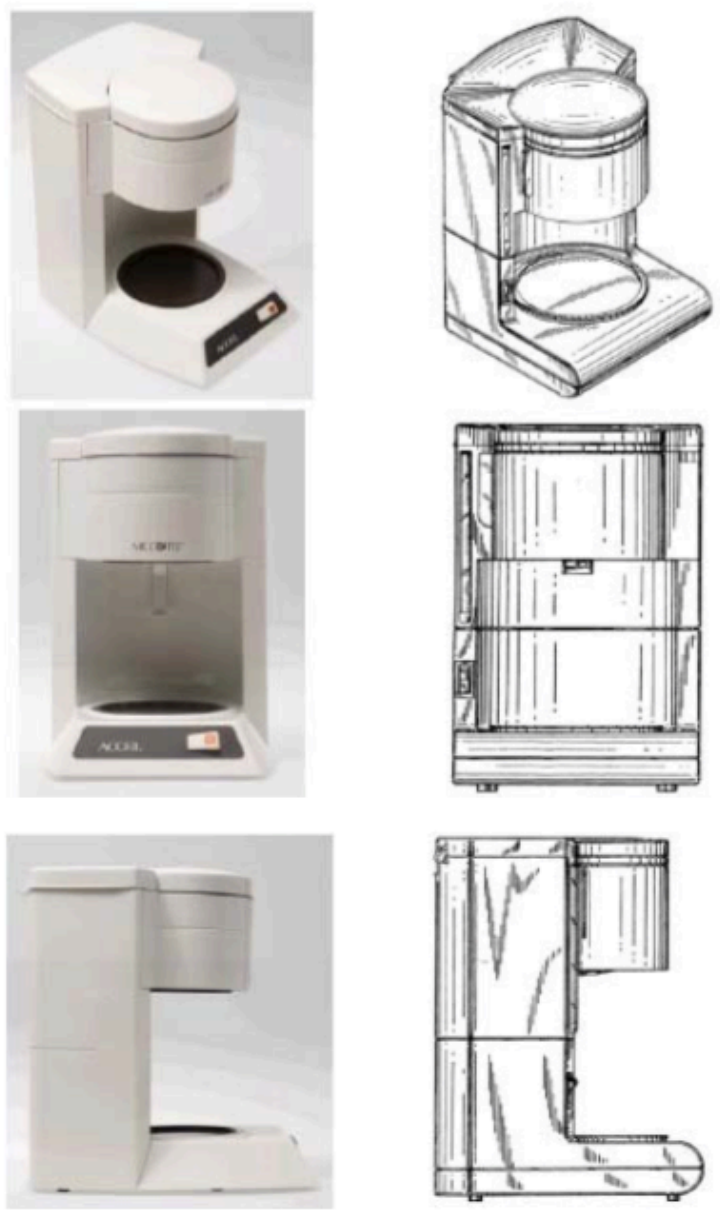

AR 10/12
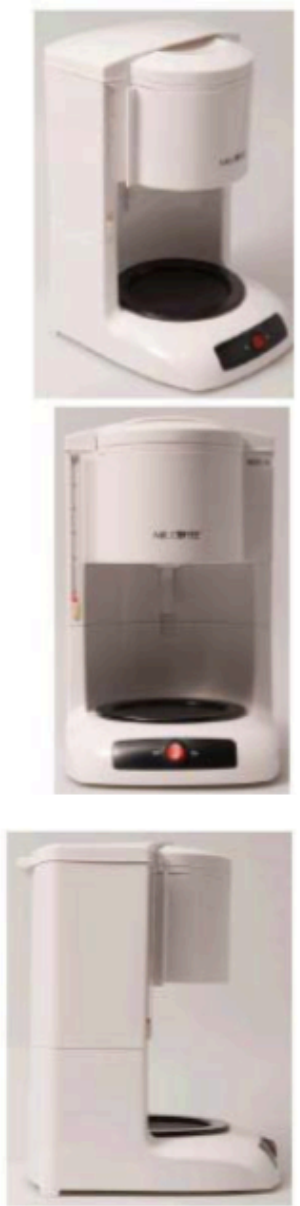

$\underline{\text { Top View }}^{4}$
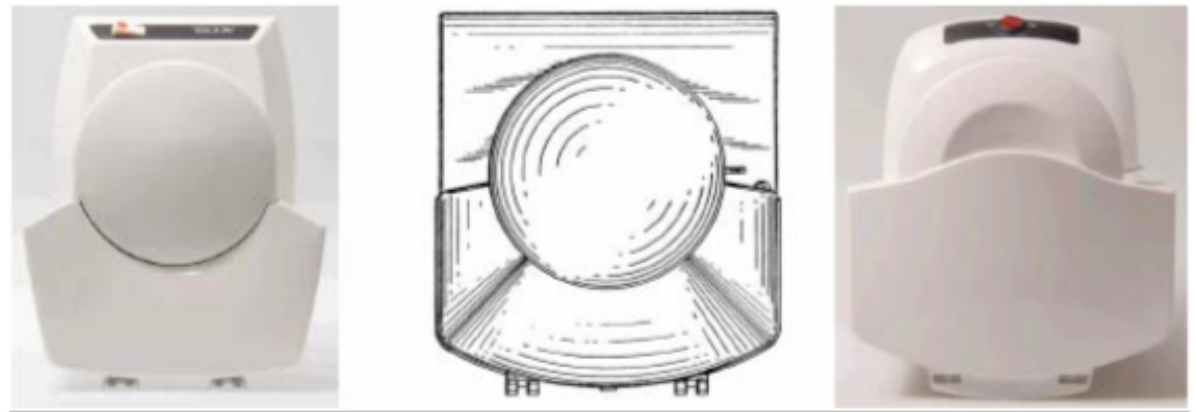
Because the AR 10/12 and the ' 585 differ at the very feature that primarily distinguishes the ' 585 from the Accel, no ordinary observer familiar with the Accel would be deceived into believing that the AR $10 / 12$ and the ' 585 are the same. Indeed, since it is difficult to tell the '585 and the Accel apart without focusing on their bases, it would be unreasonable to conclude that any observer capable of distinguishing those two machines would confuse the AR 10/12 and the '585, which also have different bases. Additionally, the AR 10/12's unique lid configuration, which distances it from both the 585 and the prior art, further solidifies the conclusion that no genuine issue of material fact as to non-infringement exists here.

The Court remains mindful of the Federal Circuit's admonition to analyze the design as a whole and not engage in an element-byelement comparison of the devices in question. Nonetheless, when the prior art is used as a frame of reference, the tops and bases of the devices in question dominate the overall visual impressions they make. As Egyptian Goddess itself recognized, where a particular design element sharply distinguishes, against the context of the prior art, the claimed design from the accused design, it is not error to focus on that element in the infringement analysis.

Plaintiff argues that summary judgment cannot be granted here because, unlike in Egyptian Goddess, the AR 10/12 is closer to the patented design than the prior art. Plaintiff contends that the AR $10 / 12$ is closer to the " 585 patent than the Accel because the "body" of the AR 10/12 - the region from "the bottom of the lid to the top of the base" - is "substantially identical" to the body of the "585 design. The Court does not find this argument persuasive. First, in focusing on the "body" of the design, plaintiff has chosen a frame of reference that conveniently excludes the salient points of comparison - the top and the base. Under this framework, the Accel itself could be found to infringe, because to the layman's eye, its "body" is not readily distinguishable from the '585 patent. This is exactly the type of absurd result that consideration of the prior art is meant to avoid. Secondly, whether the accused device is "closer" to the patented design than to the prior art is not the controlling inquiry. Egyptian Goddess notes that strong similarities between the accused design and the prior art are an indication of non-infringement, but it does not require a mechanical determination - which in this case of "crowded art" would be impractical - that the accused device is "closer" to either the patent or the prior art. Instead, Egyptian Goddess requires an assessment of how the prior art will impact the ordinary observer's perception of the accused and claimed designs. Here, for example, though reasonable jurors might disagree on whether the AR 10/12 is "closer" to the Accel or the " 585 patent (it is different than both), no reasonable juror could dispute that an ordinary observer familiar with the Accel 
would not believe the AR 10/12 to be the "same as" the " 585 patent.

OddzOn Products, Inc. v. Just Toys, Inc.

OddzOn is a toy and sporting goods company that sells the popular "Vortex" tossing ball, a foam football-shaped ball with a tail and fin structure. The Vortex ball is OddzOn's commercial embodiment of its design patent, U.S. Patent D346,001, which issued on April 12, 1994. Just Toys, Inc., another toy and sporting goods company, sells a competing line of "Ultra Pass" balls.

OddzOn argues that the district court erred in finding a lack of infringement. We do not agree.

In Gorham, the claimed elements were purely ornamental, being limited to the scroll work on the handle portion of flatware. If, on the other hand, a design contains both functional and ornamental features, the patentee must show that the perceived similarity is based on the ornamental features of the design. The patentee must establish that an ordinary person would be deceived by reason of the common features in the claimed and accused designs which are ornamental.

In construing the claim of OddzOn's patent, the district court carefully noted the ornamental features that produced the overall "rocketlike" appearance of the design. We agree with the district court's claim construction, which properly limits the scope of the patent to its overall ornamental visual impression, rather than to the broader general design concept of a rocket-like tossing ball.

OddzOn argues that the shape of a football with an arrow-like tail is an ornamental feature because "it is not required for a tossing ball." While OddzOn correctly states that there are many ways of designing "tossing balls," it is undisputed that the ball in question is specifically designed to be thrown like a football, yet travel farther than a traditional foam football. It is the football shape combined with fins on a tail that give the design these functional qualities. The tail and fins on OddzOn's design add stability in the same manner as do the tail and fins found on darts or rockets. They are no less functional simply because 'tossing balls' can be designed without them.

Because the accused products are clearly similar to OddzOn's design in terms of their football shape and their tail and fins, it was incumbent on OddzOn to submit evidence establishing that the ornamental aspects of their football-with-tail-and-fin combination accounted for the similarity perceived by the survey participants. None of the evidence, when viewed in the light most favorable to OddzOn, would support a jury verdict that the accused devices are similar to the patented design with its football-shaped ball, slender tailshaft, and three fins which seemingly protrude out of the football and gently flare outwardly.

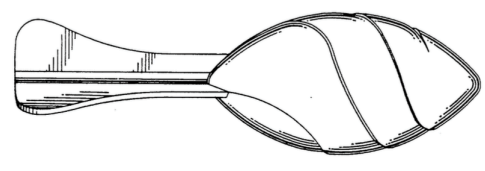

'001 design

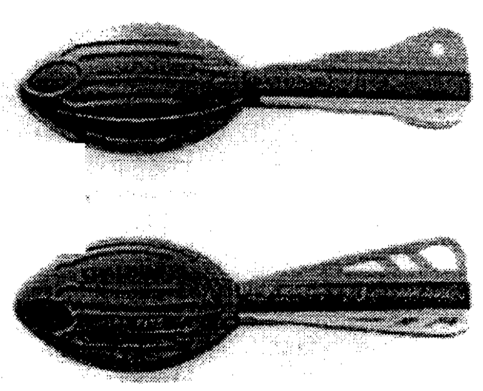

Ultra Pass balls

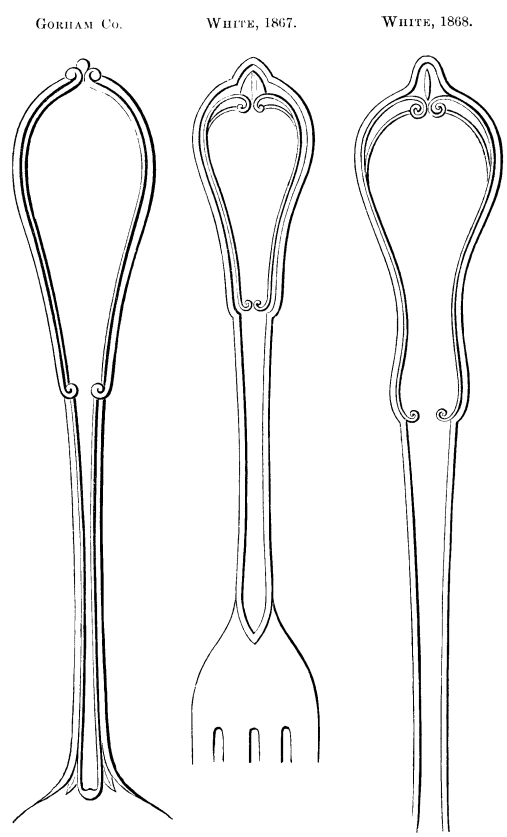

Plaintiff's and defendant's designs from Gorham 
35 U.S.C. § 289

Additional remedy for infringement of design patent
OddzOn also submitted evidence establishing that Just Toys' balls were returned to $\mathrm{OddzOn}$ by retailers on nineteen different occasions. The district court excluded this evidence of alleged "actual confusion" on the ground of lack of relevance. We agree with OddzOn that the exclusion of the "actual confusion" evidence on relevance grounds was an abuse of discretion. Given the low threshold for relevancy, it is clear that the evidence was relevant. We find this error harmless, however, because it does not change the result of OddzOn's appeal.

\section{L.A. Gear, Inc. v. Thom McAn Shoe Co.}

Although design patent analysis requires comparison of the claimed design with the accused articles, Melville has not argued that the patent drawing differs from the embodiment in the L.A. Gear shoe, and has offered no reason why the finding of substantial similarity between the actual shoes was not applicable to the infringement analysis. When the patented design and the design of the article sold by the patentee are substantially the same, it is not error to compare the patentee's and the accused articles directly; indeed, such comparison may facilitate application of the Gorham criterion of whether an ordinary purchaser would be deceived into thinking that one were the other.

Design patent infringement relates solely to the patented design, and does not require proof of unfair competition in the marketplace, or allow of avoidance of infringement by labelling.

\section{Infringement: Prohibited Conduct}

\section{Patent Act}

Whoever during the term of a patent for a design, without license of the owner, (1) applies the patented design, or any colorable imitation thereof, to any article of manufacture for the purpose of sale, or (2) sells or exposes for sale any article of manufacture to which such design or colorable imitation has been applied shall be liable to the owner to the extent of his total profit, but not less than $\$ 250$.

Nothing in this section shall prevent, lessen, or impeach any other remedy which an owner of an infringed patent has under the provisions of this title, but he shall not twice recover the profit made from the infringement.

A few notes: 
1. Section 289 provides additional remedies; the clear implication is that the usual theories of direct, inducing, and contributory patent infringement under $\S 271$ are also available for design patents. (See Milo \& Gabby below.)

2. As with utility patents, there is no requirement of copying from the plaintiff; design patents give a general right to exclude anyone from using the patented design.

3. Design patents probably also borrow their rules on intent from utility patent law: one can infringe without knowing of the patent or intending to infringe it.

4. Both prongs of $\S 289$ have explicitly commercial thresholds: they turn on "the purpose of sale" and on "sells or exposes for sale," respectively.

5. $\S 289$ is silent on questions of indirect liability. There is essentially no caselaw on point.

\section{Milo \& Gabby, LLC v. Amazon.com}

In this action, Plaintiffs, Milo \& Gabby, LLC and Karen Keller, sought money damages from Defendant, Amazon.com, Inc., for its "offering to sell" products that allegedly infringe certain design patents. Amazon has stipulated that the allegedly infringing products are substantially similar to the designs covered by the Milo \& Gabby patents.

When a third-party seller wants to offer a new product for sale on the Amazon.com platform, the third-party seller is responsible for sending Amazon, via an automated file upload system, content related to the new product, such as a product description, an image of the product, and the product's price. This content is used to automatically generate a "product detail page" and, in some instances, to create advertisements related to the new product. The third-party seller is responsible for the uploaded content, and specifically represents and warrants that it has the right to grant Amazon a license to use all content, trademarks, and other materials provided by it. Under Amazon's Intellectual Property Violations Policy, third-party sellers are responsible for ensuring that the products they offer for sale are legal. With respect to images, third-party sellers agree that it is their responsibility to "ensure that they have all the necessary rights for the images they submit." Third-party sellers may ship their products to customers directly or, for a fee, use the "Fulfillment by Amazon" ("FBA") service. Third-party sellers who use Amazon's FBA service retain legal title to their products, while Amazon provides fulfillment services for the products, such as storage and shipping.D547,587

While the Federal Circuit has most often addressed "offer to sell" liability in the jurisdictional context, analyzing where the offer took place, this Court is not aware of any Federal Circuit case directly ad-
144 F. Supp. 3d 1251 (W.D. Wash. 2015)

How much does it matter that the plaintiff held design rather than utility patents? Not at all, or less than zero?

The description of Amazon's operations is taken from an earlier unreported opinion, available at $2015 \mathrm{WL}$ 4394673 (July 16, 2015).

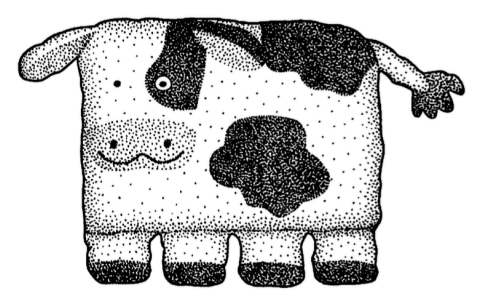

U.S. Des. Pat. No. , "Cow-Shaped Pillow Case" 
dressing the central issue before this Court-that is, who made the alleged "offer to sell." Thus, this Court acknowledges its difficulty in reaching its conclusion in this matter.

Nonetheless, based on the factual determinations made by the Jury, the Court concludes that Amazon did not "offer to sell the alleged infringing products in this case. The Jury specifically found the following:

- Amazon, through its website, did not communicate a description of the allegedly infringing products;

- Amazon, through its website, did not communicate the price at which the allegedly infringing product could be purchased;

- Amazon did not provide the descriptions of the allegedly infringing products;

- Amazon did not set the price at which the allegedly infringing products could be purchased;

- Amazon did not set the quantity(ies) of the allegedly infringing product(s) for sale on its website;

- Amazon, through its website, did not communicate that it was willing to enter into a bargain to sell the allegedly infringing products

Based on these findings, and having reviewed the evidence and testimony presented in this matter, the Court can only conclude that Amazon did not offer to sell the alleged infringing products because there was no manifestation of the willingness of Amazon to enter into a bargain, so made as to justify another person in understanding that his assent to that bargain is invited and will conclude it.

However, the Court is troubled by its conclusion and the impact

If the third-party sellers are infringing by both selling and offering to sell the infringing products, could Milo \& Gabby hold Amazon liable for contributory patent infringement or inducing patent infringement under $\S 271$ (b) or (c)? Does § 289 work against Amazon? it may have on the many small retail sellers in circumstances similar to the Plaintiffs. There is no doubt that we now live in a time where the law lags behind technology. This case illustrates that point. Amazon's representative, Christopher Poad, testified that Amazon completely changed the online market place by creating a platform where any seller can offer products to Amazon's customers. He further testified that Amazon allows sellers to offer their products with minimal effort, by simply filling out an online information form, clicking on an agreement to Amazon's terms and conditions, and providing certain banking information. Amazon then offers those sellers both payment processing and fulfillment services, all with an asserted interest in providing the best service to their customers. Mr. Poad also testified that when customers cannot resolve problems with a particular seller, Amazon will often step in to make things right. As a result, Amazon enables and fosters a market place reaching millions of customers, where anyone can sell anything, while at the same time taking little 
responsibility for "offering to sell" or "selling" the products.1 Indeed, under the current case law, Amazon has been able to disavow itself from any responsibility for "offering to sell" the products at all. The purpose of adding "offer[] to sell" to section 271(a) was to prevent generating interest in a potential infringing product to the commercial detriment of the rightful patentee. In this instance, the Court is not convinced that such purpose has been fulfilled. However, that is a subject which must be addressed to Congress and not the courts.

\section{Defenses}

\section{Jazz Photo Corp. v. International Trade Com'n}

[Fuji Photo Film Co. sold disposable cameras.] The cameras are intended by the patentee to be used only once. After the film is exposed the photo-processor removes the film container by breaking open a pre-weakened portion of the plastic casing which is accessed by removal of the cardboard cover. Discarded LFFPs, subsequently purchased and refurbished by the respondents, are the subject of this action.

We conclude that for used cameras whose first sale was in the United States with the patentee's authorization, and for which the respondents' activities were limited to the steps of (1) removing the cardboard cover, (2) cutting open the plastic casing, (3) inserting new film and a container to receive the film, (4) replacing the winding wheel for certain cameras, (5) replacing the battery for flash cameras, (6) resetting the counter, (7) resealing the outer case, and (8) adding a new cardboard cover, precedent requires that the described activities be deemed to be permissible repair.

[Most of the opinion dealt with the repair/reconstruction distinction as it bore on the exhaustion of Fuji's utility patents. But the court also discussed exhaustion of Fuji's design patents.]

The patented designs depict the exterior shape of the camera. The exterior design is unaffected by the "remanufacturing" process; it remains in its original form in the outer box and plastic structure of the camera. The respondents do not dispute that their cameras have the same design as the original cameras; indeed, their argument is that their cameras are the original cameras, repaired for reuse.

For original cameras that have been permissibly repaired, the principle of exhaustion applies to the design patents as well as to the utility patents. The design patent right, like all patent rights, is exhausted by unrestricted first sale in the United States, and is not infringed by the importation and resale of the repaired articles in their original design.
264 F.3d 1094 (2001)

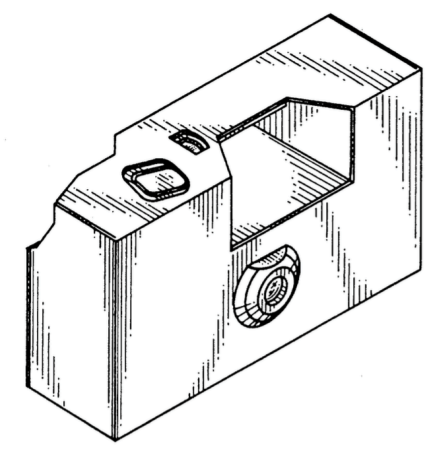

Figure 1, U.S. Des. Pat. No. D345,750, "Single use camera." 
14 Chi.-Kent L. J. Intell. Prop. 553 (2015)

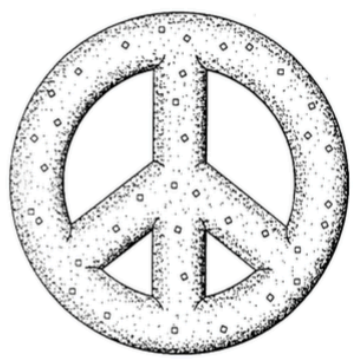

FIG.1

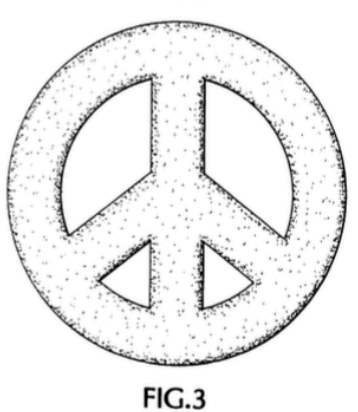

'184 design

\section{Ralph D. Clifford \& Richard J. Peltz-Steele}

The Constitutionality of Design Patents

A federal case in 2013, closed upon voluntary dismissal without a court opinion, nicely demonstrates the need for a fair use defense in design patent law. Until the expiration of its 14-year term in April 2014, patent D423,184 protected this "pretzel," which we call the Peace Pretzel.

Plaintiff Leslie Friend of Pittsburgh, Pennsylvania, purchased the design patent in the last year of its validity from the sister of the inventor, Michael Lamont, who had passed away in 2007. Friend's attorneys told media that Friend planned to start a pretzel business. She then discovered the design on offer from an online Massachusetts pretzel purveyor called Laurel Hill Foods. Laurel Hill sold pretzel chips in the shape of a peace sign in three flavors - "everything," sea salt, and honey multigrain- which Laurel Hill bought from a Pennsylvania company, Keystone Pretzels. Friend sued Laurel Hill and Keystone.

Commentators on the Friend lawsuit suggested that Laurel Hill pretzel chips were not deep enough, in dimension, to run afoul of the Peace Pretzel design patent, in which figure 2 suggests a depth of dough equivalent to the width depicted in figure 1. We disagree. Employing design patent infringement analysis, the minimal novelty requirement would be satisfied by the peace-sign shape of the pretzel dough, which is what differentiates the product from the traditional pretzel knot. That very novelty is the defining characteristic of Laurel Hill pretzel chips. The ordinary observer very well might purchase the one, supposing it to be the other. So Friend had a strong lawsuit on her hands, even while she never got her pretzel business off the ground, and the impetus for Lamont's initial conception in 1999 was all but forgotten. Neither news reports nor the case record explain why Friend voluntarily dismissed with prejudice just four months after filing, but it is reasonable to speculate that a settlement was reached.

The missing piece in the Friend lawsuit, and the unresolved problem presented by design patents, is fair use. Insofar as Friend was a sympathetic plaintiff, Laurel Hill and Keystone were profiting off the ingenuity of another and may have been expected fairly to pay up. But change the defendant to a non-commercial user, and the case takes on a different cast. Imagine a city rally for Ukrainian-Russian peace at which a sponsoring ethnic bakery makes and gives away peace-sign-shaped pretzels. Or suppose that a German-American citizens group decides to counter community angst over immigration by uniting local persons of different backgrounds in Oktoberfest beer gardens to dialog over homemade peace-sign-shaped pretzels. Peacesign-shaped cookies, adorned or not with sugar crystals, or other ed- 
ibles, also might run afoul of the design patent, as the controlling diagrams say nothing about the edible ingredients.

Farther afield, suppose shaped pretzels become objets d'art. A latter-day Andy Warhol or redirected Thomas Forsyth might create a range of artwork meant to comment on the inequality of food distribution around the world, even employing bread dough as ironic medium. The Peace Pretzel might be just one entry in a series of works, perhaps alongside a doughy stalk of wheat, a floury planet earth, and a bready bas-relief of scythe-wielding farm workers.

We can complicate the case further if we trade out the peace sign for a more controversial symbol. To choose a plaintiff that engenders less sympathy, suppose that the multinational oil and gas company $\mathrm{BP}$ obtained a design patent on a distinctive container for motor oil-let us borrow the double-sphere bottle in which POM Wonderful sells fruit juice. After the BP oil spill, a protestor and artist creates a sculpture depicting a blackened, oil-sodden pelican, surrounded by upturned BP oil bottles, also blackened,but recognizable by their shape. The artist might re-create (make) the bottles, or use discarded bottles. The artist might auction off (sell) the sculpture and donate the proceeds to an environmental advocacy group.

Critical training is hardly required to perceive the artist's message favoring environmental protection, or inversely, blaming BP for environmental degradation. But the work plainly runs afoul of the design patents, as the artist has made or used, and sold, the patented bottles. The ordinary observer properly perceives the BP bottles; indeed, the artist might be using BP bottles, which our auction winner buys because they are what they appear to be.

Without the structural safeguards and fair use defense that shape copyrights to accommodate free speech, design patents exclude the activists and artists from political advocacy and social commentary. These functions lie at the heart of First Amendment protection, and for good reason. If design patents can be perverted to freeze out this speech, then the public policy goals of free speech395 are not achieved.

It is unnecessary to craft a new strict scrutiny test under the First Amendment because the copyright fair use doctrine provides a welldrawn test designed already to accommodate the balance between the IP Clause and the First Amendment. The deep similarity of copyrights and design patents, notwithstanding their semantic differences and historical divergence, further suggest the appropriateness of fair use to design patents with only slight adaptations that can be done as a matter of constitutional law, without modification to statutory patent law

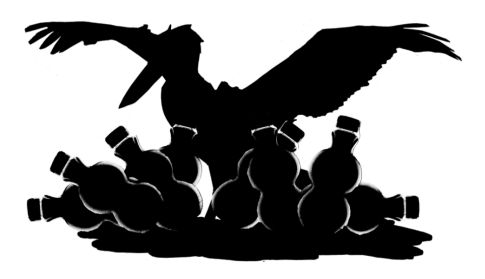

Hypothetical anti-BP protest sculpture 
Look again at the Eames Lounge Chair. Could its design be effectivey protected with a design patent?

\section{E Sui Generis Regimes}

There are two sui generis design-protection regimes codified in the Copyright Act. Neither has been extensively used. Compare them to copyright, to design patent, and to each other.

\section{Semiconductor Masks}

Under the Semiconductor Chip Protection Act of 1984, the "mask works" used to create computer chips are protected by a special sui

17 U.S.C. ch. 9

70 Minn. L. Rev. 471 (1985) generis IP regime. It is codified in the Copyright Act and borrows extensively from copyright law in some respects, while relaxing the application of the useful article rule. As will be seen, the SCPA also borrows from trade secret law. Does the resulting hybrid make sense?

\section{Pamela Samuelson \\ Creating a New Kind of Intellectual Property: Applying the Lessons of the Chip Law to Computer Programs}

Semiconductor chip products are most frequently manufactured by a process known as "photolithography" or "masking." After the two and three dimensional features of shape and configuration of a chip have been determined, the layout (or "topography") of the chip can be fixed in pictorial form - a so-called "composite" drawing of the various layers of the chip, shown in different colors on a very large sheet of paper. The same information can be recorded in digital form, by storing all the relevant coordinates of points in the composite drawing. This information is then used to generate a series of "masks," which are stencils used to manufacture chips. Chips are manufactured by etching material (or otherwise removing it) away from semiconductor wafers and depositing material (or otherwise placing it) on the wafers. The etching and depositing processes configure the chips to the patterns comprising the mask. The masks are used to control the etching and depositing processes.

Congress generally allows utilitarian works to be freely copied if they do not meet the patent standards of novelty and invention. For chip designs, however, Congress made an exception. The House Committee [debating the Semiconductor Chip Protection Act of 1984] perceived the chip to be "at the vortex" of the new information society. "More than perhaps any other invention, the semiconductor chip has brought us into the information age." Laying out the pattern of circuits so that hundreds of thousands or even a million transistors can be fit efficiently and economically onto the surface of a chip is "a 
fine art and also a costly one." The period of time from the initial layout of the design to the successful manufacture of the first chip can "take the innovating chip firm years, consume thousands of hours of engineer and technician time, and cost millions of dollars. The development costs for a single new chip can reach $\$ 100$ million." By comparison, copying a chip's design is very cheap. In several months, for a cost of less than $\$ 50,000$, a pirate firm can duplicate the mask work of an innovator. This piracy was perceived to be a clear threat, not only to the health of the U.S. semiconductor industry, but to the growth of American information industries.

The major argument in favor of sui generis protection for chip designs, as reflected in the House Report, was actually an anti-copyright argument. Mask works and chip products were not subject matters that historically had been regarded as copyrightable, and the House Committee believed there were sound reasons for refusing to extend copyright protection to include them. The Register of Copyrights had refused to register mask works and chip products because they were "utilitarian" in a copyright sense; that is, they had a function beyond merely portraying an appearance or conveying information.

Although copyright sometimes had been extended to artistic features of utilitarian works, such features were only protected by copyright when they could be identified separately from and were capable of existing independently of the utilitarian aspects of the work. In the case of chips and chip masks, this "separate-identification-andindependent-existence" test could not be met. That is, a copyright for a chip product or chip mask would have to be a copyright on its functional features.

The House Committee recognized that mask works were in some respects similar to maps, technical drawings, photographs, and audiovisual works, all clearly copyrightable. The Committee described these similarities as "superficial," however, and found mask works to be "in fact very dissimilar in function and nature of creativity" from these other items. Mask works were to be protected because of

the technical and creative skill employed in laying out or designing electronic circuitry. Mask works have no intrinsic aesthetic purpose. Even if the layouts convey information, that is not their sole or main purpose: their primary purpose is to be used in the manufacture of a useful article - semiconductor chip products.
This is a mask for the Intel 4004, released in 1971 -- hundreds of times simpler than the state of the art in 1984, and millions of times simpler than current chips. 


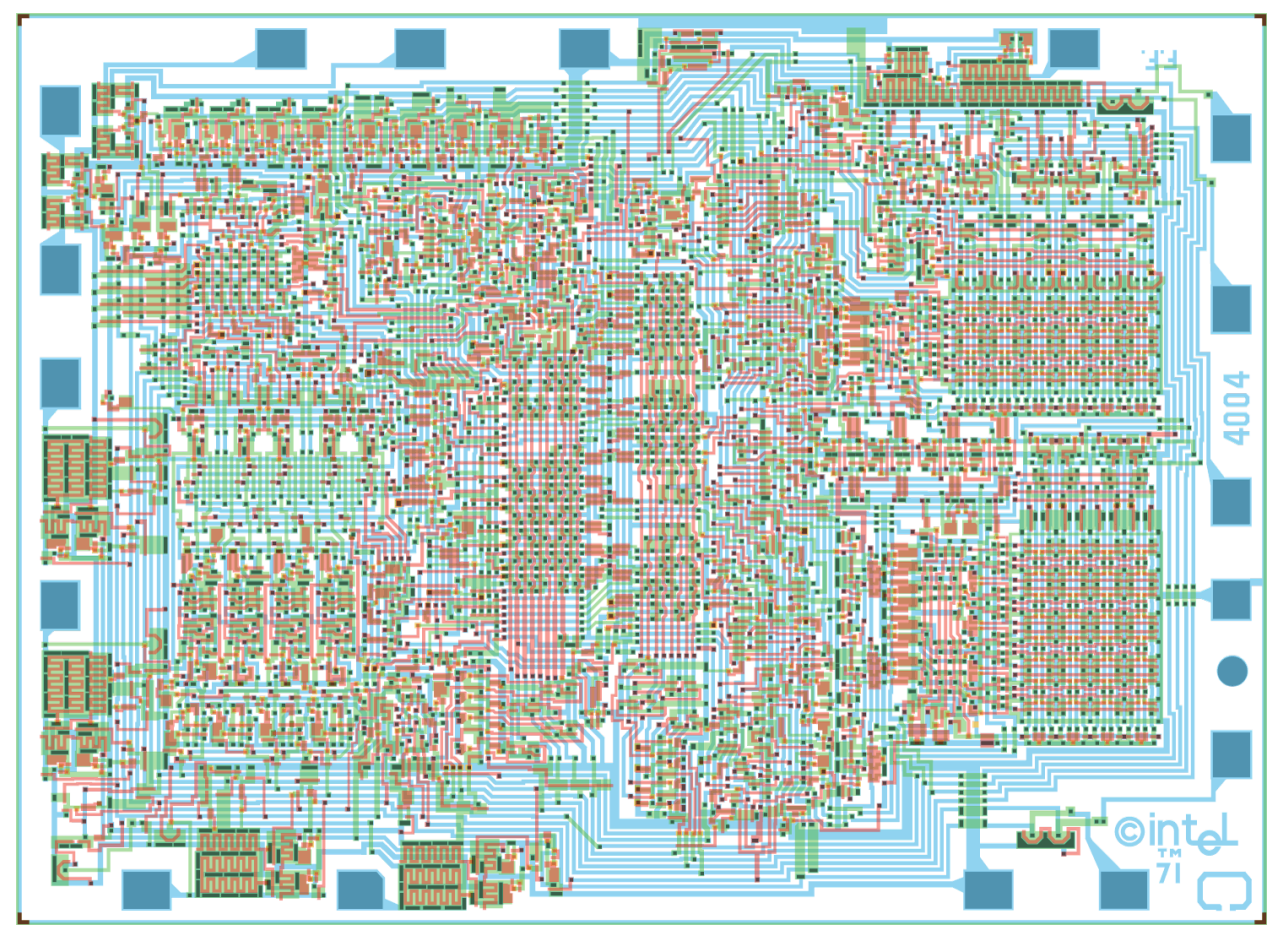

92 Va. L. Rev. 1687 (2006)

\section{The Piracy Paradox, Innovation and Intellectual Property in Fashion Design}

In 1984, Congress adopted the Semiconductor Chip Protection Act. The SCPA protects "mask works," which are the stencils used to control the process of etching onto silicon wafers the circuitry that make up a microprocessor.

Under the SCPA, a mask work is protected if it is fixed in a semiconductor chip and is original. The SCPA requires that mask works either be registered with the Copyright Office or be commercially exploited as a condition of protection.

Once an owner complies with the SCPA's formalities, he possesses the exclusive right for a period of ten years "to reproduce the mask work by optical, electronic, or any other means." As in copyright law, the exclusive right of reproduction granted is not limited to identical copies. The owner of a mask work protected by the SCPA has the right to enjoin any work that is "substantially similar" to the protected work. The SCPA also gives the owner an exclusive right for the same ten-year period "to import or distribute" a chip for which the protected mask work has been used in production.

\section{Altera Corp. v. Clear Logic, Inc.}

This case involves an infringement action by Altera against Clear Logic under the Semiconductor Chip Protection Act of 1984. A jury found for Altera on all claims and a judgment was entered for 
\$30.6 million in damages, \$5.4 million in prejudgment interest and $\$ 394,791.68$ in costs. The district court judge also entered an injunction preventing Clear Logic from engaging in those activities against Altera. We affirm the judgment and the injunction.

\section{Overview}

Altera and Clear Logic are competitors in the semiconductor industry. Altera manufactures programmable logic devices ("PLDs"), which are chips that can be programmed to perform various logic functions. A customer uses Altera's MAX+PLUS II software to program the PLD to perform the desired function. The software helps to route the functions through the thousands of transistors that make up the PLD, ideally achieving the maximum functionality for the particular function desired. Because the PLD can be programmed and reprogrammed, the customer, working with Altera, can continue to work with the PLD and the software until the PLD meets the customer's exact needs. This process can take months.

Clear Logic manufactures a different type of chip: ApplicationSpecific Integrated Circuits ("ASICs"). These chips are designed to perform one specific function and cannot be programmed by the customer. They use less power, are smaller and, for a customer with a large order, are often cheaper. Customers will sometimes start with PLDs and switch to ASICs once they have determined exactly what they need the chips to do. Traditionally, a company that converts from PLDs to ASICs must again start from a high level of description and work toward the end product, the ASIC. This can take a few months and there is a substantial risk that even after the initial attempt, the first chip will not work and more time and money will have to be invested in perfecting the product.

Clear Logic works from a different business model. When customers program Altera devices, using the Altera software, a file called a bitstream is generated. Clear Logic asks customers to send the bitstream to Clear Logic, and Clear Logic uses the bitstream to create an ASIC for the customer. Clear Logic only produces ASICs that are compatible with Altera chips. The laser process Clear Logic uses to create chips with the bitstream allows for a turnaround time of just a few weeks, and rarely produces an incompatible chip.

\section{The Semiconductor Chip Design Process and the Semiconductor Chip Protection Act}

Altera asserts that the placement of groupings of transistors on the chip was copied, and does not specifically address the layout of the transistors within those groupings. Clear Logic argues that the placement of the groupings is a system or an idea and is not entitled to protection under the SCPA. We reject this contention; the boundaries
This is one of a very small handful of reported cases on the SCPA. 
and organization of these groupings are more than conceptual.

Commentators have suggested analyzing the levels of abstraction in the production of a computer program or a mask work to identify the distinction between ideas and expression, and the degree of similarity, in these formats. Under this approach, we identify the broad idea behind the design and assess each successive step in the design process, identifying the point at which the idea becomes protectable expression.

In considering the chip design process, we recognize, as do the parties, that with each step, the ideas become more concrete until they are finally expressed in the layout of the transistors in the mask work. The customer's idea is at the highest level of abstraction, and the schematics and floor plans convey more concrete ideas, $1086^{*} 1086$ designating how the chip may be structured or organized. These drawings are preliminary sketches that would not be protected under traditional copyright principles. It is not until the level of the mask work, the piece of the process that Congress chose to protect, that there is an expression of that idea. Those ideas that are physically expressed in the mask work are subject to protection under the SCPA.

The district court correctly determined that the organization of the groupings is physically a part of the mask work. The mask work is structured according to the groupings that Altera highlighted and the district court correctly allowed the jury to determine whether those similarities constituted an infringement of the act. Unlike the outline of an article or the chapters in a book, these groupings physically dictate where certain functions will occur on a chip and describe the interaction of parts of the chip. The placement of logic groupings in a mask work is not an abstract concept; it is embodied in the chip and affects the chip's performance and efficiency as well as the chip's timing. It is the province of the jury to determine whether those aspects of the mask work are material, and whether the similarity between the mask works is substantial.

\section{ReVERSE ENGINEERING}

The SCPA specifically protects the right of

(1) a person to reproduce the mask work solely for the purpose of teaching, analyzing, or evaluating the concepts or techniques embodied in the mask work or the circuitry, logic flow, or organization of components used in the mask work; or

(2) a person who performs the analysis or evaluation described in paragraph (1) to incorporate the results of such conduct in an original mask work which is made to be distributed.

This reverse engineering provision explicitly protects industry prac- 
tices and encourages innovation. The second mask work must not be substantially identical to the original, and as long as there is evidence of substantial toil and investment in creating the second mask work, rather than mere plagiarism, the second chip will not infringe the original chip, even if the layout of the two chips is, in substantial part, similar.

The legislative history, relying on the testimony of industry representatives, indicated that most cases would probably present clear cut evidence of direct copying or of innovation and that in cases falling into the gray area between outright copying and complete originality, the courts should consider the presence or absence of a paper trail by the second firm. A firm that simply copied another firm's mask work would have no evidence of its own investment and labor, whereas a legitimate reverse engineering job would require a trail of paper work documenting the analysis of the original chip as well as the development of an independent design. In Brooktree, the Federal Circuit analyzed the defendant's paper trail, but held that "the sheer volume of paper" was not dispositive.

The SCPA's reverse engineering provision allows copying the entire mask work. It does not distinguish between the protectable and non-protectable elements of the chip as long as the copying is for the purpose of teaching, evaluating, or analyzing the chip. Although the product created from that analysis must be original, the process of studying the chip is not limited to copying ideas or concepts. The district court's instructions initially define "legitimate reverse engineering" to allow copying and analyzing only "non-protectable concepts or techniques." This is an incorrect statement of the law. [The incorrect statement was held not to have been prejudicial.]

\section{Vessel Hulls}

The Vessel Hull Design Protection Act of 1988 is also codified in the Copyright Act. Like the SCPA, the VHDPA borrows from copyright law while also easing the useful article rule. Pay attention to how closely Maverick Boat hews to copyright - or doesn't.

Bonito Boats, Inc. v. Thunder Craft Boats, Inc.

We must decide today what limits the operation of the federal patent system places on the States' ability to offer substantial protection to utilitarian and design ideas which the patent laws leave otherwise unprotected.

In September 1976, petitioner Bonito Boats developed a hull design for a fiberglass recreational boat which it marketed under the trade name Bonito Boat Model 5VBR. Designing the boat hull required substantial effort on the part of Bonito. A set of engineering 
"My vast erudition on the subject allows me to formulate a highly technical and scrupulously accurate description of plug molding: Take a boat, turn it upside-down, and spread Silly Putty all over it; after you remove the goop, then turn it right-side-up, and pour silicone in the resulting space. Now, you have a new boat that is identical to the old boat. That is 'plug molding,' also known as 'hull splashing."' David Nimmer, Copyright and the Fall Line31 Cardozo Arts \& Ent. L.J. 803 (2013) drawings was prepared, from which a hardwood model was created. The hardwood model was then sprayed with fiberglass to create a mold, which then served to produce the finished fiberglass boats for sale. The 5VBR was placed on the market sometime in September 1976.

In May 1983, after the Bonito 5VBR had been available to the public for over six years, the Florida Legislature enacted Fla. Stat. § 559.94. The statute makes "[i]t ... unlawful for any person to use the direct molding process to duplicate for the purpose of sale any manufactured vessel hull or component part of a vessel made by another without the written permission of that other person." The statute also makes it unlawful for a person to "knowingly sell a vessel hull or component part of a vessel duplicated in violation of subsection (2)."

On December 21, 1984, Bonito filed this action in the Circuit Court of Orange County, Florida. The complaint alleged that Thunder Craft Boats had violated the Florida statute by using the direct molding process to duplicate the Bonito 5VBR fiberglass hull, and had knowingly sold such duplicates in violation of the Florida statute.

It is readily apparent that the Florida statute does not operate to prohibit "unfair competition" in the usual sense that the term is understood. [For the most part] the common-law tort of unfair competition has been limited to protection against copying of nonfunctional aspects of consumer products which have acquired secondary meaning such that they operate as a designation of source. In contrast to the operation of unfair competition law, the Florida statute is aimed directly at preventing the exploitation of the design and utilitarian conceptions embodied in the product itself.

In this case, the Bonito 5VBR fiberglass hull has been freely exposed to the public for a period in excess of six years. For purposes of federal law, it stands in the same stead as an item for which a patent has expired or been denied: it is unpatented and unpatentable. Yet, the Florida statute allows petitioner to reassert a substantial property right in the idea, thereby constricting the spectrum of useful public knowledge.

That the Florida statute does not remove all means of reproduction and sale does not eliminate the conflict with the federal scheme. In essence, the Florida law prohibits the entire public from engaging in a form of reverse engineering of a product in the public domain. This is clearly one of the rights vested in the federal patent holder, but has never been a part of state protection under the law of unfair competition or trade secrets.

It is for Congress to determine if the present system of design and utility patents is ineffectual in promoting the useful arts in the context of industrial design. By offering patent-like protection for ideas deemed unprotected under the present federal scheme, the Florida 
statute conflicts with the strong federal policy favoring free competition in ideas which do not merit patent protection. We therefore agree with the majority of the Florida Supreme Court that the Florida statute is preempted by the Supremacy Clause, and the judgment of that court is hereby affirmed.

\section{Copyright Act}

(a) Designs Protected. -

(1) In general. - The designer or other owner of an original design of a useful article which makes the article attractive or distinctive in appearance to the purchasing or using public may secure the protection provided by this chapter upon complying with and subject to this chapter.

(2) Vessel features. - The design of a vessel hull, deck, or combination of a hull and deck, including a plug or mold, is subject to protection under this chapter, notwithstanding section 1302(4).

(b) Definitions. - For the purpose of this chapter, the following terms have the following meanings:

(1) A design is "original" if it is the result of the designer's creative endeavor that provides a distinguishable variation over prior work pertaining to similar articles which is more than merely trivial and has not been copied from another source.

(2) A "useful article" is a vessel hull or deck, including a plug or mold, which in normal use has an intrinsic utilitarian function that is not merely to portray the appearance of the article or to convey information. An article which normally is part of a useful article shall be deemed to be a useful article.

(3) A "vessel" is a craft -

(A) that is designed and capable of independently steering a course on or through water through its own means of propulsion; and

(B) that is designed and capable of carrying and transporting one or more passengers.

Protection under this chapter shall not be available for a design that is -

(1) not original;

(2) staple or commonplace, such as a standard geometric figure, a
17 U.S.C. S 1301

Designs protected

Why am I including such extensive excerpts from a rarely used sui generis statute for boat designs? Wrong question! The right question is why Congress drafted such a detailed and extensive suigeneris statute for boat designs. Pay close attention to the definitions.
17 U.S.C S 1302

Designs not subject to protection 
17 U.S.C $\$ 1303$

Revisions, adaptations, and rearrangements

17 U.S.C § 1304

Commencement of protection

17 U.S.C $§ 1305$

Term of protection

17 U.S.C $§ 1308$

Exclusive rights familiar symbol, an emblem, or a motif, or another shape, pattern, or configuration which has become standard, common, prevalent, or ordinary;

(3) different from a design excluded by paragraph (2) only in insignificant details or in elements which are variants commonly used in the relevant trades;

(4) dictated solely by a utilitarian function of the article that embodies it; or

(5) embodied in a useful article that was made public by the designer or owner in the United States or a foreign country more than 2 years before the date of the application for registration under this chapter.

Protection for a design under this chapter shall be available notwithstanding the employment in the design of subject matter excluded from protection under section 1302 if the design is a substantial revision, adaptation, or rearrangement of such subject matter. Such protection shall be independent of any subsisting protection in subject matter employed in the design, and shall not be construed as securing any right to subject matter excluded from protection under this chapter or as extending any subsisting protection under this chapter.

The protection provided for a design under this chapter shall commence upon the earlier of the date of publication of the registration under section 1313(a) or the date the design is first made public as defined by section 1310(b).

(a) In General. - Subject to subsection (b), the protection provided under this chapter for a design shall continue for a term of 10 years beginning on the date of the commencement of protection under section 1304.

(b) Expiration. - All terms of protection provided in this section shall run to the end of the calendar year in which they would otherwise expire.

The owner of a design protected under this chapter has the exclusive right to -

(1) make, have made, or import, for sale or for use in trade, any useful article embodying that design; and

(2) sell or distribute for sale or for use in trade any useful article embodying that design. 
(b) Acts of Sellers and Distributors. - A seller or distributor of an infringing article who did not make or import the article shall be deemed to have infringed on a design protected under this chapter only if that person -

(1) induced or acted in collusion with a manufacturer to make, or an importer to import such article, except that merely purchasing or giving an order to purchase such article in the ordinary course of business shall not of itself constitute such inducement or collusion; or

(2) refused or failed, upon the request of the owner of the design, to make a prompt and full disclosure of that person's source of such article, and that person orders or reorders such article after receiving notice by registered or certified mail of the protection subsisting in the design.

(c) Acts Without Knowledge. - It shall not be infringement under this section to make, have made, import, sell, or distribute, any article embodying a design which was created without knowledge that a design was protected under this chapter and was copied from such protected design.

(d) Acts in Ordinary Course of Business. - A person who incorporates into that person's product of manufacture an infringing article acquired from others in the ordinary course of business, or who, without knowledge of the protected design embodied in an infringing article, makes or processes the infringing article for the account of another person in the ordinary course of business, shall not be deemed to have infringed the rights in that design under this chapter except under a condition contained in paragraph (1) or (2) of subsection (b). Accepting an order or reorder from the source of the infringing article shall be deemed ordering or reordering within the meaning of subsection (b)(2).

(e) Infringing Article Defined. - As used in this section, an "infringing article" is any article the design of which has been copied from a design protected under this chapter, without the consent of the owner of the protected design. An infringing article is not an illustration or picture of a protected design in an advertisement, book, periodical, newspaper, photograph, broadcast, motion picture, or similar medium. A design shall not be deemed to have been copied from a protected design if it is original and not substantially similar in appearance to a protected design.

(g) Reproduction for Teaching or Analysis. - It is not an infringement of the exclusive rights of a design owner for a person to reproduce the design in a useful article or in any other form solely for the purpose of teaching, analyzing, or evaluating the appear- 
17 U.S.C $\$ 1310$

Application for registration

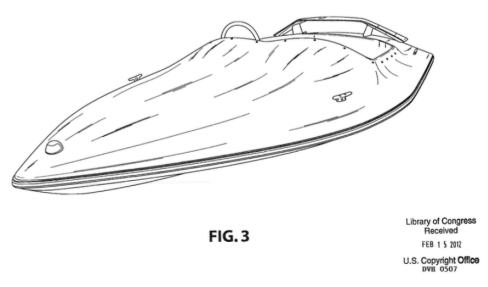

Diagram from vessel hull registration DVH0507 (2012)

17 U.S. Code $\S 1313$

Examination of application and issue or refusal of registration

17 U.S.C § 1329

Relation to design patent law

418 F.3d 1186 (11th Cir. 2005)

This is the only reported case alleging infringement under the VHDPA.

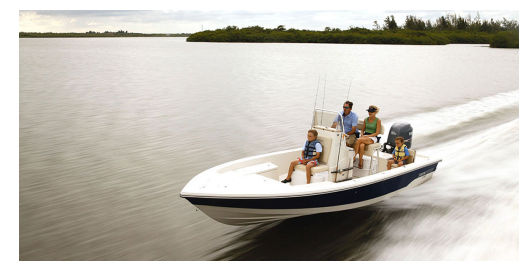

Pathfinder 2200 TRS (updated version of design at issue) ance, concepts, or techniques embodied in the design, or the function of the useful article embodying the design.

(a) Time Limit for Application for Registration. - Protection under this chapter shall be lost if application for registration of the design is not made within 2 years after the date on which the design is first made public.

(h) Pictorial Representation of Design. - The application for registration shall be accompanied by two copies of a drawing or other pictorial representation of the useful article embodying the design, having one or more views, adequate to show the design, in a form and style suitable for reproduction, which shall be deemed a part of the application.

(a) Determination of Registrability of Design; Registration. - Upon the filing of an application for registration in proper form under section 1310, and upon payment of the fee prescribed under section 1316, the Administrator shall determine whether or not the application relates to a design which on its face appears to be subject to protection under this chapter, and, if so, the Register shall register the design. Registration under this subsection shall be announced by publication. The date of registration shall be the date of publication.

The issuance of a design patent for an original design for an article of manufacture shall terminate any protection of the original design under this chapter.

Maverick Boat Co., Inc. v. American Marine Holdings, Inc. Maverick, $\mathrm{AMH}$, and Blazer are manufacturers of recreational boats, and each company manufactures a boat known as the "bay boat." Maverick introduced its Pathfinder $2200 \mathrm{~V}-\mathrm{Hull}$ bay boat at its July 1998 dealer meeting, and it sold more than 30 of these boats that same year. Following this initial sale, however, Maverick became aware of problems with the boat's tooling. Specifically, Maverick became aware of customer complaints about the "sheer line" (the intersection of the hull sides with the top of the boat's deck) on the boat. Paul Ellig, who was primarily responsible for correcting the sheer line, testified at trial that the irregularities in the boat's lines were not intended to be present in the original boat and, thus, were the result of mistakes.

Because the sheer line was off, other boat lines, including the "style line" (the offset made on the hull sides to establish a unique graphic form or signature of the model or brand name) and the "chine line" (the line formed by the intersection of the hull lines with the 
bottom of the boat), were also off. Ellig testified that once an element of a boat is changed because of an irregularity, other aspects of the boat are also affected. Maverick corrected these lines in a "revised design." However, at trial, Maverick did not introduce any records to show the changes that it made to any of the boat's lines: Maverick did not introduce any internal memoranda, drawings, correspondence, or documents of any kind that refer to the "revised design."

For a period of time after the original model had been retooled, both the "original design" and the "revised design" were in production. On or about May 4, 1999, Maverick began shipping boats with the revised design. The name and model number of the boat remained the same, and Maverick's advertisements never mentioned the design change. Also, during the time that Maverick sold both the "original design" and the "revised design," it never informed its dealers or the public which design they were obtaining.

On February 27, 2001, Maverick submitted the application for Registration Number DVH 0049 to the United States Copyright Office. Maverick admitted in its pleadings that pursuant to 17 U.S.C. $\S$ 1302(5), DVH 0049 is invalid because it was for the "original design," which was made public more than two years prior to the date of its application.

On April 10, 2001, Maverick submitted a second application, for the Pathfinder 2200 V-Hull, Registration Number DVH 0056, to the United States Copyright Office. The registration states that the design is a "new improved version of earlier design. Revised original hull (forward) shape, style line location." Leffew photographed a Pathfinder $2200 \mathrm{~V}-\mathrm{Hull}$ and submitted the photographs with the application for DVH 0056. But, Leffew did not know the model year of the boat depicted in the photographs that he submitted. In fact, when Leffew photographed the boats for each application, he did not know whether he was photographing a boat with an original or revised design.

During the summer of 2001, Maverick learned that AMH was marketing a boat with a vessel hull that appeared to have been copied from a Pathfinder 2200 V-Hull. Maverick asked Lee Dana, an architect and small craft designer, to analyze the respective hull designs and make a determination as to their similarities. On December 3, 2001, Dana sent a letter to Maverick stating, in part, that "it is very probable that the mold for the 22 Pro-Line was 'back cast' from a 22 Pathfinder Hull." [Similarly for Blazer's 2220 bay boat.]

\section{A. Cancellation of DVH 0056}

Maverick argued in the district court (as it does here) that its revised design is a substantial revision of the original design and, thus, that it is entitled to protection pursuant to 17 U.S.C. $\S 1303$. The district

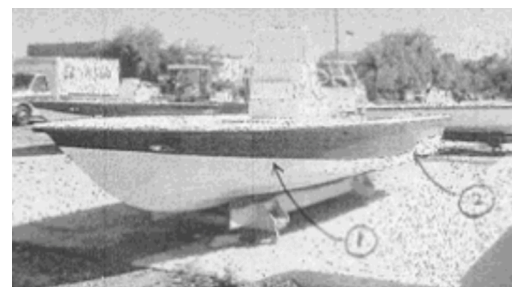

Photograph of Pathfinder 2200 from registration no. DVH 0056

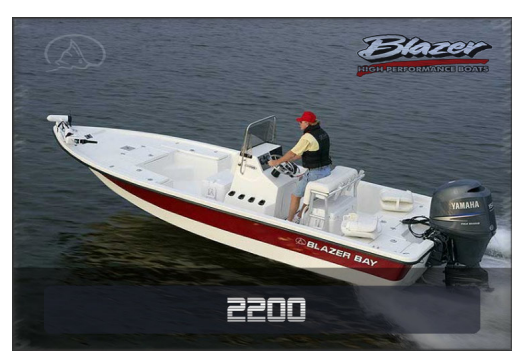

Blazer 2200 
court disagreed and specifically found that the design Maverick registered in DVH 0056 was not a "substantial revision, adaptation, or rearrangement" of the original Pathfinder 2200 V-Hull design as required by 17 U.S.C. $\S 1303$.

The district court correctly determined that the changes made to the original design were merely corrections to a mistake, and not substantial. AMH and Blazer's expert witness, Augusto Villalon, testified that the changes made to the original design were minimal (such as straightening the sheer line) and that they did not affect the design of the boat. Maverick did not proffer any expert testimony as to the differences between the two boats. In fact, Maverick did not attempt to secure an original design to compare it with a revised design, and it did not point to any specific differences between the two boats - either apparent to the naked eye or based on specific measurements - that would demonstrate the extent of the differences in the two designs. Moreover, Maverick failed to introduce any records to reflect the actual changes between the original design and the alleged revised design; there was no change made to the name of the boat or the model number of the boat; the two boats were held out to the public as the same boat; nothing in Maverick's advertising indicated that there was an original and a revised design; and Maverick sold both versions simultaneously without any representation that one was an original design and the other a revised design.

We conclude that the district court was correct in finding that the changes made by Maverick to the original Pathfinder 2200 V-Hull design were merely corrections to a mistake. In fact, the correction of an unintended problem does not create a new design, but merely makes the original design what it was always intended to be. Accordingly, we agree with the district court's finding that Maverick is not entitled to the protection offered by the VHDPA for DVH 0056.

\section{B. AMH and Blazer's Infringement}

Because we agree with the district court that Maverick's Pathfinder $2200 \mathrm{~V}-\mathrm{Hull}$ design is not protected under the VHDPA, we need not address Maverick's infringement claim. The district court, however, addressed it for the sake of argument; so, we will discuss it briefly. [The district court had written:

There is no dispute that $\mathrm{AMH}$ and Blazer used the Pathfinder $2200 \mathrm{~V}-\mathrm{Hull}$ as a starting point for the development of the allegedly infringing boat. However, this fact alone does not constitute infringement. There are ten differences between the Pathfinder 2200 V-Hull and the Pro-Line 22. Mr. Deal himself testified that there are a number of differences between the decks of the Pathfinder 
2200 V-Hull and the Pro-Line 22. These differences include: the cockpit sole was raised by two inches at the aft end, an anchor compartment was added, the aft platform was raised and its compartments redesigned, and the entire deck surface was covered with a special non-skid material. In addition to the differences in the deck, the hull of the Pro-Line 22 is six inches longer than the hull of the Pathfinder $2200 \mathrm{~V}-\mathrm{Hull}$. The changes AMH made in getting from the Pathfinder $2200 \mathrm{~V}-\mathrm{Hull}$ as its starting point to the Pro-Line 22 demonstrate that the Pro-Line 22 is an original and is "not substantially similar in appearance" to the allegedly protected design of the Pathfinder 2200 $\mathrm{V}-\mathrm{Hull}$, particularly where the protected design includes the deck of the vessel.]

After reviewing the record, we cannot say that those findings are clearly erroneous. In fact, the evidence at trial clearly showed that the differences between the hulls of AMH's Pro-Line 22 and Maverick's Pathfinder 2200 V-Hull were substantially greater than the minimal differences between the designs in Maverick's invalid DVH 0049 and DVH 0056. Thus, at a minimum, Maverick cannot credibly claim that DVH 0056 is valid over the admittedly invalid DVH 0049, while at the same time claiming that AMH's accused boat (which is substantially different) is an infringement of DVH 0056.

\section{F Fashion}

Fashion offers a fascinating case study in the limits of the various techniques for protecting designs. This section finishes with materials on a proposed fashion-specific legal regime. Does it solves the recurring problems of design law, or just create new ones?

\section{Copyright}

Jack Adelman, Inc. v. Sonners \& Gordon, Inc.

The bill of complaint alleges that the defendants have infringed plaintiff's copyright of a drawing of a dress by making and selling a dress like the one in plaintiff's drawing.

Does the copyright of a drawing of a dress give the owner of that copyright the exclusive monopoly to produce the dress itself? This depends solely upon the extent of the rights secured by the copyright owner upon filing his drawing in the copyright office.

Plaintiff stated in its application that it was filing a drawing for registration. The dress itself could hardly be classed as work of art
Congress responded to Maverick Boat by amending the VHDPA to clarify that it applies to "a vessel hull or deck." Where does that leave the test for infringement under the VHDPA?

112 F. Supp. 187 (S.D.N.Y. 1934) 
and filed in the Register's office. Moreover, [a Copyright Office regulation] lists "garments" among those articles in which "The exclusive right to make and sell ... should not be sought by copyright registration." All the plaintiff could accomplish under this section was to register its drawing, and unless we read into the statute something which is not there plaintiff secured no exclusive monopoly of the dress shown in the drawing. This seems clear if it be kept in mind that it is the drawing which is assumed to be a work of art and not the dress. It follows that plaintiff's copyright gives it the exclusive right to make copies or reprints of the drawing only, and that it gives the copyright owner no monopoly of the article illustrated.

Plaintiff cites Bracken $v$. Rosenthal which held that a photograph of a copyrighted piece of sculpture was an infringement. But the distinction is plain. A dress is not copyrightable. A picture of a dress is; and the statute expressly includes sculpture.

35 F.2d 279 (2d Cir. 1929)

(Learned Hand, J.)

\section{Cheney Bros. v. Doris Silk Corporation}

The plaintiff, a corporation, is a manufacturer of silks, which puts out each season many new patterns, designed to attract purchasers by their novelty and beauty. Most of these fail in that purpose, so that not much more than a fifth catch the public fancy. Moreover, they have only a short life, for the most part no more than a single season of eight or nine months. It is in practice impossible, and it would be very onerous if it were not, to secure design patents upon all of these; it would also be impossible to know in advance which would sell well, and patent only those. Besides, it is probable that for the most part they have no such originality as would support a design patent. Again, it is impossible to copyright them under the Copyright Act, or at least so the authorities of the Copyright Office hold. So it is easy for any one to copy such as prove successful, and the plaintiff, which is put to much ingenuity and expense in fabricating them, finds itself without protection of any sort for its pains.

Taking advantage of this situation, the defendant copied one of the popular designs in the season beginning in October, 1928, and undercut the plaintiff's price.

The plaintiff asks for protection only during the season, and needs no more, for the designs are all ephemeral. It seeks in this way to disguise the extent of the proposed innovation, and to persuade us that, if we interfere only a little, the solecism, if there be one, may be pardonable. But the reasoning which would justify any interposition at all demands that it cover the whole extent of the injury. A man whose designs come to harvest in two years, or in five, has prima facie as good right to protection as one who deals only in annuals. Nor could we consistently stop at designs; processes, machines, and secrets have an equal claim. The upshot must be that, whenever any 
one has contrived any of these, others may be forbidden to copy it. That is not the law. In the absence of some recognized right at common law, or under the statutes - and the plaintiff claims neither - a man's property is limited to the chattels which embody his invention. Others may imitate these at their pleasure.

True, it would seem as though the plaintiff had suffered a grievance for which there should be a remedy, perhaps by an amendment of the Copyright Law, assuming that this does not already cover the case, which is not urged here. It seems a lame answer in such a case to turn the injured party out of court, but there are larger issues at stake than his redress. Judges have only a limited power to amend the law; when the subject has been confided to a Legislature, they must stand aside, even though there be an hiatus in completed justice. An omission in such cases must be taken to have been as deliberate as though it were express, certainly after long-standing action on the subject-matter. Indeed, we are not in any position to pass upon the questions involved. We must judge upon records prepared by litigants, which do not contain all that may be relevant to the issues, for they cannot disclose the conditions of this industry, or of the others which may be involved. Congress might see its way to create some sort of temporary right, or it might not. Its decision would certainly be preceded by some examination of the result upon the other interests affected. Whether these would prove paramount we have no means of saying; it is not for us to decide. Our vision is inevitably contracted, and the whole horizon may contain much which will compose a very different picture.

Fashion Originators' Guild of America v. Federal Trade Commission The Circuit Court of Appeals, with modifications not here challenged, affirmed a Federal Trade Commission decree ordering petitioners to cease and desist from certain practices found to have been done in combination and to constitute "unfair methods of competition" tending to monopoly.

Some of the members of the combination design, manufacture, sell and distribute women's garments - chiefly dresses. Others are manufacturers, converters or dyers of textiles from which these garments are made. Fashion Originators' Guild of America (FOGA), an organization controlled by these groups, is the instrument through which petitioners work to accomplish the purposes condemned by the Commission. The garment manufacturers claim to be creators of original and distinctive designs of fashionable clothes for women, and the textile manufacturers claim to be creators of similar original fabric designs. After these designs enter the channels of trade, other manufacturers systematically make and sell copies of them, the copies usually selling at prices lower than the garments copied. Peti- 


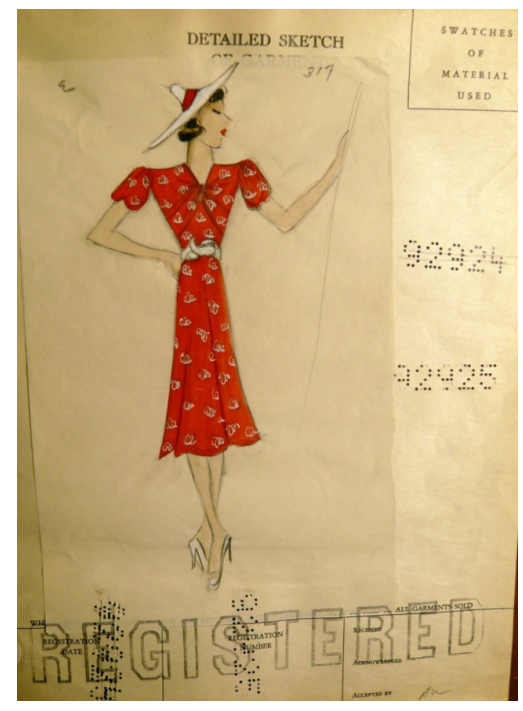

Fashion Originators Guild registration

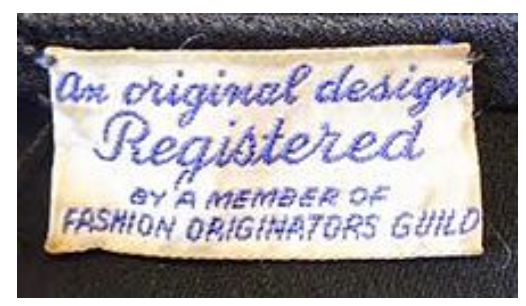

Fashion Originators Guild label

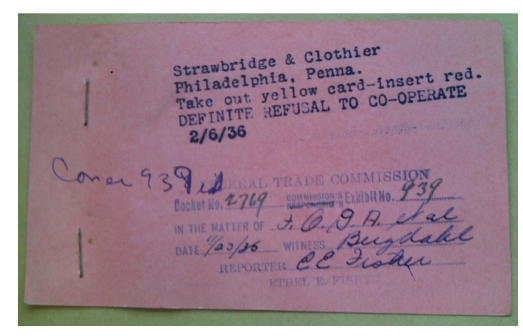

Fashion Originators Guild red card tioners call this practice of copying unethical and immoral, and give it the name of "style piracy." And although they admit that their "original creations" are neither copyrighted nor patented, and indeed assert that existing legislation affords them no protection against copyists, they nevertheless urge that sale of copied designs constitutes an unfair trade practice and a tortious invasion of their rights. Because of these alleged wrongs, petitioners, while continuing to compete with one another in many respects, combined among themselves to combat and, if possible, destroy all competition from the sale of garments which are copies of their "original creations." They admit that to destroy such competition they have in combination purposely boycotted and declined to sell their products to retailers who follow a policy of selling garments copied by other manufacturers from designs put out by Guild members. As a result of their efforts, approximately 12,000 retailers throughout the country have signed agreements to "cooperate" with the Guild's boycott program, but more than half of these signed the agreements only because constrained by threats that Guild members would not sell to retailers who failed to yield to their demands - threats that have been carried out by the Guild practice of placing on red cards the names of noncooperators (to whom no sales are to be made), placing on white cards the names of cooperators (to whom sales are to be made), and then distributing both sets of cards to the manufacturers.

The one hundred and seventy-six manufacturers of women's garments who are members of the Guild occupy a commanding position in their line of business. In 1936, they sold in the United States more than $38 \%$ of all women's garments wholesaling at $\$ 6.75$ and up, and more than $60 \%$ of those at $\$ 10.75$ and above. The power of the combination is great; competition and the demand of the consuming public make it necessary for most retail dealers to stock some of the products of these manufacturers. And the power of the combination is made even greater by reason of the affiliation of some members of the National Federation of Textiles, Inc. - that being an organization composed of about one hundred textile manufacturers, converters, dyers, and printers of silk and rayon used in making women's garments. Those members of the Federation who are affiliated with the Guild have agreed to sell their products only to those garment manufacturers who have in turn agreed to sell only to cooperating retailers.

The Guild maintains a Design Registration Bureau for garments, and the Textile Federation maintains a similar Bureau for textiles. The Guild employs 'shoppers' to visit the stores of both cooperating and non-cooperating retailers, for the purpose of examining their stocks, to determine and report as to whether they contain copies of registered designs. An elaborate system of trial and appellate tribunals exists, for the determination of whether a given garment is in fact a 
copy of a Guild member's design. In order to assure the success of its plan of registration and restraint, and to ascertain whether Guild regulations are being violated, the Guild audits its members books. And if violations of Guild requirements are discovered, as, for example, sales to red-carded retailers, the violators are subject to heavy fines.

Paragraph 3 of the Clayton Act declares "It shall be unlawful for any person engaged in commerce to make a sale or contract for sale of goods on the condition, agreement or understanding that the purchaser thereof shall not use or deal in the goods of a competitor or competitors of the seller, where the effect of such sale, or contract for sale may be to substantially lessen competition or tend to create a monopoly in any line of commerce." The relevance of this section of the Clayton Act to petitioners' scheme is shown by the fact that the scheme is bottomed upon a system of sale under which (1) textiles shall be sold to garment manufacturers only upon the condition and understanding that the buyers will not use or deal in textiles which are copied from the designs of textile manufacturing Guild members; (2) garment manufacturers shall sell to retailers only upon the condition and understanding that the retailers shall not use or deal in such copied designs. And the Federal Trade Commission concluded in the language of the Clayton Act that these understandings substantially lessened competition and tended to create a monopoly. We hold that the Commission, upon adequate and unchallenged findings, correctly concluded that this practice constituted an unfair method of competition.

Not only does the plan in the respects above discussed thus conflict with the principles of the Clayton Act; the findings of the Commission bring petitioners' combination in its entirety well within the inhibition of the policies declared by the Sherman Act itself. Section 1 of that Act makes illegal every contract, combination or conspiracy in restraint of trade or commerce among the several states; Section 2 makes illegal every combination or conspiracy which monopolizes or attempts to monopolize any part of that trade or commerce. And among the many respects in which the Guild's plan runs contrary to the policy of the Sherman Act are these: it narrows the outlets to which garment and textile manufacturers can sell and the sources from which retailers can buy; subjects all retailers and manufacturers who decline to comply with the Guild's program to an organized boycott; takes away the freedom of action of members by requiring each to reveal to the Guild the intimate details of their individual affairs; and has both as its necessary tendency and as its purpose and effect the direct suppression of competition from the sale of unregistered textiles and copied designs.

But petitioners further argue that their boycott and restraint of in-
15 U.S.C. § 14

15 U.S.C. §§ 1,2

In the proceedings below, Judge Learned Hand wrote for the Second Circuit, "The author of a design for a dress should be deemed to be on the same footing as the author of a drawing or a picture; and the author of a drawing or a picture has a "common-law property" in its reproduction. While we have been unable to discover any case which squarely presented the situation -- that is, in which "intellectual property", not covered by the copyright act then in existence, was challenged because of its "publication" -- there are plenty of general expressions in the books that the "common-law property" does not survive. We conclude therefore that, regardless of whether the Guild's designs could be registered or not, "publication" of them was a surrender of all its "common-law property" in them." 
169 F. Supp. 142 (S.D.N.Y. 1959)

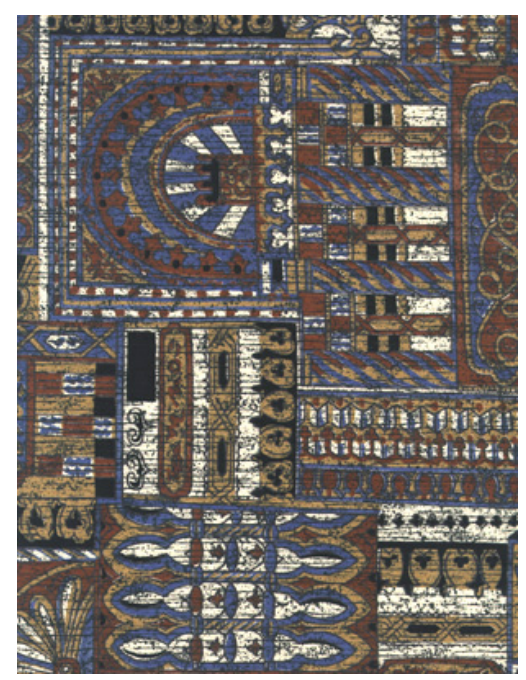

Peter Pan's fabric terstate trade is not within the ban of the policies of the Sherman and Clayton Acts because "the practices of FOGA were reasonable and necessary to protect the manufacturer, laborer, retailer and consumer against the devastating evils growing from the pirating of original designs and had in fact benefited all four." The Commission declined to hear much of the evidence that petitioners desired to offer on this subject. As we have pointed out, however, the aim of petitioners' combination was the intentional destruction of one type of manufacture and sale which competed with Guild members. The purpose and object of this combination, its potential power, its tendency to monopoly, the coercion it could and did practice upon a rival method of competition, all brought it within the policy of the prohibition declared by the Sherman and Clayton Acts. Under these circumstances it was not error to refuse to hear the evidence offered, for the reasonableness of the methods pursued by the combination to accomplish its unlawful object is no more material than would be the reasonableness of the prices fixed by unlawful combination.

\section{Peter Pan Fabrics, Inc. v. Brenda Fabrics, Inc.}

Plaintiff Peter Pan Fabrics has obtained certificate of copyright covering a design printed upon dress fabric. The design is known as "Style 680, Range 1, Byzantium". Defendant is producing and selling a printed fabric almost indisguishable from plaintiff's.

The problem to be decided is whether a design printed upon dress fabric is a proper subject of copyright. In Bleistein, Mr. Justice Holmes dispelled the idea that the word "art" in the Copyright Act imported any idea of merit or high degree or appeal to the better educated classes. In Mazer, Mr. Justice Reed said in the opinion of the court:

It is clear Congress intended the scope of the copyright statute to include more than the traditional fine arts. Herbert Putnam, Esq., then Librarian of Congress and active in the movement to amend the copyright laws, told the joint meeting of the House and Senate Committees:

The term "works of art" is deliberately intended as a broader specification than "works of the fine arts" in the present statute with the idea that there is subject-matter (for instance, of applied design, not yet within the province of design patents), which may properly be entitled to protection under the copyright law.

In Dr. Putnam's statement before the joint meeting we have an authoritative construction of the term "works of art" in the Copyright Act as including "applied design". No better description of the sub- 
ject matter of this litigation could be devised.

I therefore find that plaintiffs' design is a proper subject of copyright both as a work of art and as a print. It was described in the application for copyright as a work of art but that does not preclude sustaining its copyrightability on the ground that it is a print.

\section{Varsity Brands, Inc. v. Star Athletica, LLC}

Are cheerleading uniforms truly cheerleading uniforms without the stripes, chevrons, zigzags, and color blocks? That is the question that strikes at the heart of this appeal. Plaintiffs have registered copyrights for multiple graphic designs that appear on the cheerleading uniforms and warm-ups they sell. Defendant also sells cheerleading gear bearing graphic designs that, according to Varsity, are substantially similar to the designs for which Varsity has valid copyrights.

Qestion One: We begin our analysis by first identifying whether Varsity's designs are "pictorial, graphic, or sculptural works." Varsity's designs, for which they received copyright registration, are "two-dimensional works of ... graphic ... art."

Question Two: Are Varsity's designs "design[s] of ... useful article[s?] Varsity's designs are sketches that depict cheerleading crop tops and skirts - the components of a cheerleading uniform. In other words, they are designs of cheerleading uniforms and sportswear, which have an "intrinsic utilitarian function that is not merely to portray the appearance of [clothing] or to convey information."

Question Three: What are the "utilitarian aspects" of cheerleading uniforms? Cheerleading uniforms have "an intrinsic utilitarian function," namely to cover the body, wick away moisture, and withstand the rigors of athletic movements. Star contends that cheerleading uniforms identify the wearer as a cheerleader and a member of a cheerleading team. But this is no different than saying that a utilitarian aspect of a cheerleading uniform is to convey to others the fact that the wearer of the uniform is a cheerleader for a particular team. And therefore Star's purported utilitarian aspect of a cheerleading uniform is an impermissible factor.

It also appears that Star makes one final argument as to why Varsity's graphic designs cannot "be identified separately from, and are [in]capable of existing independently of, the utilitarian aspects of the article": the designs' "decorative function" is one of the "utilitarian aspects" of a cheerleader uniform.

To the extent that Star contends that pictorial, graphic, or sculptural features are inextricably intertwined with the utilitarian aspects of a cheerleading uniform because they serve a decorative function, we reject that argument. Such a holding would render nearly all artwork unprotectable. Under this theory of functionality, Mondrian's painting would be unprotectable because the painting decorates the
799 F.3d 468 (6th Cir. 2015), cert granted, 136 S. Ct. 1823 (2016)

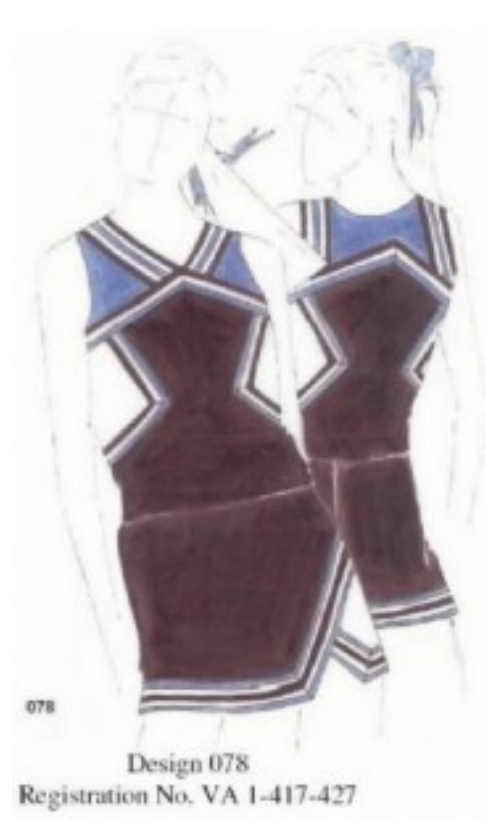

Varsity uniform design 


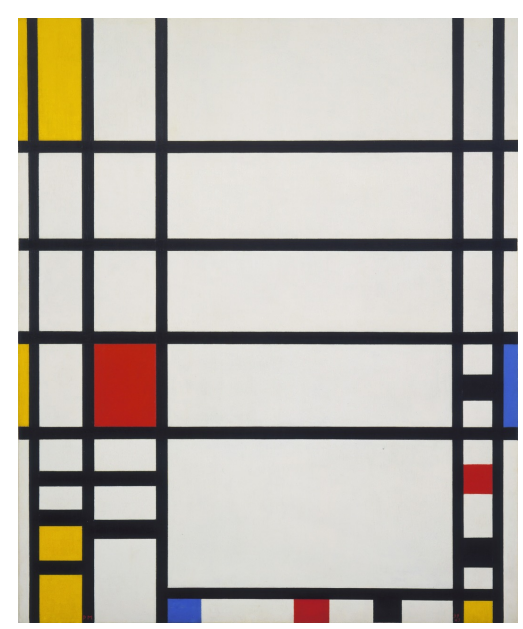

Piet Mondrian, Trafalgar Square (193943) room in which it hangs. But paintings are copyrightable. It would also render the designs on laminate flooring unprotectable because the flooring would be otherwise unattractive. But the Copyright Act protects flooring designs that hide wear or other imperfections in the product. And statuettes adorning the base of a lamp would not be copyrightable under this theory because they serve the function of decorating an otherwise boring lamp base. But they are copyrightable under certain circumstances.Mazen Finally, holding that the decorative function is a "utilitarian aspect[] of [an] article," would make all fabric designs, which serve no other function than to make a garment more attractive, ineligible for copyright protection. But it is well-established that fabric designs are eligible for copyright protection. We therefore conclude that a pictorial, graphic, or sculptural work's "decorative function" does not render it unable to "be identified separately from," or "[in]capable of existing independently of, the utilitarian aspects of the article."

Question Four: Can we identify pictorial, graphic, or sculptural features separately from the parts of the cheerleading-uniform design, which cover the body, permit free movement, and wick moisture? We can identify graphic features of Varsity's designs - the arrangement of stripes, chevrons, zigzags, and color-blocking. The district court concluded that these graphic features are not separately identifiable from a cheerleading uniform because a cheerleading uniform "without team colors stripes, chevrons, and similar designs typically associated with sports in general, and cheerleading in particular, is not recognizable as a cheerleading uniform." We disagree. First, Varsity's graphic designs do not enhance the cheerleading uniform's functionality qua clothing. A plain white cheerleading top and plain white skirt still cover the body and permit the wearer to cheer, jump, kick, and flip. The top and skirt are still easily identified as cheerleading uniforms without any stripes, chevrons, zigzags, or colorblocking. Moreover, the record establishes that not all cheerleading uniforms must look alike to be cheerleading uniforms. The five Varsity designs are examples of how a cheerleading uniform still looks like a cheerleading uniform no matter how different the arrangement of the stripes, chevrons, colorblocks, and zigzags appear on the surface of the uniform. All of Varsity's graphic designs are interchangeable. Varsity's customers choose among the designs in the catalog, including the five designs at issue, select one of the designs, and then customize the color scheme. The interchangeability of Varsity's designs is evidence that customers can identify differences between the graphic features of each design, and thus a graphic design and a blank cheerleading uniform can appear "side by side" - one as a graphic design, and one as a cheerleading uniform. We therefore conclude that each of these graphic design concepts can be identified separately 
from the utilitarian aspects of the cheerleading uniform.

Question Five: Can the arrangement of stripes, chevrons, color blocks, and zigzags "exist[] independently of" the utilitarian aspects of a cheerleading uniform? We believe they can. Varsity's designers sketch their designs and select, place, and arrange various graphic elements, such as stripes, lines, chevrons, inverted chevrons, angles, curves, coloring, and shapes. Varsity's production department either applies these graphic designs onto cheerleading uniforms or recreates the designs by sewing panels of fabric together. Varsity's designs may be incorporated onto the surface of a number of different types of garments, including cheerleading uniforms, practice wear, t-shirts, warm-ups, and jackets, among other things. This evidence establishes that the designs are transferrable to articles other than the traditional cheerleading uniform (crop top and skirt). In addition, the interchangeability of Varsity's various designs is evidence that the graphic design on the surface of the uniform does not affect whether the uniform still functions as a cheerleading uniform. Indeed, nothing (save perhaps good taste) prevents Varsity from printing or painting its designs, framing them, and hanging the resulting prints on the wall as art. We therefore conclude the arrangement of stripes, chevrons, color blocks, and zigzags are wholly unnecessary to the performance of the garment's ability to cover the body, permit free movement, and wick moisture.

Because we conclude that the graphic features of Varsity's designs "can be identified separately from, and are capable of existing independently of, the utilitarian aspects of [cheerleading uniforms]," we hold that Varsity's graphic designs are copyrightable subject matter. This conclusion is faithful to the statutory text of the Copyright Act and consistent with other courts' treatment of the protectability of clothing and the pictorial and graphic features that appear on clothing under the Copyright Act. Courts have drawn a line between "fabric design" and "dress design." "Fabric designs" are "designs imprinted on a fabric, such as a rose petal, which in a completed dress may appear repeatedly throughout the dress fabric, or may appear but once on a given dress." Nimmer. Take the work of Piet Mondrian, for example. Mondrian's artwork or design is separable as a work of art because not only is it possible to recreate the design on t-shirts, grocery bags, cellphone cases, or notebooks, but also it actually has been done: Yves St. Laurent used Mondrian's famous color-blocking and thick, black stripes to create cocktail dresses known as the "Mondrian look." Mondrian's arrangement of color blocks and use of stripes are pictorial and graphic features "that can be identified separately from, and are capable of existing independently of, the utilitarian aspects of" Yves St. Laurent's dress.

In contrast, it is impossible either physically or conceptually to

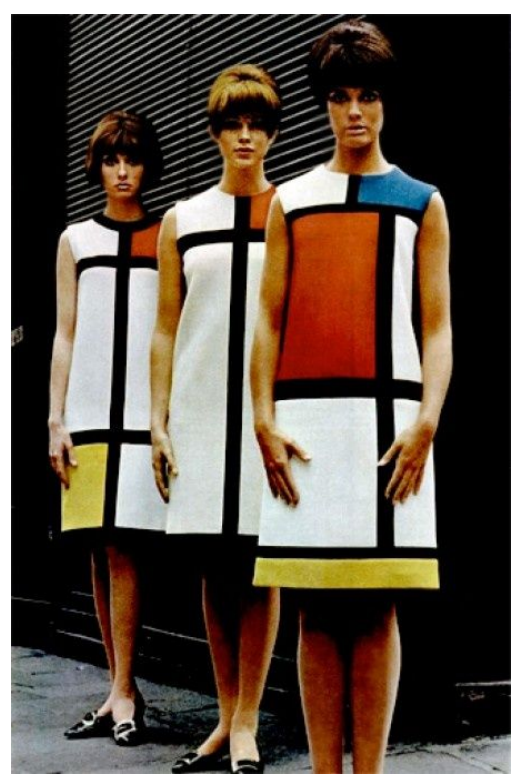

YSL Mondrian dresses 
Knitwaves: 71 F.3d at 996 (2d Cir. 1995)

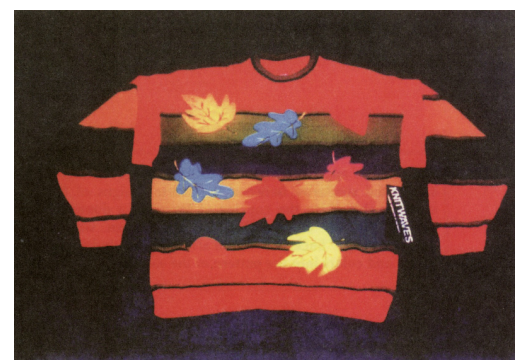

Sweater from Knitwaves

Jovani: 808 F. Supp. 2d 542 (S.D.N.Y. 2011)

Galiano: 416 F. 3d 411 (5th Cir. 2005) separate a "dress design," which "graphically sets forth the shape, style, cut, and dimensions for converting fabric into a finished dress or other clothing garment," from the utilitarian aspects of clothing, i.e., to cover, protect, and warm the body. Nimmer The shapes of the neckline (v-neck, square-neck, crew-neck), sleeves (short, long, puffy), skirt shape (a-line, pencil, midi, maxi), trouser cut (pleated, plain-front, cuffed), or pockets (patch, welt, jetted) - these are the components of a design that are inextricably connected with the utilitarian aspects of clothing: pockets store pencils or pens; pants and skirts cover the legs; shirts cover the torso modestly or less modestly depending on the neckline. The designs of these components of an article of clothing "can[not] be identified separately from, [or be] capable of existing independently of, the utilitarian aspects of the article [of clothing]."

The Copyright Act protects fabric designs, but not dress designs. A designer may obtain valid copyrights for "a multicolored striped sweater with puffy leaf appliques" and a cardigan, "which has a squirrel and leaves appliqued onto its multipaneled front." Knitwaves, Inc. $v$. Lollytogs Ltd. The sweater has a utilitarian function - to provide warm cover for the torso and arms - and the sweaters still perform that function without the leaf or squirrel designs. Similarly, the design of a rose and "the placement of that rose repeated in horizontal rows against an ornate background" on fabric receive copyright protection. Folio Impressions. But the creative arrangement of sequins, beads, ribbon, and tulle, which form the bust, waistband of a dress, do not qualify for copyright protection because each of these elements (bust, waistband, and skirt) all serve to clothe the body. Jovani Fashion, Ltd. v. Cinderella Divine, Inc. And a collection of uniforms, which includes chef hats shaped like vegetables, tuxedo jackets with a "distinctive shawl collar styling with a deep V neckline," and semi-fitted jackets with princess seams and star buttons, does not receive copyright protection. Galiano v. Harrah's Operating Co., Inc. Creative and arguably attractive as these articles may be, they are merely inventive designs used to cover the wearer's body and hair. Thus, the design of these hats and jackets (useful articles) "can[not] be identified separately from," and are not "capable of existing independently of, the utilitarian aspects of" a hat or a jacket.

Because we believe that the graphic features of Varsity's cheerleading-uniform designs are more like fabric design than dress design, we hold that they are protectable subject matter under the Copyright Act. We therefore enter summary judgment for Varsity solely on the issue of the protectability of Varsity's designs as pictorial, graphic, or sculptural works. We express no opinion about whether Varsity's designs are ineligible for copyright protection be- 
cause they lack originality or any other reason.

McKEAGUE, Circuit Judge, dissenting.

I agree with the majority's general approach. We first define the work's function and then ask whether the claimed elements can be identified separately from, or exist independently of, that function. I depart with the majority's analysis, however, in how the function of these designs is defined. I would hold that there is no conceptual separability and that Varsity's designs are not copyrightable. I therefore dissent.

Function. The majority explains that the function of a cheerleading uniform is to wick away moisture and "permit the wearer to cheer, jump, kick, and flip." That broad definition could be used to describe all athletic gear. But the particular athletic uniforms before us serve to identify the wearer as a cheerleader. Without stripes, braids, and chevrons, we are left with a blank white pleated skirt and crop top. As the district court recognized, the reasonable observer would not associate this blank outfit with cheerleading. This may be appropriate attire for a match at the All England Lawn Tennis Club, but not for a member of a cheerleading squad.

Clothing provides many functions, but a uniform at its core identifies its wearer as a member of a group. It follows that the stripes, braids, and chevrons on a cheerleading uniform are integral to its identifying function. The majority rejects this categorization because this holding would purportedly "render nearly all artwork unprotectable." That's not true. It renders unprotectable only artwork that is integral to an item's utilitarian function. In defining that function, we are confined by caselaw and by common sense. Take a dresser, for example. The function of a dresser is to store clothes and other articles. Any ornamental designs displayed on the surface of a dresser are not integral to that function. Those ornamental designs would therefore be copyrightable. In contrast, a painting is not subject to the separability analysis because it does not qualify as a "useful article."

Separability. Once function is properly defined, it logically follows: the placement of the stripes, braids, and chevrons is not separable from that function. In Jovani, in relation to a prom dress, the court excluded from copyright "the arrangement of decorative sequins and crystals on the dress bodice; horizontal satin ruching on the dress waist; and layers of tulle on the skirt." Here, as in that case, there is no evidence that Varsity's designers exercised artistic judgment independently of functional influences, rather than as a merger of aesthetic and functional considerations. In both cases, the designers' aesthetic considerations merged with functional concerns: to cover the body in an attractive way for a special occasion, and to identify the 
wearer as a member of a particular cheerleading squad. Without the stripes, braids, and chevrons, a blank shell of a cheerleading uniform would lose an important dimension of its functional utility.

It is apparent that either Congress or the Supreme Court (or both) must clarify copyright law with respect to garment design. The law in this area is a mess - and it has been for a long time. The majority takes a stab at sorting it out, and so do I. But until we get much-needed clarification, courts will continue to struggle and the business world will continue to be handicapped by the uncertainty of the law.

\section{Trademark}

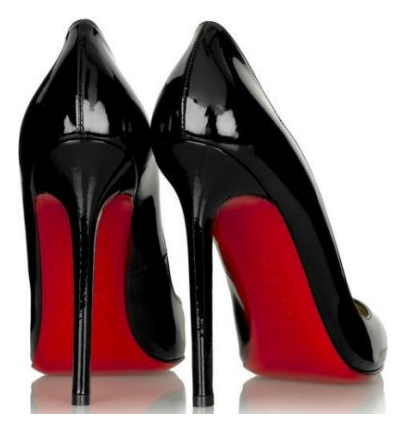

Louboutin Pigalle red-sole shoe

\section{Christian Louboutin v. Yves Saint Laurent America}

Sometime around 1992 designer Christian Louboutin had a bright idea. He began coloring glossy vivid red the out-soles of his high fashion women's shoes. Whether inspired by a stroke of original genius or, as competitor YSL retorts, copied from King Louis XIV's red-heeled dancing shoes, or Dorothy's famous ruby slippers in "The Wizard of Oz," or other styles long available in the contemporary market - including those sold by YSL Christian Louboutin deviated from industry custom. In his own words, this diversion was meant to give his line of shoes "energy," a purpose for which he chose a shade of red because he regarded it as "engaging, flirtatious, memorable and the color of passion," as well as "sexy." In pursuit of the red sole's virtues, Louboutin invested substantial amounts of capital building a reputation and good will, as well as promoting and protecting Louboutin's claim to exclusive ownership of the mark as its signature in women's high fashion footwear.

Over the years, the high fashion industry responded. Christian Louboutin's bold divergence from the worn path paid its dividends. Louboutin succeeded to the point where, in the high-stakes commercial markets and social circles in which these things matter a great deal, the red outsole became closely associated with Louboutin. Leading designers have said it, including YSL, however begrudgingly. Film stars and other A-list notables equally pay homage, at prices that for some styles command as much as \$1,000 a pair. And even at that expense, a respectable niche of consumers wears the brand, to the tune of about 240,000 pairs a year sold in the United States, with revenues of approximately $\$ 135$ million projected for 2011. When Hollywood starlets cross red carpets and high fashion models strut down runways, and heads turn and eyes drop to the celebrities' feet, lacquered red outsoles on high-heeled, black shoes flaunt a glamorous statement that pops out at once. For those in the know, cognitive bulbs instantly flash to associate: "Louboutin." This recognition is 
acknowledged, for instance, at least by a clientele of the well-heeled, in the words of a lyrical stylist of modern times:

Boy, watch me walk it out ... Walk this right up out the house I'm throwin' on my Louboutins ...

The PTO awarded a trademark with Registration No. 3,361,597 (the "Red Sole Mark") to Louboutin on January 1, 2008. The certificate of registration includes both a verbal description of the mark and a line drawing intended to show placement of the mark as indicated [in the margin.] The verbal description reads: "THE MARK CONSISTS OF A LACQUERED RED SOLE ON FOOTWEAR."

YSL, a fashion house founded in 1962, produces seasonal collections that include footwear. According to YSL, red outsoles have appeared occasionally in YSL collections dating back to the 1970s. Louboutin takes issue with four shoes from YSL's Cruise 2011 collection: the Tribute, Tribtoo, Palais and Woodstock models. Each of the challenged models bears a bright red outsole as part of a monochromatic design in which the shoe is entirely red (or entirely blue, or entirely yellow, etc.).

Courts have approved the use of a single color as a trademark for industrial products. See, e.g., Qualitex (green-gold for pads used on dry cleaning presses); In re Owens-Corning Fiberglas Corp. (pink for fibrous glass insulation). In some industrial markets the design, shape and general composition of the goods are relatively uniform, so as to conform to industry-wide standards. Steel bolts, fiber glass wall insulation and cleaning press pads, for example, are what they are regardless of which manufacturer produces them. The application of color to the product can be isolated to a single purpose: to change the article's external appearance so as to distinguish one source from another.

But, whatever commercial purposes may support extending trademark protection to a single color for industrial goods do not easily fit the unique characteristics and needs - the creativity, aesthetics, taste, and seasonal change - that define production of articles of fashion. That distinction may be readily visualized through an image of the incongruity presented by use of color in other industries in contrast to fashion. Can one imagine industrial models sashaying down the runways in displays of the designs and shades of the season's collections of wall insulation? The difference for Lanham Act purposes, as elaborated below, is that in fashion markets color serves not solely to identify sponsorship or source, but is used in designs primarily to advance expressive, ornamental and aesthetic purposes.

In the fashion industry, the Lanham Act has been upheld to permit the registration of the use of color in a trademark, but only in distinct patterns or combinations of shades that manifest a conscious
Jennifer Lopez, "Louboutins" (Epic Records 2009)

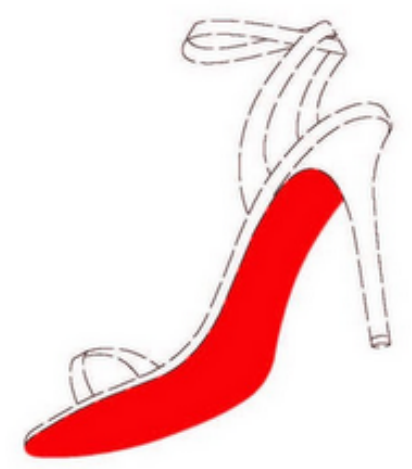

Line drawing from Louboutin's registration

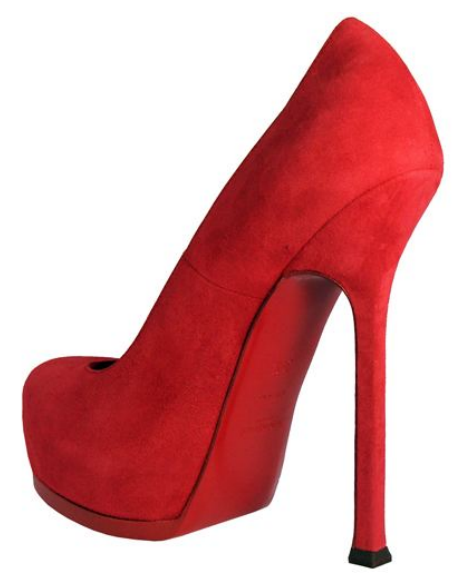

YSL monochromatic Tribtoo in suede Owens-Corning: 774 F.2d 1116 (Fed. Cir. 1985) 
Euro Moda: No. 08 Civ. 5781, 2009 WL 1675080 (S.D.N.Y. June 10, 2009) effort to design a uniquely identifiable mark embedded in the goods. See, e.g., , Dooney $\mathcal{E}$ Bourke ("LV" monogram combined in a pattern of rows with 33 bright colors); Burberry Ltd. v. Euro Moda, Inc. (registered Burberry check pattern entitled to statutory presumption of validity). In these cases the courts clearly point out that the approved trademark applies to color not as an abstract concept, or to a specific single shade, but to the arrangement of different colors and thus their synergy to create a distinct recognizable image purposely intended to identify a source while at the same time serving as an expressive, ornamental or decorative concept.

The narrow question presented here is whether the Lanham Act extends protection to a trademark composed of a single color used as an expressive and defining quality of an article of wear produced in the fashion industry. In other words, the Court must decide whether there is something unique about the fashion world that militates against extending trademark protection to a single color, although such registrations have sometimes been upheld in other industries.

To answer this question, and recognizing the fanciful business from which this lawsuit arises, the Court begins with a fanciful hypothetical. Suppose that Monet, having just painted his water lilies, encounters a legal challenge from Picasso, who seeks by injunction to bar display or sale of those works. In his complaint, Picasso alleges that Monet, in depicting the color of water, used a distinctive indigo that Picasso claims was the same or too close to the exquisite shade that Picasso declares is "the color of melancholy," the hallmark of his Blue Period, and is the one Picasso applied in his images of water in paintings of that collection. By virtue of his long-standing prior use of that unique tinge of blue in context, affirmed by its registration by the trademark office, Picasso asserts exclusive ownership of the specific tone to portray that color of water in canvas painting. Should a court grant Picasso relief?

The creative energies of painter and fashion designer are devoted to appeal to the same sense in the beholder and wearer: aesthetics. Both strive to please patrons and markets by creating objects that not only serve a commercial purpose but also possess ornamental beauty (subjectively perceived and defined). Quintessentially, both painting and fashion embrace matters of taste. In consequence, they share vicissitudes natural to any matter of palate or palette. They change as the seasons change. Styles, features, whole lines come and go with passing likes and dislikes, to be replaced by new articles with origins from regions where genius charts a different course. Items fall in and out of fashion in all nuances of the word, conveying not only currency but seasonality and transience. Perhaps capturing something of that relative inconstancy, painting and fashion share a vocabulary. They speak in ethereal terms like fanciful, inventive, eccentric, whimsical, 
visionary, and, to quote Louboutin again, "engaging, flirtatious" - all words which also have in common an aim to evoke and affect things of the moment.

These creative means also share a dependence on color as an indispensable medium. Color constitutes a critical attribute of the goods each form designs. Alone, in combinations, in harmonious or even incongruous blends, in varying patterns and shapes, the whole spectrum of light serves as a primal ingredient without which neither painting nor fashion design as expressive and ornamental art would flourish. For, color depicts elemental properties. As it projects expression of the artist's mental world, it captures the mutability, the fancy, the moods of the visual world, in both spheres working as a means to execute singular concepts born of imagination for which not just any other shade will do. Hence, color in this context plays a unique role. It is a feature purposely given to an article of art or design to depict the idea as the creator conceived it, and to evoke an effect intended. In ornamenting, it draws attention to itself, and to the object for which its tone forms a distinct expressive feature. From these perspectives, color in turn elementally performs a creative function; it aims to please or be useful, not to identify and advertise a commercial source.

But, as an offshoot of color, perhaps most crucial among the features painting and fashion design share as commerce and art, are two interrelated qualities that both creative fields depend upon to thrive, and indeed to survive: artistic freedom and fair competition. In both forms, the greatest range for creative outlet exists with its highest, most vibrant and all-encompassing energies where every pigment of the spectrum is freely available for the creator to apply, where every painter and designer in producing artful works enjoys equal freedom to pick and choose color from every streak of the rainbow. The contrary also holds. Placing off limit signs on any given chromatic band by allowing one artist or designer to appropriate an entire shade and hang an ambiguous threatening cloud over a swath of other neighboring hues, thus delimiting zones where other imaginations may not veer or wander, would unduly hinder not just commerce and competition, but art as well.

No one would argue that a painter should be barred from employing a color intended to convey a basic concept because another painter, while using that shade as an expressive feature of a similar work, also staked out a claim to it as a trademark in that context. If as a principle this proposition holds as applied to high art, it should extend with equal force to high fashion. The law should not countenance restraints that would interfere with creativity and stifle competition by one designer, while granting another a monopoly invested with the right to exclude use of an ornamental or functional medium 
"The 'classic" aesthetic functionality cases are actually about cognitive or psychological responses in consumers, not aesthetics per se. Based on that observation, I propose that aesthetic functionality should only be found by courts when the product feature at issue triggers a positive cognitive, psychological, or aesthetic response among a substantial composite of the relevant consumers and that response predates the trademark owner's activities." Justin Hughes, Cognitive and Aesthetic Functionality in Trademark Law, 36 Cardozo L. Rev. 1227 (2015) necessary for freest and most productive artistic expression by all engaged in the same enterprise.

The question of whether the use of a single color in the fashion industry can constitute a valid mark necessarily raises another one: whether a single color may be "functional" in that context. Use of a single color has been held functional, and therefore not protectable under the Lanham Act, in other contexts. See, e.g., Brunswick Corp (black for marine outboard engines held functional because it is "compatible with a wide variety of boat colors and [can] make objects appear smaller"); Deere $\&$ Co. v. Farmhand, Inc. (green for farm equipment held functional because farmers "prefer to match their loaders to their tractor"), These cases illustrate the principle that aesthetic appeal can be functional; often we value products for their looks.

Louboutin's claim to "the color red" is, without some limitation, overly broad and inconsistent with the scheme of trademark registration established by the Lanham Act. Awarding one participant in the designer shoe market a monopoly on the color red would impermissibly hinder competition among other participants. YSL has various reasons for seeking to use red on its outsoles - for example, to reference traditional Chinese lacquer ware, to create a monochromatic shoe, and to create a cohesive look consisting of color-coordinating shoes and garments. Presumably, if Louboutin were to succeed on its claim of trademark infringement, YSL and other designers would be prohibited from achieving those stylistic goals. In this respect, Louboutin's ownership claim to a red outsole would hinder competition not only in high fashion shoes, but potentially in the markets for other women's wear articles as well. Designers of dresses, coats, bags, hats and gloves who may conceive a red shade for those articles with matching monochromatic shoes would face the shadow or reality of litigation in choosing bands of red to give expression to their ideas.

The effects of this specter - the uncertainty and apprehension it generates - are especially acute in the fashion industry because of its grounding on the creative elements discussed above. Fashion is dependent on colors. It is subject to temporal change. It is susceptible to taste, to idiosyncrasies and whims and moods, both of designers and consumers. Thus, at any moment when the market and the deities of design, by whatever fancy they decide those things, proclaim that "passion" is in for a given season and must be expressed in reds in the year's various collections, Louboutin's claim would cast a red cloud over the whole industry, cramping what other designers could do, while allowing Louboutin to paint with a full palette.

Louboutin would thus be able to market a total outfit in his red, while other designers would not. And this impediment would apply not just with respect to Louboutin's registered "the color red," but, 
on its theory as pressed in this litigation, to a broader band of various other shades of red which would be available to Louboutin but which it could bar others from using.

Louboutin asserts that it is the color depicted in the registration's drawing, and not the verbal reference to the "color red," that controls. In its reply brief, Louboutin identified that color for the first time as Pantone No. 18-1663 TP, or "Chinese Red," part of the PANTONE TEXTILE color system. Yet that identification raises additional issues. Louboutin cannot amend or augment its PTO registration by representations it makes in this litigation. Accordingly, the color that governs here remains, as Louboutin points out, the shade of red depicted in the registration's drawing. As Louboutin concedes, however, because of varying absorption and reflection qualities of the material to which it is applied, a color as it manifests on paper would appear quite different - some lighter, some darker hues - on other mediums such as leather and cloth. A competitor examining the Louboutin registration drawing for guidance as to what color it applies to may therefore remain unable to determine precisely which shade or shades it encompasses and which others are available for it to safely use.

Moreover, YSL has represented to the Court that the precise color of the styles Louboutin challenges is not Chinese Red, and that YSL has never used Pantone No. 18-1663 TP on its outsoles. Undaunted, Louboutin insists that YSL has nonetheless infringed the Red Sole Mark because its challenged shoe models use a shade confusingly too close to Chinese Red. Yet Louboutin cannot provide a satisfactory explanation as to why those models - but not others previously made by YSL that also bear a red outsole - are confusingly similar to its claimed mark. The larger question this conflict poses is how close to a protected single color used in an item of fashion can the next competitor approach without encountering legal challenge from the first claimant of a shade as a trademark.

In response to this legal dilemma, Louboutin proposes that the Court simply draw a designated range both above and below the borderlines of Pantone No. 18-1663 TP, and declare all other stripes of red within that zone forbidden to competitors. Its suggested metric references Olay Co., Inc. v. Cococare Prods., Inc. (issuing injunction requiring infringer to use "a discernibly different pink, at least $40 \%$ different in terms of [Pantone Matching System] tones" from that used by registrant). Louboutin's proposal would have the effect of appropriating more than a dozen shades of red - and perhaps other colors as well ${ }^{-}$and goes far beyond the injunction upon which Louboutin

\footnotetext{
${ }^{6}$ Louboutin's suggestion that the Court require other designers to stay some percentage away from Chinese Red raises the question: some percentage of what? Chinese Red, like any color, is made up of a certain combination of other colors.
} 
relies. In Olay, the protectable interest was not "in the color pink alone," but rather in the color in combination with graphics and packaging. Here, Louboutin's claimed mark is, in essence, the color red alone when used on the soles of "high fashion" footwear. Moreover, although Louboutin attempts in these proceedings to limit the scope of the mark to high-heeled footwear, no such limitation appears on the face of the registration.

The other options Louboutin's claim would leave other competitors are no more practical or palatable. As YSL endeavored to do during a deposition of Christian Louboutin in connection with this action, other designers could seek advance clearance from Christian Louboutin himself, spreading the fan of shades before him to see at what tint his red light changes to amber. Or they could go to court and ask for declaratory relief holding that a proposed red sole is not close enough to Chinese Red to infringe Louboutin's mark, thereby turning the judge into an arbiter of fashion design. Though Qualitex points out that in trademark disputes courts routinely are called upon to decide difficult questions involving shades of differences in words or phrases or symbols, the commercial contexts in which the application of those judgments generally has arisen has not entailed use of a single color in the fashion industry, where distinctions in designs and ideas conveyed by single colors represent not just matters of degree but much finer qualitative and aesthetic calls.

Because Louboutin's registration specifies that it covers women's high fashion "designer footwear," the description is broad enough to encompass all styles of shoes, not just the high-heeled model illustrated in the PTO registration. Louboutin's argument that it would not pursue a claim of infringement based upon red outsoles on, for example, flat shoes, wedges or kitten heels, is cold comfort to competing designers. In fact, in one case in Paris, Louboutin sought to enforce its French trademark for a "shoe sole in the color red" against the company Zara France, S.A.R.I., which is not a high-end retailer.

Another dimension of uncertainty the Red Sole Mark creates pertains to its coating. Louboutin's claim extends not just to the base of "the color red," but also to its gloss. In the registration, it is described more specifically as "lacquered" red. Thus, it is not clear, for example, whether the protection of Louboutin's trademark would apply to a "Chinese Red" outsole that was not shiny, but entirely flat. In fact, that issue has surfaced in this case. YSL asserts that the color

Based on the Court's research, this combination can be expressed in various metrics, such as a combination of RGB (red, green, blue) or CMYK (cyan, magenta, yellow, black), or HSB (hue, saturation, brightness). In Adobe Color Picker, a variance of just 10 percent in any of these inputs, in either direction, yields more than a dozen shades visibly different from Chinese Red, in some cases so different as to appear to the casual observer pink on one side of Chinese Red or orange on the other. 
tone of some of the shoes Louboutin challenges is not lacquered at all but a flat red. By bringing this litigation, Louboutin is of course calling upon the Court to pass judgment as well on the degree of buffing that a competitor may give to a Chinese Red outsole before it begins to infringe on Louboutin's rights.

Finally, conferring legal recognition on Louboutin's claim raises the specter of fashion wars. If Louboutin owns Chinese Red for the outsole of high fashion women's shoes, another designer can just as well stake out a claim for exclusive use of another shade of red, or indeed even Louboutin's color, for the insole, while yet another could, like the world colonizers of eras past dividing conquered territories and markets, plant its flag on the entire heel for its Chinese Red. And who is to stop YSL, which declares it pioneered the monochrome shoe design, from trumping the whole footwear design industry by asserting rights to the single color shoe concept in all shades? And these imperial color wars in women's high fashion footwear would represent only the opening forays. What about hostile color grabs in the markets for low-fashion shoes? Or for sports shoes? Or expanding beyond footwear, what about inner linings, collars, or buttons on coats, jackets, or dresses in both women's and men's apparel?

In sum, the Court cannot conceive that the Lanham Act could serve as the source of the broad spectrum of absurdities that would follow recognition of a trademark for the use of a single color for fashion items. Because the Court has serious doubts that Louboutin possesses a protectable mark, the Court finds that Louboutin cannot establish a likelihood that it will succeed on its claims for trademark infringement and unfair competition under the Lanham Act.

\section{Christian Louboutin v. Yves Saint Laurent America}

The District Court's holding that a single color can never serve as a trademark in the fashion industry is inconsistent with the Supreme Court's decision in Qualitex.

\section{The "Functionality" Defense}

Although the theory of aesthetic functionality was proposed as early as 1938, the first court to adopt the theory as the basis for denial of protection of a design was the United States Court of Appeals for the Ninth Circuit in Pagliero v. Wallace China Co.. In Pagliero, the Court of Appeals determined that the Wallace China Company was not entitled to the exclusive use of a particular floral design on hotel china, despite its "creation of a substantial market for its products bearing these designs by virtue of extensive advertising." The design, the Court held, was "functional" because it satisfied "a demand for the aesthetic as well as for the utilitarian." Because the "particular feature is an important ingredient in the commercial success of the
696 F.3d 206 (2d Cir. 2012)

Pagliero: 198 F.2d 339 (9th Cir. 1952) 
product, the interest in free competition permits its imitation in the absence of a patent or copyright."

Despite its apparent counterintuitiveness (how can the purely aesthetic be deemed functional, one might ask?), our Court has long accepted the doctrine of aesthetic functionality. We have rejected, however, the circular "important ingredient" test formulated by the Pagliero court, which inevitably penalized markholders for their success in promoting their product. Instead, we have concluded that Lanham Act protection does not extend to configurations of ornamental features which would significantly limit the range of competitive designs available. Accordingly, we have held that the doctrine of aesthetic functionality bars protection of a mark that is necessary to compete in the relevant market.

We note that a product feature's successful source indication can sometimes be difficult to distinguish from the feature's aesthetic function, if any. Therefore, in determining whether a mark has an aesthetic function so as to preclude trademark protection, we take care to ensure that the mark's very success in denoting (and promoting) its source does not itself defeat the markholder's right to protect that mark. Because aesthetic function and branding success can sometimes be difficult to distinguish, the aesthetic functionality analysis is highly fact-specific.

We now turn to the per se rule of functionality for color marks in the fashion industry adopted by the District Court - a rule that would effectively deny trademark protection to any deployment of a single color in an item of apparel. As noted above, Qualitex expressly held that "sometimes a color will meet ordinary legal trademark requirements, and, when it does so, no special legal rule prevents color alone from serving as a trademark." In other words, the Supreme Court specifically forbade the implementation of a per se rule that would deny protection for the use of a single color as a trademark in a particular industrial context. Qualitex requires an individualized, factbased inquiry into the nature of the trademark, and cannot be read to sanction an industry-based per se rule. The District Court created just such a rule, on the theory that "there is something unique about the fashion world that militates against extending trademark protection to a single color."

Even if Qualitex could be read to permit an industry-specific per se rule of functionality (a reading we think doubtful), such a rule would be neither necessary nor appropriate here. We readily acknowledge that the fashion industry, like other industries, has special concerns in the operation of trademark law; it has been argued forcefully that United States law does not protect fashion design adequately. Indeed, the case on appeal is particularly difficult precisely because, as the District Court well noted, in the fashion industry, color can serve 
as a tool in the palette of a designer, rather than as mere ornamentation.

Nevertheless, the functionality defense does not guarantee a competitor the greatest range for his creative outlet, but only the ability to fairly compete within a given market.

\section{The Red Sole Mark}

Having determined that no per se rule governs the protection of single-color marks in the fashion industry, any more than it can do so in any other industry, we turn our attention to the Red Sole Mark. The Red Sole Mark has acquired limited secondary meaning as a distinctive symbol that identifies the Louboutin brand, and it is therefore a valid and protectable mark as modified below.

We see no reason why a single-color mark in the specific context of the fashion industry could not acquire secondary meaning - and therefore serve as a brand or source identifier - if it is used so consistently and prominently by a particular designer that it becomes a symbol, the primary significance of which is to identify the source of the product rather than the product itself.

In light of the evidence in the record, including extensive consumer surveys submitted by both parties during the preliminary injunction proceedings, and of the factual findings of the District Court, we think it plain that Louboutin's marketing efforts have created what the able district judge described as "a ... brand with worldwide recognition." We hold that the lacquered red outsole, as applied to a shoe with an "upper" of a different color, has "come to identify and distinguish" the Louboutin brand, and is therefore a distinctive symbol that qualifies for trademark protection.

We further hold that the record fails to demonstrate that the secondary meaning of the Red Sole Mark extends to uses in which the sole does not contrast with the upper - in other words, when a red sole is used on a monochromatic red shoe. As the District Court observed, "When Hollywood starlets cross red carpets and high fashion models strut down runways, and heads turn and eyes drop to the celebrities' feet, lacquered red outsoles on high-heeled, black shoes flaunt a glamorous statement that pops out at once." As clearly suggested by the District Court, it is the contrast between the sole and the upper that causes the sole to "pop," and to distinguish its creator.

The evidentiary record further demonstrates that the Louboutin mark is closely associated with contrast. For example, Pinault, the chief executive of YSL's parent company, wrote that the "distinctive signature" of the Mark is in its "contrast with the general presentation of the shoe, particularly its upper." Of the hundreds of pictures of Louboutin shoes submitted to the District Court, only four were monochrome red. And Louboutin's own consumer surveys show 
that when consumers were shown the YSL monochrome red shoe, of those consumers who misidentified the pictured shoes as Louboutinmade, nearly every one cited the red sole of the shoe, rather than its general red color.

Because we conclude that the secondary meaning of the mark held by Louboutin extends only to the use of a lacquered red outsole that contrasts with the adjoining portion of the shoe, we modify the Red Sole Mark, pursuant to Section 37 of the Lanham Act, insofar as it is sought to be applied to any shoe bearing the same color "upper" as the outsole. We therefore instruct the Director of the Patent and Trade Office to limit the registration of the Red Sole Mark to only those situations in which the red lacquered outsole contrasts in color with the adjoining "upper" of the shoe.

In sum, we hold that the Red Sole Mark is valid and enforceable as modified. This holding disposes of the Lanham Act claims brought by both Louboutin and YSL because the red sole on YSL's monochrome shoes is neither a use of, nor confusingly similar to, the Red Sole Mark. Having limited the Red Sole Mark as described above, and having established that the red sole used by YSL is not a use of the Red Sole Mark, it is axiomatic that we need not - and should not - address either the likelihood of consumer confusion or whether the modified Mark is functional.

\section{Design Patent}

\section{Kal Raustiala \& Christopher Sprigman}

The Piracy Paradox, Innovation and Intellectual Property in Fashion Design

The design patent provision fails to shelter fashion design for two principal reasons.

The first reason is doctrinal. Unlike copyright, which extends to all "original" expression, that is, all expression not copied in its entirety from others and that contains a modicum of creativity, design patents are available only for designs that are truly "new," and does not extend to designs that are merely reworkings of previously existing designs. Because so many apparel designs are reworkings and are not "new" in the sense that the patent law requires, most will not qualify for design patent protection.

There is, moreover, a second and more substantial limitation to the relevance of design patent as a form of protection for fashion designs. The process of preparing a patent application is expensive, the waiting period lengthy (more than eighteen months, on average, for design patents), and the prospects of protection uncertain (the United States Patent and Trademark Office rejects roughly half of all applica- 
tions for design patents). Given the short shelf-life of many fashion designs, the design patent is simply too slow and uncertain to be relevant.

\section{Sui Generis Protection?}

\section{James Surowiecki \\ The Piracy Paradox}

Designers' frustration at seeing their ideas mimicked is understandable. But this is a classic case where the cure may be worse than the disease. There's little evidence that knockoffs are damaging the business. Fashion sales have remained more than healthy-estimates value the global luxury-fashion sector at a hundred and thirty billion dollars - and the high-end firms that so often see their designs copied have become stronger. More striking, a recent paper by the law professors Kal Raustiala and Christopher Sprigman suggests that weak intellectual-property rules, far from hurting the fashion industry, have instead been integral to its success. The professors call this effect "the piracy paradox."

The paradox stems from the basic dilemma that underpins the economics of fashion: for the industry to keep growing, customers must like this year's designs, but they must also become dissatisfied with them, so that they'll buy next year's. Many other consumer businesses face a similar problem, but fashion-unlike, say, the technology industry-can't rely on improvements in power and performance to make old products obsolete. Raustiala and Sprigman argue persuasively that, in fashion, it's copying that serves this function, bringing about what they call "induced obsolescence." Copying enables designs and styles to move quickly from early adopters to the masses. And since no one cool wants to keep wearing something after everybody else is wearing it, the copying of designs helps fuel the incessant demand for something new.

The situation is not necessarily easy on designers, who have to keep coming up with new ideas rather than being able to milk a trend for years. But it means that in the industry as a whole there is more innovation, more competition, and probably more sales than there otherwise would be. And the absence of copyrights and patents also creates a more fertile ground for that innovation, since designers are able to take other people's ideas in new directions. Had the designers who came up with the pinstripe or the stiletto heel been able to bar others from using their creations, there would have been less innovation in fashion, not more.

If copying were putting a serious dent in designers' profits, it might slow the pace of innovation, since designers would have less
The New Yorker (Sept. 24, 2007) 
incentive to produce good work. But while knockoffs undoubtedly do steal some sales from originals, they are, for the most part, targeted at an entirely different market segment-people who appreciate high style but can't afford high prices. That limits the damage knockoffs do, as does the fact that fashion is one of the few industries in the world where people are still willing to pay a considerable premium to own original brands instead of imitations. (That's why counterfeits, which pretend to be original products, are illegal.) The best evidence of this is the fact that luxury-goods makers, far from cutting their prices in response to the knockoff boom, have instead been able to raise prices consistently. In fact, given the importance to fashion of what the law professor Jonathan Barnett calls "aspirational utility" - the enjoyment people get from imitating the life style of the rich and famous - one might think of knockoffs as being like gateway drugs: access to the lower-quality version makes buyers all the more interested in eventually getting the real stuff.

61 Stan. L. Rev. 1147 (2009)

\section{Scott Hemphill \& Jeannie Suk}

\section{The Law, Culture, and Economics of Fashion}

Copying in fashion is not a new problem. U.S. designers in the early 20th century - and, before that, French couturiers - were plagued by competitors who made sketches at shows or measured the seams of procured originals to discern their patterns, and then used local labor to make the copies. Often, these copies could be accomplished quickly, and the copies reached the market before the original.

What has changed is not the fact or speed of copying, but the large scale and low cost at which rapid copies can be made. (For comparison, just think of music, where rapid copying has long been feasible, while large-scale, low-cost rapid copying is a new phenomenon.) Today, a pattern can be based upon an Internet broadcast of the runway show and transmitted electronically to a low- cost contract manufacturer overseas. A gradual easing in import quotas, begun in 1995, has increased scale and thereby lowered overseas manufacturing costs. Electronic communications and express shipping ensure that prototypes and finished articles can be brought to market quickly. As a result, thousands of inexpensive copies of a new design can be produced, from start to finish, in six weeks or less.

The most striking consequence of low-cost, high-scale, rapid copying is not in beating an original to market, but in the ability to wait and see which designs succeed, and copy only those. Copyists can choose a target after retailers have made their buying decisions, or even after the product reaches stores, and customers have begun to buy. Such copyists can reach market well before the relevant trend has ended.

Retailers and manufacturers exploit the resulting opportunity. 
They sell copies at a discount to the original - necessarily, given the lower quality - but earn a profit thanks to lower unit costs and the avoided expense of design. The most notorious copyist retailer is Forever 21, though copying also extends to a wide range of department stores and specialty clothing retailers.

Copying is not a necessary element of the fast-fashion business model. Even retailers that sell copies do not sell only copies. And some fast-fashion firms eschew line-for-line copies. For example, the two leading fast-fashion firms, Zara and H\&M, avoid close copying. Although Zara and H\&M may have become conflated with Forever 21 in the public mind, their strategies are different. Like the copyists, they move product to market very quickly. But their on-trend product, reactive though it is to the latest offerings of top designers, is not a precise copy. Instead, it is an adaptation or interpretation, developed by in-house designers.

A common normative response against the idea of intellectual property protection for fashion design grows out of the assumption that fashion is a visible marker of status. On this theory, making it more difficult to copy fashion may seem undesirable because it would promote the ability of wealthy people to enjoy and signal their status through apparel that only they can have, and thwart those who want to purchase cheaper knockoffs of those goods. After all, if rampant copying makes available cheaper knockoffs, that may disrupt the ability of the wealthy to distinguish themselves as a group through the signal of fashion. On this view, perhaps permission to copy effectively softens the socially stratifying effects of fashion, while legal restrictions on copying would reinforce them.

But there is much more to fashion than signals about status. In light of the broader and more varied communicative and expressive aspects of fashion, status is only one of a wide variety of signals that fashion makes possible. Fashion has the potential to afford a broad vocabulary for the expression of a vast range of possible messages. Conscious or not, people's fashion choices signify and communicate, with meaningful individual and collective valences. We have identified this dynamic between differentiation and flocking as the key to the experience of fashion in social life. People use fashion to signal individual differences while also partaking in common movement with the collectivity.

The current intellectual property regime, in which legal protection from design copying is lacking, tends, if anything, to push fashion consumption and production in the direction of status and luxury rather than more polyvalent innovation. In sum, we have noted two distortions. The first is toward the creation of designs that are legally more difficult to copy. Trademark and trade dress already protect the most salient status-signaling items in fashion, those adorned with lo- 
gos of high-end brands. Therefore, those who want to enable effective status signal-jamming should be critical of trademark protection, and not necessarily resist copyright protection for fashion design. The second distortion is toward the creation of goods that are naturally (as opposed to legally) more difficult to copy, or goods that are more difficult for design copying to harm - for example, goods involving unusual or expensive materials or difficult workmanship.

The result of these distortions is to push creators toward the highend realm of status and luxury, and away from devoting creative resources to design innovation. In a regime that protected original designs from copying, we would expect to see a shift in resources from developing brand-name or luxury goods or attempting close copies of designs toward developing a richer, more polycentric language of fashion that draws on and reinvents available inspirations and influences. We would expect to see greater range and variety in fashion innovation that would enlarge the vocabulary and the set of symbols with which we may produce meaning.

At bottom, though, the main reason not to accommodate the lovers of cheap fashion knockoffs is more basic. It is the same reason that we do not have a legal regime that permits people freely to make and sell photocopies of another author's book and retain the profits. It is the theory of incentives. Obviously, people always want to purchase inexpensive copies of creative works or have them for free. The reason to disallow it is not to deprive them of that benefit but rather to provide creators with an incentive to create. That is no less true in fashion.

Innovative Design Protection Act of 2012

S. 3523 (as introduced Sept. 10, 2012)

A BILL

To amend title 17, United States Code, to extend protection to fashion design, and for other purposes. [The IDPA would have amended chapter 13 as follows:]

17 U.S.C. S 1301

Designs protected (a) Designs Protected. -

(1) In general. - The designer or other owner of an original design of a useful article which makes the article attractive or distinctive in appearance to the purchasing or using public may secure the protection provided by this chapter upon complying with and subject to this chapter.

(2) Vessel features. - The design of a vessel hull, deck, or combination of a hull and deck, including a plug or mold, is subject to protection under this chapter, notwithstanding section 1302(4). 
(4) Fashion Design. -- A fashion design is subject to protection under this chapter.

(b) Definitions. - For the purpose of this chapter, the following terms have the following meanings:

(1) A design is "original" if it is the result of the designer's creative endeavor that provides a distinguishable variation over prior work pertaining to similar articles which is more than merely trivial and has not been copied from another source.

(2) A "useful article" is a vessel hull or deck, including a plug or mold, or an article of apparel, which in normal use has an intrinsic utilitarian function that is not merely to portray the appearance of the article or to convey information. An article which normally is part of a useful article shall be deemed to be a useful article.

(8) A "fashion design"

(A) is the appearance as a whole of an article of apparel, including its ornamentation; and

(B) includes original elements of the article of apparel or the original arrangement or placement of original or non-original elements as incorporated in the overall appearance of the article of apparel that --

(i) are the result of a designer's own creative endeavor; and

(ii) provide a unique, distinguishable, non-trivial and nonutilitarian variation over prior designs for similar types of articles.

(10) The term 'apparel' means --

(A) an article of men's, women's, or children's clothing, including undergarments, outerwear, gloves, footwear, and headgear;

(B) handbags, purses, wallets, tote bags, and belts; and

(C) eyeglass frames.

(11) In the case of a fashion design, the term 'substantially identical' means an article of apparel which is so similar in appearance as to be likely to be mistaken for the protected design, and contains only those differences in construction or design which are merely trivial."; and

(c) Rule Of Construction. -- In the case of a fashion design under this chapter, those differences or variations which are considered non-trivial for the purposes of establishing that a design is subject to protection under subsection (b)(8) shall be considered non-trivial for the purposes of establishing that a defendant's design is not substantially identical under subsection (b)(11) and section 1309(e) 
17 U.S.C S 1302

Designs not subject to protection

17 U.S.C § 1303

Revisions, adaptations, and rearrangements

17 U.S.C $\S 1305$

Term of protection
Protection under this chapter shall not be available for a design that is -

(1) not original;

(2) staple or commonplace, such as a standard geometric figure, a familiar symbol, an emblem, or a motif, or another shape, pattern, or configuration which has become standard, common, prevalent, or ordinary;

(3) different from a design excluded by paragraph (2) only in insignificant details or in elements which are variants commonly used in the relevant trades;

(4) dictated solely by a utilitarian function of the article that embodies it; or

(5) (A) in the case of a design of a vessel hull embodied in a useful article that was made public by the designer or owner in the United States or a foreign country more than 2 years before the date of the application for registration under this chapter.

(B) in the case of a fashion design, embodied in a useful article that was made public by the designer or owner in the United States or a foreign country before the date of enactment of this chapter or more than 3 years before the date upon which protection of the design is asserted under this chapter.

Protection for a design under this chapter shall be available notwithstanding the employment in the design of subject matter excluded from protection under section 1302 if the design is a substantial revision, adaptation, or rearrangement of such subject matter. Such protection shall be independent of any subsisting protection in subject matter employed in the design, and shall not be construed as securing any right to subject matter excluded from protection under this chapter or as extending any subsisting protection under this chapter. The presence or absence of a particular color or colors or of a pictorial or graphic work imprinted on fabric shall not be considered in determining the protection of a fashion design under section 1301 or 1302 or in determining infringement under section 1309.

(a) In General. - Subject to subsection (b), the protection provided under this chapter

(a) for a design of a vessel hull, shall continue for a term of 10 years beginning on the date of the commencement of protection under section 1304; and

(b) for a fashion design, shall continue for a term of 3 years begin- 
ning on the date of the commencement of protection under section 1304.

(d) Fashion Design. -

(1) In General. -- In the case of a fashion design, the owner of the design shall provide written notice of the design protection to any person the design owner has reason to believe has violated or will violate this chapter.

(3) Commencement of Action. -- An action for infringement of a fashion design under this chapter shall not commence until the date that is 21 days after the date on which written notice required under this subsection was provided to the defendant.

(4) Limitation on Damages. -- A person alleged to be undertaking action leading to infringement under this chapter shall be held liable only for damages and profits accrued after the date on which the action for infringement is commenced against such person under paragraph (3).

The owner of a design protected under this chapter has the exclusive right to -

(1) make, have made, or import, for sale or for use in trade, any useful article embodying that design; and

(2) sell or distribute for sale or for use in trade any useful article embodying that design.

(b) Acts of Sellers, Importers and Distributors. - A retailer, seller, importer or distributor of an infringing article who did not make or import the article shall be deemed to have infringed on a design protected under this chapter only if that person -

(1) induced or acted in collusion with a manufacturer to make, or an importer to import such article, except that merely purchasing or giving an order to purchase such article in the ordinary course of business shall not of itself constitute such inducement or collusion; or

(2) refused or failed, upon the request of the owner of the design, to make a prompt and full disclosure of that person's source of such article, and that person orders or reorders such article after receiving notice by registered or certified mail of the protection subsisting in the design.

(c) Acts Without Knowledge. - It shall not be infringement under this section to make, have made, import, sell, offer for sale, or distribute, any article embodying a design which was created

17 U.S.C § 1306

Design notice

17 U.S.C § 1308 Exclusive rights

Infringement 
without knowledge either actual or reasonably inferred from the totality of the circumstances that a design was protected under this chapter and was copied from such protected design.

(d) Acts in Ordinary Course of Business. - A person who incorporates into that person's product of manufacture an infringing article acquired from others in the ordinary course of business, or who, without knowledge of the protected design embodied in an infringing article, makes or processes the infringing article for the account of another person in the ordinary course of business, shall not be deemed to have infringed the rights in that design under this chapter except under a condition contained in paragraph (1) or (2) of subsection (b). Accepting an order or reorder from the source of the infringing article shall be deemed ordering or reordering within the meaning of subsection (b)(2).

(e)(f) Infringing Article Defined. - (1) In General. -- As used in this section, an "infringing article" is any article the design of which has been copied from a design protected under this chapter, without the consent of the owner of the protected design. An infringing article is not an illustration or picture of a protected design in an advertisement, book, periodical, newspaper, photograph, broadcast, motion picture, or similar medium. (2) Vessel Hull Design. -- In the case of a design of a vessel hull, a design shall not be deemed to have been copied from a protected design if it is original and not substantially similar in appearance to a protected design. (3) Fashion Design. -- In the case of a fashion design, a design shall not be deemed to have been copied from a protected design if that design -- (A) is not substantially identical in overall visual appearance to and as to the original elements of a protected design; or $(B)$ is the result of independent creation.

(g)(h) Reproduction for Teaching or Analysis. - It is not an infringement of the exclusive rights of a design owner for a person to reproduce the design in a useful article or in any other form solely for the purpose of teaching, analyzing, or evaluating the appearance, concepts, or techniques embodied in the design, or the function of the useful article embodying the design.

(i) Home Sewing Exception. --

(1) In general. -- It is not an infringement of the exclusive rights of a design owner for a person to produce a single copy of a protected design for personal use or for the use of an immediate family member, if that copy is not offered for sale or use in trade during the period of protection.

(2) Rule of Construction. -- Nothing in this subsection shall be construed to permit the publication or distribution of instructions or 
patterns for the copying of a protected design.

(a) Time Limit for Application for Registration. - In the case of a design of a vessel hull, protection under this chapter shall be lost if application for registration of the design is not made within 2 years

17 U.S.C § 1310

Application for registration after the date on which the design is first made public. Registration shall not apply to fashion designs. 


\section{Software}

The programmer, like the poet, works only slightly removed from pure thought-stuff. He builds his castles in the air, from air, creating by exertion of the imagination. Few media of creation are so flexible, so easy to polish and rework, so readily capable of realizing grand conceptual structures. Yet the program construct, unlike the poet's words, is real in the sense that it moves and works, producing visible outputs separate from the construct itself. The magic of myth and legend has come true in our time. One types the correct incantation on a keyboard, and a display screen comes to life, showing things that never were nor could be.

Software presents a subtly different functionality problem than physical designs do. Software is plainly functional: when run on a computer, it does something. But there are at least two distinct ways in which software might be more than just functional. First, the software's code might contain nonexpressive elements: multiple different programs can do the same thing, so a programmer typically has at least some design choices not dictated by a given function. Second, the thing the software does might be expressive: it might show a movie or play a song. (Recall Stern's treatment of a video game as an audiovisual work.) Complicating matters even more, a program's output might itself be both aesthetic and functional, which is typically the case for user interfaces. Pay attention to how each body of intellectual property law teases out these different aspects of software.

\section{A Trade Secret}

Trade secret protection is obviously available and effective for software used internally within a business. The more interesting question is whether and how a business can make software available to 


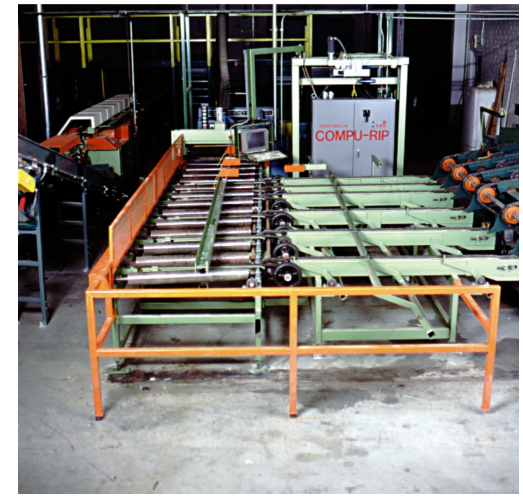

Barr-Mullin Compu-Rip rip saw feeder

184 Cal. App. 4th 210 (2010)

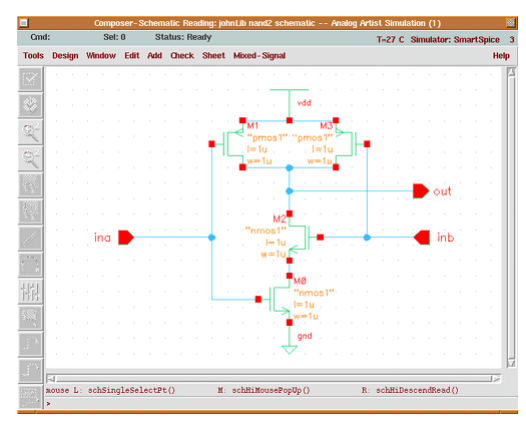

SmartSpice screenshot others while mainting at least some of the software's design as a secret. A later chapter will consider whether contractual restrictions help, but for now, focus on the practical question of what software necessarily discloses to its users.

\section{Barr-Mullin, Inc. v. Browning}

According to defendants, the COMPU-RIP software is not a trade secret since it is (1) not subject to reasonable efforts to maintain its secrecy and (2) defendants reverse engineered this software. The COMPU-RIP software is contained in the form of "programmable read-only memory chips" (PROMS) imbedded in the COMPU-RIP machinery. These PROMS contain only the "object code" version of the computer program. This is the version of the computer software which is "read" by the computer's machinery. Computer programmers do not write computer software in object code; rather, the software is written in "source code" and then translated into object code so that the computer can execute the program. Since the COMPU-RIP software was sold in PROM form, the source code was not available to the general public.

The affidavits of Timothy Toombs and Gary Ruggles, who holds a Ph.D. in Electrical Engineering, indicate that because the COMPURIP software is distributed in object code form it is practically impossible to make any meaningful changes to the software. This evidence establishes the COMPU-RIP software was subject to reasonable efforts to maintain its secrecy. As to the question of reverse engineering, the affidavits indicate that it is practically impossible to make any modification to the COMPU-RIP software using only the object code contained in the PROMS. We find the evidence presented establishes the COMPU-RIP software was not "readily ascertainable" through reverse engineering.

\section{Silvaco Data Systems v. Intel Corp.}

Silvaco develops and markets computer applications for the electronic design automation (EDA) field, which covers the entire complex process of designing electronic circuits and systems. Among the various subcategories of EDA software are circuit simulators, which permit the designer to create a virtual model of a proposed circuit in order to test its properties before incurring the expense and delay of manufacturing a working prototype.

Among Silvaco's software products is SmartSpice, an analog circuit emulator. In December 2000, Silvaco filed a suit against Circuit Semantics, Inc. (CSI), a competing developer of EDA software, alleging that CSI, aided by two former Silvaco employees, had misappropriated trade secrets used in SmartSpice, and had incorporated them in its own product, DynaSpice. Silvaco eventually secured a judg- 
ment against CSI. It then brought actions against several purchasers of CSI software, including Intel. It alleged that by using CSI's software, these end users had misappropriated the Silvaco trade secrets assertedly incorporated in that software.

The parties appear to agree, and we may accept for purposes of this opinion, that "source code" describes the text in which computer programs are originally written by their human authors using a highlevel programming language. 1 . One who possesses the source code for a program may readily ascertain its underlying design, and may directly incorporate it, or pieces of it, into another program. In order to yield a functioning computer application, however, source code must generally be translated or "compiled" into machine-readable (executable) code. After a program is compiled, it may still be represented as text, but the text is not readily intelligible to human beings, consisting of strings of binary (base 2) or hexadecimal (base 16) numbers. 5 For this reason, the source code for many if not most commercial software products is a secret, and may remain so despite widespread distribution of the executable program.

\section{A. Question Presented}

The contention presents a question of law: whether a defendant can be liable for misappropriation of a trade secret which is admittedly embodied in source code, based upon the act of executing, on his own computer, executable code allegedly tainted by the incorporation of design features wrongfully derived from the plaintiff's source

\footnotetext{
${ }^{4}$ This is an accurate enough description where, as here, the facts conform to what one writer has called the "Standard Scenario." Ed Felten, Source Code and Object Code. In this scenario, human programmers write a program in a high-level programming language; this source code is then processed through software known as a compiler to produce object code that may be executed on a machine. Departures from the standard scenario, however, are increasingly common. Another writer asserts that among programmers the terms "source" and "object" do not really describe "well-defined classes of code" but are "actually relative terms." David S. Touretzky, Source vs. Object Code: A False Dichotomy He continues, "Given a device for transforming programs from one form to another, source code is what goes into the device, and object code (or 'target' code) is what comes out. The target code of one device is frequently the source code of another." The upshot seems to be that the correct use of these terms reflects variables that may not have any particular legal significance. Here, the essential variable for legal purposes is the extent to which the code reveals the underlying design, i.e., the methods and algorithms used by the developer. See Felten (suggesting distinctions based on whether code is in "'he form in which programmers customarily read and edit it"' and the extent to which it is "human-readable"). The distinguishing feature for our purposes is that what the parties call "source" code is written by programmers and readily understood by them, whereas object or machine code is compiled by and for machines and does not readily yield its underlying design to human understanding.

${ }^{5}$ For example, the instruction Mov for an Intel 32-bit microprocessor may be represented as 1011000001100001 in binary code or B० 61 in hexadecimal.
} 
code. It is undisputed that the object code executed by Intel could not disclose the underlying source code or permit the exploitation of its features and design. It could not, in short, impart knowledge of the trade secret. The question is whether, in such circumstances, Intel could be found to have misappropriated Silvaco's trade secrets.

\section{B. Trade Secret}

It is critical to any CUTSA cause of action - and any defense - that the information claimed to have been misappropriated be clearly identified. Pursuant to this requirement, Silvaco filed a document, under seal, designating the trade secrets claimed by it. The designation identified trade secrets in six categories. The first five categories referred only to source code.

The sixth category of claimed trade secrets was described as "the ... trade secrets identified in Exhibit B ... and the source code implementing such trade secrets." Exhibit B consists of 22 pages of technical verbiage most of which may be readily intelligible only to those within the EDA field. This much, however, seems reasonably clear: the exhibit does not designate information as such but rather describes various features, functions, and characteristics of the design and operation of Silvaco's software products. Thus the first of the 24 listed subcategories is a "proprietary method" of carrying out a function apparently found in competing programs as well. This asserted secret is also described as "a methodology for" implementing that function, apparently in an unusual way, which "contributes to performance and accuracy improvements." This "trade secret methodology" is "implemented" by two named "modules," also described as "functions," which "represent part" of the critical "algorithm." Three "unique features" of this method are listed: The "integration" of two other operations; a "method" of "changing and controlling" a variable, which "affects the performance of the simulation"; and a mode

Do you understand what the court is talking about here? Did the court? Silvaco's lawyers? of "implementation" that produces "efficiency."

Silvaco's sixth category thus appears to attempt to characterize various aspects of the underlying design as trade secrets. The design may constitute the basis for a trade secret, such that information concerning it could be actionably misappropriated; but it is the information - not the design itself - that must form the basis for the cause of action. And while the finished (compiled) product might have distinctive characteristics resulting from that design - such as improved performance - they cannot constitute trade secrets because they are not secret, but are evident to anyone running the finished program. Indeed, to the extent they tend to disclose the underlying design, it ceases to be a protectable secret for that same reason. The sixth category therefore fails to describe a trade secret other than source code. Since none of the other categories even purport to do so, Intel is quite 
correct to premise its argument on the proposition that the only trade secrets at issue are found in Silvaco's source code.

\section{Misappropriation}

Misappropriation of a trade secret may be achieved through three types of conduct: "acquisition," "disclosure," or "use."

There is no suggestion that Intel ever disclosed Silvaco's source code to anyone, and it is difficult to see how it might have done so since there is no evidence that it ever had the source code to disclose. Silvaco emphasizes that wrongful acquisition of a trade secret may be actionable in itself. But there is no basis to suppose that Intel ever "acquired" the source code constituting the trade secrets.

Silvaco has never explained how any conduct by Intel constituted "use" of its source code. One clearly engages in the "use" of a secret, in the ordinary sense, when one directly exploits it for his own advantage, e.g., by incorporating it into his own manufacturing technique or product. But "use" in the ordinary sense is not present when the conduct consists entirely of possessing, and taking advantage of, something that was made using the secret.

One who bakes a pie from a recipe certainly engages in the "use" of the latter; but one who eats the pie does not, by virtue of that act alone, make "use" of the recipe in any ordinary sense, and this is true even if the baker is accused of stealing the recipe from a competitor, and the diner knows of that accusation. Yet this is substantially the same situation as when one runs software that was compiled from allegedly stolen source code. The source code is the recipe from which the pie (executable program) is baked (compiled). Nor is the analogy weakened by the fact that a diner is not ordinarily said to make "use" of something he eats. His metabolism may be said to do so, or the analogy may be adjusted to replace the pie with an instrument, such as a stopwatch. A coach who employs the latter to time a race certainly makes "use" of it, but only a sophist could bring himself to say that coach "uses" trade secrets involved in the manufacture of the watch.

Intel appears to have been in substantially the same position as the customer in the pie shop who is accused of stealing the secret recipe because he bought a pie with knowledge that a rival baker had accused the seller of using the rival's stolen recipe. The customer does not, by buying or eating the pie, gain knowledge of the recipe used to make it.

Strong considerations of public policy reinforce the commonsense conclusion that using a product does not constitute a "use" of trade secrets employed in its manufacture. If merely running finished software constituted a use of the source code from which it was compiled, then every purchaser of software would be exposed to liability if it 
were later alleged that the software was based in part upon purloined source code. This risk could be expected to inhibit software sales and discourage innovation to an extent far beyond the intentions and purpose of CUTSA.

\section{B Patent}

\section{Subject Matter}

a Then

417 F.2d 1395 (CCPA 1969)

For a discussion of the mathematics involved, see Andrew Chin, Ghost in the "New Machine", 16 N.C. J.L. \& Tech. 623 (2015).

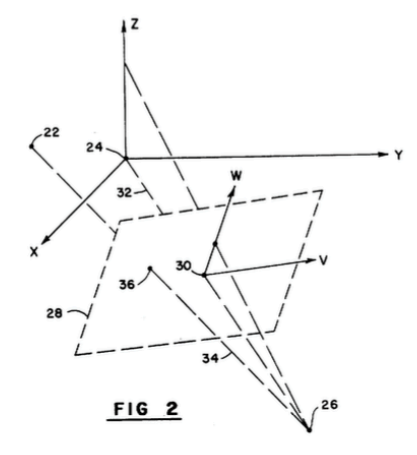

Figure 2 from the application

The patent ultimately issued as U.S. Pat. No. 3,519,997

\section{In re Bernhart}

[Two Boeing employees developed a mathematical technique to display two-dimensional representations of three-dimensional objects. They claimed, for example:]

13 A plotting method ... comprising:

(a) a first step of programming the computer to compute the position of planar Cartesian coordinate axes in the given plane relative to the given set of object points ...

(c) the step of applying the computer output to the input of a planar plotting apparatus adapted to provide on a plane a succession of straightline segments that connect between sequential points having positions corresponding to the coordinates computed by the second step.

18 A system for providing a drawing of an object comprising in combination: electronic digital computer means programmed to respond to applied signals (xe,ye,ze) and a series of groups of signals (xi,yi,zi) to provide a corresponding series of pairs of output signals (vi,wi) with the relationship between signals $(x i, y i, z i)$ and $(x e, y e, z e)$ to the signals (vi,wi) being defined as follows ...

Looking first at the apparatus claims, these claims recite, and can be infringed only by, a digital computer in a certain physical condition, i. e., electro-mechanically set or programmed to carry out the recited routine. Accordingly, we think it clear that applicants have not defined as their invention anything in which the human mind could be used as a component. Nor are the "printed matter" cases, cited by the board, supra, controlling as to these apparatus claims either on the facts or in principle. On their facts, those cases dealt with claims defining as the invention certain novel arrangements of printed lines or characters, useful and intelligible only to the human mind. Here the invention as defined by the claims requires that the information be processed not by the mind but by a machine, the computer, and that 
the drawing be done not by a draftsman but by a plotting machine.

There is one further rationale used by both the board and the examiner, namely, that the provision of new signals to be stored by the computer does not make it a new machine, i.e. it is structurally the same, no matter how new, useful and unobvious the result. This rationale really goes more to novelty than to statutory subject matter but it appears to be at the heart of the present controversy. To this question we say that if a machine is programmed in a certain new and unobvious way, it is physically different from the machine without that program; its memory elements are differently arranged. The fact that these physical changes are invisible to the eye should not tempt us to conclude that the machine has not been changed. If a new machine has not been invented, certainly a "new and useful improvement" of the unprogrammed machine has been, and Congress has said in $\S 101$ that such improvements are statutory subject matter for a patent. It may well be that the vast majority of newly programmed machines are obvious to those skilled in the art and hence unpatentable under $\S 103$. We are concluding here that such machines are statutory under $\S 101$, and that claims defining them must be judged for patentability in light of the prior art.

\section{In re Alappat}

[Alappat's invention dealt with the problem of displaying continuous analog signals on a discrete digital display. Illuminating only the closest pixels to the signal results in jagged, uneven edges. In Alappat's method, all the pixels close to the signal are illuminated, with brightness proportional to how close they are to the signal.] Employing this anti-aliasing technique eliminates any apparent discontinuity, jaggedness, or oscillation in the waveform, thus giving the visual appearance of a smooth continuous waveform. In short, and in lay terms, the invention is an improvement in an oscilloscope comparable to a TV having a clearer picture.Figure 4 from the application

Claim 15, the only independent claim in issue, reads:

A rasterizer for converting vector list data representing sample magnitudes of an input waveform into antialiased pixel illumination intensity data to be displayed on a display means comprising:

(a) means for determining the vertical distance between the endpoints of each of the vectors in the data list;

(b) means for determining the elevation of a row of pixels that is spanned by the vector;

(c) means for normalizing the vertical distance and elevation; and
33 F.3d 1526 (Fed. Cir. 1994)

(Rich, J.)

images/alappat.png

The patent issued as U.S. Pat. No. $5,440,676$ 
(d) means for outputting illumination intensity data as a predetermined function of the normalized vertical distance and elevation.

The Board erred in its reasoning that claim 15 is unpatentable merely because it "reads on a general purpose digital computer 'means' to perform the various steps under program control." Alappat admits that claim 15 would read on a general purpose computer programmed to carry out the claimed invention, but argues that this alone also does not justify holding claim 15 unpatentable as directed to nonstatutory subject matter. We agree. We have held that such programming creates a new machine, because a general purpose computer in effect becomes a special purpose computer once it is programmed to perform particular functions pursuant to instructions from program software.

Under the Board's reasoning, a programmed general purpose computer could never be viewed as patentable subject matter under $\S 101$. This reasoning is without basis in the law. The Supreme Court has never held that a programmed computer may never be entitled to patent protection. Indeed, the Benson court specifically stated that its decision therein did not preclude "a patent for any program servicing a computer." Consequently, a computer operating pursuant to software may represent patentable subject matter, provided, of course, that the claimed subject matter meets all of the other requirements of Title 35. In any case, a computer, like a rasterizer, is apparatus not mathematics.

Archer, Chief Judge, dissenting:

I disagree with the majority's conclusion that Alappat's "rasterizer," which is all that is claimed in the claims at issue, constitutes an invention or discovery within 35 U.S.C. $§ 101$. Alappat has arranged known circuit elements to accomplish nothing other than the solving of a particular mathematical equation represented in the mind of the reader of his patent application.

Consider for example the discovery or creation of music, a new song. Music of course is not patentable subject matter; a composer cannot obtain exclusive patent rights for the original creation of a musical composition. But now suppose the new melody is recorded on a compact disc. In such case, the particular musical composition will define an arrangement of minute pits in the surface of the compact disc material, and therefore will define its specific structure. Alternatively suppose the music is recorded on the rolls of a player piano or a music box.

Through the expedient of putting his music on known structure, can a composer now claim as his invention the structure of a com- 
pact disc or player piano roll containing the melody he discovered and obtain a patent therefor? The answer must be no. The composer admittedly has invented or discovered nothing but music. The discovery of music does not become patentable subject matter simply because there is an arbitrary claim to some structure.

And if a claim to a compact disc or piano roll containing a newly discovered song were regarded as a "manufacture" and within $\S 101$ simply because of the specific physical structure of the compact disc, the "practical effect" would be the granting of a patent for a discovery in music. Where the music is new, the precise structure of the disc or roll would be novel under $\S 102$. Because the patent law cannot examine music for "nonobviousness," the Patent and Trademark Office could not make a showing of obviousness under $\S 103$. The result would well be the award of a patent for the discovery of music.

Alappat admits that each of the circuitry elements of the claimed "rasterizer" is old. He says they are merely "form." Thus, they are only a convenient and basic way of electrically representing the mathematical operations to be performed, that is, converting vector data into matrix or raster data. In Alappat's view, it is the new mathematic operation that is the "substance" of the claimed invention or discovery. Claim 15 as a whole thus claims old circuitry elements in an arrangement defined by a mathematical operation, which only performs the very mathematical operation that defines it. Rather than claiming the mathematics itself, which of course Alappat cannot do, Alappat claims the mathematically defined structure. But as a whole, there is no "application" apart from the mathematical operation that is asserted to be the invention or discovery. What is going on here is a charade.

This is not to say that digital circuitry cannot be an element in an otherwise statutory machine. Under Diehr, it can.26

Thus unlike the rubber curing process in Diehr, the claimed rasterizer here is not an application of mathematics in an otherwise statutory process or product. The rasterizer is simply the mathematical conversion of data. In Diehr, the input data were derived by a claimed component of the overall rubber curing process - the press and thermocouple - which fed data to the claimed computer. Here, however, as the specification and claims indicate, the waveform data converted by the claimed rasterizer are not required to come from a particular machine connected up to the rasterizer, and, as Alappat admits, it does not matter how the data are selected. The sets of waveform num-

\footnotetext{
${ }^{26}$ Likewise, but not present in this case, improved digital circuitry itself, such as faster digital processors, would be statutory subject matter. Unlike the "rasterizer" in this case, they are not simply a claimed arrangement of circuit elements defined by a mathematical operation which does nothing more than solve the operation that defines it.
} 
bers converted by the claimed rasterizer could come simply from the mind and hand of a person. The end product of the claimed rasterizer is not precisely cured rubber as it was in Diehr but rather different data as a mathematical function of the original data. Sure the data have some use. Most data have uses, and that is why people spend time calculating data. But just having some use for data does not make the creation of particular data patentable. Alappat's claimed rasterizer is newly discovered mathematics and not the invention or discovery of a process or product applying it.

Finally, a "general purpose computer" issue has been raised as an aside in this case. Getting back to the music analogy, Alappat is like a composer who claims his song on a compact disc, and then argues that the compact disc is equivalent to a player piano or a music box with the song on a roll or even sheet music because they all represent the same song. The composer is thus clearly asking for (and getting from the majority) a patent for the discovery of a song and a patent covering every physical manifestation of the song.

Thus, a known circuit containing a light bulb, battery, and switch is not a new machine when the switch is opened and closed to recite a new story in Morse code, because the "invention or discovery" is merely a new story, which is nonstatutory subject matter. An old stereo playing a new song on a compact disc is not a new machine because the invention or discovery is merely a new song, which is nonstatutory subject matter. The "perforated rolls [of a player piano] are parts of a machine which, when duly applied and properly operated in connection with the mechanism to which they are adapted, produce musical tones in harmonious combination." White-Smith. Yet a player piano playing Chopin's scales does not become a "new machine" when it spins a roll to play Brahms' lullaby. 29

149 F.3d 1368 (Fed. Cir. 1998)

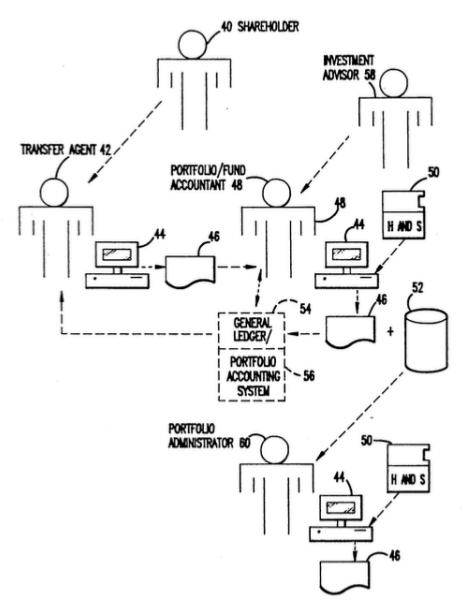

Figure 4 from the patent

\section{State Street Bank \& Trust Co. v. Signature Financial Group}

The patented invention [U.S. Pat No. 5,193,056] relates generally to a system that allows an administrator to monitor and record the financial information flow and make all calculations necessary for several mutual funds to pool their investment funds into a single portfolio.

Unpatentable mathematical algorithms are identifiable by showing they are merely abstract ideas constituting disembodied concepts or truths that are not "useful." From a practical standpoint, this means that to be patentable an algorithm must be applied in a "useful" way. In Alappat, we held that data, transformed by a machine

\footnotetext{
${ }^{29}$ Of course, a player piano itself could be a new machine, for example in relation to a music box, and, likewise, a player piano capable because of design of improved piano-playing might also be a new machine. In such cases, the invention or discovery is the quality of the structure of the piano - its mode of operation - and not the particular piece of music being played.
} 
through a series of mathematical calculations to produce a smooth waveform display on a rasterizer monitor, constituted a practical application of an abstract idea (a mathematical algorithm, formula, or calculation), because it produced "a useful, concrete and tangible result" - the smooth waveform.

Similarly, in Arrhythmia Research Technology Inc. v. Corazonix Corp., we held that the transformation of electrocardiograph signals from a patient's heartbeat by a machine through a series of mathematical calculations constituted a practical application of an abstract idea (a mathematical algorithm, formula, or calculation), because it corresponded to a useful, concrete or tangible thing - the condition of a patient's heart.

Today, we hold that the transformation of data, representing discrete dollar amounts, by a machine through a series of mathematical calculations into a final share price, constitutes a practical application of a mathematical algorithm, formula, or calculation, because it produces "a useful, concrete and tangible result" - a final share price momentarily fixed for recording and reporting purposes and even accepted and relied upon by regulatory authorities and in subsequent trades.

b Now

\section{Alice Corp. v. CLS Bank Int'I}

The patents at issue in this case disclose a computer-implemented scheme for mitigating "settlement risk" (i.e., the risk that only one party to a financial transaction will pay what it owes) by using a third-party intermediary. The question presented is whether these claims are patent eligible under 35 U.S.C. S 101, or are instead drawn to a patent-ineligible abstract idea. We hold that the claims at issue are drawn to the abstract idea of intermediated settlement, and that merely requiring generic computer implementation fails to transform that abstract idea into a patent-eligible invention.

A

Petitioner Alice Corporation is the assignee of several patents that disclose schemes to manage certain forms of financial risk. According to the specification largely shared by the patents, the invention "enabl[es] the management of risk relating to specified, yet unknown, future events." The specification further explains that the "invention relates to methods and apparatus, including electrical computers and data processing systems applied to financial matters and risk management."
Arrythmia: 958 F.2d 1053 (Fed. Cir. 1992)

134 S. Ct. 2347 (2014) 
The claims at issue relate to a computerized scheme for mitigating "settlement risk" - i.e., the risk that only one party to an agreedupon financial exchange will satisfy its obligation. In particular, the claims are designed to facilitate the exchange of financial obligations between two parties by using a computer system as a third-party intermediary. The intermediary creates "shadow" credit and debit records (i.e., account ledgers) that mirror the balances in the parties' real-world accounts at "exchange institutions" (e.g., banks). The intermediary updates the shadow records in real time as transactions are entered, allowing only those transactions for which the parties' updated shadow records indicate sufficient resources to satisfy their mutual obligations. At the end of the day, the intermediary instructs the relevant financial institutions to carry out the "permitted" transactions in accordance with the updated shadow records, thus mitigating the risk that only one party will perform the agreed-upon exchange.

In sum, the patents in suit claim (1) the foregoing method for exchanging obligations (the method claims), (2) a computer system configured to carry out the method for exchanging obligations (the system claims), and (3) a computer-readable medium containing program code for performing the method of exchanging obligations (the media claims). All of the claims are implemented using a computer; the system and media claims expressly recite a computer, and the parties have stipulated that the method claims require a computer as well.

\section{II}

Section 101 of the Patent Act defines the subject matter eligible for patent protection. We have long held that this provision contains an important implicit exception: Laws of nature, natural phenomena, and abstract ideas are not patentable.

We have described the concern that drives this exclusionary principle as one of pre-emption. See, e.g., Bilski v. Kappos, (upholding the patent "would pre-empt use of this approach in all fields, and would effectively grant a monopoly over an abstract idea"). Laws of nature, natural phenomena, and abstract ideas are the basic tools of scientific and technological work. Monopolization of those tools through the grant of a patent might tend to impede innovation more than it would tend to promote it," thereby thwarting the primary object of the patent laws. We have repeatedly emphasized this concern that patent law not inhibit further discovery by improperly tying up the future use of these building blocks of human ingenuity.

At the same time, we tread carefully in construing this exclusionary principle lest it swallow all of patent law. At some level, all inventions embody, use, reflect, rest upon, or apply laws of nature, natural 
phenomena, or abstract ideas.. Thus, an invention is not rendered ineligible for patent simply because it involves an abstract concept. See Diamond v. Diehr. "Applications" of such concepts "to a new and useful end," we have said, remain eligible for patent protection.

Accordingly, in applying the S 101 exception, we must distinguish between patents that claim the building blocks of human ingenuity and those that integrate the building blocks into something more, thereby transforming them into a patent-eligible invention, The former would risk disproportionately tying up the use of the underlying ideas, and are therefore ineligible for patent protection. The latter pose no comparable risk of pre-emption, and therefore remain eligible for the monopoly granted under our patent laws.

\section{III}

In Mayo, we set forth a framework for distinguishing patents that claim laws of nature, natural phenomena, and abstract ideas from those that claim patent-eligible applications of those concepts. First, we determine whether the claims at issue are directed to one of those patent-ineligible concepts. If so, we then ask, what else is there in the claims before us? To answer that question, we consider the elements of each claim both individually and as an ordered combination to determine whether the additional elements transform the nature of the claim into a patent-eligible application. We have described step two of this analysis as a search for an "inventive concept" - i.e., an element or combination of elements that is sufficient to ensure that the patent in practice amounts to significantly more than a patent upon the ineligible concept itself.

\section{$A$}

We must first determine whether the claims at issue are directed to a patent-ineligible concept. We conclude that they are: These claims are drawn to the abstract idea of intermediated settlement.

The "abstract ideas" category embodies the longstanding rule that an idea of itself is not patentable. In Gottschalk v. Benson, for example, this Court rejected as ineligible patent claims involving an algorithm for converting binary-coded decimal numerals into pure binary form, holding that the claimed patent was "in practical effect a patent on the algorithm itself." And in Parker v. Flook, we held that a mathematical formula for computing "alarm limits" in a catalytic conversion process was also a patent-ineligible abstract idea.

We most recently addressed the category of abstract ideas in Bilski. The claims at issue in Bilski described a method for hedging against the financial risk of price fluctuations. Claim 1 recited a series of steps for hedging risk, including: (1) initiating a series of financial transactions between providers and consumers of a commodity; (2)
Diehr: 450 U.S. 175 (1981)

Benson: 409 U. S. 63 (1972)

Flook: 437 U.S. 584 (1978) 
identifying market participants that have a counterrisk for the same commodity; and (3) initiating a series of transactions between those market participants and the commodity provider to balance the risk position of the first series of consumer transactions. Claim 4 put the concept articulated in claim 1 into a simple mathematical formula. The remaining claims were drawn to examples of hedging in commodities and energy markets.

All members of the Court agreed that the patent at issue in Bilski claimed an abstract idea. Specifically, the claims described the basic concept of hedging, or protecting against risk. The Court explained that "hedging is a fundamental economic practice long prevalent in our system of commerce and taught in any introductory finance class." The concept of hedging as recited by the claims in suit was therefore a patent-ineligible abstract idea, just like the algorithms at issue in Benson and Flook.

It follows from our prior cases, and Bilski in particular, that the claims at issue here are directed to an abstract idea. Petitioner's claims involve a method of exchanging financial obligations between two parties using a third-party intermediary to mitigate settlement risk. The intermediary creates and updates "shadow" records to reflect the value of each party's actual accounts held at "exchange institutions," thereby permitting only those transactions for which the parties have sufficient resources. At the end of each day, the intermediary issues irrevocable instructions to the exchange institutions to carry out the permitted transactions.

On their face, the claims before us are drawn to the concept of intermediated settlement, i.e., the use of a third party to mitigate settlement risk. Like the risk hedging in Bilski, the concept of intermediated settlement is a fundamental economic practice long prevalent in our system of commerce. The use of a third-party intermediary (or "clearing house") is also a building block of the modern economy. Thus, intermediated settlement, like hedging, is an "abstract idea" beyond the scope of $\S 101$.

\section{$B$}

Because the claims at issue are directed to the abstract idea of intermediated settlement, we turn to the second step in Mayo's framework. We conclude that the method claims, which merely require generic computer implementation, fail to transform that abstract idea into a patent-eligible invention.

1

At Mayo step two, we must examine the elements of the claim to determine whether it contains an "inventive concept" sufficient to "transform" the claimed abstract idea into a patent-eligible application. A 
claim that recites an abstract idea must include "additional features" to ensure "that the claim is more than a drafting effort designed to monopolize the abstract idea."

The introduction of a computer into the claims does not alter the analysis at Mayo step two. In Benson, for example, we considered a patent that claimed an algorithm implemented on a general-purpose digital computer. Because the algorithm was an abstract idea, the claim had to supply a new and useful application of the idea in order to be patent eligible. But the computer implementation did not supply the necessary inventive concept; the process could be carried out in existing computers long in use. We accordingly held that simply implementing a mathematical principle on a physical machine, namely a computer, is not a patentable application of that principle.

Flook is to the same effect. There, we examined a computerized method for using a mathematical formula to adjust alarm limits for certain operating conditions (e.g., temperature and pressure) that could signal inefficiency or danger in a catalytic conversion process. Once again, the formula itself was an abstract idea and the computer implementation was purely conventional. In holding that the process was patent ineligible, we rejected the argument that implementing a principle in some specific fashion will automatically fall within the patentable subject matter of $\S 101$. Thus, Flook stands for the proposition that the prohibition against patenting abstract ideas cannot be circumvented by attempting to limit the use of the idea to a particular technological environment.

In Diehr, by contrast, we held that a computer-implemented process for curing rubber was patent eligible, but not because it involved a computer. The claim employed a well-known mathematical equation, but it used that equation in a process designed to solve a technological problem in conventional industry practice. The invention in Diehr used a thermocouple to record constant temperature measurements inside the rubber mold - something the industry had not been able to obtain. The temperature measurements were then fed into a computer, which repeatedly recalculated the remaining cure time by using the mathematical equation. These additional steps transformed the process into an inventive application of the formula. In other words, the claims in Diehr were patent eligible because they improved an existing technological process, not because they were implemented on a computer.

These cases demonstrate that the mere recitation of a generic computer cannot transform a patent-ineligible abstract idea into a patenteligible invention. Stating an abstract idea "while adding the words 'apply it"' is not enough for patent eligibility. Mayo. Nor is limiting the use of an abstract idea to a particular technological environment. Stating an abstract idea while adding the words "apply it with a com- 
puter" simply combines those two steps, with the same deficient result. Thus, if a patent's recitation of a computer amounts to a mere instruction to implement an abstract idea on a computer, that addition cannot impart patent eligibility.

The fact that a computer necessarily exists in the physical, rather than purely conceptual, realm, is beside the point. There is no dispute that a computer is a tangible system (in $\S 101$ terms, a "machine"), or that many computer-implemented claims are formally addressed to patent-eligible subject matter. But if that were the end of the $\S 101$ inquiry, an applicant could claim any principle of the physical or social sciences by reciting a computer system configured to implement the relevant concept. Such a result would make the determination of patent eligibility depend simply on the draftsman's art, thereby eviscerating the rule that laws of nature, natural phenomena, and abstract ideas are not patentable.

The representative method claim in this case recites the following steps: (1) "creating" shadow records for each counterparty to a transaction; (2) "obtaining" start-of-day balances based on the parties' realworld accounts at exchange institutions; (3) "adjusting" the shadow records as transactions are entered, allowing only those transactions for which the parties have sufficient resources; and (4) issuing irrevocable end-of-day instructions to the exchange institutions to carry out the permitted transactions. Petitioner principally contends that the claims are patent eligible because these steps "require a substantial and meaningful role for the computer." As stipulated, the claimed method requires the use of a computer to create electronic records, track multiple transactions, and issue simultaneous instructions; in other words, the computer is itself the intermediary.

In light of the foregoing, the relevant question is whether the claims here do more than simply instruct the practitioner to implement the abstract idea of intermediated settlement on a generic computer. They do not.

Taking the claim elements separately, the function performed by the computer at each step of the process is purely conventional. Using a computer to create and maintain "shadow" accounts amounts to electronic recordkeeping - one of the most basic functions of a computer. The same is true with respect to the use of a computer to obtain data, adjust account balances, and issue automated instructions; all of these computer functions are well-understood, routine, conventional activities previously known to the industry. In short, each step does no more than require a generic computer to perform generic computer functions.

Considered as an ordered combination, the computer compo- 
nents of petitioner's method add nothing that is not already present when the steps are considered separately. Viewed as a whole, petitioner's method claims simply recite the concept of intermediated settlement as performed by a generic computer. The method claims do not, for example, purport to improve the functioning of the computer itself. Nor do they effect an improvement in any other technology or technical field. Instead, the claims at issue amount to "nothing significantly more" than an instruction to apply the abstract idea of intermediated settlement using some unspecified, generic computer. Under our precedents, that is not enough to transform an abstract idea into a patent-eligible invention.

\section{C}

Petitioner's claims to a computer system and a computer-readable medium fail for substantially the same reasons. Petitioner conceded below that its media claims rise or fall with its method claims. As to its system claims, petitioner emphasizes that those claims recite "specific hardware" configured to perform "specific computerized functions." But what petitioner characterizes as specific hardware a "data processing system" with a "communications controller" and "data storage unit," for example - is purely functional and generic. Nearly every computer will include a "communications controller" and "data storage unit" capable of performing the basic calculation, storage, and transmission functions required by the method claims. As a result, none of the hardware recited by the system claims offers a meaningful limitation beyond generally linking the use of the method to a particular technological environment, that is, implementation via computers.

Put another way, the system claims are no different from the method claims in substance. The method claims recite the abstract idea implemented on a generic computer; the system claims recite a handful of generic computer components configured to implement the same idea. This Court has long warned against interpreting § 101 in ways that make patent eligibility depend simply on the draftsman's art. Holding that the system claims are patent eligible would have exactly that result.

Because petitioner's system and media claims add nothing of substance to the underlying abstract idea, we hold that they too are patent ineligible under $\S 101$.

McRO, Inc. v. Bandai Namco Games America Inc.

[3D animators depict facial expressions by defining the positions of --- F.3d --- (Fed Cir. Sept. 13, 2016) the vertices for a character's face as it pronounces different phonemes, like "ahh." The set of vertex positions for a phoneme is a "morph target"; the set of positions for a face at rest is the "neutral model." 


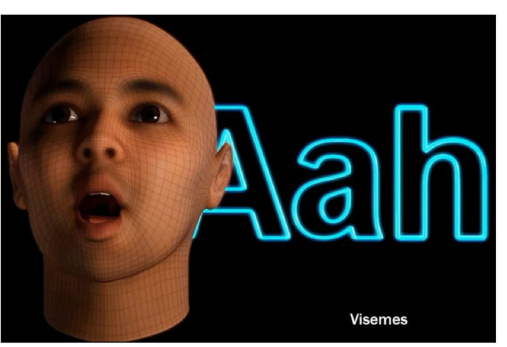

Example morph target for the "ahh" phoneme

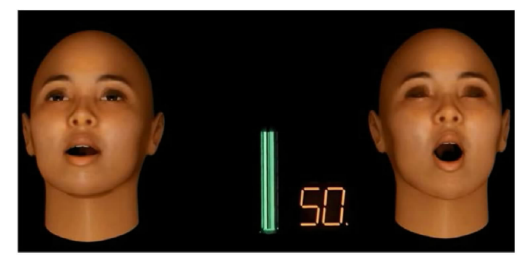

Two facial expression models

\begin{tabular}{|r|l|l|}
\hline time (sec) & phoneme & word \\
\hline 0 & & Sil \\
\hline 1.895 & h & hello \\
\hline 1.965 & eh & \\
\hline 1.995 & l & \\
\hline 2.105 & o & \\
\hline 2.137 & w & there \\
\hline 2.165 & dh & \\
\hline 2.235 & eh & \\
\hline 2.335 & r & \\
\hline 2.435 & sil & how \\
\hline 2.475 & h & \\
\hline 2.545 & a & \\
\hline 2.601 & w & are \\
\hline 2.635 & AA & \\
\hline 2.66 & r & you \\
\hline 2.695 & y & \\
\hline 2.835 & uw & today \\
\hline 2.885 & t & \\
\hline 2.945 & ah & \\
\hline 2.985 & d & \\
\hline 3.045 & e & \\
\hline 3.16 & y & \\
\hline 3.225 & sil & \\
\hline & & \\
\hline
\end{tabular}

Timed transcript of phonemes
The difference between a morph target and the neutral model is the target's "delta set."Traditionally, animators would identify the "keyframes" for morph targets by working from a "timed transcrpt" that listed when the character pronounced each phoneme. A computer would then automatically generate intermediate facial expressions between two keyframes by blending the morph targets for the two.]

For example, the face halfway between the neutral model and the "oh" face can be expressed simply by setting the "oh" morph weight to 0.5 , i.e., $50 \%$, as shown [in the margin] to the left. The model halfway to the next syllable, in turn, could be expressed by setting both the "oh" morph weight and that for the next syllable each to 0.5 , creating a blend of those two delta sets. Because the pronounced phoneme and drawn keyframe corresponded in time, this prior art process synchronized the lips and facial expression of the 3-D character.

The patents [Nos. 6,307,576 and 6,611,278] criticize the preexisting keyframe approach as "very tedious and time consuming, as well as inaccurate due to the large number of keyframes necessary to depict speech." Essentially, the patents aim to automate a 3-D animator's tasks, specifically, determining when to set keyframes and setting those keyframes. This automation is accomplished through rules that are applied to the timed transcript to determine the morph weights. The patents describe many exemplary rule sets that go beyond simply matching single phonemes from the timed transcript with the appropriate morph target. Instead, these rule sets aim to produce more realistic speech by "taking into consideration the differences in mouth positions for similar phonemes based on context."

One exemplary set of rules provided and applied in the specification of the ' 576 patent is for a character transitioning from silence through saying "hello." This exemplary set of rules provides for inserting a transition starting shortly before the first syllable after a silence. The transition marks when the character begins to transition from silence, shown by the closed-mouthed neutral model, to the morph target for the first syllable, with its open-mouthed shape. That is, the rule automates a character's facial expressions so the character will wait until shortly before it starts speaking to begin opening its mouth. In terms of the prior art method, the effect of this rule is to automatically create a keyframe at a point that no phoneme is being pronounced. If instead no transition were placed at that position, the resulting animation would have an unrealistic quality. The character would open its mouth gradually from the beginning of the sequence through its first utterance as a result of the computer interpolating a continuous transition between those two points. In the prior art system, an animator would have to subjectively identify the problem- 
atic sequence and manually fix it by adding an appropriate keyframe. The invention, however, uses rules to automatically set a keyframe at the correct point to depict more realistic speech, achieving results similar to those previously achieved manually by animators.

Claim 1 of the '576 patent is representative and dispositive of the asserted claims 3 for the purposes of appeal:

A method for automatically animating lip synchronization and facial expression of three-dimensional characters comprising:

- obtaining a first set of rules that define output morph weight set stream as a function of phoneme sequence and time of said phoneme sequence;

- obtaining a timed data file of phonemes having a plurality of sub-sequences;

- generating an intermediate stream of output morph weight sets and a plurality of transition parameters between two adjacent morph weight sets by evaluating said plurality of sub-sequences against said first set of rules;

- generating a final stream of output morph weight sets at a desired frame rate from said intermediate stream of output morph weight sets and said plurality of transition parameters; and

- applying said final stream of output morph weight sets to a sequence of animated characters to produce lip synchronization and facial expression control of said animated characters.

The defendants are generally video game developers and publishers.

The district court determined that claim 1 of the '567 patent is "drawn to the abstract idea of automated rules-based use of morph targets and delta sets for lip-synchronized three-dimensional animation." We disagree.

Courts must be careful to avoid oversimplifying the claims by looking at them generally and failing to account for the specific requirements of the claims. Here, the claims are limited to rules with specific characteristics. As the district court recognized during claim construction, "the claims themselves set out meaningful requirements for the first set of rules: they define a morph weight set stream as a function of phoneme sequence and times associated with said phoneme sequence." They further require "applying said first set of rules to each sub-sequence of timed phonemes." The specific, claimed features of these rules allow for the improvement realized by the invention. 
As the specification confirms, the claimed improvement here is allowing computers to produce "accurate and realistic lip synchronization and facial expressions in animated characters" that previously could only be produced by human animators. As the district court correctly recognized, this computer automation is realized by improving the prior art through "the use of rules, rather than artists, to set the morph weights and transitions between phonemes." The rules are limiting in that they define morph weight sets as a function of the timing of phoneme sub-sequences. Defendants do not dispute that processes that automate tasks that humans are capable of performing are patent eligible if properly claimed; instead, they argue that the claims here are abstract because they do not claim specific rules. This argument echoes the district court's finding that the claims improperly purport to cover all rules. The claimed rules here, however, are limited to rules with certain common characteristics, i.e., a genus.

Claims to the genus of an invention, rather than a particular species, have long been acknowledged as patentable. Patent law has evolved to place additional requirements on patentees seeking to claim a genus; however, these limits have not been in relation to the abstract idea exception to $\S 101$. Rather they have principally been in terms of whether the patentee has satisfied the tradeoff of broad disclosure for broad claim scope implicit in 35 U.S.C. $\S 112$. It is selfevident that genus claims create a greater risk of preemption, thus implicating the primary concern driving $\S 101$ jurisprudence, but this does not mean they are unpatentable.

Claim 1 is focused on a specific asserted improvement in computer animation, i.e., the automatic use of rules of a particular type. We disagree with Defendants' arguments that the claims simply use a computer as a tool to automate conventional activity. While the rules are embodied in computer software that is processed by generalpurpose computers, Defendants provided no evidence that the process previously used by animators is the same as the process required by the claims. Defendants concede an animator's process was driven by subjective determinations rather than specific, limited mathematical rules. McRO states that animators would initially set keyframes at the point a phoneme was pronounced to represent the corresponding morph target as a starting point for further fine tuning. This activity, even if automated by rules, would not be within the scope of the claims because it does not evaluate sub-sequences, generate transition parameters or apply transition parameters to create a final morph weight set. It is the incorporation of the claimed rules, not the use of the computer, that "improved [the] existing technological process" by allowing the automation of further tasks. CLS Bank This is unlike Flook, Bilski, and Alice, where the claimed computer-automated pro- 
cess and the prior method were carried out in the same way.

Further, the automation goes beyond merely organizing existing information into a new form or carrying out a fundamental economic practice. The claimed process uses a combined order of specific rules that renders information into a specific format that is then used and applied to create desired results: a sequence of synchronized, animated characters. While the result may not be tangible, there is nothing that requires a method be tied to a machine or transform an article to be patentable. The concern underlying the exceptions to $\S 101$ is not tangibility, but preemption.

The limitations in claim 1 prevent preemption of all processes for achieving automated lip-synchronization of 3-D characters. McRO has demonstrated that motion capture animation provides an alternative process for automatically animating lip synchronization and facial expressions. Even so, the absence of complete preemption does not demonstrate patent eligibility. The narrower concern here is whether the claimed genus of rules preempts all techniques for automating 3-D animation that rely on rules. Claim 1 requires that the rules be rendered in a specific way: as a relationship between sub-sequences of phonemes, timing, and the weight to which each phoneme is expressed visually at a particular timing (as represented by the morph weight set). The specific structure of the claimed rules would prevent broad preemption of all rules-based means of automating lip synchronization, unless the limits of the rules themselves are broad enough to cover all possible approaches. There has been no showing that any rules-based lip-synchronization process must use rules with the specifically claimed characteristics.

Defendants' attorney's argument that any rules-based lipsynchronization process must use the claimed type of rules has appeal, but no record evidence supports this conclusion. Defendants again rely only on the patents' description of one type of rules, but the description of one set of rules does not mean that there exists only one set of rules, and does not support the view that other possible types of rules with different characteristics do not exist. The only information cited to this court about the relationship between speech and face shape points to the conclusion that there are many other possible approaches to automating lip synchronization using rules. For example, Amicus Public Knowledge cites Kiyoshi Honda, Physiological Processes of Speech Processing, as support for the proposition that the claimed rules reflect natural laws. Honda shows, however, that the interaction between vocalization and facial expression is very complex, and there are relationships present other than those required by the claimed rules. This complex interaction permits development of alternative rules-based methods of animating lip synchronization and facial expressions of three-dimensional characters, such as sim- 
ulating the muscle action underlying characters' facial expressions. Under these circumstances, therefore, we need not assume that future alternative discoveries are foreclosed.

Because we find that claim 1 is not directed to ineligible subject matter, we do not reach Alice step two.

\section{Synopsys, Inc. v. Mentor Graphics Corp.}

Synopsys, Inc. appeals the District Court for the Northern District of California's grant of summary judgment invalidating certain claims of U.S. Patent Nos. 5,530,841, 5,680,318, and 5,748,488 under 35 U.S.C. $\S 101$.

\section{BACKGROUND}

In the early days of logic circuits, a designer was required to specify his design in great detail. He would do so in the form of a schematic diagram that identified individual hardware components and the interconnections between them or via a set of Boolean logic equations that specified the precise functionality of the design. A fabrication facility would then build the corresponding physical circuit based on the architecture presented in the detailed design.

Over time, logic circuits became more and more complex. As complexity increased, many designers began to focus on the higher-level functionality of their designs. [New computer languages known as "hardware description languages"] allowed designers to describe only the desired operation of the logic circuit rather than having to specify the actual individual components and interconnections of the logic circuit.

The introduction of HDLs necessitated the development of computerized design tools that could translate the functional description of the logic circuit into a detailed design for fabrication. Early computerized design tools, however, could only recognize and translate simple circuit elements.

The Gregory Patents describe constructs known as "control flow graphs," and "assignment conditions," that provide a scheme to translate HDL-based functional descriptions of logic circuits into hardware component descriptions of those same circuits without requiring the designer to instantiate any individual hardware components.

Representative claim 1 and the associated portion of the specification of U.S. Pat. No. 5,530,841 detail the method of using assignment conditions to translate from a functional description of a level sensitive latch into a hardware component description of that same latch. Claim 1 reads:

A method for converting a hardware independent user description of a logic circuit, that includes flow control statements in- 
cluding an IF statement and a GOTO statement, and directive statements that define levels of logic signals, into logic circuit hardware components comprising:

converting the flow control statements and directive statements in the user description for a logic signal $Q$ into an assignment condition $A L(Q)$ for an asynchronous load function $\mathrm{AL}($ ) and an assignment condition $\mathrm{AD}(\mathrm{Q})$ for an asynchronous data function $\mathrm{AD}()$; and

generating a level sensitive latch when both said assignment condition $\mathrm{AL}(\mathrm{Q})$ and said assignment condition $\mathrm{AD}(\mathrm{Q})$ are nonconstant;

wherein said assignment condition $\mathrm{AD}(\mathrm{Q})$ is a signal on a data input line of said flow through latch;

said assignment condition $\mathrm{AL}(\mathrm{Q})$ is a signal on a latch gate line of said flow through latch; and

an output signal of said flow through latch is said logic signal Q.

A level sensitive latch is a basic form of memory. It is a hardware component that stores a binary input (i.e., the value " 1 " or " 0 "), but only when a specified condition is true. A level sensitive latch can be described functionally using HDL code as follows:

If (COND)

$\mathrm{Q}:=\mathrm{D}$

else

endif

Here, "D" represents the input to the latch and "Q" the output. The relationship between input $\mathrm{D}$ and output $\mathrm{Q}$ is dictated by the "flow control statement" defined by the line of code "If(COND)." In this example, when condition "COND" is true (i.e., has the value "1"), the code flows to the immediately following line of code - i.e., "Q: = $D^{\prime \prime}$ - and output $Q$ is assigned the value of input $D$. In contrast, when condition COND is false (i.e., has the value " 0 "), the code skips the directive statement "Q: $=\mathrm{D}$ " and flows directly to the line of code "else." In this example, no instructions follow "else." The value of output $Q$ therefore remains unchanged. In sum, when condition COND is true, output $Q$ is assigned the value of input $D$; when condition COND is false, output $Q$ retains its prior value regardless of whether the value of input $D$ remains the same or changes.

The claimed method takes the functional description of the latch as an input. It then converts the functional description into an equivalent description in the form of (1) an asynchronous load function; and (2) an asynchronous data function. Here, the asynchronous load 
function for output $Q$ is COND because output $Q$ is assigned a new value (i.e., it is "loaded") whenever condition COND is true. The asynchronous data function for $\mathrm{Q}$ is "COND* ${ }^{*}$ " because output $\mathrm{Q}$ is assigned the value " 1 " if, and only if, both condition COND and input $\mathrm{D}$ are true.

The assignment conditions associated with the functional description of the latch are summarized in the table below:

Assignment Conditions

\begin{tabular}{ccccccc} 
Variable & $\mathrm{AL}()$ & $\mathrm{AD}()$ & $\mathrm{SL}()$ & $\mathrm{SD}()$ & $\mathrm{DC}()$ & $\mathrm{Z}()$ \\
\hline $\mathrm{Q}$ & $\mathrm{COND}$ & $\mathrm{COND}{ }^{*} \mathrm{D}$ & 0 & 0 & 0 & 0 \\
\hline Claim 1 & specifies that where & as here & the & asynchrono
\end{tabular}

Claim 1 specifies that where, as here, the asynchronous load function and the asynchronous data function are non-constant, the claimed method generates a level sensitive latch. A hardware component description of the level sensitive latch is shown below:

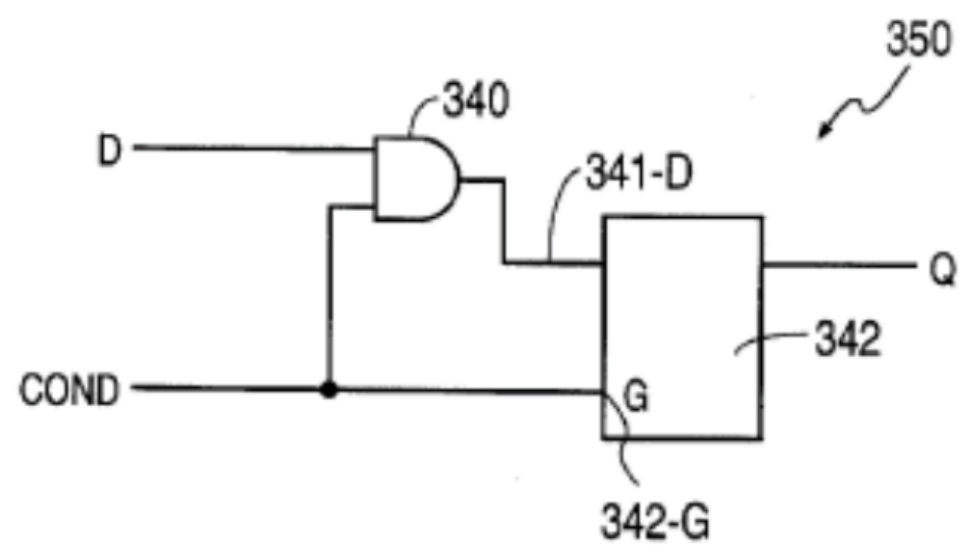

Importantly, the Gregory Patents make clear that HDL code existed in the prior art. The HDL code for the level sensitive latch shown in Table 8 was already well known by the time the claimed inventions of the Gregory Patents were conceived. The same is true of the circuit diagram for a level sensitive latch shown in Figure 8A; circuit diagrams like this existed long before the Gregory Patents. What Gregory instead claims to have invented is a process for interpreting the HDL code in Table 8 that uses the assignment conditions of Table 9 to identify the circuit diagram of Figure $8 \mathrm{~A}$ as the hardware that performs the function recited in the HDL code. At bottom, the information provided in Table 8 (code), Table 9 (assignment conditions), and Figure 8A (circuit diagram) are all equivalent representations of the same thing: a level sensitive latch.

I. Alice Step 1: Are the Asserted Claims directed to an abstract IDEA? 
The district court based its Alice Step 1 analysis on a basic premise: "the claims are directed to a mental process." We held in CyberSource Corp. v. Retail Decisions, Inc. that mental processes are" a subcategory of unpatentable abstract ideas." As we explained:

Methods which can be performed entirely in the human mind are unpatentable not because there is anything wrong with claiming mental method steps as part of a process containing non-mental steps, but rather because computational methods which can be performed entirely in the human mind are the types of methods that embody the basic tools of scientific and technological work that are free to all men and reserved exclusively to none.

While the Supreme Court has altered the $\S 101$ analysis since CyberSource in cases like Mayo and Alice, we continue to treat analyzing information by steps people go through in their minds, or by mathematical algorithms, without more, as essentially mental processes within the abstract-idea category.

Although the Asserted Claims are devoid of any reference to a computer or any other physical component, Synopsys suggests that the "complexity" of the claimed methods would make it implausible - if not impossible - for a skilled logic circuit designer to perform the methods mentally or with pencil and paper.

Synopsys' argument is belied by the actual claims at issue. Claim 1 recites a method of changing one description of a level sensitive latch (i.e., a functional description) into another description of the level sensitive latch (i.e., a hardware component description) by way of a third description of that very same level sensitive latch (i.e., assignment conditions). As demonstrated above and in the patent specification itself the method can be performed mentally or with pencil and paper. The skilled artisan must simply analyze a four-line snippet of HDL code and translate this short piece of code into assignment conditions and further translate those two assignment conditions into a schematic representation of a level sensitive latch.

Although an understanding of logic circuit design is certainly required to perform the steps, the limited, straightforward nature of the steps involved in the claimed method make evident that a skilled artisan could perform the steps mentally. The inventors of the Gregory Patents confirmed this point when they admitted to performing the steps mentally themselves.

Synopsys next argues that even if the Asserted Claims could be performed mentally they would, in practice, be performed on a computer. In support of this argument, counsel for Synopsys during oral argument pointed to the "200 pages of code" attached to the specifications of the Gregory Patents that he contended reveal the "true

I.e., turn Table 8 into Table 9 and then into Figure $8 \mathrm{~A}$ 
novelty" of the Asserted Claims.

While Synopsys may be correct that the inventions of the Gregory Patents were intended to be used in conjunction with computer-based design tools, the Asserted Claims are not confined to that conception. On their face, the claims do not call for any form of computer implementation of the claimed methods. Because the Asserted Claims make no mention of employing a computer or any other physical device, they are so broad as to read on an individual performing the claimed steps mentally or with pencil and paper.

For this reason, we need not decide whether a computerimplemented version of the invention would not be "directed to" an abstract idea. And, for the same reasons, Synopsys cannot rely on our decisions in Enfish, LLC v. Microsoft Corp. and McRO to support the patentability of the Asserted Claims. In Enfish, we held that claims directed to a specific improvement to the way computers operate to store and retrieve data were not unpatentably abstract. In McRO, we similarly held that claims that recited a specific asserted improvement in computer animation were not directed to an unpatentable abstract idea. By their terms and the district court's unchallenged constructions, the Asserted Claims do not involve the use of a computer in any way. The Asserted Claims thus cannot be characterized as an improvement in computer technology.

Synopsys' argument that "the asserted claims do not preempt all conversions" from functional descriptions of logic circuits to hardware component descriptions of logic circuits likewise misses the mark. While preemption may signal patent ineligible subject matter, the absence of complete preemption does not demonstrate patent eligibility.

We recognize that defining the precise abstract idea of patent claims in many cases is far from a straightforward exercise. But, here, the Asserted Claims are drawn to the abstract idea of: translating a functional description of a logic circuit into a hardware component description of the logic circuit. As detailed above, this translation is a mental process.

\section{Alice Step 2: Do the Asserted Claims include an inventive CONCEPT?}

Synopsys equates the inventive concept inquiry with novelty and contends that the Asserted Claims contain an inventive concept because they were not shown to have been anticipated by or obvious over the prior art. That position misstates the law. A claim for a new abstract idea is still an abstract idea. The search for a $\S 101$ inventive concept is thus distinct from demonstrating $\S 102$ novelty.

That being said, the contours of what constitutes an inventive concept are far from precise. 
In DDR Holdings, LLC v. Hotels.com, L.P., we held that claims "directed to systems and methods of generating a composite web page that combines certain visual elements of a 'host' website with content of a third-party merchant" contained the requisite inventive concept. We explained that the claims at issue involved a technological solution that overcame a specific challenge unique to the Internet.

In BASCOM Global Internet Servs., Inc. v. ATET Mobility LLC, we likewise held that claims "directed to filtering content on the Internet" contained an inventive concept. We recognized that "the limitations of the claims, taken individually, recite generic computer, network and Internet components, none of which is inventive by itself." We explained, however, that "an inventive concept can be found in the non-conventional and non-generic arrangement of known, conventional pieces." We found that the claims at issue contained just such an inventive arrangement through "the installation of a filtering tool at a specific location, remote from the end-users, with customizable filtering features specific to each end user." The claimed custom filter could be located remotely from the user because the invention exploited the ability of Internet service providers to associate a search request with a particular individual account. This technical solution overcame defects in prior art embodiments and elevated an otherwise abstract idea to a patentable invention.

The Asserted Claims contain no such technical solution. To the extent the Asserted Claims add anything to the abstract idea, it is the use of assignment conditions as an intermediate step in the translation process. But, given that the claims are for a mental process, assignment conditions, which merely aid in mental translation as opposed to computer efficacy, are not an inventive concept that takes the Asserted Claims beyond their abstract idea. The Asserted Claims do not introduce a technical advance or improvement. They contain nothing that amounts to significantly more than a patent upon the abstract idea itself.

\section{Procedures}

\section{Williamson v. Citrix Online, LLC}

[U.S. Patent No. 6,155,840] describes methods and systems for "distributed learning" that utilize industry standard computer hardware and software linked by a network to provide a classroom or auditorium-like metaphor-i.e., a "virtual classroom" environment. The objective is to connect one or more presenters with geographically remote audience members. The disclosed inventions purport to provide "the benefits of classroom interaction without the detrimental effects of complicated hardware or software, or the costs and

DDR Holdings: 773 F.3d 1245 (Fed. Cir. 2014)

BASCOM: 827 F.3d 1341 (Fed. Cir. 2016)

Are McRO and Synopsys compatible? 
inconvenience of convening in a separate place."

There are three main components of the "distributed learning" system set forth in the '840 patent: (1) a presenter computer, (2) audience member computers, and (3) a distributed learning server. The distributed learning server implements a "virtual classroom" over a computer network, such as the Internet, to facilitate communication and interaction among the presenter and audience members. The presenter computer is used by the presenter to communicate with the audience members and control information that appears on the audience member's computer screen. An audience member's computer is used to display the presentation and can be used to communicate with the presenter and other audience members.

Means-plus-function claiming occurs when a claim term is drafted in a manner that invokes 35 U.S.C. $§ 112$, para. 6, which states:

An element in a claim for a combination may be expressed as a means or step for performing a specified function without the recital of structure, material, or acts in support thereof, and such claim shall be construed to cover the corresponding structure, material, or acts described in the specification and equivalents thereof.

In enacting this provision, Congress struck a balance in allowing patentees to express a claim limitation by reciting a function to be performed rather than by reciting structure for performing that function, while placing specific constraints on how such a limitation is to be construed, namely, by restricting the scope of coverage to only the structure, materials, or acts described in the specification as corresponding to the claimed function and equivalents thereof.

We begin with the observation that the claim limitation in question is not merely the introductory phrase "distributed learning control module," but the entire passage "distributed learning control module for receiving communications transmitted between the presenter and the audience member computer systems and for relaying the communications to an intended receiving computer system and for coordinating the operation of the streaming data module." This passage, as lengthy as it is, is nonetheless in a format consistent with traditional means-plus-function claim limitations. It replaces the term "means" with the term "module" and recites three functions performed by the "distributed learning control module."

Having found that the "distributed learning control module" is subject to application of $\S 112$, para. 6, we next determine whether the specification discloses sufficient structure that corresponds to the claimed function. We conclude that it does not.

The district court identified three claimed functions associated with the "distributed learning control module" term: (1) receiving 
communications transmitted between the presenter and the audience member computer systems; (2) relaying the communications to an intended receiving computer system; and (3) coordinating the operation of the streaming data module. The district court then found that the specification fails to disclose structure corresponding to the "coordinating" function. On appeal, it is undisputed that the claimed "coordinating" function is associated with the "distributed learning control module." Thus, we must ascertain whether adequate structure corresponding to this function is disclosed in the specification.

The district court was correct that the specification of the ' 840 patent fails to disclose corresponding structure. The written description of the ' 840 patent makes clear that the distributed learning control module cannot be implemented in a general purpose computer, but instead must be implemented in a special purpose computer - a general purpose computer programmed to perform particular functions pursuant to instructions from program software. A special purpose computer is required because the distributed learning control module has specialized functions as outlined in the written description. In cases such as this, involving a claim limitation that is subject to $\S 112$, para. 6 that must be implemented in a special purpose computer, this court has consistently required that the structure disclosed in the specification be more than simply a general purpose computer or microprocessor. We require that the specification disclose an algorithm for performing the claimed function. The algorithm may be expressed as a mathematical formula, in prose, or as a flow chart, or in any other manner that provides sufficient structure.

Because the ' 840 patent fails to disclose any structure corresponding to the "coordinating" function of the "distributed learning control module," we affirm the judgment that claims 8-16 are invalid for indefiniteness.

Mark A. Lemley

\section{Software Patents and the Return of Functional Claiming}

Functional claiming is back. While experienced patent lawyers today generally avoid writing their patent claims in means-plus-function format, software patentees have increasingly been claiming to own the function of their program, not merely the particular way they achieved that goal. They have effectively captured ownership not of what they built, but of anything that achieves the same goal, no matter how different it is. They claim to own the function itself.

Fortunately, the solution to the problem is correspondingly simple: we must take seriously the dictate of Section 112(f). If we limit patent claims that purport to cover functions to the actual structure, material, or acts the patentee built or described, the result will be that software patents will cover, not every possible way of implement- 
ing a goal, but the way the patentee actually implemented the goal "and equivalents thereof." And in computer software, the "structure" or "acts" that perform the function are not simply "a computer" or "a client-server system" but "a computer programmed in a particular way." That is, the structure of a software patent must involve software, not just the hardware substrate on which all software runs. Specifically, as recent Federal Circuit indefiniteness cases have shown, patentees will have to disclose the algorithms they use to achieve particular ends, and the patent will be limited to those algorithms and equivalents thereof. This will leave room for later entrants to design around the patent and develop different algorithms to achieve the same result.

\section{Obviousness}

\section{Apple Inc. v. Samsung Electronics Co., Ltd.}

The jury found claim 8 of [Apple's] U.S. Patent No. 8,046,721 infringed and not invalid. The district court later denied Samsung's requested JMOL and entered judgment accordingly. On February 26, 2016, a panel of this court reversed the denial of JMOL with regard to the jury verdict of non-obviousness as to the '721 patent. We agree with the district court that the jury's fact findings supported the conclusion that claim 8 would have been obvious.

The '721 patent discloses a portable device with a touch-sensitive display that can be "unlocked via gestures" performed on the screen. The patent teaches that a "problem associated with using touch screens on portable devices is the unintentional activation or deactivation of functions due to unintentional contact with the touch screen."

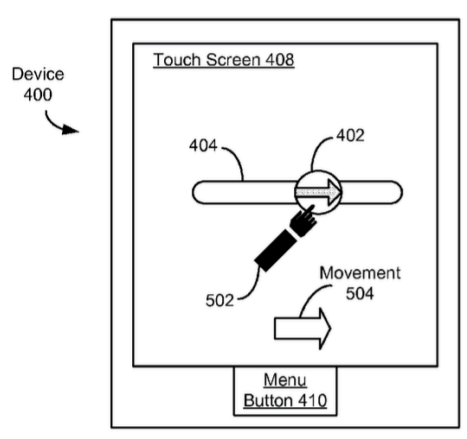

Figure 5B from the ' 721 patent

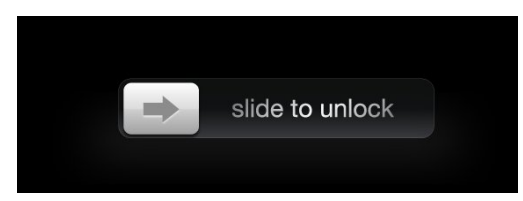

iPhone lock screen
"Unintentional activation or deactivation of functions due to unintentional contact with the touch screen" is commonly referred to as "pocket dialing." Greg Christie, an inventor of the "721 patent, described the problem he and his colleagues set out to solve:

We were worried about accidental use, pocket dialing, the phone getting shut down accidentally, or since we were going to have all these features on the phone, like e-mail and messaging, we were worried that, you know, mail could be sent accidentally or deleted accidentally or the phone would answer itself simply because the touch surface-you know, if it was like, like, the touch surface against your leg in your pocket, we were worried that just, like, you know, jostling around, moving around would trigger things on the screen.

The "721 patent also describes the importance of making phone acti- 
vation as "user-friendly" and "efficient" as possible. It teaches:

Accordingly, there is a need for more efficient, userfriendly procedures for unlocking such devices, touch screens, and/or applications. More generally, there is a need for more efficient, user-friendly procedures for transitioning such devices, touch screens, and/or applications between user interface states (e.g., from a user interface state for a first application to a user interface state for a second application, between user interface states in the same application, or between locked and unlocked states). In addition, there is a need for sensory feedback to the user regarding progress towards satisfaction of a user input condition that is required for the transition to occur.

Mr. Christie testified that the ease of the user interface was a central design consideration when developing the slide to unlock feature:

We thought to introduce some sort of definite gesture. We knew we wanted to have some instruction. We knew we wanted the interface to be obvious to the customer. It would be possibly the first experience even in a retail environment. They're deciding whether they want to buy it. They pick up this iPhone, you know, it would be very bad if they looked at the phone that they had heard so much about and they look at it and say "I can't figure out how to use this. I don't know how to unlock it. It's locked." At the same time, we knew that people would be unlocking their phone, you know, tens or hundreds of times a day, so we didn't want the instruction to be, you know, insulting or talk down to the customer. We didn't want it to be cumbersome, something that they would grow tired of after a while.

Apple's expert, Dr. Cockburn, explained that there was a tension between preventing pocket dialing and ease of use: "It has to work. It has to succeed in preventing accidental activation by mistake. But yet it needs to be something that's easy to do, but not so easy that it can occur by accident, and it succeeds in that."

Apple asserted claim 8, which depends from claim 7, against several Samsung devices. These claims recite:

7. A portable electronic device, comprising:

a touch-sensitive display;

memory;

one or more processors; and

one or more modules stored in the memory and configured 
KEYLOCK - UNLOCKING THE UNIT

The ON/OFF switch is located on the left side of the $\mathrm{N} 1$, below the screen.

1. Press the power button once.

The text "Right sweep to unlock"

to unlock your unit.

Neonode N1 Quickstart Guide illustration

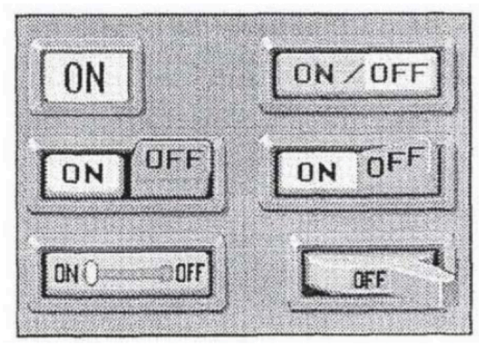

Illustration from Plaisant paper for execution by the one or more processors, the one or more modules including instructions:

to detect a contact with the touch-sensitive display at a first predefined location corresponding to an unlock image;

to continuously move the unlock image on the touchsensitive display in accordance with the movement of the detected contact while continuous contact with the touch-sensitive display is maintained, wherein the unlock image is a graphical, interactive user-interface object with which a user interacts in order to unlock the device; and

to unlock the hand-held electronic device if the unlock image is moved from the first predefined location on the touch screen to a predefined unlock region on the touch-sensitive display.

8. The device of claim 7 , further comprising instructions to display visual cues to communicate a direction of movement of the unlock image required to unlock the device.

Samsung argues claim 8 would have been obvious in light of the combination of Neonode and Plaisant. "Neonode" refers to the Neonode N1 Quickstart Guide. Neonode discloses a mobile device with a touch-sensitive screen. It explains that a user may unlock the device by pressing the power button. After the user presses the power button, text appears instructing the user to "Right sweep to unlock." Sweeping right then unlocks the unit.

"Plaisant" refers to a video and corresponding two-page paper published in 1992 titled "Touchscreen Toggle Design" by Catherine Plaisant and Daniel Wallace. The authors of the paper conducted an experiment to determine which controls ("toggles") users prefer on wall-mounted controllers for "entertainment, security, and climate control systems." These controllers were intended to be installed "flushmounted into the wall or the cabinetry." The authors presented six alternative unlocking mechanisms to a group of fifteen undergraduate students, including a "slider toggle" where a user could activate the controller by "grab[bing] the pointer and slid[ing] it to the other side." The students preferred "toggles that are pushed" over "toggles that slide," and generally ranked the slider fifth of the six alternatives. The paper also notes that sliders "were not preferred," "sliding is a more complex task than simply touching," and that "sliders are more difficult to implement than buttons."

On appeal, Apple does not contest that, together, Neonode and Plaisant disclose all the elements of claim 8 . Rather, the parties dis- 
pute whether a person of ordinary skill in the art would have been motivated to combine one of the unlocking mechanisms disclosed in Plaisant with Neonode. Samsung argues "there was no evidence of any kind suggesting that Plaisant's application to a wall-mounted device would lead inventors not to combine Plaisant with Neonode." Its expert, Dr. Greenberg, testified that a person of ordinary skill "would be highly interested" in both references because "they both deal with touch base systems, they both deal with user interfaces." Dr. Greenberg testified that "a person looking at this would just think it natural to combine these two, as well taking the ideas in Plaisant, the slider, and putting them on the Neonode is, is just a very routine thing to think about in terms of interaction design." Samsung points to the Plaisant reference which states that sliding movement "is less likely to be done inadvertently."

Apple counters that a skilled artisan designing a mobile phone would not have been motivated to turn to a wall-mounted air conditioning controller to solve the pocket dialing problem. Its expert, Dr. Cockburn, testified that a person of ordinary skill would not have been naturally motivated to combine Neonode and Dr. Cockburn testified that the way the Plaisant controllers "were intended to be used was the touch screen would be mounted into a wall or into cabinetry and it would be used to control, for remote control, office or home appliances, like air conditioning units or heaters." He also explained to the jury that Plaisant itself discloses that sliding toggles were less preferred than the other switches disclosed. Apple points to Plaisant's teachings that "sliders were not preferred," "sliding is a more complex task," and "sliders are more difficult to implement." Apple argues there was substantial evidence for the jury to conclude that there would not have been a motivation to combine Plaisant and Neonode to arrive at the claimed invention.

The district court determined that a reasonable jury could have found that a person of ordinary skill would not have been motivated to combine Plaisant and Neonode:

A reasonable jury could infer from [Dr. Cockburn's] testimony that an ordinary artisan would not have been motivated to combine elements from a wall-mounted touchscreen for home appliances and a smartphone, particularly in view of the "pocket dialing" problem specific to mobile devices that Apple's invention sought to address.

Additionally, Dr. Cockburn explained that Plaisant "teach[es] away from the use of sliding," because it "tells you not to use the sliding [toggle] mechanism." We agree with the district court that on this record, the jury's implicit fact findings that Plaisant would not have provided a skilled artisan with a motivation to combine its slider tog- 
gle switch with Neonode is supported by substantial evidence. In addition to the statements in Plaisant, the court explained:

Dr. Cockburn testified, contrary to Dr. Greenberg, that a person of ordinary skill in the art would not have been motivated to combine the Neonode and Plaisant in such a way as to invent claim 8 . He provided two reasons. First, Plaisant described "toggle designs" intended to be used with a "touch screen [that] would be mounted into a wall or into cabinetry" for controlling "office or home appliances, like air conditioning units or heaters." A reasonable jury could infer from this testimony that an ordinary artisan would not have been motivated to combine elements from a wall-mounted touchscreen for home appliances and a smartphone, particularly in view of the "pocket dialing" problem specific to mobile devices that Apple's invention sought to address.

We agree with the district court's analysis. Because the jury found the issue of validity in favor of Apple, we presume it resolved the conflicting expert testimony and found that a skilled artisan would not have been motivated to combine the slider toggle in Plaisant with the cell phone disclosed in Neonode. The question for our review is whether substantial evidence supports this implied fact finding. We conclude that it does. Neonode discloses a mobile phone. Plaisant discloses a wall-mounted air conditioning controller. The jury had both references before it. Although Samsung presents arguments for combining the two references, these arguments were before the jury. We agree with the district court: "A reasonable jury could infer from this testimony that an ordinary artisan would not have been motivated to combine elements from a wall-mounted touchscreen for home appliances and a smartphone, particularly in view of the 'pocket dialing' problem specific to mobile devices that Apple's invention sought to address."

The record includes Plaisant and Neonode and all that these references teach, including Plaisant's reference to inadvertent activation, complexity, difficult implementability, and that users do not prefer sliders. Though the prior art references each relate to touchscreens, the totality of the evidence supports the conclusion that it would not have been obvious for a skilled artisan, seeking an unlock mechanism that would be both intuitive to use and solve the pocket dialing problem for cell phones, to look to a wall-mounted controller for an air conditioner. The two-page Plaisant paper published in 1992 reported the results of a user-preference survey of fifteen undergraduates on six different computer-based switches. That a skilled artisan would look to the Plaisant paper directed to a wall-mounted interface screen for 
appliances and then choose the slider toggle, which the study found rated fifth out of six options in usability, to fulfill a need for an intuitive unlock mechanism that solves the pocket dialing problem for cell phones seems far from obvious.

[The en banc court also discussed secondary considerations. Among other things, it noted:

- Industry praise. - When Steve Jobs unveiled the slide to unlock feature, the audience burst into cheers.

- Copying. - Internal Samsung documents praised the iPhone's slide to unlock feature as "a creative way of solving UI complexity" and concluded that Samsung's designs would be better if they were more like the iPhone's.

- Commercial success. - Apple wanted a vivid easily comprehensible demonstration of how its iPhone touch screens worked to make customers comfortable with it. Slide to unlock was the first feature shown in Apple's first iPhone commercial. These facts were evidence that the iPhone's commercial success was due in part to slide to unlock.

- Long-felt need. - Apple's experts testified to the deficiencies of numerous previous "frustrating" solutions to the pocketdialing problem, and internal Samsung documents showed that it had tried four other alternatives and concluded they were all inferior to slide to unlock.]

\section{Copyright}

Software copyright has been intensely controversial.

\section{Subject Matter}

Some of the most important software subject-matter holdings arose in the context of similarity analyses. In order to explain whether the defendant's allegedly infringing software, courts must first filter out the unprotectable aspects of plaintiff's software. Thus, Whelan and Altai are included here rather in a section on similarity because of their importance to subsequent caselaw.

\section{Apple Computer, Inc. v. Franklin Computer Corp.}

Apple, one of the computer industry leaders, manufactures and markets personal computers (microcomputers), related peripheral equipment such as disk drives (peripherals), and computer programs (software). It presently manufactures Apple II computers and distributes over 150 programs. Apple has sold over 400,000 Apple II computers, employs approximately 3,000 people, and had annual sales of $\$ 335,000,000$ for fiscal year 1981 . 

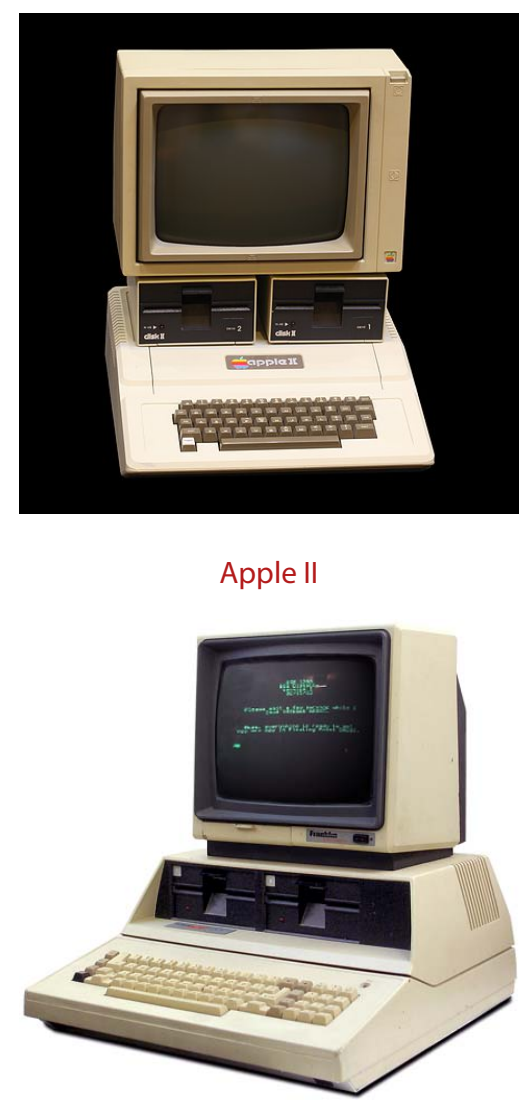

Franklin ACE 100

Programs sold by Franklin in conjunction with its ACE 100 computer were virtually identical with those covered by fourteen Apple copyrights. The variations that did exist were minor, consisting merely of such things as deletion of reference to Apple or its copy-

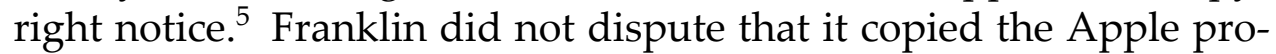
grams. Its witness admitted copying each of the works in suit from the Apple programs.

Franklin's principal defense is that the Apple operating system programs are not capable of copyright protection.

\section{A. Copyrightability of a Computer Program Expressed in Object Code}

Certain statements by the district court suggest that programs expressed in object code, as distinguished from source code, may not be the proper subject of copyright. We find no basis in the statute for any such concern. The district court here questioned whether copyright was to be limited to works designed to be "read" by a human reader as distinguished from read by an expert with a microscope and patience. The suggestion that copyrightability depends on a communicative function to individuals stems from the early decision of White-Smith, which held a piano roll was not a copy of the musical composition because it was not in a form others, except perhaps for a very expert few, could perceive. However, it is clear from the language of the 1976 Act and its legislative history that it was intended to obliterate distinctions engendered by White-Smith.

Under the statute, copyright extends to works in any tangible means of expression "from which they can be perceived, reproduced, or otherwise communicated, either directly or with the aid of a machine or device." Further, the definition of "computer program" adopted by Congress in the 1980 amendments is "sets of statements or instructions to be used directly or indirectly in a computer in order to bring about a certain result." As source code instructions must be translated into object code before the computer can act upon them, only instructions expressed in object code can be used "directly" by the computer.

The district court also expressed uncertainty as to whether a computer program in object code could be classified as a "literary work." However, the category of "literary works", one of the seven copyrightable categories, is not confined to literature in the nature of Hemingway's For Whom the Bell Tolls. The definition of "literary works" in section 101 includes expression not only in words but also "numbers, or other ... numerical symbols or indicia", thereby expanding

\footnotetext{
${ }^{5}$ For example, 8 bytes of memory were altered in the Autostart ROM program so that when the computer is turned on "ACE 100" appears on the screen rather than "Apple II." The Franklin DOS 3.3 program also had 16 bytes (out of 9000 ) that allowed use of upper and lower case.
} 
the common usage of "literary works." Cf. Harcourt, Brace $\mathcal{E}$ World, Inc. v. Graphic Controls Corp. (the symbols designating questions or response spaces on exam answer sheets held to be copyrightable "writings" under 1909 Act); Reiss v. National Quotation Bureau, Inc. (code book of coined words designed for cable use copyrightable). Thus a computer program, whether in object code or source code, is a "literary work" and is protected from unauthorized copying, whether from its object or source code version.

\section{Copyrightability of Computer Operating System Programs}

We turn to the heart of Franklin's position on appeal which is that computer operating system programs, as distinguished from application programs, are not the proper subject of copyright. Franklin argues that an operating system program is either a "process", "system", or "method of operation" and hence uncopyrightable.

Franklin's attack on operating system programs as "methods" or "processes" seems inconsistent with its concession that application programs are an appropriate subject of copyright. Both types of programs instruct the computer to do something. Therefore, it should make no difference whether these instructions tell the computer to help prepare an income tax return (the task of an application program) or to translate a high level language program from source code into its binary language object code form (the task of an operating system program such as "Applesoft"). Since it is only the instructions which are protected, a "process" is no more involved because the instructions in an operating system program may be used to activate the operation of the computer than it would be if instructions were written in ordinary English in a manual which described the necessary steps to activate an intricate complicated machine. There is, therefore, no reason to afford any less copyright protection to the instructions in an operating system program than to the instructions in an application program.

Franklin's argument that an operating system program is part of a machine mistakenly focuses on the physical characteristics of the instructions. But the medium is not the message. We have already considered and rejected aspects of this contention in the discussion of object code and ROM. The mere fact that the operating system program may be etched on a ROM does not make the program either a machine, part of a machine or its equivalent. Furthermore, as one of Franklin's witnesses testified, an operating system does not have to be permanently in the machine in ROM, but it may be on some other medium, such as a diskette or magnetic tape, where it could be readily transferred into the temporary memory space of the computer. In fact, some of the operating systems at issue were on diskette.

\footnotetext{
Does this reasoning make the SCPA pointless? Should conductor mask designs be registered as literary works because they are equivalent to computer programs? For that matter, what does this reasoning suggest about the Federal Circuit's "new machine" justifica-

tion for software patents?
}

Harcourt, Brace: 329 F. Supp. 517 (S.D.N.Y. 1971)

Reiss: 276 F. 717 (S.D.N.Y. 1921)

Wait! Is Applesoft an operating system or an application? 
45 U.S.P.Q.2d 1827 (ND Cal Feb. 2, 1998)

This description of digital typefaces is taken from Blake Fry, Why Typefaces Proliferate Without Copyright Protection, 8 J. Telecomm. \& High Tech. L. 425 (2010)

Eltra: 579 F.2d 294 (4th Cir. 1978)
Adobe Systems Inc. v. Southern Software Inc.

[Computer outline fonts are a set of points, selected by the font's designer, describing the outside of a letter. The advantage of outlined computer fonts is that since only the outline of the letter is described, a character can be enlarged or shrunk by simply increasing or decreasing the distance between the points. For displaying or printing, software connects these lines, and shades in the letter.]

Computer programs are protectable literary works. Typeface designs are not copyrightable. Eltra Corp. v. Ringer. A computer program is not rendered unprotectable merely because its output is not protectable. Thus, the fact that a computer program produces unprotectable typefaces does not make the computer program itself unprotectable.

In a 1988 Copyright Office Policy Decision, the Copyright Office determined that digitized typefaces were not copyrightable because they were not computer programs and required little selection or arrangement beyond that dictated by the uncopyrightable typeface design. However, in 1992 the Copyright Office issued a final regulation regarding the registrability of "computer programs that generate typefaces" which appears to back off the 1988 policy decision. The 1992 Regulation states:

The Copyright Office is persuaded that creating scalable typefonts using already digitized typeface represents a significant change in the industry since our previous Policy Decision. We are also persuaded that computer programs designed for generating typeface in conjunction with printing devices may involve original computer instructions entitled to protection under the Copyright Act. For example, the creation of scalable font output programs to produce harmonious fonts consisting of hundreds of characters typically involves many decisions in drafting the instructions that drive the printer. The expression of these decisions is neither limited by the unprotectible shape of the letters nor functionally mandated. This expression, assuming it meets the usual standard of authorship, is thus registrable as a computer program.

Defendants state that "merely manipulating an unprotectable font image to create another, slightly different (but still unprotectable) font image cannot possibly give rise to protectable expression" Defendants assert that no matter what points are selected by the Adobe editor performing the process, they correspond directly to, and hence are determined by, the unprotectable font shape. Therefore, because the output is not protected and there cannot be any creativity in what the editor does to obtain the output, nothing is protectable. 
The evidence presented shows that there is some creativity in designing the font software programs. While the glyph dictates to a certain extent what points the editor must choose, it does not dictate every point that must be chosen. Adobe has shown that font editors make creative choices as to what points to select based on the image in front of them on the computer screen. The code is determined directly from the selection of the points. That some creativity is involved is illustrated by the fact that two independently working programmers using the same data and same tools can produce an indistinguishable output but will have few points in common. Accordingly, the court finds that the Adobe font software programs are protectable original works of authorship. Thus, any copying of the points is copying of literal expression, that is, in essence, copying of the computer code itself.

Whelan Associates, Inc. v. Jaslow Dental Laboratory, Inc. [Jaslow, a dental laboratory, hired Whelan, a software development firm, to develop dental laboratory bookkeeping software called Dentalab. Whelan kept the copyright; Jaslow marketed the software to other dental firms and received a 35\% commission. One of Jaslow's owner/officers allegedly used his access to the Dentalab software to develop a competing dental-firm bookkeeping program, Dentcom, which was written in a different programming language: BASIC rather than EDL.]

The Arnstein ordinary observer test, which was developed in cases involving novels, plays, and paintings, is of doubtful value in cases involving computer programs on account of the programs' complexity and unfamiliarity to most members of the public. We therefore join the growing number of courts which do not apply the ordinary observer test in copyright cases involving exceptionally difficult materials, like computer programs, but instead adopt a single substantial similarity inquiry according to which both lay and expert testimony would be admissible.

It is well, though recently, established that copyright protection extends to a program's source and object codes. In this case, however, the district court did not find any copying of the source or object codes, nor did the plaintiff allege such copying. Rather, the district court held that the Dentalab copyright was infringed because the overall structure of Dentcom was substantially similar to the overall structure of Dentalab. The question therefore arises whether mere similarity in the overall structure of programs can be the basis for a copyright infringement, or, put differently, whether a program's copyright protection covers the structure of the program or only the program's literal elements, i.e., its source and object codes.

The copyrights of other literary works can be infringed even when 
Fox v. MCA: 715 F.2d 1327, 1329 (9th Cir. 1983)

Krofft: 562 F.2d 1157 (9th Cir. 1977) there is no substantial similarity between the works' literal elements. One can violate the copyright of a play or book by copying its plot or plot devices. See, e.g., Twentieth Century-Fox Film Corp. v. MCA, Inc. (13 alleged distinctive plot similarities between Battlestar Galactica and Star Wars may be basis for a finding of copyright violation); Sid \& Marty Krofft Television v. McDonald's Corp. (similarities between McDonaldland characters and H.R. Pufnstuf characters can be established by "total concept and feel" of the two productions. By analogy to other literary works, it would thus appear that the copyrights of computer programs can be infringed even absent copying of the literal elements of the program. Defendants contend, however, that what is true of other literary works is not true of computer programs. They assert two principal reasons, which we consider in turn.

Defendants argue that the structure of a computer program is, by definition, the idea and not the expression of the idea, and therefore that the structure cannot be protected by the program copyright.

Just as Baker focused on the end sought to be achieved by Selden's book, the line between idea and expression may be drawn with reference to the end sought to be achieved by the work in question. In other words, the purpose or function of a utilitarian work would be the work's idea, and everything that is not necessary to that purpose or function would be part of the expression of the idea. Where there are various means of achieving the desired purpose, then the particular means chosen is not necessary to the purpose; hence, there is expression, not idea.

It is clear that the purpose of the utilitarian Dentalab program was to aid in the business operations of a dental laboratory. It is equally clear that the structure of the program was not essential to that task: there are other programs on the market, competitors of Dentalab and Dentcom, that perform the same functions but have different structures and designs. The conclusion is thus inescapable that the detailed structure of the Dentalab program is part of the expression, not the idea, of that program.

\section{Computer Associates Intern., Inc. v. Altai, Inc.}

The essentially utilitarian nature of a computer program complicates the task of distilling its idea from its expression. In order to describe both computational processes and abstract ideas, its content combines creative and technical expression. The variations of expression found in purely creative compositions, as opposed to those contained in utilitarian works, are not directed towards practical application. For example, a narration of Humpty Dumpty's demise, which would clearly be a creative composition, does not serve the same ends as, say, a recipe for scrambled eggs - which is a more process oriented text. Thus, compared to aesthetic works, computer programs hover even 
more closely to the elusive boundary line described in $\S 102(b)$.

To the extent that an accounting text and a computer program are both a set of statements or instructions to bring about a certain result, they are roughly analogous. In the former case, the processes are ultimately conducted by human agency; in the latter, by electronic means. In either case, as already stated, the processes themselves are not protectable. But the holding in Baker goes farther. The Court concluded that those aspects of a work, which "must necessarily be used as incident to" the idea, system or process that the work describes, are also not copyrightable. Selden's ledger sheets, therefore, enjoyed no copyright protection because they were "necessary incidents to" the system of accounting that he described. From this reasoning, we conclude that those elements of a computer program that are necessarily incidental to its function are similarly unprotectable.

We think that Whelan's approach to separating idea from expression in computer programs relies too heavily on metaphysical distinctions and does not place enough emphasis on practical considerations.

We think that district courts would be well-advised to undertake a three-step procedure in order to determine whether the non-literal elements of two or more computer programs are substantially similar. This approach breaks no new ground; rather, it draws on such familiar copyright doctrines as merger, scenes a faire, and public domain.

In ascertaining substantial similarity under this approach, a court would first break down the allegedly infringed program into its constituent structural parts. Then, by examining each of these parts for such things as incorporated ideas, expression that is necessarily incidental to those ideas, and elements that are taken from the public domain, a court would then be able to sift out all non-protectable material. Left with a kernel, or possible kernels, of creative expression after following this process of elimination, the court's last step would be to compare this material with the structure of an allegedly infringing program. The result of this comparison will determine whether the protectable elements of the programs at issue are substantially similar so as to warrant a finding of infringement.

\section{Step One: Abstraction}

As applied to computer programs, the abstractions test will comprise the first step in the examination for substantial similarity. Initially, in a manner that resembles reverse engineering on a theoretical plane, a court should dissect the allegedly copied program's structure and isolate each level of abstraction contained within it. This process begins with the code and ends with an articulation of the program's 
Steven R. Englund, Note, Idea, Process, or Protected Expression?: Determining the Scope of Copyright Protection of the Structure of Computer Programs, 88 Mich. L. Rev. 866 (1990) ultimate function. As an anatomical guide to this procedure, the following description is helpful:

At the lowest level of abstraction, a computer program may be thought of in its entirety as a set of individual instructions organized into a hierarchy of modules. At a higher level of abstraction, the instructions in the lowestlevel modules may be replaced conceptually by the functions of those modules. At progressively higher levels of abstraction, the functions of higher-level modules conceptually replace the implementations of those modules in terms of lower-level modules and instructions, until finally, one is left with nothing but the ultimate function of the program. A program has structure at every level of abstraction at which it is viewed. At low levels of abstraction, a program's structure may be quite complex; at the highest level it is trivial.

\section{Step Two: Filtration}

Once the program's abstraction levels have been discovered, the substantial similarity inquiry moves from the conceptual to the concrete. We endorse, a successive filtering method for separating protectable expression from non-protectable material. This process entails examining the structural components at each level of abstraction to determine whether their particular inclusion at that level was "idea" or was dictated by considerations of efficiency, so as to be necessarily incidental to that idea; required by factors external to the program itself; or taken from the public domain and hence is nonprotectable expression. The structure of any given program may reflect some, all, or none of these considerations.

Strictly speaking, this filtration serves the purpose of defining the scope of plaintiff's copyright. By applying well developed doctrines of copyright law, it may ultimately leave behind a core of protectable material. Further explication of this second step may be helpful.

\section{(a) Elements Dictated by Efficiency}

In the context of computer program design, the concept of efficiency is akin to deriving the most concise logical proof or formulating the most succinct mathematical computation. Thus, the more efficient a set of modules are, the more closely they approximate the idea or process embodied in that particular aspect of the program's structure.

While, hypothetically, there might be a myriad of ways in which a programmer may effectuate certain functions within a program, i.e., express the idea embodied in a given subroutine - efficiency concerns may so narrow the practical range of choice as to make only one 
or two forms of expression workable options. Of course, not all program structure is informed by efficiency concerns. It follows that in order to determine whether the merger doctrine precludes copyright protection to an aspect of a program's structure that is so oriented, a court must inquire whether the use of this particular set of modules is necessary efficiently to implement that part of the program's process being implemented. If the answer is yes, then the expression represented by the programmer's choice of a specific module or group of modules has merged with their underlying idea and is unprotected.

Efficiency is an industry-wide goal. Since, as we have already noted, there may be only a limited number of efficient implementations for any given program task, it is quite possible that multiple programmers, working independently, will design the identical method employed in the allegedly infringed work. Of course, if this is the case, there is no copyright infringement.

\section{(b) Elements Dictated By External Factors}

In many instances it is virtually impossible to write a program to perform particular functions in a specific computing environment without employing standard techniques. This is a result of the fact that a programmer's freedom of design choice is often circumscribed by extrinsic considerations such as (1) the mechanical specifications of the computer on which a particular program is intended to run; (2) compatibility requirements of other programs with which a program is designed to operate in conjunction; (3) computer manufacturers' design standards; (4) demands of the industry being serviced; and (5) widely accepted programming practices within the computer industry.

The district court in Q-Co Industries, Inc. v. Hoffman rested its holding on what, perhaps, most closely approximates a traditional scenes a faire rationale. There, the court denied copyright protection to four program modules employed in a teleprompter program. This decision was ultimately based upon the court's finding that "the same modules would be an inherent part of any prompting program."

\section{(c) Elements taken From the Public Domain}

Material found in the public domain is free for the taking and cannot be appropriated by a single author even though it is included in a copyrighted work. We see no reason to make an exception to this rule for elements of a computer program that have entered the public domain by virtue of freely accessible program exchanges and the like. Thus, a court must also filter out this material from the allegedly infringed program before it makes the final inquiry in its substantial similarity analysis. 


\section{Step Three: Comparison}

The third and final step of the test for substantial similarity that we believe appropriate for non-literal program components entails a comparison. Once a court has sifted out all elements of the allegedly infringed program which are "ideas" or are dictated by efficiency or external factors, or taken from the public domain, there may remain a core of protectable expression. In terms of a work's copyright value, this is the golden nugget. At this point, the court's substantial similarity inquiry focuses on whether the defendant copied any aspect of this protected expression, as well as an assessment of the copied portion's relative importance with respect to the plaintiff's overall program.

\section{Evidentiary Analysis}

The district court took the first step in the analysis set forth in this opinion when it separated the program by levels of abstraction. The district court stated:

As applied to computer software programs, this abstractions test would progress in order of "increasing generality" from object code, to source code, to parameter lists, to services required, to general outline. In discussing the particular similarities, therefore, we shall focus on these levels.

Moving to the district court's evaluation of OSCAR 3.5's structural components, we agree with Judge Pratt's systematic exclusion of nonprotectable expression. With respect to code, the district court observed that after the rewrite of OSCAR 3.4 to OSCAR 3.5, "there remained virtually no lines of code that were identical to ADAPTER." Accordingly, the court found that the code "present[ed] no similarity at all."

Next, Judge Pratt addressed the issue of similarity between the two programs' parameter lists and macros. He concluded that, viewing the conflicting evidence most favorably to CA, it demonstrated that "only a few of the lists and macros were similar to protected elements in ADAPTER; the others were either in the public domain or dictated by the functional demands of the program." As discussed above, functional elements and elements taken from the public domain do not qualify for copyright protection. With respect to the few remaining parameter lists and macros, the district court could reasonably conclude that they did not warrant a finding of infringement given their relative contribution to the overall program. In any event, the district court reasonably found that, for lack of persuasive evidence, CA failed to meet its burden of proof on whether the macros 
and parameter lists at issue were substantially similar.

The district court also found that the overlap exhibited between the list of services required for both ADAPTER and OSCAR 3.5 was "determined by the demands of the operating system and of the applications program to which it was to be linked through ADAPTER or OSCAR" In other words, this aspect of the program's structure was dictated by the nature of other programs with which it was designed to interact and, thus, is not protected by copyright.

Finally, in his infringement analysis, Judge Pratt accorded no weight to the similarities between the two programs' organizational charts, "because the charts were so simple and obvious to anyone exposed to the operation of the programs." CA argues that the district court's action in this regard "is not consistent with copyright law" that "obvious" expression is protected, and that the district court erroneously failed to realize this. However, to say that elements of a work are "obvious," in the manner in which the district court used the word, is to say that they "follow naturally from the work's theme rather than from the author's creativity." This is but one formulation of the scenes a faire doctrine, which we have already

Oracle America, Inc. v. Google Inc.

This action was the first of the so-called "smartphone war" cases tried to a jury. This order includes the findings of fact and conclusions of law on a central question tried simultaneously to the judge, namely the extent to which, if at all, certain replicated elements of the structure, sequence and organization of the Java application programming interface are protected by copyright.

Sun Microsystems, Inc. ("Sun") developed the Java" platform" for computer programming and released it in 1996. The aim was to relieve programmers from the burden of writing different versions of their computer programs for different operating systems or devices. The Java platform, through the use of a virtual machine, enabled software developers to write programs that were able to run on different types of computer hardware without having to rewrite them for each different type. With Java, a software programmer could "write once, run anywhere."

The Java virtual machine ("JVM") plays a central role in the overall Java platform. The Java programming language itself - which includes words, symbols, and other units, together with syntax rules for using them to create instructions - is the language in which a Java programmer writes source code, the version of a program that is in a human-readable language. For the instructions to be executed, they must be converted (or compiled) into binary machine code (object

\footnotetext{
${ }^{1}$ Oracle acquired Sun in 2010.
}

872 F. Supp. 2d 974 (N.D. Cal. 2012)

The facts here are drawn primarily from the Court of Appeals' opinion, which immediately follows. 
code) consisting of 0s and Is understandable by the particular computing device. In the Java system, source code is first converted into "bytecode," an intermediate form, before it is then converted into binary machine code by the Java virtual machine that has been designed for that device.

Sun wrote a number of ready-to-use Java programs to perform common computer functions and organized those programs into groups it called "packages." These packages, which are the application programming interfaces at issue in this appeal, allow programmers to use the prewritten code to build certain functions into their own programs, rather than write their own code to perform those functions from scratch. They are shortcuts. Sun called the code for a specific operation (function) a "method." It defined "classes" so that each class consists of specified methods plus variables and other elements on which the methods operate. To organize the classes for users, then, it grouped classes (along with certain related "interfaces") into "packages." The parties have not disputed the district court's analogy: Oracle's collection of API packages is like a library, each package is like a bookshelf in the library, each class is like a book on the shelf, and each method is like a how-to chapter in a book.

The original Java Standard Edition Platform ("Java SE") included eight packages of pre-written programs. The district court found, and Oracle concedes to some extent, that three of those packages java.lang.java.io, and java.util - were "core" packages, meaning that programmers using the Java language had to use them in order to make any worthwhile use of the language. By 2008, the Java platform had more than 6,000 methods making up more than 600 classes grouped into 166 API packages. There are 37 Java API packages at issue in this appeal, three of which are the core packages identified by the district court. These packages contain thousands of individual elements, including classes, subclasses, methods, and interfaces.

Every package consists of two types of source code - what the parties call (1) declaring code; and (2) implementing code. Declaring code is the expression that identifies the prewritten function and is sometimes referred to as the "declaration" or "header." As the district court explained, the "main point is that this header line of code introduces the method body and specifies very precisely the inputs, name and other functionality." The expressions used by the programmer from the declaring code command the computer to execute the associated implementing code, which gives the computer the step-bystep instructions for carrying out the declared function.

For example, one of the Java API packages at issue is "java. lang." Within that package is a class called "math," and within "math" there are several methods, including one that is designed to find the larger of two numbers: "max." To invoke this method from another pro- 
gram (or class), the following call could be included in the program:

int $a=j$ ava. lang. Math.max $(2,3)$;

Upon reaching this statement, the computer would go and find the max method under the Math class in the java.lang package, input ' 2 ' and ' 3 ' as arguments, and then return a ' 3 ,' which would then be set as the value of 'a.' The declaration for the "max" method, as defined for integers, is

public static int $\max$ (int $x$, int $y$ ) \{

The word "public" means that other programs can call on it. (If this instead says "private," then it can only be accessed by other methods inside the same class.) The word "static" means that the method can be invoked without creating an instance of the class. (If this instead is an instance method, then it would always be invoked with respect to an object.) The word "int" means that an integer is returned by the method. (Other alternatives are "boolean," "char," and "String" which respectively mean "true/false," "single character," and "character string.") Each of these three parameters is drawn from a short menu of possibilities, each possibility corresponding to a very specific functionality. The word "max" is a name and any name (other than a reserved word [i.e, a few names like "int" and "public" that have specific and rigidly defined roles in the Java language]) could have been used.. The phrase "(int $x$, int $y$ )" identifies the arguments that must be passed into the method, stating that they will be in integer form. The " $x$ " and the " $y$ " could be "a" and "b" or "arg1" and "arg2," so there is a degree of creativity in naming the arguments. Finally, " $\{$ " is the beginning marker that tells the compiler that the method body is about to follow. The marker is mandatory.

Although Oracle owns the copyright on Java SE and the API packages, it offers three different licenses to those who want to make use of them. The first is the General Public License, which is free of charge and provides that the licensee can use the packages - both the declaring and implementing code - but must "contribute back" its innovations to the public. This arrangement is referred to as an "open source" license. The second option is the Specification License, which provides that the licensee can use the declaring code and organization of Oracle's API packages but must write its own implementing code. The third option is the Commercial License, which is for businesses that want to use and customize the full Java code in their commercial products and keep their code secret. Oracle offers the Commercial License in exchange for royalties. To maintain Java's "write once, run anywhere" motto, the Specification and Commercial Licenses require that the licensees' programs pass certain tests to ensure compatibility with the Java platform. 
The accused product is Android, a software platform that was designed for mobile devices and competes with Java in that market. Google acquired Android, Inc. in 2005 as part of a plan to develop a smartphone platform. Later that same year, Google and Sun began discussing the possibility of Google taking a license to use and to adapt the entire Java platform for mobile devices. They also discussed a possible co-development partnership deal with Sun under which Java technology would become an open-source part of the Android platform, adapted for mobile devices. The parties negotiated for months but were unable to reach an agreement. The point of contention between the parties was Google's refusal to make the implementation of its programs compatible with the Java virtual machine or interoperable with other Java programs. Because Sun/Oracle found that position to be anathema to the "write once, run anywhere" philosophy, it did not grant Google a license to use the Java API packages.

When the parties' negotiations reached an impasse, Google decided to use the Java programming language to design its own virtual machine - the Dalvik virtual machine ("Dalvik VM") - and "to write its own implementations for the functions in the Java API that were key to mobile devices." Google developed the Android platform, which grew to include 168 API packages - 37 of which correspond to the Java API packages at issue in this appeal.

With respect to the 37 packages at issue, "Google believed Java application programmers would want to find the same 37 sets of functionalities in the new Android system callable by the same names as used in Java." To achieve this result, Google copied the declaring source code from the 37 Java API packages verbatim, inserting that code into parts of its Android software. In doing so, Google copied the elaborately organized taxonomy of all the names of methods, classes, interfaces, and packages - the "overall system of organized names - covering 37 packages, with over six hundred classes, with over six thousand methods. The parties and district court referred to this taxonomy of expressions as the "structure, sequence, and organization" or "SSO" of the 37 packages. It is undisputed, however, that Google wrote its own implementing code [with some exceptions not here relevant].

Google released the Android platform in 2007, and the first Android phones went on sale the following year. Oracle indicated at oral argument that Android phones contain copies of the accused portions of the Android software. Android smartphones rapidly grew in popularity and now comprise a large share of the United States market. Google provides the Android platform free of charge to smartphone manufacturers and receives revenue when customers use particular functions on the Android phone. Although Android uses the 
Java programming language, it is undisputed that Android is not generally Java compatible. As Oracle explains, "Google ultimately designed Android to be incompatible with the Java platform, so that apps written for one will not work on the other."

\section{Application of Controlling Law to Controlling Facts}

All agree that everyone was and remains free to program in the Java language itself. All agree that Google was free to use the Java language to write its own API. While Google took care to provide fresh line-by-line implementations (the 97 percent), it generally replicated the overall name organization and functionality of 37 packages in the Java API (the three percent). The main issue addressed herein is whether this violated the Copyright Act and more fundamentally whether the replicated elements were copyrightable in the first place.

This leads to the first holding central to this order and it concerns the method level. As long as the specific code written to implement a method is different, anyone is free under the Copyright Act to write his or her own method to carry out exactly the same function or specification of any and all methods used in the Java API. Contrary to Oracle, copyright law does not confer ownership over any and all ways to implement a function or specification, no matter how creative the copyrighted implementation or specification may be. The Act confers ownership only over the specific way in which the author wrote out his version. Others are free to write their own implementation to accomplish the identical function, for, importantly, ideas, concepts and functions cannot be monopolized by copyright.

To return to our example, one method in the Java API carries out the function of comparing two numbers and returning the greater. Google - and everyone else in the world - was and remains free to write its own code to carry out the identical function so long as the implementing code in the method body is different from the copyrighted implementation. This is a simple example, but even if a method resembles higher mathematics, everyone is still free to try their hand at writing a different implementation, meaning that they are free to use the same inputs to derive the same outputs so long as the implementation in between is their own.

Much of Oracle's evidence at trial went to show that the design of methods in an API was a creative endeavor. Of course, that is true. Inventing a new method to deliver a new output can be creative, even inventive, including the choices of inputs needed and outputs returned. But such inventions - at the concept and functionality level - are protectable only under the Patent Act. Under the Copyright Act, no matter how creative or imaginative a Java method specification may be, the entire world is entitled to use the same method specification (inputs, outputs, parameters) so long as the line-by-line
Wait. Why is everyone free to program in Java? Is everyone free to program in Java? 
implementations are different. To repeat the Second Circuit's phrasing, "there might be a myriad of ways in which a programmer may express the idea embodied in a given subroutine." Altai The method specification is the idea. The method implementation is the expression. No one may monopolize the idea.

To carry out any given function, the method specification as set forth in the declaration must be identical under the Java rules (save only for the choices of argument names). Any other declaration would carry out some other function. The declaration requires precision. Significantly, when there is only one way to write something, the merger doctrine bars anyone from claiming exclusive copyright ownership of that expression. Therefore, there can be no copyright violation in using the identical declarations. Nor can there be any copyright violation due to the name given to the method (or to the arguments), for under the law, names and short phrases cannot be copyrighted.

In sum, Google and the public were and remain free to write their own implementations to carry out exactly the same functions of all methods in question, using exactly the same method specifications and names. Therefore, at the method level - the level where the heavy lifting is done - Google has violated no copyright, it being undisputed that Google's implementations are different.

Even so, the second major copyright question is whether Google was and remains free to group its methods in the same way as in Java, that is, to organize its Android methods under the same class and package scheme as in Java. For example, the Math classes in both systems have a method that returns a cosine, another method that returns the larger of two numbers, and yet another method that returns logarithmic values, and so on. As Oracle notes, the rules of Java did not insist that these methods be grouped together in any particular class. Google could have placed its trigonometric function (or any other function) under a class other than Math class. Oracle is entirely correct that the rules of the Java language did not require that the same grouping pattern (or even that they be grouped at all, for each method could have been placed in a stand-alone class). There was nothing in the rules of the Java language that required that Google replicate the same groupings even if Google was free to replicate the same functionality.

The main answer to this argument is that the overall scheme of file name organization is also a command structure for a system or method of operation of the application programming interface. The commands are (and must be) in the form 
java.package.Class.method()

and each calls into action a pre-assigned function.

That a system or method of operation has thousands of commands arranged in a creative taxonomy does not change its character as a method of operation. Yes, it is creative. Yes, it is original. But it is nevertheless a command structure, a system or method of operation - a long hierarchy of over six thousand commands to carry out pre-assigned functions. For that reason, it cannot receive copyright protection.

Interoperability sheds further light on the character of the command structure as a system or method of operation. Surely, millions of lines of code had been written in Java before Android arrived. These programs necessarily used the java.package.Class.method() command format. These programs called on all or some of the specific 37 packages at issue and necessarily used the command structure of names at issue. Such code was owned by the developers themselves, not by Oracle. In order for at least some of this code to run on Android, Google was required to provide the same java.package.Class.method() command system using the same names with the same "taxonomy" and with the same functional specifications. Google replicated what was necessary to achieve a degree of interoperability - but no more, taking care, as said before, to provide its own implementations.

That interoperability is at the heart of the command structure is illustrated by Oracle's preoccupation with what it calls "fragmentation," meaning the problem of having imperfect interoperability among platforms. When this occurs, Java-based applications may not run on the incompatible platforms. For example, Java-based code using the replicated parts of the 37 API packages will run on Android but will not if a 38th package is needed. Such imperfect interoperability leads to a "fragmentation" - a Balkanization - of platforms, a circumstance which Sun and Oracle have tried to curb via their licensing programs. In this litigation, Oracle has made much of this problem, at times almost leaving the impression that if only Google had replicated all 166 Java API packages, Oracle would not have sued. While fragmentation is a legitimate business consideration, it begs the question whether or not a license was required in the first place to replicate some or all of the command structure. (This is especially so inasmuch as Android has not carried the Java trademark, and Google has not held out Android as fully compatible.) The immediate point is this: fragmentation, imperfect interoperability, and Oracle's angst over it illustrate the character of the command structure as a functional system or method of operation. 
750 F.3d 1339 (Fed. Cir. 2014)

Why the Federal Circuit? Because the case originally included patent claims, giving the Federal Circuit appellate jurisdiction. Note that the Federal Circuit here is technically applying Ninth Circuit law.

Atari: 975 F. 2d 832 (Fed. Cir. 1992)

\section{Oracle America, Inc. v. Google Inc.}

We are mindful that the application of copyright law in the computer context is often a difficult task. On this record, however, we find that the district court failed to distinguish between the threshold question of what is copyrightable - which presents a low bar - and the scope of conduct that constitutes infringing activity. The court also erred by importing fair use principles, including interoperability concerns, into its copyrightability analysis. For the reasons that follow, we conclude that the declaring code and the structure, sequence, and organization of the 37 Java API packages are entitled to copyright protection.

\section{Declaring Source Code}

Under the merger doctrine, a court will not protect a copyrighted work from infringement if the idea contained therein can be expressed in only one way. For computer programs, this means that when specific parts of the code, even though previously copyrighted, are the only and essential means of accomplishing a given task, their later use by another will not amount to infringement.

In Atari Games Corp. v. Nintendo of America Inc., for example, Nintendo designed a program - the 10NES - to prevent its video game system from accepting unauthorized game cartridges. Nintendo "chose arbitrary programming instructions and arranged them in a unique sequence to create a purely arbitrary data stream" which "serves as the key to unlock the NES." Because Nintendo produced expert testimony "showing a multitude of different ways to generate a data stream which unlocks the NES console," we concluded that Nintendo's specific choice of code did not merge with the process.

The evidence showed that Oracle had unlimited options as to the selection and arrangement of the 7000 lines Google copied. Using the district court's "java.lang. Math.max" example, Oracle explains that the developers could have called it any number of things, including "Math.maximum" or "Arith.larger." This was not a situation where Oracle was selecting among preordained names and phrases to create its packages. As the district court recognized, moreover, "the Android method and class names could have been different from the names of their counterparts in Java and still have worked." Because alternative expressions were available, there is no merger.

We further find that the district court erred in focusing its merger analysis on the options available to Google at the time of copying. It is well-established that copyrightability and the scope of protectable activity are to be evaluated at the time of creation, not at the time of infringement. The focus is, therefore, on the options that were available to Sun/Oracle at the time it created the API packages. Of course, once 
Sun/Oracle created "java.lang.Math.max," programmers who want to use that particular package have to call it by that name. But nothing prevented Google from writing its own declaring code, along with its own implementing code, to achieve the same result. In such circumstances, the chosen expression simply does not merge with the idea being expressed.

The district court is correct that words and short phrases such as names, titles, and slogans are not subject to copyright protection. The court failed to recognize, however, that the relevant question for copyrightability purposes is not whether the work at issue contains short phrases - as literary works often do - but, rather, whether those phrases are creative. And, by dissecting the individual lines of declaring code at issue into short phrases, the district court further failed to recognize that an original combination of elements can be copyrightable.

By analogy, the opening of Charles Dickens' A Tale of Two Cities is nothing but a string of short phrases. Yet no one could contend that this portion of Dickens' work is unworthy of copyright protection because it can be broken into those shorter constituent components. The question is not whether a short phrase or series of short phrases can be extracted from the work, but whether the manner in which they are used or strung together exhibits creativity.

Although the district court apparently focused on individual lines of code, Oracle is not seeking copyright protection for a specific short phrase or word. Instead, the portion of declaring code at issue is 7,000 lines, and Google's own "Java guru" conceded that there can be "creativity and artistry even in a single method declaration." Because Oracle exercised creativity in the selection and arrangement of the method declarations when it created the API packages and wrote the relevant declaring code, they contain protectable expression that is entitled to copyright protection.

\section{The Structure, Sequence, and Organization of the API Packages}

The district court found that the SSO of the Java API packages is creative and original, but nevertheless held that it is a system or method of operation and, therefore, cannot be copyrighted. In reaching this conclusion, the district court seems to have relied upon language contained in a First Circuit decision, Lotus Development Corp. v. Borland International, Inc..

In Lotus, it was undisputed that the defendant copied the menu command hierarchy and interface from Lotus 1-2-3, a computer

\footnotetext{
${ }^{7}$ he district court did not find merger with respect to the structure, sequence, and organization of Oracle's Java API packages. Nor could it, given the court's recognition that there were myriad ways in which the API packages could have been organized.
}

"It was the best of times, it was the worst of times, it was the age of wisdom, it was the age of foolishness, it was the epoch of belief, it was the epoch of incredulity, it was the season of Light, it was the season of Darkness, it was the spring of hope, it was the winter of despair, we had everything before us, we had nothing before us, we were all going direct to Heaven, we were all going direct the other way -in short, the period was so far like the present period, that some of its noisiest authorities insisted on its being received, for good or for evil, in the superlative degree of comparison only." Charles Dickens, A Tale of Two Cities

"Mr. Burns: This is a thousand monkeys working at a thousand typewriters. Soon, they'll have written the greatest novel known to man. Let's see ... 'It was the best of times, it was the blurst of times!' You stupid monkey!" The Simpsons, "Last Exit to Springfield" (episode 9F15).

Lotus: 49 F.3d 807 (1st Cir. 1995), aff'd without opinion by equally divided court, 516 U.S. 233 (1996) 
spreadsheet program that enables users to perform accounting functions electronically on a computer. The menu command hierarchy referred to a series of commands - such as "Copy," "Print," and "Quit" - which were arranged into more than 50 menus and submenus. Although the defendant did not copy any Lotus source code, it copied the menu command hierarchy into its rival program. The question before the court was whether a computer menu command hierarchy is copyrightable subject matter.

Although it accepted the district court's finding that Lotus developers made some expressive choices in selecting and arranging the command terms, the First Circuit found that the command hierarchy was not copyrightable because, among other things, it was a "method of operation" under Section 102(b). In reaching this conclusion, the court defined a "method of operation" as "the means by which a person operates something, whether it be a car, a food processor, or a computer." Because the Lotus menu command hierarchy provided "the means by which users control and operate Lotus 1-2-3," it was deemed unprotectable. For example, if users wanted to copy material, they would use the "Copy" command and the command terms would tell the computer what to do. According to the Lotus court, the "fact that Lotus developers could have designed the Lotus menu command hierarchy differently is immaterial to the question of whether it is a 'method of operation.' The court further indicated that, "[i]f specific words are essential to operating something, then they are part of a 'method of operation' and, as such, are unprotectable."

On appeal, Oracle argues that the district court's reliance on Lotus is misplaced because it is distinguishable on its facts and is inconsistent with Ninth Circuit law. We agree. First, while the defendant in Lotus did not copy any of the underlying code, Google concedes that it copied portions of Oracle's declaring source code verbatim. Second, the Lotus court found that the commands at issue there (copy, print, etc.) were not creative, but it is undisputed here that the declaring code and the structure and organization of the API packages are both creative and original. Finally, while the court in Lotus found the commands at issue were "essential to operating" the system, it is undisputed that - other than perhaps as to the three core packages Google did not need to copy the structure, sequence, and organization of the Java API packages to write programs in the Java language.

More importantly, however, the Ninth Circuit has not adopted the court's "method of operation" reasoning in Lotus, and we conclude that it is inconsistent with binding precedent. Specifically, we find that Lotus is inconsistent with Ninth Circuit case law recognizing that the structure, sequence, and organization of a computer program is eligible for copyright protection where it qualifies as an expression of an idea, rather than the idea itself. We find, moreover, that the 
hard and fast rule set down in Lotus and employed by the district court here - i.e., that elements which perform a function can never be copyrightable - is at odds with the Ninth Circuit's endorsement of the abstraction-filtration-comparison analysis.

Here, the district court recognized that the $\mathrm{SSO}$ "resembles a taxonomy," but found that "it is nevertheless a command structure, a system or method of operation - a long hierarchy of over six thousand commands to carry out pre-assigned functions."12 In other words, the court concluded that, although the SSO is expressive, it is not copyrightable because it is also functional. The problem with the district court's approach is that computer programs are by definition functional - they are all designed to accomplish some task. If we were to accept the district court's suggestion that a computer program is uncopyrightable simply because it "carr[ies] out pre-assigned functions," no computer program is protectable. That result contradicts Congress's express intent to provide copyright protection to computer programs, as well as binding Ninth Circuit case law finding computer programs copyrightable, despite their utilitarian or functional purpose.

On appeal, Oracle does not - and concedes that it cannot - claim copyright in the idea of organizing functions of a computer program or in the "package-class-method" organizational structure in the abstract. Instead, Oracle claims copyright protection only in its particular way of naming and organizing each of the 37 Java API packages. Oracle recognizes, for example, that it "cannot copyright the idea of programs that open an internet connection," but "it can copyright the precise strings of code used to do so, at least so long as other language is available to achieve the same function." Thus, Oracle concedes that Google and others could employ the Java language - much like anyone could employ the English language to write a paragraph without violating the copyrights of other English language writers. And, that Google may employ the "package-class-method" structure much like authors can employ the same rules of grammar chosen by other authors without fear of infringement. What Oracle contends is that, beyond that point, Google, like any author, is not permitted to employ the precise phrasing or precise structure chosen by Oracle to flesh out the substance of its packages - the details and arrangement of the prose.

\section{Google's Interoperability Arguments are Irrelevant to Copyrightability}

Oracle also argues that the district court erred in invoking interoperability in its copyrightability analysis. Specifically, Oracle argues

\footnotetext{
${ }^{12}$ This analogy by the district court is meaningful because taxonomies, in varying forms, have generally been deemed copyrightable. See, e.g., Practice Management
} 
that Google's interoperability arguments are only relevant, if at all, to fair use - not to the question of whether the API packages are copyrightable. We agree.

The district court characterized Accolade and Sony Computer Entertainment $v$. Connectix Corp. as "close analogies" to this case. According to the court, both decisions "held that interface procedures that were necessary to duplicate in order to achieve interoperability were functional aspects not copyrightable under Section 102(b)." The district court's reliance on Accolade and Connectix in the copyrightability context is misplaced, however. Both cases were focused on fair use, not copyrightability. In Accolade, for example, the only question was whether Accolade's intermediate copying was fair use. The court never addressed the question of whether Sega's software code, which had functional elements, also contained separable creative expression entitled to protection.

This is not a case where Google reverse-engineered Oracle's Java packages to gain access to unprotected functional elements contained therein. Had Google reverse engineered the programming packages to figure out the ideas and functionality of the original, and then created its own structure and its own literal code, Oracle would have no remedy under copyright whatsoever. Instead, Google chose to copy both the declaring code and the overall SSO of the 37 Java API packages at issue.

We disagree with Google's suggestion that Accolade and Connectix created an "interoperability exception" to copyrightability. Because copyrightability is focused on the choices available to the plaintiff at the time the computer program was created, the relevant compatibility inquiry asks whether the plaintiff's choices were dictated by a need to ensure that its program worked with existing third-party programs. Whether a defendant later seeks to make its program interoperable with the plaintiff's program has no bearing on whether the software the plaintiff created had any design limitations dictated by external factors. Stated differently, the focus is on the compatibility needs and programming choices of the party claiming copyright protection - not the choices the defendant made to achieve compatibility with the plaintiff's program. Consistent with this approach, courts have recognized that, once the plaintiff creates a copyrightable work, a defendant's desire "to achieve total compatibility... is a commercial and competitive objective which does not enter into the ... issue of whether particular ideas and expressions have merged." Apple $v$. Franklin

Whether Google's software is "interoperable" in some sense with any aspect of the Java platform (although as Google concedes, certainly not with the JVM) has no bearing on the threshold question of whether Oracle's software is copyrightable. It is the interoperability 
and other needs of Oracle - not those of Google - that apply in the copyrightability context, and there is no evidence that when Oracle created the Java API packages at issue it did so to meet compatibility requirements of other pre-existing programs.

Google maintains on appeal that its use of the "Java class and method names and declarations was 'the only and essential means' of achieving a degree of interoperability with existing programs written in the Java language." Indeed, given the record evidence that Google designed Android so that it would not be compatible with the Java platform, or the JVM specifically, we find Google's interoperability argument confusing. While Google repeatedly cites to the district court's finding that Google had to copy the packages so that an app written in Java could run on Android, it cites to no evidence in the record that any such app exists and points to no Java apps that either pre-dated or post-dated Android that could run on the Android platform. The compatibility Google sought to foster was not with Oracle's Java platform or with the JVM central to that platform. Instead, Google wanted to capitalize on the fact that software developers were already trained and experienced in using the Java API packages at issue. Google's interest was in accelerating its development process by leveraging Java for its existing base of developers. Although this competitive objective might be relevant to the fair use inquiry, we conclude that it is irrelevant to the copyrightability of Oracle's declaring code and organization of the API packages.

Finally, to the extent Google suggests that it was entitled to copy the Java API packages because they had become the effective industry standard, we are unpersuaded. Google cites no authority for its suggestion that copyrighted works lose protection when they become popular, and we have found none. In fact, the Ninth Circuit has rejected the argument that a work that later becomes the industry standard is uncopyrightable. See Practice Management. Info. Corp. v. Am. Med. Ass'n (noting that the district court found plaintiff's medical coding system entitled to copyright protection, and that, although the system had become the industry standard, plaintiff's copyright did not prevent competitors "from developing comparative or better coding systems and lobbying the federal government and private actors to adopt them. It simply prevents wholesale copying of an existing system."). Google was free to develop its own API packages and to lobby programmers to adopt them. Instead, it chose to copy Oracle's declaring code and the SSO to capitalize on the preexisting community of programmers who were accustomed to using the Java API packages. That desire has nothing to do with copyrightability. For these reasons, we find that Google's industry standard argument has no bearing on the copyrightability of Oracle's work.

[On remand, the jury found that Google's copying was a fair use.
Practice Management: 121 F.3d 516, (9th Cir. 1997) 
The District Court declined to set aside the verdict. The case is now on appeal again on a variety of grounds.]

\section{Tetris Problem}

Based on Tetris Holding, LLC v. Xio Interactive, Inc., 863 F. Supp. 2d 394 (D.N.J. 2012) and Spry Fox LLC v. LOLApps Inc., 104 U.S.P.Q.2d 1299 (W. D. Wash 2012)

17 U.S.C. § 117

Limitations on exclusive rights: Computer programs
Your client, Thoth Software, would like to create and sell a version of Tetris for the Digix gaming console. What aspects of the game can Thoth imitate without fear of liability? The name? Falling blocks? The shapes of the blocks? Their colors? Lines that disappear when completely filled in? The music? The graphics around the play field?

\section{Defenses}

When in 1980 Congress confirmed that software was copyrightable as a literary work, it rewrote Section 117 to codify a kind of limited exhaustion rule for software. Accolade shows that the courts have also used fair use to create a fairly robust reverse engineering defense to software copyright. Although it arises in the DMCA context, Corley shows how the courts have applied the First Amendment to software copyright.

\section{Copyright Act}

(a) Making of Additional Copy or Adaptation by Owner of Copy. Notwithstanding the provisions of section 106, it is not an infringement for the owner of a copy of a computer program to make or authorize the making of another copy or adaptation of that computer program provided:

(1) that such a new copy or adaptation is created as an essential step in the utilization of the computer program in conjunction with a machine and that it is used in no other manner, or

(2) that such new copy or adaptation is for archival purposes only and that all archival copies are destroyed in the event that continued possession of the computer program should cease to be rightful.

(b) Lease, Sale, or Other Transfer of Additional Copy or Adaptation. Any exact copies prepared in accordance with the provisions of this section may be leased, sold, or otherwise transferred, along with the copy from which such copies were prepared, only as part of the lease, sale, or other transfer of all rights in the program. Adaptations so prepared may be transferred only with the authorization of the copyright owner.

(c) Machine Maintenance or Repair. - Notwithstanding the provisions of section 106, it is not an infringement for the owner or 
lessee of a machine to make or authorize the making of a copy of a computer program if such copy is made solely by virtue of the activation of a machine that lawfully contains an authorized copy of the computer program, for purposes only of maintenance or repair of that machine, if -

(1) such new copy is used in no other manner and is destroyed immediately after the maintenance or repair is completed; and

(2) with respect to any computer program or part thereof that is not necessary for that machine to be activated, such program or part thereof is not accessed or used other than to make such new copy by virtue of the activation of the machine.

\section{Sega Enterprises Ltd. v. Accolade, Inc.}

Sega develops and market video entertainment systems, including the "Genesis" console and video game cartridges. Sega licenses its copyrighted computer code and its "SEGA" trademark to a number of independent developers of computer game software. Those licensees develop and sell Genesis-compatible video games in competition with Sega. Accolade is not and never has been a licensee of Sega.

Accolade reverse engineered Sega's video game programs in order to discover the requirements for compatibility with the Genesis console. As part of the reverse engineering process, Accolade transformed the machine-readable object code contained in Sega's game cartridges into human-readable source code using a process called "disassembly" or "decompilation"] Accolade purchased a Genesis console and three Sega game cartridges, wired a decompiler into the console circuitry, and generated printouts of the resulting source code. Accolade engineers studied and annotated the printouts in order to identify areas of commonality among the three game programs. They then loaded the disassembled code back into a computer, and experimented to discover the interface specifications for the Genesis console by modifying the programs and studying the results. At the end of the reverse engineering process, Accolade created a development manual that incorporated the information it had discovered about the requirements for a Genesis-compatible game. The manual contained only functional descriptions of the interface requirements and did not include any of Sega's code.

[In creating its own games for the Genesis, Accolade] did not copy Sega's programs, but relied only on the information concerning inter-

\footnotetext{
${ }^{2}$ Disassembly devices are commercially available and are widely used within the software industry.
}

977 F.2d 1510 (9th Cir. 1992)

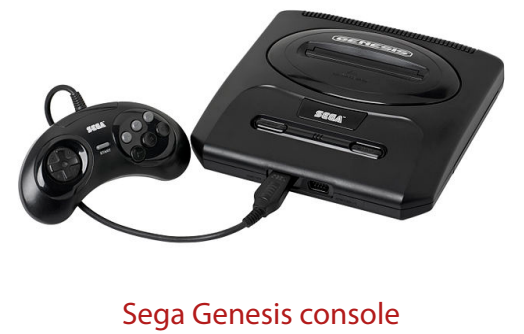

What about cases like Barr-Mullin and Silvaco, which asserted that reverse engineering object code was impossible? 


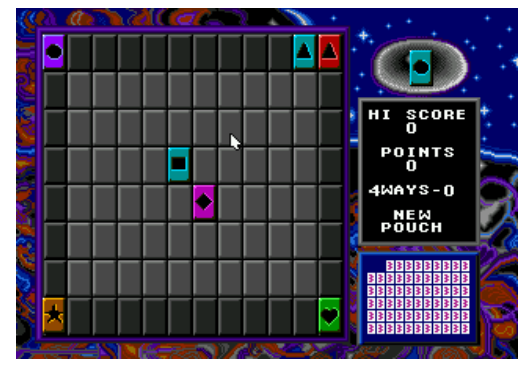

Ishido screenshot face specifications for the Genesis that was contained in its development manual. With the exception of the interface specifications, none of the code in Accolade's games is derived in any way from its examination of Sega's code. In 1990, Accolade released "Ishido", a game which it had originally developed and released for use with the Macintosh and IBM personal computer systems, for use with the Genesis console.

Accolade contends that its disassembly of copyrighted object code as a necessary step in its examination of the unprotected ideas and functional concepts embodied in the code is a fair use. Because, in the case before us, disassembly is the only means of gaining access to those unprotected aspects of the program, and because Accolade has a legitimate interest in gaining such access (in order to determine how to make its cartridges compatible with the Genesis console), we agree with Accolade. Where there is good reason for studying or examining the unprotected aspects of a copyrighted computer program, disassembly for purposes of such study or examination constitutes a fair use.

There is no evidence in the record that Accolade sought to avoid performing its own creative work. Indeed, most of the games that Accolade released for use with the Genesis console were originally developed for other hardware systems.

Accolade copied Sega's software solely in order to discover the functional requirements for compatibility with the Genesis console - aspects of Sega's programs that are not protected by copyright. To the extent that there are many possible ways of accomplishing a given task or fulfilling a particular market demand, the programmer's choice of program structure and design may be highly creative and idiosyncratic. However, computer programs are, in essence, utilitarian articles - articles that accomplish tasks. As such, they contain many logical, structural, and visual display elements that are dictated by the function to be performed, by considerations of efficiency, or by external factors such as compatibility requirements and industry demands. Altai

Sega argues that even if many elements of its video game programs are properly characterized as functional and therefore not protected by copyright, Accolade copied protected expression. Sega is correct. The record makes clear that disassembly is wholesale copying. Because computer programs are also unique among copyrighted works in the form in which they are distributed for public use, however, Sega's observation does not bring us much closer to a resolution of the dispute.

The unprotected aspects of most functional works are readily accessible to the human eye. The systems described in accounting textbooks or the basic structural concepts embodied in architectural 
plans, to give two examples, can be easily copied without also copying any of the protected, expressive aspects of the original works. Computer programs, however, are typically distributed for public use in object code form, embedded in a silicon chip or on a floppy disk. For that reason, humans often cannot gain access to the unprotected ideas and functional concepts contained in object code without disassembling that code - i.e., making copies. If disassembly of copyrighted object code is per se an unfair use, the owner of the copyright gains a de facto monopoly over the functional aspects of his work aspects that were expressly denied copyright protection by Congress.

\section{Universal City Studios, Inc. v. Corley}

Our case concerns a security device, CSS computer code, that prevents access by unauthorized persons to DVD movies. The CSS code is embedded in the DVD movie. Access to the movie cannot be obtained unless a person has a device, a licensed DVD player, equipped with computer code capable of decrypting the CSS encryption code. In its basic function, CSS is like a lock on a homeowner's door, a combination of a safe, or a security device attached to a store's products.

DeCSS is computer code that can decrypt CSS. In its basic function, it is like a skeleton key that can open a locked door, a combination that can open a safe, or a device that can neutralize the security device attached to a store's products. DeCSS enables anyone to gain access to a DVD movie without using a DVD player.

The initial use of DeCSS to gain access to a DVD movie creates no loss to movie producers because the initial user must purchase the DVD. However, once the DVD is purchased, DeCSS enables the initial user to copy the movie in digital form and transmit it instantly in virtually limitless quantity, thereby depriving the movie producer of sales. The advent of the Internet creates the potential for instantaneous worldwide distribution of the copied material.

[The District Court found that DeCSS was a "technology" that was "primarily designed" to circumvent CSS in violation of $\S 1201$ (a)(2) of the DMCA. It enjoined the defendant-appellants from posting the DeCSS code to the Internet.]

At first glance, one might think that Congress has as much authority to regulate the distribution of computer code to decrypt DVD movies as it has to regulate distribution of skeleton keys, combinations to safes, or devices to neutralize store product security devices. However, despite the evident legitimacy of protection against unauthorized access to DVD movies, just like any other property, regulation of decryption code like DeCSS is challenged in this case because DeCSS differs from a skeleton key in one important respect: it not only is capable of performing the function of unlocking the encrypted
273 F.3d 429 (2001)

The District Court noted in a footnote, "Professor Touretzky of Carnegie Mellon University convincingly demonstrated that computer source and object code convey the same ideas as various other modes of expression, including spoken language descriptions of the algorithm embodied in the code. He drew from this the conclusion that the preliminary injunction irrationally distinguished between the code, which was enjoined, and other modes of expression that convey the same idea, which were not, although of course he had no reason to be aware that the injunction drew that line only because that was the limit of the relief plaintiffs sought. With commendable candor, he readily admitted that the implication of his view that the spoken language and computer code versions were substantially similar was not necessarily that the preliminary injunction was too broad; rather, the logic of his position was that it was either too broad or too narrow. Once again, the question of a substantially broader injunction need not be addressed here, as plaintiffs have not sought broader relief." 
DVD movie, it also is a form of communication, albeit written in a language not understood by the general public. As a communication, the DeCSS code has a claim to being "speech," and as "speech," it has a claim to being protected by the First Amendment.

Computer programs are not exempted from the category of First Amendment speech simply because their instructions require use of a computer. A recipe is no less "speech" because it calls for the use of an oven, and a musical score is no less "speech" because it specifies performance on an electric guitar. Arguably distinguishing computer programs from conventional language instructions is the fact that programs are executable on a computer. But the fact that a program has the capacity to direct the functioning of a computer does not mean that it lacks the additional capacity to convey information, and it is the conveying of information that renders instructions "speech" for purposes of the First Amendment. The information conveyed by most "instructions" is how to perform a task.

The Appellants vigorously reject the idea that computer code can be regulated according to any different standard than that applicable to pure speech, i.e., speech that lacks a nonspeech component. Although recognizing that code is a series of instructions to a computer, they argue that code is no different, for First Amendment purposes, than blueprints that instruct an engineer or recipes that instruct a cook. We disagree. Unlike a blueprint or a recipe, which cannot yield any functional result without human comprehension of its content, human decision-making, and human action, computer code can instantly cause a computer to accomplish tasks and instantly render the results of those tasks available throughout the world via the Internet. The only human action required to achieve these results can be as limited and instantaneous as a single click of a mouse. These realities of what code is and what its normal functions are require a First Amendment analysis that treats code as combining nonspeech and speech elements, i.e., functional and expressive elements.

We recognize that the functional capability of computer code cannot yield a result until a human being decides to insert the disk containing the code into a computer and causes it to perform its function (or programs a computer to cause the code to perform its function). Nevertheless, this momentary intercession of human action does not diminish the nonspeech component of code, nor render code entirely speech, like a blueprint or a recipe.

Neither the DMCA nor the posting prohibition is concerned with whatever capacity DeCSS might have for conveying information to a human being, and that capacity, as previously explained, is what arguably creates a speech component of the decryption code. The DMCA and the posting prohibition are applied to DeCSS solely because of its capacity to instruct a computer to decrypt CSS. That func- 
tional capability is not speech within the meaning of the First Amendment. The Government seeks to justify both the application of the DMCA and the posting prohibition to the Appellants solely on the basis of the functional capability of DeCSS to instruct a computer to decrypt CSS, i.e., without reference to the content of the regulated speech. This type of regulation is therefore content-neutral, just as would be a restriction on trafficking in skeleton keys identified because of their capacity to unlock jail cells, even though some of the keys happened to bear a slogan or other legend that qualified as a speech component.

As a content-neutral regulation with an incidental effect on a speech component, the regulation must serve a substantial governmental interest, the interest must be unrelated to the suppression of free expression, and the incidental restriction on speech must not burden substantially more speech than is necessary to further that interest. The Government's interest in preventing unauthorized access to encrypted copyrighted material is unquestionably substantial, and the regulation of DeCSS by the posting prohibition plainly serves that interest. Moreover, that interest is unrelated to the suppression of free expression.

Posting DeCSS on the Appellants' web site makes it instantly available at the click of a mouse to any person in the world with access to the Internet, and such person can then instantly transmit DeCSS to anyone else with Internet access. Although the prohibition on posting prevents the Appellants from conveying to others the speech component of DeCSS, the Appellants have not suggested, much less shown, any technique for barring them from making this instantaneous worldwide distribution of a decryption code that makes a lesser restriction on the code's speech component.

\section{Trademark}

While trademark and trade dress law are excellent for protecting trademarks for software, they don't do particularly well protecting software qua software.

Apple Inc. v. Samsung Electronics Co., Ltd.

Apple sued Samsung in April 2011. On August 24, 2012, the first jury reached a verdict that numerous Samsung smartphones infringed and diluted Apple's patents and trade dresses in various combinations. The diluted trade dresses are Trademark Registration No. $3,470,983$ and an unregistered trade dress defined in terms of certain elements in the configuration of the iPhone.

The '983 trade dress is a federally registered trademark. The '983 trade dress claims the design details in each of the sixteen icons on the 


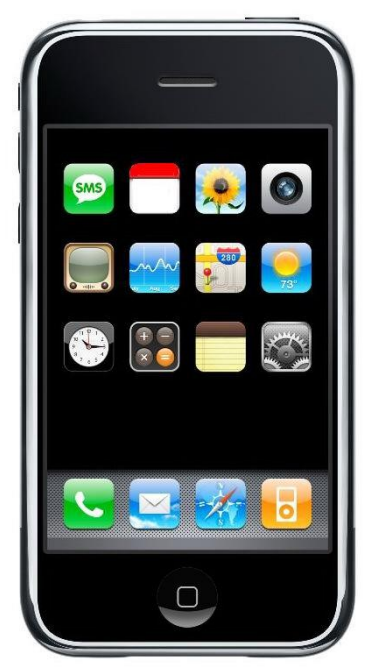

Apple's '983 trade dress registration
iPhone's home screen framed by the iPhone's rounded-rectangular shape with silver edges and a black background:

The first icon depicts the letters "SMS" in green inside a white speech bubble on a green background; ...

the seventh icon depicts a map with yellow and orange roads, a pin with a red head, and a red-and-blue road sign with the numeral "280" in white; ...

the sixteenth icon depicts the distinctive configuration of applicant's media player device in white over an orange background.

It is clear that individual elements claimed by the ' 983 trade dress are functional. For example, there is no dispute that the claimed details such as "the seventh icon depicts a map with yellow and orange roads, a pin with a red head, and a red-and-blue road sign with the numeral '280' in white" are functional. Apple's user interface expert testified on how icon designs promote usability. This expert agreed that "the whole point of an icon on a smartphone is to communicate to the consumer using that product, that if they hit that icon, certain functionality will occur on the phone." The expert further explained that icons are "visual shorthand for something" and that "rectangular containers" for icons provide "more real estate" to accommodate the icon design. Apple rebuts none of this evidence.

Apple contends instead that Samsung improperly disaggregates the '983 trade dress into individual elements to argue functionality. But Apple fails to explain how the total combination of the sixteen icon designs in the context of iPhone's screen-dominated roundedrectangular shape - all part of the iPhone's "easy to use" design theme - somehow negates the undisputed usability function of the individual elements. Apple's own brief even relies on its expert's testimony about the "instant recognizability due to highly intuitive icon usage" on "the home screen of the iPhone." Apple's expert was discussing an analysis of the iPhone's overall combination of icon designs that allowed a user to recognize quickly particular applications to use. The iPhone's usability advantage from the combination of its icon designs shows that the '983 trade dress viewed as a whole "s nothing other than the assemblage of functional parts. There is no separate overall appearance which is non-functional. The undisputed facts thus demonstrate the functionality of the '983 trade dress.

\section{E Design Patent}

The Apple-Samsung smartphone litigation has put design patents on the map in a good way. We saw in the previous chapter that they provided a natural solution to the problem of protecting three- 
dimensional designs. How well do they fit software, and what aspects of software might they cover?

\section{Michael Risch \\ Functionality and Graphical User Interface Design Patents}

17 Stan. Tech. Rev. 53 (2013)

Today, design patents cover only images displayed on a screen. As many claims are written, merely viewing an image on a blog page or in a PDF file associated with this Article (which includes some patented images) would constitute infringement. From a theoretical point of view, something seems off about that: viewing an image on a display screen can hardly be considered an article of manufacture, yet the law outlaws precisely such use, even if one is simply viewing the patent itself on a computer!

Thus, the second threshold question is whether an ephemeral image, viewable anywhere and in any context, can be considered an "article of manufacture" under the statute. The guidelines, issued in 1996, give surprisingly little attention to this question. Courts have long held that "surface ornamentation" constitutes an article of manufacture, and displayed images are part of a surface. Thus, the guidelines only ask whether the image is part of a display, not whether an ephemeral image is they type of thing that should ever be protected.

Even if one accepts that copyrightable works should be protected by design patent, this does not mean that all copyrightable expression qualifies for patent protection. Consider, for example, protection of structure, sequence, and organization of factual information. This may well be protected by copyright, but does not fall under the design patent umbrella.

Protection of user interfaces essentially merges the copyright law's fixation requirement with patent law's "article of manufacture" requirement. Fixation is the cornerstone of copyright: no work can be protected if it is not fixed in a tangible medium. But fixation is far from permanent; loading a file into computer memory is sufficiently fixed, even if the computer could be turned off or the memory changed.

The question, then, is whether any image present in computer memory - fixed, to be sure - becomes an "article of manufacture," even if it is not displayed on the screen at all times. Thus far, the PTO has said yes, and courts have not asked the question, assuming that if a patent is issued, then it must be an article of manufacture. Indeed, design patents now protect "animations," which are a series of images that move in sequence, such as a spinning icon or a simulated folding of a page to emulate a book on a display screen.

Protection of displays appears to rest on two seminal cases issued by that Court of Customs \& Patent Appeals, the precursor to the Federal Circuit. The first case is Hruby, which held that the shape of water 
moving in a fountain could be a patented design, even though the water was moving and could be turned off. The second precedent is In re Zahn in which the C.C.P.A. ruled that a portion of a manufacture could be separated by a "broken line" to separate the new, protectable design from the preexisting remainder of the article. Though the notion that a portion of an article could be patented is more than 140 years old, the Zahn court's broken line rule leads to the near ubiquity of broken lines in graphical displays that separate the image from the rest of the display.

Despite the apparent reasonableness of Hruby and Zahn with respect to the facts of those cases, their extension to user interfaces is troubling. Courts and commentators have simply not asked the difficult questions. Collapsing fixation, animation, and display screen into an "article of manufacture" leaves design patents on a very slippery slope.

For example, there is no theoretical bar to protecting every displayed copyrightable work with a design patent. Every television show and movie is theoretically a novel and non-obvious design to be incorporated into display screens everywhere. Indeed, every photograph captured and displayed on every mobile device might be protected. Every doodle on an electronic Etch-a-Sketch could be patented. Any use of the material would be infringing, without any consideration of fair use, the ideas represented by the work, or even the First Amendment.

Further, and perhaps more unsettling, the only apparent reason why such claims have not been made before is that nobody thought to do so, because there is no body of law to avoid such an outcome. The PTO has almost no tools to reject small, or even large, snippets of movies. While only a single inventive design may be covered by a patent, multiple patents might be filed on different - but importantsegments of audiovisual works, sufficient to block all downstream use with no fair use defense. A design patent protecting four or five screen captures from the famous Hitler Downfall movie scene would eliminate all claims to fair use of that short but endlessly entertaining parody clip. The PTO has no track record of rigorously examining images to determine whether they are novel or obvious. Even if it did, the exact combination of images in that screen is unlikely to appear elsewhere.

This parade of horribles might be solved in two ways. First, courts could recognize that an article of manufacture (or portion thereof) requires more than copyright fixation. Instead, an article of manufacture requires permanence at the point of manufacture, display, and use. To be sure, many elements might be hidden at one point or another, such as bottoms of drawers, collapsible devices, folding elements that become hidden, or even water fountains. But each of 
these examples is different in kind from the ephemeral images on a display screen. Ephemeral images can be configured by moving bits in memory, and as such, they are not ornamental articles of manufacture; instead, they are displays of information. In short, the PTO's 1996 concern about patenting images was well founded, but the solution was not to add "on a display screen" to patent claims. Instead, the solution was to recognize that images divorced from manufacture do not qualify as articles - they can be shown on any article, any screen, and any device, and that is not what design patents are meant to protect.

A second solution might recognize that modern commercial products live under a big tent. As such, there may be times when the design of the product includes designs on the screen. However, protection for displayed surface designs should be limited in a number of ways to ensure that the design is an ornamental article of manufacture, rather than an ephemeral image.

\section{Smartphone Problem}

Here are Figure 1 from Design Patent 604,305 (left), assigned to Apple, and a picture of the Samsung Galaxy S (right). Does the Galaxy S infringe the ' 305 pagent?

Based on Apple Inc. v. Samsung Electronics Co., Ltd., 786 F.3d 983 (Fed. Cir. 2015) 


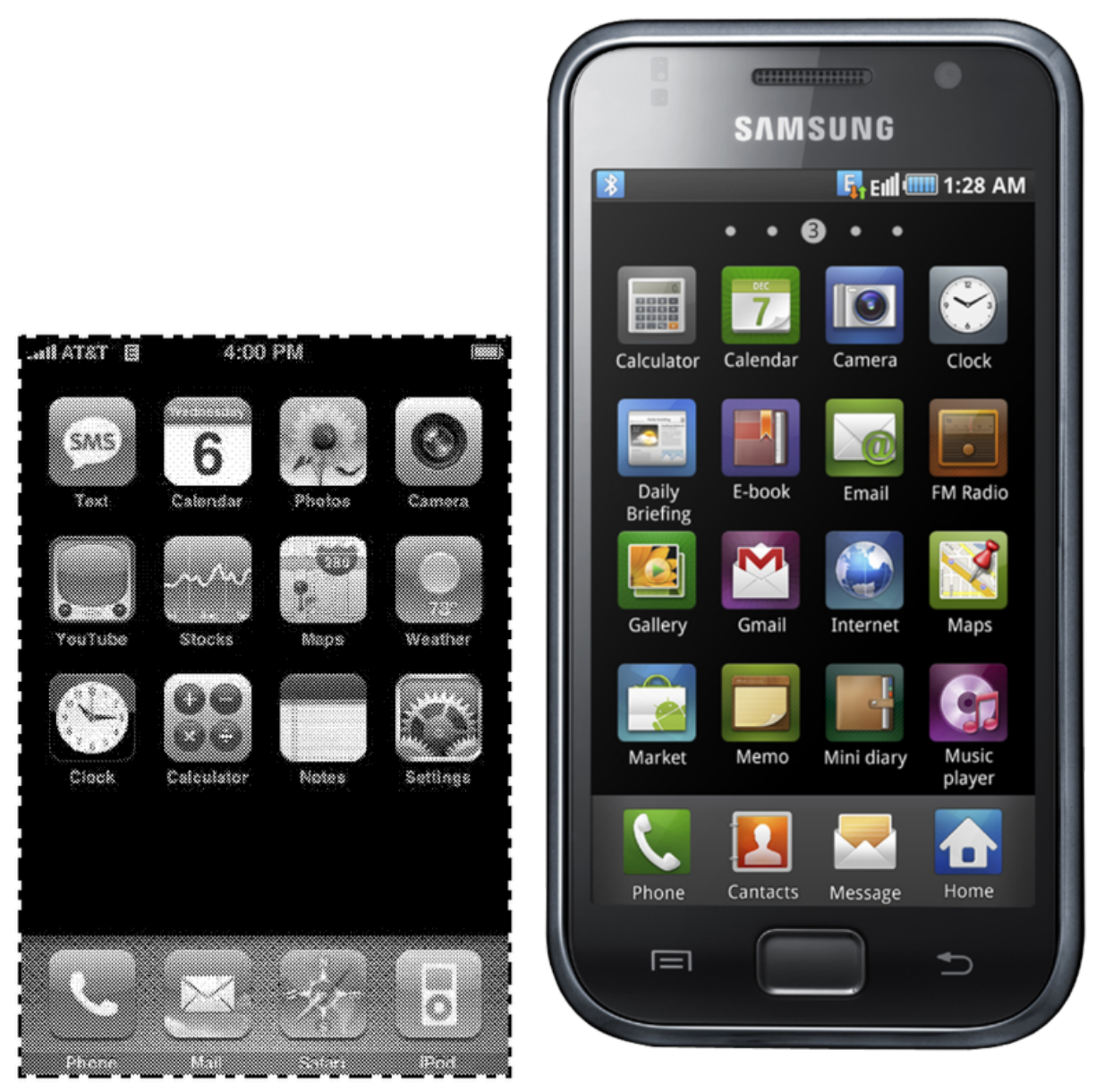




\section{1}

\section{Biotechnology}

Biotechnology raises not one but two recurring intellectual property issues. The first is that its subject matter is a mix of the natural and the artificial. As we saw in Mayo and Myriad, drawing the line between the two can be difficult and contentious. The second distinctive problem of biotechnology is that biology is exceptionally complicated; biological systems are unpredictable and hard to model. What's more, the biological systems we most care about - living human bodies are nost just complicated beyond our present understanding but also so precious that experiments on them cannot be undertaken lightly. This means that biological innovation is often slow and amazingly expensive, but also amazingly valuable when successful. These facts inflect the IP system in some important ways. Most importantly, they give rise to an extensive and intensive regulatory regime that restricts how drugs and similar medical technologies are researched and commercialized. Like a supertanker steaming through a boat pond, this regime has drawn the intellectual property system along into its wake.

\section{A Patent}

\section{Subject Matter}

Association for Molecular Pathology v. Myriad Genetics, Inc.

[According to the Supreme Court's summary, human DNA consists of a long string of nucleotides, each of which is one of four molecular fragments commonly abbreviated A, C, T, and G. Each sequence of three nucleotides codes for one of twenty amino acids, the molecules from which the body builds proteins. A gene is sequence of nucleotides that code for the amino acids making up a protein; put another way, a gene contains the information the body uses to make a particular protein. Naturally occurring DNA sequences contain 
portions, called "introns," that do not actually code for amino acids; those portions are ignored when the body makes proteins from genes. The remaining portions of DNA, which do code for amino acids and which are used in making proteins, are called "exons."

Myriad discovered that mutations in two human genes, BRCA1 and BRCA2, substantially increased a woman's risk of developing breast cancer. It developed and marketed a test for these mutations. It also obtained multiple patents related to the discovery and the test, which it used to prevent competition from other tests. Claim 1 of patent $5,747,282$, for example, claimed " an isolated DNA coding for a BRCA1 polypeptide," with "the amino acid sequence set forth in [an attachment listing a sequence of 1,863 amino acids]." Other claims covered cDNA (short for "complementary DNA"), which is created using synthetic laboratory methods by copying naturally occurring DNA. The resulting molecule differs in that it contains only exons and omits the introns.]

It is undisputed that Myriad did not create or alter any of the genetic information encoded in the BRCA1 and BRCA2 genes. The location and order of the nucleotides existed in nature before Myriad found them. Nor did Myriad create or alter the genetic structure of DNA. Instead, Myriad's principal contribution was uncovering the precise location and genetic sequence of the BRCA1 and BRCA2 genes within chromosomes 17 and 13 . The question is whether this renders the genes patentable.

Myriad recognizes that our decision in Diamond v. Chakrabarty is central to this inquiry. In Chakrabarty, scientists added four plasmids to a bacterium, which enabled it to break down various components of crude oil. The Court held that the modified bacterium was patentable. It explained that the patent claim was "not to a hitherto unknown natural phenomenon, but to a nonnaturally occurring manufacture or composition of matter - a product of human ingenuity having a distinctive name, character and use." The Chakrabarty bacterium was new "with markedly different characteristics from any found in nature," due to the additional plasmids and resultant "capacity for degrading oil." In this case, by contrast, Myriad did not create anything. To be sure, it found an important and useful gene, but separating that gene from its surrounding genetic material is not an act of invention.

Groundbreaking, innovative, or even brilliant discovery does not by itself satisfy the $\S 101$ inquiry.

Nor are Myriad's claims saved by the fact that isolating DNA from the human genome severs chemical bonds and thereby creates a nonnaturally occurring molecule. Myriad's claims are simply not expressed in terms of chemical composition, nor do they rely in any way on the chemical changes that result from the isolation of a par- 
ticular section of DNA. Instead, the claims understandably focus on the genetic information encoded in the BRCA1 and BRCA2 genes. If the patents depended upon the creation of a unique molecule, then a would-be infringer could arguably avoid at least Myriad's patent claims on entire genes (such as claims 1 and 2 of the '282 patent) by isolating a DNA sequence that included both the BRCA1 or BRCA2 gene and one additional nucleotide pair. Such a molecule would not be chemically identical to the molecule "invented" by Myriad. But Myriad obviously would resist that outcome because its claim is concerned primarily with the information contained in the genetic sequence, not with the specific chemical composition of a particular molecule.

cDNA does not present the same obstacles to patentability as naturally occurring, isolated DNA segments. As already explained, creation of a cDNA sequence from mRNA results in an exons-only molecule that is not naturally occurring. Petitioners concede that cDNA differs from natural DNA in that "the non-coding regions have been removed." They nevertheless argue that cDNA is not patent eligible because "the nucleotide sequence of cDNA is dictated by nature, not by the lab technician." That may be so, but the lab technician unquestionably creates something new when cDNA is made. cDNA retains the naturally occurring exons of DNA, but it is distinct from the DNA from which it was derived. As a result, cDNA is not a "product of nature" and is patent eligible under $\S 101$, except insofar as very short series of DNA may have no intervening introns to remove when creating cDNA. In that situation, a short strand of cDNA may be indistinguishable from natural DNA.

Justice SCALIA, concurring in part and concurring in the judgment.

I join the judgment of the Court, and all of its opinion except Part I-A and some portions of the rest of the opinion going into fine details of molecular biology. I am unable to affirm those details on my own knowledge or even my own belief. It suffices for me to affirm, having studied the opinions below and the expert briefs presented here, that the portion of DNA isolated from its natural state sought to be patented is identical to that portion of the DNA in its natural state; and that complementary DNA (cDNA) is a synthetic creation not normally present in nature.

\section{In re Roslin Institute (Edinburgh)}

On July 5, 1996, Keith Henry Stockman Campbell and Ian Wilmut successfully produced the first mammal ever cloned from an adult somatic cell: Dolly the Sheep. A clone is an identical genetic copy of a cell, cell part, or organism.

Campbell and Wilmut obtained a patent on the somatic method of
The Court draws a distinction between unpatentable genomic DNA and patentable CDNA, but the difference between these two types of DNA lies in how they are made, not their sequence. A cDNA generated from an organism without introns (e.g. bacteria) will have the exact same sequence as genomic DNA. Furthermore, the splice junctions in human CDNA are natural: they were not designed by an inventor.

-Eric Grote, Legal and Scientific Flaws in the Myriad Genetics Litigation (unpublished draft 2014). 


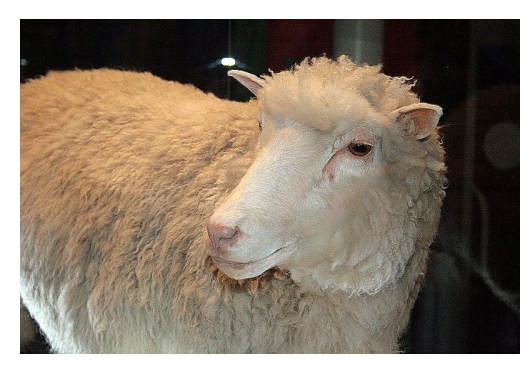

Dolly the Sheep

Funk Bros.: 333 U.S. 127 (1948) cloning mammals, which has been assigned to Roslin. See U.S. Patent No. 7,514,258. The ' 258 patent is not before us in this appeal. Instead, the dispute here concerns the Patent and Trademark Office's (PTO) rejection of Campbell's and Wilmut's claims to the clones themselves, set forth in the '233 application, titled Quiescent Cell Populations for Nuclear Transfer.

The '233 application claims the products of Campbell's and Wilmut's cloning method: cattle, sheep, pigs, and goats. Claim 155 and 164 is representative:

155. A live-born clone of a pre-existing, non-embryonic, donor mammal, wherein the mammal is selected from cattle, sheep, pigs, and goats.

Even before the Supreme Court's recent decision in Myriad, the Court's opinions in Chakrabarty and Funk Bros. Seed Co. v. Kalo Inoculant $\mathrm{Co}$., made clear that naturally occurring organisms are not patentable.

In Funk Bros, the Supreme Court considered a patent that claimed a mixture of naturally occurring strains of bacteria that helped leguminous plants extract nitrogen from the air and fix it in soil. The Court concluded that this mixture of bacteria strains was not patent eligible because the patentee did not alter the bacteria in any way. Critically, in Funk Bros., the Court explained:

We do not have presented the question whether the methods of selecting and testing the non-inhibitive strains are patentable. We have here only product claims. The patentee does not create a state of inhibition or of non-inhibition in the bacteria. Their qualities are the work of nature. Those qualities are of course not patentable. For patents cannot issue for the discovery of the phenomena of nature. The qualities of these bacteria, like the heat of the sun, electricity, or the qualities of metals, are part of the storehouse of knowledge of all men. They are manifestations of laws of nature, free to all men and reserved exclusively to none.

Thus, while the method of selecting the strains of bacteria might have been patent eligible, the natural organism itself - the mixture of bacteria - was unpatentable because its "qualities are the work of nature" unaltered by the hand of man.

The patent at issue in Chakrabarty claimed a genetically engineered bacterium that was capable of breaking down various components of crude oil. The patent applicant created this non-naturally occurring bacterium by adding four plasmids to a specific strain of bacteria. The Court held that the modified bacterium was patentable because it was "new" with "markedly different characteristics from any found in na- 
ture and one having the potential for significant utility." As the Court explained, the patentee's "discovery is not nature's handiwork, but his own."

Accordingly, discoveries that possess "markedly different characteristics from any found in nature," are eligible for patent protection. In contrast, any existing organism or newly discovered plant found in the wild is not patentable. See also In re Beineke (holding that a newly discovered type of plant is not eligible for plant patent protection, in part, because such a plant was not "in any way the result of the patent applicant's creative efforts or indeed anyone's creative efforts.").

While Roslin does not dispute that the donor sheep whose genetic material was used to create Dolly could not be patented, Roslin contends that copies (clones) are eligible for protection because they are "the product of human ingenuity" and "not nature's handiwork, but their own." Roslin argues that such copies are either compositions of matter or manufactures within the scope of $\S 101$. However, Dolly herself is an exact genetic replica of another sheep and does not possess markedly different characteristics from any farm animals found in nature. Dolly's genetic identity to her donor parent renders her unpatentable.

Supreme Court decisions regarding the preemptive force of federal patent law confirm that individuals are free to copy any unpatentable article, such as a live farm animal, so long as they do not infringe a patented method of copying. In Sears, Roebuck \& Co. $v$. Stiffel Co., the question was whether the defendant could be held liable under state law for copying a lamp design whose patent protection had expired. The Court explained that "when the patent expires the monopoly created by it expires, too, and the right to make the article - including the right to make it in precisely the shape it carried when patented - passes to the public." The Court further clarified that "an unpatentable article, like an article on which the patent has expired, is in the public domain and may be made and sold by whoever chooses to do so." Roslin's claimed clones are exact genetic copies of patent ineligible subject matter. Accordingly, they are not eligible for patent protection.

Roslin argues that its claimed clones are patent eligible because they are distinguishable from the donor mammals used to create them. First, Roslin contends that "environmental factors" lead to phenotypic differences that distinguish its clones from their donor mammals. A phenotype refers to all the observable characteristics of an organism, such as shape, size, color, and behavior, that result from the interaction of the organism's genotype with its environment. A mammal's phenotype can change constantly throughout the life of that organism not only due to environmental changes, but also the physiological and morphological changes associated with aging.
Beineke: 690 F.3d 1344 (Fed. Cir. 2012)

Sears, Roebuck: 376 U.S. 225 (1964) 
Roslin argues that environmental factors lead to phenotypic differences between its clones and their donor mammals that render their claimed subject matter patentable. However, these differences are unclaimed. Indeed, the word "cloned" in the pending claims connotes genetic identity, and the claims say nothing about a phenotypic difference between the claimed subject matter and the donor mammals. Moreover, Roslin acknowledges that any phenotypic differences came about or were produced quite independently of any effort of the patentee. Contrary to Roslin's arguments, these phenotypic differences do not confer eligibility on their claimed subject matter. Any phenotypic differences between Roslin's donor mammals and its claimed clones are the result of environmental factors, uninfluenced by Roslin's efforts.

Second, Roslin urges that its clones are distinguishable from their original donor mammals because of differences in mitochondrial DNA, which originates from the donor oocyte rather than the donor nucleus. Mitochondria are the organelles (cellular bodies) that produce the energy eukaryotic cells need to function. Mitochondria possess their own DNA, which is distinct from the DNA housed in the cell's nucleus. In the cloning process, the clone inherits its mitochondrial DNA from its donor oocyte, instead of its donor somatic cell. Therefore, Dolly's mitochondrial DNA came from the oocyte used to create her, not her donor mammary cell. Roslin argues that this difference in mitochondrial DNA renders its product claims patent eligible.

But any difference in mitochondrial DNA between the donor and cloned mammals is, too, unclaimed. Furthermore, Roslin's patent application does not identify how differences in mitochondrial DNA influence or could influence the characteristics of cloned mammals.

Finally, Roslin argues that its clones are patent eligible because they are time-delayed versions of their donor mammals, and therefore different from their original mammals. But this distinction cannot confer patentability. The difficulty with the time-delayed characteristic is that it is true of any copy of an original.

Ariosa Diagnostics, Inc. v. Sequenom, Inc.

In 1996, Drs. Dennis Lo and James Wainscoat discovered cell-free fetal DNA ("cffDNA") in maternal plasma and serum, the portion of maternal blood samples that other researchers had previously discarded as medical waste. cffDNA is non-cellular fetal DNA that circulates freely in the blood stream of a pregnant woman. Applying a combination of known laboratory techniques to their discovery, Drs. Lo and Wainscoat implemented a method for detecting the small fraction of paternally inherited cffDNA in maternal plasma or serum to determine fetal characteristics, such as gender. The invention, com- 
mercialized by Sequenom as its MaterniT21 test, created an alternative for prenatal diagnosis of fetal DNA that avoids the risks of widely-used techniques that took samples from the fetus or placenta. In 2001, Drs. Lo and Wainscoat obtained U.S Patent No. 6,258,540, which relates to this discovery.

The parties agree that the patent does not claim cffDNA or paternally inherited cffDNA. Instead, the '540 patent claims certain methods of using cffDNA. The steps of the method of claim 1 of the '540 patent include amplifying the cffDNA contained in a sample of a plasma or serum from a pregnant female and detecting the paternally inherited cffDNA. Amplifying cffDNA results in a single copy, or a few copies, generating thousands to millions of copies of that particular DNA sequence. In the amplification step, DNA is extracted from the serum or plasma samples and amplified by polymerase chain reaction ("PCR") or another method. PCR exponentially amplifies the cffDNA sample to detectable levels.

Ariosa makes and sells the Harmony Test, a non-invasive test used for prenatal diagnosis of certain fetal characteristics. [Sequenom threatened suit and Ariosa filed an action seeking a declaratory judgment of noninfringement.]

It is undisputed that the existence of cffDNA in maternal blood is a natural phenomenon. Sequenom does not contend that Drs. Lo and Wainscoat created or altered any of the genetic information encoded in the cffDNA, and it is undisputed that the location of the nucleic acids existed in nature before Drs. Lo and Wainscoat found them. The method ends with paternally inherited cffDNA, which is also a natural phenomenon. The method therefore begins and ends with a natural phenomenon. Thus, the claims are directed to matter that is naturally occurring.

Because the claims at issue are directed to naturally occurring phenomena, we turn to the second step of Mayo's framework. In the second step, we examine the elements of the claim to determine whether the claim contains an inventive concept sufficient to "transform" the claimed naturally occurring phenomenon into a patenteligible application. For process claims that encompass natural phenomenon, the process steps are the additional features that must be new and useful.

Like the patentee in Mayo, Sequenom contends that the claimed methods are patent eligible applications of a natural phenomenon, specifically a method for detecting paternally inherited cffDNA. Using methods like PCR to amplify and detect cffDNA was wellunderstood, routine, and conventional activity in 1997. The method at issue here amounts to a general instruction to doctors to apply routine, conventional techniques when seeking to detect cffDNA. Because the method steps were well-understood, conventional and routine, the method of detecting paternally inherited cffDNA is not new 
and useful. The only subject matter new and useful as of the date of the application was the discovery of the presence of cffDNA in maternal plasma or serum.

Sequenom argues that there are numerous other uses of cffDNA aside from those claimed in the ' 540 patent, and thus, the ' 540 patent does not preempt all uses of cffDNA. While preemption may signal patent ineligible subject matter, the absence of complete preemption does not demonstrate patent eligibility. In this case, Sequenom's attempt to limit the breadth of the claims by showing alternative uses of cffDNA outside of the scope of the claims does not change the conclusion that the claims are directed to patent ineligible subject matter. Where a patent's claims are deemed only to disclose patent ineligible subject matter under the Mayo framework, as they are in this case, preemption concerns are fully addressed and made moot.

Linn, Circuit Judge, concurring:

I join the court's opinion invalidating the claims of the ' 540 patent only because I am bound by the sweeping language of the test set out in Mayo. In my view, the breadth of the second part of the test was unnecessary to the decision. This case represents the consequence perhaps unintended - of that broad language in excluding a meritorious invention from the patent protection it deserves and should have been entitled to retain.

The Supreme Court's blanket dismissal of conventional postsolution steps leaves no room to distinguish Mayo from this case, even though here no one was amplifying and detecting paternallyinherited cffDNA using the plasma or serum of pregnant mothers. Indeed, the maternal plasma used to be routinely discarded, because, as Dr. Evans testified, "nobody thought that fetal cell-free DNA would be present."

It is hard to deny that Sequenom's invention is truly meritorious. Prior to the '540 patent, prenatal diagnoses required invasive methods, which presented a degree of risk to the mother and to the pregnancy. The available techniques were time-consuming or required expensive equipment. In a groundbreaking invention, Drs. Lo and Wainscoat discovered that there was cell-free fetal DNA in the maternal plasma. The Royal Society lauded this discovery as "a paradigm shift in non-invasive prenatal diagnosis," and the inventors' article describing this invention has been cited well over a thousand times. The commercial embodiment of the invention, the MaterniT21 test, was the first marketed non-invasive prenatal diagnostic test for fetal aneuploidies, such as Down's syndrome, and presented fewer risks and a more dependable rate of abnormality detection than other tests. Unlike in Mayo, the '540 patent claims a new method that should be patent eligible. While the instructions in the claims at issue in Mayo 
had been widely used by doctors - they had been measuring metabolites and recalculating dosages based on toxicity/inefficacy limits for years - here, the amplification and detection of cffDNA had never before been done. The new use of the previously discarded maternal plasma to achieve such an advantageous result is deserving of patent protection.

In short, Sequenom's invention is nothing like the invention at issue in Mayo. But for the sweeping language in the Supreme Court's Mayo opinion, I see no reason, in policy or statute, why this breakthrough invention should be deemed patent ineligible.

\section{DNA Copyright Problem}

Two law professors collaborated with a biotechnology company to create what they called "Prancer":

a DNA sequence that provides a set of instructions for the synthesis of a protein comprising 231 amino acids linked together in a specific order. The set of instructions is coded in the standard genetic code, and is interpretable by most living biological systems. The encoded protein is fluorescent, which is a useful functional attribute in biotechnology.

Is Prancer a copyrightable work of authorship?

\section{Ownership}

The doctrines here are familiar. Schering illustrates some of the inherent difficulty in determining novelty (and also infringement) given that biological systems transform substances in complex ways. Eli Lilly v. Zenith considers the novelty implications of clinical drug testing.

\section{Schering Corp. v. Geneva Pharmaceuticals}

The District Court correctly determined that that U.S. Patent No. 4,282,233 inherently anticipates claims 1 and 3 of Patent No. $4,659,716$.

Schering owns the '233 and '716 patents on antihistamines. Antihistamines inhibit the histamines that cause allergic symptoms.

The prior art '233 patent covers the antihistamine loratadine, the active component of a pharmaceutical that Schering markets as CLARITIN. Unlike conventional antihistamines when CLARITIN was launched, loratadine does not cause drowsiness.

The more recent '716 patent at issue in this case covers a metabolite of loratadine called descarboethoxyloratadine (DCL).. A metabolite is the compound formed in the patient's body upon ingestion of a
The Copyright Office said "no." Its reasoning, along with the professors' response, are detailed in Christopher $\mathrm{M}$. Holman, Claes Gustafsson, \& Andrew W. Torrance, Are Engineered Genetic Sequences Copyrightable?, 35 Biotech. L. Rep. 103 (2016). But try not to peek before you try your hand at coming up with the best reasons for and against!

339 F.3d 1373 (Fed. Cir. 2003) 


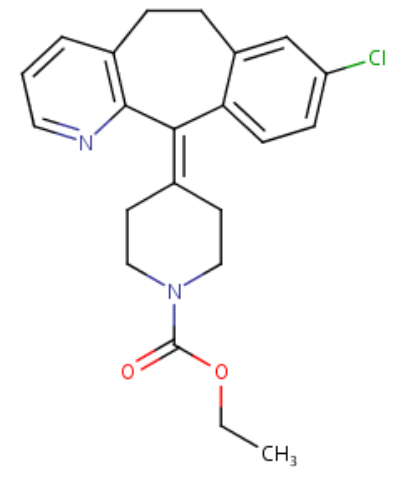

Loratadine

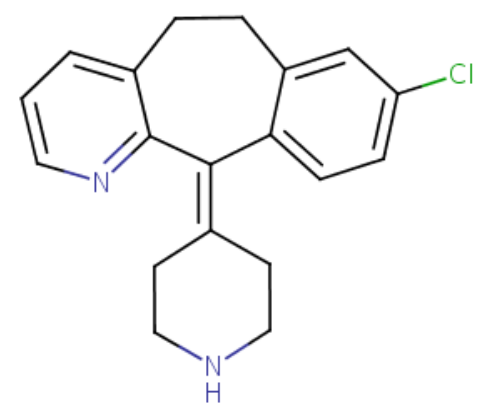

Descarboethoxyloratadine pharmaceutical. The ingested pharmaceutical undergoes a chemical conversion in the digestion process to form a new metabolite compound. The metabolite DCL is also a non-drowsy antihistamine. The '716 patent issued in April 1987 and will expire in April 2004 (the'233 patent issued in 1981 and has since expired).

A patent is invalid for anticipation if a single prior art reference discloses each and every limitation of the claimed invention. Moreover, a prior art reference may anticipate without disclosing a feature of the claimed invention if that missing characteristic is necessarily present, or inherent, in the single anticipating reference. Inherent anticipation does not require that a person of ordinary skill in the art at the time would have recognized the inherent disclosure.

DCL is not formed accidentally or under unusual conditions when loratadine is ingested. The record shows that DCL necessarily and inevitably forms from loratadine under normal conditions. DCL is a necessary consequence of administering loratadine to patients.

This court recognizes that this may be a case of first impression, because the prior art does not disclose any compound that is identifiable as DCL. In this court's prior inherency cases, a single prior art reference generally contained an incomplete description of the anticipatory subject matter, i.e., a partial description missing certain aspects. Inherency supplied the missing aspect of the description.

This court sees no reason to modify the general rule for inherent anticipation in a case where inherency supplies the entire anticipatory subject matter. The patent law principle "that which would literally infringe if later in time anticipates if earlier," bolsters this conclusion. Similarly, if granting patent protection on the disputed claim would allow the patentee to exclude the public from practicing the prior art, then that claim is anticipated. The public remains free to make, use, or sell prior art compositions or processes, regardless of whether or not they understand their complete makeup or the underlying scientific principles which allow them to operate. The doctrine of anticipation by inherency, among other doctrines, enforces that basic principle. Thus, inherency operates to anticipate entire inventions as well as single limitations within an invention.

Turning to this case, the use of loratadine would infringe claims 1 and 3 of the ' 716 patent covering the metabolite DCL. This court has recognized that a person may infringe a claim to a metabolite if the person ingests a compound that metabolizes to form the metabolite. An identical metabolite must then anticipate if earlier in time than the claimed compound.

This court's conclusion on inherent anticipation in this case does not preclude patent protection for metabolites of known drugs. With proper claiming, patent protection is available for metabolites of known drugs. Cf. In re Kratz (stating that a naturally occurring straw- 
berry constituent compound does not anticipate claims to the substantially pure compound); In re Bergstrom (stating that a material occurring in nature in less pure form does not anticipate claims to the pure material).

But those metabolites may not receive protection via compound claims. In this case, for instance, claims 1 and 3 broadly encompass compounds defined by structure only. Such bare compound claims include within their scope the recited compounds as chemical species in any surroundings, including within the human body as metabolites of a drug. As this case holds, these broad compound claims are inherently anticipated by a prior art disclosure of a drug that metabolizes into the claimed compound.

A skilled patent drafter, however, might fashion a claim to cover the metabolite in a way that avoids anticipation. For example, the metabolite may be claimed in its pure and isolated form, as in Kratz and Bergstrom, or as a pharmaceutical composition (e.g., with a pharmaceutically acceptable carrier). The patent drafter could also claim a method of administering the metabolite or the corresponding pharmaceutical composition. The ' 233 patent would not provide an enabling disclosure to anticipate such claims because, for instance, the '233 patent does not disclose isolation of DCL.

\section{Eli Lilly and Co. v. Zenith Goldline Pharm. Inc.}

Defendants have failed to prove by clear and convincing evidence that the HGAA, HGAB, and HGAC Phase I clinical trials of olanzapine were public. These studies were conducted by Lilly personnel in the Lilly clinic. Lilly restricted access to the facility and provided fulltime security. In addition, the studies were fully controlled by Lilly. The volunteers, who were healthy and not suffering from schizophrenia, were paid by Lilly for their services, remained in the research ward for the duration of the study, and were closely monitored by doctors and medical staff employed by Lilly. Only Lilly employees administered the drug. The fact that the volunteers were allowed visitors does not change the analysis.

Defendants' argument that the clinical trials were "public" because the patients did not sign a confidentiality agreement is unpersuasive and legally unsound. First, because the patients were not informed of the identity of the compound they were taking and were kept at Lilly facilities at all times, a confidentiality agreement would have been superfluous. Second, the presence or absence of a confidentiality agreement is not controlling. It is simply one of many factors to be taken into consideration.

Even if Lilly's Phase I clinical trials of olanzapine constituted a public use of the compound more than one year prior to Lilly's application for its patent, it was an experimental use. The evidence 
demonstrates that the art with respect to this type of atypical antipsychotic drug was highly unpredictable. Small structural changes led to very different properties. Furthermore, the art was plagued with unpredicted side effects that rendered otherwise promising compounds useless in the clinical setting. These side effects could only be understood when the compounds were tested in actual patients. Olanzapine was conceived as a compound that would have antipsychotic activity but not produce flumezapine's toxic effects in schizophrenic patients. Accordingly, testing olanzapine in actual schizophrenic patients was required to prove it would "work for its intended purpose," i.e., as a safe, aty pical antipsychotic drug used to treat human patients suffering from or susceptible to psychotic disorders. These Phase I clinical trials in healthy human volunteers were required by regulatory agencies before the compound could be tested in schizophrenic patients. For these reasons, the clinical tests constitute an experimental use and negate a finding that they were a "public use" as defined in patent law.

\section{Infringement: Similarity}

When are two substances the "same" for purposes of patent infringement? In the biotechnology context, the answer is not always straightforward.

Boehringer Ingelheim Vetmedica, Inc. v. Schering-Plough Corp.

Porcine Reproductive Respiratory Syndrome (also known as "Mystery Swine Disease" or Swine Infertility and Respiratory Syndrome), swept through commercial pig herds in the 1980s. A previously unknown disease, PRRS had its most pronounced effect on young and newborn piglets. Up to thirty percent of the piglets in litters from infected sows were stillborn, and up to eighty percent of piglets in infected herds died before weaning. The financial consequences to the commercial pig industry were severe.

Researchers seeking a cause for PRRS could not identify any known pathogen behind the epidemic (hence the name "Mystery Swine Disease"). Scientists at Boehringer were the first to solve the mystery, discovering that a previously unknown virus was responsible for the disease.

Boehringer began with a homogenate of lung, brain, spleen, liver, and kidney tissues from an infected piglet. Samples of this combined homogenate were then added to a panel of 15 different cultured mammalian cell lines. While viruses themselves are too small to see without the aid of an electron microscope, a viral infection often gives rise to morphological changes in the host cell. An observable change in a host cell due to viral infection is known as a cytopathic effect, or CPE. 
These changes may include cell rounding, disorientation, swelling or shrinking, death, or detachment from the culture surface, and are visible with ordinary microscopes as perturbations of the cultured cell monolayer. Boehringer's scientists found evidence of a virus present in PRRS-infected animals when they observed a CPE in cultured MA104 embryonic monkey kidney cells, one of the 15 cell lines inoculated with PRRS homogenate.

Continued propagation of a virus requires that the virus be passaged, which entails removing [a portion] of the culture and adding it to a fresh culture of cells. Boehringer scientists passaged the PRRS virus eight times on MA-104 cells, and deposited a sample of the virus from the eighth passage with the American Type Culture Collection (ATCC), which assigned it deposit number VR-2332.

The "778 patent claims this process for growing and isolating the PRRS virus: inoculating cultured monkey cells with the PRRS virus, and incubating the inoculated cells until a CPE is observed. Claim 2 is the only claim at issue in this case, and depends from claim 1:

1. A method of growing and isolating swine infertility and respiratory syndrome virus, ATCC-VR2332, which comprises inoculating the virus on a full or partial sheet of simian cells in the presence of serum in a suitable grown medium and incubating the inoculated cell sheet at about $34 \mathrm{C}$. to $37 \mathrm{C}$. until CPE is observed.

2. The method as recited in claim 1 wherein the simian cell line is MA-104.

Schering, like Boehringer, developed a vaccine against PRRS by attenuating the PRRS virus in cell culture. Attenuation is a process wherein a virus is repeatedly passaged on a cultured cell line, sometimes under altered culture conditions (such as lowered temperature). Variant viruses that are better adapted to grow on the cultured cell line will grow faster than the original virus; after many serial passages, such a variant will completely replace the original in the culture. Frequently, however, those variants adapted to grow in a particular environment (such as cultured monkey kidney cells) are illsuited to grow or cause disease in the original environment (a live pig). If the attenuated virus will not productively infect pigs, but retains enough structural similarity to the original virus such that an immune response mounted against the attenuated virus will protect the pig against the original virus, then the attenuated virus may be used as a vaccine to protect against PRRS. Both Boehringer and Schering developed attenuated viruses effective as vaccines against PRRS.

Boehringer filed suit against Schering, alleging that Schering's vaccine virus, which is also grown on MA-104 monkey kidney cells, was prepared by a process that infringed the method claimed by the 
'778 patent.

Boehringer argues that the term "ATCC-VR2332" should be understood as a "prototype" or "generic" term for all PRRS viruses, rather than as a reference to the deposited strain. Boehringer chose to claim its virus using the term "ATCC-VR2332," a term on its face referring to a particular ATCC deposit. Boehringer did not use the broader term "PRRS virus," nor did Boehringer attempt to claim the virus in terms of the more general functional and structural properties disclosed by the specification. Boehringer did not choose to define the term "ATCC-VR2332" in the specification, nor did Boehringer state that ATCC-VR2332 was a "generic" or "prototype" virus, nor did Boehringer assert that viruses related to but not identical to the isolated strain were within the scope of the invention. These choices must be held against it. We therefore conclude that the district court properly construed "ATCC-VR2332" to refer to the strain of virus deposited with the ATCC.

Schering argues that no reasonable jury could find that Schering's VR2525 virus is equivalent to the ATCC-VR2332 viral strain recited by the claim in suit. Under the "function-way-result" analysis, Schering focuses on the fact that ATCC-VR2332 is a pathogenic virus, causing PRRS, while Schering's VR2525 is not. Schering argues that this distinction precludes a finding of equivalence, because Schering's virus generates a protective immune response when administered to pigs, while a pig inoculated with ATCC-VR2332 develops PRRS. Thus, when administered to pigs, VR2525 resembles ATCC-VR2332 in neither function, way, nor result. Schering's argument, however, flies in the face of the basic principle that the relevant analysis is of the role played by each element in the context of the specific patent claim, not whether the accused element is capable of performing different roles than the claim element in other contexts. What happens when the virus is administered to a pig is irrelevant to the assessment of whether the two viral strains are equivalent in the in vitro culture method defined by claim 2. The jury was presented with expert testimony from which it could conclude that VR2525 plays the same role as VR2332 in performance of the claimed method. The fact that, in other contexts, VR2525 can perform other functions in different ways to yield a different result is not relevant.

Schering further argues that a finding of no substantial differences is precluded by the evidence that there are at least 73 nucleotide differences between VR2525 and ATCC-VR2332 in a particular region of their RNA genomes. Schering's expert (as well as Boehringer's) noted that even a single nucleotide substitution can have a substantial effect on viral function. Schering proposes that in the face of this evidence, no reasonable jury could have concluded that two viruses having at least 73 nucleotide divergences lack substantial differences. 
However, the uncontroversial fact that even a single nucleotide or amino acid substitution may drastically alter the function of a gene or protein is not evidence of anything at all. The mere possibility that a single mutation could affect biological function cannot as a matter of law preclude an assertion of equivalence, and Schering made no showing that any of these substitutions actually affected any property of the virus relevant to the claim at hand. While it may be reasonable to assume that genetic similarity is a relevant comparison between the viruses for purposes of the claimed method, the jury was presented with expert testimony that the two viral genomes are highly similar overall and that any differences between the two are insignificant. A reasonable jury could easily rely on this testimony to conclude that the genetic differences between VR2525 and ATCC-VR2332 are insubstantial in the context of the claimed method.

\section{Defenses}

\section{Bowman v. Monsanto Co.}

Under the doctrine of patent exhaustion, the authorized sale of a patented article gives the purchaser, or any subsequent owner, a right to use or resell that article. Such a sale, however, does not allow the purchaser to make new copies of the patented invention. The question in this case is whether a farmer who buys patented seeds may reproduce them through planting and harvesting without the patent holder's permission. We hold that he may not.

\section{I}

Respondent Monsanto invented a genetic modification that enables soybean plants to survive exposure to glyphosate, the active ingredient in many herbicides (including Monsanto's own Roundup). Monsanto markets soybean seed containing this altered genetic material as Roundup Ready seed. Farmers planting that seed can use a glyphosate-based herbicide to kill weeds without damaging their crops. Two patents issued to Monsanto cover various aspects of its Roundup Ready technology, including a seed incorporating the genetic alteration.

Monsanto sells, and allows other companies to sell, Roundup Ready soybean seeds to growers who assent to a special licensing agreement. That agreement permits a grower to plant the purchased seeds in one (and only one) season. He can then consume the resulting crop or sell it as a commodity, usually to a grain elevator or agricultural processor. But under the agreement, the farmer may not save any of the harvested soybeans for replanting, nor may he supply them to anyone else for that purpose. These restrictions reflect the ease of producing new generations of Roundup Ready seed. Because 
glyphosate resistance comes from the seed's genetic material, that trait is passed on from the planted seed to the harvested soybeans: Indeed, a single Roundup Ready seed can grow a plant containing dozens of genetically identical beans, each of which, if replanted, can grow another such plant - and so on and so on. The agreement's terms prevent the farmer from co-opting that process to produce his own Roundup Ready seeds, forcing him instead to buy from Monsanto each season.

Petitioner Vernon Bowman is a farmer in Indiana who, it is fair to say, appreciates Roundup Ready soybean seed. He purchased Roundup Ready each year, from a company affiliated with Monsanto, for his first crop of the season. In accord with the agreement just described, he used all of that seed for planting, and sold his entire crop to a grain elevator (which typically would resell it to an agricultural processor for human or animal consumption).

Bowman, however, devised a less orthodox approach for his second crop of each season. Because he thought such late-season planting "risky," he did not want to pay the premium price that Monsanto charges for Roundup Ready seed. He therefore went to a grain elevator; purchased "commodity soybeans" intended for human or animal consumption; and planted them in his fields. Those soybeans came from prior harvests of other local farmers. And because most of those farmers also used Roundup Ready seed, Bowman could anticipate that many of the purchased soybeans would contain Monsanto's patented technology. When he applied a glyphosate-based herbicide to his fields, he confirmed that this was so; a significant proportion of the new plants survived the treatment, and produced in their turn a new crop of soybeans with the Roundup Ready trait. Bowman saved seed from that crop to use in his late-season planting the next year and then the next, and the next, until he had harvested eight crops in that way. Each year, that is, he planted saved seed from the year before (sometimes adding more soybeans bought from the grain elevator), sprayed his fields with glyphosate to kill weeds (and any nonresistant plants), and produced a new crop of glyphosate-resistant i.e., Roundup Ready - soybeans.

After discovering this practice, Monsanto sued Bowman for infringing its patents on Roundup Ready seed. Bowman raised patent exhaustion as a defense, arguing that Monsanto could not control his use of the soybeans because they were the subject of a prior authorized sale (from local farmers to the grain elevator). The District Court rejected that argument, and awarded damages to Monsanto of $\$ 84,456$. 
The doctrine of patent exhaustion limits a patentee's right to control what others can do with an article embodying or containing an invention. Under the doctrine, the initial authorized sale of a patented item terminates all patent rights to that item. And by exhaust[ing] the [patentee's] monopoly" in that item, the sale confers on the purchaser, or any subsequent owner, the right to use [or] sell" the thing as he sees fit. Univis. We have explained the basis for the doctrine as follows: "[T] he purpose of the patent law is fulfilled with respect to any particular article when the patentee has received his reward ... by the sale of the article"; once that "purpose is realized the patent law affords no basis for restraining the use and enjoyment of the thing sold." Id.

Consistent with that rationale, the doctrine restricts a patentee's rights only as to the "particular article" sold; it leaves untouched the patentee's ability to prevent a buyer from making new copies of the patented item. The purchaser of the patented machine does not acquire any right to construct another machine either for his own use or to be vended to another. Rather, a second creation of the patented item calls the monopoly, conferred by the patent grant, into play for a second time. That is because the patent holder has "received his reward" only for the actual article sold, and not for subsequent recreations of it. If the purchaser of that article could make and sell endless copies, the patent would effectively protect the invention for just a single sale. Bowman himself disputes none of this analysis as a general matter: He forthrightly acknowledges the "well settled" principle "that the exhaustion doctrine does not extend to the right to 'make' a new product."

Unfortunately for Bowman, that principle decides this case against him. Under the patent exhaustion doctrine, Bowman could resell the patented soybeans he purchased from the grain elevator; so too he could consume the beans himself or feed them to his animals. Monsanto, although the patent holder, would have no business interfering in those uses of Roundup Ready beans. But the exhaustion doctrine does not enable Bowman to make additional patented soybeans without Monsanto's permission (either express or implied). And that is precisely what Bowman did. He took the soybeans he purchased home; planted them in his fields at the time he thought best; applied glyphosate to kill weeds (as well as any soy plants lacking the Roundup Ready trait); and finally harvested more (many more) beans than he started with. That is how "to 'make' a new product," to use Bowman's words, when the original product is a seed. Because Bowman thus reproduced Monsanto's patented invention, the exhaustion doctrine does not protect him.

Were the matter otherwise, Monsanto's patent would provide scant benefit. After inventing the Roundup Ready trait, Monsanto 
would, to be sure, receive its reward for the first seeds it sells. But in short order, other seed companies could reproduce the product and market it to growers, thus depriving Monsanto of its monopoly. And farmers themselves need only buy the seed once, whether from Monsanto, a competitor, or (as here) a grain elevator. The grower could multiply his initial purchase, and then multiply that new creation, ad infinitum - each time profiting from the patented seed without compensating its inventor. Bowman's late-season plantings offer a prime illustration. After buying beans for a single harvest, Bowman saved enough seed each year to reduce or eliminate the need for additional purchases. Monsanto still held its patent, but received no gain from Bowman's annual production and sale of Roundup Ready soybeans. The exhaustion doctrine is limited to the "particular item" sold to avoid just such a mismatch between invention and reward.

Bowman principally argues that exhaustion should apply here because seeds are meant to be planted. The exhaustion doctrine, he reminds us, typically prevents a patentee from controlling the use of a patented product following an authorized sale. And in planting Roundup Ready seeds, Bowman continues, he is merely using them in the normal way farmers do. Bowman thus concludes that allowing Monsanto to interfere with that use would "creat[e] an impermissible exception to the exhaustion doctrine" for patented seeds and other "self-replicating technologies.

But it is really Bowman who is asking for an unprecedented exception - to what he concedes is the "well settled" rule that "the exhaustion doctrine does not extend to the right to 'make' a new product." Reproducing a patented article no doubt "uses" it after a fashion. But as already explained, we have always drawn the boundaries of the exhaustion doctrine to exclude that activity, so that the patentee retains an undiminished right to prohibit others from making the thing his patent protects. See, e.g., Cotton-Tie Co. v. Simmons (holding that a purchaser could not "use" the buckle from a patented cotton-bale tie to "make" a new tie). That is because, once again, if simple copying were a protected use, a patent would plummet in value after the first sale of the first item containing the invention. The undiluted patent monopoly, it might be said, would extend not for 20 years (as the Patent Act promises), but for only one transaction. And that would result in less incentive for innovation than Congress wanted. Hence our repeated insistence that exhaustion applies only to the particular item sold, and not to reproductions.

Nor do we think that rule will prevent farmers from making appropriate use of the Roundup Ready seed they buy. Bowman himself stands in a peculiarly poor position to assert such a claim. As noted earlier, the commodity soybeans he purchased were intended not for planting, but for consumption. Indeed, Bowman conceded in deposi- 
tion testimony that he knew of no other farmer who employed beans bought from a grain elevator to grow a new crop. So a non-replicating use of the commodity beans at issue here was not just available, but standard fare. And in the more ordinary case, when a farmer purchases Roundup Ready seed qua seed - that is, seed intended to grow a crop - he will be able to plant it. Monsanto, to be sure, conditions the farmer's ability to reproduce Roundup Ready; but it does not could not realistically - preclude all planting. No sane farmer, after all, would buy the product without some ability to grow soybeans from it. And so Monsanto, predictably enough, sells Roundup Ready seed to farmers with a license to use it to make a crop. Applying our usual rule in this context therefore will allow farmers to benefit from Roundup Ready, even as it rewards Monsanto for its innovation.

Still, Bowman has another seeds-are-special argument: that soybeans naturally "self-replicate or 'sprout' unless stored in a controlled manner," and thus "it was the planted soybean, not Bowman" himself, that made replicas of Monsanto's patented invention. Brief for Petitioner 42; see Tr. of Oral Arg. 14 (“[F]armers, when they plant seeds, they don't exercise any control ... over their crop" or "over the creative process"). But we think that blame-the-bean defense tough to credit. Bowman was not a passive observer of his soybeans' multiplication; or put another way, the seeds he purchased (miraculous though they might be in other respects) did not spontaneously create eight successive soybean crops. As we have explained, Bowman devised and executed a novel way to harvest crops from Roundup Ready seeds without paying the usual premium. He purchased beans from a grain elevator anticipating that many would be Roundup Ready; applied a glyphosate-based herbicide in a way that culled any plants without the patented trait; and saved beans from the rest for the next season. He then planted those Roundup Ready beans at a chosen time; tended and treated them, including by exploiting their patented glyphosate-resistance; and harvested many more seeds, which he either marketed or saved to begin the next cycle. In all this, the bean surely figured. But it was Bowman, and not the bean, who controlled the reproduction (unto the eighth generation) of Monsanto's patented invention.

Our holding today is limited - addressing the situation before us, rather than every one involving a self-replicating product. We recognize that such inventions are becoming ever more prevalent, complex, and diverse. In another case, the article's self-replication might occur outside the purchaser's control. Or it might be a necessary but incidental step in using the item for another purpose. Cf. 17 U.S.C. $\S 117(\mathrm{a})(1)$ ("[I]t is not [a copyright] infringement for the owner of a copy of a computer program to make ... another copy or adaptation of that computer program provide[d] that such a new copy or adap- 
$\S 287(c)(1)$

Limitation on damages and other remedies; marking and notice

Why are doctors special?
69 F.3d 1560 (Fed. Cir. 1995)

(Rich, J.) tation is created as an essential step in the utilization of the computer program"). We need not address here whether or how the doctrine of patent exhaustion would apply in such circumstances. In the case at hand, Bowman planted Monsanto's patented soybeans solely to make and market replicas of them, thus depriving the company of the reward patent law provides for the sale of each article. Patent exhaustion provides no haven for that conduct.

With respect to a medical practitioner's performance of a medical activity that constitutes an infringement under section 271(a) or (b), the provisions of sections 281, 283, 284, and 285 [i.e., all meaningful remdedies] shall not apply against the medical practitioner or against a related health care entity with respect to such medical activity.

\section{B Plants}

\section{Plant Patents}

Imazio Nursery, Inc. v. Dania Greenhouses

At least as early as 1892, legislation was proposed to grant patent rights for plantrelated inventions. Plant patent legislation was supported by such prominent individuals as Thomas Edison who stated that "nothing that Congress could do to help farming would be of greater value and permanence than to give to the plant breeder the same status as the mechanical and chemical inventors now have through the law." It was also supported by Luther Burbank, a leading plant breeder of the day, whose widow stated that her late husband "said repeatedly that until Government made some such provision [for plant patent protection] the incentive to create work with plants was slight and independent research and breeding would be discouraged to the great detriment of horticulture."

The Townsend-Purnell Plant Patent Act was passed by Congress on May 13, 1930 and was signed by President Hoover on May 23, 1930. It was the first legislation anywhere in the world to grant patent rights to plant breeders and was enacted to "afford agriculture, so far as practicable, the same opportunity to participate in the benefits of the patent system as has been given to industry, and thus assist in placing agriculture on a basis of economic equality with industry."

Before enactment of the Plant Patent Act, two factors were thought to prevent plants from being patentable subject matter. The first was the belief that plants, even those bred by man, were products of nature and therefore not subject to patent protection. The second factor was that plants were not considered amenable to the "written description" requirement of the predecessor of 35 U.S.C. $\S 112$, first para- 
graph. In promulgating the Plant Patent Act, Congress addressed both concerns. It explained that the work of the plant breeder "in aid of nature" was subject to patent protection. Additionally, the written description requirement, applicable to utility patents, was relaxed in favor of a "description ... as complete as is reasonably possible."

As originally enacted, the provisions for plant patent protection were made as amendments to the general patent law. With the promulgation of the 1952 Patent Act, the plant patent provisions were included as a separate chapter of the statute. It should be noted that although the plant patent provisions were separated from the utility patent provisions with the enactment of the 1952 Patent Act, the statute explicitly states that "the provisions of this title relating to patents for inventions shall apply to patents for plants, except as otherwise provided."

The only amendment to the plant patent provisions since enactment of the 1952 Patent Act came in 1954 when section 161 was amended to preclude patent protection for plants found in an uncultivated state, thereby broadening the statute to include plants found in a cultivated state and subsequently asexually reproduced.

\section{Mark D. Janis \& Jay P. Kesan \\ U.S. Plant Variety Protection: Sound and Fury...?}

Congress never adopted explicit legislation implementing fully the patent approach to the problem of incentives for plant breeding. Instead, in the Townsend-Purnell Plant Patent Act of 1930, Congress created a plant patent regime limited to varieties that had been asexually reproduced.

The House Report accompanying the plant patent legislation acknowledged that the asexual reproduction requirement "greatly narrows the scope of the bill." The bill proposed "to give the necessary incentive to preserve new varieties" by encouraging breeders to multiply asexually the new and valuable varieties that they discovered, but the bill did not "give any patent protection to the right of propagation of the new variety by seed, irrespective of the degree to which the seedlings come true to type."

For U.S. law purposes, then, the plant patent legislation created a distinction between plants propagated asexually and plants reproduced via seed. It might be tempting to view the distinction as inevitable, flowing as a matter of necessity from the intrinsic qualities of plants. By extension, the appearance of sui generis plant variety regimes would likewise seem to rest on a straightforward, biological rationale.

In fact, the introduction of the asexual/sexual distinction in U.S. plant intellectual property law was as much a matter of political expediency as it was a matter of biology, as a careful analysis of the his-
39 Houston L. Rev. 727 (2002) 
tory of the plant patent legislation reveals. $\frac{38}{}$ Major nursery operators - whose varieties were easily propagated asexually - comprised the chief lobbying influence advocating patent protection for plant innovation, and put recognition of plant breeding as "invention" on equal footing with invention in other industrial sectors. By contrast, seed companies saw themselves predominantly as brokers rather than as developers of new varieties. In addition, the nursery operators dealt in ornamentals and fruits, while the seed companies dealt in staples of the food supply. One may assume that patent protection extending to the latter may have been politically unpalatable at the outset of the Great Depression.

\section{Patent Act}

35 U.S.C. § 161

Patents for plants

35 U.S.C. § 162

Description, claim

35 U.S.C. § 163

Grant

37 C.F.R. § 1.164

Claim

37 C.F.R. $§ 1.165$

Plant drawings
Whoever invents or discovers and asexually reproduces any distinct and new variety of plant, including cultivated sports, mutants, hybrids, and newly found seedlings, other than a tuber propagated plant or a plant found in an uncultivated state, may obtain a patent therefor, subject to the conditions and requirements of this title.

The provisions of this title relating to patents for inventions shall apply to patents for plants, except as otherwise provided.

No plant patent shall be declared invalid for noncompliance with section 112 if the description is as complete as is reasonably possible.

In the case of a plant patent, the grant shall include the right to exclude others from asexually reproducing the plant, and from using, offering for sale, or selling the plant so reproduced, or any of its parts, throughout the United States, or from importing the plant so reproduced, or any parts thereof, into the United States.

\section{Code of Federal Regulations}

The claim shall be in formal terms to the new and distinct variety of the specified plant as described and illustrated, and may also recite the principal distinguishing characteristics. More than one claim is not permitted.

(a) Plant patent drawings should be artistically and competently executed and must comply with the requirements of $\S 1.84$. View numbers and reference characters need not be employed

\footnotetext{
${ }^{38}$ Professor Cary Fowler has provided an insightful study of the subject. See generally Cary Fowler, The Plant Patent Act of 1930: A Sociological History of its Creation, 82 J. Pat. \& Trademark Off. Soc'y 621 (2000).
} 
unless required by the examiner. The drawing must disclose all the distinctive characteristics of the plant capable of visual representation.

(b) The drawings may be in color. The drawing must be in color if color is a distinguishing characteristic of the new variety. Two copies of color drawings or photographs must be submitted.

The applicant may be required to furnish specimens of the plant, or its flower or fruit, in a quantity and at a time in its stage of growth as may be designated, for study and inspection. Such specimens, properly packed, must be forwarded in conformity with instructions furnished to the applicant. When it is not possible to forward such specimens, plants must be made available for official inspection where grown.

37 C.F.R. § 1.166

Specimens 


\section{(12) United States Plant Patent Zaiger et al.}

(10) Patent No.: $\quad$ US PP15,399 P3

(45) Date of Patent: $\quad$ Dec. 7, 2004
(54) CHERRY TREE NAMED 'ROYAL KAY'

(50) Latin Name: Prunus avium

Varietal Denomination: Royal Kay

(76) Inventors: Gary Neil Zaiger, 1907 Elm Ave., Modesto, CA (US) 95358; Leith Marie Gardner, 1207 Grimes Ave., Modesto, CA (US) 95358; Grant Gene Zaiger, 4005 California Ave., Modesto, CA (US) 95358

$(*) \quad$ Notice: Subject to any disclaimer, the term of this patent is extended or adjusted under 35 U.S.C. 154 (b) by 93 days.

(21) Appl. No.: 10/302,701

(22) Filed: Nov. 25, 2002

\section{Prior Publication Data}

US 2004/0103463 P1 May 27, 2004

(51) Int. Cl. $^{7}$ A01H 5/00

(52)
Primary Examiner-Anne Marie Grunberg

\section{ABSTRACT}

A new and distinct variety of cherry tree (Prunus avium). The following features of the tree and its fruit are characterized with the tree budded on 'Mahaleb' Rootstock (nonpatented), grown on Handford sandy loam soil with Storie Index rating 95, in USDA Hardiness Zone 9, near Modesto, Calif., with standard commercial fruit growing practices such as pruning, thinning, spraying, irrigation and fertilization. Its novelty consist of the following combination of desirable features:

1. Vigorous, upright tree growth.

2. Fruit maturing in the early season.

3. Fruit with attractive red skin color.

4. Heavy and regular production of large size fruit.

5. Fruit with very good flavor and eating quality.

6. Fruit with good handling and storage quality.

\section{Drawing Sheet}

\section{1}

\section{BACKGROUND OF THE VARIETY}

1. Field of the Invention

In the field of plant genetics, we conduct an extensive and continuing plant-breeding program including the organization and asexual reproduction of orchard trees, and of which plums, peaches, nectarines, apricots, cherries and interspecifics are exemplary. It was against this background of our activities that the present variety of cherry tree was originated and asexually reproduced by us in our experimental orchard located near Modesto, Stanislaus County, Calif.

\section{Prior Varieties}

Among the existing varieties of cherry trees, which are known to us, and mentioned herein, are 'Stella' Cherry (non-patented) and 'Early Burlat' Cherry (non-patented).

\section{STATEMENT REGARDING FEDERALLY SPONSORED RESEARCH AND DEVELOPMENT}

Not applicable.

\section{ORIGIN OF THE VARIETY}

The present new variety of cherry tree (Prunus avium) was developed by us in our experimental orchard located near Modesto, Calif. The new cherry tree was selected in 1992 from a group of open pollinated seedlings grown from seed of a selected seedling with the field identification number 13HA431. The seedling cherry tree (13HA431) originated as a third generation seedling from open pollinated seed of 'Stella' Cherry (non-patented) and was selected to be used as a parent in our cherry breeding program. We grew a large number of these open pollinated seedlings on their own root under careful observation and selected the present variety for asexual reproduction due to

\section{2}

it's heavy fruit production, early maturity, and good fruit quality.

\section{ASEXUAL REPRODUCTION OF THE VARIETY}

Asexual reproduction of the new and distinct variety of cherry tree was by budding to 'Mahaleb' Rootstock (nonpatented), as performed by us in our experimental orchard located near Modesto, Calif., and shows that reproductions run true to the original tree and all characteristics of the tree and its fruit are established and transmitted through succeeding asexual propagations.

\section{SUMMARY OF THE NEW VARIETY}

15 The present new variety of cherry tree is of large size, vigorous, upright growth and a regular bearer of large fruit with medium firmness, very good flavor and eating quality. The fruit is further characterized by its attractive red skin color and early fruit maturity. In comparison to the standard

20 commercial cherry variety 'Early Burlat' (non-patented), the new variety blooms approximately 7 days earlier and the fruit is approximately 3 days earlier in maturity. In comparison to 'Stella' Cherry (non-patented), the new variety blooms approximately 7 days earlier and the fruit matures 25 approximately 25 days earlier. In comparison to its parent plant, the instant plant ripens earlier.

\section{PHOTOGRAPH OF THE VARIETY}

The accompanying color photographic illustration shows typical specimens of the foliage and fruit of the present new cherry variety. The illustration shows the upper and lower surface of the leaves, an exterior and sectional view of a fruit divided in its suture plane to show flesh color, pit cavity and the stone remaining in place. The photographic illustration was taken shortly after being picked (shipping ripe) and the 


\section{US PP15,399 P3}

3

colors are as nearly true as is reasonably possible in a color representation of this type.

\section{DESCRIPTION OF THE VARIETY}

The following is a detailed botanical description of the new variety of cherry tree, 7 years of age, its flowers, foliage and fruit, as based on observations of specimens grown near Modesto, Calif., with color in accordance with Munsell Book of Color.

Tree:

Size.-Large. Tree pruned to 4 to 5 meters in height for economical harvesting of fruit.

Vigor--Vigorous. Tree growth reaching 1 to 2 meters the first growing season. Growth rate varies with soil type and depth, cultural practices and climatic conditions.

Form.-Upright. During the first and second growing seasons scaffolds are selected and tied down to increase crotch angle and help spread tree to desired width of 3 to 4 meters.

Branching habit.-Upright. Crotch angle approximately $40^{\circ}$ when juvenile, upon maturity the weight of the fruit tends to increase the branch angles.

Productivity.-Very productive. Produces adequate fruit set annually.

Bearer-Regular. Adequate fruit set for three consecutive years.

Fertility.-Self sterile, pollinator required.

Density.-Medium dense. Usually pruned to form open vase shape to enhance health of fruit spurs and fruit color throughout the tree.

Hardiness.-Hardy. Tree grown in USDA Hardiness Zone 9. Winter chilling requirement is approximately 750 hours at or below $45^{\circ} \mathrm{F}$.

Trunk:

Size.-Large. Measured $20.3 \mathrm{~cm}$ in circumference at $25.4 \mathrm{~cm}$ above ground on a 7 year old tree. Varies with soil type, climatic conditions and cultural practices.

Stocky.-Medium stocky.

Texture.-Medium rough, increases slightly with age of tree.

Branches:

Color-Varies from $5 \mathrm{Y} 6 / 2$ to $7.5 \mathrm{Y} 6 / 2$.

Size.-Medium. Average circumference $12.1 \mathrm{~cm}$ at 1.2 meters above ground.

Surface texture. Smooth on new growth, becomes medium rough on mature growth.

Lenticels.-Numerous. Average of 35 in a 25.8 square $\mathrm{cm}$ section. Average length $3.1 \mathrm{~mm}$, increases in size as branches grow larger. Average width $1.6 \mathrm{~mm}$. Color - 5YR 5/8.

Color:- New growth varies from $5 \mathrm{Y} 4 / 6$ to $5 \mathrm{Y} 5 / 4$. Old Leaves: growth $7.5 \mathrm{R} 5 / 2$, varies with age of growth.

Size.-Large. Average length $126.1 \mathrm{~mm}$. Average width $60.9 \mathrm{~mm}$

Form.-Varies between ovate and lanceolate.

Apex.-Acuminate.

Base.-Cuneate.

Margin.-Serrate.

Thickness.-Medium.

Surface texture-Upper surface relatively smooth, slight indentation over leaf veins, glabrous. Lower
4

surface relatively smooth, slight ridges created by midrib and pinnate venation, glabrous.

Petiole.-Average length $38.1 \mathrm{~mm}$. Average width 1.6 $\mathrm{mm}$. Grooved longitudinally. Color of upper surface varies from $5 \mathrm{R} 2 / 4$ to $5 \mathrm{R} 2 / 6$. Color of lower surface varies from $2.5 \mathrm{GY} 5 / 6$ to $2.5 \mathrm{GY} 5 / 8$.

Glands.-Reniform. Large size. Number varies from 1 to 2. Average number 2. Average length $1.5 \mathrm{~mm}$. Average width $1.3 \mathrm{~mm}$. Located primarily on the upper portion of the petiole. Color varies from $2.5 \mathrm{GY} 8 / 4$ to $7.5 \mathrm{R} 3 / 8$ when exposed to the sun.

Color-Upper surface varies from $5 \mathrm{GY} 3 / 4$ to $5 \mathrm{GY}$ $4 / 4$. Lower surface varies from $2.5 \mathrm{GY} 4 / 4$ to $2.5 \mathrm{GY}$ $5 / 4$.

Midvein.-Color varies from 5 Y $5 / 6$ to 5 Y $6 / 6$.

Flower buds:

Size. - Large. Average length $15.5 \mathrm{~mm}$. Average diameter $6.9 \mathrm{~mm}$.

Hardiness.-Hardy in all stone fruit growing areas in California.

Form.-Plump, conical.

Pedicel.-Average length $25.4 \mathrm{~mm}$. Average width 2.5 $\mathrm{mm}$. Color varies from $2.5 \mathrm{GY} 5 / 4$ to $2.5 \mathrm{GY} 6 / 4$.

Color:-N 9.5/.

Number of buds per spur-Average 5, varies from 3 to 8.

Flowers:

Size. $\leqq$ Large. Average height $21.2 \mathrm{~mm}$. Average diameter $34.7 \mathrm{~mm}$.

Petals.-Number - 5, alternately arranged to sepals. Nearly orbicular, narrows at point of attachment. Outer edge slightly cleft. Average length $16.5 \mathrm{~mm}$. Average width $15.6 \mathrm{~mm}$.

Sepals. - Number - 5, alternately arranged to petals. Triangular shape. Both upper and lower surfaces glabrous. Average length $7.3 \mathrm{~mm}$. Average width 4.6 $\mathrm{mm}$. Color - upper surface $2.5 \mathrm{GY} 5 / 4$, lower surface $2.5 \mathrm{GY} 6 / 4$.

Stamens.-Average number per flower 30. Average filament length $11.8 \mathrm{~mm}$. Filament color $\mathrm{N} \mathrm{9.5/.}$ Color of anthers 1.25 Y $8 / 12$.

Pollen.-Abundant, pollinator required - not selffruitful. Color $-1.25 \mathrm{Y} \mathrm{8/12.}$

Pistil. - Number per flower - usually one. Average length $16.5 \mathrm{~mm}$, stigma is usually at the same height as the anthers. Surface - glabrous. Color $-2.5 \mathrm{GY}$ $9 / 6$.

Fragrance. - Slight to moderate aroma.

Blooming period.-Date of First Bloom Mar. 9, 2002. Date of Petal Fall Mar. 22, 2002. Varies slightly with climatic conditions.

Color. $\mathrm{N}$ 9.5/.

Number flowers per flower bud.-Average 4, varies from 2 to 4.

Pedicel.-Medium length. Average length $26.1 \mathrm{~mm}$. Average width $2.7 \mathrm{~mm}$. Color $2.5 \mathrm{GY} 8 / 4$.

Fruit:

Maturity when described. - Firm ripe.

Date of first picking.-May 2, 2002.

Date of last picking. - May 9, 2002. Varies slightly with climatic conditions.

Size.-Large. Average diameter axially $28.5 \mathrm{~mm}$. Average transversely in suture plane $25.4 \mathrm{~mm}$. Average weight 6.9 grams. Average weight varies slightly with fertility of the soil, amount of fruit set and climatic conditions. 


\section{US PP15,399 P3}

\section{5}

Form.-Globose. Slightly flattened at apex and base.

Suture.-Shallow, relatively smooth.

Ventral surface.-Smooth, nearly rounded.

Apex.-Varies from slightly retuse to rounded.

Base.-Retuse.

Cavity.-Rounded. Average depth $1.8 \mathrm{~mm}$. Average diameter $2.2 \mathrm{~mm}$

Stem:

Size.-Medium. Average length $34.9 \mathrm{~mm}$. Average width $1.6 \mathrm{~mm}$

Color:-Varies from $2.5 \mathrm{GY} 4 / 4$ to $2.5 \mathrm{GY} 5 / 4$. Flesh:

Ripens.-Evenly.

Texture. - Smooth, relatively meaty.

Fibers.-Few, small and tender.

Firmness. - Medium firm, comparable to 'Early Burlat' Cherry (non-patented).

Aroma. - Slight.

Amydgalin.-Undetected.

Eating quality.-Good.

Flavor-Very good, good balance between acid and sugar.

Juice.-Moderate amount, enhances flavor.

Brix.-Average of $13.5^{\circ}$, varies slightly with amount of fruit per tree and climatic conditions.

Color:-Varies from $2.5 \mathrm{R} 4 / 8$ to $5 \mathrm{R} 3 / 8$. Varies with fruit maturity. Pit cavity color $5 \mathrm{R} 2 / 6$. Skin:

Thickness.-Medium.

Surface. Smooth.

Bloom.-Wanting.

Tendency to crack.-None during dry weather, only slight tendency to crack in wet weather, varies with stage of fruit maturity.

Color-Varies from 2.5R 2/4 to 5R 3/10.

Tenacity.-Tenacious to flesh.

Stone:

Astringency.-None.

Type-Clingstone.

Size-Medium. Average length $11.3 \mathrm{~mm}$. Average width $8.9 \mathrm{~mm}$. Average thickness $7.2 \mathrm{~mm}$.

Form.-Ovoid.

Base.-Slightly rounded.

Apex.-Round to slight apical point.

Surface. - Smooth, except for ridges near suture.

Sides.-Equal to unequal. Some stones have one side extending further from suture plane.

\section{6}

Ridges.-A small, narrow ridge on each side of suture, extending from base to apex.

Tendency to split. - None. Kernal:

Color-Varies from 10YR $7 / 6$ to $10 \mathrm{YR} 7 / 8$ when dry.

Form.-Ovoid.

Taste.-Bitter.

Viability.-Viable. Good embryo development.

Size.-Average length $7.9 \mathrm{~mm}$. Average width $5.1 \mathrm{~mm}$. Average depth $4.4 \mathrm{~mm}$.

Skin color:-Varies from 10 YR $5 / 6$ to 10 YR $6 / 8$ when dry.

Use: Dessert. Market - local and long distance.

Keeping quality: Good. Held well for 21 days in cold storage at $38^{\circ}$ to $42^{\circ} \mathrm{F}$. and maintained good appearance and eating quality.

Shipping quality: Good. Minimal bruising or scarring in packing and shipping trials.

Plant disease resistance/susceptibility: No specific testing for relative plant/fruit disease has been designed. Under close observation during planting, growing and harvesting of fruit, under normal cultural and growing conditions near Modesto, Calif., no particular plant/fruit disease resistance or susceptibility has been observed. Any variety or selection observed during indexing of plant characteristics with abnormal susceptibility is destroyed and eliminated from our breeding program.

The present new variety of cherry tree, its flowers, foliage and fruit herein described may vary in slight detail due to climate, soil conditions and cultural practices under which the variety may be grown. The present description is that of the variety grown under the ecological conditions prevailing near Modesto, Calif.

It is claimed:

1. A new and distinct variety of cherry tree, substantially as illustrated and described, characterized by its large size, vigorous, upright growth and being a regular and productive bearer of large size fruit with very good flavor and eating quality; the fruit is further characterized by its attractive red skin color and by maturing in the early season with good handling and shipping qualities, and in comparison to 'Early Burlat' Cherry (non-patented), the new variety blooms approximately 7 days earlier and the fruit is approximately 3 days earlier in maturity. 


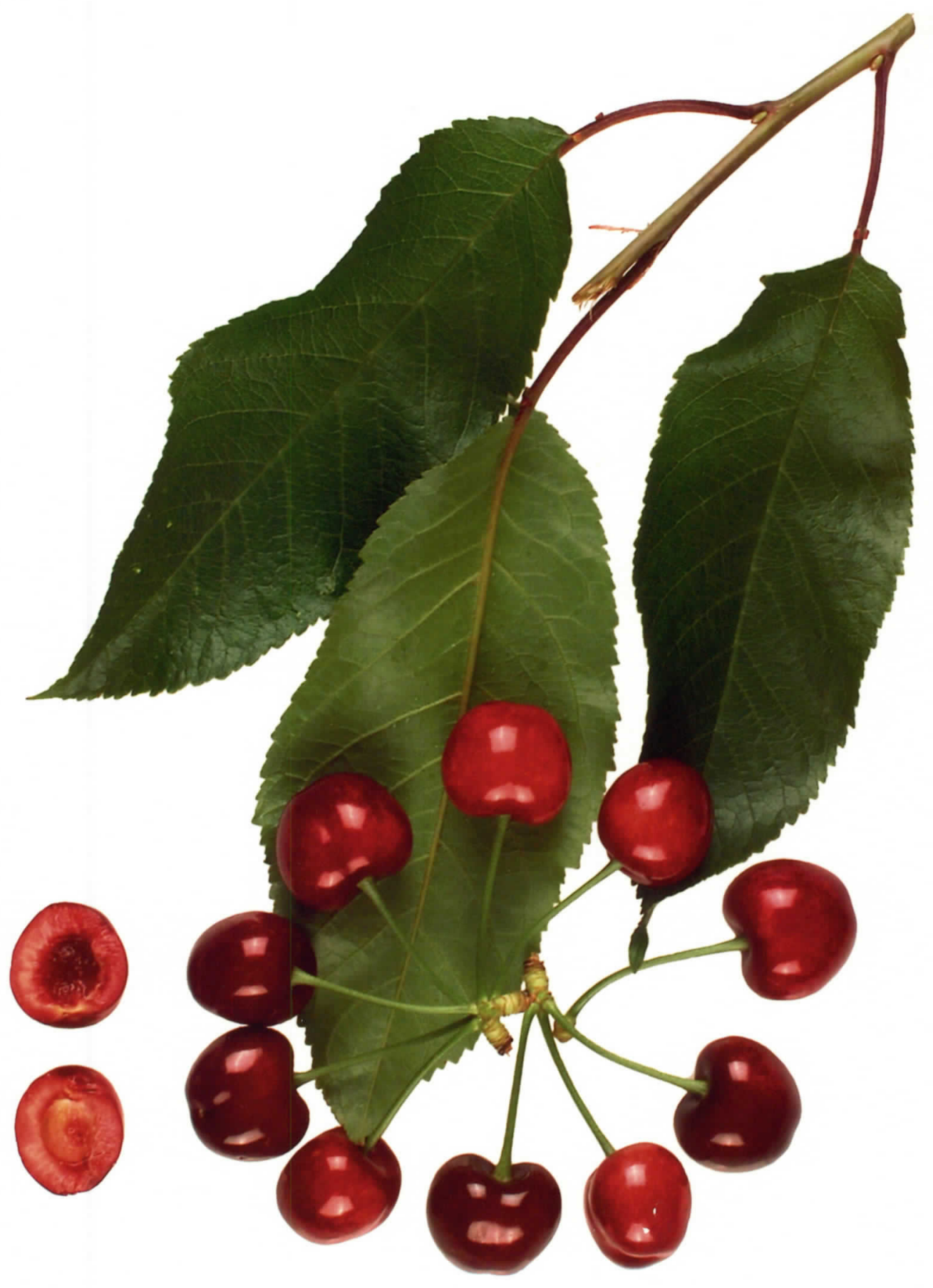




\section{a Subject Matter}

Times and taxonomies change. Today, plants are classified as eukaryotes (whose cells have organelles with membranes), along with animals, fungi, many amoebas and algae, and much more. Bacteria are prokaryotes (which lack such organelles) and make up their own domain of life. Asking whether bacteria are plants or animals is like asking whether Africans are from Mexico or Ecuador.

\section{In re Arzberger}

This is an appeal from a decision rejecting the single claim of appellant's application for a plant patent. The alleged invention is described by the examiner in his statement to the Board of Appeals as follows:

This application relates to a species of bacteria. This species of bacteria is named by applicant Clostridium saccharo-butyl-acetonicum-liquefaciens and cultured by him from Louisiana cane field soil. These bacteria are useful for producing butyl alcohol, acetone, and ethyl alcohol when grown in a suitable nutrient carbohydrate medium. Reproduction of these bacteria is asexual, by binary fission.

We are of the opinion that, while bacteria possess some of the characteristics of plants and some of the characteristics of animals, it is generally recognized by scientists that the characteristics of plants predominate in bacteria, and bacteria are usually scientifically classified as plants.

In Webster's New International Dictionary the first definition of "plant" reads as follows: "1. A young tree, shrub, or herb, planted or ready to plant; a slip, cutting, or sapling; ${ }^{* * *}$." The third definition is a lengthy description of plants from a scientific standpoint, and in this definition bacteria are mentioned.

We think it may fairly be said that in the common language of the people, the meaning of the word "plant" is as stated in the first definition, above quoted. At any rate, whether Congress intended to include in the term "plant" all organic matter which may be scientifically classified as plants is open to such doubt as to warrant resort to the legislative history of the provision here involved. It is sufficient to say that it fairly appears therefrom that the word "plant" as used therein was used in its popular sense and not in its scientific sense, and that the bill was designed for the benefit of agriculturalists and horticulturalists.

It will be observed that the reports of the Committees state that the bill provides that any person who invents or discovers a new and distinct variety of plant shall be given by patent an exclusive right to propagate that plant by asexual reproduction, and propagation by asexual reproduction is defined in the reports to be "by grafting, budding, cuttings, layering, division, and the like, but not by seeds." While it is true that the bacteria here involved are asexually reproduced, it is not here claimed that appellant propagates them by any 
of the methods above set out, and we do not understand that appellant claims that the bacteria here involved are capable of being reproduced by any of such methods. This, we think, is a strong indication of the character of plants intended to be embraced in the enactment of the legislation under consideration.

That the scientific meaning of a word is not always controlling in the interpretation of statutes was established in the case of Nix v. Hedden, where, in the interpretation of a tariff statute, the Supreme Court held that a tomato is a vegetable, although it is scientifically classified as a fruit. The court in its opinion stated: "Botanically speaking, tomatoes are the fruit of a vine, just as are cucumbers, squashes, beans, and peas. But in the common language of the people, whether sellers or consumers of provisions, all these are vegetables which are grown in kitchen gardens, and which, whether eaten cooked or raw, are, like potatoes, carrots, parsnips, turnips, beets, cauliflower, cabbage, celery, and lettuce, usually served at dinner in, with, or after the soup, fish, or meats which constitute the principal part of the repast, and not, like fruits generally, as dessert."

So here, we think that Congress, in the use of the word "plant," was speaking "in the common language of the people," and did not use the word in its strict, scientific sense. The Patent Office tribunals were correct in holding that the subject matter of the claim before us is not within the plant provision.

b Procedures

\section{In re Greer}

Appellant's invention relates to a variety of Bermuda grass found growing in a bed of, and allegedly distinct from, a variety of Bermuda grass known as Zimmerly Select. The particular characteristics relied upon by appellant to distinguish his grass from known varieties of Bermuda grass are set forth in the claim which reads as follows:

1. A new and distinct variety of BERMUDA GRASS PLANT, substantially as shown and described, characterized particularly by its outstanding reproductive properties, its large, glossy rhizomes, its high level of resistance to common Bermuda grass diseases and the large percentage of above ground stolons which remain green in freezing weather.

With regard to the "outstanding reproductive" characteristics of the claimed grass, the specification, in substance, indicates that when the stolons 1 of the grass are planted they cover the soil surface as quickly

\footnotetext{
${ }^{2}$ Webster's Third New International Dictionary, 1971 edition, provides the fol-
} 
as do the rhizomes when planted (in fact faster).

In support of the claim that the plant produces "large, glossy rhizomes" the specification states that "some are almost as large in diameter as a lead pencil." Additionally it states that they "penetrated the soil from one inch to two and one-half inches deeper than Coastal Bermuda [grass] rhizomes grown under identical conditions." The specification also indicates that by visual observation of rhizomes, it could be seen that the rhizomes of the claimed grass were larger than those of other Bermuda grasses grown the same way. However, no actual measurements are reported.

To support the claim that the new grass is distinct from others because of the large percentage of stolons remaining green in freezing weather, the specification indicates that a test plot of the claimed grass remained green under the same winter conditions where Zimmerly Select, Coastal Bermuda, and native Bermuda had become dormant.

The claim that the grass is disease resistant is based on the failure of the applicant and other growers of his grass to observe disease in plots of the grass. However, the specification also reveals that other varieties of Bermuda grass grown at the same locations also remained free of disease.

In conformance with the usual procedure for the examination of applications for plant patents, the application was submitted by the Patent Office to the Department of Agriculture for its evaluation of the assertions made in the specification supporting the claim that the grass was a distinct and new variety of plant. In due course a report was provided by the Department of Agriculture to the Patent Office.

1. The claimed grass is reported as superior to five other varieties of bermudagrass in its ability to withstand freezing weather. No comparative data were included in the application to show the relative winter survival of the claimed grass vs. other varieties. In addition to the lack of survival data, it [is] not clear from the application that all varieties were planted and managed in the same fashion.

2. The claimed grass is reported to have a high level of resistance to common bermudagrass diseases.It is stated, however, that no disease was noted on bermudagrass varieties grown at the same locations as the claimed grass.

lowing definitions: stolon - a horizontal branch from the base of a plant that is either above or below ground and produces new plants from buds at its tip or nodes (as in the strawberry); rhizome - a more or less elongate stem or branch of a plant that is often thickened or tuber shaped as a result of deposits of reserve food material, is usu. horizontal and underground, produces shoots above and roots below, and is distinguished from a true root in possessing buds, nodes and usu. scalelike leaves - called also rootstalk. 
This information does not support the claim for disease resistance as the named varieties differ greatly in their reaction to disease (from highly susceptible to highly resis$\operatorname{tant)}$....

In support of its conclusion that the rejection under $\S 112$ should be affirmed the board cited the following excerpt from the legislative history of the Plant Patent Act of 1930:

Modern methods of identification, together with such amplification thereof as may reasonably be expected, will render it possible and practicable to describe clearly and precisely the characteristics of a particular variety. When this can not be done by an applicant for a patent, the variety is not clearly distinguishable as a distinct variety, and no patent would issue.

From it the board reasoned as follows:

Accordingly, we believe it to be clear that the instant failure to adequately differentiate the claimed grass from other known varieties of Bermuda grass must result in the denial of a patent. We will sustain the rejection.

Appellant has attacked the soundness of the board's decision principally on the ground that $\S 162$ relieves the applicant for a plant patent of the strict requirements of $\S 112$.

In view of the statute, we must agree with appellant that a disclosure containing a description not fully in compliance with $\S 112$ might still be adequate under $\S 162$. In this regard this court, recognizing present technological limitations, has concluded that there is no requirement for a how-to-make disclosure in a plant patent application. See LeGrice.

Nevertheless, we do not agree that it was contemplated by Congress that $\S 162$ would operate to allow an applicant to allege characteristics which might be capable of distinguishing one variety of plant from another without sufficient disclosure to establish that these characteristics are indeed present in the claimed plant and absent in the varieties to which it is most closely related.

In the instant case we do not doubt that Bermuda grass having different reproductive properties, disease resistance, etc., when compared to the same properties of known varieties, would be a distinct variety of Bermuda grass. However, if, as is true in this case, the characteristics chosen to define the new plant are meaningless unless compared with predecessor plant varieties, it is incumbent upon the applicant to provide information of such a character that a meaningful comparison can be made. It is our view that the Patent Office in 
this case was justified in its conclusion that the criteria used to support the claim did not allow for such a meaningful comparison.

\section{c Ownership}

\section{Ex parte Moore}

This is an appeal from the final rejection of the following claim:

The new and distinct variety of peach tree as shown and described, characterized by its hardiness and resistance to cold and the late time of ripening of the fruit.

Mr. Francis Miller built a house in 1918 and the following year he noticed a small peach tree growing in his yard which he believed sprang from a peach seed planted by one of the men who worked on the house the preceding year. He protected the tree from injury and watered and fertilized it along with the grass and other vegetation in the yard. The tree lived some twelve years or more and before annual crops of large, luscious peaches. During all of this time Miller had no idea that the peach tree in his yard was a new variety. In so far as he was concerned, it was just a peach tree.

In 1928, when the tree was about ten years old and after it had borne seven annual crops, Mr. William Moore, the applicant in the application here on appeal, who was a friend of Miller and an orchardist and developer of new varieties of orchard trees by profession, saw the peach tree in Miller's yard and recognized that it was a new variety. He requested permission to take grafts for the purpose of asexually reproducing the tree on his own farm and with Miller's consent he took ten scions and grafted them on native root stock and had produced several successive generations from the original tree at the time the instant application was filed, thus demonstrating that the peach tree was in fact a new variety.

The issue in this appeal turns about the meaning to be given the word "discovers" in 35 U.S.C. § 161. It is the examiner's view that Miller is the one who discovered the new seedling peach tree rather than appellant because, according to two affdavits by Miller of record, Miller "noticed" or "took notice" of the existence of the new seedling growing in his yard and cultivated it long before appellant Moore observed it and recognized it as a new variety. That the seedling was growing in Miller's yard and that Miller was aware of its existence is corroborated by an affidavit by appellant, also of record in the case. The examiner's position, as we understand it, is that it was the intent of Congress that the word "discovers" in 35 U.S.C. 161 be read as meaning "finds", and Miller is the one who found the peach tree, not appellant. 
Appellant's view, on the other hand, is that although Miller may have found the seedling in the sense that he became aware of its presence in his yard, he did not "find" the new variety because he had no appreciation that the tree was different from other peach trees in the vicinity and, lacking such appreciation, he did not asexually reproduce it and thus establish that the tree was in fact a new variety. In contrast to this he argues that appellant was the one who realized that the tree might perhaps be a new variety and took steps to determine that fact by asexual reproduction through five generations. Since appellant was the first to discover the fact that the tree in Miller's yard was a new variety and then took steps by asexual reproduction to establish the fact that it was a new variety, it is appellant's view that he is the one who really was the discoverer of the new variety under the meaning of the statute.

After careful consideration of the examiner's position as developed at length in his answer, as well as that of appellant, we are of the opinion that appellant Moore is the one who discovered the new variety according to the intent of the statute.

If the word "discovers," as used in the statute, is to be construed as meaning "finds," and "finds" is construed as merely becoming aware of the existence of a plant without any appreciation that it is a new variety and no attempt is made to perpetuate the variety by asexual reproduction, it seems to us that the constitutional objective of advancing the progress of science and useful arts will to a large degree be nullified in so far as found seedlings are concerned. To illustrate; had the matter been left entirely in Miller's hands he would have done nothing to preserve the variety because, although he knew it was a peach tree, so far as he was aware, it had no unusual characteristics and was just an ordinary peach tree. When it had lived out its life span of twelve years and died, the new variety would have been lost for all time. Miller found a peach tree but he did not discover a new variety.

\section{Dunn v. Ragin v. Carlile}

This is an interference involving an application filed March 1, 1940, by Arthur A. Dunn, an application filed October 14, 1939, by Robert Lee Ragin and an application filed May 8, 1937, by Charles W. Carlile. Dunn and Carlile are represented by the same attorney and the Dunn application is assigned to Carlile.

The invention relates to a new variety of seedless orange and orange tree of the so-called pineapple type. The new variety of orange tree defined in the issue count originated as a mutation or bud variation, commonly called a bud sport, on a pineapple orange tree growing in a cultivated orange grove located in Brevard County, Florida. All the parties to this interference rely upon the propagation of trees 
from the same bud variation as establishing their respective rights to a patent. While this fact might appear to present a question of originality it is believed that the real issue is purely one of priority among the applicants.

It has long been held that an invention comprises two main inventive acts, conception, and reduction to practice. The question of what constitutes a conception and reduction to practice has been dealt with and decided in an abundance of cases and this question is so well defined in these cases as to require no further comment or citation. In each of these previously decided cases the inventions involved related to a new and useful art, machine, manufacture, or composition of matter. None have related to a new variety of plant. By analogy, however, it may be said that there must be a conception and reduction to practice in cases involving the invention or discovery of a new plant as well as in the previously referred to cases.

The question of what constitutes a reduction to practice is not believed to present any real problem. A reduction to practice may ordinarily be an actual reduction to practice, that is an actual successful building of a machine or performance of the art or process and so on, or it may be a constructive reduction to practice by the filing of a valid allowable application for a patent describing and claiming the invention. The principle of a constructive reduction to practice is a pure fiction of law and came into being as a result of judicial interpretation on the theory that a valid application for a patent completes the invention and makes it available to the public enabling any one of this group skilled in the art to which it relates to reproduce or perform the invention disclosed.

It should be noted that the statute provides as a prerequisite to the filing of an application for a plant patent that the alleged new variety of plant be asexually reproduced. It seems evident therefore that the filing of an application could not complete the invention but that an actual reduction to practice prior to the filing date of the application is an essential requirement. The mere filing of an application for a patent for a new variety of plant would not enable anyone to reproduce such a plant. The plant must actually be in being and reproductions thereof must be obtainable by one of the usual forms of asexual propagation as for example grafting, budding, inarching, division or the like. It would appear therefore that the filing of an application for a plant patent by itself can not properly be considered a constructive reduction to practice because of the statutory prerequisite.

It is believed that an actual reduction to practice is completed when the new variety is actually reproduced by any satisfactory method of asexual propagation and it is determined that the progeny in fact possess the characteristic or characteristics which distinguish it as a new variety. In the case under consideration an actual reduc- 
tion to practice would be established when by asexual propagation citrus trees were produced which bore fruits having all the attributes of the variety known as a pineapple orange with the exception of its habit of containing seeds.

A new variety may popularly be said to be conceived or discovered when an individual becomes aware of its existence. An inventor can not properly be said to have discovered a new variety of plant until he is certain that it is in fact a new variety. In cases like the instant case, where the new variety is produced by bud variation it is believed the conception or discovery occurs when the asexual reproduction establishes the bud variation to be in fact a true bud variation or new variety, since the only real test of a true bud variety is its ability to be perpetuated through bud propagation.

The facts as related in the Dunn record are that in 1930 or at least sometime prior to $1933 \mathrm{R}$. V. Williams, an employee on the grove adjoining that owned by Dunn, discovered a seedless orange growing on a tree in the Dunn grove. He communicated knowledge of his discovery to Dunn and Dunn went to the location designated and found that one limb of the tree bore seedless oranges, while the remainder of the tree bore fruit heavily seeded in accordance with the standard characteristics of the variety. Dunn testified that he observed the tree from year to year until 1937 in order to determine if the habit was fixed. In January of that year the senior party Carlile was at the Dunn grove picking fruit, his company having purchased the crop. Dunn informed Carlile of the seedless tree and allegedly requested him to reproduce the same. Later the tree and all rights in it were sold to Carlile who ultimately removed it and transplanted it in his own nursery. Carlile cut budwood from the tree and budded the same to root stock in order to produce additional specimens. In November 1938 the trees thus reproduced had fruit sufficiently matured to determine that they were in fact seedless orange trees of the pineapple type. At least three generations of such trees had been produced and had borne fruit by the time the testimony was given in this case. Trees were sold as early as July, 1938 to a Mr. MacDonald in Miami and all have since produced seedless oranges.

The Ragin story is as follows: In 1934 Ragin obtained permission from Dunn to cut budwood on the Dunn grove. While cutting budwood he met the witness Williams who informed him that he had found a seedless orange. Williams did not designate the exact tree and Ragin sought it out while cutting budwood. Ragin took budwood and budded some to root stock but also top-worked several trees in order to get more rapid growth. Top-working consists of cutting out the crown of a mature tree and budding or grafting to it the new growth desired. In 1935 the trees thus top-worked were shown to Springer, nursery inspector for the Florida Plant Board. At 
that time Ragin told Springer that the new growth was of seedless oranges. The following year Springer again inspected the same trees which were then bearing fruit. He cut fruit and found it to be in fact seedless. He later inspected other trees and found the fruit thereon to be seedless. Springer's testimony stands unchallenged and must be accepted as true. Since Springer testified that he cut fruit the following summer it must be held that Ragin actually reduced to practice no later than the end of the summer of 1936 that is September 15, 1936.

The party Dunn first learned of the seedless oranges sometime prior to 1933 according to the testimony in his behalf. Thereafter he did nothing until he sold the tree to Carlile. Dunn insists that Carlile was his agent in reducing the invention to practice and that he not only sold the tree but also sold his rights in the invention. Since there was no conception until the invention was reduced to practice Dunn could not have sold anything except the tree for he had nothing else to sell. Since Dunn did nothing he can not be held to be an inventor. Even if it were held that the reduction to practice by Carlile did inure to the benefit of Dunnhis effective date for conception and reduction to practice would not be earlier than November, 1938. This date is considerably later than September 15, 1936, the date established for Ragin.

Dunn contends however that the finding of the parent tree constituted the conception or discovery contemplated by the statute. If it be assumed without so holding that this contention is correct, Dunn could not prevail since it is not believed that he has established any diligence during the required period. If Dunn's testimony is to be accepted at its face value it would appear that he did absolutely nothing beyond merely observing the tree for a period of seven years. . Dunn's excuse for failure to act is not believed to be either convincing or adequate and award must be made in favor of Ragin.

\section{In re LeGrice}

The issue on these consolidated appeals is whether appellant is entitled under 35 U.S.C. § 161 to a patent on each of his applications serial numbers 709,127 and 709,128, filed January 15, 1958, each entitled 'Rosa Floribunda Plant.' The Patent Office Board of Appeals affirmed the final rejection of both applications under 35 U.S.C. § 102(b) on the ground that the inventions had been described in printed publications in England more than one year prior to the dates of filing of the said applications. The publications occur in the National Rose Society Annual of England and in catalogues. The Annual describes appellant as having raised the roses described and the catalogues show color pictures of these roses. There is no dispute that the publications relate to and picture the identical roses which were originated by ap- 
pellant and which he now seeks to patent.

We think it is sound law, consistent with the public policy underlying our patent law, that before any publication can amount to a statutory bar to the grant of a patent, its disclosure must be such that a skilled artisan could take its teachings in combination with his own knowledge of the particular art and be in possession of the invention.

In view of the long line of cases dealing with other types of inventions antedating 1930, we think Congress, by failing to provide otherwise, intended that the provisions of section 102(b), as applied to plant patents, should not be interpreted otherwise than they had been with respect to other inventions, i.e., that only an 'enabling' publication is effective as a bar to a subsequent patent.

While man can and does assist nature by the cross-pollination of selected parent plants, the actual creation of the new plant, because of the almost infinite number of possible combinations between the genes and chromosomes, is not presently subject to a controlled reproduction by act of man. While those skilled in this art now understand the mechanics of plant reproduction and the general principles of plant heredity, they are not presently able to control the factors which govern the combinations of genes and chromosomes required to produce a new plant having certain predetermined desired properties.

Appellant in his brief points out:

The description of a plant in a plant patent or in a printed publication at best can only recite, as historical facts, that at one time a certain plant existed, was discovered in a certain manner, and was asexually reproduced. This information may be interesting history, but cannot enable others to reproduce the plant. Prior public use and sale of a plant are the avenues by which a plant enters the public domain.

In the case of manufactured articles, processes and chemical compositions, a different situation prevails. Written descriptions and drawings in publications can often enable others to manufacture the article, practice the process or produce the chemical composition.

We therefore hold that the descriptions in the printed publications here in issue do not meet the requirement of an 'enabling' description, as the statute has been interpreted in numerous cases.

We do not agree with the examiner and the board that this creates an "anomaly" when dealing with plant patents which requires that "plant publications must be totally ignored as printed publications." Instead, it requires that the facts of each case be carefully considered to determine whether the description in the printed publication in question does in fact place the invention in the possession of the pub- 
lic. Each case must be decided on its own particular facts in determining whether, in fact, the description in the printed publication is adequate to put the public in possession of the invention and thus bar patentability of a plant under the conditions stated in section 102(b). While the present knowledge of plant genetics may mean as a practical matter, that the descriptions in such general publications as are here involved cannot be relied upon as a statutory bar under section 102(b), we must be mindful of the scientific efforts which are daily adding to the store of knowledge in the fields of plant heredity and plant eugenics which one skilled in this art will be presumed to possess.

Yoder Bros., Inc. v. California-Florida Plant Corp.

Normally, the three requirements for patentability are novelty, utility, and nonobviousness. For plant patents, the requirement of distinctness replaces that of utility, and the additional requirement of asexual reproduction is introduced.

The concept of novelty refers to novelty of conception, rather than novelty of use; no single prior art structure can exist in which all of the elements serve substantially the same function. As applied to plants, the Patent Office Board of Appeals held that a "new" plant had to be one that literally had not existed before, rather than one that had existed in nature but was newly found, such as an exotic plant from a remote part of the earth.Ex parte Foster In Green, the court indicated that the Board believed that novelty was to be determined by a detailed comparison with other known varieties.

The legislative history of the Plant Patent Act is of considerable assistance in defining "distinctness." The Senate Report said:

In order for the new variety to be distinct it must have characteristics clearly distinguishable from those of existing varieties and it is immaterial whether in the judgment of the Patent Office the new characteristics are inferior or superior to those of existing varieties. Experience has shown the absurdity of many views held as to the value of new varieties at the time of their creation.

The characteristics that may distinguish a new variety would include, among others, those of habit; immunity from disease; or soil conditions; color of flower, leaf, fruit or stems; flavor; productivity, including ever-bearing qualities in case of fruits; storage qualities; perfume; form; and ease of asexual reproduction. Within any one of the above or other classes of characteristics the differences which would suffice to make the variety a distinct variety, will necessarily be differences of degree. 
A definition of "distinctness" as the aggregate of the plant's distinguishing characteristics seems to us a sensible and workable one.

The third requirement, nonobviousness, is the hardest to apply to plants, though we are bound to do so to the best of our ability. Rephrasing the John Deere tests for the plant world, we might ask about (1) the characteristics of prior plants of the same general type, both patented and nonpatented, and (2) the differences between the prior plants and the claims at issue. We see no meaningful way to apply the third criterion to plants - i. e. the level of ordinary skill in the prior art. Criteria one and two are reminiscent of the "distinctness" requirement already in the Plant Patent Act. Thus, if we are to give obviousness an independent meaning, it must refer to something other than observable characteristics.

We think that the most promising approach toward the obviousness requirement for plant patents is reference to the underlying constitutional standard that it codifies - namely, invention.

The general thrust of the "invention" requirement is to ensure that minor improvements will not be granted the protection of a seventeen year monopoly by the state. In the case of plants, to develop or discover a new variety that retains the desirable qualities of the parent stock and adds significant improvements, and to preserve the new specimen by asexually reproducing it constitutes no small feat.

This Court's case dealing with the patent on the chemical compound commonly known as the drug "Darvon," Eli Lilly \& Co. v. Generix Drug Sales, provides some insight into the problem of how to apply the "invention" requirement to a new and esoteric subject matter. The court first noted that

analogical reasoning is necessarily restricted in many chemical patent cases because of the necessity for physiological experimentation before any use can be determined. In fact, such lack of predictability of useful result from the making of even the slightest variation in the atomic structure or spatial arrangement of a complex molecule deprives the instant claims of obviousness and anticipation of most of their vitality.

The court resolved the apparent dilemma by looking to the therapeutic value of the new drug instead of to its chemical composition:

Reason compels us to agree that novelty, usefulness and non-obviousness inhere in the true discovery that a chemical compound exhibits a new needed medicinal capability, even though it be closely related in structure to a known or patented drug.

The same kind of shift in focus would lead us to a more produc-
Eli Lilly v. Generix, Inc.: 460 F.2d 1096 (5th Cir. 1972) 
tive inquiry for plant patents. If the plant is a source of food, the ultimate question might be its nutritive content or its prolificacy. A medicinal plant might be judged by its increased or changed therapeutic value. Similarly, an ornamental plant would be judged by its increased beauty and desirability in relation to the other plants of its type, its usefulness in the industry, and how much of an improvement it represents over prior ornamental plants, taking all of its characteristics together.

d Infringement

Imazio Nursery, Inc. v. Dania Greenhouses

\section{BACKGROUND}

Bruno Imazio, the owner of Imazio Nursery, Inc. (Imazio), is the inventor of the U.S. Plant Patent No. 5,336, which is entitled "Heather Named Erica Sunset." According to the '336 patent, Mr. Imazio discovered Erica Sunset heather in 1978 "as a seedling of unknown pollen parentage growing in a cultivated field of Erica persoluta, the variety believed to be the seed parent, where it was noticed because of its early blooming and particularly because of its reaching full bloom, from base to tip, more than a month before the parent plant begins to bloom." It was the early blooming of the Erica Sunset, during the Christmas and Valentine's Day seasons, that distinguished the Erica Sunset from other known varieties.

The sole claim of the '336 patent recites:

A new variety of Heather persoluta, substantially as herein shown and described, particularly characterized by its profuse production of blooms over the entire length of the stem beginning in early December.

In April 1992, Imazio sued Coastal for patent infringement alleging that Coastal's "Holiday Heather" infringed the '336 patent.

The trial court adopted the standard that the Plant Patent Act "bars the asexual reproduction and sale of any plant which is the same variety (i.e., has the same essential characteristics) as the patented plant, whether or not the infringing plant was originally cloned from the patented plant." The district court also addressed whether independent creation could be a defense to plant patent infringement. The district court stated that "independent creation is not a proper defense to patent infringement" and asserted that "the courts' recognition of an independent creation defense would inadvertently entice deliberate infringement, with a fraudulent defense of independent creation asserted." 
On the merits of the infringement charge, the trial court reviewed the testimony of both parties' experts and found that the "undisputed evidence thus shows that the patented Erica Sunset heather and the Holiday Heather are the same plants both morphologically (internal and external characteristics) and phenologically (blooming cycle)." The trial court concluded that Imazio had "successfully demonstrated that the Holiday Heather is an asexual reproduction of the Erica Sunset."

\section{Statutory Construction}

We first consider the scope of protection of plant patents.

\section{The meaning of the term "variety"}

The parties dispute the meaning of the term "variety" in section 161. Imazio argues that in providing plant patent protection for "any distinct and new variety of plant," it was intended that a plant patent cover "all plants of that new and distinct variety, i.e., all plants having the same essential and distinctive characteristics." Thus, argues Imazio, "variety" should be construed in its technical, taxonomical sense and should be interpreted to encompass more than just clones of a single plant. Coastal, on the other hand, contends that "variety" should be construed in the vernacular sense as "something different from others of the same general kind." Coastal maintains that by use of the term "variety" Congress did not intend to afford plant patent protection to a range of plants but intended only to protect a single plant.

The Plant Patent Act does not define "variety." However, the legislative history of the Plant Patent Act states:

new and distinct varieties fall into three classes - sports, mutants, and hybrids. In the first class of cases, the sports, the new and distinct variety results from bud variation and not seed variation. A plant or portion of a plant may suddenly assume an appearance or character distinct from that which normally characterizes the variety or species. In the second class of cases, the mutants, the new and distinct variety results from seedling variation by self pollenization of species. In the third class of cases, the hybrids, the new and distinct variety results from seedlings of cross pollenization of two species, two varieties, or a species and a variety.

Thus, upon passage of the Plant Patent Act, a patentable variety could be either a sport, mutant, or hybrid. In addition, by amendment in 1954, Congress added another class of plants, newly found seedlings, subject to the exception that such seedlings found in an 
uncultivated state cannot be patented.

Section 161 also requires that a patentable variety be new. Additionally, the variety must be distinct. As to this requirement, the legislative history states that

in order for the new variety to be distinct it must have characteristics clearly distinguishable from those of existing varieties. The characteristics that may distinguish a new variety would include, among others, those of habit; immunity from disease; resistance to cold, drought, heat, wind, or soil conditions; color of flower, leaf, fruit, or stems; flavor; productivity, including ever-bearing qualities in case of fruits; storage qualities; perfume; form; and ease of asexual reproduction. Within any one of the above or other classes of characteristics the differences which would suffice to make the variety a distinct variety, will necessarily be differences of degree.

The legislative history is clear that Congress intended that distinct and new cultivated sports, mutants, hybrids, and newly found seedlings be entitled to plant patent protection.

Although the legislative history does not answer the question of what "variety" means in terms of whether a single plant or a range of plants is protected by a plant patent, in addition to being distinct and new, a patentable plant must also be asexually reproduced. As discussed below, this additional requirement informs the scope of protection of plant patents and hence directs the meaning of "variety" in $\S 161$.

\section{The significance of the asexual reproduction requirement}

The legislative history defines asexual reproduction as reproduction by "grafting, budding, cuttings, layering, division, and the like, but not by seeds." The legislative history further states that

whether the new variety is a sport, mutant, or hybrid, the patent right granted is a right to propagate the new variety by asexual reproduction. It does not include the right to propagate by seeds. This limitation in the right granted recognizes a practical situation and greatly narrows the scope of the bill. Whether the new variety is a hybrid, mutant or sport, there is never more than one specimen of it produced except through asexual reproduction. For example, without asexual reproduction there would have been but one true McIntosh or Greening apple tree. These varieties of apples could not have been preserved had it not been through human effort in the asexual reproduc- 
tion of the two original trees. They could not have been reproduced true to the type by nature through seedlings.

The legislative history additionally sets forth that plants sought to be patented

must be asexually reproduced in order to have their identity preserved. This is necessary since seedlings either of chance or self-pollenization from any of these would not preserve the character of the individual.

It is clear from the legislative history that as a result of the asexual reproduction requirement, only a single plant, i.e., reproduction from one original specimen in the words of Congress, is protected by a plant patent. At the time of enactment, Congress recognized that the asexual reproduction prerequisite greatly narrowed the scope of protection of plant patents but found such a limitation necessary to ensure that the characteristics of the plant to be patented were maintained. Additionally, it has since been recognized that as intimated by Congress, asexual reproduction confirms the existence of a new variety by separating variations resulting from fluctuations in environmental conditions from true plant variations.

Due to the asexual reproduction prerequisite, plant patents cover a single plant and its asexually reproduced progeny. See Senate Report at 6 (Plant patent protection encourages "those who own the single specimen to reproduce it asexually and create an adequate supply."). Thus, the term "variety" in section 161 must be interpreted consistently with this requirement. Accordingly, "variety" in section 161 cannot be read as affording plant patent protection to a range of plants, as asserted by Imazio.

\section{INFRINGEMENT}

As to the first step, consistent with our analysis above, the scope of the claim of the' 336 patent is the asexual progeny of the Heather persoluta shown and described in the ' 336 patent specification. To perform the second step of the infringement analysis, we first look to the language of the statute.

Section 163 grants to plant patentees the right to exclude others from asexually reproducing the plant or selling or using the plant so reproduced. 35 U.S.C. $\S 163$. As stated above, the trial court held that asexual reproduction is shown if the patentee can prove that the alleged infringing plant has the same essential characteristics as the patented plant. We disagree.

We must construe the term "asexual reproduction" in section 163 in the same way as we did in section 161. Thus, for purposes of plant patent infringement, the patentee must prove that the alleged infringing plant is an asexual reproduction, that is, that it is the progeny of 
the patented plant.

Below, the parties disputed whether independent creation is a proper defense to plant patent infringement. The trial court refused to recognize such a defense stating that the "patent holder would have great difficulties enforcing his patent rights if a defendant were allowed to raise independent creation as an affirmative defense." The trial court reasoned that it would be hard for the patentee to refute evidence of independent creation because all such evidence would be in the defendant's control.

We must reject the trial court's analysis of the independent creation defense because it is contrary to the plain meaning of the statute. The statute requires asexual reproduction of the patented plant for there to be infringement. It is necessarily a defense to plant patent infringement that the alleged infringing plant is not an asexual reproduction of the patented plant. Part of this proof could be, thus, that the defendant independently developed the allegedly infringing plant. However, the sine qua non is asexual reproduction. That is what the patentee must prove and what the defendant will seek to disprove.

The judgment of infringement of the '336 patent is reversed. The case is remanded for further proceedings consistent with this opinion.

170 F. Supp. 519 (E.D. Tex. 1958)

\section{Armstrong Nurseries, Inc. v. Smith}

In 1955, Defendant Dyess requested Defendant Hood to grow roses for him and agreed to furnish Defendant Hood or make available for Defendant Hood's use the requisite budwood. In accordance with such agreement Defendant Dyess did subsequently furnish and make available to Defendant Hood a quantity of budwood for different varieties with which Defendant Hood dormant budded or caused to be dormant budded approximately 73,000 rose plants in a certain field in his possession and under his control.

Among said 73,000 rose plants were approximately 1,500 rose plants, more or less, characterized by a vigorous upright-growing habit; the production of flat glossy, dark green, medium size foliage during spring growing with increase in size until attainment of large proportions during late summer and fall; high resistance to mildew and anthracnose; by long moderately heavy stems having a fairly large number of medium to large thorns in the spring diminishing in late season until relative freedom of thorns is reached; by the shape of bud and open bloom combined with wide contrast between outer surface petal color and inner surface petal color and extreme brilliance of the latter in the opening bud and newly opening flower, substantially as shown and described in Plant Patent No. 792, being of the variety of rose plant commonly known as 'Forty-Niner'. 
Defendant Hood was unaware when he first budded the aforesaid 73,000 rose plants that any of them were of the aforesaid patented varieties. Later when the crop came on and Defendant Hood questioned Defendant Dyess in respect of the varieties of said patented rose plants, Defendant Dyess told Defendant Hood that those plants which were in fact of the variety shown and described in the Plant Patent No. 792 and commonly known as 'Forty-Niner' were a new variety known as 'Fifty-Five.'

Defendant Hood has never possessed and does not now possess a proper license or sub license (grower) authorizing him to asexually reproduce, grow, sell, or use the aforesaid patented rose plants.

By reason of his unauthorized dormant budding and cultivation of the aforesaid patented rose plants, Defendant Hood has infringed Plant Patent No. 792.

At the time Defendant Dyess furnished Defendant Hood the aforesaid budwood Defendant Dyess did not possess a current valid growing license or sub license, and by his dealings with Defendant Hood in respect of said budwood and the rose plants subsequently grown by Defendant Hood, he actively induced the infringement of said Plant Patents by Defendant Hood and is an infringer of the rights of said patentees under said respective plant patents.

\section{Plant Variety Protection Act}

Senate Report No. 1246, 91 st Congress, 2d Session (1970)

Plant Variety Protections Act

Under the patent law, patent protection is limited to those varieties of plants which reproduce asexually, that is, by such methods as grafting or budding. No protection is available to those varieties of plants which reproduce sexually, that is, generally by seeds. Thus, patent protection is not available with respect to new varieties of most of the economically important agricultural crops, such as cotton or soybeans.

Subsequently, legislation was introduced to encourage the development of novel varieties of sexually reproduced plants by the issuance of certificates of plant variety protection by the Department of Agriculture to establish such protection, was reported by the Committee on Agriculture and Forestry, and on August 24 this legislation was referred to this committee for the purpose of reviewing its impact on the plant patent statute. The committee recommends the bill, S. 3070, favorably as amended. 
No.

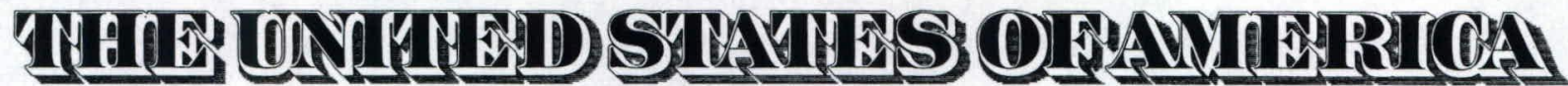

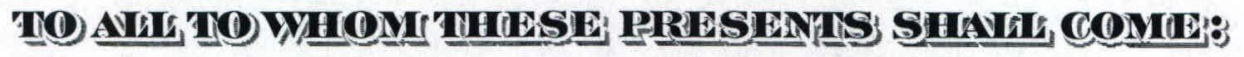

\section{Seminis Vegetable Seeds, Inc.}

\author{
Whereas, THERE HAS BEEN PRESENTED TO THE
}

Secretary of Agriculture

An application requesting a certificate of protection for an alleged distinct variety of sexually reproduced, or tuber propagated plant, the name and description of which are contained in the application and exhibits, a copy of which is hereunto annexed and made a part hereof, and the various requirements of $\mathrm{LAW}$ in such cases made and provided have been complied with, and the title thereto is, from the records of the PLANT VARIETY PROTECTION OFFICE, in the applicant(s) indicated in the said copy, and Whereas, upon due examination made, the said applicant(s) is (are) adjudged to be entitled to a certificate of plant variety protection under the LAW.

Now, therefore, this certificate of plant variety protection is to grant unto the said applicant(s) and the successors, heirs or assigns of the said applicant(s) for the term of TWENTY years from the date of this grant, subject to the payment of the required fees and periodic replenishment of viable basic seed of the variety in a public repository as provided by LAW, the right to exclude others from selling the variety, ar offering it for sale, or reproducing it, or importing it, or exporting it, or conditioning it for pagation, or stocking it for any of the above purposes, or using it in producing a hybrid or different $\mathrm{y}$ therefrom, to the extent provided by the PLANT VARIETY PROTECTION ACT. (84 STAT. 1542, AS ED, 7 U.S.C. 2321 ET SEQ.)

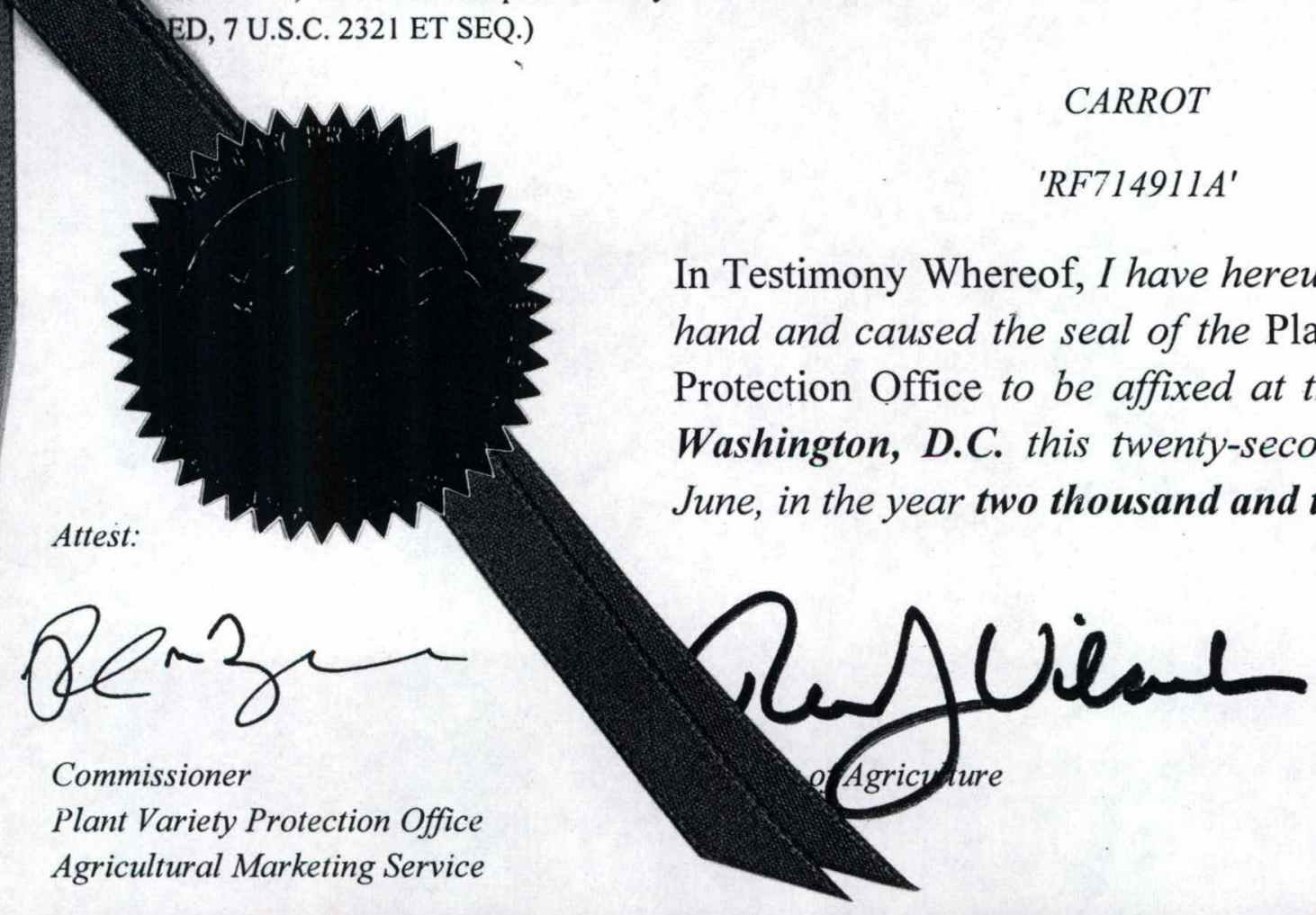


U.S. DEPARTMENT OF AGRICULTURE

AGRICULTURAL MARKETING SERVICE

SCIENCE AND TECHNOLOGY - PLANT VARIETY PROTECTION OFFICE

APPLICATION FOR PLANT VARIETY PROTECTION CERTIFICATE

(Instructions and information collection burden statement on reverse)

\section{NAME OF OWNER}

Seminis Vegetable Seeds, Inc.

4. ADDRESS (Street and No., or R.F.D. No., City, State, and ZIP Code, and Country)

2700 Camino del Sol

Oxnard, CA 93030-7967

\section{. IF THE OWNER NAMED IS NOT A "PERSON", GIVE FORM
ORGANIZATION (corporation, partnership, association, etc.)}

\section{Corporation} STATE OF INCORPORATION

\section{California}

10. NAME AND ADDRESS OF OWNER REPRESENTATIVE(S) TO SERVE IN THIS APPLICATION. (First person listed will receive all papers)

\section{Carol Miller}

Seminis Vegetable Seeds, Inc.

37437 State Hwy 16

Woodland, CA 95695

\section{Sara Boeke}

Seminis Vegetable Seeds, Inc.

P.O. Box $97, \mathrm{NL}-6700 \mathrm{AB}$

Wageningen, Netherlands
The following statements are made in accordance with the Privacy Act of 1974 (5 U.S.C. 552a) and the Paperwork Reduction Act (PRA) of 1995.

Application is required in order to determine if a plant variety protection certificate is to be issued (7 U.S.C. 2421). Information is held confidential until certificate is issued (7 U.S.C. 2426).

\section{TEMPORARY DESIGNATION OR 1 3. VARIETY NAME}

RF 71-4911A

5. TELEPHONE (include area code)

(805) 647-1572

6AX (include area code)

(805) $918-2545$

9. DATE OF INCORPORATION

\section{June 1962}

FILING DATE

$$
\text { June 5, } 2008
$$

(1)

FILING AND EXAMINATION FEES:

$\$ 4382.00$

DATE $6 / 5 / 08$

CERTIFICATION FEE:

$\$ 768.00$

DATE $3 / 18 / 10$

\begin{tabular}{|l|l|l|}
\hline 11. TELEPHONE (Include area code) & 12. FAX (Include area code) & 13. E-MAIL \\
\hline
\end{tabular}

\begin{tabular}{l|l} 
(530) 669-6274 & $(530) 669-6112$
\end{tabular}

carol.I.miller@seminis.com

14. CROP KIND (Common Name)

16. FAMILY NAME (Botanical)

18. DOES THE VARIETY CONTAIN ANY TRANSGENES? (OPTIONAL)

Carrot

15. GENUS AND SPECIES NAME OF CROP

Umbelliferae

Daucus carota

17. IS THE VARIETY A FIRST GENERATION HYBRID?

$\square$ YES $\square$ NO

IF SO, PLEASE GIVE THE ASSIGNED USDA-APHIS REFERENCE NUMBER FOR THE APPROVED PETITION TO DEREGULATE THE GENETICALLY MODIFIED PLANT FOR COMMERICALIZATION

19. CHECK APPROPRIATE BOXFOR EACH ATTACHMENT SUBMITTED

(Follow instructions on reverse)

a. Exhibit A. Origin and Breeding History of the Variety

b. $\square$ Exhibit B. Statement of Distinctness

c. Exhibit C. Objective Description of Variety

d. $\square$ Exhibit D. Additional Description of the Variety (Optional)

e. Exhibit E. Statement of the Basis of the Owner's Ownership

20. DOES THE OWNER SPECIFY THAT SEED OF THIS VARIETY BE SOLD AS A CLASS OF CERTIFIED SEED? (See Section 83(a) of the Plant Variety Protection Act)

$\square$ YES (If "yes", answer items 21 and 22 below) $\square$ No (If "no", go to item 23)

21. DOES THE OWNER SPECIFY THAT SEED OF THIS VARIETY BE LIMITED AS TO NUMBER OF CLASSES?

$\square$ YES $\square$ NO

IF YES, WHICH CLASSES? $\square$ FOUNDATION $\square$ REGISTERED $\square$ CERTIFIED

22. DOES THE OWNER SPECIFY THAT SEED OF THIS VARIETY BE LIMITED AS TO NUMBER OF GENERATIONS?

f. $\nabla$ Exhibit $F$. Declaration Regarding Deposit

g. $\square$ Voucher Sample $(3,000$ viable untreated seeds or, for tuber propagated varieties, verification that tissue culture will be deposited and maintained in an approved public repository)

g. $\square$ Filing and Examination Fee $(\$ 4,382)$, made payable to "Treasurer of the United States" (Mail to the Plant Variety Protection Office)

23. HAS THE VARIETY (INCLUDING ANY HARVESTED MATERIAL) OR A HYBRID PRODUCED FROM THIS VARIETY BEEN SOLD, DISPOSED OF, TRANSFERRED, OR USED IN THE U. S. OR FROM THIS VARIETY
OTHER COUNTRIES?

$\square$ YES $\square$ NO

IF YES, YOU MUST PROVIDE THE DATE OF FIRST SALE, DISPOSITION, TRANSFER, OR USE FOR EACH COUNTRY AND THE CIRCUMSTANCES. (Please use space indicated on reverse.)
IF YES, SPECIFY THE NUMBER 1,2,3, etc. FOR EACH CLASS.

$\square_{\text {foundation }} \square_{\text {Registered }} \quad \square$ Certified (If additional explanation is necessary, please use the space indicated on the reverse.)

24. IS THE VARIETY OR ANY COMPONENT OF THE VARIETY PROTECTED BY INTELLECTUAL PROPERTY RIGHT (PLANT BREEDER'S RIGHT OR PATENT)?

$\square$ YES $\square$ NO

IF YES, PLEASE GIVE COUNTRY, DATE OF FILING OR ISSUANCE AND ASSIGNED REFERENCE NUMBER. (Please use space indicated on reverse.)

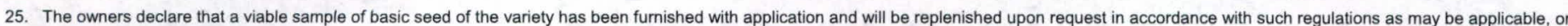
for a tuber propagated variety a tissue culture will be deposited in a public repository and maintained for the duration of the certificate

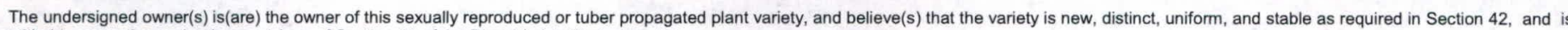
entitled to protection under the provisions of Section 42 of the Plant Variety Protection Act.

Owner(s) is (are) informed that false representation herein can jeopardize protection and result in penalties.

\begin{tabular}{|c|c|c|c|}
\hline SIGNATURE OF OYYNER & & SIGNATURE OF OWNER & \\
\hline $\begin{array}{l}\text { NAME (Please print or type) } \\
\text { Carol L. Miller }\end{array}$ & & NAME (Please print or type) & \\
\hline $\begin{array}{l}\text { CAPACITY OR TITLE } \\
\text { PVP Specialist }\end{array}$ & $\begin{array}{r}\text { DATE } \\
L\end{array}$ & CAPACITY OR TITLE & DATE \\
\hline
\end{tabular}


GENERAL INSTRUCTIONS: To be effectively filed with the Plant Variety Protection Office (PVPO), ALL of the following items must be received in the PVPO: (1) Completed application form signed by the owner; (2) completed exhibits A, B, C, E, F; (3) for a tuber reproduced variety, verification that a viable (in the sense that it will reproduce an entire plant) tissue culture will be deposited and maintained in an approved public repository; and (4) payment by credit card or check drawn on a U.S. bank for $\$ 4,382$ ( $\$ 518$ filing fee and $\$ 3,864$ examination fee), payable to "Treasurer of the United States" (See Section 97.6 of the Regulations and Rules of Practice). NEW: With the application for a seed reproduced variety or by direct deposit soon after filing, the applicant must provide at least 3,000 viable untreated seeds of the variety per se, and for a hybrid variety at least 3,000 untreated seeds of each line necessary to reproduce the variety. Partial applications will be held in the PVPO for not more than 90 days; then returned to the applicant as un-filed. Mail application and other requirements to Plant Variety Protection Office, AMS, USDA, Room 401, NAL Building, 10301 Baltimore Avenue, Beltsville, MD 20705-2351. Retain one copy for vour files. All items on the face of the application are self explanatory unless noted below. Corrections on the application form and exhibits must be initialed and dated. DO NOT use masking materials to make corrections. If a certificate is allowed, you will be requested to send a payment by credit card or check payable to "Treasurer of the United States" in the amount of $\$ 768$ for issuance of the certificate. Certificates will be issued to owner, not licensee or agent.

NOTES: It is the responsibility of the applicant/owner to keep the PVPO informed of any changes of address or change of ownership or assignment or owner's representative during the life of the application/certificate. The fees for filing a change of address; owner's representative; ownership or assignment; or any modification of owner's name is specified in Section 97.175 of the regulations. (See Section 101 of the Act, and Sections 97.130, 97.131, 97.175(h) of the Regulations and Rules of Practice.)

\author{
Plant Variety Protection Office \\ Telephone: (301) 504-5518 \\ General E-mail: PVPOmail@usda.gov \\ Homepage: http://www.ams.usda.gov/science/pvpo/PVPindex.htm
}

\title{
SPECIFIC INSTRUCTIONS:
}

To avoid conflict with other variety names in use, the applicant must check the appropriate recognized authority and provide evidence that the permanent name of the application variety (even if it is a parental, inbred line) has been cleared by the appropriate recognized authority before the Certificate of Protection is issued. For example, for agricultural and vegetable crops, contact: U.S. Department of Agriculture, Agricultural Marketing Service, Livestock and Seed Programs, Seed Regulatory and Testing Branch, 801 Summit Crossing Place, Suite C, Gastonia, North Carolina 28054-2193 Telephone: (704) 810-8870. http://www.ams.usda.gov/lsg/seed.htm.

\section{ITEM}

19a. Give: (1) the genealogy, including public and commercial varieties, lines, or clones used, and the breeding method;

(2) the details of subsequent stages of selection and multiplication;

(3) evidence of uniformity and stability; and

(4) the type and frequency of variants during reproduction and multiplication and state how these variants may be identified

19b. Give a summary of the variety's distinctness. Clearly state how this application variety may be distinguished from all other varieties in the same crop. If the new variety is most similar to one variety or a group of related varieties:

(1) identify these varieties and state all differences objectively;

(2) attach replicated statistical data for characters expressed numerically and demonstrate that these are clear differences; and

(3) submit, if helpful, seed and plant specimens or photographs (prints) of seed and plant comparisons which clearly indicate distinctness.

19c. Exhibit C forms are available from the PVPO Office for most crops; specify crop kind. Fill in Exhibit C (Objective Description of Variety) form as completely as possible to describe your variety.

19d. Optional additional characteristics and/or photographs. Describe any additional characteristics that cannot be accurately conveyed in Exhibit C. Use comparative varieties as is necessary to reveal more accurately the characteristics that are difficult to describe, such as plant habit, plant color, disease resistance, etc.

19e. Section 52(5) of the Act requires applicants to furnish a statement of the basis of the applicant's ownership. An Exhibit E form is available from the PVPO.

20. If "Yes" is specified (seed of this variety be sold by variety name only, as a class of certified seed), the applicant MAY NOT reverse this affirmative decision after the variety has been sold and so labeled, the decision published, or the certificate issued. However, if "No" has been specified, the applicant may change the choice. (See Regulations and Rules of Practice, Section 97.103).

23. See Sections 41,42 , and 43 of the Act and Section 97.5 of the regulations for eligibility requirements.

24. See Section 55 of the Act for instructions on claiming the benefit of an earlier filing date.

22. CONTINUED FROM FRONT (Please provide a statement as to the limitation and sequence of generations that may be certified.)

23. CONTINUED FROM FRONT (Please provide the date of first sale, disposition, transfer, or use for each country and the circumstances, if the variety (including any harvested material) or a hybrid produced from this variety has been sold, disposed of, transferred, or used in the U.S. or other countries.)

24. CONTINUED FROM FRONT (Please give the country, date of filing or issuance, and assigned reference number, if the variety or any component of the variety is protected by intellectual property right (Plant Breeder's Right or Patent).)

U.S. Patent Application No. 11/874,629 Entitled "Carrots Having Increased Lycopene Content" by Robert V. Maxwell filed $18-O c t-07$.

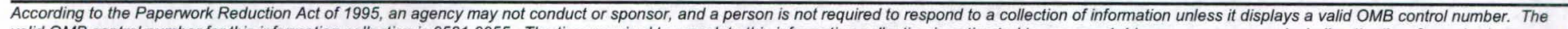

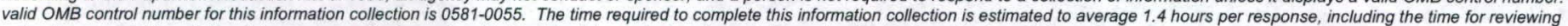
instructions, searching existing data sources, gathering and maintaining the data needed, and completing and reviewing the collection of information.

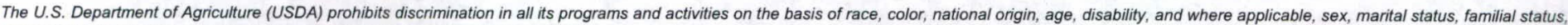

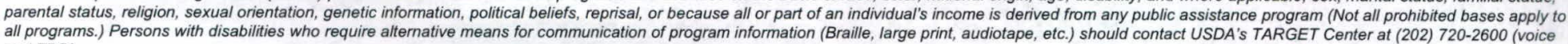
all programs.

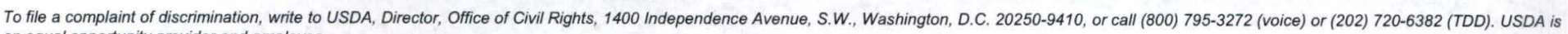
an equal opportunity provider and employer. 


\section{EXHIBIT A \\ Origin and Breeding History of Red Carrot Male Sterile, RF 71-4911A}

RF 71-4911A was developed via work based at the Seminis Breeding Station in Payette, Idaho. Reproductive cycles were carried out at Payette, while the vegetative cycles were performed at the Elmore Forms, Inc. property near Brawley, California. Roots are grown at the Southern California location and transported to Idaho for seed production.

Line RF 71-4911A exhibits a number of improved traits including uniform red color throughout an internal root cross-section and high petaloid male-sterility stability. A pedigree breeding system was used for line development and improvement. The development of the line can be summarized as follows.

Sept. 2000 Planted seeds of 'Nutri-red' and 'USDA line 4367S' (an orange male sterile line released by the USDA) in the Imperial Valley, California.

Feb. 2001 Harvested roots of 'Nutri-red' and 'USDA line 4367S' for F1 hybrids. Planted individual roots selected from 'Nutri-red' and made crosses with 'USDA line 4367S', establishing new sub-line populations of 'Nutri-red' with their respective hybrids.

Sept. $2001 \quad$ Planted hybrid seed and new sub-lines in California.

Feb. 2002 Harvested hybrids of 'Nutri-red' sub-lines and 'USDA line 4367S' (all orange roots) in preparation of first backcross to the respective sub-lines.

Sept. 2002 Planted BC1 seed in California with the respective sub-lines.

Feb. 2003 Selected red roots within the BC1 population and prepared for backcrossing, again, to the 'Nutri-red' sub-lines.

Sept. 2003 Planted BC2 seed in California with the respective sub-lines.

Feb. 2004 Most backcrosses appeared to be nearly stable, though some orange roots caused concern about the possible genetic inheritance. Red roots were again selected and prepared for backcrossing to 'Nutri-red' sub-lines.

Sept. 2004 Planted BC3 seed in California with the respective sub-lines.

Feb. 2005 Harvested roots and found that $100 \%$ of all backcross populations had complete expression of lycopene. Selected best lines for hybrid production and possible increase, one set of lines being RF 71-4911A \& B.

Sept. 2005/6 Planted new hybrids and backcross lines for potential advancement and seed increase.

Feb. 2006/7 Evaluated and selected best hybrid combinations.

In summary, individual roots of 'Nutri-red' were found which lacked the fertility restorer gene. Repeated backcrossing of an orange carrot with male-sterile cytoplasm to one of these 'Nutri-red' roots resulted in the development of RF 71-4911A in a stable, red pigmented phenotype.

From observations made during two generations of multiplication and seed increases (during 2005 and 2006), RF 71-4911A was found to be uniform and stable within commercially acceptable limits. As is true with other carrot varieties, a small percentage of off-types can occur within commercially acceptable limits for almost any characteristic during the course of repeated multiplications. No variants are know or expected to occur. 
EXHIBIT B

RF $714911 \mathrm{~A}$

\section{Statement of Distinctness for Red Carrot, RF 71-4911A}

RF 71-4911A is the result of work to develop a male sterile line derived from a population of 'Nutri-red', a red carrot release developed by Seminis Vegetable Seeds, Inc. Individual roots of 'Nutri-red' were selected and crossed with a known male sterile line of orange color. The progeny were evaluated for flower type to identify any 'Nutri-red' root selections that lacked the nuclear fertility restorer gene. One root in particular, identified as RF 714911B, was found to be lacking this gene. Continued backcrossing of the male sterile progeny to the male sterile maintainer resulted in the development of RF 71-4911A.

The RF 71-4911A population is a more slender and refined carrot type, somewhat similar to the original 'Nutri-red' population. Roots are medium to narrow in diameter with a gradual taper to the root tip. They have a very smooth skin texture.

To our knowledge, the most similar variety to RF 71-4911A is 'Nutri-red'. The comparative characteristics which best distinguish the two varieties include, but may not be limited to:

- Root Base: the roots of RF 71-4911A have a semi-blunt base, whereas the roots of 'Nutri-red' have a pointed base.

- Root Exterior Color: the exterior root color of RF 71-4911A is light red with an RHS color chart value of $184 \mathrm{C}$, whereas 'Nutri-red' is dark red with an RHS color chart value of 59D.

- Flower Type: the flowers of RF 71-4911A are 100\% male sterile, whereas the flowers of 'Nutri-red' are $100 \%$ male fertile.

- Flower Color: the flowers of RF 71-4911A are green with an RHS color chart value of 194C, whereas the flowers of 'Nutri-red' are white with an RHS color chart value of N155D.

The following photographs of RF 71-4911A and 'Nutri-red' depict the visual differences described above:
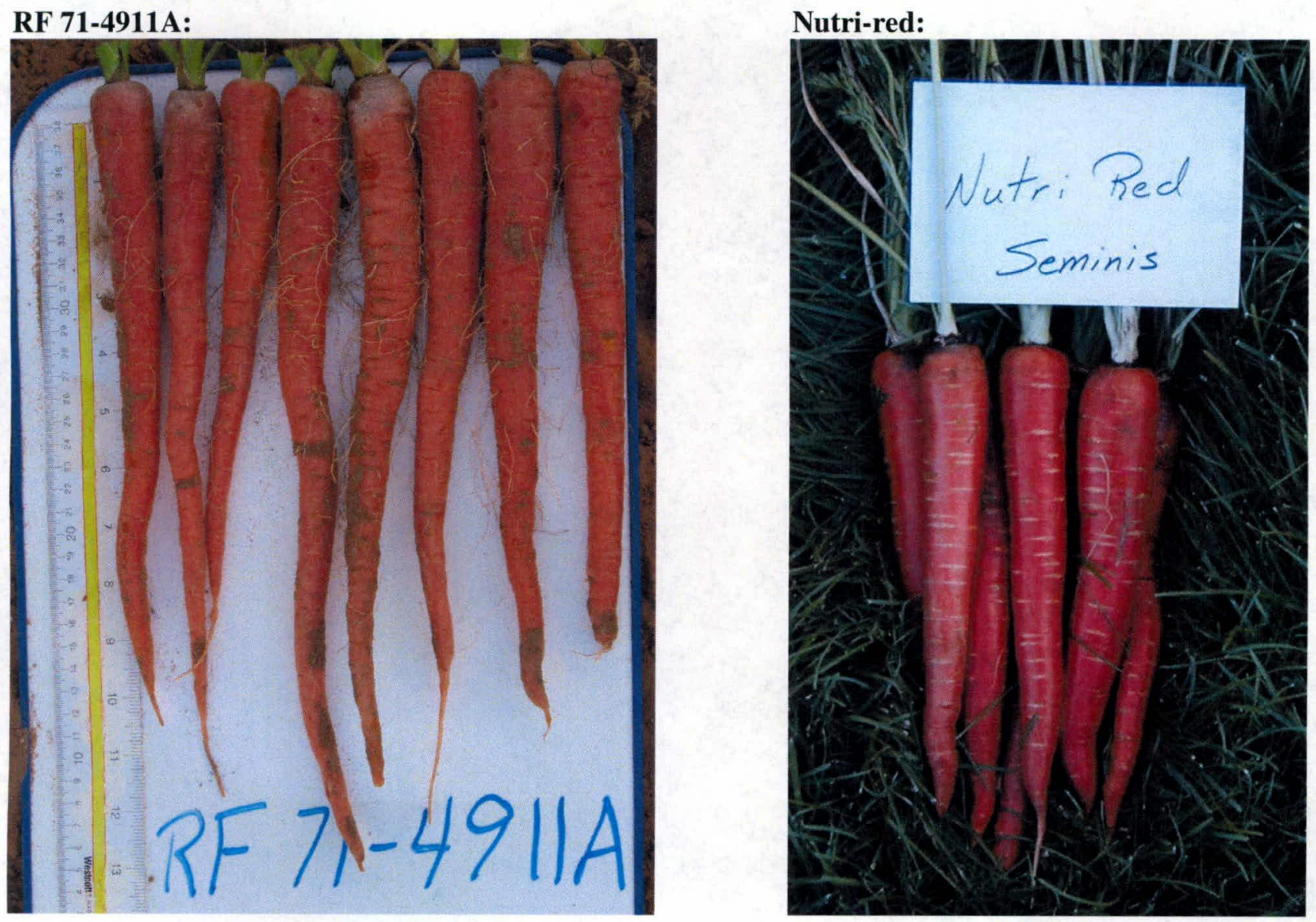


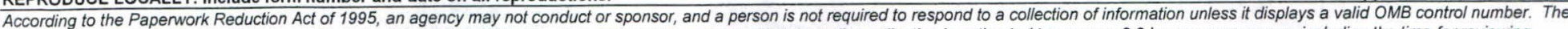

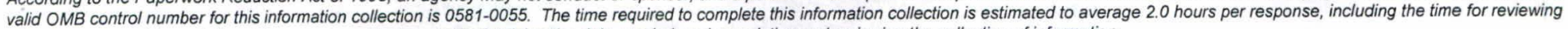
instructions, searching existing data sources, gathering and maintaining the data needed, and completing and reviewing the collection of information.

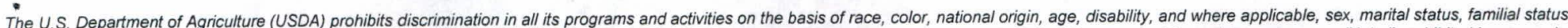

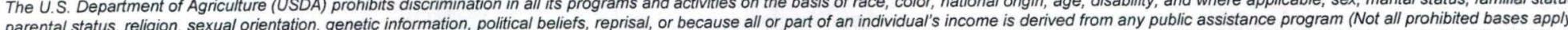

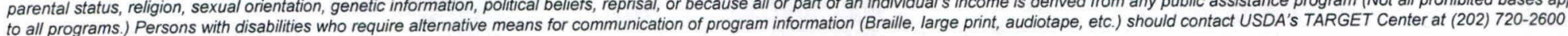
(voice and TDD)

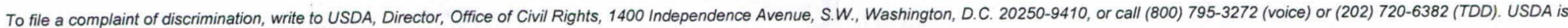
an equal opportunity provider and employer.

U.S. DEPARTMENT OF AGRICULTURE

Exhibit C

AGRICULTURAL MARKETING SERVICE SCIENCE AND TECHNOLOGY

PLANT VARIETY PROTECTION OFFICE BELTSVILLE, MD 20705

\section{OBJECTIVE DESCRIPTION OF VARIETY} Carrot (Daucus carota)

\begin{tabular}{|c|c|c|}
\hline $\begin{array}{l}\text { SaME OF APPLICANT (S) } \\
\text { Seminis Veqetable Seeds. Inc. }\end{array}$ & REFPRARY OR EXPERIMENTAL DESIGNATION & RF 714 \\
\hline ADDRESS (Street and No. or RD No., City, State, Zip Code and Country) & & FOR OFFICIAL USE ONLY \\
\hline $\begin{array}{l}2700 \text { Camino del Sol } \\
\text { Oxnard, CA } 93030\end{array}$ & & PVPO NUMBER \\
\hline
\end{tabular}

\section{PLEASE READ ALL INSTRUCTIONS CAREFULLY}

In the spaces on the left, enter the appropriate numbers that describe the characteristics of the application variety. On the right, enter the appropriate numbers that describe the characteristics of the most similar comparison variety. Right justify whole numbers by adding leading zeros if necessary. The variety that you choose for comparison should be the most similar one in terms of overall morphology, background and maturity. The comparison variety should be grown in field trials with the application variety for 2-3 location/years (environments) in the region and season of best adaptability. At least one year of trials should be conducted within the United States of America. In general, measurements of quantitative traits should be taken from one trial on 15-25 randomly selected plants or plant parts to obtain averages and statistics that describe a typical field of the variety. (Form technical content last updated Feb. 2003.) Application Variety

1. TYPE:

6e $1=$ Amsterdam $2=$ Flakee $3=$ Berlicum $4=$ Chantenay $5=$ Danvers $6=$ Imperator $\quad 7=$ Nantes $8=$ Other (Specify) Comparison Variety Comparison Variety Name Nutri-red Le Type

\section{REGION OF ADAPTATION IN THE U.S.A.}

$71=$ Northeast $\quad 2=$ Northwest $3=$ Southeast $\quad 4=$ Southwest $5=$ North Central $6=$ South Central $\quad 7=$ Most Regions

\section{Region of Adaptability}

\section{MARKET MATURITY}

120 No Days from Seeding to Harvest

$1 \underline{2}$ Days to Market Maturity

\section{PLANT TOP: (At Harvest Stage)}

2 Habit: $1=$ Erect $2=$ Semi-erect $3=$ Prostrate

$042 \mathrm{~cm}$ Plant Top Height (from Shoulder to Top of Crown)

O 12 mm Plant Top Neck Diameter

1 Top Attachment: $1=$ Single $\quad 2=$ Multiple

5. LEAF: (At Harvest Stage)

2 Name of Color Chart: 1= Munsell Book of Color 2= RHS Colour Chart $3=$ Other (Specify)

3 Blade Color: 1= Light Green $2=$ Medium Green 3 = Dark Green $4=$ Other (Specify)

Color Chart Value

$132 \beta$

\section{Habit \\ $050 \mathrm{~cm}$ Plant Top Height \\ O 3 O mm Plant Top Neck Diameter \\ 1 Top Attachment}

\section{Name of Color Chart \\ 3 Blade Color:}

Color Chart Value 


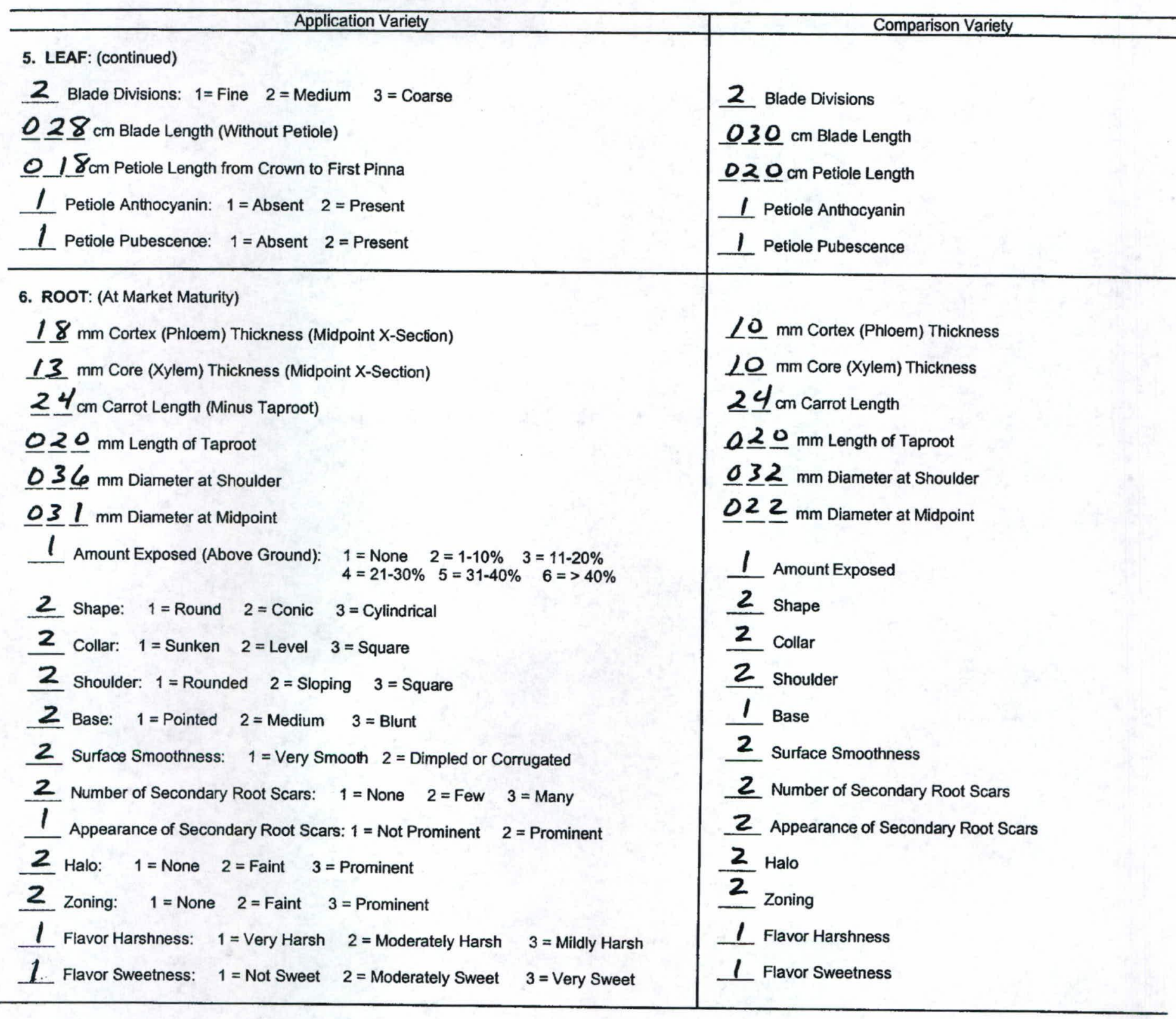

Notes:

Halo: Cross-section showing color difference between xylem and phloem.

Zoning: Longitudinal cut showing color difference between xylem and phloem. 


\section{COLORS:}

Color choices: $1=$ White $\quad 2=$ Yellow $\quad 3=$ Orange $\quad 4=$ Red $\quad 5=$ Purple $\quad 6=$ Green $\quad 7=$ Salmon $\quad 8=$ Light $\quad 9=$ Dark $\quad 10=$ Other (describe) Color Examples: $\underline{0} \underline{2}=$ Yellow; $\underline{3} \underline{4}=$ Orange-Red; $\underline{9} \underline{4}=$ Dark Red

2 Name of Color Chart: $1=$ Munsell Book of Color $2=$ RHS Colour Chart $3=$ Other (Specify)

Above Ground Exterior Color: $\underline{84}$ Shoulder (Color chart value _ 184C, $\quad 94$ Shoulder (Color chart value $59 \mathrm{D}$ ) Above Ground Exterior Color: $\underline{8} 4$ Skin (Color chart value $184 \mathrm{C}$ ) 94 Skin (Color chart value $59 \mathrm{D}$ ) Below Ground Exterior Color: $8 \underline{4}$ Shoulder (Color chart value $184 \mathrm{C}$ ) $9 \underline{4}$ Shoulder (Color chart value $59 \mathrm{D}$ ) Below Ground Exterior Color: 84 skin (Color chart value _ 184C) 94 skin (Color chart value 59D)

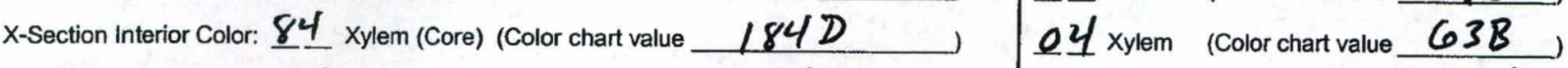
X-Section Interior Color: 84 Phloem (Color chart value $184 \mathrm{D}$ ) 04 Phloem (Color chart value $63 \mathrm{~A}$ )

\section{FLOWER:}

Q6 Flower Color (Color chart value $194 \mathrm{C}$

\section{U I Flower Color (Color chart value N/SSD,}

2 Male Fertility: $1=$ Fertile $2=$ Male-Sterile $3=$ Other

2 Anthers: $1=$ Normal $2=$ Petaloid $3=$ Other 1 Male Fertility 1 Anthers

\section{SEED:}

$125 \mathrm{~cm}$ Height of Seed Stalk

2 Stalk Pubescence: $1=$ Absent 2 = Little 3 = Moderate $4=$ Heavy

120 mm Diameter of First Order Umbel

2 Seed Spines: $1=$ Absent 2 = Present

$205 \mathrm{mg}$ per 100 seeds

9 $5 \mathrm{~cm}$ Height of Seed Stalk

2 Stalk Pubescence

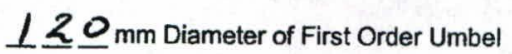

2 Seed Spines

210 mg per 100 Seeds

8. DISEASE REACTIONS: ( 1 = Susceptible; 2 = Resistant; give races if known)

1 Alternaria Blight

I Aster Yellows

_ Cavity Spot

__ Cercospora Blight

_ Motley Dwarf Virus

_ Powdery Mildew

__ Pythium Root Dieback

1 Schlerotinia Decay

_ Other (Specify)

1 Alternaria Blight

1 Aster Yellows

I Cavity Spot

_ Cercospora Blight

1 Motley Dwarf Virus

1 Powdery Mildew

1 Pythium Root Dieback

I Schlerotinia Decay Other (Specify) $\quad N / A$

9. INSECT REACTIONS: ( 1 = Susceptible; 2 = Resistant; give races if known)

I Root Knot Nematode

_ Other (Specify)

$N / A$

1 Root Knot Nematode

- Other (Specify) $\quad N / A$ 
Exhibit C (Carrot)
10. PHYSIOLOGICAL REACTIONS: $(1=$ Susceptibie and $2=$ Resistant $)$
$\leq$ Bolting
2 Root Splitting
2 Bolting
2 Root Splitting

COMMENTS: 
U.S. DEPARTMENT OF AGRICULTURE

AGRICULTURAL MARKETING SERVICE

\section{EXHIBIT E}

STATEMENT OF THE BASIS OF OWNERSHIP

\section{NAME OF APPLICANT(S)}

Seminis Vegetable Seeds, Inc.

4. ADDRESS (Street and No., or R.F.D. No., City, State, and ZIP, and Country)

2700 Camino del Sol

Oxnard, California 93030
Application is required in order to determine if a plant variety protection certificate is to be issued (7 U.S.C. 2421). The information is held confidential until the certificate is issued (7 U.S.C. 2426).

\section{TEMPORARY DESIGNATION OR EXPERIMENTAL NUMBER \\ RF 71-4911A}

5. TELEPHONE (Include area code)

(805) $647-1572$

3. VARIETY NAME

7. PVPO NUMBER

9. Is the applicant (individual or company) a U.S. national or a U.S. based company? If no, give name of country. $\square$ YES $\square$ NO

10. Is the applicant the original owner?

a. If the original rights to variety were owned by individual(s), is (are) the original owner(s) a U.S. National(s)?

$\square$ YES $\square$ NO If no, give name of country

b. If the original rights to variety were owned by a company(ies), is (are) the original owner(s) a U.S. based company?

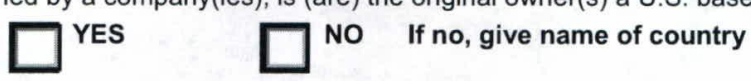

11. Additional explanation on ownership (Trace ownership from original breeder to current owner. Use the reverse for extra space if needed):

The variety named in this application was developed by the Seminis Vegetable Seeds, Inc., employee (breeder) identified below. By agreement between the employee and Seminis Vegetable Seeds, Inc., all rights to any invention, discovery, or development made by an employee are assigned to the Company. No rights to such an invention, discovery, or development are retained by the employee.

Employee (Breeder): Rob Maxwerll

Site Location: Payette, Idaho

\section{PLEASE NOTE:}

Plant variety protection can only be afforded to the owners (not licensees) who meet the following criteria:

1. If the rights to the variety are owned by the original breeder, that person must be a U.S. national, national of a UPOV member country, or national of a country which affords similar protection to nationals of the U.S. for the same genus and species.

2. If the rights to the variety are owned by the company which employed the original breeder(s), the company must be U.S. based, owned by nationals of a UPOV member country, or owned by nationals of a country which affords similar protection to nationals of the U.S. for the same genus and species.

3. If the applicant is an owner who is not the original owner, both the original owner and the applicant must meet one of the above criteria.

The original breeder/owner may be the individual or company who directed the final breeding. See Section 41(a)(2) of the Plant Variety Protection Act for definitions.

According to the Paperwork Reduction Act of 1995, an agency may not conduct or sponsor, and a person is not required to respond to a collection of information unless it displays a valid OMB control number. The valid OMB control number for this information collection is 0581-0055. The time required to complete this information collection is estimated to average 0.1 hour per response, including the time for reviewing the instructions, searching existing data sources, gathering and maintaining the data needed, and completing and reviewing the collection of information.

The U.S. Department of Agricuiture (USDA) prohibits discrimination in all its programs and activities on the basis of race, color, national origin, gender, religion, age, disability, sexual orientation, marital or family status, political beliefs, parental status, or protected genetic information. (Not all prohibited bases apply to all programs.) Persons with disabilities who require alternative means for communication of program information (Braille, large print, audiotape, etc.) should contact USDA's TARGET Center at 202-720-2600 (voice and TDD).

To file a complaint of discrimination, write USDA, Director, Office of Civil Rights, Room 326-W, Whitten Building, 14th and Independence Avenue, SW, Washington, D.C. 20250-9410 or call (202) 720-5964 (voice and TDD). USDA is an equal opportunity provide and employer. 


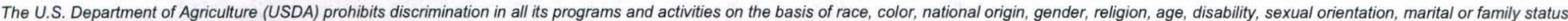

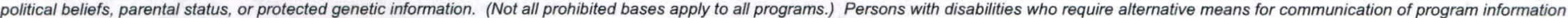
(Braille, large print, audiotape, etc.) should contact USDA's TARGET Center at 202-720-2600 (voice and TDD).

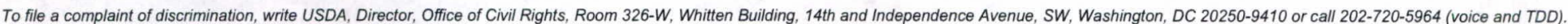
USDA is an equal opportunity provider and employer.

\section{U.S. DEPARTMENT OF AGRICULTURE AGRICULTURAL MARKETING SERVICE SCIENCE AND TECHNOLOGY PLANT VARIETY PROTECTION OFFICE \\ BELTSVILLE, MD 20705}

EXHIBIT F

DECLARATION REGARDING DEPOSIT

\begin{tabular}{|c|c|c|}
\hline \multirow[t]{2}{*}{$\begin{array}{l}\text { NAME OF OWNER (S) } \\
\text { Seminis Vegetable Seeds, Inc. }\end{array}$} & \multirow{2}{*}{$\begin{array}{l}\text { ADDRESS (Street and No. or RD No., City, State, and Zip Code and Country) } \\
2700 \text { Camino del Sol } \\
\text { Oxnard, CA } 93030\end{array}$} & $\begin{array}{l}\text { TEMPORARY OR EXPERIMENTAL DESIGNATION } \\
\text { RF } 71-4911 \mathrm{~A}\end{array}$ \\
\hline & & VARIETY NAME \\
\hline NAME OF OWNER REPRESENTATIVE (S) & ADDRESS (Street and No. or RD No., City, State, and Zip Code and Country) & FOR OFFICIAL USE ONLY \\
\hline Carol L. Miller & $\begin{array}{l}37437 \text { State Highway } 16 \\
\text { Woodland, CA } 95695\end{array}$ & $\begin{array}{l}\text { PVPO NUMBER } \\
\# 20080\end{array}$ \\
\hline
\end{tabular}

I do hereby declare that during the life of the certificate a viable sample of propagating material of the subject variety will be deposited, and replenished as needed periodically, in a public repository in the United States in accordance with the regulations established by the Plant Variety Protection Office.

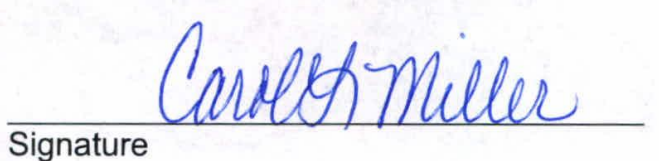

Signature

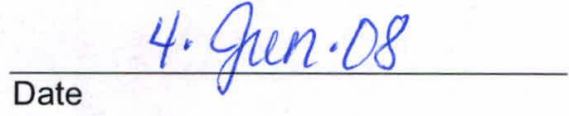




\section{Plant Variety Protection Act}

(a) In general. - The breeder of any sexually reproduced or tuber propagated plant variety (other than fungi or bacteria) who has so reproduced the variety, or the successor in interest of the breeder, shall be entitled to plant variety protection for the variety, subject to the conditions and requirements of this chapter, if the variety is -

(1) new ...

(2) distinct ...

(3) uniform, in the sense that any variations are describable, predictable, and commercially acceptable;

(4) stable, in the sense that the variety, when reproduced, will remain unchanged with regard to the essential and distinctive characteristics of the variety with a reasonable degree of reliability commensurate with that of varieties of the same category in which the same breeding method is employed.

(6) Sexually reproduced. - The term "sexually reproduced" includes any production of a variety by seed, but does not include the production of a variety by tuber propagation.

(7) Tuber propagated. - The term "tuber propagated" means propagated by a tuber or a part of a tuber.

(9) Variety. - The term "variety" means a plant grouping within a single botanical taxon of the lowest known rank, that, without regard to whether the conditions for plant variety protection are fully met, can be defined by the expression of the characteristics resulting from a given genotype or combination of genotypes, distinguished from any other plant grouping by the expression of at least one characteristic and considered as a unit with regard to the suitability of the plant grouping for being propagated unchanged. A variety may be represented by seed, transplants, plants, tubers, tissue culture plantlets, and other matter.

b Procedures

\section{Plant Variety Protection Act}

An application for a certificate recognizing plant variety rights shall contain:
7 U.S.C § 2402

Right to plant variety protection; plant varieties protectable

As enacted in 1970, the PVPA exempted "okra, celery, peppers, tomatoes, carrots, and cucumbers" as a result of lobbying by the Campbell's Soup Company. The exemption was repealed in 1980. Tuber-propagated plants, such as potatoes, were added in 1994.

7 U.S.C § 2401 (a)

Definitions and rules of construction

7 U.S.C § 2422

Content of application 
(1) The name of the variety except that a temporary designation will suffice until the certificate is to be issued. The variety shall be named in accordance with regulations issued by the Secretary.

(2) A description of the variety setting forth its distinctiveness, uniformity, and stability and a description of the genealogy and breeding procedure, when known. The Secretary may require amplification, including the submission of adequate photographs or drawings or plant specimens, if the description is not adequate or as complete as is reasonably possible, and submission of records or proof of ownership or of allegations made in the application. An applicant may add to or correct the description at any time, before the certificate is issued, upon a showing acceptable to the Secretary that the revised description is retroactively accurate. Courts shall protect others from any injustice which would result. The Secretary may accept records of the breeder and of any official seed certifying agency in this country as evidence of stability where applicable.

(3) A statement of the basis of the claim of the applicant that the variety is new.

(4) A declaration that a viable sample of basic seed (including any propagating material) necessary for propagation of the variety will be deposited and replenished periodically in a public repository in accordance with regulations to be established hereunder.

(5) A statement of the basis of applicant's ownership.

7 U.S.C § 2321

Establishment

7 U.S.C § 2329

Register of protected plant varieties

7 U.S.C § 2330(a)(1)

Publications

50 U.S.P.Q.2d 1213 (N.D. Cal. 1998)
There is hereby established in the Department of Agriculture an office to be known as the Plant Variety Protection Office, which shall have the functions set forth in this chapter.

The Secretary [of Agriculture] shall maintain a register of descriptions of United States protected plant varieties.

The Secretary [of Agriculture] may publish, or cause to be published, in such format as the Secretary shall determine to be suitable, the descriptions of plant varieties protected including drawings and photographs.

Genecorp, Inc. v. Progeny Advanced Genetics, Inc.

Genecorp has filed a complaint against Progeny alleging infringement of Plant Variety Protection Certificate No. 8400060 which covers a variety of leaf lettuce known as Genecorp Green. The Genecorp Green Certificate was issued on August 31, 1986 and will expire on 
August 31, 2004.

Genecorp's complaint alleges that Progeny infringed the Genecorp Green Certificate by producing, marketing and selling a variety of leaf lettuce known as Savannah Green. On May 28, 1996 Progeny filed Plant Variety Protection Certificate Application No. 9600262 for Savannah Green.

On February 10, 1997, Genecorp initiated a protest proceeding against Progeny's Savannah Green PVP Application by filing a Petition to Protest. According to plaintiff's counsel, the Plant Variety Protection Office has advised that "it generally takes two years to process an application for a Plant Variety Protection Certificate."

Defendant Progeny argues that Genecorp's infringement suit should be stayed because the doctrine of primary jurisdiction requires that the Savannah Green PVP Application be processed before the suit continues. The doctrine of primary jurisdiction comes into play whenever enforcement of a claim requires the resolution of issues which, under a regulatory scheme, have been placed within the special competence of an administrative body. Primary jurisdiction would require a court to refer such issues to the administrative body and stay further proceedings so as to give the parties a reasonable opportunity to seek an administrative ruling. Two factors are used to determine whether the doctrine of primary jurisdiction applies: (1) the desirable uniformity that results when the administrative agency rules first and (2) the expert and specialized knowledge that the administrative agency could apply to an issue.

Here, primary jurisdiction does not apply on the basis of uniformity because the PVP Office will not resolve important questions regarding Genecorp's infringement claim when it decides whether to issue a PVP Certificate for Savannah Green. To obtain a PVP Certificate, the applicant need only show that the variety is new, distinct, uniform and stable.It does not appear that the PVP Office makes any findings or can provide any remedy with respect to infringement when it examines a PVP Application. Instead, the PVP Act provides that a civil action shall be the remedy for infringement available to the owner of PVP certificate.

At first it appears that if the PVP Office issues a PVP Certificate for Savannah Green and if a proceeding in this court results in a finding of infringement of Genecorp Green, then the two decisions will not produce desired uniformity. This seems to be a problem because the issuance of a PVP Certificate means implicitly that the PVP Office found Savannah Green to be "clearly distinct" from Genecorp Green. However, the issuance of a PVP Certificate for Savannah Green would not mean that Progeny did not commit any acts that constitute infringement of the Genecorp Green Certificate. To prove its infringement claim, Genecorp must show either that Savannah 
Green is a variety to which the infringement provision of the PVP Act applies or that Progeny committed infringement of the Genecorp Green certificate in the process of creating Savannah Green. Therefore, the desire for uniformity does not justify primary jurisdiction in this case because the PVP Office will not make sufficient findings as to infringement, if at all, when it examines the Savannah Green application.

While the PVP Office does have expert and specialized knowledge, the PVP Act itself has not restricted determinations of "clearly distinguishable" exclusively to the PVP Office. Therefore, primary jurisdiction does not warrant a stay on this ground because the PVP Act allows courts to make determinations of what is "clearly distinguishable" and does not appear to mandate that the PVP Office be the primary forum for resolution of the issue.

Finally, defendant Progeny contends that a stay is warranted in this case because stays are routinely granted in patent reexamination cases. The court disagrees because the Savannah Green Application and the protest by Genecorp are significantly different from a patent reexamination proceeding. In particular, the fact that the patent in dispute in a reexamination proceeding has already been issued is significant because the existence of a patent creates certain intellectual property rights in the holder of the patent. In this case, no rights have been conferred on defendant Progeny by way of its Savannah Green Application. Therefore, the court finds that the Savannah Green PVP Application process is significantly different from a patent reexamination and that a stay is not required on this ground.

\section{Plant Variety Protection Act}

PVPA § 83

7 U.S.C § 2483

Contents and term of plant variety protection (b) Term. -

(1) In general. - Except as provided in paragraph (2), the term of plant variety protection shall expire 20 years from the date of issue of the certificate in the United States, except that ... (B) in the case of a tree or vine, the term of the plant variety protection shall expire 25 years from the date of issue of the certificate.

(2) Exceptions. - If the certificate is not issued within three years from the effective filing date, the Secretary may shorten the term by the amount of delay in the prosecution of the application attributed by the Secretary to the applicant.

(c) Expiration upon failure to comply with regulations; notice. - The term of plant variety protection shall also expire if the owner fails to comply with regulations, in force at the time of certifi- 
cating, relating to replenishing seed in a public repository, or requiring the submission of a different name for the variety, except that this expiration shall not occur unless notice is mailed to the last owner recorded as provided in section 2531(d) of this title and the last owner fails, within the time allowed thereafter, not less than three months, to comply with said regulations, paying an additional fee to be prescribed by the Secretary.

c Ownership

\section{Plant Variety Protection Act}

(a) In general. - The breeder of any sexually reproduced or tuber propagated plant variety ... shall be entitled to plant variety protection for the variety ... if the variety is -

(1) new, in the sense that, on the date of filing of the application for plant variety protection, propagating or harvested material of the variety has not been sold or otherwise disposed of to other persons, by or with the consent of the breeder, or the successor in interest of the breeder, for purposes of exploitation of the variety (A) in the United States, more than 1 year prior to the date of filing [or longer periods for activity outside of the United States]

(2) distinct, in the sense that the variety is clearly distinguishable from any other variety the existence of which is publicly known or a matter of common knowledge at the time of the filing of the application;

(3) uniform ...; and

(4) stable...

(b) Multiple applicants. -

(1) In general. - If 2 or more applicants submit applications on the same effective filing date for varieties that cannot be clearly distinguished from one another, but that fulfill all other requirements of subsection (a), the applicant who first complies with all requirements of this chapter shall be entitled to a certificate of plant variety protection, to the exclusion of any other applicant.

(2) Requirements completed on same date. -

(A) In general. - Except as provided in subparagraph (B), if 2 or more applicants comply with all requirements for protection on the same date, a certificate shall be issued for each variety.

(B) Varieties indistinguishable. - If the varieties that are the
7 U.S.C § 2402

Right to plant variety protection; plant varieties protectable

As enacted in 1970, the PVPA used a "date of determination" priority system that substantially resembled the preAIA "first to invent" priority system. The PVPA was amended in 1994 to switch to an AIA-like "date of filing" system to enable the U.S. to ratify the International Union for the Protection of New Varieties of Plants. 
7 U.S.C § 2401

Definitions and rules of construction subject of the applications cannot be distinguished in any manner, a single certificate shall be issued jointly to the applicants. (a) Definitions. - As used in this chapter:

(2) Breeder. - The term "breeder" means the person who directs the final breeding creating a variety or who discovers and develops a variety. If the actions are conducted by an agent on behalf of a principal, the principal, rather than the agent, shall be considered the breeder. The term does not include a person who redevelops or rediscovers a variety the existence of which is publicly known or a matter of common knowledge.

(b) Rules of construction. - For the purposes of this chapter:

(1) Sale or disposition for nonreproductive purposes. - The sale or disposition, for other than reproductive purposes, of harvested material produced as a result of experimentation or testing of a variety to ascertain the characteristics of the variety, or as a by-product of increasing a variety, shall not be considered to be a sale or disposition for purposes of exploitation of the variety.

(2) Sale or disposition for reproductive purposes. - The sale or disposition of a variety for reproductive purposes shall not be considered to be a sale or disposition for the purposes of exploitation of the variety if the sale or disposition is done as an integral part of a program of experimentation or testing to ascertain the characteristics of the variety, or to increase the variety on behalf of the breeder or the successor in interest of the breeder.

(3) Sale or disposition of hybrid seed. - The sale or disposition of hybrid seed shall be considered to be a sale or disposition of harvested material of the varieties from which the seed was produced.

(4) Application for protection or entering into a register of varieties. - The filing of an application for the protection or for the entering of a variety in an official register of varieties, in any country, shall be considered to render the variety a matter of common knowledge from the date of the application, if the application leads to the granting of protection or to the entering of the variety in the official register of varieties, as the case may be.

(5) Distinctness. - The distinctness of one variety from another may be based on one or more identifiable morphological, 
physiological, or other characteristics (including any characteristics evidenced by processing or product characteristics, such as milling and baking characteristics in the case of wheat) with respect to which a difference in genealogy may contribute evidence.

(6) Publicly known varieties. -

(A) In general. - A variety that is adequately described by a publication reasonably considered to be a part of the public technical knowledge in the United States shall be considered to be publicly known and a matter of common knowledge.

(B) Description. - A description that meets the requirements of subparagraph (A) shall include a disclosure of the principal characteristics by which a variety is distinguished.

(C) Other means. - A variety may become publicly known and a matter of common knowledge by other means.

\section{d Defenses}

Somewhat unusually, we need to talk about defenses before discussing what constitutes infringement under the PVPA. The reason is that one particular defense, the "brown-bagging" provision, has cast such a long shadow over the (relatively scant) PVPA caselaw that it drives many of the interpretive controversies. For now, take it for granted that obviously large-scale commercialization - like sales on the open market between strangers of PVPA-protected seeds to farmers who then plant the seeds and sell them on the open market to strangers, and so on - infringe. We will return to the details in the next subsection.

\section{Plant Variety Protection Act}

The Secretary may declare a protected variety open to use on a basis of equitable remuneration to the owner, not less than a reasonable royalty, when the Secretary determines that such declaration is necessary in order to insure an adequate supply of fiber, food, or feed in this country and that the owner is unwilling or unable to supply the public needs for the variety at a price which may reasonably be deemed fair. Such declaration shall remain in effect not more than two years. In the event litigation is required to collect such remuneration, a higher rate may be allowed by the court.

Nothing in this chapter shall abridge the right of any person, or the successor in interest of the person, to reproduce or sell a variety de-
PVPA § 44

7 U.S.C § 2404

Public interest in wide usage

PVPA § 112

7 U.S.C § 2542

Grandfather clause 
PVPA § 113

7 U.S.C § 2543

Right to save seed; crop exemption

PVPA § 114

7 U.S.C. § 2544

Research exemption

PVPA § 115

7 U.S.C $\$ 2545$

Intermediary exemption

81 Notre Dame L. Rev. 105 (2005) veloped and produced by such person more than one year prior to the effective filing date of an adverse application for a certificate of plant variety protection.

Except to the extent that such action may constitute an infringement under subsections (3) and (4) of section 2541[1] of this title, it shall not infringe any right hereunder for a person to save seed produced by the person from seed obtained, or descended from seed obtained, by authority of the owner of the variety for seeding purposes and use such saved seed in the production of a crop for use on the farm of the person, or for sale as provided in this section. A bona fide sale for other than reproductive purposes, made in channels usual for such other purposes, of seed produced on a farm either from seed obtained by authority of the owner for seeding purposes or from seed produced by descent on such farm from seed obtained by authority of the owner for seeding purposes shall not constitute an infringement. A purchaser who diverts seed from such channels to seeding purposes shall be deemed to have notice under section 2567 of this title that the actions of the purchaser constitute an infringement.

The use and reproduction of a protected variety for plant breeding or other bona fide research shall not constitute an infringement of the protection provided under this chapter.

Transportation or delivery by a carrier in the ordinary course of its business as a carrier, or advertising by a person in the advertising business in the ordinary course of that business, shall not constitute an infringement of the protection provided under this chapter.

\section{Jim Chen \\ The Parable of the Seeds}

\section{A. The PVPA in Overview}

The PVPA contains an intriguing limitation designed to preserve the "public interest in wide usage" in an otherwise protected variety." The Secretary of Agriculture may "declare a protected variety open to use on a basis of equitable remuneration to the owner," but only if the Secretary determines that compulsory licensing of a protected variety "is necessary in order to insure an adequate supply of fiber, food, or feed in this country and that the owner is unwilling or unable to supply the public needs for the variety at a price which may reasonably be deemed fair." Compulsory licensing under this provision "shall remain in effect not more than two years."

To my knowledge, however, the PVPA's "public interest" provision has never been invoked. Evidently, at no time since 1970 has 
the United States approached so precarious a state of food security that the Secretary of Agriculture has felt compelled to compromise proprietary interests conferred under the PVPA.

The PVPA contains two further limitations of arguably greater interest to breeders and policy-makers. The PVPA's extravagantly complicated and controversial "crop exemption" in principle permits a farmer "to save seed" from protected varieties and to "use such saved seed in the production of a crop." The other exemption, known as the PVPA's "research exemption," declares simply that "the use and reproduction of a protected variety for plant breeding or other bona fide research shall not constitute infringement."

These exemptions represent the most significant distinctions between the PVPA and the Patent Act. But for its crop and research exemptions, the PVPA might be the legal tool of choice for commercial plant breeders seeking to protect their investment in new plant varieties. Whereas patents are relatively expensive to obtain and set a higher threshold for protection," plant variety protection is easier and cheaper to obtain. In contrast with the PVPA's relatively modest request for "a description of the variety setting forth its distinctiveness, uniformity and stability and a description of the genealogy and breeding procedure, when known," the Patent Act demands far more extensive obligations of description and disclosure. Nothing in the PVPA imposes the equivalent of the Patent Act's requirements of nonobviousness and enablement. In particular, the absence of a nonobviousness requirement is a significant difference if one accepts that the nonobviousness criterion performs the principal work of discriminating between patent-worthy and patent-unworthy inventions. In short, whereas the Patent Act offers robust protection in exchange for a comprehensive disclosure of the technology underlying a new plant variety, the PVPA grants much weaker protection upon delivery of a lower-quality disclosure.

Given the historic difficulty that plant breeders have encountered in attempting to satisfy the Patent Act's description requirement, the PVPA provides an alternative, more accessible legal system in which the plant genome essentially speaks for itself. The PVPA's exemptions, however, have effectively diverted many plant breeders toward the Patent Act. In exchange for fulfilling the Patent Act's more rigorous process, plant breeders can evade the PVPA's research and crop exemptions. Quite significantly, the right to save seed of plants registered under the PVPA does not impart the right to save seed of plants patented under the Patent Act. Patent-holders are also immune, unlike their counterparts whose varieties are protected only under the PVPA, from the use of a certified plant variety to develop a new inbred line. The PVPA defines the "use" of a protected "variety in producing a hybrid or different variety" as infringement, but excludes 
from that definition the use of a protected variety in "developing" such a variety.

\section{B. The Crop Exemption}

Section 113 has always allowed farmers who plant seed protected by a PVPA certificate to engage in a "bona fide sale for other than reproductive purposes, made in channels usual for such other purposes." This uncontroversial aspect of the crop exemption protects farmer-tomarket sales of a crop grown from protected seeds as food or feed or for other nonreproductive purposes. Indeed, if the PVPA lacked this exemption, the statute would bar farmers from selling any protected crop whose seed is sold for food or fiber. Throughout the history of the PVPA, section 113 has also permitted farmers "to save seed produced by [them] from seed obtained, or descended from seed obtained, by authority of the owner of the variety for seeding purposes and to use such saved seed in the production of a crop" for on-farm use. This facet of the crop exemption protects the traditional agricultural practice known as "bin run," or the use of seed from one crop to produce subsequent crops. At least with respect to self-pol- linated crops such as wheat, soybeans, and cotton, all of which reproduce true-to-type, legal protection of bin run effectively restricts a breeder to a single sale of each variety to each individual grower of a particular crop. (Cross-pollinated hybrid crops such as corn, sorghum, and sunflowers are a different matter; because they lose hybrid vigor after a single planting, farmers must buy new seed each planting season.) The bin run exemption is a robust version of copyright law's "first sale" doctrine: the plant breeder gets exactly one chance to sell the information "encoded" in PVPA-certified seed to any individual farmer.

As enacted in 1970, however, section 113 also allowed "a person, whose primary farming occupation is the growing of crops for sale for other than reproductive purposes, to sell such saved seed to other persons so engaged, for reproductive purposes." This version of the statute prevailed for nearly a quarter century. Its effect was plain: the old crop exemption enabled farmers to go directly into the business of selling PVPA-protected seeds alongside the plant breeders. In one of the earliest cases interpreting section 113, a federal court of appeals recognized the incompatibility between brown-bag sales under the crop exemption and the PVPA's overarching purpose of spurring the development of new plant varieties:

In purpose and operation, the farmer exemption appears to be at odds with the primary purpose of the Act. While the main body of the Act assures developers of novel varieties the exclusive right to sell and reproduce that variety, 
the crop exemption dilutes that exclusivity by allowing individual farmers to sell the protected variety without liability. The broader the construction given the exemp- tion, the smaller the incentive for breeders to invest the substantial time and effort necessary to develop new strains. The less time and effort that is invested, the smaller the chance of discovering superior agricultural products. If less time and effort is invested, long-term benefits to the farmer in the form of superior crops and higher yields will be lost.

The legal firestorm over brown-bagging would not go wholly unchecked. The judicial and legislative branches of the United States government eventually intervened. In the 1995 decision of Asgrow, the Supreme Court limited brown-bag sales to "only such seed as [a farmer] has saved for the purpose of replanting his own acreage." While the Asgrow case awaited the Supreme Court's decision on the merits, Congress in 1994 repealed the brown-bagging provisions of the PVPA's crop exemption. In conformity with the Supreme Court's presumptive refusal to grant retroactive effect to statutes, Asgrow governed only cases filed under the PVPA as that statute read before its 1994 amendments; all post-1994 sales of seed protected under the PVPA have conveyed no brown-bagging privileges on farmers.

By eliminating farmers as a significant source of competition for commercially developed seed, the legislative rejection of brownbagging restored much of the PVPA's value to commercial plant breeders. The 1994 amendment also represented a significant setback for the recognition of farmers' rights in American law.

\section{The Research Exemption}

The PVPA generally withholds liability from "any act done privately and for noncommercial purposes." The statute's more focused research exemption provides that "[t]he use and reproduction of a protected variety for plant breeding or other bona fide research shall not constitute infringement." The presence of a research exemption separate from the noncommercial acts exemption may suggest that a competing plant breeder can lawfully appropriate a protected variety without authority and use it in a breeding program to develop new commercial varieties, at least as long as such new varieties are different enough not to be "essentially derived" from the original protected variety. The interpretation of the research exemption is vital to the proper functioning of the PVPA, because its coverage, if misconstrued, could overlap entirely with the statute's def- inition of infringement. Congress expected that PVPA infringement would "almost never" arise through "independent work, but by willful reproduction starting from the protected variety itself." 
Does chasing selfs violate the trade secret rights of the first breeder? Does the answer depend on how the competing breeder obtained the hybrid seeds? See Pioneer Hi-Bred Intern. $v$. Holden Foundation Seeds, Inc., 35 F. 3d 1226 (8th Cir. 1994).
PVPA infringement almost invariably begins with a supply of protected seed. Coupled with sufficient knowledge of agronomy and a penchant for experimentation, access to PVPA-protected reproductive matter may enable other parties to propagate specimens of a protected plant for purposes other than feed, fiber, or food. This is true even of hybrids, which over the course of the twentieth century became the predominant form of cultivar in many crops. Traditionally associated with allogamous, or cross-pollinating, crops such as maize, sunflower, brassicas, curcurbits, carrots, beets, and onions, the use of hybrid cultivars has become common even in certain autogamous (i.e., self-pollinating) crops, including sorghum, tomato, and peppers and in the production of allogamous crops in nonindustrialized countries. Hybrid corn, perhaps the most commercially valuable crop produced by this technique, begins with the development of two inbred lines by self-pollination and selection until each line is relatively homozygous. The use of pollen from the male inbred line to fertilize silks on the female inbred line then yields hybrid seed.

Despite all precautions, each bag of hybrid seeds contains a small amount of inbred seeds. These "chasing selfs," if planted, reproduce the parent lines true-to-type. With sufficient patience and land, a competing plant breeder, a farmer, or an academic researcher can use chasing selfs to unlock the inbred parent lines of a hybrid variety of corn, sorghum, or sunflower. Planting all the seeds from a bag of hybrid seed in a configuration that puts adequate space between plants facilitates ready identification of any inadvertently included inbred plants. Lacking heterosis, or hybrid vigor, inbred plants look different from the taller hybrids. In the past decade, major commercial seed breeders have resolved several lawsuits alleging breach of intellectual property rights through use of the "chasing selfs" technique.

The crucial issue presented by the research exemption is the definition of "plant breeding or other bona fide research." This verbal formulation defines the extent of research activities shielded from PVPA liability. The plain language of the research exemption shields only genuine, bona fide research activities. Surreptitious acts, such as efforts to isolate chasing sefs in a bag of hybrid seed, cannot constitute "plant breeding or other bona fide research." Whatever else it might be, it is hard to imagine how surreptitious exploitation of another party's proprietary seed for the purpose of duplicating that variety could be viewed as a "good faith" activity. There is nothing "bona fide" about converting another company's proprietary plant variety. Competitors do not enjoy some sort of open-ended "breeder's exemption" entitling them to unauthorized exploitation of proprietary seed. 
e Infringement

\section{Plant Variety Protection Act}

(a) Acts constituting infringement. - Except as otherwise provided in this subchapter, it shall be an infringement of the rights of the owner of a protected variety to perform without authority, any of the following acts in the United States, or in commerce which can be regulated by Congress or affecting such commerce, prior to expiration of the right to plant variety protection but after either the issue of the certificate or the distribution of a protected plant variety with the notice under section 2567 of this title:

(1) sell or market the protected variety, or offer it or expose it for sale, deliver it, ship it, consign it, exchange it, or solicit an offer to buy it, or any other transfer of title or possession of it;

(2) import the variety into, or export it from, the United States;

(3) sexually multiply, or propagate by a tuber or a part of a tuber, the variety as a step in marketing (for growing purposes) the variety;

(4) use the variety in producing (as distinguished from developing) a hybrid or different variety therefrom;

(5) use seed which had been marked "Unauthorized Propagation Prohibited" or "Unauthorized Seed Multiplication Prohibited" or progeny thereof to propagate the variety;

(6) dispense the variety to another, in a form which can be propagated, without notice as to being a protected variety under which it was received;

(7) condition the variety for the purpose of propagation, except to the extent that the conditioning is related to the activities permitted under section 2543 of this title;

(8) stock the variety for any of the purposes referred to in paragraphs (1) through (7);

(9) perform any of the foregoing acts even in instances in which the variety is multiplied other than sexually, except in pursuance of a valid United States plant patent; or

(10) instigate or actively induce performance of any of the foregoing acts.

(c) Applicability to certain plant varieties. - This section shall apply equally to -

(1) any variety that is essentially derived from a protected variety, unless the protected variety is an essentially derived
7 U.S.C § 2541

Infringement of plant variety protection

"Owners may give notice to the public by physically associating with or affixing to the container of seed of a variety or by fixing to the variety, a label containing either the words 'Unauthorized Propagation Prohibited' or the words 'Unauthorized Seed Multiplication Prohibited' and after the certificate issues, such additional words as 'U.S. Protected Variety"' 7 U.S.C. § 2567 
PVPA § 41 (a)

7 U.S.C § 2401 (a)

Definitions and rules of construction variety;

(2) any variety that is not clearly distinguishable from a protected variety;

(3) any variety whose production requires the repeated use of a protected variety; and

(4) harvested material (including entire plants and parts of plants) obtained through the unauthorized use of propagating material of a protected variety, unless the owner of the variety has had a reasonable opportunity to exercise the rights provided under this chapter with respect to the propagating material.

(d) Acts not considered infringing. - It shall not be an infringement of the rights of the owner of a variety to perform any act concerning propagating material of any kind, or harvested material, including entire plants and parts of plants, of a protected variety that is sold or otherwise marketed with the consent of the owner in the United States, unless the act involves further propagation of the variety or involves an export of material of the variety, that enables the propagation of the variety, into a country that does not protect varieties of the plant genus or species to which the variety belongs, unless the exported material is for final consumption purposes.

(e) Private noncommercial uses. - It shall not be an infringement of the rights of the owner of a variety to perform any act done privately and for noncommercial purposes.

(3) Essentially derived variety. -

(A) In general. - The term "essentially derived variety" means a variety that-

(i) is predominantly derived from another variety (referred to in this paragraph as the "initial variety") or from a variety that is predominantly derived from the initial variety, while retaining the expression of the essential characteristics that result from the genotype or combination of genotypes of the initial variety;

(ii) is clearly distinguishable from the initial variety; and

(iii) except for differences that result from the act of derivation, conforms to the initial variety in the expression of the essential characteristics that result from the genotype or combination of genotypes of the initial variety.

(B) Methods. - An essentially derived variety may be obtained by the selection of a natural or induced mutant or of a so- 
maclonal variant, the selection of a variant individual from plants of the initial variety, backcrossing, transformation by genetic engineering, or other method.

\section{Delta and Pine Land Co. v. Sinkers Corp.}

Delta Pine and Land is a developer and breeder of cotton planting seed. It holds numerous PVP Certificates protecting its novel seed varieties. DPL sells these protected cottonseed varieties through approved distributors. The authorized distributors sell seed to growers who plant the seed, harvest the cotton, and then dispose of all excess protected cottonseed.

Sinkers's principal business activity consists of delinting and conditioning cottonseed for use as planting seed. Cotton growers bring undelinted cottonseed to Sinkers, Sinkers delints the cottonseed per their request, and then turns the cottonseed over to whomever the grower specifies. The delinting process is an essential step in preparing cottonseed for planting. Virtually all cotton farmers in the United States utilize delinted cottonseed in planting their crops.

The PVPA gives the holder of a PVP Certificate rather broad exclusive rights. However, at the time this case was brought in the district court, there was one express, broad exemption to these exclusive rights. ${ }^{3}$ The PVPA allowed a farmer to save seed and to use such "saved seed" to produce crops on his own farm, and furthermore allowed certain "farmer-to-farmer" sales of excess saved seed. This exemption was contained in 7 U.S.C. $\$ 2543$, which provided as follows:

Except to the extent that such action may constitute an infringement under [\$§ 2541(3) and (4)], it shall not infringe any right hereunder for a person to save seed produced by him from seed obtained . . . by authority of the owner of the variety for seeding purposes and use such saved seed in the production of a crop for use on his farm, or for sale as provided in this section: Provided, that without regard to $[\S 2541(3)]$ it shall not infringe any right hereunder for a person, whose primary farming occupation is the growing of crops for sale for other than reproductive purposes, to sell such saved seed to other persons so engaged, for reproductive purposes.

The Supreme Court later interpreted this exemption to mean that, for a farmer to meet the requirements of the above proviso, the farmer

\footnotetext{
${ }^{3}$ his exemption is no longer part of the PVPA. The pertinent language was deleted from the statute in 1994 greatly narrowing this sole express exemption. The amendments deleting certain language, however, apply only to PVP Certificates issued after April 4, 1995, that were not pending on or before that date.
}

177 F.3d 1343 (1999)

The court described the delinting process as follows: "To process cottonseed, such as a farmer might purchase from Delta, the seed is first taken to a gin where most of the fiber or lint is separated from the seed. The seed can then be taken to a delinter, such as Sinkers. The delinting process removes the remaining lint. Undelinted, but ginned, cottonseed arrives at Sinkers's Kennett facility in a truck. In some cases, individual farmers bring cottonseed to the facility in pickup trucks. In other cases, however, large quantities of cottonseed, from many different distributors, farmers and farming cooperatives, arrive in tractor-trailer rigs. Upon its arrival at Sinkers's facility, undelinted cottonseed is placed in a "run bin". The seed is then fed into an auger, where it is wetted with a sulfuric acid solution. From there, the seed passes through a centrifuge where the solution is spun off. The seed emerges in a damp-dry condition and is passed through two dryers and two buffers. In the drying and buffing process, all remaining lint is separated from the seed. After culls, sticks and debris are removed from the bulk seed, the seed is treated with chemicals (if the client so requests-this is the "conditioning" stage of the process, the seed having by now been delinted), and then placed in fifty-pound bags After the seed has been bagged, it is loaded onto trucks and transported to its next destination, which may or may not be the place from which the seed was sent, depending on the instructions given to the delinter." 
People's Gin Co: 694 F.2d 1012 (5th Cir. 1983) may sell for reproductive purposes only so much seed as he has saved for the purpose of replanting his own acreage. Asgrow Seed Co. v. Winterboer Presumably, such sales occur only when the farmer reduces or eliminates his cotton acreage, and, thus, has "saved seed" for which he or she has no farming use. Otherwise, there has been little case law interpreting the PVPA. But the language of the statute is clear: the only express exemption to a PVP Certificate holder's rights is that included in section 2543 for farmer-to-farmer transfers of protected seed. In the instant case, however, the district court implied an additional exemption to the rights of a PVP Certificate holder. We must decide if the court was correct in its discernment and its definition of this exemption.

I. Transfer of Possession Without Authority: 7 U.S.C. § 2541(1)

Delta alleges that Sinkers infringed their rights under 7 U.S.C. § 2541(1) "merely by virtue of its transfer of possession of seed without the benefit of an exemption from PVPA liability." Sinkers's defense rested on an extension of the express exemption for the farmerto-farmer sales that it viewed as implied in the PVPA, as previously interpreted. Sinkers argued that it was a mere passive third-party to the lawful transfers of possession incident to sales arranged between farmers under the express exemption and therefore could not itself be liable. Until Asgrow, the leading case on the farmer-to-farmer exemption was Delta and Pine Land Co. v. Peoples Gin Co.. It remains the only other significant precedent on implied exemptions under the PVPA.

In People's Gin Co, the sole issue was whether the involvement of a third party broker rendered otherwise exempt sales between farmers ineligible for the exemption. The Fifth Circuit held that 7 U.S.C. $\S 2543$ "only exempts sales of the protected variety from one farmer directly to another farmer accomplished without the active intervention of a third party." That case concerned the infringement liability of a farmer's co-operative which was brokering exchanges of seed between its members. The fact that the farmer's cooperative, Peoples Gin Company, also ran a gin was not an issue in that case, as the whole focus was on the cooperative's brokering activities. In the instant case, however, the district court made a fact-finding that Sinkers did not broker or actively intervene to arrange the sales that led to the transfers of possession challenged by Delta. We must agree with that fact-finding because on this record it cannot be seen as clearly erroneous. Indeed, it is essentially undisputed. Therefore, we see this case as entirely distinguishable on its facts from People's Gin Co. The issue raised in this case, then, is one of first impression. It is whether a passive third-party to a sales transaction, such as a ginner or a delinter, can be held liable for infringement under 7 U.S.C. § 2541(1), as a participant in unauthorized possession transfers, if they fall outside 
the farmer-to-farmer exemption.

The district court, in resolving this issue, relied on People's Gin Co and in particular the language "active intervention" used by the Fifth Circuit to distinguish between exempt and non-exempt farmerto-farmer sales. People's Gin Co focused solely on sales - selling the protected seed, offering it for sale or soliciting an offer to buy it, and did not reach the transfer of possession clause at issue in the instant case. The district court acknowledged this distinction, but still decided that as this was a subsection (1) case, if the Fifth Circuit had drawn a distinction with regards to selling and buying seed, then that distinction could be drawn with regards to the transfer of possession clause. Accordingly, the district court applied an active/passive (or broker/non-broker) distinction to the subsection (1) transfer of possession claim in the instant case, even though Sinkers was obviously not a broker, holding that:

the passive conduct of [Sinkers] on the facts here [does] not ... constitute a delivery, shipment or transfer of possession of seed by [Sinkers] within the meaning of $\S 2541(1)$, regardless of whether the seed involved is protected or the underlying sale or transfer involving [Sinkers's] customer is within the $\S 2543$ exemption.

Today we hold that the district court's interpretation of 7 U.S.C. $\S$ 2541(1) is erroneous. Because the plain language of subsection (1) itself does not require the transfer act to be an "active" one, i.e., by a broker, the subsection necessarily appears to comprehend a situation where infringement by transfer of possession could occur without the delinter or a third party brokering a sale, or deciding to whom to transfer possession, but rather was nonetheless transferring possession without authorization from the PVP Certificate holder. Applying the exemption more broadly to grant blanket immunity to a delinter conflicts with the provision providing for liability for any transfer of possession of protected seed.

There is, to be sure, a statement in People's Gin Co that:

A sale is exempt if the seller instructs his cooperative to forward his seed to a particular named buyer. In that situation, the cooperative has not arranged the sale. Nor has it played an active role in the transaction. It has merely served as the vehicle for the transfer of possession.

We agree with the district court that such a factual scenario was not present and hence not at issue in People's Gin Co and consequently this statement is dictum.

More importantly, we do not believe the adaptation of Peoples to this case by the district court was consistent with the structure and 
purpose of the prohibition on unauthorized and non-exempt transfers of possession in subsection (1). The district court is, in effect, adding limiting language ("actively") to subsection (1) that was left out by Congress in subsection (1) and used by Congress only in subsection (8). The district court found that Sinkers did not induce anyone to take possession of or sell the seed. The district court also found that Sinkers did not transfer title to the seed. However, Sinkers undeniably transferred possession[5] of the seed, when it delivered the seed to whomever its customer requested delivery be made. Sinkers was given control over the undelinted seed by the farmer or cooperative that delivered the seed to Sinkers, and then Sinkers transferred control of the delinted seed to the farmer or cooperative identified as the recipient by Sinkers's customer. For these reasons, we hold there is no requirement associated with subsection (1) of active intervention or brokering, as there is with subsection (8).

On the other hand, the broadest possible reading of subsection (1) does not make much sense to us, either. We cannot imagine that Congress would have meant to make a completely innocent thirdparty liable for infringement because it transferred possession of seed to a farmer at the request of another farmer, its customer. An example of when Congress could not have meant to impose liability might be where a single farmer, Joan, brings in one truckload of seed to be delinted, and Farmer Bob picks the seed up in a transfer of possession that is illegal, because, unbeknownst to the delinter, Joan does not actually farm cotton. Thus, while the transaction appears to fall within the exemption for farmer-to-farmer transfer, actually it does not. The delinter, we think, should be liable for all illegal transfers of possession, when not brokered by them, only if it has scienter. That is, when transferring possession of protected seed under instructions from its customer, the delinter is liable only if it knows the transfer is not within the exemption for farmer-to-farmer transfers. Absent scienter, however, involvement in farmer-to-farmer transfers outside the express exemption, should not subject delinters and ginners to liability for infringement.

The dissent disagrees with this test, arguing, in effect, that delinters and ginners should not be liable for infringement, even with scienter, as long as they did not broker the transfer of possession of the seed. We do not believe that Congress meant for delinters and ginners to be exempt from infringement of the PVPA, even when they are following the instructions of their customers, if they know they are participating in an illegal activity. An example of a scenario highlighting this difference between the dissent's view and our own might be one in which Farmer Joan brings in her seed to be delinted, and signs a contract for two points of delivery. Farmer Joan has had a bumper harvest of protected cottonseed this year, in our example, 
and Farmer Bob has had a terrible year. Farmer Joan agrees to sell her excess protected seed to Farmer Bob, so that he doesn't have to pay the higher prices charged by the PVP Certificate holder for the protected seed. Farmer Joan tells the delinter that she would like half of her seed delinted and returned to her so that she can replant the same acreage that she had the year before (e.g., the "saved seed" allowed under Asgrow). Farmer Joan then tells the delinter that she would like the other half of her protected seed delinted and delivered to Farmer Bob to use for reproductive purposes on his farm. The delinter at this point clearly has scienter, and knows that Farmer Joan, at least, is participating in an unlawful activity. We cannot believe that Congress did not mean for the delinter to be found liable for infringing the PVPA in this scenario, but that is the result the dissent's test would cause. According to their "brokerage test", the delinter has done nothing wrong here. We feel that if Congress meant the delinters and ginners to be able to follow unquestioningly their customer's orders and still avoid liability, surely they would have written an express per se exemption into the PVPA, just as they did for common carriers.

We therefore hold that the correct reading of subsection (1) requires that a delinter, ginner, or other third-party transferor facilitating a farmer-to-farmer sale know (knowledge is presumed in a scenario where the third party brokers the transaction) or should reasonably know that its unauthorized transfer of possession is an infringing transaction, i.e., that the sale is not exempt under section 2543. Liability for infringement under subsection (1) thus turns on knowledge. If Sinkers knew, or should have known, that the transfer of possession was not within the farmer-to-farmer exemption, then it can be held liable for infringing subsection (1), but only then.

We note that the district court also erred in stating that "the passive conduct of Sinkers on the facts here does not constitute infringement regardless of whether the seed involved is within the $\$ 2543$ exemption." Under Asgrow a farmer is allowed to save seed to replant his or her own acreage the next year. In order to plant the seed it must be delinted. Therefore, Asgrow must also carve an exemption out for the transfer of possession of protected seed to a delinter if it is only the seed the farmer is saving for his or her own acreage. Whether the seed involved is within the section 2543 exemption thus becomes a crucial and important question.

We note that the scenario where the seed is returned to the farmer or cooperative from which the seed was received potentially complicates application of the "should have known" standard, as a farmer is entitled to save seed for reproductive use on his own farm, and may in fact save seed for several years of future plantings. However, there are still "red flags" which a delinter such as Sinkers can spot. If
The common carrier exception is in PVPA § 115, 7 U.S.C. §2545, excerpted above. 
a farmer returns year after year with more seed than he or she could possibly use, based either on Sinkers's knowledge of the actual size of the farmer's acreage or, imply an absurdly large amount of seed, then clearly this seed is not being saved for reproductive purposes just for the farmer's own acreage, and Sinkers would have scienter.

We note that the dissent expresses concern over the "paper trail" that it speculates this test will create. First of all, the certificate holder is required to prove that the ginners and/or delinters knew or should have known they were processing "hot seed." Thus, there is no burden on the ginner or delinter to disprove anything. Accordingly, in many situations no record keeping would be needed.

Presumably the ginners and delinters process seed full-time. This would suggest that they work with the same farmers from year to year, and have some idea of how much seed is a reasonable amount of saved seed for a particular farmer, or farming cooperative lawfully to bring in for processing. It should be obvious, for example, that enough seed to replant forty square miles of cotton fields is not a reasonable amount for a cooperative to bring in as saved seed for processing. In such a case, but only then, the ginner or delinter may indeed want to ask for written reassurance that it will not be breaking the law by processing this huge quantity of seed, because processing inevitably requires transferring possession of the seed, once delinted or ginned, to someone. However, this written assurance does not impart immunity. If the certificate holder can prove actual knowledge, or show that the delinter or ginner should have known it was handling hot seed, the delinter or ginner is still liable for infringement of the PVPA. We note, furthermore, that while, of course, on this record we could not describe the contents of a standard contract between a farmer or cooperative and a delinter or ginner, it is reasonable to assume that it would address: the price per pound for the processing; the delivery terms; and the condition the farmer can expect the seed to be in when it is returned or re-delivered by the ginner and/or delinter. This contract may also specify the chemical conditioning treatments the farmer or cooperative wants the seed exposed to ("So ... they tell you ... whether they want [the seed] double treated or triple treated"); the amount of cleaning the seed should be given ("we have ... some farmers that like to have the seed ... cleaned a little heavy [,t]ake a little more waste out to give you a better seed"); it may give the farmer a warranty that his seed will not be mixed with colored cottonseed, that his seed will not be mixed with non-USDA approved seed, and that he will receive the same variety of seed back that he dropped off to be processed. We do not believe, with this many other specifications which may be present in a contract for cottonseed processing, that it is placing a significant burden on the delinters or ginners to place one more paragraph in the contract, thus pro- 
viding some limited protection against liability. Accordingly, our test hardly "creates" a complex record-keeping regime. One apparently already exists.

\section{Active Inducement by Brokerage: 7 U.S.C. § 2541(8)}

Delta next alleged that by willfully ignoring the large quantities of apparently protected seed that Sinkers was processing without its authority, Sinkers actively induced unlawful transfers of possession by others, and thus infringed Delta's rights under 7 U.S.C. § 2541(8). The district court found, as stated above, that Sinkers did not intervene as a third-party in the transfers of possession of the protected seed. We agree, for it was not clear error for the district court to find that Sinkers did not broker protected seed transfers and did not actively induce anyone to transfer possession of the seed to other parties in any way violative of the statute. Sinkers merely turned delinted seed over to whomever its customers, such as Nodena, identified. In subsection (8) of section 2541, the critical words "instigate or actively induce", clearly evince congressional intent to limit liability under this subsection to those such as brokers, who perform such functions when they arrange transfers of seed, in the instant case via the delinter, between independent sellers and buyers. The district court correctly found, however, that Sinkers did not perform either of these functions. Certainly, its findings are not clearly erroneous. Indeed, the facts seem undisputed. Delta argues here only that Sinkers recklessly or with willful indifference transferred possession of large quantities of protected seed in violation of the PVPA. This might be true, but we make no decision on that issue here, because, even if the allegation is true, it is insufficient to trigger 7 U.S.C. § 2541(8). Sinkers did not broker the sale or transfer of possession of any protected seed, or otherwise instigate or actively induce others to infringe.

\section{The Notice Requirement: 7 U.S.C. § 2541(6)}

Finally, we address the issue of the notice required under subsection (6) of 7 U.S.C. § 2541. The district court only summarily addressed this issue, holding that "the Court would read the "under which it was received' clause of $\S 2541$ (6) to limit the notice requirement to instances in which the seed was received with a label stating that it was a protected variety." We vacate the judgment based on this holding by the district court. The proper test is not whether a physical label is somehow attached to the seed when the seed is received, but rather whether through that or other means the one in receipt, here Sinkers, knew, or should have known that the seed is a protected variety. Subsection (6) provides that it is infringement to "dispense the novel variety to another ... without notice as to being a protected variety under which it was received." The notice that must be received is 
not restricted to actual notice, or to notice in the form of labels on the seed, as the district court concluded, or else Congress would surely have included language indicating such restrictions.

By comparison, a patentee seeking to give notice to the public that an item is patented is required by Congress to mark it according to a specific list of acceptable methods as detailed in 35 U.S.C. $\S 287$. The language here is much broader, and merely reads that dispensing of the novel variety without notice that it is a novel variety infringes the rights of the holder of the PVP Certificate covering the novel variety. Because Congress gave specific notice requirements in 35 U.S.C. § 287, and omitted these requirements in subsection (6), we read the latter statute not to require express notice, or labels on receipt, in order for a failure to give notice to infringe.

In the Nodena example, the district court found that references in Sinkers's own germination logs to this seed as "Lot 5" seed reflected Nodena's own designation of the seed in that manner to indicate that the seed was DPL-50 seed. Under the test applied by the district court, because this seed arrived with no physical tag on it to indicate that it was protected DPL-50 seed, Sinkers had no responsibility to notify its transferee that the transferred seed was protected seed. However, Sinkers was informed by Nodena that it was Lot 5 seed, according to the notations in its own logs. If on remand the district court finds that Sinkers had notice, i.e., that it knew the term "Lot 5" was Nodena's way of designating protected DPL-50 seed, then Sinkers infringed Delta's PVPA rights when it did not label the bags containing Nodena's delinted seed as protected seed. We further understand that in order to protect the vigor and germination ability of the cottonseed, the delinter and ginner need to know the type of seed they are processing so that they know how to process it, e.g., the proper storage method, the amount of moisture to expose it to, and the temperature least likely to cause it to germinate early. Early maturation seed that has undergone no chemical treatments by the manufacturer, is processed differently from late maturation seed that may have been genetically altered to not be affected by herbicides. It is, therefore, likely that they are accurately informed by the cooperative and farmers of the varieties of seed being delivered for processing and that they may want to take affirmative steps, e.g., germination tests, to assure themselves of the exact varieties accepted for processing, lest they become liable for harming the seed. Once a ginner or delinter has determined the variety of cottonseed undergoing processing, it has an affirmative duty to label the cottonseed with the variety upon returning or re-delivering the cotton-seed.

Clevenger, Circuit Judge, dissenting:

I agree that some limit must be placed on the transfer of posses- 
sion statute to avoid absurd results. Even the Supreme Court has noted that this statute is virtually impossible to parse satisfactorily. See Asgrow

Some 17 years ago, the Fifth Circuit (which incidentally knows more about cotton growing, ginning and delinting than we) grappled with the Act and found another way of placing some sensible limits on the transfer and labeling provisions of the Act. In People's Gin Co, that court held that a party who is but a passive participant in a farmer-to-farmer transfer cannot be held liable under the Act. In that case, the defendants were found to have arranged sales transactions among the farmers; not being merely passive, they were held liable under the Act. From 1983 until today, People's Gin Co has been the law of the Cotton Belt. Indeed, when this case was brought, the plaintiffs were under the impression that Sinkers had been actively participating in arranging the farmer-to-farmer transfers, and that this presumably would be an easy case for them to win under the law of People's Gin Co. As is so often the case, however, discovery proved the plaintiffs wrong: the evidence proves, as a matter of fact, that Sinkers has been a mere passive conduit in the farmer-to-farmer sales. For that reason, the district court simply applied the law of the Cotton Belt and relieved Sinkers from liability under the Act. The court quite reasonably noted that a delinter who is merely passively carrying out the instruction of its customers in delivering or releasing delinted seed is not substantively different from a delinter who merely returns the delinted seed to the person who asked it to be delinted. The court opined, and I agree, that a mere return of delinted seed to the sender should not violate the transfer of possession provision.

The majority prefers not to follow the lead of the Fifth Circuit. I think it is a mistake to read a scienter requirement into the transfer of possession provision. It seems clear that Congress put the scienter element where it belongs, in section 2541(8).

Under the law as stated in People's Gin Co, ginners and delinters were saved the need to create a "paper trail" to protect completely passive conduct from liability under the Act. Under the rule devised by the majority in this case, ginners and delinters will become paperkeeping traffic cops. Ginners and delinters will have to keep uptodate records on the membership of cotton cooperatives, including the acreage planted in cotton each season by each member of the cooperative. Under the majority's rule, a forty member cooperative (forty farms of roughly a square mile each) will be a prima facie suspect of delivering excess seed to the ginner or delinter. Ginners and delinters will also have to keep current with any increase in acreage purchased by farmers during the course of a year, so they can satisfy themselves that a farmer is not delivering too much seed for ginning or delinting. Presumably ginners and delinters will want to ask those who 
deliver seed to them to provide them with certificates that say something like "the seed we are delivering is within the current section 2543 exemption." Those who deliver the seed to those who deliver it to ginners and delinters will also want some kind of certificate, to the same effect. The paper trail presumably will lead right back to the section 2543 farmer who is trying to save seed for his own use, or for sale as now permitted under section 2543. I can see mountains of paper piling up throughout the Cotton Belt. I can also see lots of work for lawyers trying and defending this kind of case. And many headaches for judges, who will have to decide if a case is lost, or won, when there are (as there inevitably will be) glitches here and there in the paper trial that, in a perfect, Federal Circuit world, will lead from farmer Joan on her south 40 to her neighbor with the truck who brings her seed to a coop, which gives the seed to a another to take it first to the ginner, then to the delinter and finally either back to Joan or to the person who buys her seed. Now all of this seems like a whole lot of trouble being visited on a settled law that went unchallenged for a very long time, and only got challenged in this case when the proofs under the settled law ran against the plaintiff.

The majority responds to my concern by guessing what goes into a cottonseed delinting contract, assuming farmer Joan signs such a contract, and then postulating that all a ginner or delinter needs to do to avoid liability is to stick a clause in the contract saying something like "you promise me that the amount of seed you are delivering does not exceed the amount you can lawfully save for replanting." That it will be so easy to satisfy the scienter requirement seems to me all the more reason why we should leave settled law alone.

The majority opinion notes that Congress amended the Act in 1994. That amendment preserves the right of a farmer to save seed from the crop he produces from protected seed he has purchased. The farmer must either use such saved seed "in the production of a crop for use on the farm of the person," or sell such amount of the saved seed in a "bona fide sale for other than reproductive purposes."

This case, of course, arises under the statute before its amendment, and therefore neither the majority nor I can say with authority how the holding of the majority will apply to the future. We can predict, however, that a farmer who has purchased protected seed, and who wishes to use or sell the seed propagated by his plantings of protected seed - as the amended Act permits - will need the services of a delinter. It thus seems that, in order to avoid the absurd results that follow from an unrestrained reading of the Act, either a "passive" or a "knowing" exception to the statute, or some other escape valve, is required.

I of course recognize that I, like the majority, read an exception into an otherwise broad statute. Whether either of us is correct in so 
doing is a matter for others to determine. Perhaps the Supreme Court will wish to grapple with the Act, again.

\section{The Punchline}

JEM Ag Supply, Inc. v. Pioneer Hi-Bred International, Inc.

This case presents the question whether utility patents may be issued for plants under, or whether the Plant Variety Protection Act and the Plant Patent Act of 1930 are the exclusive means of obtaining a federal statutory right to exclude others from reproducing, selling, or using plants or plant varieties. We hold that utility patents may be issued for plants.

The United States Patent and Trademark Office (PTO) has issued some 1,800 utility patents for plants, plant parts, and seeds. Seventeen of these patents are held by Pioneer Hi-Bred International. Pioneer's patents cover the manufacture, use, sale, and offer for sale of the company's inbred and hybrid corn seed products. A patent for an inbred corn line protects both the seeds and plants of the inbred line and the hybrids produced by crossing the protected inbred line with another corn line. See, e.g., U.S. Pat. No. 5,506,367. A hybrid plant patent protects the plant, its seeds, variants, mutants, and trivial modifications of the hybrid. See U.S. Pat No. 5,491,295.

As this Court recognized over 20 years ago in Chakrabarty, the language of $\S 101$ is extremely broad. Several years after Chakrabarty, the PTO Board of Patent Appeals and Interferences held that plants were within the understood meaning of "manufacture" or "composition of matter" and therefore were within the subject matter of $\S 101$. In re Hibberd. It has been the unbroken practice of the PTO since that time to confer utility patents for plants. To obtain utility patent protection, a plant breeder must show that the plant he has developed is new, useful, and nonobvious. In addition, the plant must meet the specifications of $\S 112$, which require a written description of the plant and a deposit of seed that is publicly accessible.

The 1930 PPA conferred patent protection to asexually reproduced plants. Significantly, nothing within either the original 1930 text of the statute or its recodified version in 1952 indicates that the PPA's protection for asexually reproduced plants was intended to be exclusive. Importantly, chapter 15 nowhere states that plant patents are the exclusive means of granting intellectual property protection to plants. Although unable to point to any language that requires, or even suggests, that Congress intended the PPA's protections to be exclusive, petitioners advance three reasons why the PPA should preclude assigning utility patents for plants. We find none of these arguments to be persuasive. 
First, petitioners argue that plants were not covered by the general utility patent statute prior to 1930. Prior to 1930, two factors were thought to remove plants from patent protection. The first was the belief that plants, even those artificially bred, were products of nature for purposes of the patent law. The second obstacle to patent protection for plants was the fact that plants were thought not amenable to the written description requirement of the patent law. The PPA thus gave patent protection to breeders who were previously unable to overcome these obstacles.

This does not mean, however, that prior to 1930 plants could not have fallen within the subject matter of $\S 101$. Rather, it illustrates only that in 1930 Congress believed that plants were not patentable under $\S 101$, both because they were living things and because in practice they could not meet the stringent description requirement. Yet these premises were disproved over time. As this Court held in Chakrabarty, "the relevant distinction" for purposes of $\S 101$ is not "between living and inanimate things, but between products of nature, whether living or not, and humanmade inventions." In addition, advances in biological knowledge and breeding expertise have allowed plant breeders to satisfy $\S 101$ 's demanding description requirement.

Second, petitioners maintain that the PPA's limitation to asexually reproduced plants would make no sense if Congress intended $\S 101$ to authorize patents on plant varieties that were sexually reproduced. But this limitation once again merely reflects the reality of plant breeding in 1930. At that time, the primary means of reproducing bred plants true-to-type was through asexual reproduction. Congress thought that sexual reproduction through seeds was not a stable way to maintain desirable bred characteristics. Thus, it is hardly surprising that plant patents would protect only asexual reproduction, since this was the most reliable type of reproduction for preserving the desirable characteristics of breeding.

Third, petitioners argue that in 1952 Congress would not have moved plants out of the utility patent provision and into $\S 161$ if it had intended $\S 101$ to allow for protection of plants. Petitioners again rely on $138^{*} 138$ negative inference because they cannot point to any express indication that Congress intended $\S 161$ to be the exclusive means of patenting plants. But this negative inference simply does not support carving out subject matter that otherwise fits comfortably within the expansive language of $\S 101$, especially when $\S 101$ can protect different attributes and has more stringent requirements than does $\S 161$.

By passing the PVPA in 1970, Congress specifically authorized limited patent-like protection for certain sexually reproduced plants. Petitioners therefore argue that this legislation evidences Congress' intent to deny broader $\S 101$ utility patent protection for such plants. 
Petitioners' argument, however, is unavailing for two reasons. First, nowhere does the PVPA purport to provide the exclusive statutory means of protecting sexually reproduced plants. Second, the PVPA and $\S 101$ can easily be reconciled. Because it is harder to qualify for a utility patent than for a Plant Variety Protection (PVP) certificate, it only makes sense that utility patents would confer a greater scope of protection.

At the time the PVPA was enacted, the PTO had already issued numerous utility patents for hybrid plant processes. Many of these patents, especially since the 1950's, included claims on the products of the patented process, i. e., the hybrid plant itself. Such plants were protected as part of a hybrid process and not on their own. Nonetheless, these hybrids still enjoyed protection under $\S 101$, which reaffirms that such material was within the scope of $\S 101$.

Justice Breyer, with whom Justice Stevens joins, dissenting:

I believe that the words "manufacture" or "composition of matter" do not cover these plants. That is because Congress intended the two more specific statutes to exclude patent protection under the Utility Patent Statute for the plants to which the more specific Acts directly refer.

\section{Drug Approval}

The Food and Drug Administration oversees one of the most intensive regulatory regimes in the whole of the U.S. Code. A "new drug," for example, cannot be shipped in interstate commerce unless it has gone through the FDA approval process. Why does this matter to an IP course? First, because the structure of regulatory approval changes the IP strategies of actors affected by it. Second, because Congress has rewritten the patent laws to take account of the realities of regulatory approval for certain products. (Medtronic summarizes.) Third, because the regulatory approval gateway is itself a source of IP-like rights, which can give one company the effectively exclusive right to use the information embedded in its drug product. And fourth, because Congress has created entirely new forms of informational exclusivity to deal with the wrinkles of the system.

\section{Patent Issues}

The modern drug regulatory regime is, in one sense, oriented towards patent as its preferred form of intellectual property. But its demands have also compelled patent law to adapt to better fit.

Kara B. Swanson

Food and Drug Law as Intellectual Property Law
Cf. Anna B. Laakmann, A Property Theory of Medical Innovation, 56 Jurimetrics J. 117 (2016); Robin Feldman, Regulatory Property: The New IP, Colum. J.L. \& Arts (forthcoming)

There are similar but different regulatory regimes for the approval of animal drugs; of medical devices like syringes, pacemakers, and diagnostic tests; and of "biological products" like vaccines, blood plasma, and genetic therapies. We focus on drugs in this section because they illustrate all of the essential issues.

2011 Wisc. L. Rev. 331 
Within the nineteenth-century food and drug markets, the predominant use of intellectual property was to protect medicines. Patents were not, however, the preferred means of protecting commercial interests in medicines. Despite the use of the term "patent medicines" to describe nineteenth-century nostrums, only a small percentage of medicines were patent-protected in the nineteenth century. What were widely referred to as "patent medicines" during the nineteenth and early twentieth centuries were usually not patented. "Patent medicines" referred to proprietary medicines, medicines sold by only one manufacturer, containing a secret combination of ingredients. A historian of the entrepreneurs who sold such nostrums in the nineteenth and twentieth centuries has argued that only the least savvy sought patent protection for their recipes.

No one but the manufacturer knew what was in the pills, liquids, or ointments sold. When patients bought such medicines as selftreatment, or, as often happened, when physicians prescribed them, neither prescribing doctor nor patient knew what was being ingested. Instead, both relied upon advertising copy about the powers of the medicine and the recommended dosage.

Secrecy allowed the manufacturer to hide, for example, the fact that the medicine contained mostly water, or common household ingredients, or significant amounts of alcohol, the revelation of which, it was argued, would drive away consumers. Doctors and pharmacists further alleged that manufacturers had no compunction about changing the ingredients of a medicine to respond to fluctuations in prices of ingredients, while continuing to sell it under the same packaging, using the secrecy of their formulas to disguise shifting compositions. Businessmen bought and sold trade names rather than secret formulas, patents, or manufacturing know-how as they sought to maximize profits.

Elite regular physicians contrasted proprietary medicines based on secrecy against what they called "ethical" medicines. These medicines were the formulary medicines, known parts of the materia medica. These medicines were listed in the United States Pharmacopeia or the National Formulary, and, if mixtures, could be compounded by any druggist based on published formulae. They, too, were sold under brand names that could be protected as trademarks, but the brand name identified the manufacturer, not the particular product. These so-called ethical manufacturers who built businesses on supplying doctors and pharmacists with consistent, good quality supplies of formulary drugs were a small part of the drug market." By the turn of the twentieth century, as the campaign of regular physicians against proprietary medicines gained strength, the ethical medicines were also defined by their advertisement to physicians, rather than directly to the public. 
Regular physicians had long criticized the sale and use of proprietary medicines, even as medical journals accepted advertisements from their manufacturers and many doctors wrote prescriptions for such medicines. The critiques generally fell into three categories: (1) such nostrums were sold for far more than the value of their ingredients, and therefore were a fraud on the public's pocketbook; (2) such nostrums actively harmed their users by containing powerful drugs such as morphine; and (3) such nostrums in no way fulfilled the promises made on their labels and in their elaborate advertisements, like claims to cure cancer, tuberculosis, and syphilis. At best, consumers were being hoodwinked, and at worst, they were poisoning themselves and their children.

A campaign for comprehensive federal regulation began in earnest in 1879, when the first federal food and drug bill was introduced into Congress. From that year until 1906, such a bill was unsuccessfully introduced into every Congress. The 1906 Act as finally passed outlawed the interstate shipment of "adulterated" or "misbranded" food or drugs and their manufacture within the District of Columbia and the territories.

The proprietary medicine manufacturers quickly reduced the Act's regulatory power to inhibit their business model by winning the case United States v. Johnson. In his opinion, Justice Oliver Wendell Holmes declared that Congress had not intended to consider any claims about therapeutic value made on product labels as false or misleading, for such were merely matters of opinion, not susceptible to examination by the Bureau of Chemistry. Thus, manufacturers could continue to fill their labels with broad claims of cure. Congress attempted to strengthen the regulation of false claims of therapeutic value by passing the Sherley Amendment in 1912. This fix, however, failed to fully correct the problem, as the courts interpreted the language of the amendment prohibiting "false and fraudulent" claims to require a showing of intentional falsehood. While the FDA did pursue egregious claims of cure, with so many testimonials as to the value of their products, manufacturers could easily avoid a jury finding of intentional falsehood.

After two decades of agitation and five years of effort within the FDR administration, the new bill, the Federal Food, Drug, and Cosmetic Act, passed in 1938. The new Act was much longer and more detailed, as its drafters had sought to close perceived loopholes in the first regulatory scheme. All drugs had to bear a label with "an accurate statement of the quantity of the contents in terms of weight, measure, or numerical count" as well as the name and address of the manufacturer or distributer. Most significantly, for any non-formulary drug, the "common or usual name" of each active ingredient had to be listed on the label. Finally, many ingredients of proprietary 
medicines would be revealed to the public, even if the exact formulae were not.

From a contemporary perspective, we might assume that the purity campaign, as a campaign against trade secrets, would embrace patents as a better intellectual property regime. Patents are often understood as a complementary choice to trade secrets, offering a strong limited-term monopoly in exchange for public disclosure. Today, we are very familiar with the arguments for the use of patents to protect pharmaceuticals-patents allow a period of exclusive sales during which time the originator of a new medicine reaps monopoly pricing as a just reward for a large investment in research and development, providing the necessary reward to incentivize the risky and expensive process of drug development. Once the drug comes off patent, other manufacturers can make and sell the same drug, causing the price paid by consumers to drop.

In 1938, as the world of laboratory-created drugs was just emerging, this argument was not yet dominant. Instead, Americans, and particularly American doctors and pharmacists, were familiar with another argument regarding patents and medicines, an argument that had persisted over the previous century. This older argument described "medical patents" - a term which lumped together any patents to medicines, methods of treatment, and medical devices as unethical.

Yet, the new scientific ways of knowing had changed the landscape of both trade secrets and patents within the drug market. Chemistry made keeping secrets from competitors much more difficult. The proprietary medicines could be analyzed and their contents publicized. Manufacturers did not even necessarily need to do this work themselves; the AMA did some of this analysis and publication as part of its campaign against secrecy.

The remarkable aspect of the late 1930s in retrospect is not that medical patents became commonplace, unopposed by both the ethical manufacturers and organized medicine, but that for a brief window of time, the medical profession envisioned medical patents allowing a medically controlled drug marketplace. Rather than seeing patents as an unmitigated evil, allowing the privatization of what should be used for the public benefit, the medical profession saw them as a way of increasing its own authority, a counterweight to the profit-oriented firms and the useful, but medically uninformed, federal bureaucrats in the FDA and the patent office. Instead of patents making medical professionals unethical, the control of patents by ethical professionals would make patents, now perceived as necessary aspects of a new, more complicated pharmacopeia, ethical.

Instead, through the federal food and drug regulation and the new science, doctors traded a drug marketplace dominated by secret 
proprietaries that offered little therapeutic value for a drug marketplace dominated by new corporatized proprietaries that offered medical miracles. Organized medicine had to be content with the control it would increasingly gain as prescription drugs became a legal category. As self-dosing became less common, doctors became the key gatekeepers on the demand side of the burgeoning market in pharmaceuticals. During the course of the twentieth century, doctors gained the ability to control their patient's access to medications, but lost any hope that doctors or medically controlled organizations would exercise control over the supply side. What medications were available for doctors to prescribe would be determined by the drug companies and the FDA.

Merck KGaA v. Integra Lifesciences I, Ltd.

The Federal Food, Drug, and Cosmetic Act (FDCA) regulates the manufacture, use, or sale of drugs. Under the FDCA, a drugmaker must submit research data to the FDA at two general stages of newdrug development. First, a drugmaker must gain authorization to conduct clinical trials (tests on humans) by submitting an investigational new drug application (IND). The IND must describe "preclinical tests (including tests on animals) of the drug adequate to justify the proposed clinical testing." Second, to obtain authorization to market a new drug, a drugmaker must submit a new drug application (NDA), containing "full reports of investigations which have been made to show whether or not the drug is safe for use and whether the drug is effective in use." Pursuant to FDA regulations, the NDA must include all clinical studies, as well as preclinical studies related to a drug's efficacy, toxicity, and pharmacological properties.

Eli Lilly \& Co. v. Medtronic, Inc.

Under federal law, a patent "grant[s] to the patentee, his heirs or assigns, for the term of seventeen years, . . . the right to exclude others from making, using, or selling the invention throughout the United States." Except as otherwise provided, "whoever without authority makes, uses or sells any patented invention, within the United States during the term of the patent therefor, infringes the patent.". The parties agree that the 1984 Act was designed to respond to two unintended distortions of the 17-year patent term produced by the requirement that certain products must receive premarket regulatory approval. First, the holder of a patent relating to such products would as a practical matter not be able to reap any financial rewards during the early years of the term. When an inventor makes a potentially useful discovery, he ordinarily protects it by applying for a patent at once. Thus, if the discovery relates to a product that cannot be marketed without substantial testing and regulatory approval, the
545 U.S. 193 2005)

As amended at 21 U.S.C $\S 301$ eq seq.

21 U. S. C. § 355(i)(1)(A);

21 U.S.C. § 355(b)(1)

496 U.S. 661 (1990)

Now twenty years.

35 U.S.C. § 154.

35 U.S.C. § 271 (a) 
Roche v. Bolar: 733 F. 2d 858 (Fed. Cir. 1984)

Informally known as Hatch-Waxman, after its Congressional champions

35 U.S.C. § 156(f) (2016). NB: the language has been amended since Medtronic; this is the current version. "clock" on his patent term will be running even though he is not yet able to derive any profit from the invention.

The second distortion occurred at the other end of the patent term. In 1984, the Court of Appeals for the Federal Circuit decided that the manufacture, use, or sale of a patented invention during the term of the patent constituted an act of infringement, see § 271(a), even if it was for the sole purpose of conducting tests and developing information necessary to apply for regulatory approval. See Roche Products, Inc. v. Bolar Pharmaceutical Co. Since that activity could not be commenced by those who planned to compete with the patentee until expiration of the entire patent term, the patentee's de facto monopoly would continue for an often substantial period until regulatory approval was obtained. In other words, the combined effect of the patent law and the premarket regulatory approval requirement was to create an effective extension of the patent term.

The Drug Price Competition and Patent Term Restoration Act of 1984 sought to eliminate this distortion from both ends of the patent period. Section 201 of the Act established a patent-term extension for patents relating to certain products that were subject to lengthy regulatory delays and could not be marketed prior to regulatory approval. The eligible products were described as follows:

(1) The term 'product' means:

(A) A human drug product.

(B) Any medical device, food additive, or color additive subject to regulation under the Federal Food, Drug, and Cosmetic Act.

(2) The term 'human drug product' means the active ingredient of

(A) a new drug, antibiotic drug, or human biological product (as those terms are used in the Federal Food, Drug, and Cosmetic Act and the Public Health Service Act), or

(B) a new animal drug or veterinary biological product (as those terms are used in the Federal Food, Drug, and Cosmetic Act and the Virus-Serum-Toxin Act) ...

Section 201 provides that patents relating to these products can be extended up to five years if, inter alia, the product was "subject to a regulatory review period before its commercial marketing or use," and "the permission for the commercial marketing or use of the product after such regulatory review period [was] the first permitted commercial marketing or use of the product under the provision of law under which such regulatory review period occurred."

The distortion at the other end of the patent period was addressed by $\S 202$ of the Act. That added to the provision prohibiting patent in- 
fringement, the paragraph at issue here, establishing that "it shall not be an act of infringement to make, use, or sell a patented invention ... solely for uses reasonably related to the development and submission of information under a Federal law which regulates the manufacture, use, or sale of drugs." This allows competitors, prior to the expiration of a patent, to engage in otherwise infringing activities necessary to obtain regulatory approval.

The core of the present controversy is that petitioner interprets the statutory phrase, "a Federal law which regulates the manufacture, use, or sale of drugs," to refer only to those individual provisions of federal law that regulate drugs, whereas respondent interprets it to refer to the entirety of any Act (including, of course, the FDCA) at least some of whose provisions regulate drugs. If petitioner is correct, only such provisions of the FDCA as $\S 505$, governing premarket approval of new drugs, are covered by $\S 271(\mathrm{e})(1)$, and respondent's submission of information under FDCA $\S 515$, governing premarket approval of medical devices, would not be a noninfringing use.

It seems most implausible to us that Congress, being demonstrably aware of the dual distorting effects of regulatory approval requirements in this entire area - dual distorting effects that were roughly offsetting, the disadvantage at the beginning of the term producing a more or less corresponding advantage at the end of the term - should choose to address both those distortions only for drug products; and for other products named in $\S 201$ should enact provisions which not only leave in place an anticompetitive restriction at the end of the monopoly term but simultaneously expand the monopoly term itself, thereby not only failing to eliminate but positively aggravating distortion of the 17-year patent protection. It would take strong evidence to persuade us that this is what Congress wrought, and there is no such evidence here.

\section{Hatch-Waxman}

A firm that develops a new (or "pioneer") drug has a regulatory advantage: following approval of its NDA, no other firm is legally allowed to market the drug. A generic firm could of course submit its own NDA. This would probably be faster and cheaper than the pioneer firm's NDA: after all, it would know what drug to test and write up. But it would still be slow and expensive, because it would require a full course of clinical testing and regulatory filing. So some firms tried to argue that generic drugs required no new approval from the FDA (Generix).

In 1984, Congress enacted a grand bargain between pioneer and generic firms commonly known as Hatch-Waxman that alters this baseline in several important ways:
35 U.S.C. § $271(e)(1)$

Merck $v$. Integra is to similar effect: $\S 271(\mathrm{e})$ protects "uses of patented inventions in preclinical research, the results of which are not ultimately included in a submission to the FDA." 
1. It gives generic firms the option of filing an "abbreviated" NDA, or ANDA, in place of a full NDA based on new clinical trials (Actavis).

2. It then prohibits the FDA from approving ANDAs during certain statutory exclusivity periods. Actavis Elizabeth illustrates, and Erika Lietzan discusses.

3. It creates specialized procedures to sort out conflicting claims over patents potentially reading on generic drugs (Caraco).

4. Finally, it gives a limited form of exclusivity to generic drug firms who successfully challenge patents: 180 days during which no other ANDA can be approved for the same product. FTC v. Actavis illustrates the economic significance of this exclusivity.

\section{United States v. Generix Drug Corp.}

The active ingredients in most prescription drugs constitute less than $10 \%$ of the product; inactive "excipients" (such as coatings, binders, and capsules) constitute the rest. The term "generic drug" is used to describe a product that contains the same active ingredients but not necessarily the same excipients as a so-called "pioneer drug" that is marketed under a brand name. ${ }^{-1}$ Respondent Generix is a distributor of generic drugs manufactured by other firms.

The Government initiated this action to enjoin Generix from distributing in interstate commerce a number of generic drug products that contain eight specified active ingredients. It alleged that the FDA had never approved new drug applications with respect to any of those products.

The Court of Appeals for the Fifth Circuit, now the Eleventh Circuit held that the statutory prohibition against the sale of a "new drug" without prior approval does not apply to a drug product having the same active ingredients as a previously approved drug product, regardless of any differences in excipients. It based that conclusion on its view that the statutory requirement of evaluating the safety and effectiveness of new drugs must normally relate to active ingredients, because the precise technique of formulating the finished drug is not part of the information generally known to the medical or scientific community. Moreover, it believed that the legislative history suggested that Congress had not intended to create a productby-product licensing system.

\footnotetext{
${ }^{1}$ Generic drugs, also called "copycat" or "me-too" drugs, are usually marketed at relatively low prices because their manufacturers do not incur the research, development, and promotional costs normally associated with the creation and marketing of an original product.
} 
The Court of Appeals misread the statutory text. Generic drug products are quite plainly drugs within the meaning of the FDCA.

FTC v. Actavis, Inc.

A drug manufacturer, wishing to market a new prescription drug, must submit a New Drug Application to the federal Food and Drug Administration and undergo a long, comprehensive, and costly testing process, after which, if successful, the manufacturer will receive marketing approval from the FDA. See 21 U.S.C. § 355(b)(1) (requiring, among other things, "full reports of investigations" into safety and effectiveness; "a full list of the articles used as components"; and a "full description" of how the drug is manufactured, processed, and packed).

Once the FDA has approved a brand-name drug for marketing, a manufacturer of a generic drug can obtain similar marketing approval through use of abbreviated procedures. The Hatch-Waxman Act permits a generic manufacturer to file an Abbreviated New Drug Application specifying that the generic has the same active ingredients as and is biologically equivalent to, the already-approved brandname drug. In this way the generic manufacturer can obtain approval while avoiding the costly and time-consuming studies needed to obtain approval for a pioneer drug. The Hatch-Waxman process, by allowing the generic to piggy-back on the pioneer's approval efforts, speeds the introduction of low-cost generic drugs to market, thereby furthering drug competition.

Actavis Elizabeth LLC v. U.S. Food and Drug Admin.

The Hatch-Waxman Amendments allowed generic versions of previously approved drugs to gain approval through the submission of an ANDA. These abbreviated applications reduce the effort required to gain marketing approval by, among other things, allowing the applicant to rely on clinical studies submitted as part of a previous new drug application.

The Hatch-Waxman Amendments also grant various periods of marketing exclusivity to certain pioneer drugs. The exclusivity provisions protect these drugs from generic competition for the specified terms by preventing the submission of abbreviated applications that refer to them.

If an application submitted under subsection (b) of this section for a drug, no active ingredient (including any ester or salt of the active ingredient) of which has been approved in any other application under subsection (b) of this section, is approved after September 24, 1984, no application may be submitted under this subsection which
133 S. Ct. 2223 (2013)

625 F.3d 760 (D.C. Cir. 2010)

21 U.S.C § 355(j)(5)(f)(ii) 


\section{U.S.C. § 355(j)(5)(F)(iii)}

The Best Pharmaceuticals for Children Act gives six moths of additional exclusivity if the applicant conducts certain require forms of pediatric testing. See 21 U.S.C. § 355a.

21 C.F.R. $\S 314.108(a) \&(b)(2))$

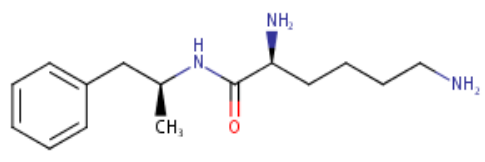

Lisdexamfetamine

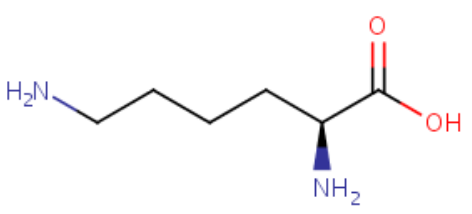

Lysine

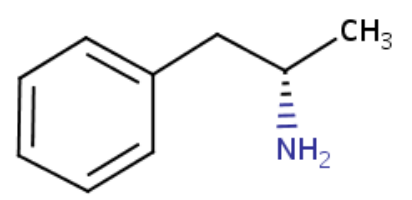

Dextroamphetamine refers to the drug for which the subsection (b) application was submitted before the expiration of five years from the date of the approval ...

In addition to this five-year period, the Amendments grant three-year exclusivity to drugs that include previously approved active ingredients if the application for the drug "contains. reports of new clinical investigations ... essential to the approval of the application and conducted or sponsored by the applicant."

The FDA has implemented these exclusivity provisions through regulations. The regulations give five years of exclusivity for each "drug product that contains a new chemical entity.". A "new chemical entity" is "a drug that contains no active moiety that has been approved by FDA in any other" new drug application. "Active moiety" is defined as "the molecule or ion ... responsible for the physiological or pharmacological action of the drug substance." [Various related forms of molecules or ions, including esters, salts, and other forms that differ only in their noncovalent bonds, are considered to be the same "active moiety."]

In 2007, the Food and Drug Administration approved Vyvanse, a name-brand drug for the treatment of attention deficit hyperactivity disorder. Two years later, Actavis submitted an application for lisdexamfetamine dimesylate, a generic version of the same drug. The FDA returned Actavis' application. It did so because it had previously determined that Vyvanse was entitled to five years of marketing exclusivity under the Hatch-Waxman Amendments to the Federal Food, Drug, and Cosmetic Act. Actavis brought this action claiming that Vyvanse was not entitled to five years of exclusivity.

Lisdexamfetamine dimesylate is a salt of lisdexamfetamine. Since, under the agency's regulations, salts are not considered active moieties, the agency's analysis centered on the lisdexamfetamine molecule alone. Lisdexamfetamine consists of a portion of lysine, a common amino acid, connected to dextroamphetamine. These two parts are linked by [a covalent bond]. Once it enters the body, lisdexamfetamine undergoes a chemical conversion to produce dextroamphetamine.

Actavis thinks this language [quoted above] prevents the FDA from granting five-year exclusivity to any drug containing a drug molecule (such as lisdexamfetamine) that eventually produces a previously approved drug molecule in the body.

Actavis relies mainly on the term "active ingredient," which it says obligates the FDA to identify the particular drug molecule that reaches the "site" of the drug's action. This molecule, Actavis argues, is necessarily the "active ingredient" of the drug in question, regardless of the form of the molecule before it enters the body. But there 
is nothing to indicate that Congress used the term in the sense Actavis urges. The Hatch-Waxman Amendments do not define active ingredient. The legislative history establishes only that Congress was concerned with providing incentives for innovation by granting fiveyear exclusivity to "new chemical entities" and is silent on what determines novelty.

Actavis argues that by using the term "active," Congress was requiring the FDA to determine the particular molecule that provides the drug's "activity," which it claims is limited to the drug's specific therapeutic effect. If this molecule has been previously approved, then five-year exclusivity is not warranted. But the FDA is right-or at least we have been given no reason to doubt - that the activity of a drug cannot be reduced to such a simple formulation. The agency has concluded that the entire pre-ingestion drug molecule should be deemed responsible for the drug's activity, which can include its "distribution within the body, its metabolism, its excretion, or its toxicity." There is no reason to believe Congress thought differently - or thought about it at all.

In the FDA's view, drug derivatives such as lisdexamfetamine are "major innovations" deserving five-year exclusivity. The FDA's regulations leave many types of drug derivatives eligible only for threeyear exclusivity. The FDA's policy is based on its view that drug derivatives containing covalent bonds are, on the whole, distinct from other types of derivative drugs such that the former are uniquely deserving of "new chemical entity" status and the resulting five-year exclusivity. We are hard pressed to second-guess the FDA's view, especially since it rests on the agency's evaluations of scientific data within its area of expertise. At best, Actavis has offered evidence that some covalent structural changes do not alter the basic properties of the drug in question and that some noncovalent structural changes do. But agencies may employ bright-line rules for reasons of administrative convenience, so long as those rules fall within a zone of reasonableness and are reasonably explained. The FDA has explained that its policy is based in part on the "difficulty in determining precisely which molecule, or portion of a molecule, is responsible for a drug's effects." Nothing in the record establishes that the FDA's approach is unreasonable. Given the complexity of the statutory regime, we defer to the agency's interpretation.

\section{Erika Lietzan \\ The Myths of Data Exclusivity}

The conventional narrative indicates that data exclusivity is affirmatively provided by the state-the subtext being that the natural state of affairs is one without data exclusivity. Many legal scholars and policy writers describe data exclusivity as comparable to intellectual
Note that Hatch-Waxman NCE activeingredient exclusivity applies only to ANDAs. Actavis remained free to submit a full NDA in support of its proposal to market lisdexamfetamine dimesylate.

20 Lewis \& Clark L. Rev. 91 (2016)

Lietzan defines data exclusivity as "prohibitions on submission or approval of abbreviated applications, which implicitly or explicitly rely on previously submitted data." 
property, as patent-like, or even as a sub-type of intellectual property. The innovative industry also tends to characterize it as a type of intellectual property. Both economic and legal scholars analogize to monopoly when describing market conditions during data exclusivity - the subtext again being that natural competition has been affirmatively blocked by the State. The key to the conventional narrative is that exclusivity is artificial and provided, as a benefit, to pioneers.

But there is another way to understand what is going on. The government requires a license to market new drugs, which it will issue after reviewing the results of research to support the marketability of the drug. Anyone may apply for a license, and indeed - subject to any relevant patent protection one or another of the companies might enjoy as well as their business judgment about the value of the investment - multiple companies may file for licenses to market the same drug or drugs that are similar. That is to say, the drug approval statutes - the regulatory apparatuses - do not preclude two, or three or more applicants from seeking approval of the same thing on the same terms. From a regulatory perspective, all face the same scientific burden - preclinical and clinical research in a full application, showing the finished product is safe and effective. The second and third applicant will have a reduced burden as a practical matter simply because approval of the first product - and the large volume of information released about the contents of the application - will eliminate much of the trial and error that the first applicant experienced. They will know what to study and what not to study, they will know how to design their trials, they will know what results to expect, and they can reverse engineer the first entrant's product to determine a suitable formulation, route of administration, dosage form, and strength. All of this will save these applicants some time and money, but the bulk of their expenses remain, deriving from the clinical trials that must still be performed to obtain a license.

After a period of time, federal law permits other companies to proval process look like from a tradesecret point of view? Does this help explain the term "data exclusivity? obtain licenses for identical or highly similar medicines without the same amount of supporting research. The drug approval statutes remove the high evidentiary hurdle and substitute a different one, with a significantly lower investment requirement. A license to market is now available for the price of comparative analytical testing and perhaps modest comparative clinical testing. As a scientific matter, these follow-on applicants are able to obtain licenses because they rely on the research performed by the earlier applicant. That these are reliance-based applications should not be controversial. FDA has conceded that as a regulatory matter a follow- on applicant uses the first entrant's research, even if sometimes couching it as using the "fact" of the first entrant's approval. Many courts charac- terizing generic drug approval use the same language. In brief, then, once 
data exclusivity expires, any applicant may justify market entry using the research paid for and submitted by the pioneer to justify its own entry to the market. This reframes data exclusivity as a period before the law gives the pioneer's competitors something not previously available to them - a faster and cheaper license, resulting from permission to rely on the pioneer's research.

When the narrative is recast, the central myth of exclusivity is exposed; it is not a grant of anything to anyone. Data exclusivity is the absence of an abbreviated pathway. It does not prevent subsequent entrants from doing exactly what the first entrant did-developing the product, testing it, submitting a full application, and launching the drug, subject to relevant patent and business considerations. Contrasting data exclusivity with market exclusivity should make this clear.

Orphan-drug exclusivity is the main example in current U.S. law of market exclusivity. An orphan drug is intended to treat a rare disease or condition; the sponsor makes this showing by demonstrating that the dis- ease affects fewer than 200,000 persons in this country or that the com- pany does not expect to recover its costs of research and development when marketing the product. If a drug has been designated as an orphan drug, then - upon approval - it is entitled to seven years of market exclusivity. This means the FDA may not approve the same drug for the same condition for seven years, even if proposed in a full application supported by original research. Orphan-drug exclusivity is an affirmatively granted right, in the sense that it prevents subsequent entrants from doing what they would ordinarily and otherwise be permitted to do - study the molecule themselves and reach the market on the same terms as the first entrant.

\section{Caraco Pharmaceutical Labs v. Novo Nordisk}

Because the FDA cannot authorize a generic drug that would infringe a patent, the timing of an ANDA's approval depends on the scope and duration of the patents covering the brand-name drug. Those patents come in different varieties. One type protects the drug compound itself. Another kind - the one at issue here - gives the brand manufacturer exclusive rights over a particular method of using the drug. In some circumstances, a brand manufacturer may hold such a method-of-use patent even after its patent on the drug compound has expired.

To facilitate the approval of generic drugs as soon as patents allow, the Hatch-Waxman Amendments and FDA regulations direct brand manufacturers to file information about their patents. The statute mandates that a brand submit in its NDA "the patent number and the expiration date of any patent which claims the drug for which the [brand] submitted the [NDA] or which claims a method of using
Lietzan defines market exclusivity as "prohibitions on submission or approval of any competing application, even if supported by a full complement of original data."

132 S. Ct. 1670 (2012)

21 U.S.C. S S 355(b)(1) 
such drug." And the regulations issued under that statute require that, once an NDA is approved, the brand provide a description of any method-of-use patent it holds. That description is known as a use code, and the brand submits it on FDA Form 3542. As later discussed, the FDA does not attempt to verify the accuracy of the use codes that brand manufacturers supply. It simply publishes the codes, along with the corresponding patent numbers and expiration dates, in a fat, brightly hued volume called the Orange Book (less colorfully but more officially denominated Approved Drug Products with Therapeutic Equivalence Evaluations).

After consulting the Orange Book, a company filing an ANDA must assure the FDA that its proposed generic drug will not infringe the brand's patents. When no patents are listed in the Orange Book or all listed patents have expired (or will expire prior to the ANDA's approval), the generic manufacturer simply certifies to that effect. Otherwise, the applicant has two possible ways to obtain approval.

One option is to submit a so-called section viii statement, which asserts that the generic manufacturer will market the drug for one or more methods of use not covered by the brand's patents. A section viii statement is typically used when the brand's patent on the drug compound has expired and the brand holds patents on only some approved methods of using the drug. If the ANDA applicant follows this route, it will propose labeling for the generic drug that "carves out" from the brand's approved label the still-patented methods of use. The FDA may approve such a modified label as an exception to the usual rule that a generic drug must bear the same label as the brand-name product. FDA acceptance of the carve-out label allows the generic company to place its drug on the market (assuming the ANDA meets other requirements), but only for a subset of approved uses - i.e., those not covered by the brand's patents.

Of particular relevance here, the FDA will not approve such an ANDA if the generic's proposed carve-out label overlaps at all with the brand's use code. The FDA takes that code as a given: It does not independently assess the patent's scope or otherwise look behind the description authored by the brand. According to the agency, it lacks "both the expertise and the authority" to review patent claims; although it will forward questions about the accuracy of a use code to the brand, its own "role with respect to patent listing is ministerial." Thus, whether section viii is available to a generic manufacturer depends on how the brand describes its patent. Only if the use code provides sufficient space for the generic's proposed label will the FDA approve an ANDA with a section viii statement.

The generic manufacturer's second option is to file a so-called paragraph IV certification, which states that a listed patent "is invalid or will not be infringed by the manufacture, use, or sale of the 
[generic] drug.". A generic manufacturer will typically take this path in either of two situations: if it wants to market the drug for all uses, rather than carving out those still allegedly under patent; or if it discovers, as described above, that any carve-out label it is willing to adopt cannot avoid the brand's use code. Filing a paragraph IV certification means provoking litigation. The patent statute treats such a filing as itself an act of infringement, which gives the brand an immediate right to sue.. Assuming the brand does so, the FDA generally may not approve the ANDA until 30 months pass or the court finds the patent invalid or not infringed. Accordingly, the paragraph IV process is likely to keep the generic drug off the market for a lengthy period, but may eventually enable the generic company to market its drug for all approved uses.

In the late 1990's, evidence mounted that some brands were exploiting this statutory scheme to prevent or delay the marketing of generic drugs, and the Federal Trade Commission (FTC) soon issued a study detailing these anticompetitive practices. That report focused attention on brands' submission of inaccurate patent information to the FDA. In one case cited by the FTC, Mylan Pharmaceuticals, Inc. $v$. Thompson, a brand whose original patent on a drug was set to expire listed a new patent ostensibly extending its rights over the drug, but in fact covering neither the compound nor any method of using it. The FDA, as was (and is) its wont, accepted the listing at its word and accordingly declined to approve a generic product. The generic manufacturer sued to delete the improper listing from the Orange Book, but the Federal Circuit held that the Hatch-Waxman Amendments did not allow such a right of action. As the FTC noted, that ruling meant that the only option for generic manufacturers in Mylan's situation was to file a paragraph IV certification (triggering an infringement suit) and then wait out the usual 30-month period before the FDA could approve an ANDA.

Congress responded to these abuses by creating a mechanism, in the form of a legal counterclaim, for generic manufacturers to challenge patent information a brand has submitted to the FDA. The provision authorizes an ANDA applicant sued for patent infringement to "assert a counterclaim seeking an order requiring the [brand] to correct or delete the patent information submitted by the [brand] under subsection (b) or (c) [of S 355] on the ground that the patent does not claim either (aa) the drug for which the [brand's NDA] was approved; or (bb) an approved method of using the drug."

The counterclaim thus enables a generic competitor to obtain a judgment directing a brand to "correct or delete" certain patent information that is blocking the FDA's approval of a generic product. This case raises the question whether the counterclaim is available to fix a brand's use code.
21 U.S.C. S 355(j)(2)(A)(vii)(IV)

35 U.S.C. S $271(e)(2)(A)$

Mylan v. THompson: 268 F.3d 1323 (Fed. Cir. 2001)

21 U.S.C. S 355(j)(5)(C)(ii)(I)

Justice Kagan's statutory construction discussion makes for entertaining reading but would take us too far afield. Here's a sample: "'Not an' sometimes means 'not any', in the way Novo claims. If your spouse tells you he is late because he 'did not take a cab,' you will infer that he took no cab at all (but took the bus instead). But now stop a moment. Suppose your spouse tells you that he got lost because he 'did not make a turn.' You would understand that he failed to make a particular turn, not that he drove from the outset in a straight line." 
The text and context of the provision demonstrate that a generic company can employ the counterclaim to challenge a brand's overbroad use code. The Hatch-Waxman Amendments authorize the FDA to approve the marketing of a generic drug for particular unpatented uses; and section viii provides the mechanism for a generic company to identify those uses, so that a product with a label matching them can quickly come to market. The statutory scheme, in other words, contemplates that one patented use will not foreclose marketing a generic drug for other unpatented ones. Within that framework, the counterclaim naturally functions to challenge the brand's assertion of rights over whichever discrete use (or uses) the generic company wishes to pursue. That assertion, after all, is the thing blocking the generic drug's entry on the market. The availability of the counterclaim thus matches the availability of FDA approval under the statute: A company may bring a counterclaim to show that a method of use is unpatented because establishing that fact allows the FDA to authorize a generic drug via section viii.

Consider the point as applied to this case. Caraco wishes to market a generic version of repaglinide for two (and only two) uses. Under the statute, the FDA could approve Caraco's application so long as no patent covers those uses, regardless whether a patent protects yet a third method of using the drug. Novo agrees that Caraco could bring a counterclaim if Novo's assertion of patent protection for repaglinide lacked any basis - for example, if Novo held no patent, yet claimed rights to the pair of uses for which Caraco seeks to market its drug. But because Novo has a valid patent on a different use, Novo argues that Caraco's counterclaim evaporates. And that is so even though, once again, Caraco has no wish to market its product for that patented use and the FDA stands ready, pursuant to the statute, to approve Caraco's product for the other two. To put the matter simply, Novo thinks the counterclaim disappears because it has a patent for a method of use in which neither Caraco nor the FDA is interested at all.

Another aspect of the counterclaim provision - its description of available remedies-dispatches whatever remains of Novo's arguments. According to the statute, a successful claimant may obtain an order requiring the brand to "correct or delete" its patent information. Our interpretation of the statute gives content to both those remedies: It deletes a listing from the Orange Book when the brand holds no relevant patent and corrects the listing when the brand has misdescribed the patent's scope. By contrast, Novo's two arguments would all but read the term "correct" out of the statute. 
Company A sues Company B for patent infringement. The two companies settle under terms that require (1) Company B, the claimed infringer, not to produce the patented product until the patent's term expires, and (2) Company A, the patentee, to pay B many millions of dollars. Because the settlement requires the patentee to pay the alleged infringer, rather than the other way around, this kind of settlement agreement is often called a "reverse payment" settlement agreement. And the basic question here is whether such an agreement can sometimes unreasonably diminish competition in violation of the antitrust laws.

Apparently most if not all reverse payment settlement agreements arise in the context of pharmaceutical drug regulation, and specifically in the context of suits brought under statutory provisions allowing a generic drug manufacturer (seeking speedy marketing approval [under an ANDA]) to challenge the validity of a patent owned by an already-approved brand-name drug owner.

The Hatch-Waxman Act requires the generic manufacturer in its Abbreviated New Drug Application to "assure the FDA" that the generic "will not infringe" the brand-name's patents. The generic can provide this assurance in one of several ways.. It can certify that the brand-name manufacturer has not listed any relevant patents. It can certify that any relevant patents have expired. It can request approval to market beginning when any still-in-force patents expire. Or, it can certify that any listed, relevant patent "is invalid or will not be infringed by the manufacture, use, or sale" of the drug described in the Abbreviated New Drug Application. Taking this lastmentioned route (called the "paragraph IV" route), automatically counts as patent infringement, and often means provoking litigation. If the brand-name patentee brings an infringement suit within 45 days, the FDA then must withhold approving the generic, usually for a 30-month period, while the parties litigate patent validity (or infringement) in court. If the courts decide the matter within that period, the FDA follows that determination; if they do not, the FDA may go forward and give approval to market the generic product.

Hatch-Waxman provides a special incentive for a generic to be the first to file an ANDA taking the paragraph IV route. That applicant will enjoy a period of 180 days of exclusivity (from the first commercial marketing of its drug). During that period of exclusivity no other generic can compete with the brand-name drug. If the first-to-file generic manufacturer can overcome any patent obstacle and bring the generic to market, this 180-day period of exclusivity can prove valuable, possibly worth several hundred million dollars. Indeed, the Generic Pharmaceutical Association said in 2006 that the "vast majority of potential profits for a generic drug manufacturer materialize during the 180-day exclusivity period." The 180-day ex-
21 U.S.C. § 355(j)(2)(A)(vii)

35 U.S.C. § $271(\mathrm{e})(2)(\mathrm{A})$

21 U.S.C § 355(j)(5)(B)(iv) 
clusivity period, however, can belong only to the first generic to file. Should that first-to-file generic forfeit the exclusivity right in one of the ways specified by statute, no other generic can obtain it.

In 1999, Solvay Pharmaceuticals, a respondent here, filed a New Drug Application for a brand-name drug called AndroGel. The FDA approved the application in 2000. In 2003, Solvay obtained a relevant patent and disclosed that fact to the FDA, as Hatch-Waxman requires.

Later the same year another respondent, Actavis, Inc. (then known as Watson Pharmaceuticals), filed an Abbreviated New Drug Application for a generic drug modeled after AndroGel. [Other parties omitted.] Solvay initiated paragraph IV patent litigation against Actavis and Paddock. Thirty months later the FDA approved Actavis' first-to-file generic product, but, in 2006, the patent-litigation parties all settled. Under the terms of the settlement Actavis agreed that it would not bring its generic to market until August 31, 2015, 65 months before Solvay's patent expired (unless someone else marketed a generic sooner). Actavis also agreed to promote AndroGel to urologists. Solvay agreed to pay an estimated \$19-\$30 million annually, for nine years, to Actavis. The companies described these payments as compensation for other services Actavis promised to perform, but the FTC contends the other services had little value. According to the FTC the true point of the payments was to compensate Actavis for agreeing not to compete against AndroGel until 2015.

On January 29, 2009, the FTC filed this lawsuit against all the settling parties. The FTC's complaint alleged that respondents violated $\S 5$ of the Federal Trade Commission Act by unlawfully agreeing "to share in Solvay's monopoly profits, abandon their patent challenges, and refrain from launching their low-cost generic products to compete with AndroGel for nine years."

Solvay's patent, if valid and infringed, might have permitted it to charge drug prices sufficient to recoup the reverse settlement payments it agreed to make to its potential generic competitors. And we are willing to take this fact as evidence that the agreement's anticompetitive effects fall within the scope of the exclusionary potential of the patent. But we do not agree that that fact, or characterization, can immunize the agreement from antitrust attack.

This Court's precedents make clear that patent-related settlement agreements can sometimes violate the antitrust laws. For one thing, to refer simply to what the holder of a valid patent could do does not by itself answer the antitrust question. The patent here may or may not be valid, and may or may not be infringed. And that exclusion may permit the patent owner to charge a higher-than-competitive price for the patented product. But an invalidated patent carries with it no such right. And even a valid patent confers no right to exclude products or processes that do not actually infringe. The paragraph 
IV litigation in this case put the patent's validity at issue, as well as its actual preclusive scope. The parties' settlement ended that litigation. The FTC alleges that in substance, the plaintiff agreed to pay the defendants many millions of dollars to stay out of its market, even though the defendants did not have any claim that the plaintiff was liable to them for damages. That form of settlement is unusual. There is reason for concern that settlements taking this form tend to have significant adverse effects on competition.

Given these factors, it would be incongruous to determine antitrust legality by measuring the settlement's anticompetitive effects solely against patent law policy, rather than by measuring them against procompetitive antitrust policies as well. Rather, the general procompetitive thrust of the Hatch-Waxman Act, its specific provisions facilitating challenges to a patent's validity, and its later-added provisions requiring parties to a patent dispute triggered by a paragraph IV filing to report settlement terms to the FTC and the Antitrust Division of the Department of Justice, all suggest the contrary.

But, one might ask, as a practical matter would the parties be able to enter into such an anticompetitive agreement? Would not a high reverse payment signal to other potential challengers that the patentee lacks confidence in its patent, thereby provoking additional challenges, perhaps too many for the patentee to "buy off?" Two special features of Hatch-Waxman mean that the answer to this question is "not necessarily so." First, under Hatch-Waxman only the first challenger gains the special advantage of 180 days of an exclusive right to sell a generic version of the brand-name product. And as noted, that right has proved valuable - indeed, it can be worth several hundred million dollars. Subsequent challengers cannot secure that exclusivity period, and thus stand to win significantly less than the first if they bring a successful paragraph IV challenge. That is, if subsequent litigation results in invalidation of the patent, or a ruling that the patent is not infringed, that litigation victory will free not just the challenger to compete, but all other potential competitors too (once they obtain FDA approval). The potential reward available to a subsequent challenger being significantly less, the patentee's payment to the initial challenger (in return for not pressing the patent challenge) will not necessarily provoke subsequent challenges. Second, a generic that files a paragraph IV after learning that the first filer has settled will (if sued by the brand-name) have to wait out a stay period of (roughly) 30 months before the FDA may approve its application, just as the first filer did. These features together mean that a reverse payment settlement with the first filer removes from consideration the most motivated challenger, and the one closest to introducing competition. It may well be that Hatch-Waxman's unique regulatory framework, including the special advantage that the 180- 
day exclusivity period gives to first filers, does much to explain why in this context, but not others, the patentee's ordinary incentives to resist paying off challengers (i.e., the fear of provoking myriad other challengers) appear to be more frequently overcome.

The FTC urges us to hold that reverse payment settlement agreements are presumptively unlawful and that courts reviewing such agreements should proceed via a "quick look" approach, rather than applying a "rule of reason." We decline to do so. That is because the likelihood of a reverse payment bringing about anticompetitive effects depends upon its size, its scale in relation to the payor's anticipated future litigation costs, its independence from other services for which it might represent payment, and the lack of any other convincing justification. The existence and degree of any anticompetitive consequence may also vary as among industries. These complexities lead us to conclude that the FTC must prove its case as in other ruleof-reason cases.

To say this is not to insist that the Commission need litigate the patent's validity, empirically demonstrate the virtues or vices of the patent system, present every possible supporting fact or refute every possible pro-defense theory. We leave to the lower courts the structuring of the present rule-of-reason antitrust litigation.

\section{Orphan Drugs}

Lietzan contrasts the "data exclusivity" granted to pioneer drugs to the "market exclusivity" granted to orphan drugs. This section considers the orphan-drug exclusivity in more detail. Because it prohibits any subsequent NDA, it is in effect a true IP regime that gives patent-like protection for the only economically significant use of a product.

\section{Genentech, Inc. v. Bowen}

As food and drug regulatory statues go, the Orphan Drug Act is relatively straightforward and politically uncontroversial. A pharmaceutical company often must spend $\$ 80$ million or more to develop a single new drug. When the potential market for a drug is small-because the number of persons afflicted with the particular disease or condition which the drug treats is relatively small - it may be impossible for the manufacturer to recover its sizable research and development investment, much less realize an acceptable return on that investment. The Act is designed to combat the general unwillingness of pharmaceutical manufacturers to invest in the development of commercial drugs for the treatment of diseases which, although devastating to their victims, afflict too small a proportion of the population to make them commercially viable. 
The Act seeks to encourage the development of "orphan drugs" by reducing the overall financial cost of development, while enhancing the developer's ability to recover that cost through sale of the drug. Specifically, the Act attempts to reduce development costs by streamlining the FDA's approval process for orphan drugs, by providing tax breaks for expenses related to orphan drug development, [by authorizing the FDA to assist in funding the clinical testing necessary for approval of an orphan drug, and by creating an Orphan Products Board to coordinate public and private development efforts. The Act seeks to enhance the orphan drug manufacturer's ability to recover his investment by granting the manufacturer seven years of exclusive marketing rights "for such drug for such [rare] disease or condition." A "rare disease or condition" is one which "affects less than 200,000 persons in the United States," or one which "affects more than 200,000 in the United States and for which there is no reasonable expectation that the cost of developing and making available in the United States a drug for such disease or condition will be recovered from sales in the United States of such drug."

Qualification for orphan drug benefits occurs in a two-step process. At any phase of the research and development process, a manufacturer who believes its drug will treat a "rare disease or condition" may apply to the FDA for designation as "a drug for a rare disease or condition." Although the Act does not limit the number of drugs that may be designated for treatment of a particular rare disease the FDA's present policy is to not consider requests for orphan drug designation made after that drug has received full FDA marketing approval for that particular disease.

While any number of drugs may receive the development-phase benefits of the Act, only one manufacturer may receive exclusive marketing rights. This post-development benefit is reserved for the first manufacturer to receive full FDA approval of its drug as safe and effective for commercial sale.

If the FDA $\ldots$ approves an application ... for a drug designated under section $360 \mathrm{bb}$ of this title for a rare disease or condition, the FDA may not approve another application ... for such drug for such disease or condition for a person who is not the holder of such approved application ... until the expiration of seven years from the date of approval of the approved application. ...

The FDA may authorize another manufacturer to produce "such drug for such disease or condition" only if the exclusive marketer consents in writing or is incapable of providing sufficient quantities of the drug.

As originally enacted, the Act limited the availability of exclusive 
marketing rights to drugs "for which a United States Letter of Patent may not be issued...." In considering the proposed legislation, the House Committee on Energy and Commerce found that many potential orphan drugs are not patentable, and stated: "In order to provide some incentive for the development of these particular orphan drugs, the Committee's bill includes an exclusive marketing right for the sponsor of such a drug." Thus, the exclusivity provision of the Act was designed to complement the patent laws, filling gaps which might leave orphan drug manufacturers unprotected.

In 1985, Congress amended the Act to delete the non-patentability criterion in the exclusivity provision. The Committee's expectation when it drafted the original provision in 1983 had been that exclusivity would be used primarily by orphan drugs that could not get product patents. However, experience under the Act demonstrated that reliance on the incentives of patent protection for all patentable orphan drugs would be insufficient. First, many patents expire before completion of the clinical testing necessary for FDA marketing approval. Second, in many cases the product patent on a drug is held by an individual or company other than the one that intends to test the drug for use against a rare disease, and prior academic publication in the area precludes issuance of a use patent. Accordingly, the fact that a product patent has been issued does not always ensure that a manufacturer will have a sufficient incentive to apply for permission to market the drug as an orphan drug.

In expanding the exclusivity provision to cover both patented and unpatented orphan drugs, the Committee noted that the provision would only benefit the sponsors of drugs with less than seven years of product patent protection available, and explained the difference between exclusivity under the Act and traditional patent protection. First, traditional patents generally offer much broader protection than orphan drug exclusivity, which is limited to treatment of a particular disease. Second, while the inviolability of a patent is limited only by the holder's ability to enforce his rights in court, orphan drug exclusivity exists only so long as the sponsor adequately supplies the market.

The Committee expressed its desire that elimination of the patentability distinction, while probably still not making orphan drugs profitable business ventures, would strengthen development by providing greater certainty to potential orphan drug sponsors. tion known as carnitine deficiency in people with inborn metabolic 
disorders. ${ }^{1}$ The FDA designated Sigma-Tau's levocarnitine drug an "orphan drug" and approved Sigma-Tau's application to market it. Its exclusivity for inborn metabolic disorders expired in 1999.

Sigma-Tau later received FDA approval for use of its levocarnitine drug for the prevention and treatment of a second rare condition carnitine deficiency in patients with end-stage renal disease who are undergoing dialysis. Sigma-Tau's exclusivity for treating carnitine deficiency in ESRD patients expires in 2006.

The FDA recently approved the applications of two drug manufacturers, private intervenor Gensia Sicor Pharmaceuticals, Inc. and Bedford Laboratories, to market and sell generic forms of SigmaTau's levocarnitine drug. The agency approved the generics for the treatment of patients with inborn metabolic disorders, the unprotected indication. The generics compete with Carnitor.

As a result of these generic drug approvals, Sigma-Tau brought suit against the FDA on May 10, 2001. Sigma-Tau sought to have the approvals rescinded, or, in the alternative, to have the FDA change the generics' labeling to protect Sigma-Tau's orphan exclusivity. Sigma-Tau submits that the generics were in fact intended for use in patients with ESRD who are undergoing dialysis, and that they thereby infringed on the seven-year period of orphan exclusivity that Carnitor currently enjoys under the ODA.

The plain language of the ODA is unambiguous, and the FDA's approvals of the generics in this case comported with the clear wording of the statute. It is apparent that the FDA did not "approve another application ... for such drug for such disease or condition" here, but rather approved "another application ... for such drug" for a different disease or condition, one that was no longer subject to exclusivity. That is, the agency approved generic versions of Sigma-Tau's levocarnitine drug for people with inborn metabolic disorders, for which the period of orphan exclusivity had expired. The FDA did not approve the generics for the treatment of ESRD patients.

By using the words "such drug for such disease or condition," Congress made clear its intention that $\S 360 \mathrm{cc}(\mathrm{a})$ was to be diseasespecific, not drug-specific. In other words, the statute as written protects uses, not drugs for any and all uses.

Sigma-Tau contends that the FDA was obligated to look beyond the labeling to what Sigma-Tau maintains is the reality of the situation, which is that most of the need for the generics - and thus most of the money to be made - lies in treating patients with ESRD. But this point is unavailing.

\footnotetext{
${ }^{1}$ Carnitine deficiency can manifest itself in many ways, including the failure to thrive in infants, cardiomyopathy, recurrent infections, muscle weakness, and liver dysfunction.
} 
The evidentiary basis for the agency's approvals must be the use for which the approvals are sought - that is, the use for which the generics are labeled. The FDA necessarily approves the generics before their manufacturers engage in any actual marketing. If we were to ignore the deference due the FDA and impose exacting evidentiary standards upon its generic drug approval process, the agency would be faced with formidable problems. This is because many of the sources of evidence and market data to which Sigma-Tau points cannot be effectively analyzed in the pre-approval context. Thus, the intended-use inquiry Sigma-Tau urges upon us might evolve into a foreseeable-use test. Then, once the FDA approved an orphan drug for a protected indication, generic competitors might be prohibited from entering the market for almost any use.

As the district court noted, not only might this course of events result in extensions of exclusivity periods that Congress never intended, but it also might frustrate the longstanding practice of Congress, the FDA, and the courts not to interfere with physicians' judgments and their prescription of drugs for off-label uses. In light of the ensuing effects on the delivery of health care and drug prices in this country, such interference with off-label use is not something we would be wise to welcome, let alone help to bring about. Even Sigma-Tau appears to agree that the medical community's foreseeable off-label use of drugs does not violate the ODA.

\section{Drug Marketing}

Even after approval, the regulatory regime for dugs creates interesting intellectual property issues because the marketing of drugs is heavily restricted. We focus on issues relating to drugs' names, physical design, and advertising.

\section{Names}

Trademark law regulates drug names to prevent confusion. But it is

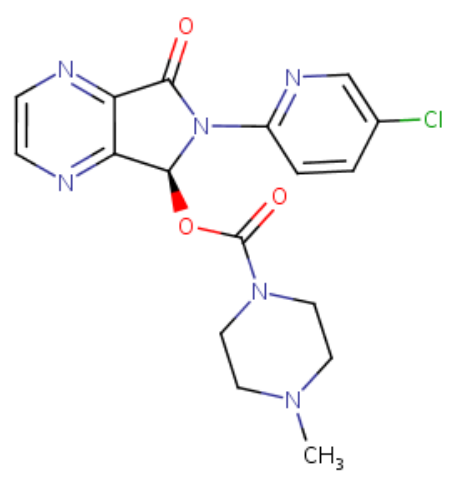

A chemical not the only body of law that does so: the FDA also limits what drug makers can and cannot call their drugs.

\section{Note on Drug Naming}

Drug names are trademarks, right? So trademark law applies? Yes, but.

Any given drug typically has numerous names. (To illustrate, we'll focus on drugs with a single active ingredient.) Consider as an example the chemical with the following molecular structure shown in the margin. It has the molecular formula $\mathrm{C}_{17} \mathrm{H}_{17} \mathrm{ClN}_{6} \mathrm{O}_{3}$, but the molecular formula is a poor name, because it is far from unique. 
Many other organic compounds also have seventeen carbon atoms, seventeen hydrogens, a chlorine, a nitrogen, and six oxygens. Instead, here are some of the names this molecule goes by:

- IUPAC Name: According to the Nomenclature of Organic Chemistry, a 1600-page guide published and regularly revised by the International Union of Pure and Applied Chemists, the preferred IUPAC name of this molecule is [(7S)-6-(5-chloropyridin-2-yl)-5-oxo-7H-pyrrolo[3,4-b]pyrazin-7-yl] 4-methylpiperazine-1-carboxylate. This name is derived by systematically listing each component of the molecule, one at a time. Here, for example, 5-chlorpoyridine-2-yl describes the ring at the right of the molecule, with the 5 specifying where the chlorine atom is attached to it and the 2 specifying where it is attached to the rest of the molecule. The Nomenclature describes in exacting detail the components, their names, the order to list them in, and the various numbers, hyphens, and other connectives that explain the components' relationship in the molecule. In trademark terms, the IUPAC name describes the molecule's structure and is intended to serve as a generic term for it.

- InChI: The IUPAC name contains components like chlorpoyridine that reflect the history of the common names people gave to molecules and their parts: pyridine is the nitrogen ring by itself. These common names don't directly reflect the underlying structure, so translating them back into the structure requires a great deal of knowledge about the different components and their names. The IUPAC has also promulgated a system, called InChI (short for "International Chemical Identifier") for converting molecular structures into more completely explicit descriptions that can be more straightforwardly converted back. The InChI for this molecule is InChI $=1 \mathrm{~S} / \mathrm{C} 17 \mathrm{H} 17 \mathrm{ClN} 603 / \mathrm{c} 1-22-6-8-23(9-7-22) 17(26) 27-16-14-13(19-4-5-20-14) 15$ (25) 24 (16) 12 The InChI individually names each atom in the molecule, so it is longer, but also a little more transparent - which makes it easier for computers to reason about molecular structure. (A similar but somewhat less rigorous description system called SMILES would describe the molecule as $\mathrm{CN} 1 \mathrm{CCN}(\mathrm{CC} 1) \mathrm{C}(=0) \mathrm{OC} 2 \mathrm{C} 3=\mathrm{NC}=\mathrm{CN}=\mathrm{C} 3 \mathrm{C}(=0) \mathrm{N} 2 \mathrm{C} 4=\mathrm{NC}=\mathrm{C}(\mathrm{C}=\mathrm{C} 4) \mathrm{Cl}$. $)$ The InChI also describes the molecule's structure and is intended to serve as a generic term for it.

- CAS Registry Number: IUPAC names and InChIs are long and can be unwieldy - imagine transcribing an InChI trying to make sure you had each digit right, or glancing at two IUPAC names to see whether they were the same. The Chemical Abstracts 
Service, operated by the American Chemical Society (the leading professional organization for chemists in the United States) maintains an index of molecules that operates on very different principles. Each molecule in the index has a systematic name given according to the system Naming and Indexing of Chemical Substances for Chemical Abstracts published by the CAS - very much like the IUPAC system but only 156 pages and different in some respects - but also an index number, which has no chemical significance, i.e. bears no relationship to the molecule's structure. Nonetheless, it is still intended to serve as a generic term for the molecule: anyone who looks up 138729-47-2 in the CAS Registry will find the molecular diagram and its systematic name, along with much more information about it. Because they are short, CAS Registry numbers are easier to read aloud and recognize at a glance; they are also commonly used in computer databases of chemicals. CAS Registry Numbers are assigned by the CAS; one must submit an application and pay a fee to obtain one. But as just noted, they are not "owned" by the applicant; the point is to make information about the chemical available to all (useful, for example, if one would like to advertise and sell a new compound one has just formulated).

- InChIKey: An interesting hybrid of the InChI and CAS Registry Number is the InChIKey. Take an InChI, and then run it through a hashing algorithm (specified by IUPAC) to yield a unique string of letters and numbers with a fixed length and format. This string has no chemical meaning, just like a CAS Registry Number. But it is decentralized like an InChI: anyone can come up with one. This molecule's InChIKey is GBBSUAFBMRNDJC-INIZCTEOSA-N.

- Adopted Name: All of these chemical names aren't particularly meaningful to humans. So humans have given the molecule an adopted name (also called a "nonproprietary name"): eszopiclone. Adopted names for drugs are assigned by the United States Adopted Names Council, which is sponsored by the American Medical Association, the United States Pharmacopeial, and the American Pharmacists Association, and collaborates with the FDA. It works with applicants - typically companies considering manufacturing drugs - to devise appropriate adopted names according to a detailed list of criteria. Here are a few of the principles:

1. A nonproprietary name should be useful primarily to health care practitioners, especially physicians, pharmacists, nurses, educators, dentists and veterinarians.

2.a The name for the active moiety of a drug should be a single 
word, preferably with no more than four syllables.

3.a A common, simple word element (a "stem") should be incorporated in the names of all members of a group of related drugs when pertinent, common characteristics can be identified, such as similarity of pharmacological action.

4. A name should be free from conflict with other nonproprietary names and with established trademarks and should be neither confusing nor misleading. ...

1. Prefixes that imply "better," "newer" or "more effective;" prefixes that evoke the name of the sponsor, dosage form, duration of action or rate of drug release should not be used. Examples include "dura," "forte," or "efex."

New adopted names are subject to a long list of specific requirements, such as that "the letter ' $f$ ' should be used instead of 'ph'." The USAN Council publishes a list of adopted names, and it also works with the applicant to forward proposed adopted names to the World Health Organization for inclusion in its own International Nonproprietary Names index. As the names of this type of name suggest, it too is meant to be generic in the sense that anyone is free to use the name to refer to the chemical - but notice how trademark considerations are starting to creep into the choice of names. Adopted names chosen this way are partly descriptive (look at those stems) and partly coined (look at the list of things the names may not describe). (Here is the USAN Council's statement on eszopiclone.)

- Established Name: The FDA considers some names to be "established names" for drugs - or, informally, the "generic name," because it generally functions as a generic name in the trademark law sense. The distinction between an adopted name and an established name is simply that the latter has the FDA's sanction as "the" generic name, not just "a" generic name. (As we will see in a moment, the FDA requires drugmakers to list the established name of their products, even when they also use a trademark). Where the USAN Council has selected an assigned name, the FDA will treat it as the established name, so the established name of this drug is also eszopiclone. But not all established names come through the USAN Council. Some drugs have "common names": i.e., the names that have come to be used generically by the public to refer to the drug. aspirin is an example.

- Proprietary Name: And now back to trademarks. When a drugmaker submits an application to the FDA, it must also list the proprietary name it proposes to market the drug under. The
For example, the stem -clone indicates a hypnotic traquilizer, the stem - cog is used for blood coagulation factors, and the stem -conazole describes an antifungal agent.

See 21 C.F.R. § 299.4

$$
\begin{aligned}
& \text { Are the following the names of drugs or } \\
& \text { of elves? } \\
& \text { - Frova } \\
& \text { - Erestor } \\
& \text { - Isentress } \\
& \text { - Qvar } \\
& \text { - Celeborn } \\
& \text { - Oropher } \\
& \text { See Which Is It: Prescription Drug or } \\
& \text { Tolkien Elf? at How Stuff Works: Enter- } \\
& \text { tainment }
\end{aligned}
$$


FDA will then engage in an extensive substantive examination of the name designed to minimize errors by medical professionals and patients. Under its Contents of a Complete Submission for the Evaluation of Proprietary Names (2016) and Best Practices in Developing Proprietary Names for Drugs (draft 2014), the FDA will, for example:

- Require that the proprietary name be different from the established name. Indeed, the proprietary name may not incorporate USAN stems at all.

- Reject proposed proprietary names that are confusingly similar to other proprietary names, established names, or ingredient names. This is a much more searching inquiry that the trademark likelihood of confusion analysis. The FDA will compare the proposed name against its Phonetic and Orthographic Computer Analysis system for lookalike and sound-alike combinations, and also conduct or require "simulation studies":

Name simulation tests should reflect the full range and variety of tasks involved in the prescribing, transcribing, dispensing, and administration of drugs, as well as tasks involved in consumer selection of OTC drugs. Simulations should include common and easily simulated characteristics of real use, such as using ruled or unruled paper, prescription pads, computer order entry, and telephone orders to approximate written, oral, and electronic prescribing in the setting of care for the proposed product (e.g., inpatient and outpatient settings, long-term care). Simulations also should approximate the diversity of real-world prescribing conditions by varying factors such as background noise, handwriting samples, different ink colors, directions for use, and different voices/accents. In addition, the simulation study should present the proprietary name with the corresponding product characteristics (e.g., strength, route, dosage, and frequency) that are likely to be used to communicate prescriptions and orders for the proposed product.

- Prevent the use of the same proprietary name on products with different active ingredients.

- Reject a proposed proprietary name that could "result in ... misbranding if it is false or misleading, such as by making 
misrepresentations with respect to safety or efficacy." The FDA elaborates:

For example, a fanciful proprietary name may misbrand a product by suggesting that it has some unique effectiveness or composition when it does not. For example, FDA likely would object to a proposed proprietary name that contained the prefix best or that sounds like best because it implies superiority over other currently available therapies. In the absence of appropriate scientific evidence to support claims that the product is superior to other competing products currently on the market to treat the condition, such a proposed name would be misleading.

Note that this review is separate and apart from the USPTO's review of a trademark application. This is true on the back end as well as the front end: someone proposing to sell a competing branded version of the same drug will need to get its name through the FDA's approval process, not just past the trademark standard. The result - as you can probably guess by now - is that the FDA's rigorous standards for proprietary names in effect create a special and distinctive trademark system for branded drugs. Here, our molecule is sold under the proprietary name Lunesta for the treatment of insomnia. The brand name doesn't directly say that it works as a sleep aid, but it certainly suggests certain appealing characteristics of one.

Senate Report No. 448, 87th Congress, 1st Session (1961) Administered Prices--Drugs

In addition to patent controls and the vast amounts spent on advertising and promotion, the control of the market by the large drug companies stems from a third source of power; this is their remarkable success in persuading physicians to prescribe by trade names rather than generic names. Where this is done the small manufacturer is automatically excluded from the market, regardless of whether the drugs are patented or non-patented, and the opportunity for price competition disappears. This state of affairs is furthered by anything which causes the physician to be apprehensive of, or have difficulty in, prescribing by generic names.

The multiplicity of names' for products in the drug industry virtually exceeds the bounds of human imagination. First, there is the chemical name which attempts to spell out the structural makeup of the drug; and here a variety of forms of expression is possible. Next comes the generic name which may or may not represent an abbrevi- 
ation of the more complex chemical name; this is the name commonly used to identify the drug in formularies, the teaching of medicine, etc. Ordinarily a drug has one generic name, but there are cases where two or three are employed. Finally a drug usually has a host of individual trade names used by the various companies engaged in the promotion of the product. In consequence, a single drug product is represented in the market by such complex body of nomenclature as to intimidate even the initiates in the field. And if one can visualize this situation for a single drug multiplied by the thousands of drugs currently marketed, he can get some impression of the chaos existing in the area of drug nomenclature.

The new so-called synthetic penicillin illustrates the problem. The chemical name for this product is alpha-phenoxyethyl penicillin potassium. This set of syllables is also used as a generic name. In addition, there are two other generic names - potassium penicillin 152 and phenethicillin potassium. Since the product is protected by patent, there are only six sellers, each of whom markets under his own trade name. Thus the prescribing physician is bombarded with promotional material for Syncillin, Darcil, Alpen, Chemipen, Dramcillin-S, and Maxipen. All of these are, of course, the same chemical compound.

Speaking of them, Dr. Walter Modell, professor of pharmacology and therapeutics at Cornell University Medical College, stated:

They are colored differently (pink, peach, green, and two shades of yellow) and are advertised as distinctive materials but no effort is made in promotional material to inform the physician who is urged to use them that they are otherwise identical.

In this example the busy practitioner is confronted with three generic names, six brand names used as the name of the drug itself, and at least five different colors. Thus, there are 14 different identification symbols for the identical drug. In terms of nomenclature, each product stands isolated; indeed, there is an attempt to conceal the identical nature of the drug.

\section{Code of Federal Regulations}

Drugs; statement of ingredients 21 C.F.R. $\S 201.10(g)$
(1) If the label or labeling of a prescription drug bears a proprietary name or designation for the drug or any ingredient thereof, the established name, if such there be, corresponding to such proprietary name or designation shall accompany such proprietary name or designation ...

(2) The established name shall be printed in letters that are at least half as large as the letters comprising the proprietary name or 
designation with which it is joined, and the established name shall have a prominence commensurate with the prominence with which such proprietary name or designation appears, taking into account all pertinent factors, including typography, layout, contrast, and other printing features.

Kos Pharmaceuticals, Inc. v. Andrx Corp.

On October 3, 2000, Kos filed an application with the PTO to register ADVICOR as the mark for a new medication designed to improve cholesterol levels. This new drug combines 20 milligrams of lovastatin (which lowers LDL, or "bad" cholesterol) with varying strengths (500, 750, or 1000 milligrams) of an extended-release formulation of niacin (which increases HDL, or "good" cholesterol). Kos has been selling its proprietary extended-release form of niacin under the trade name Niaspan since 1997. In July 2001 Kos began advertising, and in December 2001 began selling, its new combination drug, Advicor.

Shortly after Kos began marketing Advicor, it learned that Andrx planned to use the mark ALTOCOR for its own new anticholesterol medication, which would contain only a single active ingredient, an extended-release form of lovastatin, in varying strengths (10, 20, 40 or 60 milligrams). Andrx announced on January 31, 2002 that it had received preliminary marketing approval for Altocor from the FDA. On February 5, 2002, the PTO published for opposition the ALTOCOR mark, which Andrx had applied to register in December 2000.

Kos tried to dissuade or otherwise prevent Andrx from using the ALTOCOR mark several times, both before and after Andrx began selling its new drug. Kos also expressed its concerns about potential confusion to the FDA division responsible for reviewing proposed new drug names from a public health perspective, the Office of Drug Safety's Division of Medication Errors and Technical Support. The Division of Medication Errors had preliminarily approved the name Altocor in November 2001. At that time, the Division stated that the "name Advicor looks and sounds similar to Altocor," but concluded that the "difference in the written strengths" of the drugs reduced the risk of "error ... between the two products."

The parties submitted competing medical affidavits to support their respective views as to the nature and severity of potential consequences of mis-filled prescriptions. Per Kos, niacin - and thus Advicor, but not Altocor - may cause serious injury, or even death, to patients with various conditions or sensitivities to the drug. Other, less serious, side effects of niacin may worry patients who have not been warned of those effects, and who may thus discontinue needed treatment. Patients who mistakenly receive Altocor rather than Advicor are also at risk, says Kos, since the conditions the niacin is meant
369 F.3d 700 (3d Cir. 2004) 
to address will remain untreated. Andrx, on the other hand, claims that the "safety profile of both products is similar" and that there need not be "any unusual concern" about "harm to the public if the Andrx product is substituted for the KOS product."

[The District Court denied a preliminary injunction. The Court of Appeals reversed. The excerpts that follow focus on the relationship between the FDA's consideration of the proposed name and the likelihood of confusion inquiry under the Lanham Act.]

The District Court used an overly narrow definition of confusion, in effect evaluating the likelihood of misdispensing rather than confusion. Andrx also claims that "the FDA and the USPTO have determined that the marks are not confusingly similar." But neither of those proceedings can supplant the required Lanham Act analysis. First, the FDA applies a standard different from the Lanham Act "likelihood of confusion" test at issue here. The FDA reviews proposed drug names to predict potential confusion that may arise in the actual prescription process. Misdispensing is not the only type of confusion actionable under the Lanham Act. Indeed, to the extent that the FDA's proprietary name review is relevant here, the reviewing division's statement that the "name Advicor looks and sounds similar to Altocor" actually supports Kos's claim.

The facial similarity of the marks is apparent on their face. Both are seven-letter, three-syllable words that begin and end with the same letters and the same sounds. The marks are also similar in that both are coined words, not found even in approximation in the English or any other familiar language. Two names that look and sound similar will naturally seem even more similar where there are no differences in meaning to distinguish them. Nor can the similarity of coined marks be explained by, or ameliorated by virtue of, any relationship between the marks and the products identified.

The district court and the parties treated medical professionals, such as doctors, nurses and pharmacists, as the relevant consumers.12 These trained professionals may be expected to be knowledgeable about, and to exercise care in distinguishing between, medicines. We have emphasized a countervailing concern that weighs against allowing the expertise of physicians and pharmacists to trump other factors in assessing the likelihood of confusion in drug cases. Prevention of confusion and mistakes in medicines is too vital to be trifled with since confusion in such products can have serious consequences for

\footnotetext{
${ }^{12}$ We note that neither the parties nor the court below addressed the possible confusion of ultimate consumers. While doctors and pharmacists play a gate-keeping role between patients and prescription drugs, they are not the ultimate consumers. Patients are. Courts have noted that drugs are increasingly marketed directly to potential patients through, for example, "ask-your-doctor-about-Brand-X" style advertising.
} 
the patient.

Andrx argues that confusion is even less likely here than in other cases involving medical professionals since prescriptions must reflect the different chemical composition of the drugs, with Advicor prescriptions specifying strengths of two active ingredients, and Altocor only one. Of course, this difference in prescribing is not relevant to the common practice of providing samples or to any type of confusion other than misdispensing. There is no reason to believe that medical expertise as to products will obviate confusion as to source or affiliation or other factors affecting goodwill.

Advicor and Altocor are both prescription drugs used to improve cholesterol levels. The products are of the same type and serve the same function in slightly different (but overlapping) ways that may be appropriate for slightly different (but overlapping) sets of patients. That doctors will need to decide which drug to prescribe does not mean they won't see the drugs as related or otherwise associate them. Indeed, it could be argued that the opposite is true, that is, that they will associate the products because they must consider both to decide which to prescribe.

The parties submitted competing medical affidavits to support their respective views as to the nature and severity of the potential consequences of a mis-filled prescription. Andrx also disputed Kos's allegations as to the risks of misdispensing by arguing it is extremely unlikely that a pharmacist would improperly fill a prescription. The district court resolved this dispute in Andrx's favor, holding that Kos had not proven that the public would face a serious health risk absent an injunction. The colloquy at the hearing shows that the court was impressed by the FDA's statement that the "possibility of confusion was minimal," and was persuaded that "it would be difficult to imagine a situation" where the drugs would be confused "when a pharmacist is filling a prescription." We note that, although the FDA's inquiry is not equivalent to the Lanham Act "likelihood of confusion" test, its review of proprietary drug names is relevant in assessing the health risks of mis-filled prescriptions. Indeed, the purpose of FDA review is to predict potential confusion that may arise in the actual prescription process. We defer to the district court's resolution of this factual dispute because its finding is supported by the record and is thus not clearly erroneous.

We must, however, distinguish between the court's finding that Kos did not establish a "serious health risk" and its conclusion that "therefore, the public interest does not favor" injunctive relief. While we defer to the former, the court's ultimate assessment of the public interest is clearly erroneous because it does not take into account the 
right of the public not to be deceived or confused.

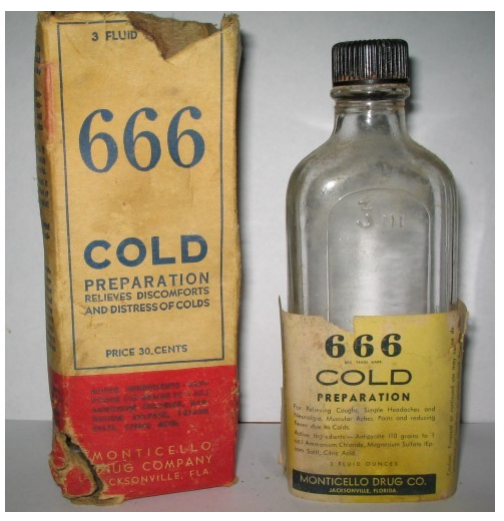

Bottle of 666 , date unknown.

329 F.3d 348 (3d Cir. 2003)

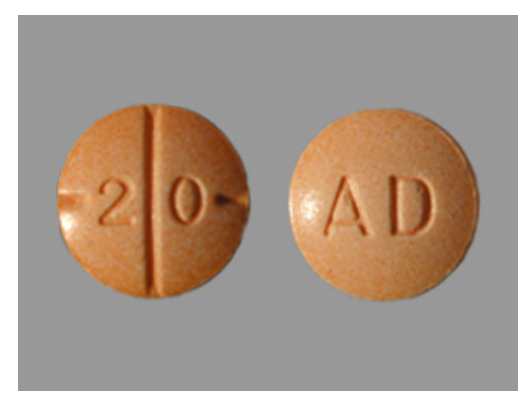

Shire 20mg Adderall mixed amphetamine salts

\section{Problem}

In United States v. 70 1/2 Dozen Bottles, and 76 1/2 Dozen Bottles of "666", 1938-1964 FDLI Jud. Rec. 89 (M.D. Ga. 1944), the Monticello Drug Company had sold a product containing quinine under the name "666". During World War II, the supply of quinine was restricted and Monticello stopped putting it in 666. It was seized and destroyed as a "misbranded drug" under the theory that keeping the same name and trade dress would mislead consumers into "accepting the new product under the impression that they were obtaining the old product." Is this theory sound? Is it consistent with what you know of trademark law?

\section{Design}

One might expect the law of drug trade dress to track the law of drug names closely. One would be wrong.

Shire US Inc. v. Barr Laboratories, Inc.

Adderall is a central nervous system stimulant used in treating attention deficit hyperactivity disorder (ADHD) available only by prescription and dispensed to patients in pharmacy vials labeled "prescription-only" as required by law. Adderall is composed of the mixed salts of a single-entity amphetamine and is a controlled substance. Shire first placed Adderall on the market in 1996 and since that time it has enjoyed substantial success so that by 2001 it had a $32 \%$ market share in the United States ADHD prescription market.

Adderall originally came in two dosage strengths and colors, 10 mg. (blue, round) and $20 \mathrm{mg}$. (orange, round). The tablets are currently either blue or pale orange/peach and either round or oval. Color and size vary with the tablet's strength, seven of which currently are prescribed: $5 \mathrm{mg}$. (blue, round), $7.5 \mathrm{mg}$. (blue, oval), $10 \mathrm{mg}$. (blue, round), $12.5 \mathrm{mg}$. (orange/peach, round), $15 \mathrm{mg}$. (orange/peach, oval), $20 \mathrm{mg}$. (orange/peach, round), and $30 \mathrm{mg}$. (orange/peach, round). Adderall tablets are scored and stamped with the mark "AD" on one side and the dosage size, e.g., "10" on the other.

Shire's product literature, promotional materials, and mailings, which its sales staff distributed to physicians, feature color pictures of the Adderall tablets and sometimes direct patients to examine the tablets to ensure that they have received exactly the drug prescribed. Shire does not advertise its products in general consumer publications, but pictures of Adderall tablets appear in the Physician's Desk Reference and in certain consumer books. While Shire continues to sell Adderall, it altered its marketing strategy for 2002 and discontin- 
ued promoting Adderall, promoting instead a patented, sustainedrelease version of the drug, Adderall XR.

Barr, a public company that develops and manufactures generic and proprietary pharmaceuticals, was the first manufacturer of a generic equivalent to Adderall. It began developing a generic amphetamine salt alternative in 1998 and started marketing it in February 2002 after submitting an ANDA" to the FDA and obtaining its approval. The FDA has approved Barr's generic amphetamine salts as safe and effective, and has classified Barr's product, which it manufactures in accordance with FDA regulations, as therapeutically equivalent to Adderall. Barr's product is the bioequivalent of Adderall, for which it thus may be interchanged freely. According to Shire, however, the products contain different inactive ingredients, and, in particular, Barr's tablets contain saccharin, a once controversial ingredient the FDA only recently removed from its list of banned substances.

Barr manufactures its generic amphetamine salts in $5 \mathrm{mg}$. (blue, oval), $10 \mathrm{mg}$. (blue, oval), $20 \mathrm{mg}$. (orange/peach, oval), and $30 \mathrm{mg}$. (orange/peach, oval) tablets. 9 Barr's generic amphetamine salts are oval and convex in shape. Both the size and the color of Barr's tablets are linked to dosage. The face of the tablets has a " $b$ " mark or the trade name Barr, and contains a numerical product code. The district court, on the basis of its physical examination of the tablets and the record before it, determined that while Barr's tablets, like Shire's, are blue and peach/light orange and those colors are keyed to dosage amounts, their shape and markings are different and "[j]uxtaposed against one another, the products are similar though not identical."

On April 30, 2002, Shire filed this action against Barr, alleging that Barr's sale of generic amphetamine salts copying Adderall's appearance constituted unfair competition and diluted Shire's rights under federal and state law. The district court found that Shire "has not credibly rebutted Barr's theory that the similar color-coding and shape of the products are particularly meaningful for ADHD patients and enhance efficacy" [and thus are functional].

Dr. Lawson F. Bernstein's declaration explains that because ADHD patients overuse visual cues, (1) when therapeutically equivalent ADHD products have similar visual recognition properties, adult ADHD patients will experience less confusion in correctly identifying the agent and/or its dosage strength; (2) given that almost all

\footnotetext{
${ }^{4}$ For Barr's product to be approved as a generic equivalent for Adderall, it was required to produce the same dosage strengths available for Adderall. Shire, however, launched its mid-range dosages (7.5 mg., $12.5 \mathrm{mg}$. and $15 \mathrm{mg}$.) after Barr filed its ANDA with the FDA. In an internal memorandum, Shire indicated that its motivation for introducing these new strengths was to "buy time" to protect market share because generic substitutes would not be available for all strengths, thereby minimizing competition from substitutes.
}

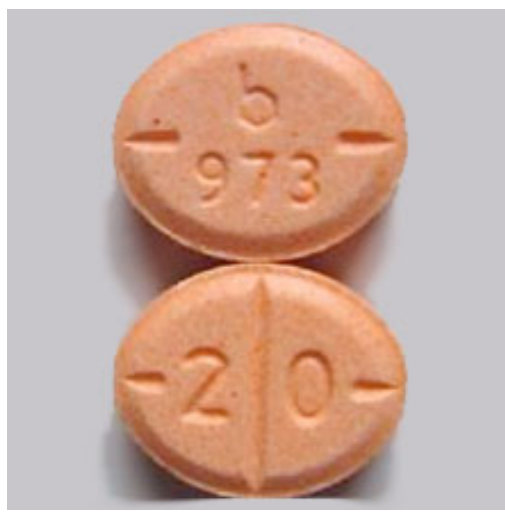

Barr 20mg mixed amphetamine salts 
patients require some initial dosage titration and a subsequent substantial majority require intermittent dosage adjustment, the color coding of a particular preparation of mixed amphetamine salts tablets confers a substantial degree of clinical functionality for the patient in the titration/adjustment process; (3) many adult patients may take multiple daily dosages of different strength amphetamine salts tablets, also inferring the usefulness of similar color-coding.

Dr. Blume's affidavit explains that a generic drug's similar appearance to the branded product "enhances patient safety and compliance with the medically prescribed dosing regimen" and that safety and compliance "would be particularly important for ADHD drugs when non-medical intermediaries (such as school secretaries) dispense mid-day doses to children [treated for ADHD]." Blume's affidavit explains, "Dosage form similarities enhance patient acceptance" and points to generic formulations of other central nervous system drugs that are identical or mirror the brand drug in color."

Gregory Drew, a registered pharmacist and Vice President of Pharmacy Health Services for Rite Aid Corporation, explains that Rite Aid prefers that "the generic tablet look as similar to the branded tablet as possible" so as to "increase patient acceptance and comfort," as well as compliance and that "all other things being equal, Rite Aid will choose to stock the generic product that most closely resembles the branded product."

Most of the opinions on which Shire relies were district court opinions from the early $1980 \mathrm{~s} 14$ which the court here was not bound to follow. In addition, the cases on which Shire relies are distinguishable on their facts.

Most significantly, though the cases involved prescription drugs, none involved controlled substances and in all of the cases there was evidence of the passing off of the defendant's product by pharmacists, or of an intent to induce illegal substitution on the defendant's part.

It is true that in several of the cases on which Shire relies, the defendant offered affidavits and declarations of pharmacists and physicians making claims relating to functionality that the courts in those cases did not credit the evidence. For example, in $S K \mathcal{E} F$, Co. v. Premo Pharmaceutical Lab., Dr. Shafer, a physician, submitted an affidavit in which he supported the sale of similarly configured generic tablets as he believed this configuration would enable the patient to feel confident that there was no change in the chemistry of the medication and

\footnotetext{
${ }^{14}$ Those cases were decided prior to: (1) the enactment in 1984 of the HatchWaxman amendment, which established a federal policy favoring the marketing of therapeutic equivalents of generic drugs, (2) the 1999 amendment to 15 U.S.C. $\S 1125(\mathrm{a})(3)$ which places the burden of proving non-functionality of unregistered trade dress on the plaintiff, and (3) the Supreme Court's decisions in Wal-Mart and TrafFix.
} 
that patients might become uneasy, confused or react adversely if the generic medication looked different from the market innovator. But we explained that the district court nevertheless "apparently chose not to credit the assertion of the Shafer affidavit, crediting instead the affidavits of Drs. Meyerson and Tannenbaum that in their experience the appearance of a drug bears no established relationship to its therapeutic efficacy." Just as in SKEF we deferred to the district court's findings of fact it is appropriate for us to do so in this case as well.

While district courts in this circuit have rejected functionality arguments similar to those the court credited in this case, other district courts, such as that in Ives Laboratories, Inc. v. Darby Drug Co. 19 , have credited similar testimony bearing on functionality. In Ives the manufacturer of the prescription drug cyclandelate sought an injunction against manufacturers of generic cyclandelate claiming that the defendants' use of the same capsule colors was "a false designation of origin" or a "false description or representation" of defendants' product. But the district court in Ives found that capsule colors were functional in several respects. "First, many elderly patients associate the appearance of their medication with its therapeutic effect. Second, some patients co-mingle their drugs in a single container and then rely on the appearance of the drug to follow their doctors' instructions. Third, to some limited extent color is also useful to doctors and hospital emergency rooms in identifying overdoses of drugs."

Jeremy A. Greene \& Aaron S. Kesselheim

Why Do the Same Drugs Look Different? Pills, Trade Dress, and Public Health

Protection of intellectual property covering the physical attributes of pills therefore served two primary purposes. One purpose of trade-dress protection was to reduce the practice of palming off. Premo Pharmaceuticals was sued for trade-dress infringement when it marketed its generic version of the diuretic hydrochlorothiazide/triamterene with a maroon-and-white capsule identical to that of brand-name drug Dyazide, produced by Smith, Kline and French. In SKEF, the Third Circuit Court of Appeals upheld trade-dress protection because near-identical pills would facilitate the practice of "unscrupulous pharmacists" in "substituting less expensive generic drugs for the brand name drugs prescribed without informing their customers and without passing along the benefit of the lower price." The court also found that the color scheme was nonfunctional be-

\footnotetext{
${ }^{19}$ The court of appeals reversed in Ives, but the Supreme Court in turn reversed the court of appeals in Inwood Laboratories, Inc. v. Ives Laboratories, Inc.
} 
Pennwalt: 472 F.Supp. 413 (E.D. Mich. 1979)

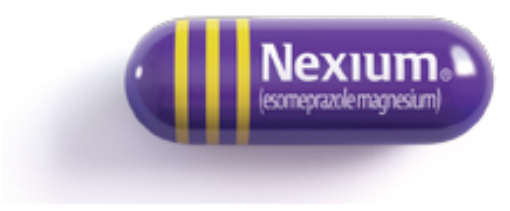

Image from AstraZeneca website at purplepill.com

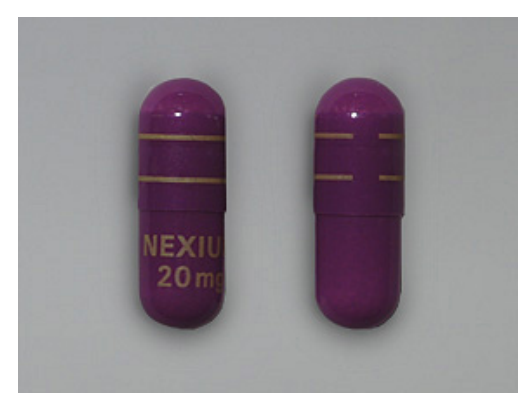

Nexium capsules

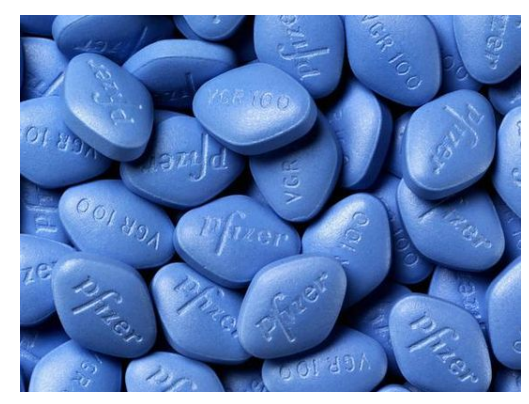

Viagra tablet cause it did not help patients identify the drug, pointing to other maroon-and-white capsules that were not diuretics.

A second purpose, the courts rationalized, was to allow tradedress protection to serve a public health function by preventing the substitution of a drug that was similar but not identical to another. In $S K \mathcal{E} F$, the two diuretic products were chemically equivalent, but their rate of absorption into the bloodstream (bioavailability) differed. In another case, a federal district court in Michigan enjoined a competitor from producing a version of the diet pill phentermine that was similar in appearance to a brand-name version because the efficacy of the hydrochloride salt of phentermine in the generic manufacturer's version did not necessarily match the efficacy of the brand-name manufacturer's phentermine resin complex, so the two drugs were not interchangeable. Pennwalt v. Zenith Laboratories. Notably, both these arguments upholding pharmaceutical trade-dress rights were meant to protect consumers from deception by the producers of look-alike drugs.

AstraZeneca's omeprazole (Prilosec) was widely promoted as "the purple pill" after its launch in 1989. As Prilosec's market exclusivity was ending, AstraZeneca launched the prescription-only follow-on product esomeprazole (Nexium) as "the new purple pill" in 2001 to encourage patients accustomed to taking Prilosec to switch to Nexium. Notably, when AstraZeneca began to sell omeprazole without a prescription as Prilosec OTC, the company changed the color of its product to salmon pink. Conversely, as Lilly's green-andcream capsule fluoxetine (Prozac, $20 \mathrm{mg}$ ) faced generic-drug competition in 2001, the company repackaged fluoxetine in pink-and-purple capsules and marketed it as a new drug, Sarafem $(20 \mathrm{mg})$, which was approved by the FDA in 2000 for the treatment of a new indication - perimenstrual dysphoric disorder. In this case, the change in color was designed to discourage physicians from prescribing the less expensive generic fluoxetine in place of Sarafem.

The 1997 FDA guidelines for expanding direct-to-consumer (DTC) advertising of prescription drugs further enhanced the power of pharmaceutical trade dress as broadcast campaigns began to include images of the pills themselves. One of the first drugs to be promoted heavily to consumers after its approval in 1998 was Viagra (sildenafil), Pfizer's drug for treating erectile dysfunction. The company included a picture of the drug in nearly all the advertisements for it, which served to identify the brand of Viagra with both the color (pale blue) and the shape (diamond) of the tablets.

[Despite Shire,] claims of trade dress remain vital in the pharmaceutical market. With increasing generic competition, trade-dress strategies are described in industry publications as ways for innovator firms to retain market share for their products after their patents 
and market exclusivity expire. During at least the past 5 years, brandname pharmaceutical companies have begun to license their trade dress to manufacturers of so-called authorized generics, which advertise the characteristic of similar appearance as a reason for consumers to use these products.

If brand-name pharmaceutical manufacturers are no longer able to rely on trade dress to protect the attributes of their products, federal policies affecting this field need to be sharply reconsidered. A first step toward reform would be to include FDA certification of pharmaceutical size, shape, and color in the drug-approval process. For example, a pill's attributes could be proposed by the manufacturer during the original New Drug Application. Currently, such a process occurs for the brand name of the medication; extending it to pill appearance should not require additional legislation. This would create a clear path for generic manufacturers to declare during the ANDA process that their products have similar appearances. Where these drugs do differ (e.g., as in dyes, fillers, or excipients), physicians or pharmacists could still locate manufacturer data from unique identifier codes embossed on pills. Further public health benefits could emerge if the reduction in trade dress helps to combat the physician's persistent use of, and the patient's preference for, costly brands when generic equivalents are available.

The obvious limitation of this approach is that it would apply only to newly introduced pharmaceutical products, leaving most of the existing therapeutic armamentarium unaffected. Therefore, we suggest that a rational scheme be created for pharmaceuticals that have already been approved whereby each distinct agent could be identified by a combination of its size, shape, and color. An example of such a scheme is the successful introduction in the United Kingdom of color-coding for metered-dose inhalers. Patients with asthma had frequently confused bronchodilators with steroid inhalers, leading the National Health Service to systematize inhaler appearance: all short-acting inhalers (bronchodilators) became blue and all preventive agents (steroids) became brown, orange, or burgundy. A similar color-coding scheme was piloted in the United States for ophthalmologic products, in which the caps on generic preparations of atropine, pilocarpine, and other drug products having multiple strengths were color-coded to match those of the innovator-drug products.

\section{Labeling and Advertising}

The FDA strictly controls what drug makers must, may, and may not say when marketing their drugs. (In particular, all approved drugs must have a "label" that gives detailed information on how to use them and on potential health risks form using them.) These rules de- 
(1999) (last updated 2002)

21 U.S.C. § 352(n)

21 CFR § 202.1

21 CFR § 202.1(e)(1) part - in several fairly significant ways - from the usual general rules for false advertising. Hatch-Waxman requires that generic versions of a drug have a label that is "the same as the labeling approved for" the drug they copy. Is it any surprise that legally mandated copying raises intellectual property issues?

\section{Consumer-Directed Broadcast Advertisements: Guidance for Industry}

This guidance is intended to assist sponsors who are interested in advertising their prescription human and animal drugs, including biological products for humans, directly to consumers through broadcast media, such as television, radio, or telephone communications systems.

The Federal Food, Drug, and Cosmetic Act (the Act) requires that manufacturers, packers, and distributors (sponsors) who advertise prescription human and animal drugs, including biological products for humans, disclose in advertisements certain information about the advertised product's uses and risks. For prescription drugs and biologics, the Act requires advertisements to contain "information in brief summary relating to side effects, contraindications, and effectiveness" . The resulting information disclosure is commonly called the brief summary.

The prescription drug advertising regulations distinguish between print and broadcast advertisements. Print advertisements must include the brief summary, which generally contains each of the risk concepts from the product's approved package labeling. Advertisements broadcast through media such as television, radio, or telephone communications systems must disclose the product's major risks in either the audio or audio and visual parts of the presentation; this is sometimes called the major statement.

Sponsors of broadcast advertisements are also required to present a brief summary or, alternatively, may make "adequate provision ... for dissemination of the approved or permitted package labeling in connection with the broadcast presentation". This is referred to as the adequate provision requirement. The regulations thus specify that the major statement, together with adequate provision for dissemination of the product's approved labeling, can provide the information disclosure required for broadcast advertisements.

The purpose of this guidance is to describe an approach that FDA believes can fulfill the requirement for adequate provision in connection with consumer-directed broadcast advertisements for prescription drug and biological products. The approach presumes that such advertisements:

- Are not false or misleading in any respect. For a prescription drug, this would include communicating that the advertised 
product is available only by prescription and that only a prescribing healthcare professional can decide whether the product is appropriate for a patient.

- Present a fair balance between information about effectiveness and information about risk.

- Include a thorough major statement conveying all of the product's most important risk information in consumer-friendly language.

- Communicate all information relevant to the product's indication (including limitations to use) in consumer-friendly language.

A sponsor wishing to use consumer-directed broadcast advertisements may meet the adequate provision requirement through an approach that will allow most of a potentially diverse audience to have reasonably convenient access to the advertised product's approved labeling. One acceptable approach to disseminating the product's approved labeling is described below. This approach includes the following components.

- Disclosure in the advertisement of an operating toll-free telephone number for consumers to call for the approved package labeling.

- Reference in the advertisement to a mechanism to provide package labeling to consumers with restricted access to sophisticated technology, such as the Internet, and those who are uncomfortable actively requesting additional product information or are concerned about being personally identified in their search for product information. [The FDA recommended print advertisements or "the availability of sufficient numbers of brochures containing package labeling in a variety of publicly accessible sites (e.g., pharmacies, doctors' offices, grocery stores, public libraries)."]

- Disclosure in the advertisement of an Internet web page (URL) address that provides access to the package labeling.

- Disclosure in the advertisement that pharmacists, physicians (or other healthcare providers), or veterinarians (in the case of animal drugs) may provide additional product information to consumers.

Letter from Robert Dean, Division Director, OPDP, FDA, to Eric Gervais Dear Mr. Gervais:

The Office of Prescription Drug Promotion (OPDP) of the U.S. Food and Drug Administration (FDA) has reviewed the Kim Kardashian Social Media Post for DICLEGIS (doxylamine succinate and 
21 U.S.C. §§ 352(a), (n); 321(n); 331(a). See 21 CFR § 202.1(e)(5)

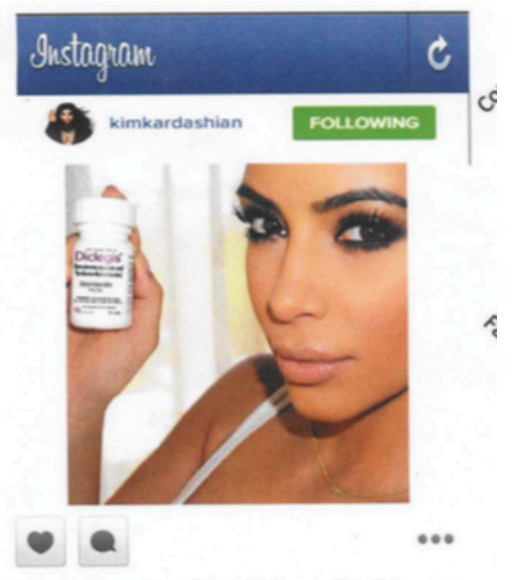

OMG. Have you heard about this? As you guys know my \#morningsickness has been pretty bad. I tried changing things about my lifestyle, like my diet, but nothing helped, so I talked to my doctor. He prescribed me \#Diclegis, and I felt a lot better and most importantly, it's been studied and there was no increased risk to the baby. I'm so excited and happy with my results that I'm partnering with Duchesnay USA to raise awareness about treating morning sickness. If you have morning sickness, be safe and sure to ask your doctor about the pill with the pregnant woman on it and find out more www.diclegis.com; www.DiclegisImportantSafetylnfo.com

The challenged Kim Kardashian Social Media Post pyridoxine hydrochloride) delayed-release tablets, for oral use (DICLEGIS) submitted by Duchesnay, Inc. (Duchesnay) under cover of Form FDA 2253. The social media post was also submitted as a complaint to the OPDP Bad Ad Program. The social media post is false or misleading in that it presents efficacy claims for DICLEGIS, but fails to communicate any risk information associated with its use and it omits material facts. Thus, the social media post misbrands DICLEGIS within the meaning of the FDCA and makes its distribution violative. These violations are concerning from a public health perspective because they suggest that DICLEGIS is safer than has been demonstrated.

According to its FDA-approved product labeling (PI) (emphasis in original):

DICLEGIS is indicated for the treatment of nausea and vomiting of pregnancy in women who do not respond to conservative management.

\section{Limitations of Use}

DICLEGIS has not been studied in women with hyperemesis gravidarum.

DICLEGIS is contraindicated in women with known hypersensitivity to doxylamine succinate, other ethanolamine derivative antihistamines, pyridoxine hydrochloride or any inactive ingredient in the formulation, as well as in women who are taking monoamine oxidase inhibitors (MAOIs). The PI for DICLEGIS includes Warnings and Precautions regarding activities requiring mental alertness and concomitant medical conditions. In addition, the most common adverse reaction reported with DICLEGIS was somnolence.

The social media post is misleading because it presents various efficacy claims for DICLEGIS, but fails to communicate any risk information. For example, the social media post includes the following claims:

OMG. Have you heard about this? As you guys know my \#morningsickness has been pretty bad. I tried changing things about my lifestyle, like my diet, but nothing helped, so I talked to my doctor. He prescribed me \#Diclegis, and I felt a lot better and most importantly, it's been studied and there was no increased risk to the baby. I'm so excited and happy with my results that I'm partnering with Duchesnay USA to raise awareness about treating morning sickness. If you have morning sickness, be safe and sure to ask your doctor about the pill with the pregnant woman on it and find out more www.diclegis.com; www.DiclegisImportantSafetyInfo.com. 
The social media post, however, entirely omits all risk information. We note the statement, "[F]ind out more www.diclegis.com; www.DiclegisImportantSafetyInfo.com[,]" appears at the end of the social media post; however, this does not mitigate the misleading omission of risk information. By omitting the risks associated with DICLEGIS, the social media post misleadingly fails to provide material information about the consequences that may result from the use of the drug and suggests that it is safer than has been demonstrated.

In addition, the social media post is misleading because it fails to provide material information regarding DICLEGIS' full approved indication, including important limitations of use. Specifically, it fails to convey that DICLEGIS has not been studied in women with hyperemesis gravidarum.

OPDP requests that Duchesnay immediately cease misbranding DICLEGIS and/or cease introducing the misbranded drug into interstate commerce.

\section{United States v. Caronia}

Under the Federal Food, Drug and Cosmetic Act, before drugs are distributed into interstate commerce, they must be approved by the FDA for specific uses. To obtain FDA approval, drug manufacturers are required to demonstrate, through clinical trials, the safety and efficacy of a new drug for each intended use or indication.

Once FDA-approved, prescription drugs can be prescribed by doctors for both FDA-approved and -unapproved uses; the FDA generally does not regulate how physicians use approved drugs. Indeed, courts and the FDA have recognized the propriety and potential public value of unapproved or off-label drug use. Off-label use is an accepted and necessary corollary of the FDA's mission to regulate in this area without directly interfering with the practice of medicine. FDA-approved indications were not intended to limit or interfere with the practice of medicine nor to preclude physicians from using their best judgment in the interest of the patient.The FDA itself has observed:

Once a drug has been approved for marketing, a physician may prescribe it for uses or in treatment regimens or patient populations that are not included in approved labeling. Such "unapproved" or, more precisely, "unlabeled" uses may be appropriate and rational in certain circumstances, and may, in fact, reflect approaches to drug therapy that have been extensively reported in medical literature.

The FDCA prohibits "misbranding." A drug is misbranded if, inter alia, its labeling fails to bear "adequate directions for use,", which
703 F.3d 149 (2d Cir. 2012)

21 U.S.C. § 352(f) 
21 C.F.R. $§ 201.5$

21 C.F.R. § 201.128.
FDA regulations define as "directions under which the lay[person] can use a drug safely and for the purposes for which it is intended." FDA regulations define intended use by reference to "the objective intent of the persons legally responsible for the labeling of drugs," which may be demonstrated by, among other evidence, "oral or written statements by such persons or their representatives" and "the circumstances that the article is, with the knowledge of such persons or their representatives, offered and used for a purpose for which it is neither labeled nor advertised."

The consequences for misbranding are criminal. Pharmaceutical manufacturers and their representatives can face misdemeanor charges for misbranding or felony charges for fraudulent misbranding. The government has repeatedly prosecuted - and obtained convictions against - pharmaceutical companies and their representatives for misbranding based on their off-label promotion. The FDCA and its accompanying regulations do not expressly prohibit the "promotion" or "marketing" of drugs for off-label use. The regulations do recognize that promotional statements by a pharmaceutical company or its representatives can serve as proof of a drug's intended use. Off-label promotional statements could thus presumably constitute evidence of an intended use of a drug that the FDA has not approved. The FDA, however, has concluded that "an approved drug that is marketed for an unapproved use (whether in labeling or not) is misbranded because the labeling of such drug does not include 'adequate directions for use."' Thus, the government has treated promotional speech as more than merely evidence of a drug's intended use - it has construed the FDCA to prohibit promotional speech as misbranding itself.

Orphan Medical manufactured the drug Xyrem, a powerful central nervous system depressant. Xyrem can cause serious side effects, including difficulty breathing while asleep, confusion, abnormal thinking, depression, nausea, vomiting, dizziness, headache, bedwetting, and sleepwalking. If abused, Xyrem can cause additional medical problems, including seizures, dependence, severe withdrawal, coma, and death. Xyrem's active ingredient is gammahydroxybutryate ("GHB"). GHB has been federally classified as the "date rape drug" for its use in the commission of sexual assaults.

Despite the risks associated with Xyrem and GHB, the FDA approved Xyrem for two medical indications. In July 2002, the FDA approved Xyrem to treat narcolepsy patients who experience cataplexy, a condition associated with weak or paralyzed muscles. In Novem-

\footnotetext{
${ }^{3} \mathrm{~A}$ drug is also misbranded if, inter alia: its label is false or misleading; the label fails to display required information prominently; its container is misleading; or it is dangerous to health when used in the dosage, manner, frequency, or duration prescribed, recommended, or suggested on the label.
} 
ber 2005, the FDA approved Xyrem to treat narcolepsy patients with excessive daytime sleepiness ("EDS"), a neurological disorder caused by the brain's inability to regulate sleep-wake cycles.

Caronia was audio-recorded on two occasions as [he] promoted Xyrem for unapproved uses, including unapproved indications [including chronic fatigue chronic pain, and restless leg] and unapproved subpopulations [patients under 16]. He was found guilty of conspiracy to introduce a misbranded drug into interstate commerce.

On appeal, Caronia principally argues that the misbranding provisions of the FDCA prohibit off-label promotion, and therefore, unconstitutionally restrict speech. Caronia argues that the First Amendment does not permit the government to prohibit and criminalize a pharmaceutical manufacturer's truthful and non-misleading promotion of an FDA-approved drug to physicians for off-label use where such use is not itself illegal and others are permitted to engage in such speech.

As off-label drug use itself is not prohibited, it does not follow that prohibiting the truthful promotion of off-label drug usage by a particular class of speakers would directly further the government's goals of preserving the efficacy and integrity of the FDA's drug approval process and reducing patient exposure to unsafe and ineffective drugs. Prohibiting off-label promotion by a pharmaceutical manufacturer while simultaneously allowing off-label use "paternalistically" interferes with the ability of physicians and patients to receive potentially relevant treatment information; such barriers to information about off-label use could inhibit, to the public's detriment, informed and intelligent treatment decisions. In fact, in granting safe harbor to manufacturers by permitting the dissemination of off-label information through scientific journals, the FDA itself recognizes that public health can be served when health care professionals receive truthful and non-misleading scientific and medical information on unapproved uses of approved drugs.

If the government is concerned that off-label promotion may mislead physicians, it could guide physicians and patients in differentiating between misleading and false promotion, exaggerations and embellishments, and truthful or non-misleading information. The government could develop its warning or disclaimer systems, or develop safety tiers within the off-label market, to distinguish between drugs. The government could require pharmaceutical manufacturers to list all applicable or intended indications when they first apply for FDA approval, enabling physicians, the government, and patients to track a drug's development. To minimize off-label use, or manufacturer evasion of the approval process for such use, the government could create other limits, including ceilings or caps on off-label prescriptions. The FDA could further remind physicians and manufacturers 
Wyeth and PLIVA are technically failureto-warn products liability cases. But if you think of an "adequate warning" as a statement required to make a product's label not misleading, they have a lot in common with false advertising law. of, and even perhaps further regulate, the legal liability surrounding off-label promotion and treatment decisions.[11] Finally, where off-label drug use is exceptionally concerning, the government could prohibit the off-label use altogether.

Accordingly, even if speech can be used as evidence of a drug's intended use, we decline to adopt the government's construction of the FDCA's misbranding provisions to prohibit manufacturer promotion alone as it would unconstitutionally restrict free speech. We construe the misbranding provisions of the FDCA as not prohibiting and criminalizing the truthful off-label promotion of FDA-approved prescription drugs.

\section{Wyeth v. Levine}

Phenergan is Wyeth's brand name for promethazine hydrochloride, an antihistamine used to treat nausea. The injectable form of Phenergan can be administered intravenously through either the "IV-push" method, whereby the drug is injected directly into a patient's vein, or the "IV-drip" method, whereby the drug is introduced into a saline solution in a hanging intravenous bag and slowly descends through a catheter inserted in a patient's vein. The drug is corrosive and causes irreversible gangrene if it enters a patient's artery.

Diana Levine's injury resulted from an IV-push injection of Phenergan. Phenergan entered Levine's artery, either because the needle penetrated an artery directly or because the drug escaped from the vein into surrounding tissue (a phenomenon called "perivascular extravasation") where it came in contact with arterial blood. As a result, Levine developed gangrene, and doctors amputated first her right hand and then her entire forearm. In addition to her pain and suffering, Levine incurred substantial medical expenses and the loss of her livelihood as a professional musician. Although Phenergan's labeling warned of the danger of gangrene and amputation following inadvertent intra-arterial injection, Levine alleged that the labeling was defective because it failed to instruct clinicians to use the IV-drip method of intravenous administration instead of the higher risk IVpush method.

The question presented is whether federal law pre-empts Levine's claim that Phenergan's label did not contain an adequate warning about using the IV-push method of administration.

Wyeth first argues that Levine's state-law claims are pre-empted because it is impossible for it to comply with both the state-law duties underlying those claims and its federal labeling duties. The FDA's premarket approval of a new drug application includes the approval of the exact text in the proposed label. Generally speaking, a manufacturer may only change a drug label after the FDA approves a supplemental application. There is, however, an FDA regulation that 
permits a manufacturer to make certain changes to its label before receiving the agency's approval. Among other things, this "changes being effected" (CBE) regulation provides that if a manufacturer is changing a label to "add or strengthen a contraindication, warning, precaution, or adverse reaction" or to "add or strengthen an instruction about dosage and administration that is intended to increase the safe use of the drug product," it may make the labeling change upon filing its supplemental application with the FDA; it need not wait for FDA approval.

Wyeth suggests that the FDA, rather than the manufacturer, bears primary responsibility for drug labeling. Yet through many amendments to the FDCA and to FDA regulations, it has remained a central premise of federal drug regulation that the manufacturer bears responsibility for the content of its label at all times. It is charged both with crafting an adequate label and with ensuring that its warnings remain adequate as long as the drug is on the market. Of course, the FDA retains authority to reject labeling changes made pursuant to the CBE regulation in its review of the manufacturer's supplemental application, just as it retains such authority in reviewing all supplemental applications. But absent clear evidence that the FDA would not have approved a change to Phenergan's label, we will not conclude that it was impossible for Wyeth to comply with both federal and state requirements.

\section{PLIVA, Inc. v. Mensing}

Metoclopramide is a drug designed to speed the movement of food through the digestive system. The Food and Drug Administration (FDA) first approved metoclopramide tablets, under the brand name Reglan, in 1980. Five years later, generic manufacturers also began producing metoclopramide. The drug is commonly used to treat digestive tract problems such as diabetic gastroparesis and gastroesophageal reflux disorder. Evidence has accumulated that long-term metoclopramide use can cause tardive dyskinesia, a severe neurological disorder. Accordingly, warning labels for the drug have been strengthened and clarified several times [in 1985, 2004, and 2009].

Gladys Mensing and Julie Demahy, the plaintiffs in these consolidated cases, were prescribed Reglan in 2001 and 2002, respectively. Both received generic metoclopramide from their pharmacists. After taking the drug as prescribed for several years, both women developed tardive dyskinesia.

In separate suits, Mensing and Demahy sued the generic drug manufacturers that produced the metoclopramide they took. Each alleged, as relevant here, that long-term metoclopramide use caused her tardive dyskinesia. Mensing and Demahy have pleaded that the Manufacturers knew or should have known of the high risk of tardive 
dyskinesia inherent in the long-term use of their product. They have also pleaded that the Manufacturers knew or should have known that their labels did not adequately warn of that risk. The parties do not dispute that, if these allegations are true, state law required the Manufacturers to use a different, safer label.

Federal law imposes far more complex drug labeling requirements. [Under Hatch-Waxman,] brand-name and generic drug manufacturers have different federal drug labeling duties. A brand-name manufacturer seeking new drug approval is responsible for the accuracy and adequacy of its label. A manufacturer seeking generic drug approval, on the other hand, is responsible for ensuring that its warning label is the same as the brand name's.

According to the FDA, the Manufacturers could have proposed indeed, were required to propose - stronger warning labels to the agency if they believed such warnings were needed. If the FDA had agreed that a label change was necessary, it would have worked with the brand-name manufacturer to create a new label for both the brand-name and generic drug.

Where state and federal law directly conflict, state law must give way. We have held that state and federal law conflict where it is impossible for a private party to comply with both state and federal requirements.

We find impossibility here. It was not lawful under federal law for the Manufacturers to do what state law required of them.

If the Manufacturers had independently changed their labels to satisfy their state-law duty, they would have violated federal law. Taking Mensing and Demahy's allegations as true, state law imposed on the Manufacturers a duty to attach a safer label to their generic metoclopramide. Federal law, however, demanded that generic drug labels be the same at all times as the corresponding brand-name drug labels. Thus, it was impossible for the Manufacturers to comply with both their state-law duty to change the label and their federal law duty to keep the label the same.

The federal duty to ask the FDA for help in strengthening the corresponding brand-name label, assuming such a duty exists, does not change this analysis. Although requesting FDA assistance would have satisfied the Manufacturers' federal duty, it would not have satisfied their state tort-law duty to provide adequate labeling. State law demanded a safer label; it did not instruct the Manufacturers to communicate with the FDA about the possibility of a safer label.

\section{SmithKline Beecham v. Watson Pharmaceuticals}

211 F.3d 21 (2d Cir. 2000)

This appeal arises out of a copyright action alleging infringement of appellant's copyright in a user's guide and audiotape developed for its Nicorette-brand gum. Appellees, in obtaining approval to sell a 
competing generic nicotine gum product, were directed by the FDA to use labeling almost identical to appellant's copyrighted guide and tape.

Appellees cannot be liable for copyright infringement because the Hatch-Waxman Amendments require generic drug producers to use the same labeling as was approved by the FDA for, and is used by, the producer of the pioneer drug.

Appellant SmithKline manufactures and sells Nicorette nicotine polacrilex gum, an over-the-counter product designed to help smokers overcome the cigarette habit.

Appellee Watson obtained FDA approval for the OTC marketing of a generic version of nicotine gum intended to compete directly with Nicorette. To obtain that approval from the FDA, Watson had to comply with the requirement imposed by the Hatch-Waxman Amendments that "the labeling proposed for [its] new drug [be] the same as the labeling approved for" Nicorette. Thus, Watson's generic nicotine gum was accompanied by a user guide and audio tape that were virtually identical to SmithKline's.

Watson asserts that this copying, having been dictated by the FDA, is a"fair use" protected under 17 U.S.C. §107. The United States, in its amicus curiae brief, argues instead that in submitting its copyrighted materials for FDA approval, SmithKline gave the FDA an implied, nonexclusive license to permit or require generic drug applicants to copy the user's guide and audiotape in their own nicotine gum packaging.

In our view, the case can more easily be disposed of on the straightforward ground that the Hatch-Waxman Amendments to the FFDCA not only permit but require producers of generic drugs to use the same labeling as was approved for, and is used in, the sale of the pioneer drug, even if that label has been copyrighted. Because those Amendments were designed to facilitate rather than impede the approval and OTC sale of generic drugs, the FDA's requirement that Watson use much of SmithKline's label precludes a copyright infringement action by SmithKline.

If SmithKline's copyright claim has merit, then Watson cannot realistically use the ANDA process to sell its generic nicotine gum because it will either have to change the label and lose FDA approval or be enjoined from using a label that infringes SmithKline's copyright. We are thus faced with a conflict between two statutes. The HatchWaxman Amendments require generic drug producers to use labeling that will infringe upon copyrights in labels of pioneer drugs. The Copyright Act seems to prohibit such copying. However, applying the familiar canon that, where two laws are in conflict, courts should adopt the interpretation that preserves the principal purposes of each, the conflict is less stark and more easily resolved than it might seem. 
The purposes of the Hatch-Waxman Amendments would be severely undermined if copyright concerns were to shape the FDA's application of the "same" labeling requirement.

Our point here is not only that Congress would have provided explicitly that the Hatch-Waxman Amendments trump the copyright laws had it foreseen the statutory conflict exposed by the present action, although we firmly believe that to be obvious. Our point is also that the profit sought by the creator of the pioneer drug label flows primarily from the administrative approval of the drug and the patent and exclusivity periods free from competition that follow. The pertinent purpose of the copyright laws - to encourage the production of creative works by according authors a property right in their works so that authors will not have to share profits from their labors with free riders - is not seriously implicated by allowing the "same" labeling requirement to trump a copyright under the Hatch-Waxman Amendments. It is simply not conceivable that, if we reject SmithKline's claim, pioneer drug producers will so fear the copying of labels by future generic drug producers that some pioneer producers - or even one of them - will lack the incentive to create labeling needed for FDA approval. 


\section{Coda}

\section{Bizarro World Redux Problem}

Your client is interested in commercializing one of the following ideas and is curious what forms of intellectual property protection she can and should use. How would you advise her to proceed?

- A 75,000-word novel about a boy who discovers that he is a wizard

- A new drug for treating heart disease, which will cost $\$ 100$ million to test in humans

- An easier-to-hold design for a pipe wrench

- A process for producing pure aluminum from aluminum ore that reduces the cost by $85 \%$.

- A catchy song about taking revenge on a cheating boyfriend, recorded in her kitchen with lots of background noise

- A recut version of a popular movie, which takes five minutes off the running time and makes it much more suspenseful and exciting

- A sketch for an elegant off-the-shoulder dress

- A joke about traffic in Los Angeles

- The perfect name for a laundromat

Now look back at the Bizarro World Problem from the first chapter. How have your answers changed? How different is our world from Bizarro World? How is ours better because it has intellectual property law, and how is it worse? 